\title{
EXPERIMENT DATA REPORT FOR SEMISCALE MOD-1 TEST S-28-4 (STEAM GENERATOR TUBE RUPTURE TEST)
}

\author{
VICENTE ESPARZA KENNETH E. SACKETT
}

October 1977

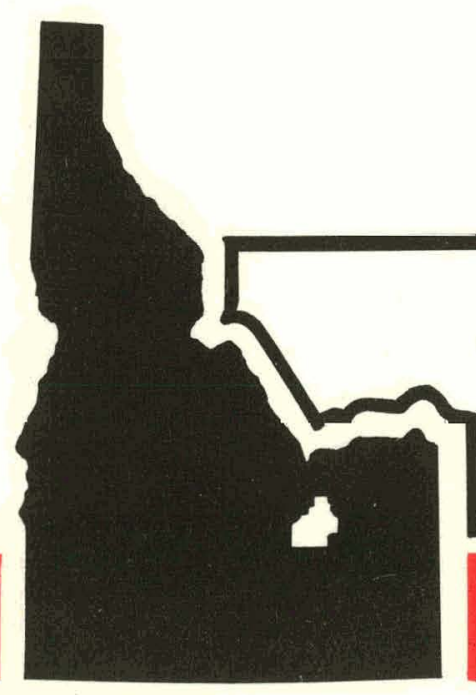

\section{$\prod_{\forall} E G_{\Sigma} G$ Idaho, Inc.}

IDAHO NATIONAL ENGINEERING LABORATORY

\section{DEPARTMENT OF ENERGY}




\section{DISCLAIMER}

This report was prepared as an account of work sponsored by an agency of the United States Government. Neither the United States Government nor any agency Thereof, nor any of their employees, makes any warranty, express or implied, or assumes any legal liability or responsibility for the accuracy, completeness, or usefulness of any information, apparatus, product, or process disclosed, or represents that its use would not infringe privately owned rights. Reference herein to any specific commercial product, process, or service by trade name, trademark, manufacturer, or otherwise does not necessarily constitute or imply its endorsement, recommendation, or favoring by the United States Government or any agency thereof. The views and opinions of authors expressed herein do not necessarily state or reflect those of the United States Government or any agency thereof. 


\section{DISCLAIMER}

Portions of this document may be illegible in electronic image products. Images are produced from the best available original document. 
Printed in the United States of America Available from

National Technical Information Service

U.S. Department of Commerce

5285 Port Royal Road

Springfield, Virginia 22161

Price: Printed Copy $\$ 11.00$; Microfiche $\$ 3.00$

"The NRC will make available data tapes and operational computer codes on research programs dealing with postulated loss-of-coolant accidents in light water reactors. Persons requesting this information must reimburse the NRC contractors for their expenses in preparing copies of the data tapes and the operational computer codes. Requests should be submitted to the Research Applications Branch, Office of Nuclear Regulatory Research, Nuclear Regulatory Commission, Washington, D.C. 20555."

\section{NOTICE}

This report was prepared as an account of work sponsored by the United States Government. Neither the the United States nor the Department of Energy, nor the Nuclear Regulatory Commission, nor any of their employees, nor any of their contractors, subcontractors, or their employees, makes any warranty, express or implied, or assumes any legal liability or responsibility for the accuracy, completeness or usefulness of any information, apparatus, product or process disclosed, or represents that its use would not infringe privately owned rights. 
TREE-NUREG-1151

EXPERIMENT DATA REPORT FOR SEMISCALE MOD-1

TEST S-28-4

(STEAM GENERATOR TUBE RUPTURE TEST)

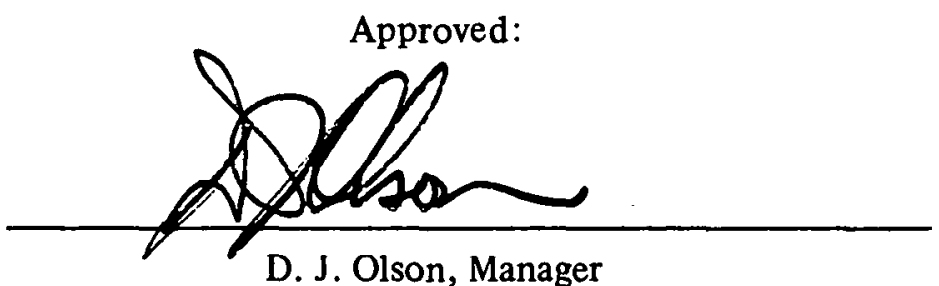

Semiscale Program

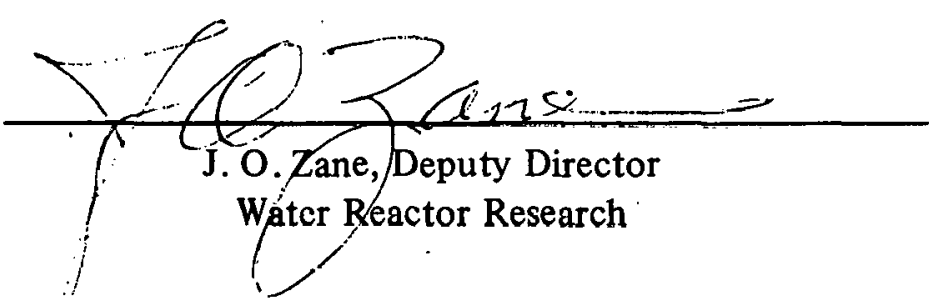

This norice

This report was prepared as an account of work

United States nor the United Statusesti. Nelidiel Ute

Energy, rior any of their employees, nor any of their

contractors, subcontractots, or their employes, makes

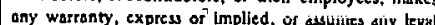

liability or responsibility for the aceurates an legal

or usefulness of any informion, eppartus, product or

or usefl hess of any inform

process disclosed, or represents that its use would not
infringe privately owned rights. 


\section{EXPERIMENT DATA REPORT FOR}

SEMISCALE MOD-1 TEST S-28-4

(STEAM GENERATOR TUBE RUPTURE TEST)

by

Vicente Esparza

Kenneth E. Sackett

EG\&G IDAHO INC.

November 1977

\section{PREPARED FOR THE}

U.S. NUCLEAR REGULATORY COMMISSION

AND

DEPARTMENT OF ENERGY

IDAHO OPERATIONS OFFICE

UNDER CONTRACT NO. EY-76-C-07-1570 


\begin{abstract}
Recorded test data are presented for Test S-28-4 of the Semiscale Mod-1 steam generator tube rupture "test series. These tests" are among several Semiscale Mod-1 experiments conducted to investigate the thermal and hydraulic phenomena accompanying a hypothesized loss-of-coolant accident in a pressurized water reactor (PWR) system.

Test S-28-4 was conducted from initial conditions of $15646 \mathrm{kPa}$ and $557 \mathrm{~K}$ to investigate the response of the Semiscale Mod-1 system to a depressurization and reflood transient following a simulated double-ended of fset shear of the broken loop cold leg piping. During the test, cooling water was injected into the cold leg of the intact and broken loops to simulate emergency core coolant injection in a PWR. Thirty steam generator tube ruptures were simulated by a controlled injection from a heated accumulator into the intact loop hot leg.
\end{abstract}

The purpose of this report is to make available the uninterpreted data from Test S-28-4 for future data analysis and test reporting activities. The data, presented in the form of graphs in engineering units, have been analyzed only to the extent necessary to ensure that they are reasonable and consistent.

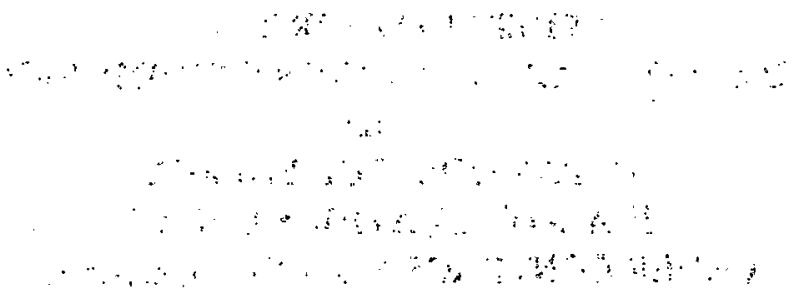




\section{SUMMARY}

Test S-28-4 was performed as part of the Semiscale Mod-1 portion of the Semiscale Program conducted by EG\&G Idaho, Inc. for the United States Government. This test is part of the steam generator tube rupture test series (Test Series 28) performed to investigate the response of the Mod-1 system to steam generator tube ruptures during a hypothesized loss-of-coolant accident (LOCA). The test objective specific to Test S-28-4 was to refine the definition of the upper limit set by Test S-28-1 and to investigate the range of steam generator tube ruptures over which high peak cladding temperatures can occur. Hardware configuration and test parameters were selected to yield a system response that simulates the response of a pressurized water reactor during a hypothesized LOCA with subsequent refill and reflood.

Test S-28-4 utilized the Semiscale Mod-1 system equipped with a pressure vessel with a 40-rod electrically heated core; an intact loop with pump, steam generator, and pressurizer; a broken loop with simulated pump, simulated steam generator, and rupture assemblies; and a pressure suppression system with header, pressure suppression tank, and heated steam supply system. High and low pressure coolant injection pumps and a coolant injection accumulator were provided for each system loop. An additional injection accumulator was provided for the intact loop hot leg. The intact loop hot leg injection flow rate was set to simulate the rupture of 30 steam generator tubes. For Test S-28-4, four heater rods were intentionally unpowered to simulate the effects of control rod guide tubes and the power in three heater rods was increased to produce a slightly peaked power profile.

The test was conducted from initial conditions of $15646 \mathrm{kPa}$ and $557 \mathrm{~K}$ (at the intact loop cold leg vessel inlet) with a simulated full size (200\%) double-ended offset shear of the broken loop cold leg piping at an initial core power level of $1.40 \mathrm{MW}$, and an initial core inlet flow rate of $9.05 \mathrm{l} / \mathrm{s}$. The instantaneous offset shear of the broken loop cold leg piping was simulated by simultaneous (within $10 \mathrm{~ms}$ ) actuation of the rupture assemblies. After initiation of blowdown, power to the heated core was reduced to simulate the predicted heat flux response of nuclear fuel rods during a LOCA. Blowdown was accompanied by simulated emergency core coolant injection into the cold leg piping of the intact and broken loops. This injection was followed by a controlled injection from a heated accumulator into the in tact loop hot leg to simulate steam generator tube ruptures.

Test S-28-4 was generally conducted as specified. Conditions which did not conform to the specified test configuration were considered acceptable for analysis purposes within the test objectives. The instrumentation used generally functioned as intended. Of 220 measurements taken, 216 produced usable data. 


\section{CONTENTS}

ABSTRACT $\ldots \ldots \ldots \ldots \ldots \ldots \ldots$ ii

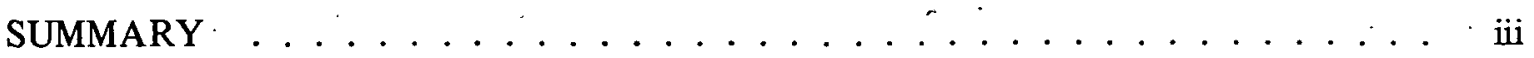

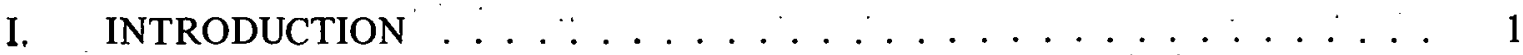

II. SYSTEM, PROCEDURES, CONDITIONS, AND

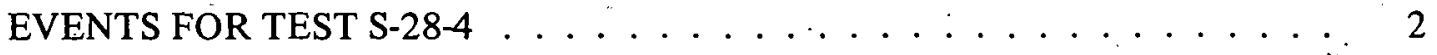

1. SYSTEM CONFIGURATION AND

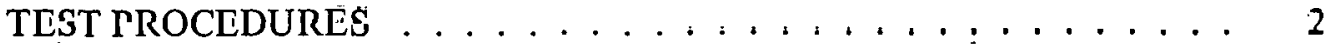

2. INITIAL TEST CONDITIONS AND

SEQUENCE OF EVENTS ..................... 5

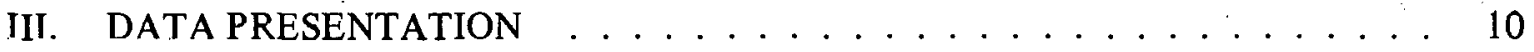

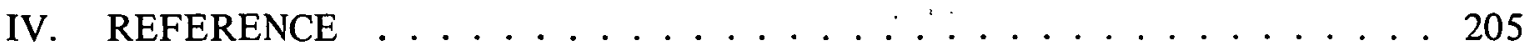

APPENDIX A - DATA ACQUISITION SYSTEM CAPABILITIES $\ldots \ldots \ldots 7$

APPENDIX B - POSTTEST ADJUSTMENTS TO DATA FROM

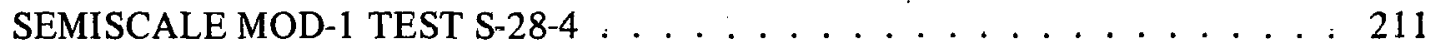

1. PRESSURE MEASUREMENTS . . . . . . . . . . . . . 213

2. DIFFERENTIAL PRESSURE MEASUREMENTS . . . . . . . . . . . 214

3. MOMENTUM FLUXX MEASUREMENT . . . . . . . . . . . . 216

4. DENSITY MEASUREMENTS . . . . . . . . . . . . . 219

APPENDIX C - SELECTED DATA WITH ESTIMATED TOTAL ERROR

BANDS FROM SEMISCALE MOD-1 TEST S-28-4 $\ldots \ldots \ldots \ldots$ 


\section{FIGURES}

1. Semiscale Mod-1 system for cold leg break

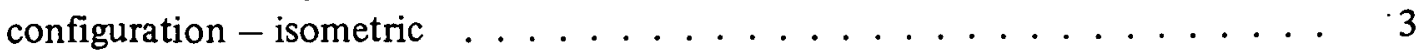

2. Semiscale Mod-1 system for cold leg break configuration - schematic $\ldots \ldots \ldots \ldots 4$

3. Semiscale Mod-1 system and instrumentation for cold leg break configuration - isometric . . . . . . . . . . . . . 11

4. Semiscale Mod-1 system and instrumentation for cold leg break configuration - schematic

5. Semiscale Mod-1 pressure vessel - cross section showing instrumentation . . . . . . . . . . . . . . 13

6. Semiscale Mod-1 pressure vessel - isometric showing instrumentation . . . . . . . . . . . . . . . . . . . 14

7. Semiscale Mod-1 pressure vessel - penetrations

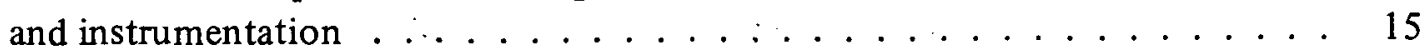

8. Semiscale Mod-1 heated core - plan view . . . . . . . . . . 16

9. Fluid temperature in intact loop hot leg (TFU-1 and RBU-2), from -20 to $600 \mathrm{~s} \ldots \ldots . \ldots . \ldots . \ldots 28$

10. Fluid temperature in intact loop hot leg (TFU-1 and RBU-2), from -6 to $42 \mathrm{~s}$

11. Fluid temperature in in tact loop hot leg (TFU-6),

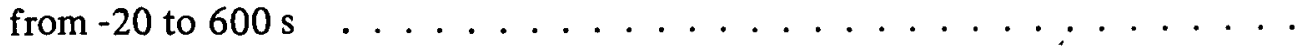

12. Fluid temperature in intact loop hot leg (TFU-6),

from -6 to $42 \mathrm{~s} \ldots \ldots \ldots . \ldots \ldots$

13. Fluid temperature in in tact loop cold leg (TFU-7 and TFU-10), from -20 to $600 \mathrm{~s} \ldots \ldots . \ldots 30$

14. Fluid temperature in in tact loop cold leg (TFU-7 and TFU-10), from -6 to $42 \mathrm{~s}$

15. Fluid temperature in intact loop cold leg (RBU-14A and TFU-14B), from -20 to $600 \mathrm{~s}$ 
16. Fluid temperature in intact loop cold leg

(RBU-14A and TFU-14B), from -6 to $42 \mathrm{~s} \ldots \ldots \ldots$. . . . . . . . 31

17. Fluid temperature in intact loop cold leg (TFU-15),

from -20 to $600 \mathrm{~s} \ldots \ldots \ldots . \ldots \ldots . \ldots \ldots$

18. Fluid temperature in intact loop cold leg (TFU-15),

from -6 to $42 \mathrm{~s} \ldots \ldots \ldots \ldots \ldots \ldots \ldots . \ldots \ldots \ldots$

19. Fluid temperature in broken loop, vessel

side (TFB-20 and TFB-23), from -20 to $600 \mathrm{~s} \ldots \ldots . \ldots 33$

20. Fluid temperature in broken loop, vesscl

side (TFB-20 and TFB-23), from -6 to $42 \mathrm{~s} \ldots \ldots . \ldots 33$

21. Fluid temperature in broken loop, pump side

(TFB-30, TFB-37, and TFB-42), from -20 to $600 \mathrm{~s} \ldots \ldots . . . . . . . .34$

22. Fluid temperature in broken loop, pump side

(TFB-30, TFB-37, and TFB-42), from -6 to $42 \mathrm{~s} \ldots \ldots \ldots . \ldots . \ldots$

23. Fluid temperature in inlet annulus (TFV-ANN-4A and

TFV-ANN-4M), from -20 to $600 \mathrm{~s} \ldots \ldots \ldots . \ldots . \ldots 35$

24. Fluid temperature in inlet annulus (TFV-ANN-4A and

TFV-ANN-4M), from -6 to $42 \mathrm{~s} \ldots \ldots \ldots . \ldots . \ldots 35$

25. Fluid temperature in downcomer annulus (TFV-ANN-35A,

TFV-ANN-70A, TFV-ANN-1 15A, and TFV-ANN-156A),

from -20 to $600 \mathrm{~s} \ldots \ldots \ldots \ldots . \ldots \ldots$

26. Fluid temperature in downcomer annulus (TFV-ANN-35A,

TFV-ANN-70A, TFV-ANN-115A, and TFV-ANN-156A),

from -6 to $42 \mathrm{~s} \ldots \ldots \ldots \ldots$. . . . . . . . . . . . . . . . . . . .

27. Fluid temperature in upper plenum (TFV-UP+13),

from -20 to $600 \mathrm{~s} \ldots \ldots \ldots \ldots \ldots \ldots \ldots$

28. Fluid temperature in upper plenum (TFV-UP+13),

from -6 to $42 \mathrm{~s} \ldots \ldots \ldots \ldots$. . . . . . . . . . . . . 37

29. Fluid temperature in lower plenum (IFV-LP-2,

TFV-LP-4, and TFV-LP-7), from -20 to $600 \mathrm{~s}$ 
30. Fluid temperature in lower plenum (TFV-LP-2, TFV-LP-4, and TFV-LP=7), from -6 to $42 \mathrm{~s} \ldots \ldots . \ldots 38$

31. Fluid temperature in core inlet (TFV-CORE-IN), from -20 to $600 \mathrm{~s} \ldots \ldots \ldots \ldots \ldots$

32. Fluid temperature in core inlet (TFV-CORE-IN), from -6 to $42 \mathrm{~s} \ldots \ldots \ldots \ldots \ldots$

33. Fluid temperature in core, Grid Spacer 5 (TFG-5CD-45), from -20 to $600 \mathrm{~s} \ldots \ldots . \ldots$. . . . . . . . 40

34. Fluid temperature in core, Grid Spacer 5 (TFG-5CD-45), from -6 to $42 \mathrm{~s}$

35. Fluid temperature in core, Grid Spacer 6 (TFG-6CD-45), from -20 to $600 \mathrm{~s}$

36. Fluid temperature in core, Grid Spacer 6 (TFG-6CD-45), from -6 to $42 \mathrm{~s}$

37. Fluid temperature in core, Grid Spacer 10 (TFG-10AB-45), from -20 to $600 \mathrm{~s}$

38. Fluid temperature in core, Grid Spacer 10 (TFG-10AB-45), from -6 to $42 \mathrm{~s}$

39. Fluid temperature in intact loop coolant injection line (TFU-ECC-14), from -20 to $600 \mathrm{~s}$

40. Fluid temperature in in tact loop coolant injection line (TFU-ECC-14), from -6 to $42 \mathrm{~s}$

41. Fluid temperature in broken loop coolant injection line (TFB-ECC-42), from -20 to $600 \mathrm{~s}$

42. Fluid temperature in broken loop coolant injection line (TFB-ECC-42), from -6 to $42 \mathrm{~s}$

43. Fluid temperature in steam generator, feedwater line (TFU-SGFW), from -20 to $600 \mathrm{~s}$

44. Fluid temperature in steam generator, feedwater line (TFU-SGFW), from -6 to $42 \mathrm{~s}$ 
45. Fluid temperature in steam generator, steam dome

(TFU-SGSD), from -20 to $600 \mathrm{~s} \ldots \ldots \ldots \ldots$

46. Fluid temperature in steam generator, steam dome (TFU-SGSD), from -6 to $42 \mathrm{~s} \ldots \ldots \ldots \ldots$. . . . . . . . . . 46

47. Fluid temperature in steam generator, secondary side (TFU-SG1, TFU-SG2, and TFU-SG3), from -20 to $600 \mathrm{~s}$

48. Fluid temperature in steam generator, secondary side (TFU-SG1, TFU-SG2, and TFU-SG3), from -6 to $42 \mathrm{~s} \ldots \ldots \ldots \ldots \ldots \ldots \ldots$

49. Fluid temperature in steam generator rupture system accumulator (TFU-SGS3), from -20 to $600 \mathrm{~s} \ldots \ldots \ldots$. . . . . . . . . . 48

50. Fluid temperature in steam generator rupture system accumulator (TFU-SGS3), from -6 to $42 \mathrm{~s} \ldots \ldots \ldots \ldots$

51. Fluid temperature in steam generator rupture system injection line (TFU-SGS), from -20 to $600 \mathrm{~s}$

52. Fluid temperature in steam generator rupture system injection line

53. Fluid temperature in steam generator rupture system (TFU-SGS-D), from -20 to $600 \mathrm{~s} \ldots \ldots \ldots$. . . . . . . . . . 50

54. Fluid temperature in steam generator rupture system (TFU-SGS-D), from -6 to $42 \mathrm{~s} \ldots \ldots \ldots . \ldots \ldots$

55. Fluid temperature in pressurizer surge line (TFU-PRIZE),

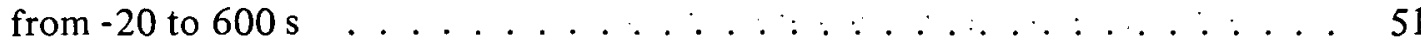

56. Fluid temperature in pressurizer surge line (TFU-PRIZE);

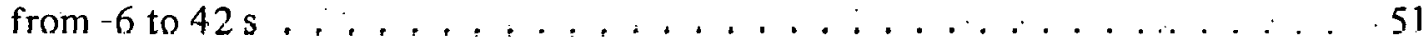

57. Fluid temperature in pressure suppression tank (TF-PSS-33 and TF-PSS-130), from -20 to $600 \mathrm{~s}$. . . . . . . . . ..... 52

58. Fluid temperature in pressure suppression tank (TF-PSS-33 and TF-PSS-130), from -6 to $42 \mathrm{~s} \ldots \ldots \ldots . . \ldots 52$ 
59. Material temperature in intact loop (TMU-1T16),

from -20 to $600 \mathrm{~s} \ldots \ldots \ldots \ldots$. . . . . . . . . . . . . 53

60. Material temperature in intact loop (TMU-1T16),

from -6 to $42 \mathrm{~s} \ldots \ldots \ldots \ldots$. . . . . . . . . . . . . 53

61. Material temperature in broken loop (TMB-20B 16),

from -20 to $600 \mathrm{~s} \ldots \ldots \ldots \ldots \ldots$. . . . . . . . . . . . . . . . .

62. Material temperature in broken loop (TMB-20B16),

from -6 to $42 \mathrm{~s} \ldots \ldots \ldots \ldots \ldots \ldots$

63. Material temperature in vessel filler (TMV-FI-115A

and TMV-FI-156A), from -20 to $600 \mathrm{~s} \ldots \ldots \ldots$. . . . . . . . 55

64. Material temperature in vessel filler (TMV-FI-115A

and TMV-FI-1 56A), from -6 to $42 \mathrm{~s} \ldots \ldots \ldots 55$

65. Material temperature in vessel filler insulator

(TMV-FO-1 56A), from -20 to $600 \mathrm{~s} \ldots \ldots \ldots$ 56 . . . . . . . . . . .

66. Material temperature in vessel filler insulator

(TMV-FO-156A), from -6 to $42 \mathrm{~s} \ldots \ldots \ldots \ldots$

67. Material temperature in vessel filler insulator

(TIV-FO-35A and TIV-FO-1'15A), from -20 to $600 \mathrm{~s} \ldots \ldots . \ldots 57$

68. Material temperature in vessel filler insulator

(TIV-FO-35A and TIV-FO-115A), from -6 to $42 \mathrm{~s} \ldots \ldots . . . . . .57$

69. Material temperature in core barrel inner diameter

(TMV-CI-70A), from -20 to $600 \mathrm{~s} \ldots \ldots \ldots \ldots$

70. Material temperature in core barrel inner diameter

(TMV-CI-70A), from -6 to $42 \mathrm{~s} \ldots \ldots \ldots . \ldots . \ldots 58$

71. Material temperature in core barrel outer diameter

(TMV-CO-70A and TMV-CO-115A), from -20 to $600 \mathrm{~s} \ldots \ldots . . . . . .59$

72. Material temperature in core barrel outer diameter

(TMV-CO-70A and TMV-CO-115A), from -6 to $42 \mathrm{~s} \ldots \ldots 59$

73. Material temperature in core housing filler (TMV-HF-115W,

TMV-HF-127W, and TMV-HF-138W), from -20 to $600 \mathrm{~s} \ldots \ldots$. . . . . . 60 
74. Material temperature in core housing filler (TMV-HF-115W, TMV-HF-127W, and TMV-HF-138W), from -6 to $42 \mathrm{~s} \ldots \ldots 60$

75. Material temperature in steam generator (TMU-SG1, TMU-SG2, and TMU-SG3), from -20 to $600 \mathrm{~s} \ldots \ldots \ldots 1$

76. Material temperature in steam generator (TMU-SG1, TMU-SG2, and TMU-SG3), from -6 to $42 \mathrm{~s} \ldots \ldots \ldots 1$

77. Core heater temperature, Rod D-4 (TH-D4-14 and TH-D4-29), from -20 to $600 \mathrm{~s} \ldots \ldots \ldots 2$

78. Core heater temperature, Rod D-4 (TH-D4-14 and I'll-U4-2y), trom -6 to $42 \mathrm{~s} \ldots \ldots \ldots . \ldots \ldots 2$

79. Core heater temperature, Rod D-5 (TH-D5-29), from

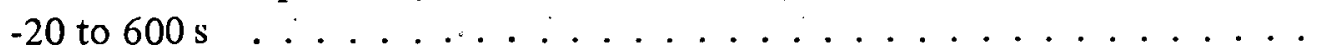

80. Core heater temperature, Rod D-5 (TH-D5-29), from

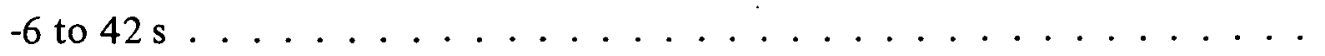

81. Core heater temperature, Rod E-4 (TH-E4-09, TH-E4-27, and TH-E4-55), from -20 to $600 \mathrm{~s}$ 64

82. Core heater temperature, Rod E-4 (TH-E4-09, TH-E4-27 and 'TH-E4-55), from -6 to $42 \mathrm{~s}$ 64

83. Core heater temperature, Rod E-5 (TH-E5-20 and TH-E5-25), from -20 to $600 \mathrm{~s} \ldots \ldots \ldots 5$

84. Core heater temperature, Rod E-5 (TH-E5-20 and

TH-E5-25), from -6 to $42 \mathrm{~s} \ldots \ldots \ldots 6$

85. Core heater temperature, Rod A-4 (TH-A4-09, . :

TH-A4-29, and TH- $44-39$ ), from -20 to 600 s . . . . . . . . . . . 66

86. Core heater temperature, Rod A4 (TH-A4-09, TH-A4-29, and TH-A4-39), from -6 to $42 \mathrm{~s} \ldots \ldots \ldots 6$

87. Core heater temperature, Rod A-5 (TH-A5-29 and TH=A5-45), from $-2 n$ tn $6 \cap n \mathrm{~s}$

88. Core heater temperature, Rod A-5 (TH-A5-29 and TH-A5-45), from -6 to $42 \mathrm{~s}$ 
89. Core heater temperature, Rod B-3 (TH-B3-32),

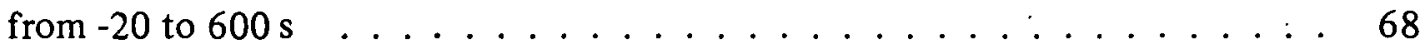

90. Core heater temperature, Rod B-3 (TH-B3-32),

from -6 to $42 \mathrm{~s} \ldots \ldots \ldots \ldots$. . . . . . . . . . . . 68

91. Core heater temperature, Rod B-5 (TH-B5-29 and

TH-B5-33), from -20 to $600 \mathrm{~s}$

92. Core heater temperature, Rod B-5 (TH-B5-29 and

93. Core heater temperature, Rod B-6 (TH-B6-29),

from -20 to $600 \mathrm{~s}$

94. Core heater temperature, Rod B-6 (TH-B6-29),

from -6 to $42 \mathrm{~s}$

95. Core heater temperature, Rod C-2 (TH-C2-38),

from -20 to $600 \mathrm{~s}$

96. Core heater temperature, Rod C-2 (TH-C2-38),

from -6 to $42 \mathrm{~s}$

97. Core heater temperature, Rod C-4 (TH-C4-20,

TH-C4-26, and TH-C4-53), from -20 to 600

98. Core heater temperature, Rod C-4 (TH-C4-20,

TH-C.4-26, and TH-C4-53), from -6 to $42 \mathrm{~s}$

99. Core heater temperature, Rod C-5 (TH-C5-28),

from $=20$ to $600 \mathrm{~s}$

100. Core heater temperature, Rod C-5 (TH-C5-28),

from -6 to $42 \mathrm{~s} \ldots \ldots \ldots \ldots \ldots$

101. Core heater temperature, Rod C-6 (TH-C6-53),

from -20 to $600 \mathrm{~s}$

102. Core heater temperalure, Rod C-6 (TH-C6-53),

from -6 to $42 \mathrm{~s}$

103. Core heater temperature, Rod C-7 (TH-C7-07

and TH-C7-15), from -20 to $600 \mathrm{~s} \ldots \ldots \ldots \ldots$. . . . . . . . . . . . 
104. Core heater temperature, Rod C-7 (TH-C7-07

and TH-C7-15), from -6 to $42 \mathrm{~s} \ldots \ldots \ldots \ldots \ldots \ldots$

105. Core heater temperature, Rod D-1 (TH-D1-21),

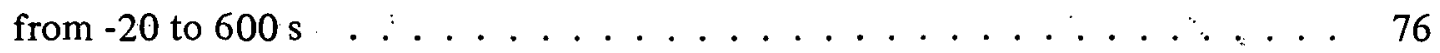

106. Core heater temperature, Rod D-1 (TH-D1-21),

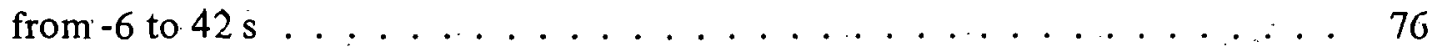

107. Core heater temperature, Rod D-2 (TH-D2-14 and

TH-D2-61), from -20 to $600 \mathrm{~s} \ldots \ldots \ldots \ldots \ldots \ldots$

108. Core heater temperature, Rod D-2 (TH-D2-14 and

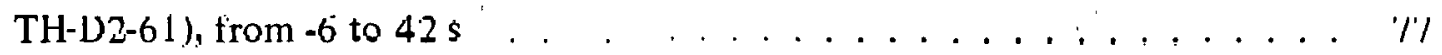

109. Core heater temperature, Rod D-3 (TH-D3-29 and

TH-D3-39), from -20 to $600 \mathrm{~s} \ldots \ldots \ldots \ldots \ldots$

110. Core heater temperature, Rod D-3 (TH-D3-29 and

TH-D3-39), from -6 to $42 \mathrm{~s}$

111. Core heater temperature, Rod D-6 (TH-D6-25),

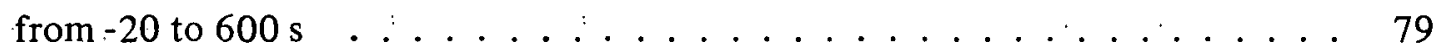

112. Core heater temperature, Rod D-6 (TH-D6-25),

from -6 to $42 \mathrm{~s} \ldots \ldots \ldots \ldots \ldots \ldots \ldots \ldots \ldots$

113. Core heater temperature, Rod D-7 (TH-D7-20),

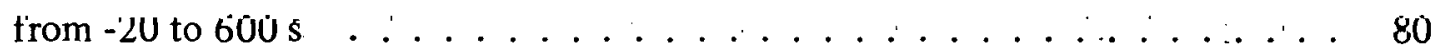

114. Core heater temperature, Rod D-7 (TH-D7-20), from -6 to $42 \mathrm{~s} \ldots \ldots \ldots \ldots \ldots \ldots \ldots \ldots \ldots$

115. Core heater temperature, Rod D-8 (TH-D8-26);

from -20 to $600 \mathrm{~s}$

116. Core heater temperature, Rod D-8 (TH-D8-26),

from -6 to $42 \mathrm{~s} \ldots \ldots \ldots \ldots \ldots \ldots \ldots \ldots \ldots \ldots$

117. Core heater temperature, Rod E-1 (TH-E1-33),

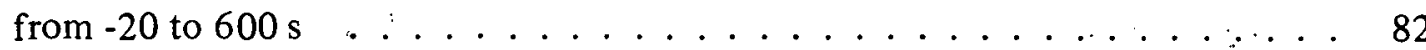

118. Core heater temperature, Rod E-1 (TH-E1-33), from -6 to $42 \mathrm{~s} \ldots \ldots \ldots \ldots \ldots \ldots \ldots \ldots \ldots$ 
119. Core heater temperature, Rod E-2 (TH-E2-33),

from -20 to $600 \mathrm{~s} \ldots \ldots \ldots \ldots$

120. Core heater temperature, Rod E-2 (TH-E2-33), from -6 to 42

121. Core heater temperature, Rod E-3 (TH-E3-05,

TH-E3-20, and TH-E3-24), from -20 to $600 \mathrm{~s}$

122. Core heater temperature, Rod E 3 (TH-E3-05,

TH-E3-20, and TH-E3-24), from -6 to $42 \mathrm{~s}$

123. Core heater temperature, Rod E-6 (TH-E6-08,

TH-E6-28, and TH-E6-37), from -20 to $600 \mathrm{~s}$

124. Core heater temperature, Rod E-6 (TH-E6-08,

TH-E6-28, and TH-E6-37), from -6 to $42 \mathrm{~s}$

125. Core heater temperature, Rod E-7 (TH-E7-44), from -20 to $600 \mathrm{~s}$

126. Core heater temperature, Rod E-7 (TH-E7-44),

from -6 to $42 \mathrm{~s}$

127. Core heater temperature, Rod E-8 (TH-E8-14

and TH-E8-29), from -20 to $600 \mathrm{~s}$

128. Core heater temperature, Rod E-8 (TH-E8-14 and

TH-E8-29), from -6 to $42 \mathrm{~s}$

129. Core heater temperature, Rod F-2 (TH-F2-07,

TH-F2-22, and TH-F2-25), from -20 to $600 \mathrm{~s}$

130. Core heater temperature, Rod F-2 (TH-F2-07, TH-F2-22, and TH-F2-25), from -6 to $42 \mathrm{~s}$

131. Core heater temperature, Rod F-4 (TH-F4-14, TH-F4-29, and TH-F4-44), from -20 to $600 \mathrm{~s}$

132. Core heater temperature, Rod F-4 (TH-F4-14, TH-F4-29, and TH-F4-44), from -6 to $42 \mathrm{~s}$

133. Core heater temperature, Rod F-5 (TH-F5-20, TH-F5-26, TH-F5-33, and TH-F5-53), from -20 to $600 \mathrm{~s}$ 
134. Core heater temperature, Rod F-5 (TH-F5-20,

TH-F5-26, TH-F5-33, and TH-F5-53),

from -6 to $42 \mathrm{~s} \ldots \ldots \ldots \ldots \ldots$

135. Core heater temperature, Rod G-3 (TH-G3-13),

from -20 to $600 \mathrm{~s} \ldots \ldots \ldots . \ldots \ldots 1$

136. Core heater temperature, Rod G-3 (TH-G3-13),

from -6 to $42 \mathrm{~s} \ldots \ldots \ldots \ldots$. . . . . . . . . . . . . 91

137. Core heater temperature, Rod G-4 (TH-G4-29,

TH-G4-33, and TH-G4-38), from -20 to $600 \mathrm{~s} \ldots \ldots$. . . . . . . . . . 92

138. Corc heatcr temperature, Rod G-4 (TH-G4-29,

TH-G4-33, and TH-G4-38), from -6 to $42 \mathrm{~s} \ldots \ldots . \ldots . . . . . . . . . .92$

139. Core heater temperature, Rod G-5 (TH-G5-14

and TH-G5-24), from -20 to $600 \mathrm{~s} \ldots \ldots$. . . . . . . . . . 93

140. Core heater temperature, Rod G-5 (TH-G5-14

and TH-G5-24), from -6 to $42 \mathrm{~s} \ldots \ldots \ldots$. . . . . . . . . . . 93

141. Core heater temperature, Rod H-5 (TH-H5-32),

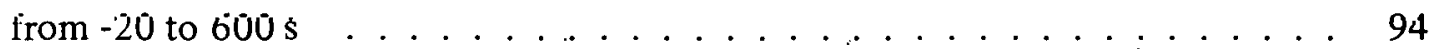

142. Core heater temperature, Rod H-5 (TH-H5-32),

frumi $-6 \mathrm{lu} 42 \mathrm{~s} \ldots \ldots \ldots \ldots \ldots \ldots$

143. Pressure in intact loop (PU-13 and PU-15L),

from -20 to $600 \mathrm{~s} \ldots \ldots \ldots \ldots$. . . . . . . . . . . . 95

144. Pressure in intact loop (PU-13 and PU-15L),

from -6 to $42 \mathrm{~s} \ldots \ldots \ldots \ldots 5$

145. Pressure in broken loop, vessel side (PB-21

and PB-23), from -20 to $600 \mathrm{~s} \ldots \ldots \ldots \ldots$

146. Pressure in broken loop, vessel side (PB-21

and PB-23), from -6 to $42 \mathrm{~s} \ldots \ldots \ldots \ldots$

147. Pressure in broken loop, vessel side (PB-CN1),

from -20 to $600 \mathrm{~s} \ldots \ldots \ldots \ldots 7$

148. Pressure in broken loop, vessel side (PB-CN1),

from -6 to $42 \mathrm{~s} \ldots \ldots \ldots \ldots \ldots$ 
149. Pressure in broken loop, pump side (PB-37

and $\mathrm{PB}-42$ ), from -20 to $600 \mathrm{~s}$

150. Pressure in broken loop, pump side (PB-37

and $\mathrm{PB}-42$ ), from -6 to $42 \mathrm{~s}$

151. Pressure in broken loop, vessel side (PB-HN1),

from -20 to $600 \mathrm{~s}$

152. Pressure in broken loop, vessel side (PB-HN1),

from -6 to $42 \mathrm{~s}$

153. Pressure in vessel (PV-UP+10 and PV-LP-166),

from -20 to $600 \mathrm{~s}$

154. Pressure in vessel (PV-UP+10 and PV-LP-166),

from -6 to $42 \mathrm{~s}$

155. Pressure in intact loop accumulator (PU-ACC1),

from -20 to $600 \mathrm{~s}$

156. Pressure in intact loop accumulator (PU-ACC1),

from -6 to $42 \mathrm{~s}$.

157. Pressure in broken loop accumulator (PB-ACC2),

from -20 to $600 \mathrm{~s}$

158. Pressure in broken loop accumulator (PB-ACC2),

from -6 to $42 \mathrm{~s} \ldots \ldots \ldots \ldots 2 \ldots \ldots \ldots$

159. Pressure in steam generator, secondary side (PU-SGSD), from -20 to $600 \mathrm{~s} \ldots \ldots \ldots$. . . . . . . . . . 103

160. Pressure in steam generator, secondary side (PU-SGSD), from -6 to $42 \mathrm{~s}$

161. Pressure in steam generator, tube rupture simulation accumulator (PU-SGS3), from -20 to $600 \mathrm{~s}$

162. Pressure in steam generator, tube rupture simulation accumulator (PU-SGS3), from -6 to $42 \mathrm{~s}$. . . . . . . . . . . . . . . . 104

163. Pressure in pressurizer (PU-PRIZE), from -20 to $600 \mathrm{~s}$ 
164. Pressure in pressurizer (PU-PRIZE),

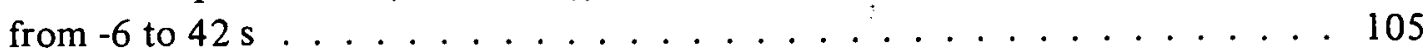

165. Pressure in pressure suppression tank (P-PSS),

from -20 to $600 \mathrm{~s} \ldots \ldots \ldots \ldots$. . . . . . . . . . . . . . . .

166. Pressure in pressure suppression tank (P-PSS),

from -6 to $42 \mathrm{~s} \ldots \ldots \ldots \ldots \ldots \ldots$

167. Differential pressure in intact loop (DPU-3-7),

from -20 to $600 \mathrm{~s} \ldots \ldots \ldots \ldots 7 . \ldots \ldots \ldots$

168. Differential pressure in intact loop (DPU-3-7),

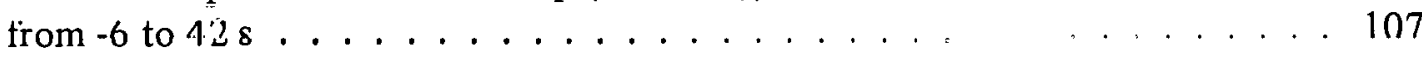

169. Differential pressure in intact loop (DPÜ-6-SGIP), from -20 to $600 \mathrm{~s} \ldots \ldots \ldots \ldots$. . . . . . . . . . . . . . . . . . .

170. Differential pressure in intact loop (DPU-6-SGIP), from -6 to $42 \mathrm{~s} \ldots \ldots \ldots \ldots$. . . . . . . . . . . . . . . . . . .

171. Differential pressure.in intact loop (DPU-SGOP-7), from -20 to $600 \mathrm{~s} \ldots \ldots \ldots . \ldots \ldots 9$

172. Differential pressure in intact loop (DPU-SGOP-7),

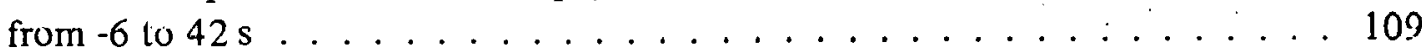

173. Differential pressure in intact loop (DPU-7-10), from -20 to $600 \mathrm{~s} \ldots \ldots \ldots \ldots \ldots \ldots \ldots$

174. Differential pressure in intact loop (DPU-7-10), from -6 to $42 \mathrm{~s} \ldots \ldots \ldots \ldots \ldots$

175. Differential pressure in intact loop (DPU-12-10), from -20 to $600 \mathrm{~s} \ldots \ldots \ldots \ldots \ldots \ldots \ldots$

176. Differential pressure in intact loop (DPU-12-1.0), from -6 to $42 \mathrm{~s} \ldots \ldots \ldots \ldots \ldots \ldots \ldots \ldots \ldots$

177. Differential pressure in intact loop, low range

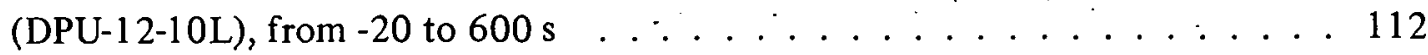

178. Differential pressure in intact loop, low range (DPU-12-10L), from -6 to $42 \mathrm{~s} \ldots \ldots \ldots \ldots \ldots \ldots 112$ 
179. Differential pressure in intact loop (DPU-12-15), from -20 to $600 \mathrm{~s} \ldots \ldots \ldots \ldots 113$

180. Differential pressure in intact loop (DPU-12-15), from -6 to $42 \mathrm{~s} \ldots \ldots \ldots \ldots \ldots 113$

181. Differential pressure in intact loop (DPU-15-3), from -20 to $600 \mathrm{~s} \ldots \ldots \ldots \ldots \ldots 114 \ldots \ldots \ldots \ldots$

182. Differential pressure in in tact loop (DPU-15-3), from -6 to $42 \mathrm{~s} \ldots \ldots \ldots \ldots \ldots 114 \ldots \ldots \ldots$

183. Differential pressure in intact loop, low range (DPU-15-3L), from -20 to $600 \mathrm{~s} \ldots \ldots \ldots 115$

184. Differential pressure in intact loop, low range (DPU-15-3L), from -6 to $42 \mathrm{~s}$

185. Differential pressure in pressurizer (DPU-PRESLL), from -20 to $600 \mathrm{~s}$ i 16

186. Differential pressure in pressurizer (DPU-PRESLL),

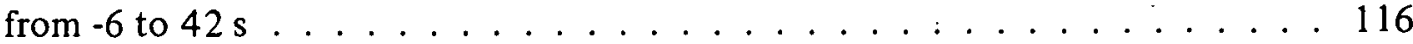

187. Differential pressure in intact loop (DPU-PR-4),

188. Differential pressure in intact loop (DPU-PR-4), from -6 to $42 \mathrm{~s}$.

189. Differential pressure in broken loop (DPB-21-IANN), from -20 to $600 \mathrm{~s}$

190. Differential pressure in broken loop (DPB-21-IANN), from -6 to $42 \mathrm{~s} \ldots \ldots \ldots \ldots \ldots \ldots$

191. Differential pressure in broken loop (DPB-23-CN1), from -20 to $600 \mathrm{~s} \ldots \ldots \ldots \ldots \ldots$

19.2. Differential pressure in broken loop (DPB-23-CN1), from -6 to $42 \mathrm{~s} \ldots \ldots \ldots \ldots$. . . . . . . . . . . . 119

193. Differential pressure in broken loop (DPB-CN1-24), from -20 to $600 \mathrm{~s}$ 
1.94. Differential pressure in broken loop (DPB-CN1-24),

from -6 to $42 \mathrm{~s} \ldots \ldots \ldots \ldots \ldots$

195. Differential pressure in broken loop (DPB-30-43),

from -20 to $600 \mathrm{~s}$

196. Differential pressure in broken loop (DPB-30-43),

from -6 to $42 \mathrm{~s} \ldots \ldots \ldots \ldots \ldots$. . . . . . . . . . . . . . . .

197. Differential pressure in broken loop (DPB-32U-36L),

from -20 to $600 \mathrm{~s} \ldots \ldots \ldots \ldots \ldots$. . . . . . . . . . . . . . . . . . 22

198. Differential pressurc in brokon loop (DPB-32U-36L),

from -6 to $42 \mathrm{~s} \ldots \ldots \ldots \ldots \ldots . \ldots \ldots 22$

199. Differential pressure in broken loop (DPB-36L-37),

from -20 to $600 \mathrm{~s}$

200. Differential pressure in broken loop (DPB-36L-37),

from -6 to $42 \mathrm{~s} \ldots \ldots \ldots \ldots \ldots$. . . . . . . . . . . . . . . . . . . . . . 23

201. Differential pressure in broken loop (DPB-38-40),

from -20 to $600 \mathrm{~s}$

202. Differential pressure in broken loop (DPB-38-40),

from -6 to $42 \mathrm{~s} \ldots \ldots \ldots \ldots \ldots$. . . . . . . . . . . . . . . . . . . . . . . .

203. Differential pressure in broken loop (DPB-40-42),

from -20 to $600 \mathrm{~s} \ldots \ldots \ldots \ldots \ldots \ldots$

204. Differential pressure in broken loop (DPB-40-42),

from -6 to $42 \mathrm{~s} \ldots \ldots \ldots \ldots \ldots . \ldots \ldots$

205. Differential pressure in broken loop

(DPB-42-HN1), from -20 to $600 \mathrm{~s} \ldots \ldots \ldots 126$

206. Differcntial pressiurc in broken loop

$(\mathrm{DPB}-42-\mathrm{HN} 1)$, from -6 to $42 \mathrm{~s} \ldots \ldots \ldots 126$

207. Differential pressure in broken loop

(DPB-HN1 43), from -20 to $6008 \ldots \ldots \ldots$. . . . . . . . . . 127

208. Differential pressure in broken loop (DPB-HN1-43),

from -6 to $42 \mathrm{~s} \ldots \ldots \ldots \ldots \ldots \ldots$

xviii 
209. Differential pressure in vessel (DPV-UP-IANN),

from -20 to $600 \mathrm{~s} \ldots \ldots \ldots \ldots \ldots \ldots \ldots$

210. Differential pressure in vessel (DPV-UP-IANN),

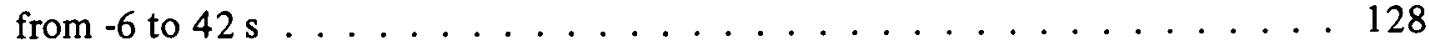

211. Differential pressure in vessel (DPV-O-9GQ),

from -20 to $600 \mathrm{~s}$. . . . . . . . . . . . . . . . . . . . . 129

212. Differential pressure in vesscl (DPV-O-9GQ),

from -6 to $42 \mathrm{~s} \ldots \ldots$. . . . . . . . . . . . . . . . . . . . . . . 129

213. Differential pressure in vessel (DPV-9-26QQ),

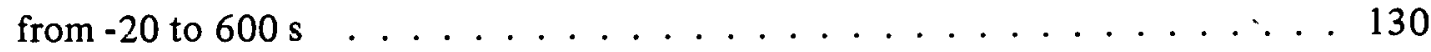

214. Differential pressure in vessel (DPV-9-26QQ),

from -6 to $42 \mathrm{~s} \ldots \ldots \ldots \ldots \ldots \ldots \ldots \ldots$

215. Differential pressure in vessel (DPV-9-166QQ),

from -20 to $600 \mathrm{~s} \ldots \ldots \ldots \ldots \ldots \ldots \ldots \ldots \ldots \ldots$

216. Differential pressure in vessel (DPV-9-166QQ),

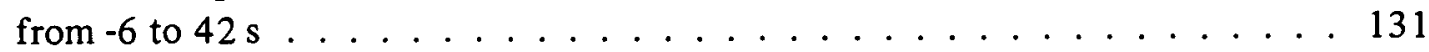

217. Differential pressure in vessel (DPV-26-55QM),

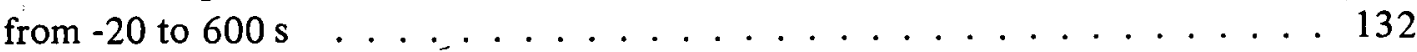

218. Differential pressure in vessel (DPV-26-55QM),

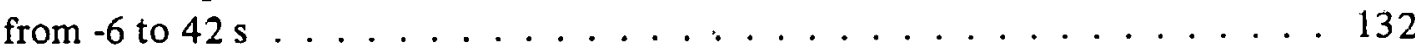

219. Differential pressure in vessel (DPV-55-110MM),

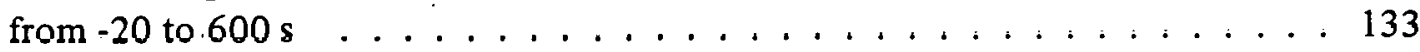

220. Differential pressure in vessel (DPV-55-110MM),

from -6 to $42 \mathrm{~s} \ldots \ldots \ldots \ldots \ldots \ldots \ldots \ldots \ldots \ldots$

221. Differential pressure in vessel (DPV-110-156MQ),

from -20 to $600 \mathrm{~s}$

222. Differential pressure in vessel (DPV-110-156MQ),

from -6 to $42 \mathrm{~s} \ldots \ldots \ldots \ldots \ldots \ldots \ldots \ldots$

223. Differential pressure in vessel (DPV-156-173QQ'),

from -20 to $600 \mathrm{~s} \ldots \ldots \ldots \ldots \ldots \ldots \ldots$ 
224. Differential pressure in vessel (DPV-156-173QQ),

from -6 to $42 \mathrm{~s} \ldots \ldots \ldots \ldots \ldots \ldots$

225. Differential pressure in vessel (DPV-166Q+10),

from -20 to $600 \mathrm{~s} \ldots \ldots \ldots \ldots \ldots \ldots$

226. Differential pressure in vessel (DPV-166Q+10),

from -6 to $42 \mathrm{~s} \ldots \ldots \ldots \ldots \ldots \ldots$

227. Differential pressure in intact loop accumulator

(DPU-ACC1-TB), from -20 to $600 \mathrm{~s} \ldots \ldots \ldots 137$

228. Differential pressure in intact loop accumülätor

(DPU-ACC1-TB), from 6 to $12 \mathrm{~g} \ldots \ldots \ldots \ldots \ldots$

229. Differential pressure in broken loop accumulator

(DPB-ACC2-TB), from -20 to $600 \mathrm{~s} \ldots \ldots \ldots \ldots$

230. Differential pressure in broken loop accumulator

(DPB-ACC2-TB), from -6 to $42 \mathrm{~s} \ldots \ldots \ldots \ldots$

231. Differential pressure in steam generator secondary

232. Differential pressure in steam gènerator secondary

(DPU-SG-SEC), from -6 to $42 \mathrm{~s}$

233. Differential pressure across steam generator outlet

orifice (DPU-SG-DISC), from -20 to $600 \mathrm{~s} \ldots \ldots$. . . . . . . . . . 140

234. Differential pressure across steam generator outlet orifice (DPU-SG-DİSC), from -6 to $42 \mathrm{~s} \ldots \ldots \ldots \ldots$

235. Differential pressure between simulated rupture injection line

and Spool 6 (DPU-SGS-6), from -20 to $600 \mathrm{~s}$

236. Differential pressure between simulated rupture injection line and Spool 6 (DPU-SGS-6), from' -6 to $42 \mathrm{~s}$

237. Differential pressure in intact loop tube rupture simulation accumulator (DPU-SGS3-TB), from -20 to $600 \mathrm{~s}$

238. Differential pressure in intact loop tube rupture simulation accumulator (DPÜ-SGS3-TB), from -6 to $42 \mathrm{~s}$ 
239. Differential pressure in pressure suppression tank (DP-PSS-TB), from -20 to $600 \mathrm{~s} \ldots \ldots \ldots 143$

240. Differential pressure in pressure suppression tank (DP-PSS-TB), from -6 to $42 \mathrm{~s} \ldots \ldots \ldots 143$

241. Volumetric flow in intact loop (FTU-1 and FTU-9), from -20 to $600 \mathrm{~s} \ldots \ldots \ldots$. . . . . . . . . . . . . . 144

242. Volumetric flow in intact loop (FTU-1 and FTU-9), from -6 to $42 \mathrm{~s} \ldots \ldots \ldots \ldots$. . . . . . . . . . . . . . . . 144

243. Volumetric flow in intact loop (FTU-13 and FTU-15), from -20 to $600 \mathrm{~s}$

244. Volumetric flow in intact loop (FTU-13 and FTU-15), from -6 to $42 \mathrm{~s} \ldots \ldots \ldots \ldots \ldots$. . . . . . . . . . . . . . . . . . . . .

245. Volumetric flow in broken loop (FTB-21), from -20 to $600 \mathrm{~s}$

246. Volumetric flow in broken loop (FTB-21), from -6 to $42 \mathrm{~s}$

247. Volumetric flow in broken loop (FTB-30 and FTB-37), from -20 to $600 \mathrm{~s}$

248. Volumetric flow in broken loop (FTB-30 and FTB-37), from -6 to $42 \mathrm{~s}$

249. Volumetric flow in core entrance (FTV-CORE-IN), from -20 to 600

250. Volumetric flow in core entrance (FTV-CORE-IN), from -6 to $42 \mathrm{~s} \ldots \ldots \ldots \ldots \ldots$. . . . . . . . . . . . . . . . . . . . . . .

251. Volumetric flow in intact loop high pressure injection line (FTU-HPIS), from -20 to $600 \mathrm{~s}$

252. Volumetric flow in intact loop high pressure injection line (FTU-HPIS), from -6 to $42 \mathrm{~s}$

253. Volumetric flow in broken loop high pressure injection line (FTB-HPIS), from -20 to $600 \mathrm{~s}$ 
254. Volumetric flow in broken loop high pressure injection line (FTB-HPIS), from -6 to $42 \mathrm{~s} \ldots \ldots \ldots . \ldots 150$

255. Volumetric flow in in tact loop low pressure injection line (FTU-LPIS), from -20 to $600 \mathrm{~s} \ldots \ldots \ldots \ldots 15 \ldots \ldots \ldots$

256. Volumetric flow in intact loop low pressure injection line (FTU-LPIS), from -6 to $42 \mathrm{~s} \ldots \ldots \ldots 151$

257. Volumetric flow in broken loop low pressure injection line (FTB-LPIS), from -20 to $600 \mathrm{~s}$

258. Volumetric flow in brokon loop low preceure injection line (FTB-LPIS), from -6 to $42 \mathrm{~s}$

259. Volumetric flow in in tact loop accumulator discharge line (FTU-ACC1), from -20 to $600 \mathrm{~s} \ldots \ldots \ldots \ldots$

260. Volumetric flow in intact loop accumulator discharge line (FTU-ACC1), from -6 to $42 \mathrm{~s} \ldots \ldots \ldots \ldots$. . . . . . 153

261. Volumetric flow in broken loop accumulator discharge line (FTB-ACC2), from -20 to $600 \mathrm{~s}$

262. Volumetric flow in broken loop accumulator discharge line (FTB-ACC2), from -6 to $42 \mathrm{~s}$

263. Volumetric flow from intact loop steam generator tube rupture simulation accurnulator (FTU=3G3), from -20 to 600.3

264. Volumetric flow from intact loop steam generator tube rupture simulation accumulator (FTU-SGS), from -6 to $42 \mathrm{~s}$

265. Volumetric flow from pressurizer (FTU-PRIZE), from -20 to $600 \mathrm{~s} \ldots \ldots \ldots \ldots \ldots \ldots$

266. Volumetric flow from pressurizer (FTU-PRIZE), from -6 to $42 \mathrm{~s}$

267. Fluid velocity in vessel (FTV-40A and FTV-40M), from -20 to $600 \mathrm{~s} \ldots \ldots \ldots \ldots \ldots \ldots \ldots$. . . . . . . . . . . . . . . . .

268. Fluid velocity in vessel (FTV-40A and FTV-40M), 
269. Momentum flux in in tact loop (FDU-1), from -20 to $600 \mathrm{~s} \ldots \ldots \ldots \ldots \ldots$. . . . . . . . . . . . . . . . . . .

270. Momentum flux in intact loop (FDU-1), from -6 to $42 \mathrm{~s} \ldots \ldots \ldots \ldots \ldots \ldots$

271. Momentum flux in intact loop (FDU-5), from -20 to $600 \mathrm{~s}$

272. Momentum flux in intact loop (FDU-5), from -6 to $42 \mathrm{~s} \ldots \ldots \ldots \ldots \ldots \ldots$

273. Momentum flux in intact loop (FDU-10), from -20 to $600 \mathrm{~s} \ldots \ldots \ldots \ldots$. . . . . . . . . . . . . . . . . . . . .

274. Momentum flux in intact loop (FDU-10), from -6 to $42 \mathrm{~s} \ldots \ldots \ldots \ldots$. . . . . . . . . . . . 160

275. Momentum flux in intact loop (FDU-13), from -20 to $600 \mathrm{~s}$

276. Momentum flux in intact loop (FDU-13), from -6 to $42 \mathrm{~s} \ldots \ldots \ldots \ldots 16 \ldots \ldots$

277. Momentum flux in broken loop (FDB-21), from -20 to $600 \mathrm{~s}$

278. Momentum flux in broken loop (FDB-21); from -6 to $42 \mathrm{~s}$

279. Momentum flux in broken loop (FDB-23), from -20 to $600 \mathrm{~s}$ s. . . . . . . . . . . . . . . . 163

280. Momentum flux in broken loop (FDB-23), from -6 to $42 \mathrm{~s} \ldots \ldots \ldots \ldots \ldots$. . . . . . . . . . . . . . . . . . . . . 63

281. Momentum flux in broken loop (FDB-30), from -20 to $600 \mathrm{~s}$ 164

282. Momentum flux in broken loop (FDB-30), from -6 to $42 \mathrm{~s}$ 164

283. Momentum flux in broken loop (FDB-37), from -20 to $600 \mathrm{~s}$ 
284. Momentum flux in broken loop (FDB-37),

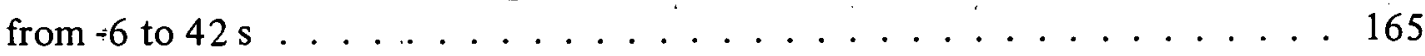

285. Momentum flux in broken.loop (FDB-42),

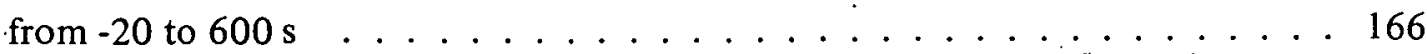

286. Momentum flux in broken loop (FDB-42),

from -6 to $42 \mathrm{~s} \ldots \ldots \ldots \ldots \ldots$

287. Momentum flux in core entrance (FDV-CORE-IN),

from -20 to $600 \mathrm{~s}$

288. Momentum flux in core entrance (FDV-CORE-IN),

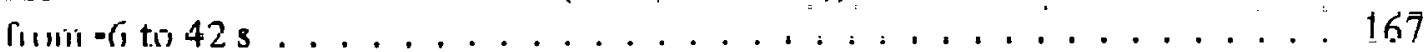

289. Density in intact loop (GÜ-1T and GU-1B),

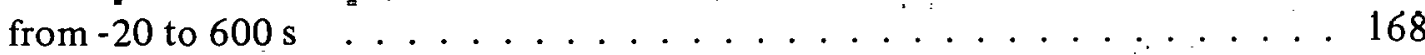

290. Density in intact loop (GU-1T and GU-1B),

from -6 to $42 \mathrm{~s} \ldots \ldots \ldots \ldots$. . . . . . . . . . . . . . . . . . . . .

291. Density in intact loop (GU-1C), from

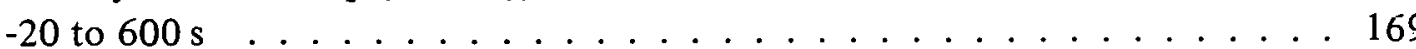

292. Density in intact loop (GU-1C), from

-6 to $42 \mathrm{~s} \ldots \ldots \ldots \ldots$. . . . . . . . . . . . . . . . 169

293. Density in intact loop (GU-5VR and GU-10VR),

from -20 to $600 \mathrm{~s}$

294. Density in intact loop (GU-5VR and GU-IUVK),

from -6 to $42 \mathrm{~s} \ldots \ldots \ldots \ldots \ldots$. . . . . . . . . . . . . . . . . . . . .

295. Density in intact loop (GU-13VR),

from -20 to $600 \mathrm{~s} \ldots \ldots \ldots \ldots \ldots$. . . . . . . . . . . . . . . . . . .

296. Density in intact loop (GU-13VR),

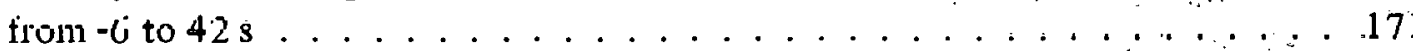

297. Density in intact loop (GU-15T and GU-15B),

from -20 to $600 \mathrm{~s}$

298. Density in intact loop (GU-15T and GU-15B),

from -6 to $42 \mathrm{~s}$. 
299. Density in intact loop (GU-15C),

from -20 to $600 \mathrm{~s}$

300. Density in intact loop (GU-15C),

from -6 to $42 \mathrm{~s} \ldots \ldots \ldots \ldots \ldots \ldots \ldots \ldots \ldots \ldots$

301. Density in broken loop (GB-21T and

GB-21B), from -20 to $600 \mathrm{~s} \ldots \ldots \ldots \ldots \ldots \ldots$

302. Density in broken loop (GB-21T and

GB-21B), from -6 to $42 \mathrm{~s}$

303. Density in broken loop (GB-21C),

from -20 to $600 \mathrm{~s}$

304. Density in broken loop (GB-21C),

from -6 to $42 \mathrm{~s} \ldots \ldots \ldots \ldots \ldots \ldots \ldots \ldots \ldots$

305. Density in broken loop (GB-23VR),

from -20 to $600 \mathrm{~s}$

306. Density in broken loop (GB-23VR),

from -6 to $42 \mathrm{~s}$

307. Density in broken loop (GB-30T and GB-30B),

from -20 to $600 \mathrm{~s}$

308. Density in broken loop (GB-30T and GB-30B),

from -6 to $42 \mathrm{~s}$

309. Density in broken loop (GB-30C),

from -20 to $600 \mathrm{~s}$

310. Density in broken loop (GB-30C),

from -6 to $42 \mathrm{~s}$

311. Density in broken loop (GB-37HZ),

from -20 to $600 \mathrm{~s}$

312. Density in broken loop (GB-37HZ),

from -6 to $42 \mathrm{~s}$

313. Density in broken loop (GB-42VR),

from -20 to $600 \mathrm{~s}$ 
314. Density in broken loop (GB-42VR),

from -6 to $42 \mathrm{~s} \ldots \ldots \ldots \ldots \ldots$. . . . . . . . . . . . . . . . . .

315. Denșity in vessel (GV-COR-150HZ),

from -20 to $600 \mathrm{~s}$

316. Density in vessel (GV-COR-150HZ),

from -6 to $42 \mathrm{~s}$

317. Density in vessel (GVLP-165HZ and

GVLP-172HZ), from -20 to $600 \mathrm{~s}$

318. Density in vessel (GVLP-165HZ and

GVLP $172 \mathrm{HZ}$ ), from 6 to 123

319. Mass flow in intact loop (FDU-1,

GU-1C), from -20 to $600 \mathrm{~s}$

320. Mass flow in intact loop (FDU-1,

GU-1C), from -6 to $42 \mathrm{~s}$

321. Mass flow in intact loop (FTU-1,

GU-1C), from -20 to $600 \mathrm{~s}$

322. Mass flow in intact loop (FTU-1,

GU-1C), from -6 to $42 \mathrm{~s}$

323. Mass flow in intact loop (FDU-5,

GU-5VR), from -20 to $600 \mathrm{~s}$

324. Mass flow in in tact loop (FDU-5,

GU-5VR), from -6 to $42 \mathrm{~s}$

325. Mass flow in intact loop (FTU-9,

GU-10VR), from -20 to $600 \mathrm{~s}$

326. Mass flow in intact loop (FTU-9,

GU-10VR), from -6 to $42 \mathrm{~s}$

327. Mass flow in intact loop (FDU-10,

GU-10VR), from -20 to $600 \mathrm{~s}$

328. Mass flow in intact loop (FDU-10,

GU-10VR), from -6 to $42 \mathrm{~s}$

xxvi 
329. Mass flow in intact loop (FDU-13,

GU-13VR), from -20 to $600 \mathrm{~s}$

330. Mass flow in intact loop (FDU-13, GU-13VR), from -6 to $42 \mathrm{~s}$

331. Mass flow in intact loop (FTU-13, GU-13VR), from -20 to $600 \mathrm{~s}$

332. Mass flow in intact loop (FTU-13, GU-13VR), from -6 to $42 \mathrm{~s}$

333. Mass flow in in tact loop (FTU-15, GU-15C), from -20 to $600 \mathrm{~s} \ldots \ldots \ldots$. . . . . . . . . . . 190

334. Mass flow in intact loop (FTU-15, GU-15C), from -6 to $42 \mathrm{~s} \ldots \ldots \ldots \ldots$. . . . . . . . . . . 190

335. Mass flow in broken loop (FDB-21, GB-21C), from -20 to $600 \mathrm{~s}$

336. Mass flow in broken loop (FDB-21, GB-21C), from -6 to $42 \mathrm{~s}$

337. Mass flow in broken loop (FTB-21, GB-21C), from -20 to $600 \mathrm{~s}$

338. Mass flow in broken loop (FTB-21, GB-21C), from -6 to $42 \mathrm{~s}$

339. Mass flow in broken loop (FDB-23, GB-23VR), from -20 to $600 \mathrm{~s}$

340. Mass flow in broken loop (FDB-23, GB-23VR), from -6 to $42 \mathrm{~s}$

341. Mass flow in broken loop (FDB-30, GB-30C), from -20 to $600 \mathrm{~s}$

342. Mass flow in broken loop (FDB-30, GB-30C), from -6 to $42 \mathrm{~s}$

343. Mass flow in broken loop (FTB-30, GB-30C), from -20 to $600 \mathrm{~s}$ 
344. Mass flow in broken loop (FTB-30,

GB-30C), from -6 to $42 \mathrm{~s}$

345. Mass flow in broken loop (FDB-37,

GB-37HZ), from -20 to $600 \mathrm{~s} \ldots \ldots 196$

346. Mass flow in broken loop (FDB-37,

GB-37HZ), from -6 to $42 \mathrm{~s} \ldots \ldots \ldots$. . . . . . . . . . 196

347. Mass flow in broken loop (FTB-37,

GB-37HZ), from -20 to $600 \mathrm{~s}$

348. Mass flow in broken loop (FTB-37,

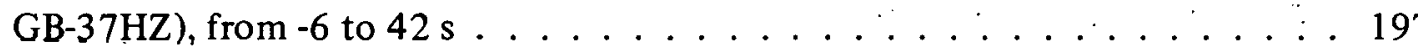

349. Mass flow in vessel (FDV-CORE-IN,

GV-COR-150HZ), from -20 to $600 \mathrm{~s}$

198

350. Mass flow in vessel (FDV-CORE-IN,

GV-COR-150HZ), from -6 to $42 \mathrm{~s}$

351. Mass flow in vessel (FTV-CORE-IN,

GV-COR-150HZ), from -20 to $600 \mathrm{~s}$

352. Mass flow in vessel (FTV-CORE-IN,

GV-COR-150HZ), from -6 to $42 \mathrm{~s}$

353. Core heater rod total power (PWRCOR T-1

and PWRCOR T-2), from 20 to $600 \mathrm{~s} \ldots \ldots \ldots$

354. Core heater rod total power (PWRCOR T-1

and PWRCOR T-2), from -6 to $42 \mathrm{~s}$

355. Core heater voltage (VOLTCOR-T),

from -20 to $600 \mathrm{~s}$

356. Core heater voltage (VOLTCOR-T),

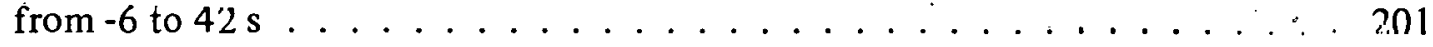

357. Core heater total current (AMPCOR-T),

from -20 to $600 \mathrm{~s}$

358. Core heater total current (AMPCOR-T),

from -6 to $42 \mathrm{~s} \ldots \ldots \ldots . \ldots . . \ldots . . \ldots 202$ 
359. Primary pump current (PUMPU-CUR),

from -20 to $600 \mathrm{~s} \ldots \ldots \ldots 203$

360. Primary pump current (PUMPU-CUR),

from -6 to $42 \mathrm{~s} \ldots \ldots \ldots \ldots$. . . . . . . . . . . . . . 203

361. Primary pump speed (PUMPU-RPM),

from -20 to $600 \mathrm{~s} \ldots \ldots \ldots$. . . . . . . . . . . . . 204

362. Primary pump speed (PUMPU-RPM),

from -6 to $42 \mathrm{~s} \ldots \ldots \ldots \ldots$. . . . . . . . . . . . . . 204

B-1. Geometry used for processing of density data

obtained from two-beam gamma densitometers . . . . . . . . . . . 221

C-1. Fluid temperature in broken

loop $($ TFB-23) . . . . . . . . . . . . . . . . . 230

C-2. Fluid temperature in downcomer

annulus (TFV-ANN-35A) . . . . . . . . . . . . . 230

C-3. Fluid temperature in lower

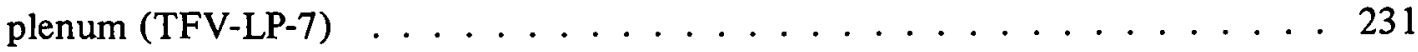

C-4. Fluid temperature in pressurizer surge line (TFU-PRIZE) $\ldots \ldots \ldots \ldots$

C-5. Material temperature in

intact loop (TMU-1T16) . . . . . . . . . . . . . . . . 232

C-6. Material temperature in

vessel filler $($ TMV-CI-70A) . . . . . . . . . . . . . . 232

C-7. Core heater temperature,

Rod E-4 (TH-E4-09) . . . . . . . . . . . . . . . . . 233

C-8. Core heater temperature,

Rod E-4 (TH-E4-27) . . . . . . . . . . . . . . . . . . 233

C.-9. Cone heater temperature,

Rod E-4 (TH-E4-55) . . . . . . . . . . . . . . . . . . . 234

C-10. Pressure in intact loop,

Spool 13 (PU-13) . . . . . . . . . . . . . . . . 234 
C-11. Pressure in broken loop, Spool 23 (PB-23) ..................... 235

C-12. Differential pressure in intact

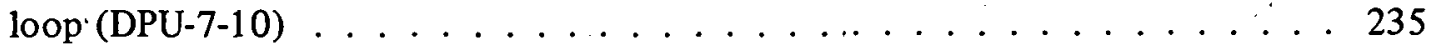

C-13: Differential pressure in intact loop (DPU-12-10) . . . . . . . . . . . . . . . 236

C:14. Differential pressure in intact

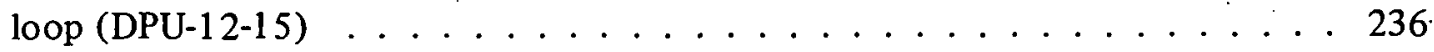

C-15. Volumetric flow in intact

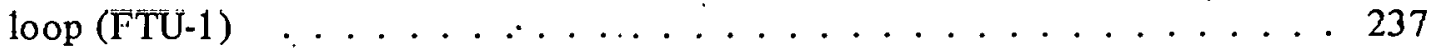

C-16: Volumetric flow in intact loop $($ FTU-15) . . . . . . . . . . . . . . . . . 237

C-17. Volumetric flow in intact loop high pressure injection line (F:TU-HPIS)

C-1 8. Volumetric flow in intact loop

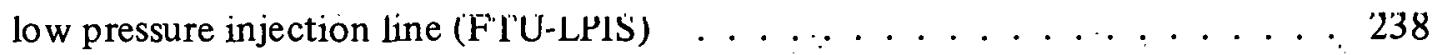

C-19. Volumetric flow in intact loop

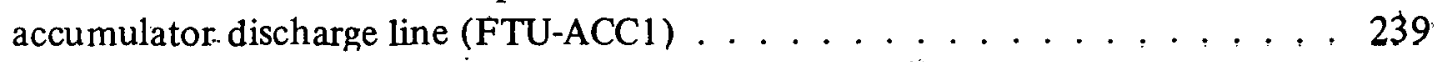

C-20. Fluid velocity in vessel

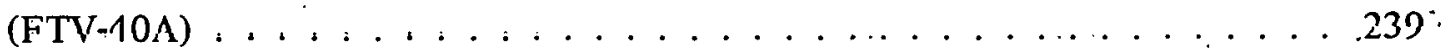

C-21. Fluid velocity in vessel (FTV-40M)

C-22. Density in intact loop (GU-1T)

C-23. Density in intact loop (GU-1B)

C-24. Density in in tact loop (GU-1C)

C-25. Density in intact loop (GU-10VR) 
C-26. Density in in tact loop

(GU-15T)

C-27. Density in intact loop

(GU-15B)

C-28. Density in intact loop

(GU-15C)

C-29. Density in broken loop

(GB-23VR)

C-30. Density in vessel

(GV-COR-150HZ)

C-31. Density in vessel

(GVLP-165HZ)

C-32. Density in vessel

(GVLP-172HZ)

C-33. Mass flow in intact loop

(FDU-1, GU-1C)

C-34. Mass flow in intact loop

(FTU-1, GU-1C) . . . . . . . . . . . . . . . 246

C-35. Mass flow in intact loop

(FDU-5, GU-5VR)

C-36. Mass flow in intact loop

(FTU-13, GU-13VR)

C-37. Mass flow in intact loop

(FTU-15, GU-15C)

C-38. Mass flow in broken loop

(FDB-21, GB-21C)

C=39. Mass flow in broken loop

(FTB-21, GB-21C)

$C-40$. Mass flow in vessel

(FTV-CORE-IN, GV-COR-150HZ) 


\section{TABLES}

I. Conditions at Blowdown Initiation $\ldots \ldots \ldots \ldots$

II. Primary Coolant Temperature Distribution

Prior to Rupture . . . . . . . . . . . . . . : . 7

III. Water Chemistry Prior to Blowdown . . . . . . . . . . 8

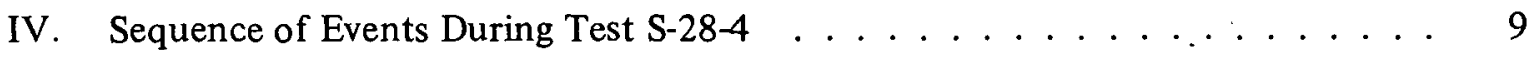

V. Data Presentation for Semiscale Mod-1 lest S-28-4 . . . . . . . . . 17

B-I. Constants for Pressure Measurement

Corrections (Test S-28-4) . . . . . . . . . . . . . . 214

B-II. Constants for Differential Pressure

Measurement Corrections (Test S-28-4) f . . . . . . . . . . 216

B-III. Constants for Momentum Flux

Measurement Corrections (Test S-28-4) f . . . . . . . . . . . 218

B-IV. Constants for Density Measurement Conversions

to Engineering Units (Test S-28-4) . . . . . . . . . . . . . . 220

C-I. Random Error Variance (Test S-28-4) . . . . . . . . . . . . . . . 226

C-II. General Measurement Engineering Error

Sources and Error Values (Test $\mathrm{S}-28-4) \ldots \ldots$. . . . . . . . . . 250

C-III. Time Periods when Flow Kegme Errors

were Applied (Test S-28-4) . . . . . . . . . . . . . . . 256 


\title{
EXPERIMENT DATA REPORT FOR SEMISCALE MOD-1
}

\author{
TEST S-28-4
}

\section{(STEAM GENERATOR TUBE RUPTURE TEST)}

\section{INTRODUCTION}

The Semiscale Mod-1 experiments represent the current phase of the Semiscale Program conducted by EG\&G Idaho, Inc. for the United States Government. The program, which is sponsored by the Nuclear Regulatory Commission through the Department of Energy ${ }^{[a]}$, is part of the overall program designed to investigate the response of a pressurized water reactor (PWR) system to a hypothesized loss-of-coolant accident (LOCA). The underlying objectives of he Semiscale program are to quantify the physical processes controlling system behavior during a LOCA and to provide an experimental data base for assessing reactor safety evaluation models. The Semiscale Mod-1 Program has the further objective of providing support to other experimental programs in the form of instrumentation assessment, optimization of test series, selection of test parameters, and evaluation of test results.

Test S-28-4 was conducted July 1, 1977 in the Semiscale Mod-1 system as part of the steam generator tube rupture test series (Test Series 28). This series was designed to obtain thermal-hydraulic response data from blowdown, refill, and reflood transients in a simulated nuclear reactor with a heated core to study system response during a LOCA with steam generator tube ruptures. The specific objective of Test S-28-4 was to refine the definition of the upper limit set by Test S-28-1 and to investigate the range of steam generator tube ruptures over which high peak cladding temperatures can occur. Hardware configuration and test parameters were selected to yield a system response that simulates the response of a PWR to a hypothesized LOCA with subsequent refill and reflood.

The purpose of this report is to present the test data in an uninterpreted but readily usable form for use by the nuclear community in advance of detailed analysis and interpretation. Section II briefly describes the system configuration, procedures, initial test conditions, and events that are applicable to. Test S-28-4; Section III presents the data graphs and provides comments and supporting information necessary for interpretation of the data. A Idescription of the overall Semiscale Program and test series, a more detailed description of the Semiscale Mod-1 system, and a description of the measurement and data processing techniques and uncertainties can be found in Reference 1.

[a] Test S-28-4 was conducted through the Energy Research and Development Administration. 


\section{SYSTEM, PROCEDURES, CONDITIONS, AND EVENTS FOR TEST S-28-4}

The following system configuration, procedures, initial test conditions, and events are specific to Test S-28-4 as indicated.

\section{SYSTEM CONFIGURATION AND TEST PROCEDURES}

The Semiscale Mod-1 system used for this test consisted of a pressure vessel with internals, including a 40-rod core with 36 electrically heated rods; an intact loop with steam generator, pump, and pressurizer; a broken loop with simulated steam generator, simulated pump, and two rupture assemblies; coolant injection accumulators for the cold legs of the intact and broken loops, and a heated accumulator for the intact loop hot leg; high and low pressure injection pumps for each of the system loops; and a pressure suppression system with a suppression tank, header, and heated steam supply system. For Test S-28-4, the volume of the lower plenum was reduced to $0.014980 \mathrm{~m}^{3}$ by the addition of a metal filler piece. Semiscale Mod-1 experimental system configuration information is described further in Reference 1. Figures 1 and 2 show the system configuration for Test S-28-4.

For Test S-28-4, 33 rods of the 40-rod electrically heated core were operated at a peak power density of approximately $35.05 \mathrm{~kW} / \mathrm{m}$, three rods (Rods D-4, E-4, and E-5) were operated at a peak power density of $36.88 \mathrm{~kW} / \mathrm{m}$ to yield a slightly peaked power profile, and four rods (Rods C-3, D-5, F-3, and F-6) were unpowered to simulate the effect of control rod guide tubes. The resulting total core power was approximately $1.40 \mathrm{MW}$.

In preparation for the test, the accumulators for the intact and broken loop cold legs were filled with treated demineralized wătèr, drained to the speciffed initial levels, and pressurized with nitrogen to $4288 \mathrm{kPa}$. The steam generator rupture system accumulator for the intact loop hot leg was filled with treated demineralized water, drained to the specified initial level, heated to $542 \mathrm{~K}$, and pressurized to $7239 \mathrm{kPa}$. The system was filled with treated demineralized water and vented at strategic points to ensure a liquid full system. Prior to warmup the system was pressurized to check for leakage, system instrumentation was checked, and transducer readings were initialized. Warmup to initial test conditions was accomplished with the heaters in the vessel core. Heatup of the broken loop piping was accomplished with bypass lines which served to allow circulation through the broken loop. During warmup, the purification and sampling systems were valved into the primary system to maintain water chemistry requirements and to provide a water sample at system conditions for subsequent analysis. At 55.6-K-temperature intervals during warinup, detector readings were sampled to allow the integrity of the measurement instrumentation and the operability of the data acquisition system to be checked.

Prior to the initial core power level being established, the pressure suppression system was pressurized to $210 \mathrm{kPa}$ with saturated steam from the steam supply system. After the 


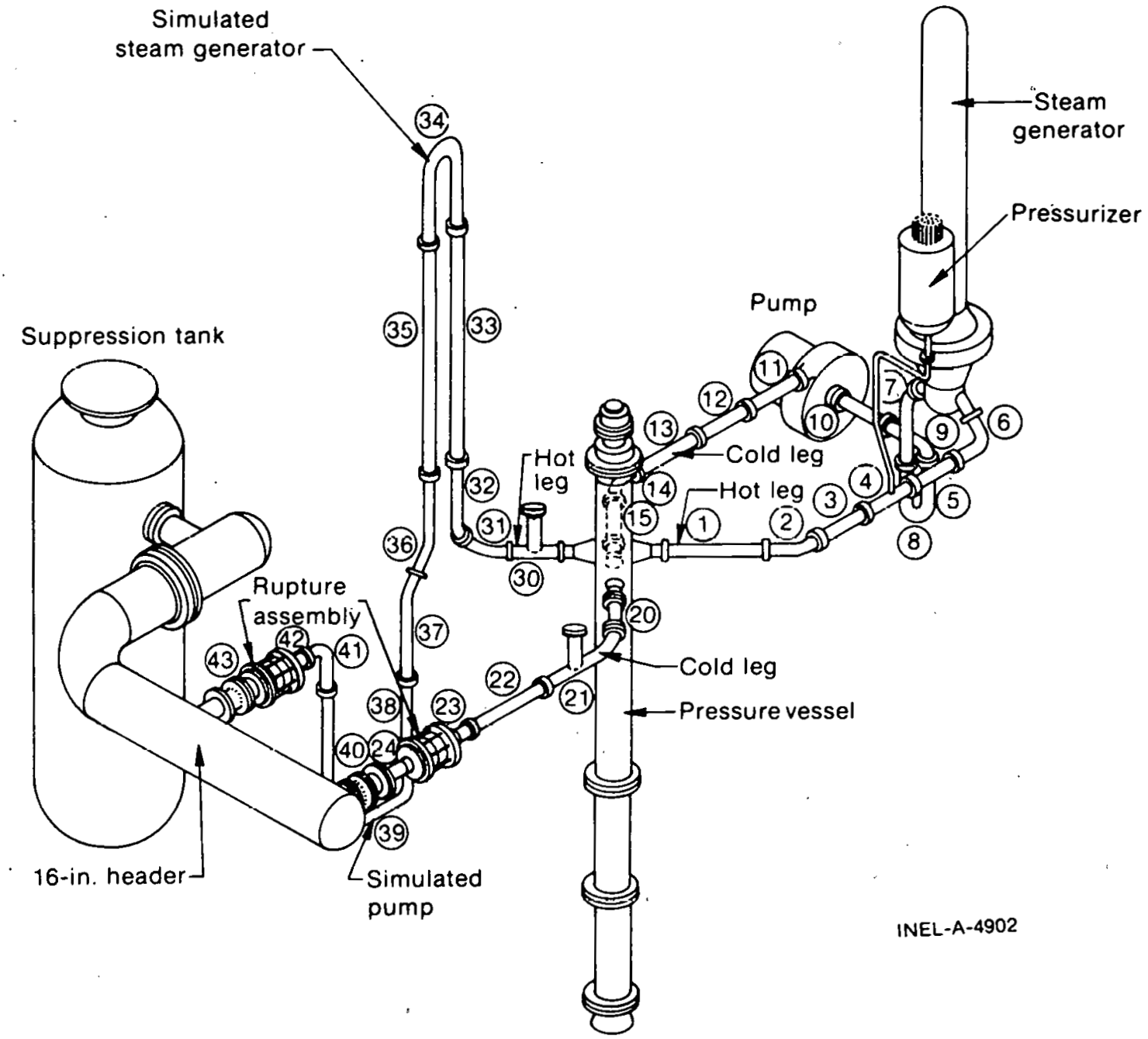

Fig. 1 Semiscale Mod-1 system for cold leg break configuration -isometric.

core power was increased to $1.40 \mathrm{MW}$, initial test conditions were held for $164 \mathrm{~s}$ to establish equilibrium in the system. At the end of this period all auxiliary systems including the bypass lines were isolated to prevent blowdown through those systems.

The system was successfully subjected to a simulated double-ended cold leg break through two rupture assemblies and two blowdown nozzles, each having a break area of $0.000243 \mathrm{~m}^{2}$. Pressure to operate the rupture assemblies and initiate blowdown was taken from an accumulator system filled with water and pressurized to $15600 \mathrm{kPa}$ with gaseous nitrogen. Immediately (within $0.02 \mathrm{~s}$ ) after initiation of blowdown, the lines to the accumulator were again isolated. The effluent from the primary system was injected into the pressure suppression system which was vented to maintain a constant pressure of $210 \mathrm{kPa}$. At blowdown, power to the primary coolant circulation pump was reduced and the pump was allowed to coast down to a speed of $1470 \mathrm{rpm}$ which was maintained for the duration 


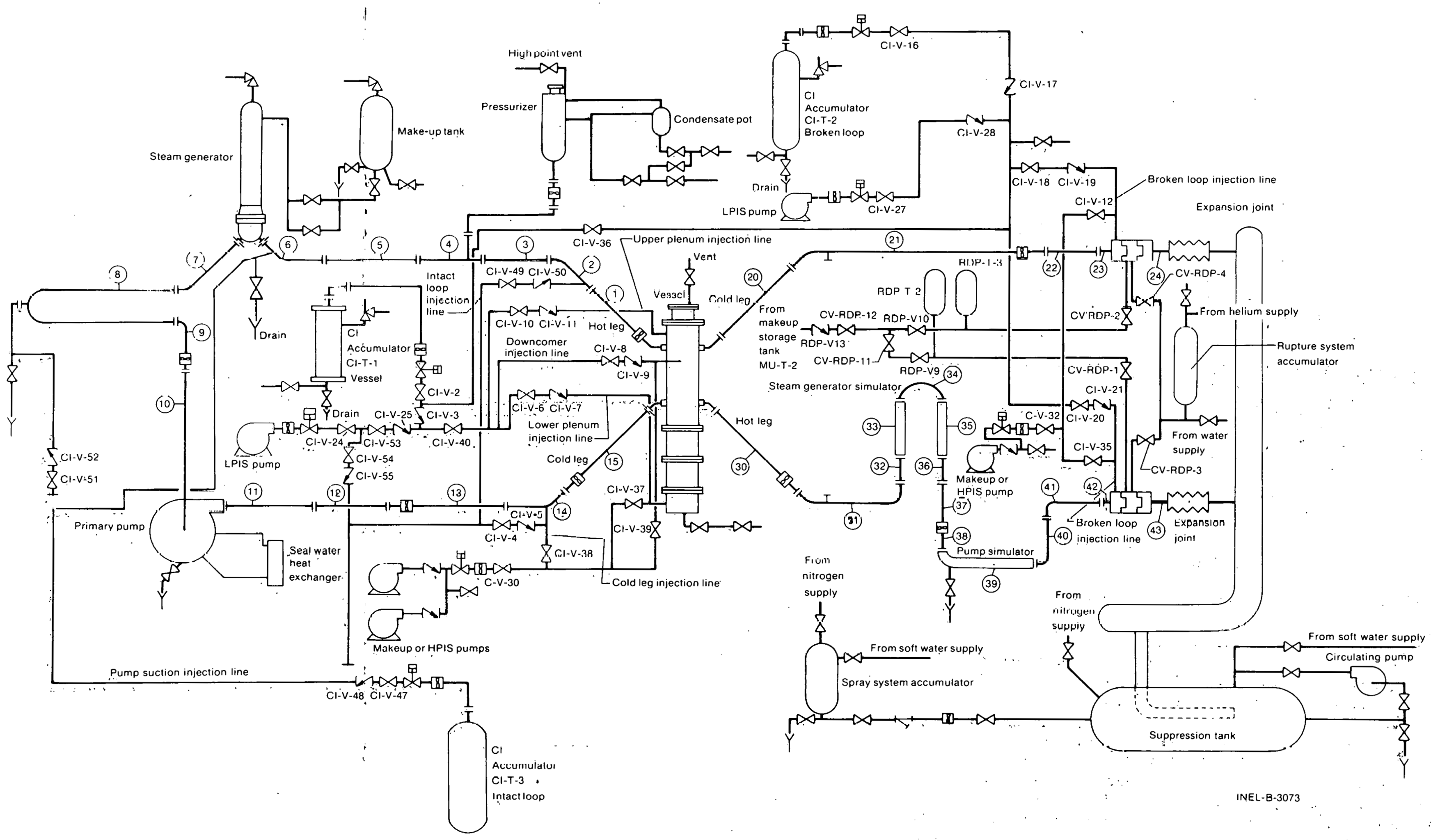

Fi.g. 2 Semiscale Mod-1 system for cold leg break configuration -schematic. 
of the test. During the blowdown transient, power to the electrically heated core was automatically controlled to simulate the thermal response of nuclear heated fuel rods.

For Test S-28-4, the coolant injection systems were arranged to discharge into both system loops at the cold leg injection points (Spool 14 and Spool 42). The high pressure coolant injection pumps were started immediately after initiation of blowdown $(0 \mathrm{~s})$ and continued to the end of the test $(640 \mathrm{~s})$. Low pressure coolant injection was initiated $28 \mathrm{~s}$ after blowdown at a system pressure of $1034 \mathrm{kPa}$ and continued until test termination $(640 \mathrm{~s})$. Coolant injection from the intact loop accumulator (CI-T-1) started $16.6 \mathrm{~s}$ after blowdown and was terminated $41 \mathrm{~s}$ after blowdown. The broken loop accumulator (CI-T-2) began injection $3.5 \mathrm{~s}$ after blowdown, nitrogen discharge began $31 \mathrm{~s}$ after rupture and was terminated $67 \mathrm{~s}$ after blowdown. The steam generator rupture system accumulator (CI-T-3) began injection at $39 \mathrm{~s}$ at a system pressure of $655 \mathrm{kPa}$ and was terminated $440 \mathrm{~s}$ after blowdown with nitrogen discharging into the system beginning $370 \mathrm{~s}$ after blowdown.

\section{INITIAL TEST CONDITIONS AND SEQUENCE OF EVENTS}

Conditions in the Semiscale Mod-1 system at initiation of blowdown are given in Tables I and II; the primary system water chemistry prior to blowdown is given in Table III; and the sequence of events relative to rupture is given in Table IV. 


\begin{tabular}{|c|c|c|c|}
\hline \multirow[b]{3}{*}{ Core power (MW) } & & \multicolumn{2}{|c|}{ Test S-28-4 } \\
\hline & & Measured $^{[a]}$ & \multirow{2}{*}{$\frac{\text { Specified }}{1.43 \pm 0.03}$} \\
\hline & $\because \div$ & 1.40 & \\
\hline \multicolumn{2}{|l|}{$\begin{array}{l}\text { Intact loop cold leg fluid } \\
\text { temperature }(K)\end{array}$} & 556.5 & $557.6 \pm 1$ \\
\hline \multicolumn{2}{|l|}{$\begin{array}{l}\text { Hot leg to cold leg temperature } \\
\text { differential }(K)\end{array}$} & 37.6 & $36.7 \pm 0.5$ \\
\hline \multicolumn{2}{|l|}{ Pressurizer pressure (kPa) } & 15646 & $15603 \pm 172$ \\
\hline \multicolumn{2}{|l|}{ Pressurizer liquid mass $(\mathrm{kg})^{[\mathrm{h}]}$} & 9.24 & 9.07 \\
\hline \multicolumn{2}{|l|}{$\begin{array}{l}\text { Steam generator feedwater } \\
\text { temperature }(K)\end{array}$} & 494 & $\begin{array}{r}497+6 \\
\text { or } \\
-17\end{array}$ \\
\hline \multicolumn{2}{|l|}{$\begin{array}{l}\text { Steam generator liquid level (from } \\
\text { bottom of tube sheet) }(\mathrm{cm})\end{array}$} & 277.7 & $294.6 \pm 5$ \\
\hline \multicolumn{2}{|l|}{$\begin{array}{l}\text { Broken loop fluid temperature. } \\
\text { (pump side) (K) }\end{array}$} & 589.5 & $591 \pm 3$ \\
\hline \multicolumn{2}{|l|}{$\begin{array}{l}\text { Broken loop fluid temperature } \\
\quad \text { (vessel side) (K) }\end{array}$} & 555 & $\begin{array}{l}\text { Not } \\
\text { Specified }\end{array}$ \\
\hline 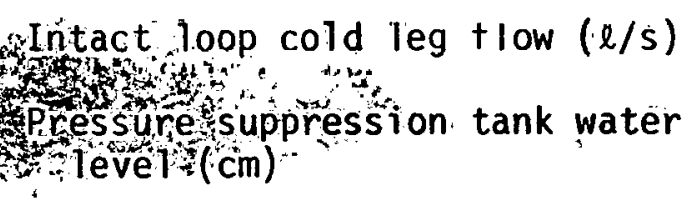 & . & $\begin{array}{l}9.05 \\
121\end{array}$ & $\begin{array}{l}{[c]} \\
121\end{array}$ \\
\hline \multicolumn{2}{|l|}{$\begin{array}{l}\text { Pressure suppression tank } \\
\text { pressure }(\mathrm{kPa})\end{array}$} & 210 & $241.3 \pm 6.9$ \\
\hline \multicolumn{2}{|l|}{$\begin{array}{l}\text { Pressure suppression tanik water } \\
\text { temperature }(K)\end{array}$} & 288 & $<297$ \\
\hline \multicolumn{4}{|c|}{$\begin{array}{l}\text { [a] Measured initial conditions are taken from digital scan read just } \\
\text { prior to blowdown. Those measured conditions which did not meet } \\
\text { the specified initial conditions were considered acceptable for } \\
\text { analysis purposes within the test objectives. }\end{array}$} \\
\hline \multicolumn{4}{|c|}{ [b] Pressurizer liquid mass including surge line. } \\
\hline \multicolumn{4}{|c|}{$\begin{array}{l}\text { [c] Flow is not specified, since it must be adjusted to achieve the } \\
\text { required differential temperature across the core. }\end{array}$} \\
\hline
\end{tabular}




\section{TABLE II}

PRIMARY COOLANT TEMPERATURE DISTRIBUTION PRIOR TO RUPTURE ${ }^{[a]}$

\begin{tabular}{llc}
\hline & \multicolumn{1}{c}{ Test S-28-4 } \\
$\begin{array}{l}\text { Vessel lower plenum (upper portion } \\
\text { above filler block) }\end{array}$ & Detector & Temperature (K) \\
Intact loop hot leg (near vessel) & TFV-LP-7 & 556 \\
Intact loop cold leg (near pump inlet) & RBU-2 & 594 \\
Intact loop cold leg (near vessel) & TFU-10 & 557 \\
Broken loop cold leg (near nozzle) & TFB-23 & 557 \\
Broken loop hot leg (near vessel) & TFB-30 & 592 \\
Broken loop cold leg (near nozzle) & TFB-42 & 590 \\
\hline [a]. Data taken from digital scan 0.5 s before blowdown. & \\
\hline
\end{tabular}




\section{TABLE III}

WATER CHEMISTRY PRIOR TO BLOWDOWN ${ }^{[\mathrm{a}]}$

\section{Test S-28-4}

$\mathrm{pH}$

10.95

Conductivity $(\mu \mathrm{mho} / \mathrm{cm})$

193

Lithium $(\mu / \mathrm{ml})$

6.4

Chrorides (ppm)

$<0.11$

Fluorides $(11 / \mathrm{ms})^{[b]}$

$<0.5$

Oxygen $(\mathrm{cc} / \ell)$

0.09

Total gas (cc/e)

127.1

Suspended solids (ppm)

[a] Water sample taken at a system pressure of approximately $15603 \mathrm{kPa}$ and a system tempera.ture of approximately $555 \mathrm{~K}$ (cold leg).

[b] Present analytica] methods prevent accurate determination of fluorides at concentrations of less than $0.4 \mathrm{ppm}$. 
TABLE IV

SEQUENCE OF EVENTS DURING TEST S-28-4[a]

\section{Event}

Core power level established

Bypass lines valved out of system

Blowdown initiated

Pump power reduced

High pressure injection system pumps

$$
\text { started [b] }
$$

ECC accumulators valved in

Steam generator feedwater and discharge valves closed

Core power decay transient started

Time Relative to Rupture (s)

\section{1}

$-2.5$

0

0

Low pressure injection system pumps

$$
\text { started [b] }
$$

Core power tripped off $[\mathrm{c}]$

[a] A time-controlled sequencer was used to control critical events during the test.

[b] Injection from ECC accumulators and high and low pressure injection system pumps does not start. until system pressure drops below accumulator or pump pressure, respectively.

[c] Core power tripped manualiy at termination of test. 


\section{DATA PRESENTATION}

The data from Semiscale Mod-1 Test S-28-4 are presented with brief comment. Processing analysis has been performed only to the extent necessary to obtain appropriate engineering units and to ensure that the data are reasonable and consistent. In all cases, in, converting transducer output to engineering units, a homogeneous fluid was assumed. Further interpretation and analysis should consider that sudden decompression processes such as those occurring during blowdown may have subjected the measurement devices to nonhomogeneous fluid conditions.

The performance of the system during Test S-28-4 was monitored by 220 detectors. The data obtained were recorded on both digital and analog data acquisition systems. The analog system was used to provide redundant data. The long term data ( -32 to $640 \mathrm{~s})$ presented in this report were recorded at an effective sample rate of 1.369 points per second. Long term plots are given for -20 to $600 \mathrm{~s}$ rather than for the full 640 -s recording time to provide better resolution. Short term data and plots ( -6 to $42 \mathrm{~s}$ ) were recorded at an effective sample rate of 19.17 points per second.

The data are presented in some instances in the form of composite graphs to facilitate comparison of the values of given variables at several locations. The scales selected for the graphs do not reflect the obtainable resolution of the data. (The data processing techniques are described further in Reference 1 and Appendix A).

Figures 3 through 8 and Table $\mathrm{V}$ provide supporting information for interpretation of the data graphs shown in Figures 9 through 362 and provide relative locations of all detectors. used during test S-28-4. Table $\mathrm{V}$ groups the measurements according to measurement type; identifies the specific measurement location and range of the detoctor and actual recording range of the data acquisition system; provides brief commenls etgarding the data; and references the measurements and cuimitents to the corresponding figure. Figircs 9 through 362 present all the blowdown and reflood data obtained. Time zero on the graphs is the time of rupture initiation. Appendix A provides information explaining the data acquisition system capabilities. Appendix B provides information explaining posttest data processing for data conversion into engineering units and data adjustments. Presented in Appendix $C$ is an analysis of selected data which provide a guide to the uncertainty associated with data measurements in the Semiscale Mod-1 system. 


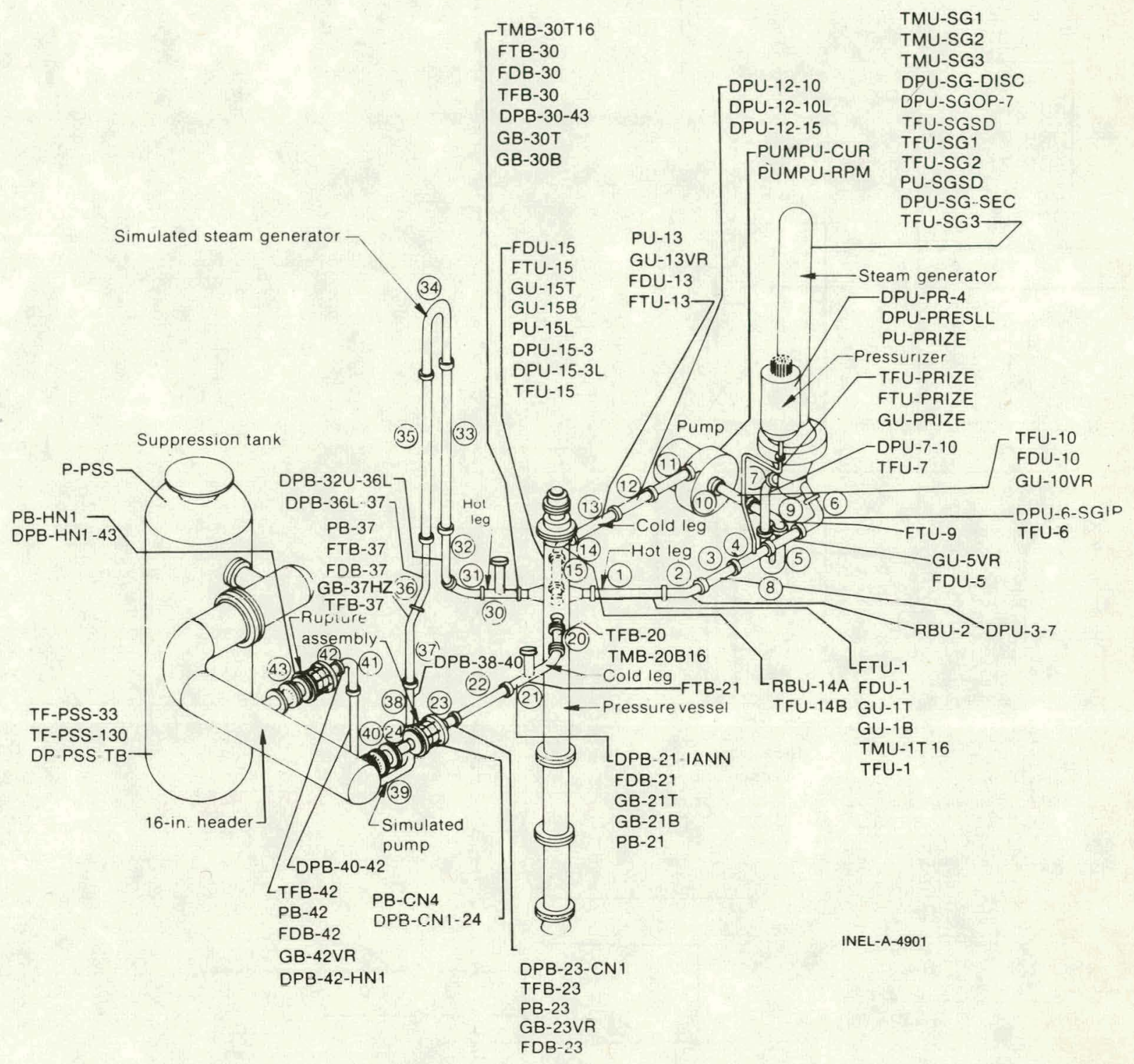

Fig. 3 Semiscale Mod-1 system and instrumentation for cold leg break configuration -- isometric. 


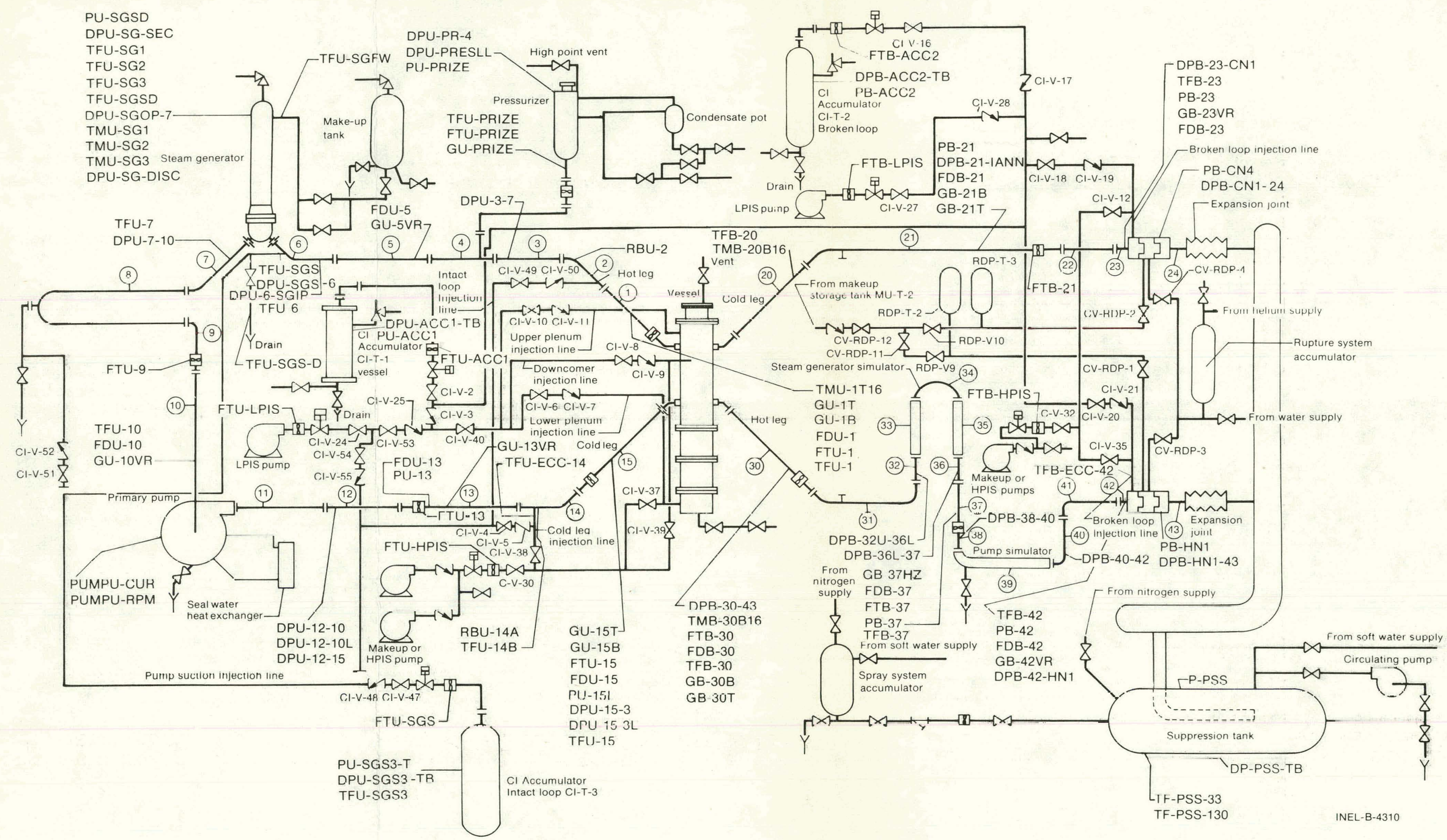

Fig. 4 Semiscale Mod-1 system and instrumentation for cold leg break configuration -- schematic. 


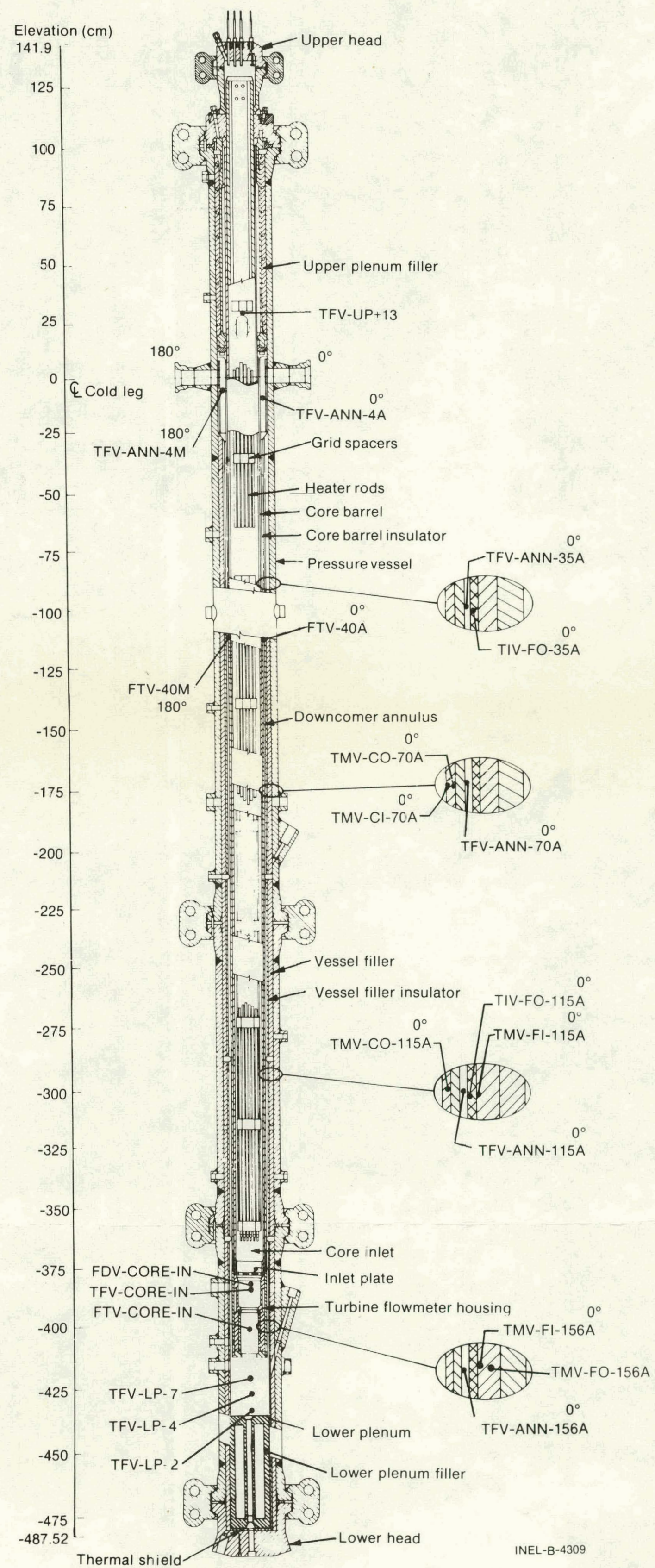

Fig. 5 Semiscale Mod-1 pressure vesse1 -- cross section showing instrumentation. 
Distance from cold leg $\&(\mathrm{~cm})$
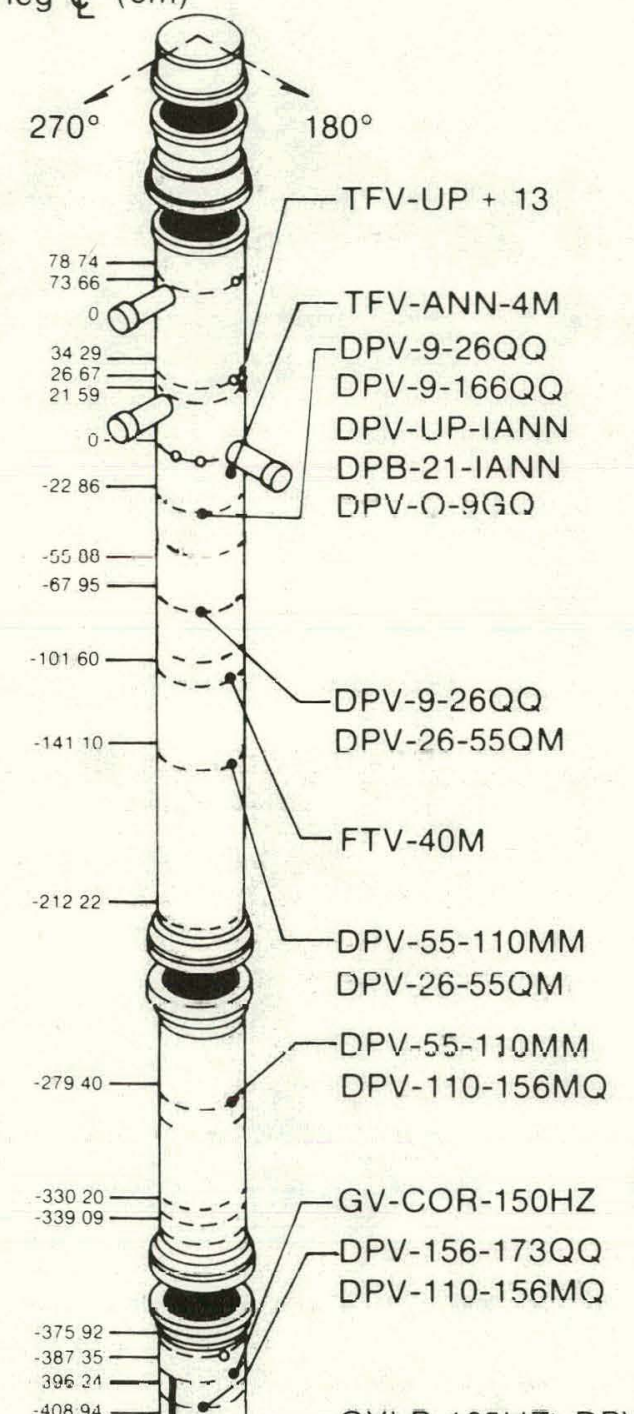

$-408.9$

-41910 GVLP-165 HZ

$-43942 \Rightarrow$ GVLP $-172 \mathrm{HZ}$

-449212
15720

15720 DPV-156-173QQ

$48752 \longrightarrow$

DPV $-166 Q+10$

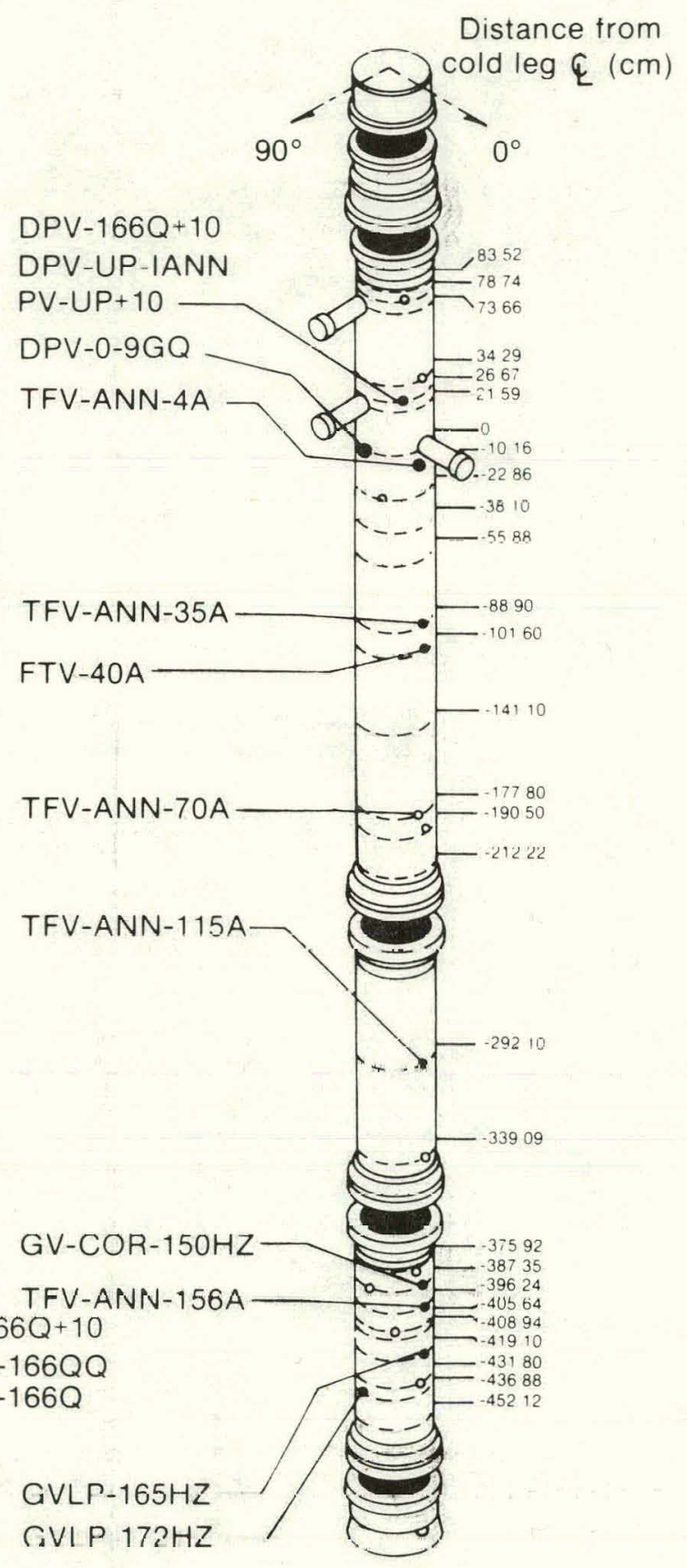

INEL-A-4307

Fig. 6 Semiscule Mod-1 pressure vessel -- isomelric showing instrumentation. 


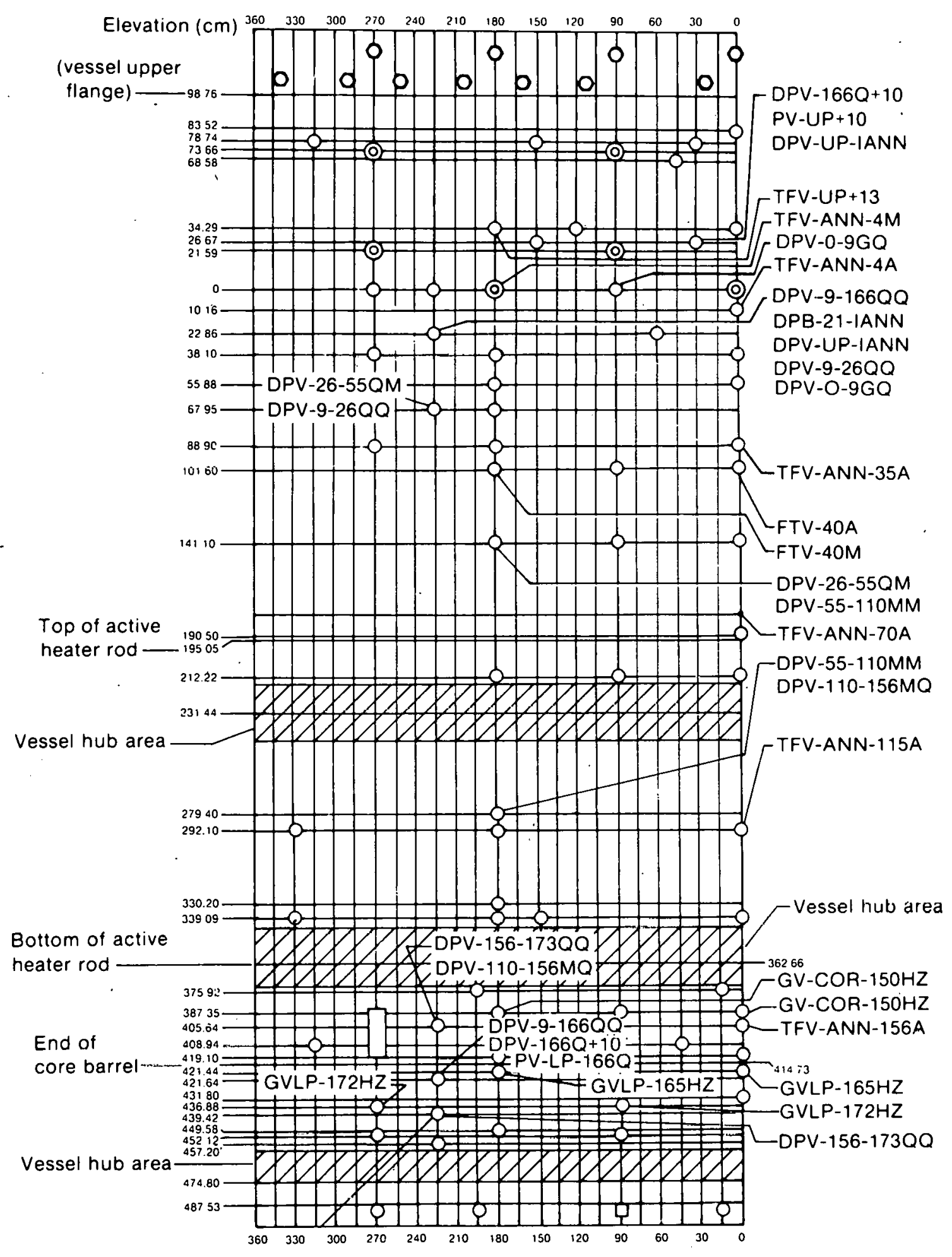

INEL-A-4306

Fig. 7 Semiscale Mod-1 pressure vessel -- penetrations and instrumentation. 


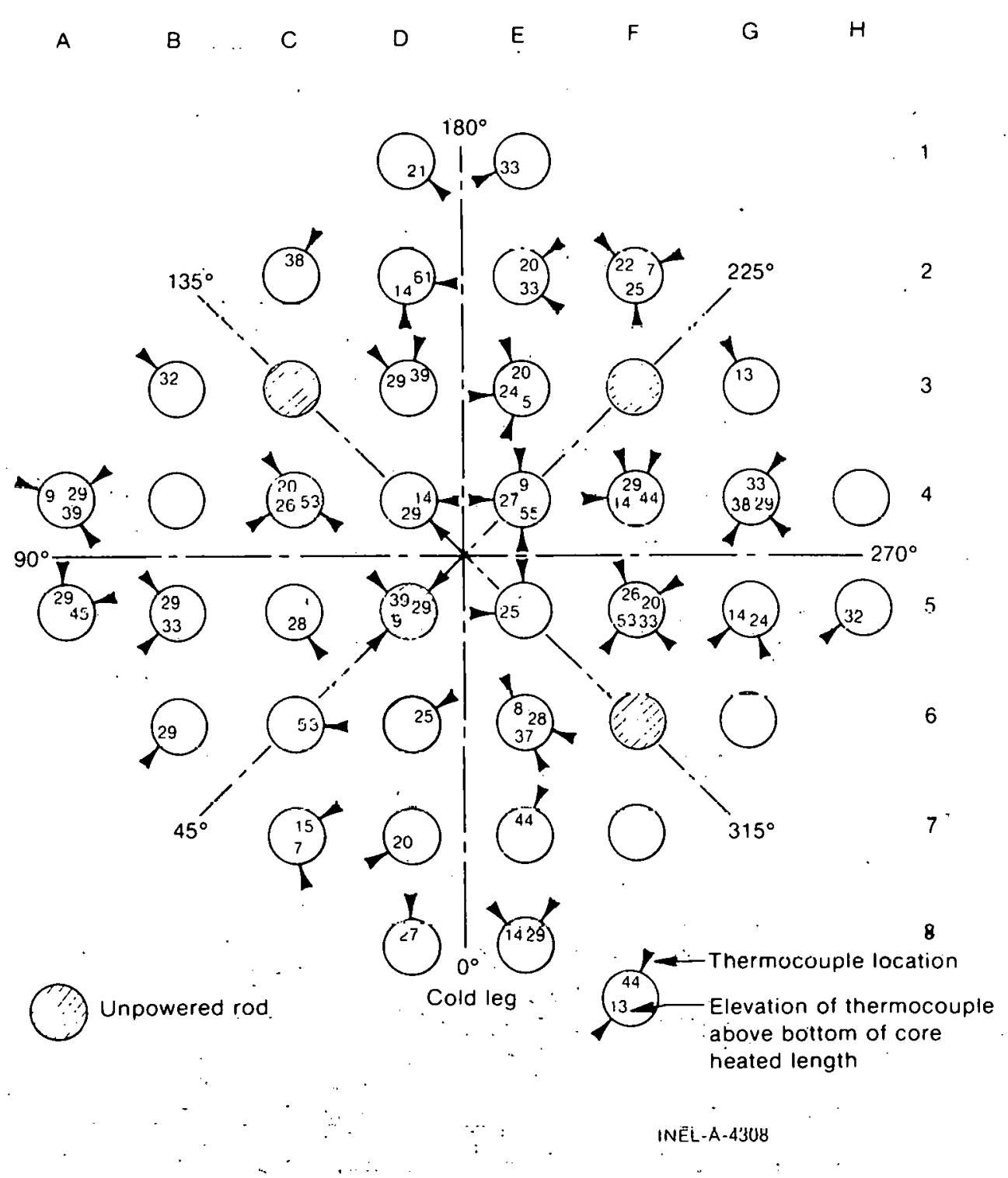

Fig. 8 Semiscale Mod- 1 heated core -- plan view. 


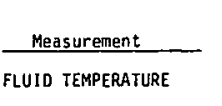

Intact Loop

TFU-1

RBU-2

TFU-6.

TFU-7

TFU:10

RBU-14A

TFU- 14B

TFU-15

Broken Loop

TFB-20

TFB-23

TFB-30

TFB-37

TFB-42

inlet Annulus

IFV-ANN-4A

TFV-ANN-4M

Euwncomer Aññulus

TFV-ANN-35A

TFV-ANN-70A

IFV-ANN=115A

IFV-ANN-156A

Upper Plenum

$T F V-U P+13$

Lower Plenum

$T F V-L P=2$

TFV-LP-4

TFB-LP-7

raro

TFV-CORE-IN

Location and Coments $[a]$
$\begin{aligned} & \text { Chromel-Alumel thermocoupies unless } \\ & \text { specified otherwise. }\end{aligned}$

Hot leg, Spool 1, $54 \mathrm{~cm}$ from yessel center.

Hot leg, Spool 2, $117 \mathrm{~cm}$ from vessel center (platínum resistance bulb).

Hot leg, Spoor 6, $290 \mathrm{~cm}$ from vessel center.

Cold leg, Spool 7, $624 \mathrm{~cm}$ from ressel center.

Cold leg, Spoot $10,367 \mathrm{~cm}$ from vessel center.

Cold leg, Spool 14, $109 \mathrm{~cm}$ from vessel center, upstream of cold leg injection port (platinum resistance
bulb).

Cold leg, Spool 14, $99 \mathrm{~cm}$ from vessel center, downstream of cold leg injection port.

cold leg, spool 15, 54 cin rivm vessel center.

Cold leg, spool 20, 52 cm from vessel center.

cold leg, Spool 23, $232 \mathrm{~cm}$ from vessel center.' ups tream of vessalside nozzle.

Hot leg, Spool $30,40 \mathrm{~cm}$ from vessei center.

cold leg, Spool 37, $703 \mathrm{~cm}$ from vessel center a long hot leg, dis-

Cold leg, Spool 42, $1054 \mathrm{~cm}$ from vessel center along hot leg, upstrean of pump-side nozzle.

$10 \mathrm{~cm}$ below cold leg ceinlerline, $0.5 \mathrm{~cm}$ from vessel wall. Type J

$0^{\circ}$.

$\frac{\operatorname{Range}^{[\mathrm{a}]}}{\text { Data Acquisition }}$

Detector $\quad \begin{gathered}\text { Data Acquisition } \\ \text { System }\end{gathered}$ Figure ${ }^{[a]}$

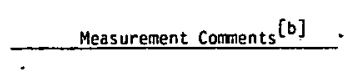

0 to $1533 x$

0 to $584 \mathrm{~K}$

0 to $820 \mathrm{~K}$

9.10

0 to $811 \mathrm{~K}$

0 to $811 \mathrm{~K}$

9. 10

11,12

13, 14

13,14

0 to $811 k$

0 to $811 k$

15, 16

15. 16

17. 18

0 to $1533 \mathrm{~K} \quad 0$ to $820 \mathrm{~K}$

19, 20

$.19,20$

21,22

21,22

21,22

$180^{\circ}$.

Centered in annulus, Type $J$ ironconstantan thernocouples.

0 to $1033 k$

0 to $701 k$

2.1. 24

${ }_{0^{\circ}}^{89} \mathrm{~cm}$ below cold leg centerline,

II to $1033 \mathrm{~K}$

0 to $701 \mathrm{~K}$

$178 \mathrm{~cm}$ below cold leg centerline,
$0^{\circ}$.

$292 \mathrm{~cm}$ below culd leg centerlíne,

$396 \mathrm{~cm}$ below cold leg centerline,

0 to $1533 \mathrm{~K}$

0 to $1533 \mathrm{~K} \quad 0$ to $820 \mathrm{~K}$

23,24

25,26

25,26

25.26

25,26

Questionable data, appears to be

27,28

In upper plenum, $34 \mathrm{~cm}$ above
coid leg centeri ine at. $180^{\circ}$.

On fluid thermocouple rack, $2.54 \mathrm{~cm}$

0 to $1533 \mathrm{~K}$

0 to $820 \mathrm{~K}$

5 rom above top of lower plenun riller block.

$10 \mathrm{~cm}$ above top of lower plenum filler block. $18 \mathrm{~cm}$ above top of Inwer plonum filler
block.

0 to $1533 \mathrm{~K}$

0 to $820 \mathrm{~K}$

29,30

29,30

29,30

In core flow mixer box, $381 \mathrm{~cm}$ below cold leg center
part of FDV-CORE-IN). 


\section{TABLE V (continued)}

\begin{tabular}{|c|c|c|c|c|c|c|}
\hline \multirow[b]{2}{*}{ Méasurement } & \multirow[b]{2}{*}{ Location and Comnents ${ }^{[\mathrm{a}]}$} & \multicolumn{2}{|c|}{ Range $^{[a]}$} & \multirow[b]{2}{*}{ Figure $^{[\mathrm{a}]}$} & & \multirow[b]{2}{*}{ Measurement Corments ${ }^{[b]}$} \\
\hline & & Detector & $\begin{array}{l}\text { Data Acquisition } \\
\text { System } \\
\end{array}$ & & & \\
\hline \multicolumn{7}{|l|}{ Core Grid Spacers } \\
\hline Grid Spacer 5 & $\begin{array}{l}140 \mathrm{~cm} \text { be low cold leg centerline, } \\
54.6 \mathrm{~cm} \text { above top of heated length. }\end{array}$ & 0 to $1533 \mathrm{~K}$ & 0 to $1579 \mathrm{~K}$ & & & \\
\hline TFG- $5 \mathrm{CO}-45$ & $\begin{array}{l}\text { Thermocouple in space def ined by } \\
\text { Columns } C \text { and } D \text {, Kows } 4 \text { and } 5 \text {. }\end{array}$ & & & 33,34 & & \\
\hline Grid Spacer 6 & $\begin{array}{l}193 \mathrm{~cm} \text { below cold leg centerline, } \\
1.3 \mathrm{~cm} \text { above top of heated length. }\end{array}$ & & & & & \\
\hline TFG- 6 CD- 45 & $\begin{array}{l}\text { Thermocouple in space defined by } \\
\text { columns } C \text { and } 0 \text {, Rows } 4 \text { and } 5 \text {. }\end{array}$ & & & 35,36 & & \\
\hline Grid Spacer 10 & $\begin{array}{l}363 \mathrm{~cm} \text { be low cold leg centerline } \\
\text { ot bottem of heatpofi lenath. }\end{array}$ & & & & & \\
\hline TFG- $10 A B-45$ & $\begin{array}{l}\text { Thernocouple in space det ined by } \\
\text { Col unns } A \text { and } B \text {, Rows } 4 \text { and } 5 \text {. }\end{array}$ & & & 37,38 & & \\
\hline Eci systen & & $050 \div 627 \mathrm{r}$ & 0 to $584 \mathrm{~K}$ & & & \\
\hline TFU-ECC-14 & $\begin{array}{l}\text { In ECC line leading to intact } \\
\text { loop spoul } 14 .\end{array}$ & & & 39,40 & & \\
\hline IFB-ECC- 42 & $\begin{array}{l}\text { In ECC line leading to broken } \\
\text { Ionn spool } 42 .\end{array}$ & & & 41,12 & & \\
\hline Stedill Generator & & 0 to $1533 \mathrm{~K}$ & 0 tn $58 \dot{4} x$ & & & · \\
\hline IFU-SGFW & $\begin{array}{l}\text { In feedwater line leading to steam } \\
\text { generator. }\end{array}$ & & & 43,44 & & . \\
\hline TFU-S6s:n & $\begin{array}{l}\text { In steam dome, } 329 \mathrm{~cm} \text { above } \\
\text { bot tom of tube sheet. }\end{array}$ & & & 45,46 & & \\
\hline TFU-5GI & $\begin{array}{l}\text { Secondary side, } 30 \mathrm{~cm} \text { above bottom } \\
\text { of tube sheet. }\end{array}$ & & & 47,40 & & \\
\hline Tru-sos & $\begin{array}{l}\text { Sarnndary side. } 61 \mathrm{~cm} \text { above bulluu } \\
\text { of tube sheet. }\end{array}$ & & . & 47,48 & & \\
\hline TFU-SG3 & $\begin{array}{l}\text { Secondary side, } 122 \mathrm{~cm} \text { above bottóm } \\
\text { of tube sheet. }\end{array}$ & & & 47,48 & & \\
\hline $\begin{array}{l}\text { Steam Generator } \\
\text { Rupturc System }\end{array}$ & & 0 to $1533 \mathrm{~K}$ & 0 to $584 \mathrm{~K}$ & & & \\
\hline TFU-SGS3 & In bottom of Accumulator Tank T-3. & & & 98,50 & & \\
\hline TFU-SGS & $\begin{array}{l}\text { In injection line leading from } \\
\text { Accupulator Tank TS } 3 \text { just upstream } \\
\text { of junction with Spooo } 6 \text {. }\end{array}$ & & & 51,52 & & . \\
\hline TFU-SGS-D & $\begin{array}{l}\text { In dratin of injection line leadting } \\
\text { frum Al.cumulator Tank T-3. }\end{array}$ & & & 53,54 & & \\
\hline Pressurizer & & & & & & \\
\hline TFU-PRIZEE & $\begin{array}{l}\text { In surge line, itudr pressurizer } \\
\text { exit, between turbine flowmeter } \\
\text { and pressurizer. }\end{array}$ & $0 \operatorname{tn} 15.33 \mathrm{~K}$ & 0 to $820 \mathrm{~K}$ & 55,56 & & \\
\hline$\frac{\text { Pressure Suppression }}{\text { System }}$ & . & 0 to $1533 \mathrm{~K}$ & 0 to $584 \mathrm{~K}$ & & & \\
\hline TF-PSS- 33 & $84 \mathrm{~cm}$ trom botzom ur lauk. & & & 57.58 & & \\
\hline$T F-P S S-130$ & $330 \mathrm{LII}$ from bottori of tank. & & & 57,58 & & \\
\hline MATERIAL TEMPERATURE & $\begin{array}{l}\text { Chrome 1-Alumel thermocoup les } \\
\text { uniess specified otherwise. }\end{array}$ & & - & & & \\
\hline Intact Loop & . & O i. $1593 \mathrm{is}$ & $0 \operatorname{ton} 82 n x$ & . & & \\
\hline TMU-1Til6 & $\begin{array}{l}\text { Hot leg, Spooi } 1, \text { top, } 1.6 \mathrm{~mm} \\
\text { from pipe ID, } 54 \mathrm{~cm} \text { from vessel } \\
\text { center. }\end{array}$ & & & 59,60 & & \\
\hline Broken Loop & & 0 to $1533 \mathrm{k}$ & 0 to $584 \mathrm{~K}$ & & & \\
\hline TMB-20B16 & $\begin{array}{l}\text { Cold leg, spool } 20 \text {, bottom, } 1.6 \mathrm{~mm} \\
\text { from pipe } 10,52 \mathrm{~cm} \text { from vessel } \\
\text { ceullet. }\end{array}$ & & . & 61,62 & & . \\
\hline Vessel riller & Type $J$ iron-constantan & 0 to $1033 \mathrm{~K}$ & 0 to $701 x$ & & & \\
\hline TMV-F I-115A & $\begin{array}{l}292 \mathrm{~cm} \text { below cold leg centerline, } \\
1.6 \mathrm{~mm} \text { from filler ID; } 0^{\circ} \text {. }\end{array}$ & & & 63,64 & . & . \\
\hline TMV-FI-156A & $\begin{array}{l}396 \mathrm{~cm} \text { below cold leg centerline, } \\
1.6 \mathrm{~mm} \text { from filler } \mathrm{gD}, 0^{\circ} \text {. }\end{array}$ & & . & 63,64 & & \\
\hline TMV-F0-156A & $\begin{array}{l}396 \mathrm{~cm} \text { below cold leg centerline, } \\
1.65 \mathrm{~cm} \text { from filler }] 0,0^{\circ} \text {. }\end{array}$ & & & 65,66 & & \\
\hline
\end{tabular}




\begin{tabular}{|c|c|c|c|c|c|}
\hline \multirow[b]{2}{*}{ Measurement } & \multirow[b]{2}{*}{ Location and Comments ${ }^{[\mathrm{a}]}$} & \multicolumn{2}{|c|}{ Range $^{[a]}$} & \multirow{3}{*}{ Figure $^{[a]}$} & \multirow[b]{2}{*}{ Measurement Comments ${ }^{[\mathrm{b}]}$} \\
\hline & & Detector & $\begin{array}{l}\text { Data Acquisition } \\
\text { System }\end{array}$ & & \\
\hline$\frac{\text { Vessel filler }}{\text { linsulator }}$ & & 0 to $1033 \mathrm{~K}$ & 0 to $701 \mathrm{~K}$ & & \\
\hline TIV-FO-35A & $\begin{array}{l}89 \mathrm{~cm} \text { below cold leg centerline, } \\
0^{\circ} .\end{array}$ & & & 67,68 & - \\
\hline TIV-FO-i15A & $\begin{array}{l}292 \mathrm{~cm} \text { belum cold leg centerline, } \\
0^{2} \text { : }\end{array}$ & & & 67,60 & \\
\hline Core Barrel & Type $\mathrm{J}$ iron-constantan the rmocouples & 0 to $1033 \mathrm{~K}$ & 0 to $701 \mathrm{k}$ & & \\
\hline TMV -C1-70A & $\begin{array}{l}178 \mathrm{~cm} \text { below cold leg centerline, } \\
1.6 \mathrm{~mm} \text { from core barrel } 10,0^{\circ} \text {. }\end{array}$ & & & 69,70 & \\
\hline TAY $-C 0-70 \mathrm{~A}$ & $\begin{array}{l}178 \mathrm{~cm} \text { below cold leg centerline, } \\
1.6 \mathrm{~mm} \text { from core barrel } 00,0^{\circ} \text {. }\end{array}$ & & & 71,72 & $\therefore$ \\
\hline TMV-CO-115A & $\begin{array}{l}292 \mathrm{~cm} \text { below cold leg centerline, } \\
1.6 \mathrm{~mm} \text { from curre borrel } 00, \mathrm{u}^{*} \text {. }\end{array}$ & & & 71,72 & . \\
\hline Core Housing Filler & & 0 to $1533 \mathrm{~K}$ & 0 to $820 \mathrm{~K}$ & & \\
\hline TMV-HF-115W & $\begin{array}{l}\text { On core housing filler, } 292 \mathrm{~cm} \\
\text { below ronld leg canterling, } \\
\text { from outer surface, } 315^{\circ} \text {. }\end{array}$ & & & 73. 74 & \\
\hline$T M V-H F-127 W$ & $\begin{array}{l}\text { On core housing filler, } 323 \mathrm{~cm} \\
\text { below cold leg centerline, } 5 \mathrm{~mm} \\
\text { from outer surface, } 315^{\circ} \text {. }\end{array}$ & & & 73,74 & \\
\hline TMV-HF-1 138W & $\begin{array}{l}\text { On core housing filler, } 351 \mathrm{~cm} \\
\text { below cold leg centerline, } 5 \text { math } \\
\text { from outer suiface, } 315^{\circ} \text {. }\end{array}$ & & & 73,74 & \\
\hline Steam Generator & & 0 to $1533 \mathrm{~K}$ & 0 to $584 \mathrm{~K}$ & & \\
\hline TMU-SGI & $\begin{array}{l}\text { Oil a steam generator tube, } 30 \mathrm{~cm} \\
\text { above bottom of tube sheet, on } 00 \\
\text { of tube. }\end{array}$ & & & 75,76 & \\
\hline TMU-5G2 & $\begin{array}{l}\text { On a steam generator tube, } 51 \mathrm{~cm} \\
\text { above bottom of tube sheet, on } 00 \\
\text { of tule. }\end{array}$ & ' & & 75,76 & \\
\hline TMU-SG3 & $\begin{array}{l}\text { On a steam generator tube, } 122 \mathrm{~cm} \\
\text { above bottom of tube sheet, on oD } \\
\text { of tube. }\end{array}$ & - & & 75,76 & \\
\hline $\begin{array}{l}\text { CORE HEATER } \\
\text { CLADDING TEMPERATURES }\end{array}$ & Chromel-Alumel thernocouples. & . & & & \\
\hline High Power Heaters & & 0 to $1533 \mathrm{x}$ & 0 to $1579 \mathrm{~K}$ & & \\
\hline $\begin{array}{l}\text { TH-04-14 } \\
\text { TH-04-29 }\end{array}$ & $\begin{array}{l}\text { Heater at, column } D_{1} \text { Roiv } 4 \text {. Thermo- } \\
\text { couples } 36 \mathrm{~cm}\left(270^{\circ}\right) \text { and } 74 \mathrm{~cm} \\
\left(315^{\circ}\right) \text { above bottom of core. }\end{array}$ & & & 77.78 & \\
\hline$T H-05-29$ & $\begin{array}{l}\text { Heater at Column Do, Row } 5 \text {. Thermo- } \\
\text { couple } 74 \mathrm{~cm}\left(225^{\circ}\right) \text { above bottom } \\
\text { of core. }\end{array}$ & & & 79,80 & . \\
\hline $\begin{array}{l}T H-[44-09 \\
T H-E 4-27 \\
T H=E 4-55\end{array}$ & $\begin{array}{l}\text { Hea tèr at column } \bar{E}, \text { Row } 4 \text {. Thermo- } \\
\text { couples } 23 \mathrm{~cm}\left(180^{\circ}\right), 69 \mathrm{~cm}\left(90^{\circ}\right) \text {. } \\
\text { ond } 140 \mathrm{~cm}\left(0^{\circ}\right) \text { above bot tom of core. }\end{array}$ & & & 81,82 & \\
\hline $\begin{array}{l}\text { TH-ES-20 } \\
\text { TH-ES-25 }\end{array}$ & $\begin{array}{l}\text { Heater at column } \mathrm{E} \text {, Row } 5 \text {. Thermo- } \\
\text { couples } 51 \mathrm{~cm}\left(180^{\circ}\right) \text { and } 64 \mathrm{~cm}\left(90^{\circ}\right) \\
\text { above bot tom of core. }\end{array}$ & & & 83,84 & \\
\hline Low Power Meaters & · & 0 to $1533 \mathrm{~K}$ & 0 to $1579 \mathrm{~K}$ & & \\
\hline $\begin{array}{l}\text { TH-A4-099 } \\
T H-A 4-29 \\
T H-A 4-39\end{array}$ & $\begin{array}{l}\text { Heater al column A, Row 4. Thermo- } \\
\text { couples } 23 \mathrm{~cm}\left(105^{\circ}\right), 74 \mathrm{~cm}\left(240^{\circ}\right) \text {, } \\
\text { and } 99 \mathrm{~cm}\left(300^{\circ}\right) \text { above bottom of } \\
\text { core. }\end{array}$ & & & 85,86 & \\
\hline $\begin{array}{l}\text { IH-AS-29 } \\
\text { TH-A5-45 } \\
\end{array}$ & $\begin{array}{l}\text { Heater at Column A, Raw } 5 \text {. Thermo- } \\
\text { coupples } 74 \mathrm{~cm}\left(180^{\circ}\right) \text { and } 114 \mathrm{~cm} \\
\left(255^{\circ}\right) \text { above bottom of core. }\end{array}$ & & & 87,88 & \\
\hline TH B3.J2 & $\begin{array}{l}\text { Heater at column } B^{8} \text { Row 3. Thermo- } \\
\text { couple } 81 \mathrm{~cm}\left(135^{\circ}\right) \text { above bottom of } \\
\text { core. }\end{array}$ & & & 89.90 & - \\
\hline $\begin{array}{l}\mathrm{TH}-85-29 \\
\mathrm{TH}-85-33\end{array}$ & $\begin{array}{l}\text { leater at Cnlumn } B_{\text {, Row }} 5 \text {. Therno- } \\
\text { couples } 74 \mathrm{~cm}\left(150^{\circ}\right) \text { and } 85 \mathrm{~cm} \\
\left(45^{\circ}\right) \text { duvive bottom of core. }\end{array}$ & - & & 91', 92 & \\
\hline$T H-86-29$ & $\begin{array}{l}\text { Heater at Column } 8, \text { Row } 6 \text {. Thermo- } \\
\text { couple } 74 \mathrm{~cm}\left(45^{\circ}\right) \text { above bottom } \\
\text { of core. }\end{array}$ & & & 93,94 & \\
\hline $\mathrm{TH}-\mathrm{C} 2-38$ & $\begin{array}{l}\text { Heater at Column Ce, Row 2. Thermo- } \\
\text { eouple g7 ciil }\left(229^{\circ}\right) \text { dbove botzom } \\
\text { of corc. }\end{array}$ & & & 05,06 & \\
\hline
\end{tabular}




\section{TABLE V (continued)}

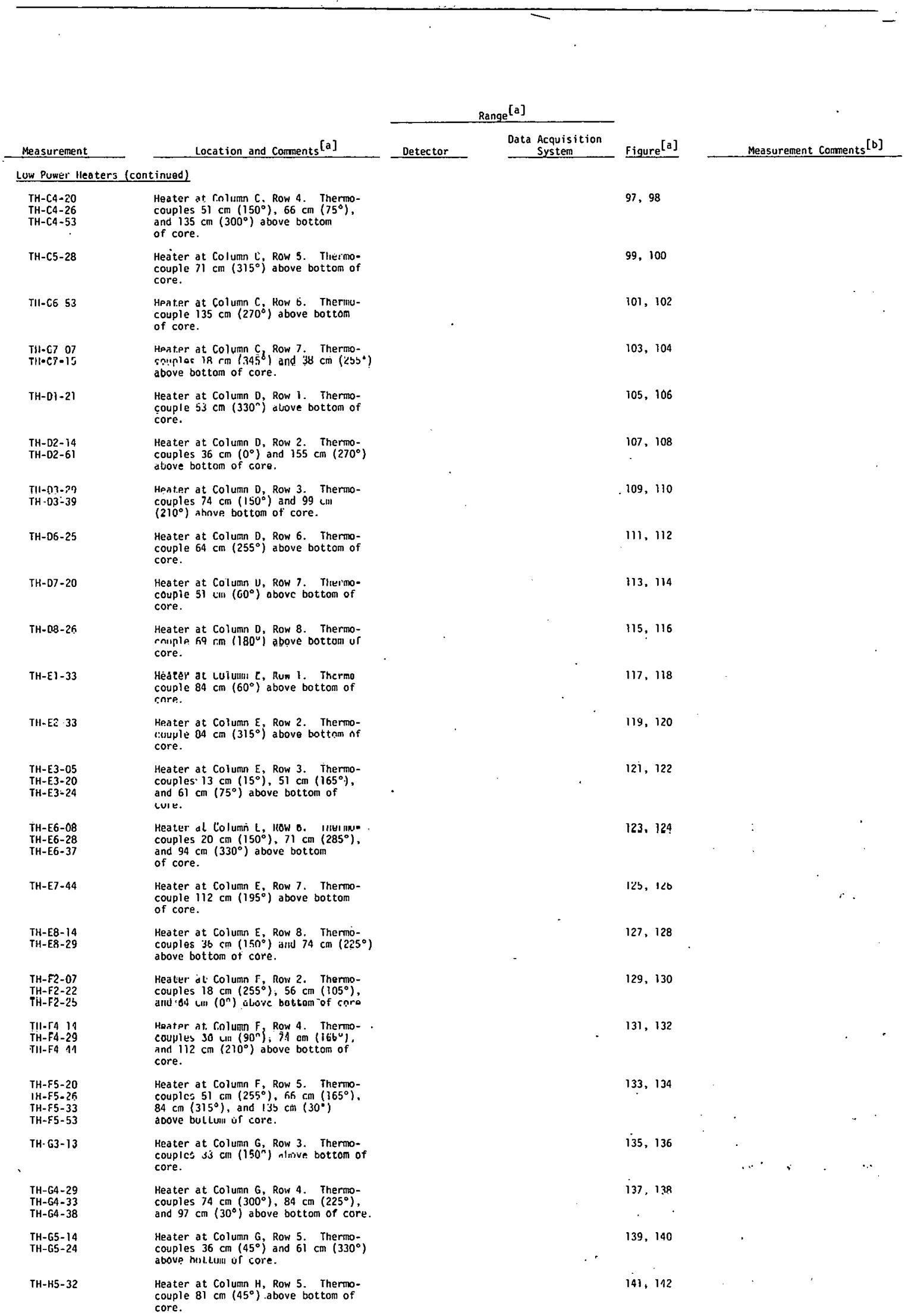




\begin{tabular}{|c|c|c|c|c|c|}
\hline \multirow[b]{2}{*}{. Measurement } & \multirow[b]{2}{*}{ Location and Comments ${ }^{[\mathrm{a}]}$} & \multicolumn{2}{|c|}{ Range $^{[a]}$} & \multirow[b]{2}{*}{$\underline{F i q u r e}^{[\mathrm{a}]}$} & \multirow[b]{2}{*}{ Measurement Compents ${ }^{[b]}$} \\
\hline & & Detector & $\begin{array}{c}\text { Data Acquisition } \\
\text { System }\end{array}$ & & \\
\hline \multicolumn{6}{|l|}{ PRESSURE } \\
\hline Intact Loop & & 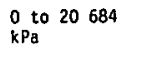 & & & \\
\hline PU-13 & $\begin{array}{l}\text { Cold leg, Spool } 13,138 \mathrm{~cm} \text { from } \\
\text { vessel center. }\end{array}$ & & 0 to $31992 \mathrm{kPa}$ & 143,144 & \\
\hline PU-15L & $\begin{array}{l}\text { Cold leg, Spool } 15,55 \mathrm{~cm} \text { from } \\
\text { vessel center, to atmosphere } \\
\text { (low range). }\end{array}$ & 0 to $3447 \mathrm{kPs}$ & O Lu $3561 \mathrm{kPa}$ & 143,144 & Detector saturated to $t=18 \mathrm{~s}$ \\
\hline Broken Loop & & $\begin{array}{l}0 \text { to } 17237 \\
\mathrm{kPa}\end{array}$ & & . & \\
\hline PB-21 & $\begin{array}{l}\text { Cold leg, Spool } 21,112 \mathrm{~cm} \text { from } \\
\text { vessel center. }\end{array}$ & 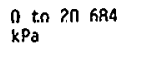 & 0 to $29666 \mathrm{kPa}$ & 145,146 & \\
\hline PB-23 & $\begin{array}{l}\text { Gold leg, Spool } 23,235 \mathrm{~cm} \text { from } \\
\text { vessel center, upstream of nozzele } \\
\text { (t,ee of of tap). }\end{array}$ & & 0 to $21440 \mathrm{kPa}$ & 145,146 & \\
\hline PB-CNI & $\begin{array}{l}\text { Cold leg, spool 23, vessel-side } \\
\text { nozzle, nozzle throat, } 245 \mathrm{~cm} \text {. } \\
\text { from vessel center along cold } \\
\text { leg, } 0^{\circ} \text {. }\end{array}$ & $\begin{array}{l}\mathrm{O} \text { to } 20684 \\
\mathrm{kPa}\end{array}$ & 0 to $30564 \mathrm{kPa}$ & 147,148 & \\
\hline PB-37 & $\begin{array}{l}\text { Cold leg, Spool } 37,718 \mathrm{~cm} \text { from } \\
\text { vessel center along hot leg. }\end{array}$ & & 0 to $21675 \mathrm{kPa}$ & 149,150 & \\
\hline PB-42 & $\begin{array}{l}\text { Cold leg, spool } 42,1057 \mathrm{~cm} \text { from } \\
\text { vessel center along hot leg, up- } \\
\text { stream of purp-side nozzle (tee } \\
\text { off oP tap). }\end{array}$ & & 0 to $20359 \mathrm{kPa}$ & 149,150 & \\
\hline PB-HNI & $\begin{array}{l}\text { Pump-side nozzle, nozzle throat, } \\
\text { lob6 cm from vessel center along } \\
\text { hot leg (tee off op tap) }\end{array}$ & & 0 to $20654 \mathrm{kPa}$ & 151,152 & \\
\hline Vessel & & & & $\cdot$ & \\
\hline$P V-U P+10$ & $\begin{array}{l}\text { In upper plenum, } 25 \mathrm{~cm} \text { above cold } \\
\text { leg centerl fite, nuvunted on standorf, } \\
30^{\circ} \text {. }\end{array}$ & $\begin{array}{l}0 \text { to } 17237 \\
\text { kYa }\end{array}$ & 0 to $21261 \mathrm{kPa}$ & 153.154 & \\
\hline PV-LP-166 & $\begin{array}{l}\text { In upper part of lower plenum, } \\
422 \mathrm{~cm} \text { be low cold leg centerline, } \\
\text { mounted on standof } \mathrm{f}, 225^{\circ} \text {. }\end{array}$ & $\begin{array}{l}\text { o to } 20684 \\
\mathrm{kPa}\end{array}$ & 0 to $34226 \mathrm{kPa}$ & 153,154 & \\
\hline ECC System & & 0 to $6895 \mathrm{kPa}$ & & & . \\
\hline PU-ACCI & In intact loop accumulator. & & 0 to $8629 \mathrm{kPa}$ & 155,156 & \\
\hline PB-ACC2 & In broken loop accumulator. & & 0 to $8368 \mathrm{kPa}$ & 157,158 & \\
\hline \multicolumn{6}{|l|}{ Stéä Genturator } \\
\hline PU-SGSO & Secondary side steam dome. & $\begin{array}{l}0 \text { to } 20684 \\
\times P a\end{array}$ & 0 to $14307 \mathrm{kPa}$ & 159,160 & \\
\hline \multicolumn{6}{|l|}{$\begin{array}{l}\text { Steam Generator } \\
\text { Rupiture System }\end{array}$} \\
\hline 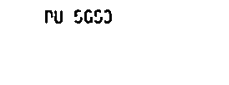 & $\begin{array}{l}\text { In vesset slinuldeing steam } \\
\text { generator tube rupture. (Vessel } \\
\text { accumblator.) }\end{array}$ & $U$ to $6895 \mathrm{kPa}$ & o to $8368 \mathrm{kPa}$ & 161,162 & \\
\hline \multicolumn{6}{|l|}{ Pressurizar } \\
\hline PU-PRIZE & Pressurizer steam dome. & $\underset{\mathrm{KPa}}{0 \text { to }} 17237$ & 0 to $22060 \mathrm{kPa}$ & 163,164 & \\
\hline \multicolumn{6}{|l|}{$\begin{array}{l}\text { Pressure Suppression } \\
\text { syst.pm }\end{array}$} \\
\hline P-PSS & Suppression tank top. & 0 to $1724 \mathrm{kPa}$ & 0 to $2173 \mathrm{kPa}$ & 165,166 & \\
\hline DIFFERENTIAL PRESSURE & $\begin{array}{l}\text { Elevation difference between } \\
\text { transdducer taps is zero unless } \\
\text { otherwise specified. }\end{array}$ & & & & \\
\hline \multicolumn{6}{|l|}{ Intact Loop } \\
\hline DPU-3-7 & $\begin{array}{l}\text { Hot leg Spool } 3,158 \mathrm{~cm} \text { from vessel } \\
\text { center to cold i ieg spool } 7 \text {. 587 cm } \\
\text { from vessel center; Spool } 3 \text { tap is } \\
46 \mathrm{~cm} \text { above Spool } 7 \text { tap. }\end{array}$ & $\frac{+1270 \mathrm{~cm}}{\text { water }}$ & $\pm 170 \mathrm{kPa}$ & 167,168 & \\
\hline DPU-6-SGIP & $\begin{array}{l}\text { Hot leg, Spool } 6,290 \mathrm{~cm} \text { from } \\
\text { vessel center to steam generator } \\
\text { inlet plenum, } 368 \mathrm{~cm} \text { from vessel } \\
\text { center. Spool } 6 \text { tap is } 41 \mathrm{~cm} \\
\text { below SGIP tap. }\end{array}$ & $\begin{array}{l}+1270 \mathrm{~cm} \\
\text { water }\end{array}$ & $\pm 170 \mathrm{kPa}$ & 169,170 & \\
\hline
\end{tabular}




\section{TAB.LE V (continued)}

\begin{tabular}{|c|c|c|c|c|c|c|}
\hline \multirow[b]{2}{*}{ Measurement } & \multirow[b]{2}{*}{ Location and Comments $[\mathrm{a}]$} & \multicolumn{3}{|c|}{ Range $^{[a]}$} & \multirow[b]{2}{*}{ Fitugers] } & \multirow[b]{2}{*}{ Measurement Cnmments ${ }^{[\mathrm{b}]}$} \\
\hline & & Detector & 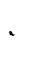 & $\begin{array}{l}\text { Data Acquisition } \\
\text { System } \\
\end{array}$ & & \\
\hline \multicolumn{7}{|c|}{ Intact Loop (continued) } \\
\hline OPU-SGOP-7 & $\begin{array}{l}\text { From steam generator outlet plenum } \\
683 \mathrm{~cm} \text { from vessel center a long } \\
\text { cold leg to cold leg Spuvl } 7,507 \mathrm{~cm} \\
\text { from vessel center, including orifice. } \\
\text { Spool } 7 \text { tap is } 89 \mathrm{~cm} \text { be low SGOP tap. }\end{array}$ & $\frac{+1270 \mathrm{~cm}}{\text { water }}$ & & $\pm 169 \mathrm{kPa}$ & 171,172 & \\
\hline OPU-7-10 & $\begin{array}{l}\text { Steam generator outlet to pump } \\
\text { inlet cold leg spool } 7 \text {, } 587 \mathrm{~cm} \\
\text { from vessel center, to cold leg } \\
\text { spool } 10,359 \mathrm{~cm} \text { from vessel } \\
\text { center. }\end{array}$ & $\begin{array}{l} \pm 127 \mathrm{~cm} \\
\text { water }\end{array}$ & & $\pm 17.2 \mathrm{kPa}$ & 173,174 & \\
\hline$O P U-12-10$ & $\begin{array}{l}\text { Pump uutlet to pump inlct, cold } \\
\text { leg spool } 12 \text {, } 192 \mathrm{~cm} \text { crom vessel } \\
\text { center, to cold leg Spool } 10,359 \mathrm{~cm} \\
\text { from vessel center, Spool } 10 \text { tap is } \\
25 \text { cm below Spool i2 tap. }\end{array}$ & $\pm 54 \mathrm{kPa}$ & - & $1043 \mathrm{lira}$ & 175. 176 & 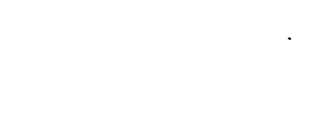 \\
\hline DPU-12-10L & $\begin{array}{l}\text { Pump outlet to pump inlet, cold } \\
\text { leg Spool } 12,192 \mathrm{~cm} \text { from vessel } \\
\text { cchtcr, to cold } 1 \mathrm{eg} \text { Spon } 10.359 \mathrm{~cm} \\
\text { from vessel center spool } 10 \text { tap is } \\
25 \mathrm{~cm} \text { below Spool i2 tap (low range). }\end{array}$ & $\underset{\text { water }}{ \pm 254 \mathrm{~cm}}$ & & $\pm 33.2 \mathrm{kPa}$ & 177,178 & $\begin{array}{l}\text { Data acquisition system } \\
\text { saturated to } t=6 \mathrm{~s} \text {. }\end{array}$ \\
\hline orU.12-15 & $\begin{array}{l}\text { Fold leg Spool 1\%, } 192 \mathrm{~cm} \text { rrum } \\
\text { vessel center, to cold leg Spool } \\
15,55 \mathrm{~cm} \text { from vessel center. }\end{array}$ & $\frac{ \pm 254 \mathrm{~cm}}{\text { water }}$ & & $\pm 33.9 \mathrm{kPa}$ & $1 / 9,180$ & \\
\hline DPU-15-3 & 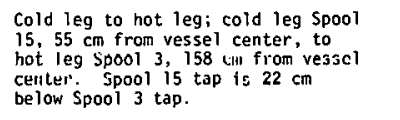 & $\begin{array}{l} \pm 1270 \mathrm{~cm} \\
\text { water }\end{array}$ & & $\pm 169 \mathrm{kPa}$ & 181,182 & \\
\hline DPHI-15-3L & 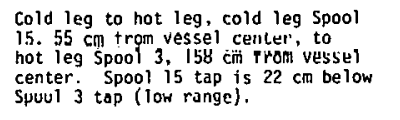 & $\frac{+254 \mathrm{~cm}}{\text { water }}$ & & $\pm 33.5 \mathrm{kPa}$ & 183,184 & $\begin{array}{l}\text { Data acquisition sys tem } \\
\text { saturated to } t=0 \mathrm{~s} \text {. }\end{array}$ \\
\hline DPU-PRESLL & $\begin{array}{l}\text { Pressurizer water level. Eleva- } \\
\text { t1un Jifference betwecn taph is } \\
135 \mathrm{~cm} \text { Lower tap is } 9 \mathrm{~cm} \text { above } \\
\text { pressurizer exit. }\end{array}$ & $\frac{ \pm 127 \mathrm{~cm}}{\text { water }}$ & & $\pm 17.1 \mathrm{kPa}$ & 185,186 & \\
\hline DPU-PR-4 & $\begin{array}{l}\text { Pressurizer bottom to spool } 4 \text {. Eleva- } \\
\text { tion difference between taps is } \\
157 \mathrm{~cm} \text {. Spool } 4 \text { tap is } 140 \mathrm{~cm} \text { be low } \\
\text { pressurizer exit. }\end{array}$ & $\pm 344 / \mathrm{kPa}$ & & $\pm 3950 \mathrm{kPa}$ & 187. 188 & $\begin{array}{l}\text { nata acquisition system } \\
\text { saturated from } \mathrm{t}=0 \text { to } \mathrm{t}=12 \mathrm{~s} \text {. }\end{array}$ \\
\hline \multicolumn{7}{|l|}{ Broken Lonp } \\
\hline DPB-21-IANN & $\begin{array}{l}\text { Cold leg Spool } 21,112 \mathrm{cmi} \text { from } \\
\text { vessel center, to vessel inlet } \\
\text { annulus, } 23 \mathrm{~cm} \text { below cold leg } \\
\text { centeri ine at } 2255^{\circ} \text { inlct annulus } \\
\text { tap is } 23 \mathrm{~cm} \text { below spool } 21 \text { tap. }\end{array}$ & $\frac{+254 \mathrm{~cm}}{\text { water }}$ & & $\pm 33.6 \mathrm{kPa}$ & 109,190 & 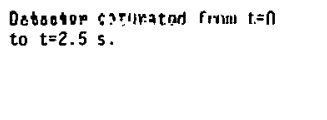 \\
\hline DPB-23-CNI & $\begin{array}{l}\text { Cold leg, Spool } 23,235 \mathrm{~cm} \text { from } \\
\text { vessel center to vessel-side } \\
\text { nozze throat, } 245 \mathrm{~cm} \text { from vessel } \\
\text { center. }\end{array}$ & $\pm 10342 \mathrm{kPa}$ & & $\pm 13843 \mathrm{kPa}$ & 191,192 & . \\
\hline OPB-CNI-24 & $\begin{array}{l}\text { Vessel-side nozzle throat, } 245 \mathrm{~cm} \\
\text { rrom vesscl canter to spoil } 74 \text {. } \\
264 \mathrm{~cm} \text { from vessel center. }\end{array}$ & $\pm 3447 \mathrm{kPa}$ & & $\pm 6961 \mathrm{kPa}$ & 193.194 & - \\
\hline $0 P 8-30-43$ & 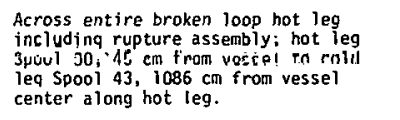 & $\pm 3447 \mathrm{kPa}$ & & $\pm b y / 3 \mathrm{kPa}$ & 195,196 & $\therefore$ \\
\hline OPB-32U-36L & 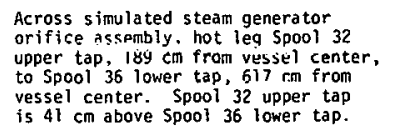 & $\pm 1379 \mathrm{kPa}$ & & $\pm 1388 \mathrm{kPo}$ & 197,198 & . \\
\hline DPB- 36L-37 & $\begin{array}{l}\text { Across nozzle assembly. Spool } 36 \\
\text { lower tap, } 617 \text { cm from vessel } \\
\text { center along hot leg to ppool } 37, \\
718 \mathrm{~cm} \text { from vessel center along } \\
\text { hot leg. Speol } 37 \text { tap is } 102 \mathrm{~cm} \\
\text { bclow Spool } 36 \text { lnwer tap. }\end{array}$ & $\pm 345 \mathrm{kPd}$ & & $\pm s 46 \mathrm{kPa}$ & ima & \\
\hline$D P B-38-40$ & 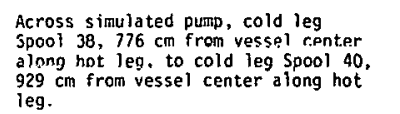 & $\pm 6895 \mathrm{kPa}$ & & $\pm 9227 \mathrm{kPa}$ & 201,202 & \\
\hline
\end{tabular}




\section{TABLE V (continued)}

\begin{tabular}{|c|c|c|c|c|c|}
\hline \multirow[b]{2}{*}{ Measurement } & \multirow[b]{2}{*}{ Location and Comments $^{[\mathrm{a}]}$} & \multicolumn{2}{|c|}{ Range $^{[a]}$} & \multirow[b]{2}{*}{ Eigure ${ }^{[a]}$} & . \\
\hline & & \multirow[t]{2}{*}{ Detector } & $\begin{array}{l}\text { Data Acquisition } \\
\text { System }\end{array}$ & & Measurement Comments ${ }^{[\mathrm{b}]}$ \\
\hline \multicolumn{5}{|c|}{ Broken Loop (continued) } & \\
\hline OPB-40-42 & 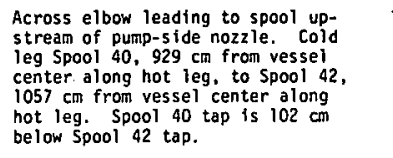 & $\begin{array}{l}+127 \mathrm{~cm} \\
\text { water }\end{array}$ & $\pm 16.2 \mathrm{kPa}$ & 203,304 & $\begin{array}{l}\text { Oata acquisition saturated } \\
\text { from } t=0 \text { to } t=1 \text { s and from } \\
t=23 \text { to } t=34 \mathrm{~s} \text {. }\end{array}$ \\
\hline DPB-42-HN1 & $\begin{array}{l}\text { Spooi } 42 \text { upstream of pump-side } \\
\text { nozzle po5s com from vessel center } \\
\text { along hot leg to nozze throat, } \\
1066 \mathrm{~cm} \text { from vessel center along } \\
\text { hot leg. }\end{array}$ & $\pm 10342 \mathrm{kPa}$ & $\begin{array}{l} \pm 13843 \mathrm{kPa} \\
\therefore\end{array}$ & 205,206 & \\
\hline DPB-HMI- 43 & $\begin{array}{l}\text { Pump-side nozzle, nozzle throat } \\
1066 \text { cm from vessel center along } \\
\text { hot } 16 \mathrm{gog} \text { to spool } 43 \text {, } 1086 \mathrm{~cm} \text { from } \\
\text { vessel center along hot leg. }\end{array}$ & $\pm 3447 \mathrm{KPa}$ & $\pm 6932 \mathrm{kPO}$ & 207,208 & - \\
\hline \multicolumn{6}{|l|}{ Vessel } \\
\hline OPV-UP-IANN & $\begin{array}{l}\text { Upper plenum, } 27 \mathrm{~cm} \text { above cold } \\
\text { leg centerline at } 30^{\circ} \text { to inlet } \\
\text { annulus, } 23 \mathrm{~cm} \text { below cold leg tenter- } \\
\text { line at } 225^{\circ} \text {. Elevation difference } \\
\text { between taps is } 48 \mathrm{~cm} \text {. }\end{array}$ & $\begin{array}{l}+762 \mathrm{~cm} \\
\text { Water }\end{array}$ & $\pm 102 \mathrm{kPa}$ & 209,210 & \\
\hline OPV-0-9GQ & $\begin{array}{l}\text { Inlet annulus cold leg centerline at } \\
90^{\circ} \text {, to } 23 \mathrm{zcm}^{2} \text { below cold leg center- } \\
\text { line at } 225^{\circ} \text {. Elevation difference } \\
\text { between taps is } 23 \text { cm. }\end{array}$ & $\frac{+127 \mathrm{~cm}}{\text { water }}$ & $\pm 18.4 \mathrm{kPa}$ & 211,212 & . \\
\hline DPV-9-26Q0 & $\begin{array}{l}\text { Inlet annulus, } 23 \mathrm{~cm} \text { below cold leg } \\
\text { centerline at } 225^{\circ} \text {, to downcomer gap. } \\
66 \mathrm{~cm} \text { below cold leg centerline ot } \\
225^{\circ} \text {. Elevation difference between } \\
\text { taps is } 43 \mathrm{~cm} \text {. }\end{array}$ & $\begin{array}{l}+127 \mathrm{~cm} \\
\text { water }\end{array}$ & $\pm 16.8 \mathrm{kPa}$ & 213,214 & \\
\hline DPV-9-16600 & $\begin{array}{l}\text { Inlet annulus, } 23 \mathrm{~cm} \text { below cold leg } \\
\text { centerl ine at } 225^{\circ} \text {, to lower plenum, } \\
422 \mathrm{~cm} \text { below cold ieg centerline } \\
\text { at } 225^{\circ} \text {. Elevation difference be- } \\
\text { tween taps is } 399 \mathrm{~cm} \text {. }\end{array}$ & $\begin{array}{l}+762 \mathrm{~cm} \\
\text { water }\end{array}$ & $\pm 101 \mathrm{kHa}$ & 215,216 & \\
\hline$D P V-26-550 M$ & $\begin{array}{l}\text { Across part of downcomer, } 66 \mathrm{~cm} \\
\left(225^{\circ}\right) \text { to } 140 \mathrm{~cm}\left(180^{\circ}\right) \text {, be } 10 \mathrm{w} \text { cold } \\
\text { leg centerline. Elevation difference } \\
\text { between taps is } 74 \mathrm{~cm} \text {. }\end{array}$ & $\frac{+127 \mathrm{~cm}}{\text { water }}$ & $\pm 21.2 \mathrm{kPa}$ & 217,218 & \\
\hline OPV-55-110NM & $\begin{array}{l}\text { Across part of downcomer, } 140 \mathrm{~cm} \\
\left(180^{\circ}\right) \text { to } 279 \mathrm{~cm}\left(180^{\circ}\right) \text {, be low } \\
\text { cold leg centerline Ee Eevation } \\
\text { difference betwcen taps is } 140 \mathrm{~cm} \text {. }\end{array}$ & $\frac{+254 \mathrm{~cm}}{\text { water }}$ & $\pm 33.8 \mathrm{kPa}$ & 219,220 & \\
\hline OPV- $110-156 \mathrm{MO}$ & $\begin{array}{l}\text { Across part of downcomer, } 279 \mathrm{~cm} \\
\left(180^{\circ}\right) \text { to } 396 \mathrm{~cm}\left(225^{\circ}, \text { below cold }\right. \\
\text { ieg center.11ine. Elevetiound difference } \\
\text { between taps is } 117 \mathrm{~cm} \text {. }\end{array}$ & $\begin{array}{l}+254 \mathrm{~cm} \\
\text { water }\end{array}$ & $\pm 33.7 \mathrm{kPa}$ & 221,222 & . \\
\hline î̀i $i-150-1 / \sin u$ & 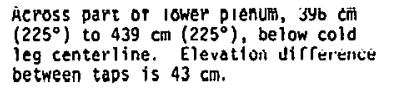 & $\begin{array}{l}\text { thl cim } \\
\text { water }\end{array}$ & $\pm 6.47 \mathrm{kPa}$ & 223,224 & \\
\hline DPV $-1660+10$ & $\begin{array}{l}\text { Lower plenum, } 422 \mathrm{~cm} \text { below cold leg } \\
\text { centerine at } 225^{\circ} \text { to upper plenum, } \\
27 \mathrm{~cm} \text { above cold leg centerline at } \\
30^{\circ} \text { Elevation difference between } \\
\text { taps is } 395 \mathrm{~cm} \text {. }\end{array}$ & $\begin{array}{l}+762 \mathrm{~cm} \\
\text { water }\end{array}$ & $\pm 101 \mathrm{kPa}$ & 225,226 & \\
\hline \multicolumn{6}{|l|}{ ECC SYSTEM } \\
\hline OPU-ACCI-TB & $\begin{array}{l}\text { Top to bot tom of intact loop } \\
\text { accumulator. Elevation difference } \\
\text { between taps is } 274 \mathrm{~cm} \text {. }\end{array}$ & $\frac{\$ 762 \mathrm{~cm}}{\text { water }}$ & $\pm 104 \mathrm{kPa}$ & 227,228 & · \\
\hline OPB-ACC2-TB & $\begin{array}{l}\text { Top to bottom of broken loop } \\
\text { accumulator. Elevation difference } \\
\text { between taps } 15213 \mathrm{~cm} \text {. }\end{array}$ & $\frac{+127 \mathrm{~cm}}{\text { water }}$ & $\pm 17.35 \mathrm{kPa}$ & 229,230 & \\
\hline Steam Generator & & & 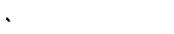 & & . \\
\hline DPU-SC-SEC & $\begin{array}{l}\text { Secondary side, differentiol pressure } \\
\text { taps at } 114 \mathrm{~cm} \text { and } 320 \mathrm{~cm} \text { above } \\
\text { bottom of tube sheet. Elevation } \\
\text { difference between taps is } 206 \mathrm{~cm} \text {. }\end{array}$ & $\frac{ \pm 254}{\text { water }}$ & $\pm 33.7 \mathrm{kPH}$ & 231.232 & \\
\hline DPU-SG-DISC & $\begin{array}{l}\text { Across venturi tube, } 168 \mathrm{~cm} \text { down- } \\
\text { stream from steang generator dis- } \\
\text { charge. }\end{array}$ & $\frac{+1270 \mathrm{~cm}}{\text { water }}$ & $\pm 170 \mathrm{KPa}$ & 233,234 & $\begin{array}{l}\text { Data acquisition system } \\
\text { saturated near } \mathrm{t}=3 \mathrm{~s} \text {. }\end{array}$ \\
\hline
\end{tabular}




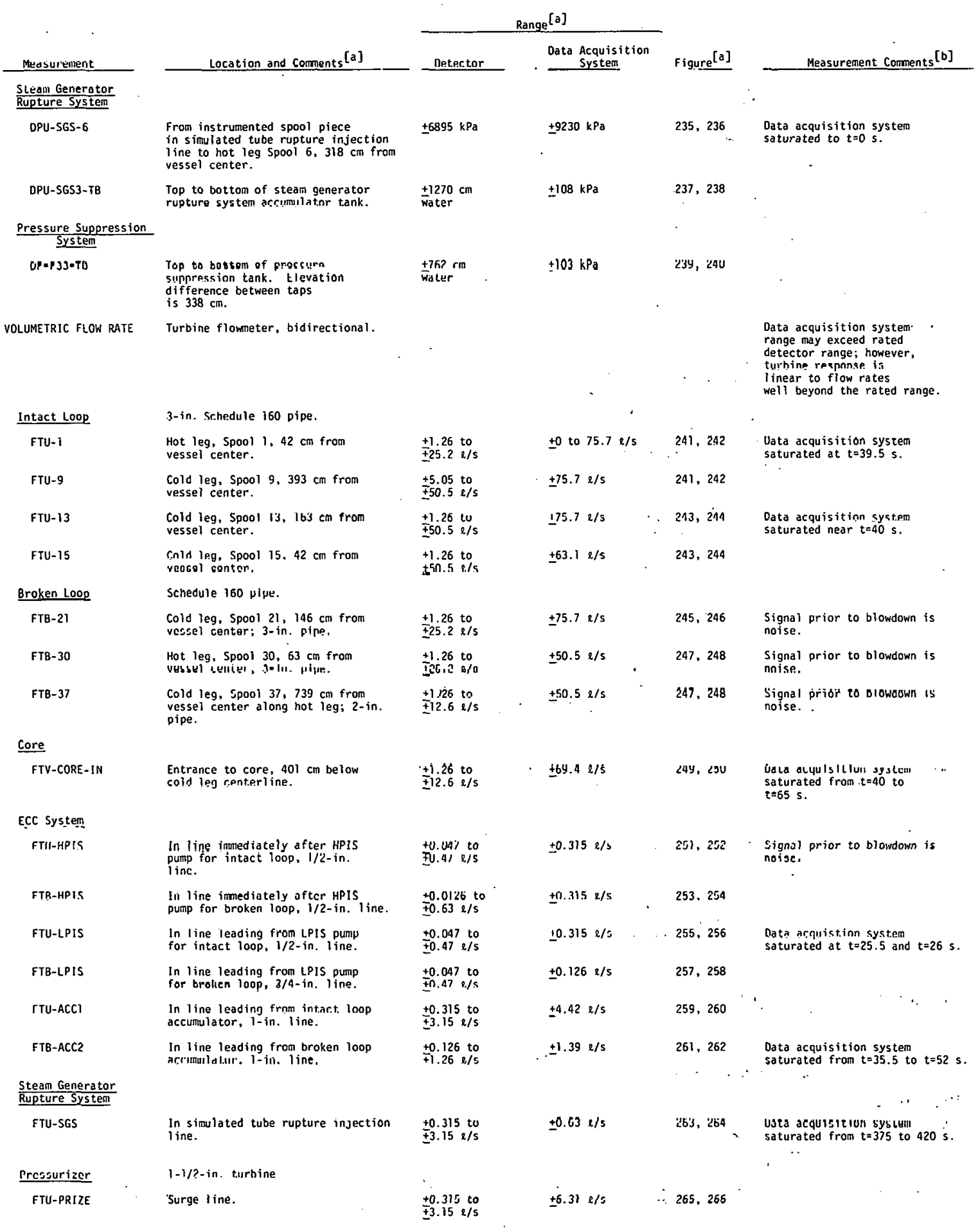




\begin{tabular}{|c|c|c|c|c|c|}
\hline \multirow[b]{2}{*}{ Measurement } & \multirow[b]{2}{*}{ Location and Comments $[\mathrm{a}]$} & \multicolumn{2}{|c|}{ Range $^{[a]}$} & \multirow[b]{2}{*}{ Figure $^{[a]}$} & \multirow[b]{2}{*}{ Measurement Comments ${ }^{[b]}$} \\
\hline & & Detector & $\begin{array}{l}\text { Data Acquisition } \\
\text { System }\end{array}$ & & \\
\hline FLUID VELOCITY & Turbine flowneter, bidirectional. & & & & \\
\hline \multicolumn{6}{|l|}{ Downcomer } \\
\hline FTV $-40 \mathrm{~A}$ & $\begin{array}{l}102 \mathrm{~cm} \text { beiow cold leg centerline, } \\
0^{\circ} \text {. }\end{array}$ & $\begin{array}{l} \pm 0.762 \text { to } \\
\pm 15.24 \mathrm{~m} / \mathrm{s}\end{array}$ & $\pm 15.24 \mathrm{~m} / \mathrm{s}$ & 267,268 & $\begin{array}{l}\text { Data acquisition system saturated } \\
\text { internittently from } t=24 \text { to } \\
t=72 \mathrm{~s} \text {. }\end{array}$ \\
\hline FTV-4OM & $\begin{array}{l}102 \mathrm{~cm} \text { be low cold leg centerline, } \\
180^{\circ} .\end{array}$ & $\begin{array}{l}+0.762 \text { to } \\
\pm 15.24 \mathrm{~m} / \mathrm{s}\end{array}$ & $\pm 15.24 \mathrm{~m} / \mathrm{s}$ & 267.268 & $\begin{array}{l}\text { Data acquisition system saturated } \\
\text { intermittently from } t=32 \text { to } \\
t=72 \mathrm{~s} \text {. }\end{array}$ \\
\hline MOMENTUM FLUX & Orag disc, bidirectional. & & & & $\begin{array}{l}\text { Orag disc data may exhibit } \\
\text { significant temperature } \\
\text { dependence. Drag disc data } \\
\text { should be used only for short- } \\
\text { term trans ient responsc. }\end{array}$ \\
\hline Intact Loop & 3-in. pipe. & & & & \\
\hline FOU-1 & $\begin{array}{l}\text { Hot leg, Spool } 1,60 \mathrm{~cm} \text { from } \\
\text { vessel center; target size } \\
2.22 \mathrm{~cm} .\end{array}$ & $\begin{array}{l} \pm 298 \text { to } \pm 17 \quad 113 \\
\mathrm{~kg} / \mathrm{m}-\mathrm{s}^{2}\end{array}$ & $\begin{array}{l} \pm 76090 \\
\mathrm{~kg} / \mathrm{m}-\mathrm{s}^{2}\end{array}$ & 269,270 & \\
\hline FOU-5 & $\begin{array}{l}\text { Hot leg, Spool } 5,256 \mathrm{~cm} \text { from } \\
\text { vessel center; target size } \\
2.54 \mathrm{~cm} .\end{array}$ & $\begin{array}{l} \pm 1.49 \text { to } \pm 2976 \\
\mathrm{~kg} / \mathrm{m}-\mathrm{s}^{2}\end{array}$ & $\frac{ \pm 6994}{\mathrm{~kg} / \mathrm{m}-\mathrm{s}^{2}}$ & 271,272 & ' \\
\hline FOU $=10$ & $\begin{array}{l}\text { Cold leg, Spool } 10.349 \mathrm{~cm} \text { from } \\
\text { vessel center; target size } 2.22 \mathrm{~cm} .\end{array}$ & $\begin{array}{l} \pm 298 \text { to } \\
\mathrm{kg} / \mathrm{m}-\mathrm{s}^{2}\end{array}$ & $\begin{array}{l} \pm 35344 \\
\mathrm{~kg} / \mathrm{m}-\mathrm{s}^{2}\end{array}$ & 273.274 & \\
\hline FDU-13 & $\begin{array}{l}\text { Cold leg, spooi } 13,138 \mathrm{~cm} \text { from } \\
\text { vessel center; target. size } 2.22 \mathrm{~cm} \text {. }\end{array}$ & $\begin{array}{l} \pm 298 \text { to } \pm 22025 \\
\mathrm{~kg} / \mathrm{m}-\mathrm{s}^{2}\end{array}$ & $\begin{array}{l} \pm 28528 \\
\mathrm{~kg} / \mathrm{m}-\mathrm{s}^{2}\end{array}$ & 275,276 & \\
\hline Broken Loop & & & & . & $\cdot$ \\
\hline FDB-21 & $\begin{array}{l}\text { Cold leg, Spool 21, } 134 \mathrm{~cm} \text { from } \\
\text { vessel center, 3-in. pipe; target } \\
\text { size } 1.67 \mathrm{~cm} \text {. }\end{array}$ & $\begin{array}{l} \pm 298 \text { to } \pm 104915 \\
\mathrm{~kg} / \mathrm{m}-\mathrm{s}^{2}\end{array}$ & $\begin{array}{l} \pm 66774 \\
\mathrm{~kg} / \mathrm{m}-\mathrm{s}^{2}\end{array}$ & 277,278 & 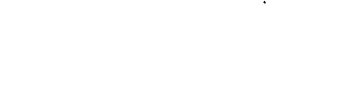 \\
\hline FOB-23 & $\begin{array}{l}\text { Cold leg, Spool 23, } 238 \text { cm from } \\
\text { vessel center, 2pstream of vessel } \\
\text { side nozzle, 2-in. pipe; target } \\
\text { size } 1.03 \mathrm{~cm} .\end{array}$ & $\frac{ \pm 298 \text { to }}{\mathrm{kg} / \mathrm{m}-\mathrm{s}^{2}} \pm 180067$ & $\underset{\mathrm{kg} / \mathrm{m}-\mathrm{s}^{2}}{+155319}$ & 279,280 & $\begin{array}{l}\text { Detector saturated from } t=0 \text { to } \\
t=2 s \text {. }\end{array}$ \\
\hline FOB-30 & $\begin{array}{l}\text { Hot leg, Spool } 30,52 \mathrm{~cm} \text { from } \\
\text { vessel center, } 3-1 \mathrm{n} \text {. pipe: target } \\
\text { size } 1.67 \mathrm{~cm} \text {. }\end{array}$ & $\frac{ \pm 298 \text { to }}{\mathrm{kg} / \mathrm{m}-\mathrm{s}^{2}} \pm 89290$ & $\begin{array}{l} \pm 67280 \\
\mathrm{~kg} / \mathrm{m}-\mathrm{s}^{2}\end{array}$ & 281,282 & $\begin{array}{l}\text { Questionable data, drag disc was } \\
\text { mounted horizontally and possibly } \\
\text { filled with cold water. }\end{array}$ \\
\hline FDB-37 & $\begin{array}{l}\text { Cold leg, spool } 37,725 \mathrm{~cm} \text { from } \\
\text { vessel center a long hot leg. steam } \\
\text { generator outlet, vertical pipe, } \\
\text { 2-in. pipe; target size } 1.03 \mathrm{~cm} \text {. }\end{array}$ & $\begin{array}{l} \pm 298 \text { to } \pm 180067 \\
\mathrm{k} \mathbf{y} / \mathrm{mI-s} \mathrm{s}^{2}\end{array}$ & $\frac{+374272}{\mathrm{~kg} / \mathrm{m} / \mathrm{s}-\mathrm{s}^{2}}$ & 283,284 & $\begin{array}{l}\text { Questionable data, orag disc was } \\
\text { mounted horizontally and filled } \\
\text { with cold woter. }\end{array}$ \\
\hline FOB -42 & 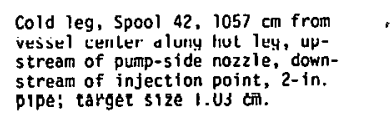 & $\begin{array}{l} \pm 298 \text { to } \\
\mathrm{kg} / \mathrm{m}-\mathrm{s}^{2}\end{array}$ & $\begin{array}{l} \pm 165320 \\
\mathrm{~kg} / \mathrm{m}-\mathrm{s}^{2}\end{array}$ & 285,286 & . \\
\hline \multicolumn{6}{|l|}{$\underline{\text { Vessel }}$} \\
\hline FDV-CORE-IN & $\begin{array}{l}\text { In core flow mixer box, } 381 \mathrm{~cm} \\
\text { below cold leg centerline; target } \\
\text { ize } 2.54 \mathrm{~cm} \text {. }\end{array}$ & $\underset{\mathrm{kg} / \mathrm{m}-\mathrm{s}^{2}}{ \pm 1.44 \text { to }} \pm 2977$ & $\frac{ \pm 1725}{\mathrm{~kg} / \mathrm{m}-\mathrm{s}^{2}}$ & 287,288 & 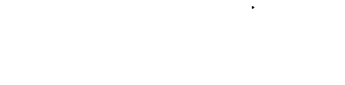 \\
\hline \multicolumn{6}{|l|}{ DENSITY } \\
\hline Intact LOOP & & $\begin{array}{l}1.6 \text { to } 1600 \\
\mathrm{~kg} / \mathrm{m}^{3}\end{array}$ & $\begin{array}{l}0 \text { to } 1000 \\
\mathrm{~kg} / \mathrm{m}^{3}\end{array}$ & ? & \\
\hline $\begin{array}{l}\text { GU-1T } \\
\text { GU-1B } \\
G U-16\end{array}$ & $\begin{array}{l}\text { Hot leg, Spool } 1,77 \mathrm{~cm} \text { from } \\
\text { vessel center. . (top) ranges } \\
270 \text { to } 360^{\circ} .8 \text { (bottom ranges } \\
30 \text { to } 330^{\circ} \text {. } C \text {, mathenatical } \\
\text { composite of } T \text { and } B \text {. }\end{array}$ & & & $\begin{array}{l}289,290 \\
291 ; \\
292\end{array}$ & \\
\hline GU-5VR & $\begin{array}{l}\text { Hot leg, Spool } 5,246 \mathrm{~cm} \text { from } \\
\text { vessel center, vertical. }\end{array}$ & & - & 293,294 & \\
\hline CU-1OVR & $\begin{array}{l}\text { Cold leg, } 50001 \text { 10. } 359 \mathrm{~cm} \text { from } \\
\text { vessel center, vertical. }\end{array}$ & & & 293. 294 & \\
\hline GU-13VR & $\begin{array}{l}\text { Cold leg, Spool } 13,142 \mathrm{~cm} \text { from } \\
\text { vessel center, vertical. }\end{array}$ & • & & 295,296 & . \\
\hline $\begin{array}{l}\text { GU-15T } \\
6 U-158 \\
\text { GU- } 15 C\end{array}$ & 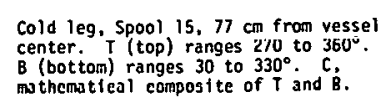 & & & $\begin{array}{l}297, \quad 298 \\
294,300\end{array}$ & \\
\hline
\end{tabular}




\section{TABLE V (continued)}

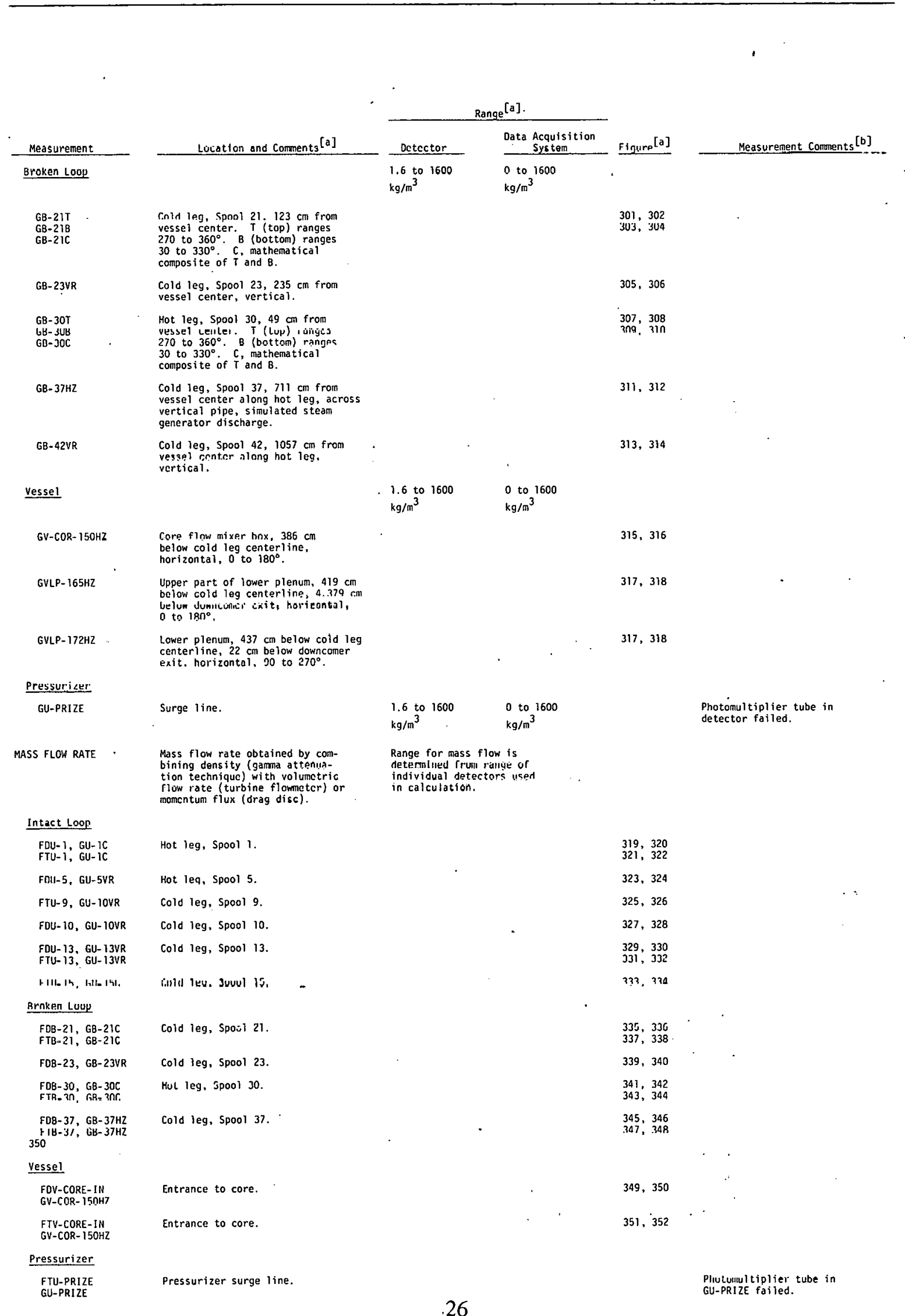




\section{TABLE V (continued)}

\begin{tabular}{|c|c|c|c|c|c|c|}
\hline \multirow[b]{2}{*}{ Measurement } & \multirow{2}{*}{\multicolumn{2}{|c|}{ Location and Comments ${ }^{[a]}$}} & \multicolumn{2}{|c|}{ Range $^{[a]}$} & \multirow[b]{2}{*}{ Flgure ${ }^{[a]}$} & \multirow[b]{2}{*}{ Measurement Comments ${ }^{[\mathrm{b}]}$} \\
\hline & & & Detector & $\begin{array}{c}\text { Data Acquisition } \\
\text { System } \\
\end{array}$ & & \\
\hline \multicolumn{7}{|c|}{ CORE CHARACTERISTICS } \\
\hline PWRCOR T-1 & Core power. & . & 0 to $1600 \mathrm{~kW}$ & 0 to $2047 \mathrm{~kW}$ & 353,354 & . \\
\hline PHRCOR $T=2$ & Core puwer. & & 0 to $1600 \mathrm{~kW}$ & $U$ to $2563 \mathrm{kN}$ & 353,354 & \\
\hline VOLTCOR-T & Core voltage. & & & 0 to $200 \mathrm{Vdc}$ & 355,356 & \\
\hline AMPCOR-T & Core current. & & 0 to $10000 \mathrm{~A}$ & O to $9645 \mathrm{~A}$ & 357,358 & \\
\hline \multicolumn{7}{|c|}{ PUMP CHARACTERISTICS } \\
\hline PUMPU-CUR & Pump current. & & 0 to $25 \mathrm{~A}$ & 0 to $44 \mathrm{~A}$ & 359,360 & \\
\hline PUMPU-RPM & Pump speed. & & 0 to $3600 \mathrm{rpm}$ & 0 to $3600 \mathrm{rpm}$ & 361,362 & \\
\hline
\end{tabular}

[a] Statements at the beginning of a measurement category regarding location and comments, range, and figure apply to all subsequent measurements within the given category unless specified otherwise.

[b] Detectors which were subjected to overrange conditions during portions of the test were capable of withstanding these conditions without change in operating or measuring characteristics when the physical conditions were again with in the detector range. 


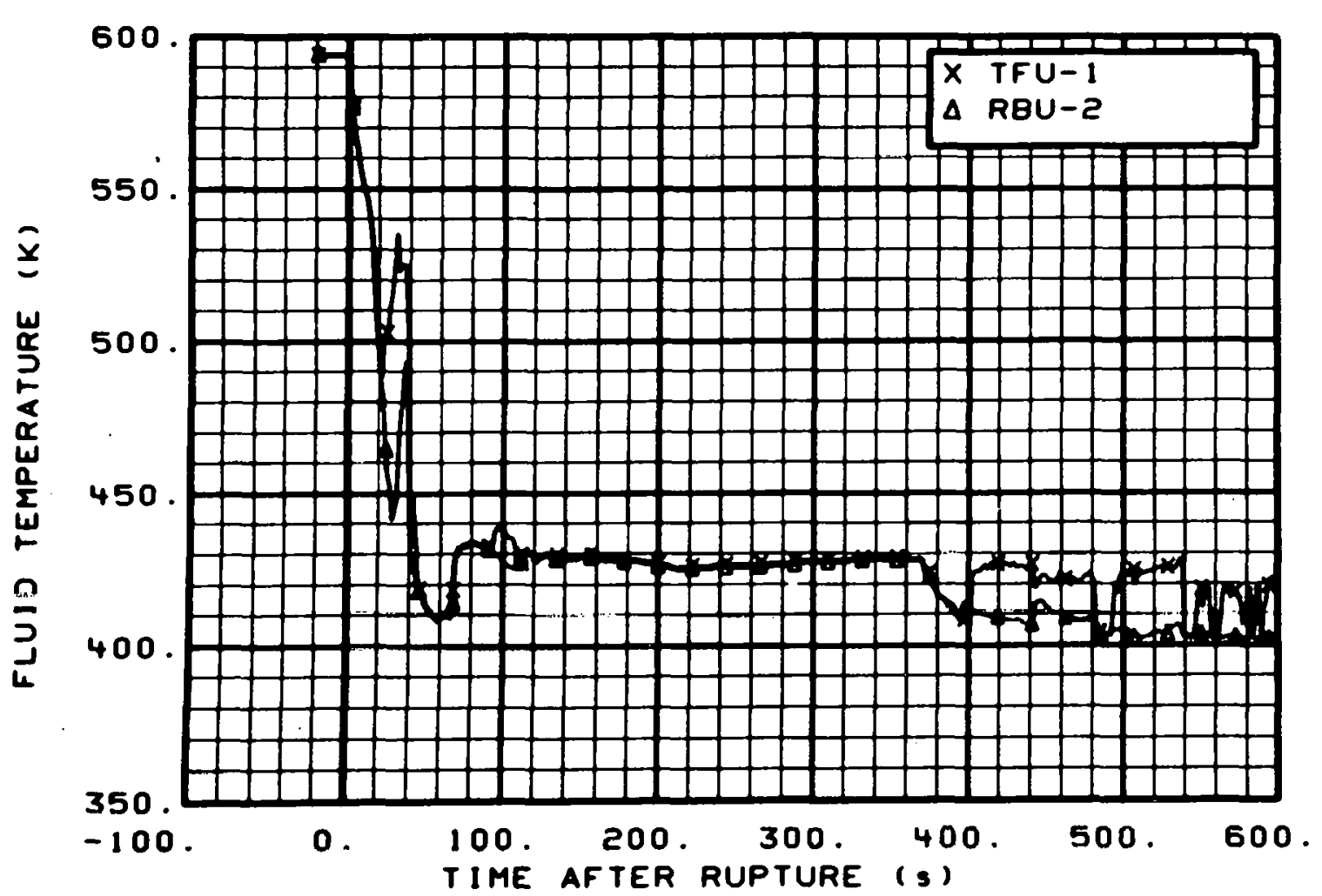

Fig. 9 Fluid temperature in intact loop hot leg (TFU-1 and RBU-2), from -20 to $600 \mathrm{~s}$.

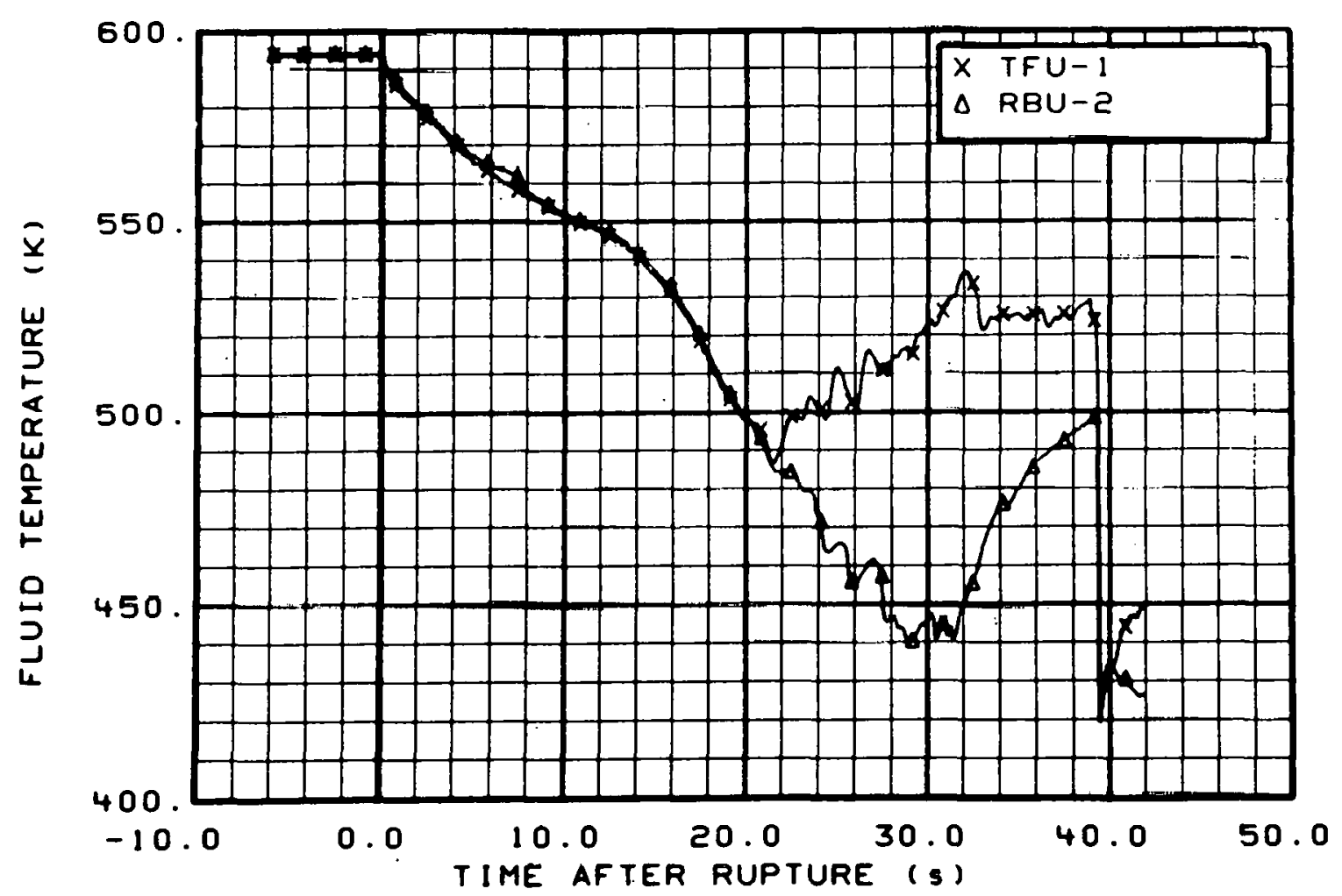

Fig. 10 Fluid temperature in intact loop hot leg (TFU-1 and RBU-2), from -6 to $42 \mathrm{~s}$. 


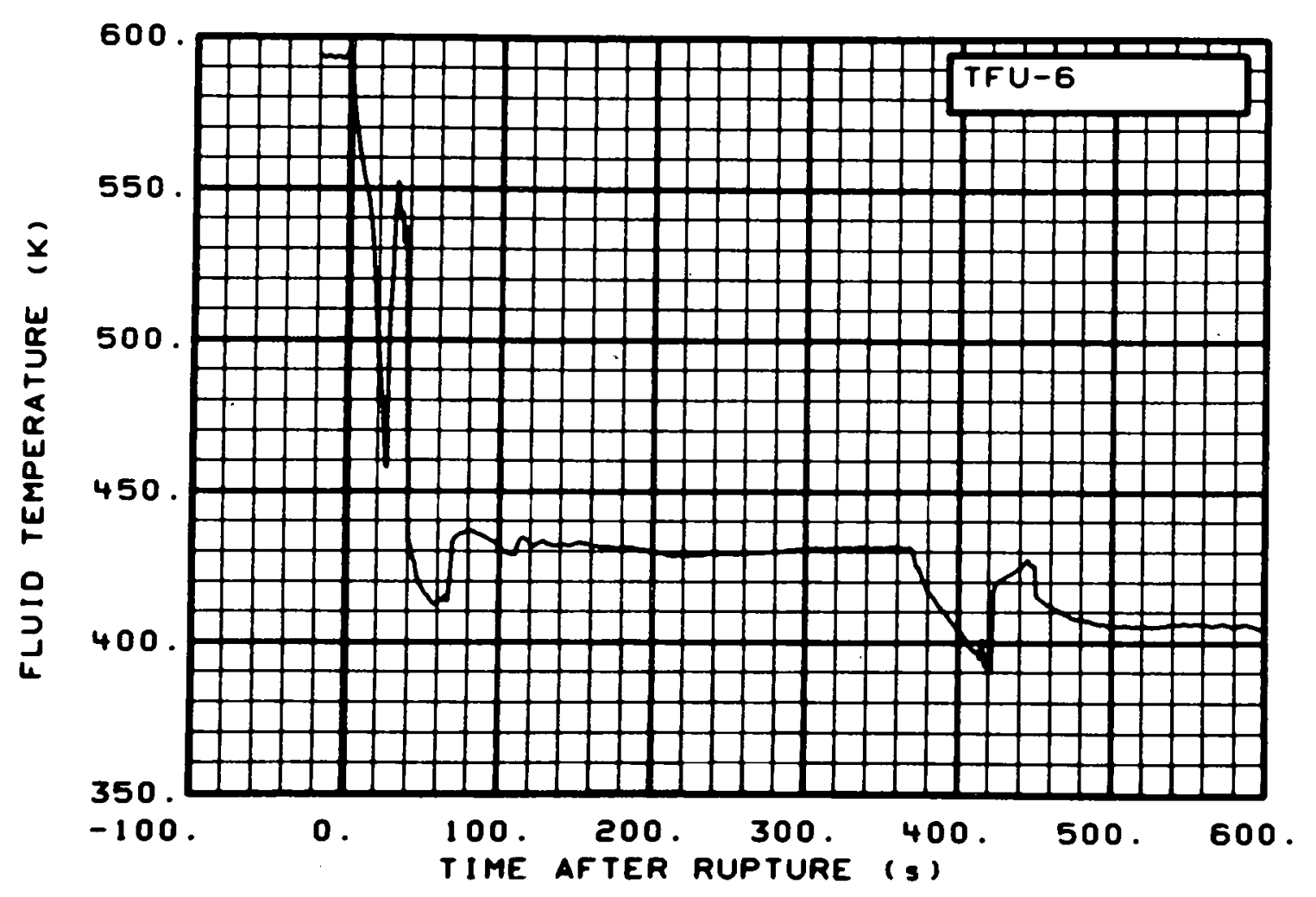

Fig. 11 Fluid temperature in intact loop hot leg (TFU-6), from -20 to $600 \mathrm{~s}$.

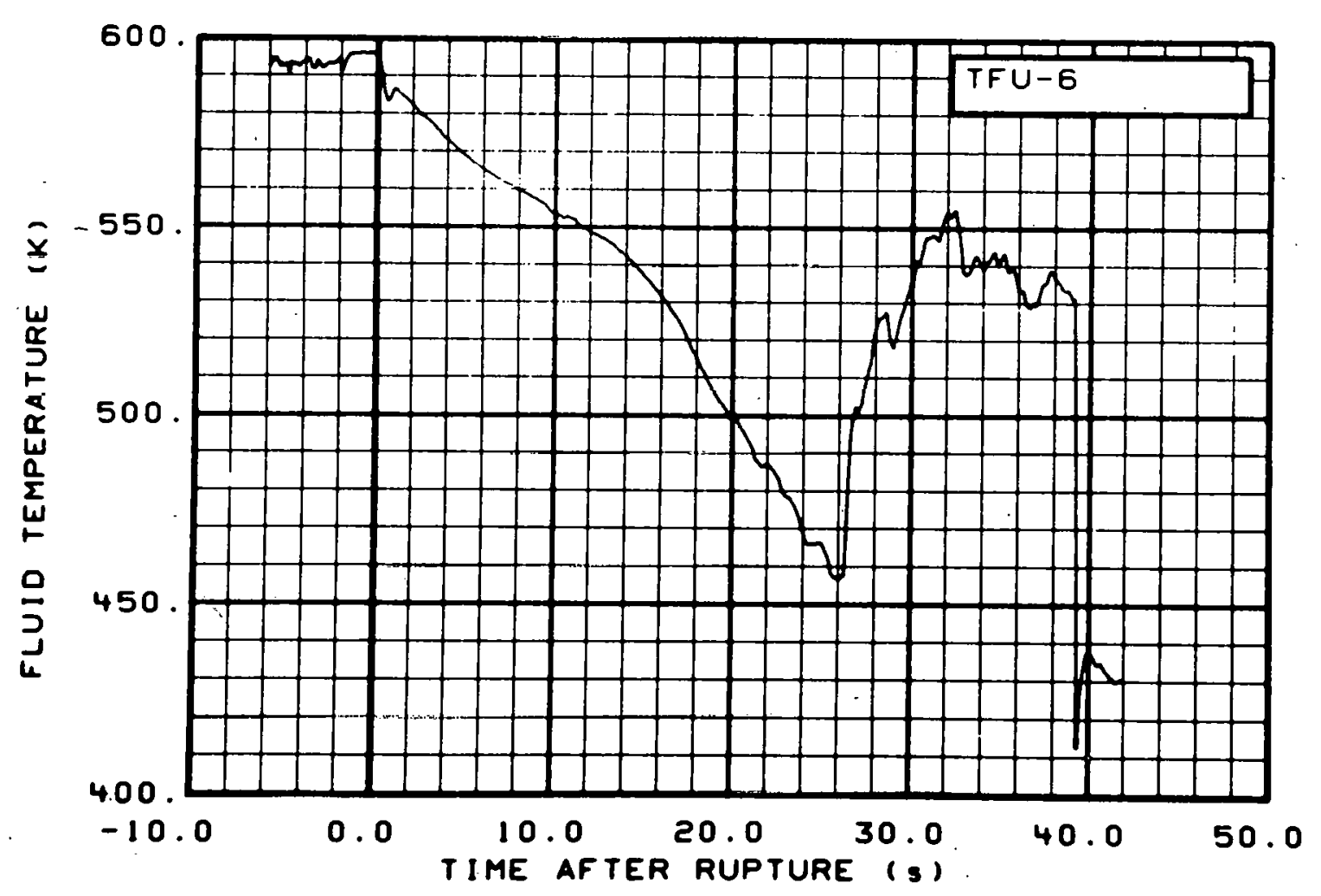

Fig. 12 Fluid temperature in intact. loop hot leg (TFU-6), from -6 to $42 \mathrm{~s}$. 


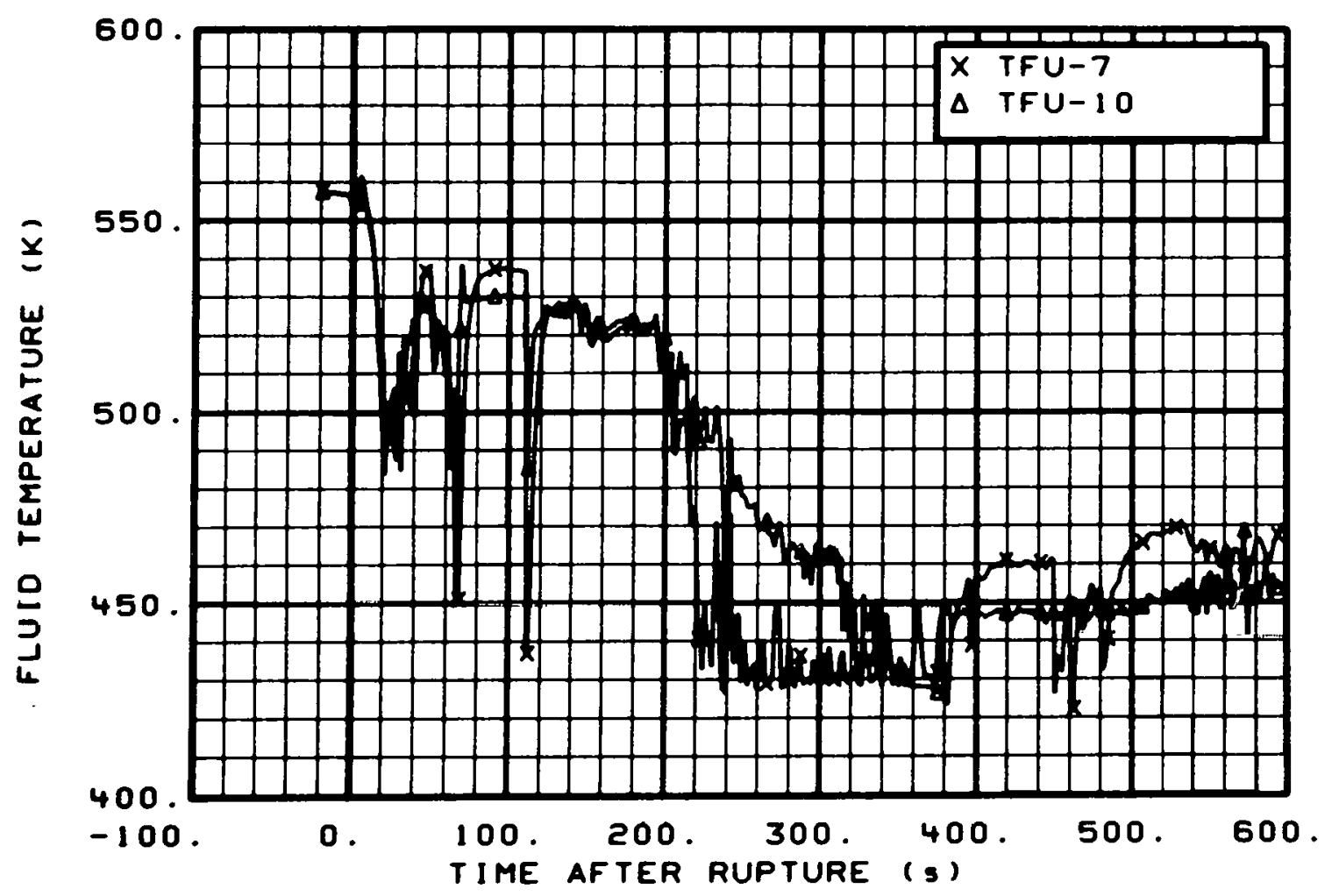

Fig. 13 Fluid temperature in intact loop cold leg (TFU-7 and TFU-10), from -20 to $600 \mathrm{~s}$.

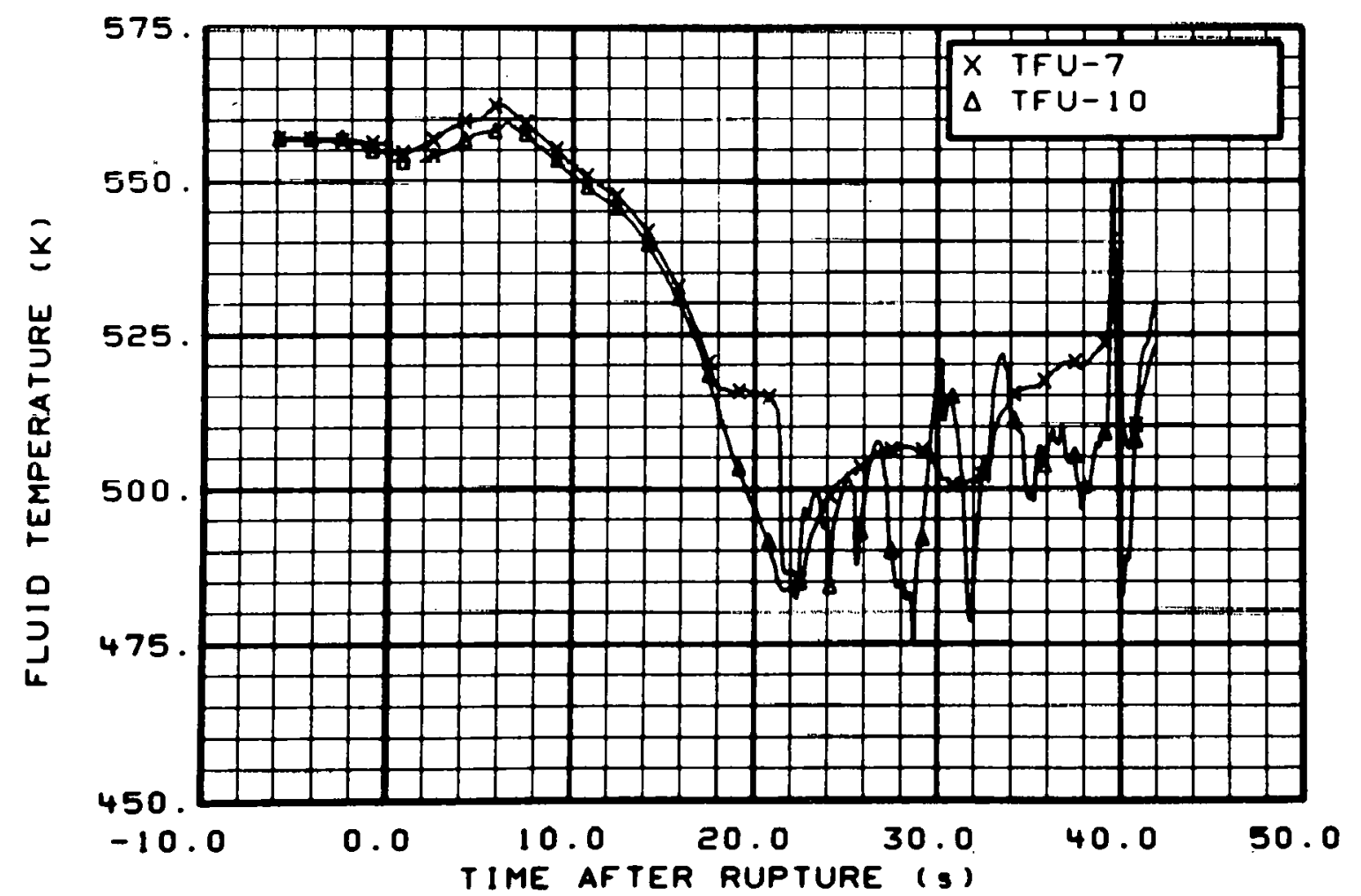

Fig. 14 Fluid temperature in intact loop cold leg (TFU-7 and TFU-10), from -6 to $42 \mathrm{~s}$. 


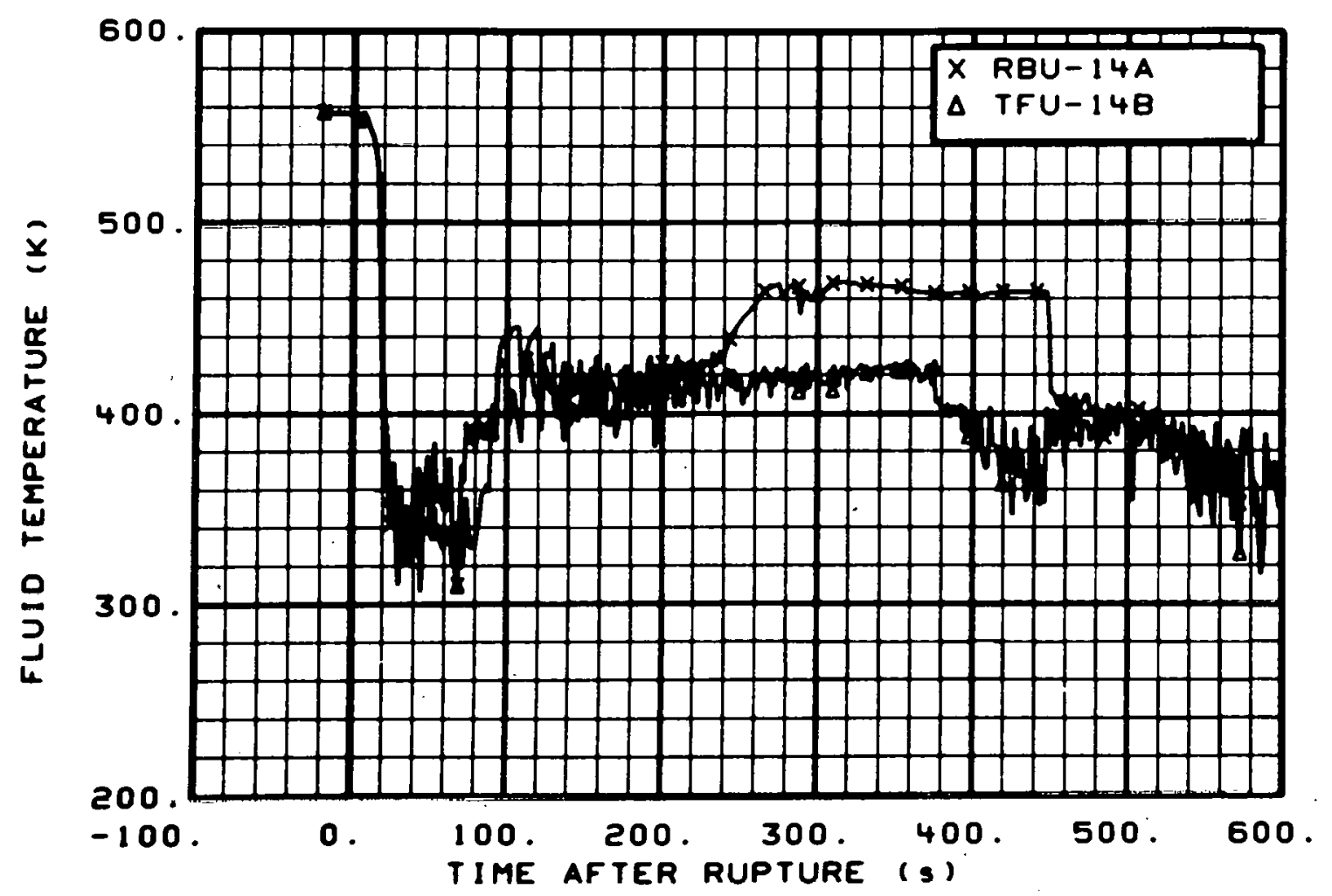

Fig. 15 Fluid temperature in intact loop cold leg (RBU-14A and TFU-14B), from -20 to $600 \mathrm{~s}$.

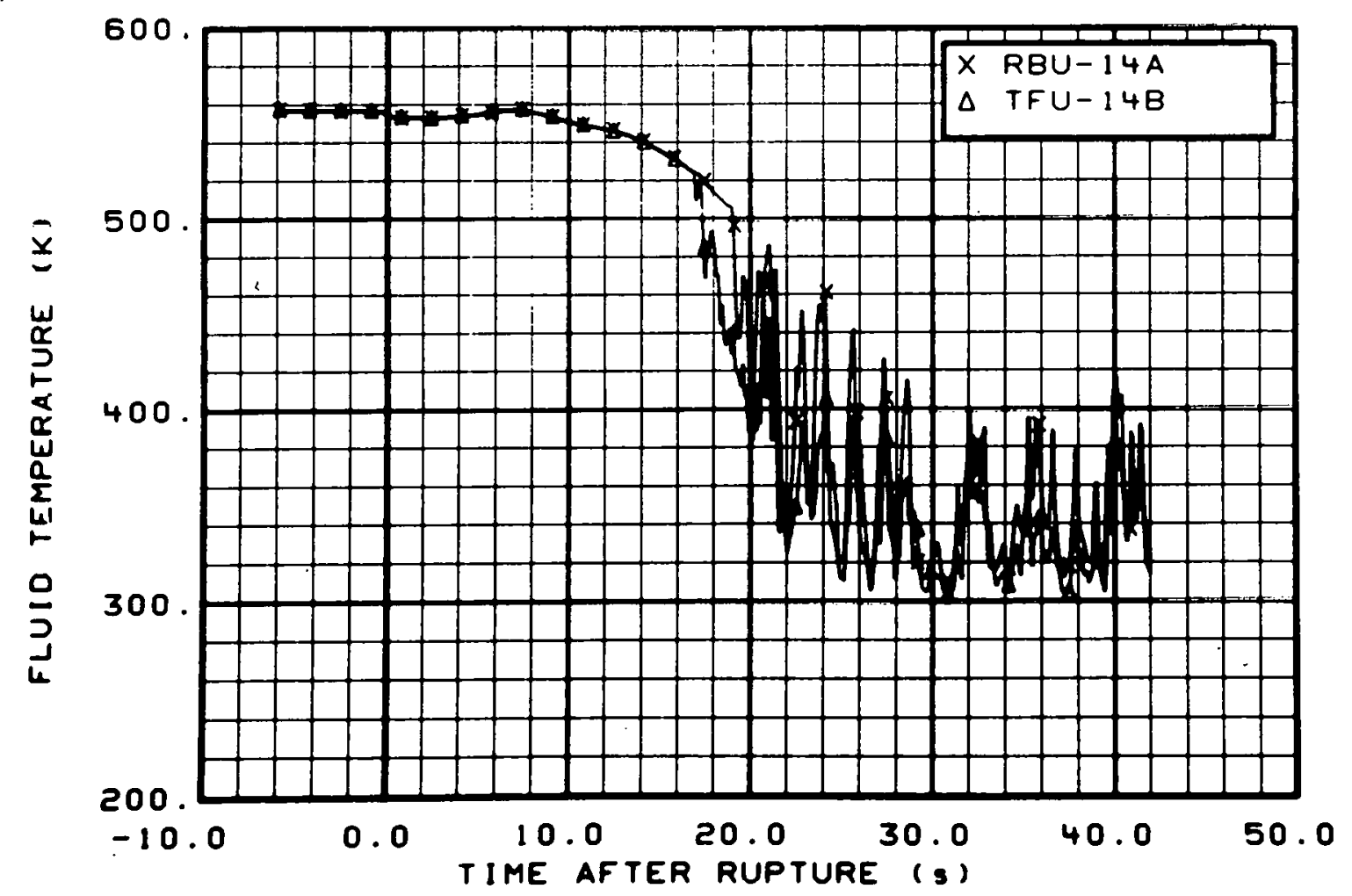

Fig. 16 Fluid temperature in intact loop cold leg (RBU-14A and TFU-14B), from -6 to $42 \mathrm{~s}$. 


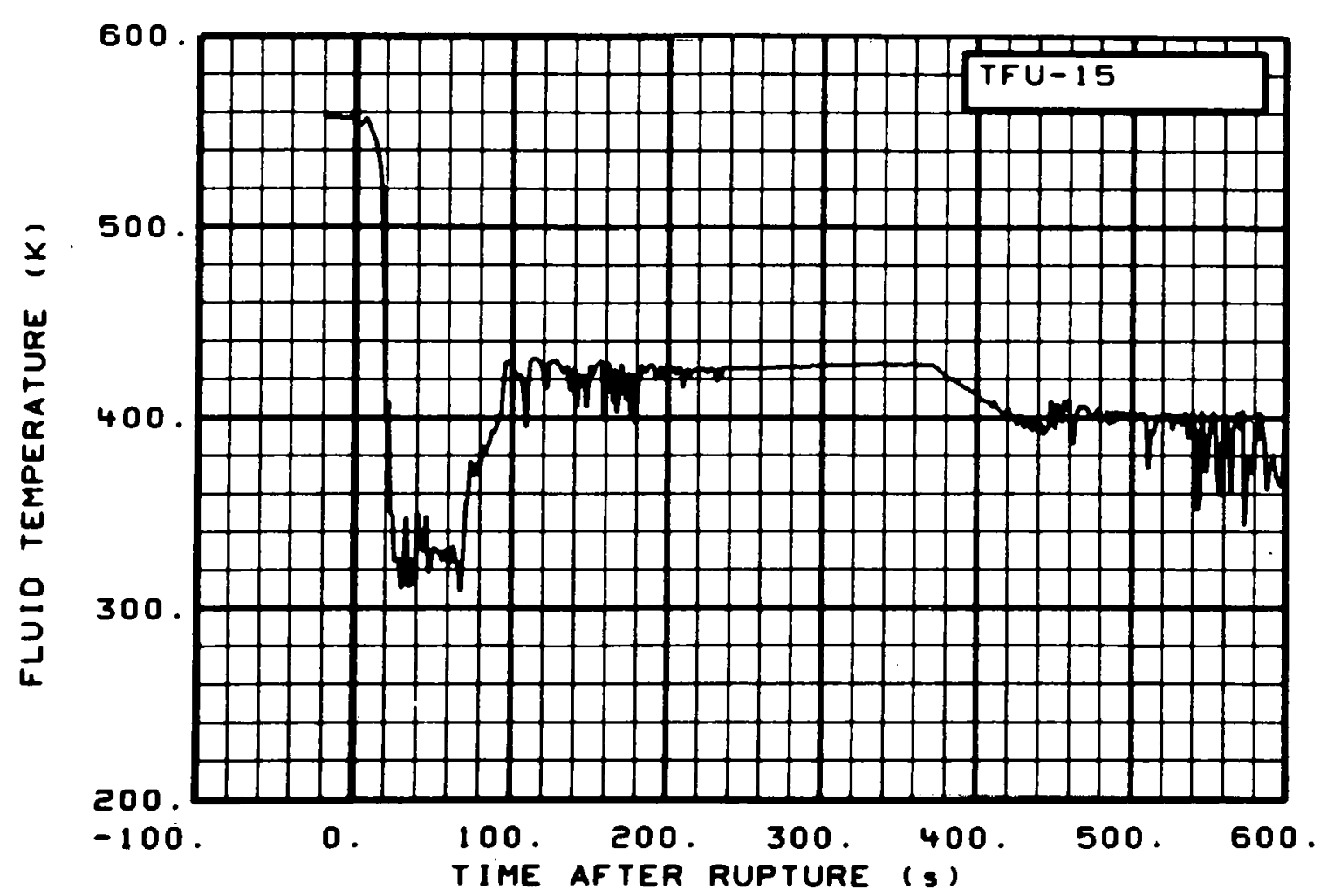

Fig. 17 Fluid temperature in intact loop cold leg (TFU-15), from -20 to $600 \mathrm{~s}$.

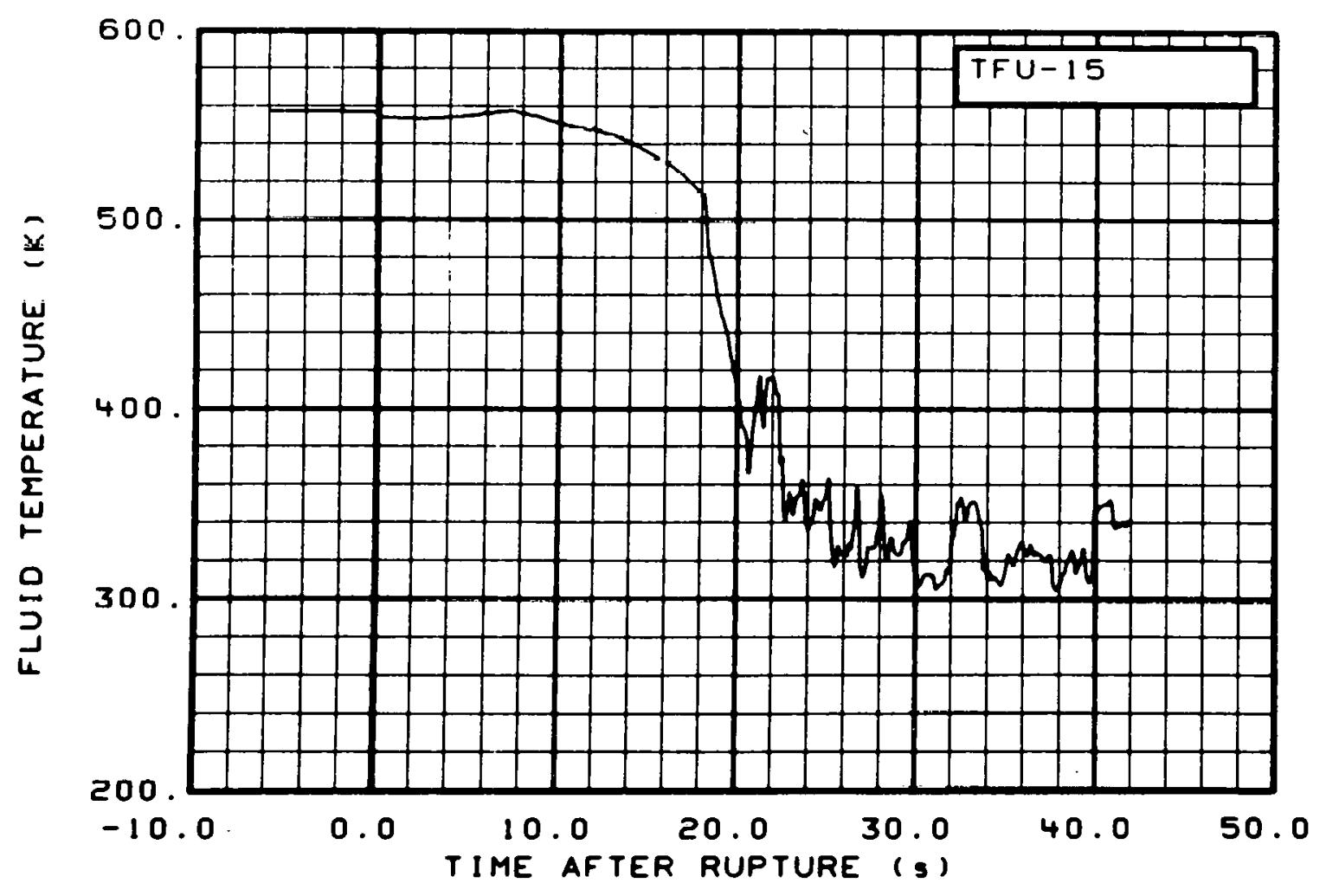

Fig. 18 Fluid temperature in intact loop cold leg (TFU-15), from -6 to $42 \mathrm{~s}$. 


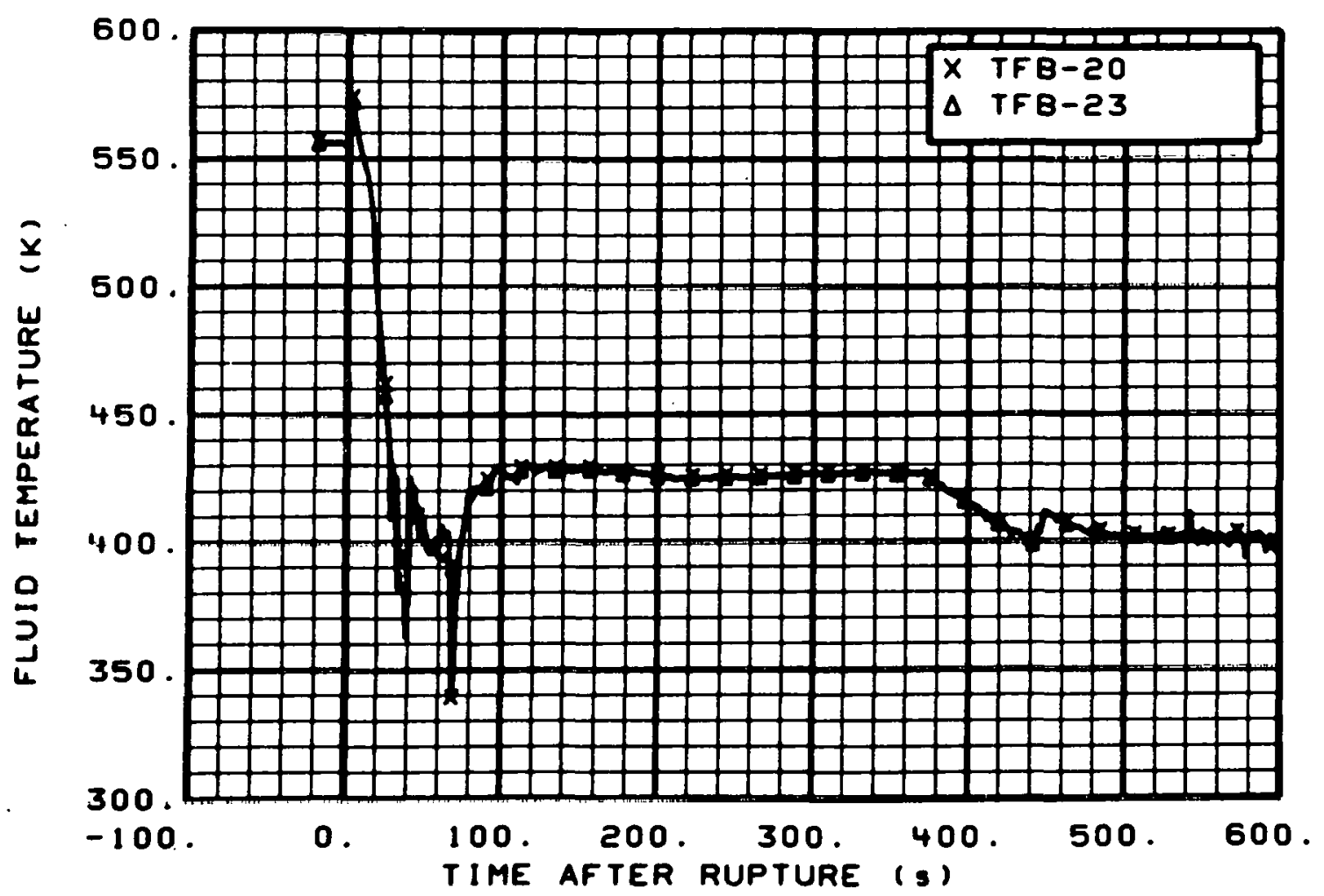

Fig. 19 Fluid temperature in broken loop, vessel side (TFB-20 and TFB-23), from -20 to $600 \mathrm{~s}$.

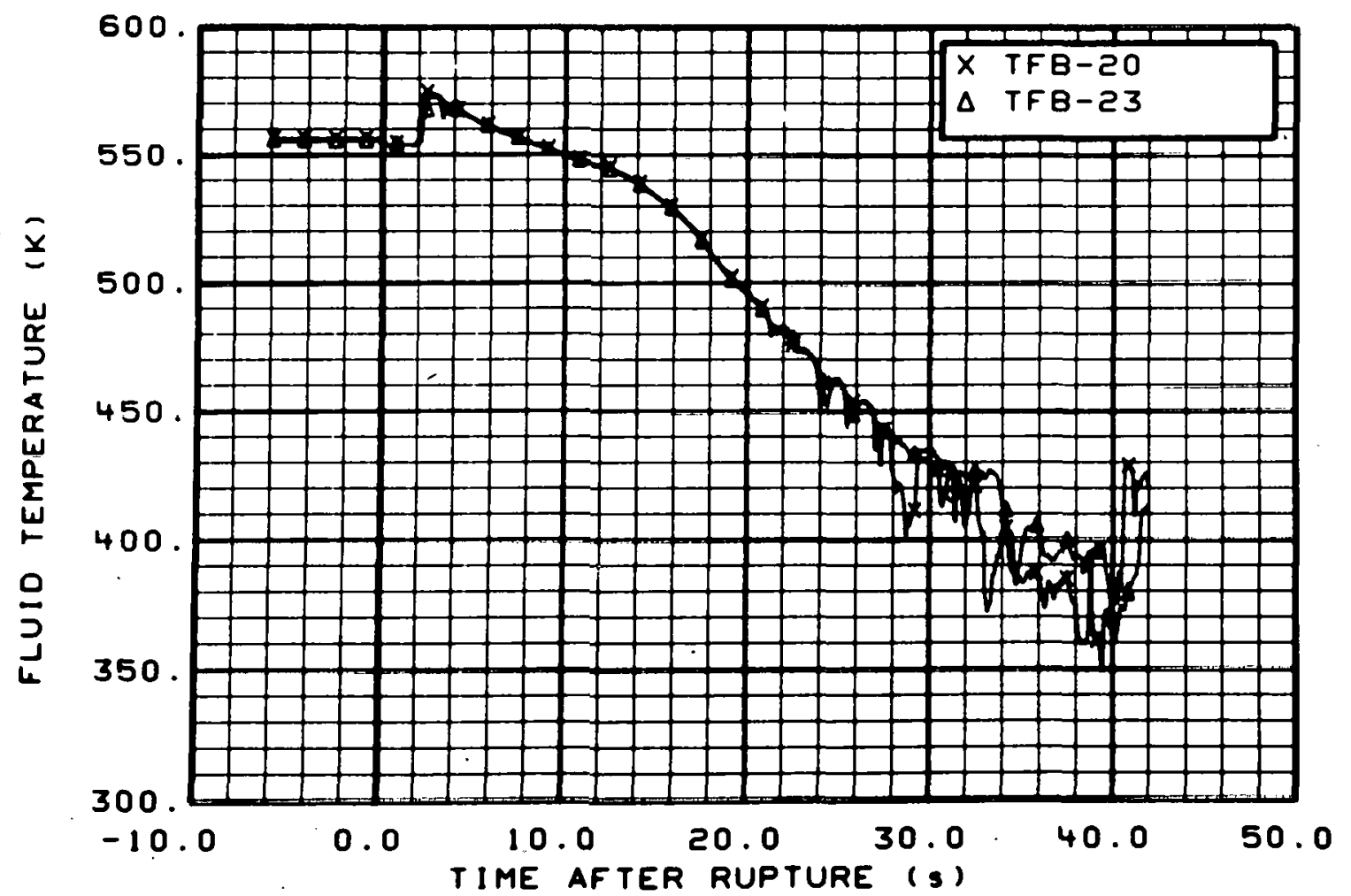

Fig. 20 Fluid temperature in broken 10op, vessel side (TFB-20 and TFB-23), from -6 to $42 \mathrm{~s}$. 


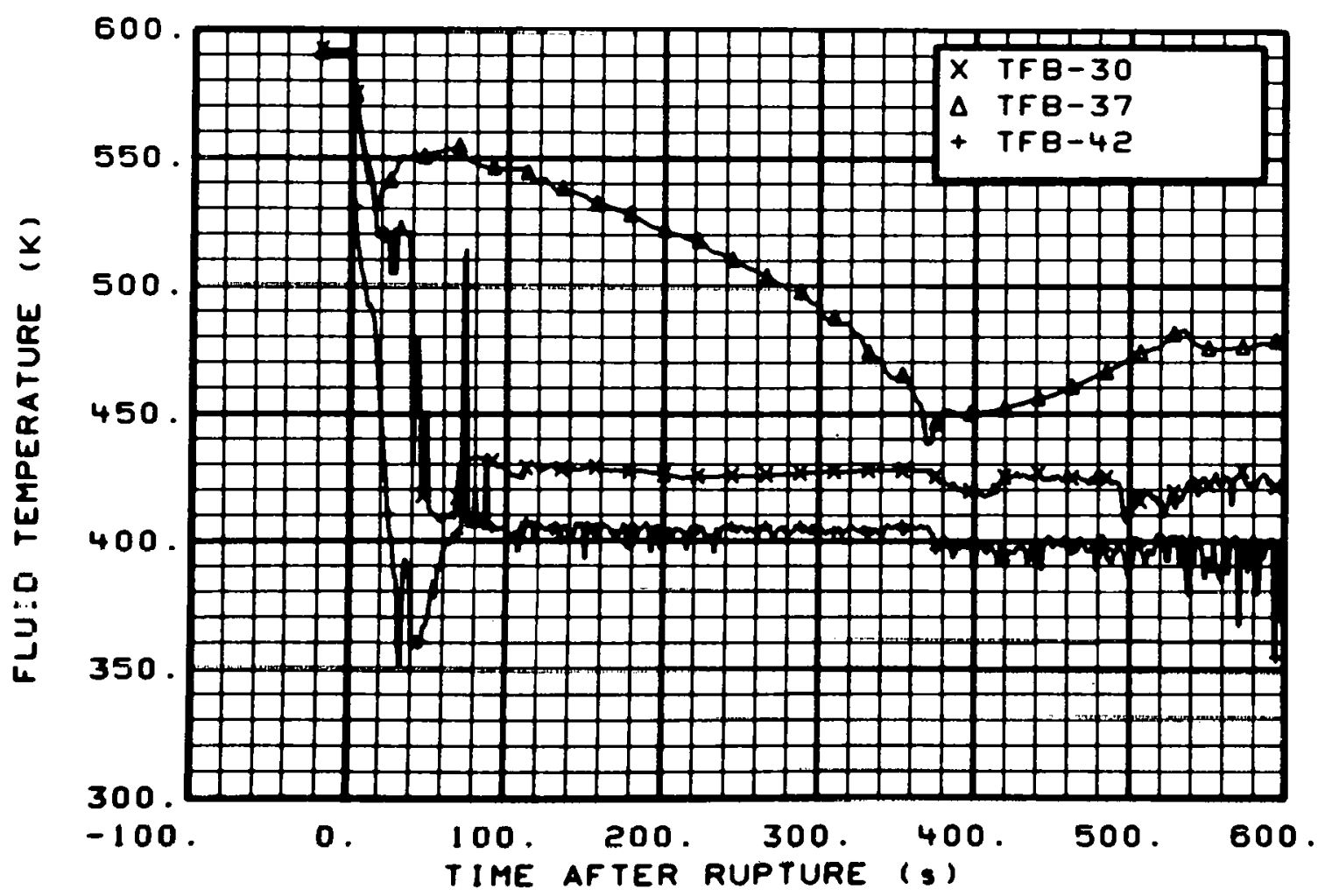

Fig. 21 Fluid temperature in broken loop, pump side (TFB-30, TFB-37, and TFB-42), from -20 to $600 \mathrm{~s}$.

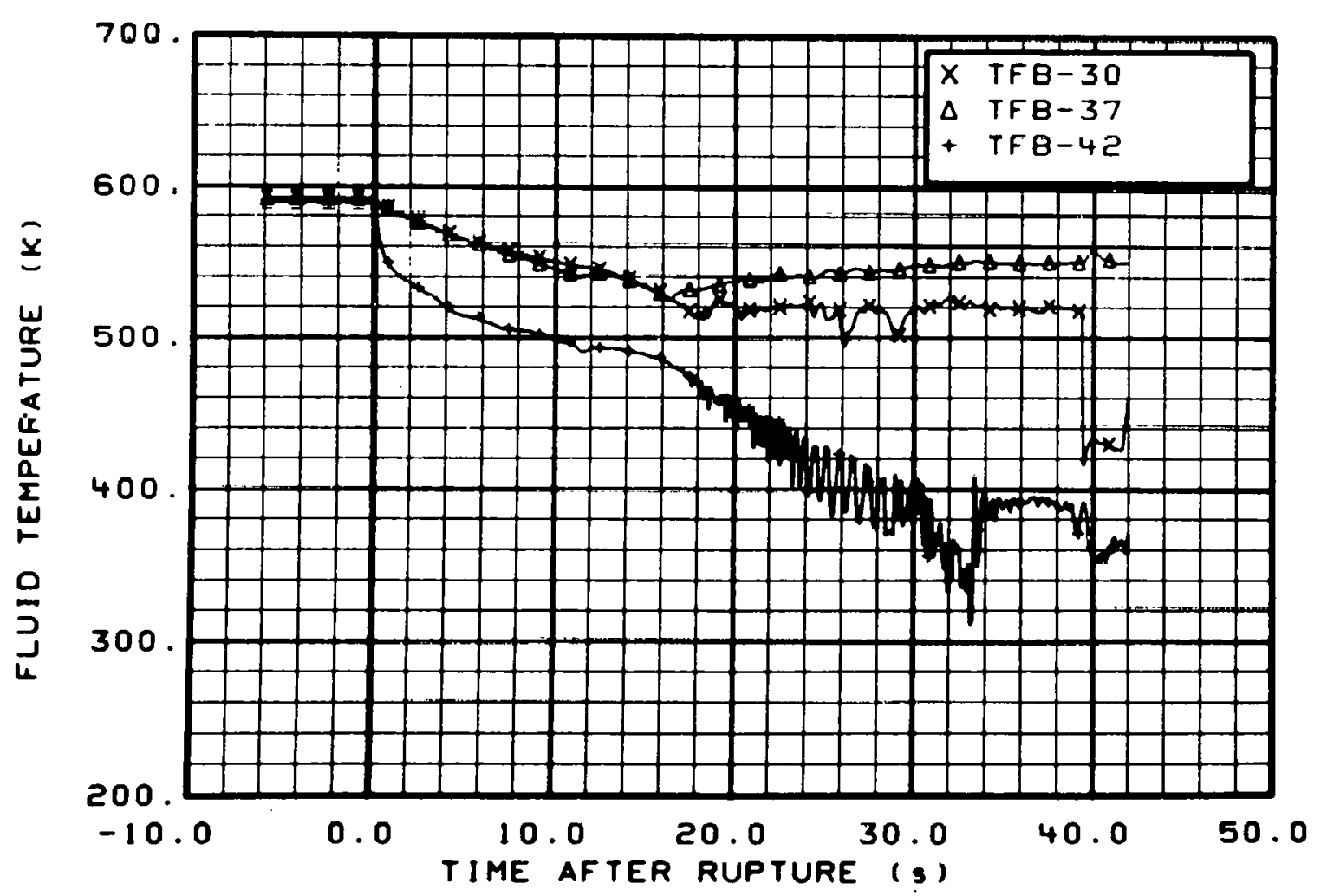

Fig. 22 Fluid temperature in broken loop, pump side (TFB-30, TFB-37, and TFB-42), from -6 to $42 \mathrm{~s}$. 


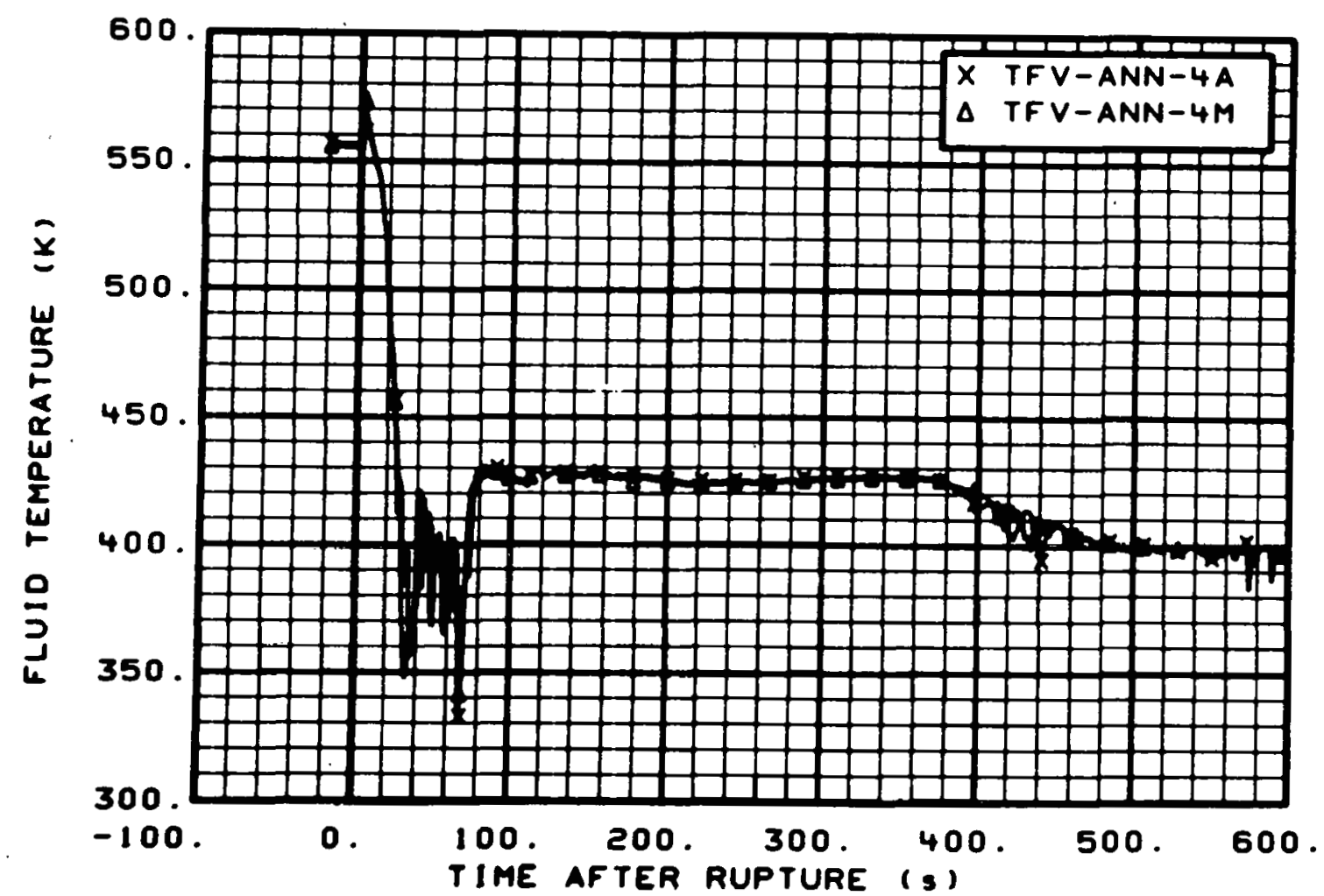

Fig. 23 Fluid temperature in inlet annulus (TFV-ANN-4A and TFV-ANN-4M), from -20 to $600 \mathrm{~s}$.

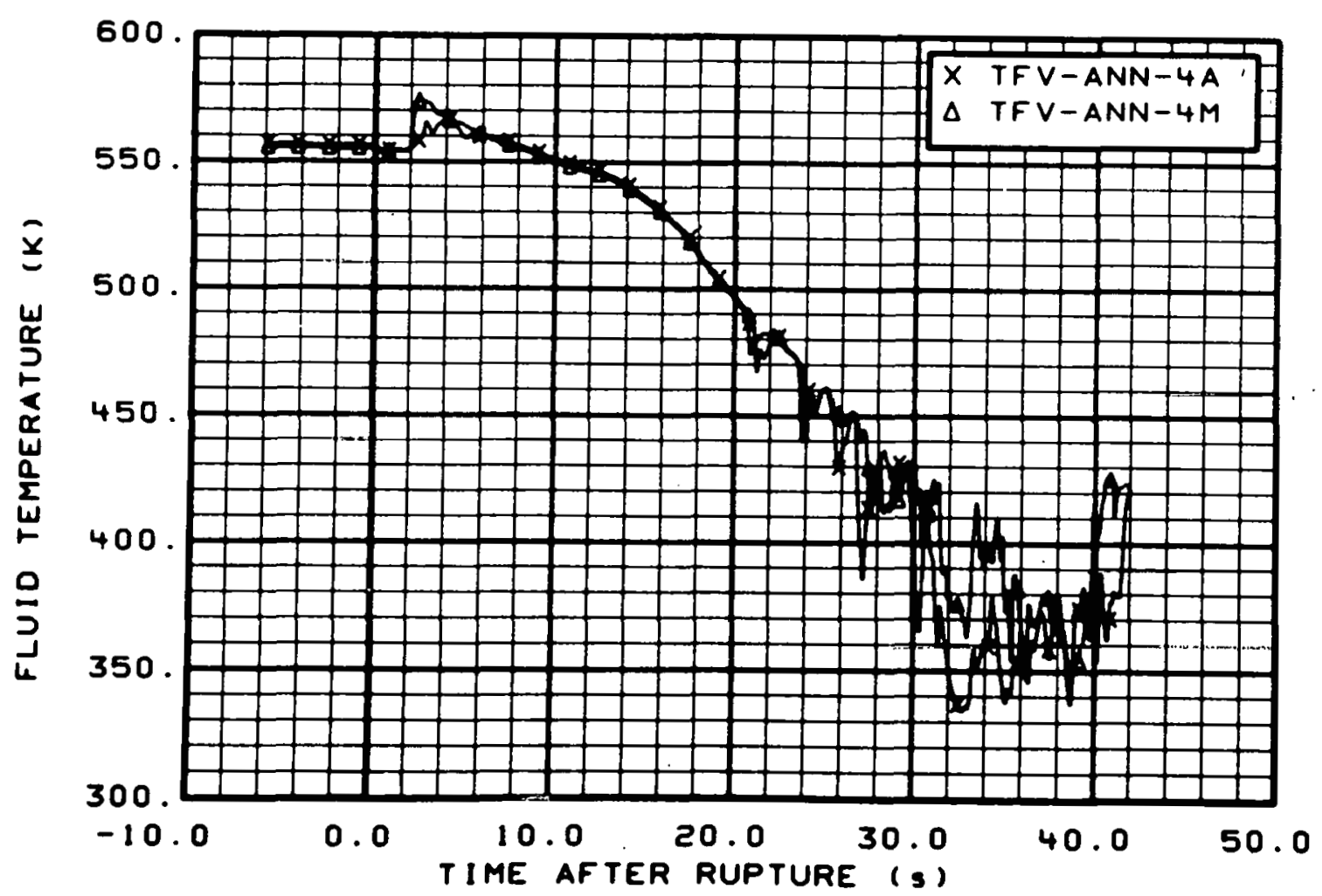

Fig. 24 Fluid temperature in inlet annulus (TFV-ANN-4A and TFV-ANN-4M), from -6 to $42 \mathrm{~s}$. 


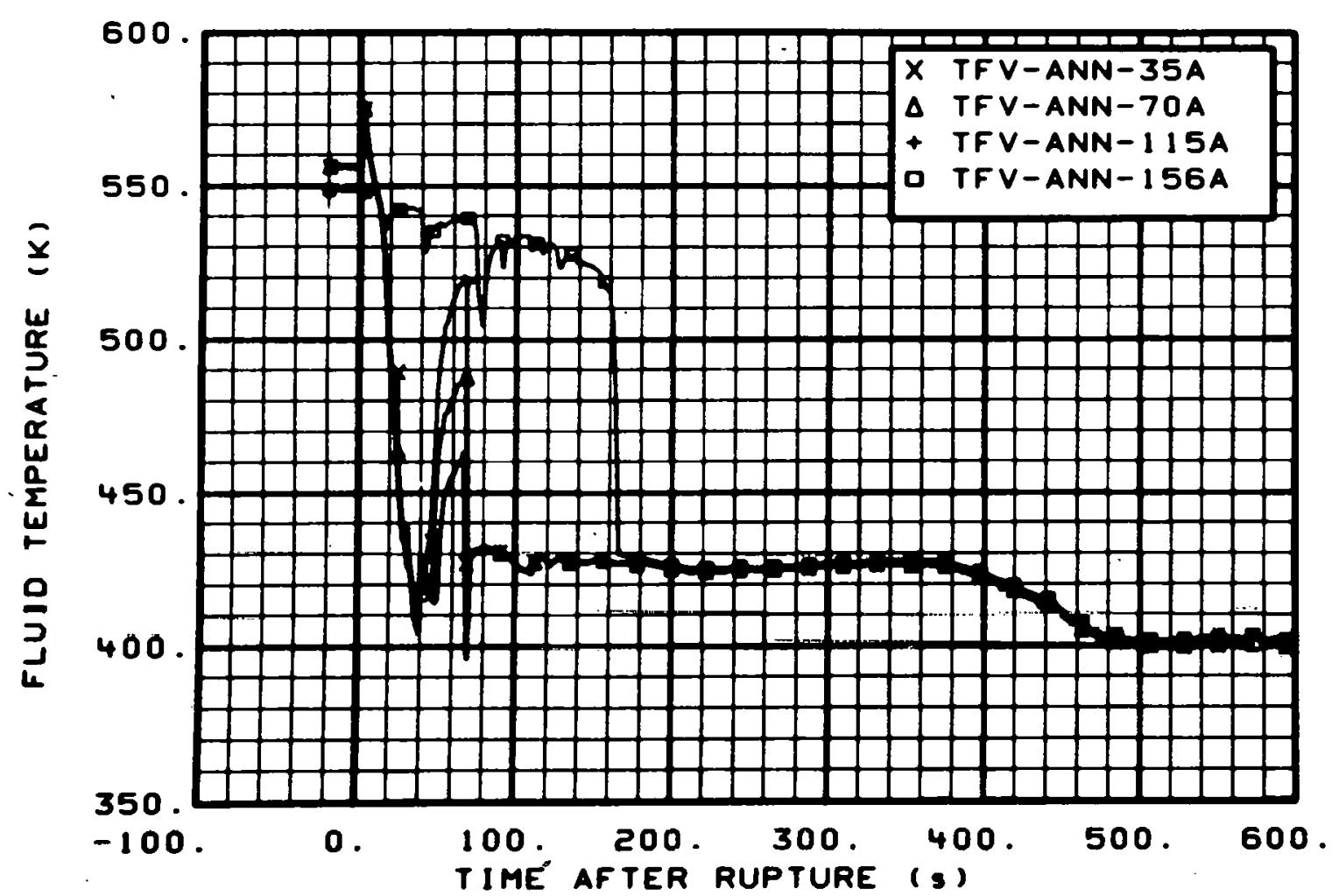

Fig. 25 Fluid temperature in downcomer annulus (TFV-ANN-35A, TFV-ANN-70A, TFV-ANN-115A, and TFV-ANN-156A), from -20 to $600 \mathrm{~s}$.

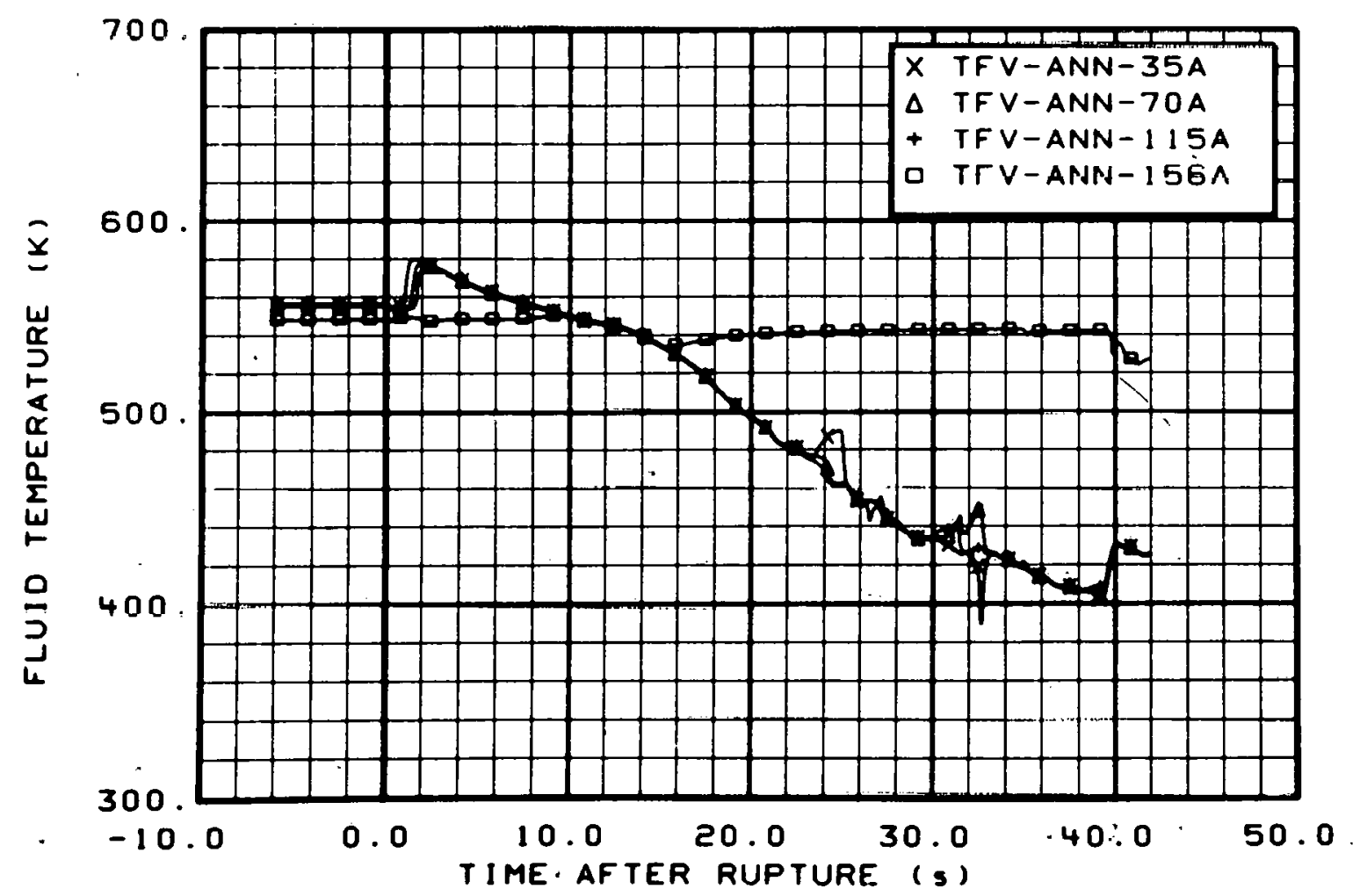

Fig. 26 Fluid temperature in downcomer annulus (TFV-ANN-35A, TFV-ANN-70A, TFV-ANN-115A, and TFV-ANN-156A), from -6 to $42 \mathrm{~s}$. 


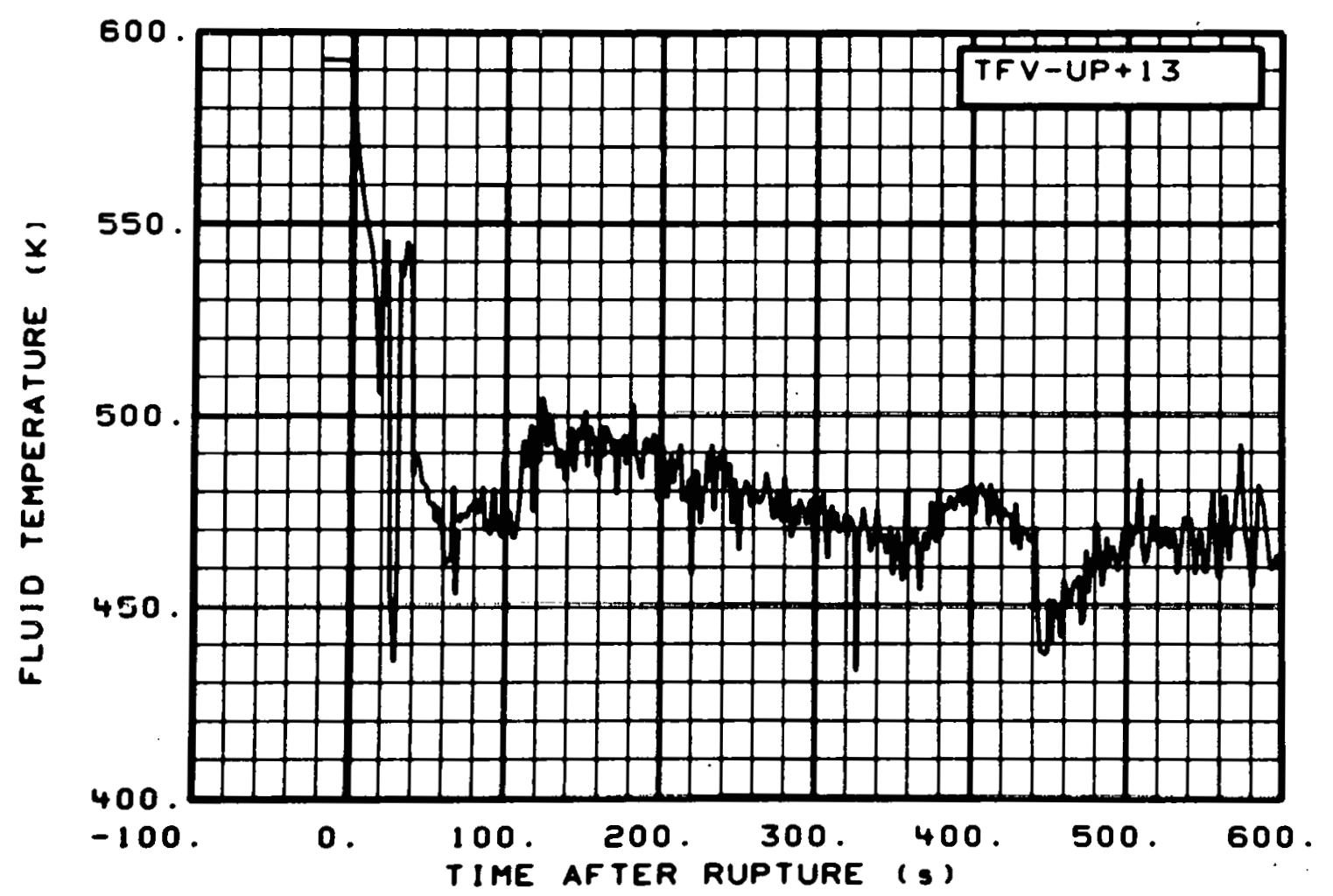

Fig. 27 Fluid temperature in upper plenum (TFV-UP+13), from -20 to $600 \mathrm{~s}$.

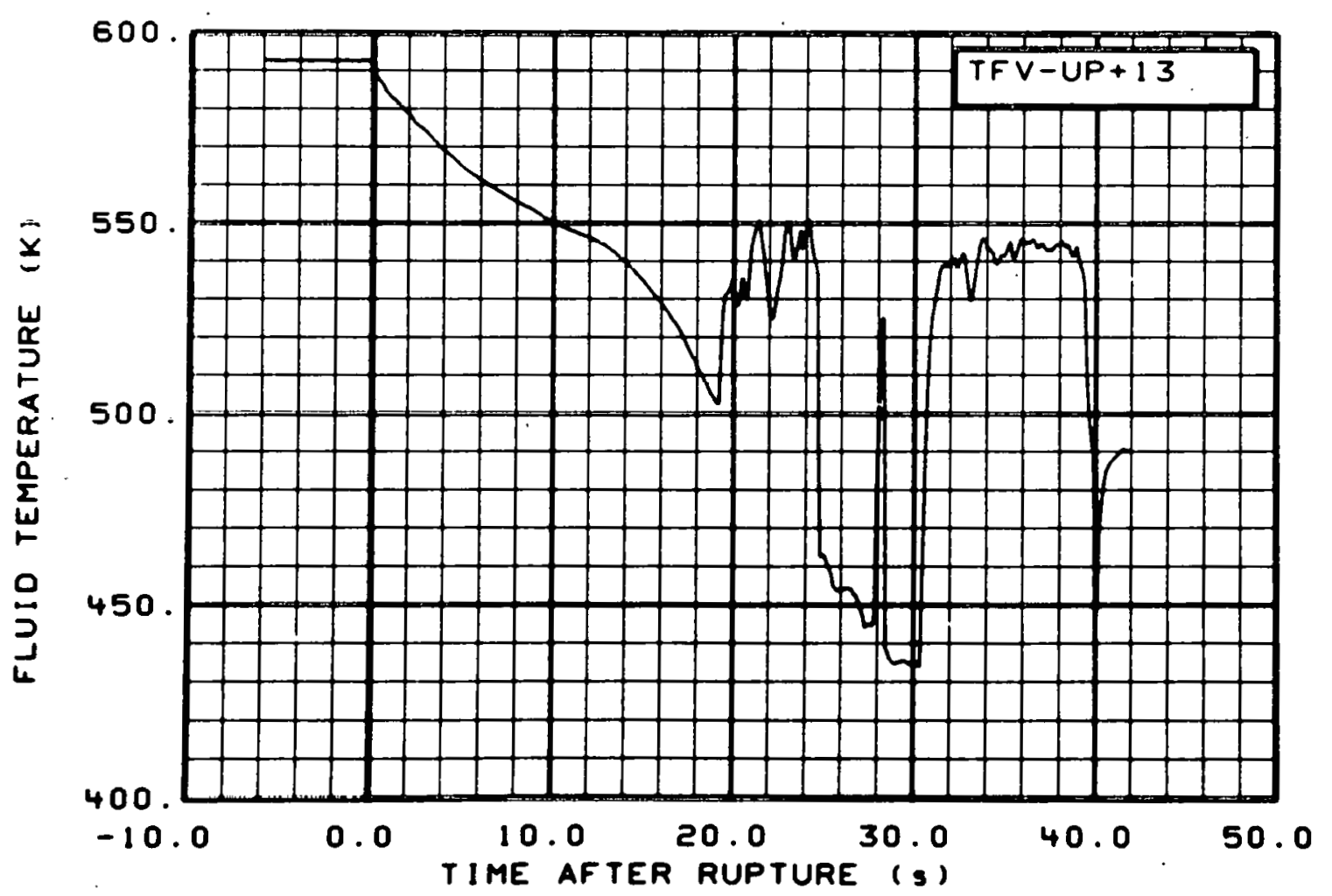

Fig. 28 Fluid temperature in upper plenum (TFV-UP+13), from -6 to $42 \mathrm{~s}$. 


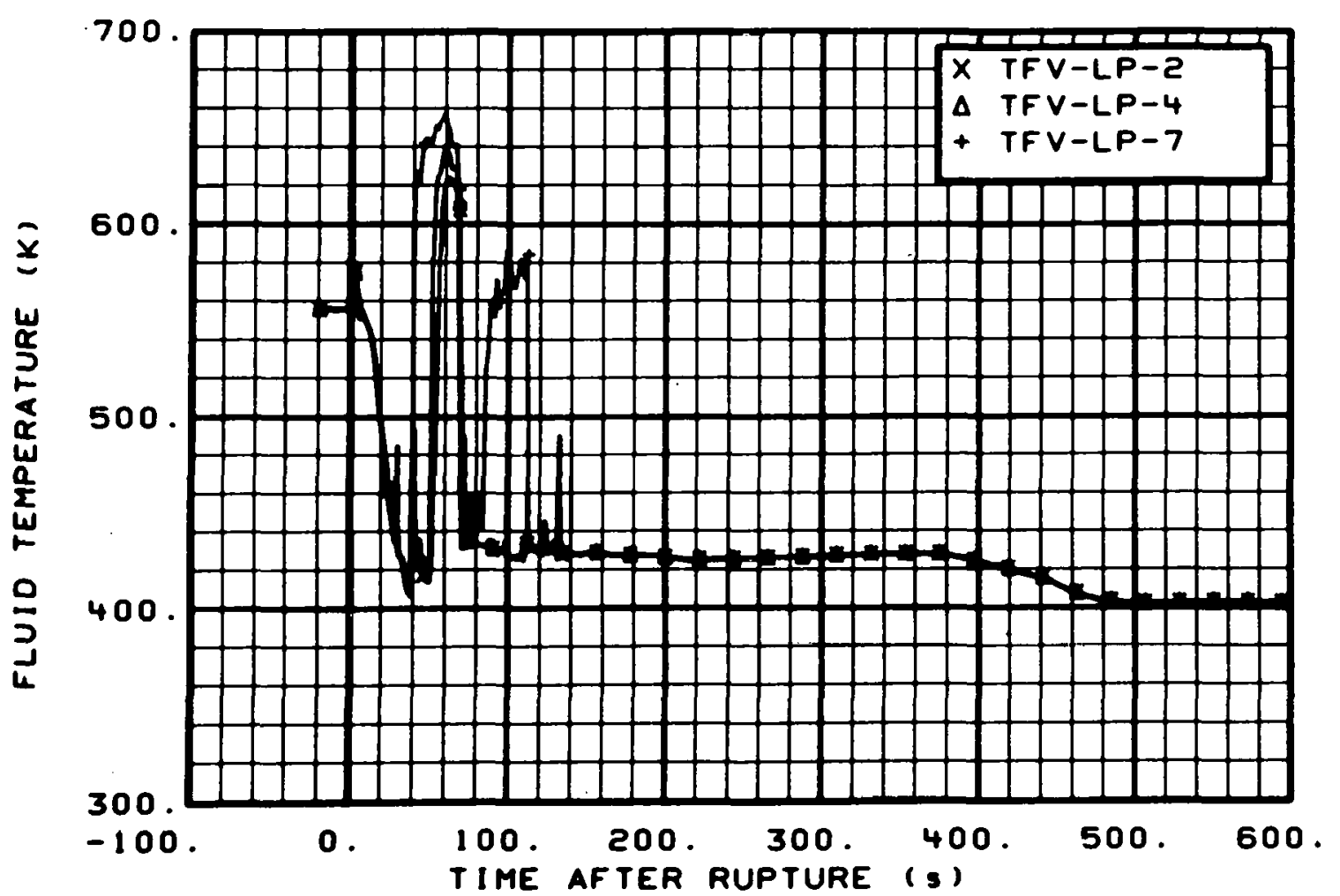

Fig. 29 Fluid temperature in lower plenum (TFV-LP-2, TFV-LP-4, and TFV-LP-7), from -20 to $600 \mathrm{~s}$.

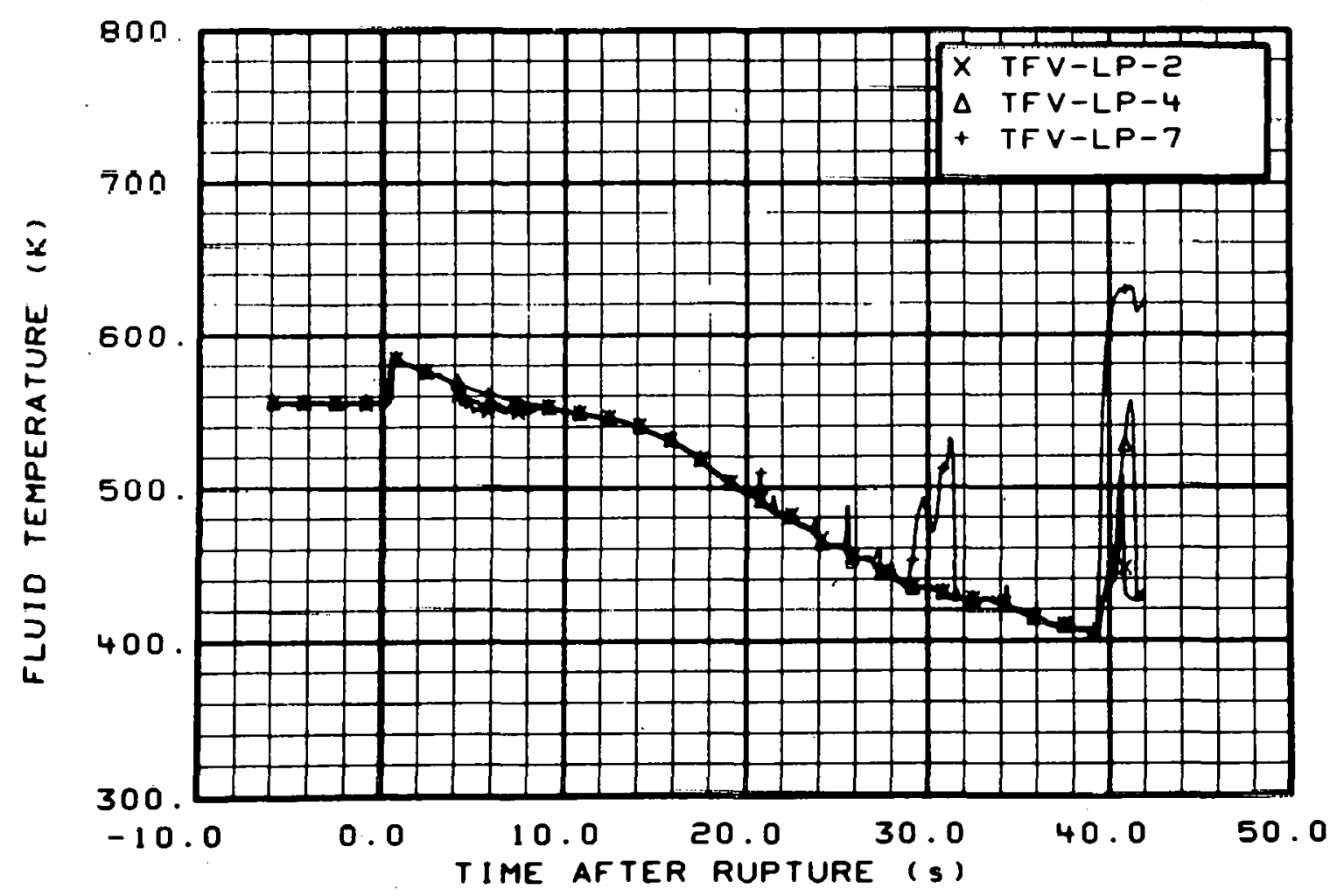

Fig. 30 Fluid temperature in lower plenum (TFV-LP-2, TFV-LP-4, and TFV-LP-7), from -6 to $42 \mathrm{~s}$. 


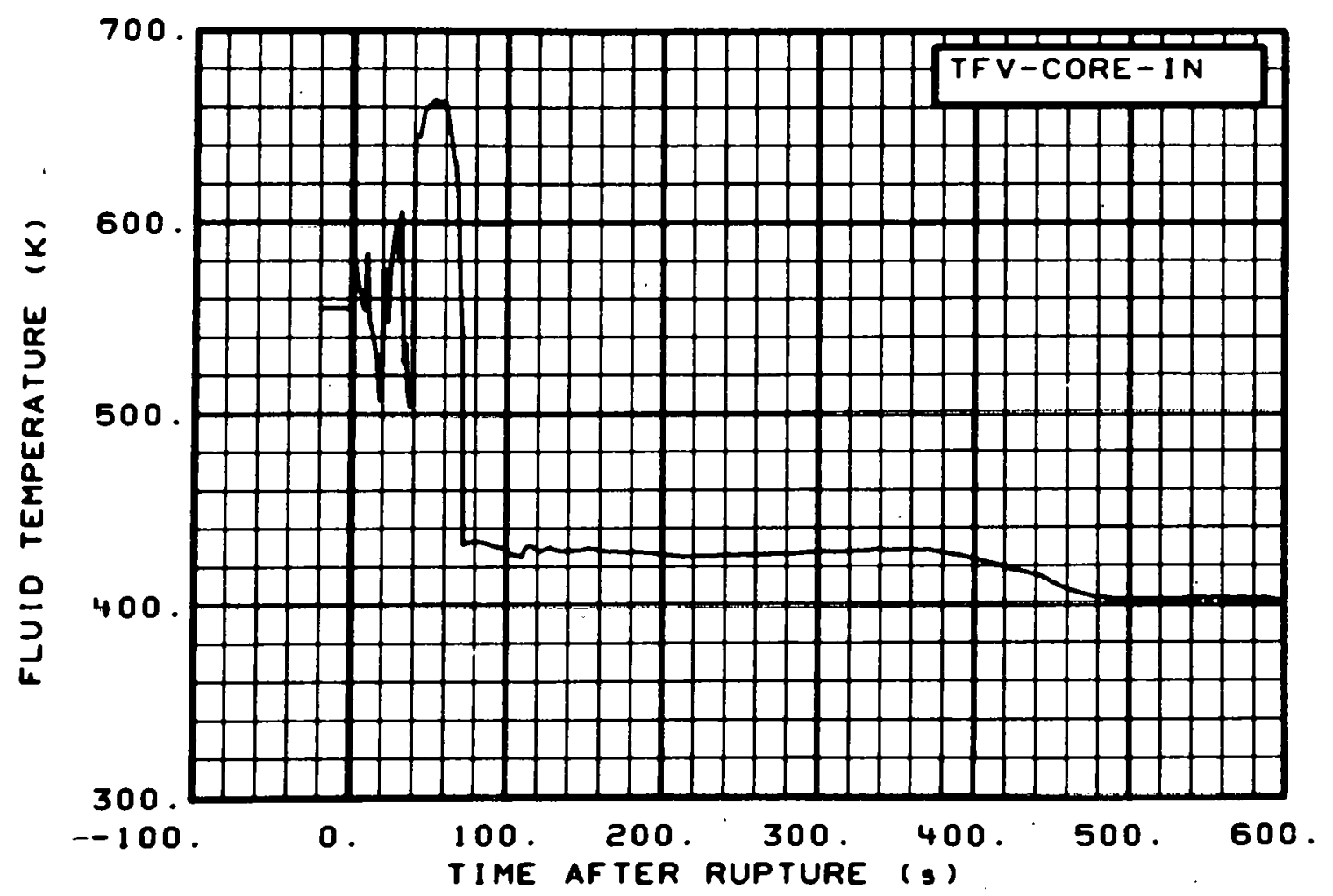

Fig. 31 Fluid temperature in core inlet (TFV-CORE-IN), from -20 to $600 \mathrm{~s}$.

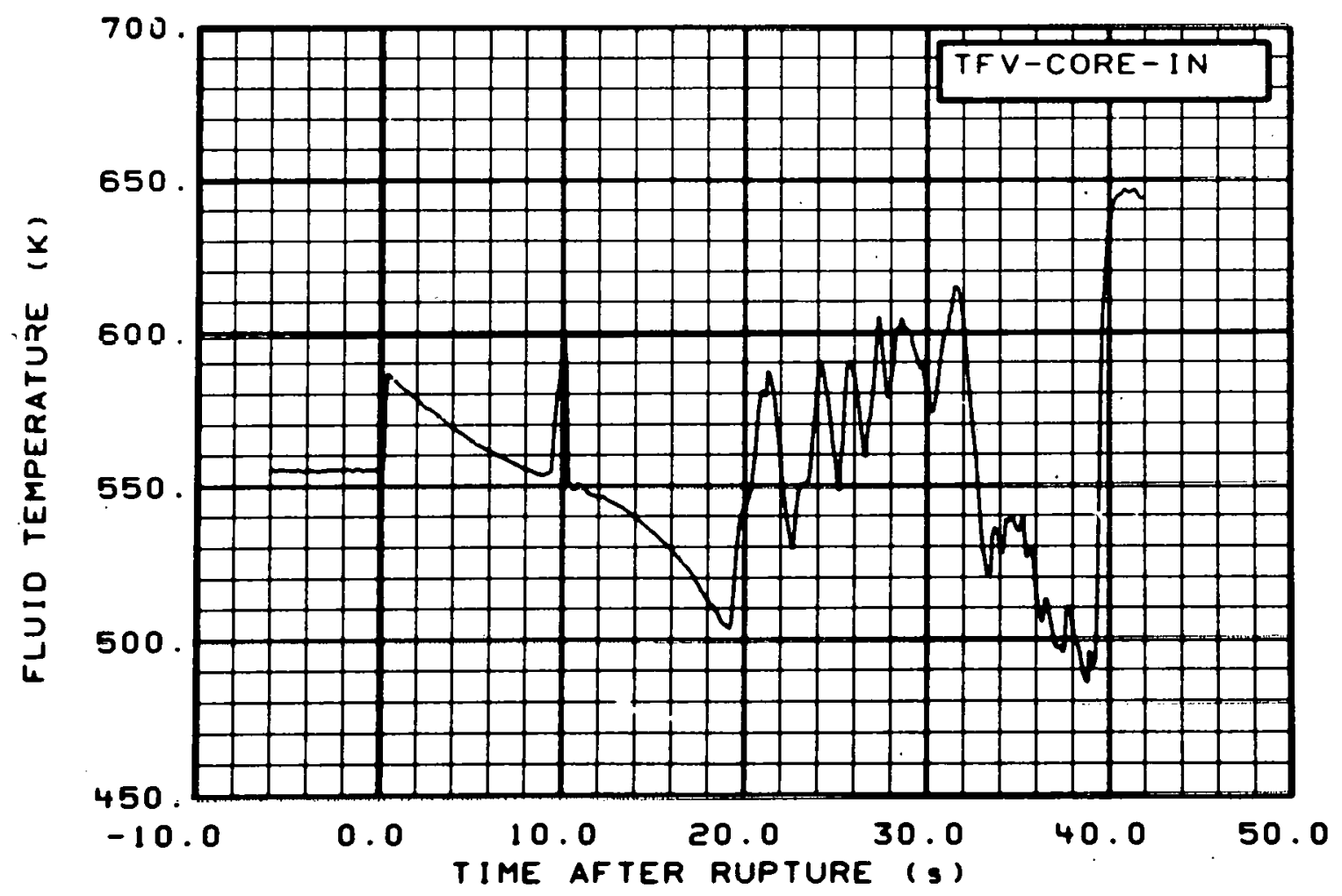

Fig. 32. Fluid temperature in core inlet. (TFV-CORE-IN), from -6 to $42 \mathrm{~s}$. 


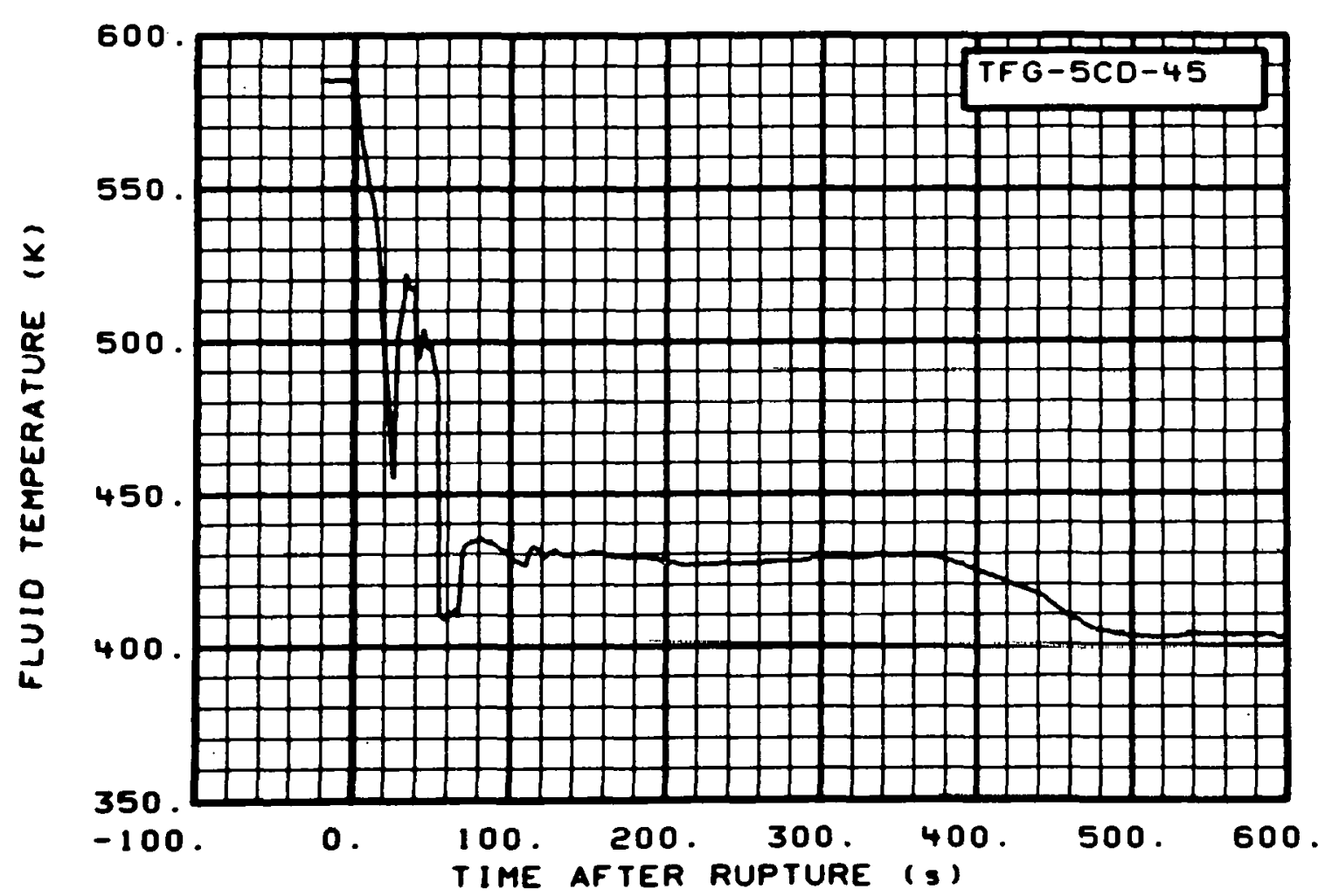

Fig. 33 Fluid temperature in core, Grid Spacer 5 (TFG-5CD-45), from -20 to $600 \mathrm{~s}$.

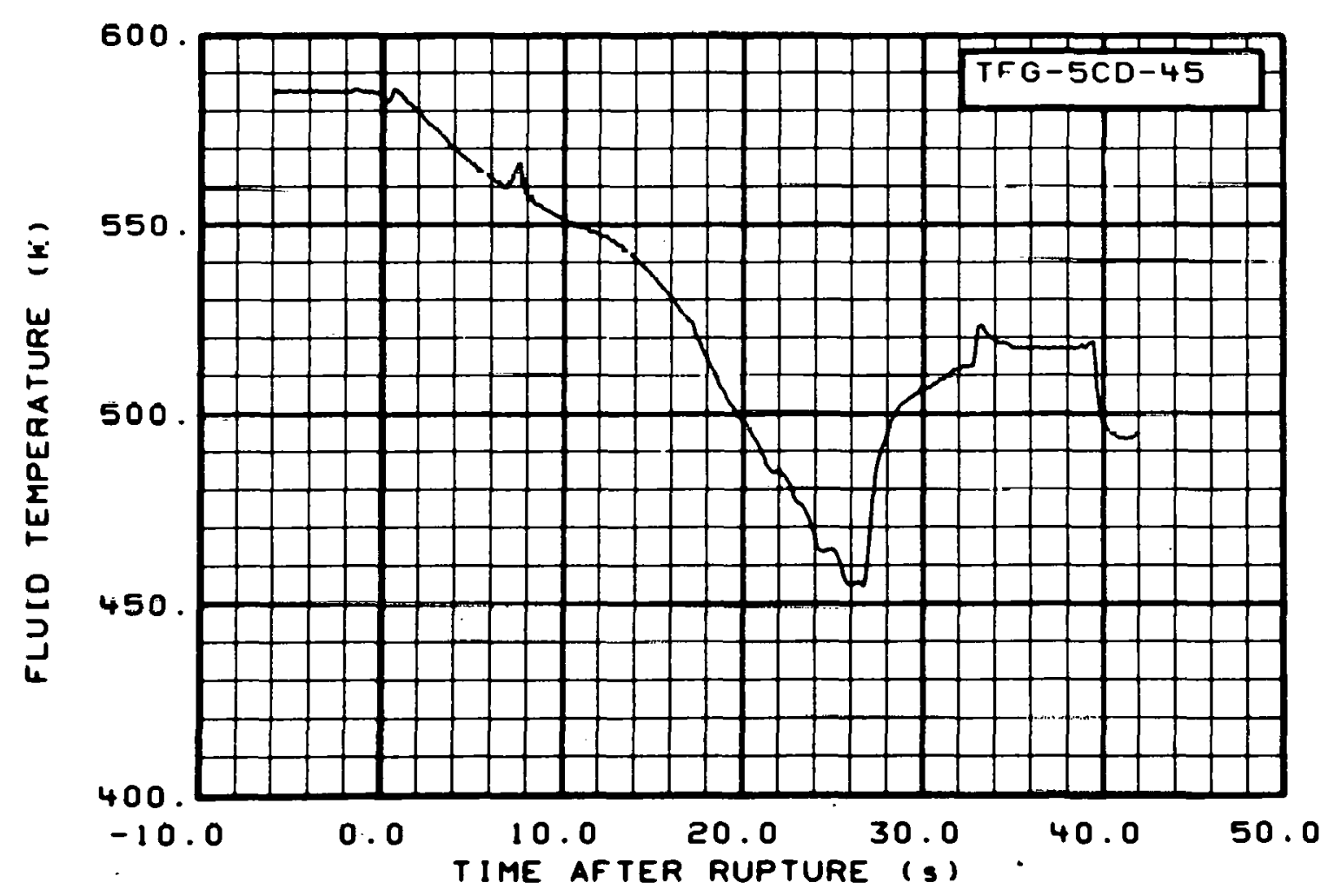

Fig. 34 Fluid temperature in core, Grid Spacer 5 (TFG-5CD-45), from -6 to 425 . 


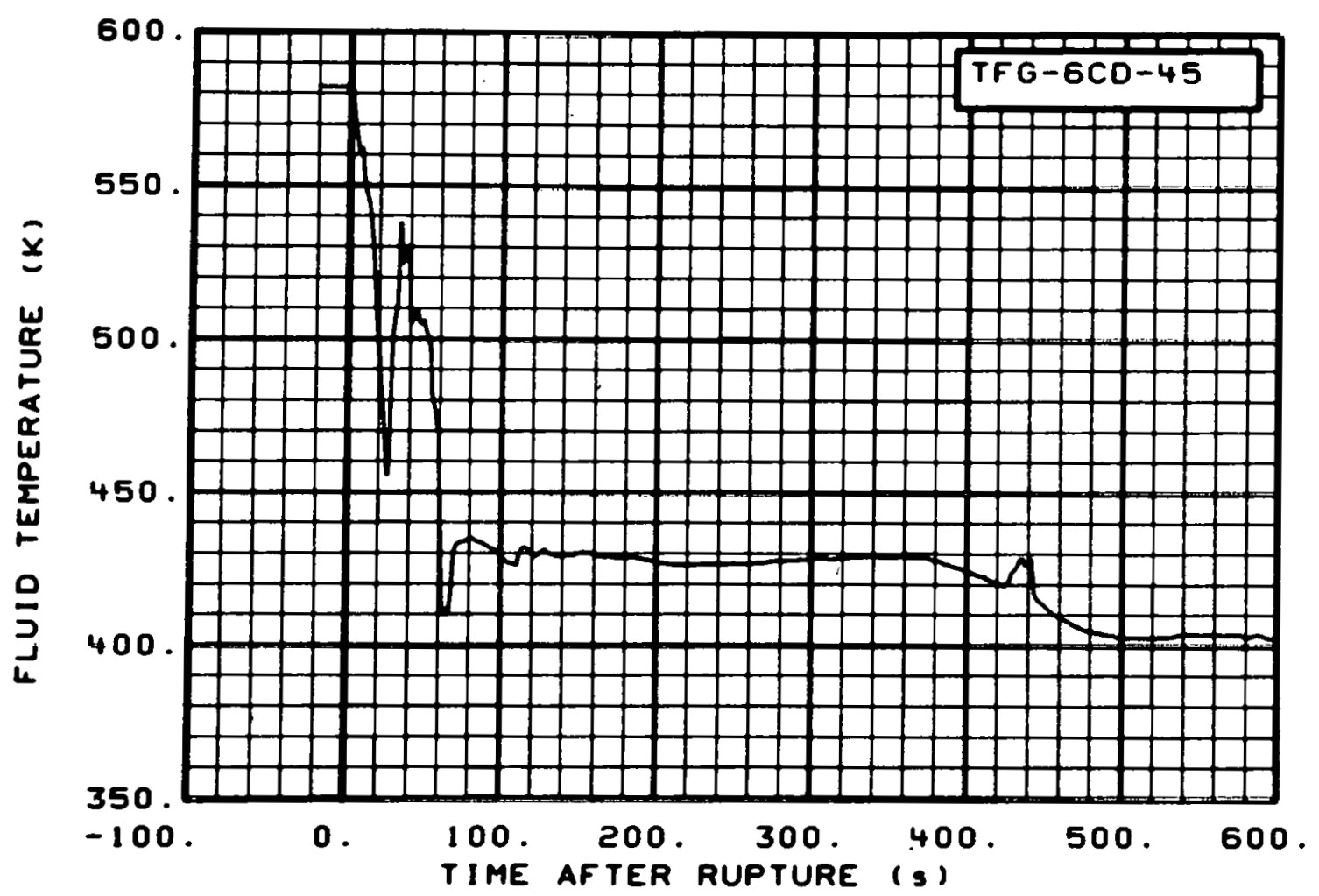

Fig. 35 Fluid temperature in core, Grid Spacer 6 (TFG-6CD-45), from -20 to $600 \mathrm{~s}$.

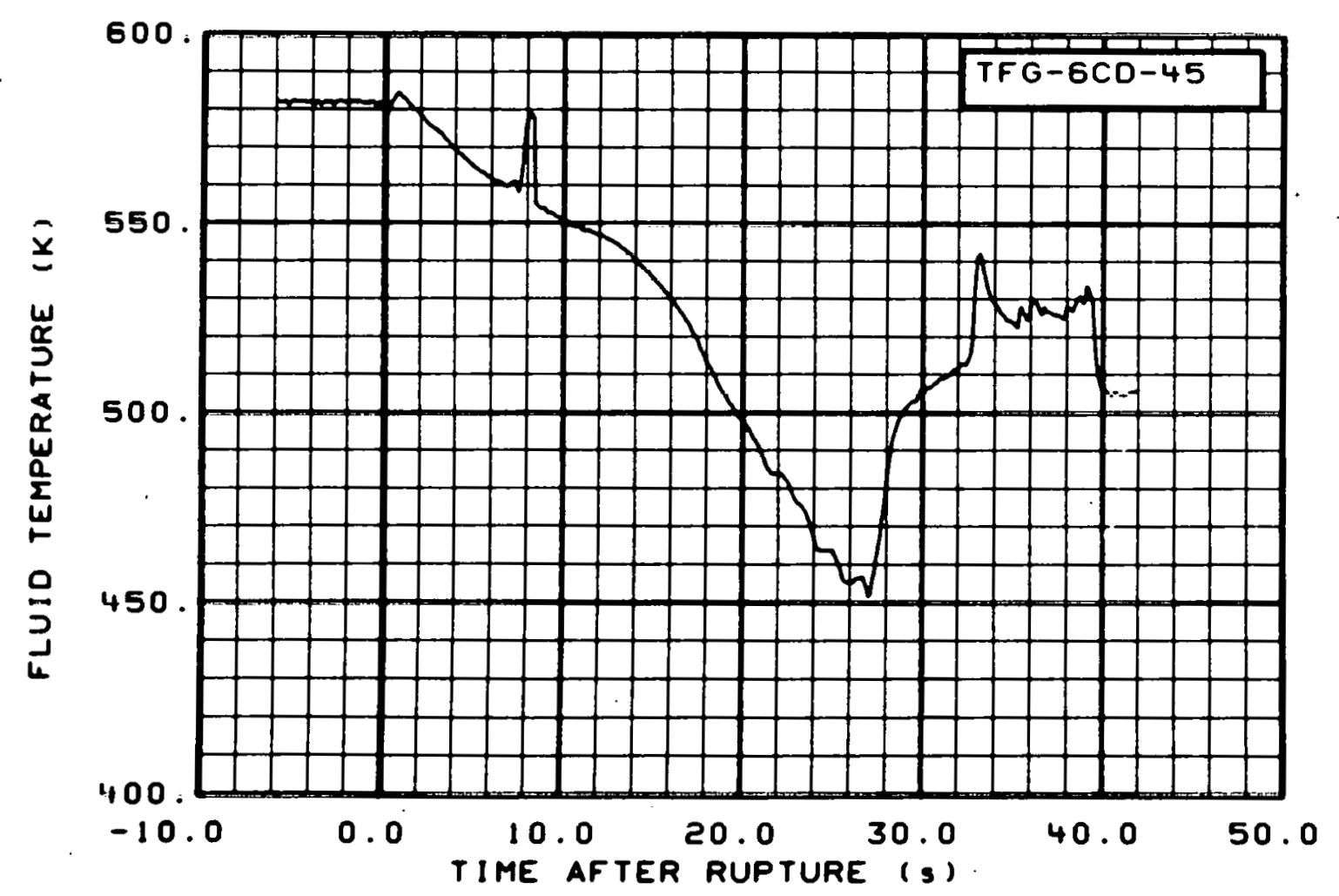

Fig. 36 Fluid temperature in core, Grid Spacer 6 (TFG-6CD-45), from -6 to $42 \mathrm{~s}$. 


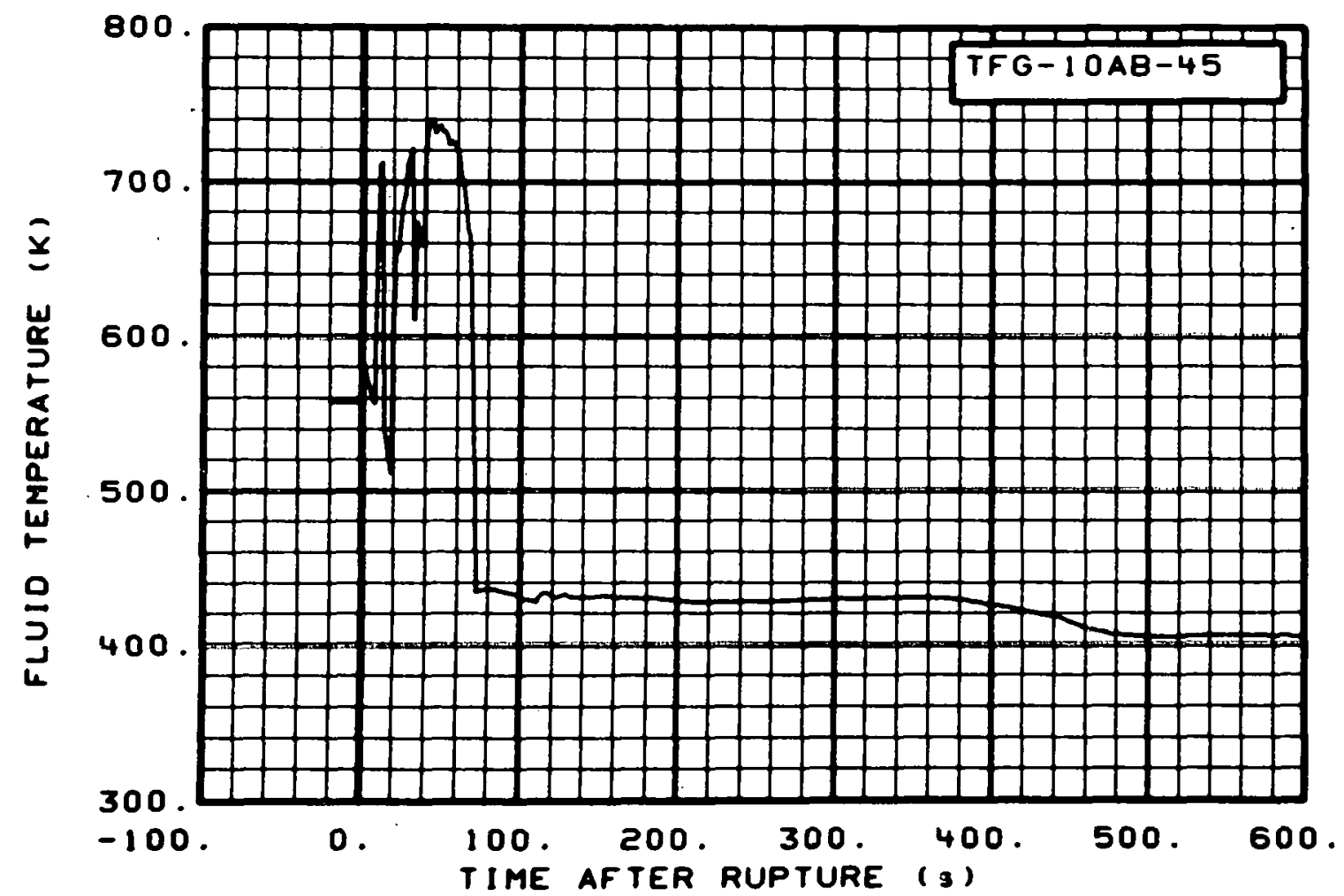

Fig. 37 Fluid temperature in core, Grid Spacer 10 (TFG-10AB-45), from -20 to $600 \mathrm{~s}$.

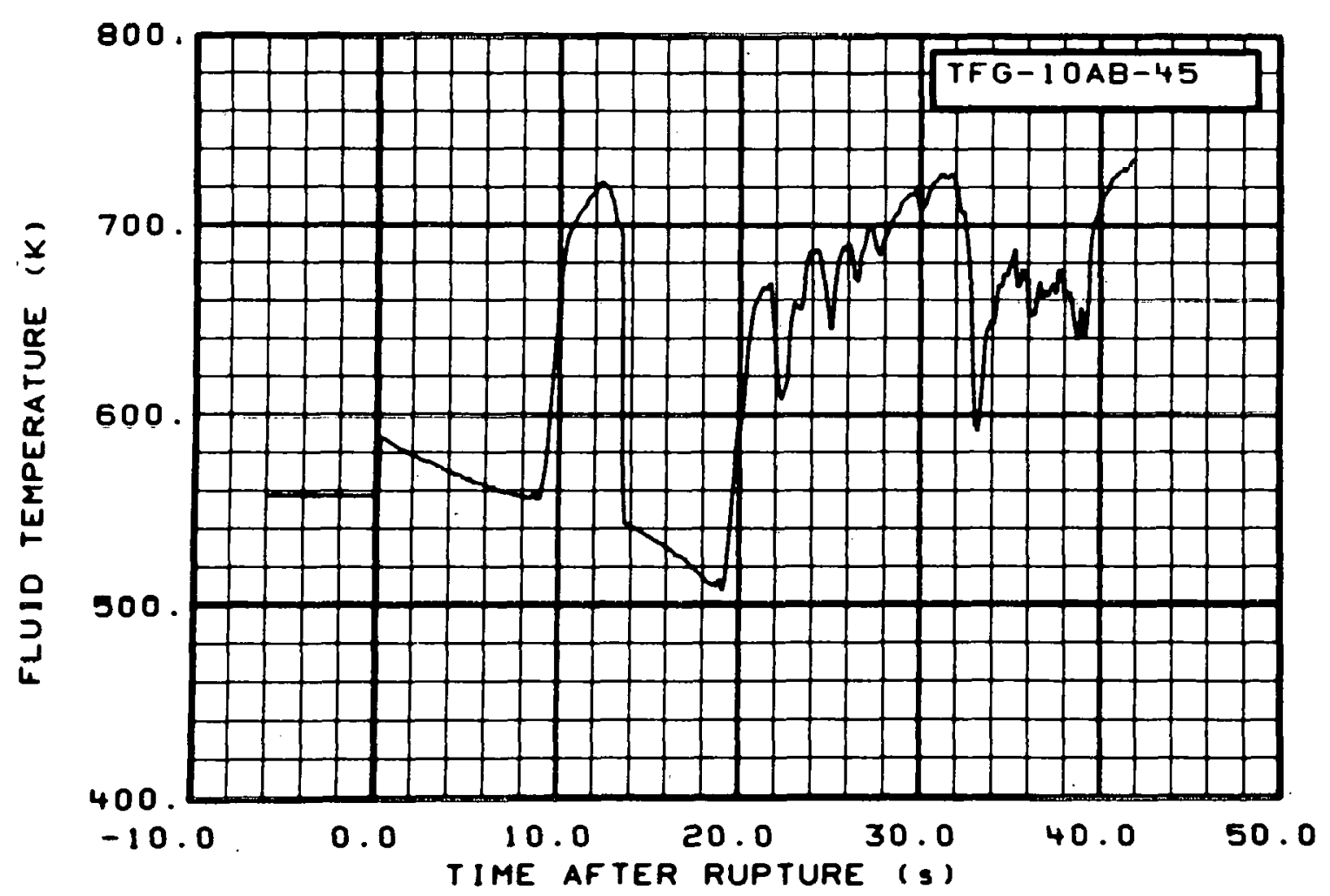

Fig. 38 Fluid temperature in core, Grid Spacer 10 (TFG-10AB-45), from -6 to $42 \mathrm{~s}$. 


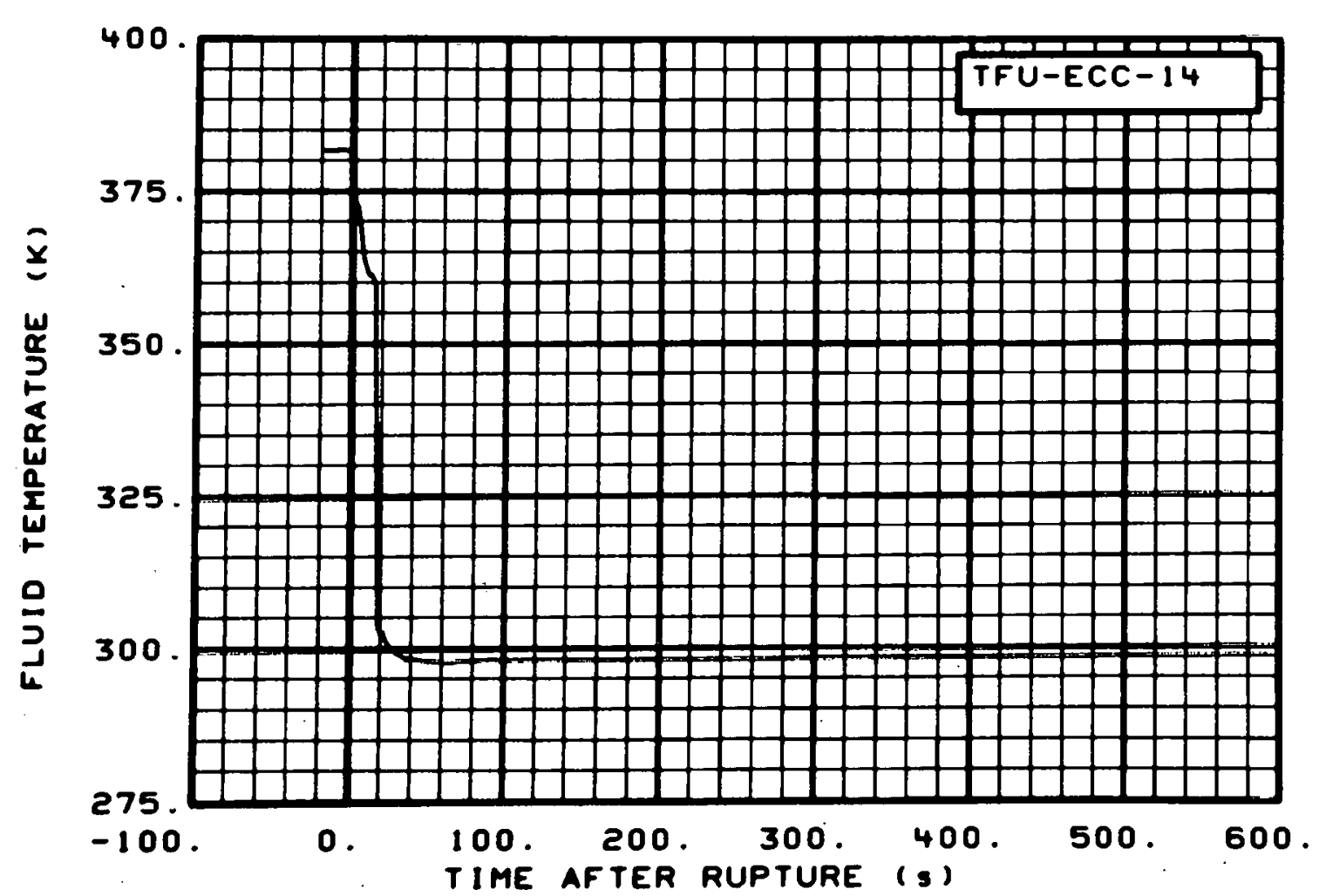

Fig. 39 Fluid temperature in intact loop coolant injection line (TFU-ECC14), from -20 to $600 \mathrm{~s}$.

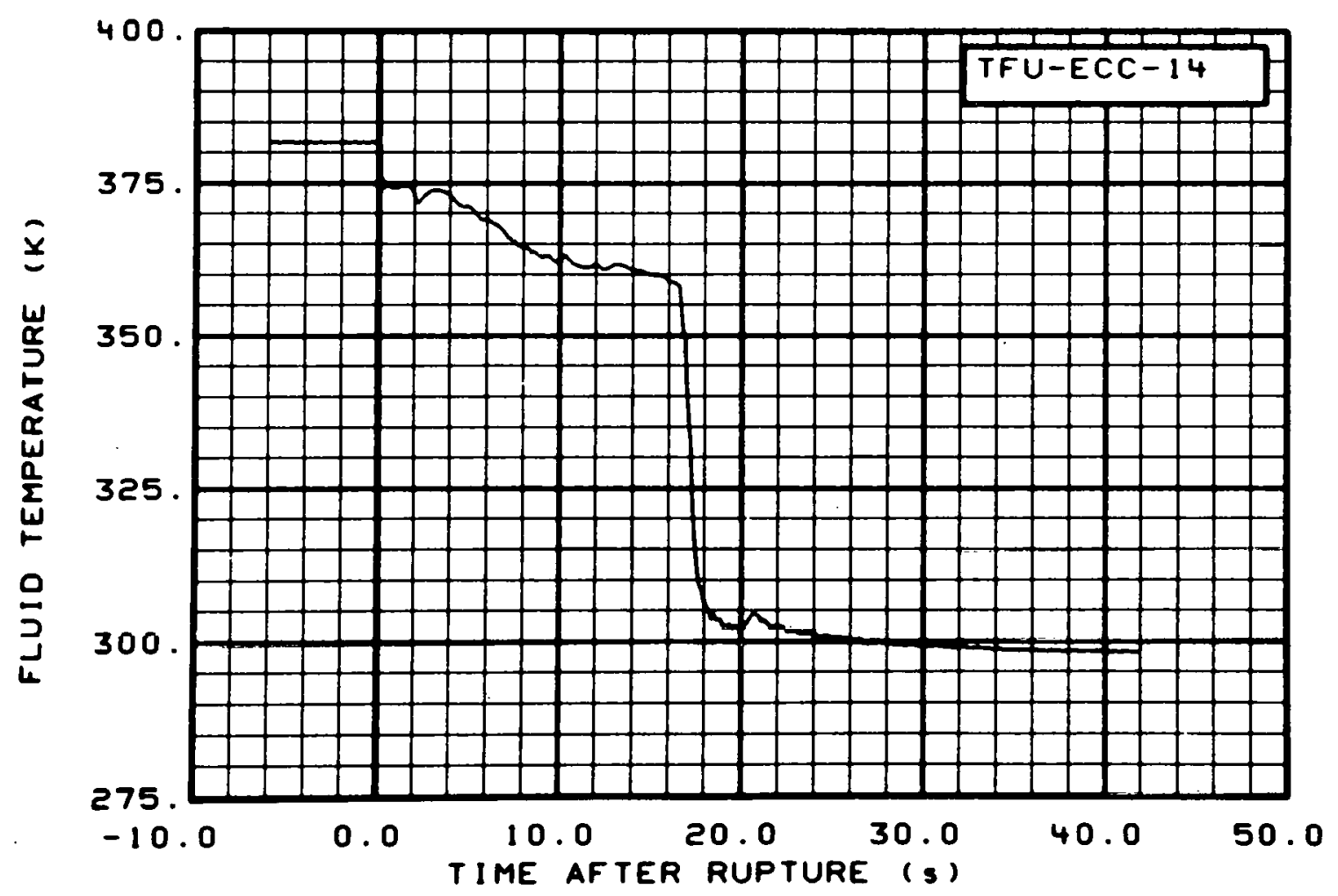

Fig. 40 Fluid temperature in intact loop coolant injection line (TFU-ECC14), from -6 to $42 \mathrm{~s}$. 


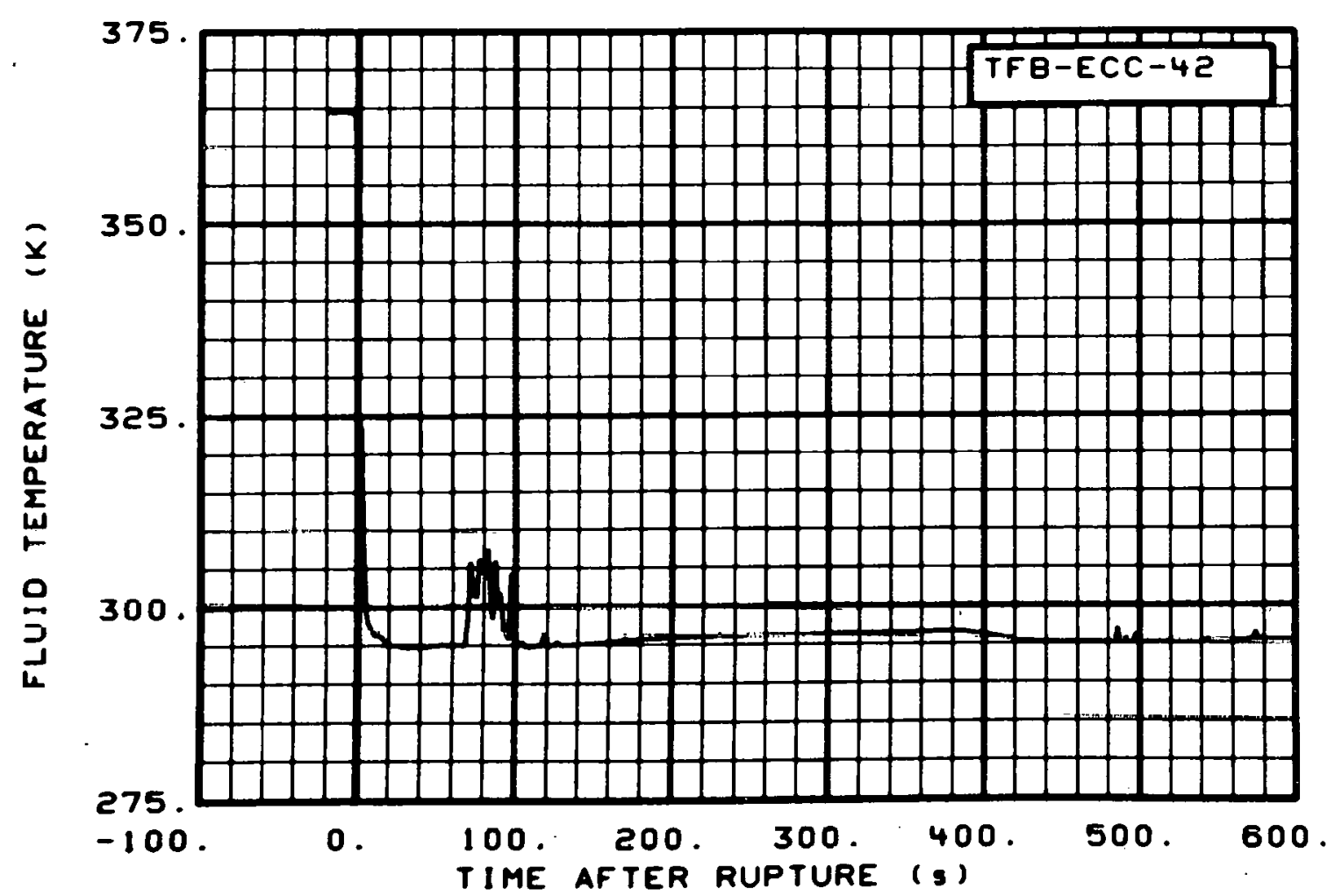

Fig. 41 Fluid temperature in broken loop coolant injection line (TFB-ECC42), from -20 to $600 \mathrm{~s}$.

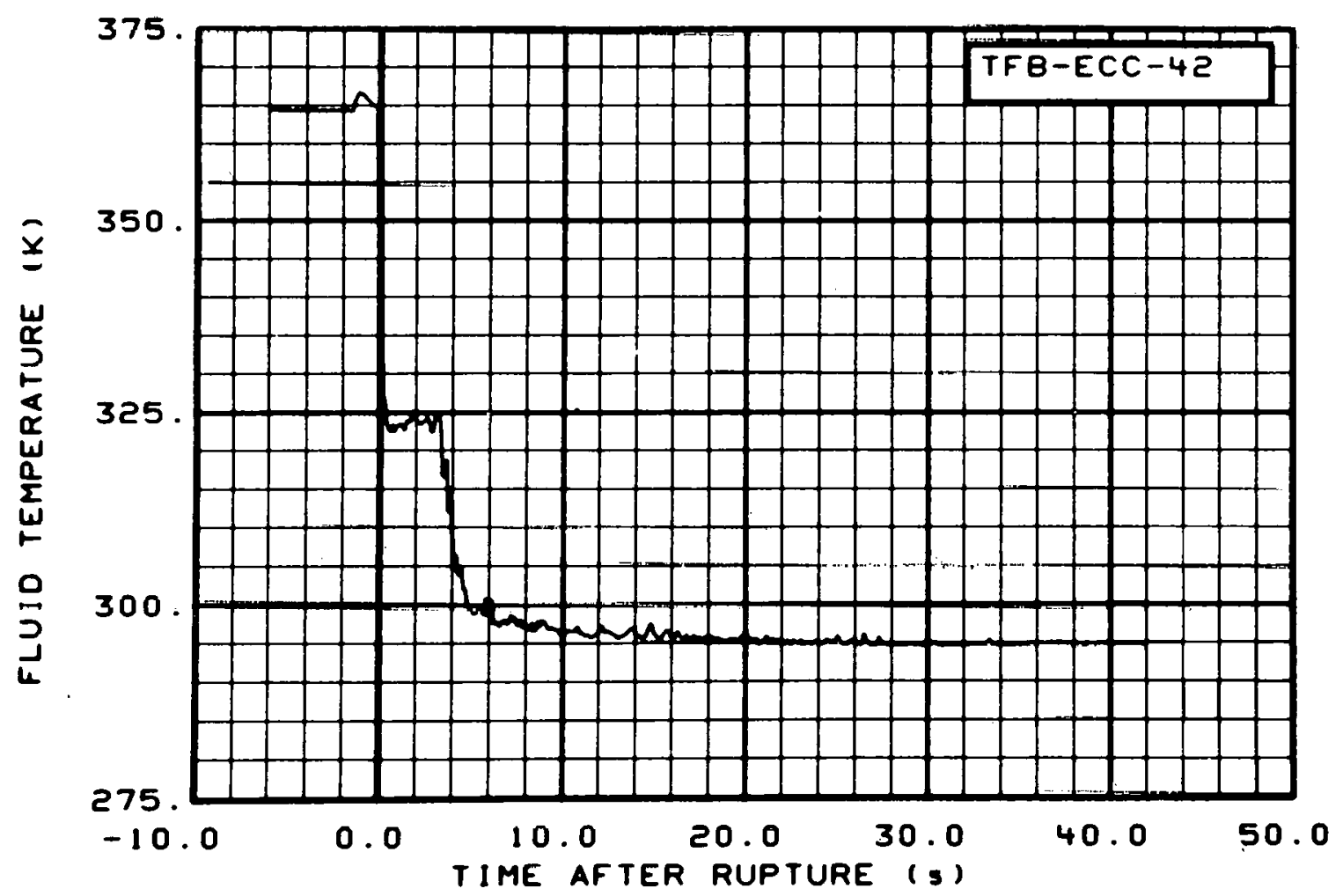

Fig. 42 Fluid temperature in broken loop coolant injection line (TFB-ECC42 ), from -6 to $42 \mathrm{~s}$. 


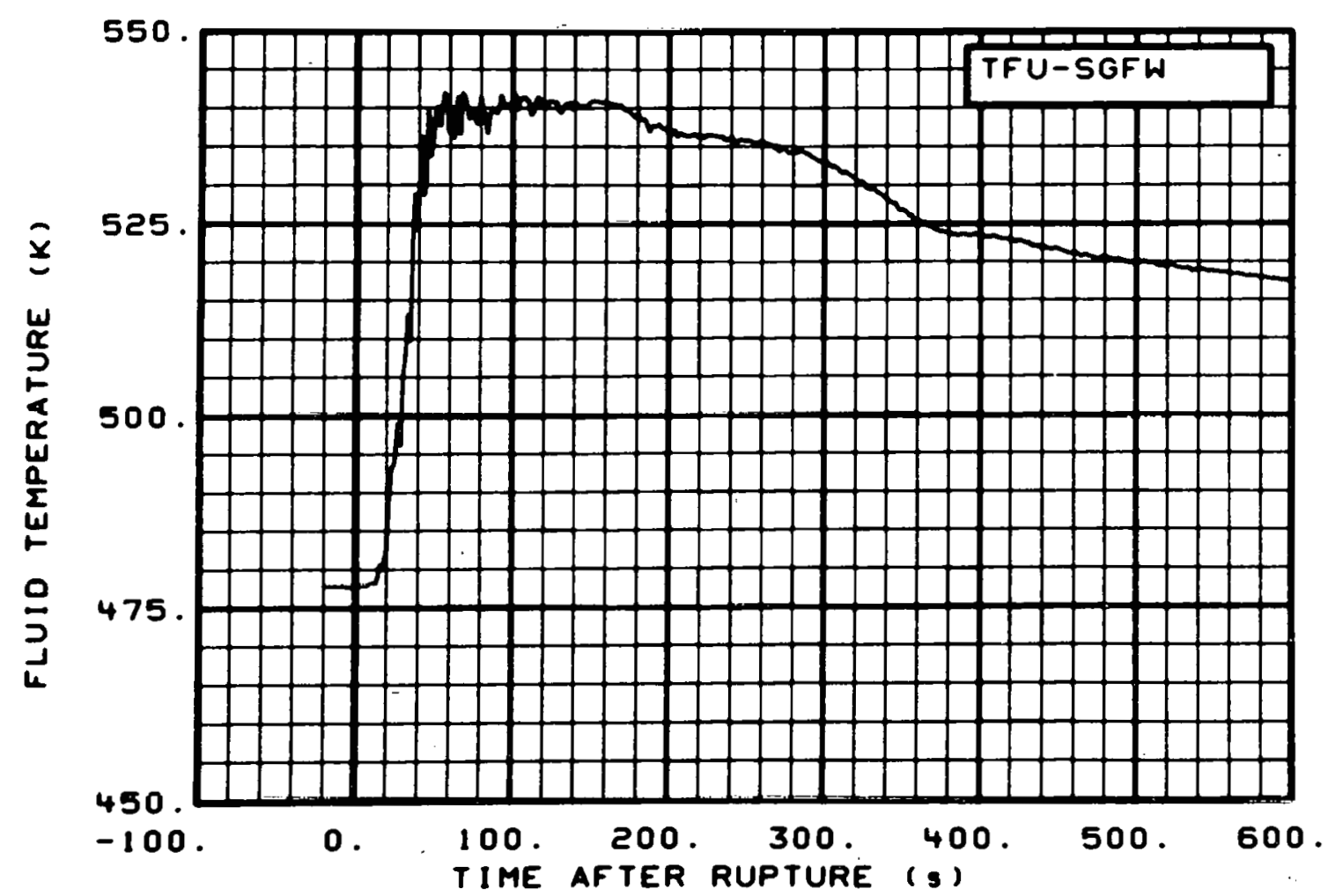

Fig. 43 Fluid temperature in steam generator, feedwater 1 ine (TFU-SGFW), from -20 to $600 \mathrm{~s}$.

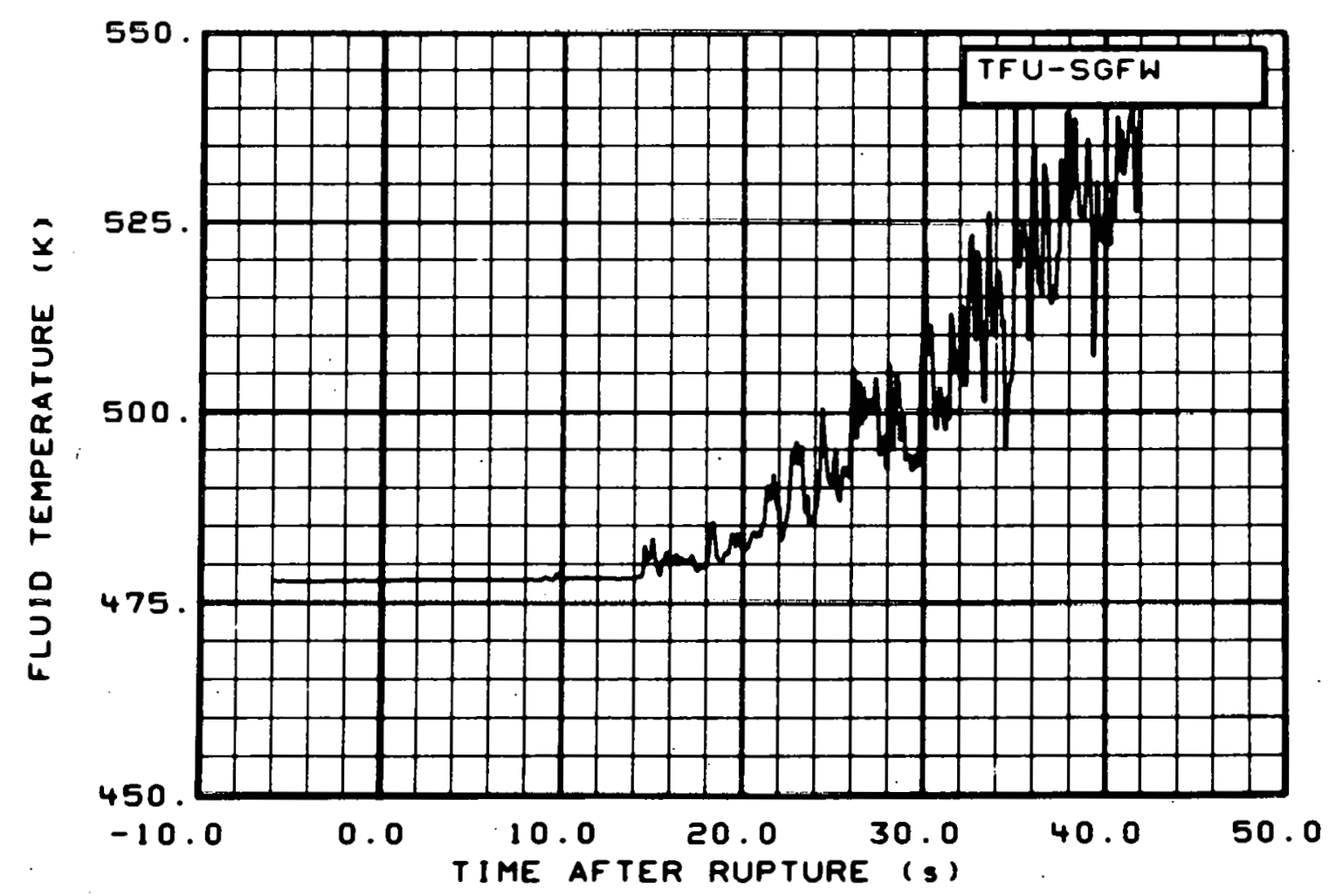

Fig. 44 Fluid temperature in steam generator, feedwater line (TFU-SGFW), from -6 to $42 \mathrm{~s}$. 


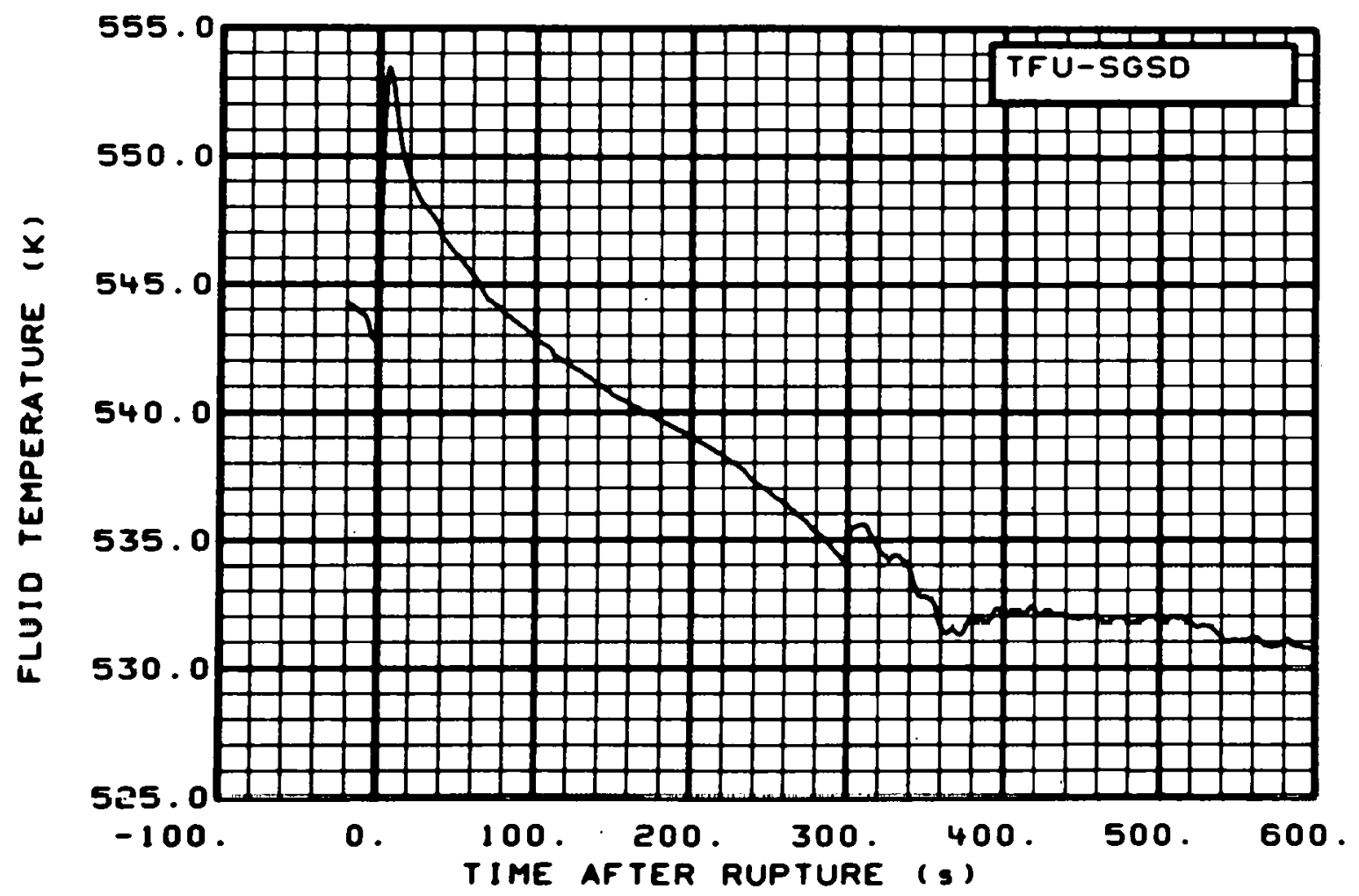

Fig. 45 Fluid temperature in steam generator, steam dome (TFU-SGSD), from -20 to $600 \mathrm{~s}$.

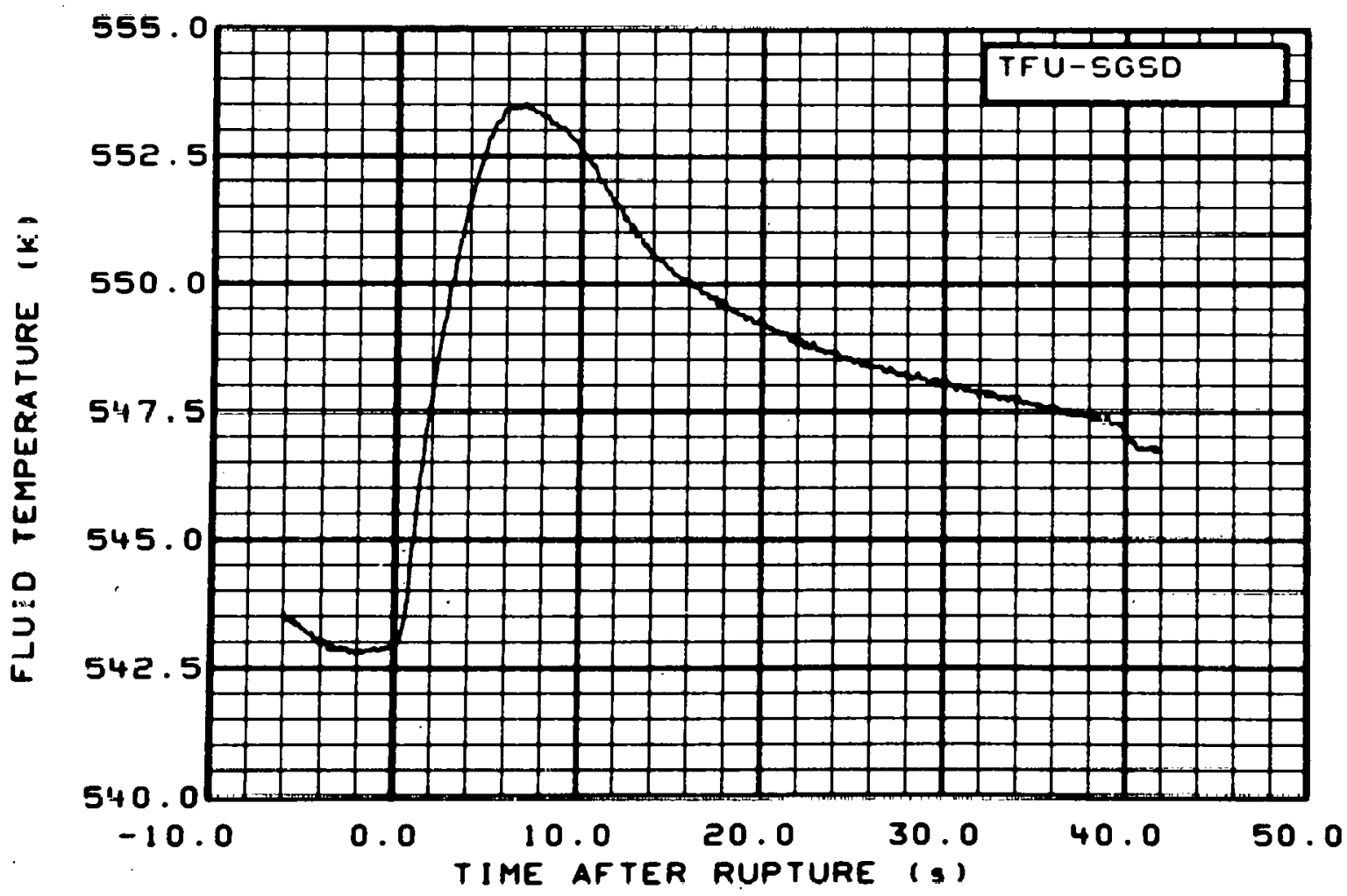

Fig. 46 Fluid temperature in steam generator, steam dome (TFU-SGSD), from -6 to $42 \mathrm{~s}$. 


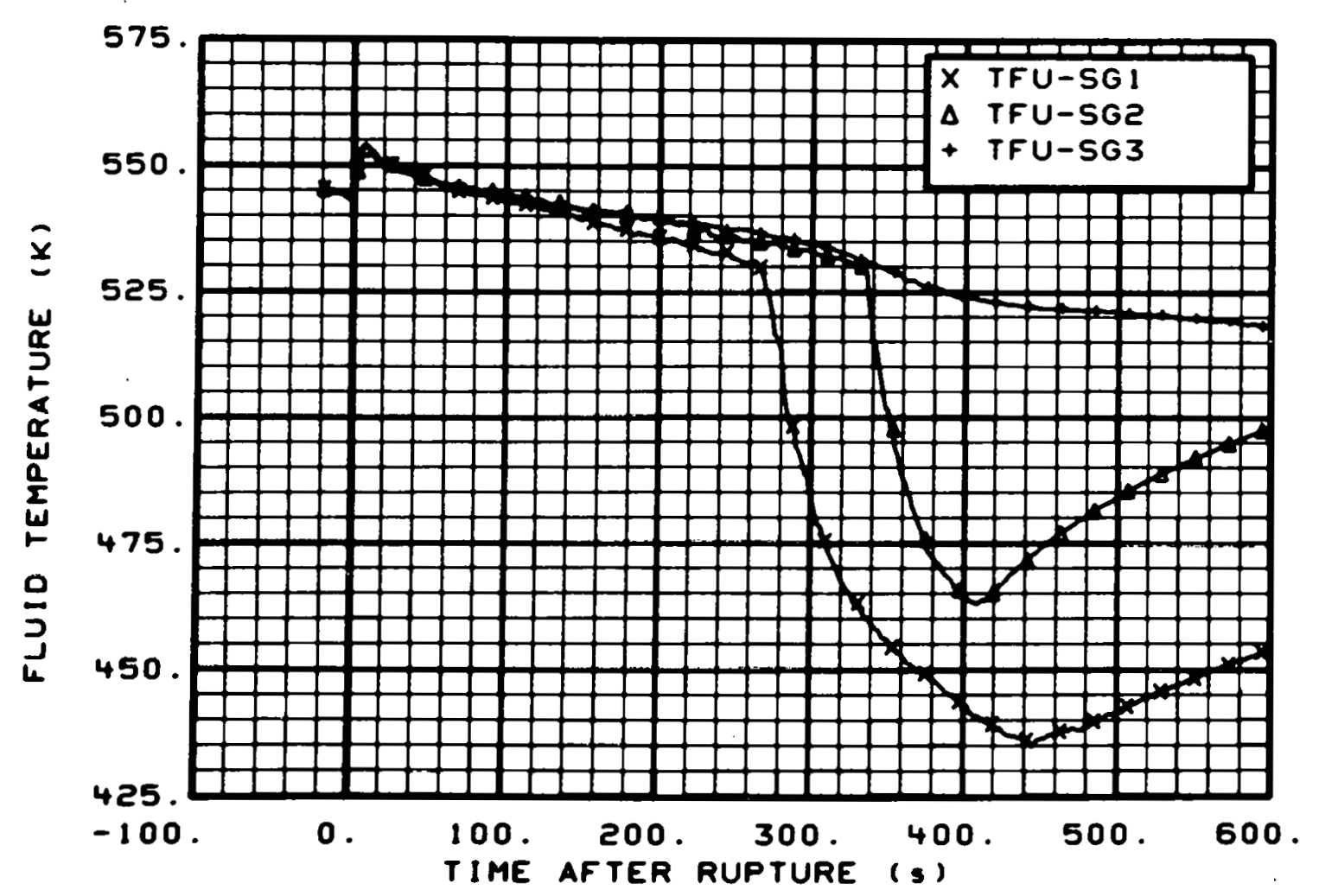

Fig. 47 Fluid temperature in steam generator, secondary side (TFU-SG1, TFU-SG2, and TFU-SG3), from -20 to $600 \mathrm{~s}$.

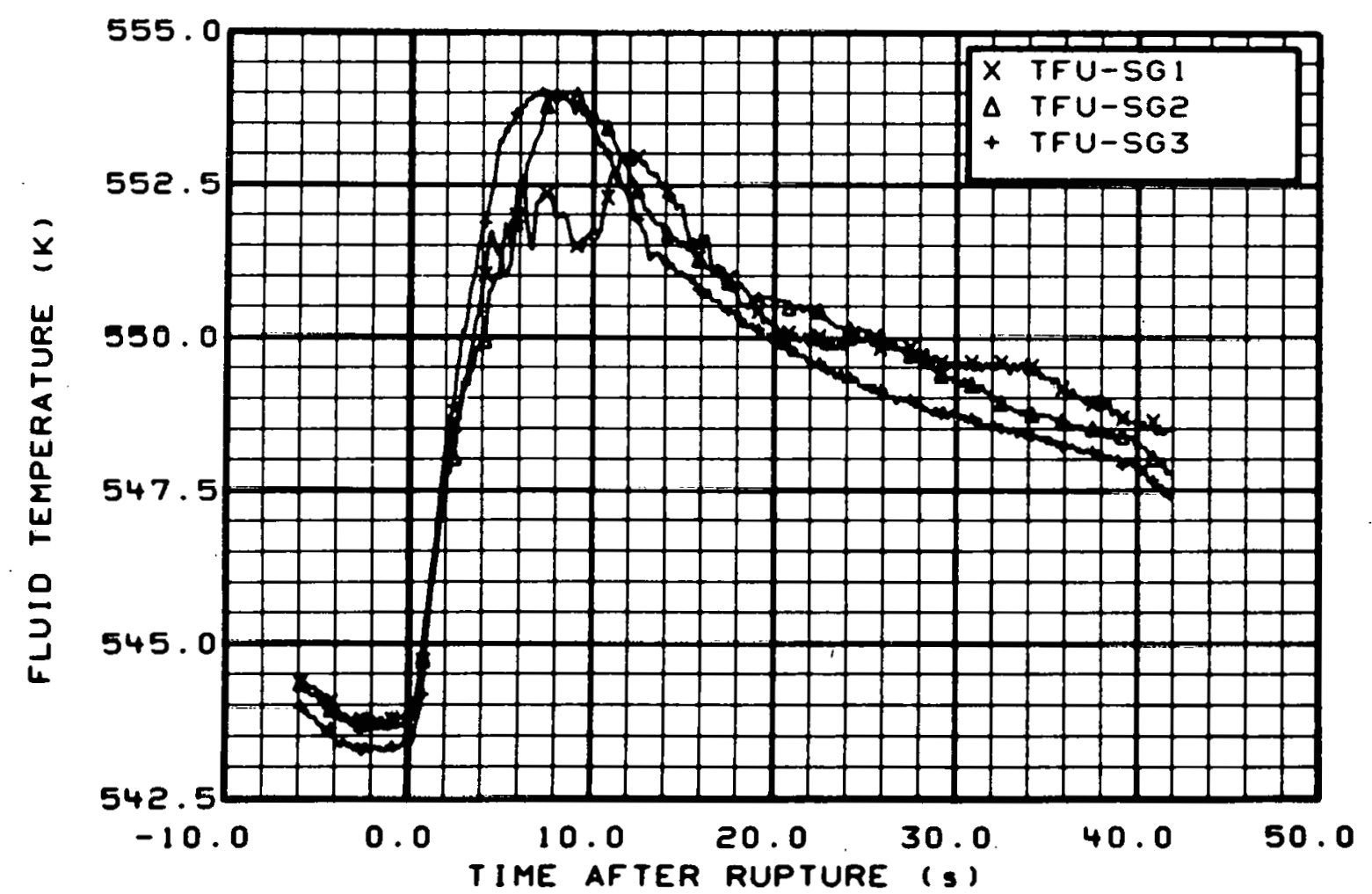

Fig. 48 Fluid temperature in steam generator, secondary side (TFU-SGI, TFU-SG2, and TFU-SG3), from -6 to $42 \mathrm{~s}$. 


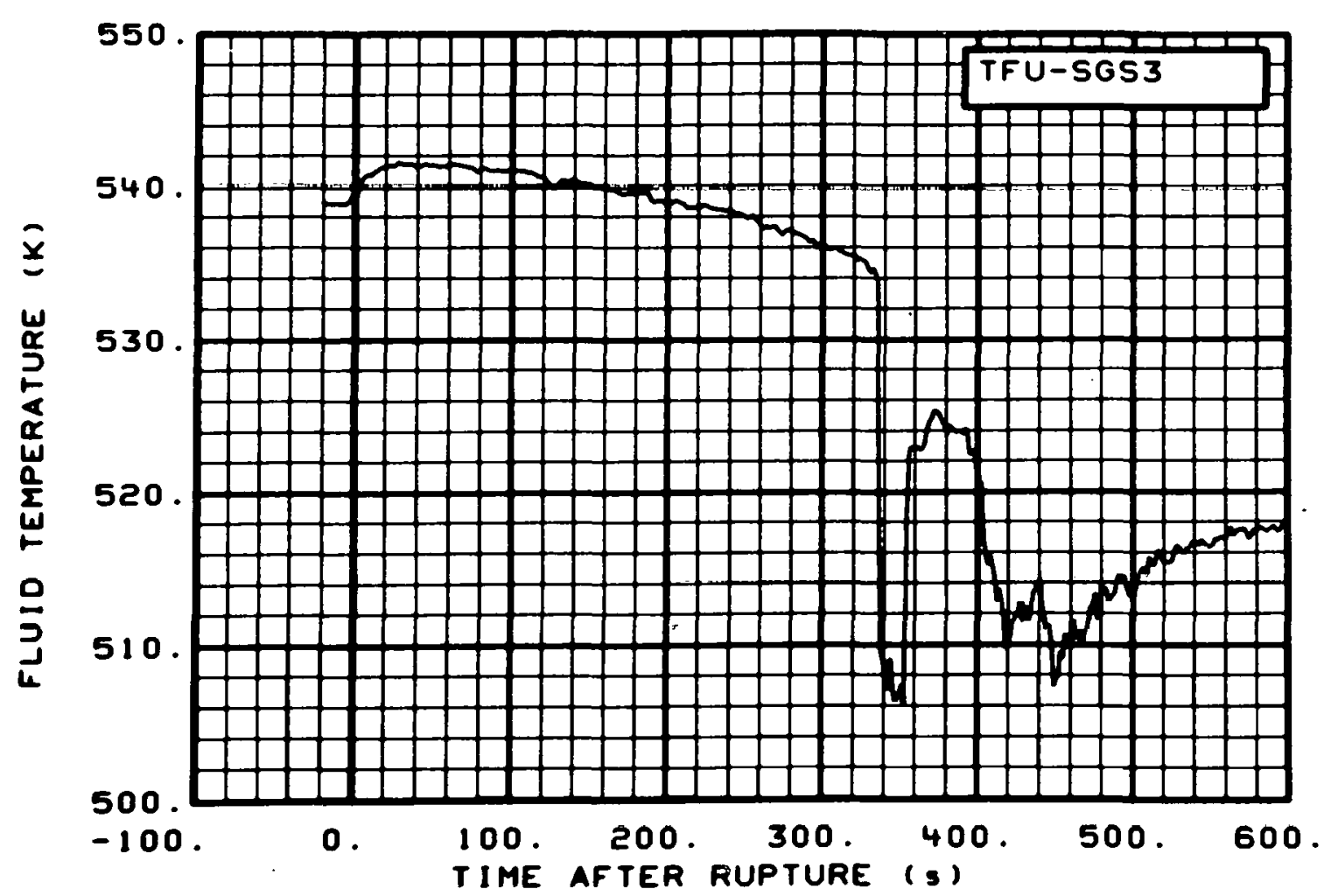

Fig. 49 Fluid temperature in steam generator rupture system accumulator (TFU-SGS3), from -20 to $600 \mathrm{~s}$.

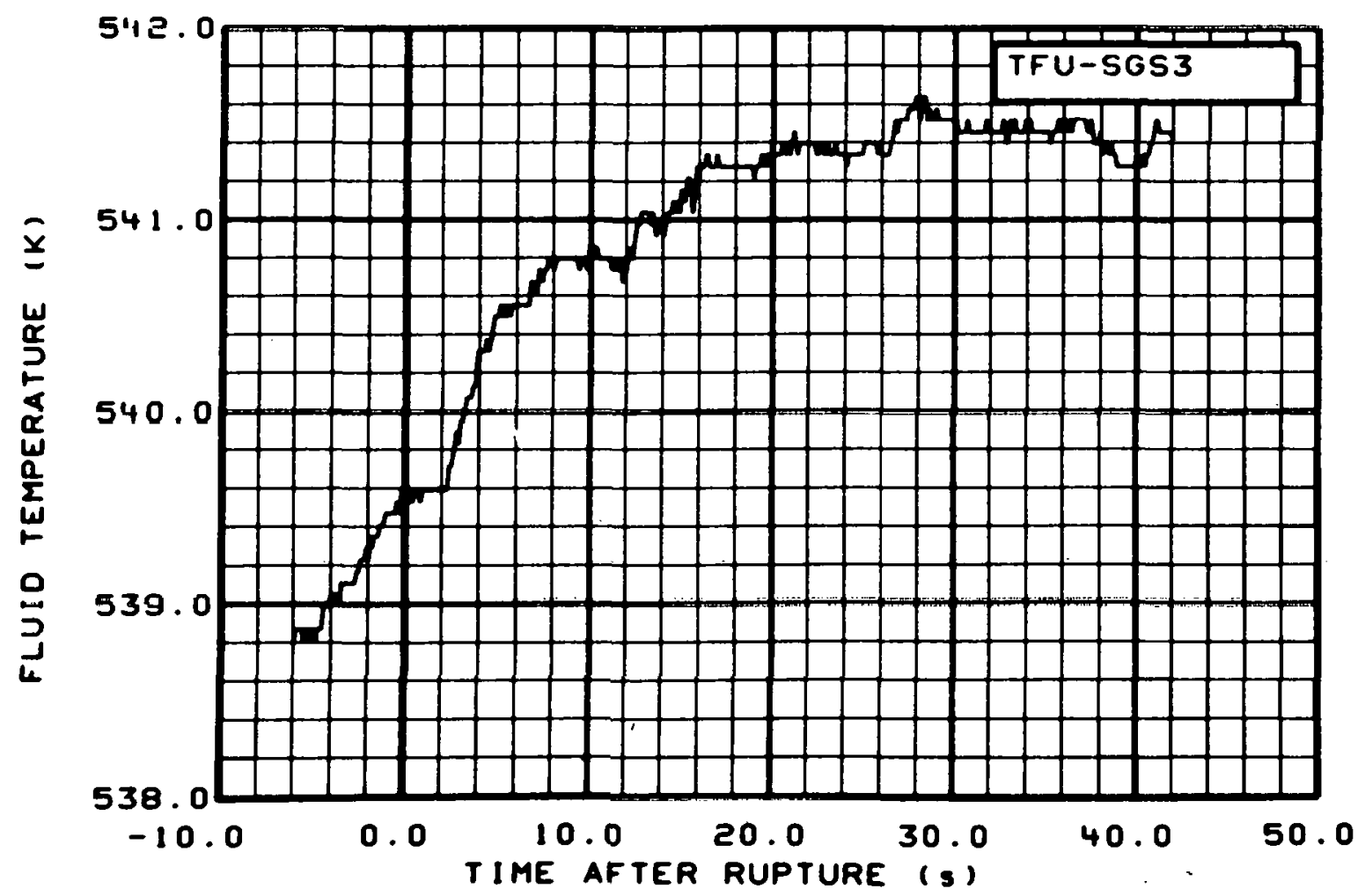

Fig. 50 Fluid temperature in steam generator rupture system accumulator (TFU-SGS3), from -6 to $42 \mathrm{~s}$. 


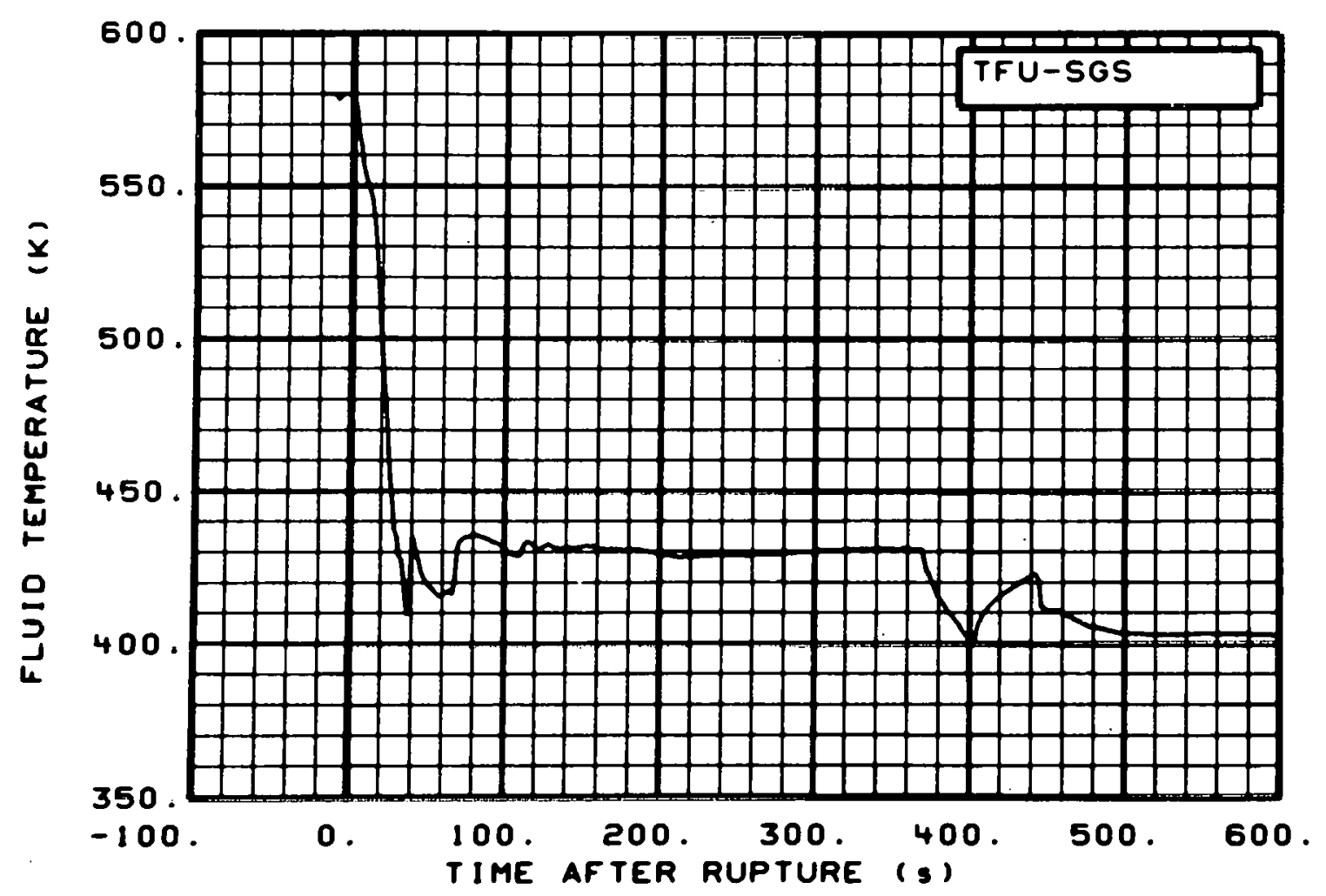

Fig. 51 Fluid temperature in steam generator rupture system injection line (TFU-SGS), from -20 to $600 \mathrm{~s}$.

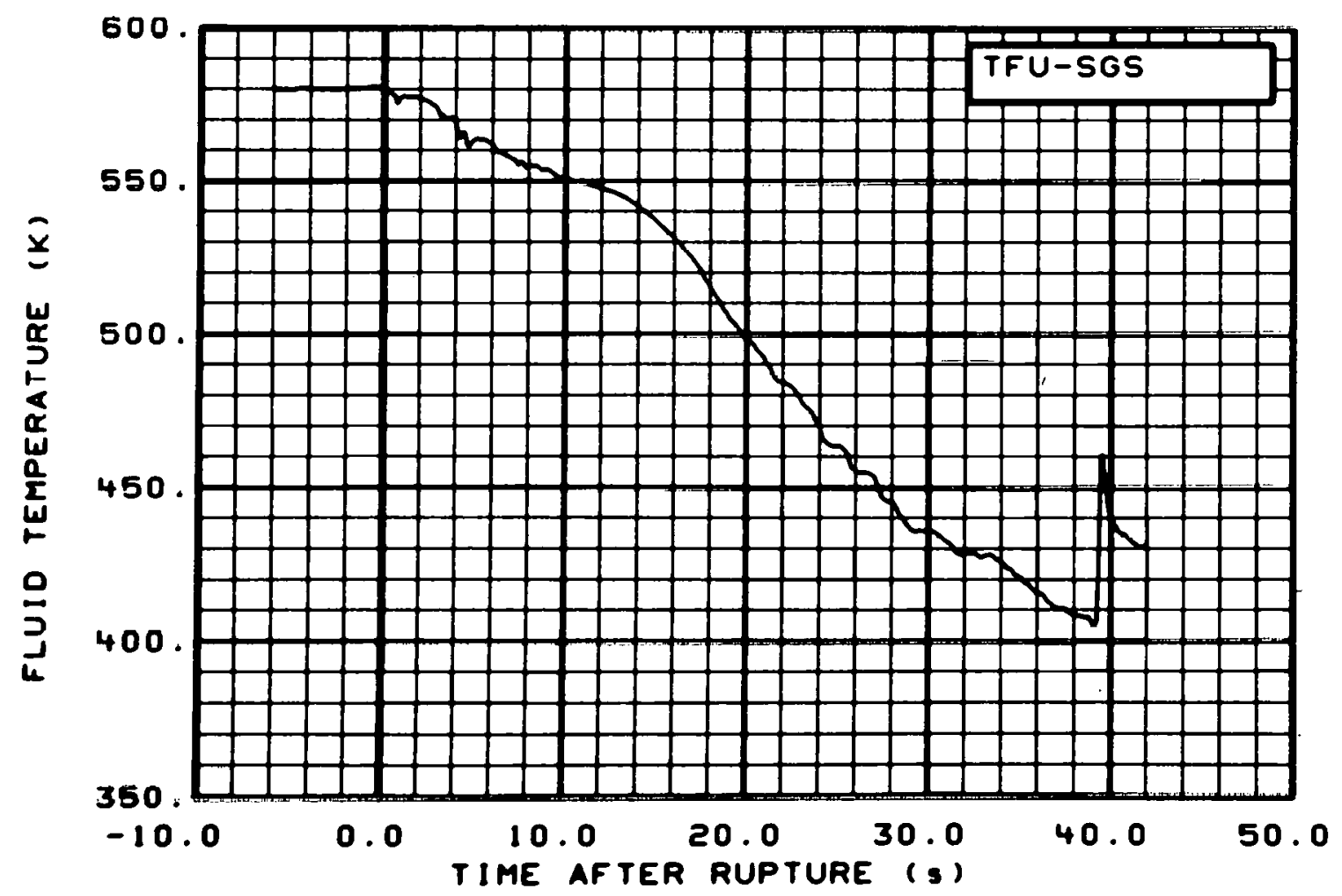

Fig. 52 Fluid temperature in steam generator rupture system injection line (TFU-SGS), from -6 to $42 \mathrm{~s}$. 


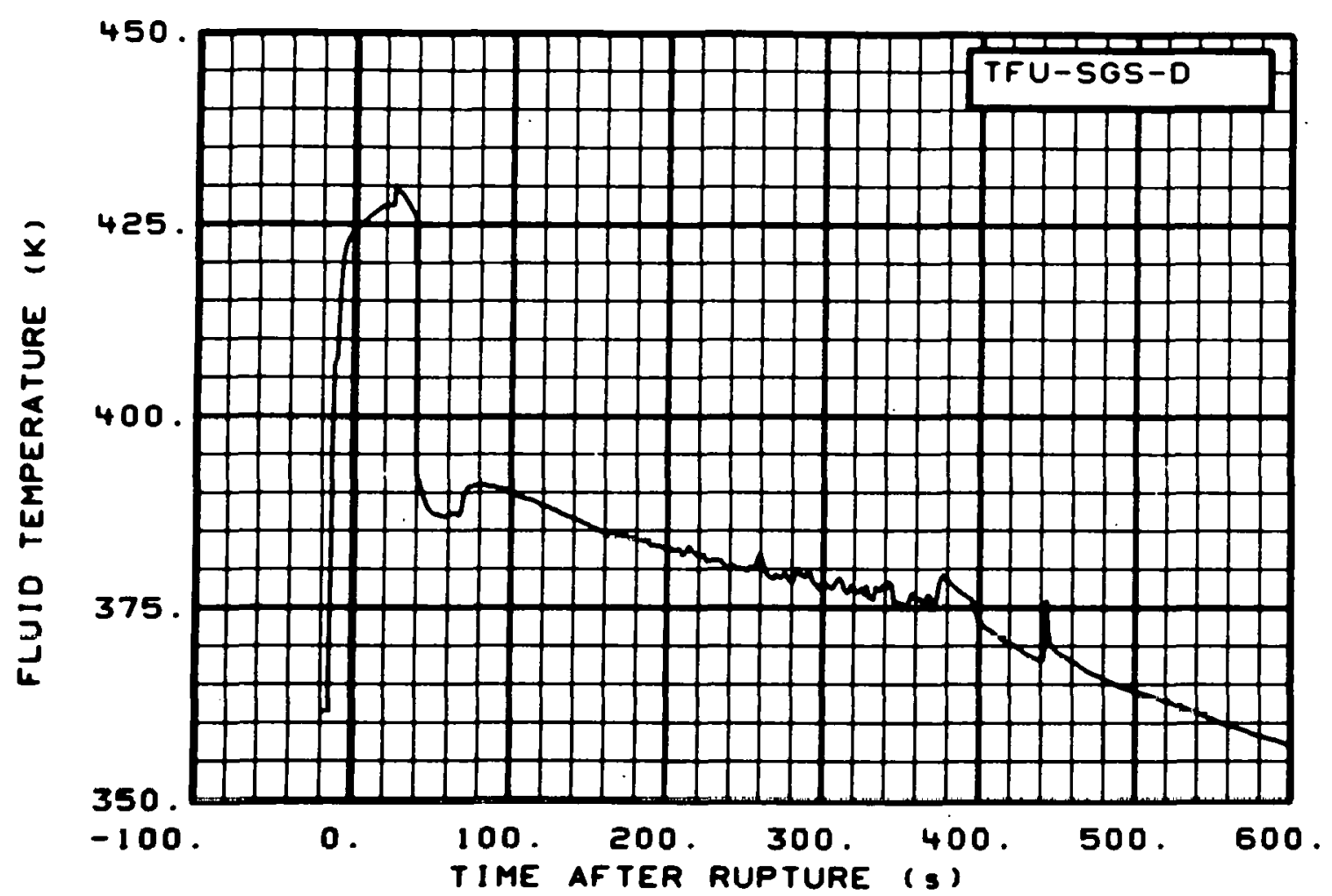

Fig. 53 Fluid temperature in steam generator rupture system (TFU-SGS-D), from -20 to $600 \mathrm{~s}$.

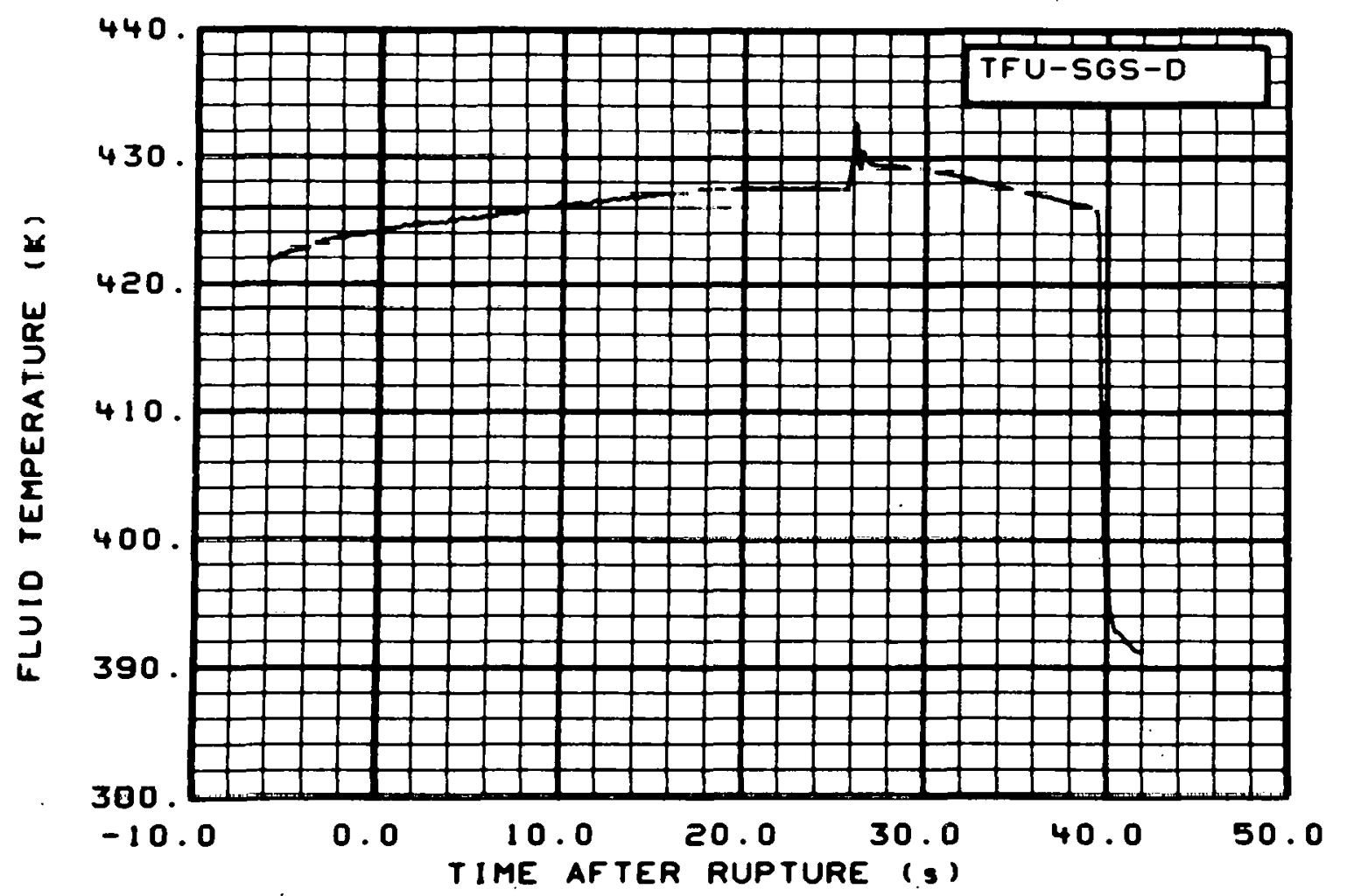

Fig. 54 Fluid temperature in steam generator rupture system (TFU-SGS-D), from -6 to $42 \mathrm{~s}$. 


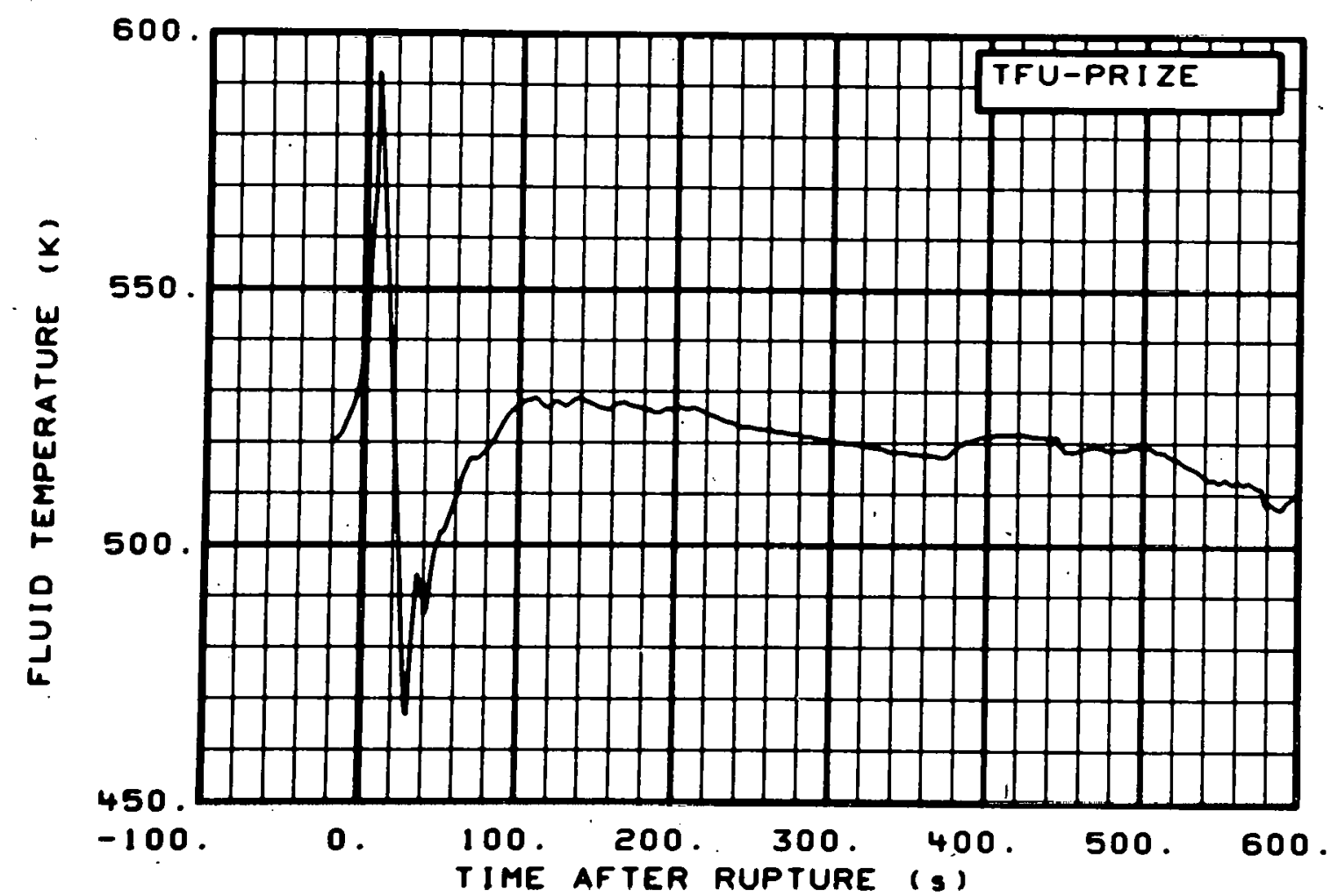

Fig. 55 Fluid temperature in pressurizer surge line (TFU-PRIZE), from -2U to $600 \mathrm{~s}$.

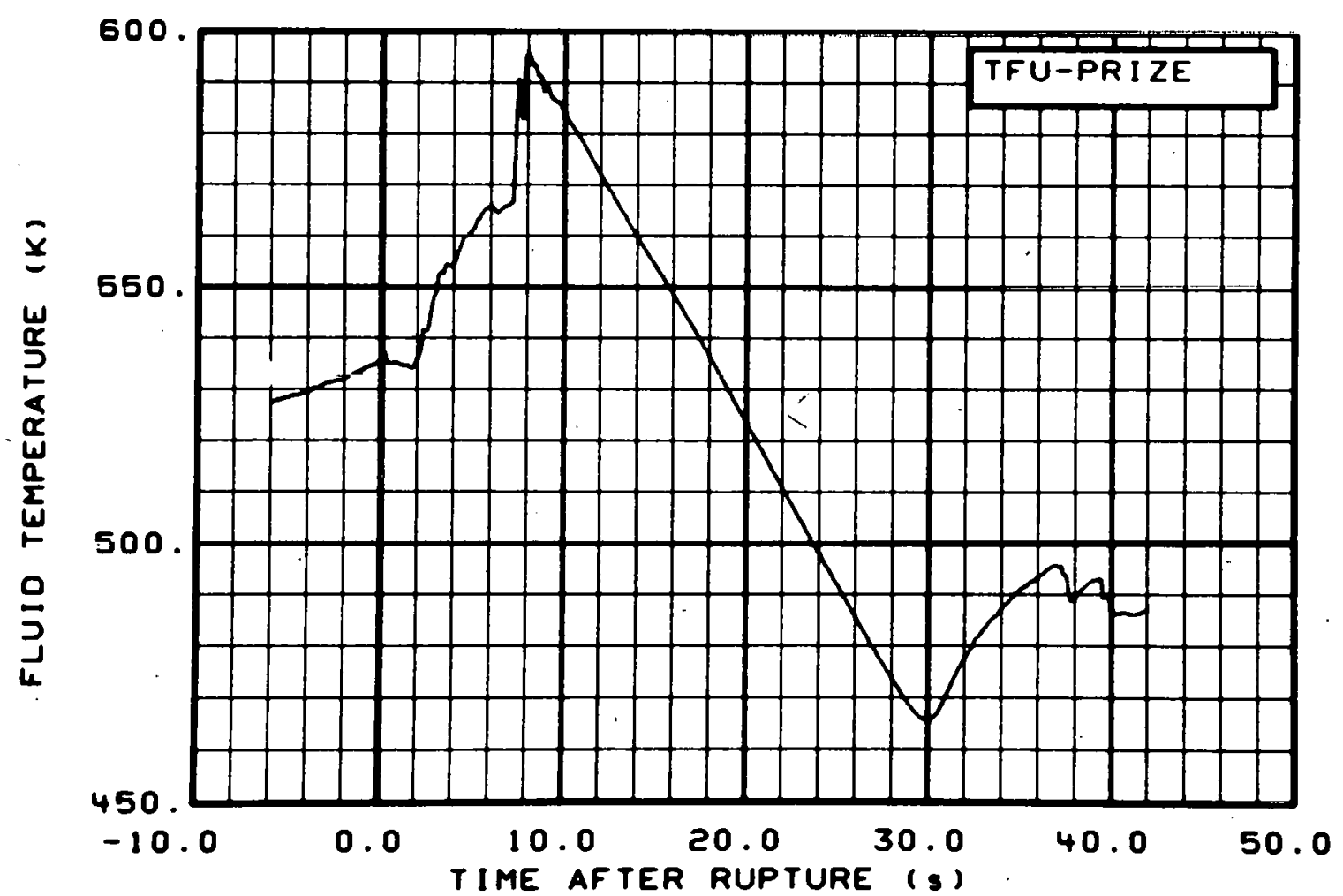

Fig. 56 Fluid temperature in pressurizer surge line (TFU-PRIZE), from -6 to $42 \mathrm{~s}$. 


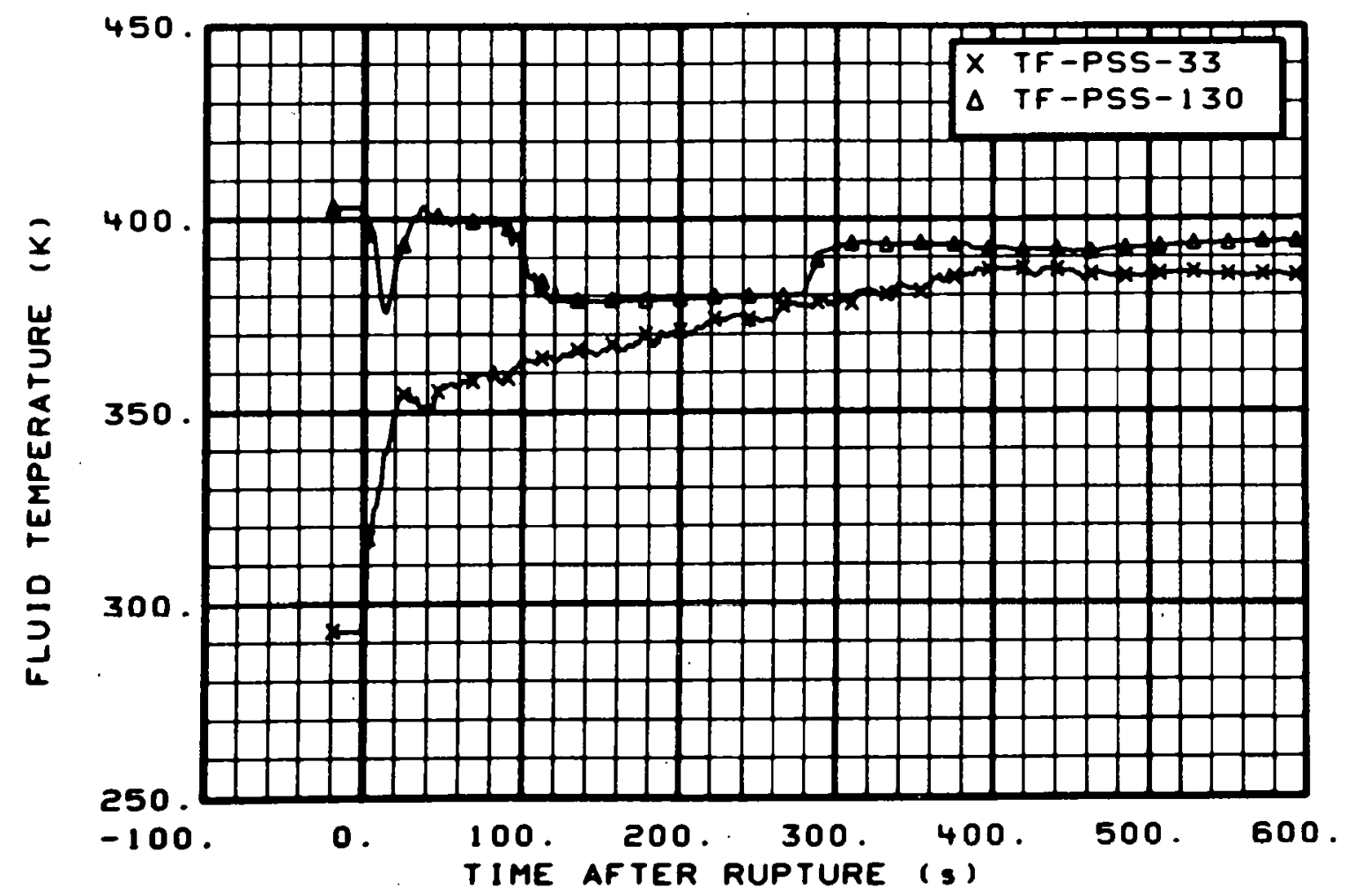

Fig. 57 Fluid temperature in pressure suppression tank (TF-PSS-33 and TF-PSS-130), from -20 to $600 \mathrm{~s}$.

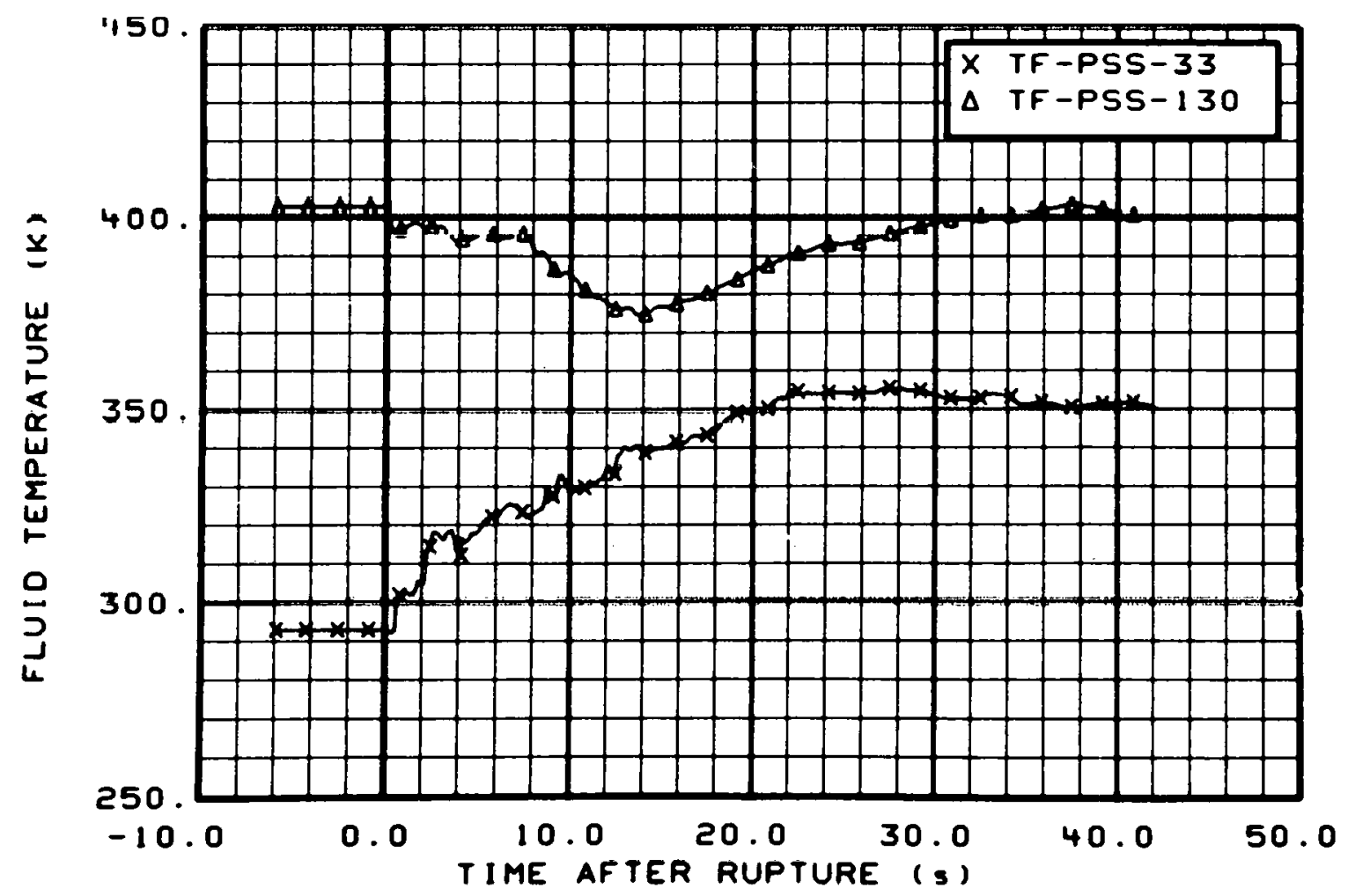

Fig. 58 Fluid temperature in pressure suppression tank (TF-PSS-33 and TF-PSS-130), from -6 to $42 \mathrm{~s}$. 


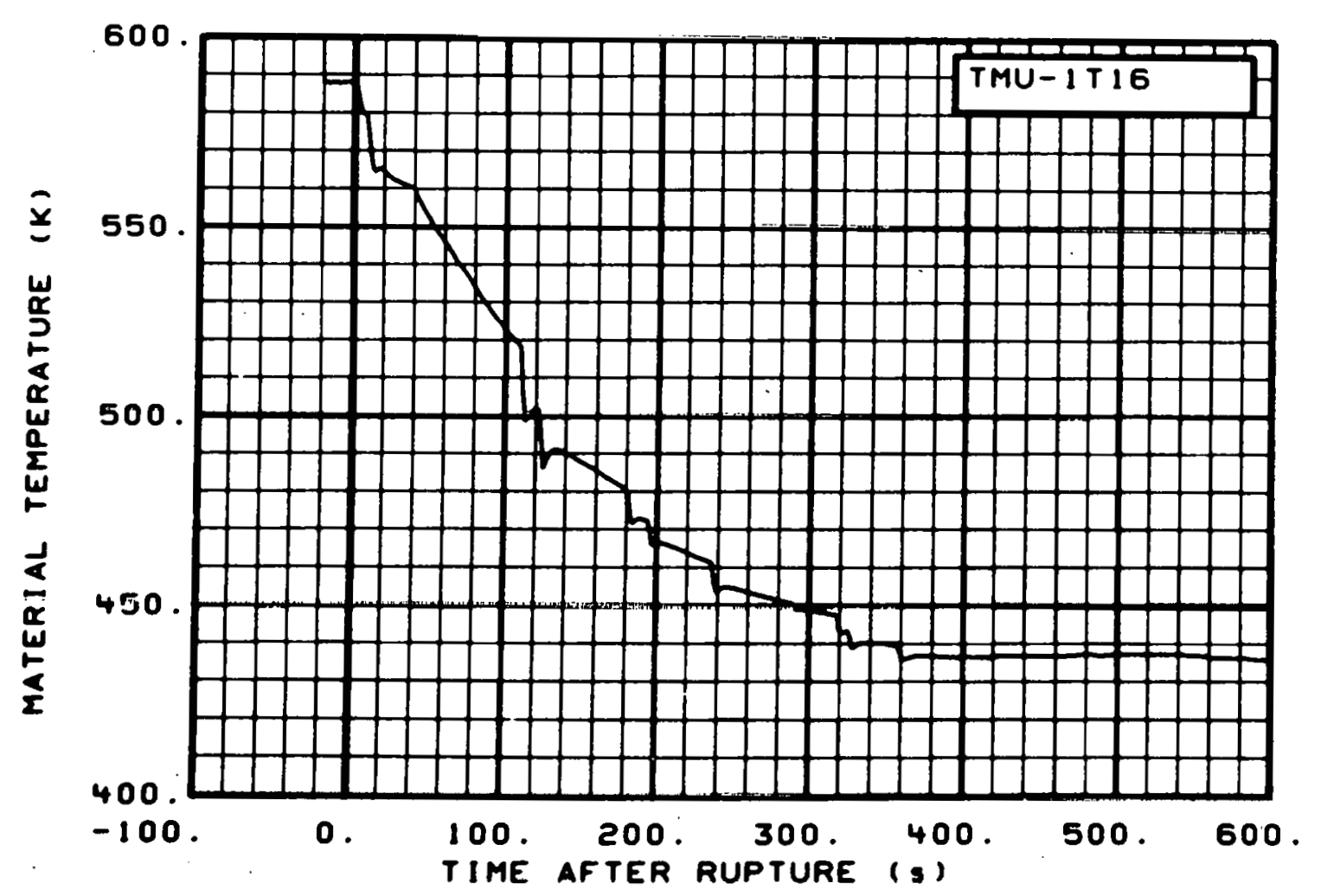

Fig. 59 Material temperature in intact loop (TMU-1T16), from -20 to $600 \mathrm{~s}$.

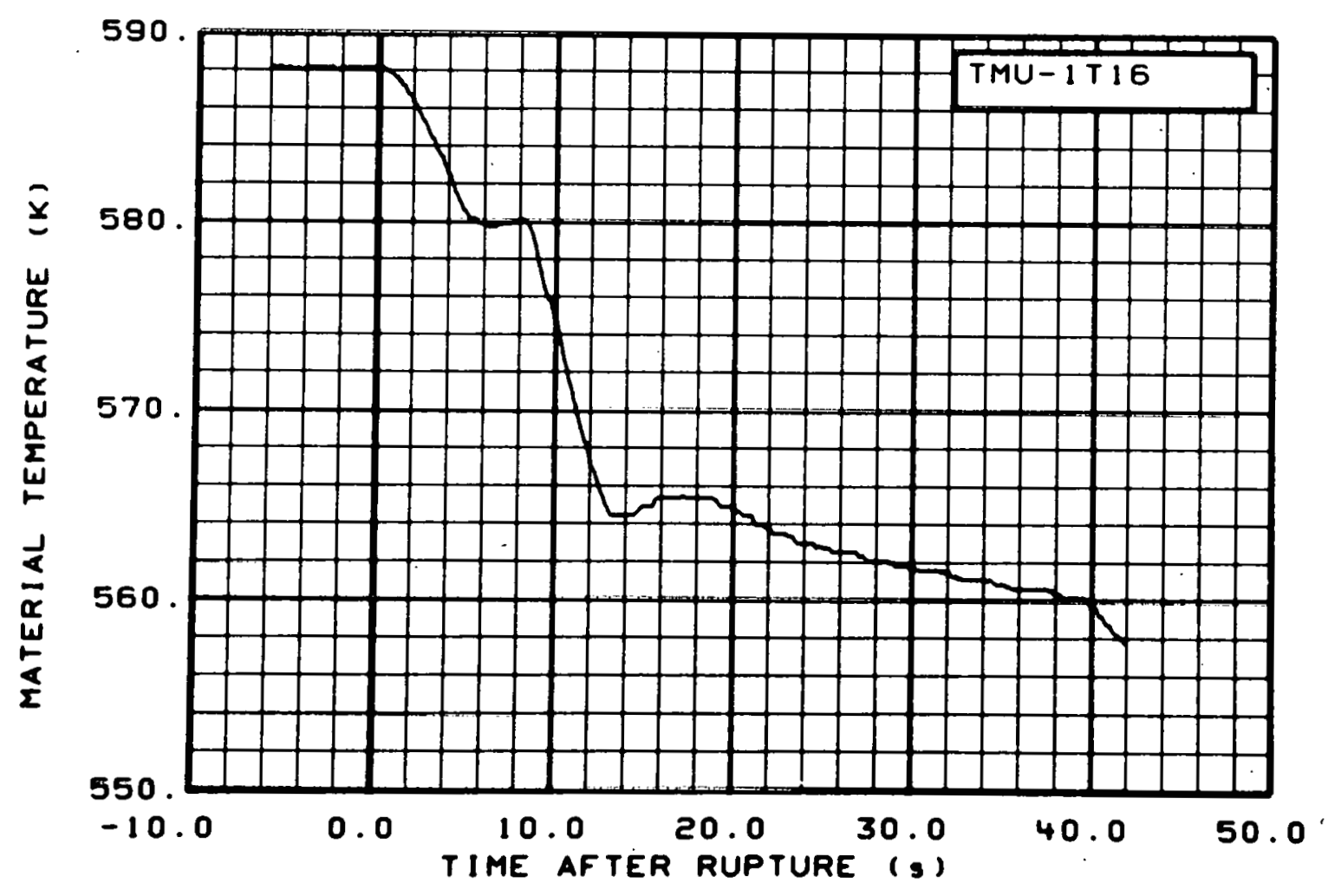

Fig. 60 Material temperature in intact loop (TMU-1T16), from -6 to $42 \mathrm{~s}$. 


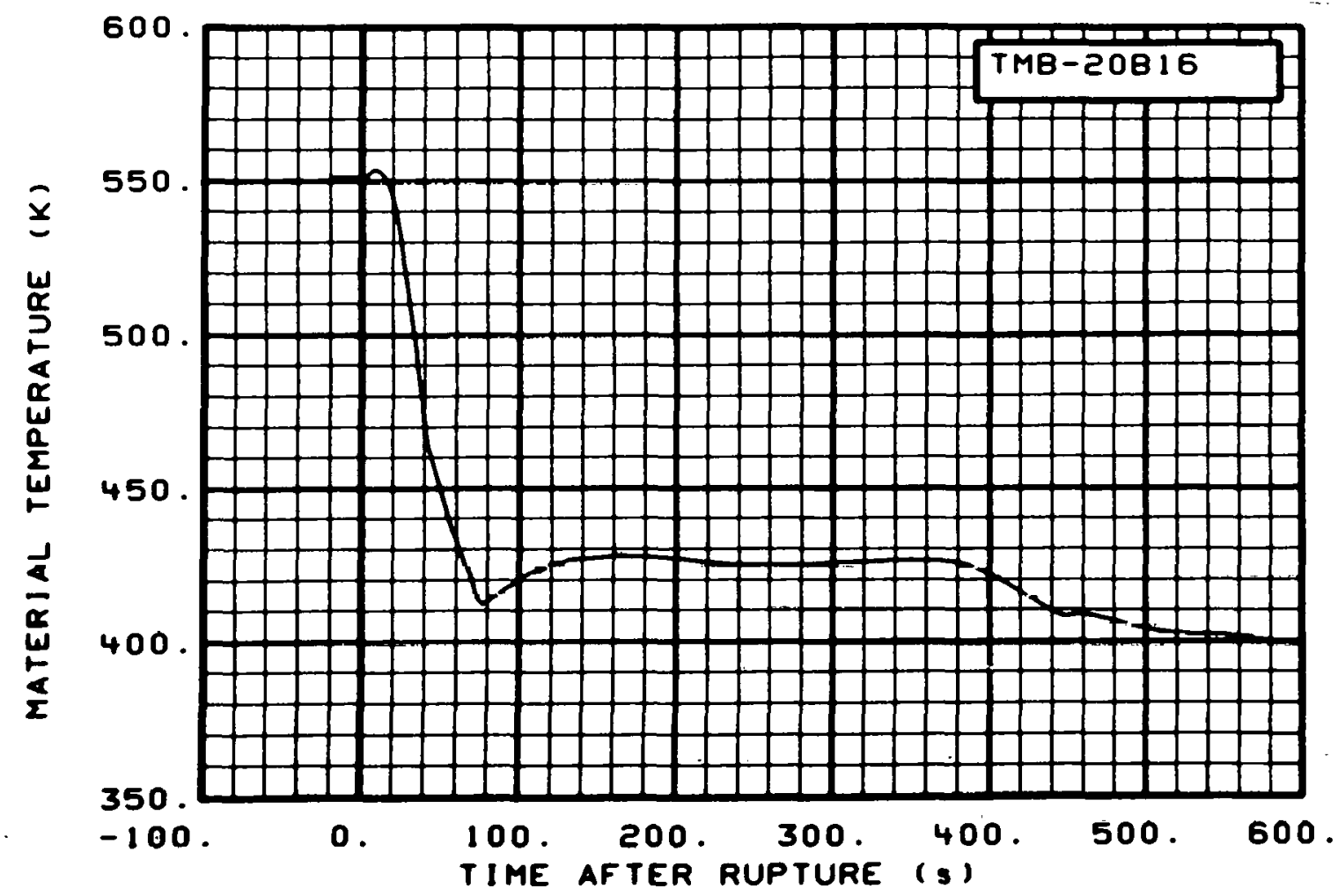

Fig. 61 Material temperature in broken loop (TMB-20B16), from -20 to $600 \mathrm{~s}$.

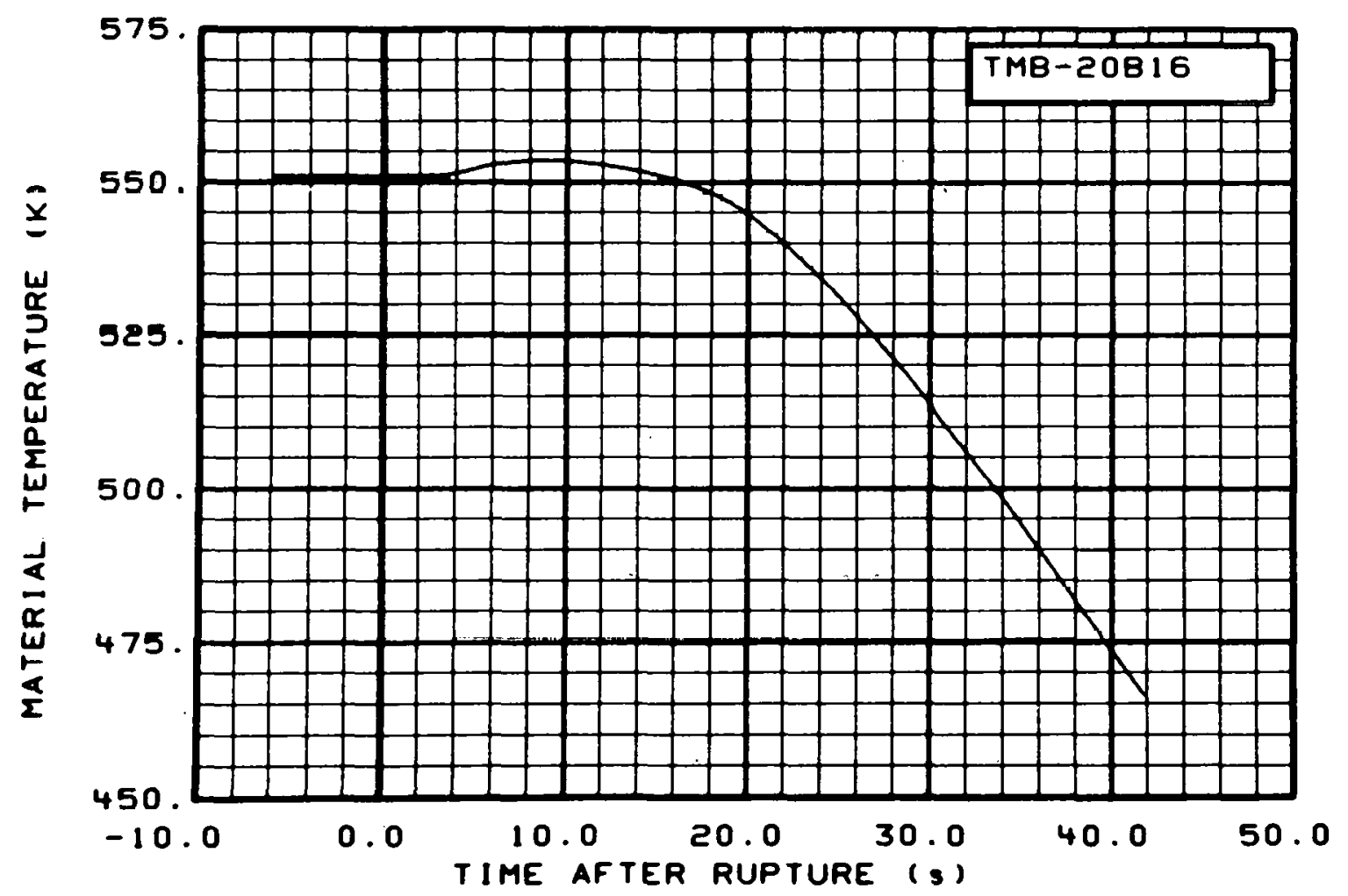

Fig. 62 Material temperature in broken loop (TMB-20B 16), from -6 to $42 \mathrm{~s}$. 


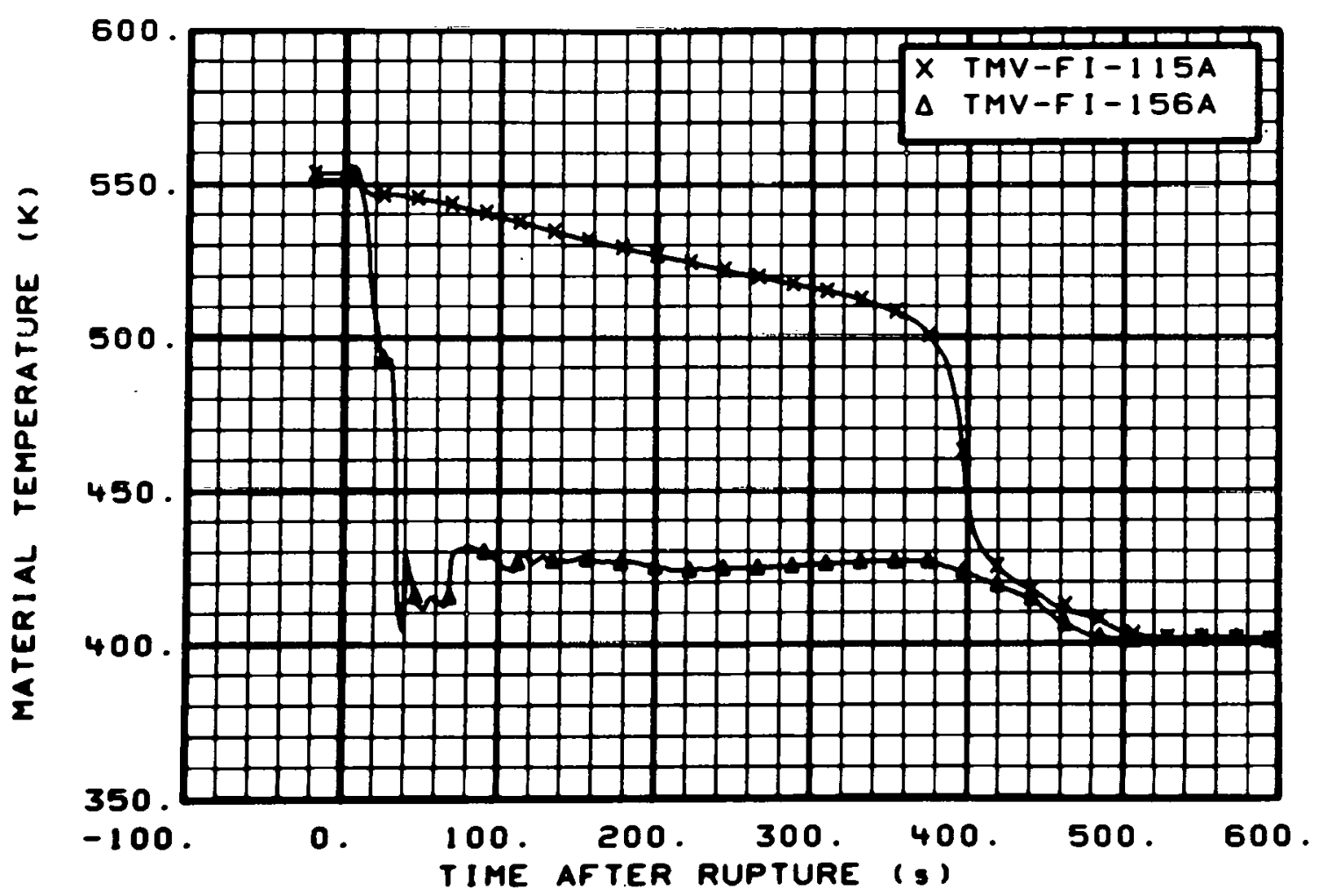

Fig. 63 Material temperature in vessel filler (TMV-FI-115A and TMV-FI$156 \mathrm{~A}$ ), from -20 to $600 \mathrm{~s}$.

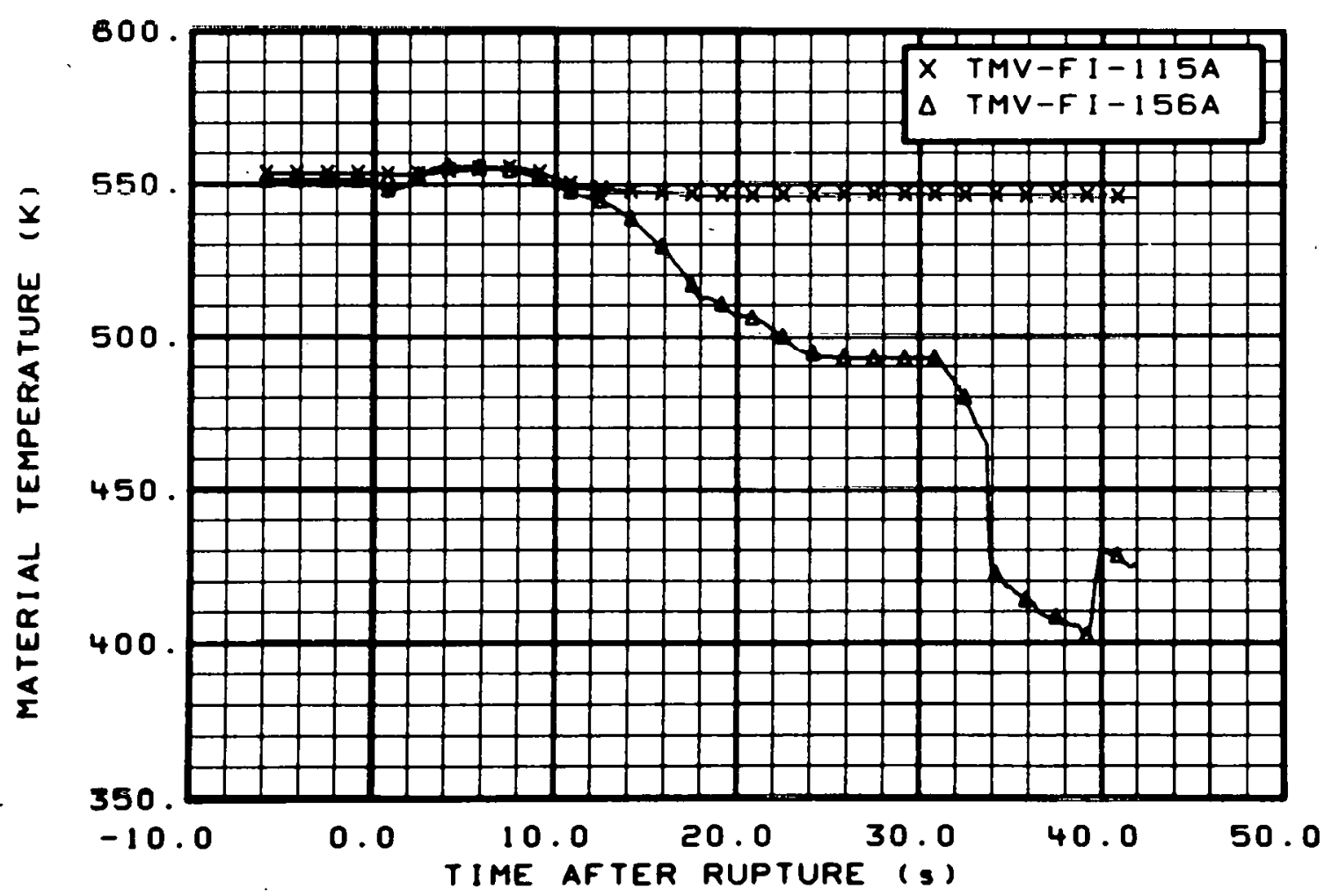

Fig. 64 Material temperature in vessel filler (TMV-FI-115A and TMV-FI$156 \mathrm{~A}$ ), from -6 to $42 \mathrm{~s}$. 


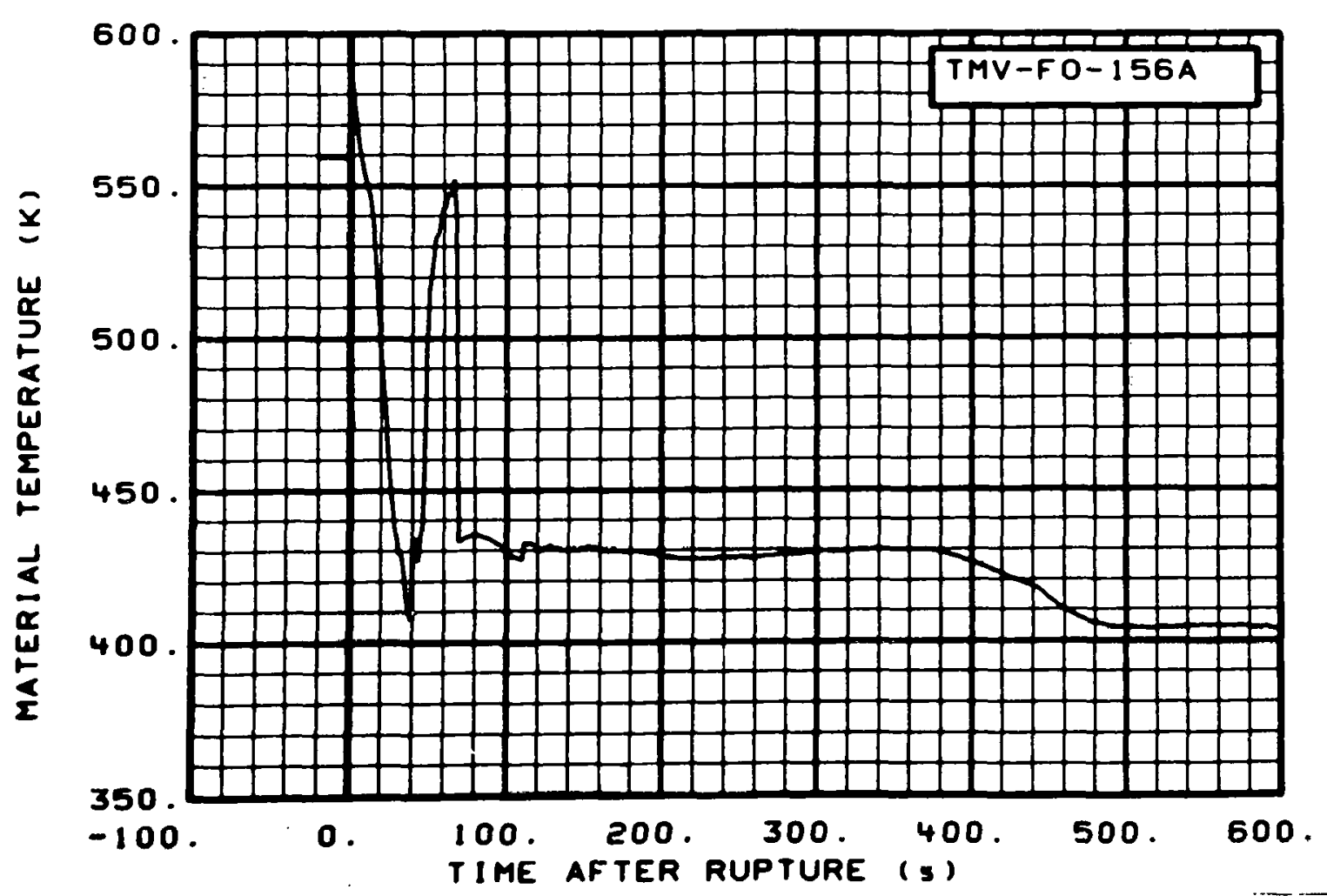

Fig. 65 Material temperature in vessel filler insulator (TMV-F0-156A), from -20 to $600 \mathrm{~s}$.

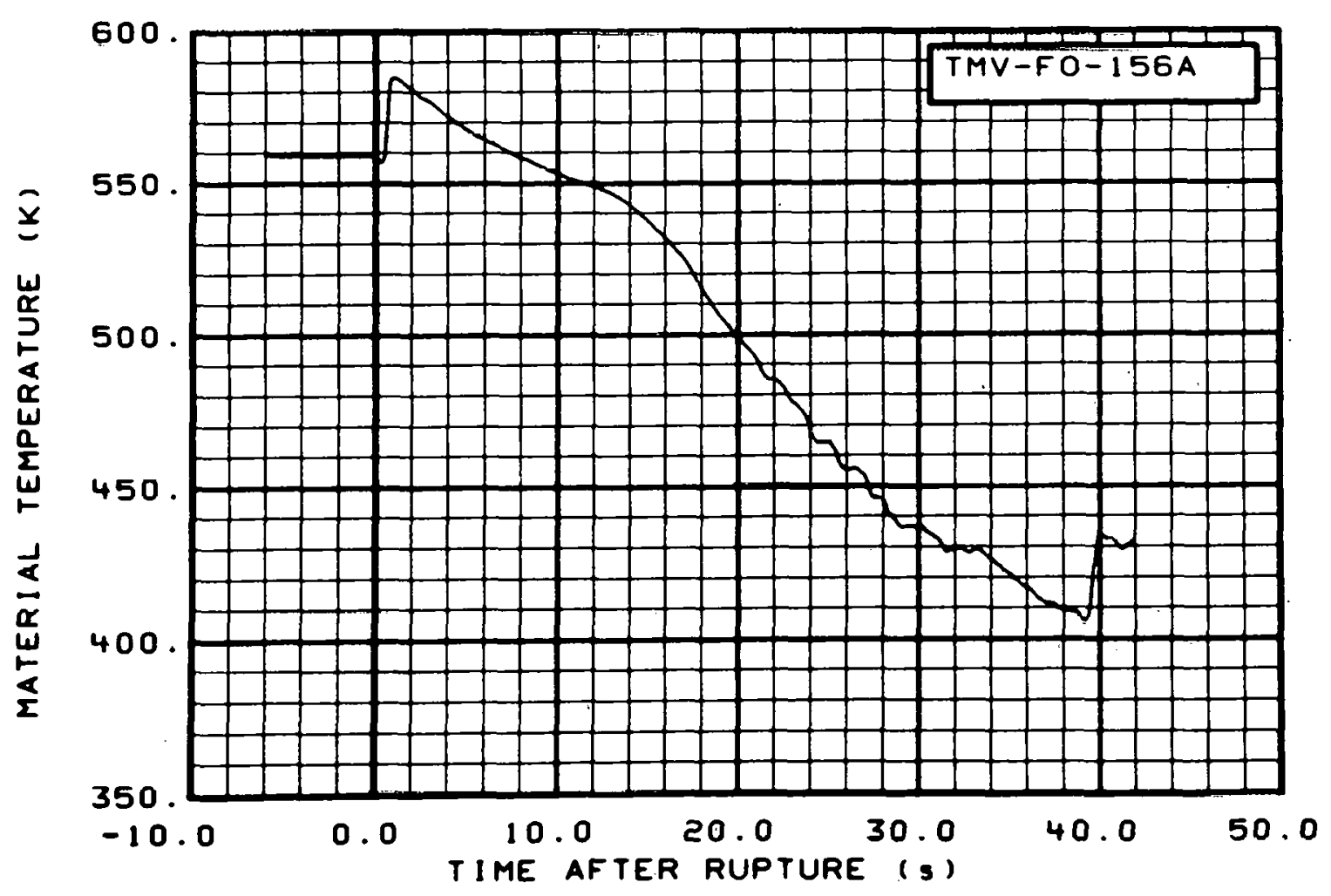

Fig. 66 Material temperature in vessel filler insulator (TMV-F0-156A), from -6 to $42 \mathrm{~s}$. 


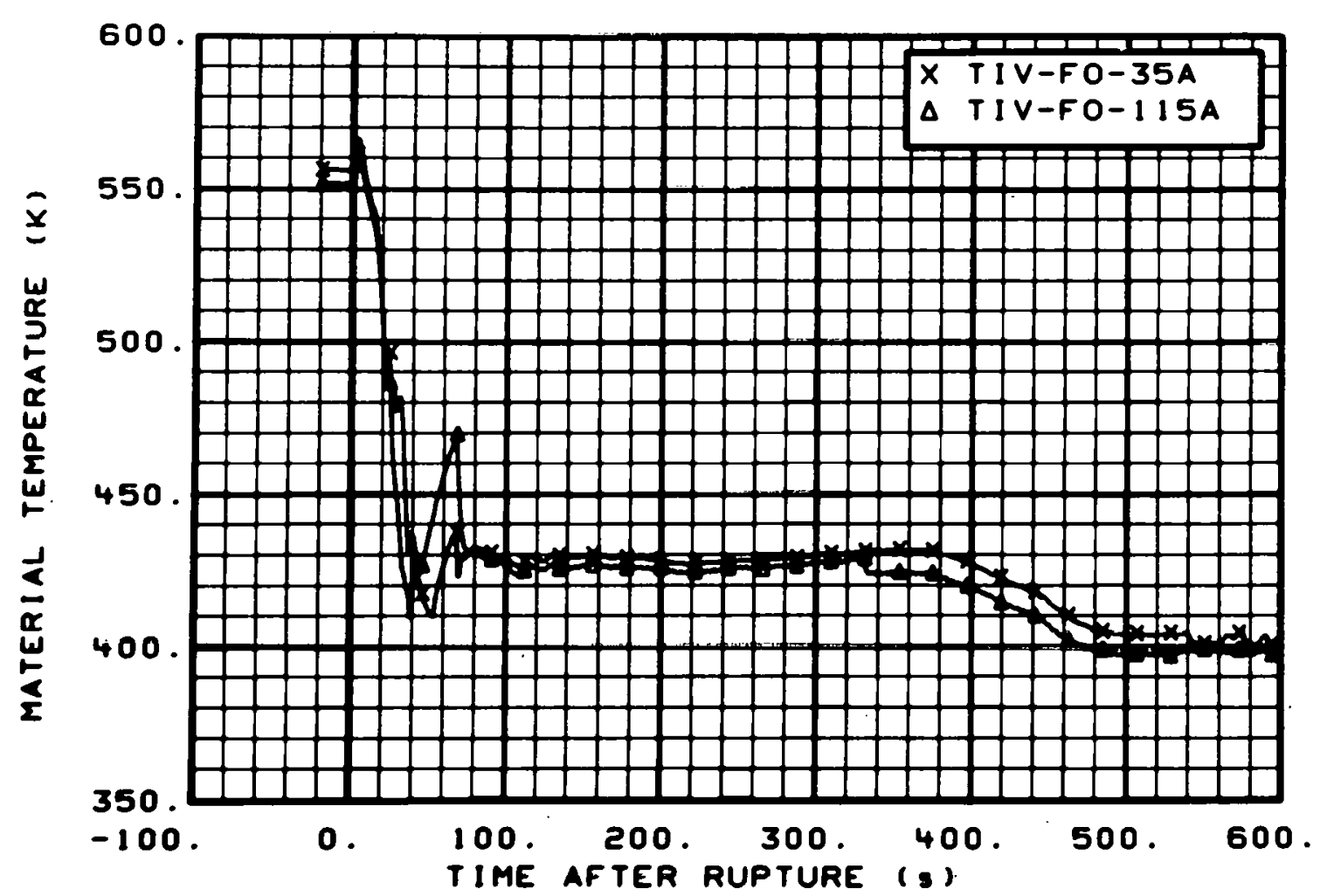

Fig: 67 Material temperature in vessel filler insulator (TIV-FO-35A and TIV-F0-115A), from -20 to $600 \mathrm{~s}$.

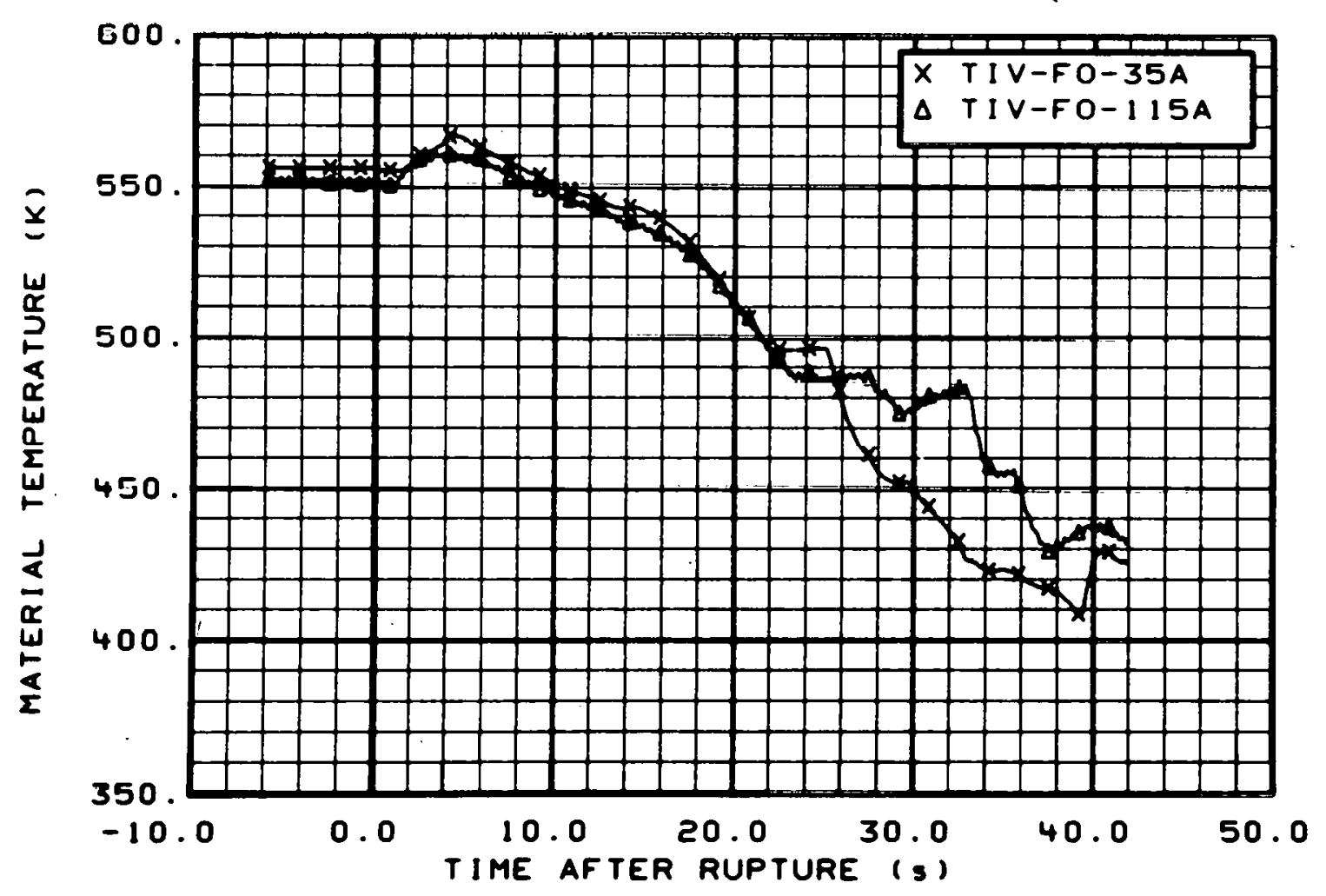

Fig. 68 Material temperature in vessel filler insulator (TIV-F0-35A and TIV-F0-115A), from -6 to $42 \mathrm{~s}$. 


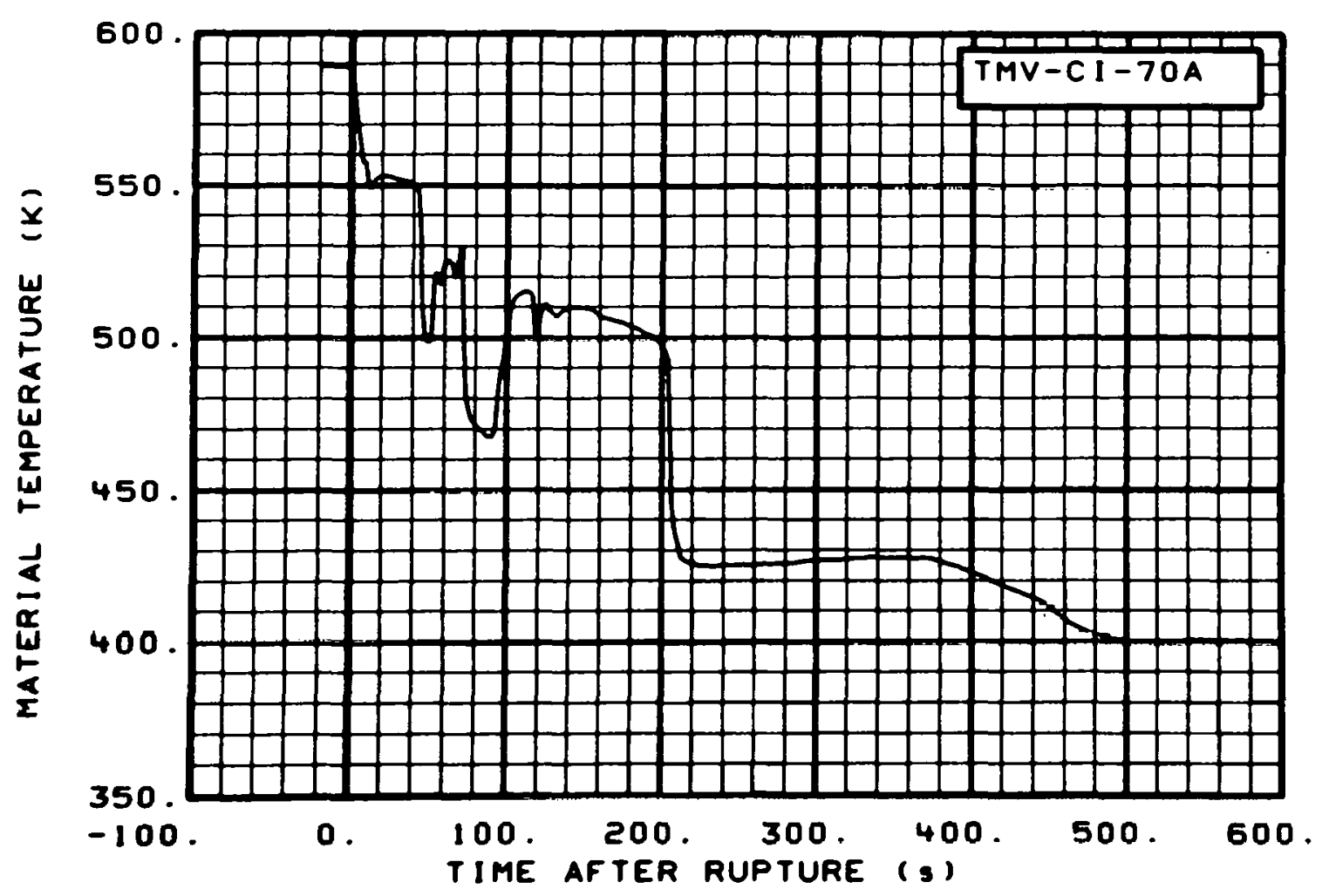

Fig. 69 Material temperature in core barrel inner diameter (TMV-CI-70A), from -20 to $600 \mathrm{~s}$.

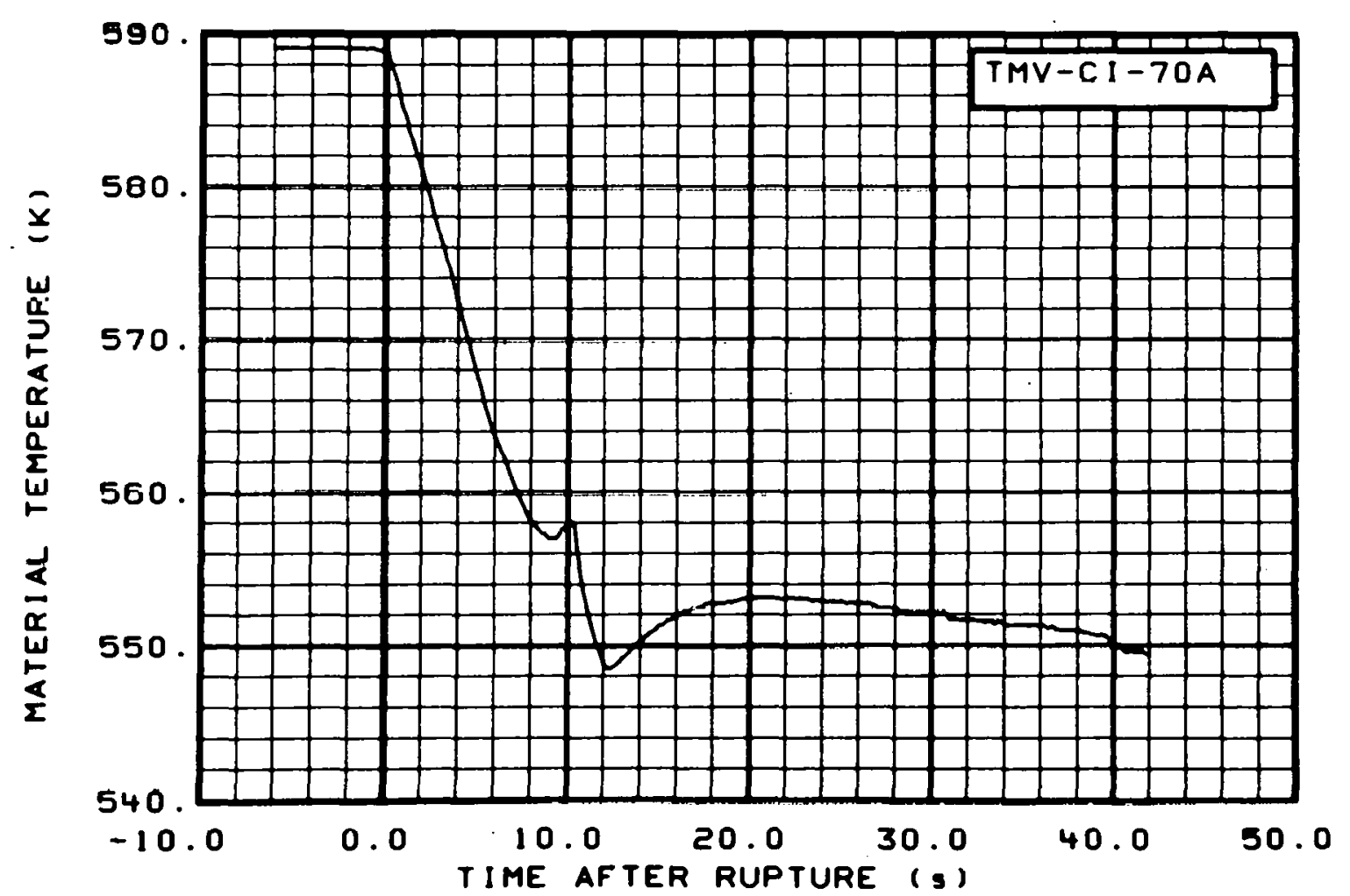

Fig. 70 Material temperature in core barrel inner diameter (TMV-CI-70A), from -6 to $42 \mathrm{~s}$. 


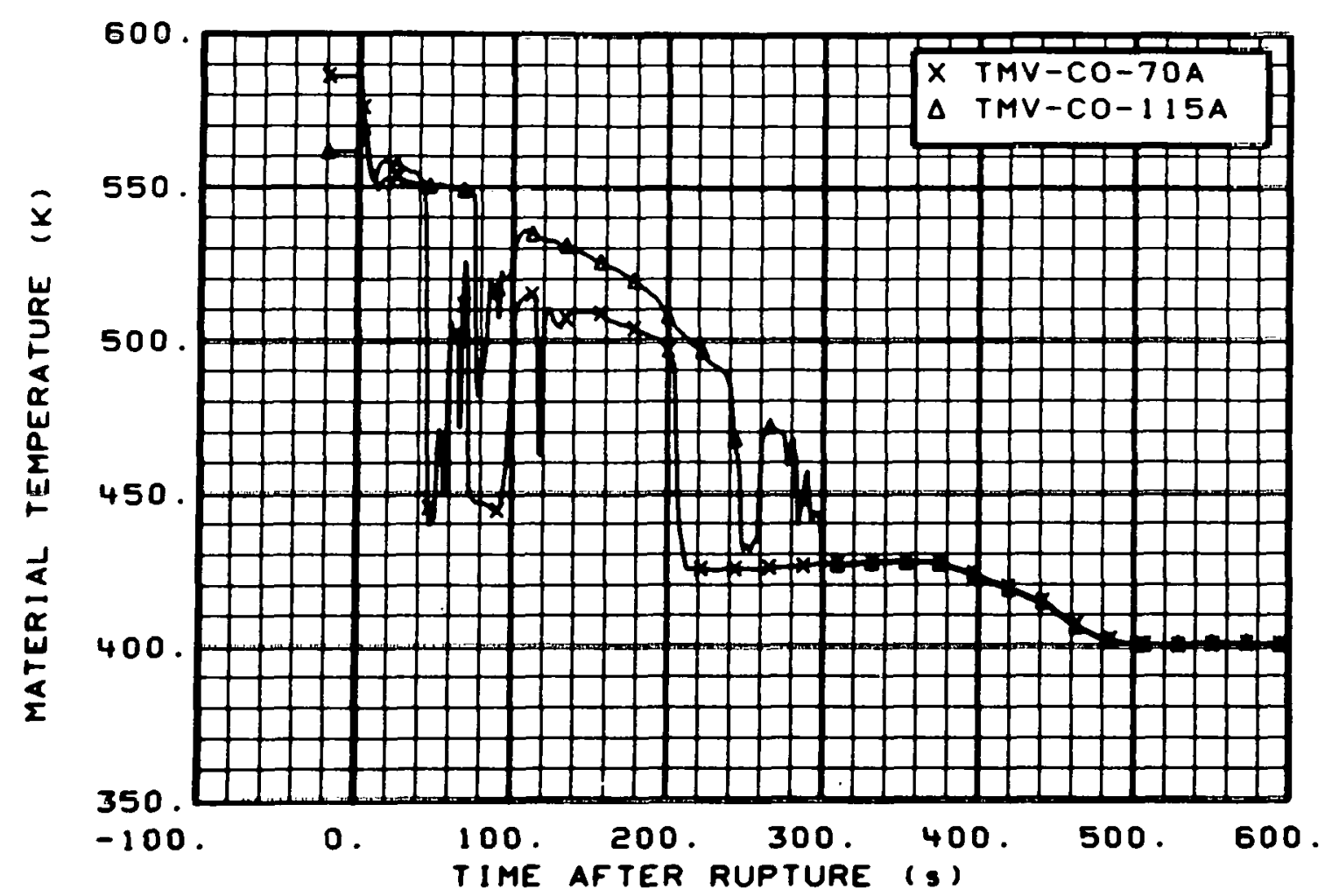

Fig. 71 Material temperature in core barrel outer diameter (TMV-CO-70A and TMV-CO-115A), from -20 to $600 \mathrm{~s}$.

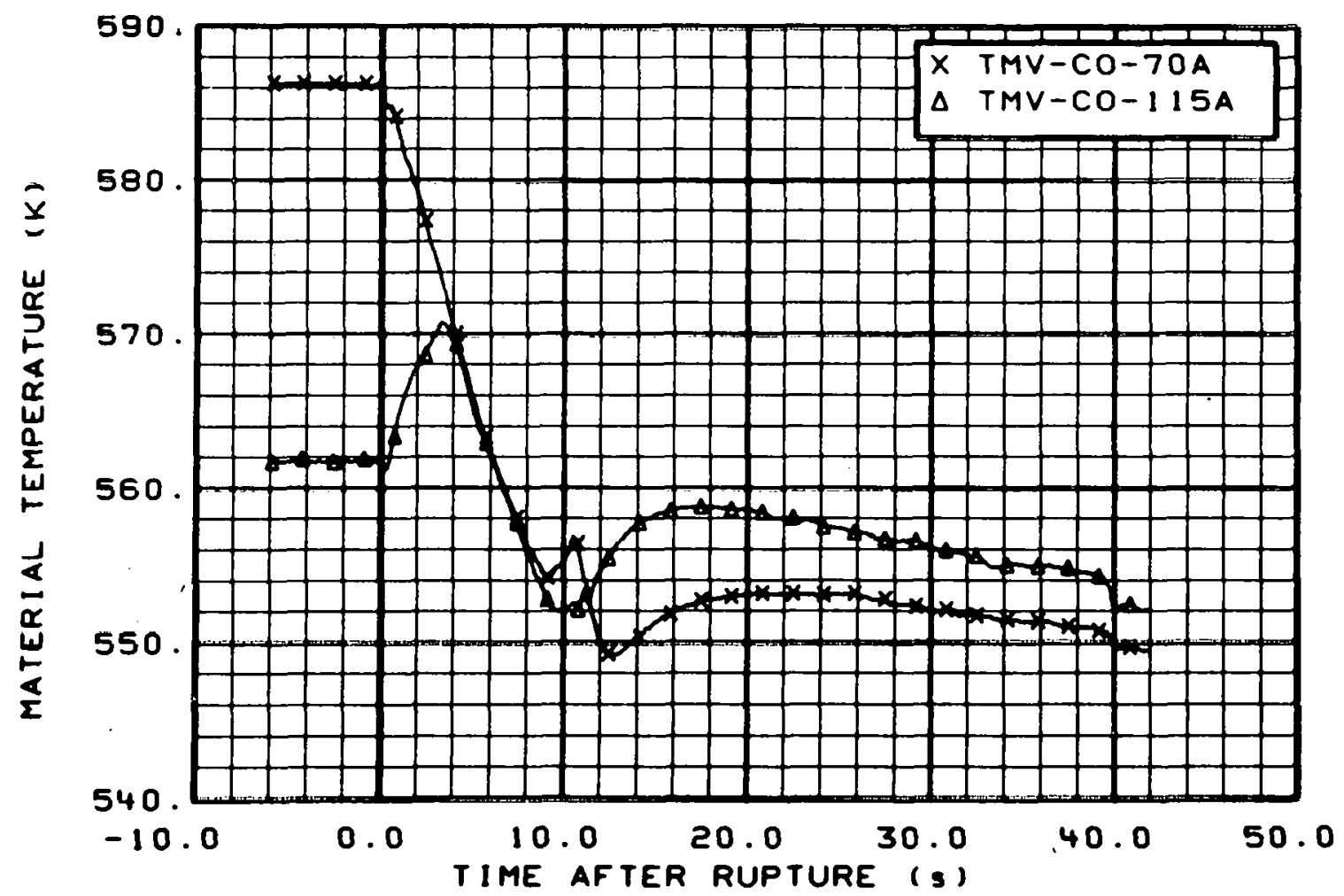

Fig. 72 Material temperature in core barrel outer diameter (TMV-CO-70A and TMV-CO-115A), from -6 to $42 \mathrm{~s}$. 


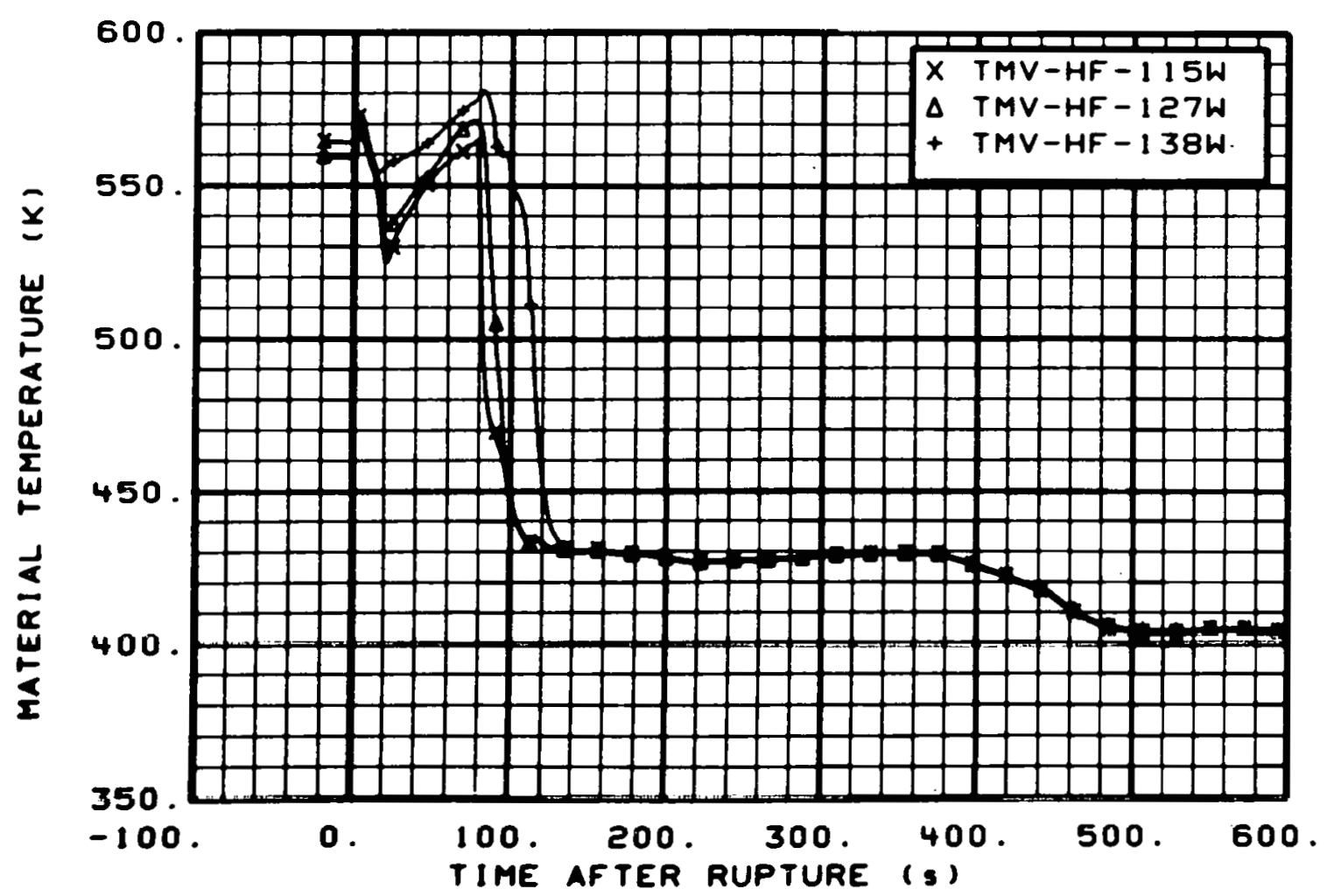

Fig. 73 Material temperature in core housing filler (TMV-HF-115W, TMV-HF$127 \mathrm{~W}$, and TMV-HF-138W), from -20 to $600 \mathrm{~s}$.

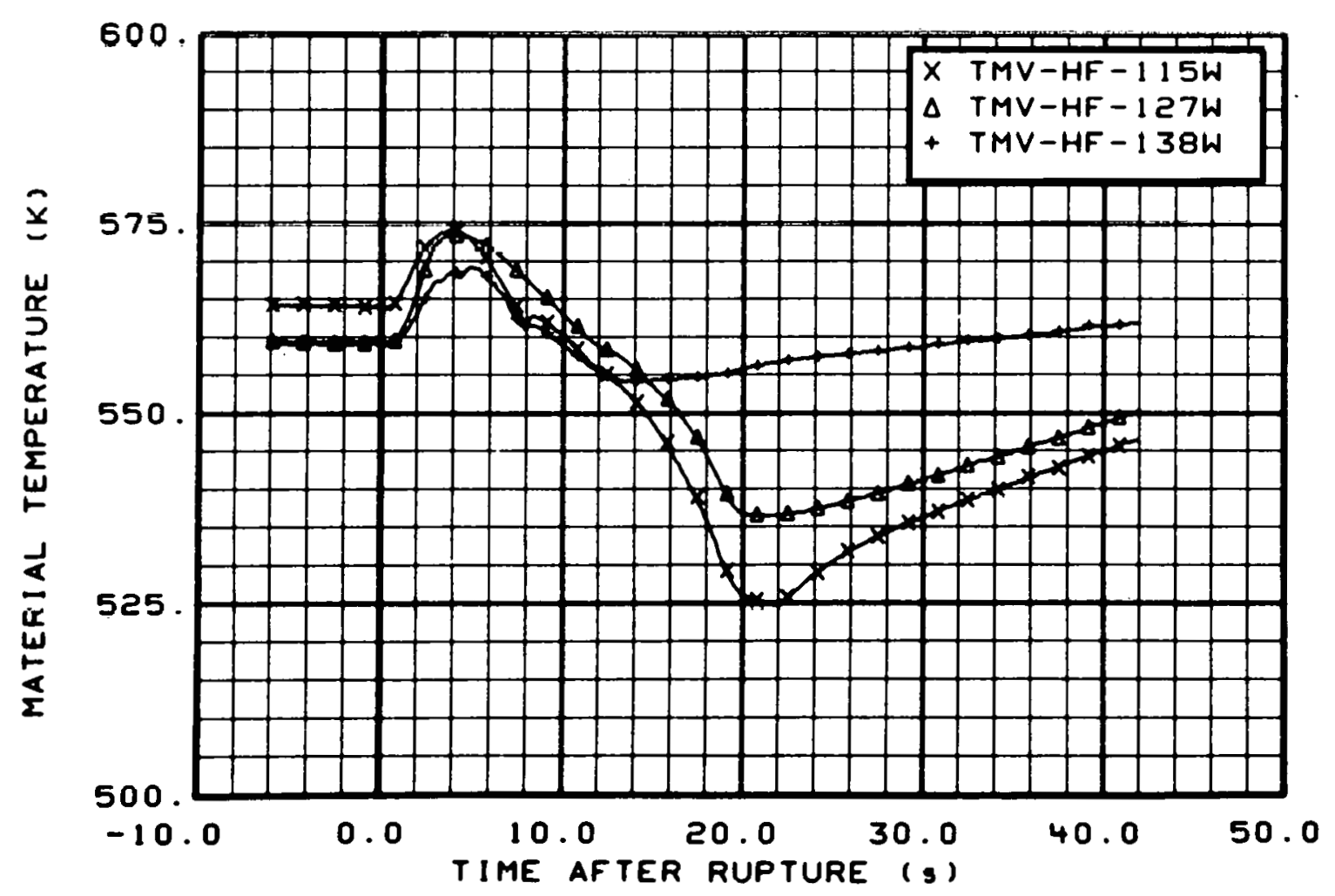

Fig. 74 Material temperature in core housing filler (TMV-HF-115W, TMV-HF127W, and TMV-HF-138W), from -6 to $42 \mathrm{~s}$. 


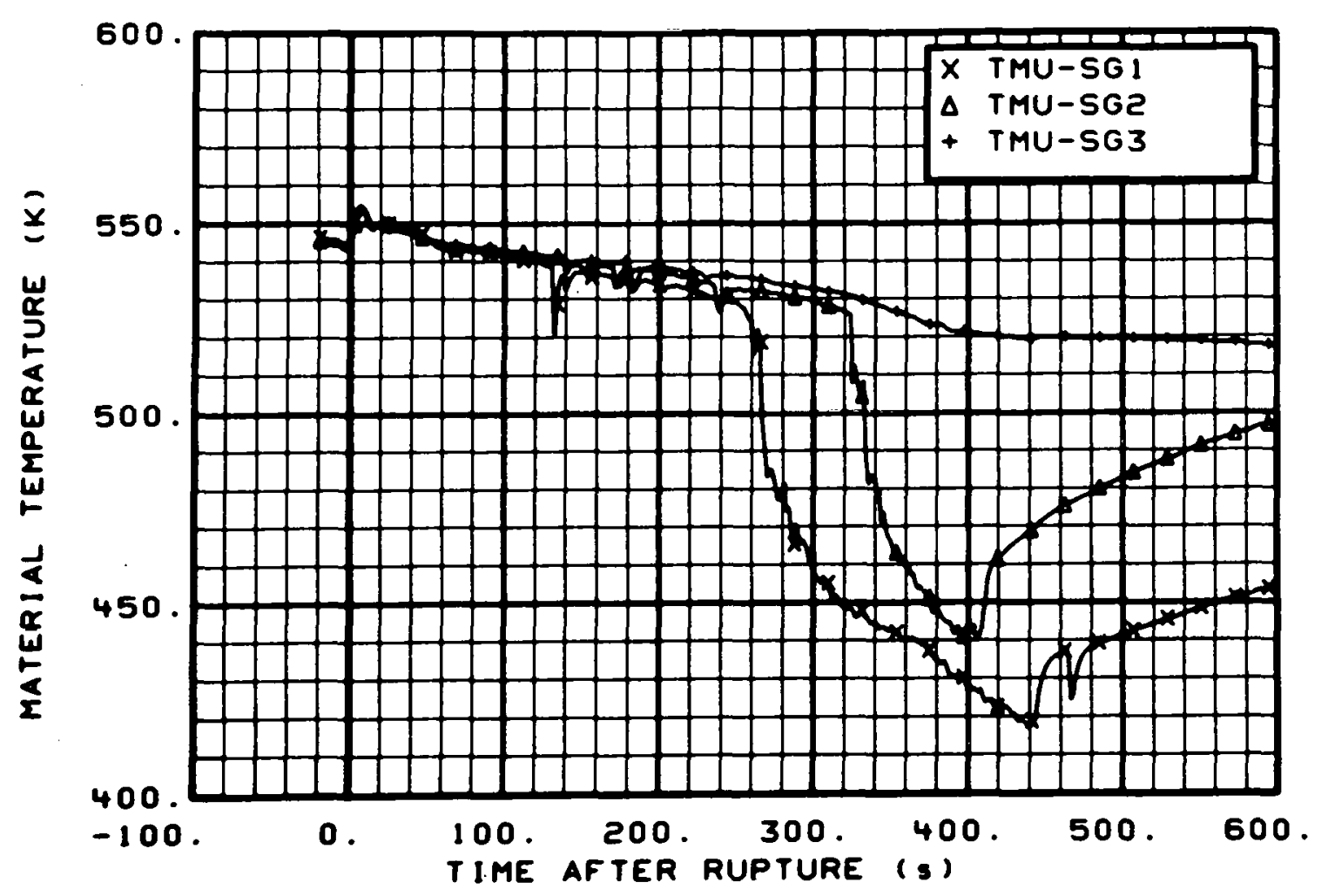

Fig. 75 Material temperature in steam generator (TMU-SG1, TMU-SG2, and TMU-SG3), from -20 to $600 \mathrm{~s}$.

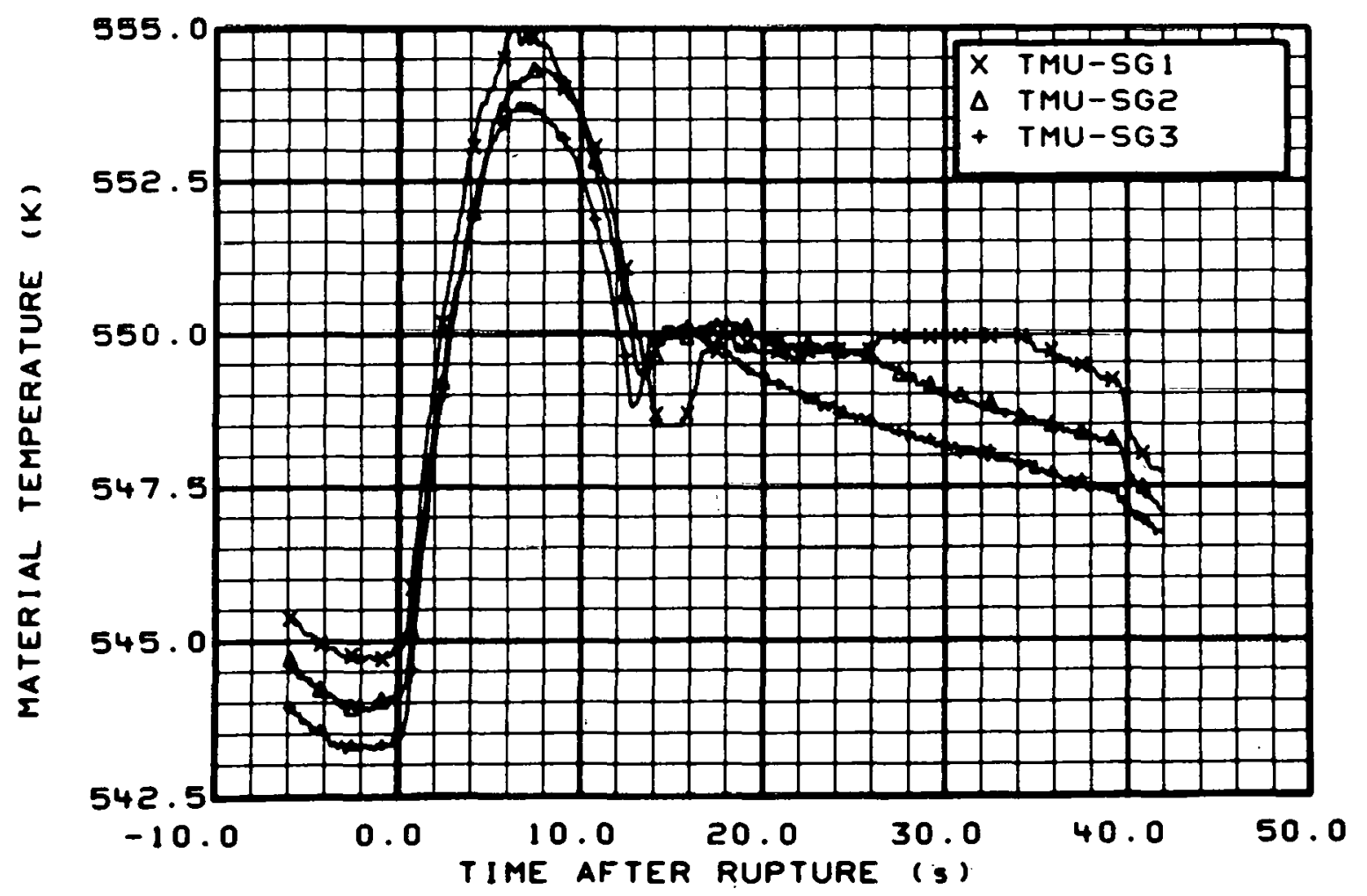

Fig. 76 Material temperature in steam generator (TMU-SGI, TMU-SG2, and TMU-SG3), from -6 to $42 \mathrm{~s}$. 


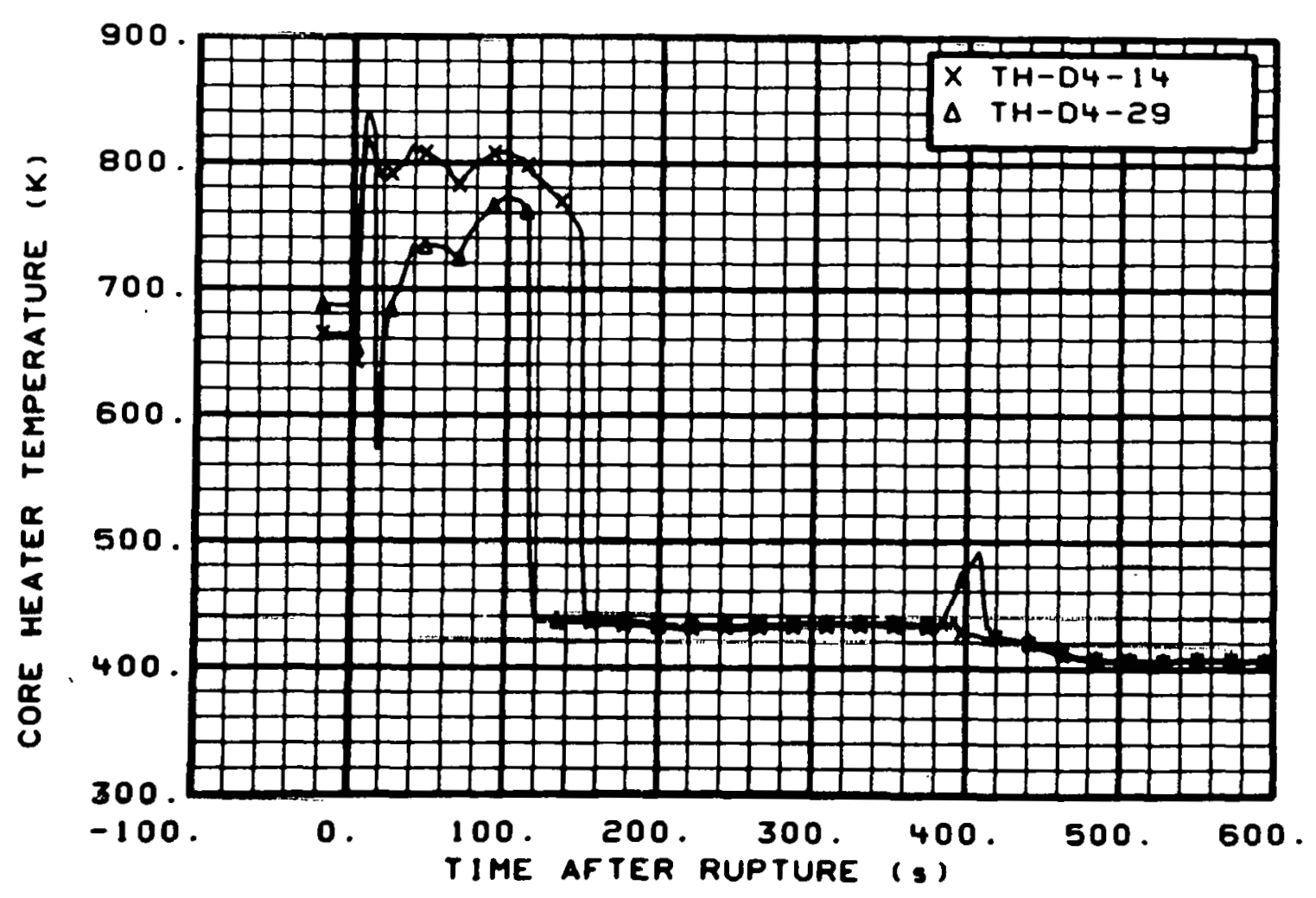

Fig. 77 Core heater temperature, Rod D-4 (TH-D4-14 and TH-D4-29), from -20 to $600 \mathrm{~s}$.

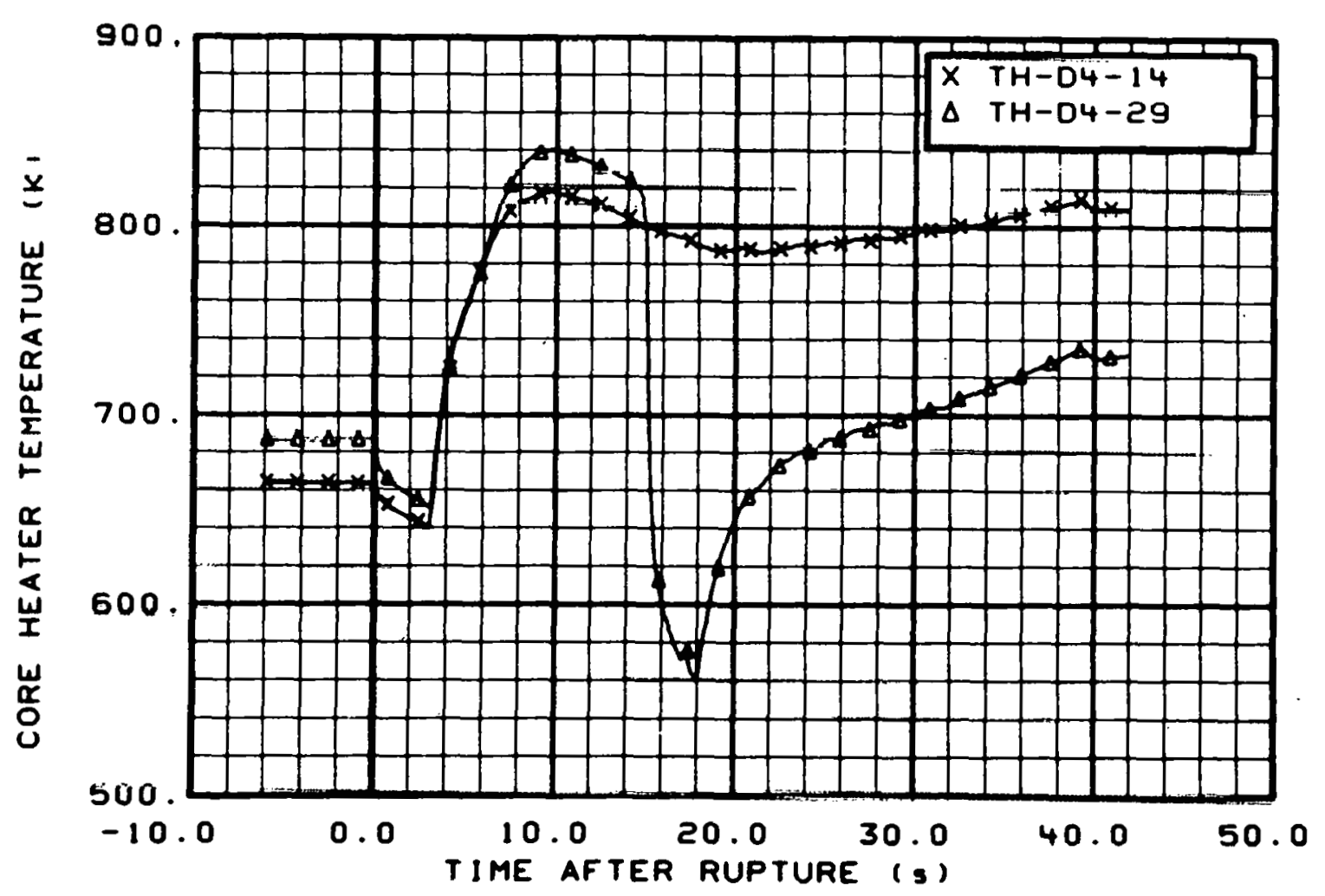

Fig. 78 Core heater temperature, Rod D-4 (TH-D4-14 and TH-D4-29), from -6 to $42 \mathrm{~s}$. 


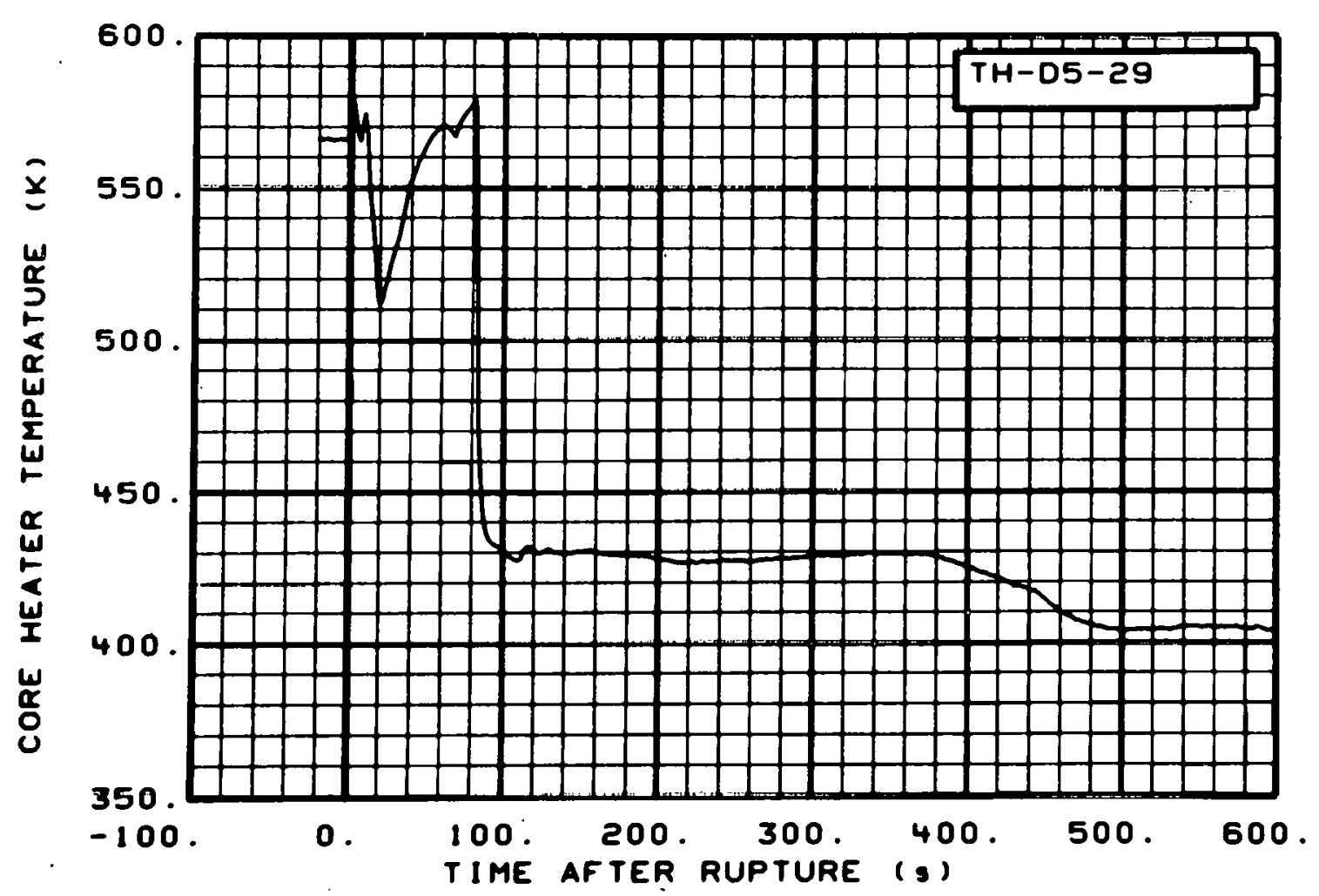

Fig. 79 Core heater temperature, Rod D-5 (TH-D5-29) from -20 to $600 \mathrm{~s}$.

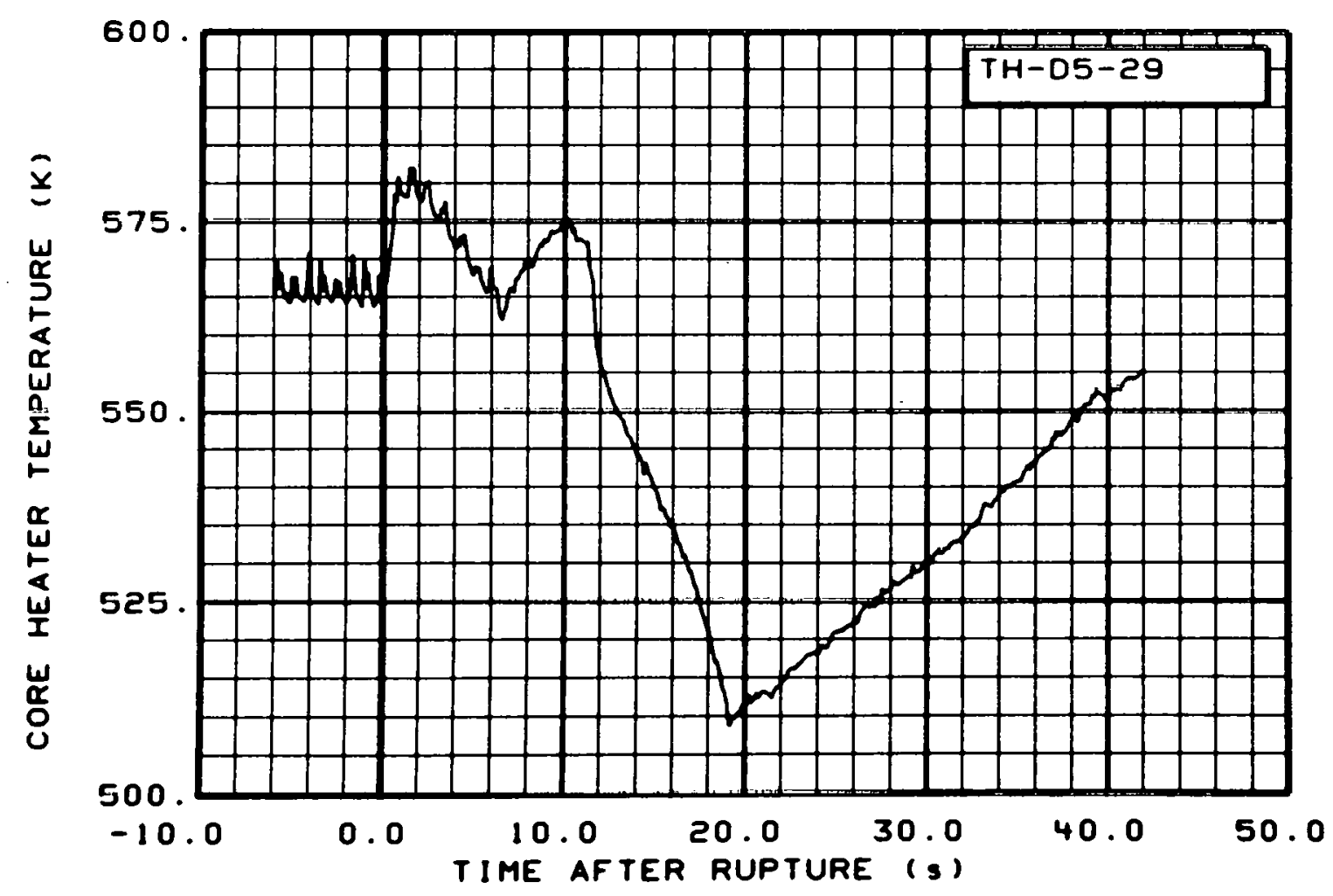

Fig. 80 Core heater temperature, Rod D-5 (TH-D5-29) from -6 to $42 \mathrm{~s}$. 


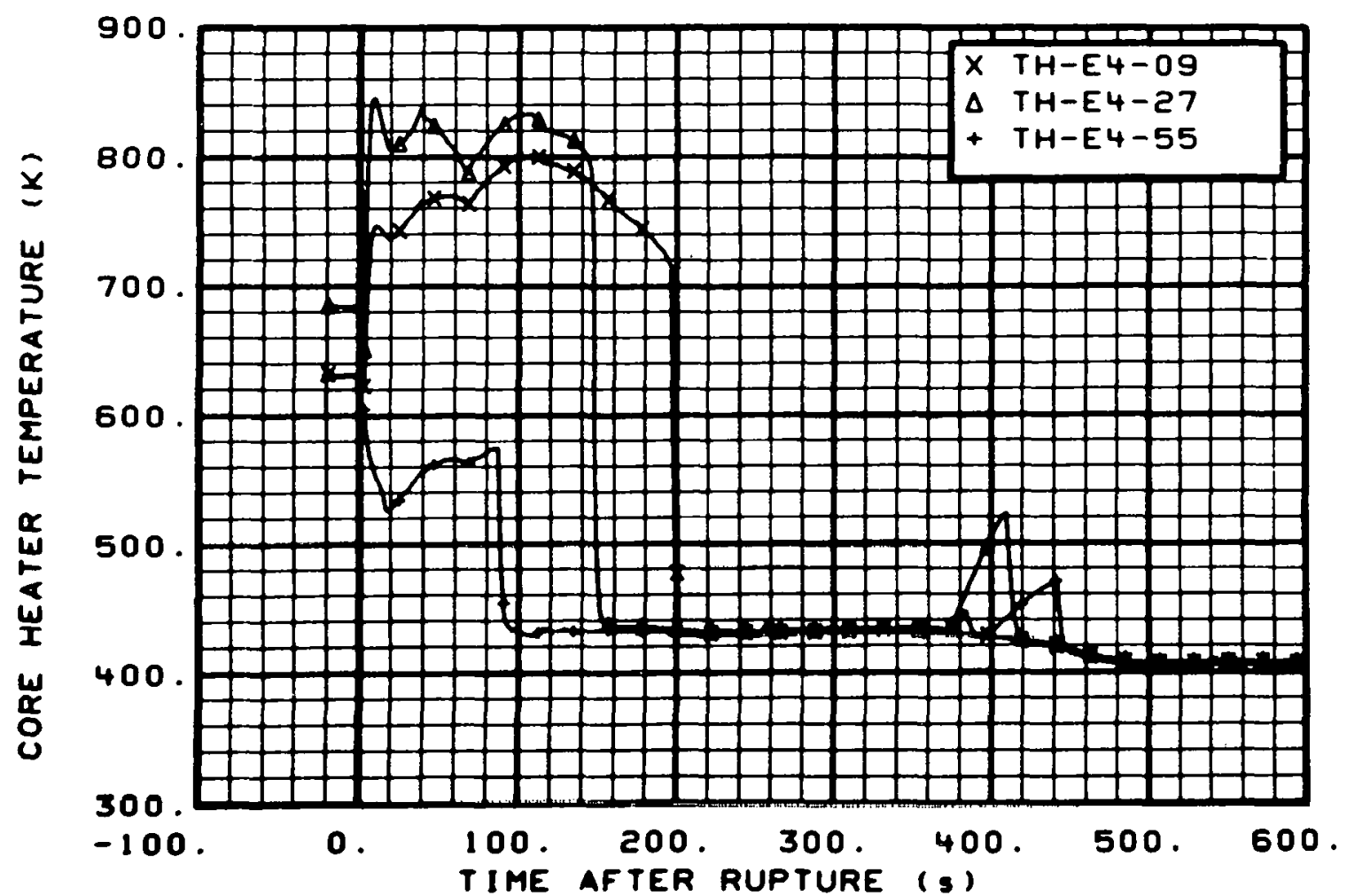

Fig. 81 Core heater temperature, Rod E-4 (TH-E4-09, TH-E4-27, and TH-E4-55), from -20 to $600 \mathrm{~s}$.

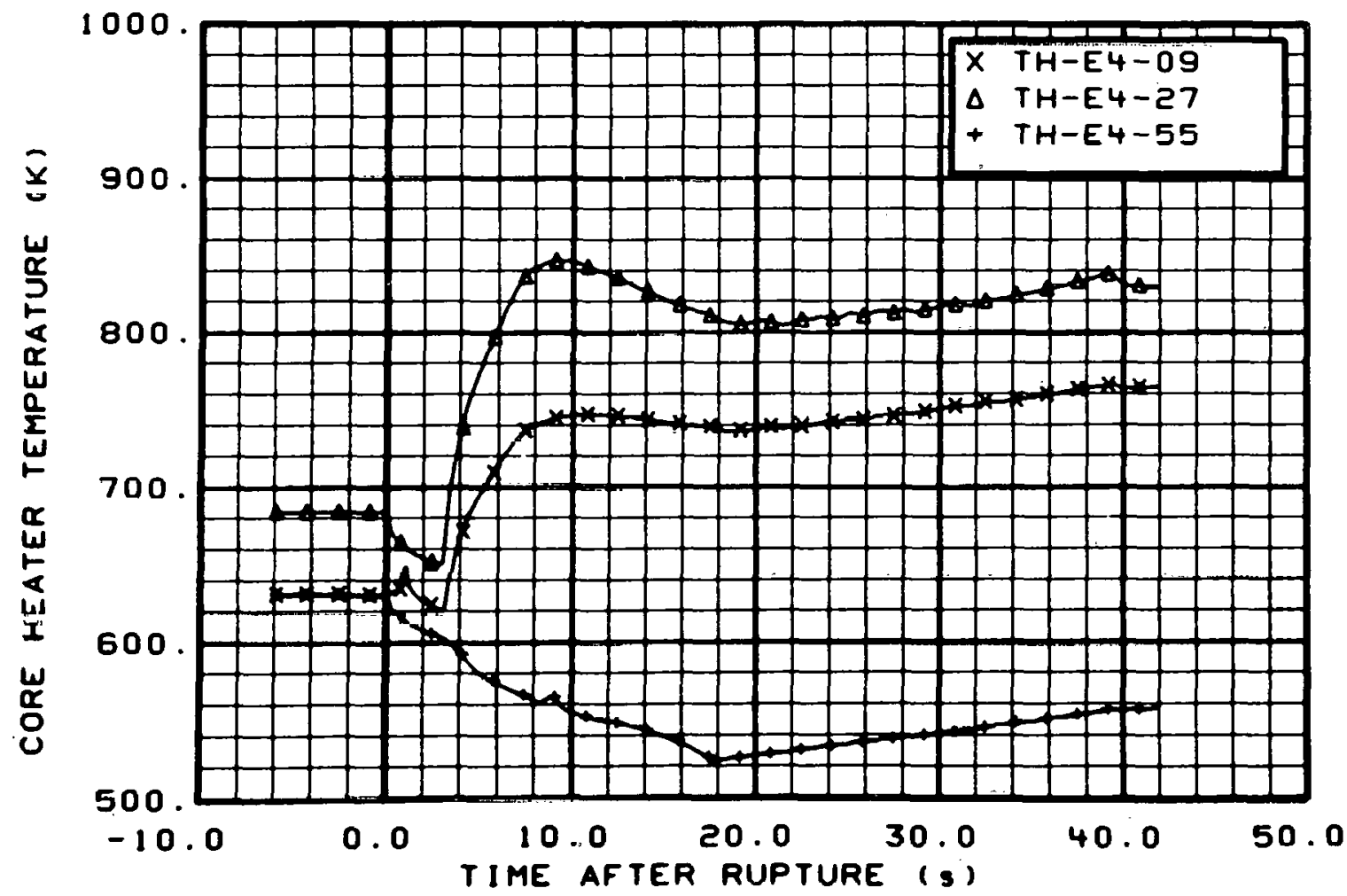

Fig. 82 Core heater temperature, Rod E-4 (TH-E4-09, TH-E4-27, and TH-E4-55), from -6 to $42 \mathrm{~s}$. 


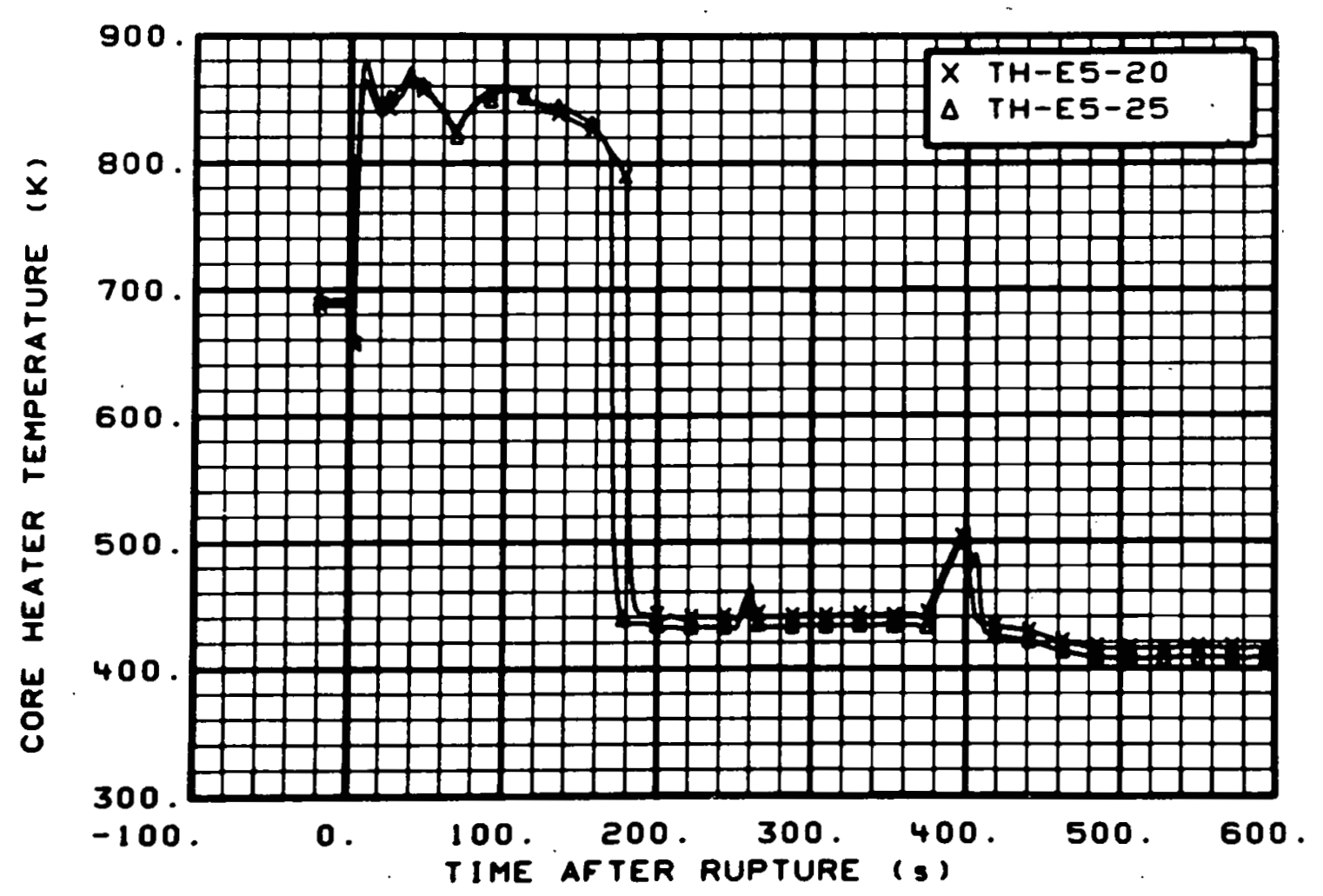

Fig. 83 Core heater temperature, Rod E-5 (TH-E5-20 and TH-E5-25), from -20 to $600 \mathrm{~s}$.

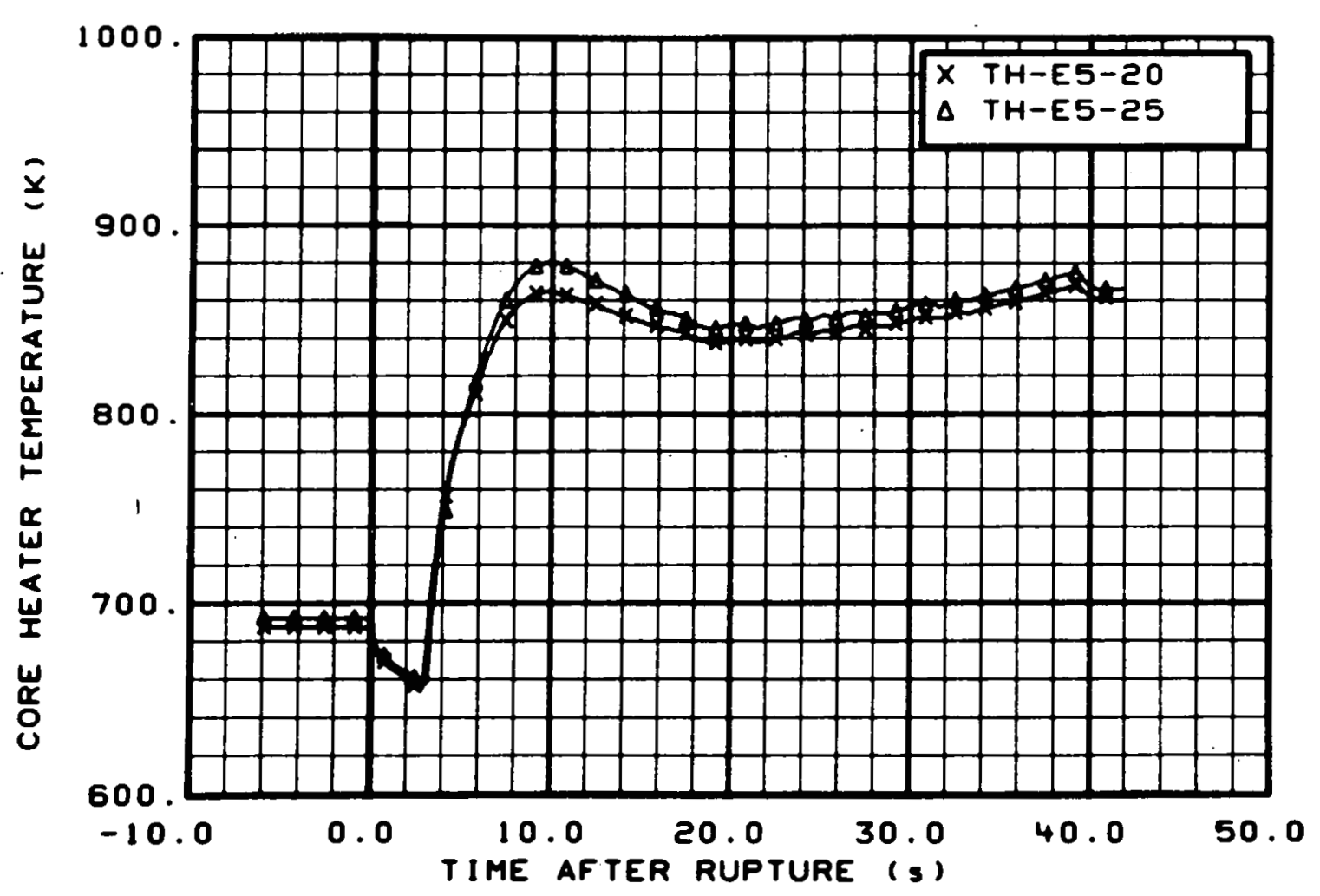

Fig. 84 Core heater temperature, Rod E-5 (TH-E5-20 and TH-E5-25), from -6 to $42 \mathrm{~s}$. 


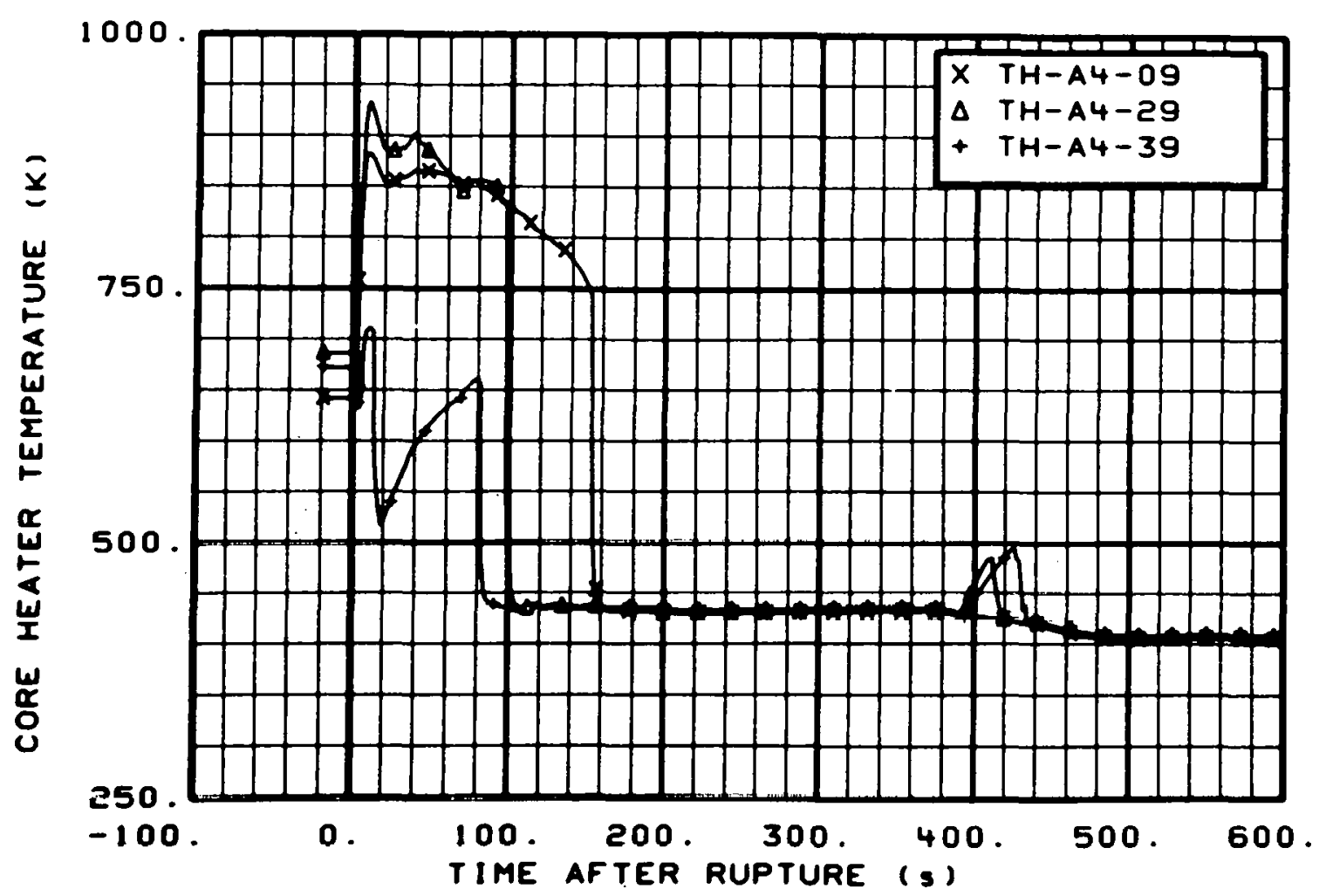

Fig. 85 Core heater temperature, Rod A-4 (TH-A4-09, TH-A4-29, and TH-A4-39), from -20 to $600 \mathrm{~s}$.

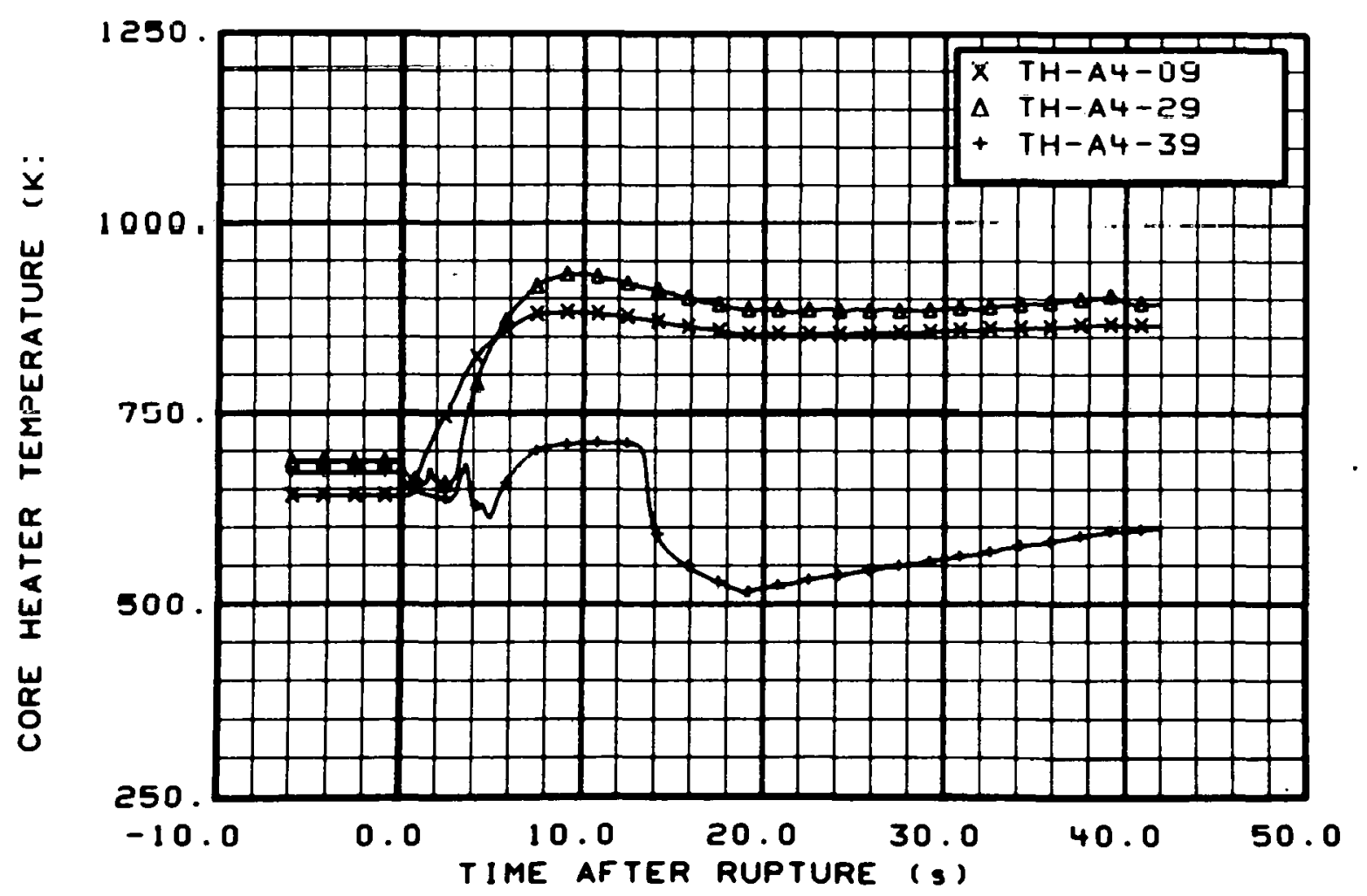

Fig. 86 Core heater temperature, Rod A-4 (TH-A4-09, TH-A4-29, and $\mathrm{TH}-\mathrm{A} 4-39$ ), from -6 to $42 \mathrm{~s}$. 


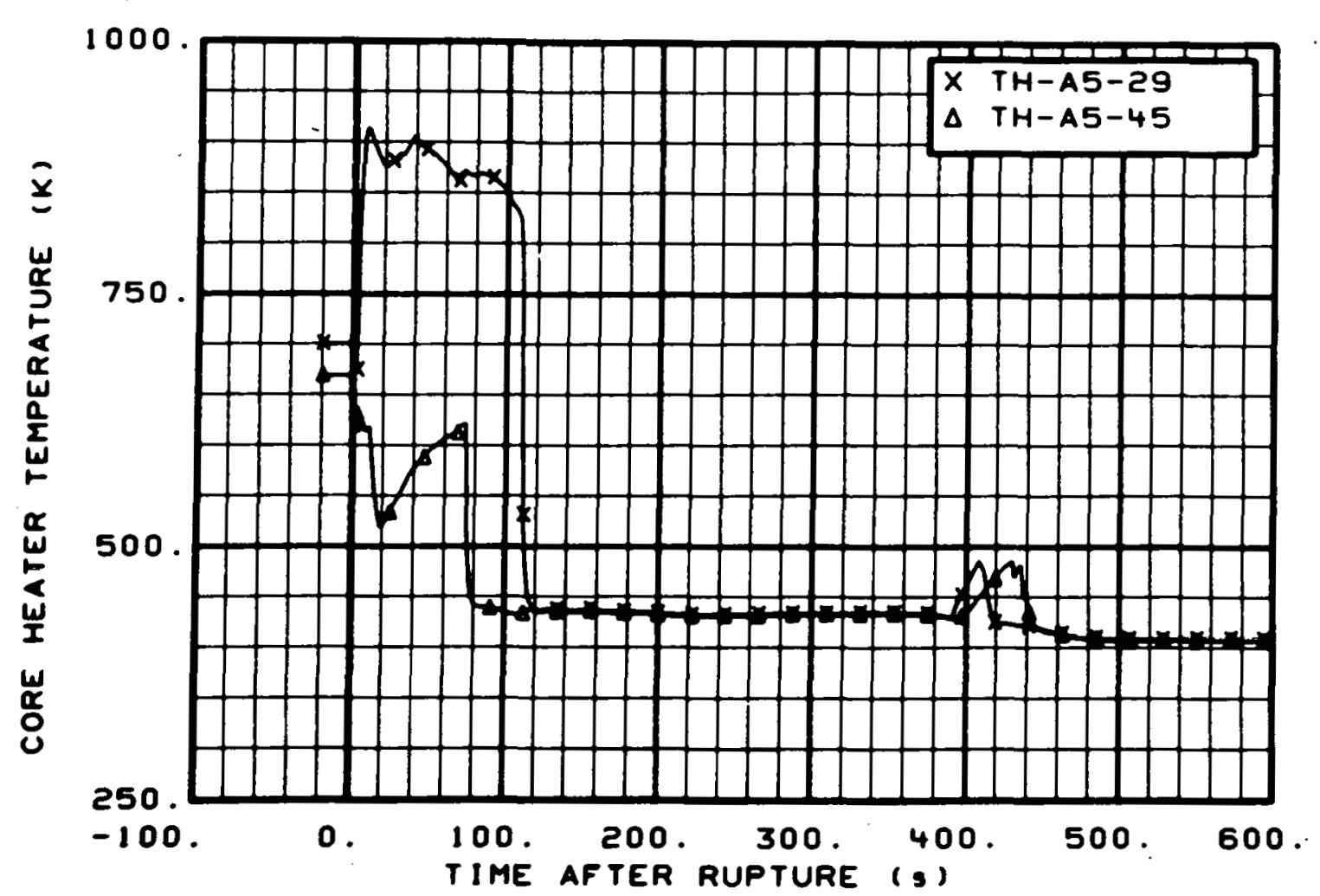

Fig. 87 Core heater temperature, Rod A-5 (TH-A5-29 and TH-A5-45), from -20 to $600 \mathrm{~s}$.

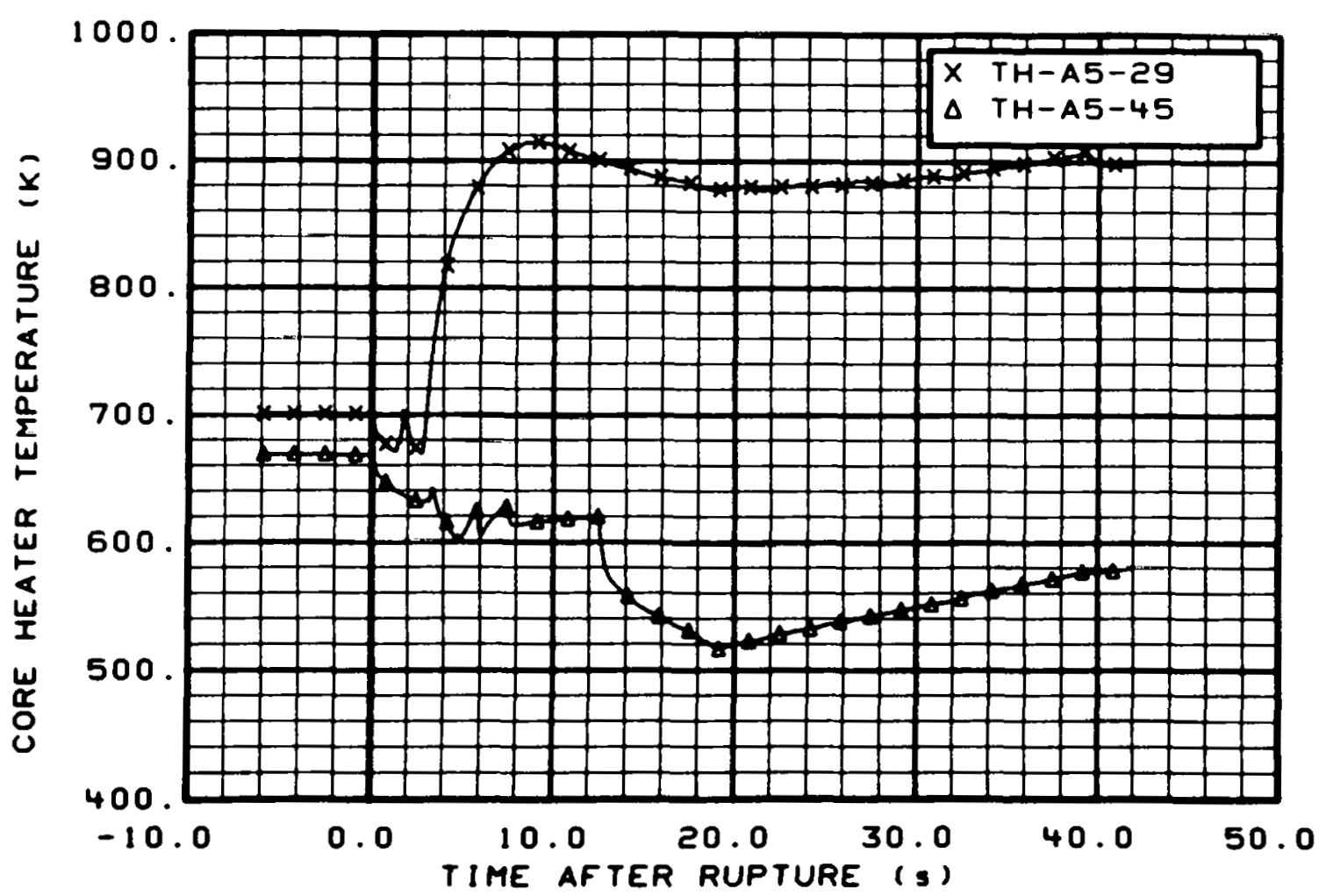

F1g. 88 Core heater temperaturc, Rod A-5 (TH=A5-29 and TH-A.5-45), from -6 to $42 \mathrm{~s}$. 


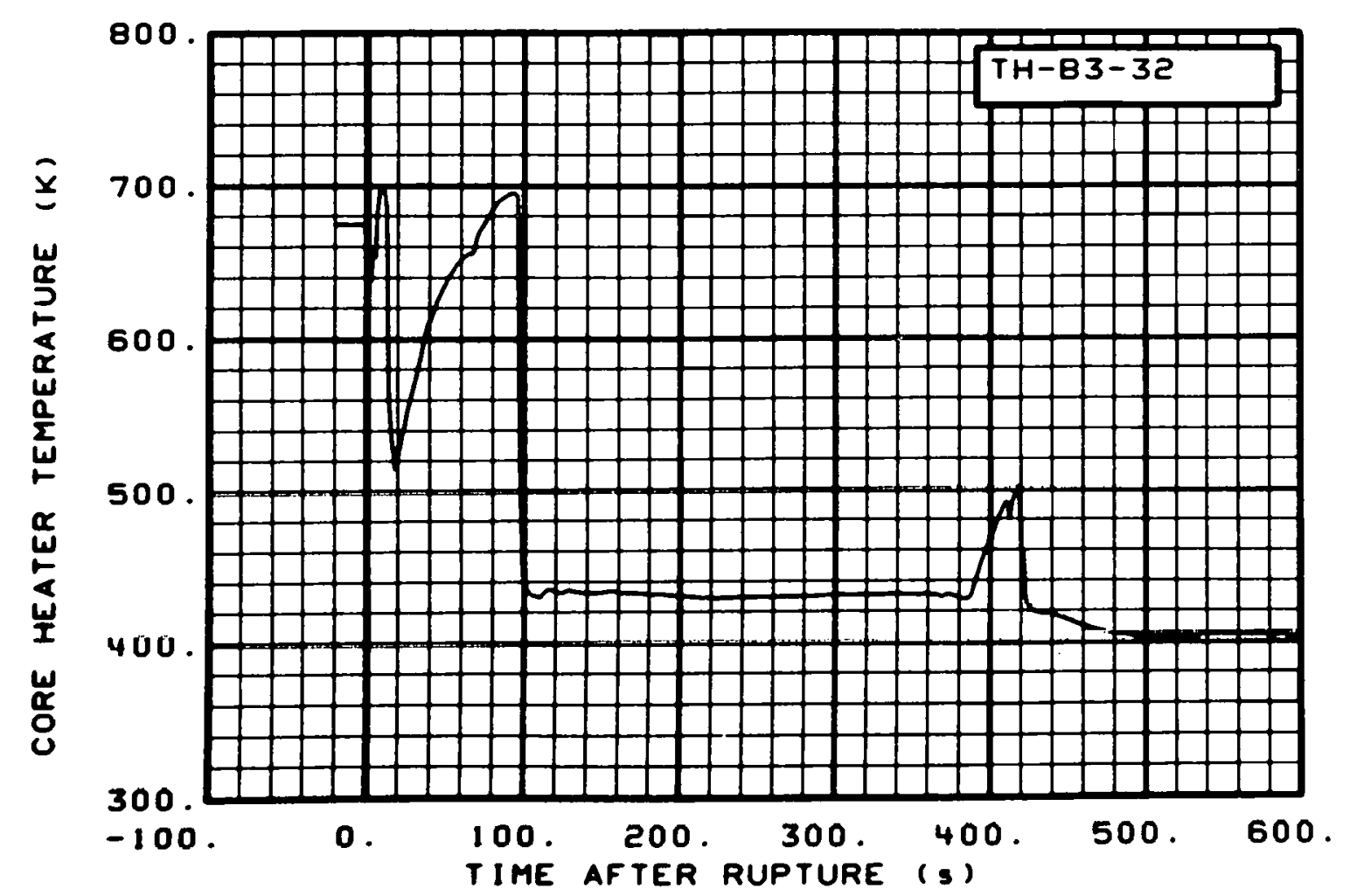

Fig. 89 Core heater temperature, Rod B-3 (TH-B3-32), from -20 to $600 \mathrm{~s}$.

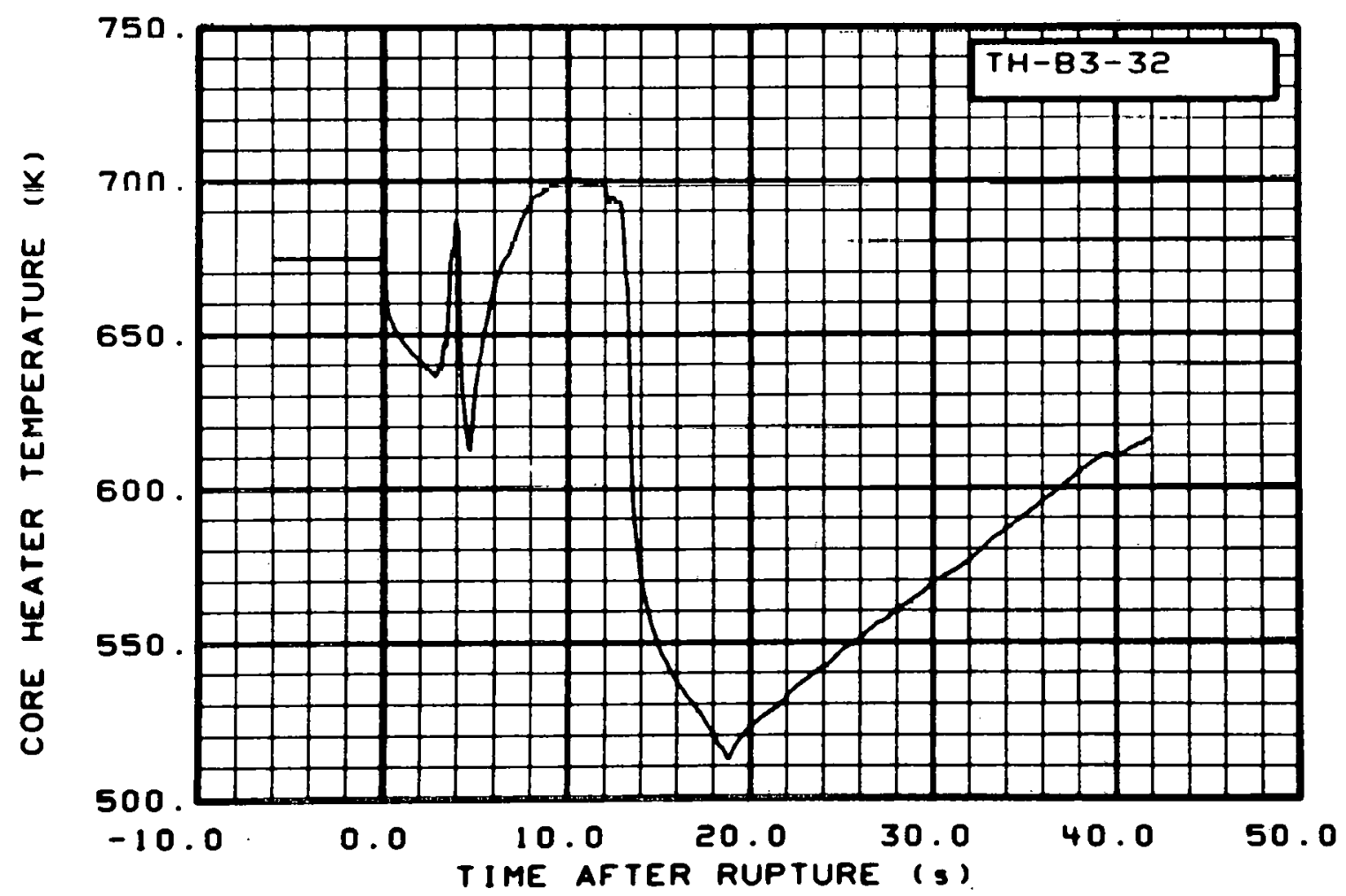

Fig. 90 Core heater temperature, Rod B-3 (TH-B3-32), from -6 to $42 \mathrm{~s}$. 


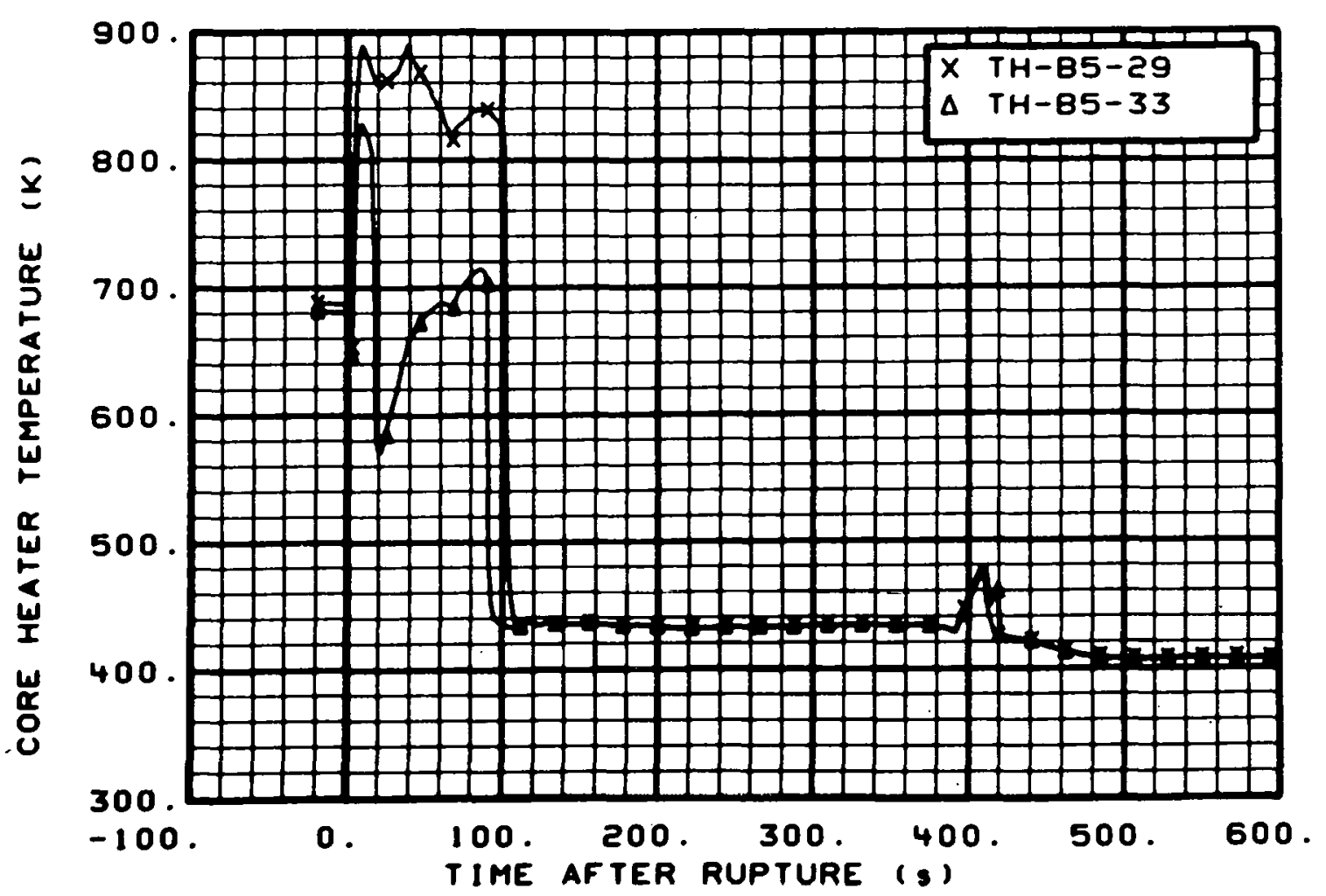

Fig. 91 Core heater temperature, Rod B-5 (TH-B5-29 and TH-B5-33), from -20 to $600 \mathrm{~s}$.

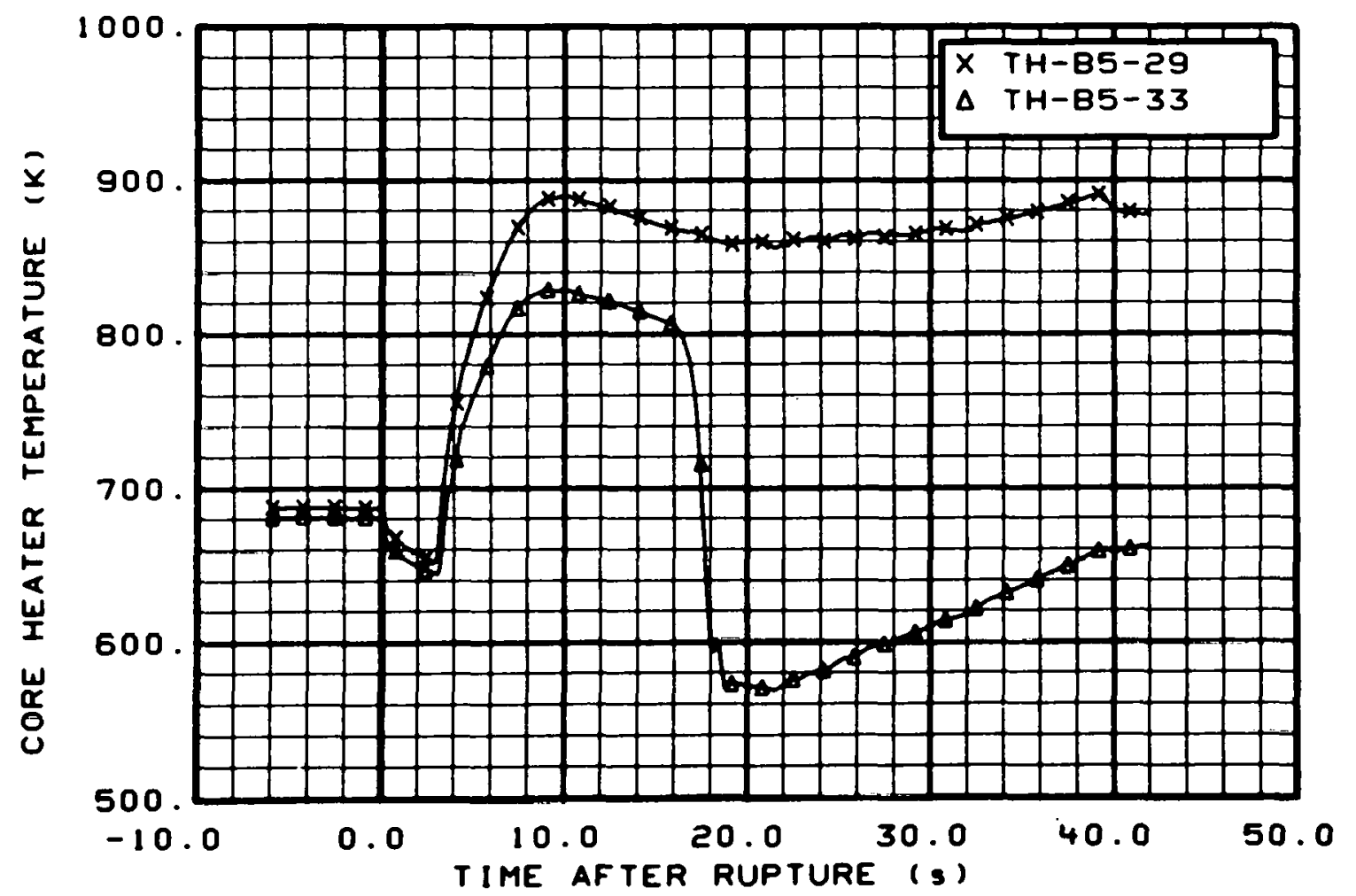

Fig. 92 Core heater temperature, Rod B-5 (TH-B5-29 and TH-B5-33), from -6 to $42 \mathrm{~s}$. 


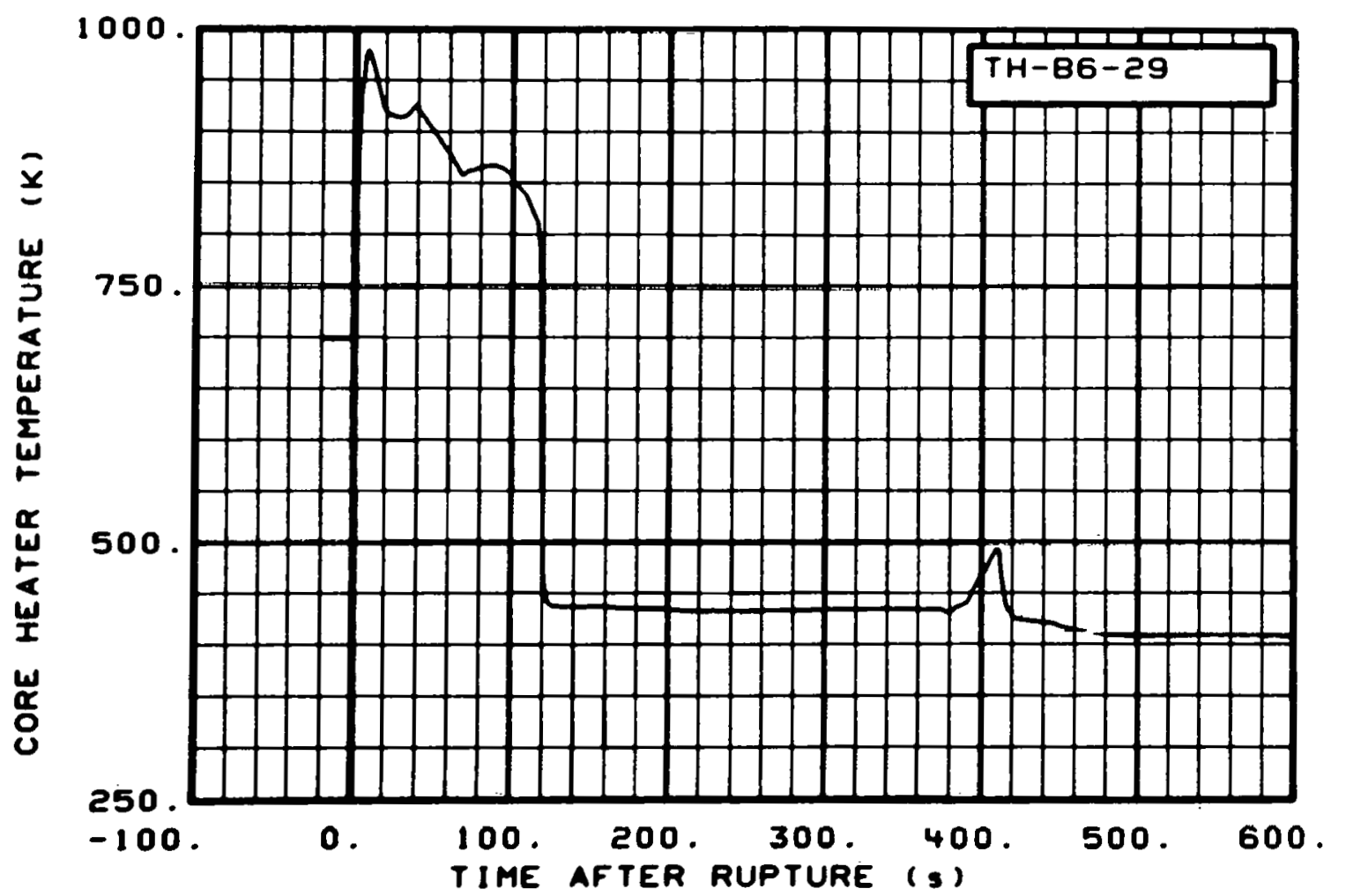

Fig. 93 Core heater temperature, Rod B-6 (TH-B6-29), from -20 to $600 \mathrm{~s}$.

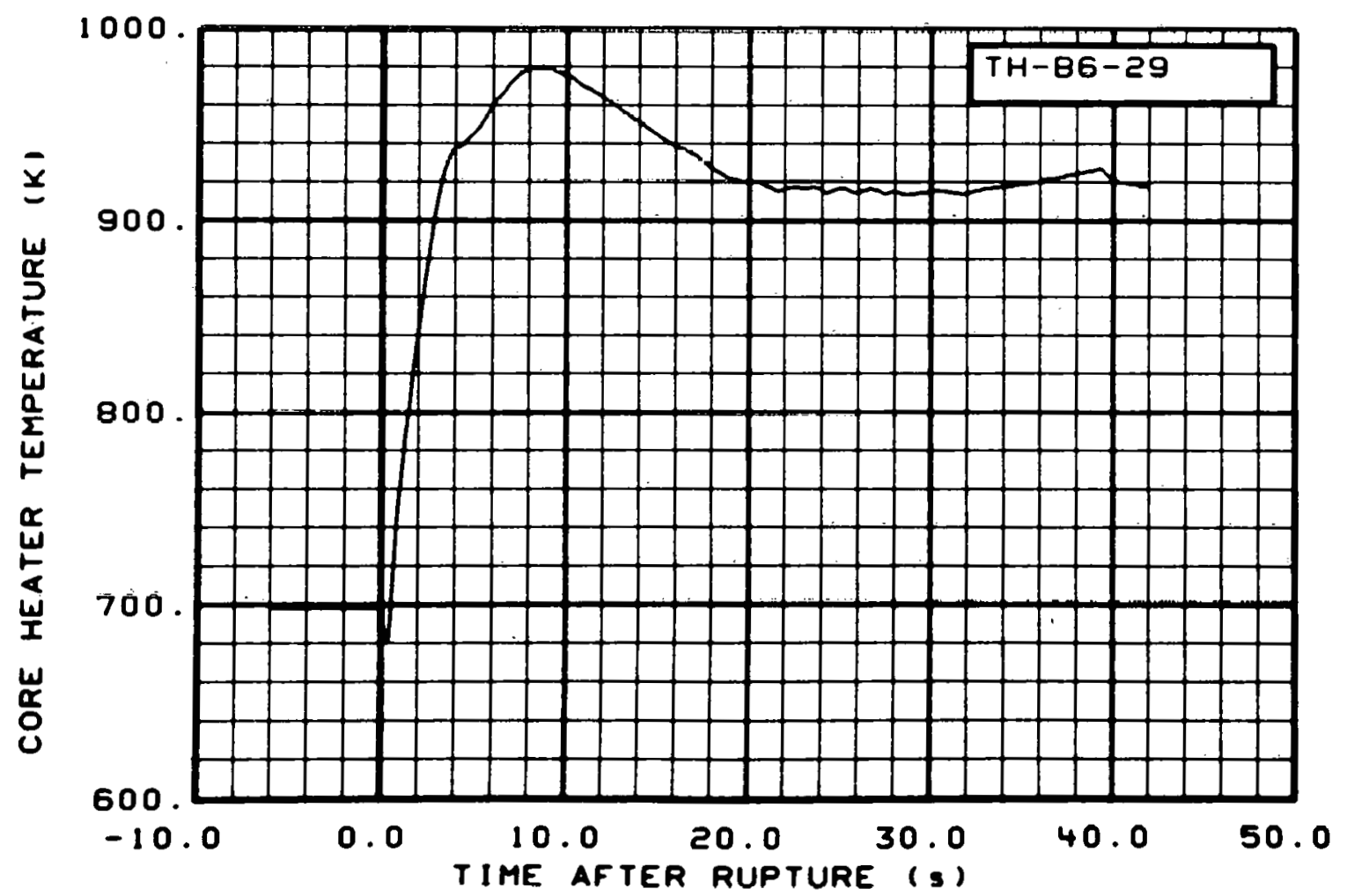

Fig. 94 Core heater temperature, Rod B-6 (TH-B6-29), from -6 to $42 \mathrm{~s}$. 


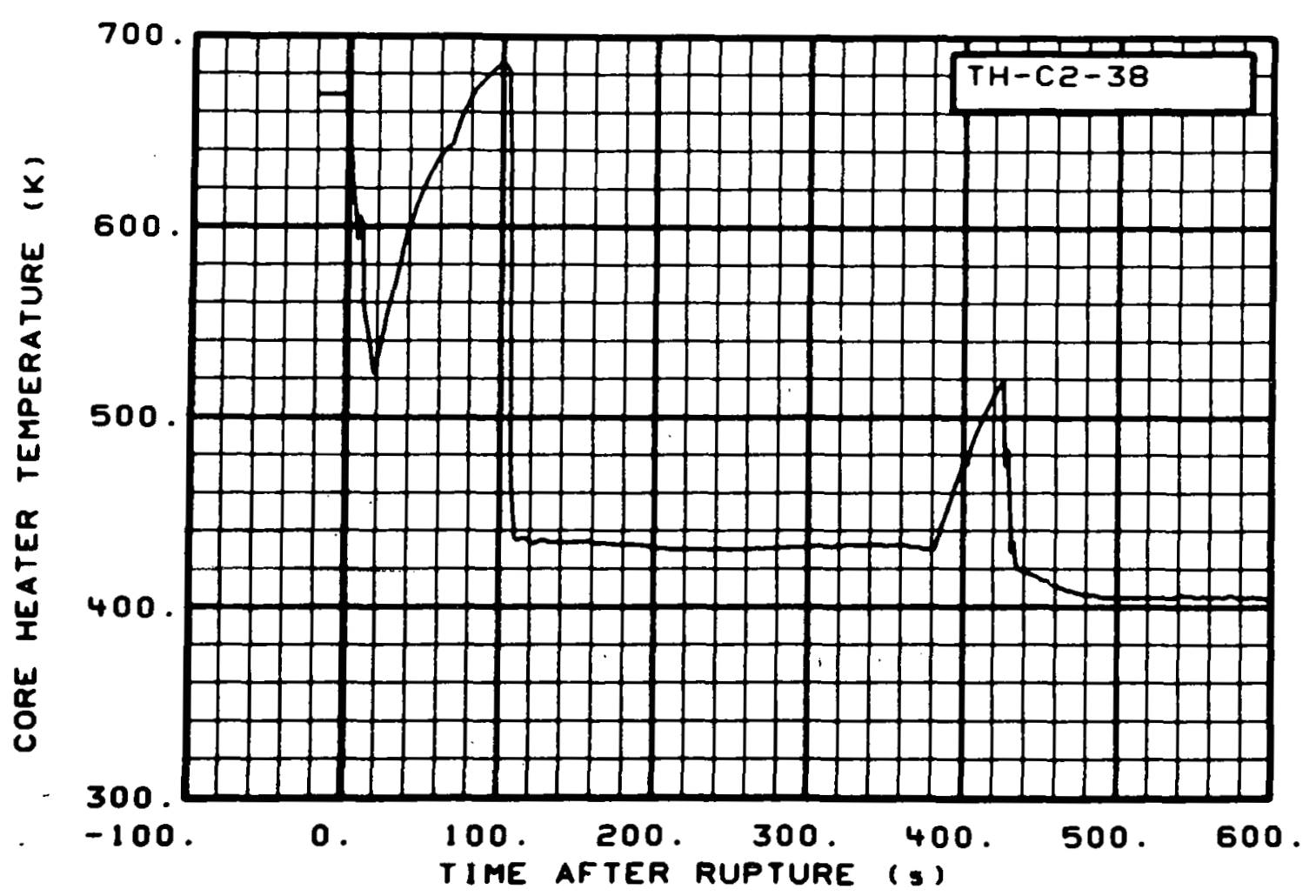

Fi'g. 95 Core heater temperature, Rod C-2 (TH-C2-38), from -20 to $600 \mathrm{~s}$.

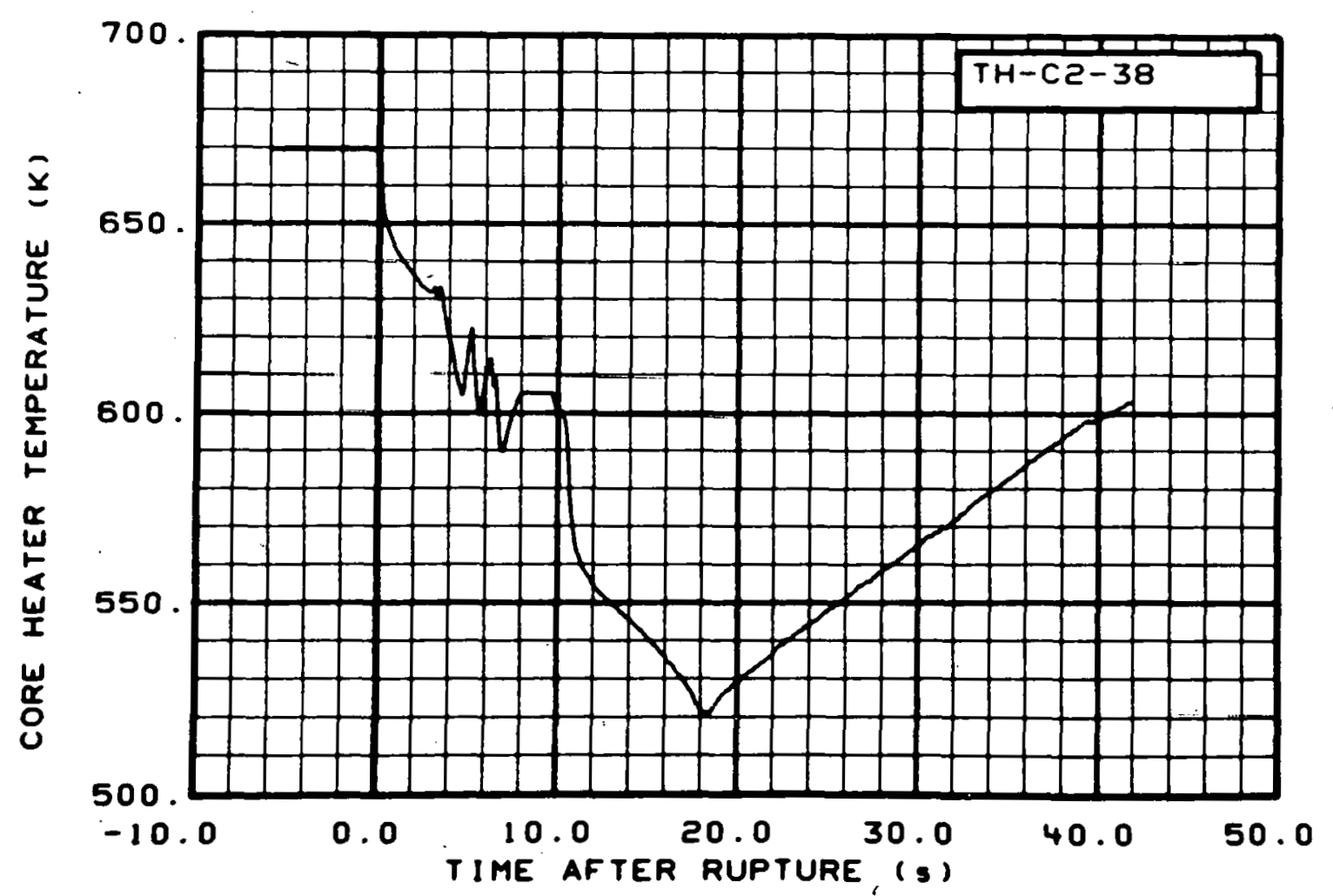

Fig. 96 Core heater temperature, Rod C-2 (TH-C2-38), from -6 to $42 \mathrm{~s}$. 


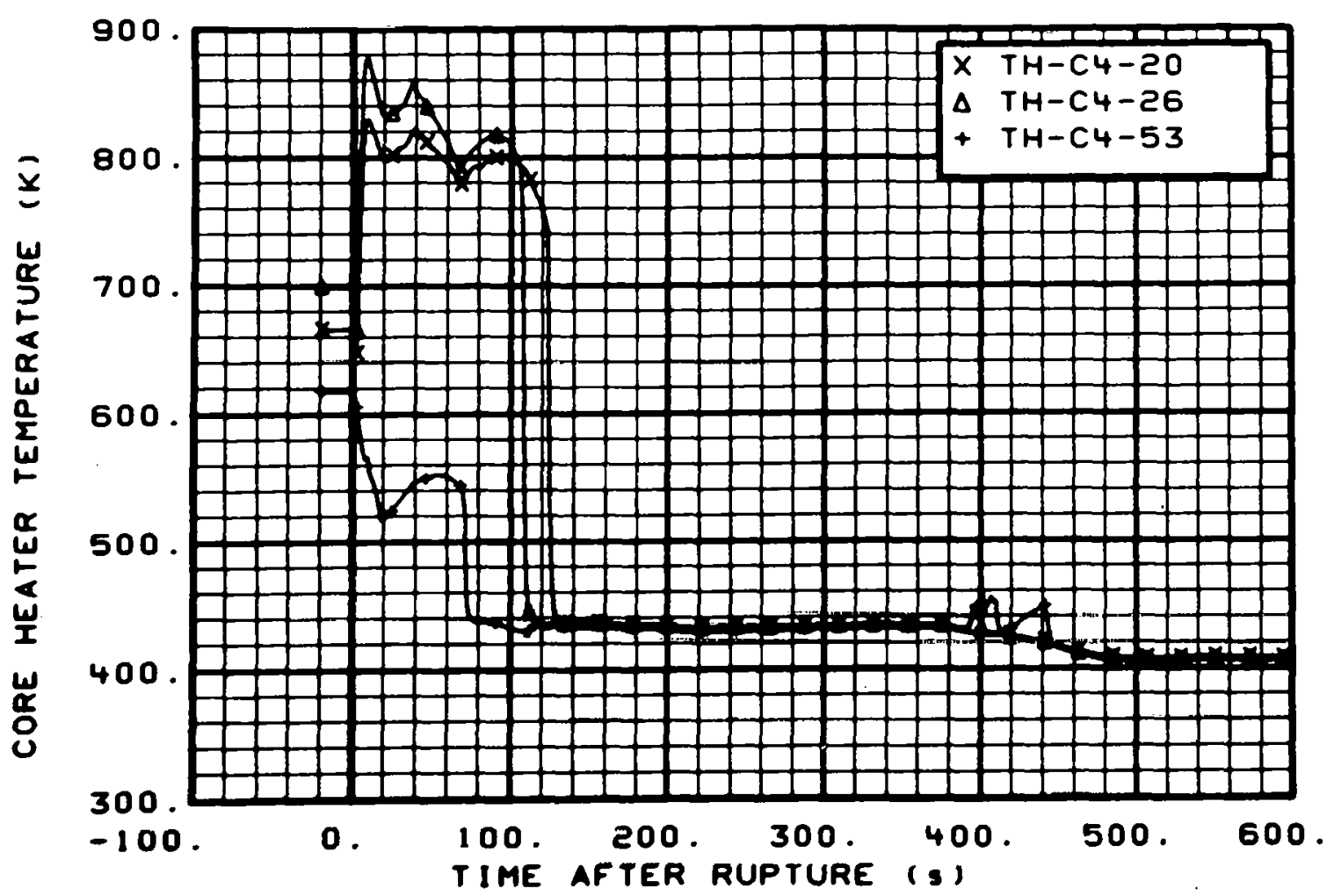

Fig. 97 Core heater temperature, Rod $\mathrm{C}-4$ (TH-C4-20, TH-C4-26, and $\mathrm{TH}-\mathrm{C} 4-53$ ), from -20 to $600 \mathrm{~s}$.

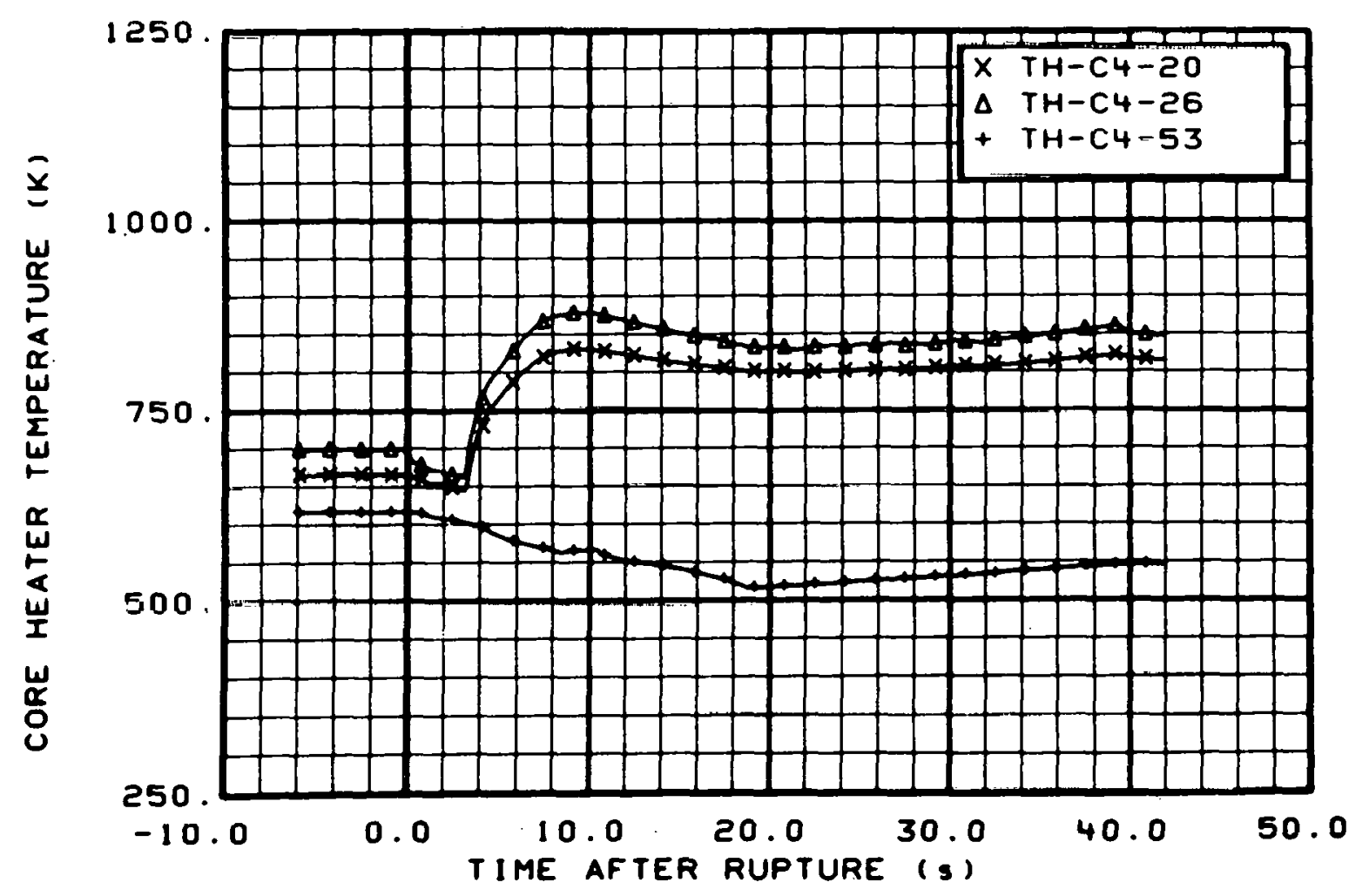

Fig. 98 Core heater temperature, Rod $\mathrm{C}-4$ (TH-C4-20, TH-C4-26, and $\mathrm{TH}-\mathrm{C} 4-53$ ), from -6 to $42 \mathrm{~s}$. 


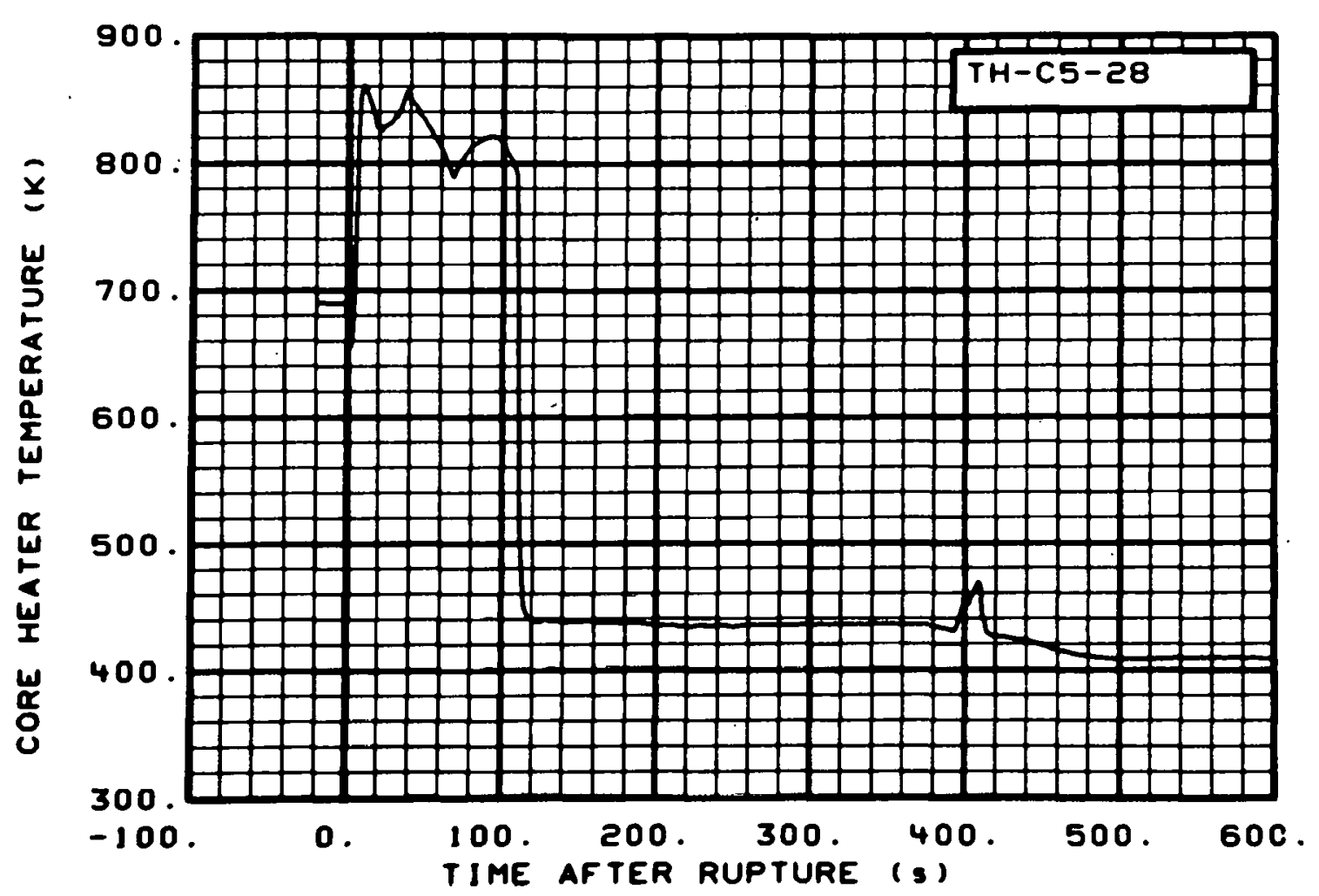

Fig. 99 Core heater temperature, Rod C-5 (TH-C5-28), from -20 to $600 \mathrm{~s}$.

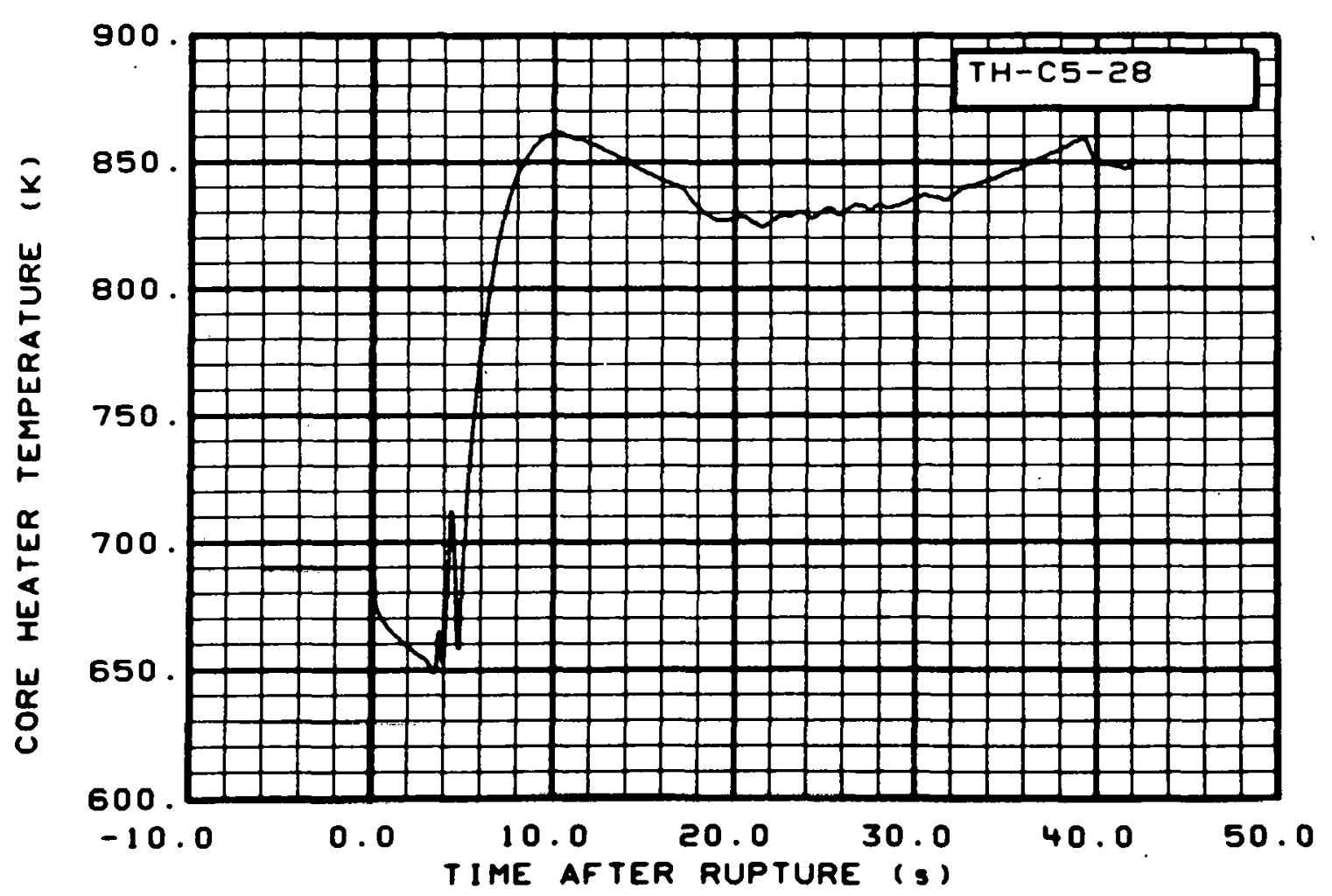

Fig. 100 Core heater temperature, Rod $\mathrm{C}-5$ (TH-C5-28), from -6 to $42 \mathrm{~s}$. 


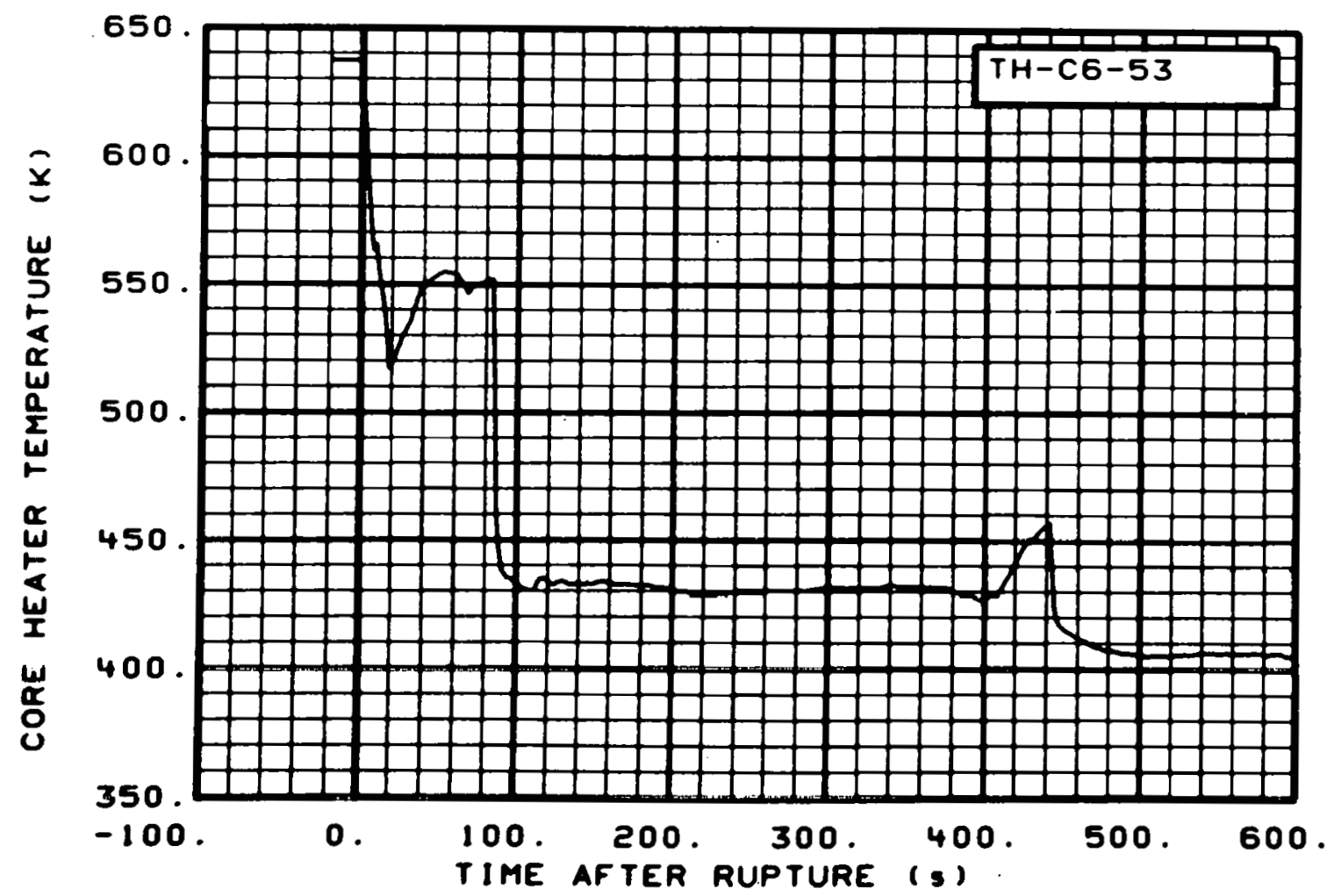

Fig. 101 Core heater temperature, Rod C-6 (TH-C6-53), from -20 to $600 \mathrm{~s}$.

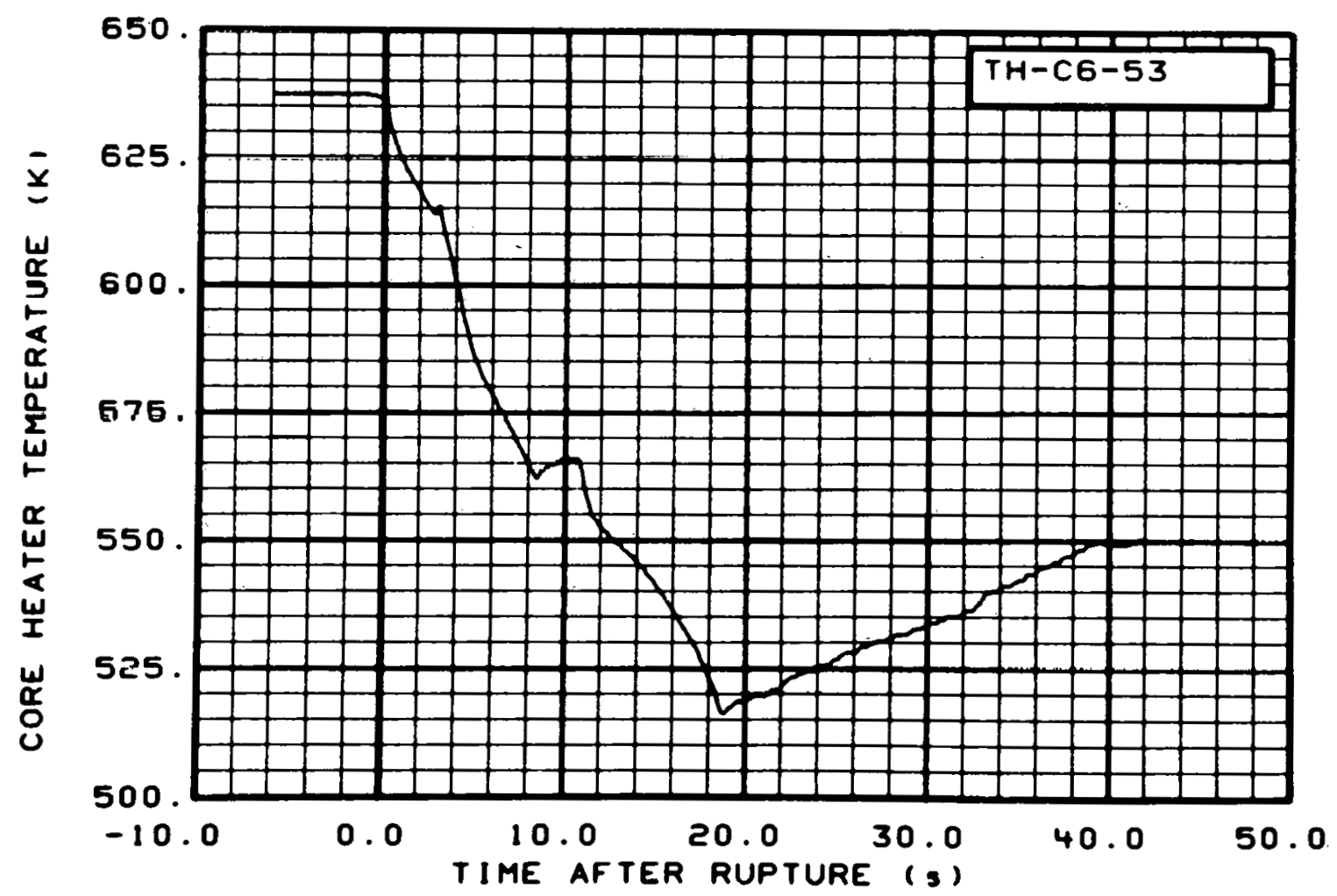

Fig. 102 Core heater temperature, Rod C-6 (TH-C6-53), from -6 to $42 \mathrm{~s}$. 


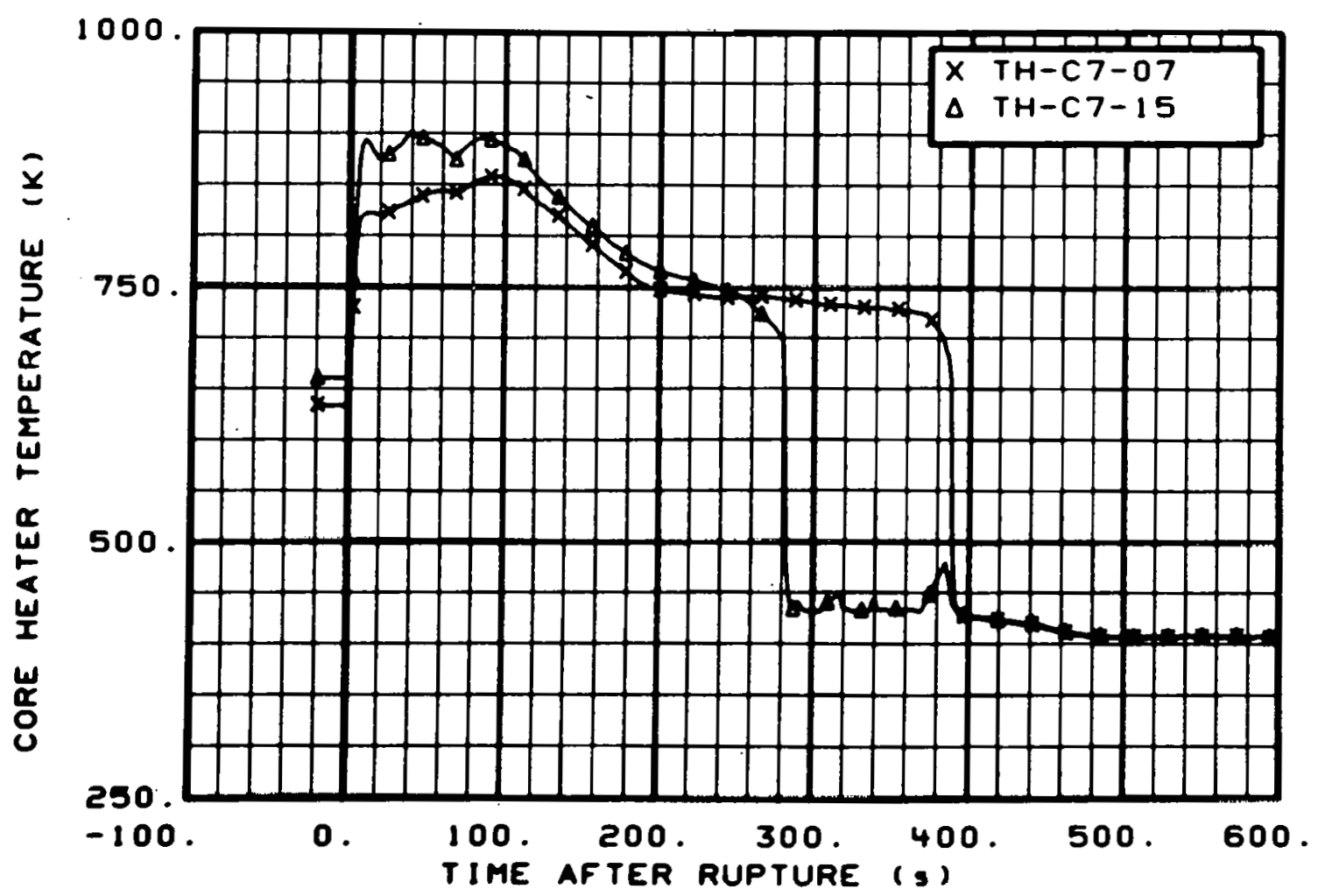

Fig. 103 Core heater temperature, Rod $\mathrm{C}-7$ (TH-C7-07 and $\mathrm{TH}-\mathrm{C} 7-15)$, from -20 to $600 \mathrm{~s}$.

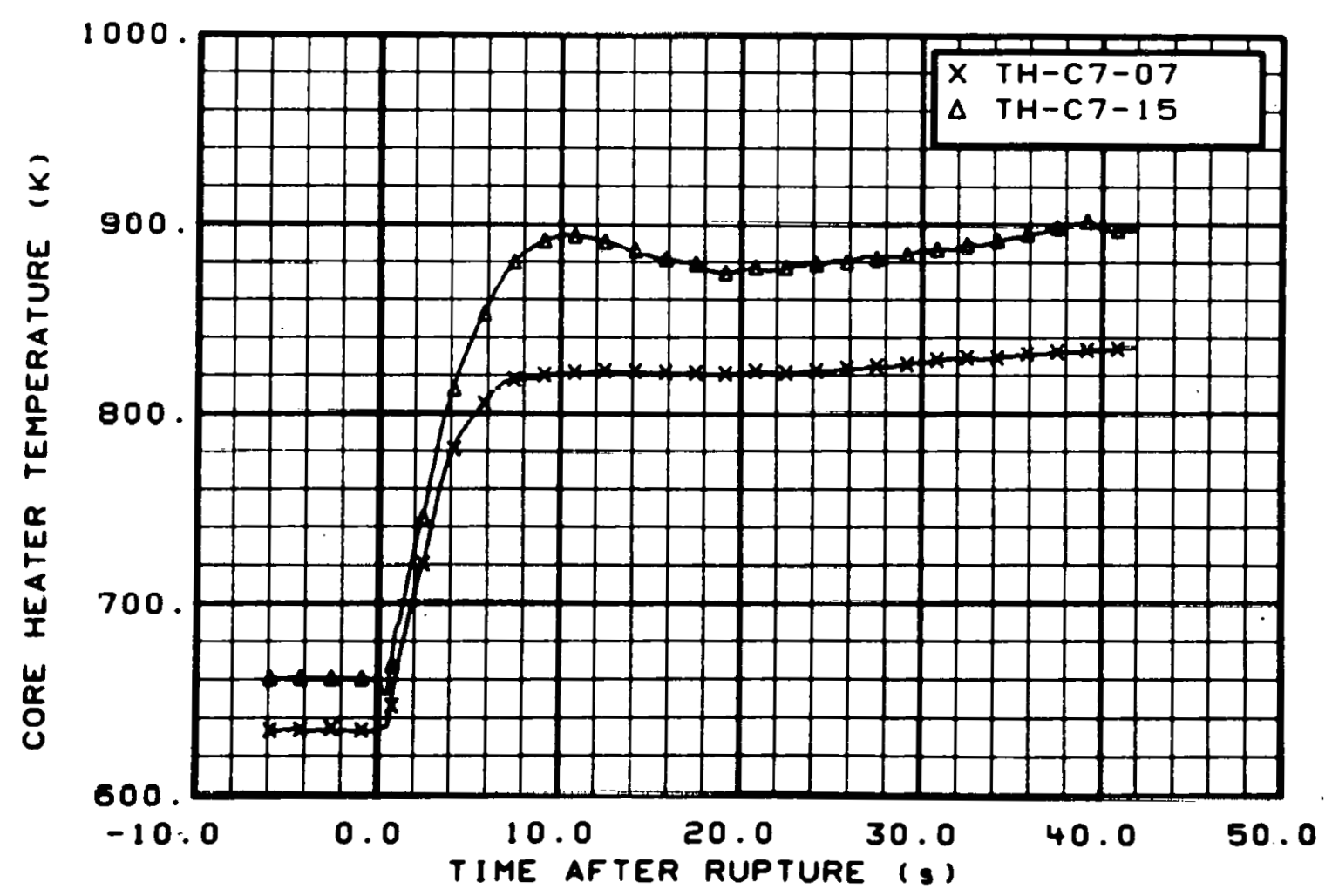

Fig. 104 Core heater temperature, Rod C-7 (TH-C7-07 and TH-C7-15), from -6 to 425 . 


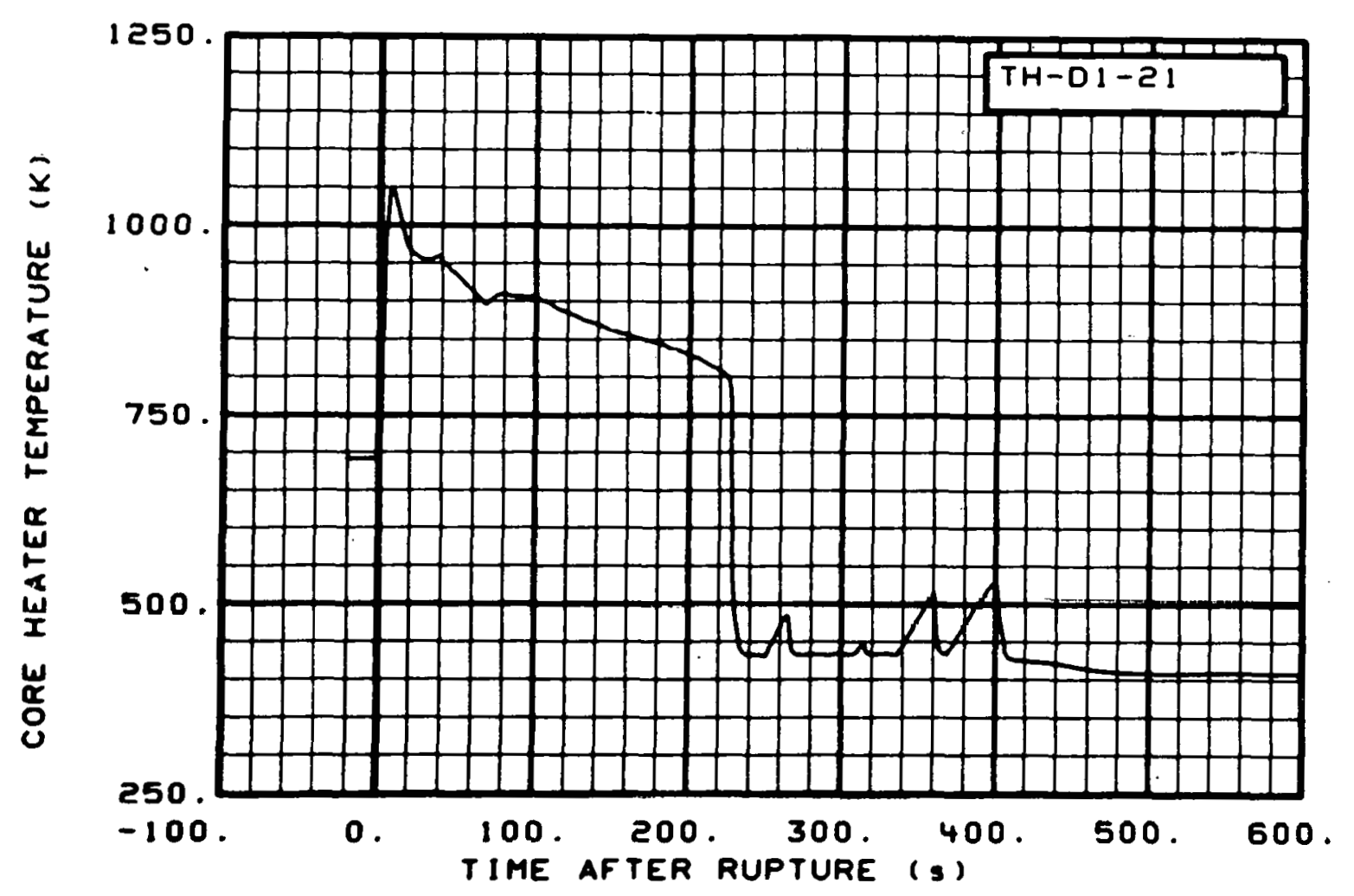

Fig. 105 Core heater temperature, Rod D-1 (TH-D1-21), from -20 to $600 \mathrm{~s}$.

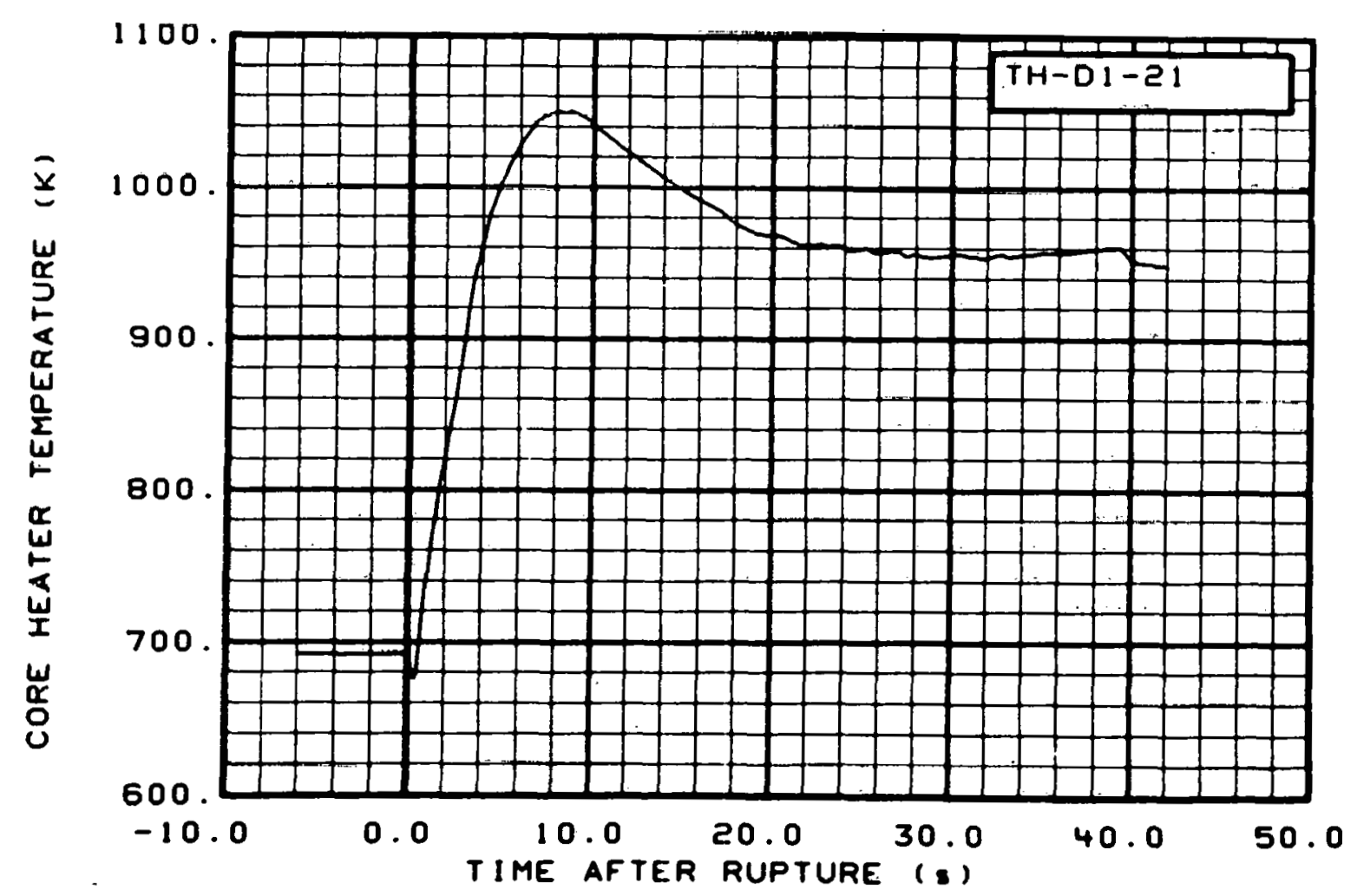

Fig. 106 Core heater temperature, Rod D-1 (TH-DI-21), from -6 to $42 \mathrm{~s}$. 


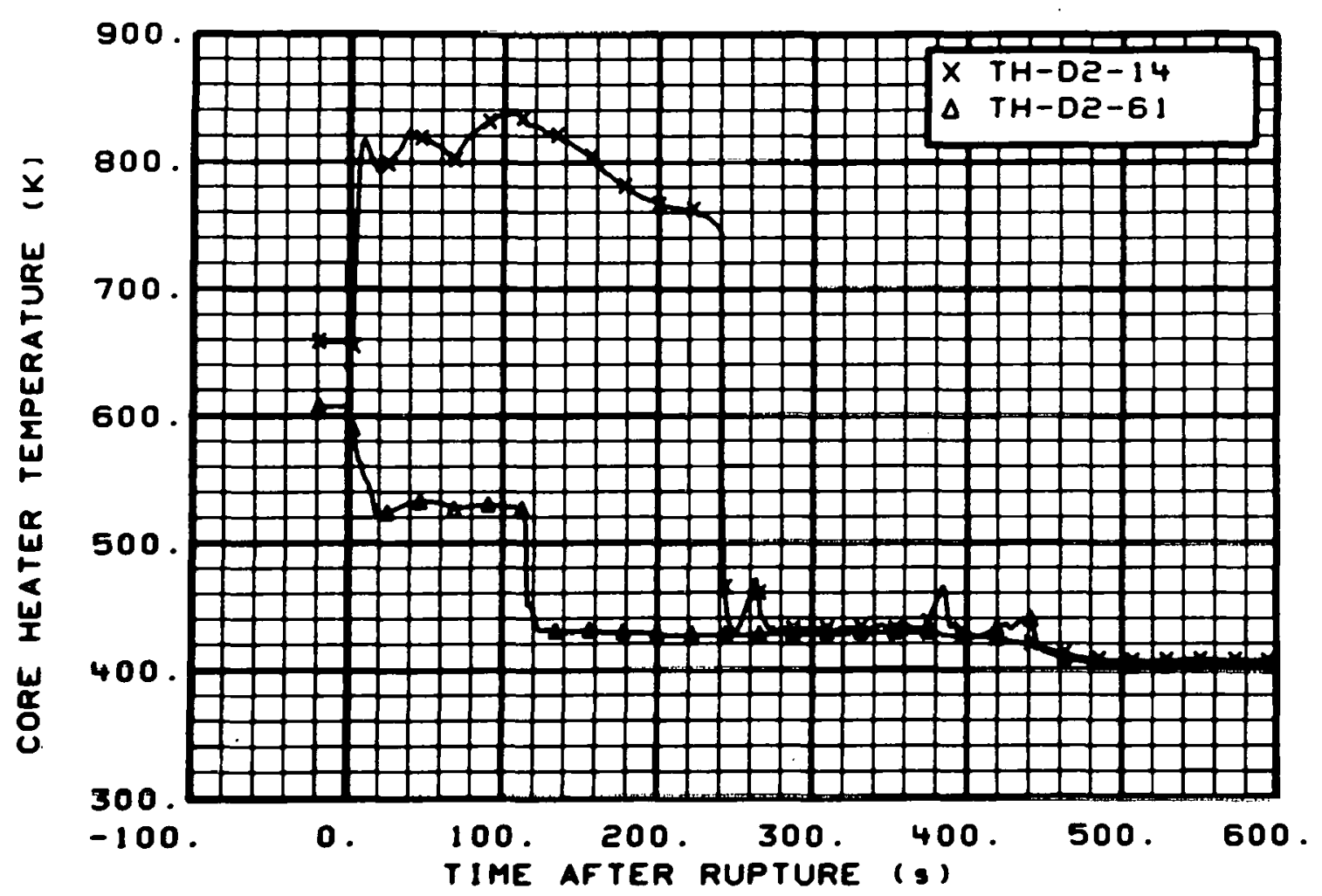

Fig. 107 Core heater temperature, Rod D-2 (TH-D2-14 and TH-D2-61), from -20 to $600 \mathrm{~s}$.

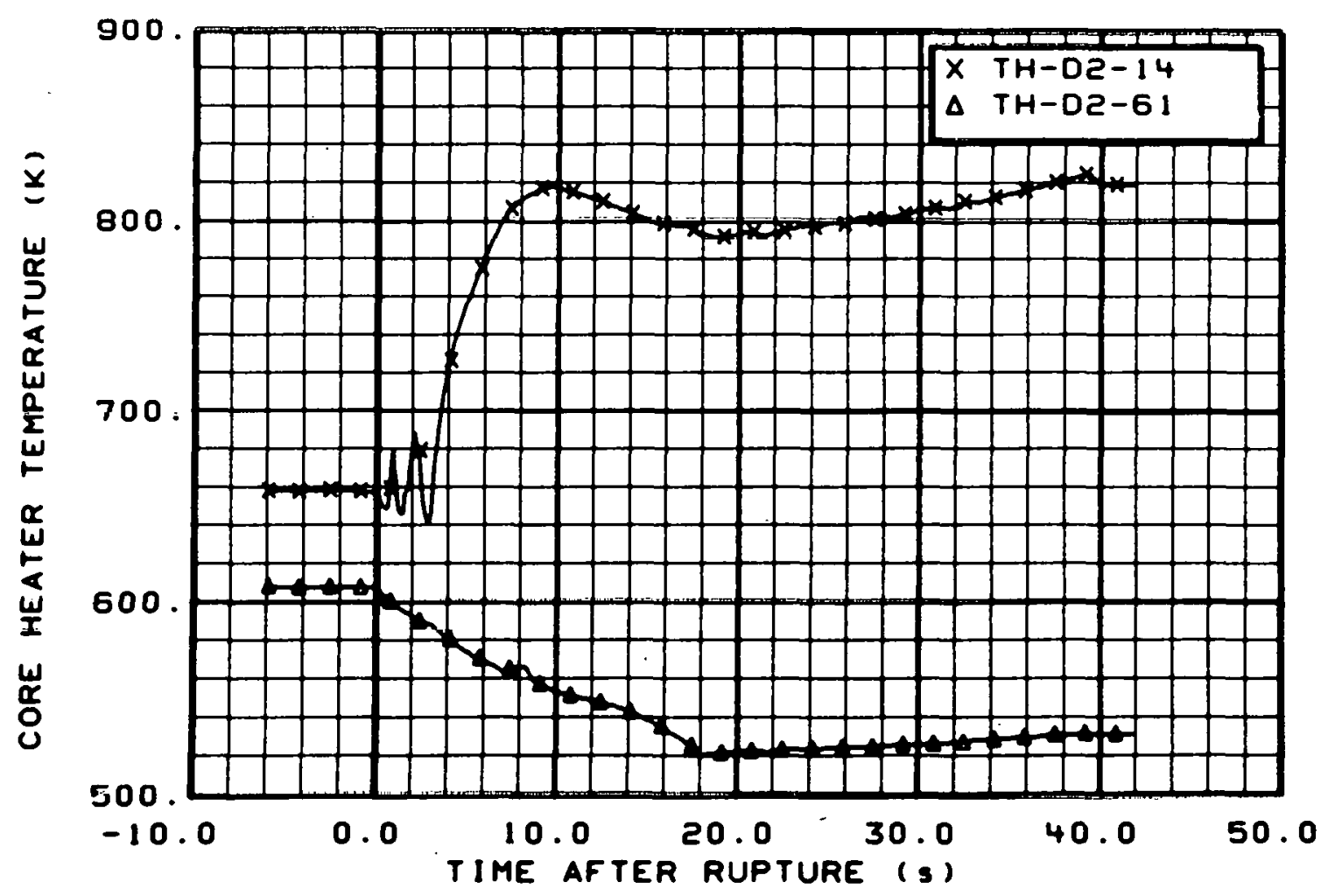

Fig. 108 Core heater temperature, Rod D-2 (TH-D2-14 and TH-D2-61), from -6 to $42 \mathrm{~s}$. 


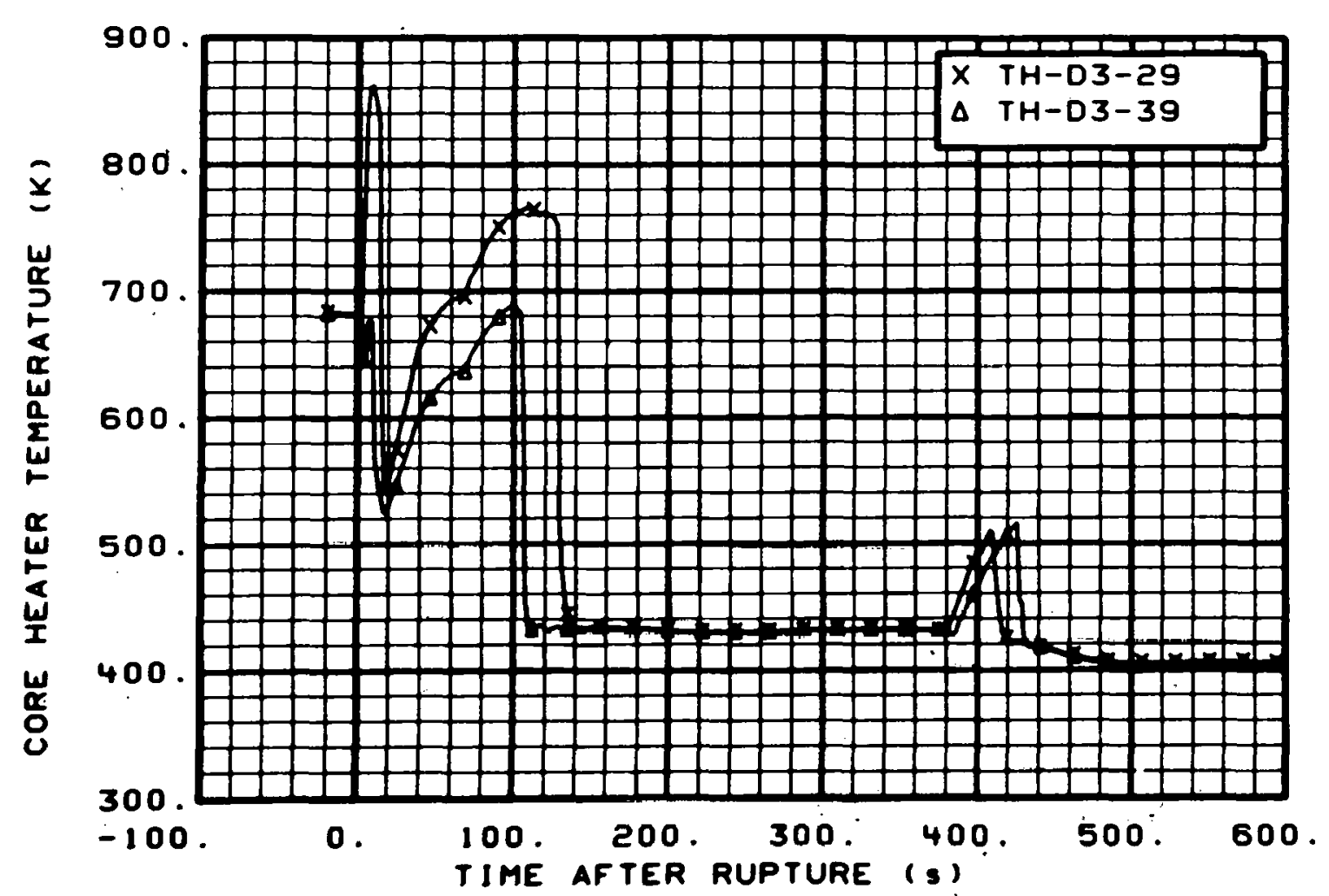

Fig. 109 Core heater temperature, Rod D-3 (TH-D3-29 and TH-D3-39), from -20 to $600 \mathrm{~s}$.

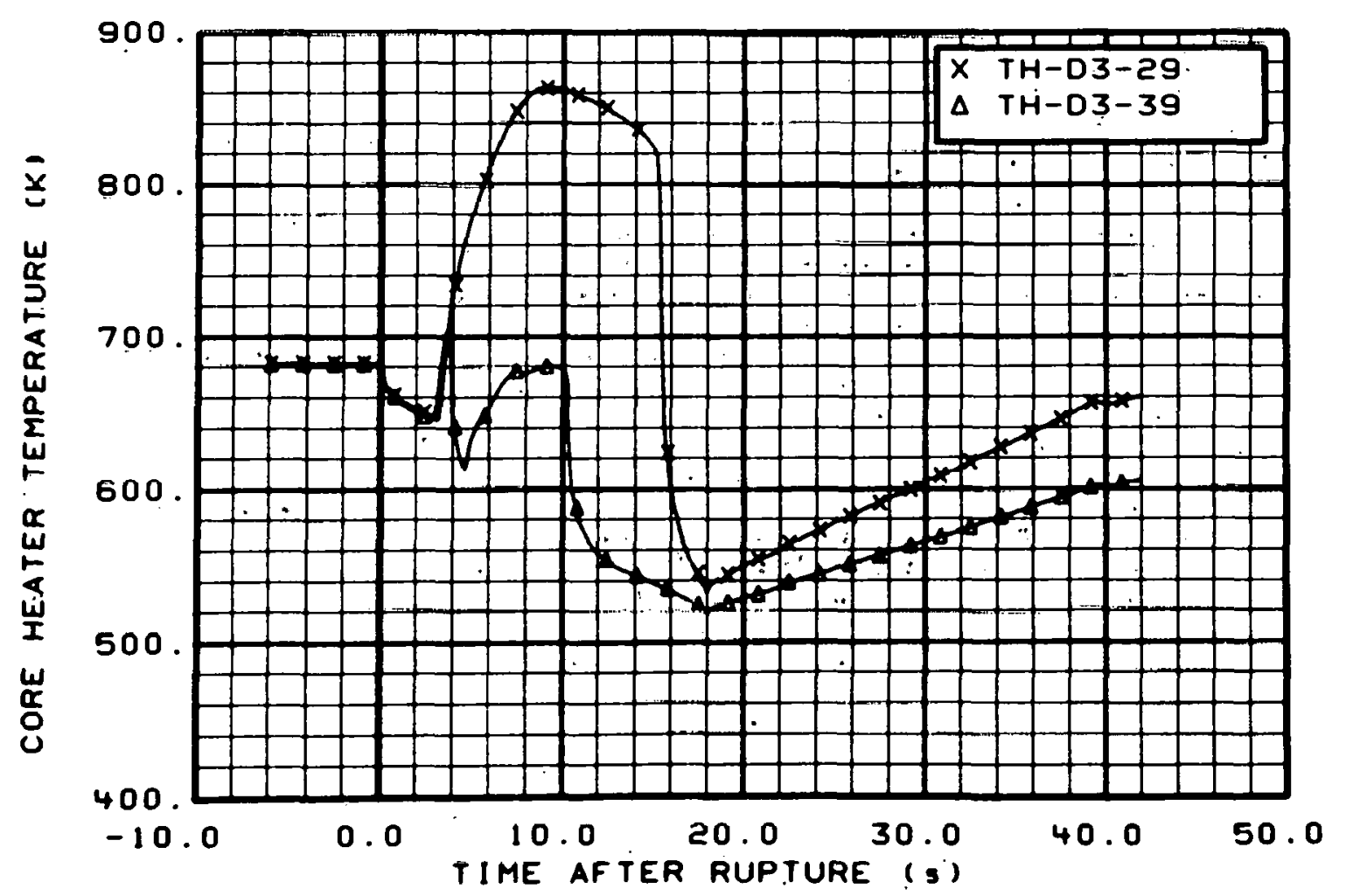

Fig. 110 Core heater temperature, Rod D-3 (TH-D3-29 and TH-D3-39), from -6 to 42 s. 


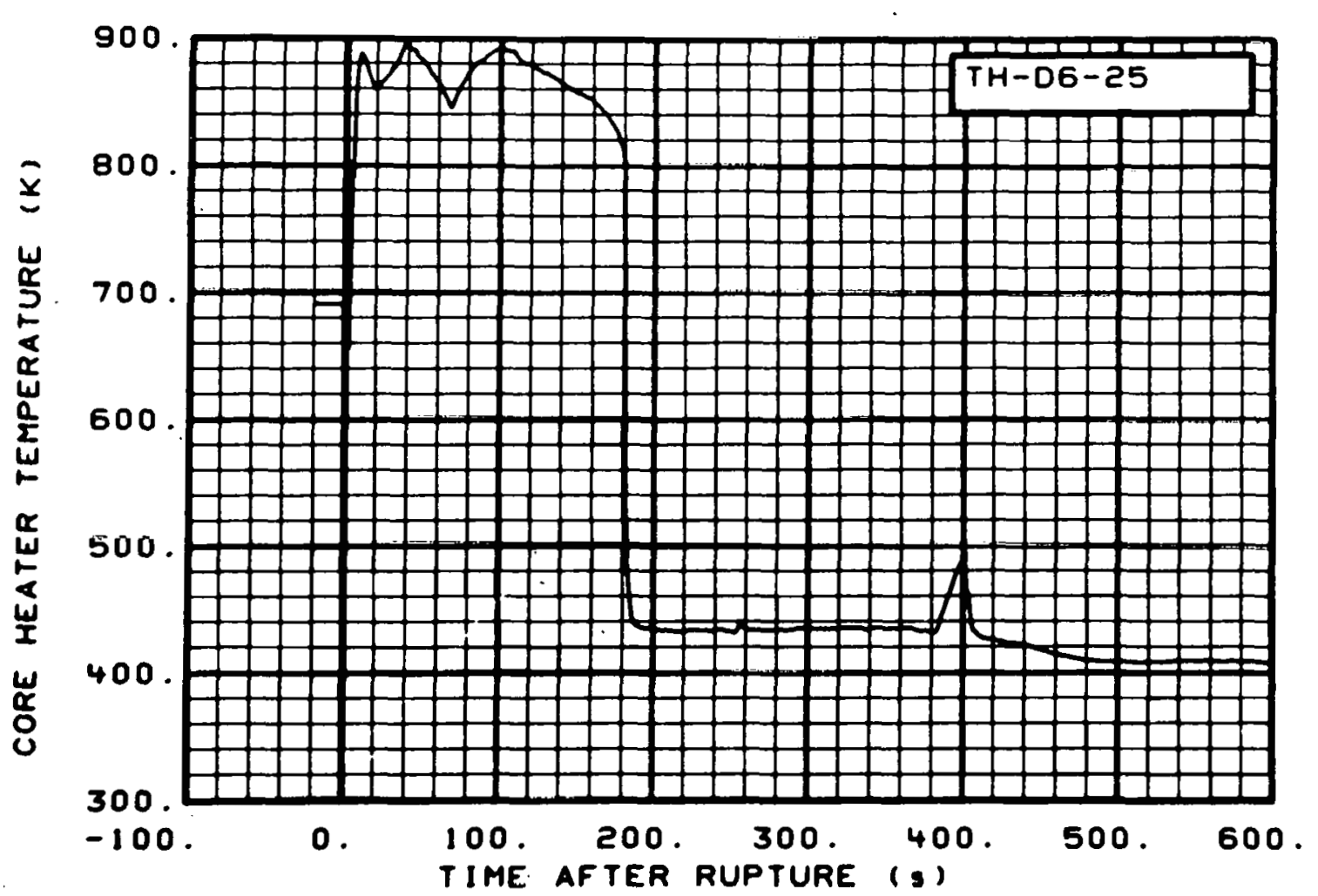

Fig. 111 Core heater temperature, Rod D-6 (TH-D6-25), from -20 to $600 \mathrm{~s}$.

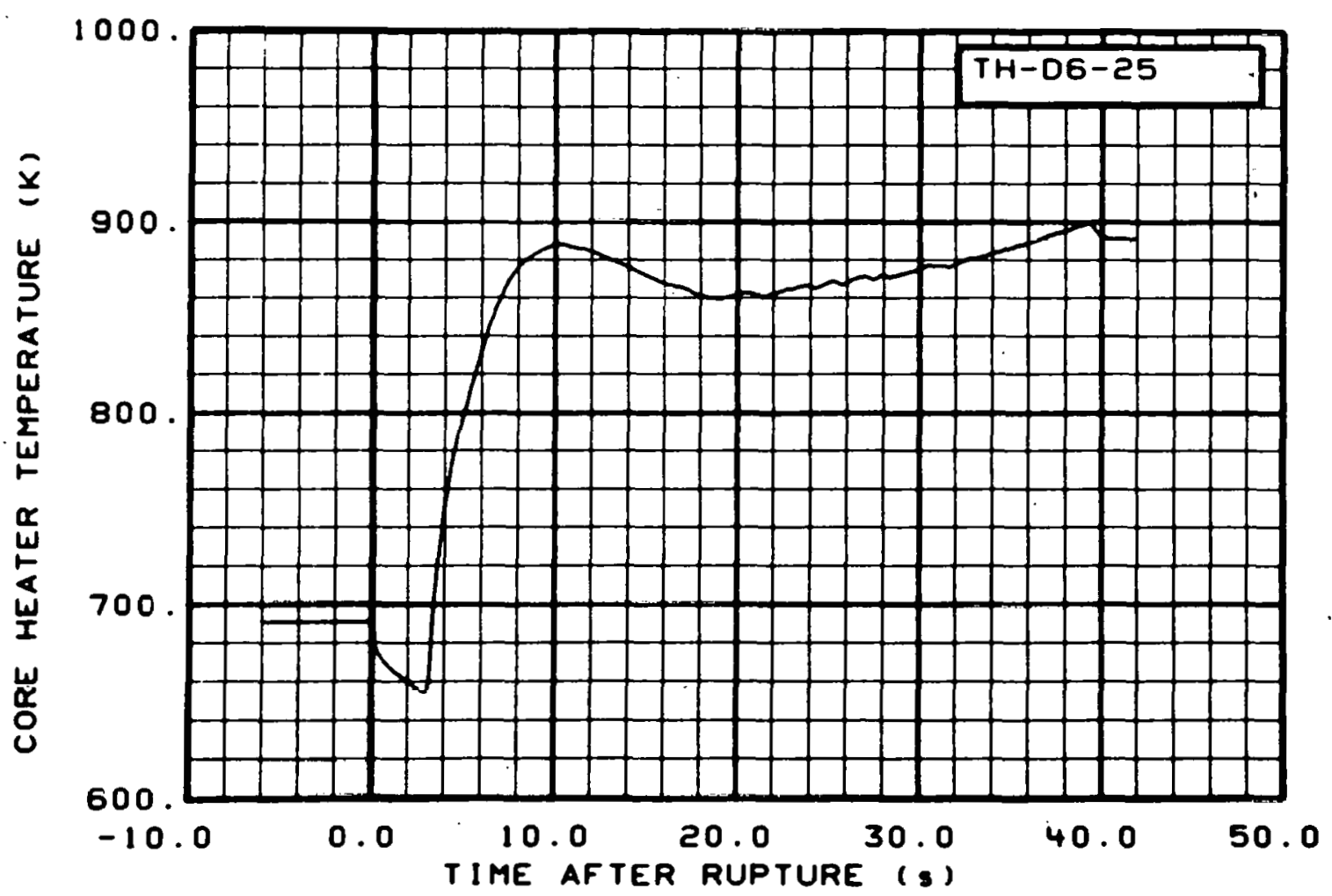

Fig. 112 Core heater temperature, $\operatorname{Rod}$ D-6 (TH-D6-25), from -6 to $42 \mathrm{~s}$. 


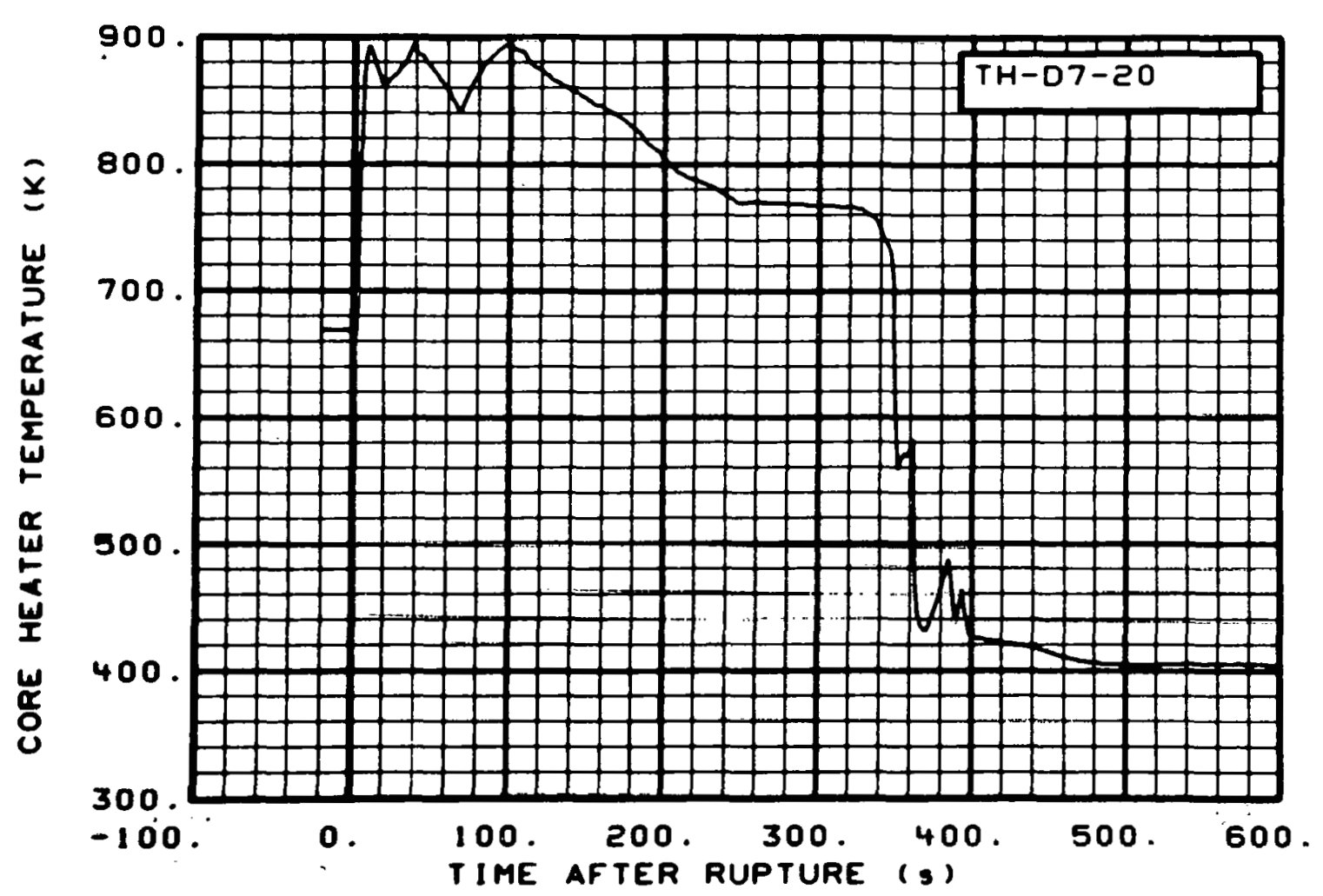

Fig. 113 Core heater temperature, Rod D-7 (TH-D\%-20), from -20 to $600 \mathrm{~s}$.

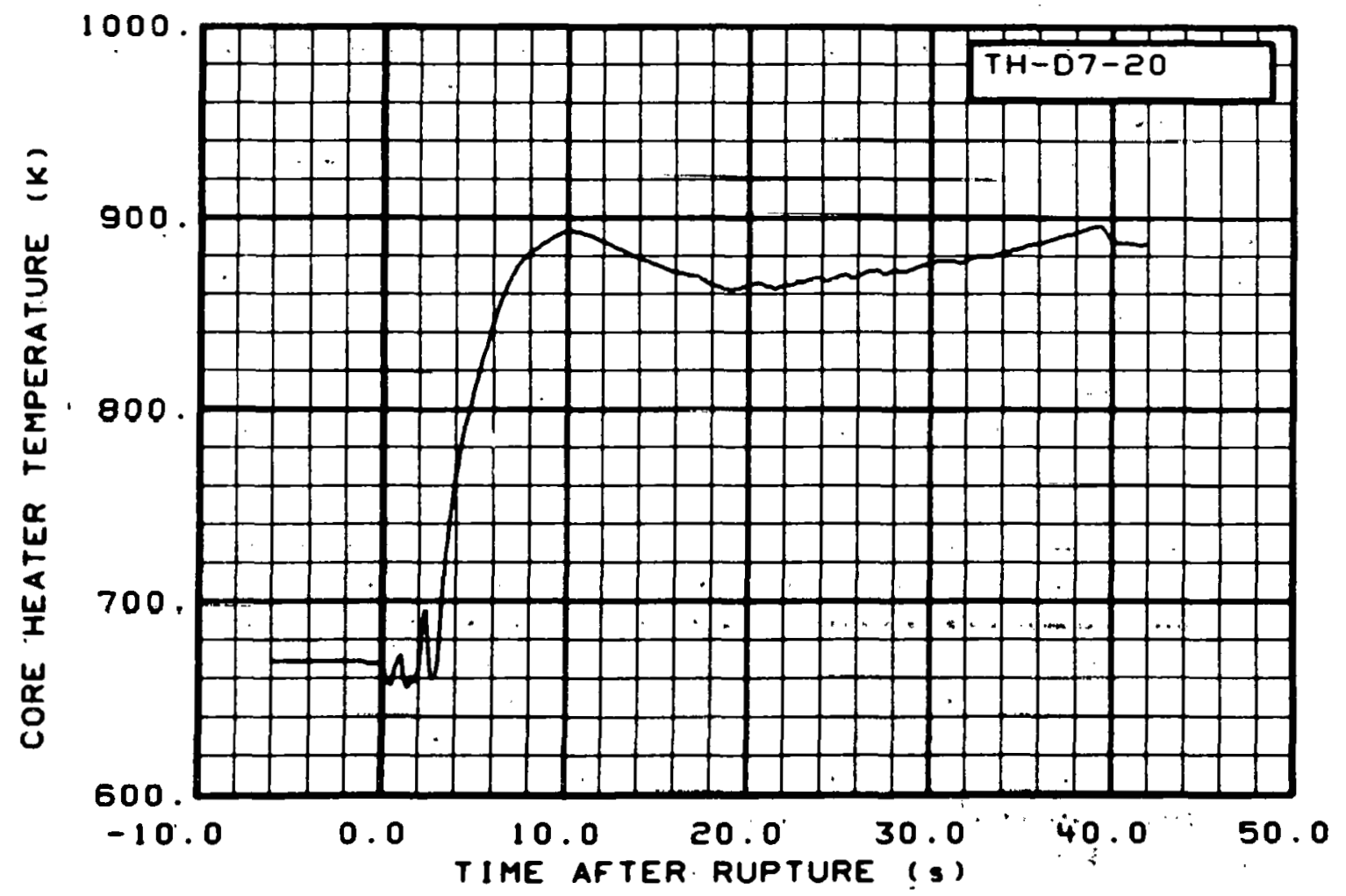

Fig. 114 Core heater temperature, Rod D-7 (TH-D7-20), from -6 to $42 \mathrm{~s}$. 


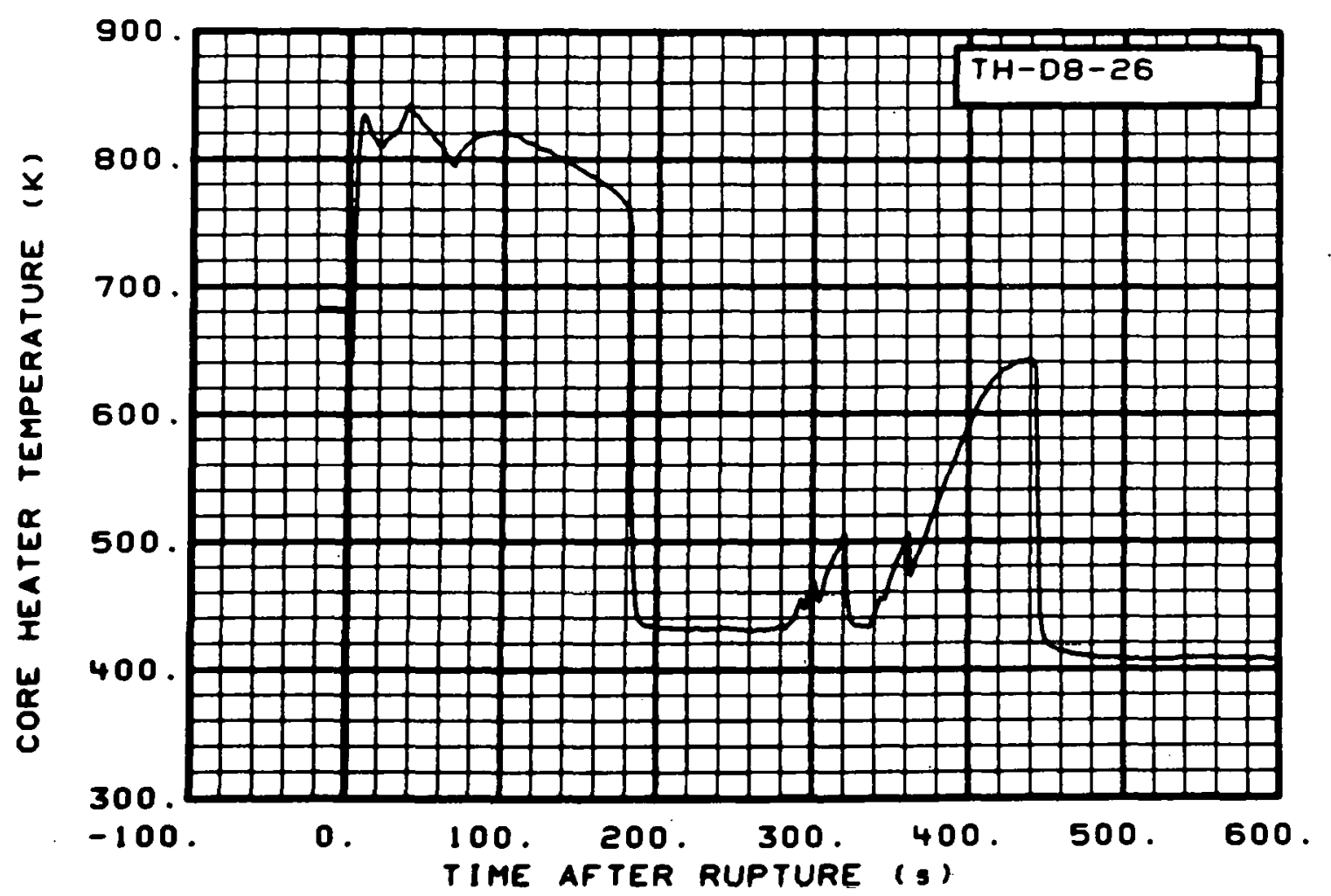

Fig. 115 Core heater temperature, Rod D-8 (TH-08-26), from -20 to $600 \mathrm{~s}$.

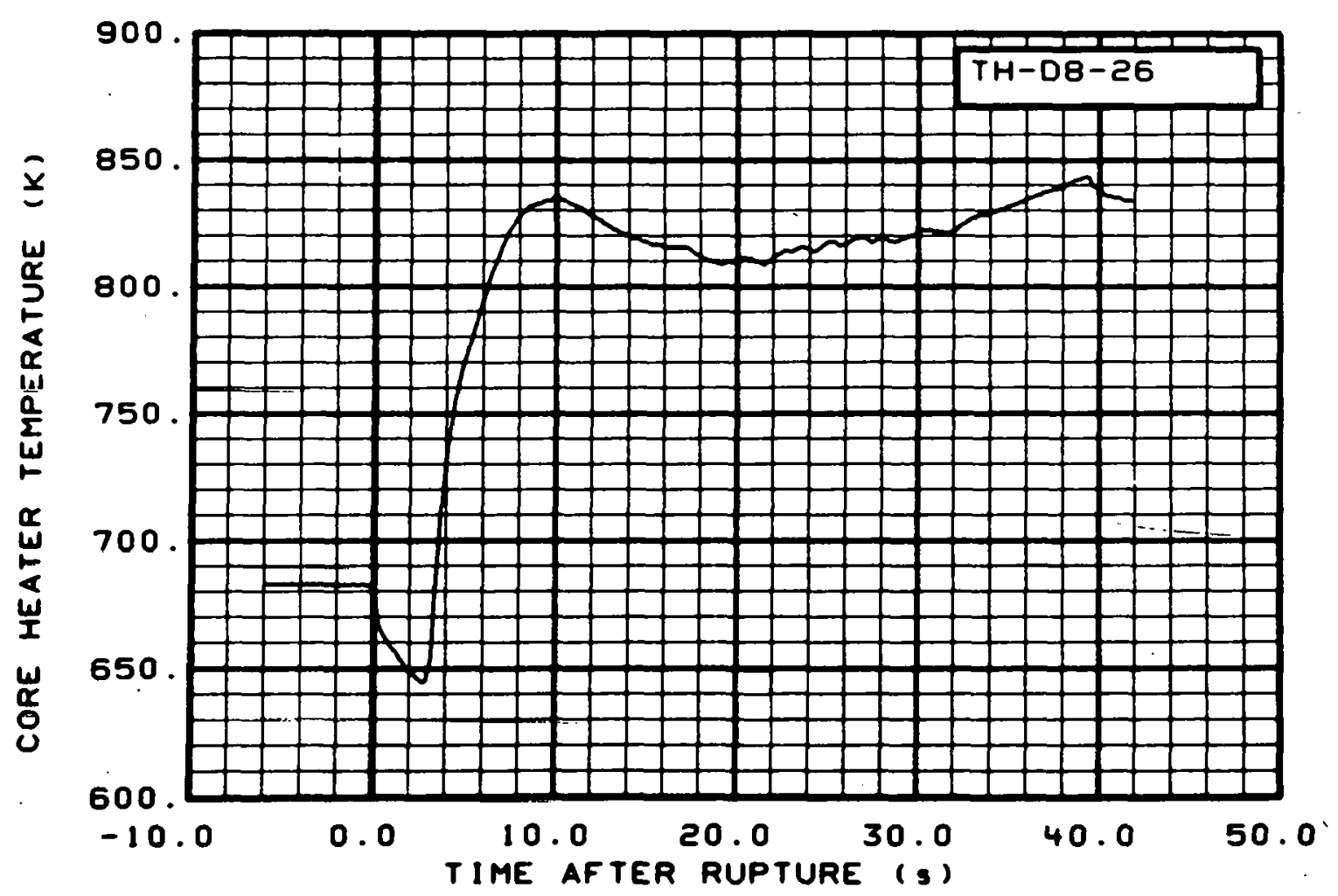

Fig. 116 Core heater temperature, Rod D-8 (TH-D8-26), from -6 to $42 \mathrm{~s}$. 


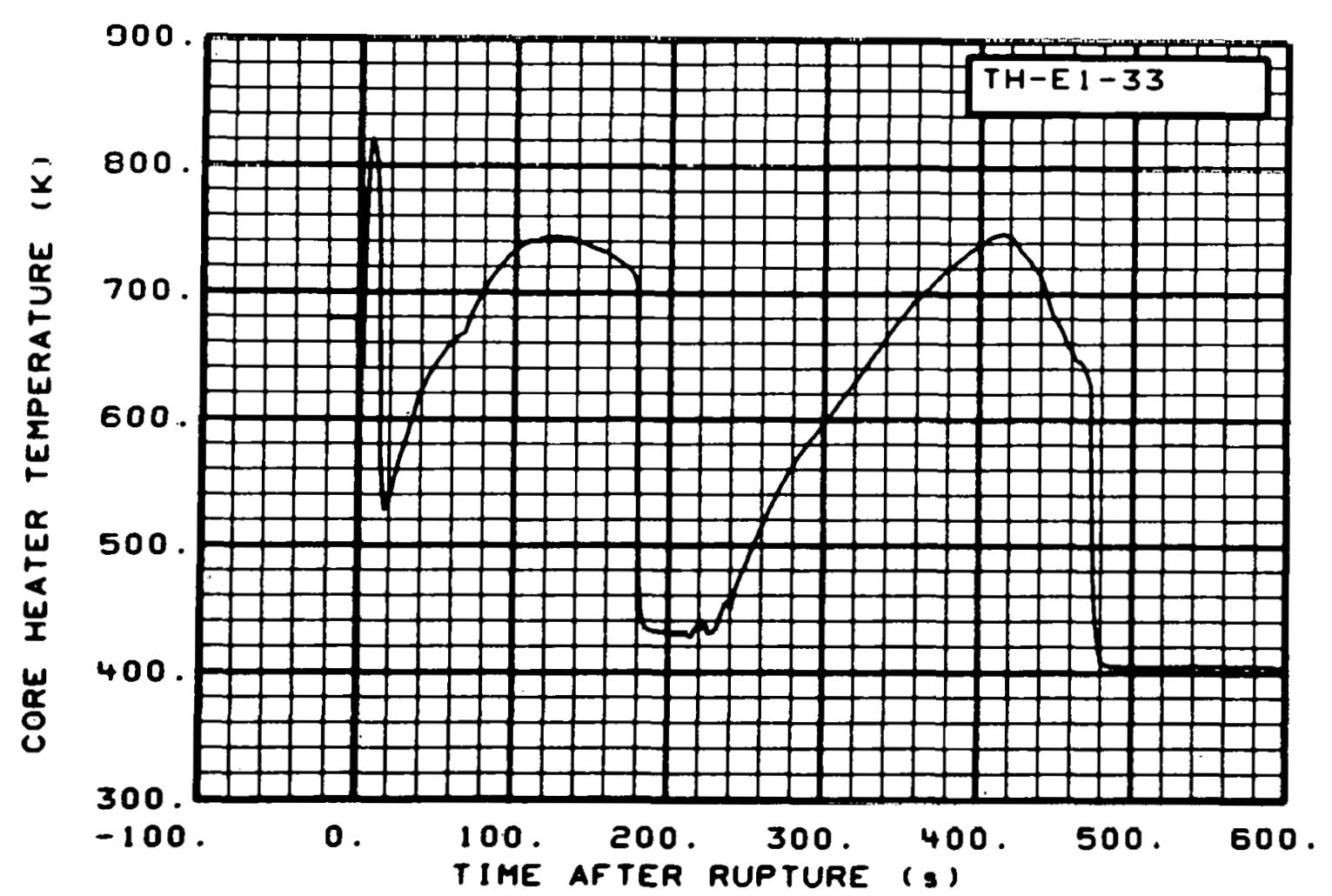

Fig. 117 Core heater temperature, Rod E-1 (TH-El-33), from -20 to $600 \mathrm{~s}$.

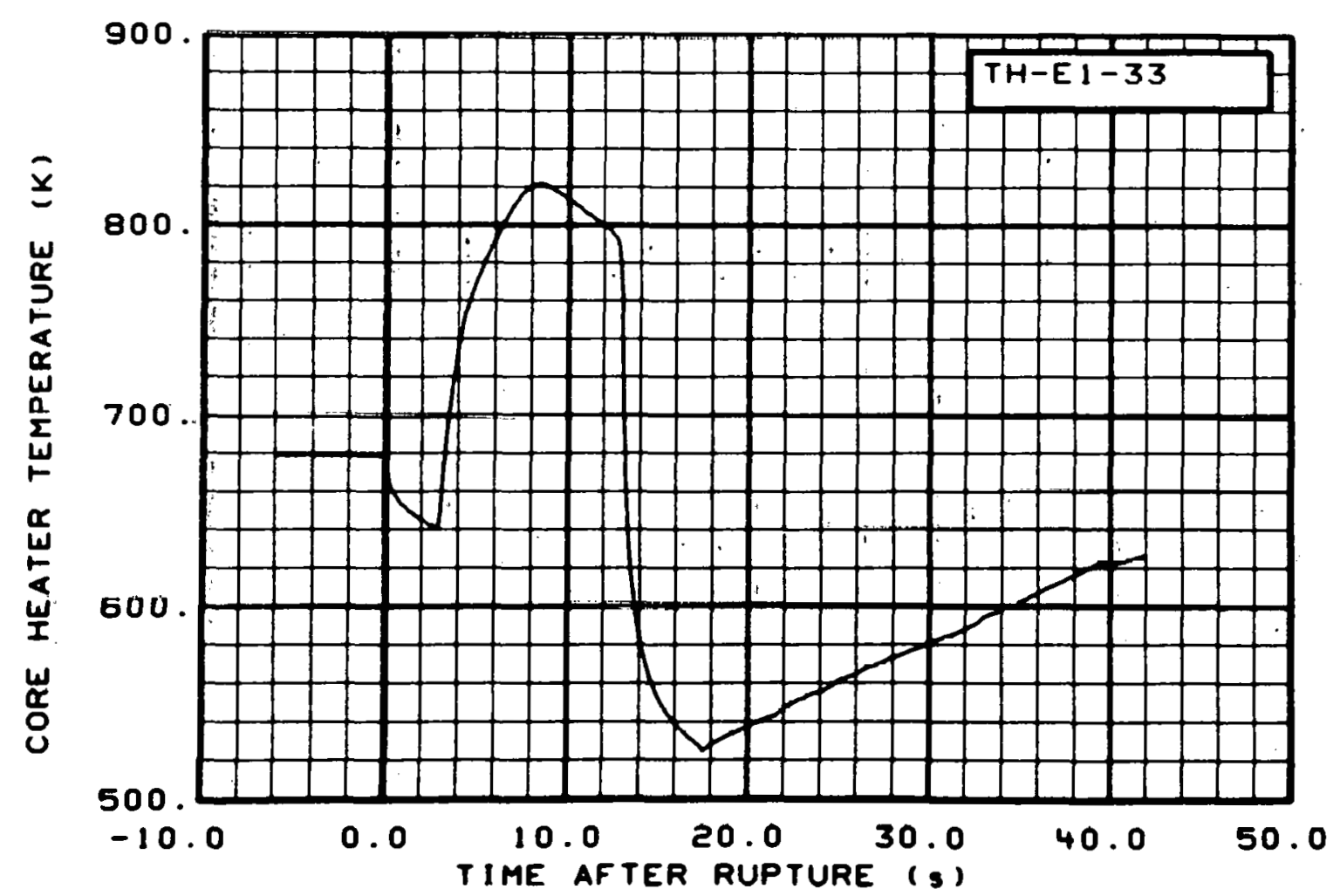

Fig. 118 Core heater temperature, Rod E-1 (TH-E1-33), from -6 to $42 \mathrm{~s}$. 


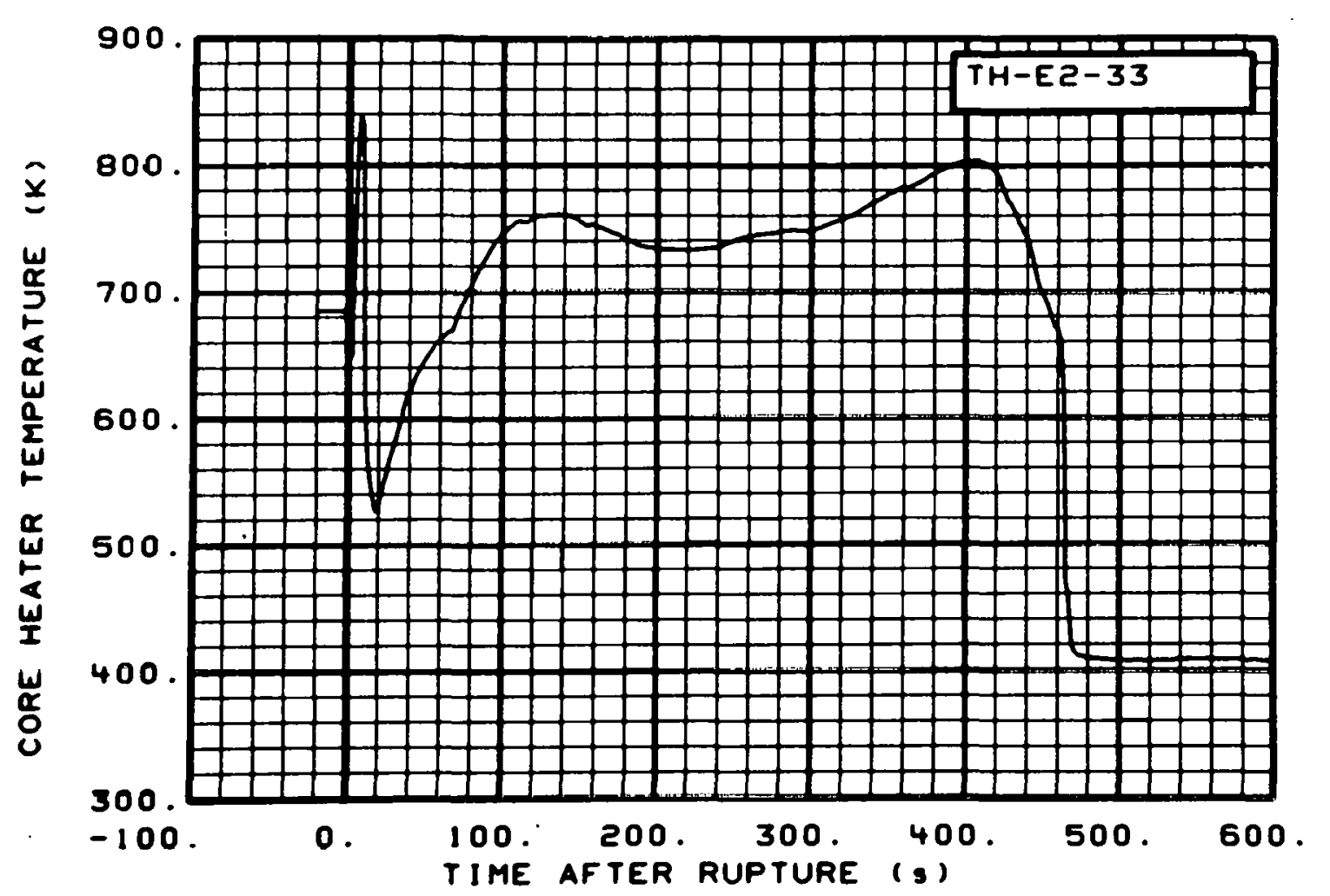

Fig. 119 Core heater temperature, Rod E-2 (TH-E2-33), from -20 to $600 \mathrm{~s}$.

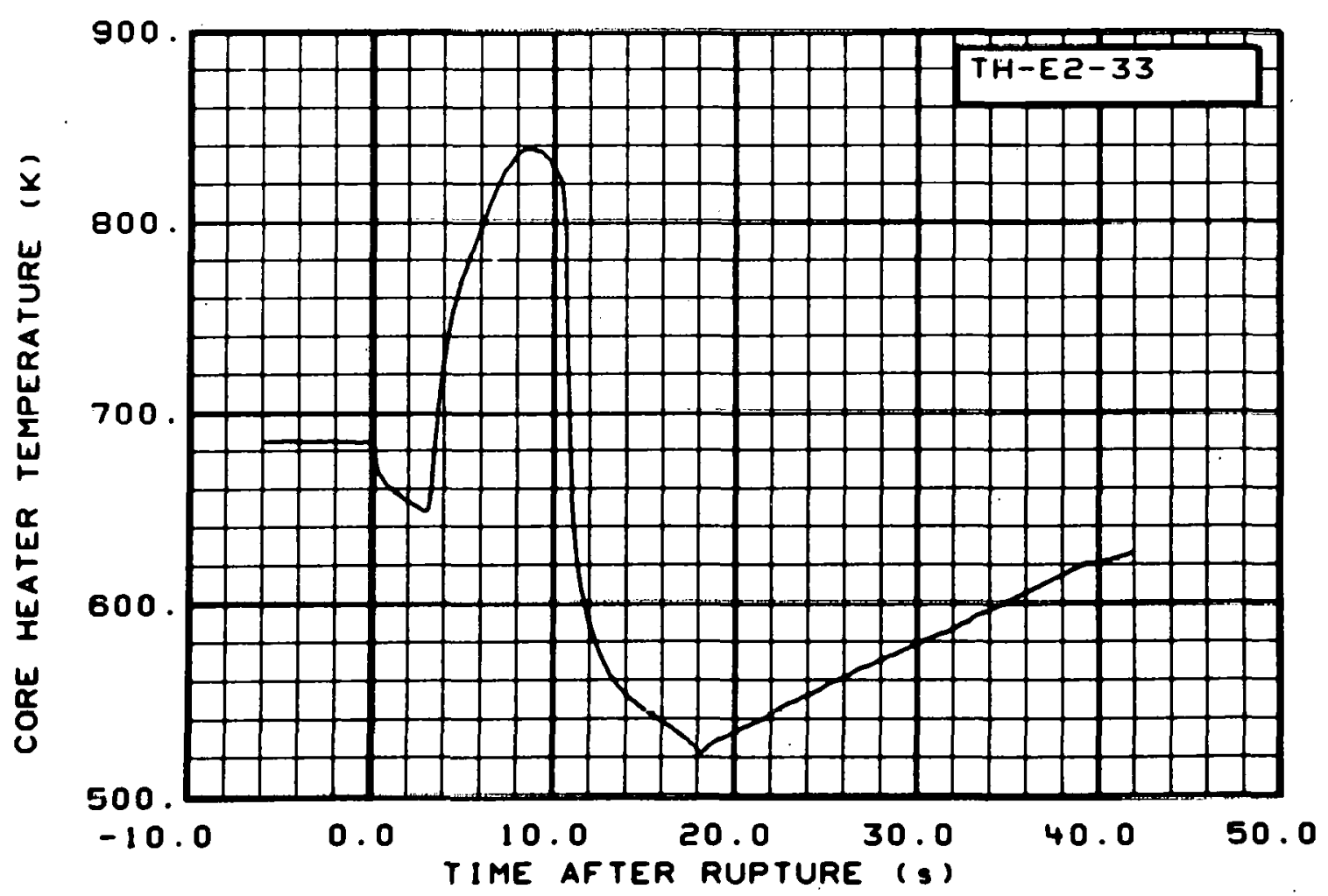

Fig. 120 Core heater temperat.ıre, Rod F-2 (TH-F2-3.3), from -6 to $42 \mathrm{~s}$. 


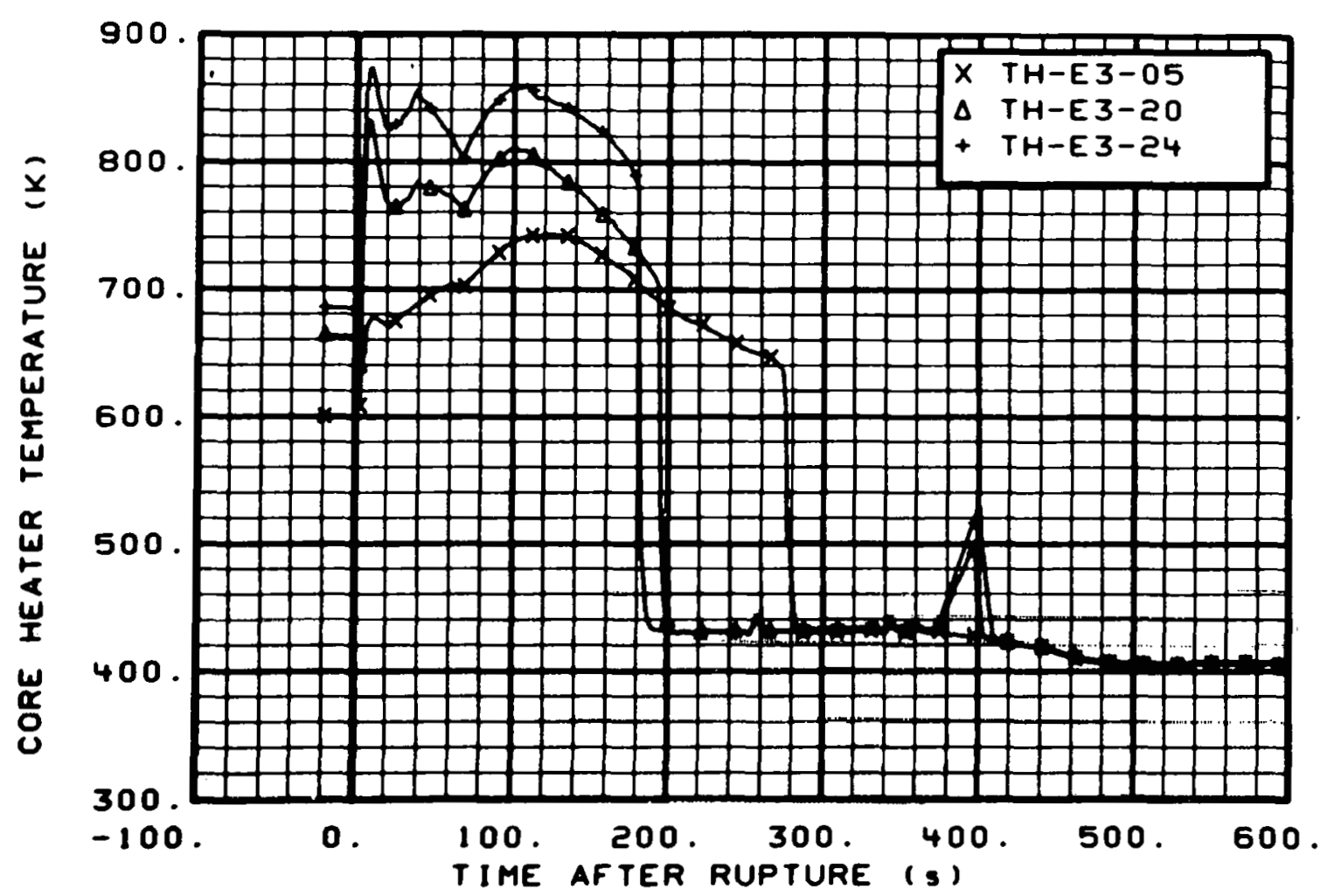

Fig. 121 Core heater temperature, Rod E-3 (TH-E3-05, TH-E3-20, and TH-E3-24), from -20 to $600 \mathrm{~s}$.

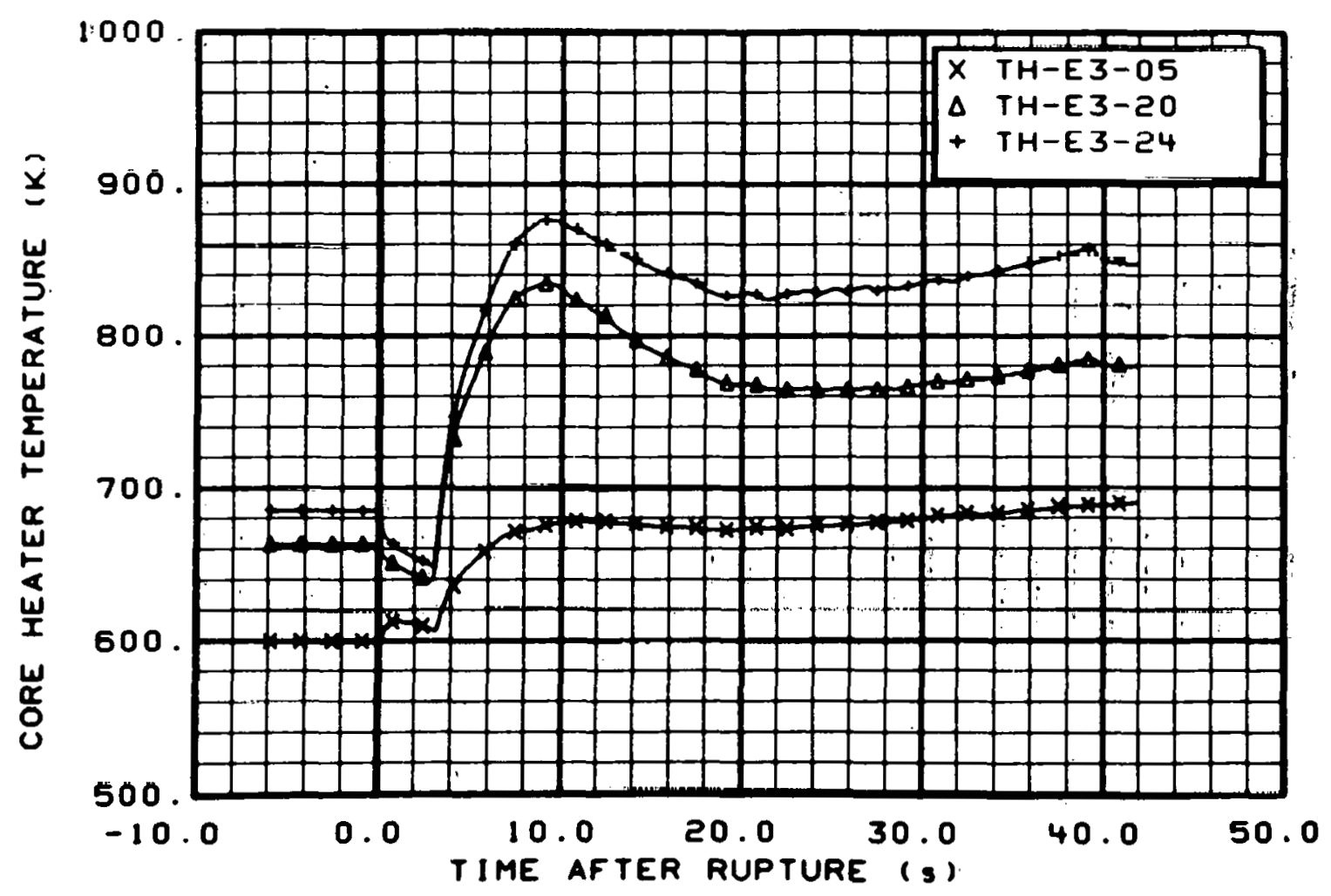

Fig. 122 Core heater temperature, Rod E-3 (TH-E3-05, TH-E3-20, and TH-E3-24), from -6 to $42 \mathrm{~s}$. 


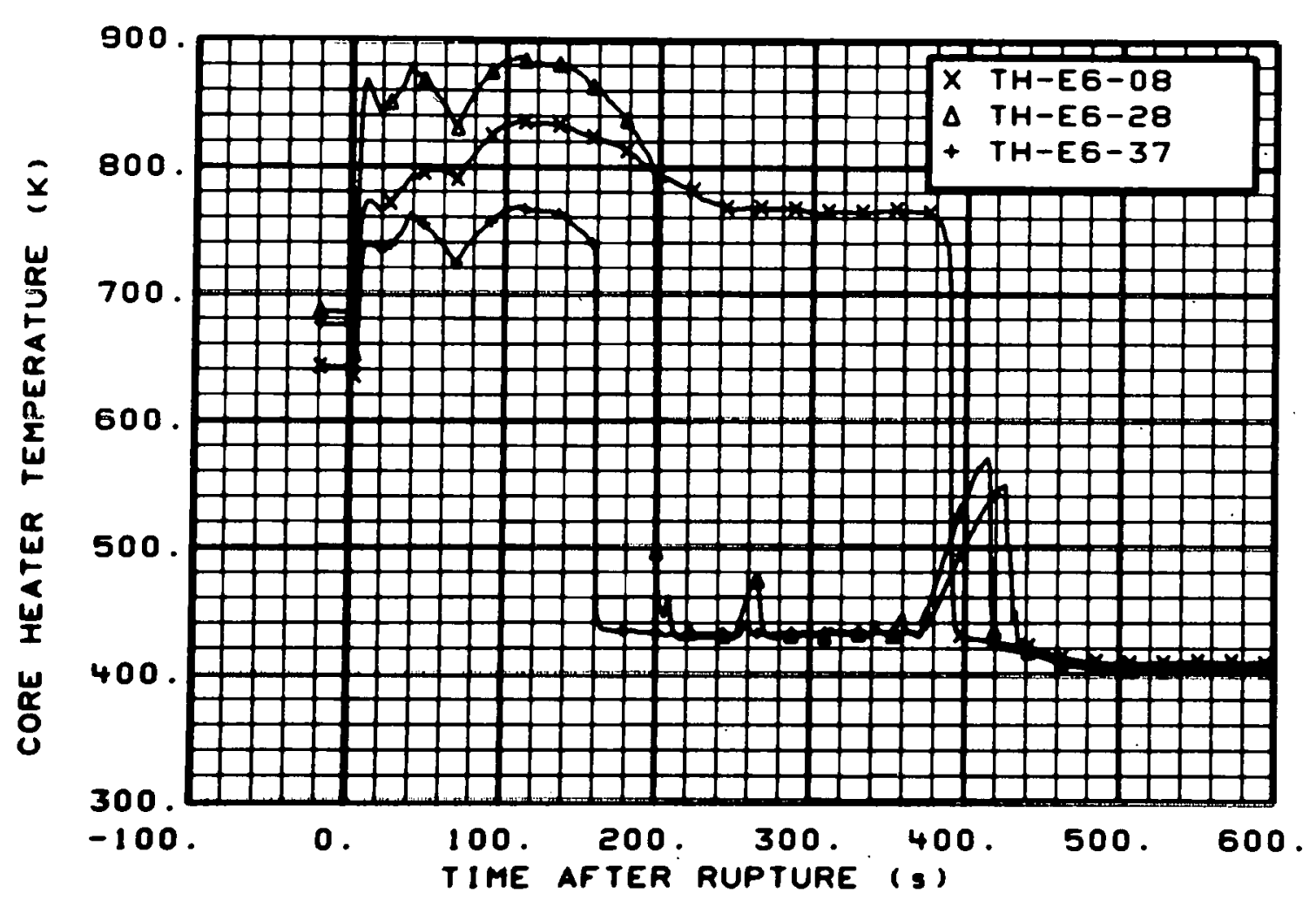

Fig. 123 Core heater temperature, Rod E-6 (TH-E6-08, TH-E6-28, and TH-E6-37), from -20 to $600 \mathrm{~s}$.

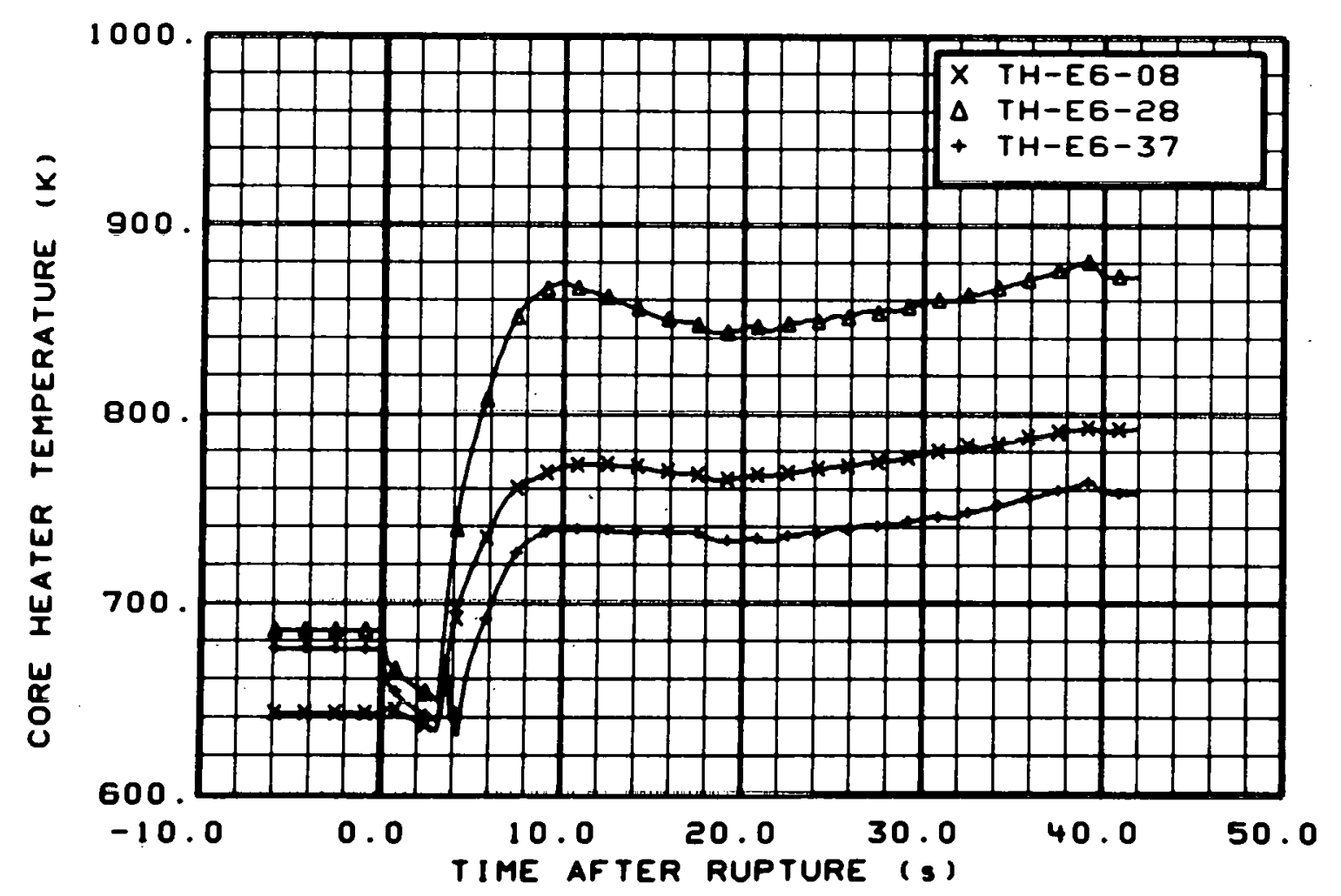

Fig. 124 Core heater temperature, Rod E-6 (TH-E6-08, TH-E6-28, and TH-E6-37), from -6 to $42 \mathrm{~s}$. 


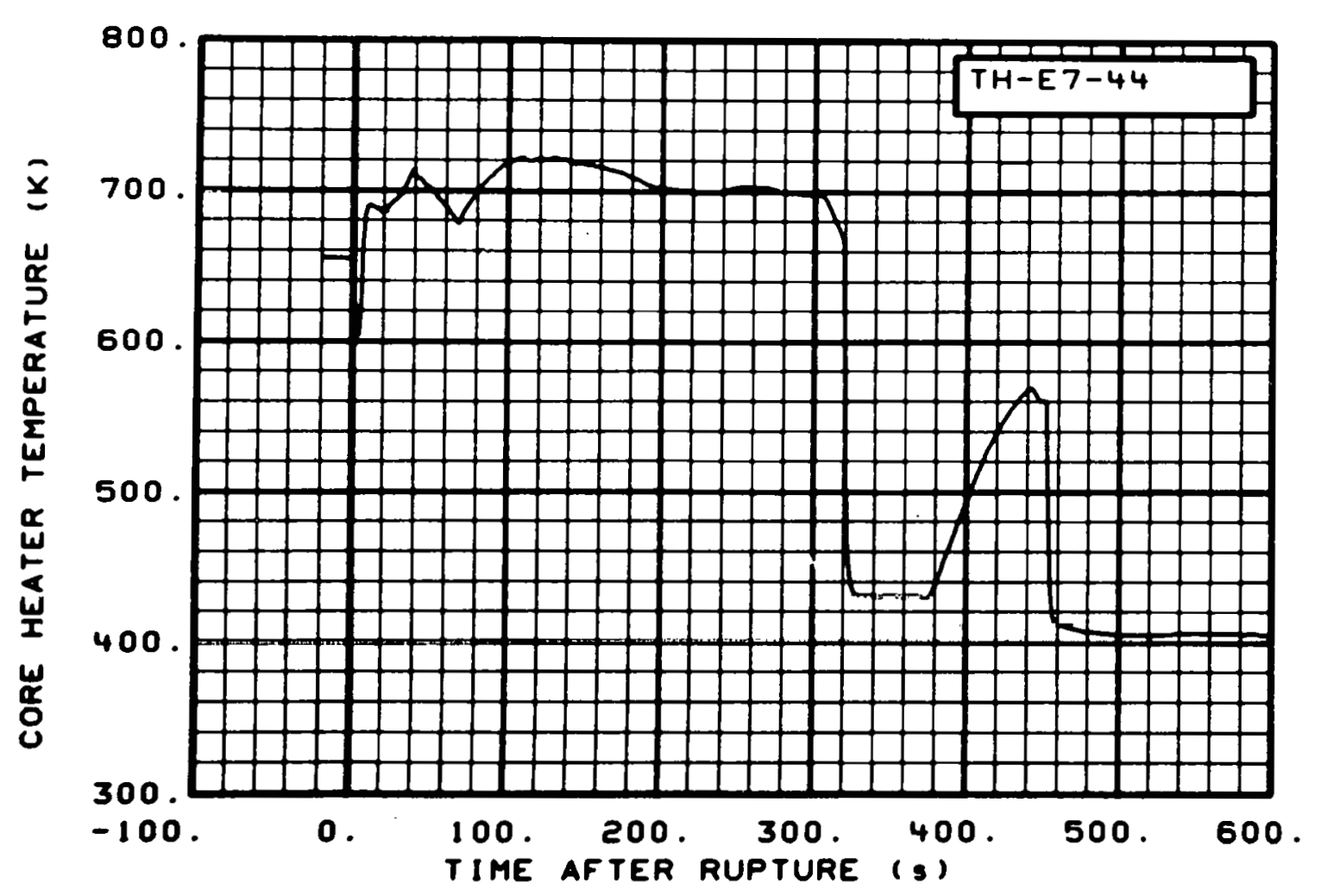

Fig. 125 Core heater temperature, Rod E-7 (TH-E7-44), from -20 to $600 \mathrm{~s}$.

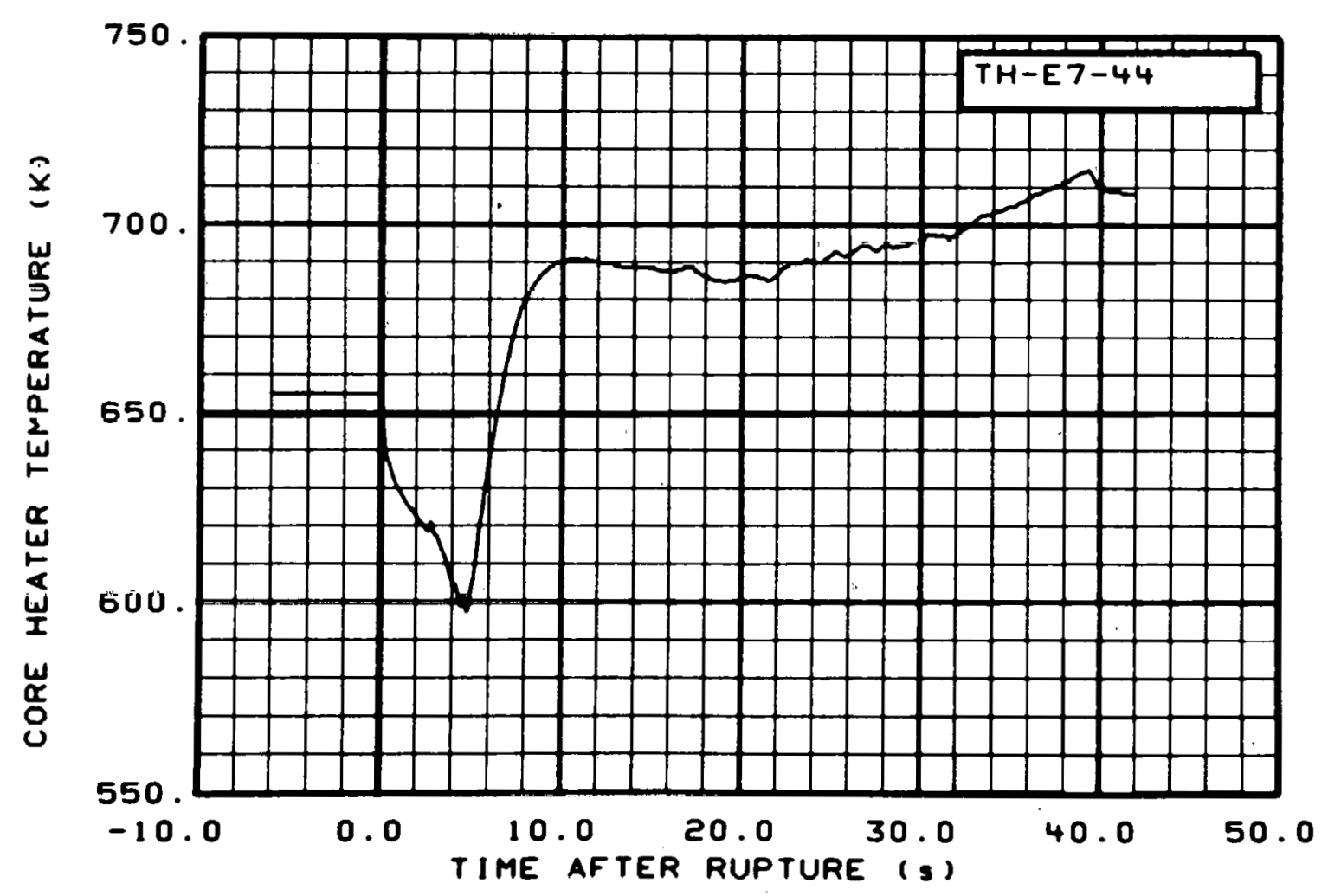

Fig. 126 Core heater temperature, Rod E-7 (TH-E7-44), from -6 to $42 \mathrm{~s}$. 


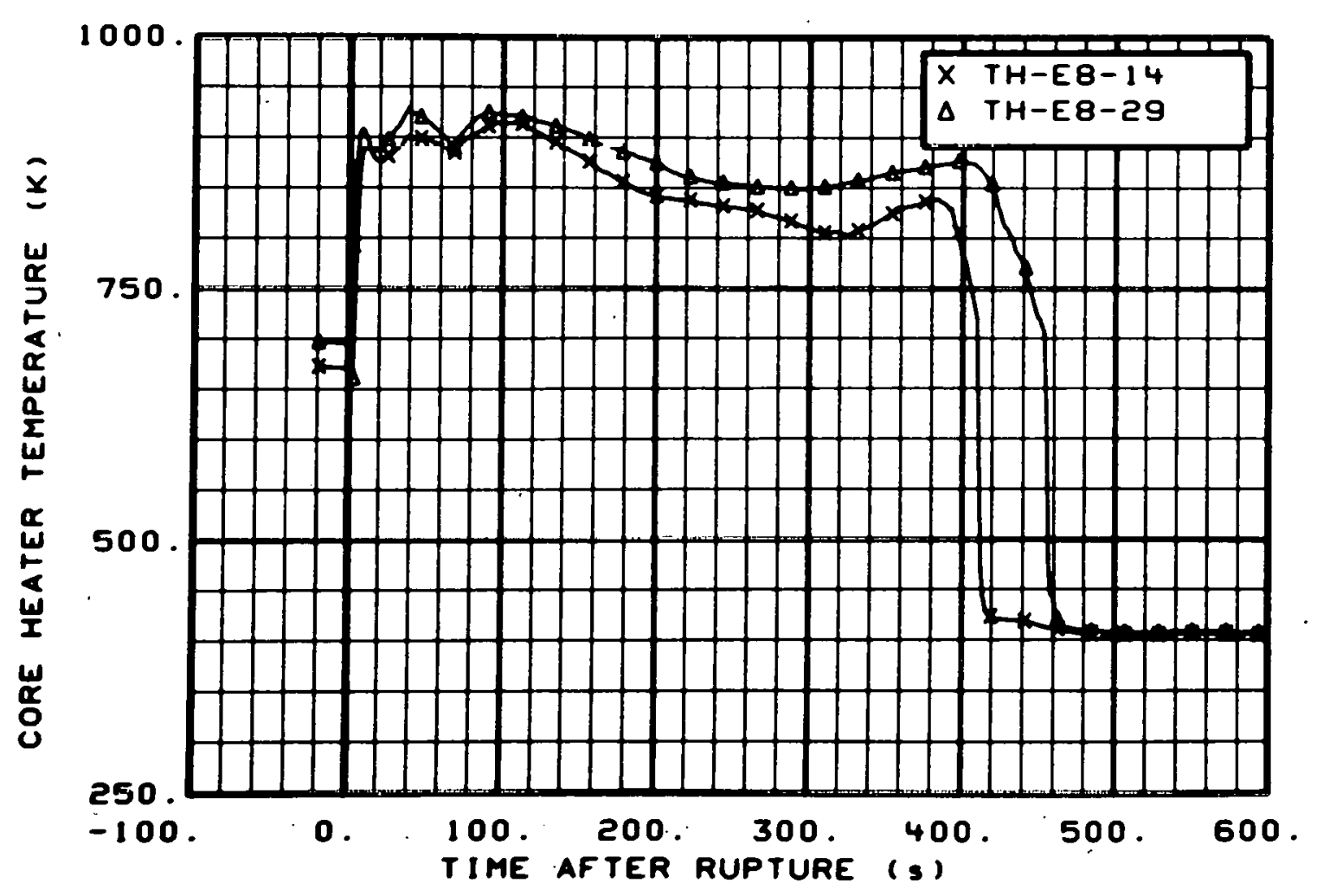

Fig. 127 Core heater temperature, Rod E-8 (TH-E8-14 and TH-E8-29), from -20 to $600 \mathrm{~s}$.

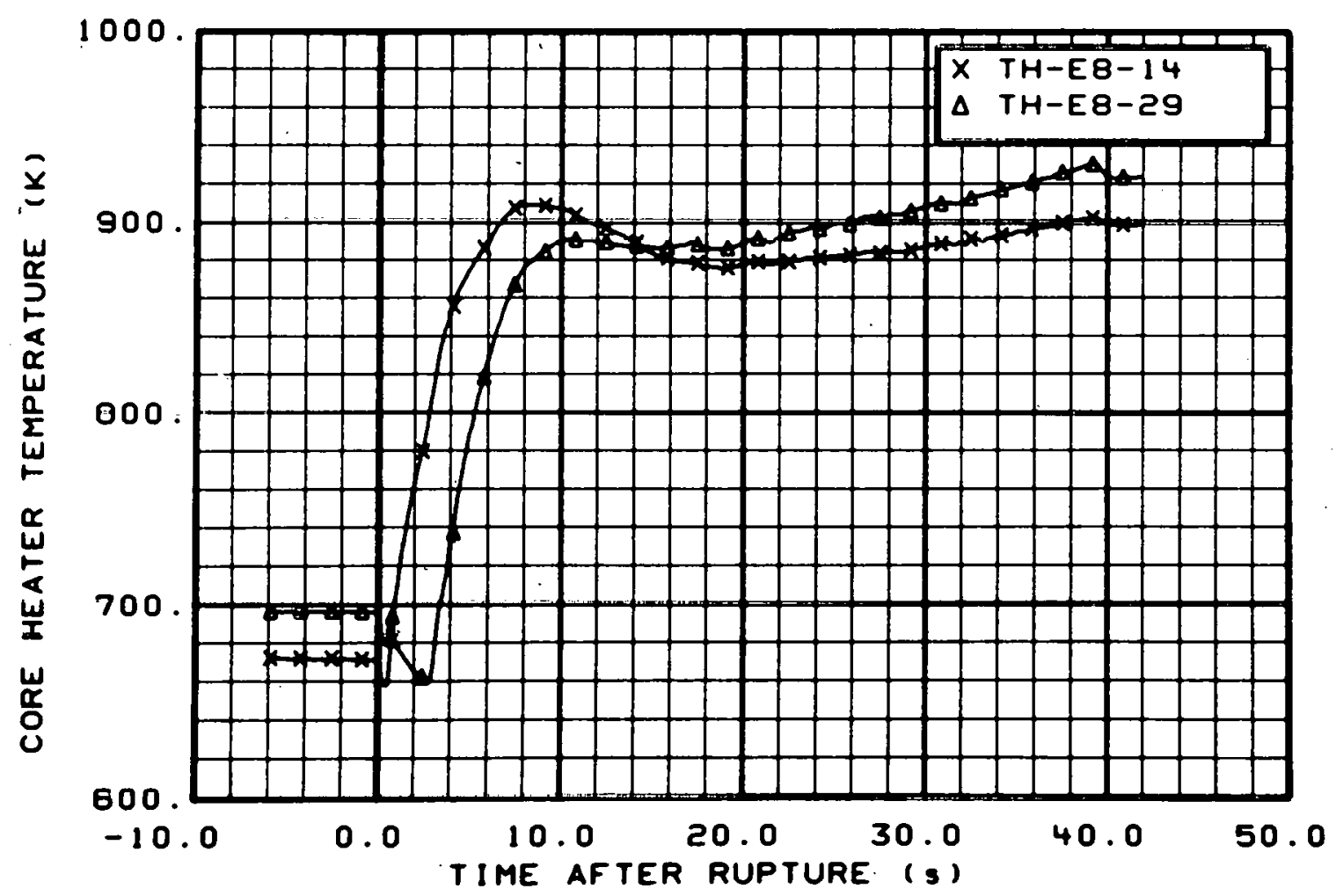

Fig. 128 Core heater temperature, Rod E-8 (TH-E8-14 and TH-E8-29), from -6 to $42 \mathrm{~s}$. 


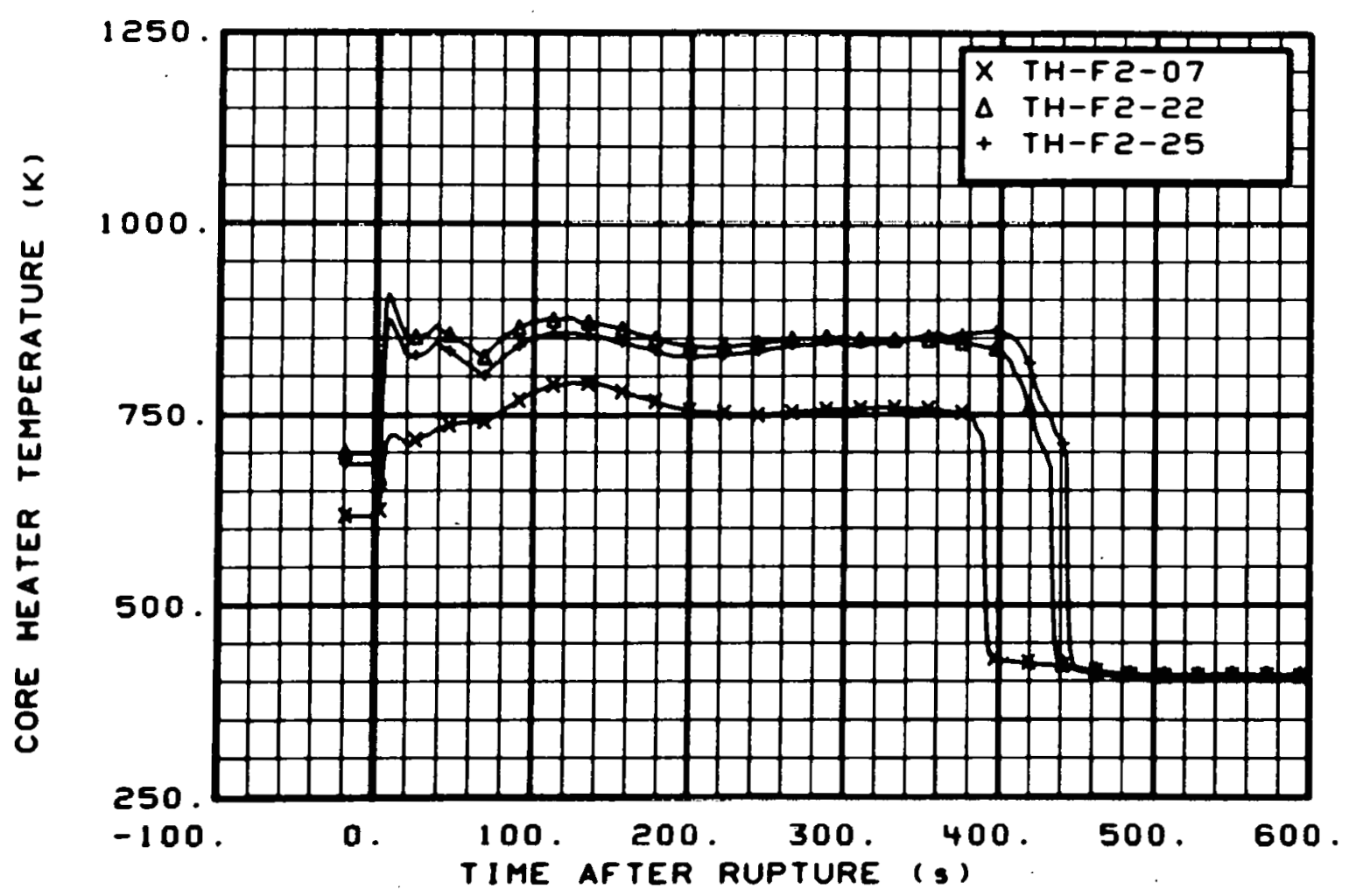

Fig. 129 Core heater temperature, Rod F-2 (TH-F2-07, TH-F2-22, and TH-F $2-25$ ), from -20 to $600 \mathrm{~s}$.

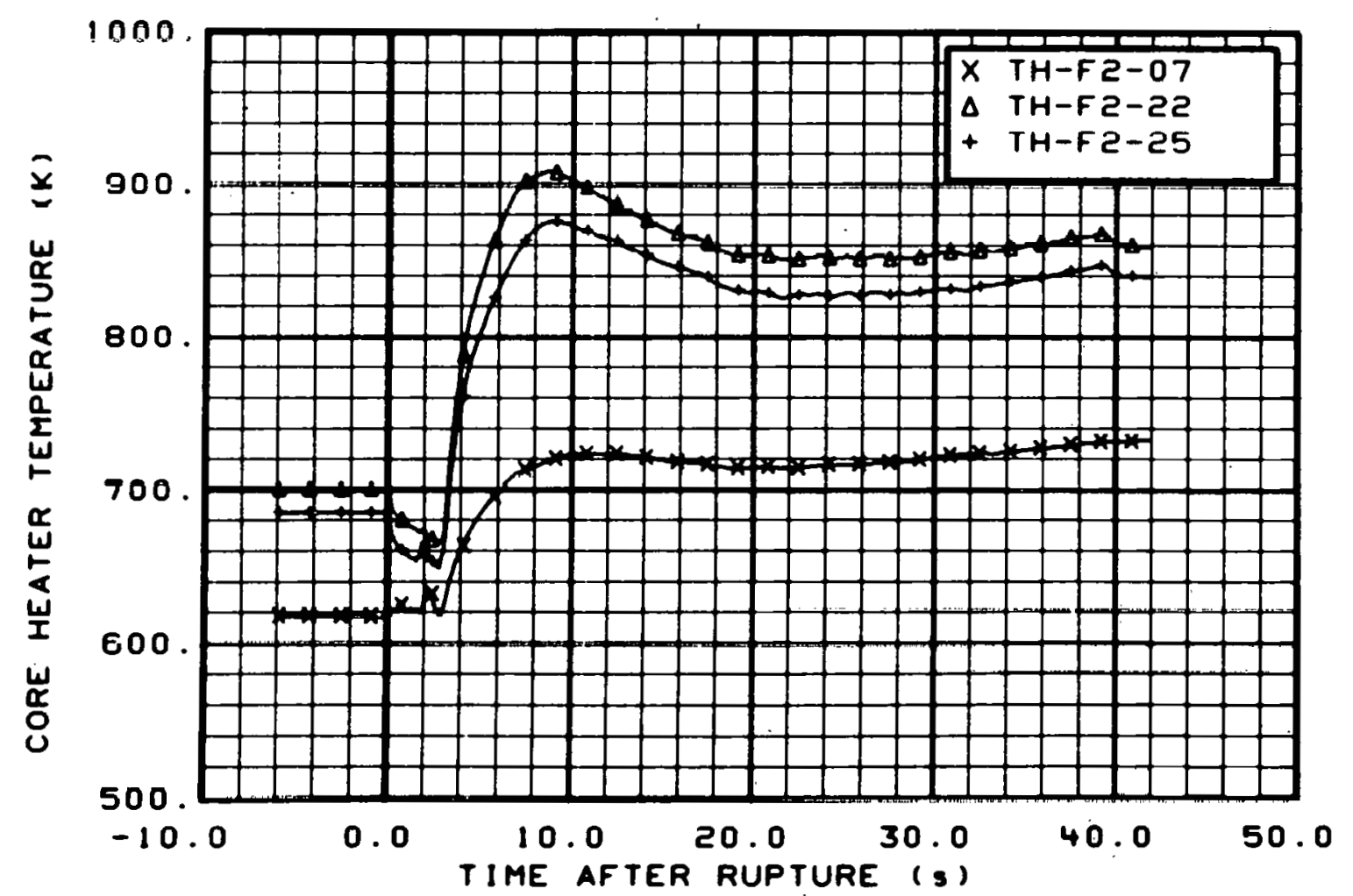

Fig. 130 Core heater temperature, Rod F-2 (TH-F2-07, TH-F2-22, and TH-F2-25), from -6 to $42 \mathrm{~s}$. 


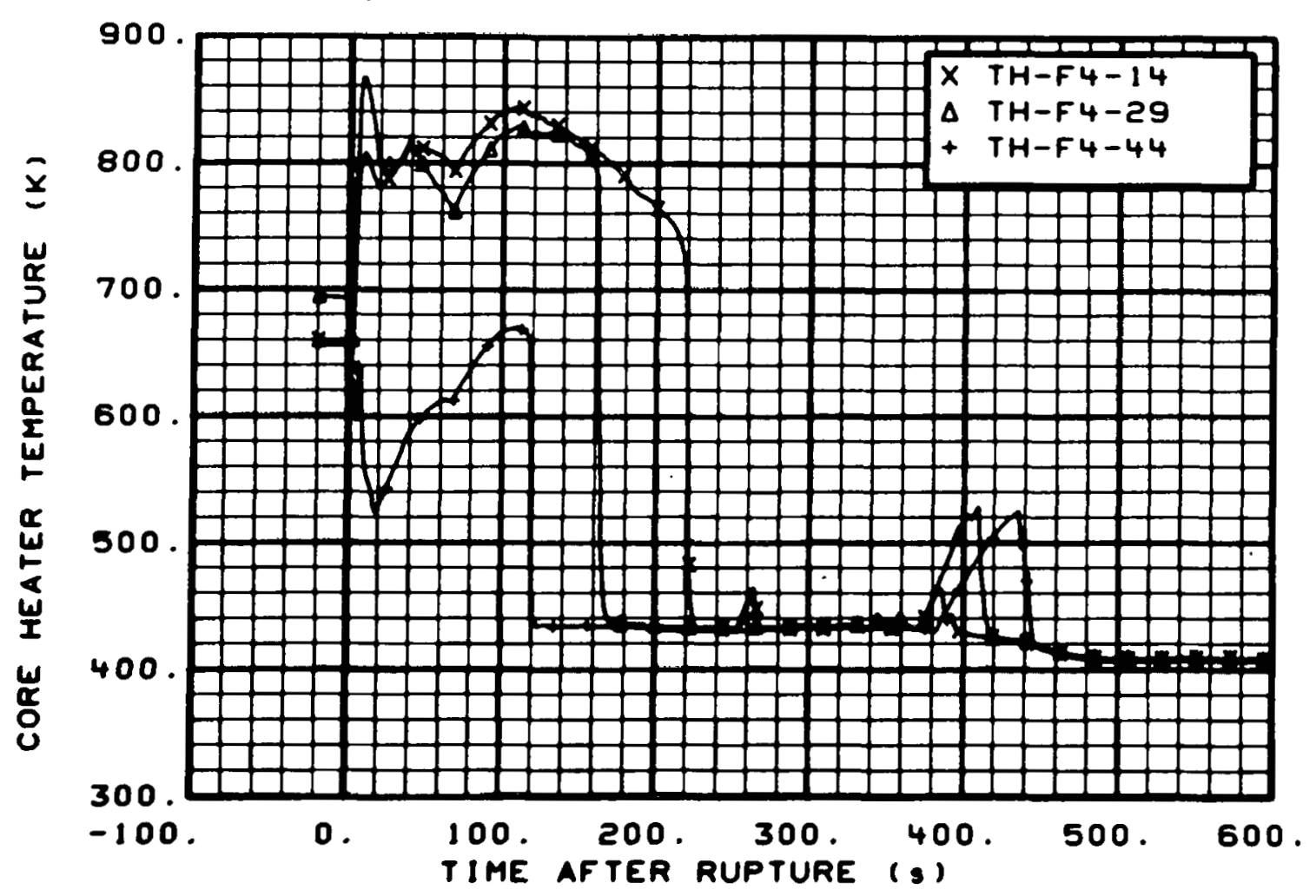

Fig. 131 Core heater temperature, Rod F-4 (TH-F4-14, TH-F4-29, and TH-F4-44), from -20 to $600 \mathrm{~s}$.

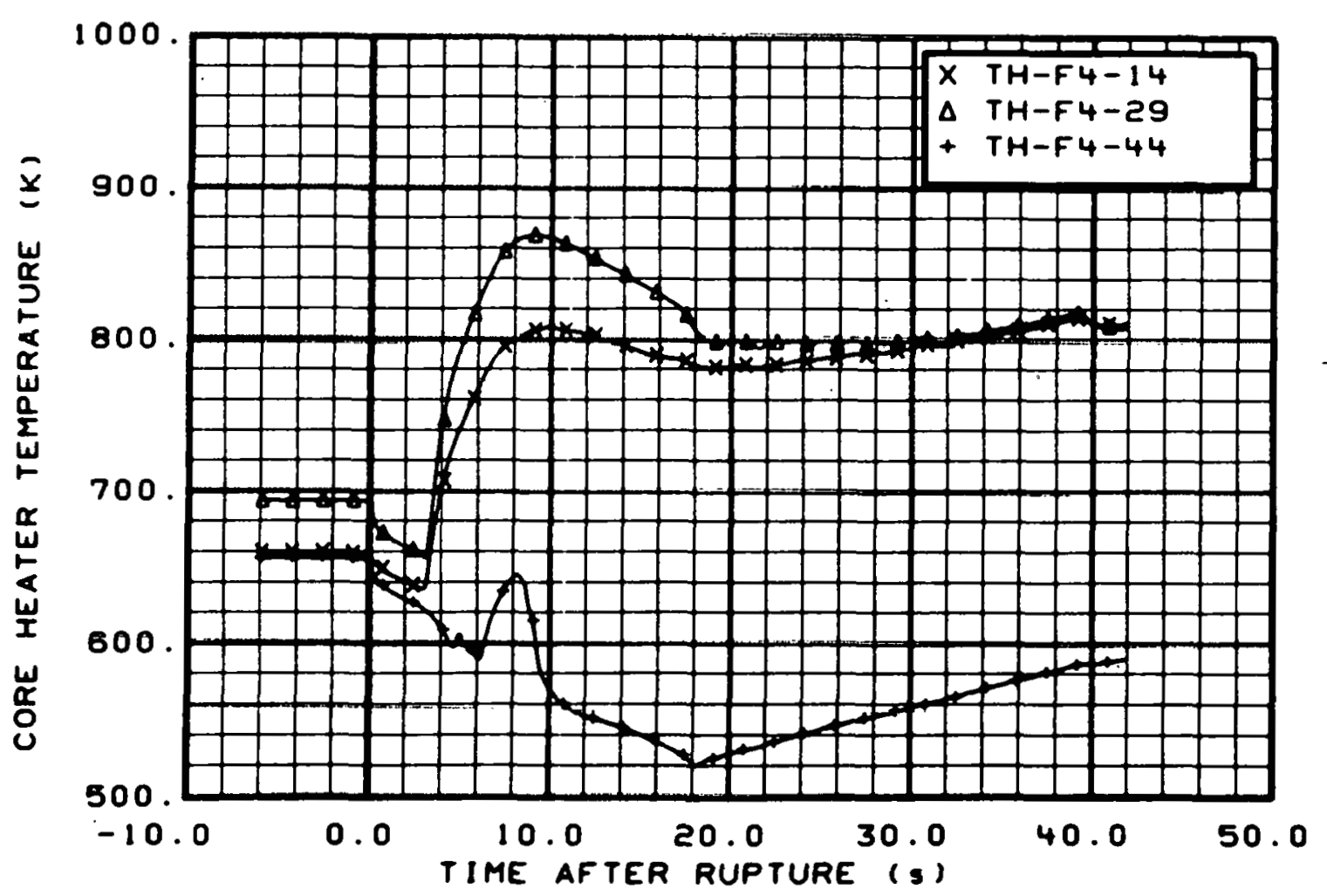

Fig. 132 Core heater temperature, Rod F-4 (TH-F4-14, TH-F4-29, and $\mathrm{TH}-\mathrm{F} 4-44$ ), from -6 to $42 \mathrm{~s}$. 


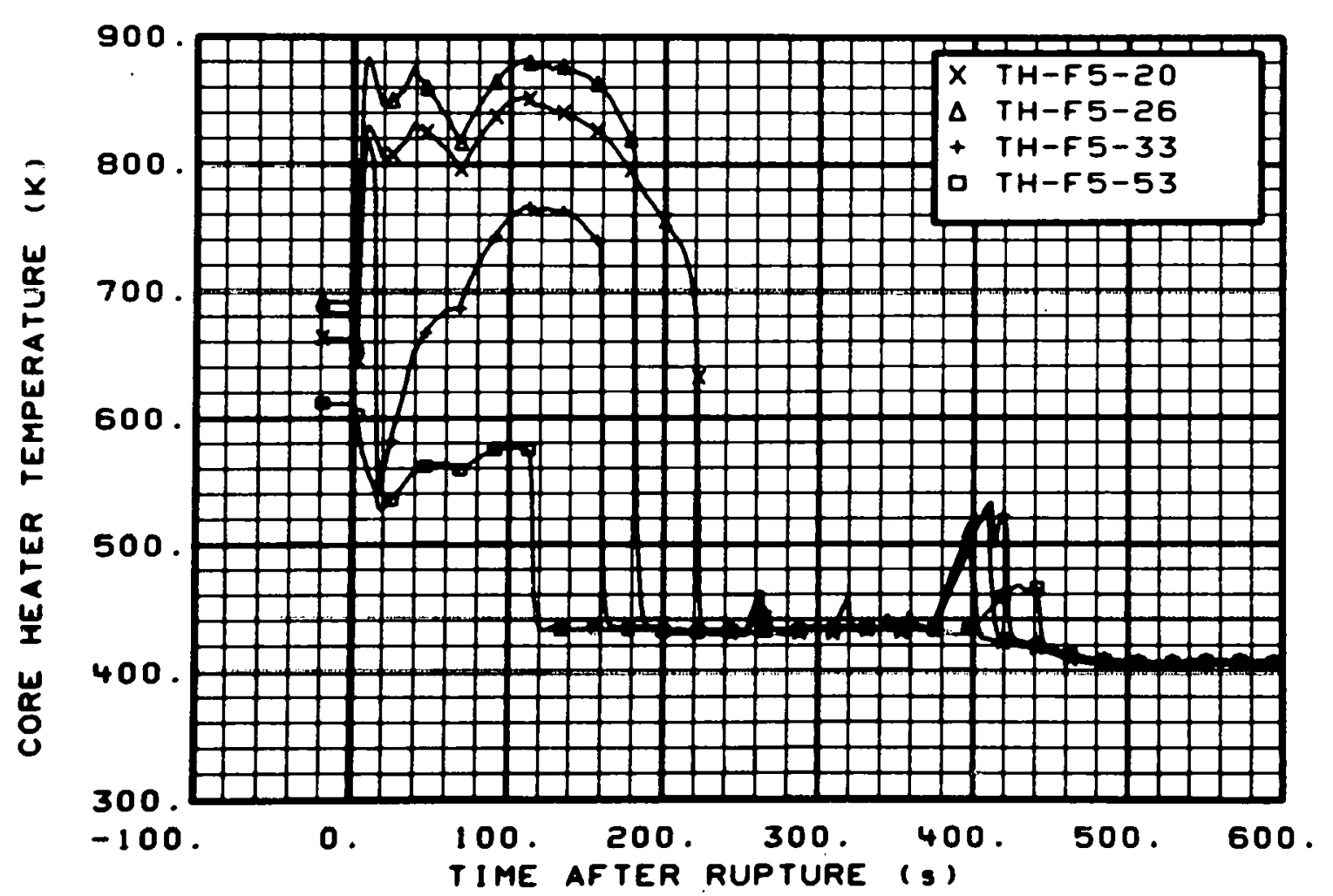

Fig. 133 Core heater temperature, Rod F-5 (TH-F5-20, TH-F5-26, TH-F5-33, and TH-F5-53), from -20 to $600 \mathrm{~s}$.

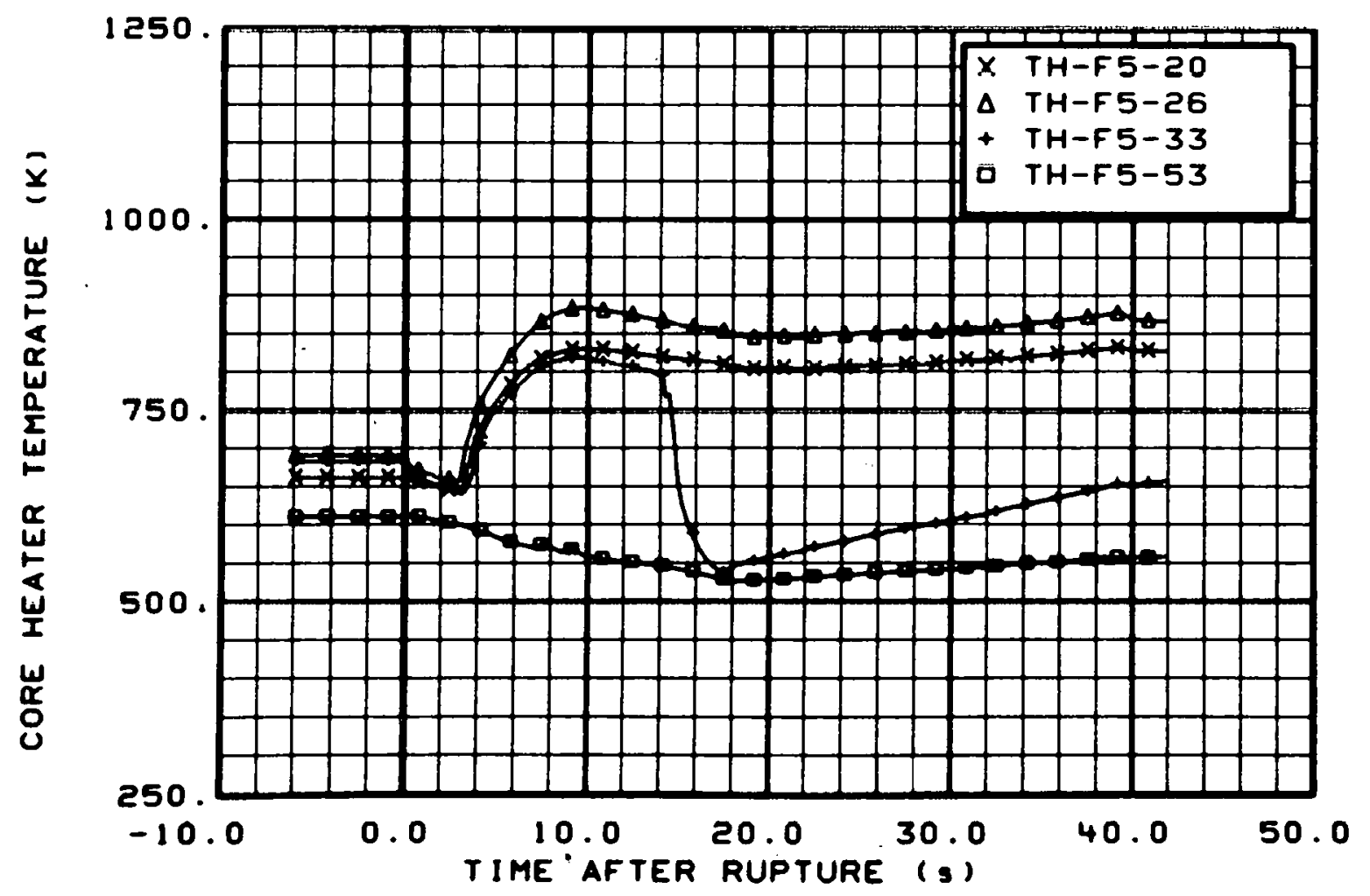

Fig. 134 Core heater temperature, Rod F-5 (TH-F5-20, TH-F5-26, TH-F5-33, and TH-F5-53), from -6 to $42 \mathrm{~s}$. 


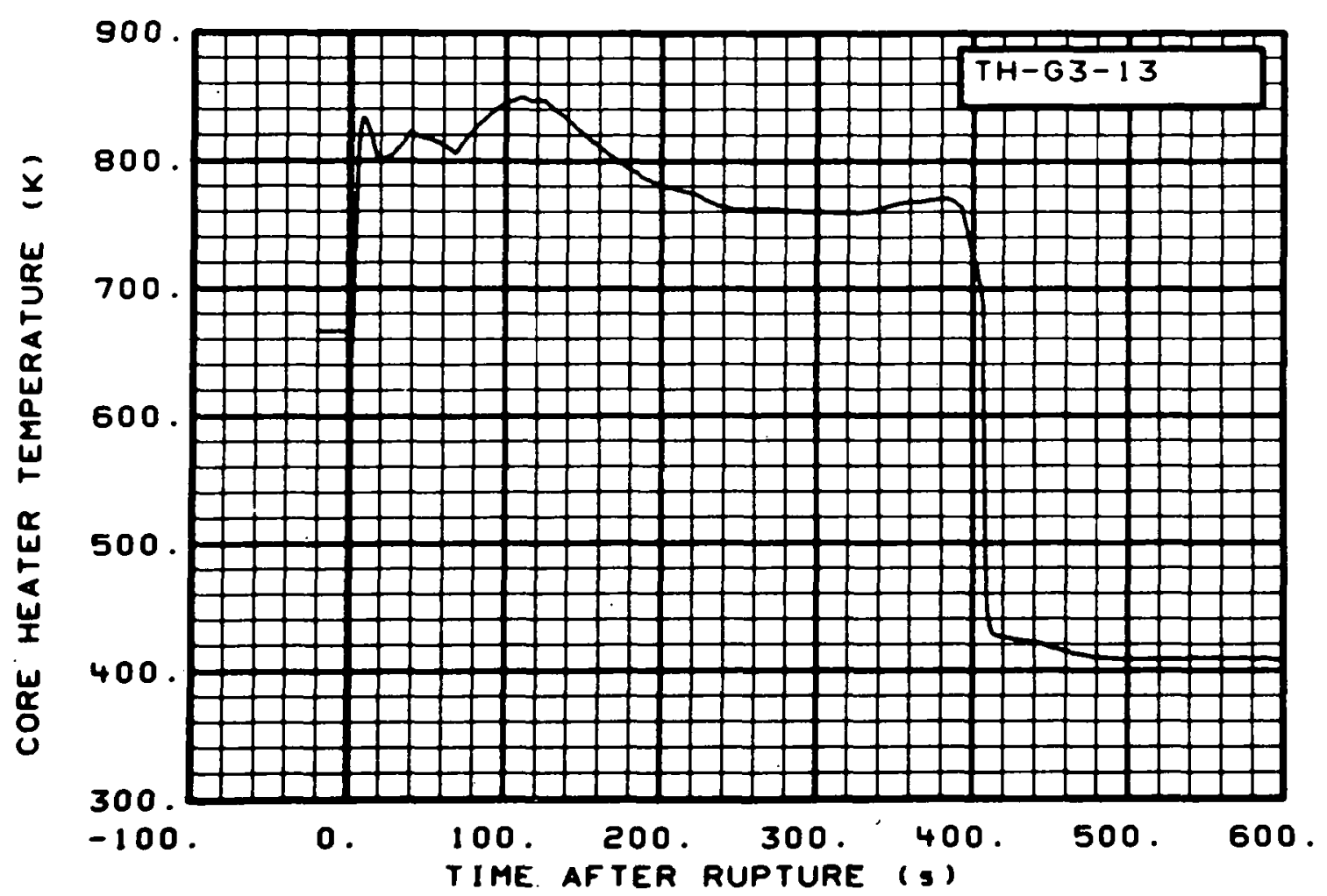

Fig. 135 Core heater temperature, Rod G-3 (TH-G3-13), from -20 to $600 \mathrm{~s}$.

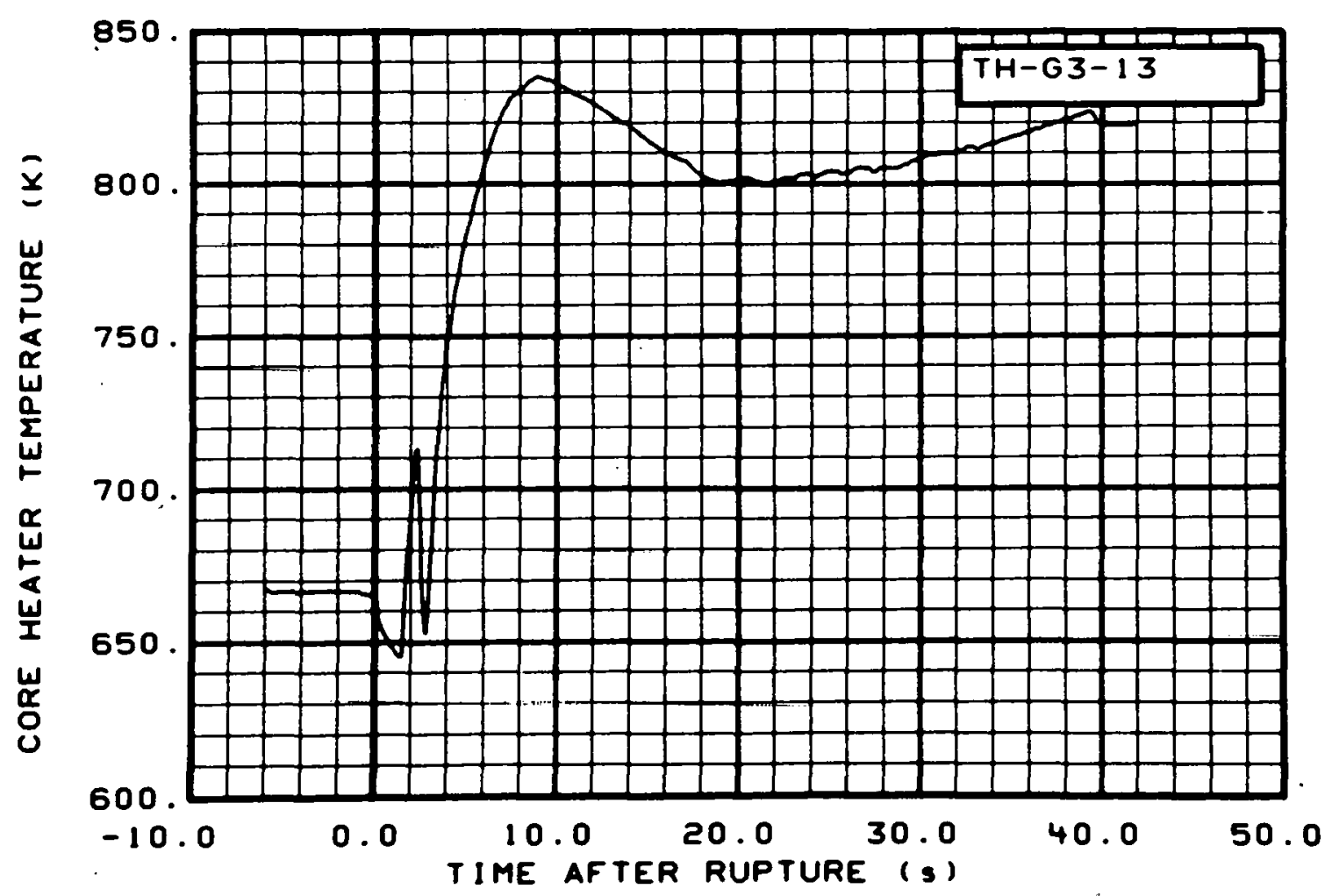

F1g. 136 Core heater temperature, Rod G-3 (TH-G3-13), from -6 to $42 \mathrm{~s}$. 


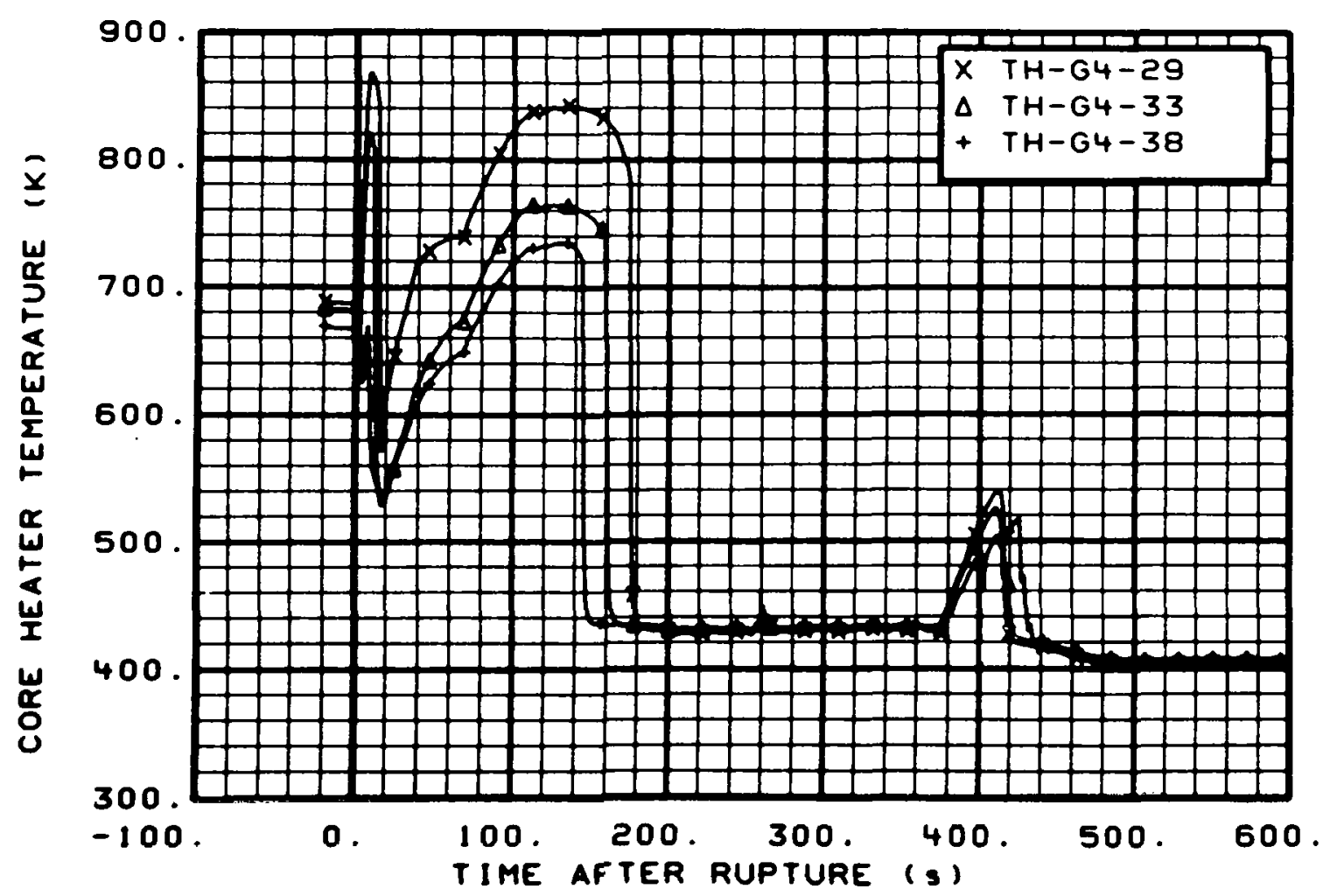

Fig. 137 Core heater temperature, Rod G-4 (TH-G4-29, TH-G4-33, and $\mathrm{TH}-\mathrm{G} 4-38$ ), from -20 to $600 \mathrm{~s}$.

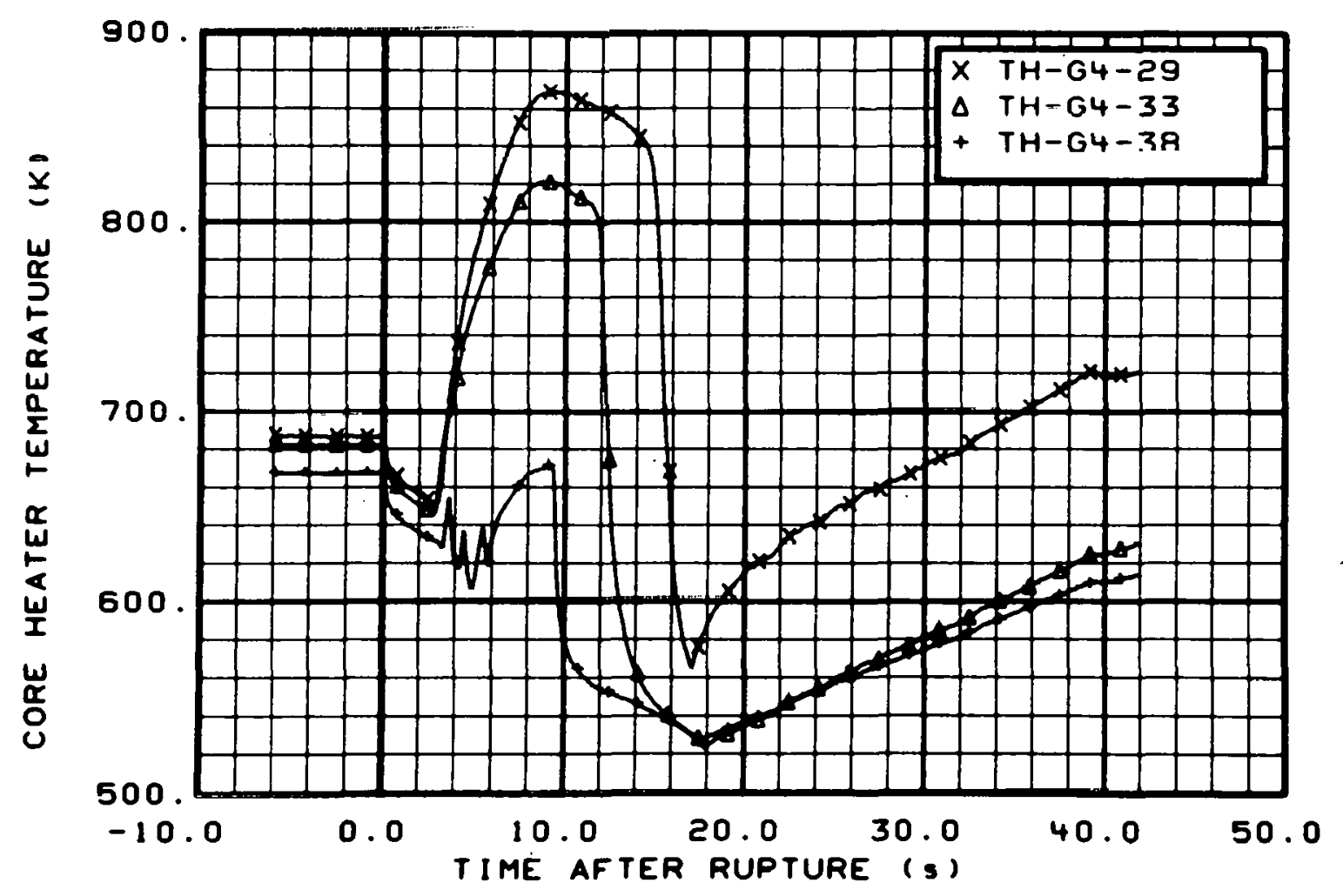

Fig. 138 Core heater temperature, Rod G-4 (TH-G4-29, TH-G4-33, and TH-G4-38), from -6 to $42 \mathrm{~s}$. 


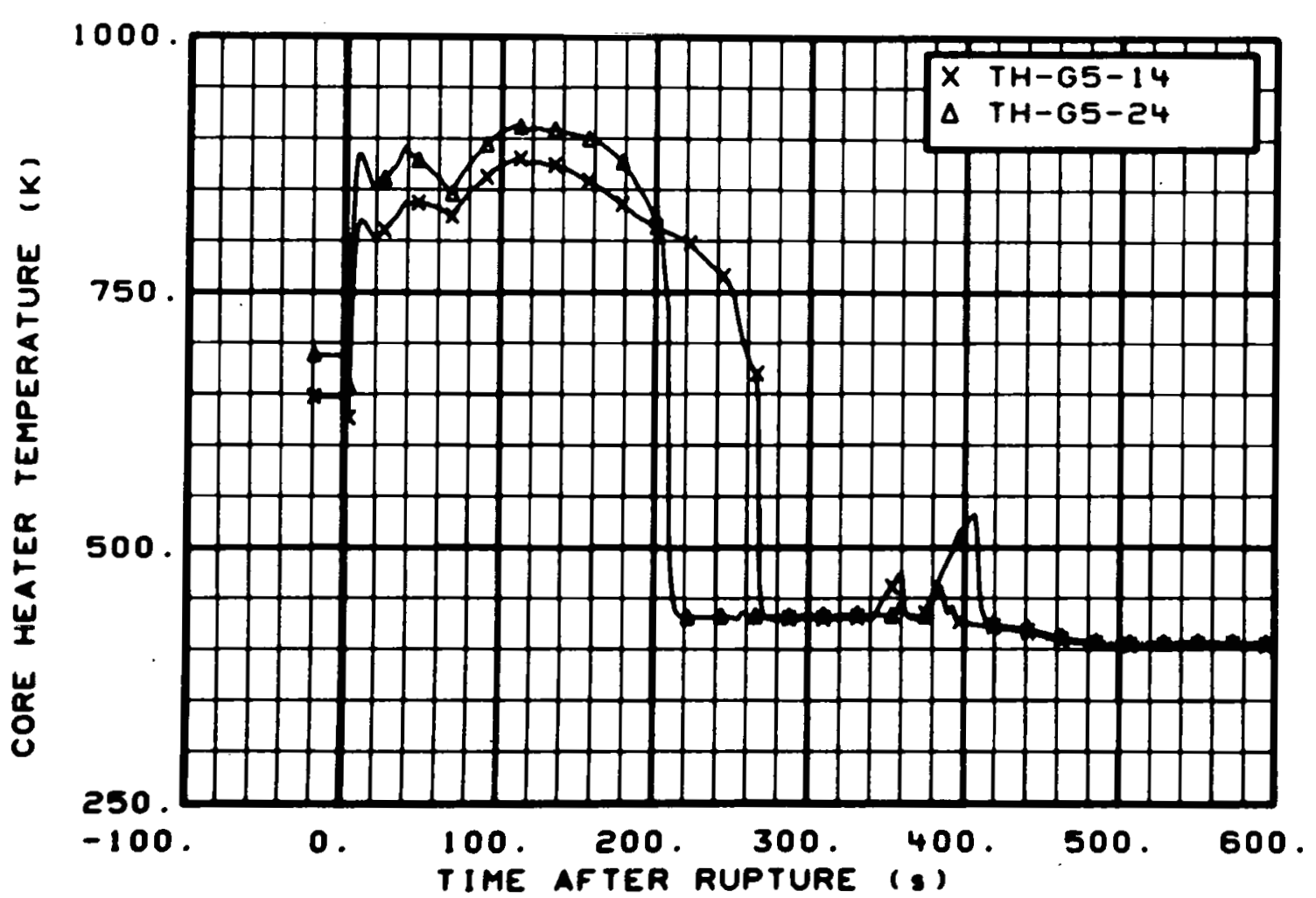

Fig. 139 Core neater temperature, Rod G-5 (TH-G5-14 and TH-G5-24), from -20 to $600 \mathrm{~s}$.

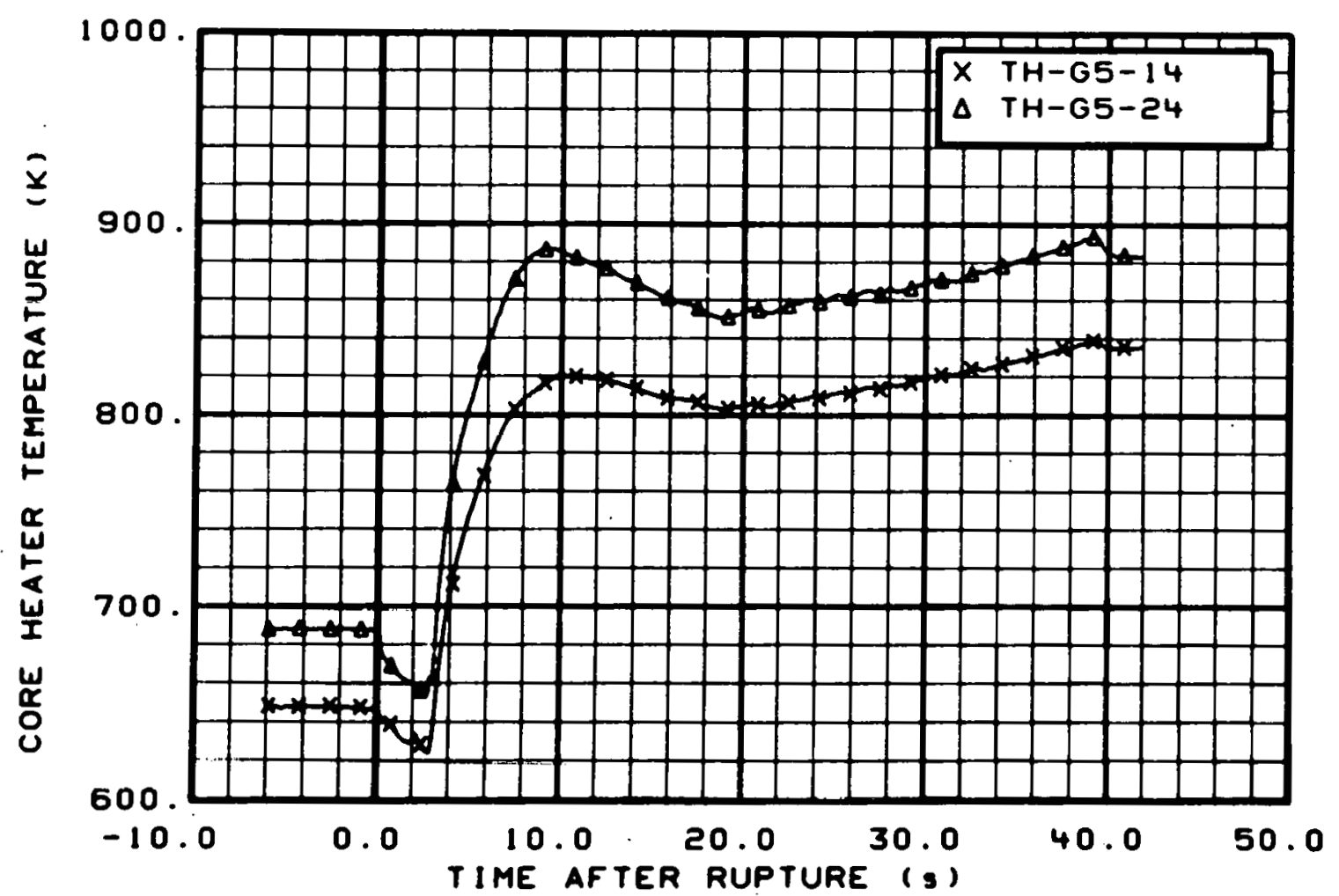

Fig. 140 Core heater temperature, Rod G-5 (TH-G5-14 and TH-G5-24), from -6 to $42 \mathrm{~s}$. 


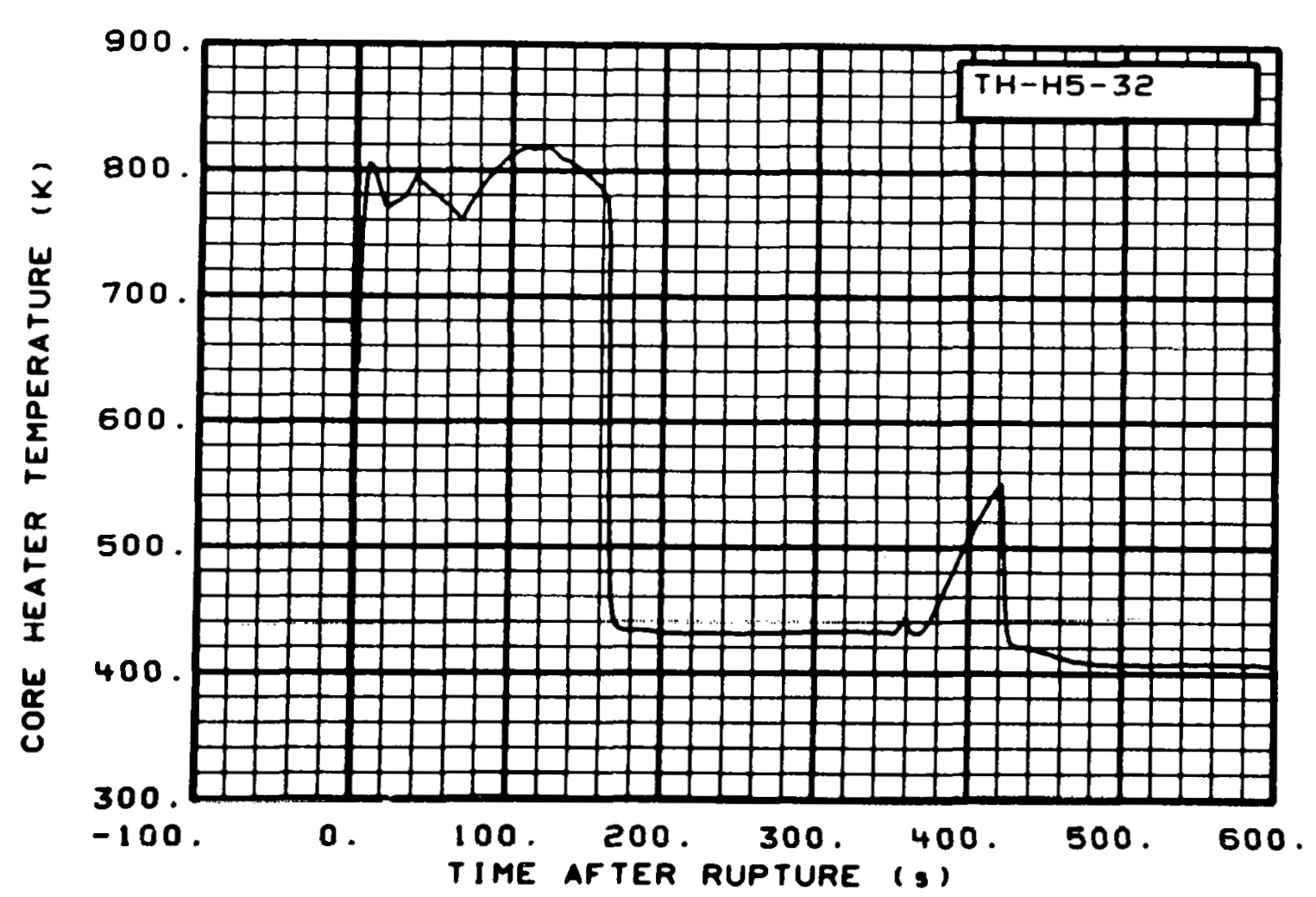

Fig. 141 Core heater temperature, Rod H-5 (TH-H5-32), from -20 to $600 \mathrm{~s}$.

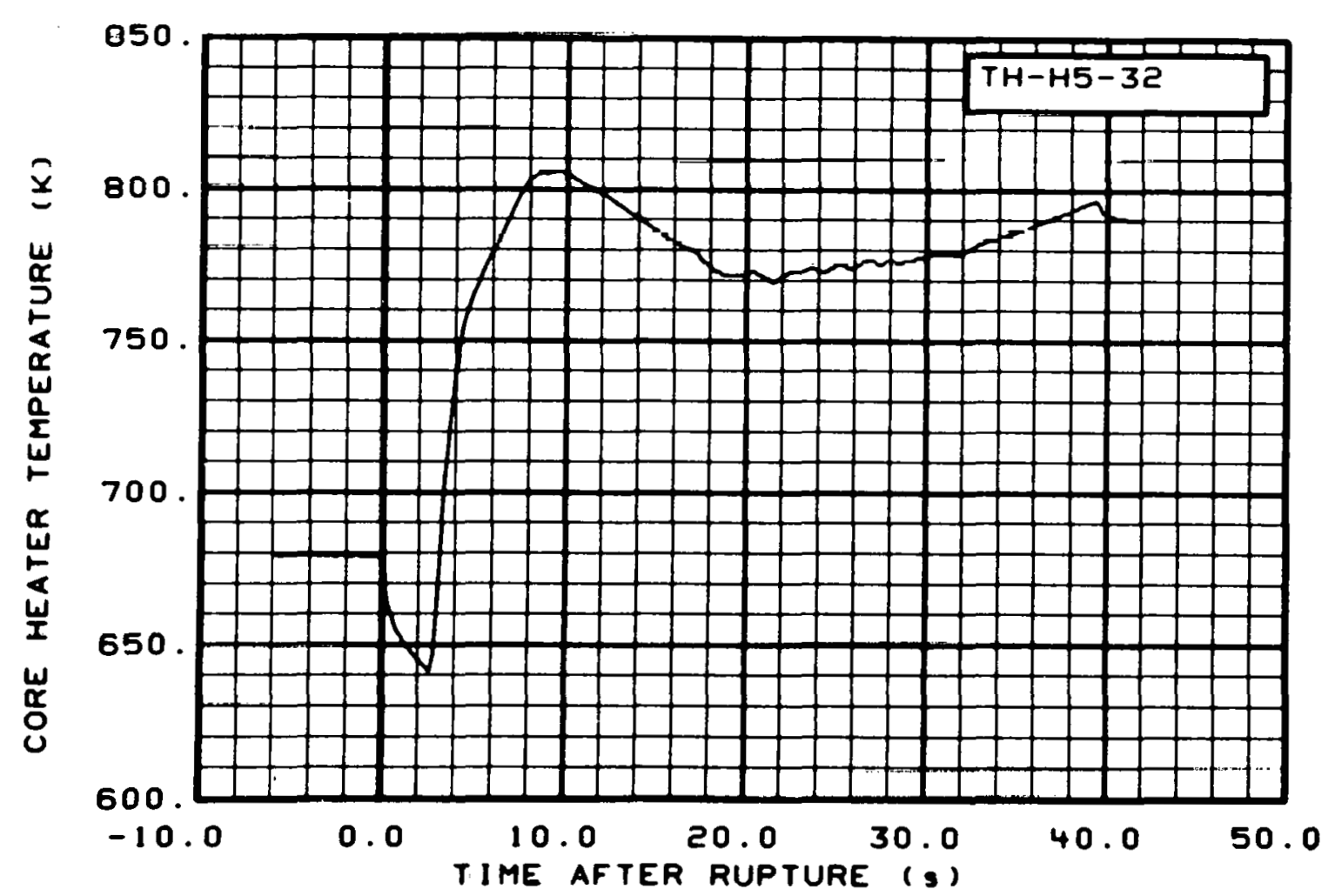

Fig. 142 Core heater temperature, Rod H-5 (TH-H5-32), from -6 to $42 \mathrm{~s}$. 


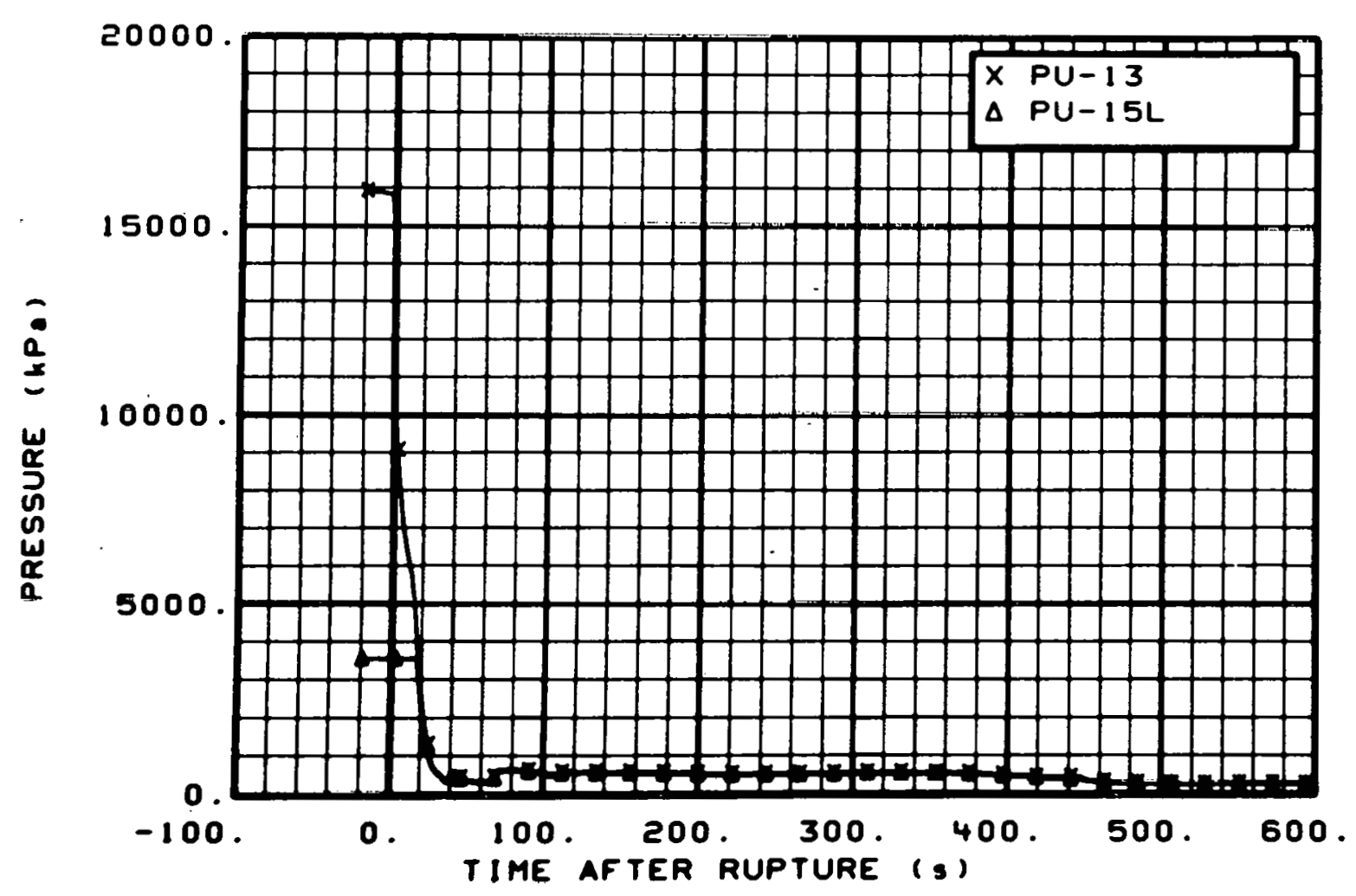

Fig. 143 Pressure in intact loop (PU-13 and PU-15L), from -20 to $600 \mathrm{~s}$.

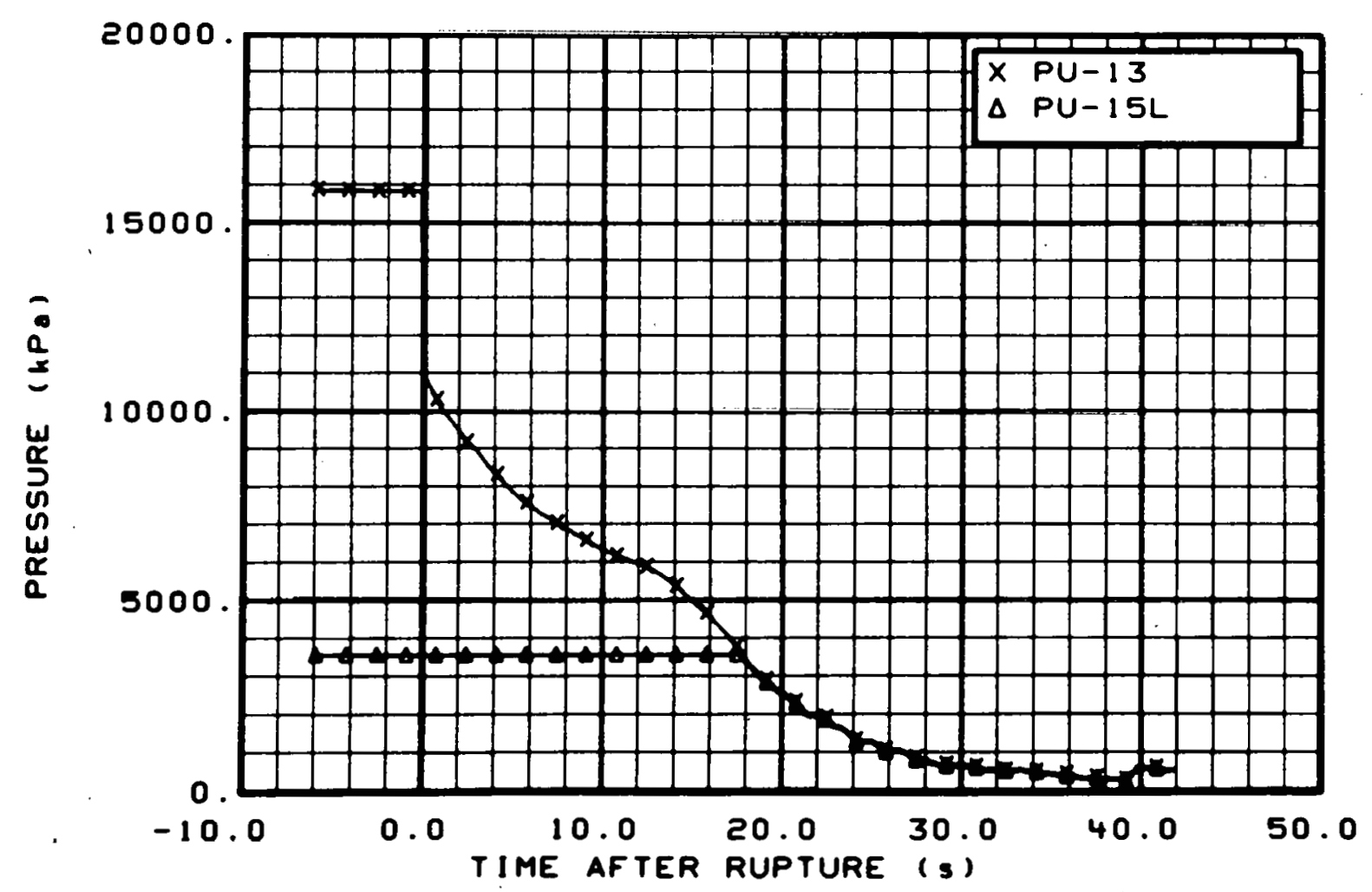

Fig. 144 Pressure in intact loop (PU-13 and PU-15L), from -6 to $42 \mathrm{~s}$. 


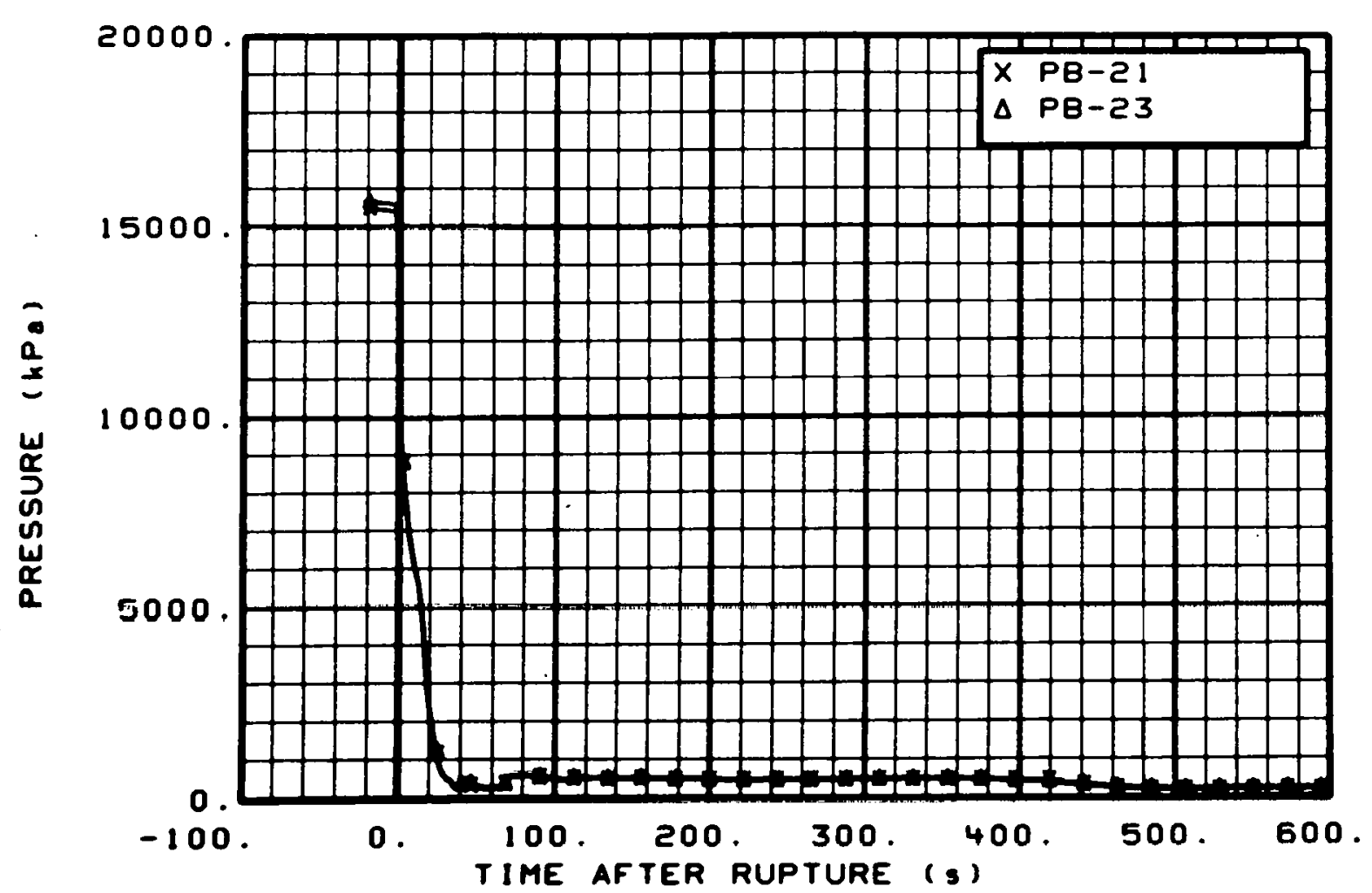

Fig. 145 Pressure in broken loop, vessel side (PB-21 and PB-23), from -20 to $600 \mathrm{~s}$.

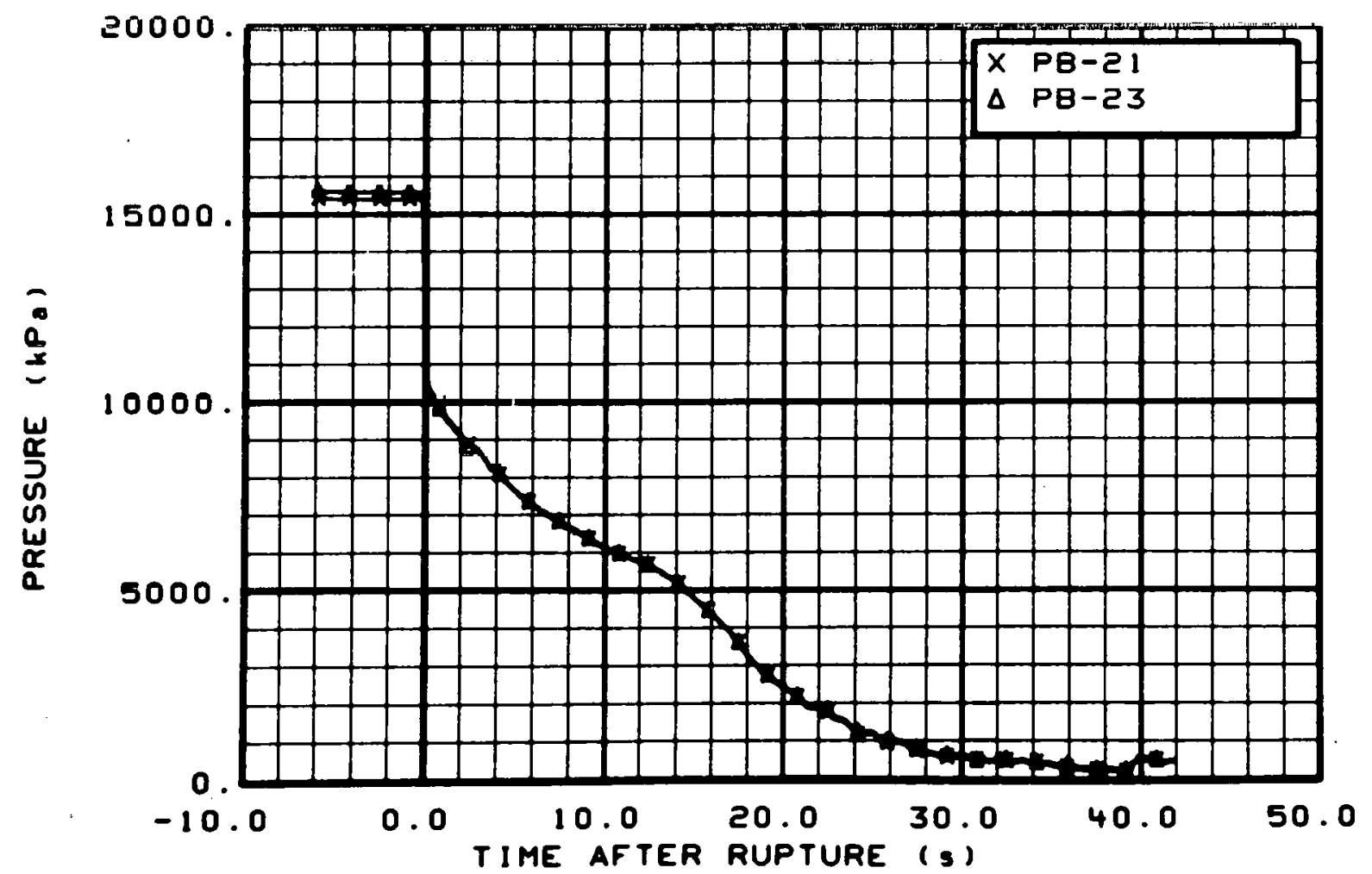

Fig. 146 Pressure in broken 10op, vessel side (PB-21 and $P B-23)$, from -6 to $42 \mathrm{~s}$. 


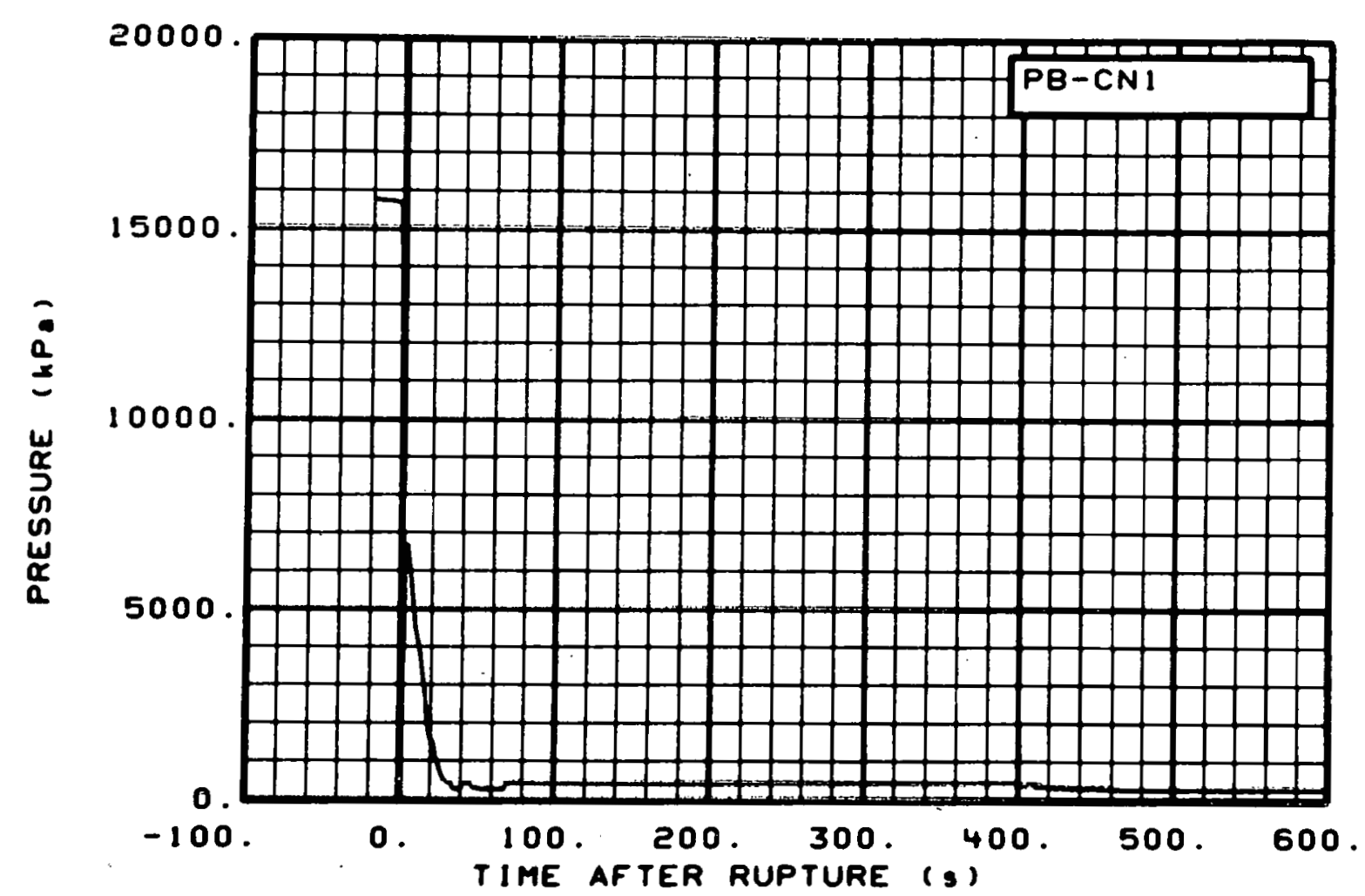

Fig. 147 Pressure in broken loop, vessel side (PB-CN1), from -20 to $600 \mathrm{~s}$.

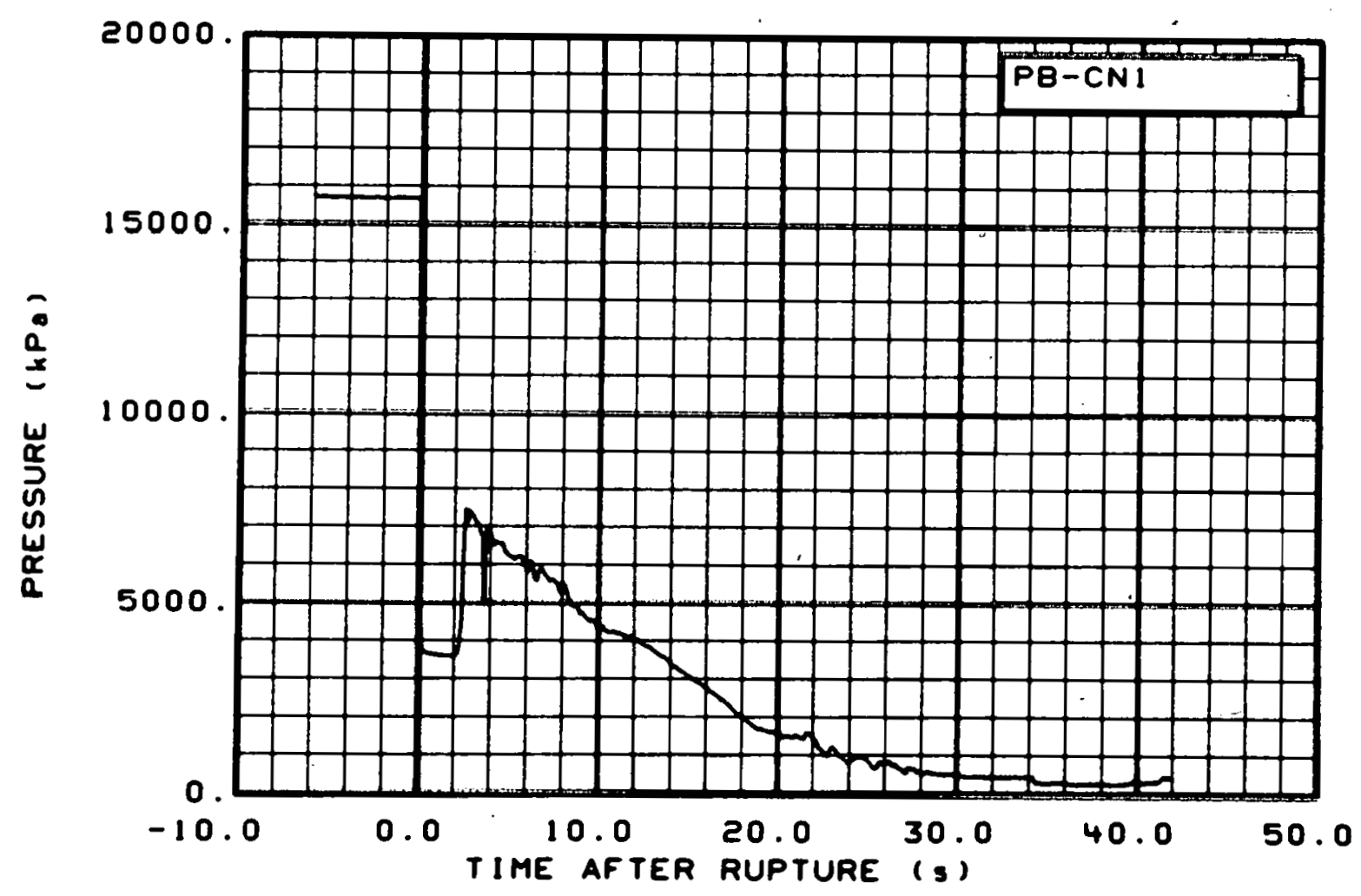

Fig. 148 Pressure in broken 10op, vessel side (PB-CN1), from -6 to $12 \mathrm{~s}$. 


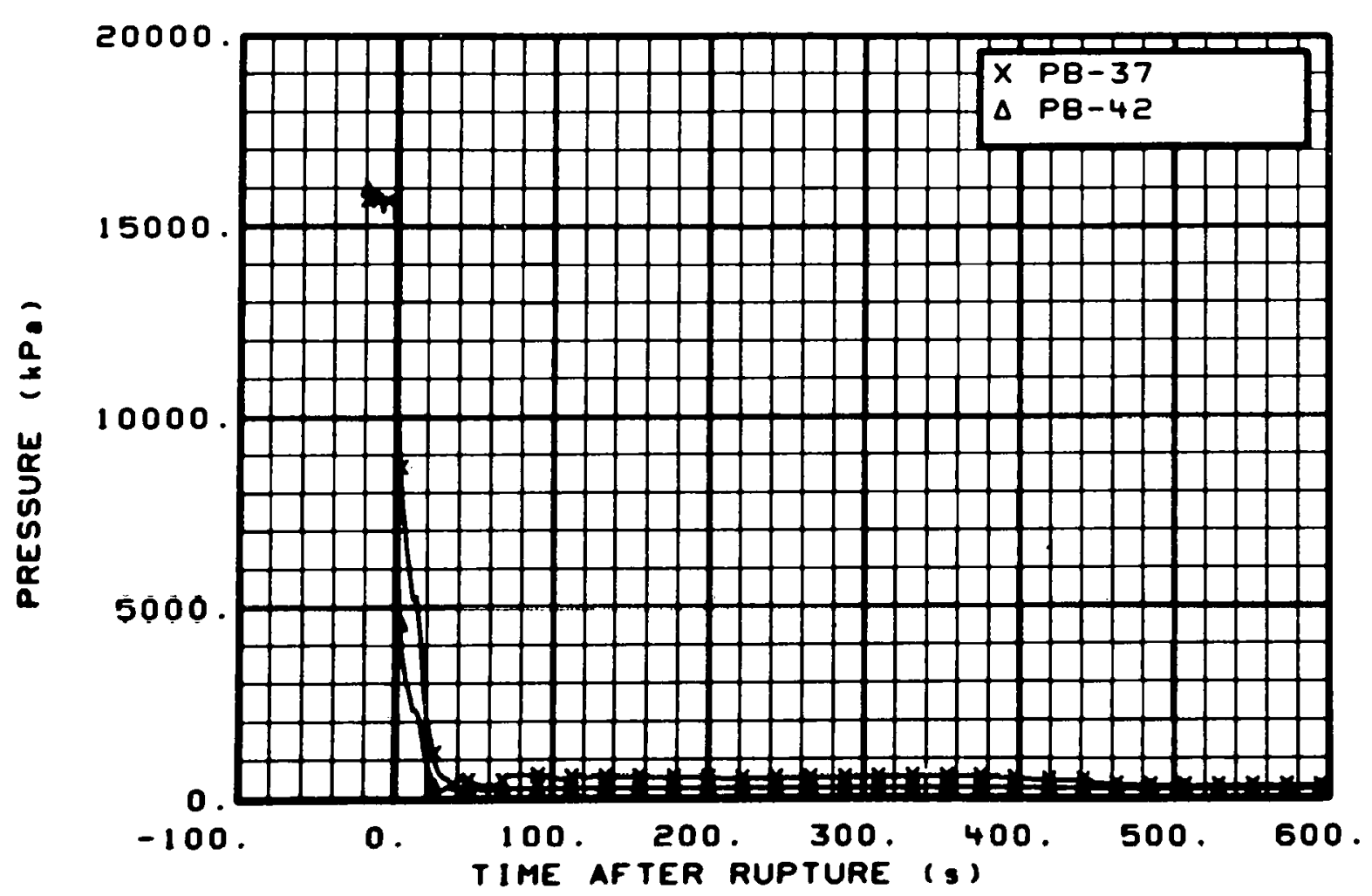

Fig. 149 Pressure in broken loop, pump side (PB-37 and PB-42), from -20 to $600 \mathrm{~s}$.

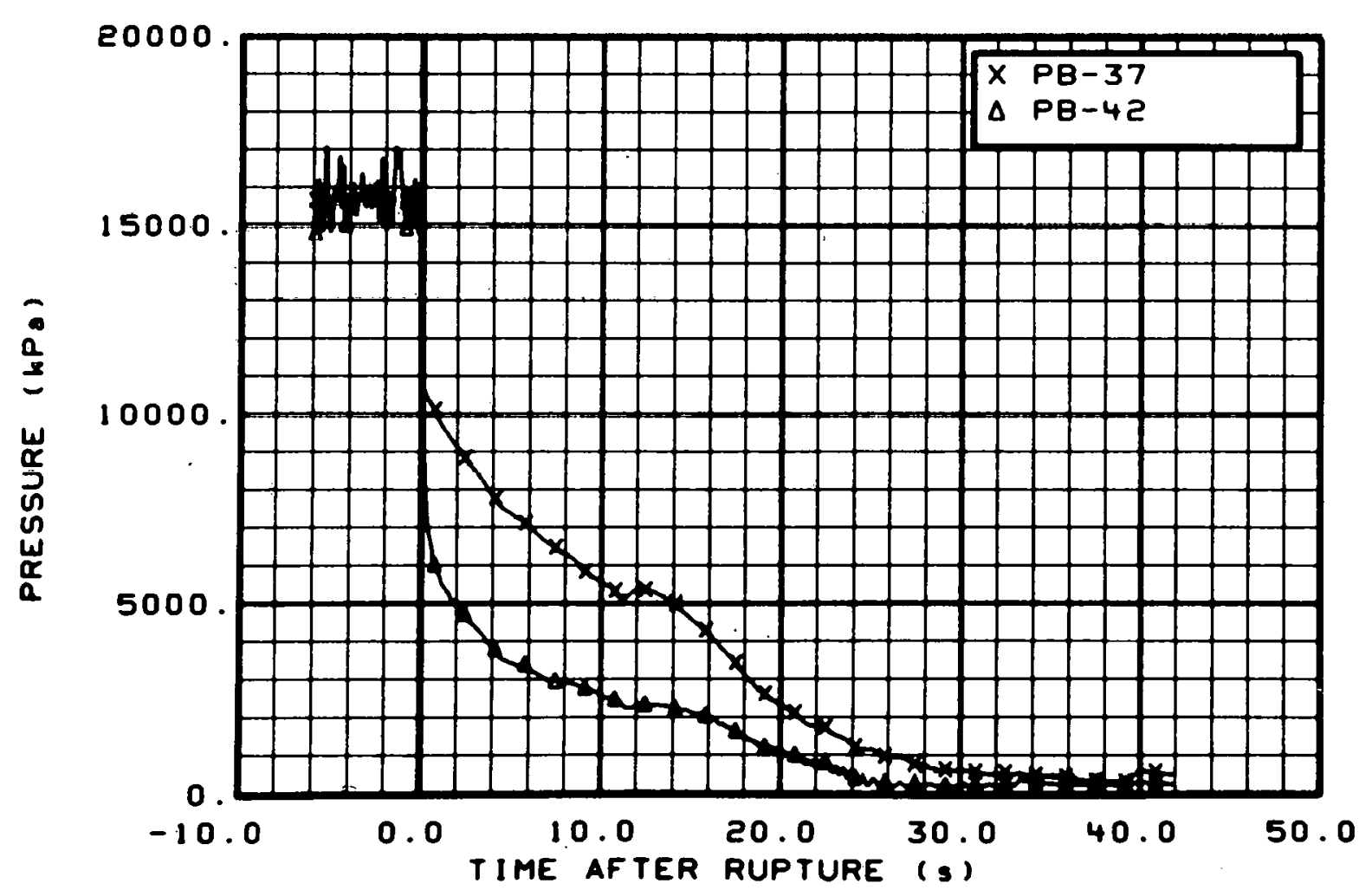

Fig. 150 Pressure in broken 100p, pump side (PB-37 and PB-42), from -6 to $42 \mathrm{~s}$. 


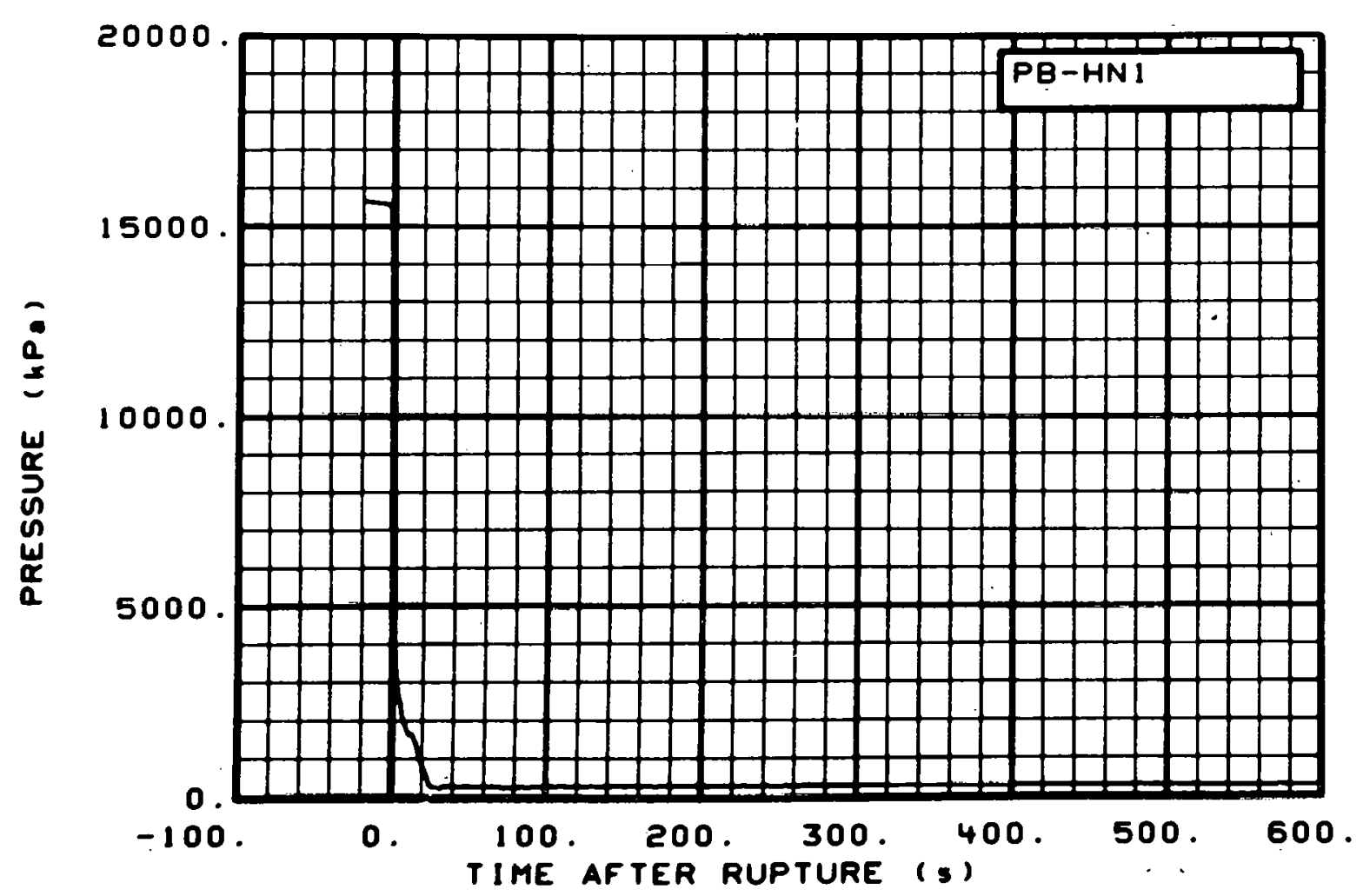

Fig. 151 Pressure in broken loop, vessel side (PB-HN1), from -20 to $600 \mathrm{~s}$.

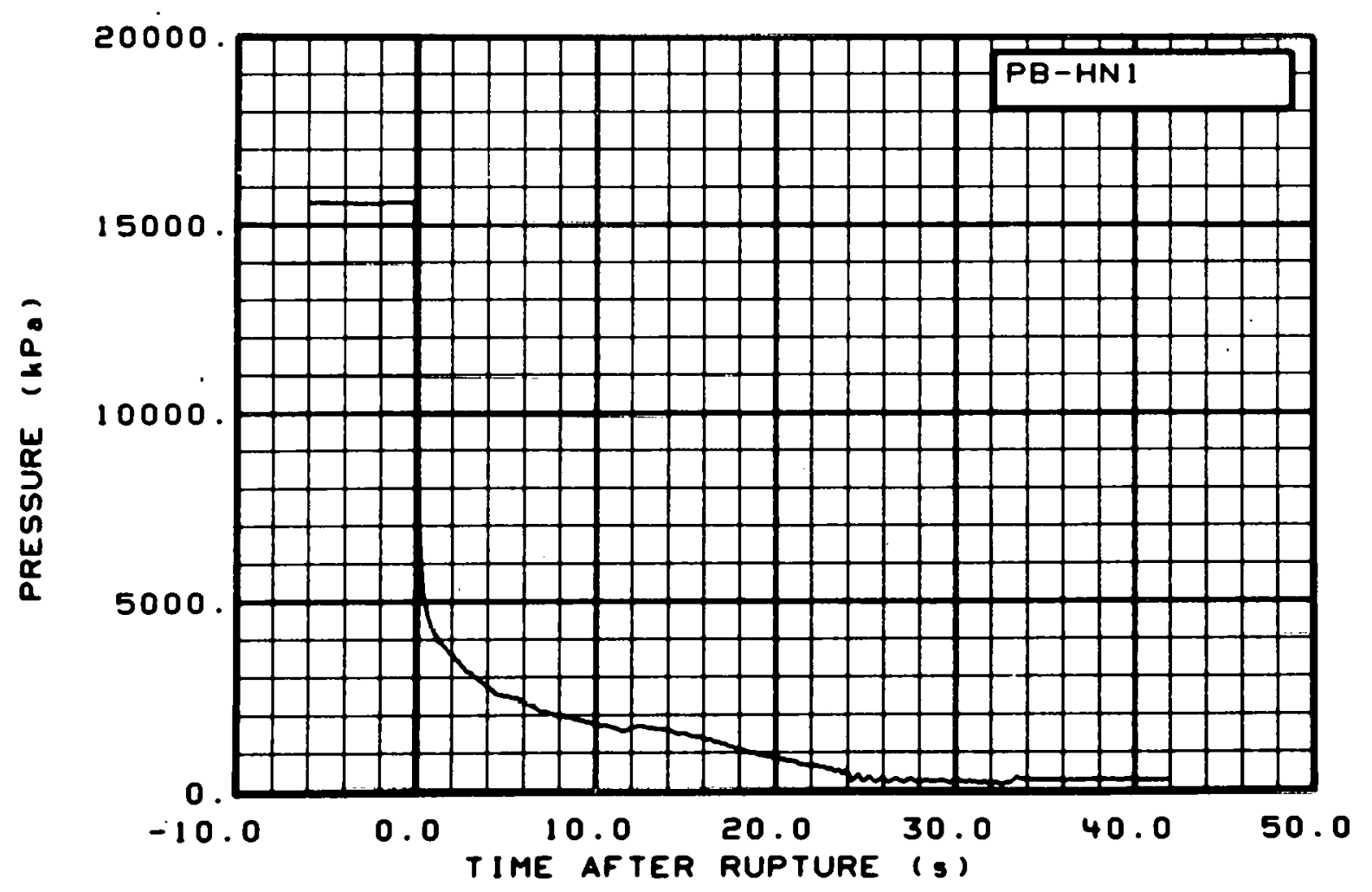

Fig. 152 Pressure in broken loop, vessel side (PB-HN1), from -6 to $42 \mathrm{~s}$. 


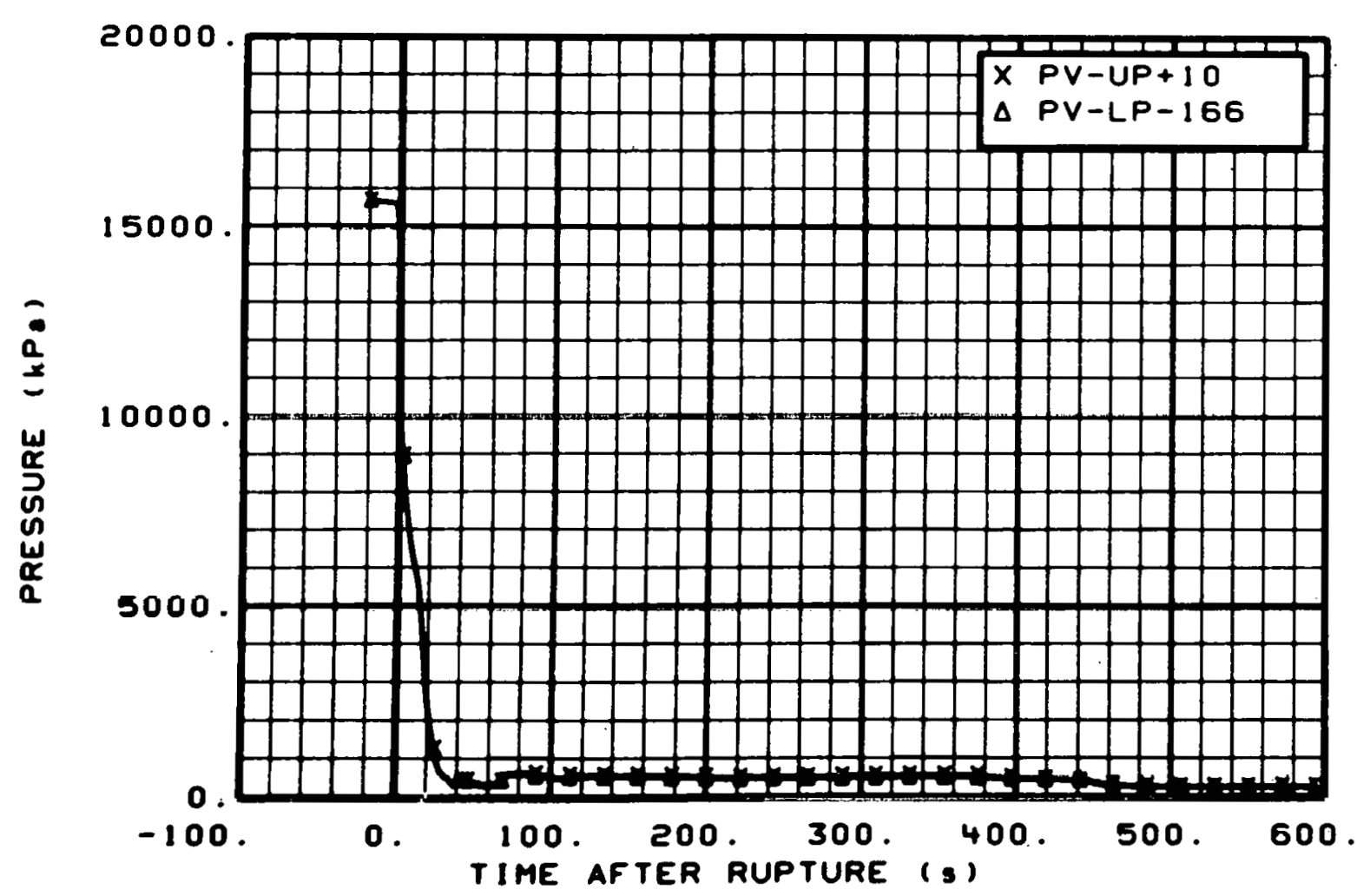

Fig. 153 Pressure in vessel (PV-UP+10 and PV-LP-166), from -20 to $600 \mathrm{~s}$.

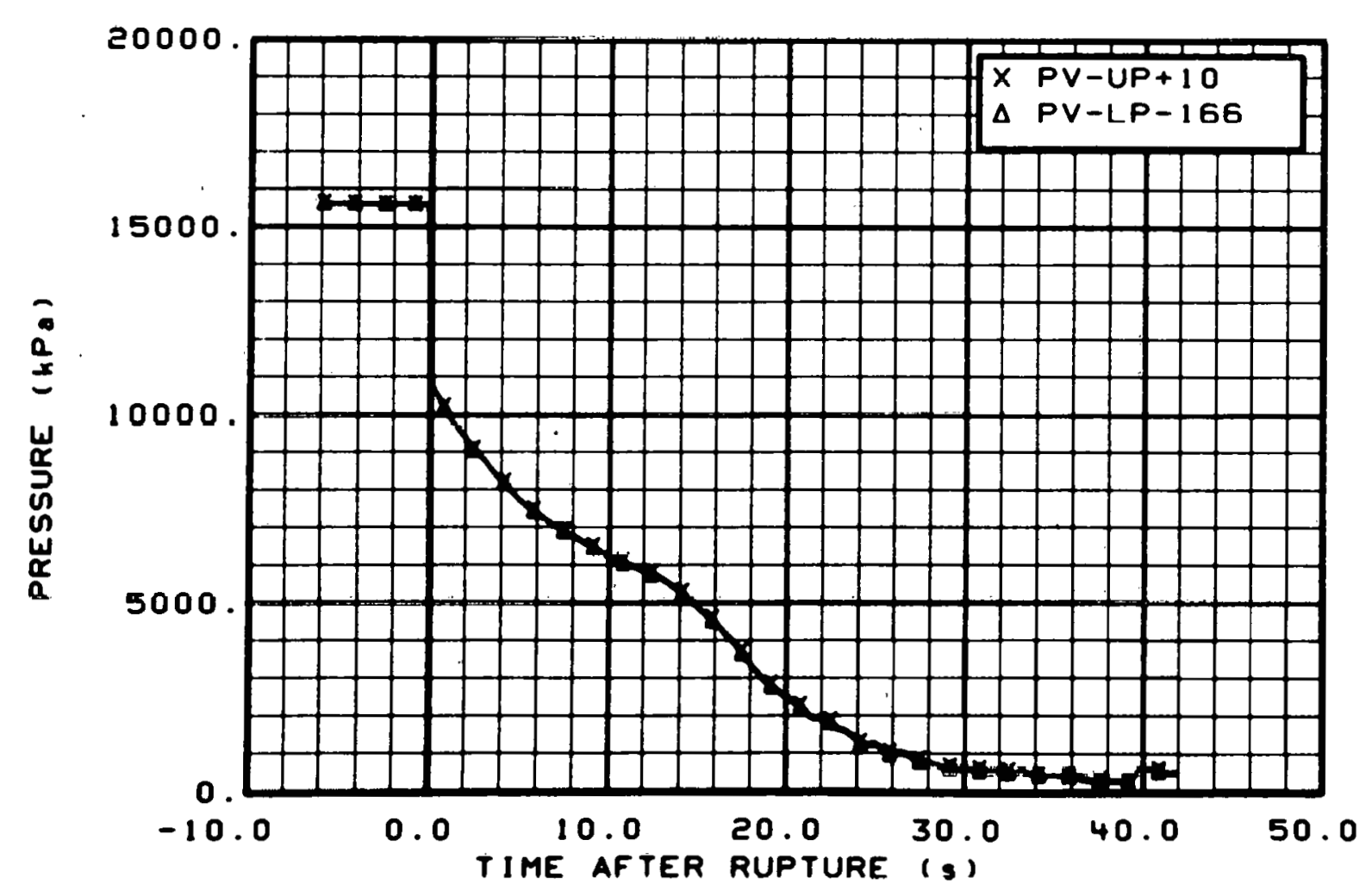

Fig. 154 Pressure in vessel (PV-UP+10 and PV-LP-166), from -6 to $42 \mathrm{~s}$. 


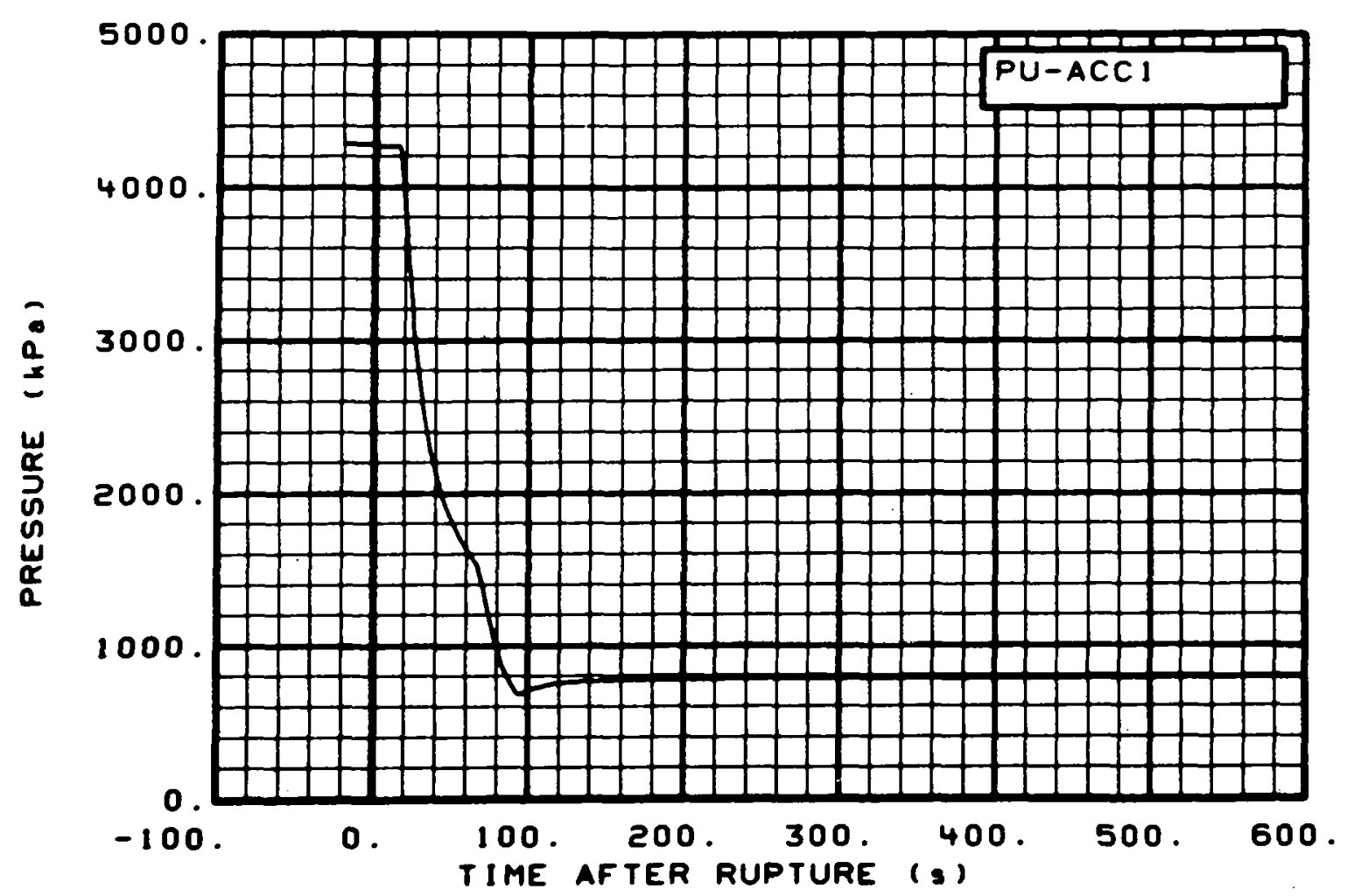

Fig. 155 Pressure in intact loop accumulator (PU-ACC1), from -20 to $600 \mathrm{~s}$.

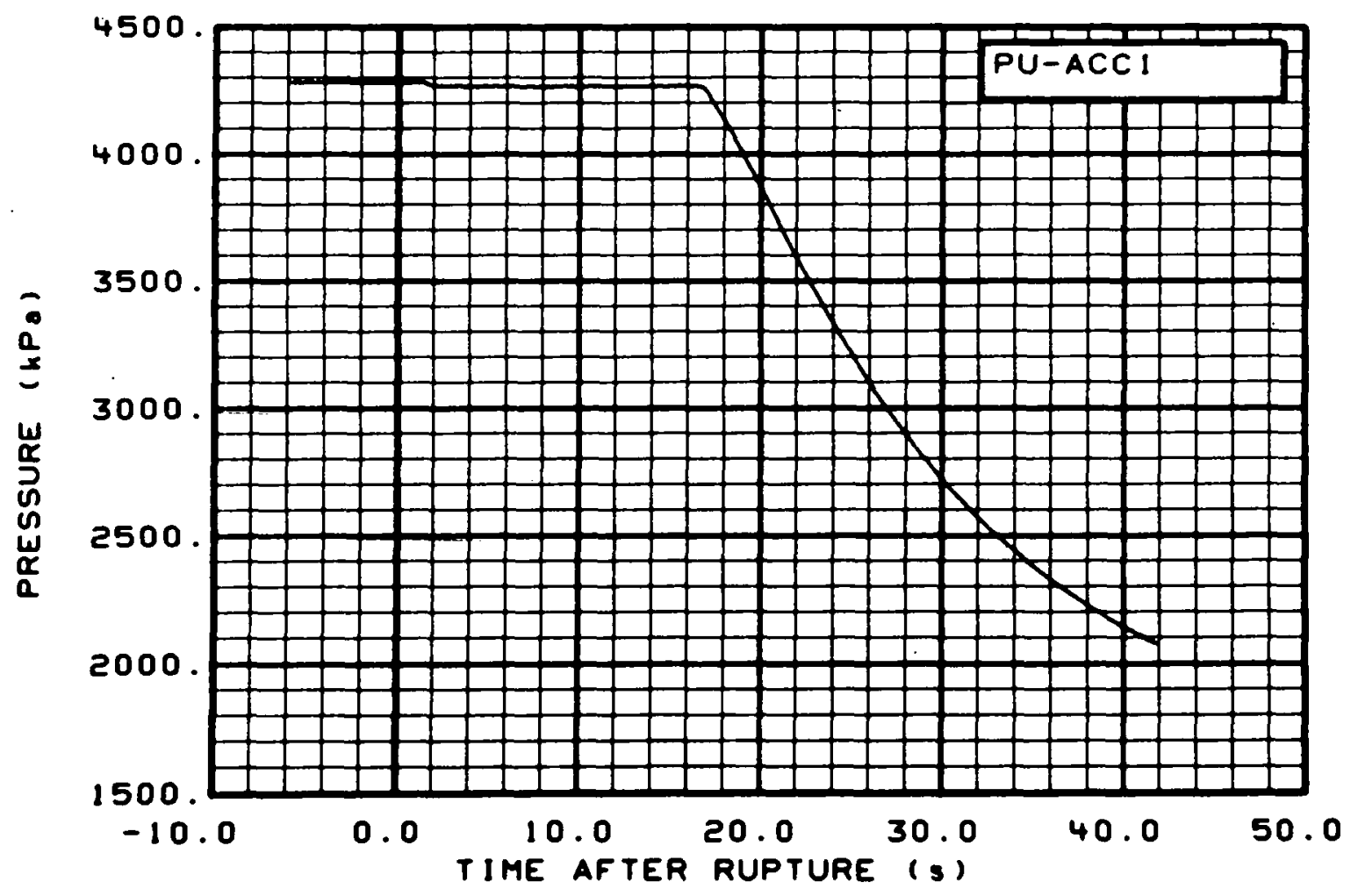

Fig. 156 Pressure in intact lnop accumulator (PU-ACC1), from -6 to $42 \mathrm{~s}$. 


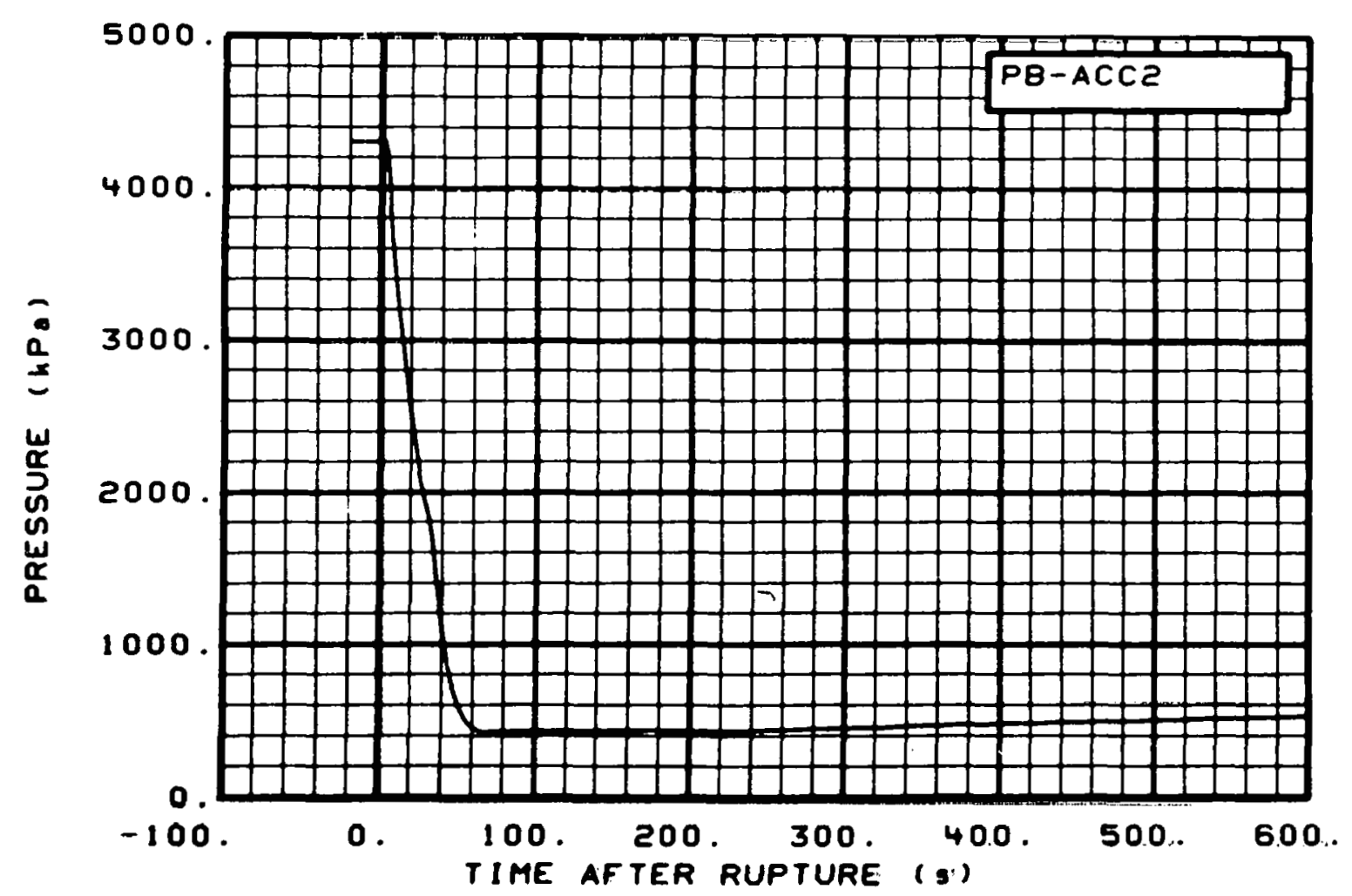

Fig. 157 Pressure in broken loop accumulator (PB-ACC2), from -20 to $600 \mathrm{~s}$.

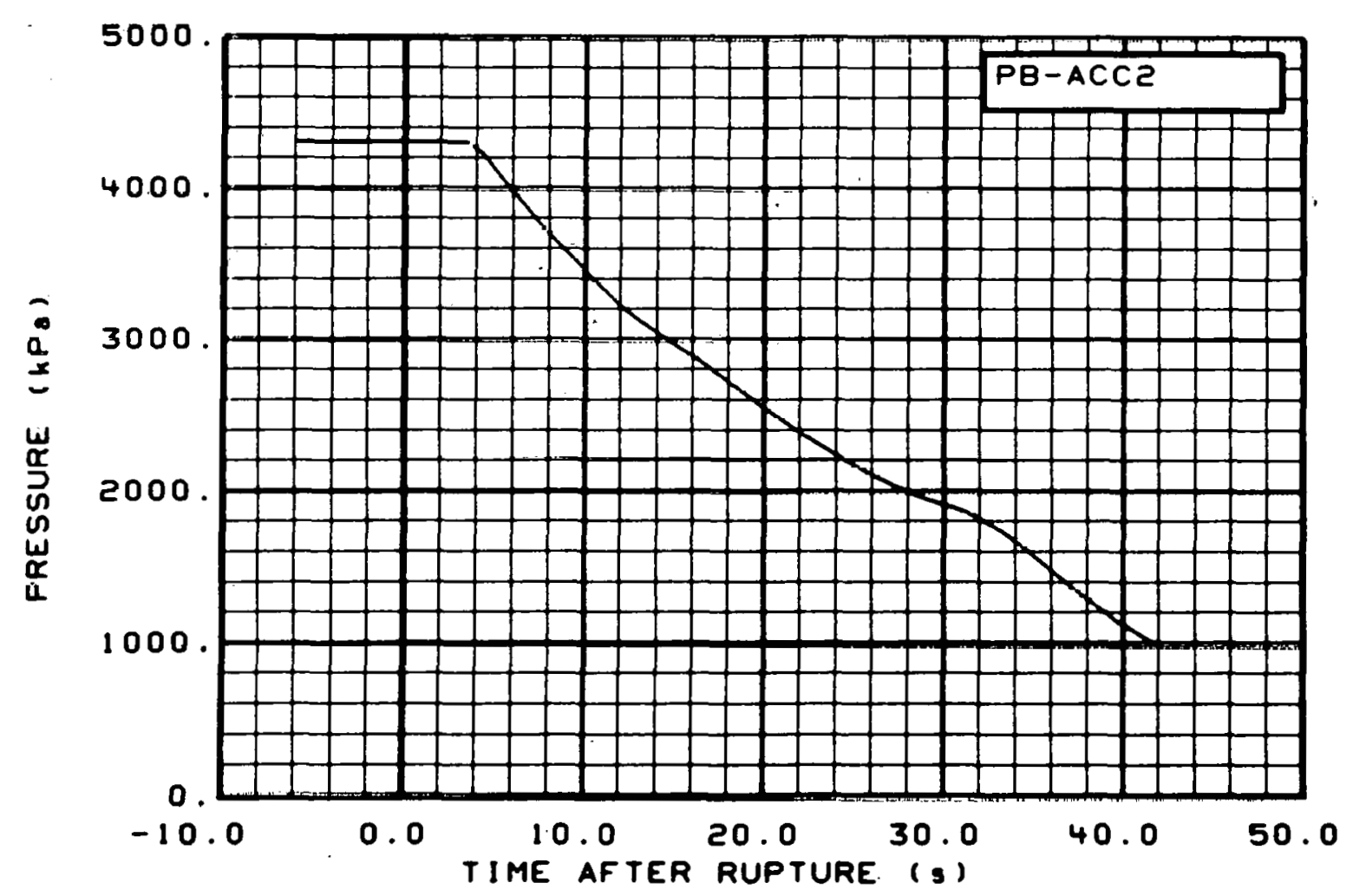

Fig. 158 Pressure in broken loop accumulator (P.B-ACC2), from -6 to $42 \mathrm{~s}$. 


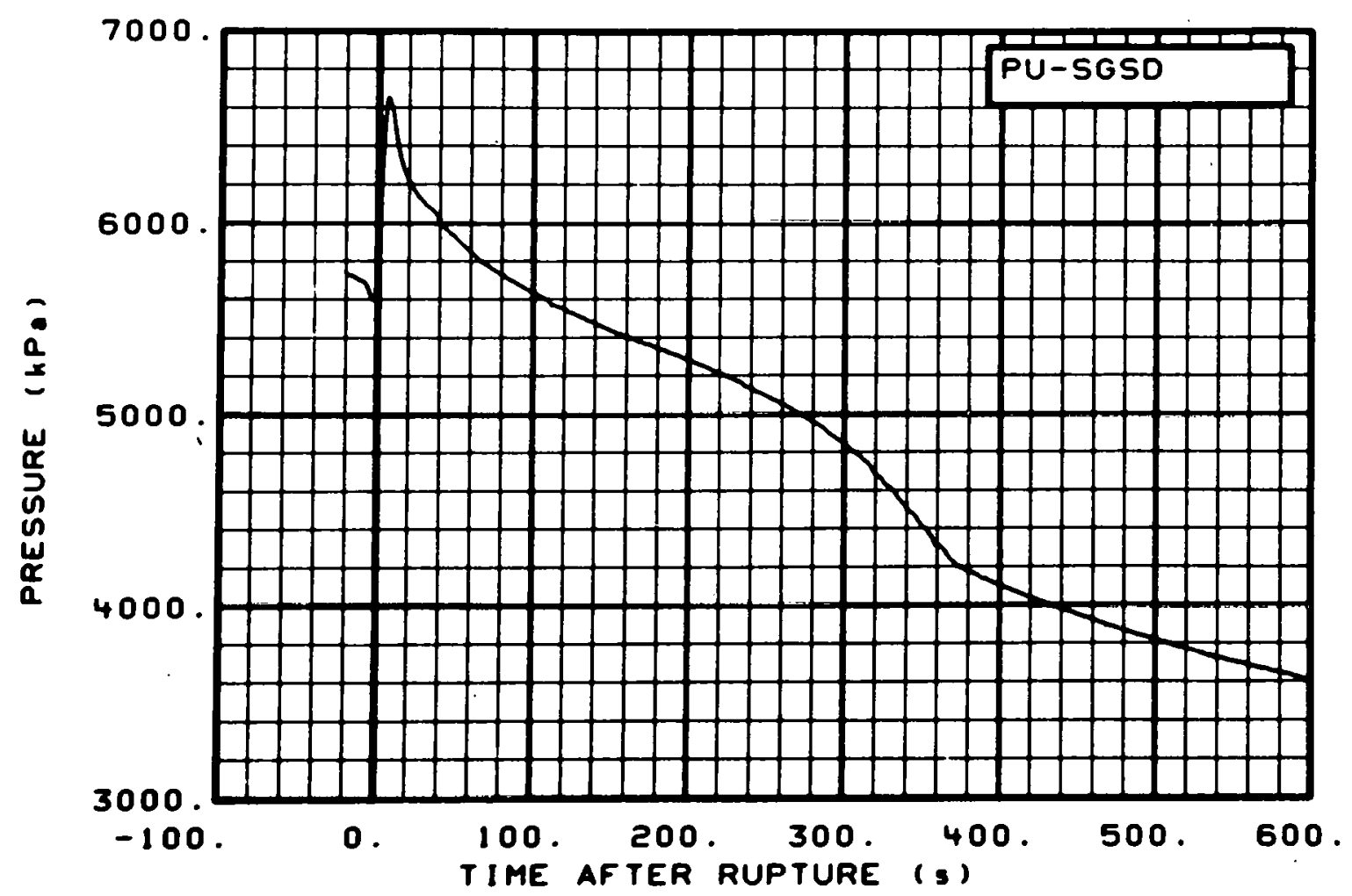

Fig. 159 Pressure in steam generator, secondary side (PU-SGSD), from -20 to $600 \mathrm{~s}$.

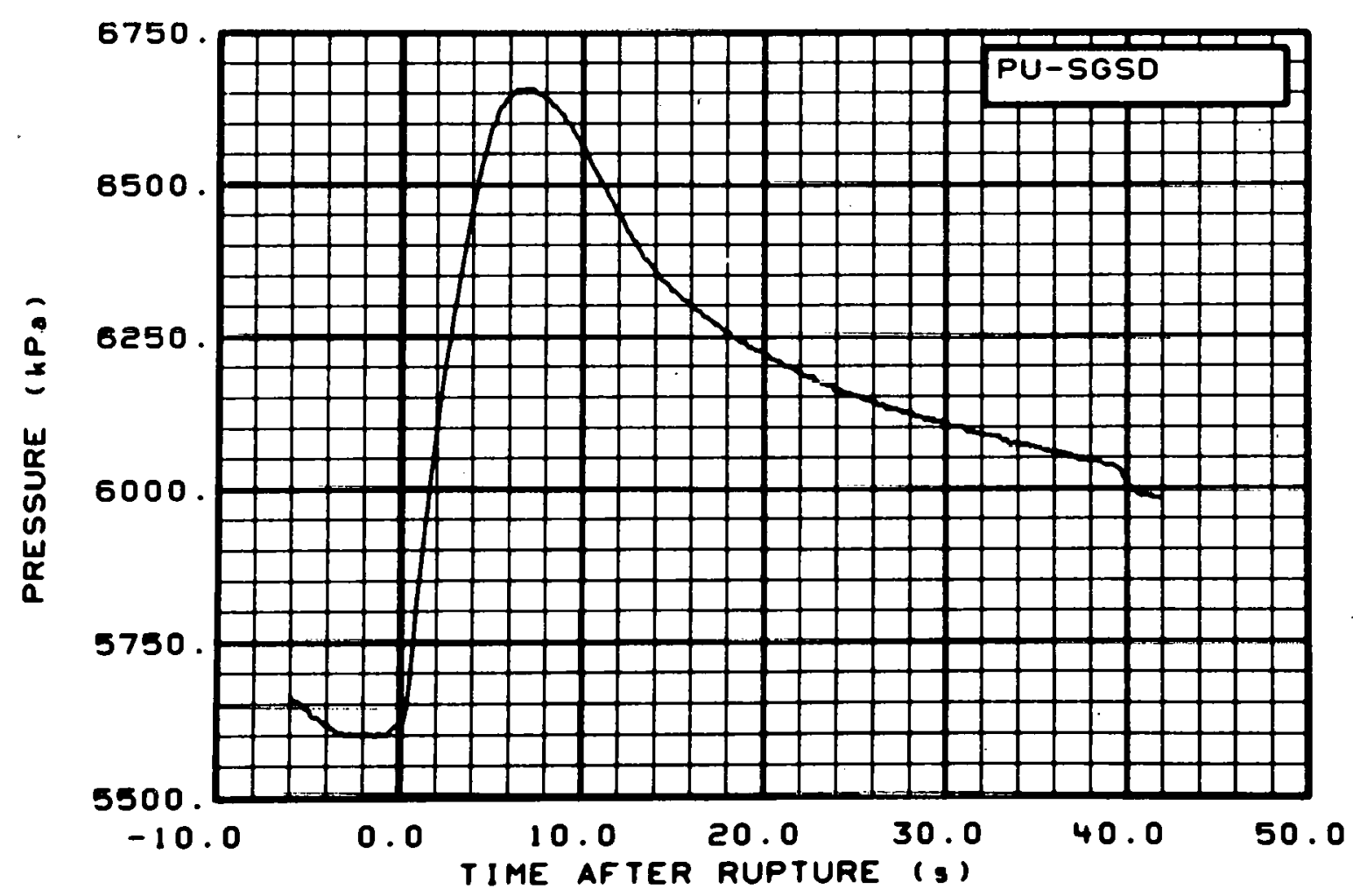

Fig. 160 Pressure in steam generator, secondary side (PU-SGSD), from -6 to $42 \mathrm{~s}$. 


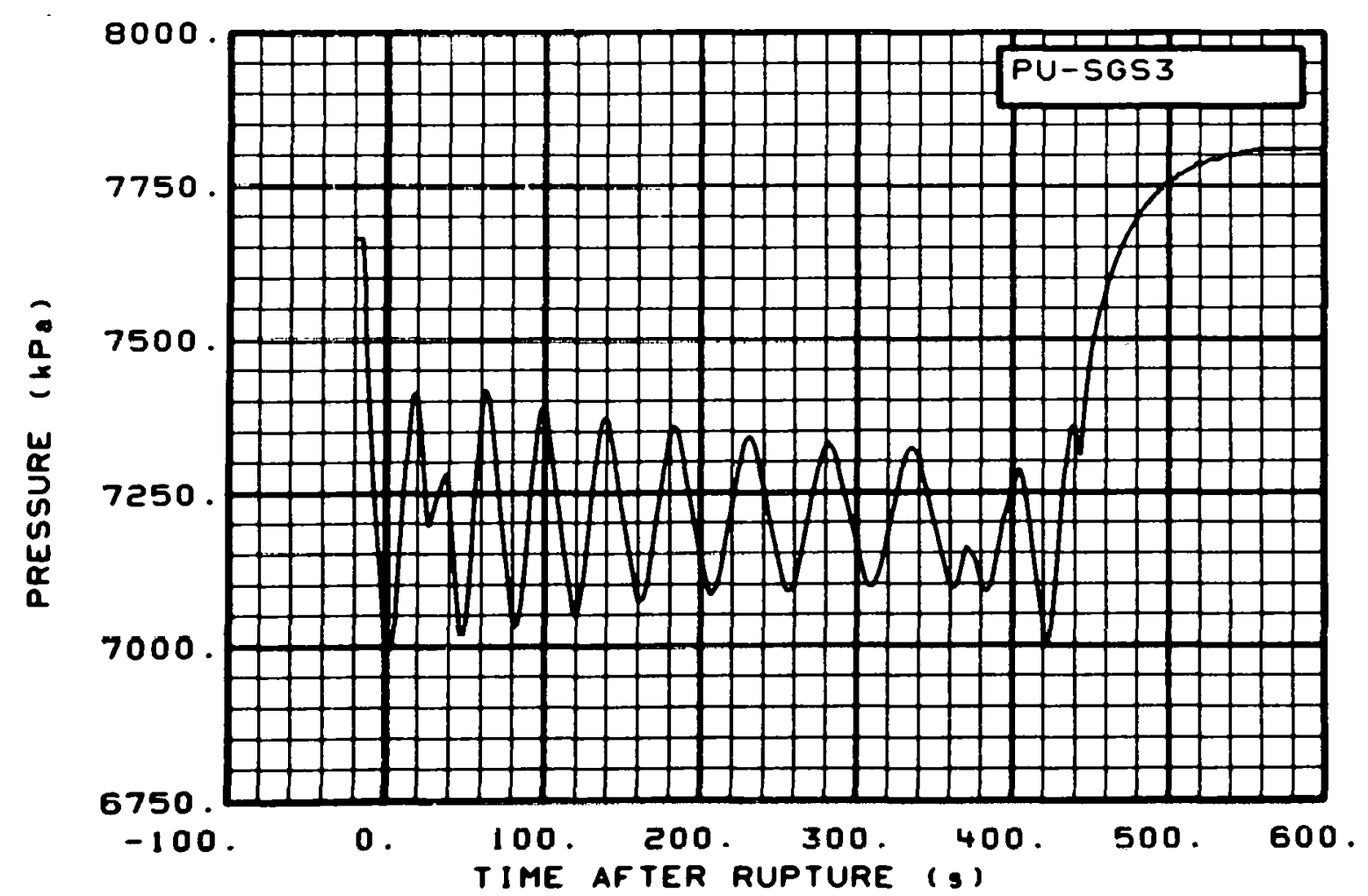

Fig. 161 Pressure in steam generator, tube rupture simulation accumulator (PU-SGS3), from -20 to $600 \mathrm{~s}$.

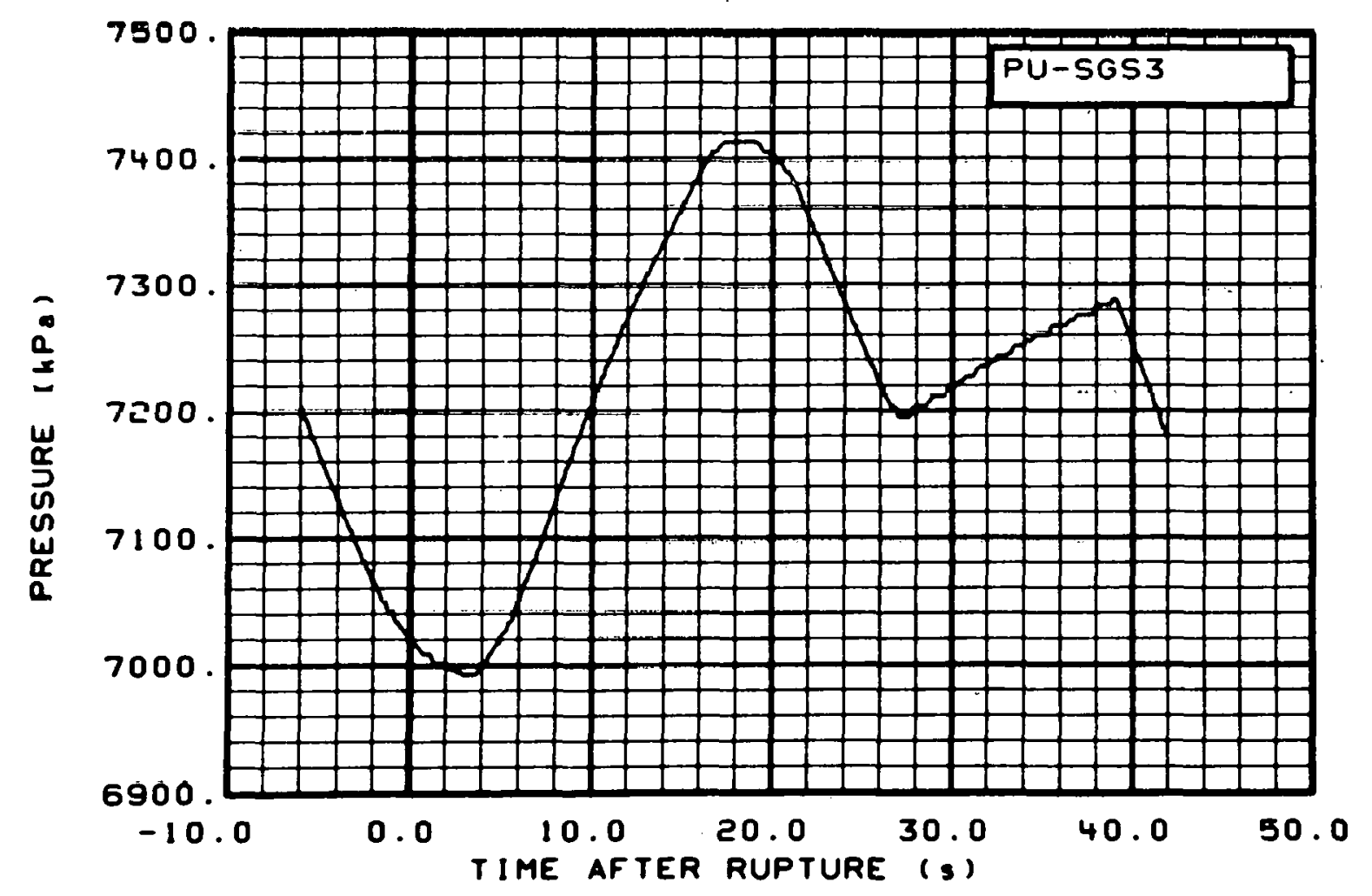

Fig. 162 Pressure in steam generator, tube rupture simulation accumulator (PU-SGS3), from -6 to $42 \mathrm{~s}$. 


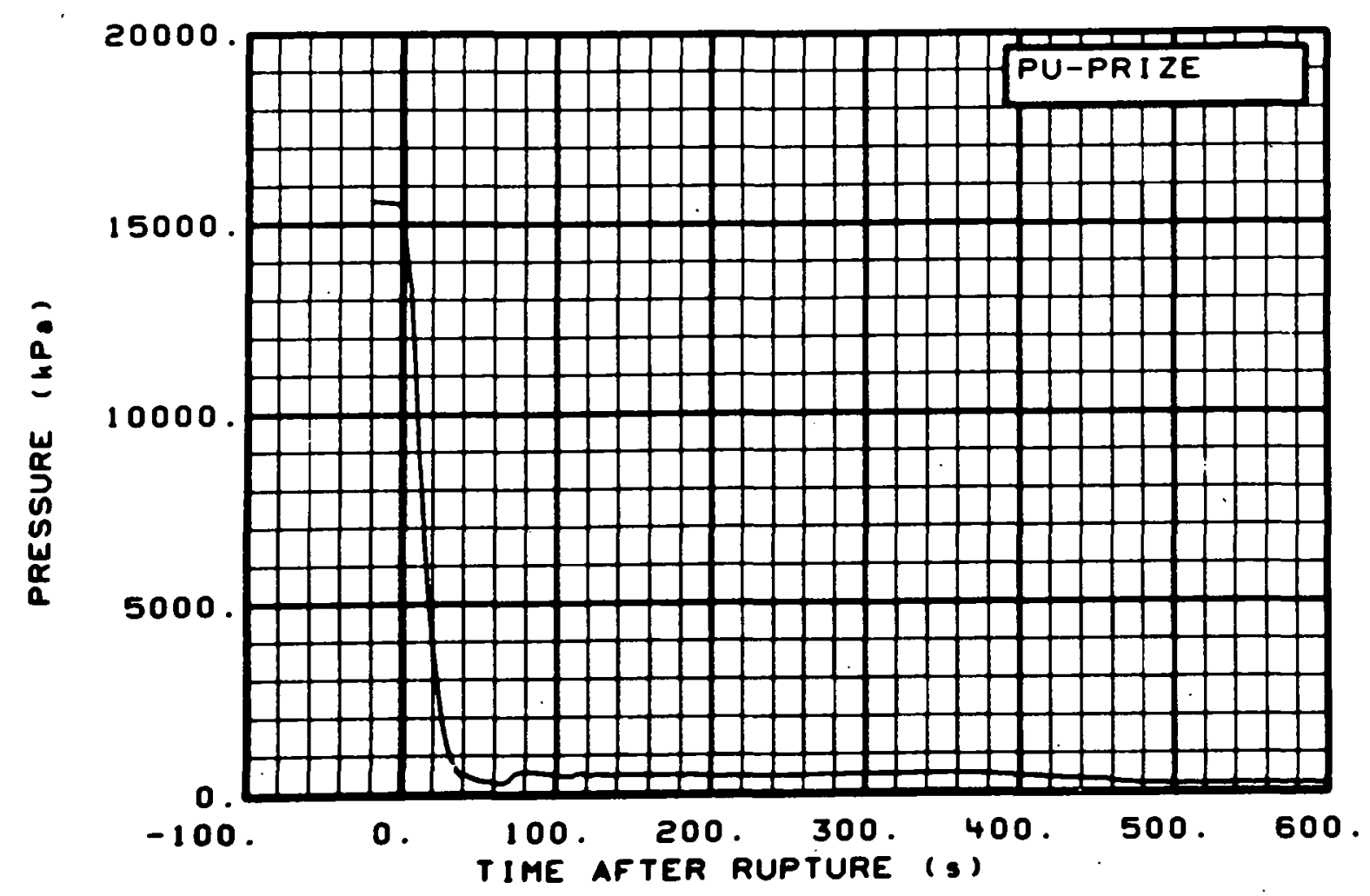

Fig. 163 Pressure in pressurizer (PU-PRIZE), from -20 to $600 \mathrm{~s}$. "

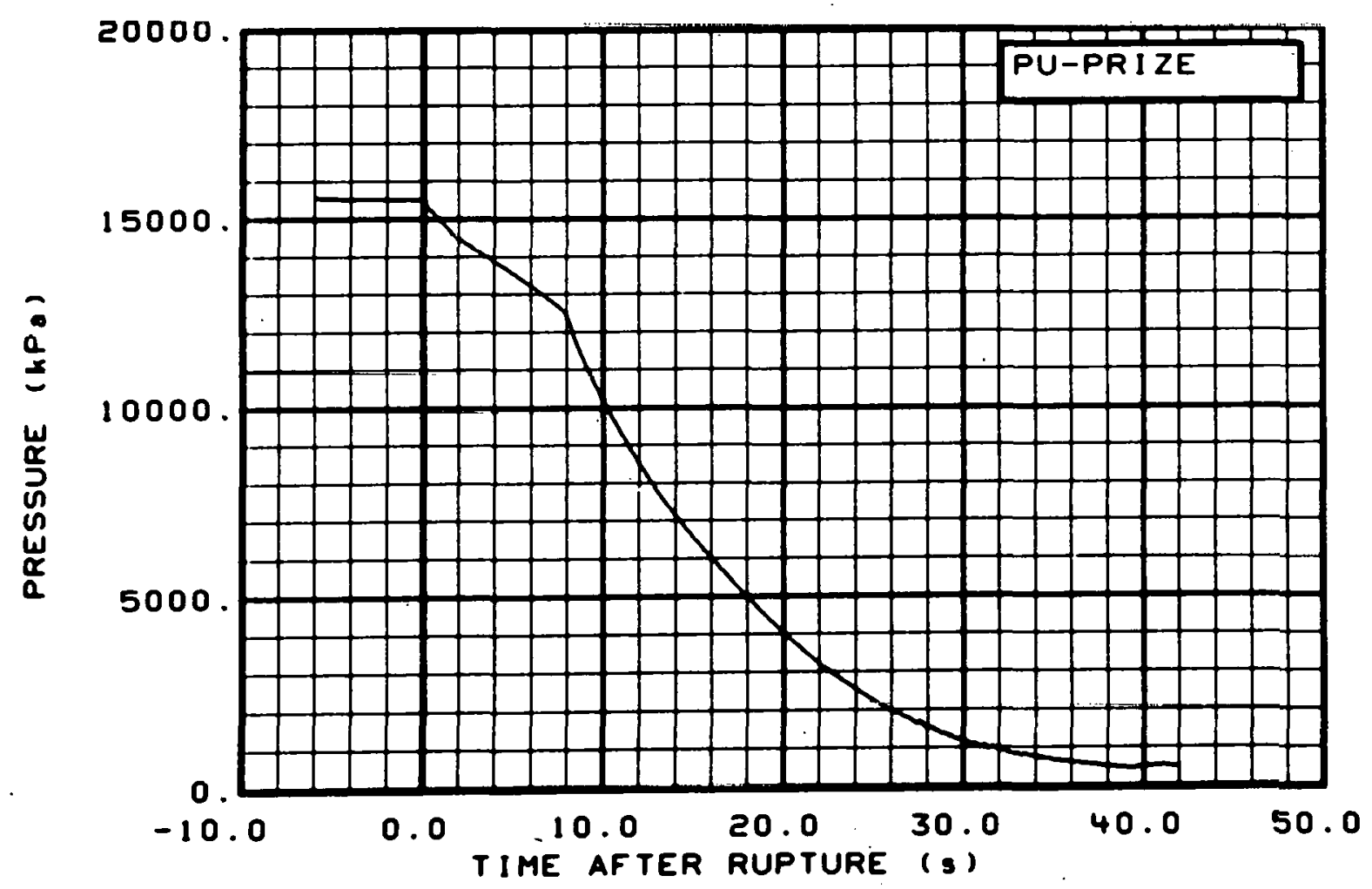

Fig. 164 Pressure in pressurizer (PU-PRIZE), from -6 to $42 \mathrm{~s}$. 


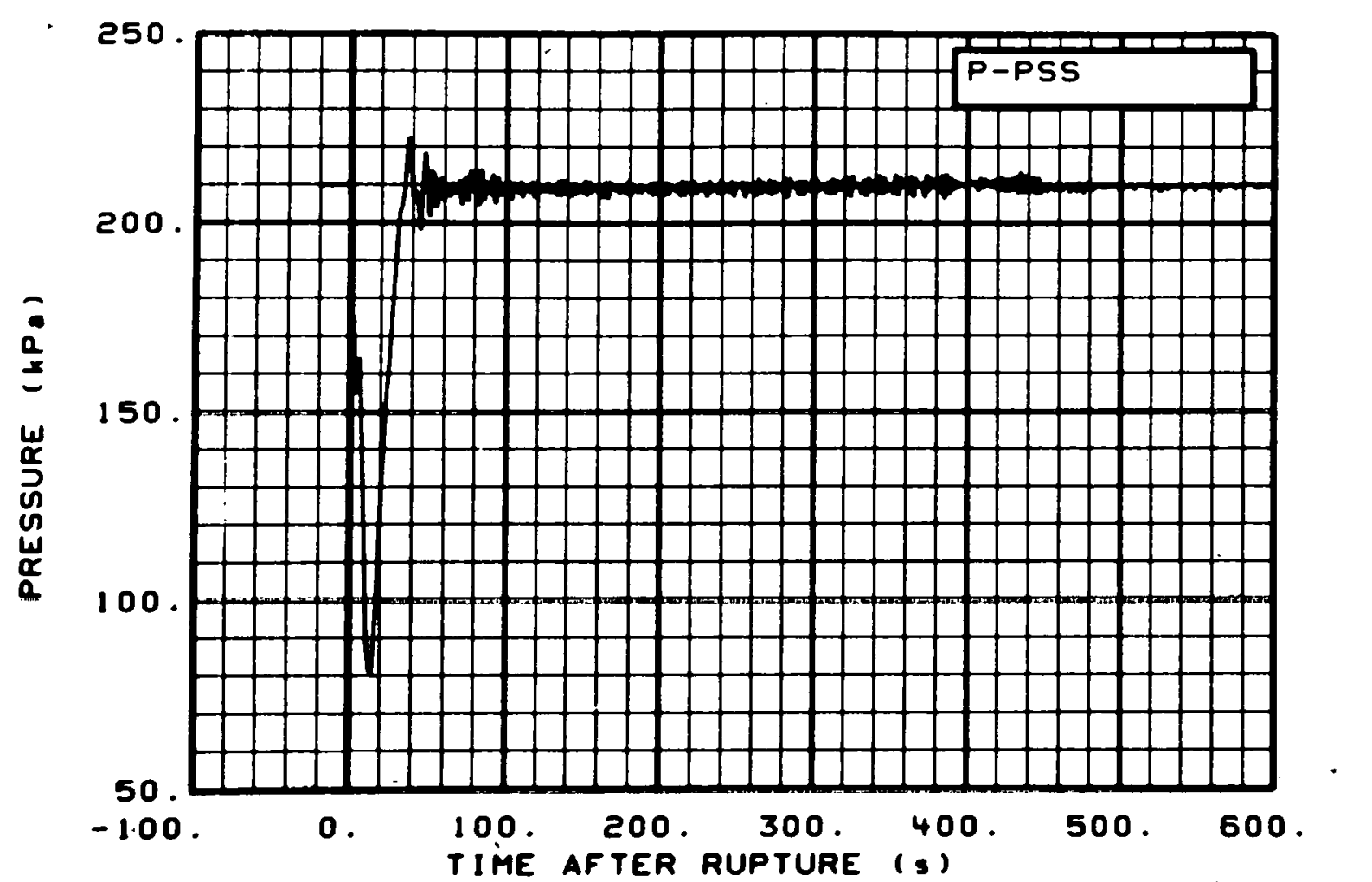

Fig. 165 Pressure in pressure suppression tank (P-PSS), from -20 to $600 \mathrm{~s}$.

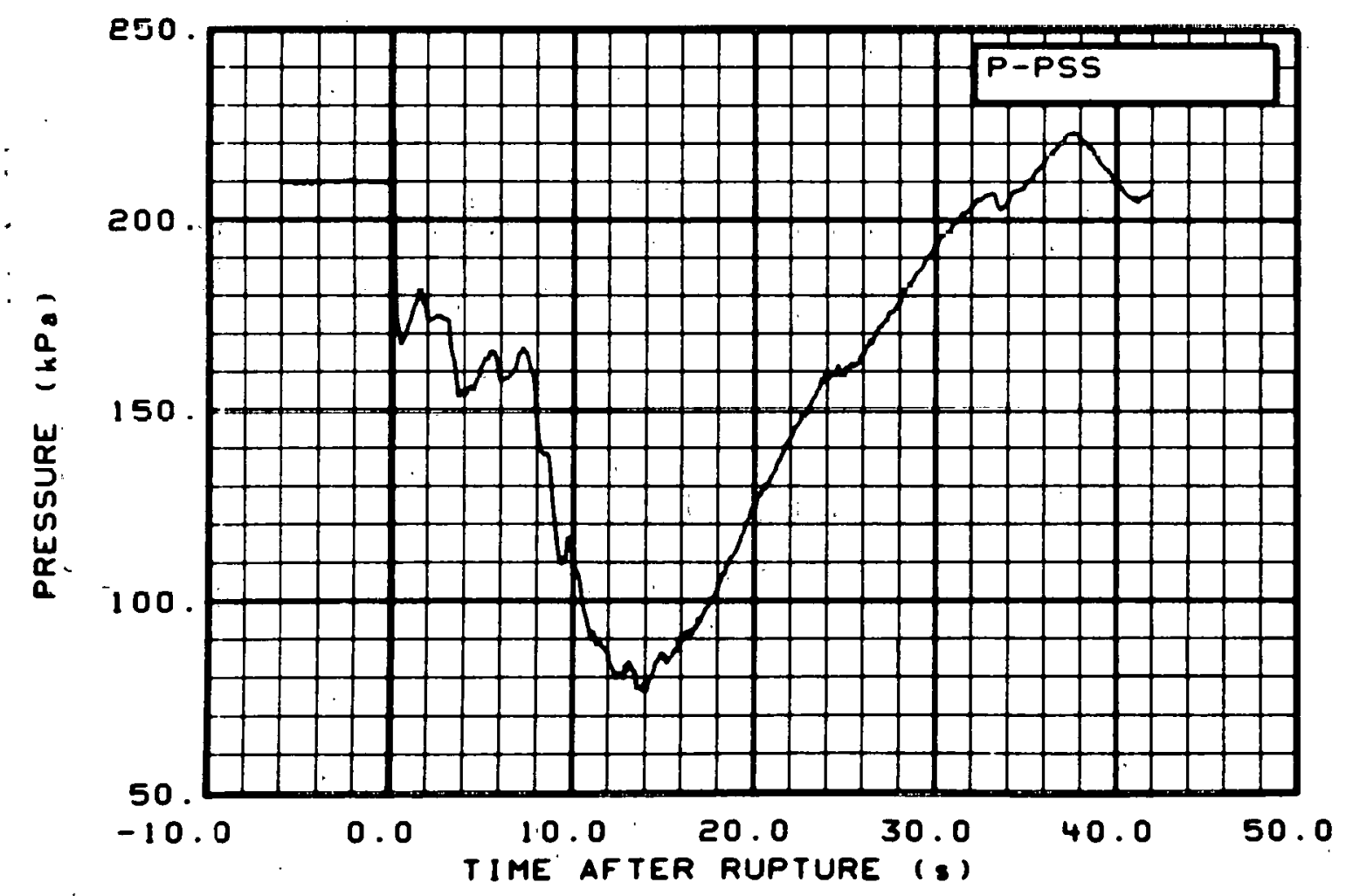

Fig. 166 Pressure in pressure suppression tank (P-PSS), from -6 to $42 \mathrm{~s}$. 


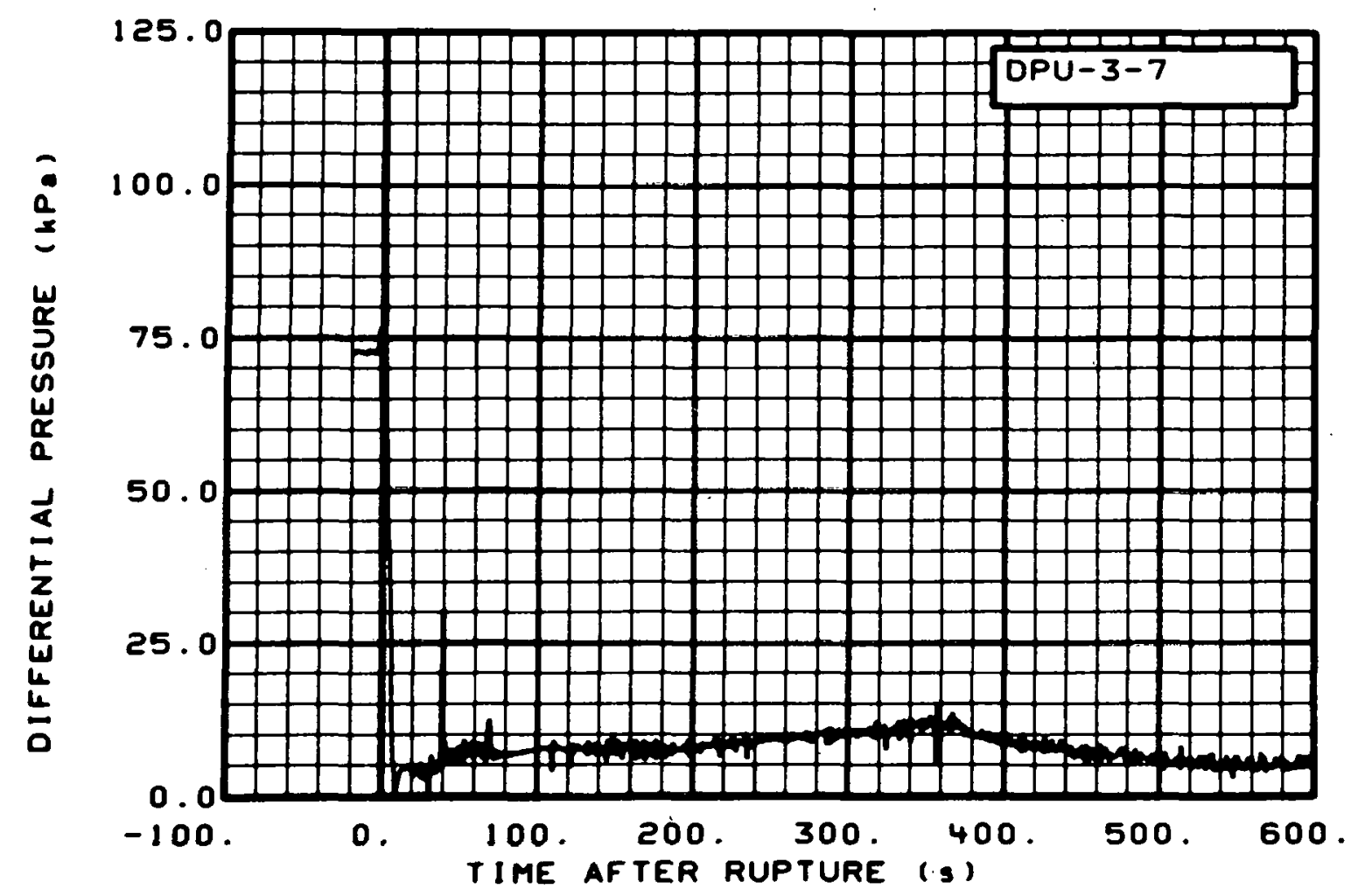

Fig. 167 Differential pressure in intact loop (DPU-3-7), from -20 to $600 \mathrm{~s}$.

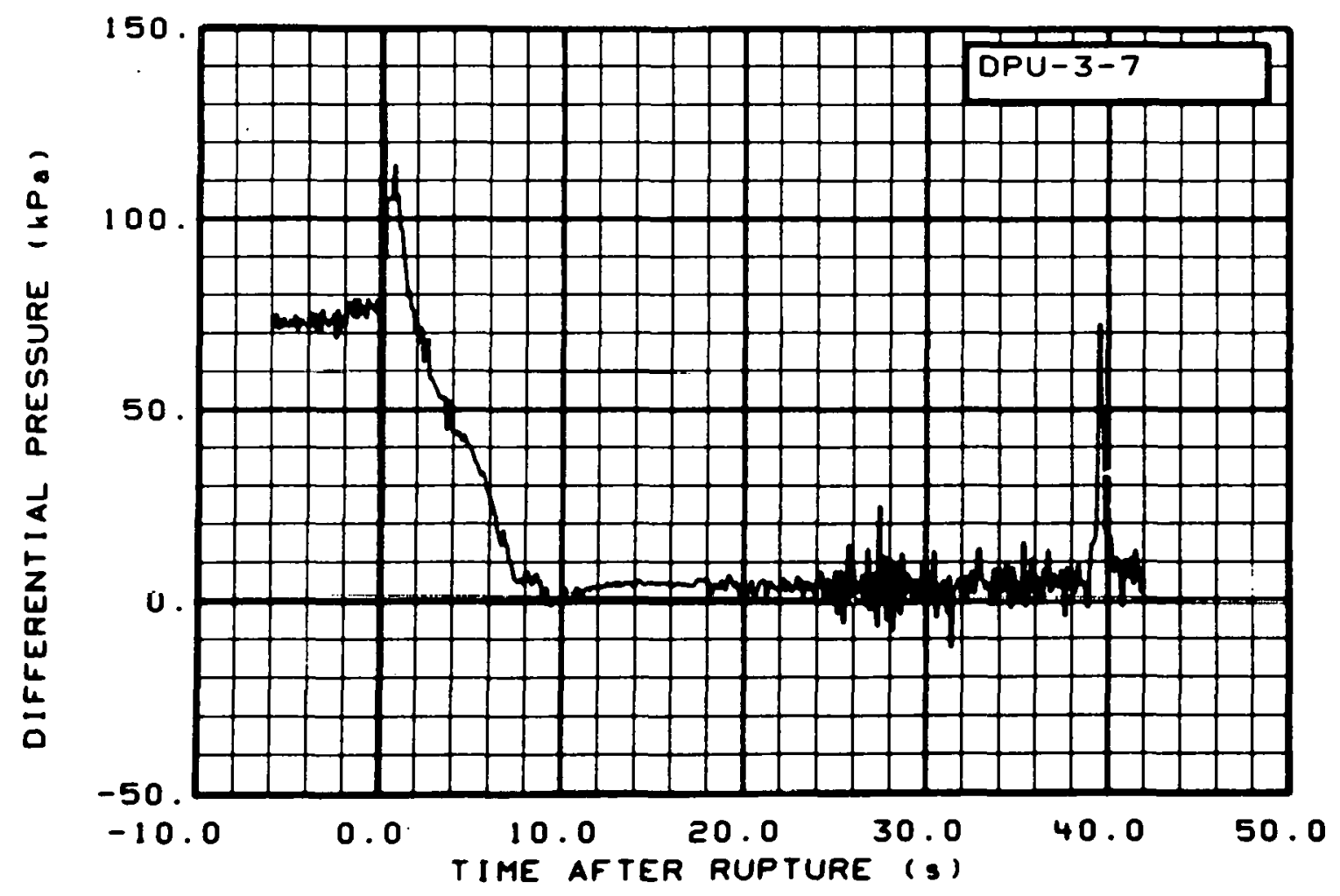

Fig. 168 Differential pressure in intact loop (DPU-3-7), from -6 to $42 \mathrm{~s}$. 


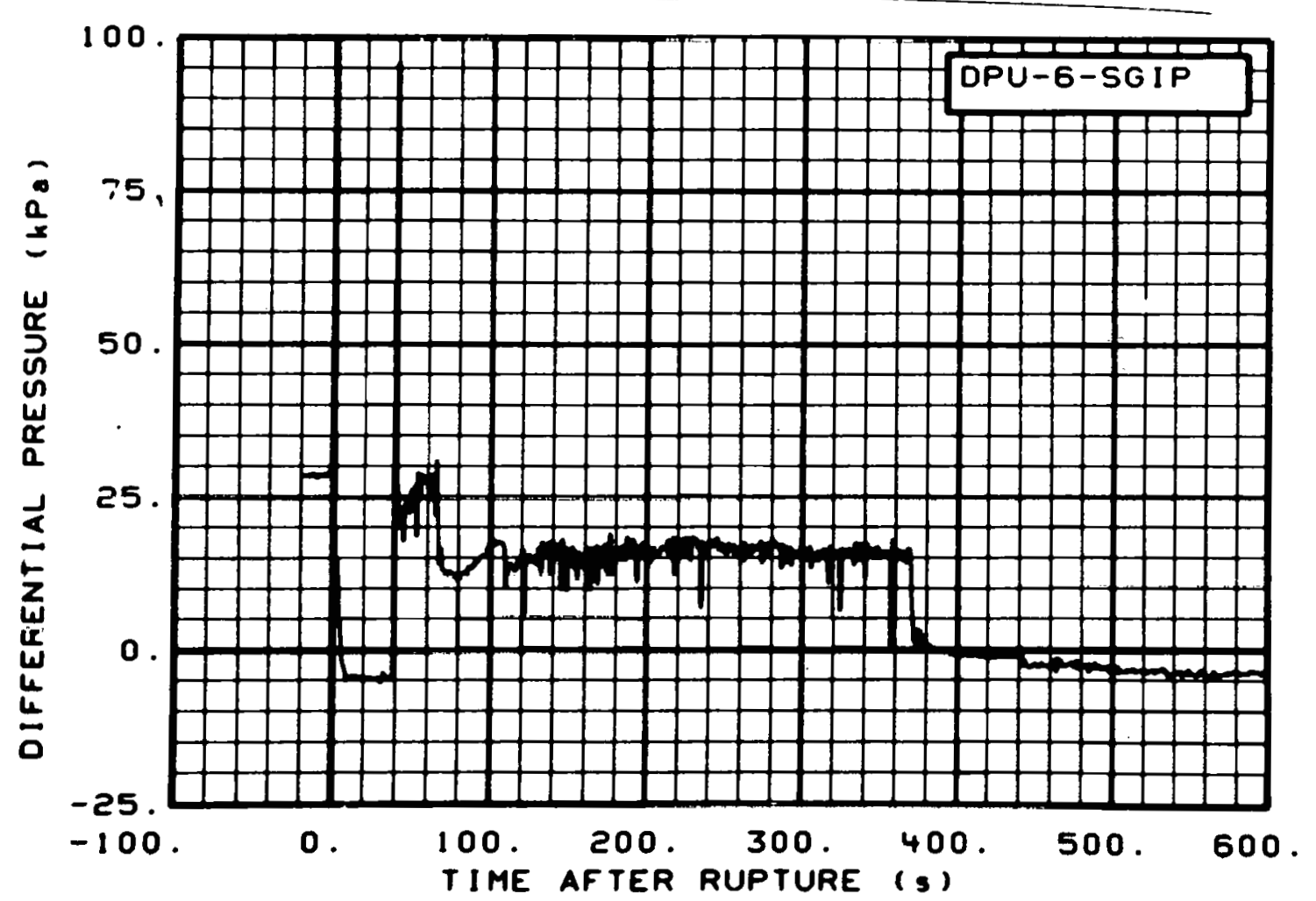

Fig. 169 Differential pressure in intact loop (DPU-6-SGIP), from -20 to $600 \mathrm{~s}$.

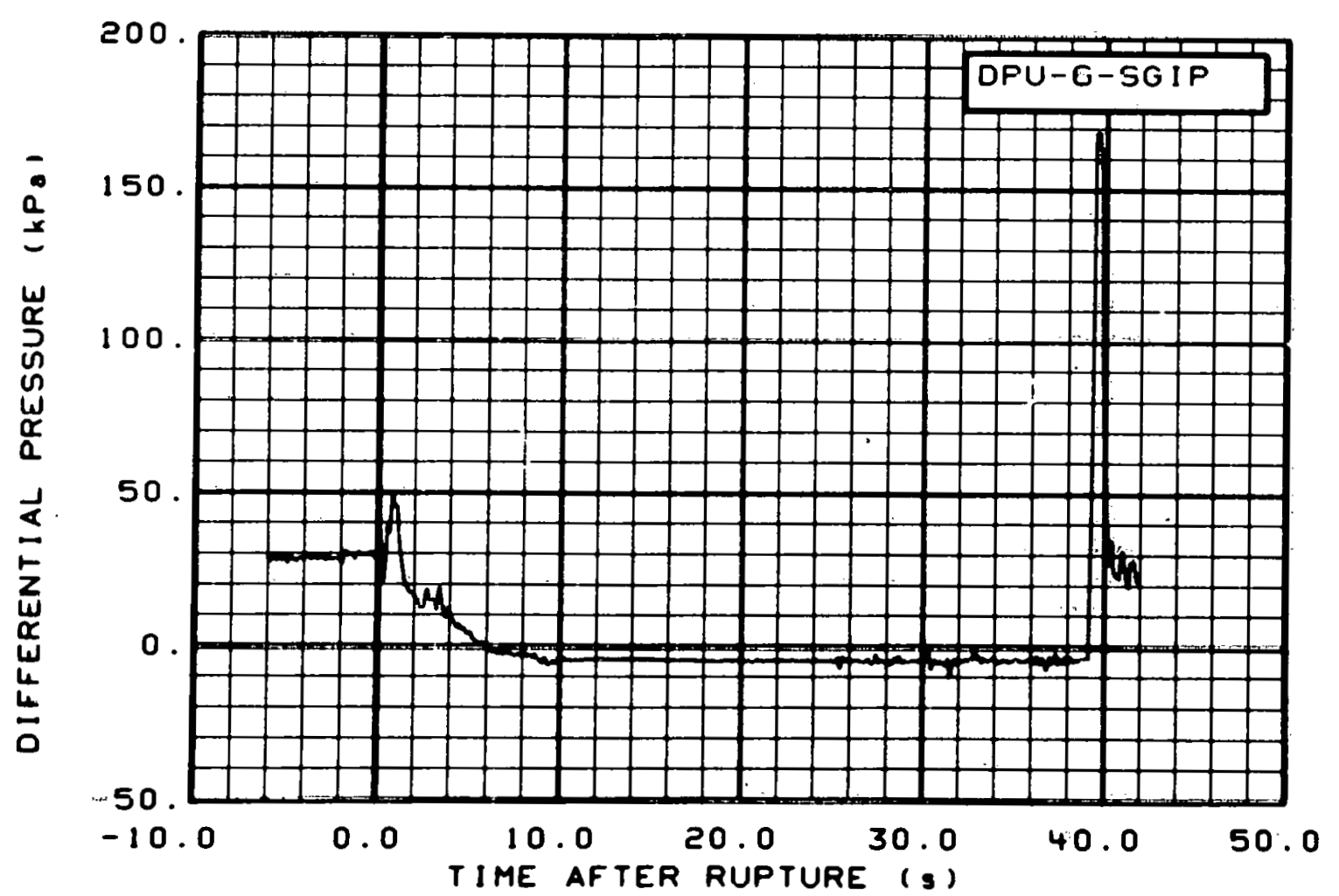

Fig. 170 Differential pressure in intact loop (DPU-6-SGIP), from -6 to $42 \mathrm{~s}$. 


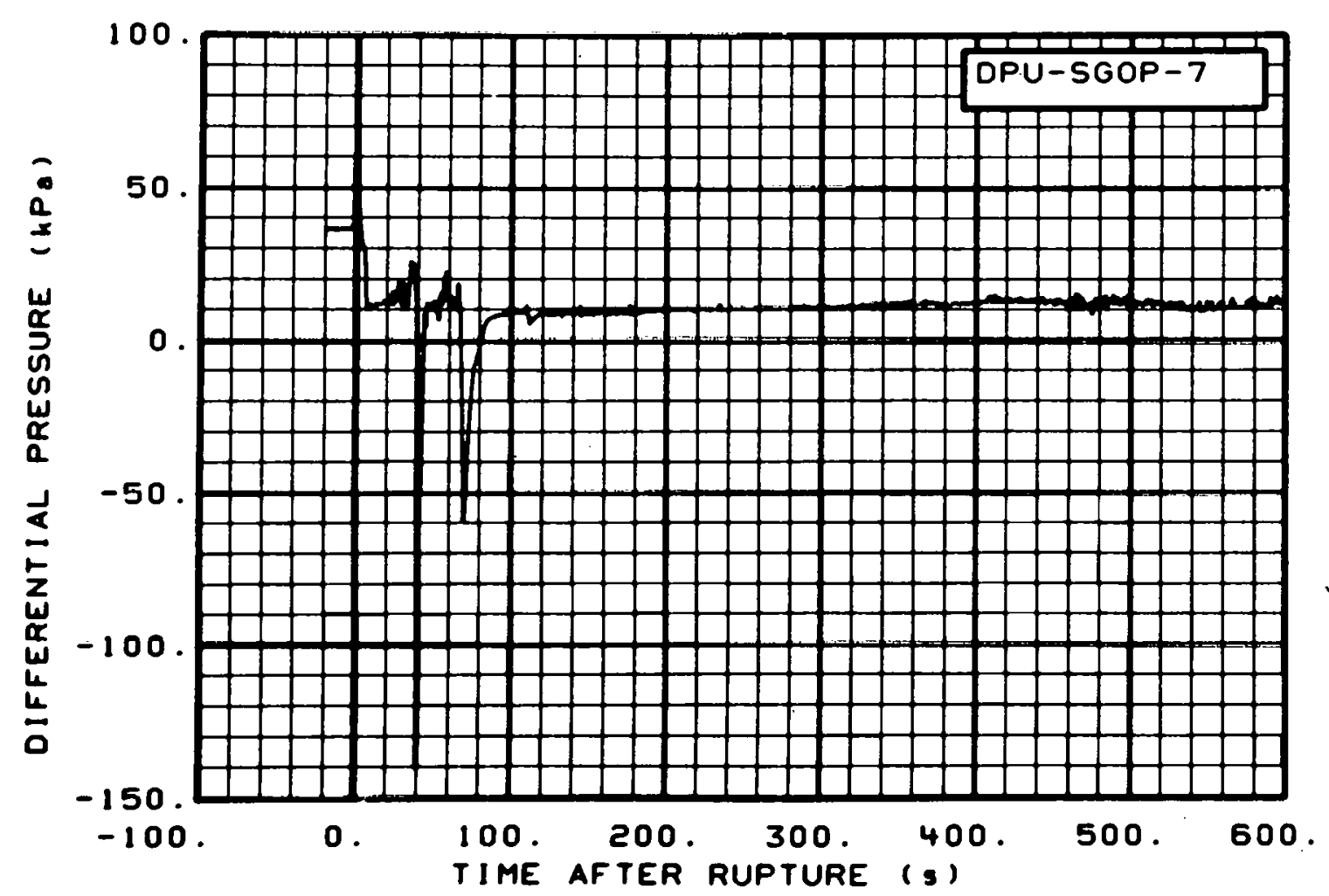

Fig. 171 Differential pressure in intact loop (DPU-SGOP-7), from -20 to $600 \mathrm{~s}$.

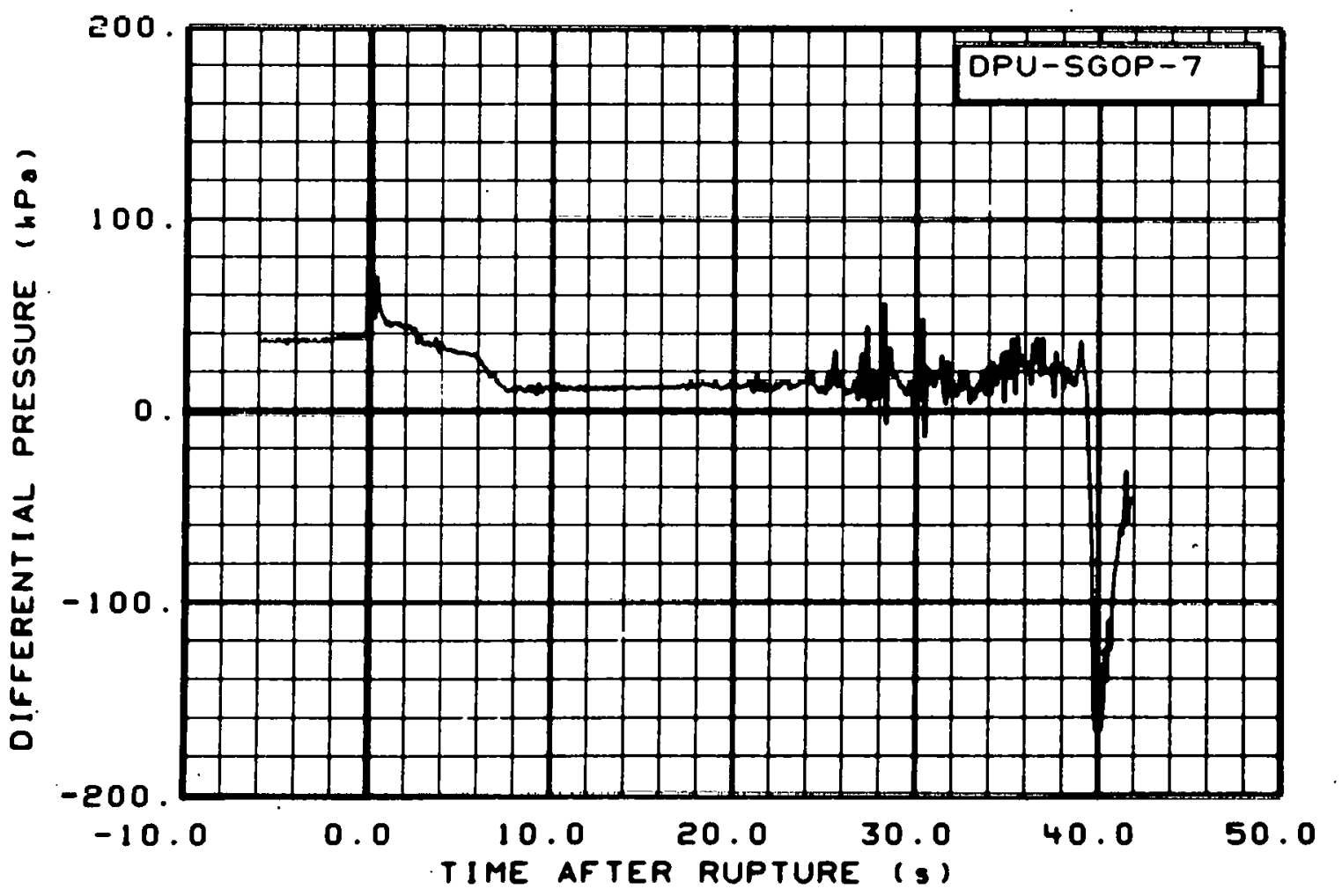

Fig. 172 Differential pressure in intact 10مp (DPII-SGOP-7), from -6 to $42 \mathrm{~s}$. 


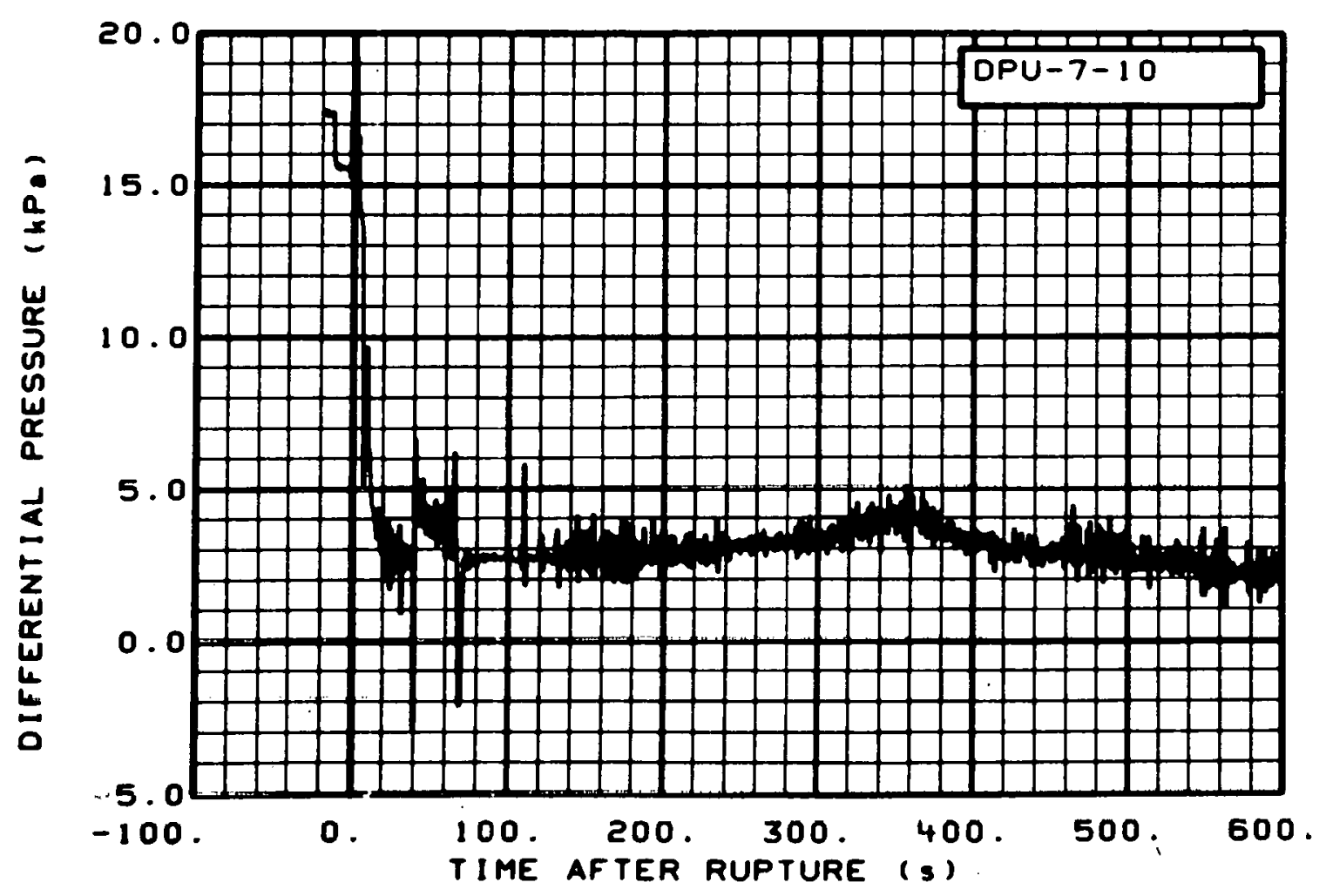

Fig. 173 Differential pressure in intact loop (DPU-7-10), from -20 to $600 \mathrm{~s}$.

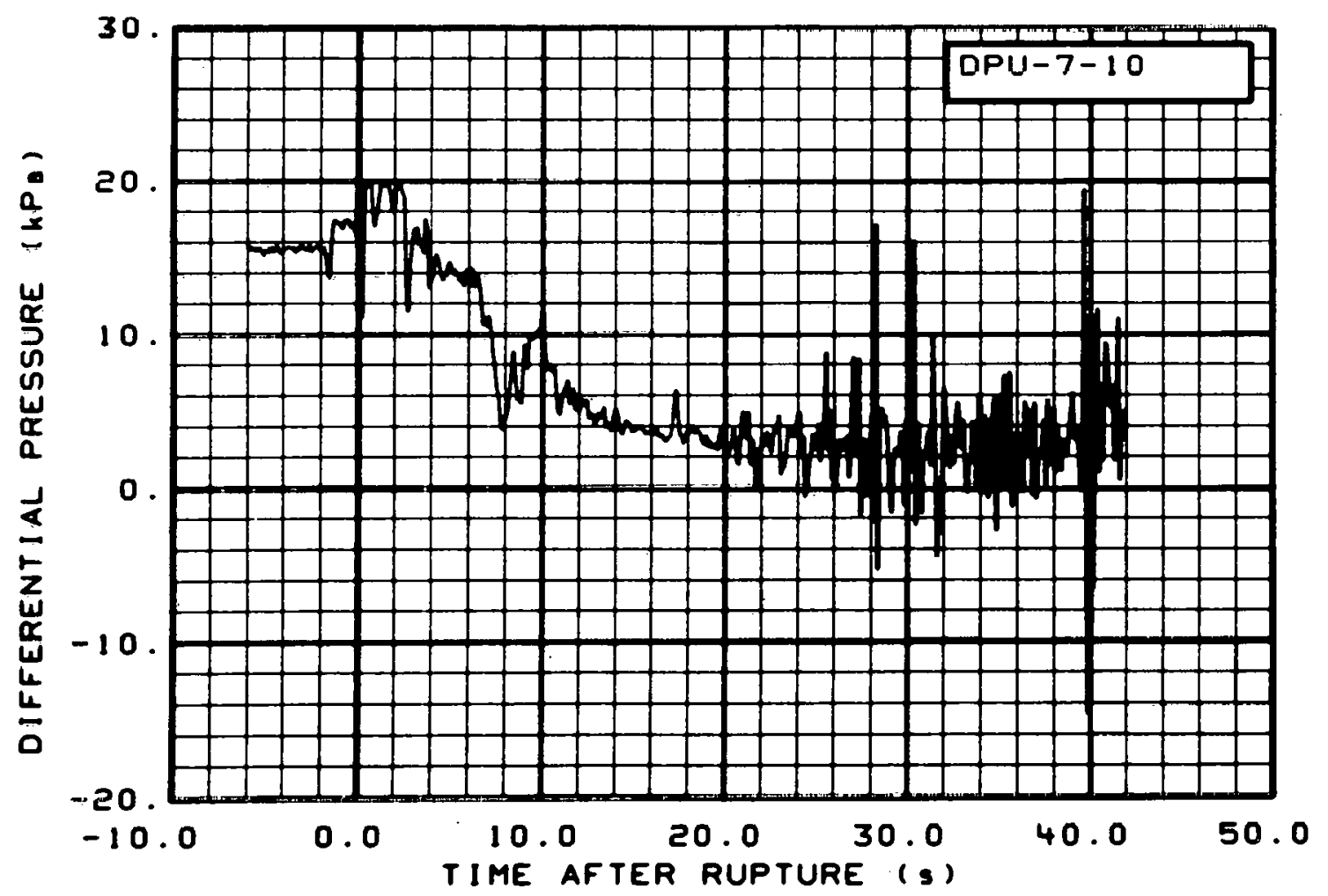

Fig. 174 Differential pressure in intact loop (DPU-7-10), from -6 to $42 \mathrm{~s}$. 


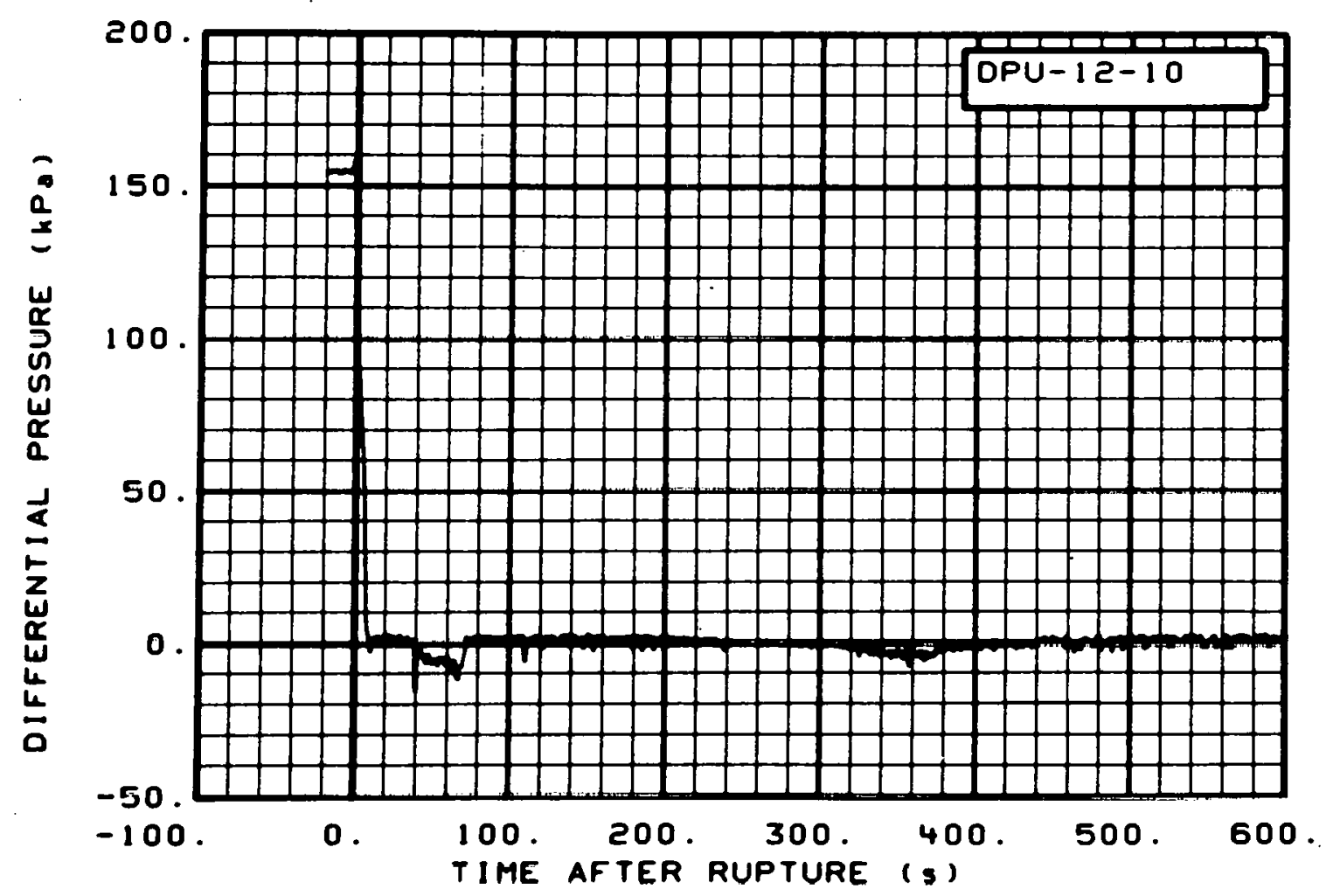

Fig. 175 Differential pressure in intact loop (DPU-12-10), from -20 to $600 \mathrm{~s}$.

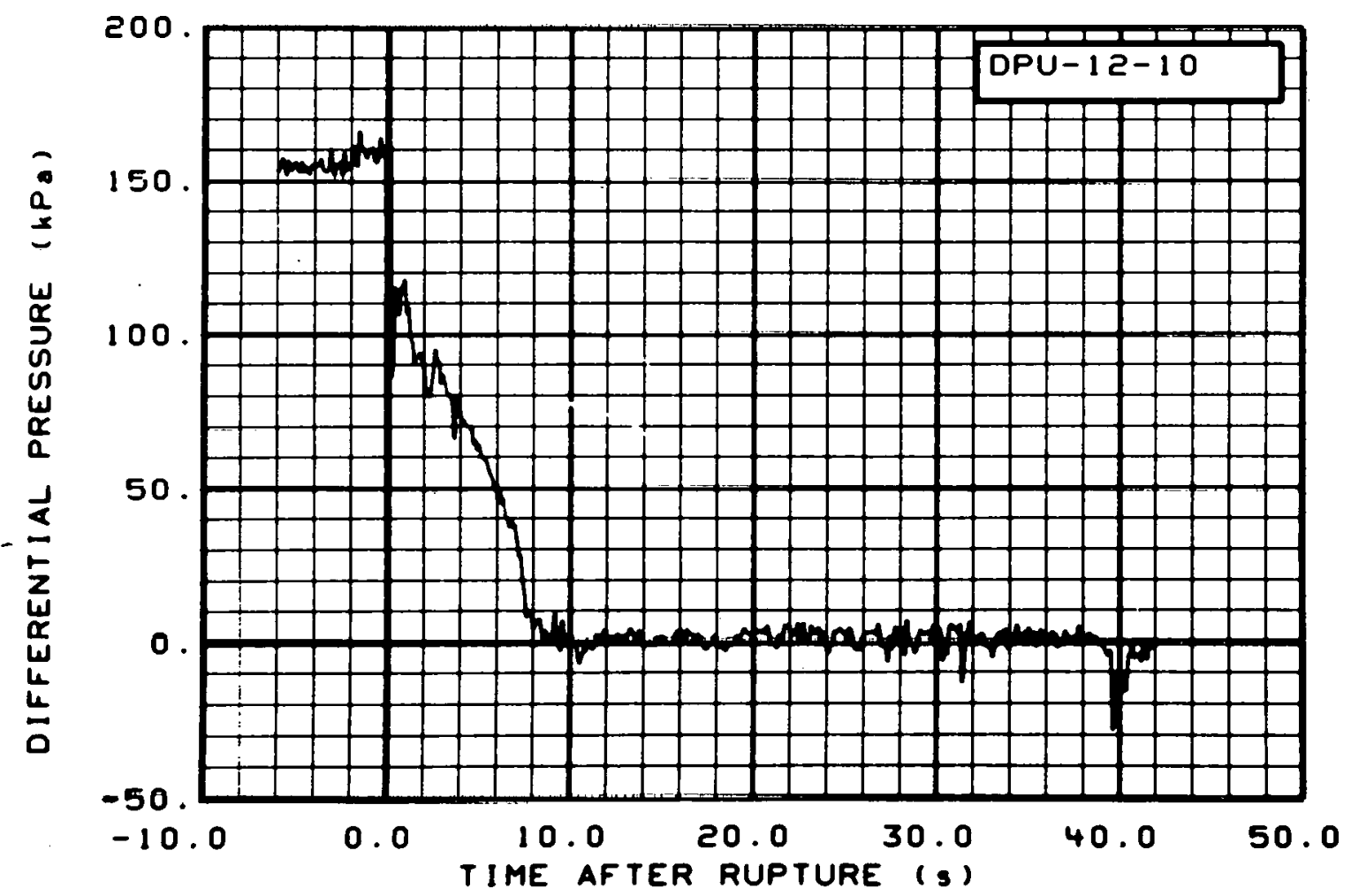

Fig. 176 Differential pressure in intact loop (DPU-12-10), from -6 to $42 \mathrm{~s}$. 


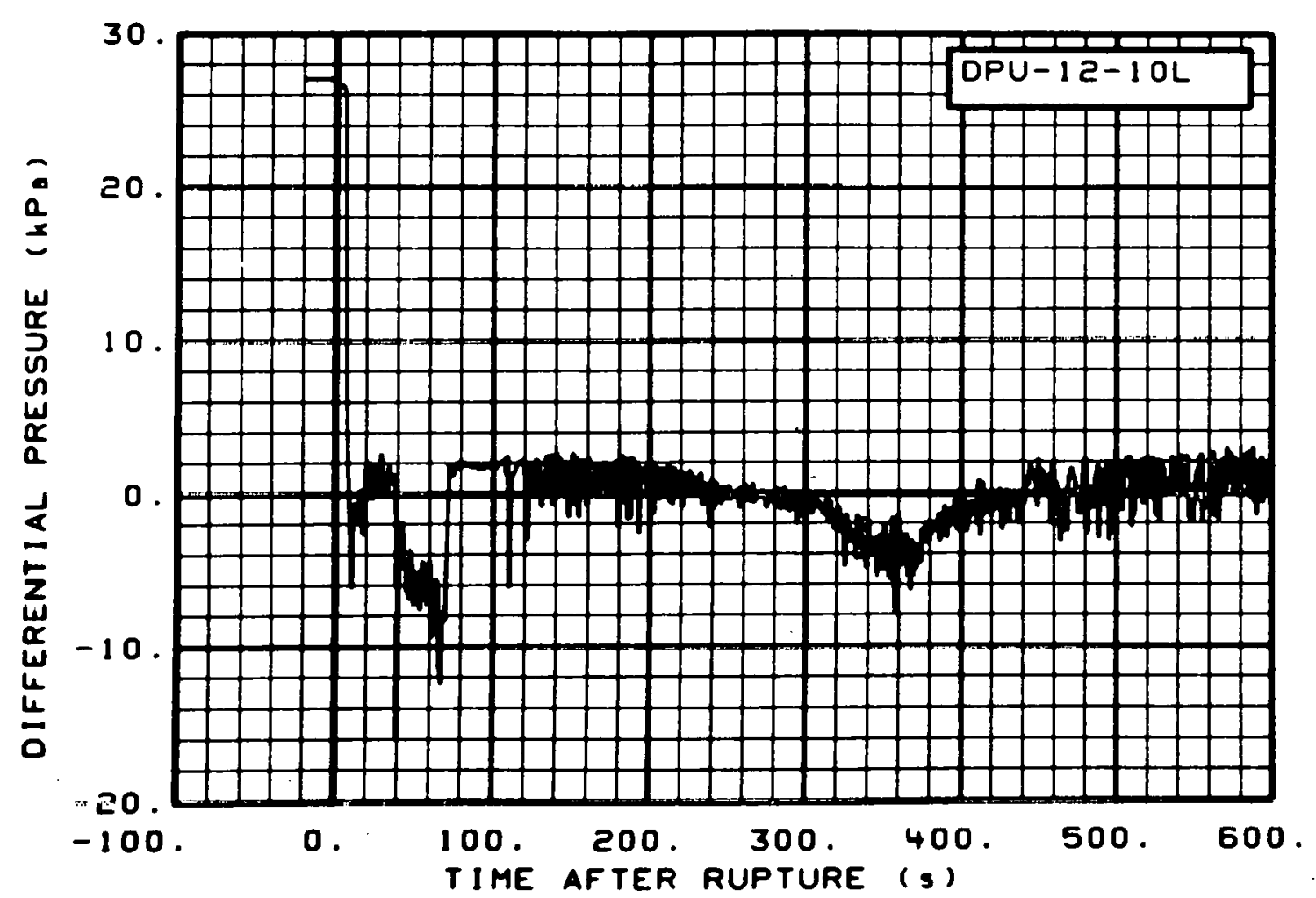

Fig. 177 Differential pressure in intact loop, low range (DPU-12-10L), from -20 to $600 \mathrm{~s}$.

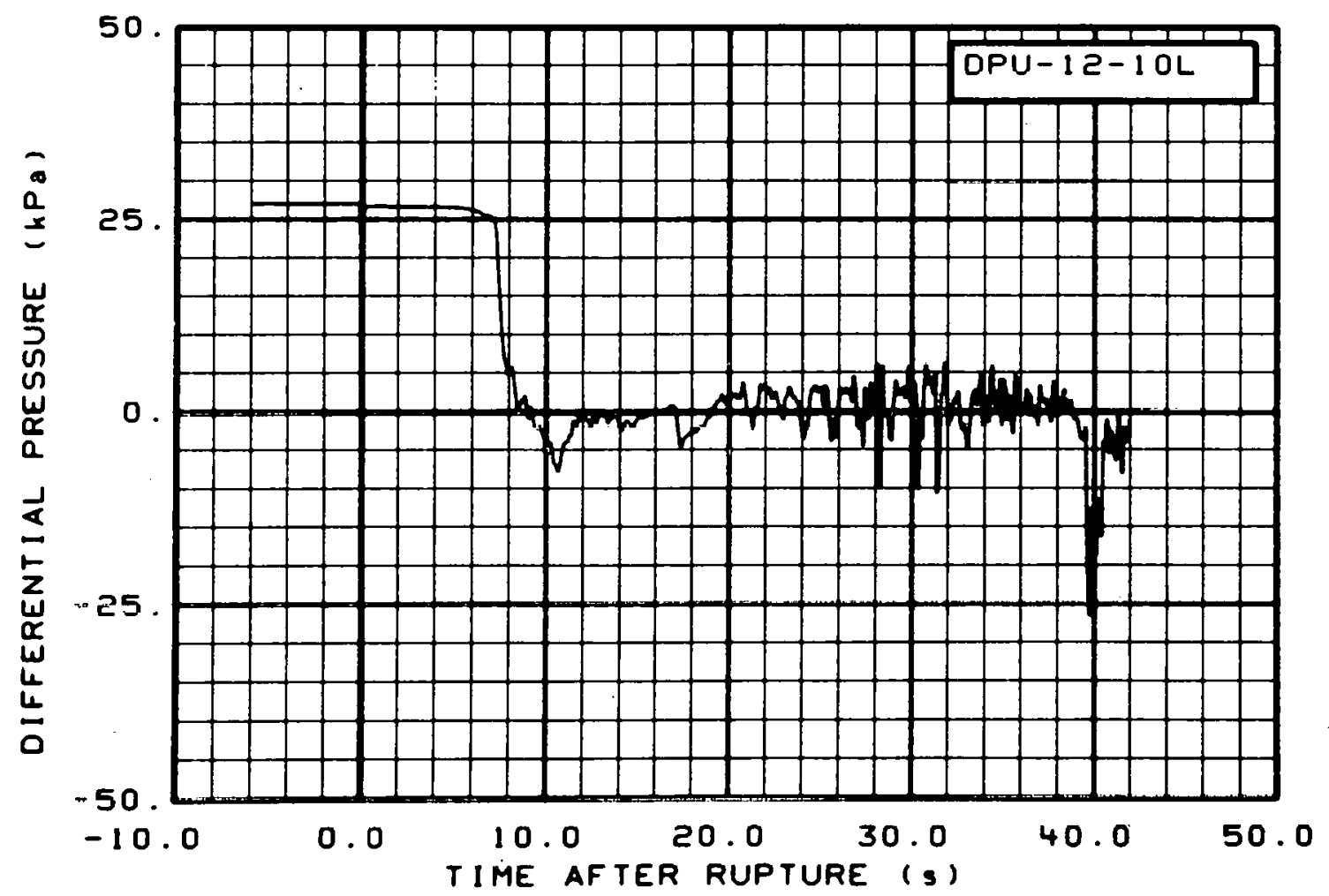

Fig. 178 Differential pressure in intact loop, low range (DPU-12-10L), from -6 to $42 \mathrm{~s}$. 


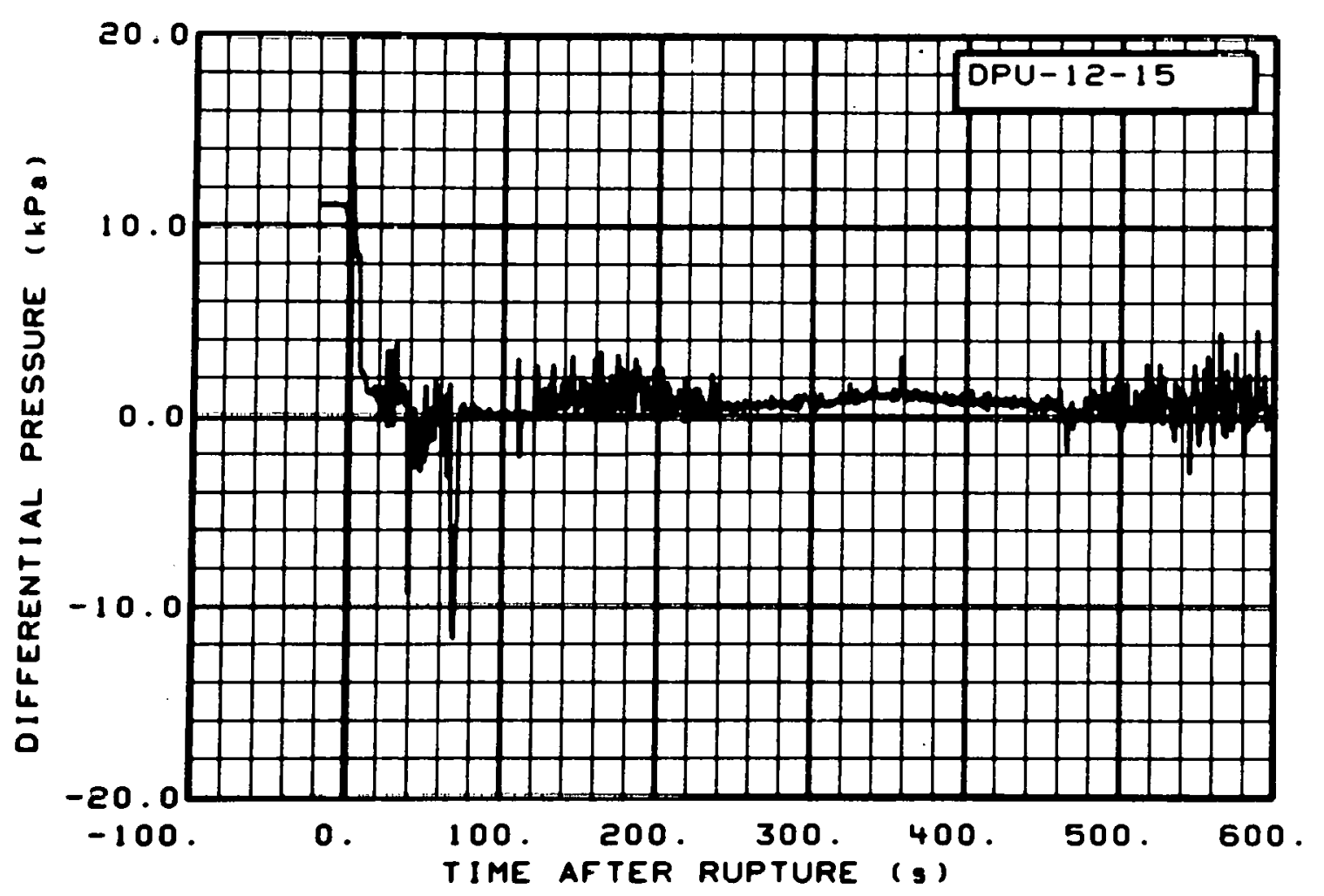

Fig. 179 Differential pressure in intact loop (DPU-12-15), from -20 to $600 \mathrm{~s}$.

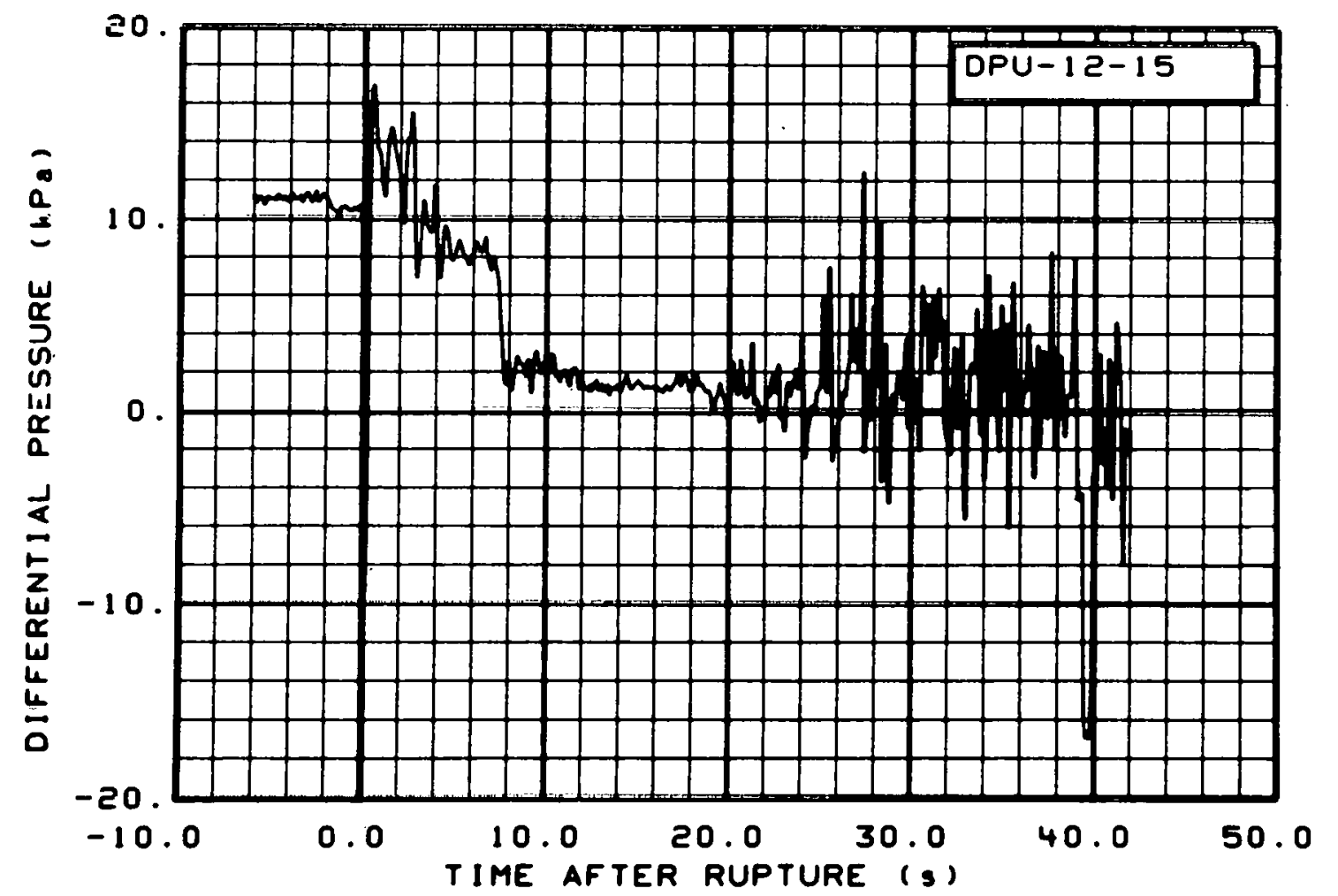

Fig. 180 Differential pressure in intact. lnop (DPII-12-15), from -6 to $42 \mathrm{~s}$. 


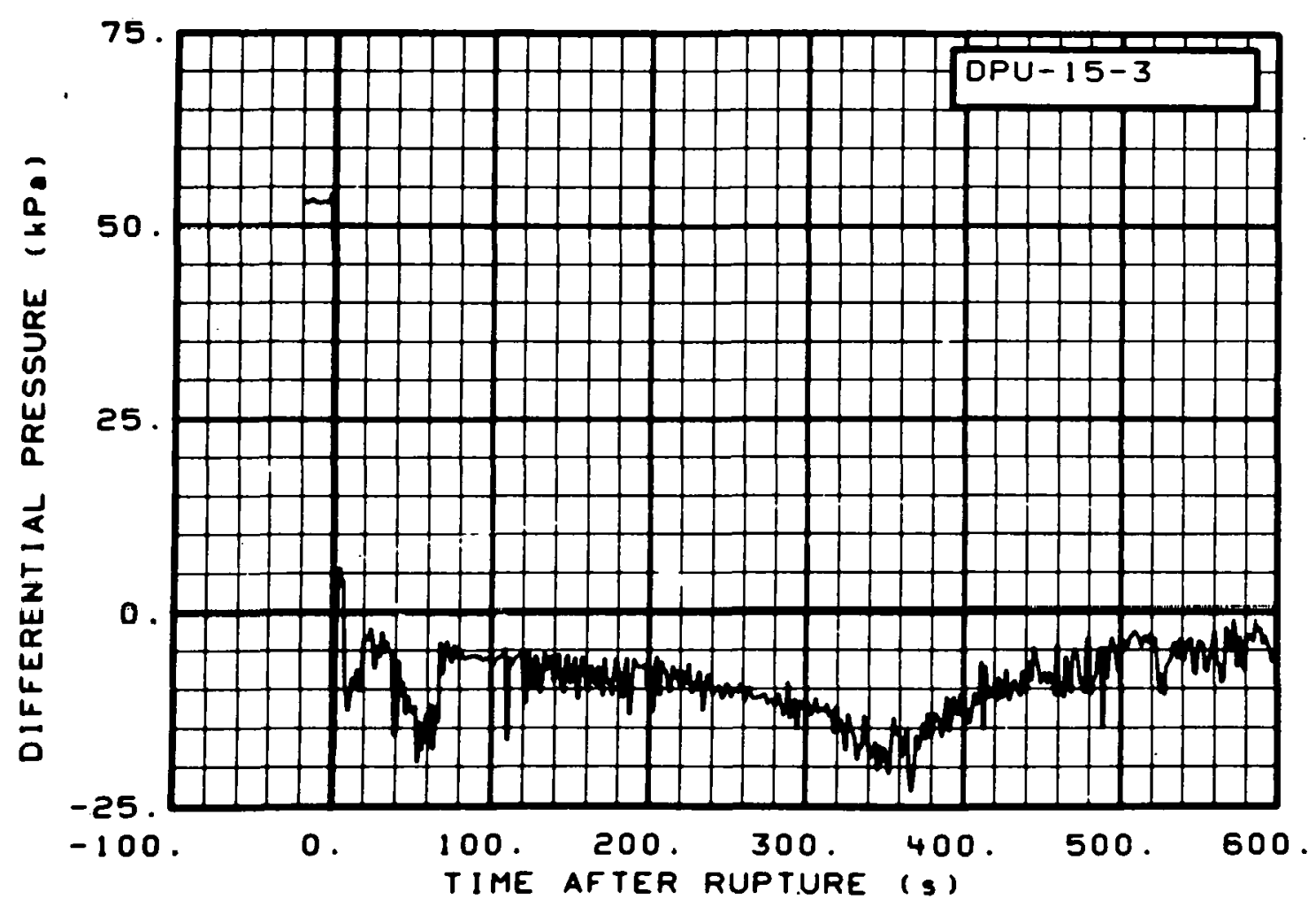

Fig. 181 Differential pressure in intact loop (DPU-15-3), from -20 to $600 \mathrm{~s}$.

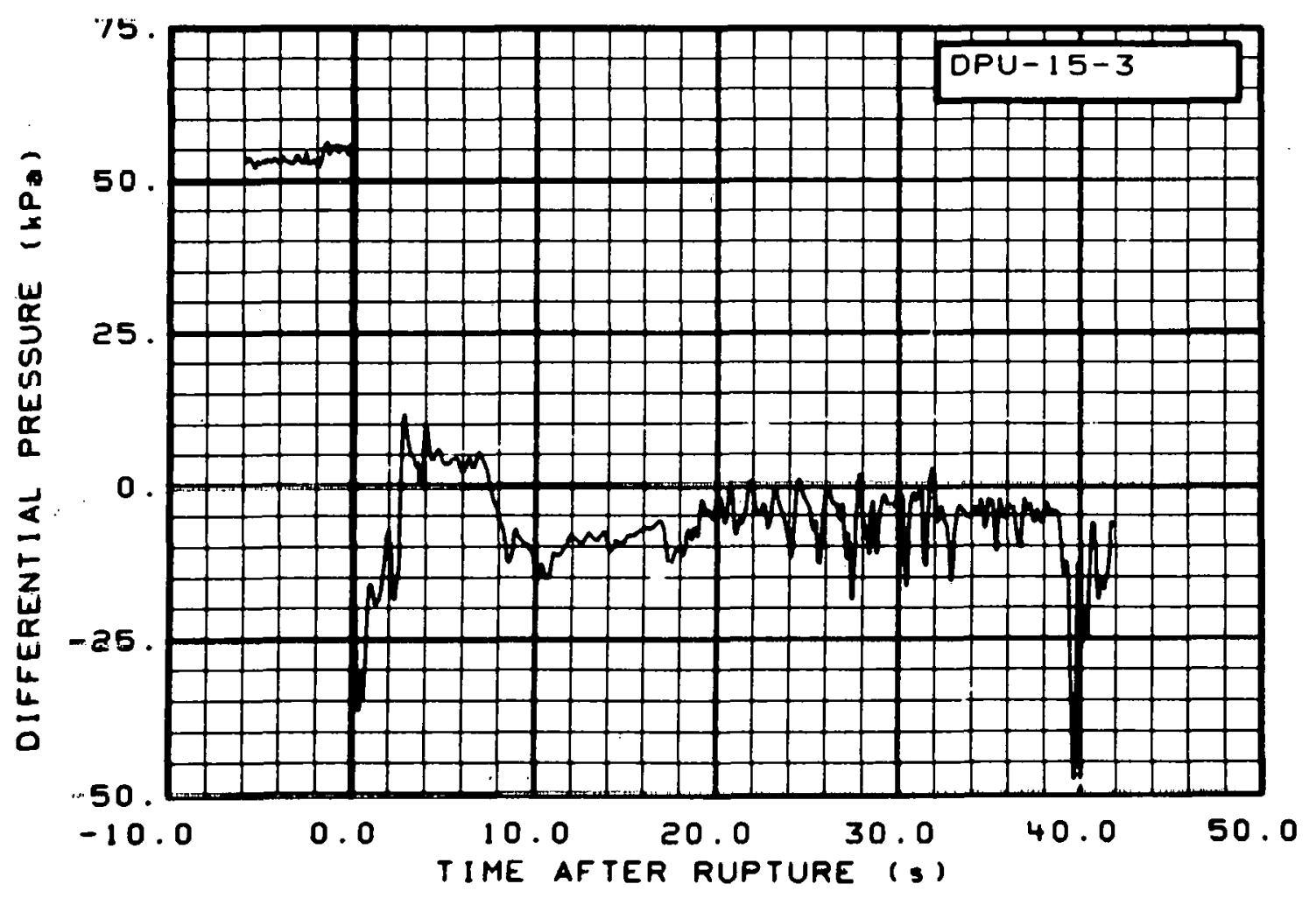

Fig. 182 Differential pressure in intact loop (DPU-15-3), from -6 to $42 \mathrm{~s}$. 


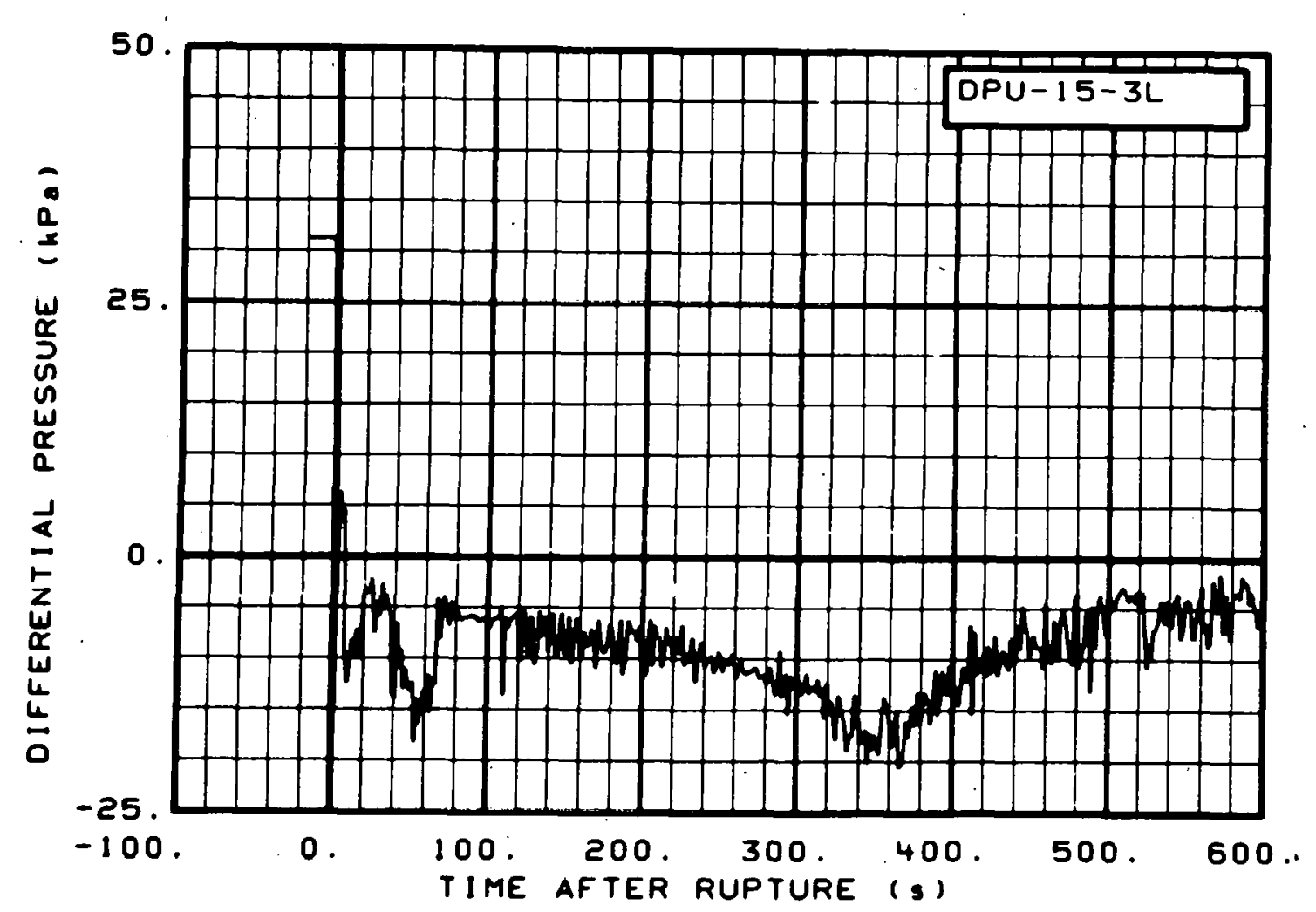

Fig. 183 Differential pressure in intact loop, low range (DPU-15-3L), from -20 to $600 \mathrm{~s}$.

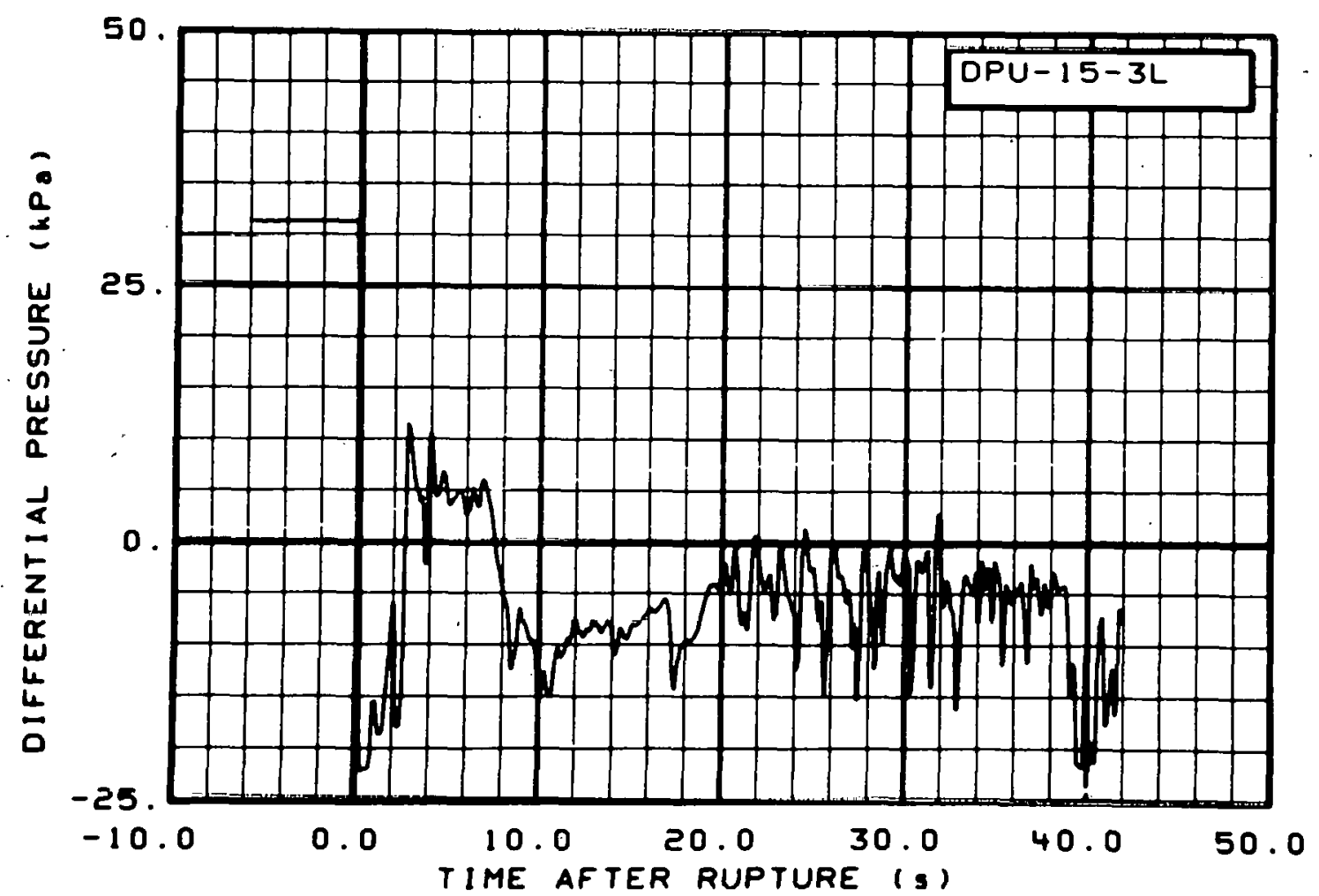

Fig. 184 Differential pressure in intact loop, low range (DPU-15-3L), from -6 to $42 \mathrm{~s}$. 


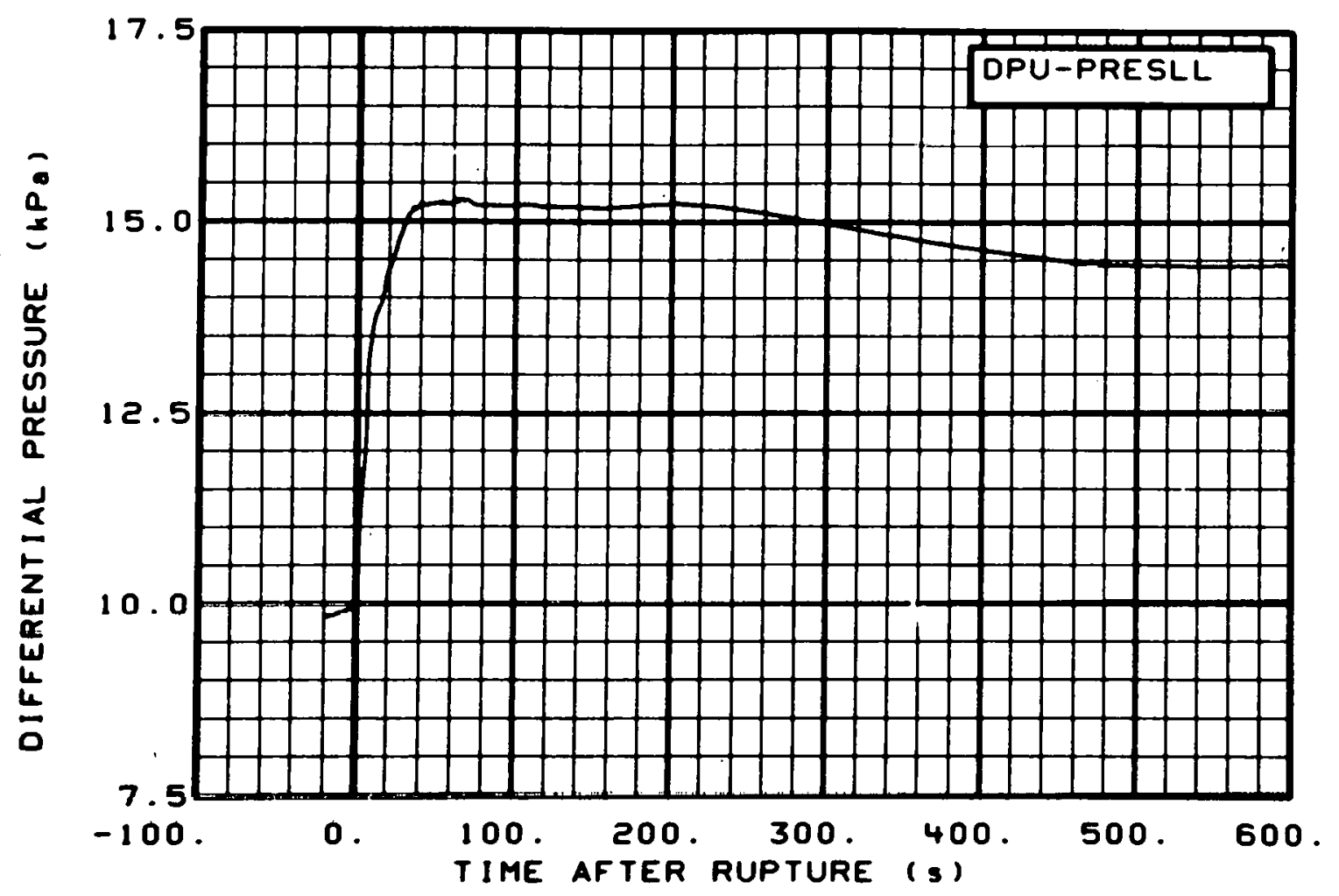

Fig. 185 Differential pressure in pressurizer (DPU-PRESLL), from -20 to $600 \mathrm{~s}$.

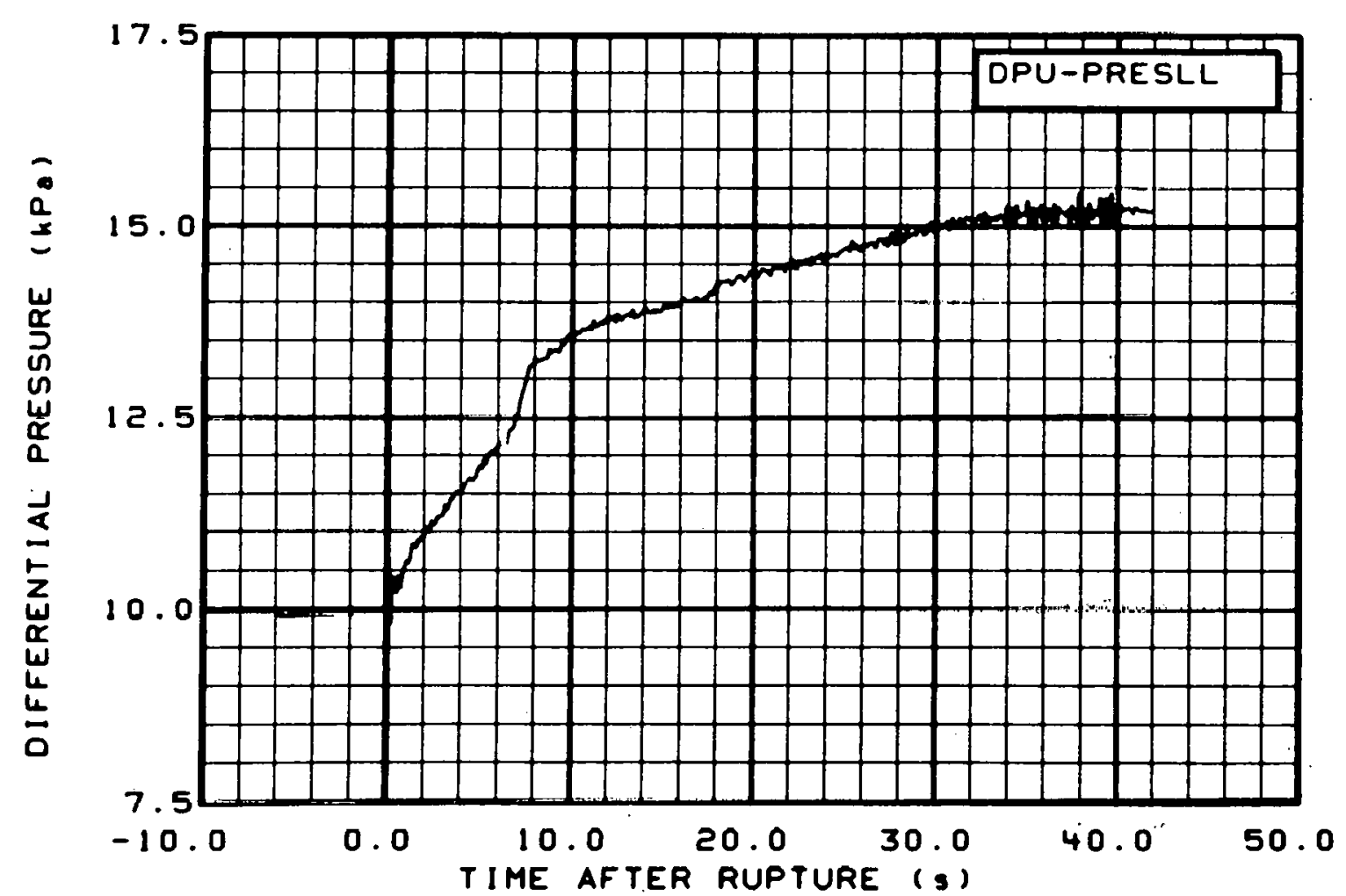

Fig. 186 Differential pressure in pressurizer (DPU-PRESLL), from -6 to $42 \mathrm{~s}$. 


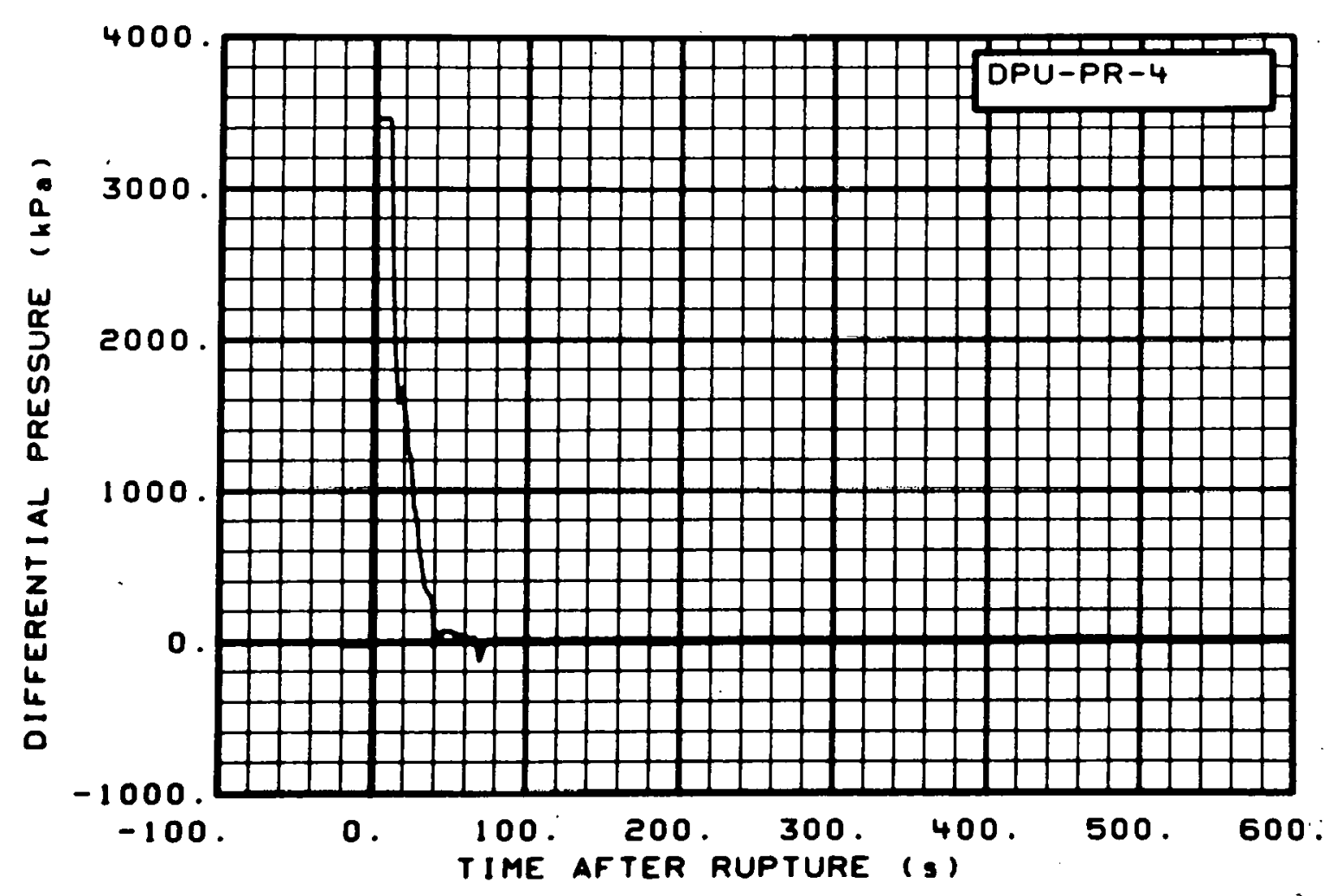

Fig. 187 Differential pressure in intact loop (DPU-PR-4), from -20 to $600 \mathrm{~s}$.

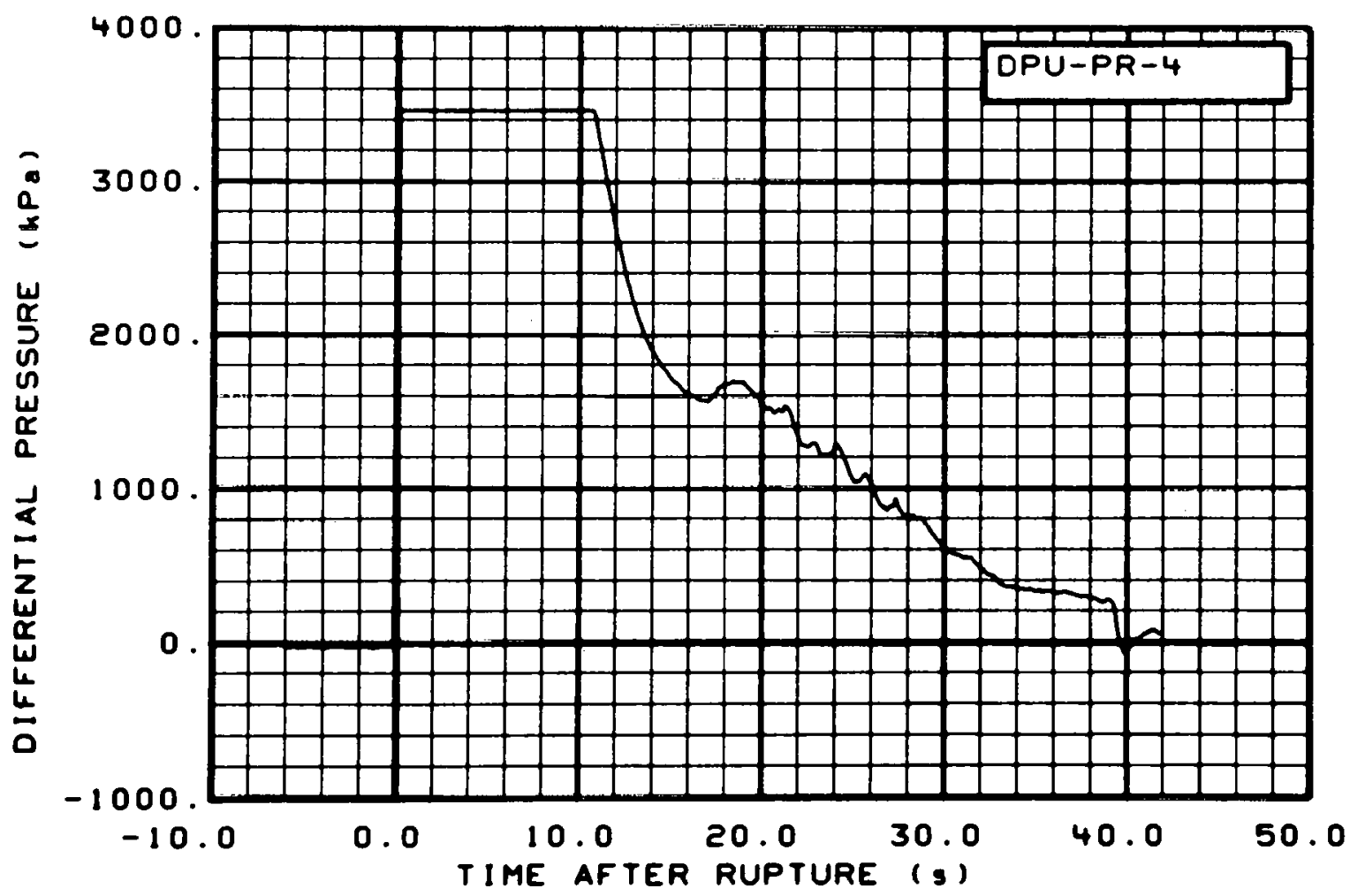

Fig. 188 Differential pressure in intact loop (DPU-PR-4), from -6 to $42 \mathrm{~s}$. 


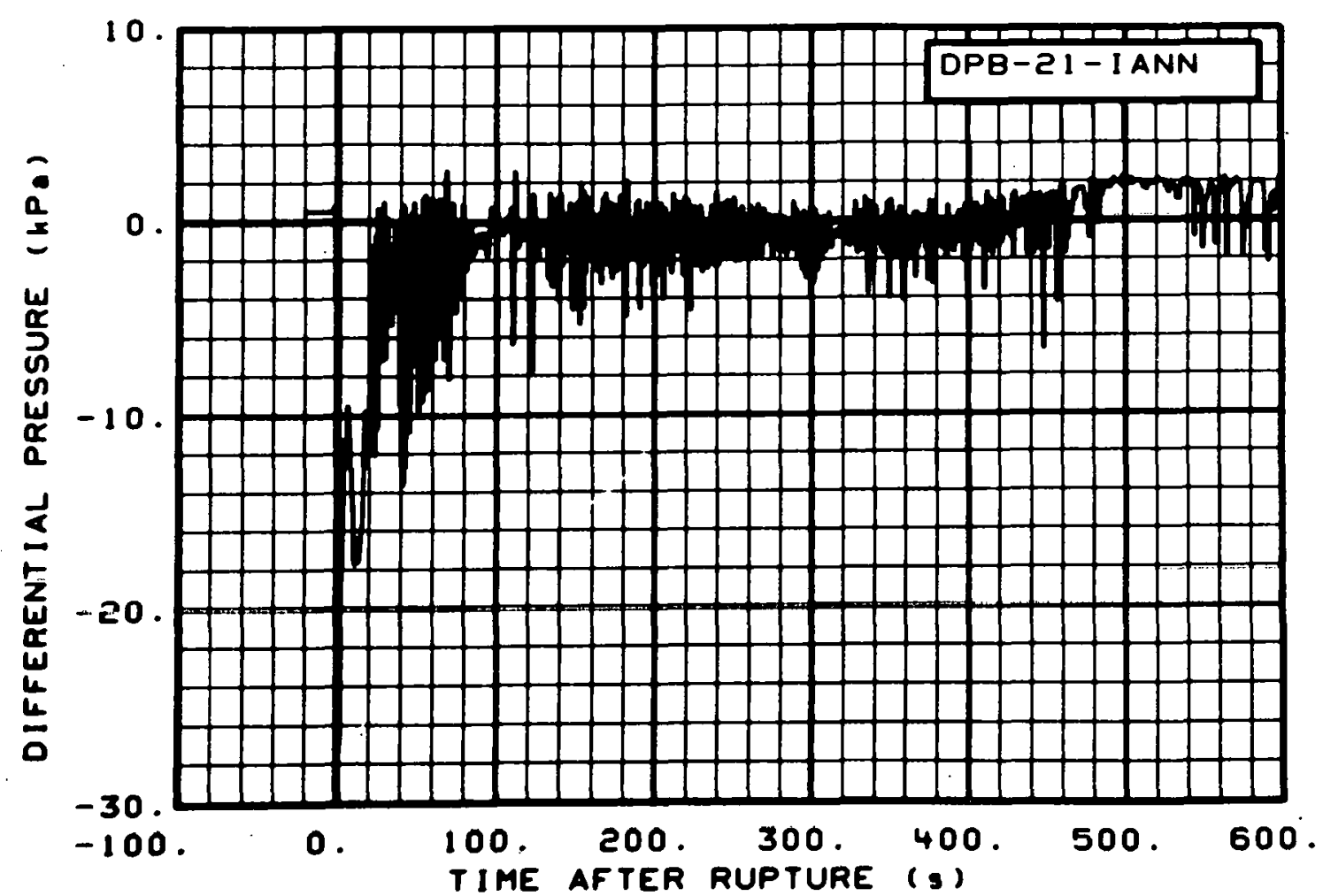

Fig. 189 Differential pressure in broken loop (DPB-21-IANN), from -20 to $600 \mathrm{~s}$.

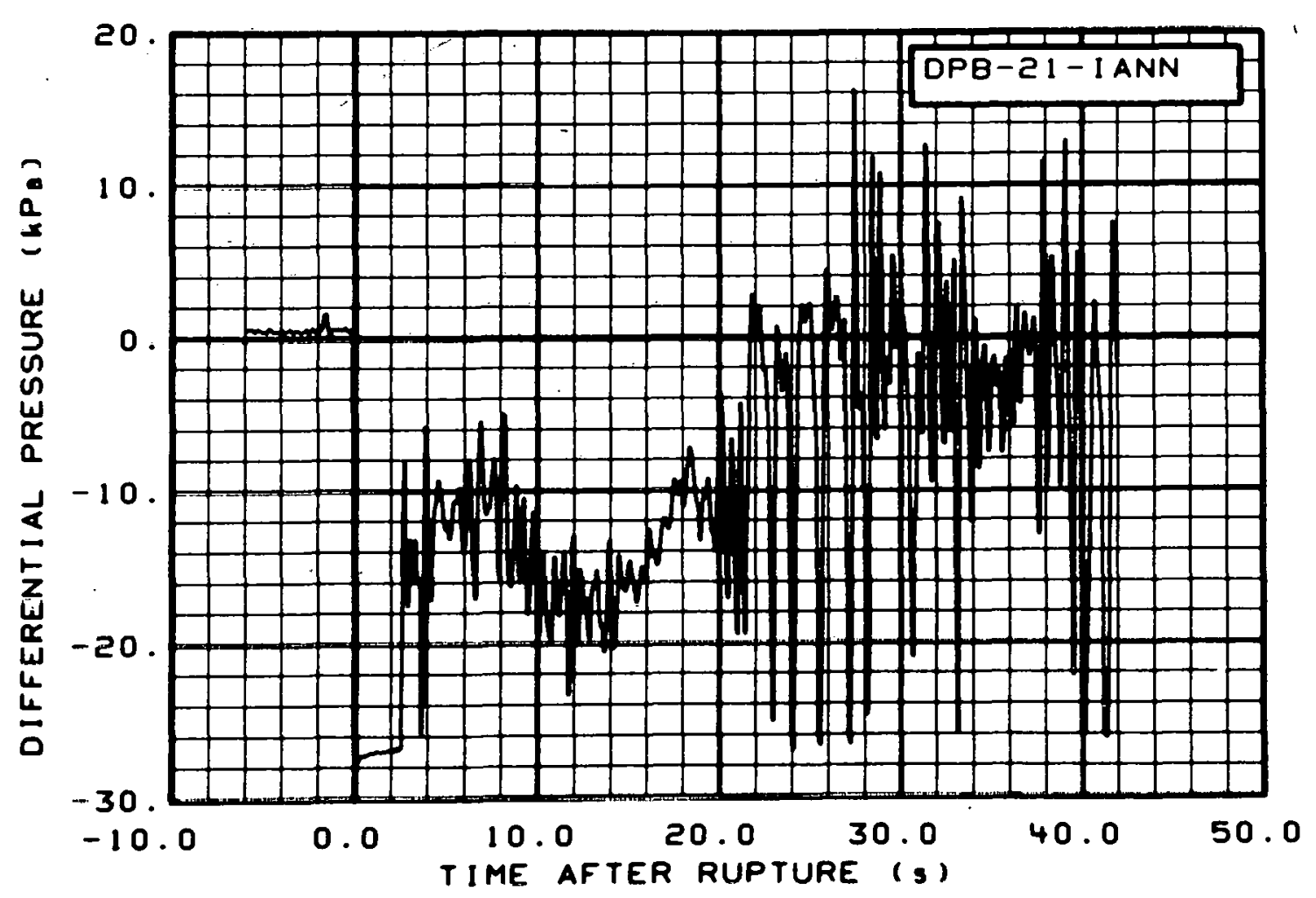

Fig. 190 Differential pressure in broken loop (DPB-21-IANN), from -6 to $42 \mathrm{~s}$. 


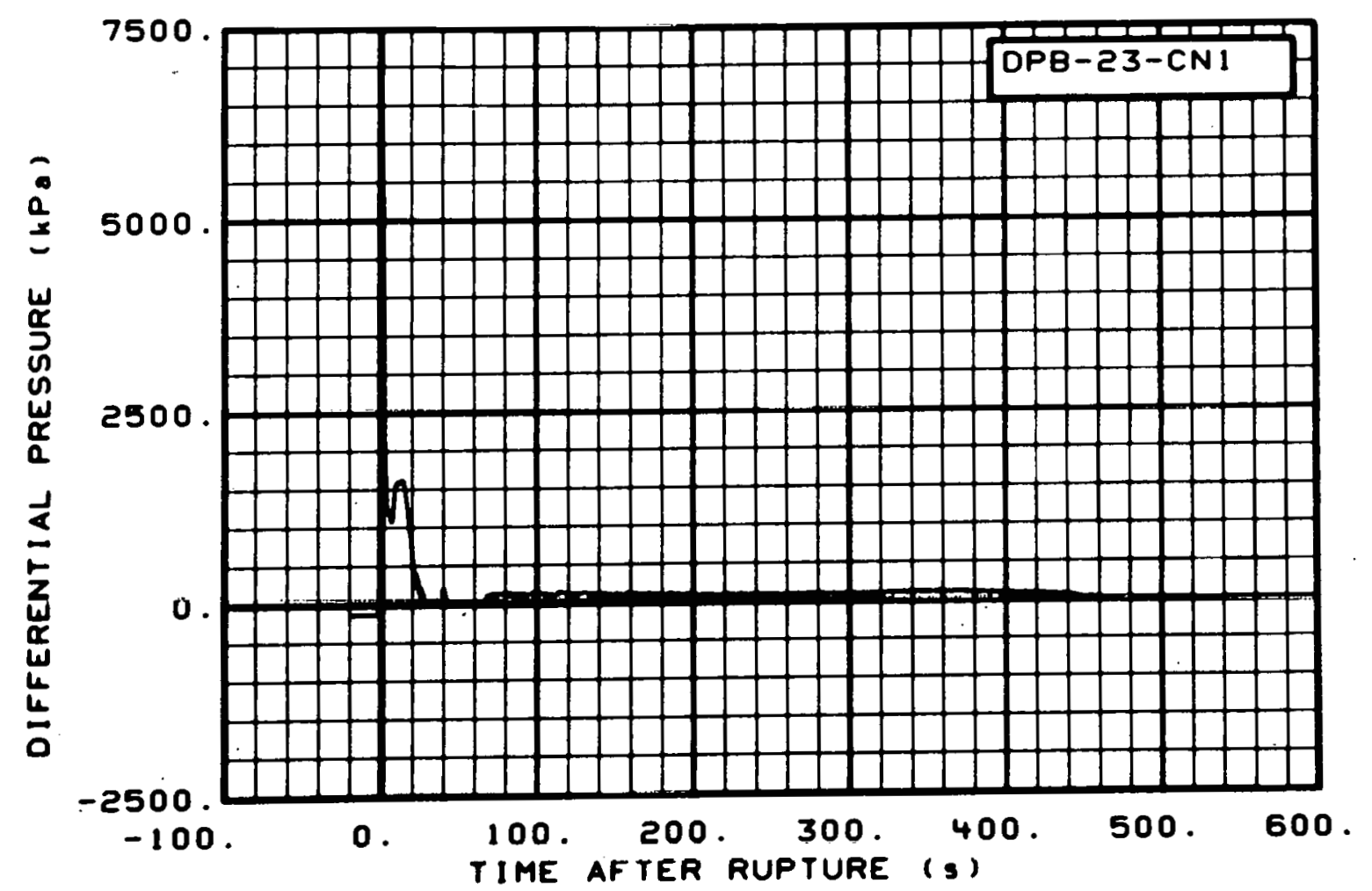

Fig. 191 Differential pressure in broken loop (DPB-23-CN1), from -20 to $600 \mathrm{~s}$.

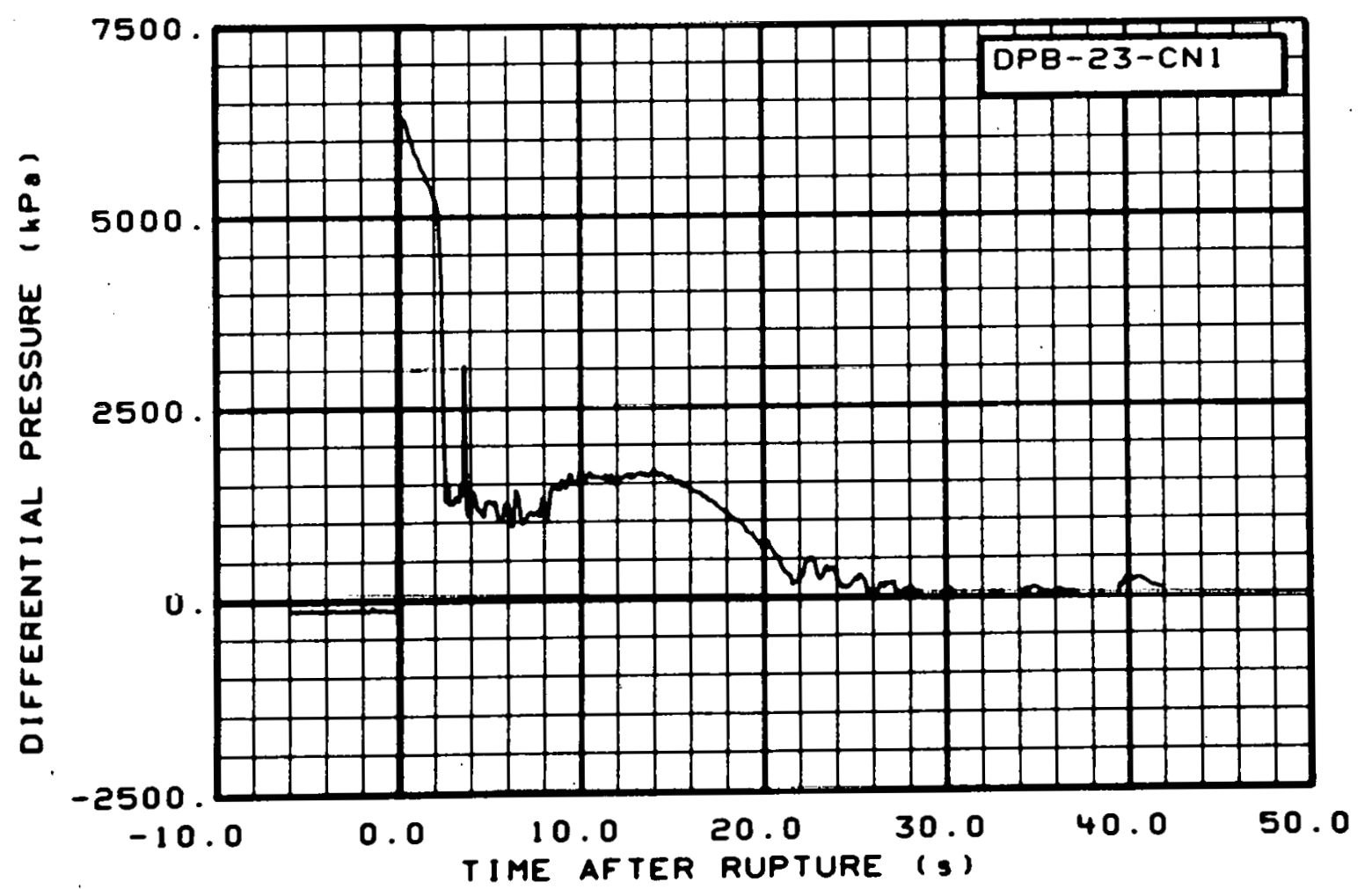

F1g. 192 Differential pressure in broken loop (DPB-23-CN1), from -6 to $42 \mathrm{~s}$. 


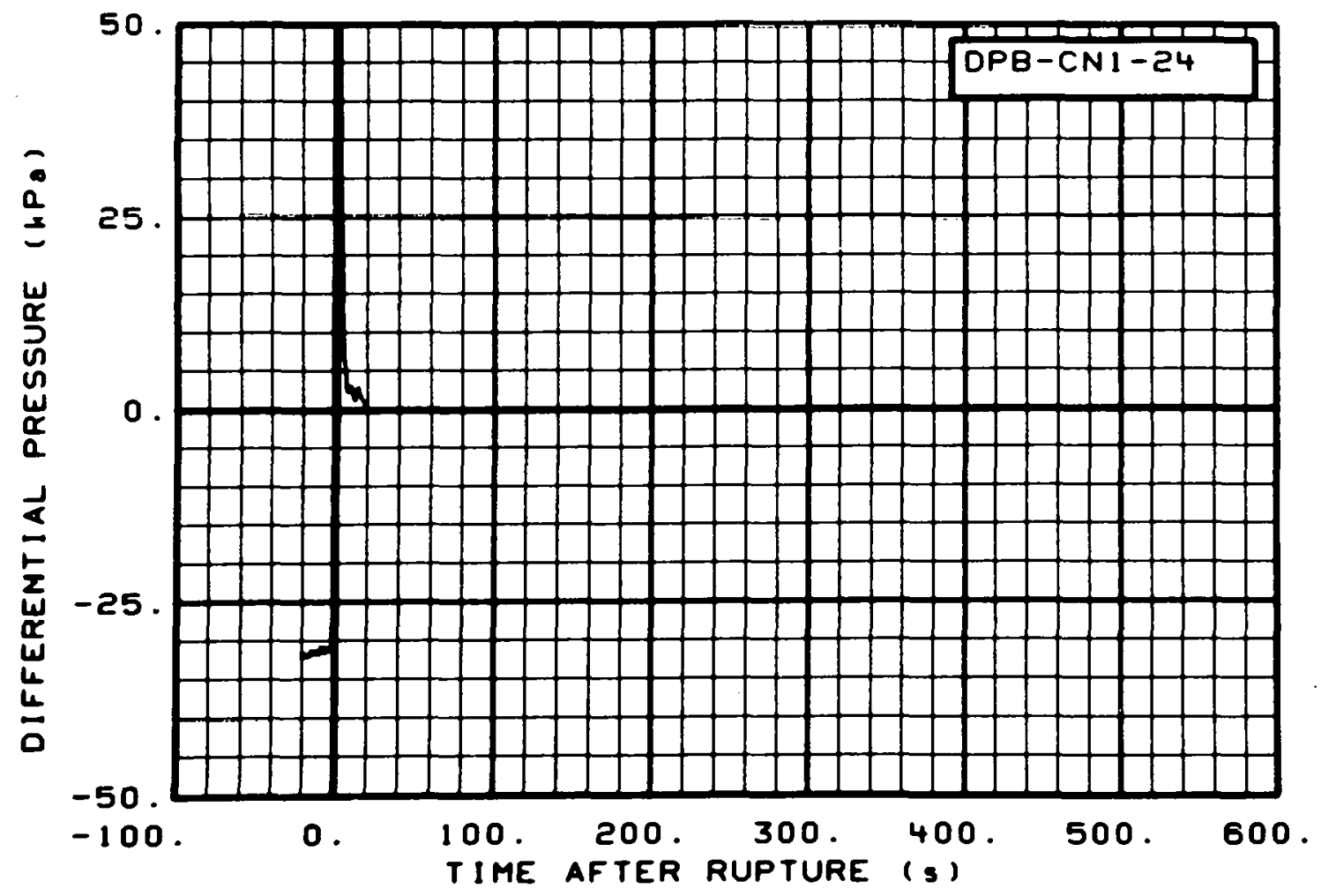

Fig. 193 Differential pressure in broken loop (DPB-CN1-24), from -20 to $600 \mathrm{~s}$.

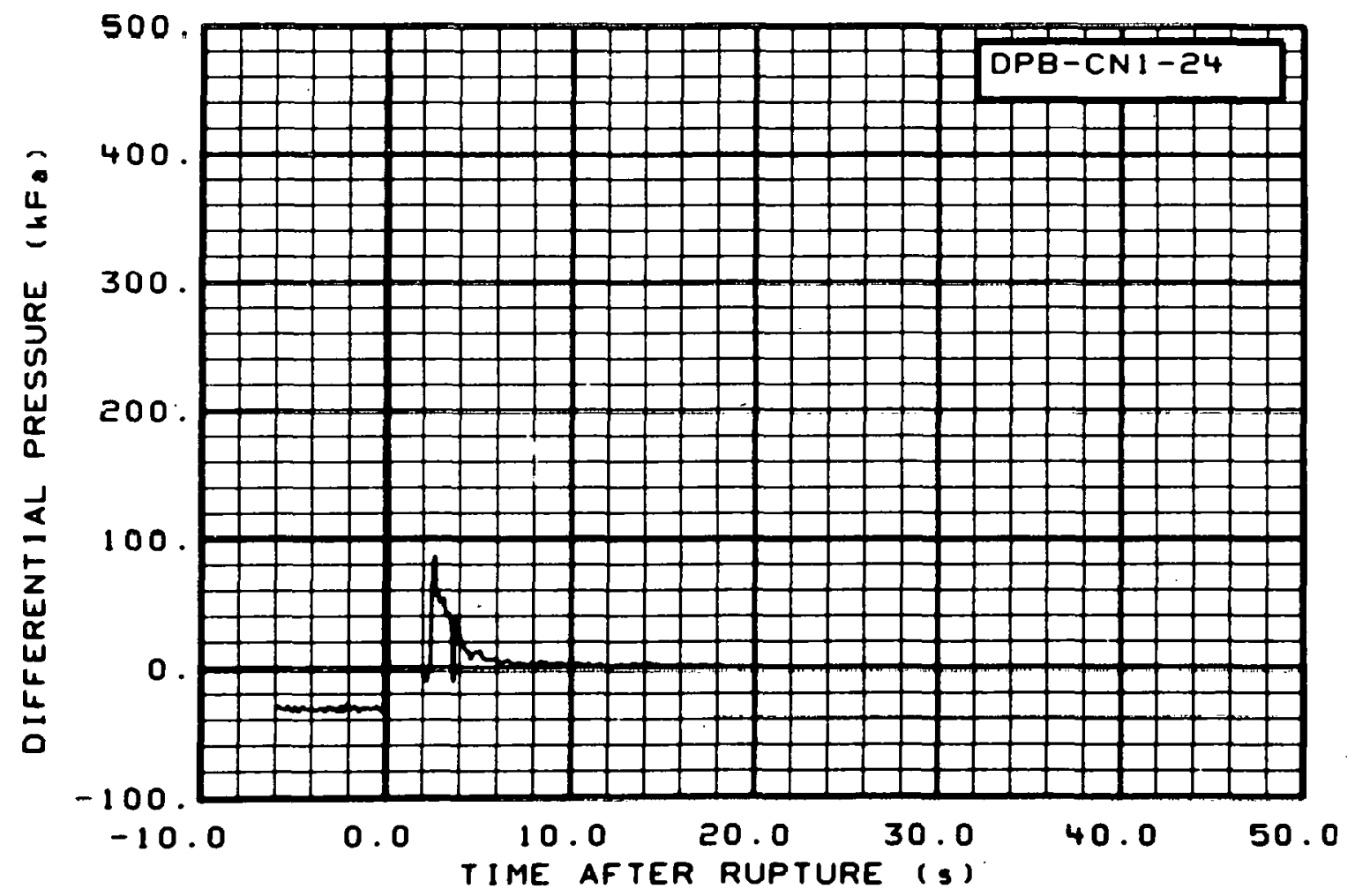

Fig. 194 Differential pressure in broken loop (DPB-CN1-24), from -6 to $42 \mathrm{~s}$. 


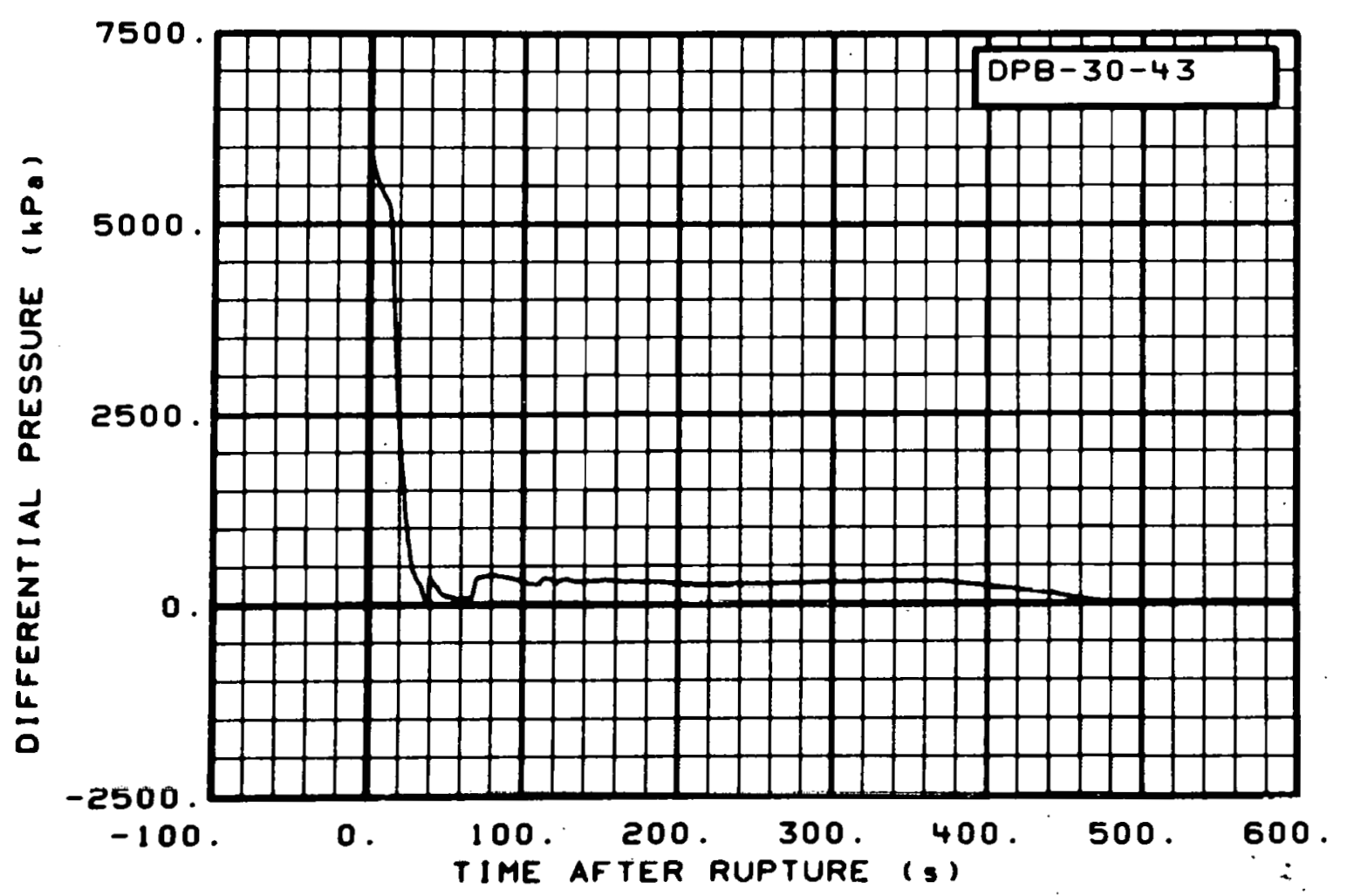

Fig. 195 Differential pressure in broken loop (DPB-30-43), from -20 to $600 \mathrm{~s}$.

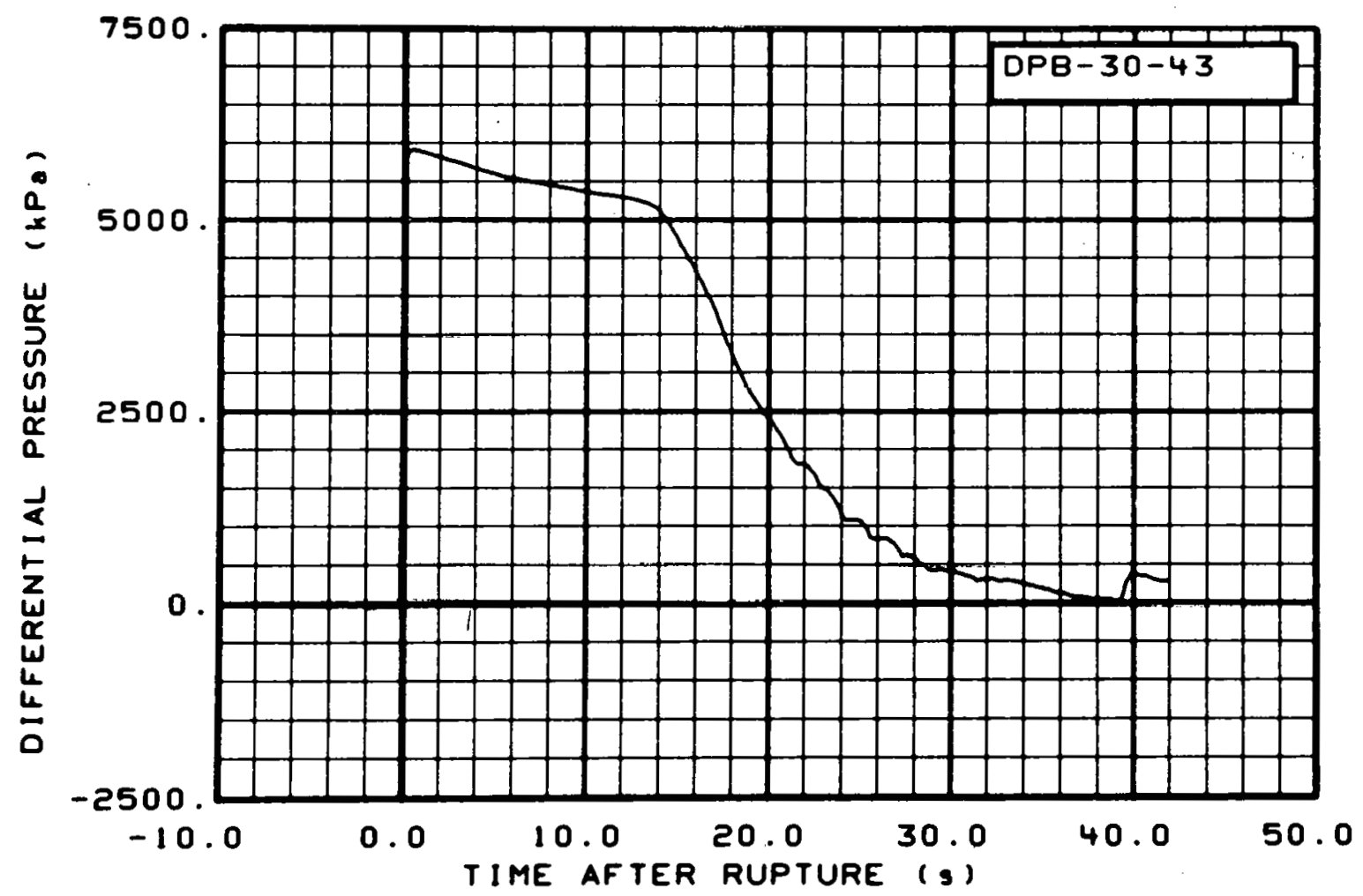

Fig. 196 Differential pressure in broken loop (DPB-30-43), from -6 to 42 s. 


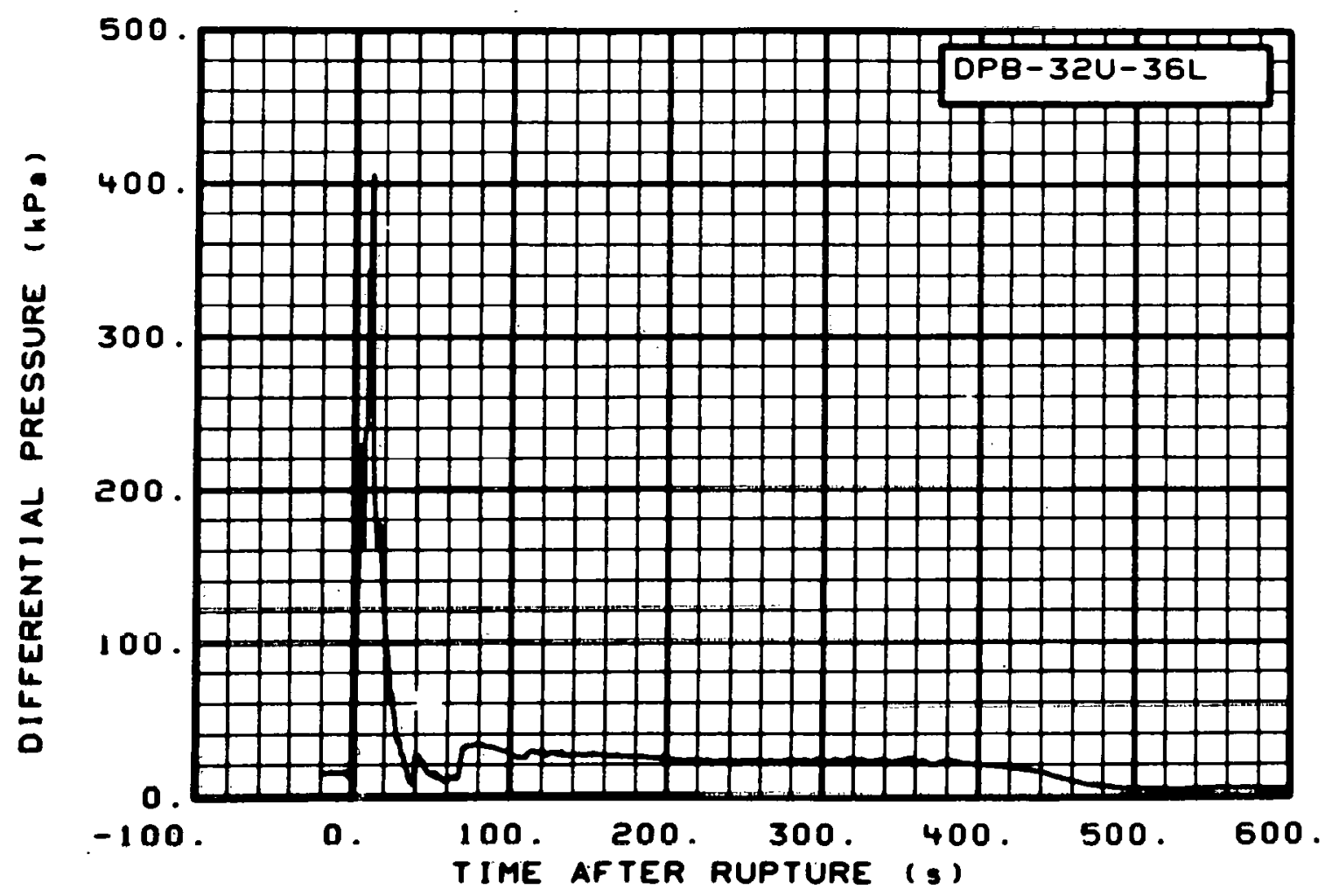

Fig. 197 Differential pressure in broken loop (DPB-32U-36L), from -20 to $600 \mathrm{~s}$.

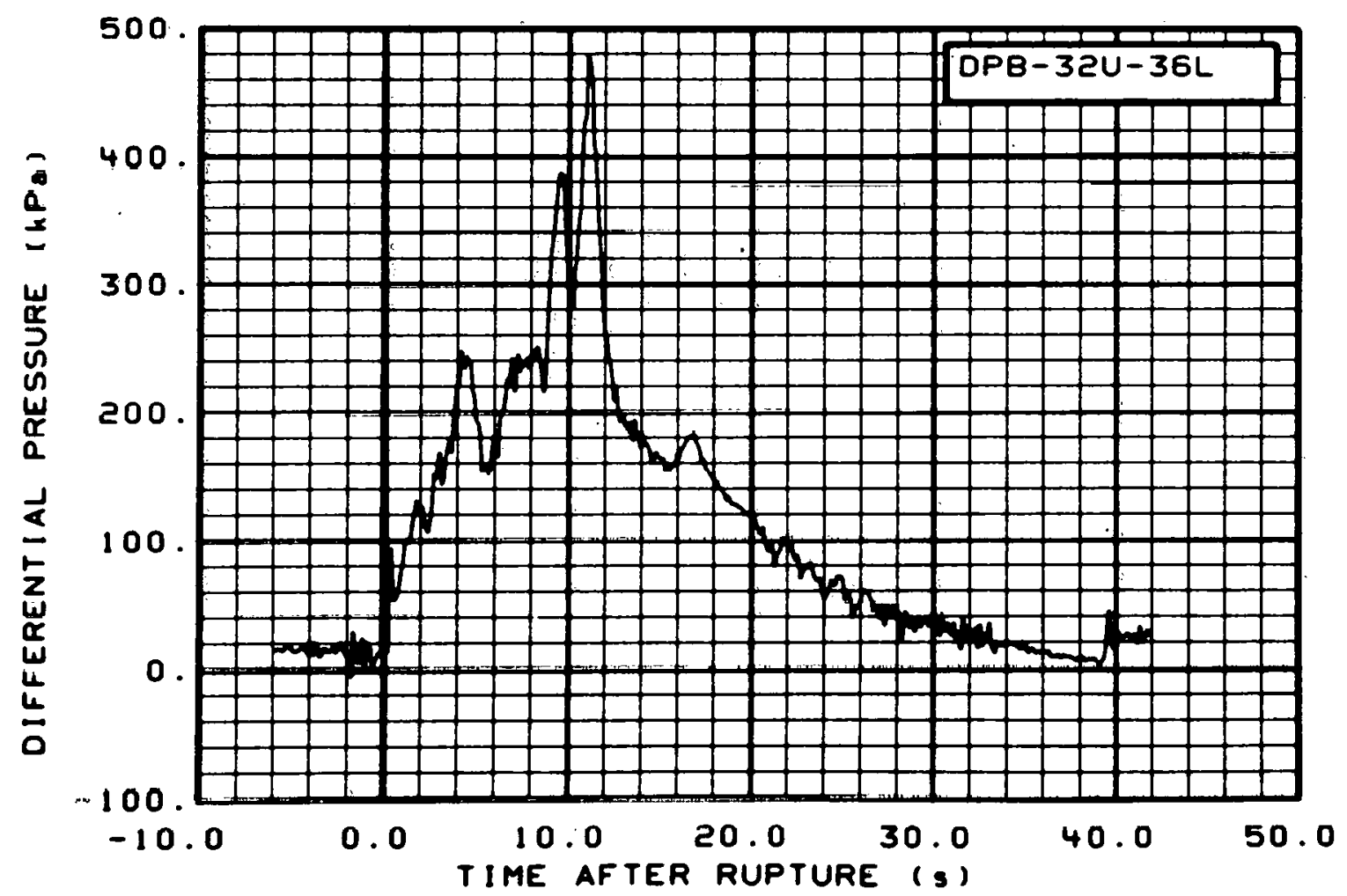

Fig. 198 Differential pressure, in broken loop (DPB-32U-36L), from -6 to $42 \mathrm{~s}$. 


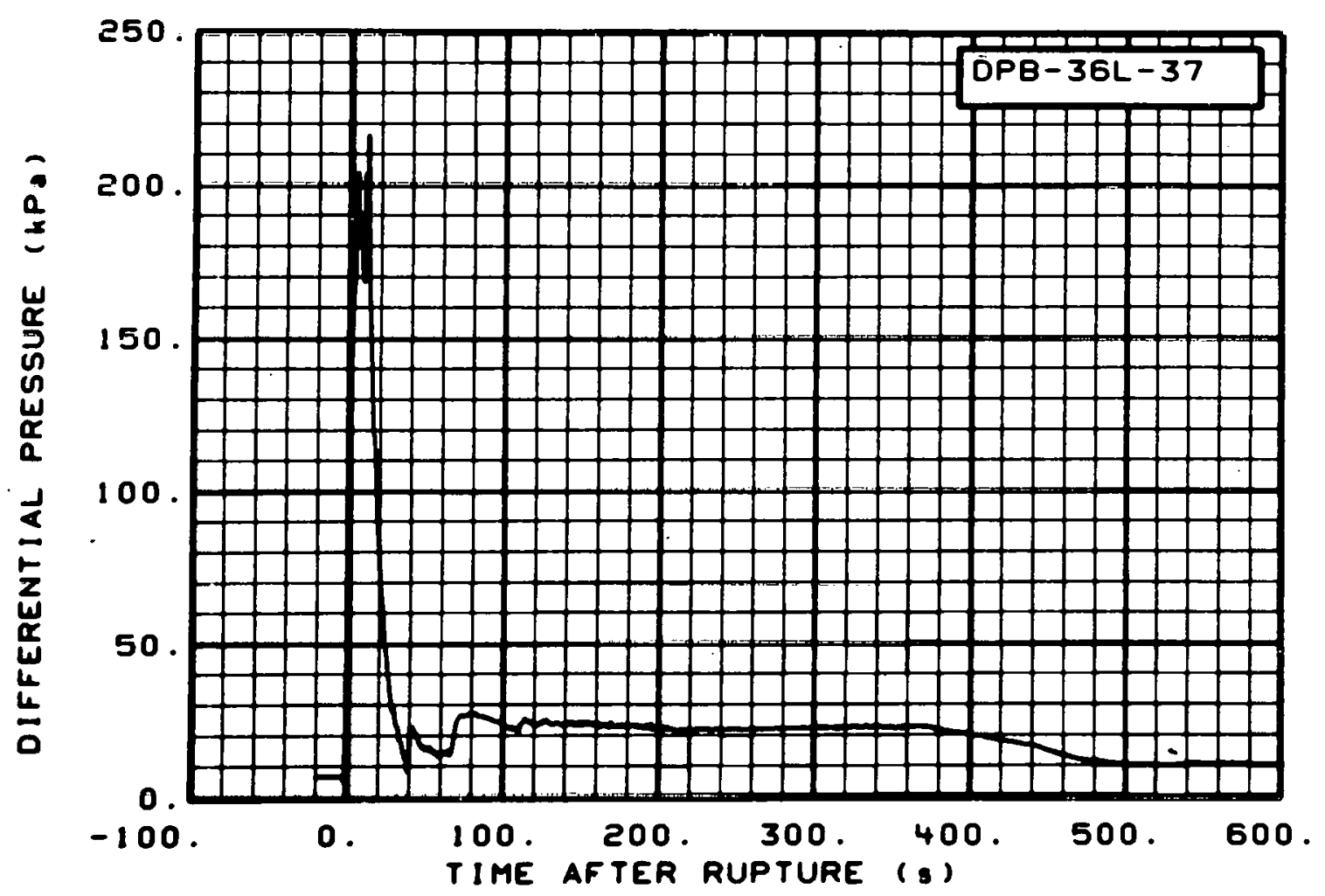

Fig. 199 Differential pressure in broken loop (DPB-36L-37), from -20 to $600 \mathrm{~s}$.

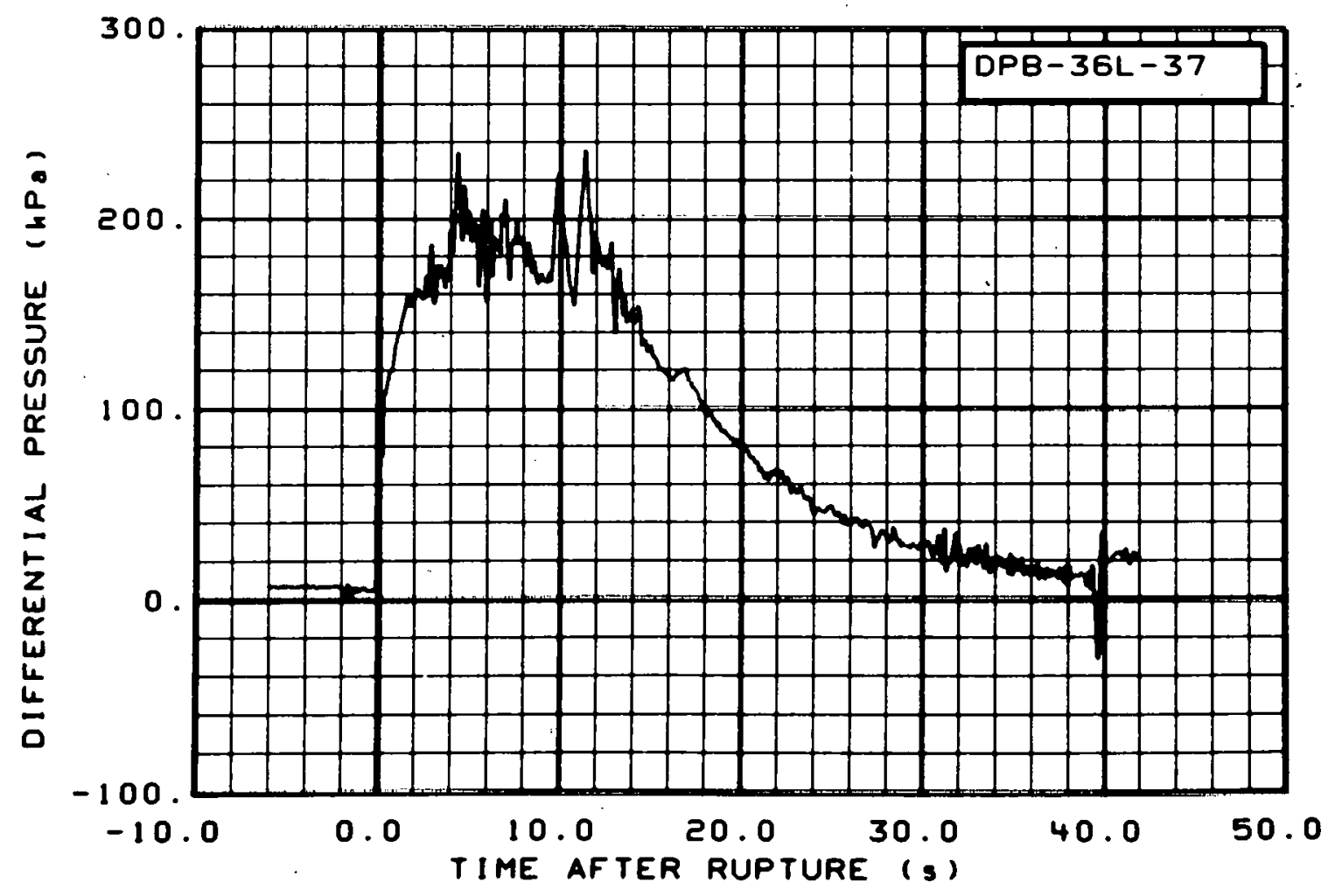

Fig. 200 Differential pressure in broken loop (DPB-36L-37), from -6 to $42 \mathrm{~s}$. 


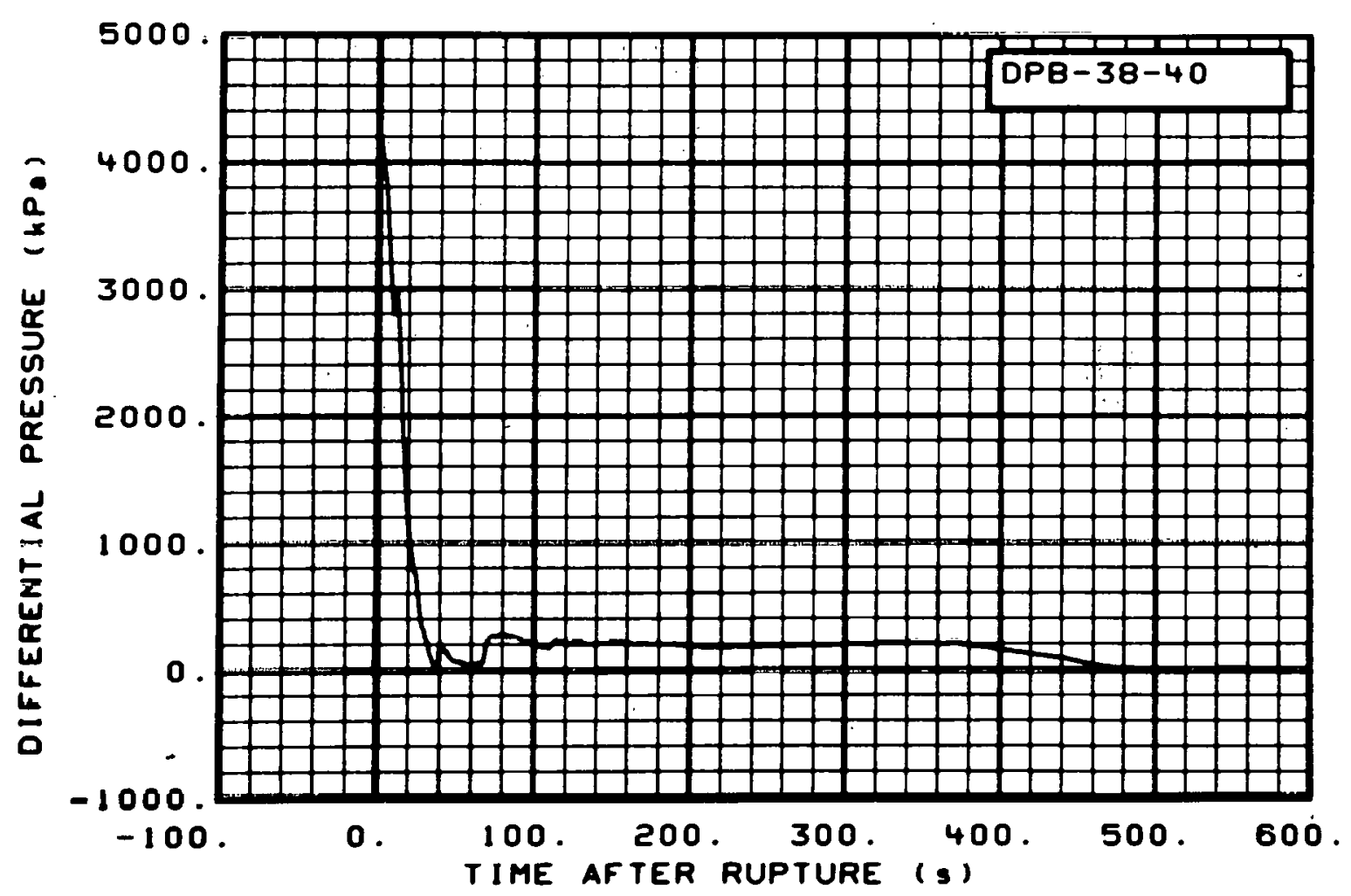

Fig. 201 Differential pressure in broken loop (DPB-38-40), from -20 to $600 \mathrm{~s}$.

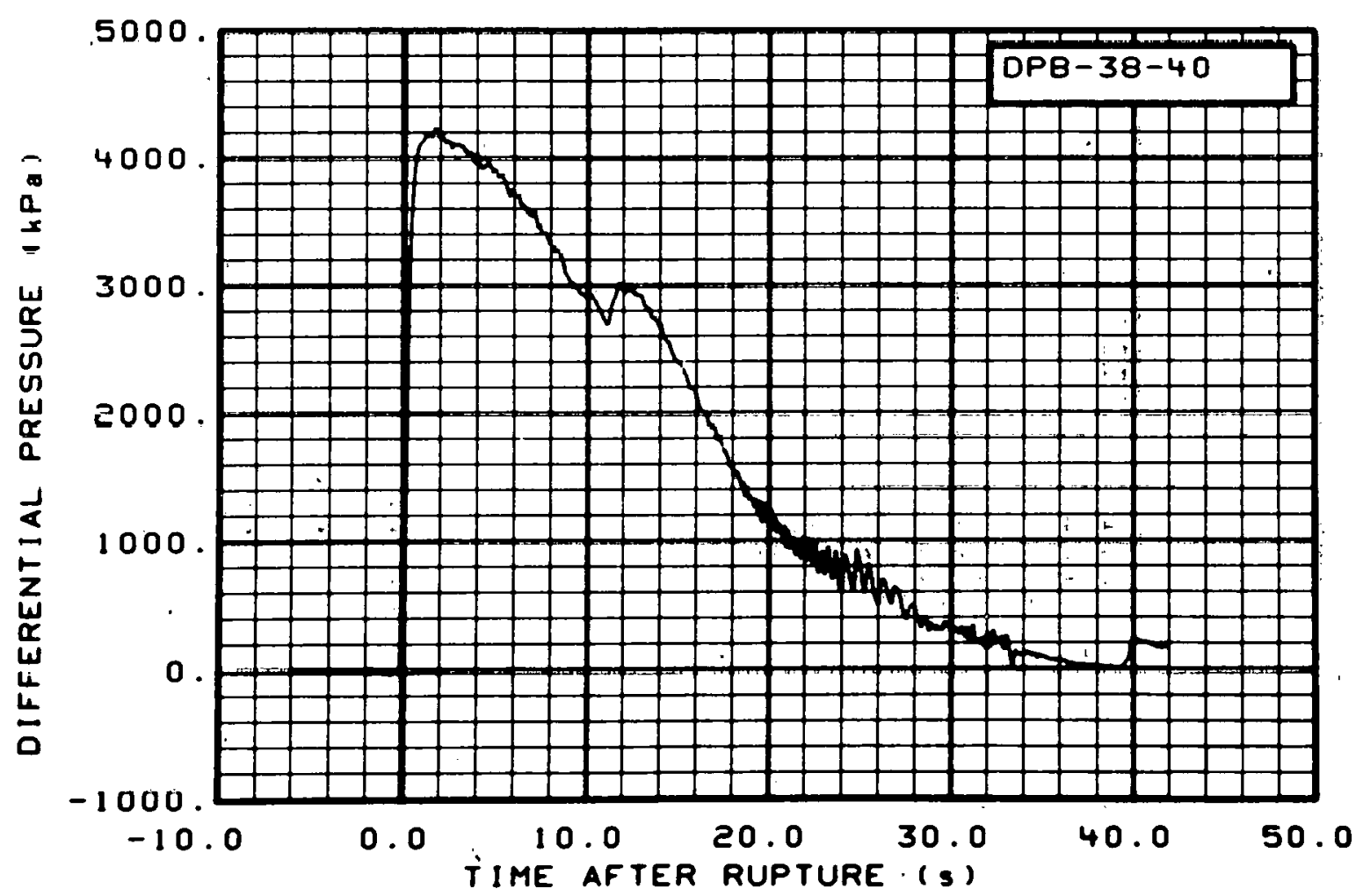

Fig. 202 Differential pressure in broken loop (DPB-38-40), from -6 to $42 \mathrm{~s}$. 


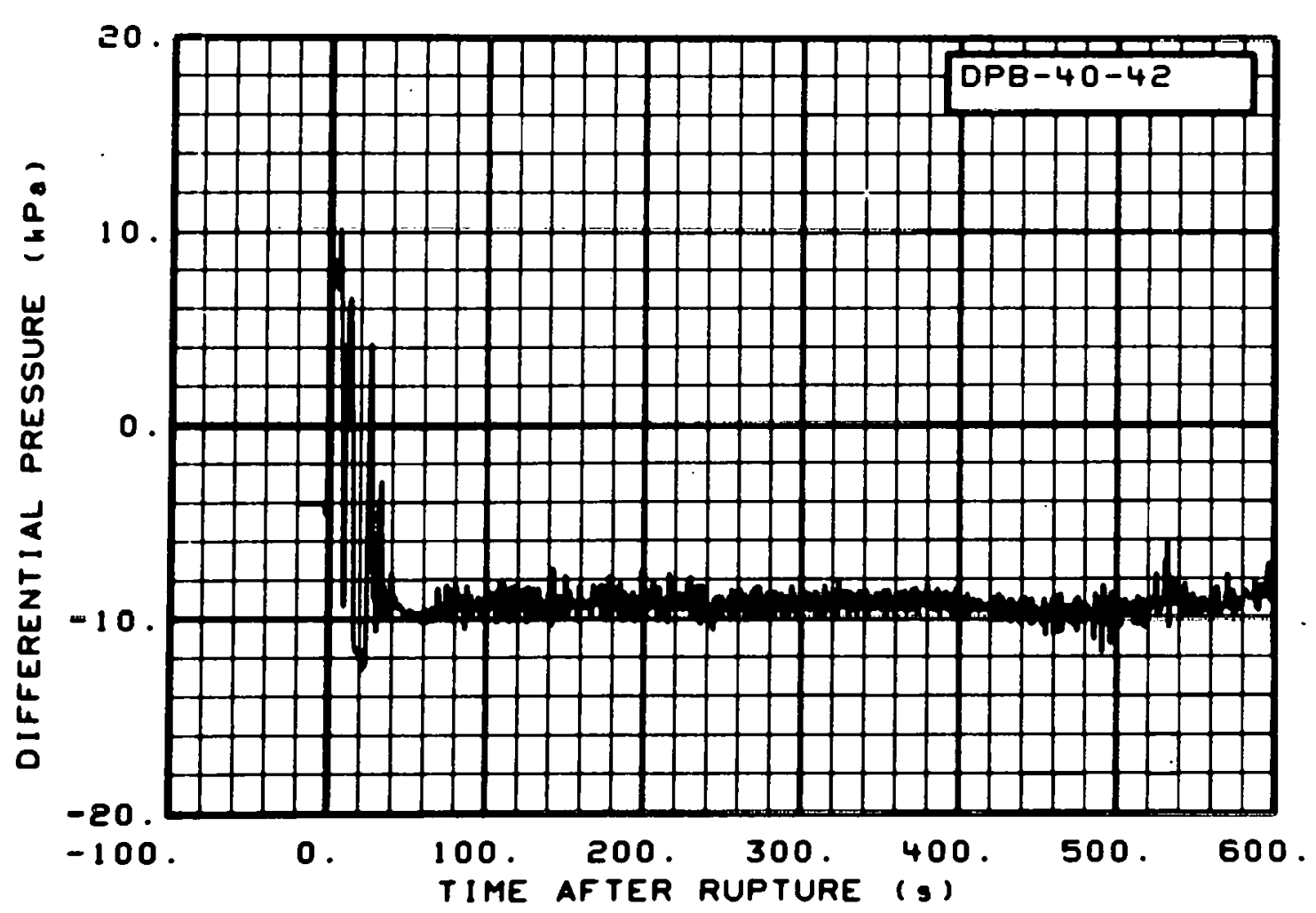

Fig. 203 Differential pressure in broken loop (DPB-40-42), from -20 to $600 \mathrm{~s}$.

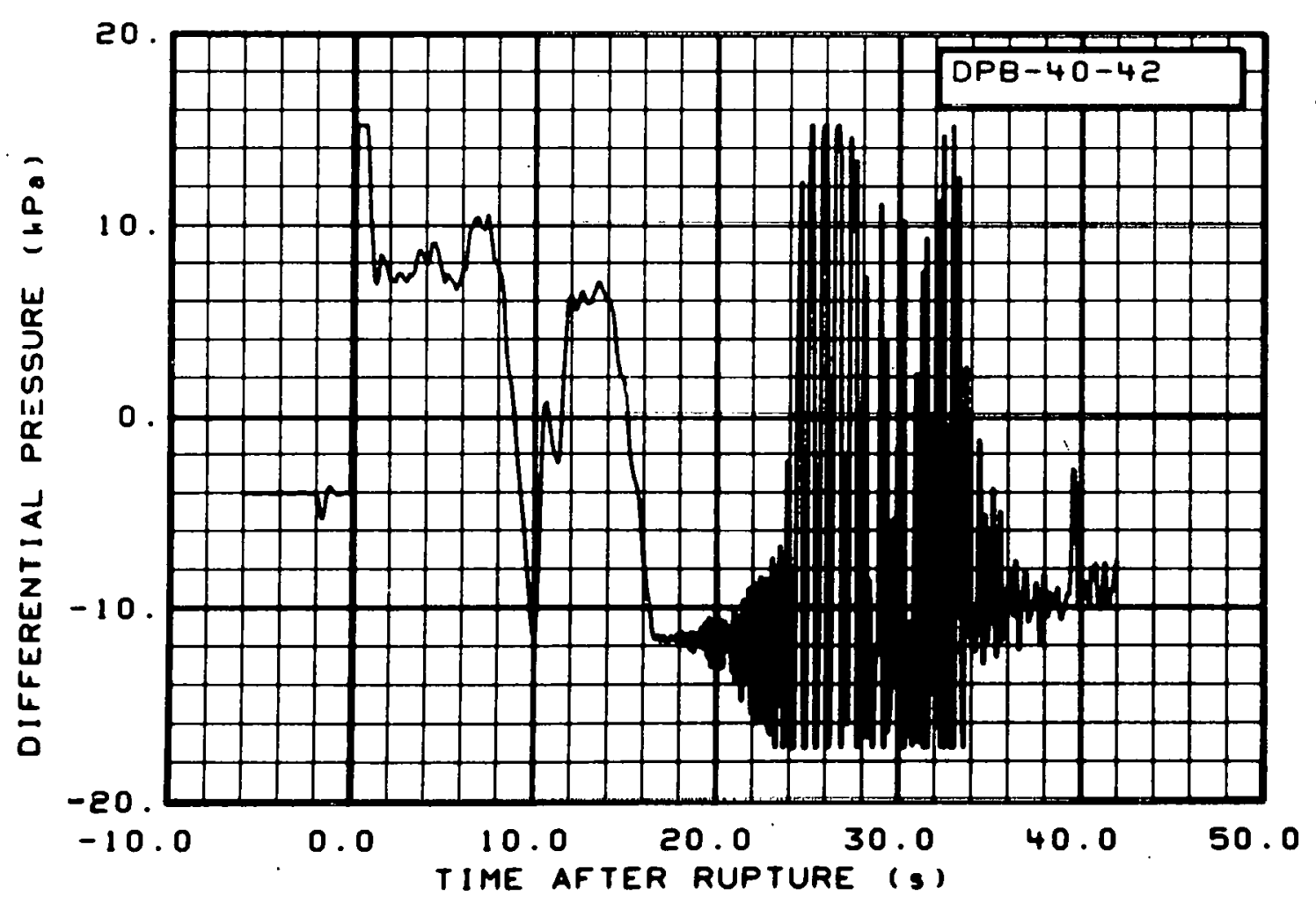

Fig. 204 Differential pressure in broken loop (DPB-40-42), from -6 to $42 \mathrm{~s}$. 


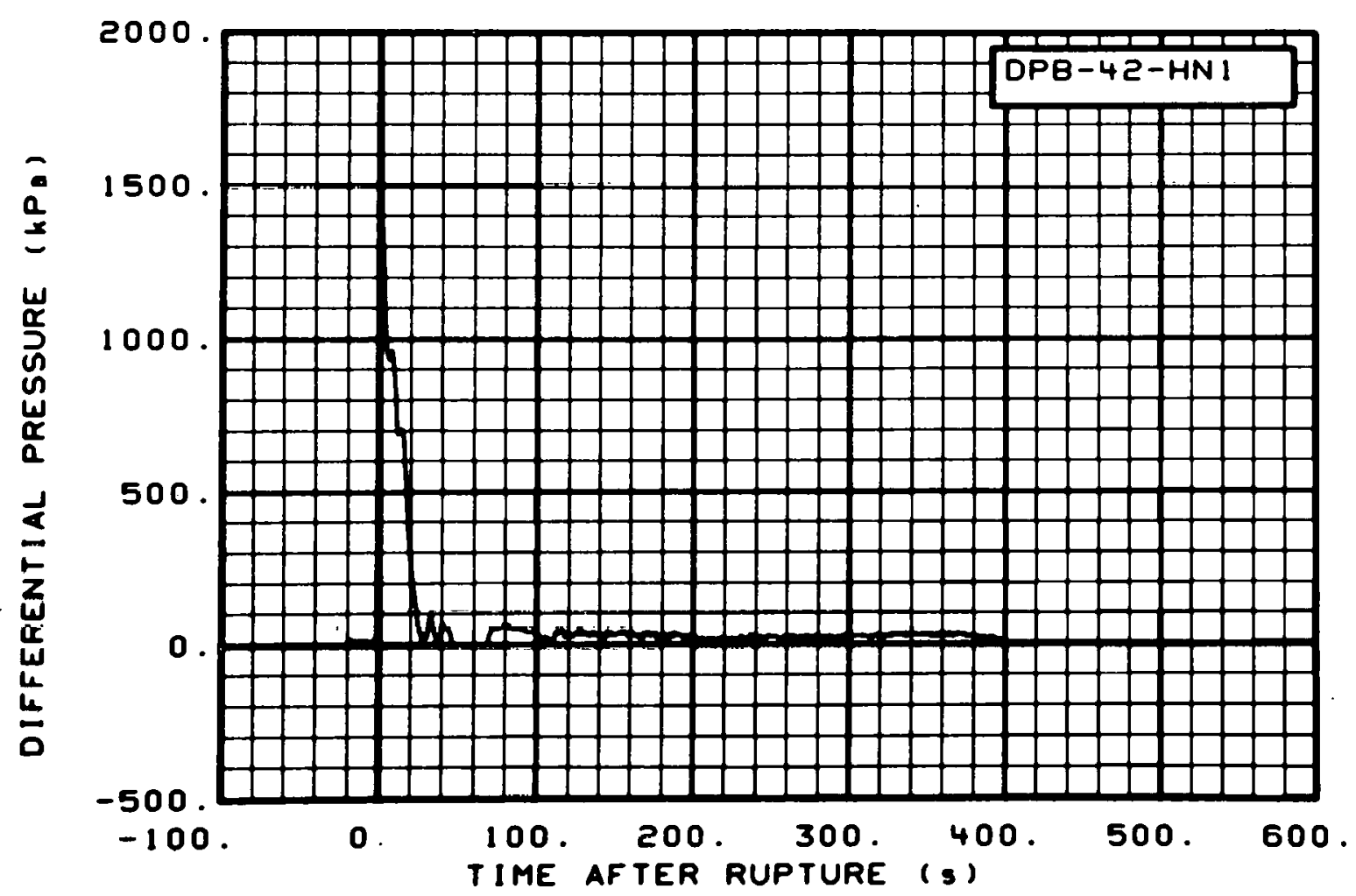

Fig. 205 Differential pressure in broken loop (DPB-42-HN1), from -20 to $600 \mathrm{~s}$.

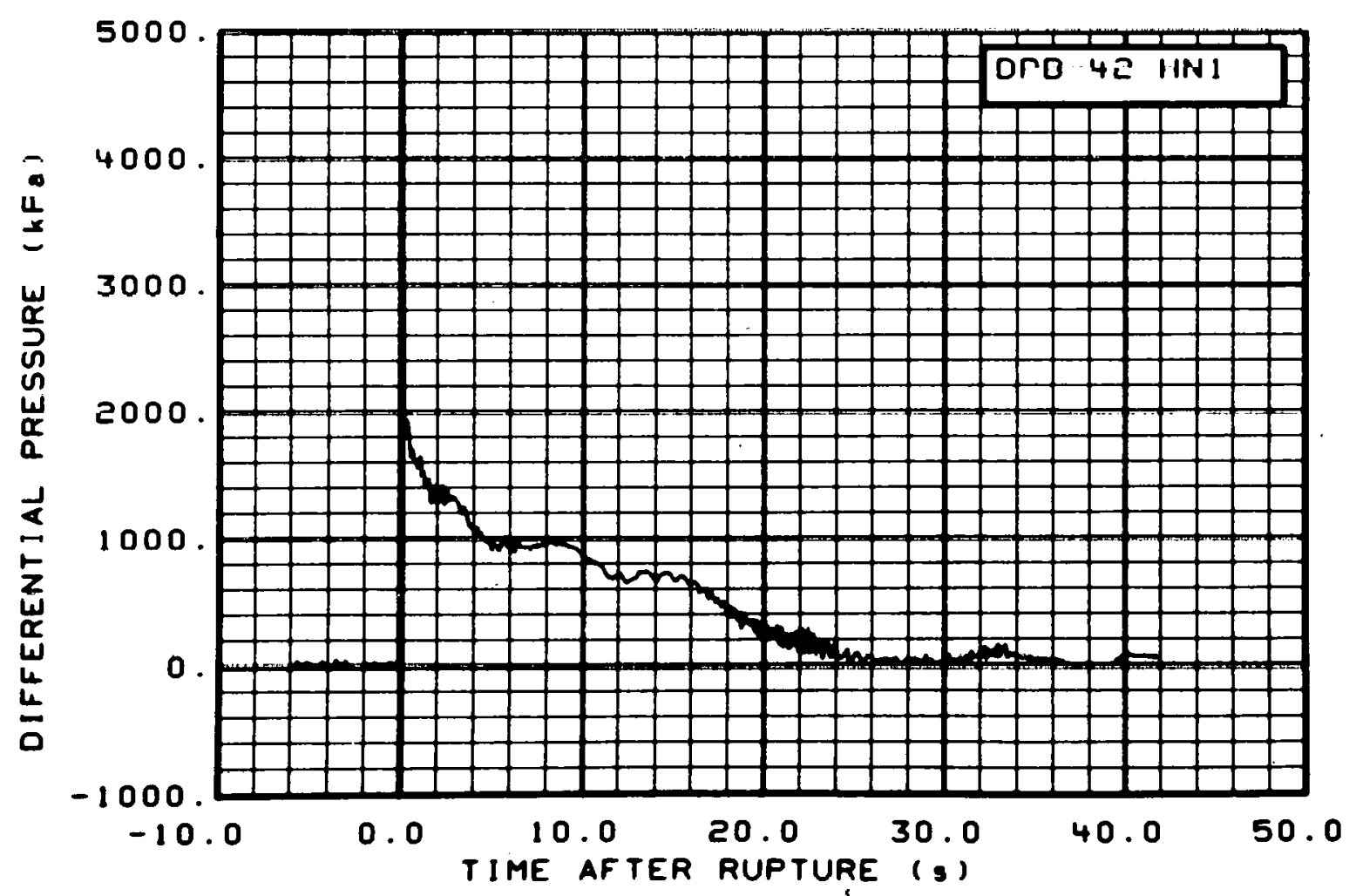

Fig. 206 Differential pressure in broken loop (DPB-42-HN1), from -6 to $42 \mathrm{~s}$. 


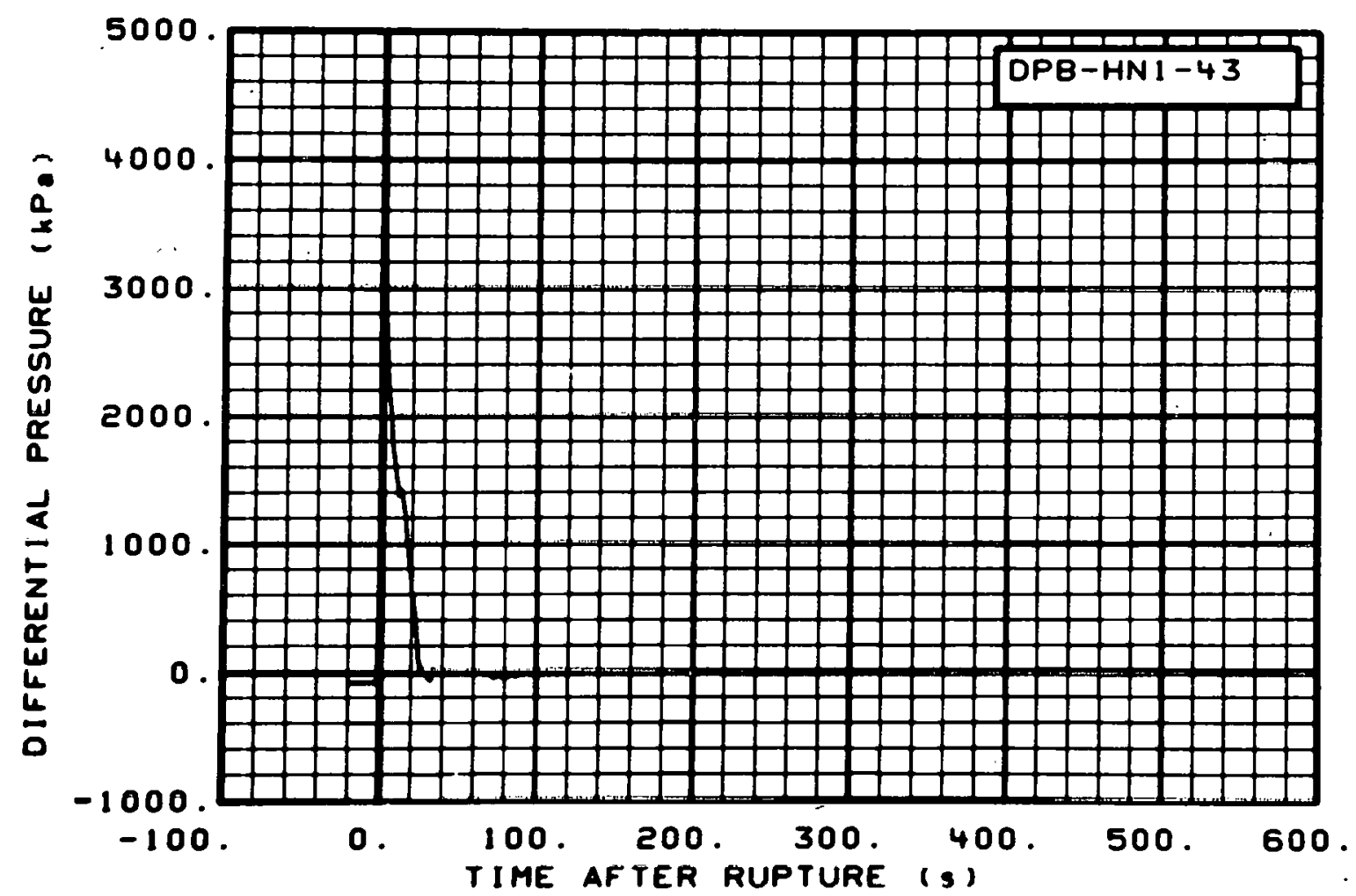

Fig. 207 Differential pressure in broken 10op (DPB-HN1-43), from -20 to $600 \mathrm{~s}$.

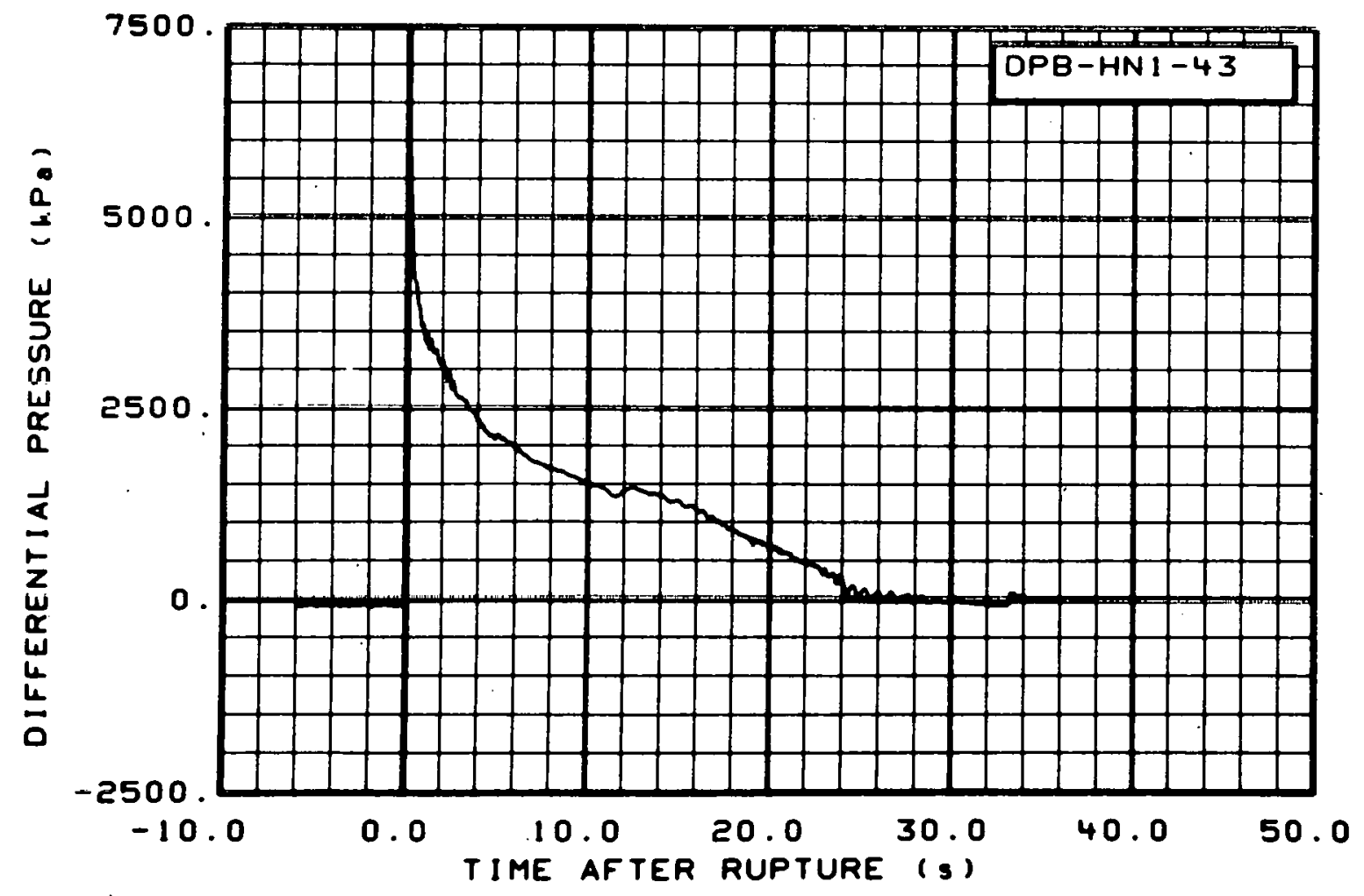

Fig. 208 Differential pressure in broken loop (DPB-HN1-43), from -6 to $42 \mathrm{~s}$. 


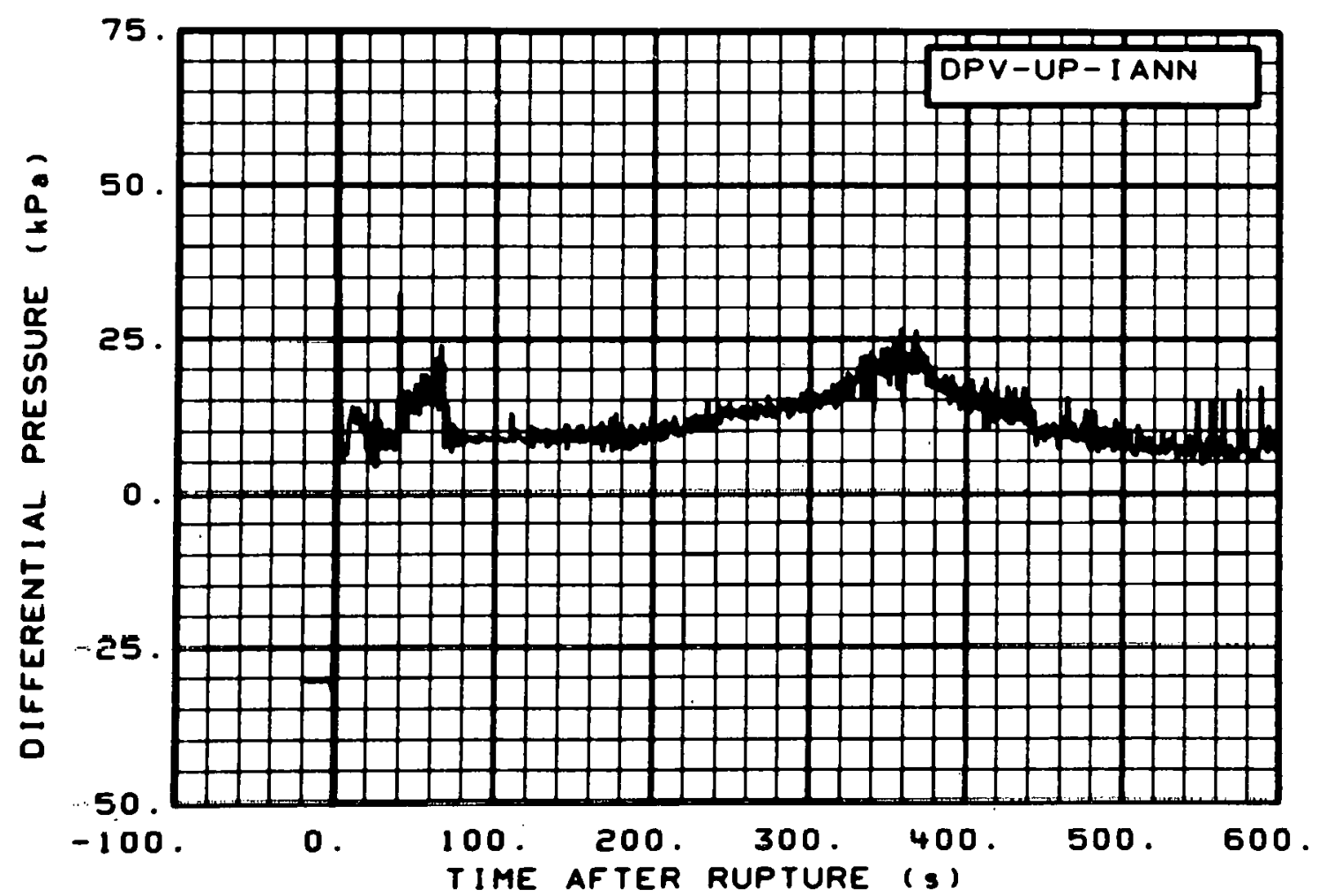

Fig. 209 Differential pressure in vessel (DPV-UP-IANN), from -20 to $600 \mathrm{~s}$.

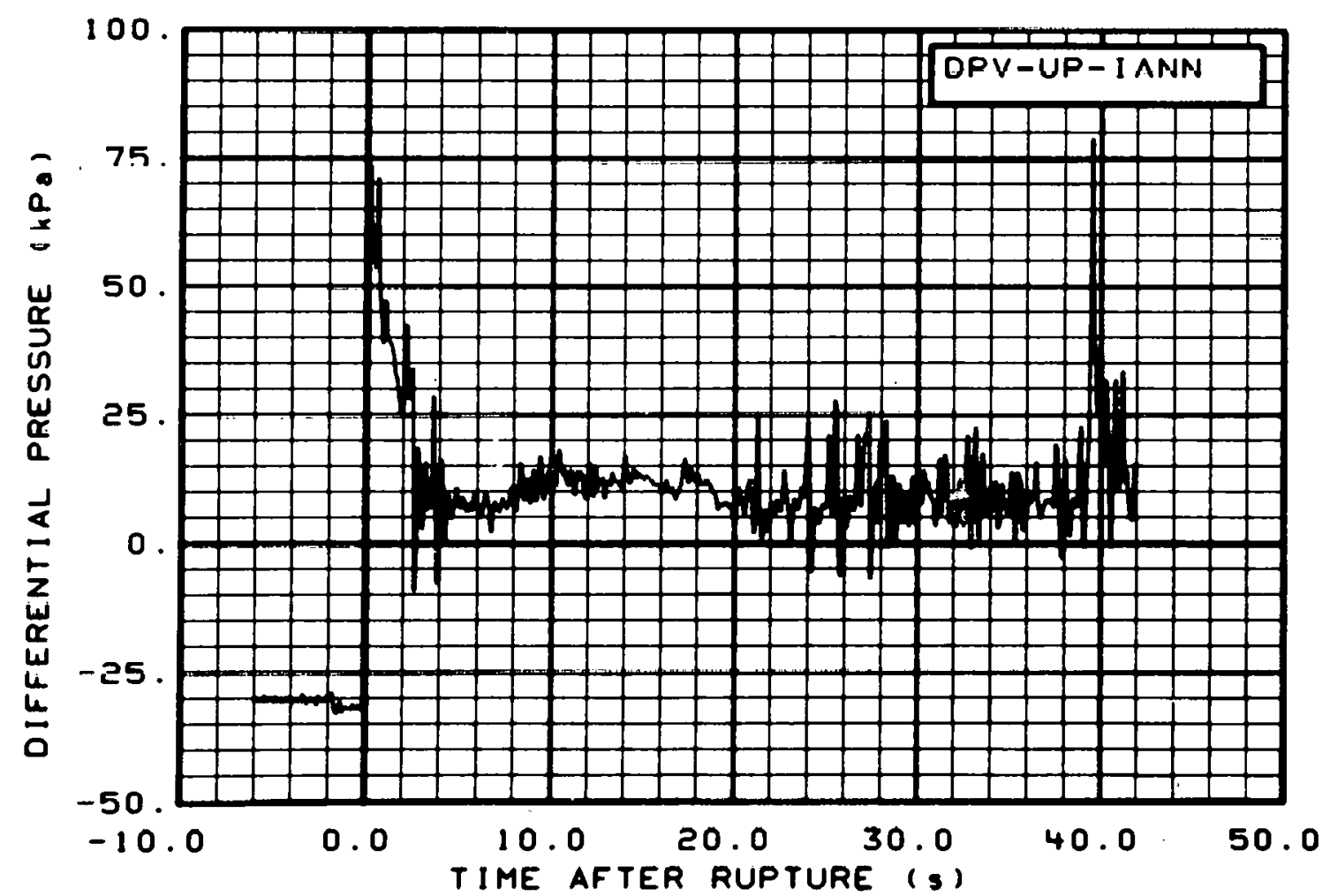

Fig. 210 Differential pressure in vessel (DPV-UP-IANN), from -6 to $42 \mathrm{~s}$. 


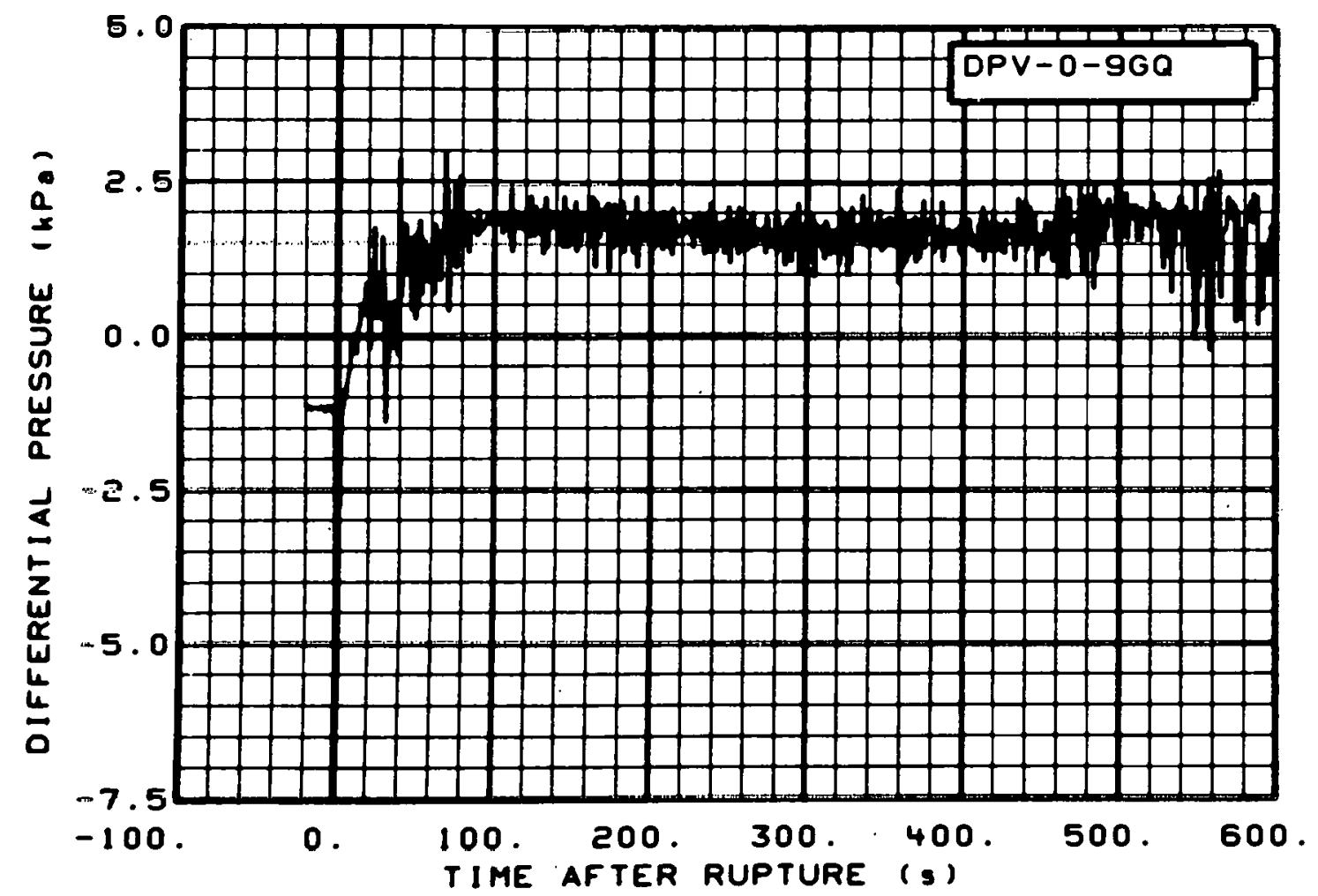

Fig. 211 Differential pressure in vessel (DPV-0-9GQ), from -20 to $600 \mathrm{~s}$.

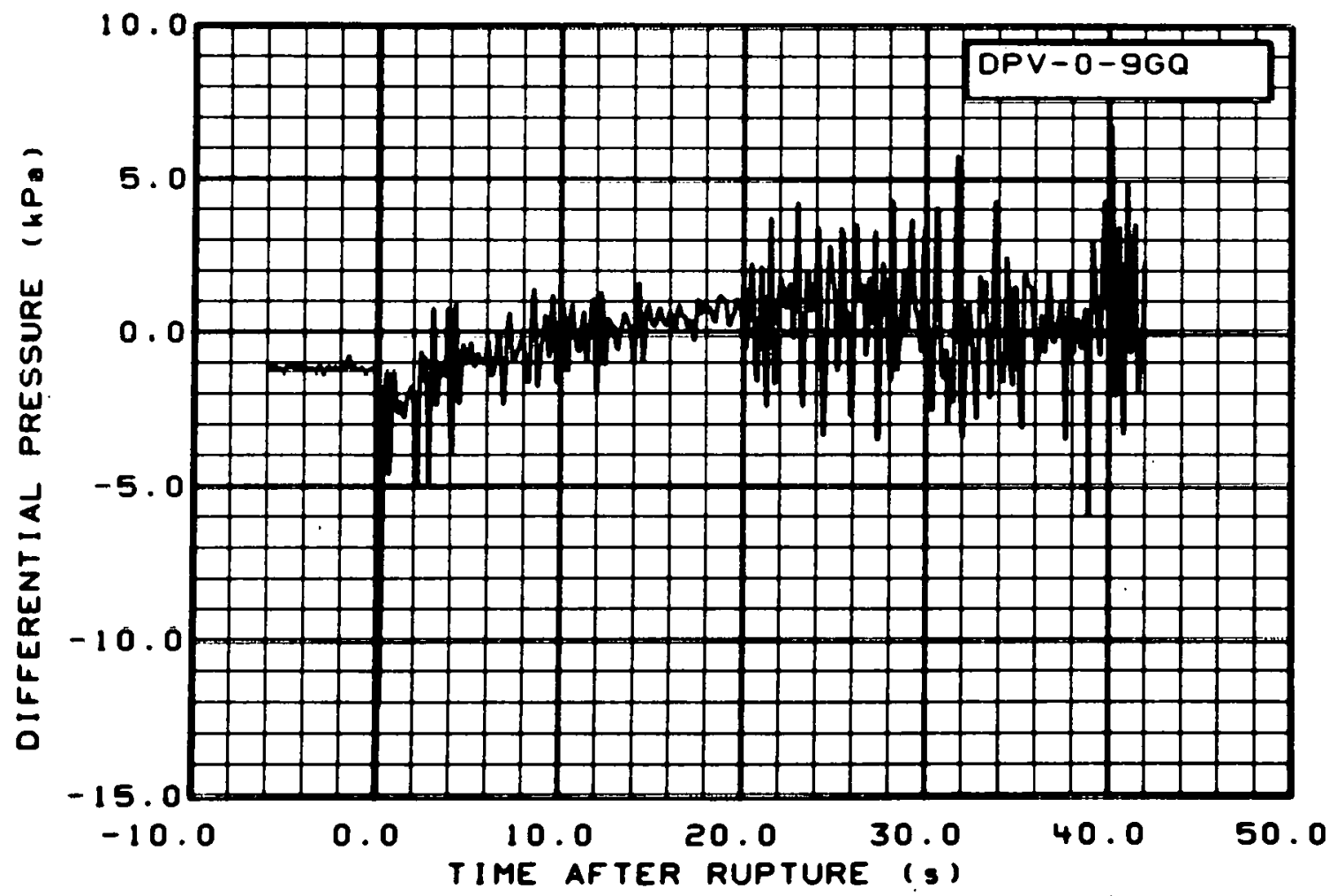

Fig. 212 Differential pressure in vessel (DPV-0-9GQ), from -6 to $42 \mathrm{~s}$. 


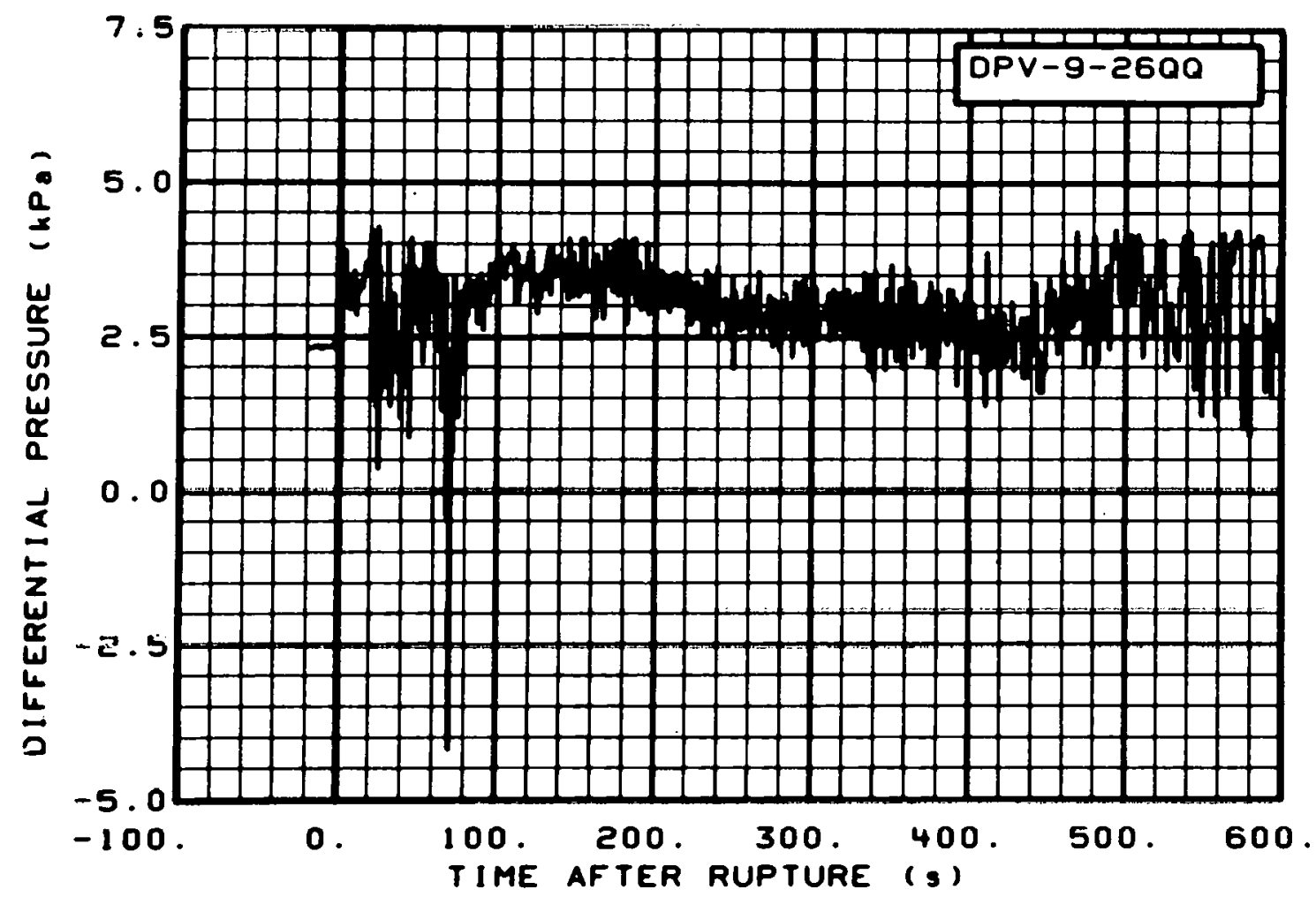

Fig. 213 Differential pressure in vessel (DPV-9-26QQ), from -20 to $600 \mathrm{~s}$.

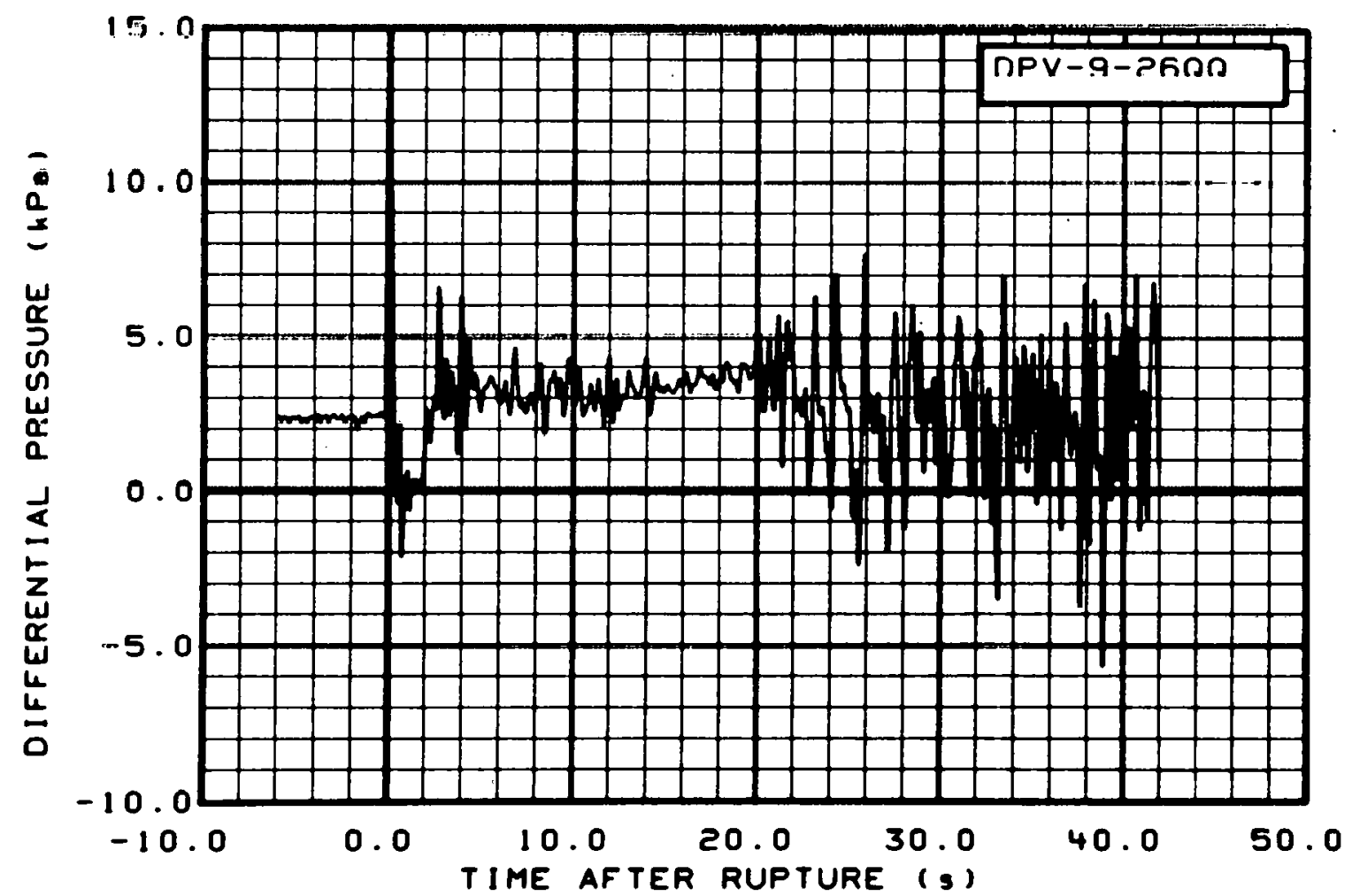

Fig. 214 Differential pressure in vessel (DPV-9-26QQ), from -6 to $42 \mathrm{~s}$. 


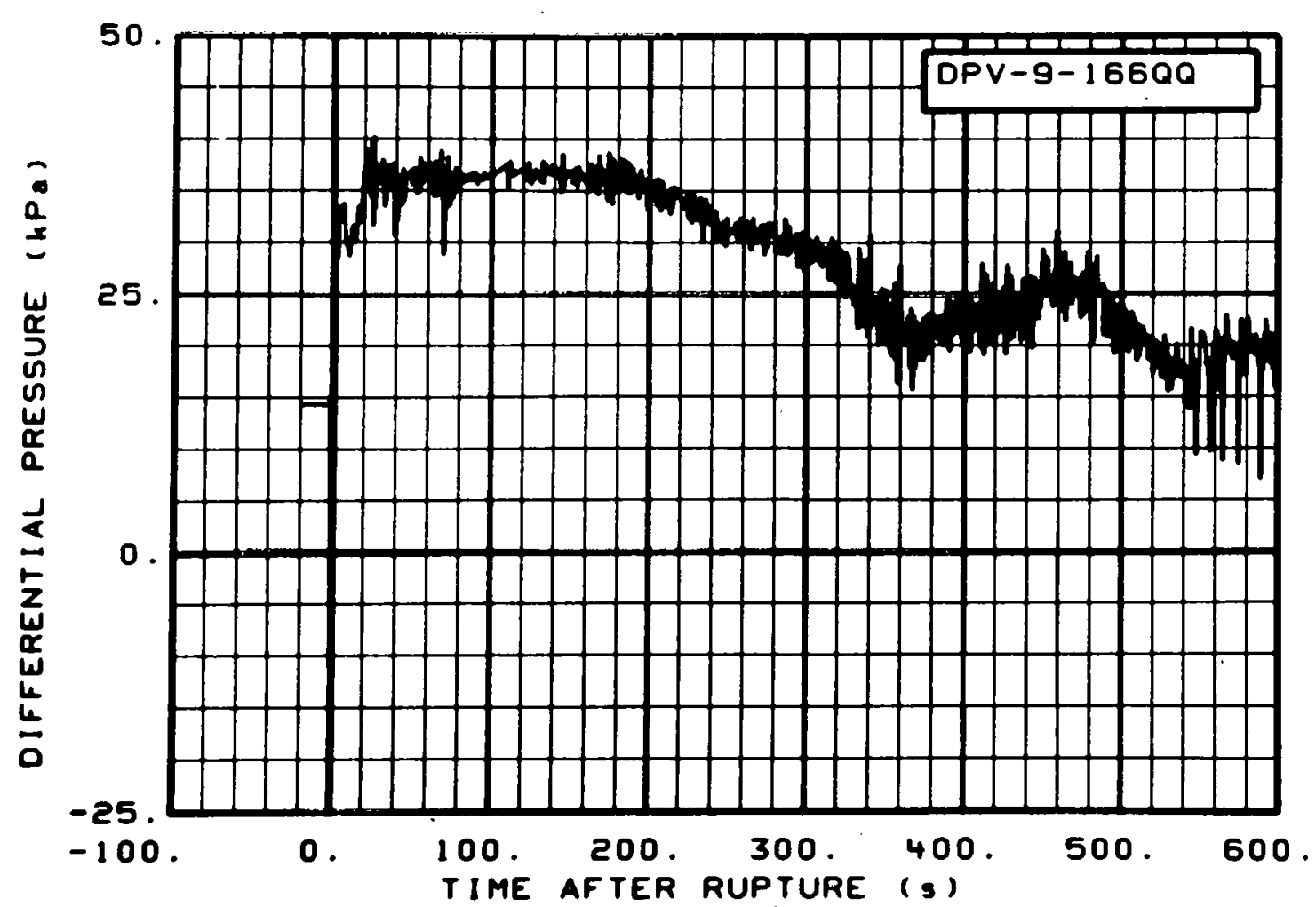

Fig. 215 Differential pressure in vessel (DPV-9-1660Q), from -20 to $600 \mathrm{~s}$.

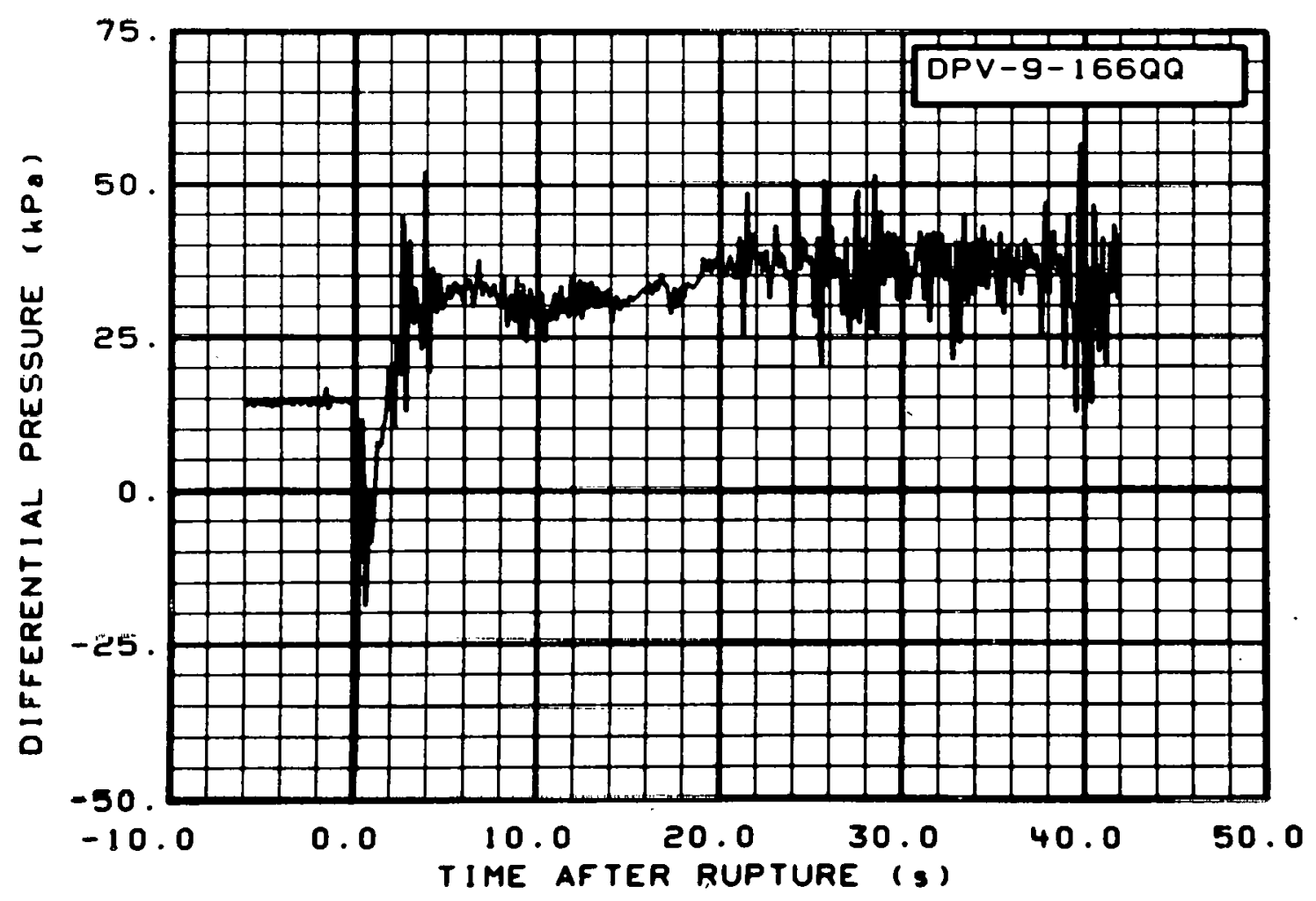

Fig. 216 Differential pressure in vessel (DPV-9-166QQ), from -6 to $42 \mathrm{~s}$. 


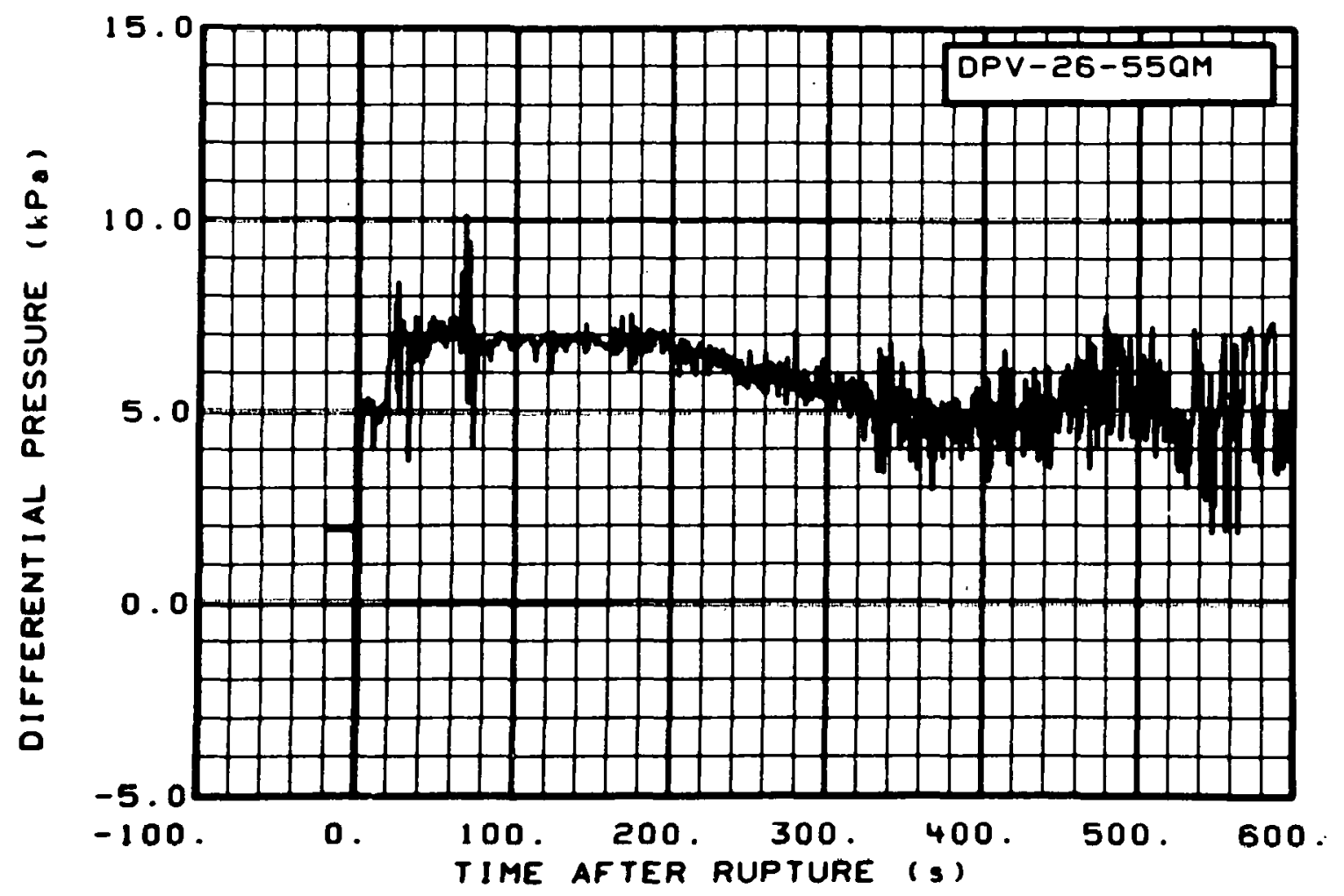

Fig. 217 Differential pressure in vessel (DPV-26-55QM), from -20 to $600 \mathrm{~s}$.

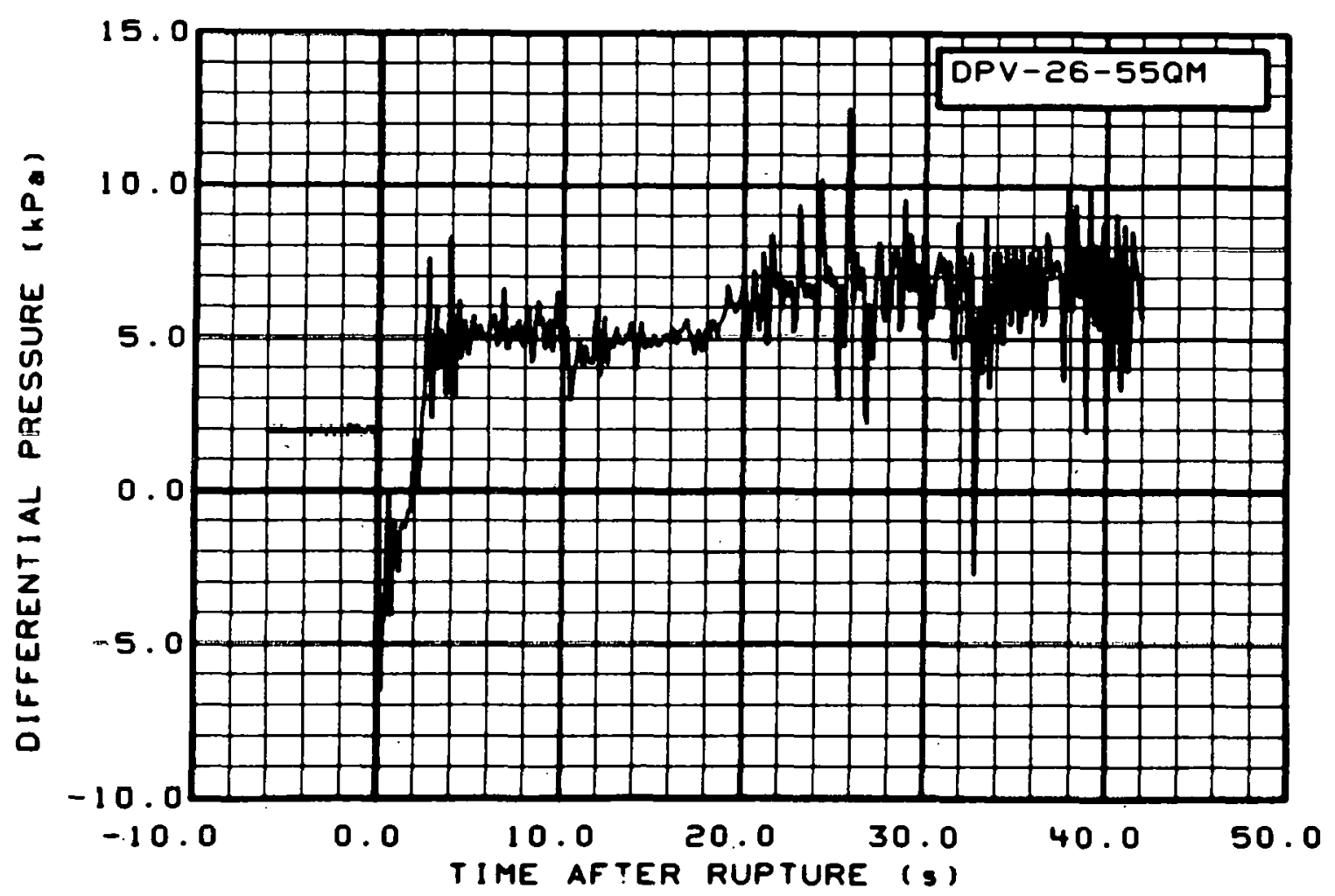

Fig. 218 Differential pressure in vessel (DPV-26-55QM), from -6 to $42 \mathrm{~s}$. 


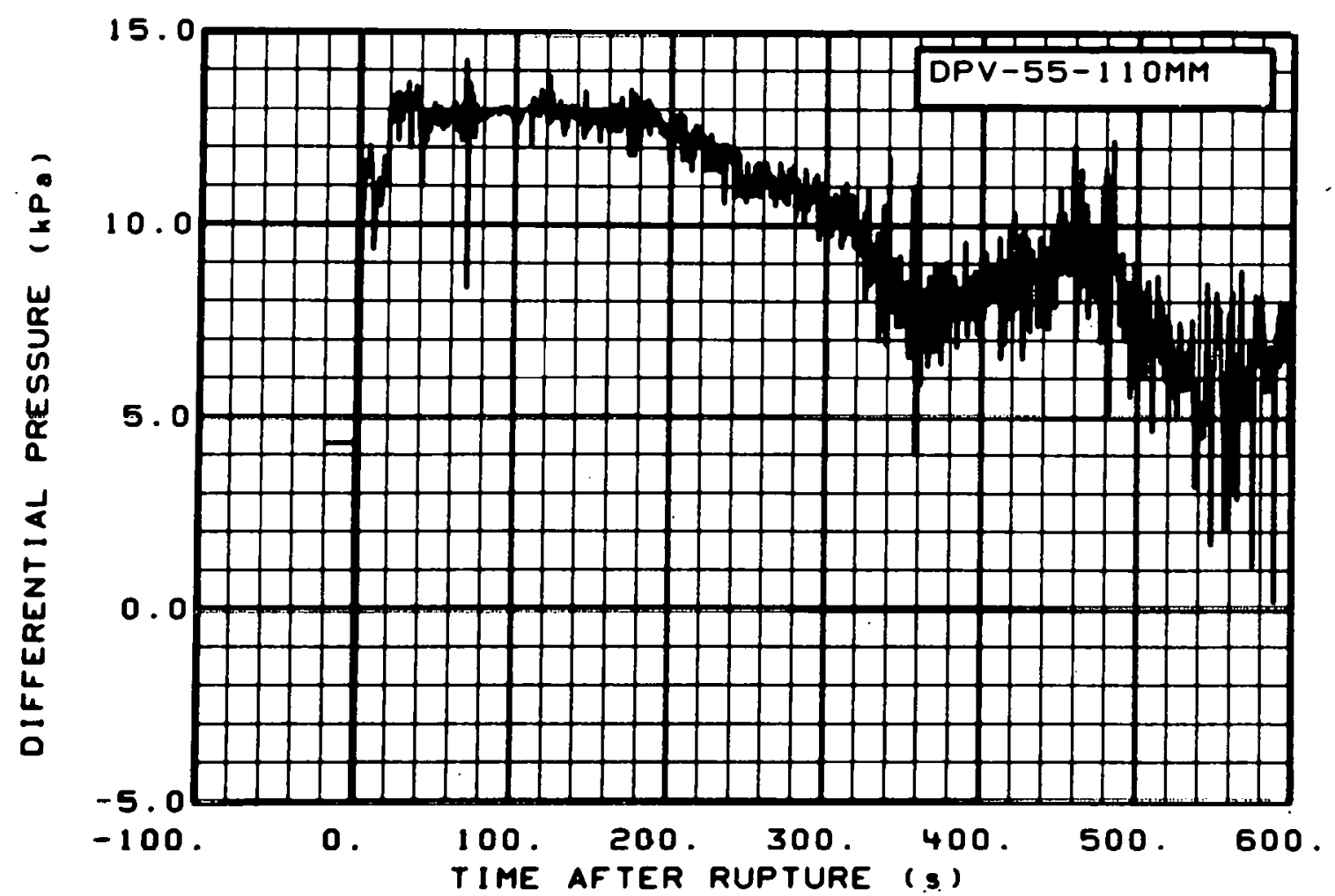

Fig. 219 Differential pressure in vessel (DPV-55-110MM), from -20 to $600 \mathrm{~s}$.

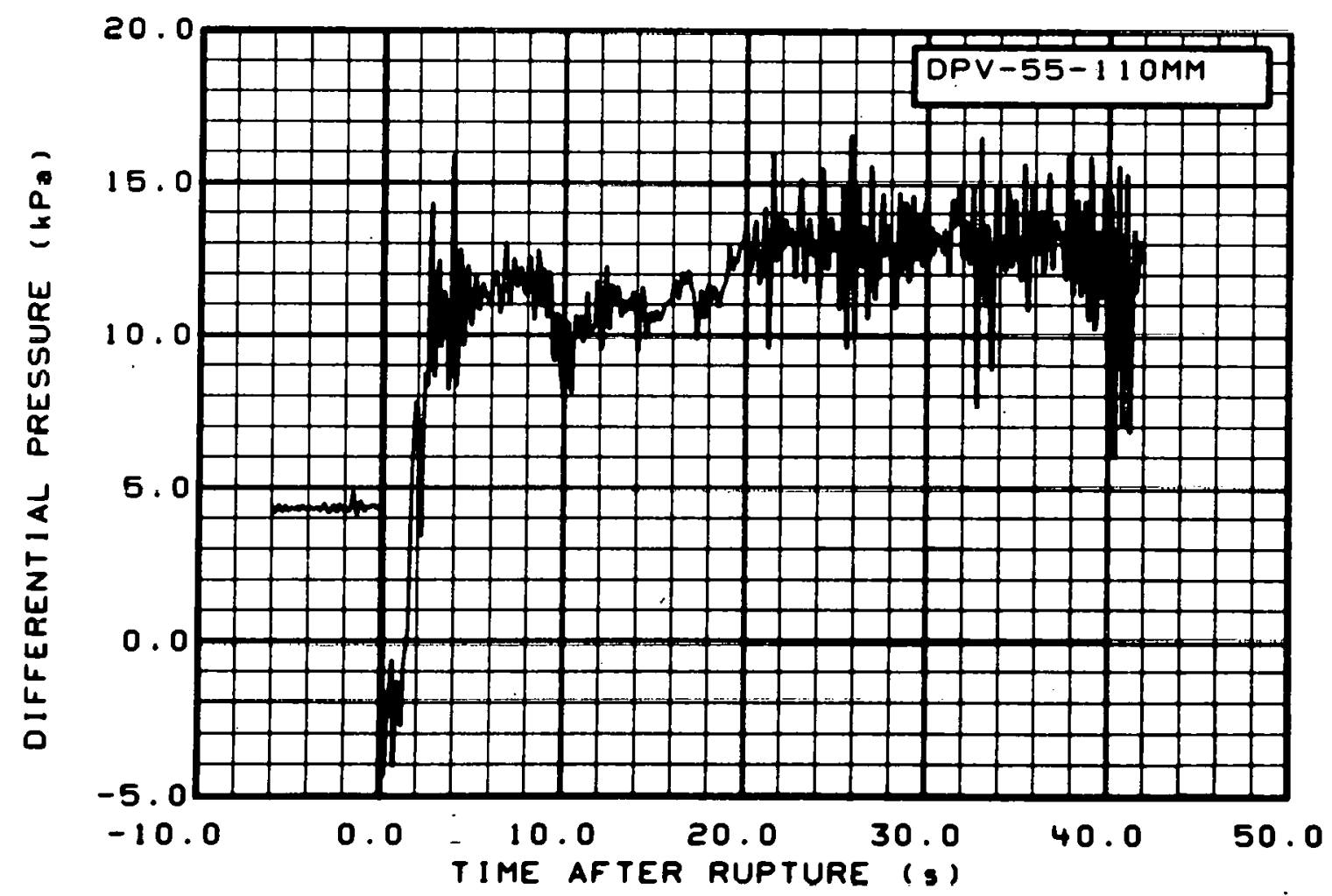

Fig. 220 Differential pressure in vesse1 (DPV-55-110MM), from -6 to $42 \mathrm{~s}$. 


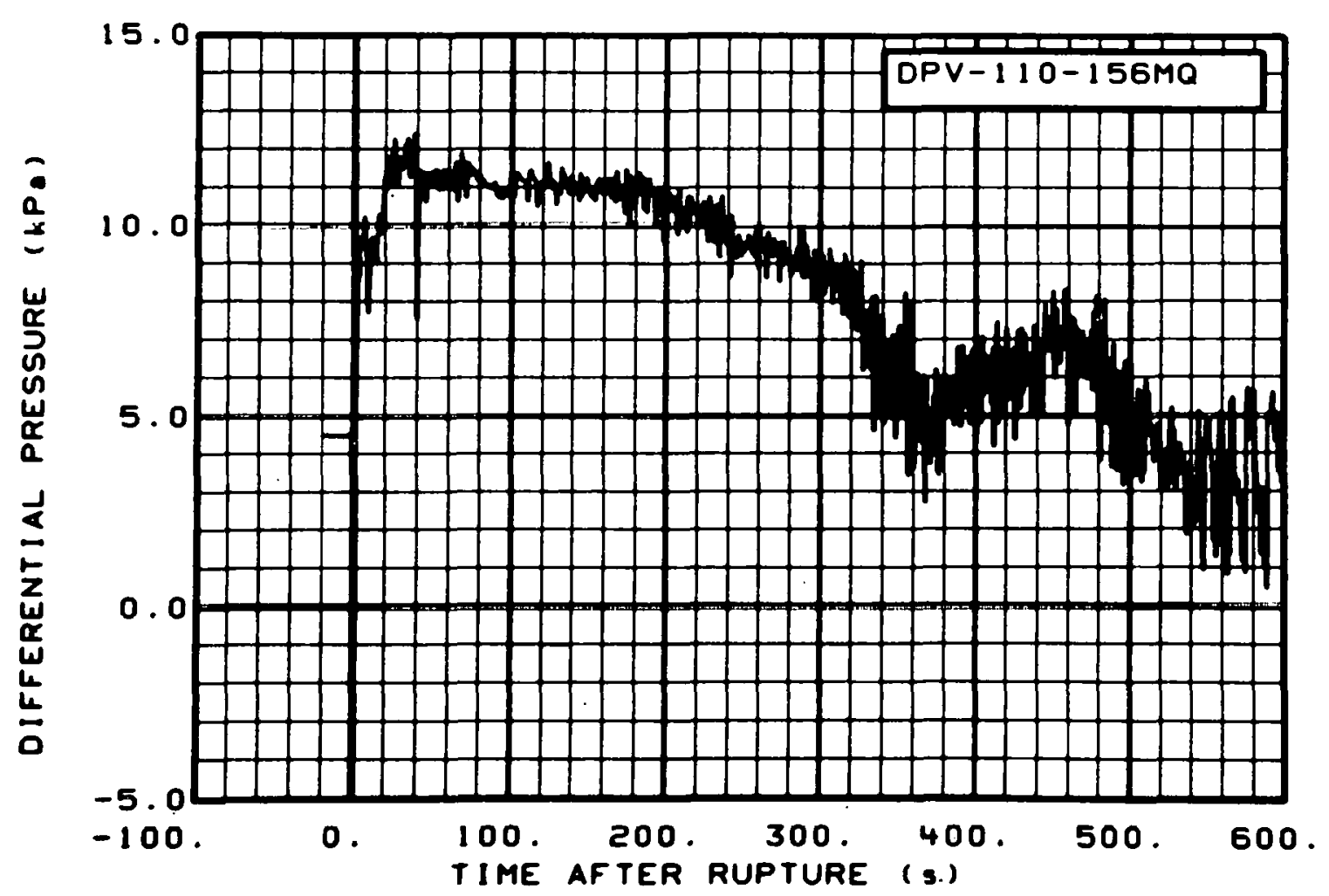

Fig. 221 Differential pressure in vessel (DPV-110-156MQ), from -20 to $600 \mathrm{~s}$.

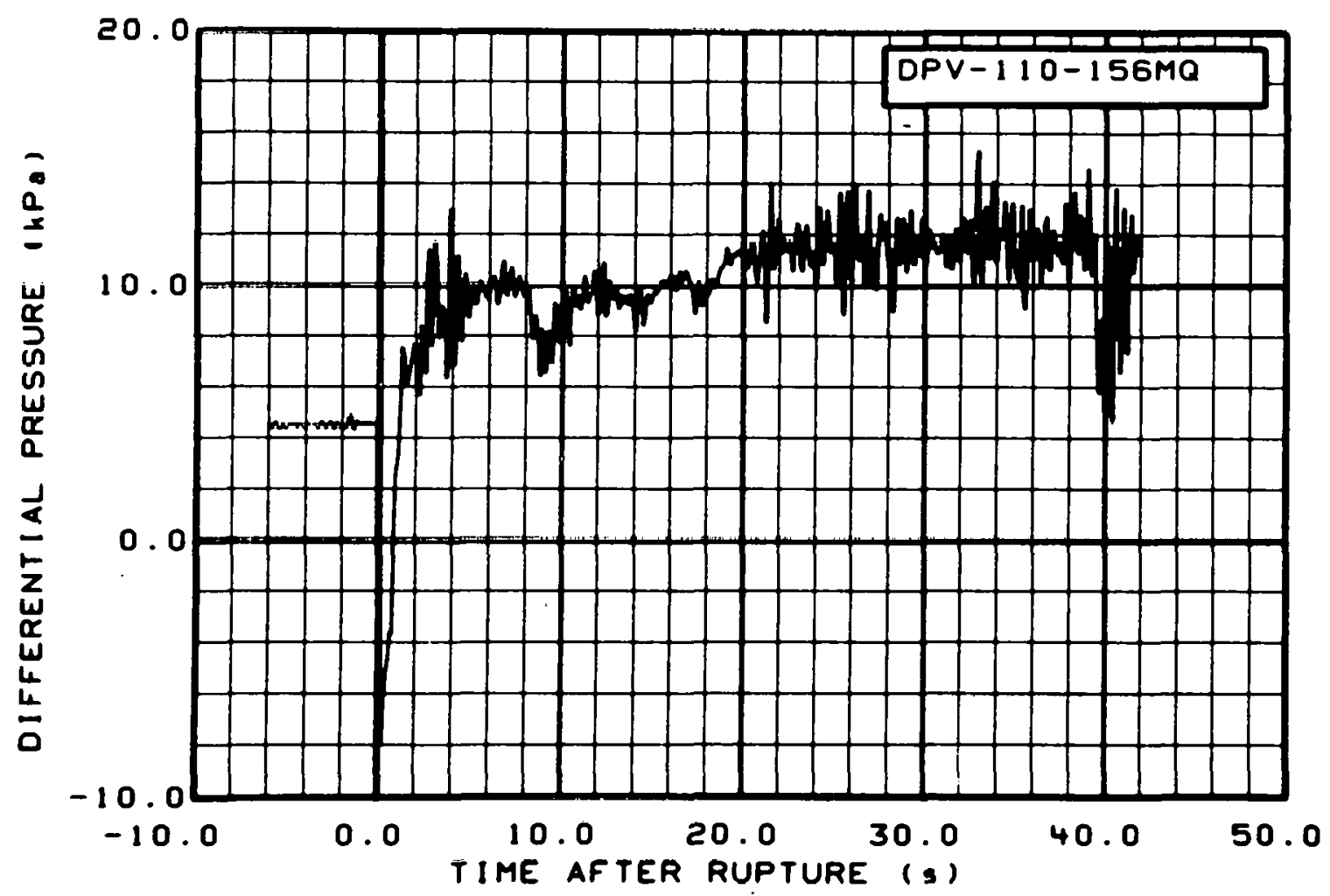

Fig. 222 Differential pressure in vessel (DPV-110-156MQ), from -6 to $42 \mathrm{~s}$. 


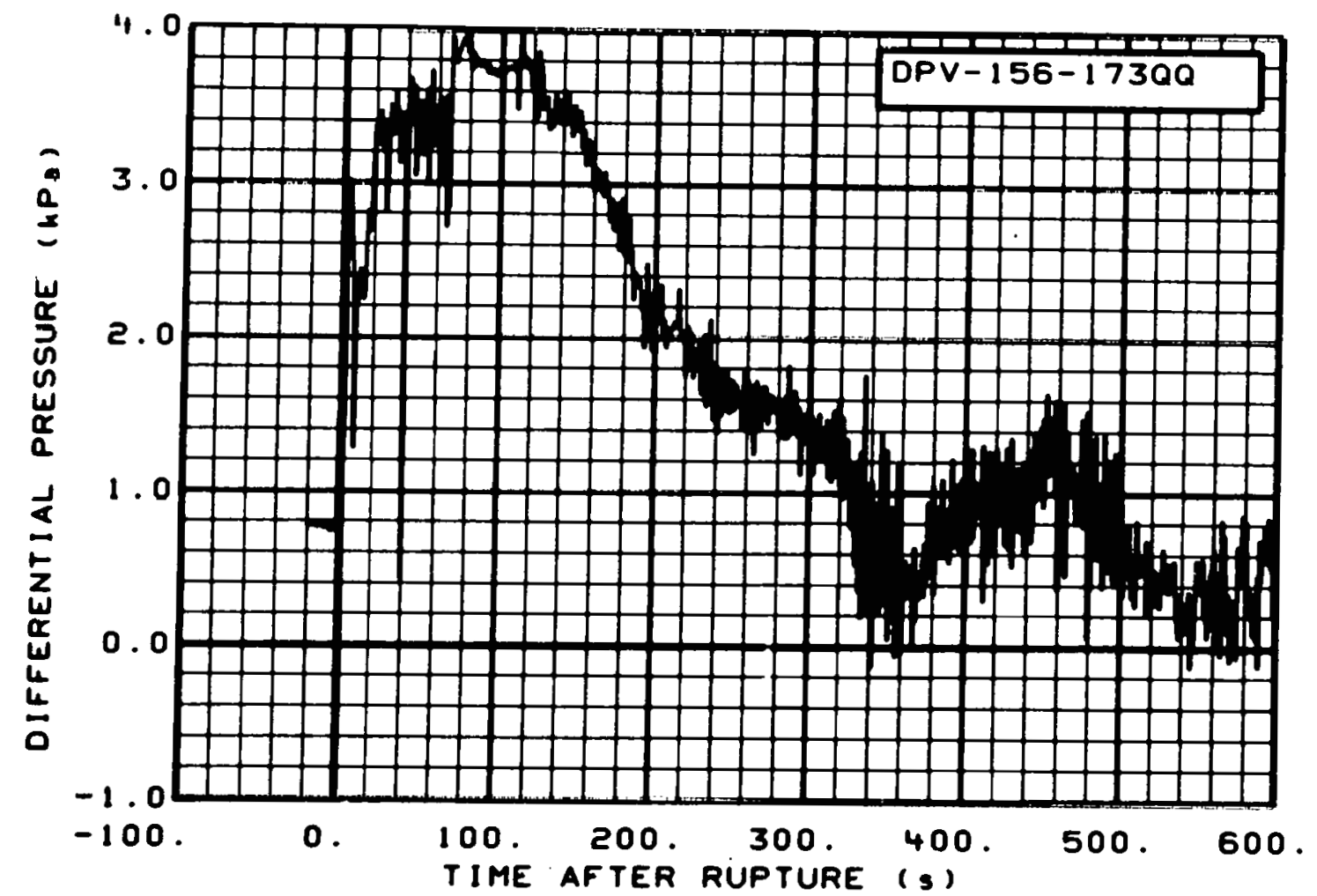

Fig. 223 Differential pressure in vessel (DPV-156-1730Q), from -20 to $600 \mathrm{~s}$.

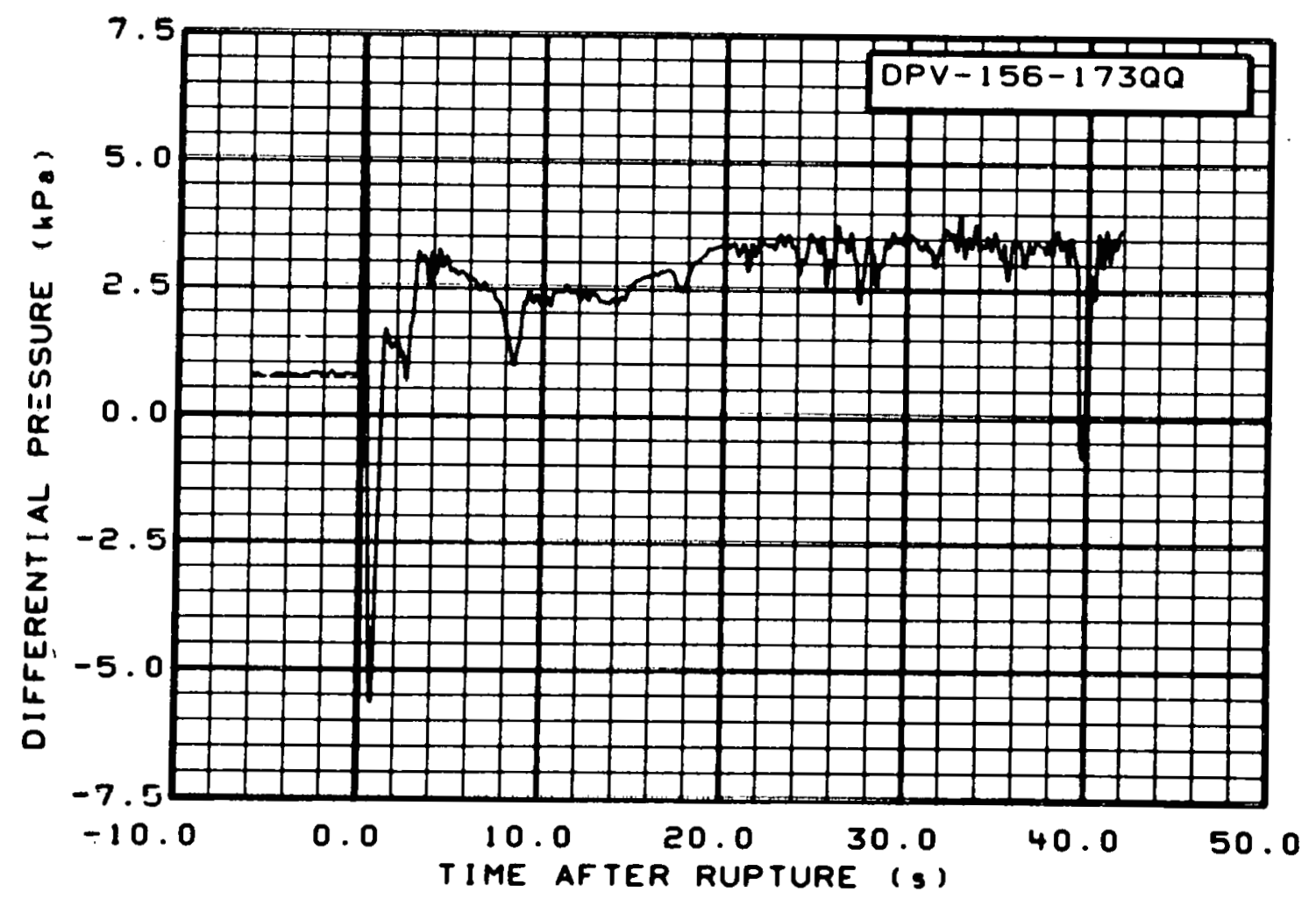

Fig. 224 Differential pressure in vessel (DPV-156-173QQ), from -6 to $42 \mathrm{~s}$. 


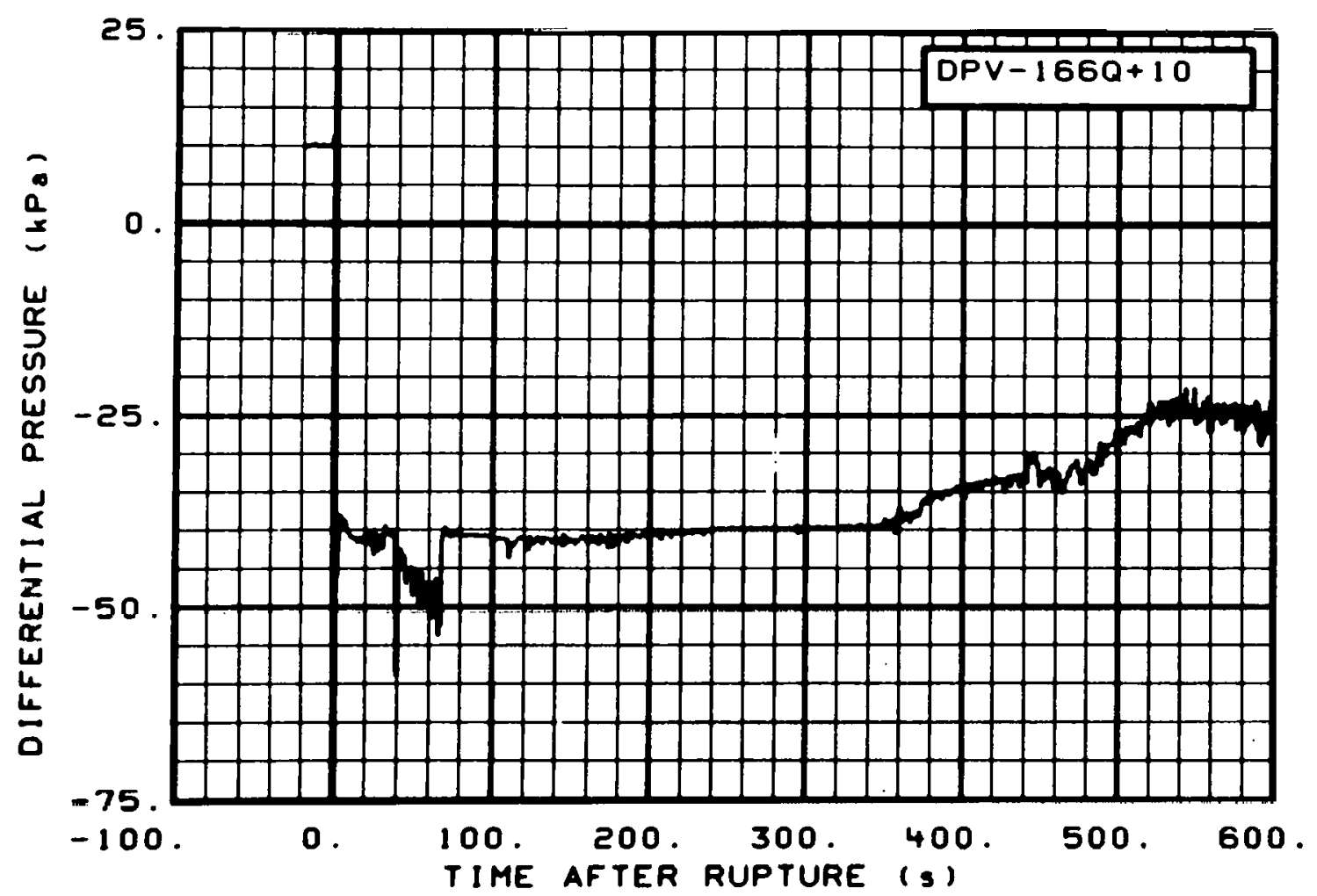

Fig. 225 Differential pressure in vessel (DPV-166Q+10), from -20 to $600 \mathrm{~s}$.

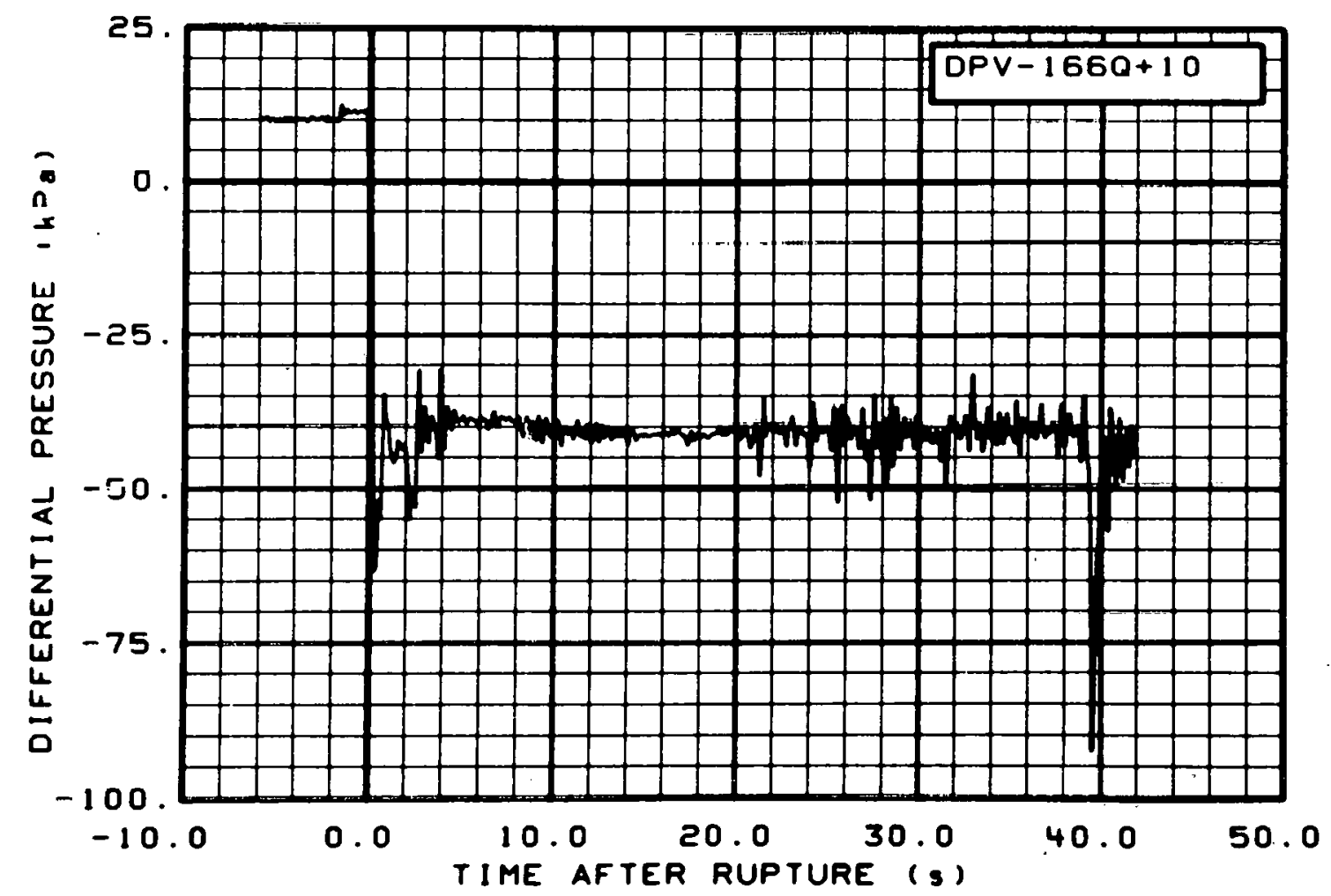

Fig. 226 Differential pressure in vessel (DPV-1660+10), from -6 to 42 s. 


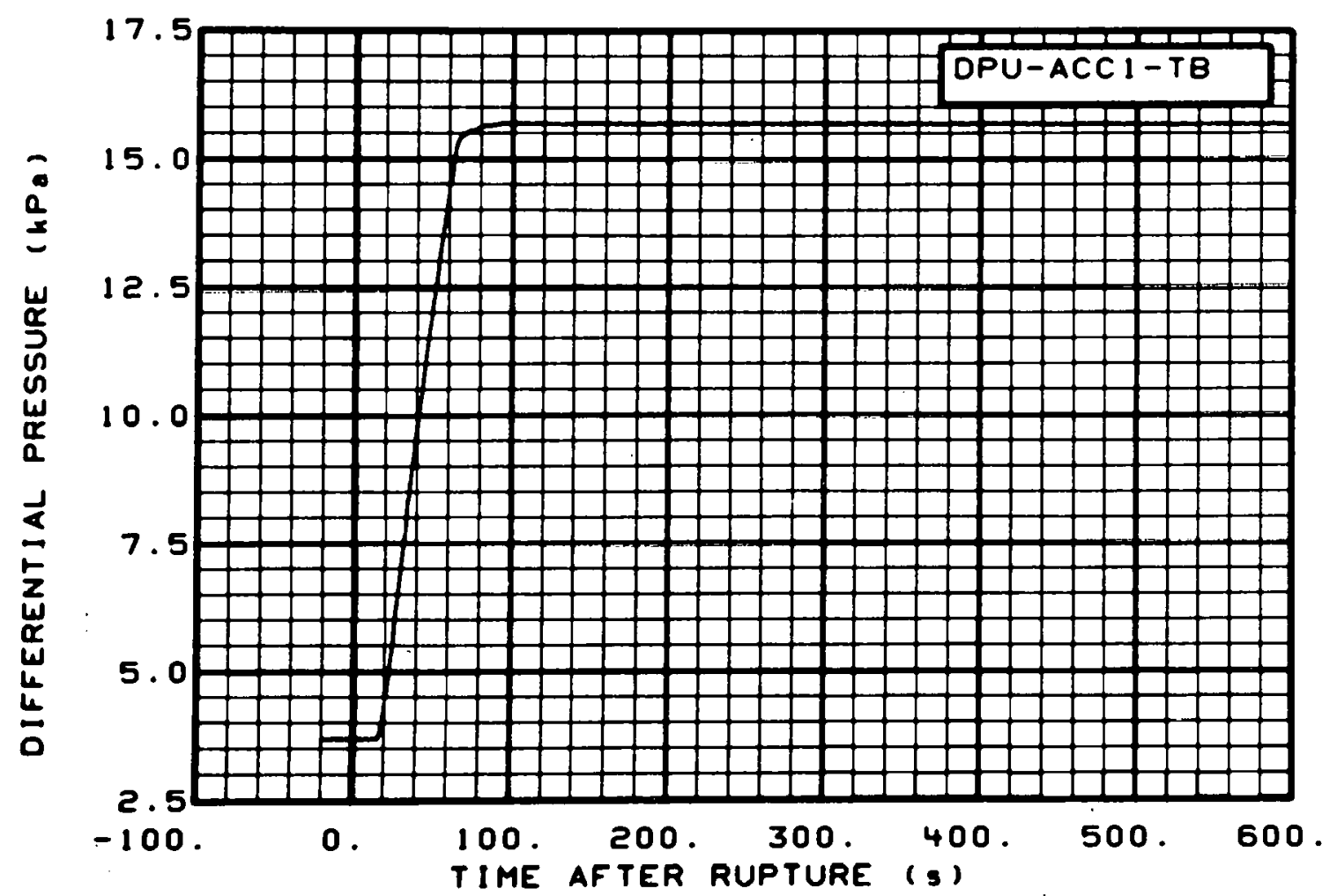

Fig. 227 Differential pressure in intact loop accumulator (DPU-ACC1-TB), from -20 to $600 \mathrm{~s}$.

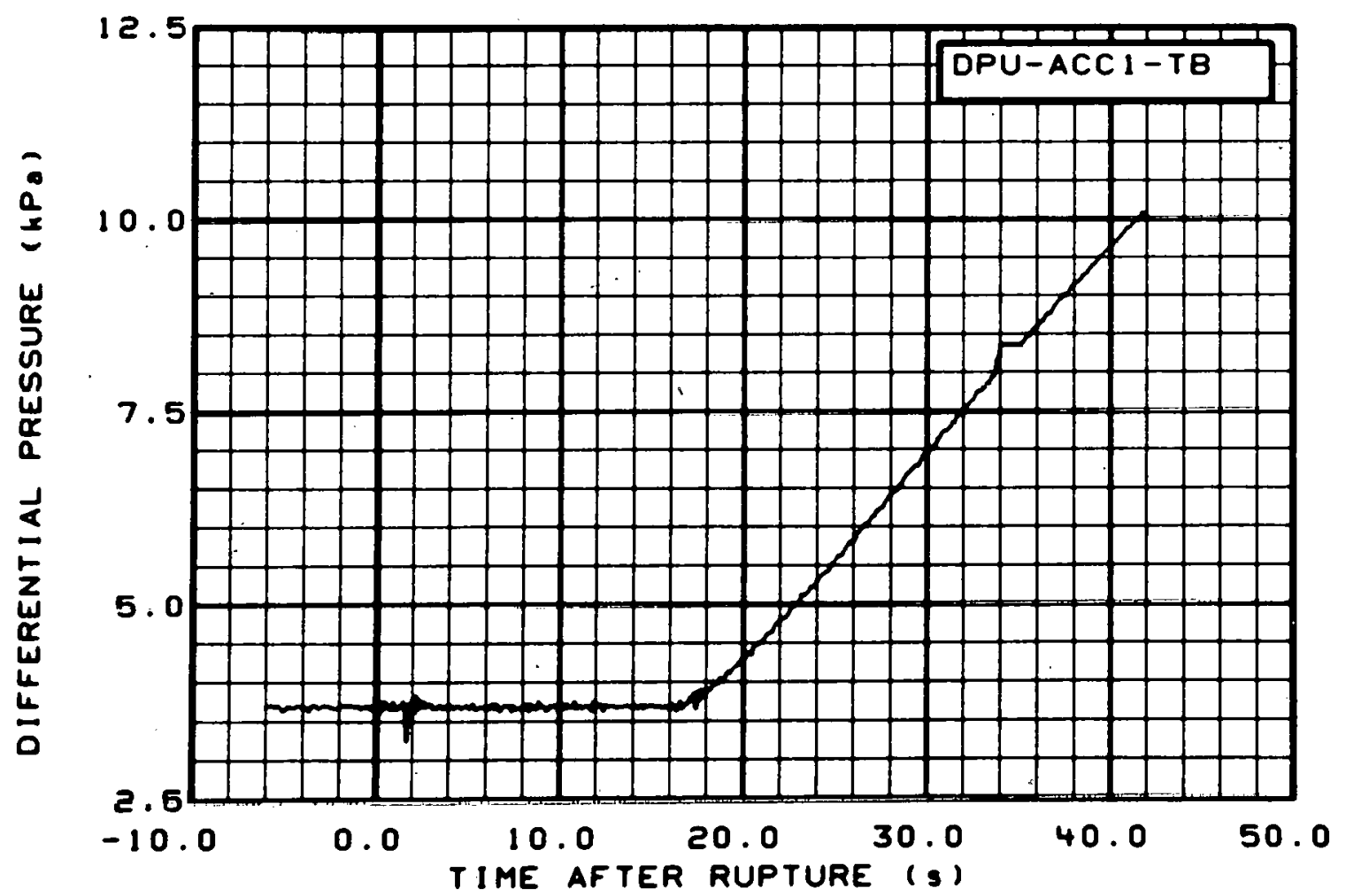

Fig. 228 Differential pressure in intact loop accumulator (DPU-ACCl-TB), from -6 to $42 \mathrm{~s}$. 


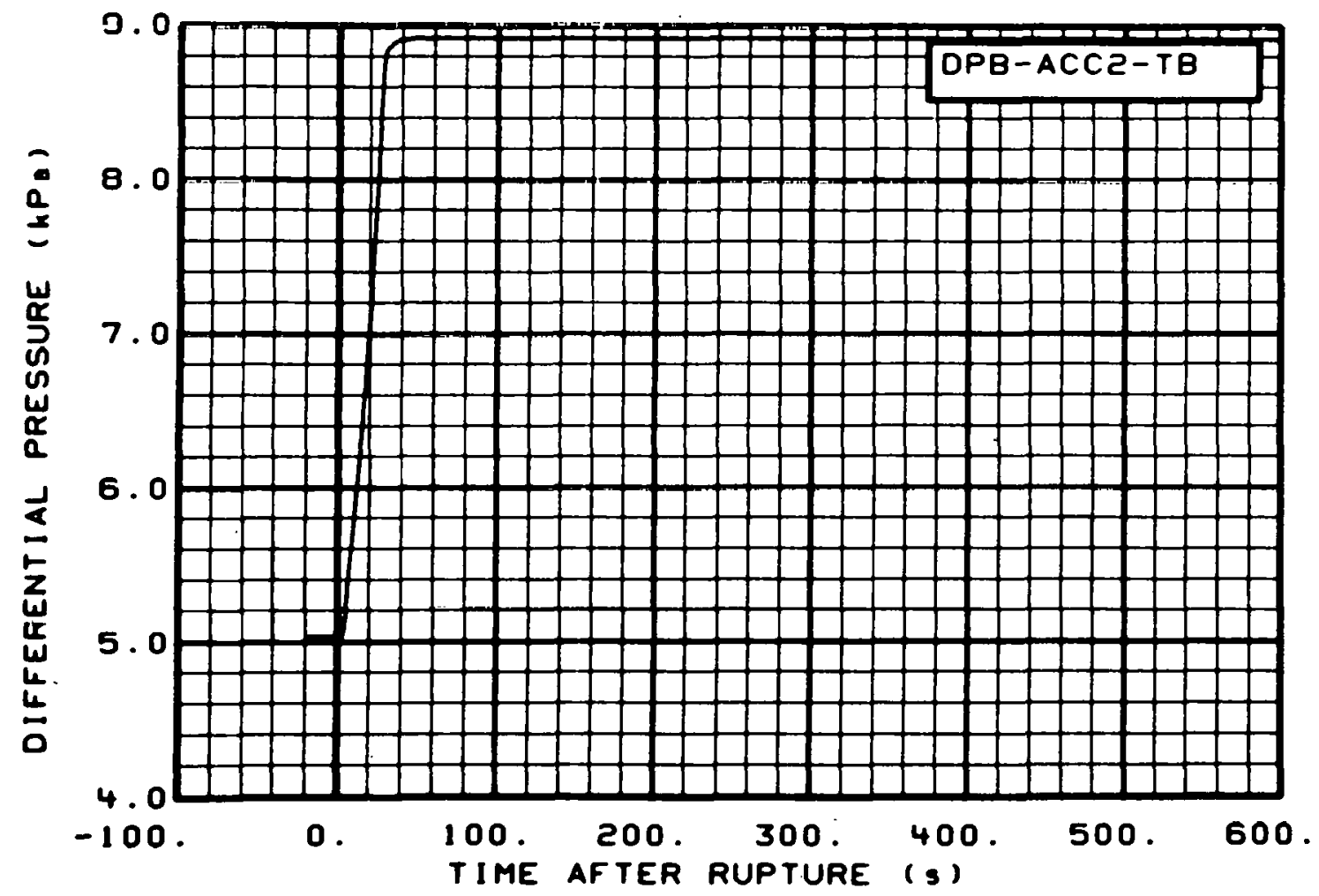

Fig. 229 Differential pressure in broken loop accumulator (DPB-ACC2-TB), from -20 to $600 \mathrm{~s}$.

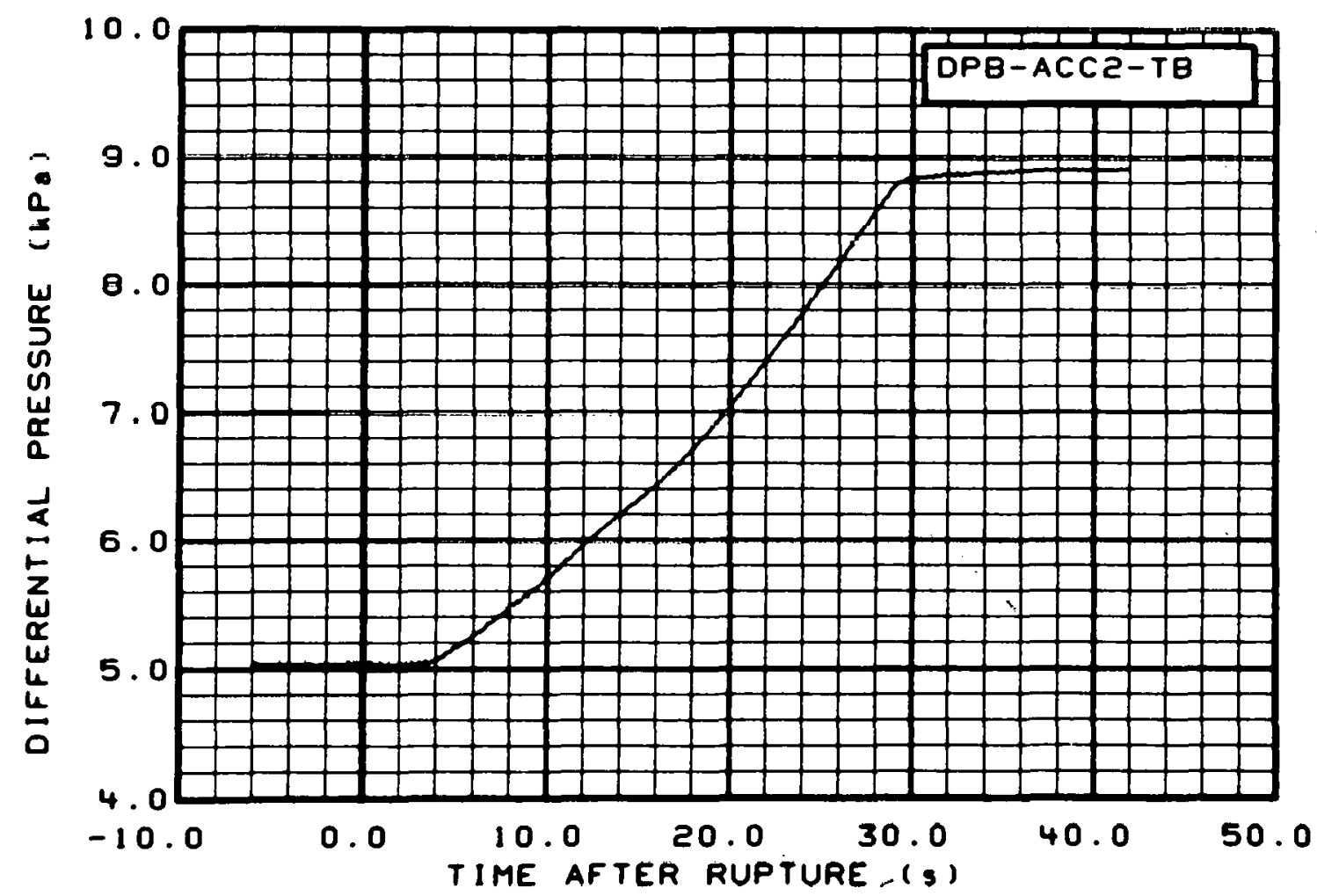

Fig. 230 Differential pressure in broken loop accumulator (DPB-ACC2-TB), from -6 to $42 \mathrm{~s}$. 


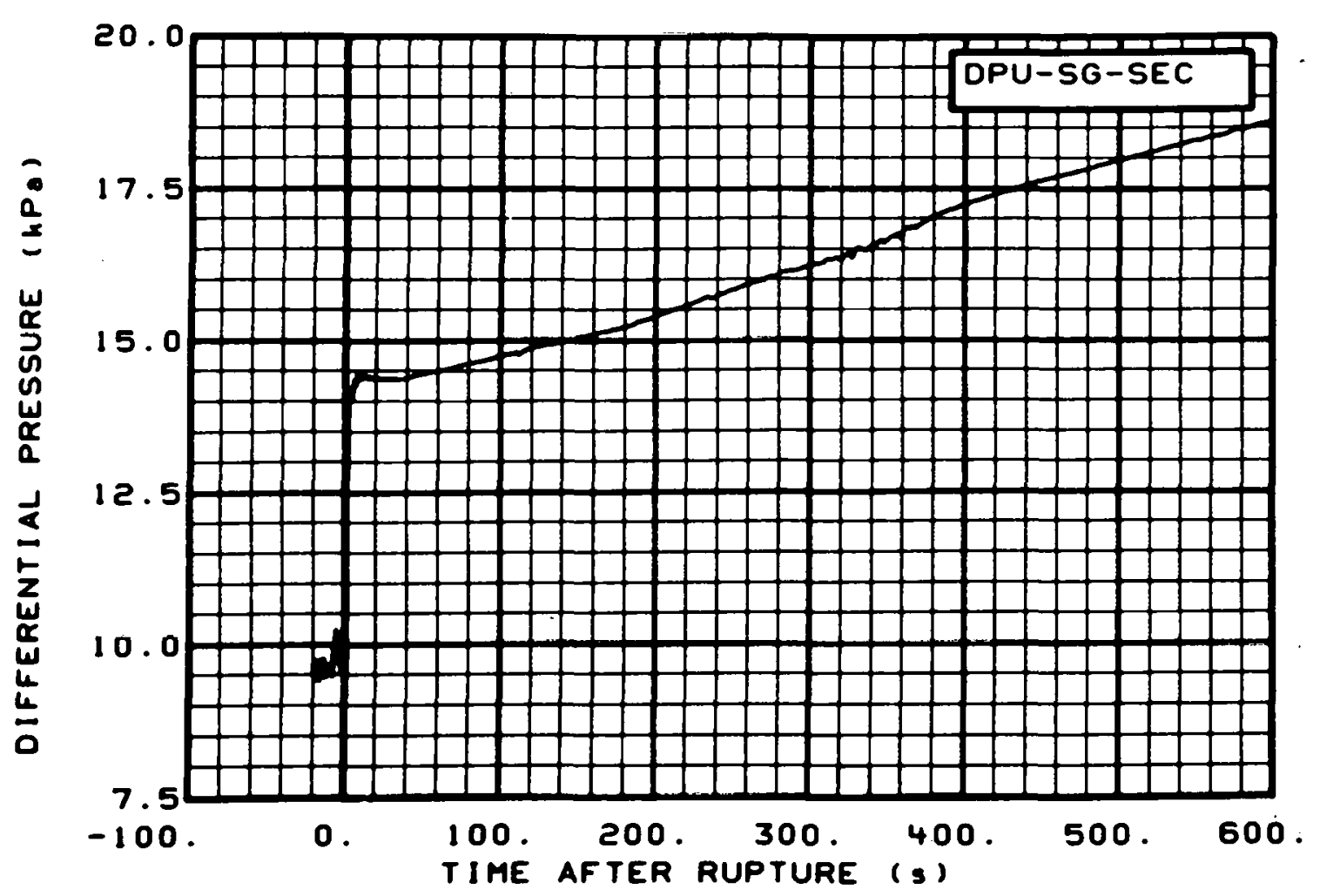

Fig. 231 Differential pressure in steam generator secondary (DPU-SG-SEC), from -20 to $600 \mathrm{~s}$.

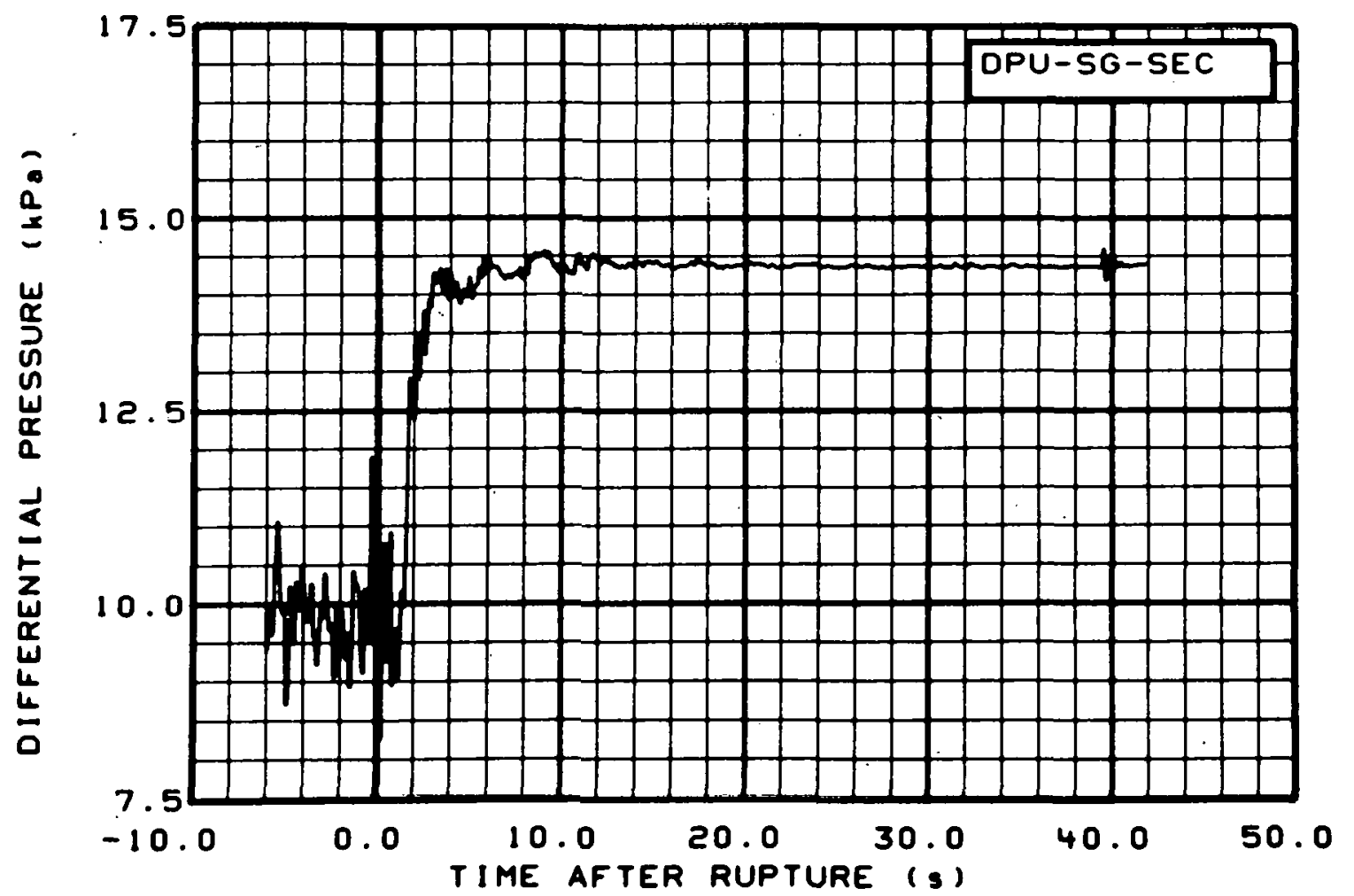

Fig. 232 Differential pressure in steam generator secondary (DPU-SG-SEC), from -6 to $42 \mathrm{~s}$. 


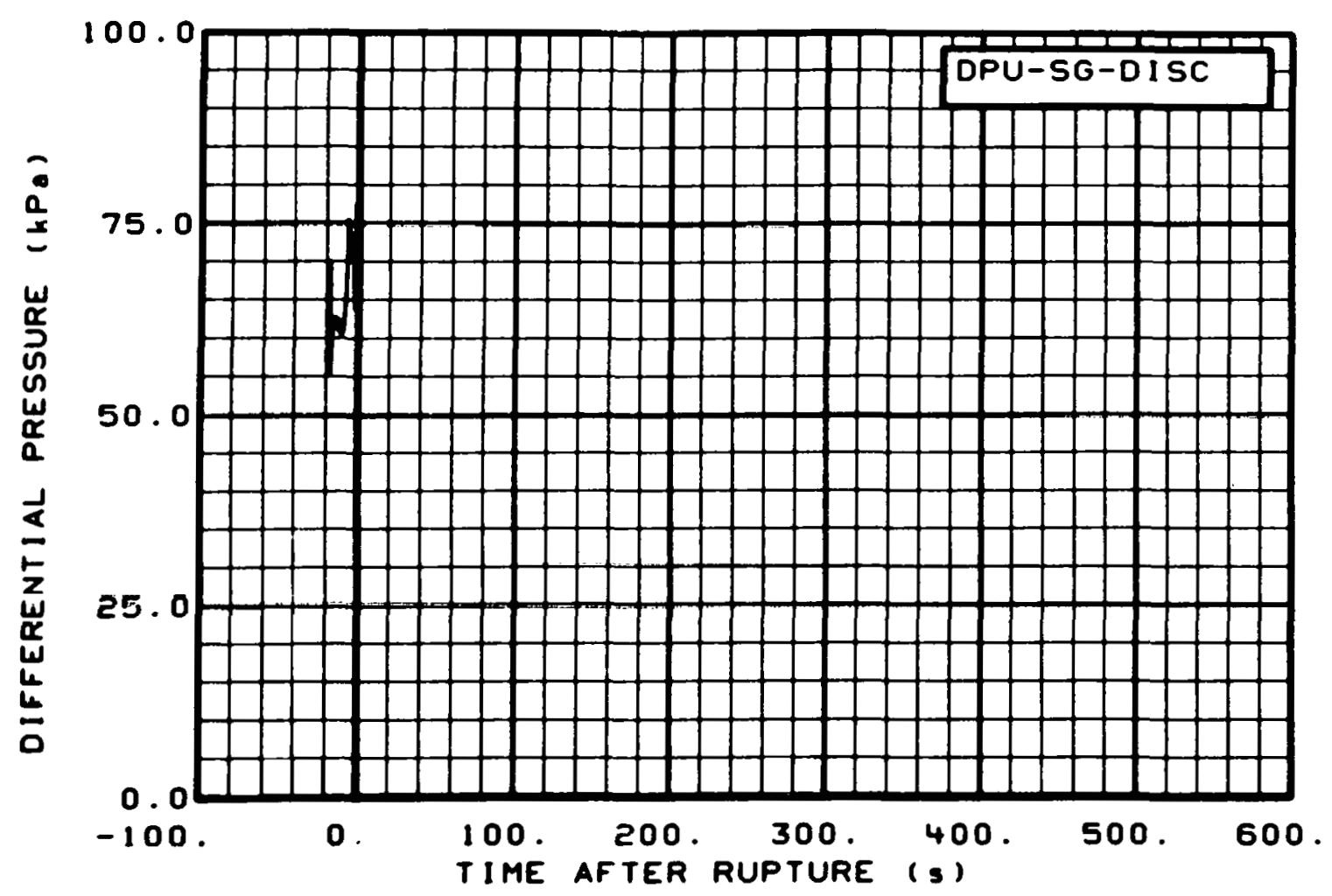

Fig. 233 Differential pressure across steam generator outlet orifice (DPU-SG-DISC), from -20 to $600 \mathrm{~s}$.

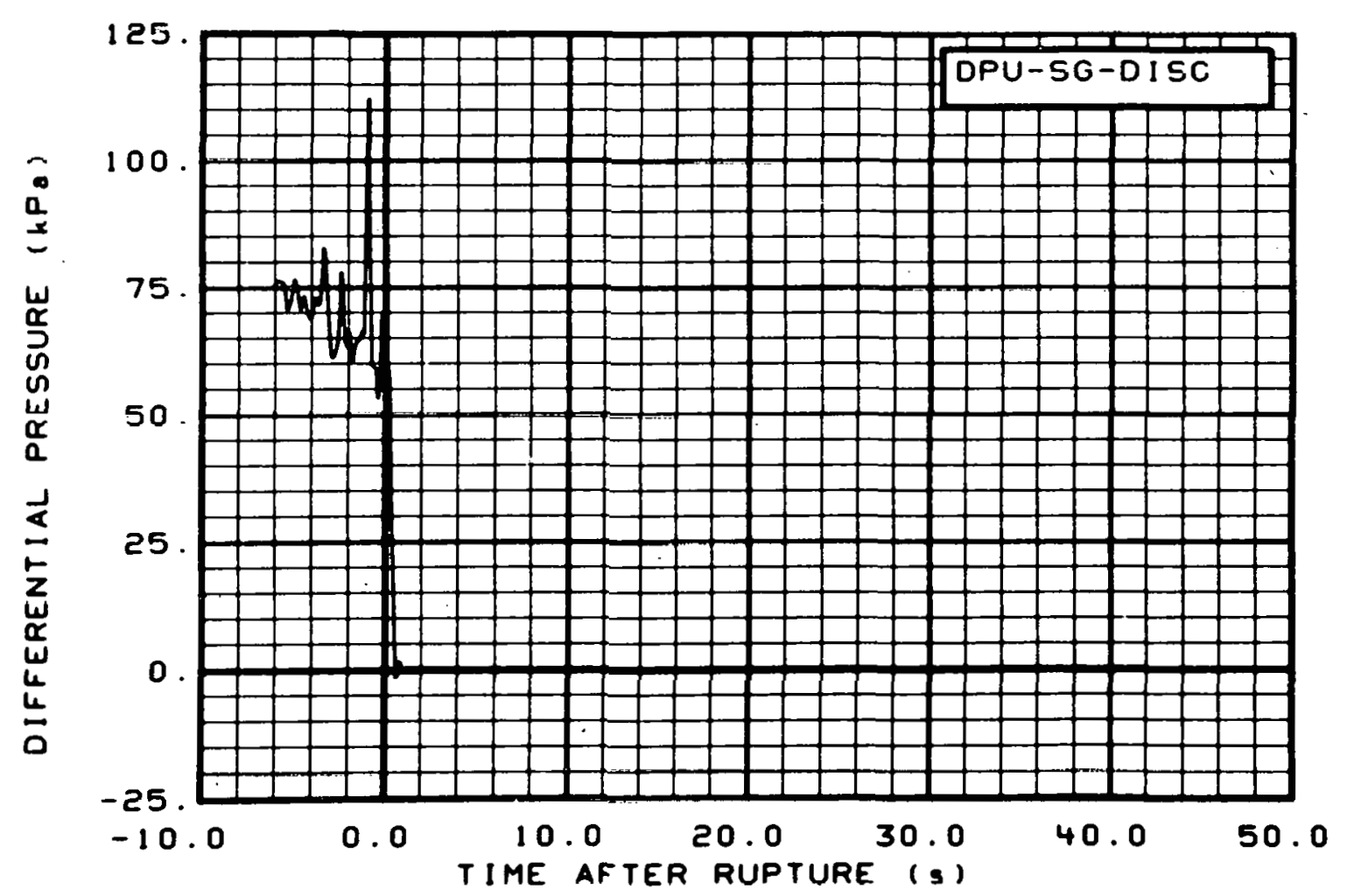

Fig. 234 Differential pressure across steam generator outlet orifice (DPU-SG-DISC), from -6 to $42 \mathrm{~s}$. 


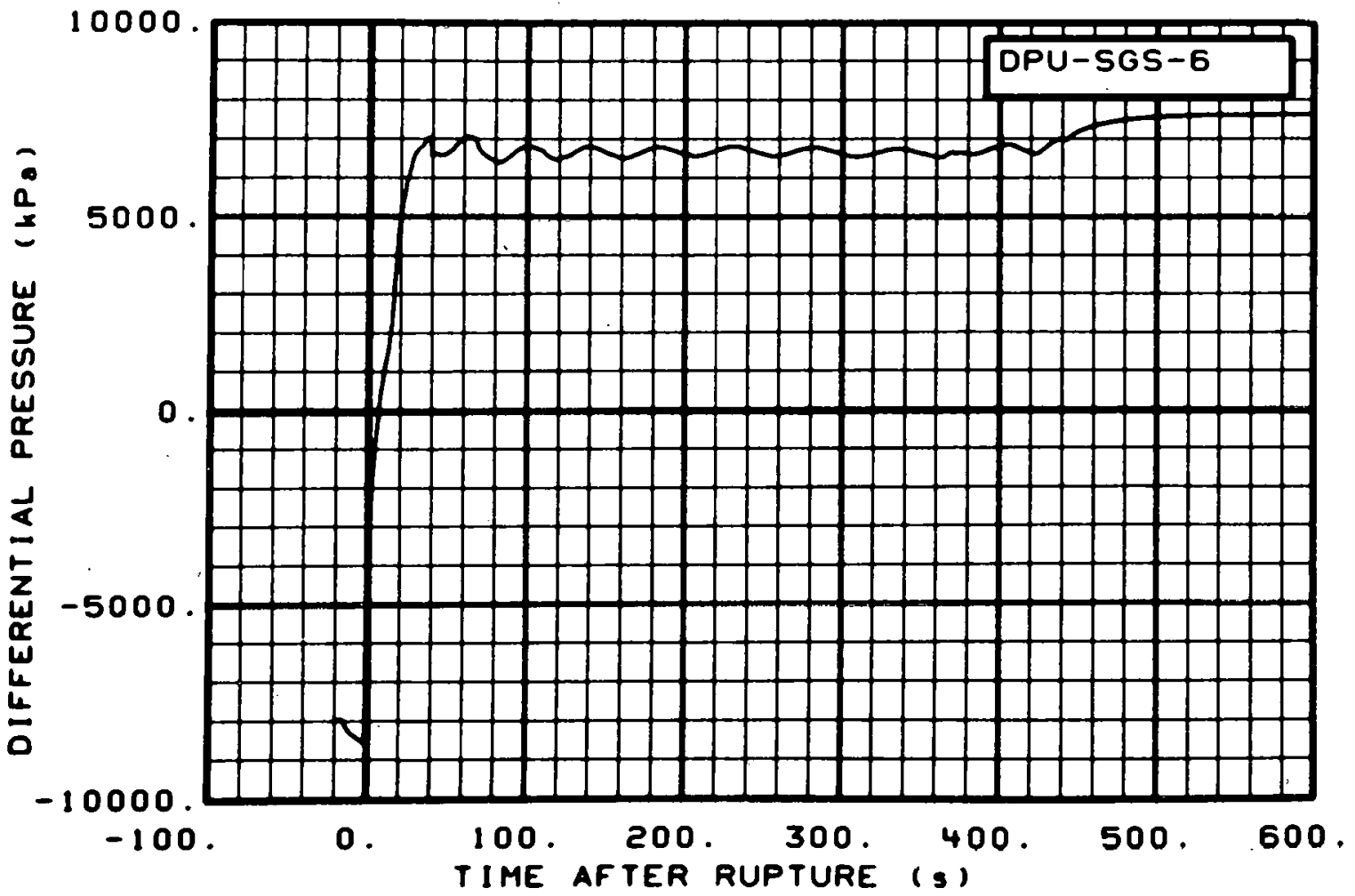

Fig. 235 Differential pressure between simulated rupture injection 1 ine and Spool 6 (DPU-SGS-6), from -20 to $600 \mathrm{~s}$.

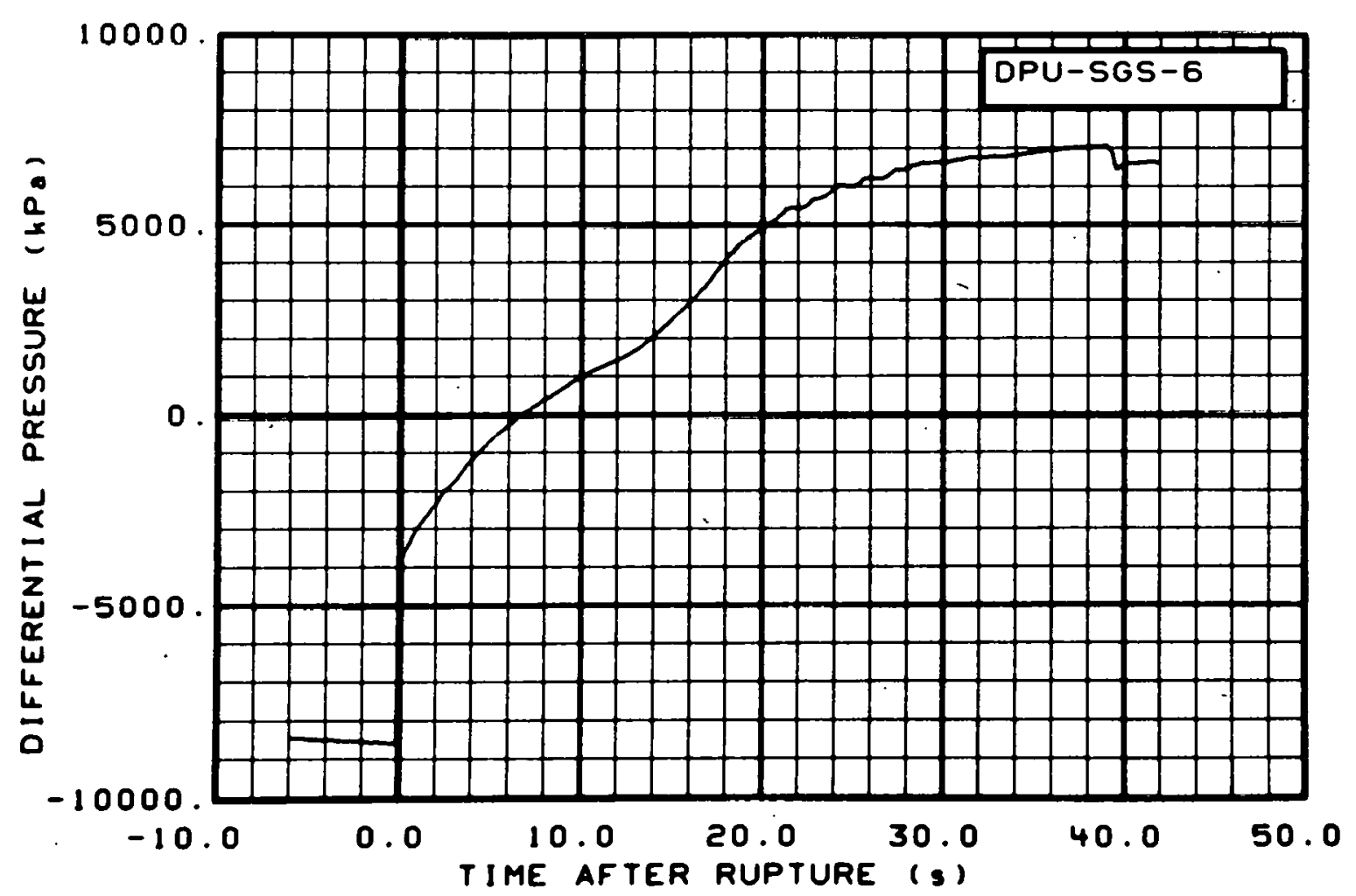

Fig. 236 Differential pressure between simulated rupture injection line and Spool 6 (DPU-SGS-6), from -6 to $42 \mathrm{~s}$. 


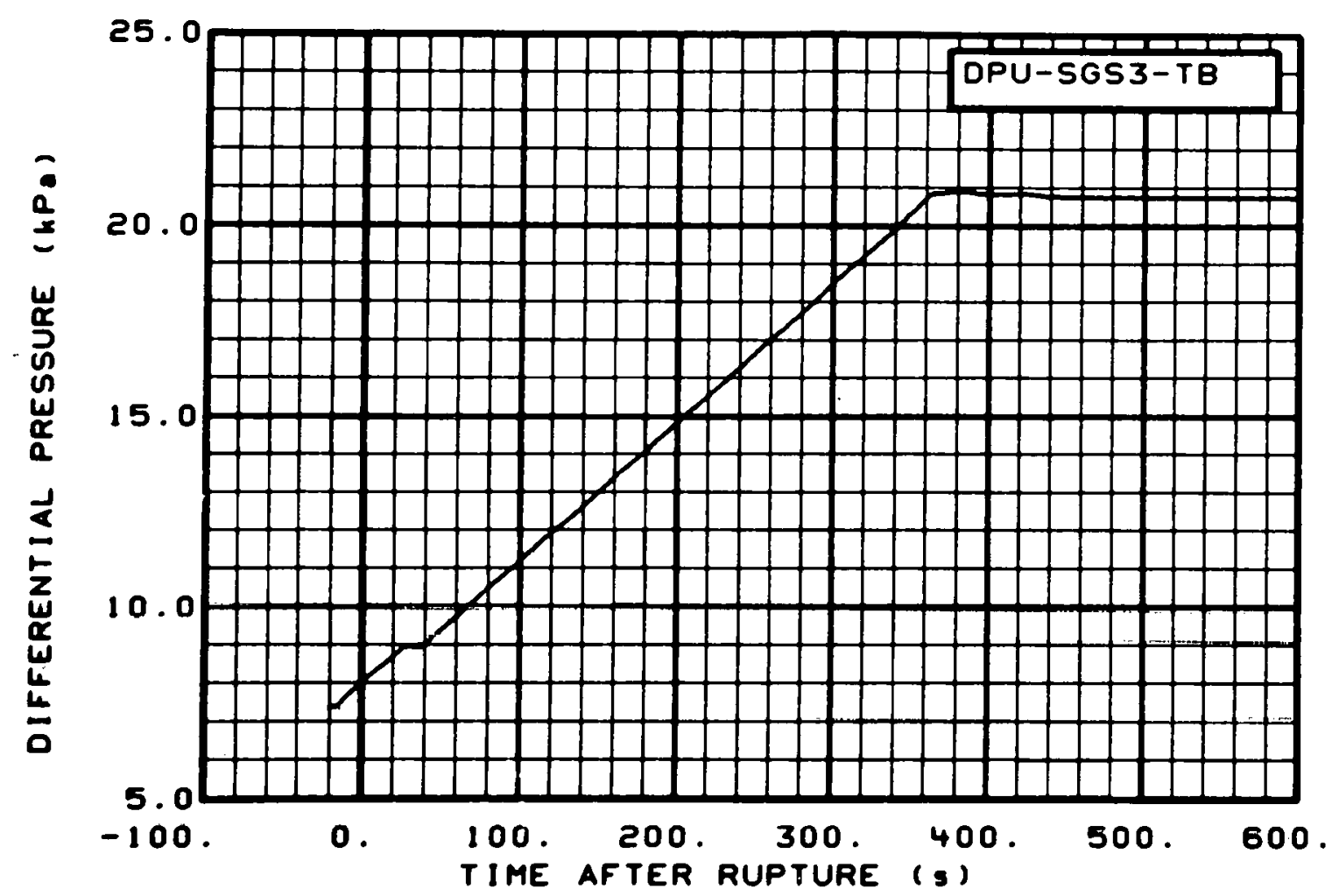

Fig. 237 Differential pressure in intact loop tube rupture simulation accumulator (DPU-SGS3-TB), from -20 to $600 \mathrm{~s}$.

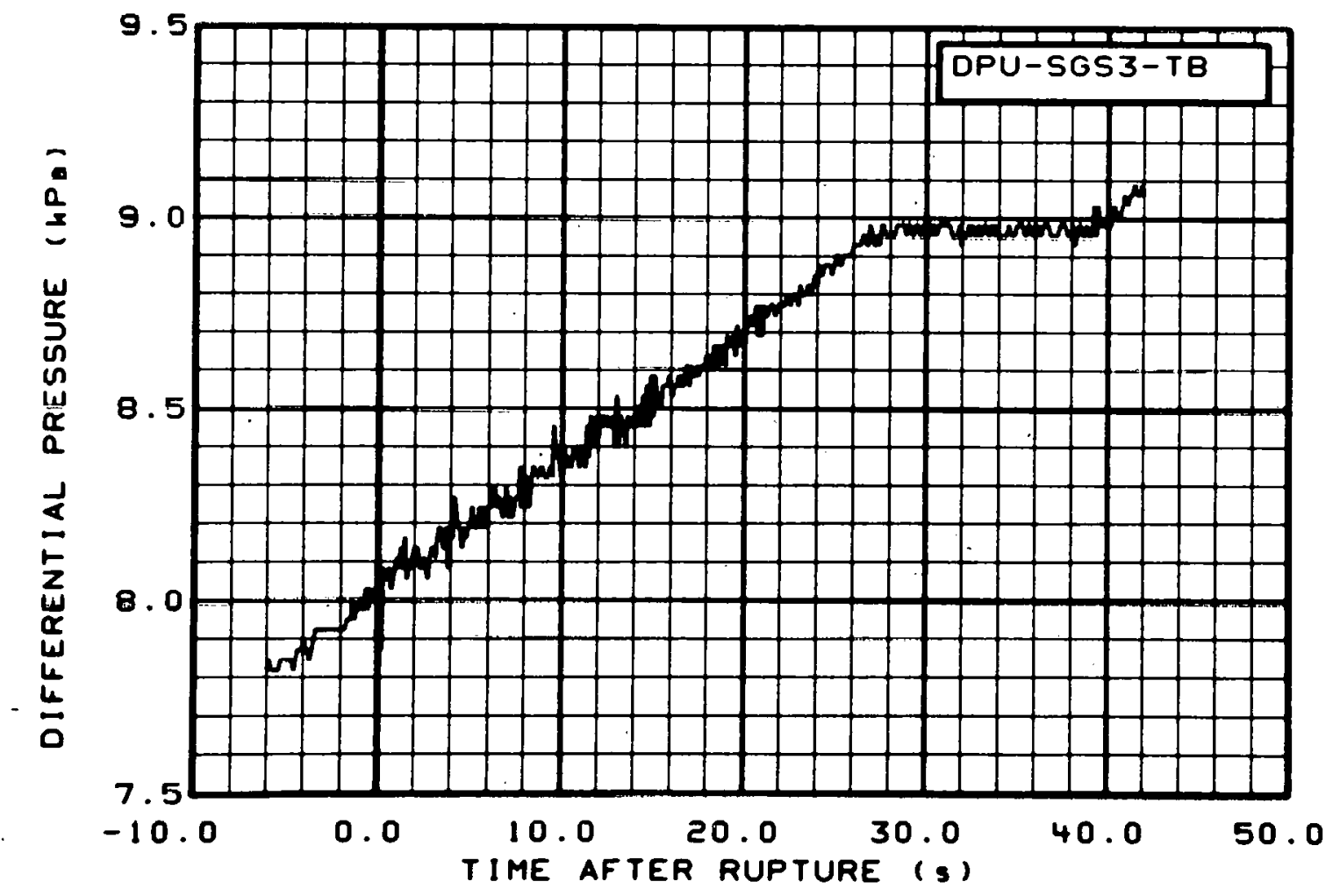

Fig. 238 Differential pressure in intact loop tube rupture simulation accumulator (DPU-SGS3-TB), from -6 - to $42 \mathrm{~s}$. 


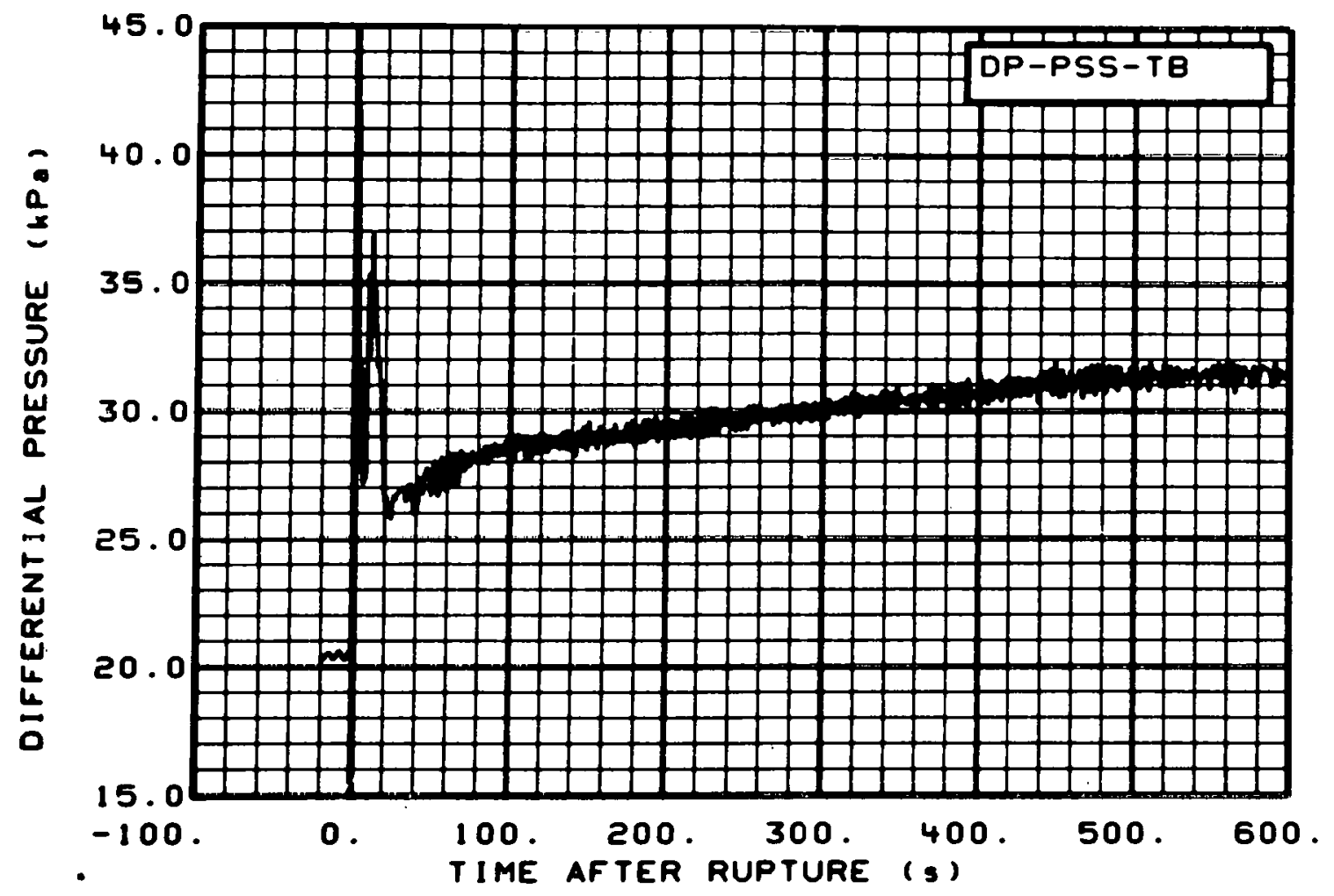

Fig. 239 Differential pressure in pressure suppression tank (DP-PSS-TB), from -20 to $600 \mathrm{~s}$.

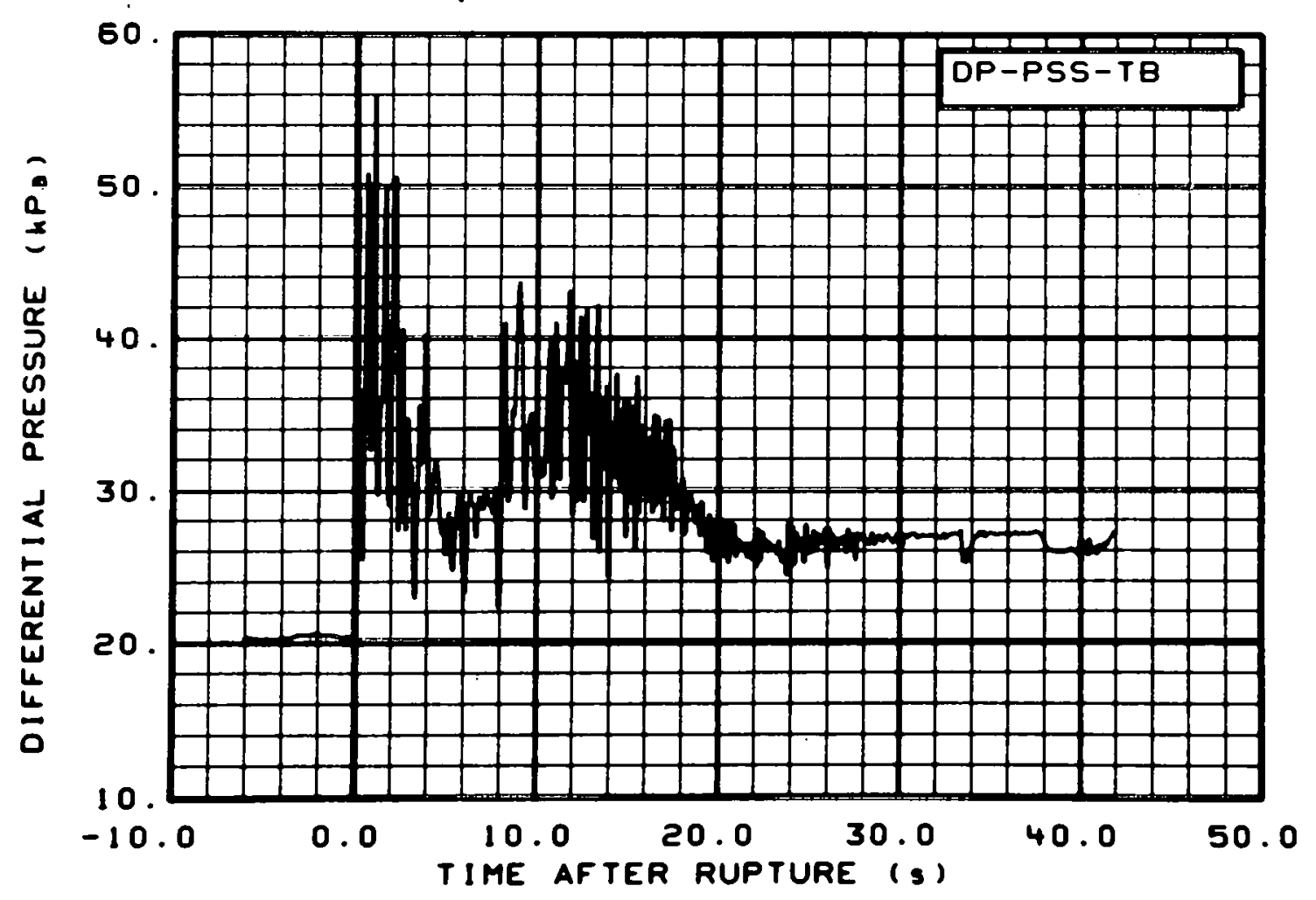

Fig. 240 Differential pressure in pressure suppression tank (DP-PSS-TB), from -6 to $42 \mathrm{~s}$. 


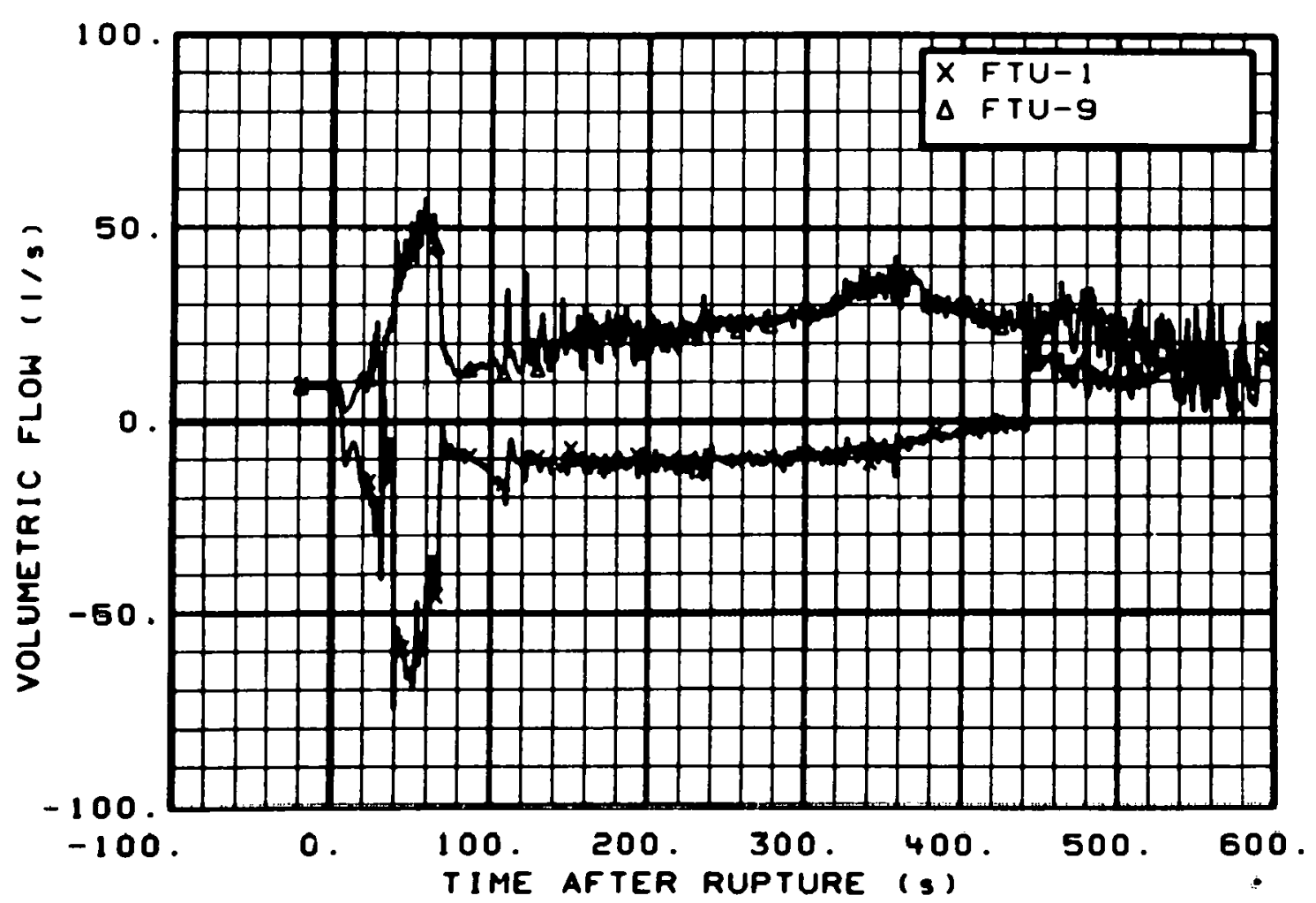

Fig. 241 Volumetric flow in intact loop (FTU-1 and FTU-9), from -20 to $600 \mathrm{~s}$.

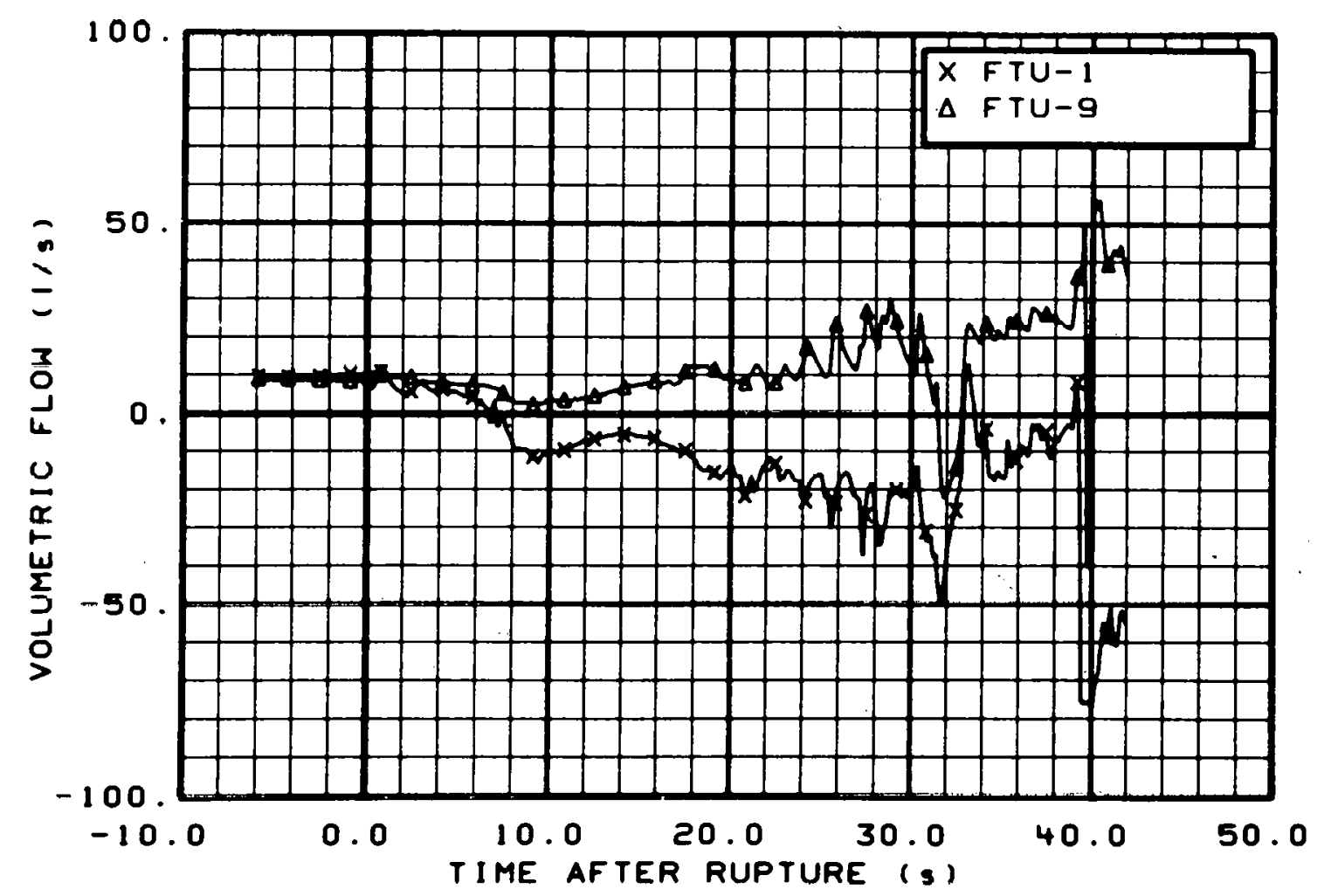

Fig. 242 Volumetric flow in intact loop (FTU-1 and FTU-9), from -6 to 42 s. 


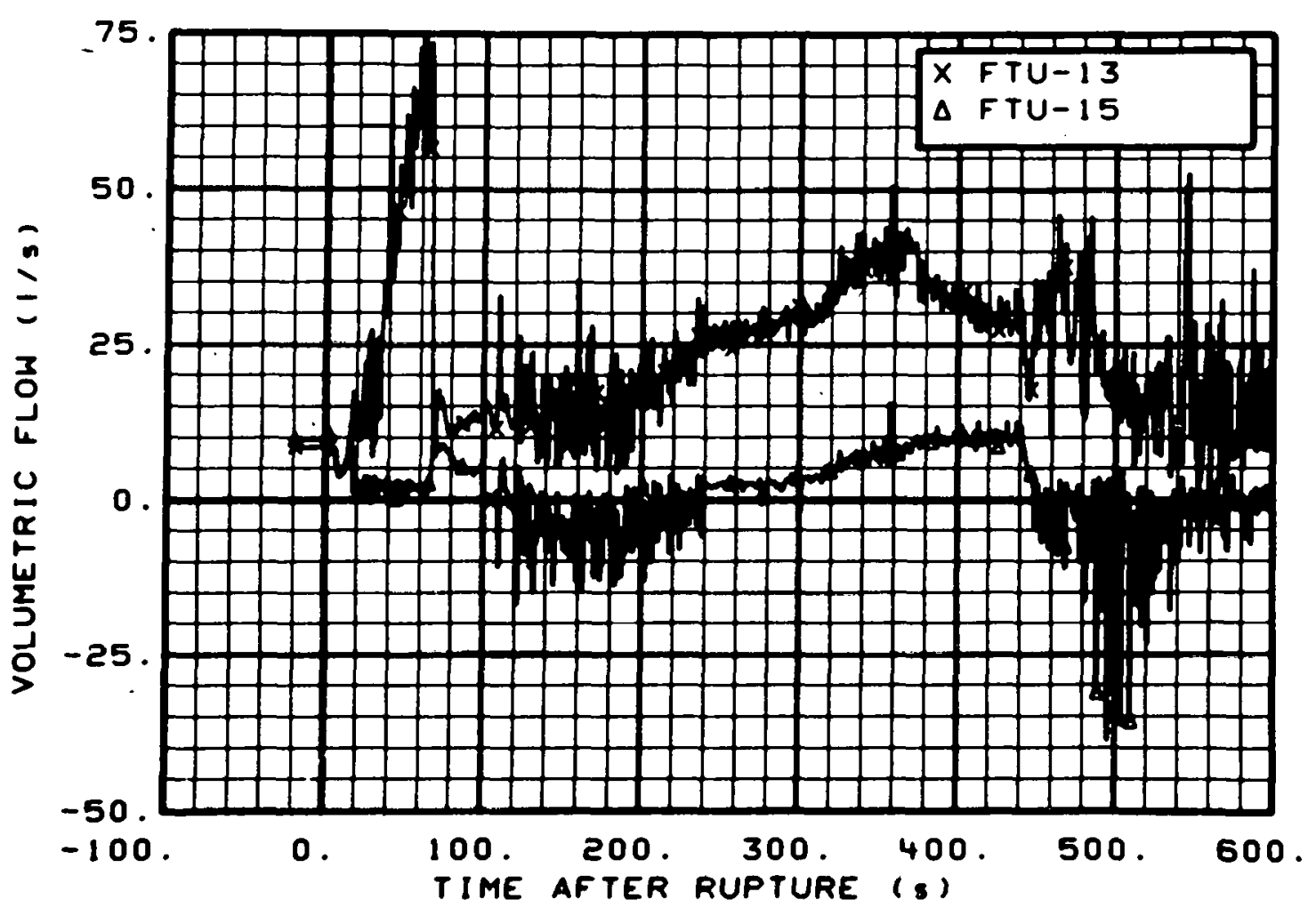

Fig. 243 Volumetric flow in intact loop (FTU-13 and FTU-15), from -20 to $600 \mathrm{~s}$.

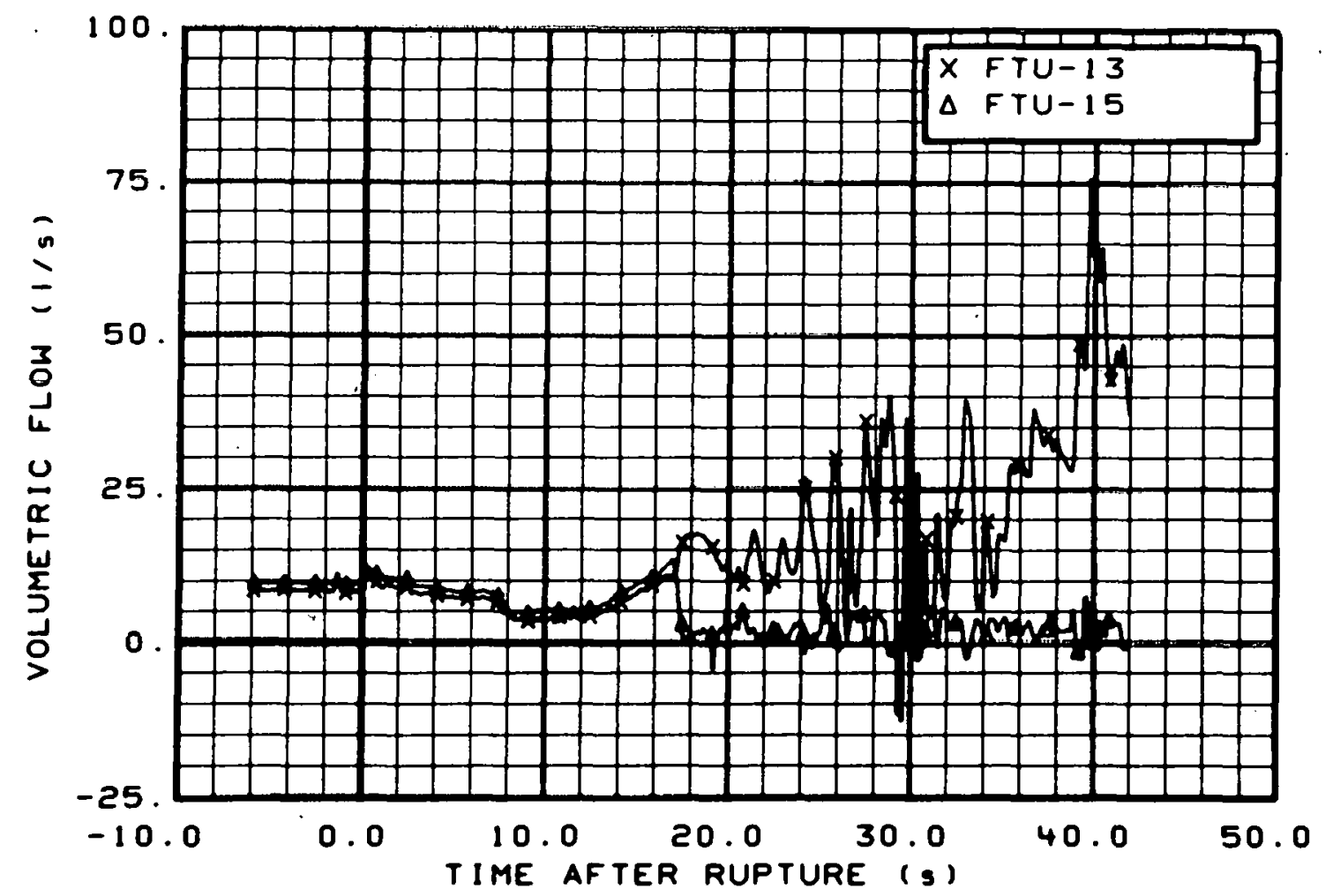

Fig, 244 Volumetric flow in intact loop (FTU-13 and FTU-15), from -6 to $42 \mathrm{~s}$. 


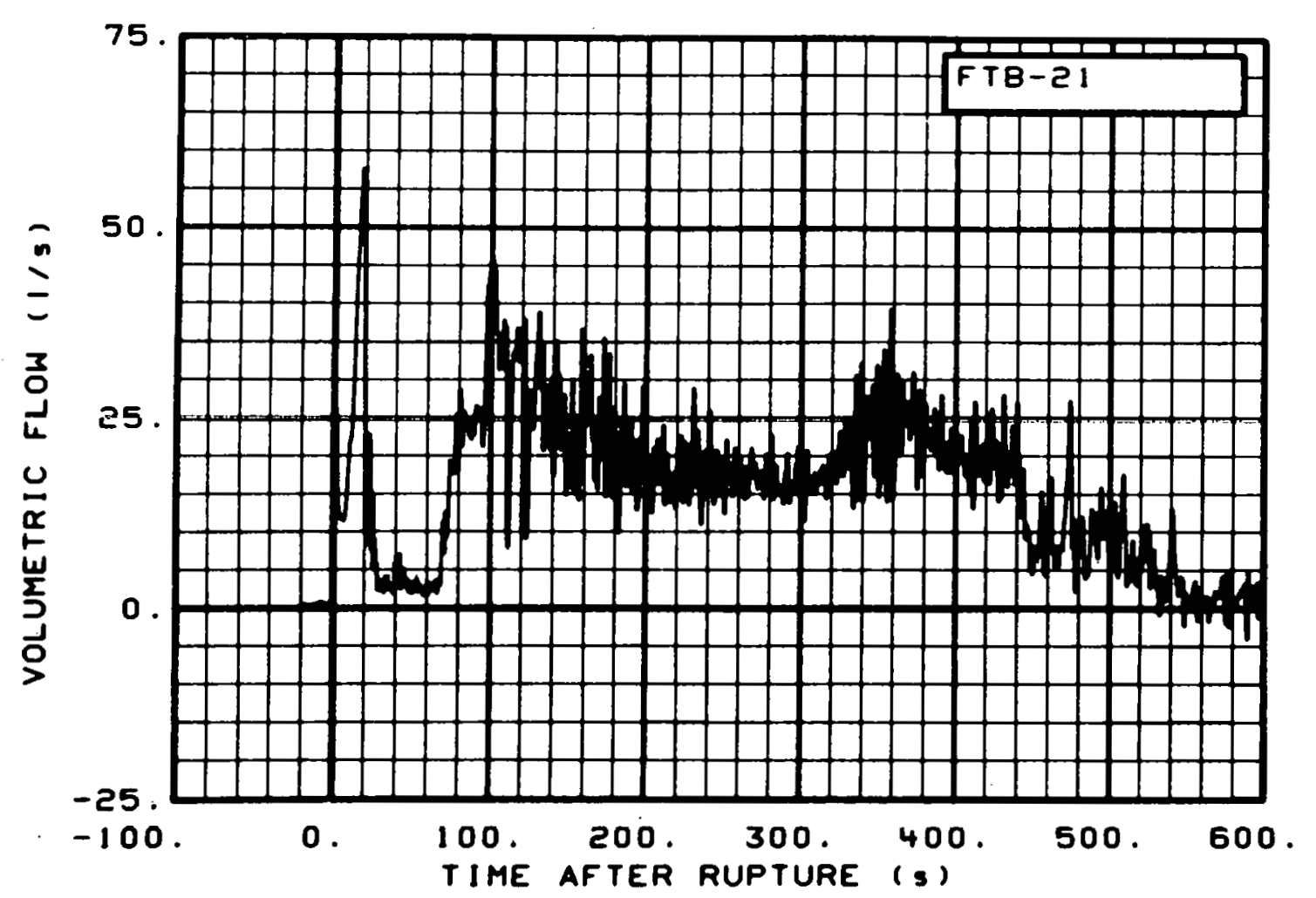

Fig. 245 Volumetric flow in broken loop (FTB-21), from -20 to $600 \mathrm{~s}$.

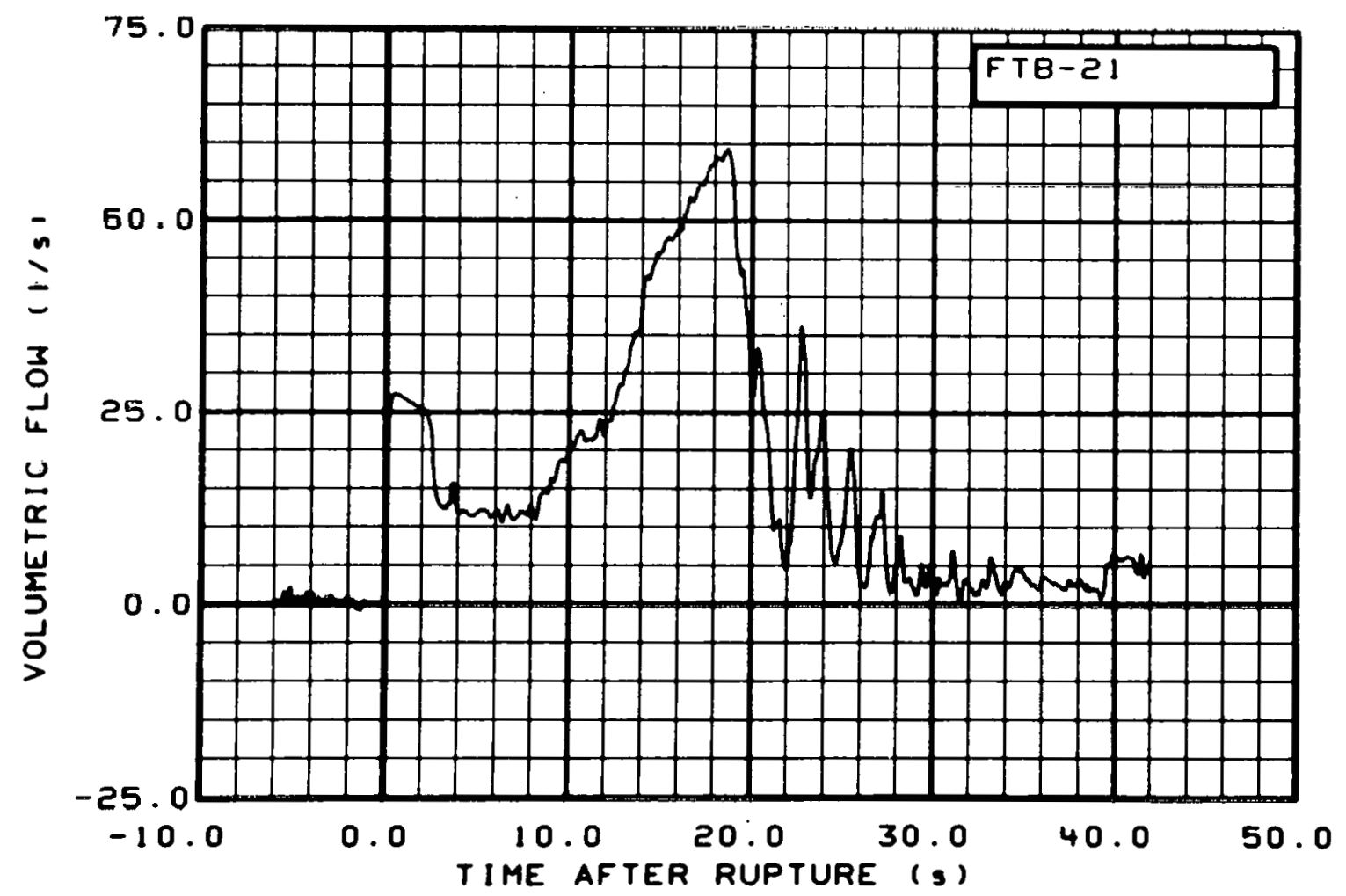

Fig. 246 Volumetric flow in broken loop (FTB-21), from -6 to $42 \mathrm{~s}$. 


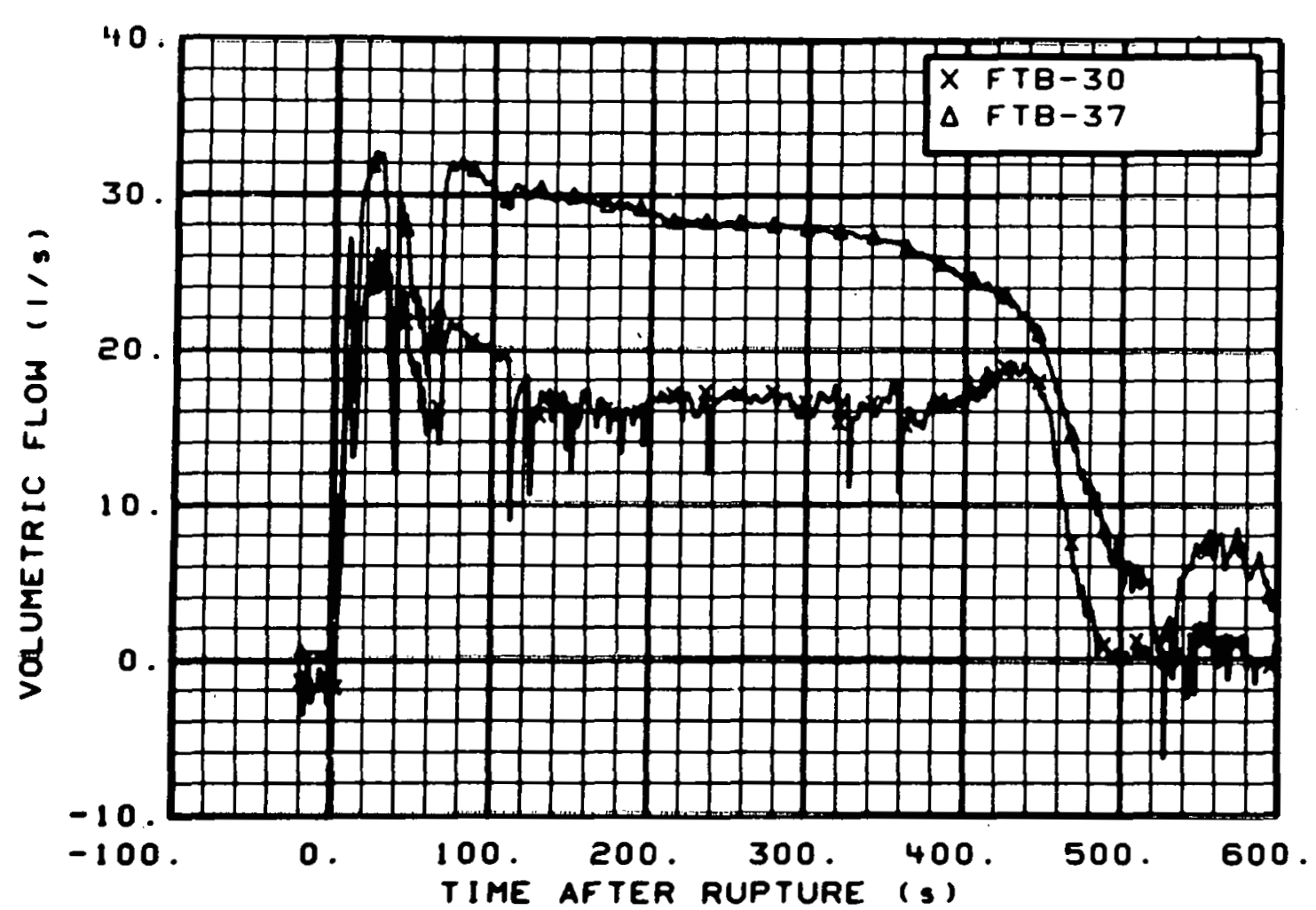

Fig. 247 Volumetric flow in broken loop (FTB-30 and FTB-37), from -20 to $600 \mathrm{~s}$.

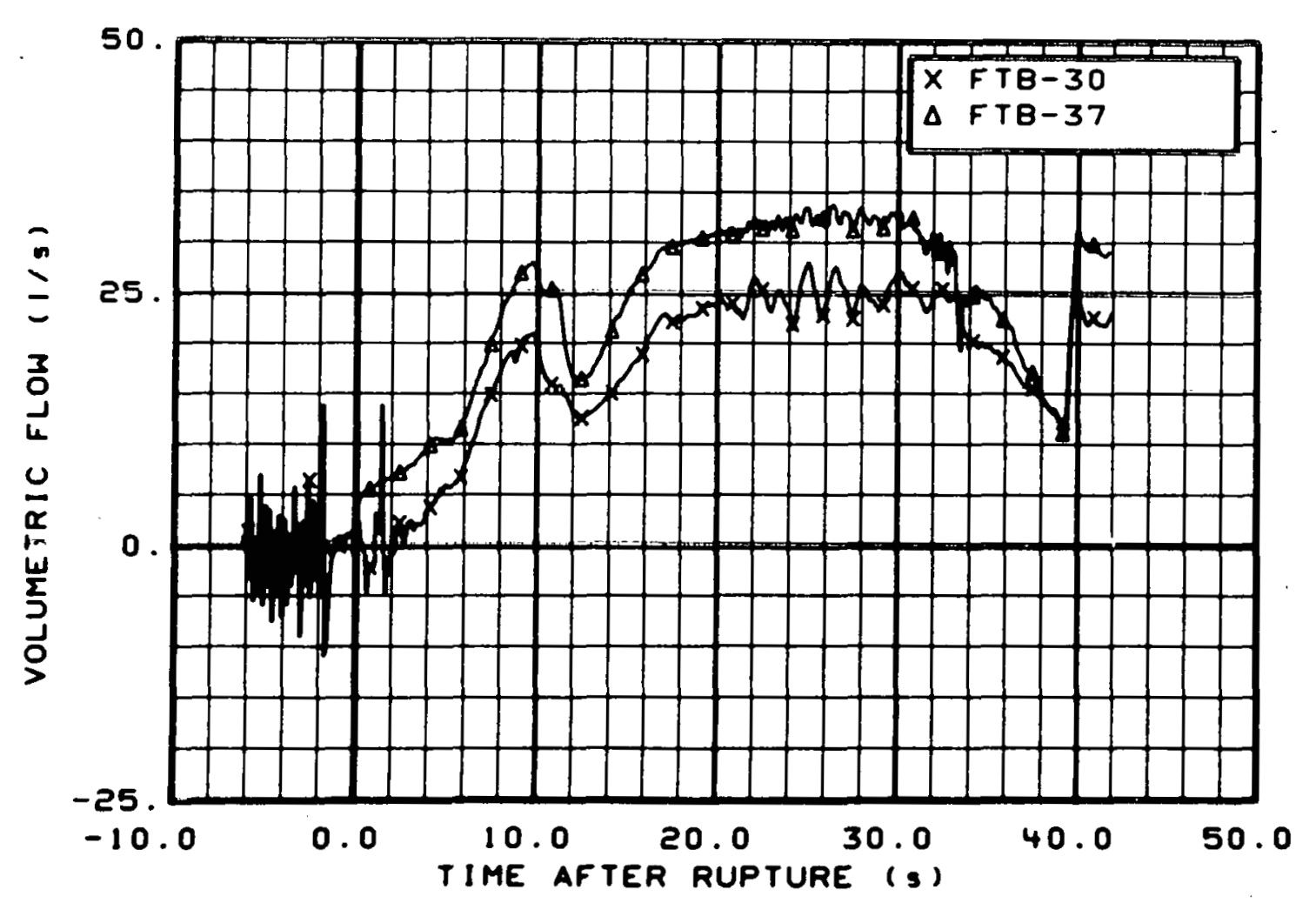

Fig. 248 Volumetric flow in hroken lnop (FTB-30 and FTB-37), from -6 to $42 \mathrm{~s}$. 


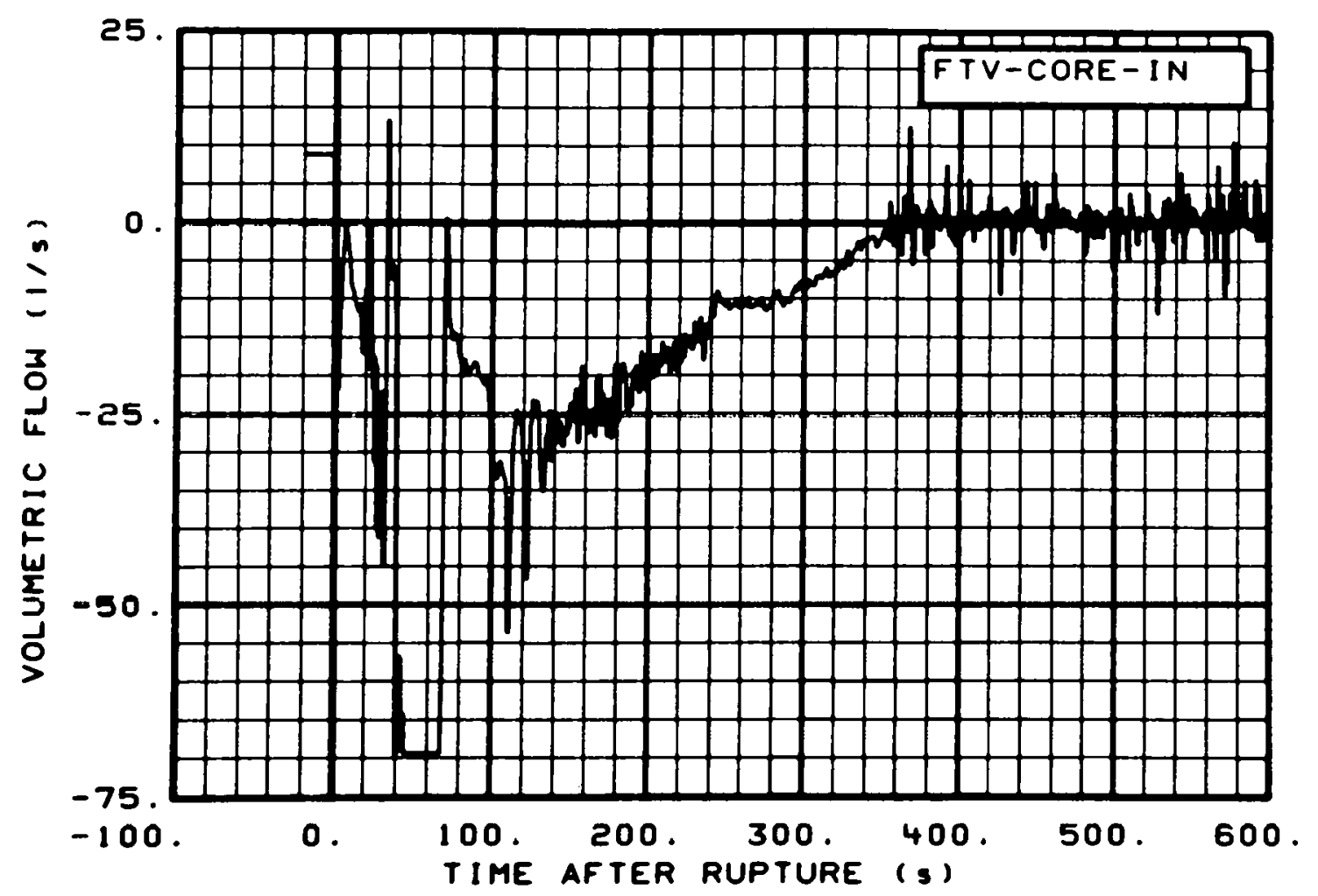

Fig. 249 Volumetric flow in core entrance (FTV-CORE-IN), from -20 to $600 \mathrm{~s}$.

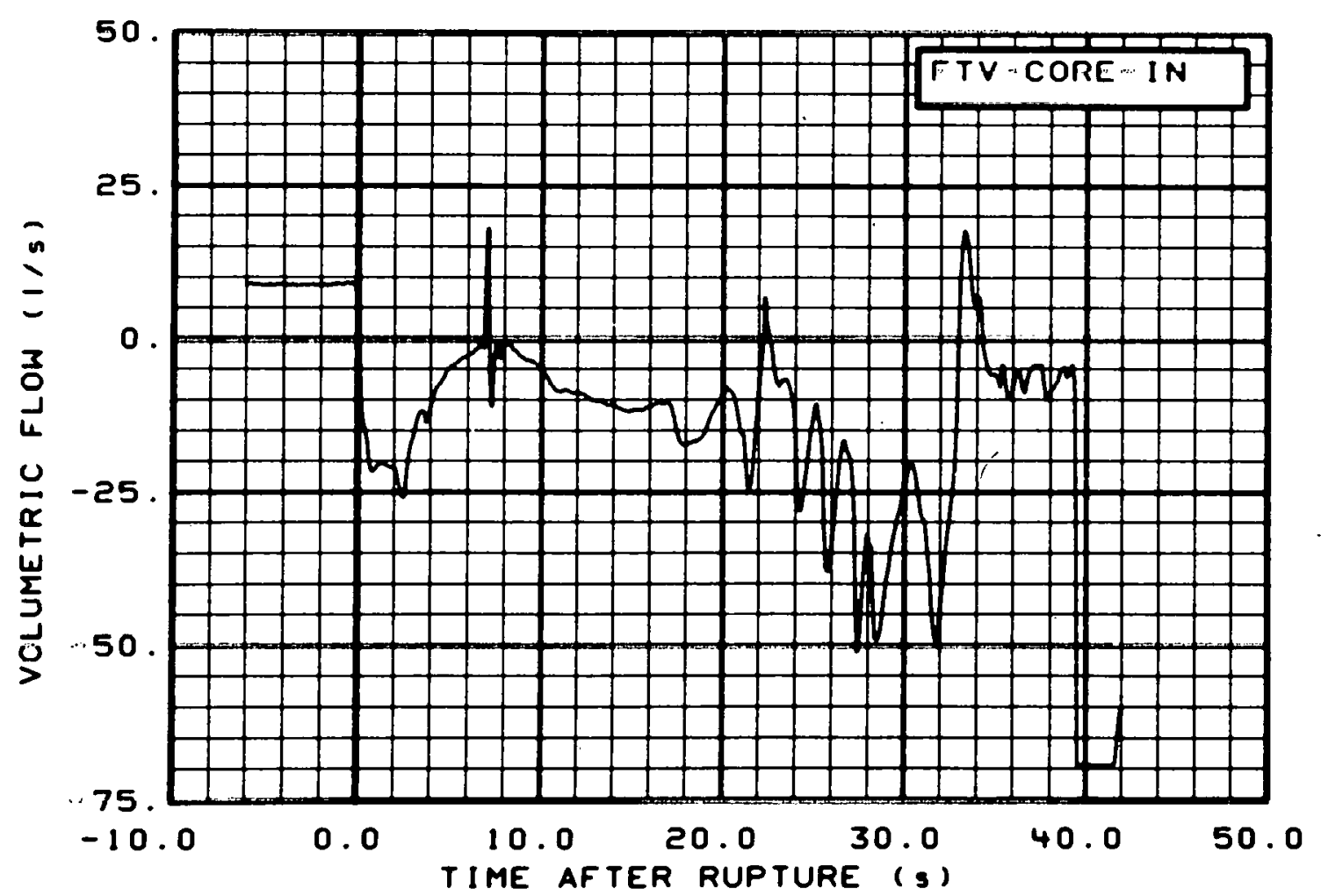

Fig. 250 Volumetric flow in core entrance (FTV-CORE-IN), from -6 to $42 \mathrm{~s}$. 


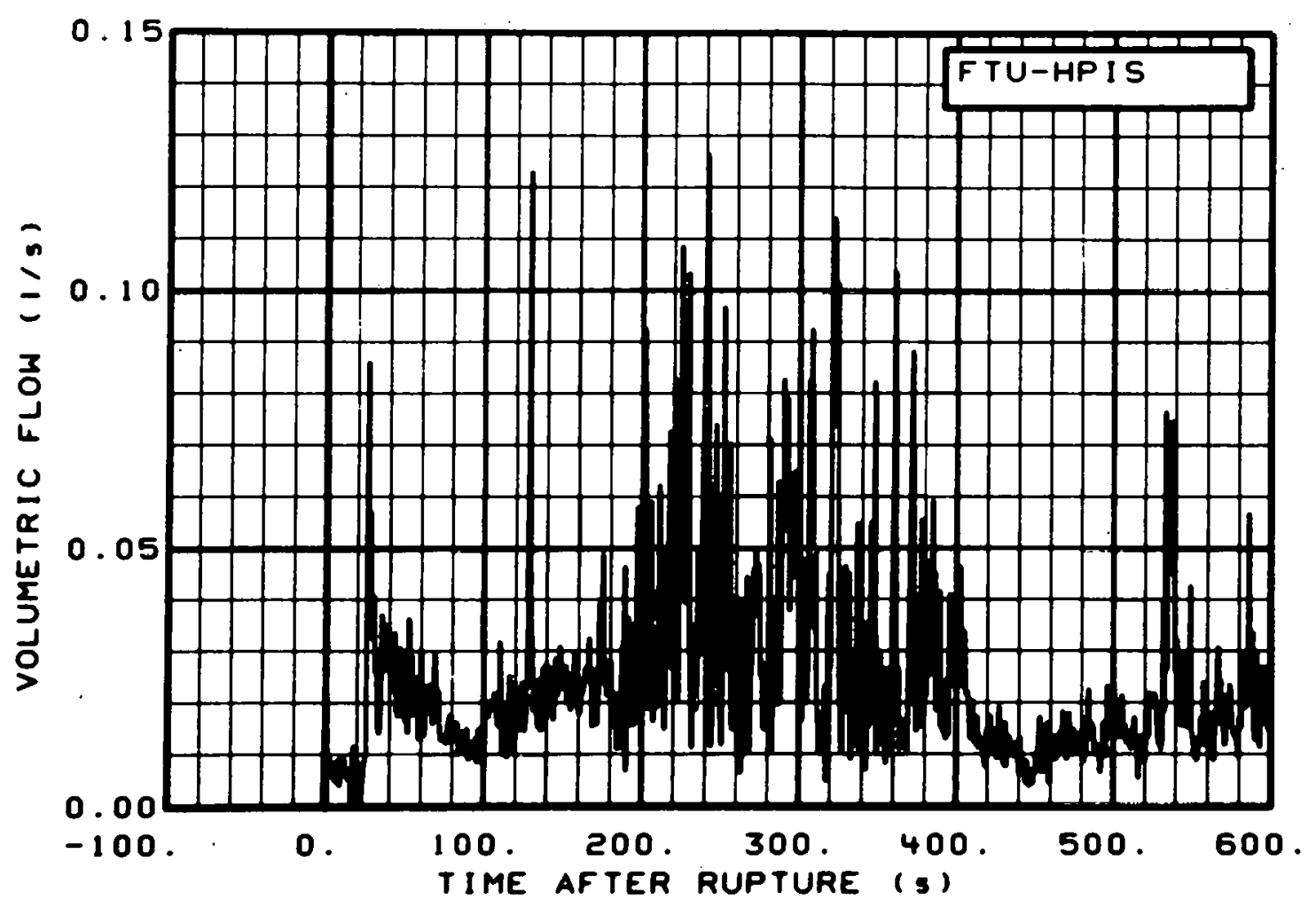

Fig. 251 Volumetric flow in intact loop high pressure injection line (FTU-HPIS), from -20 to $600 \mathrm{~s}$.

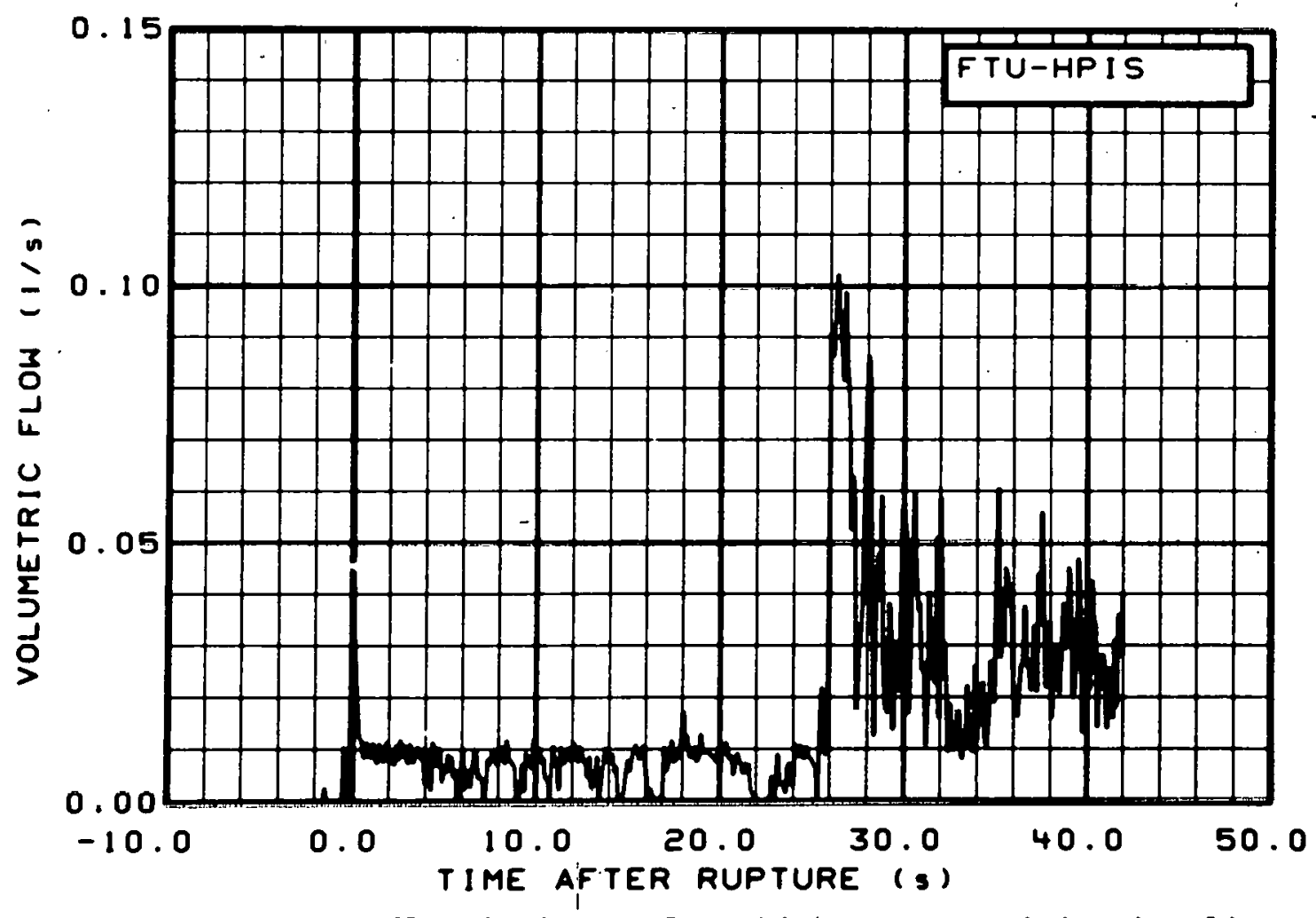

Fig. 2.52 Volumetric flow in intact loop high pressure injection line (FTU-HPIS), from -6 to $42 \mathrm{~s}$. 


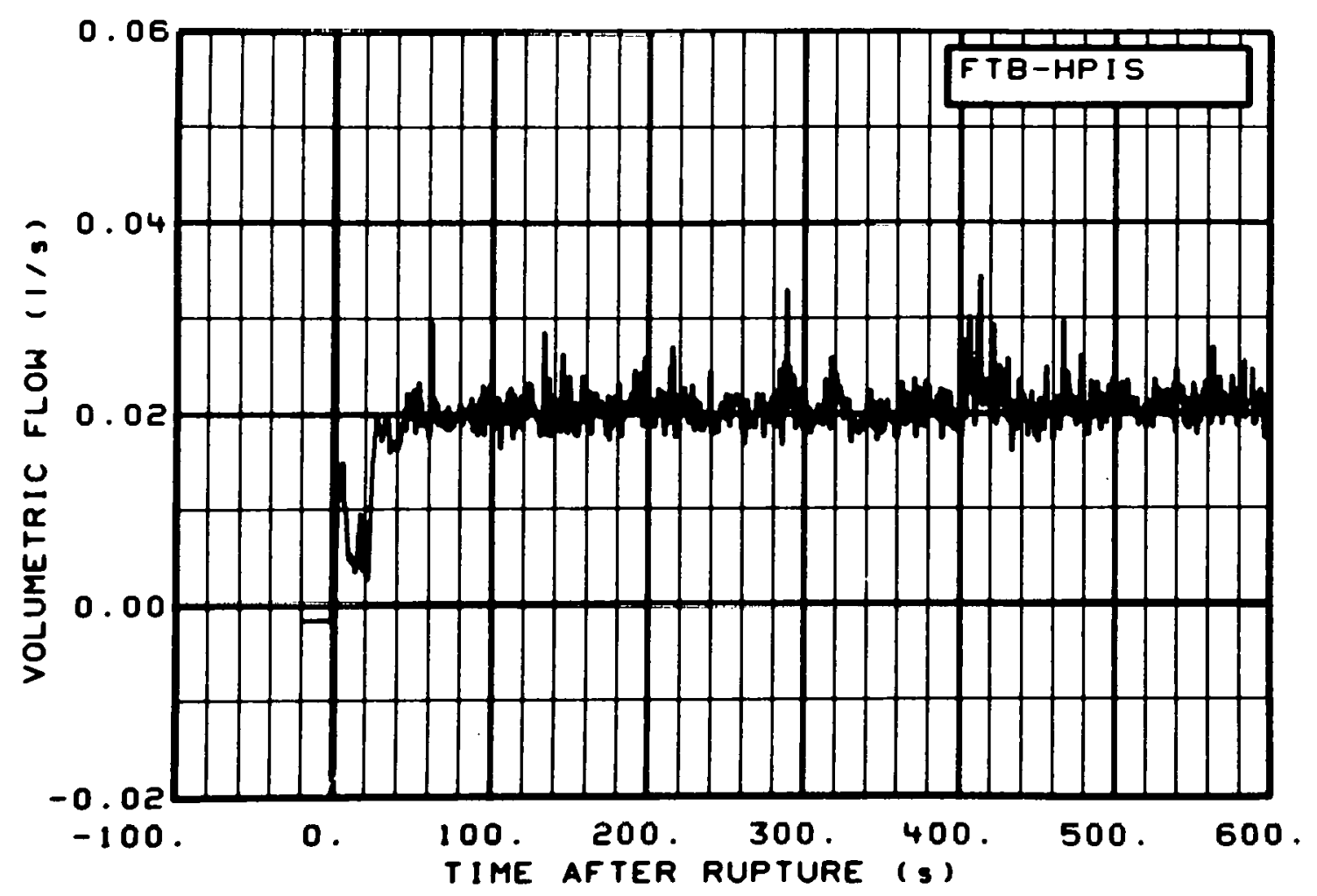

Fig. 253 Volumetric flow in broken loop high pressure injection 1 ine (FTB-HPIS), from -20 to $600 \mathrm{~s}$.

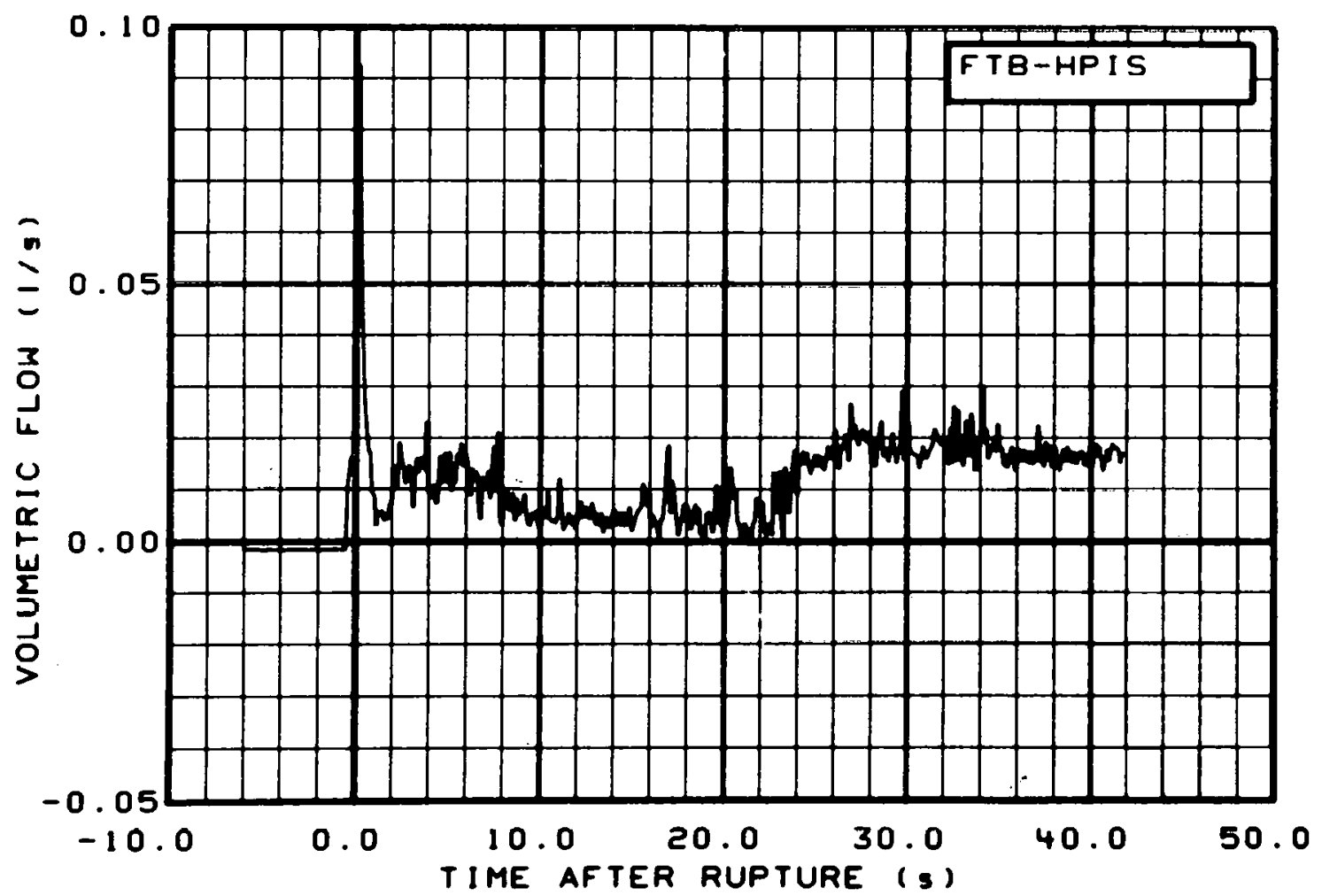

Fig. 254 Volumetric flow in broken loop high pressure injection line (FTB-HPIS), from -6 to $42 \mathrm{~s}$. 


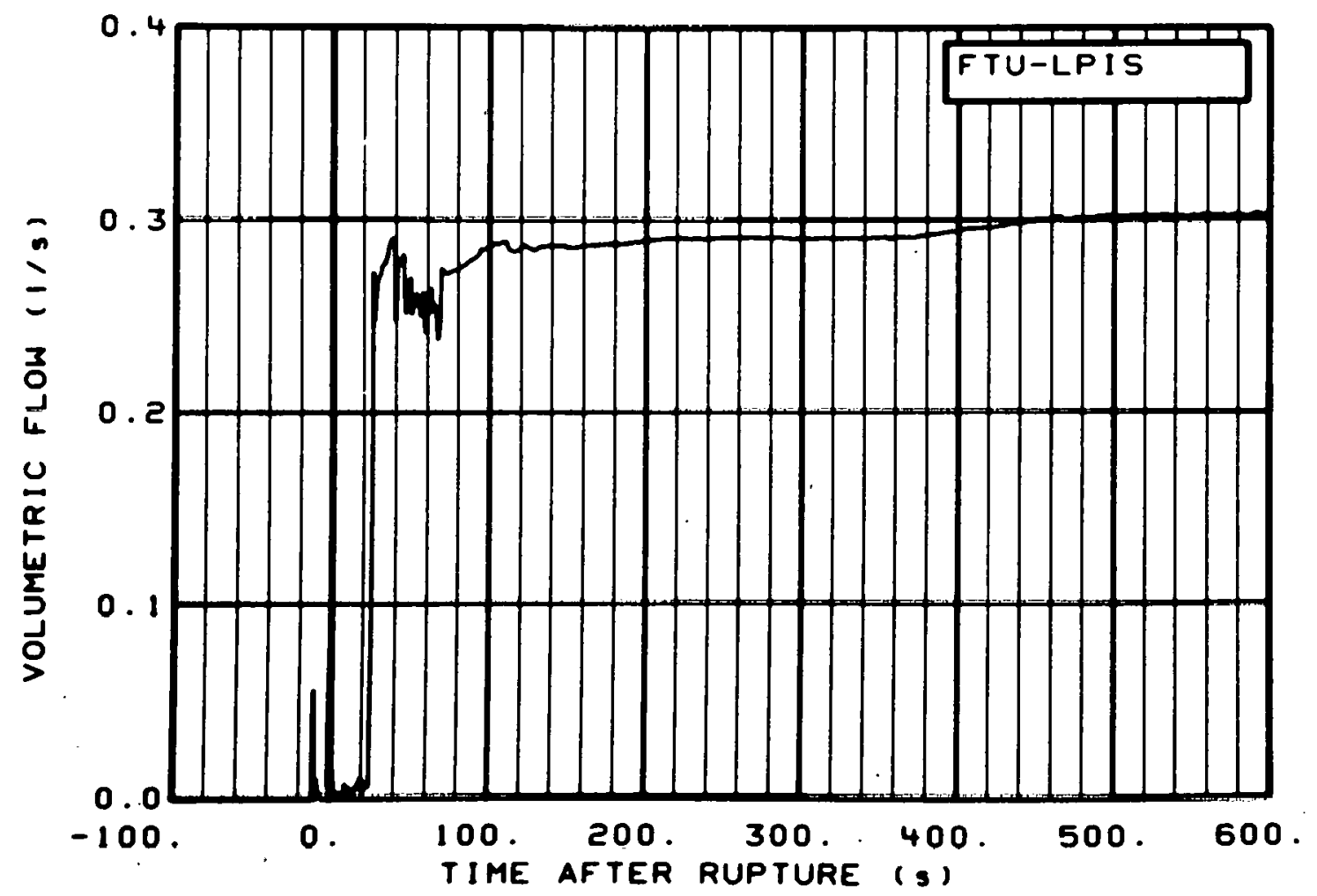

Fig. 255 Volumetric flow in intact loop low pressure injection line (FTU-LPIS), from -20 to $600 \mathrm{~s}$.

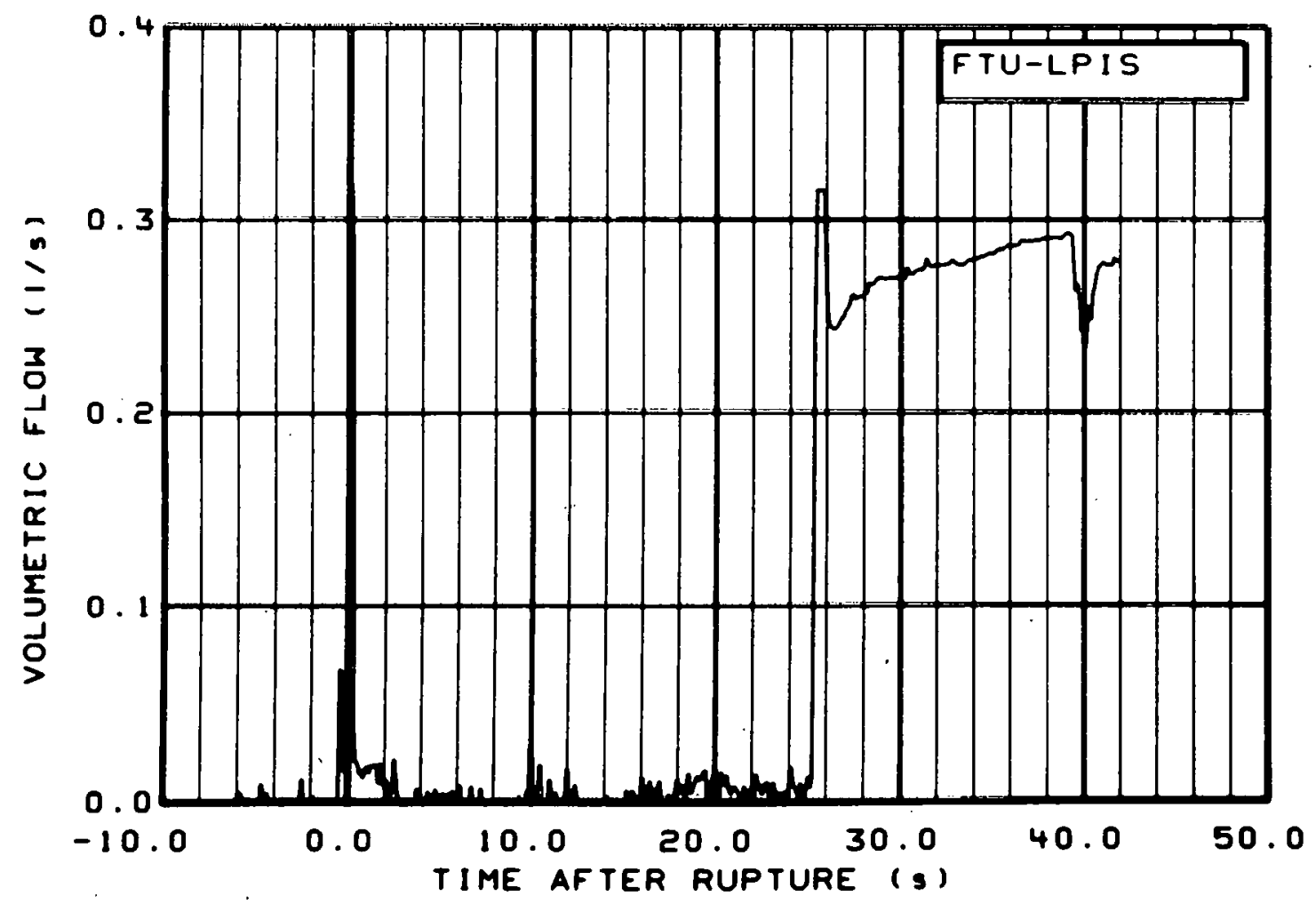

Fig. 256 Volumetric flow in intact loop low pressure injection line (FTU-LPIS), from -6 to $42 \mathrm{~s}$. 


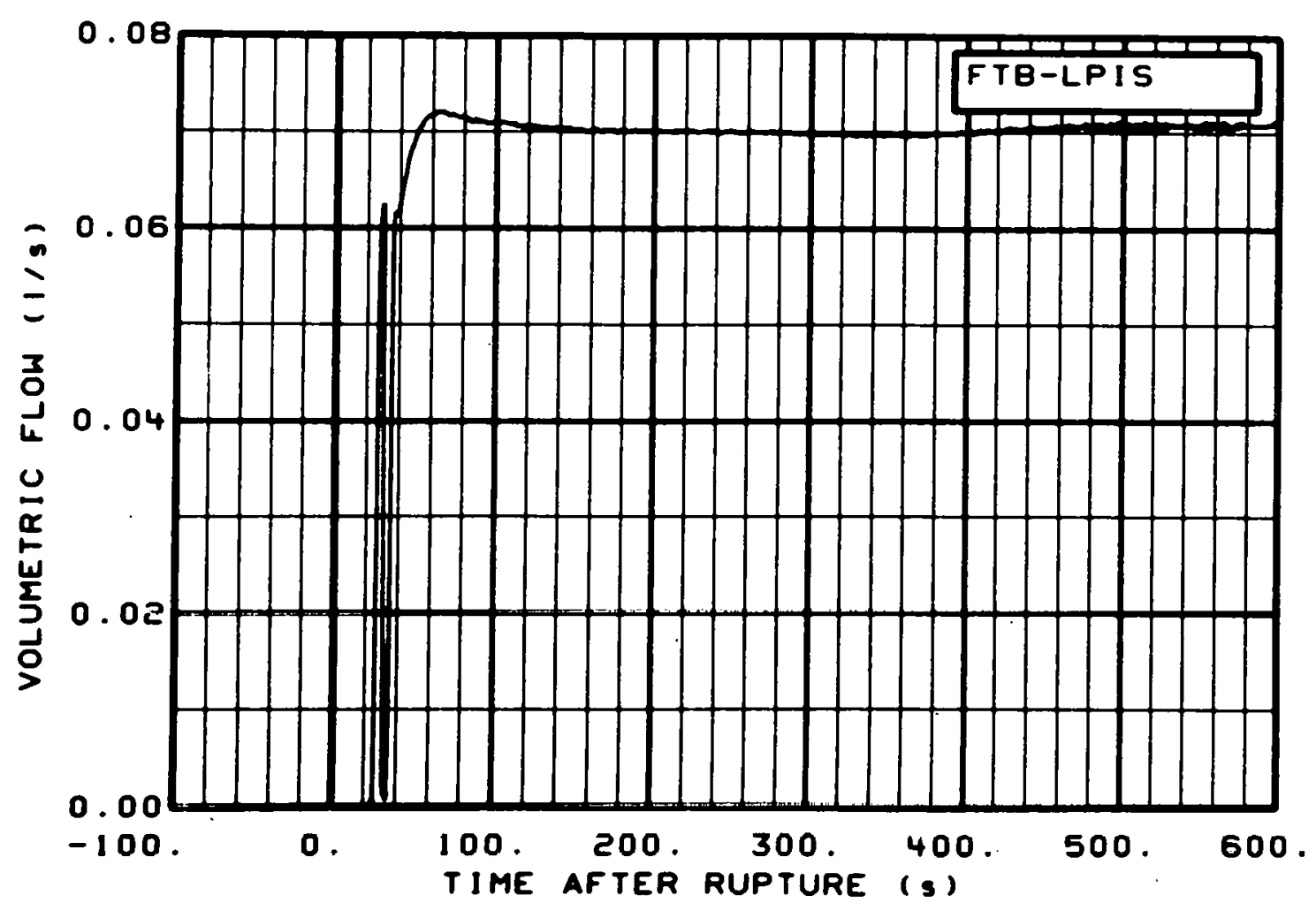

Fig. 257 Volumetric flow in broken loop low pressure injection line (FTB-LPIS), from -20 to $600 \mathrm{~s}$.

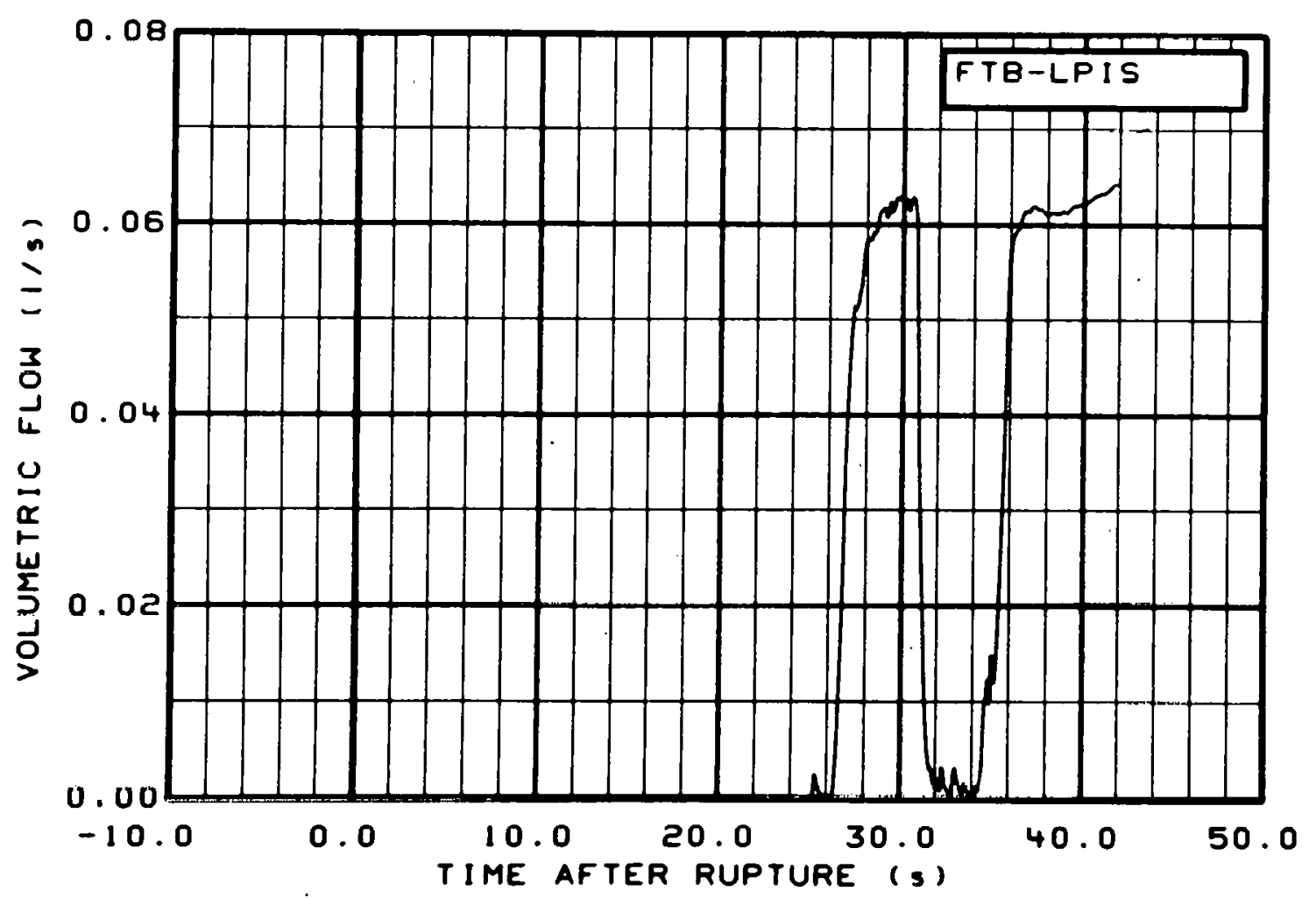

Fig. 258 Volumetric flow in broken loop low pressure injection line (FTB-LPIS), from -6 to $42 \mathrm{~s}$. 


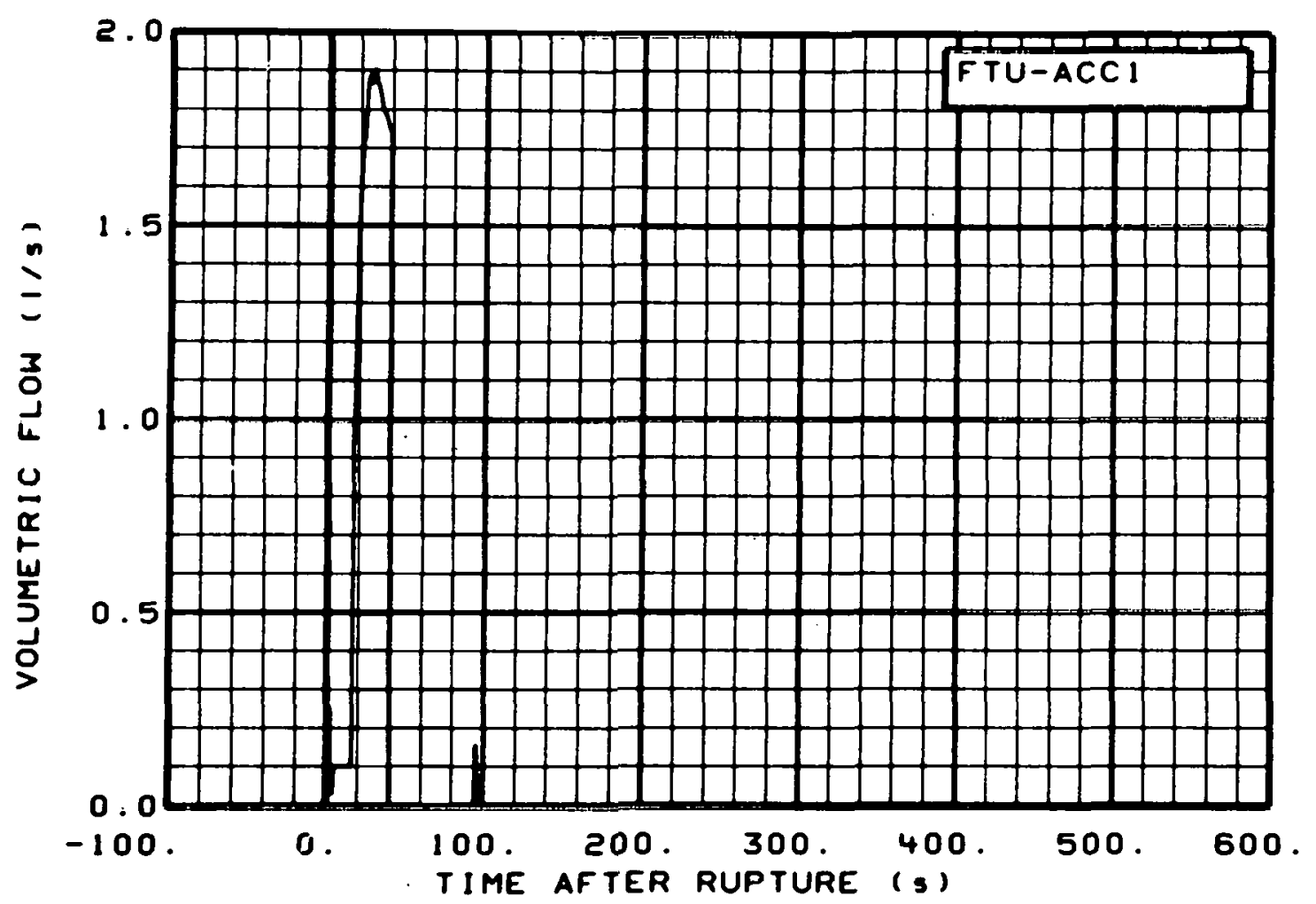

Fig. 259 Volumetric flow in intact loop accumulator discharge 1 ine. (FTU-ACCl), from -20 to $600 \mathrm{~s}$.

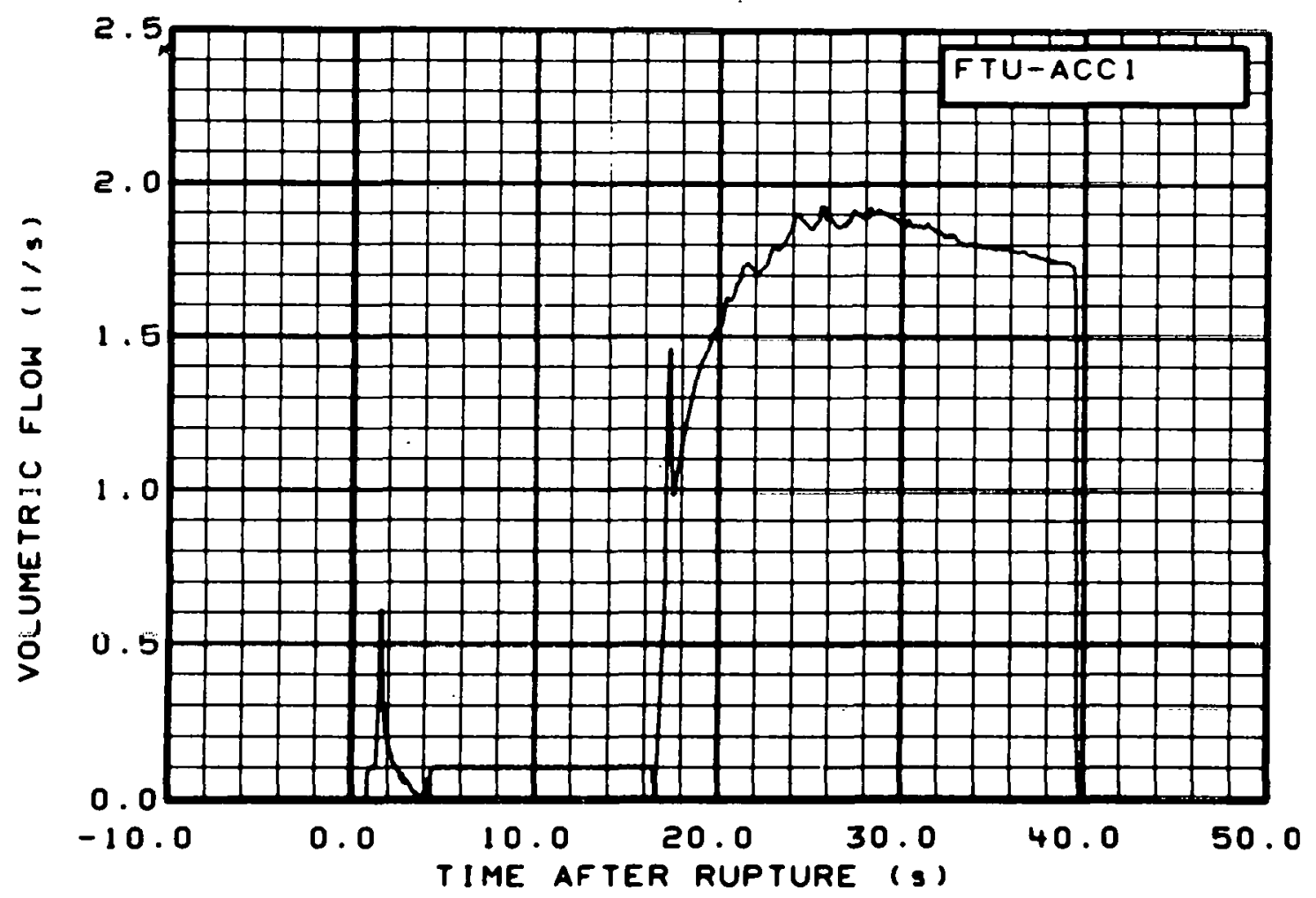

Fig. 260 Volumetric flow in intact loop accumulator discharge line (FTU-ACC1), from -6 to $42 \mathrm{~s}$. 


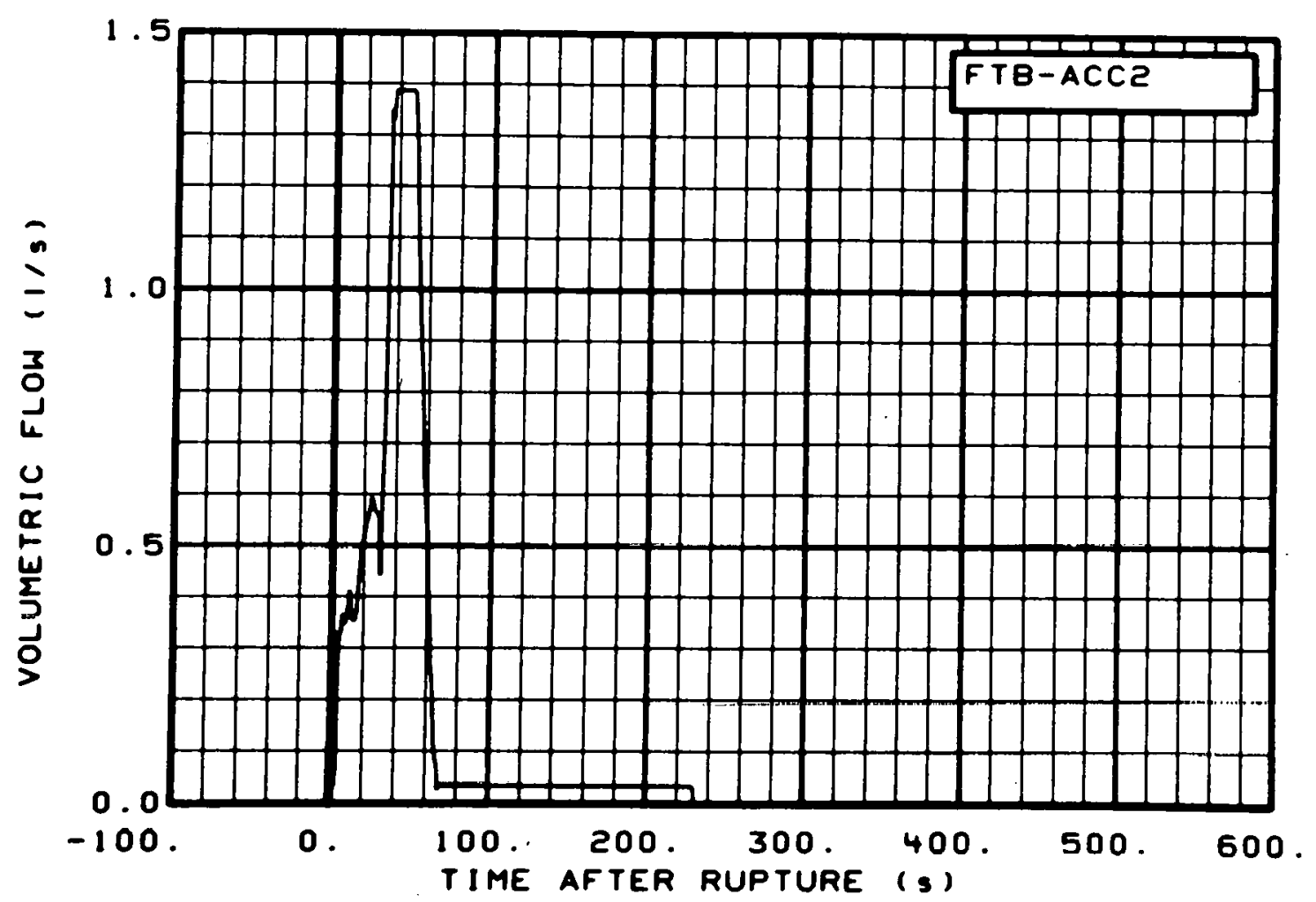

Fig. 261 Volumetric flow in broken loop accumulator discharge line (FTB-ACC2), from -20 to $600 \mathrm{~s}$.

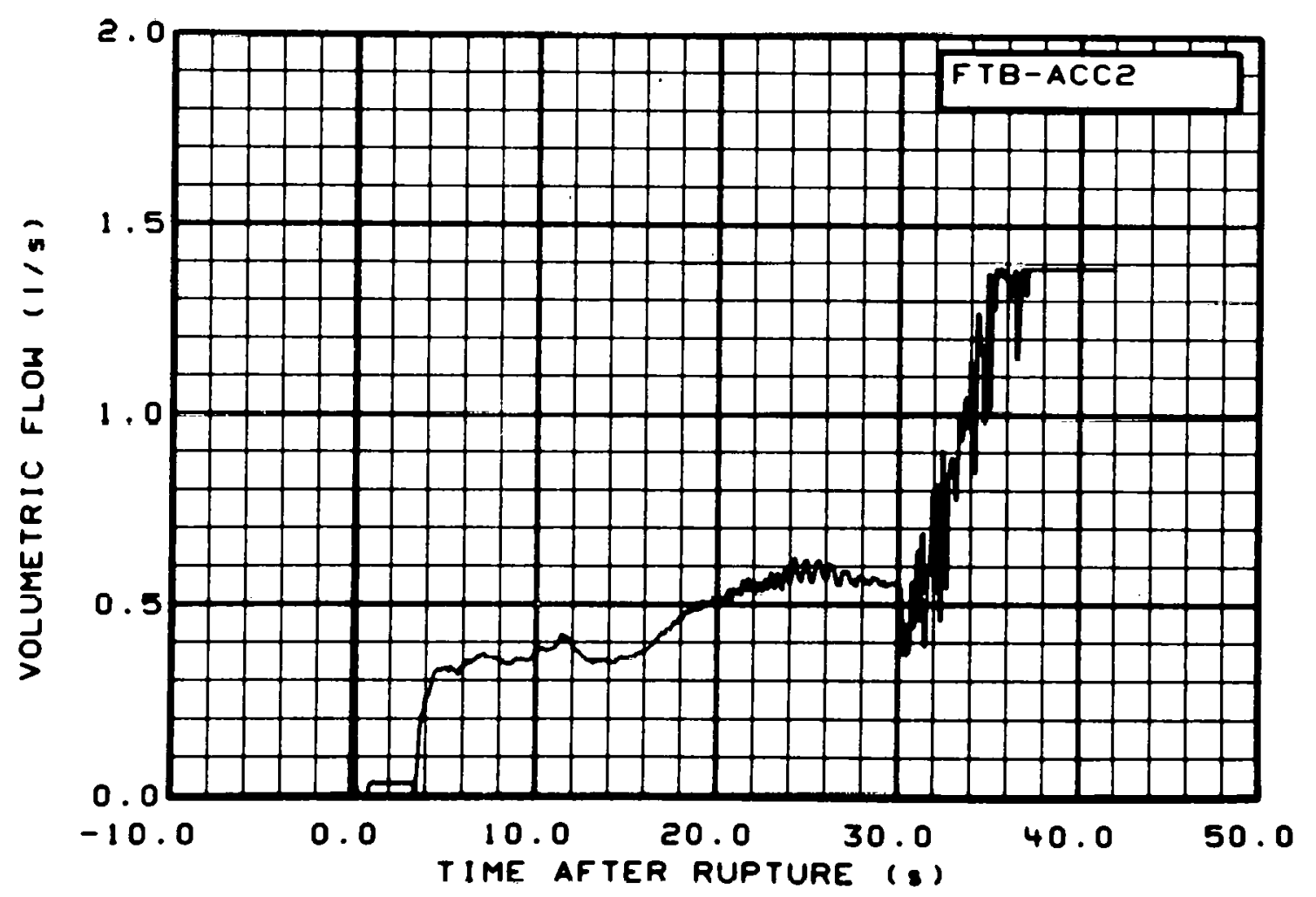

Fig. 262 Volumetric flow in broken loop accumulator discharge line (FTB-ACC2), from -6 to $42 \mathrm{~s}$. 


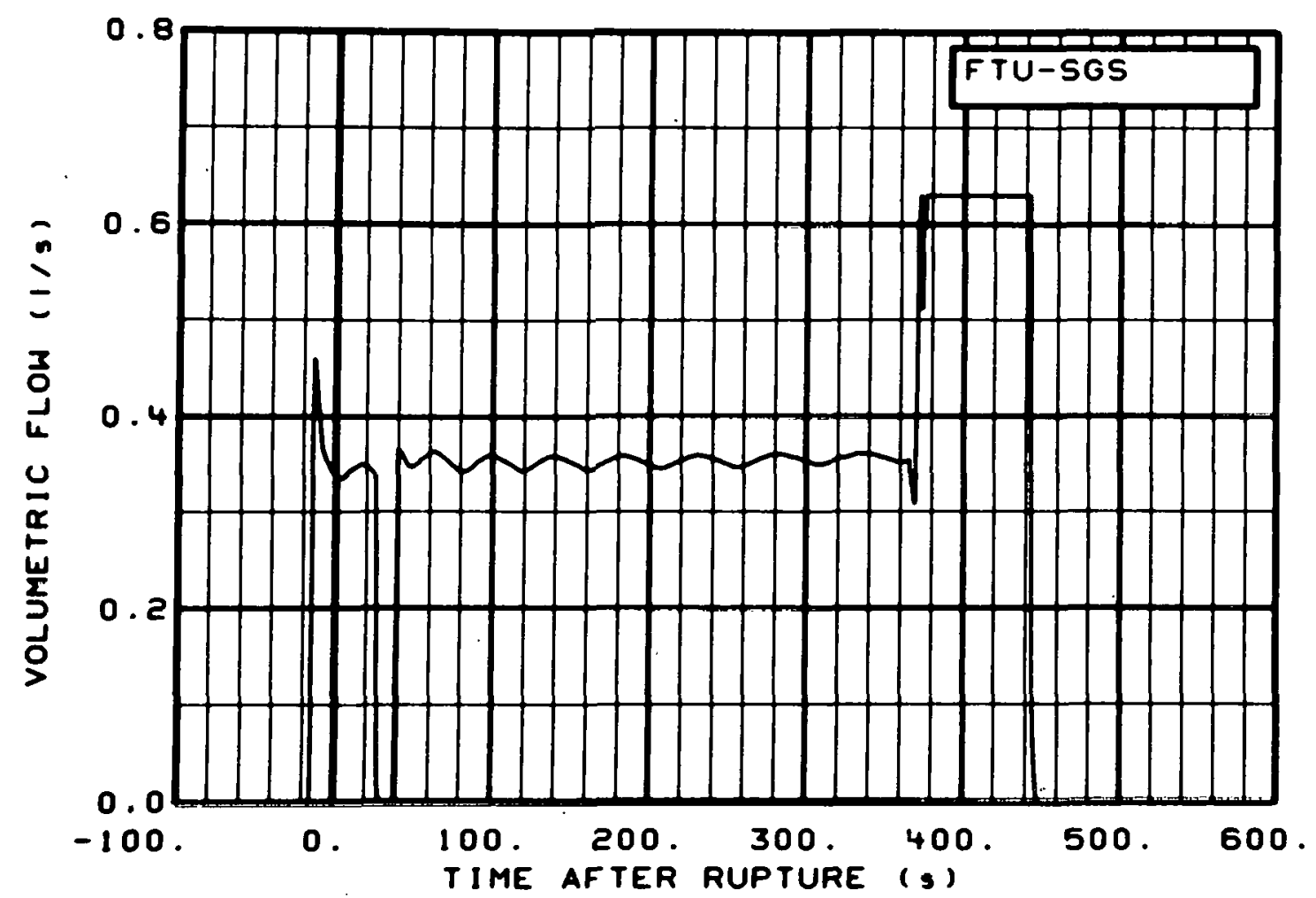

Fig. 263 Volumetric flow from intact loop steam generator tube rupture simulation accumulator (FTU-SGS), from -20 to $600 \mathrm{~s}$.

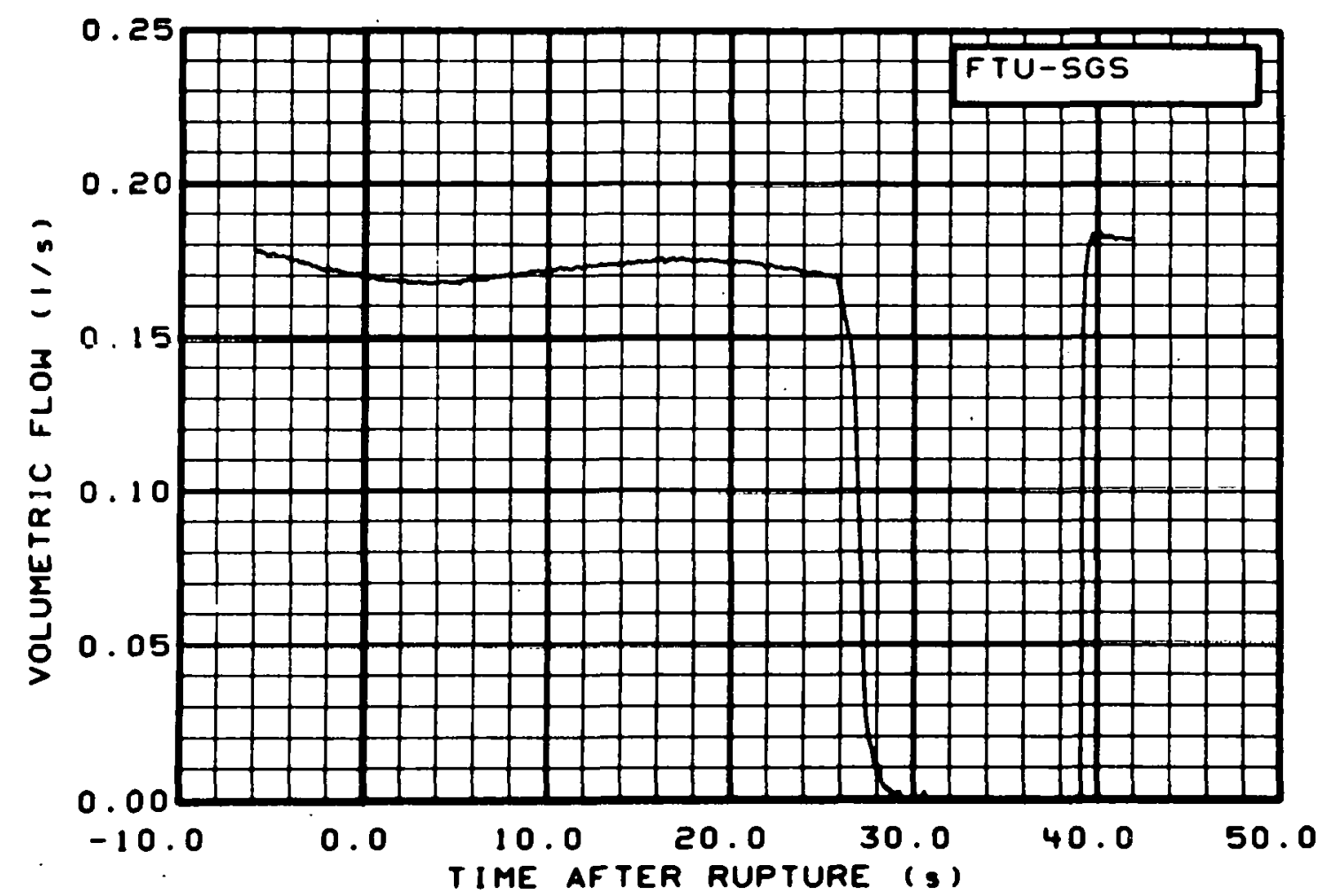

Fig. 264 Volumetric flow from intact loop steam generator tube rupture simulation accurilulator (FTU-SGS), from -6 to $42 \mathrm{~s}$. 


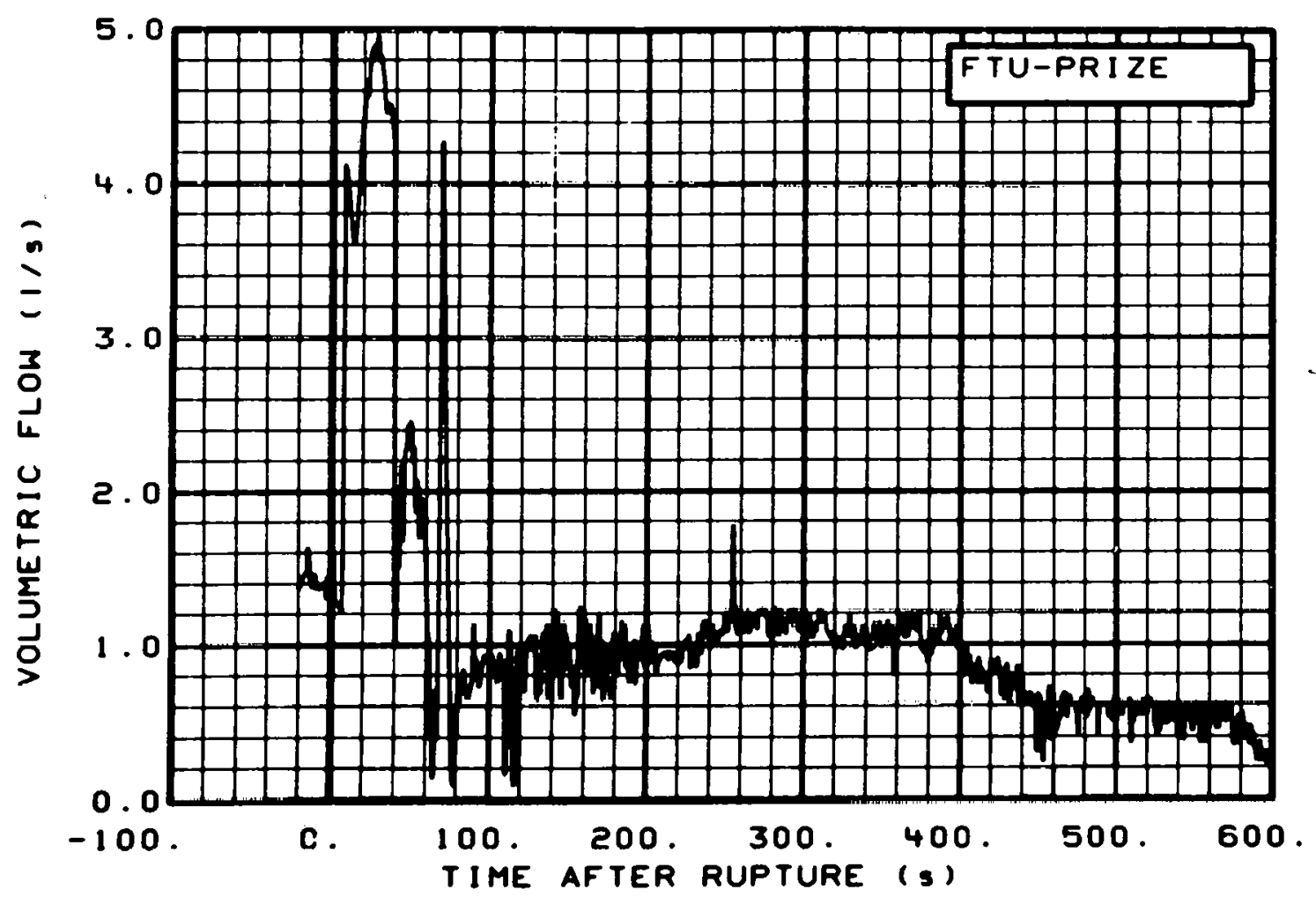

Fig. 265 Volumetric flow from pressurizer (FTU-PRIZE), from -20 to $600 \mathrm{~s}$.

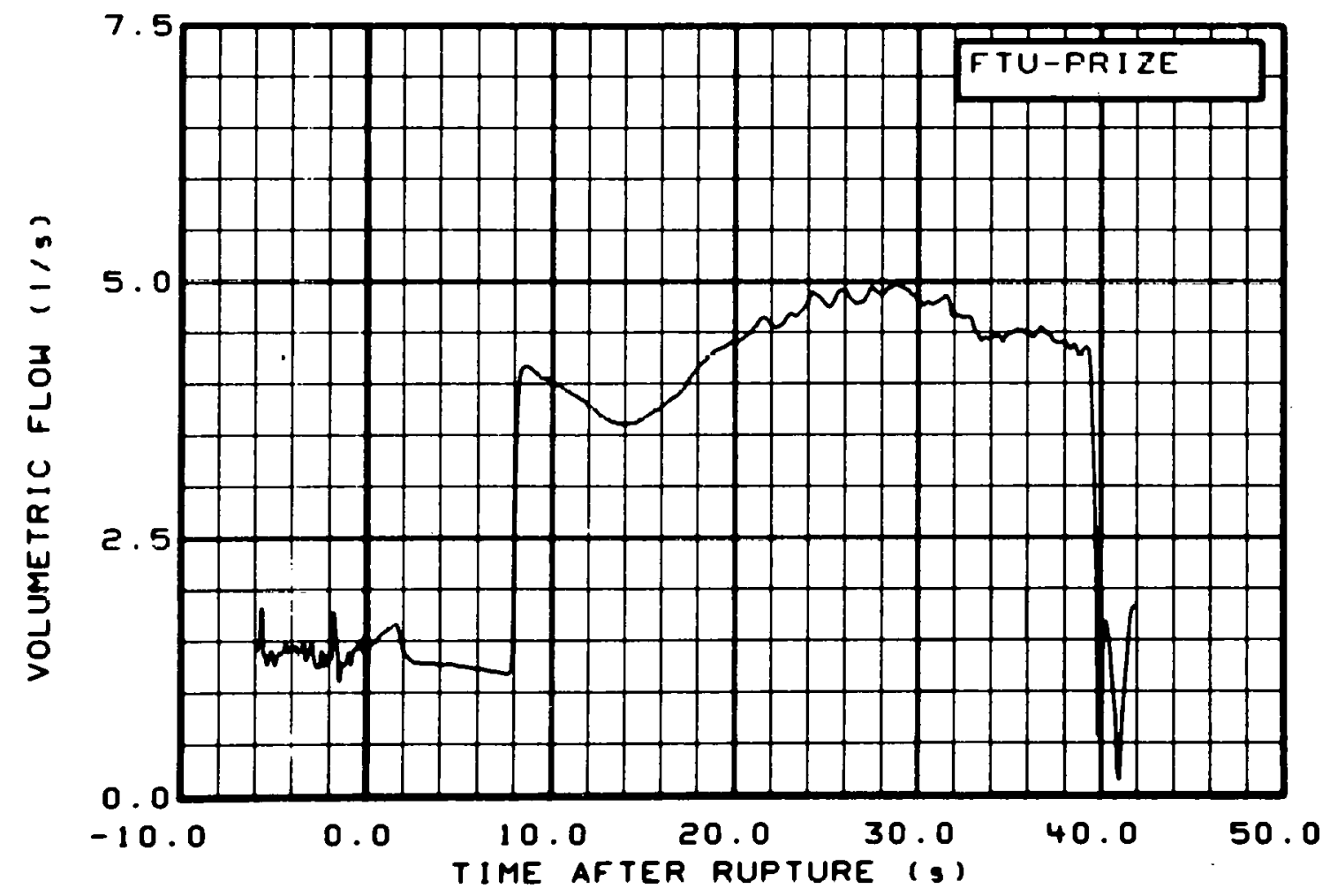

Fig. 266 Volumetric flow from pressurizer (FTU-PRIZE), from -6 to $42 \mathrm{~s}$. 


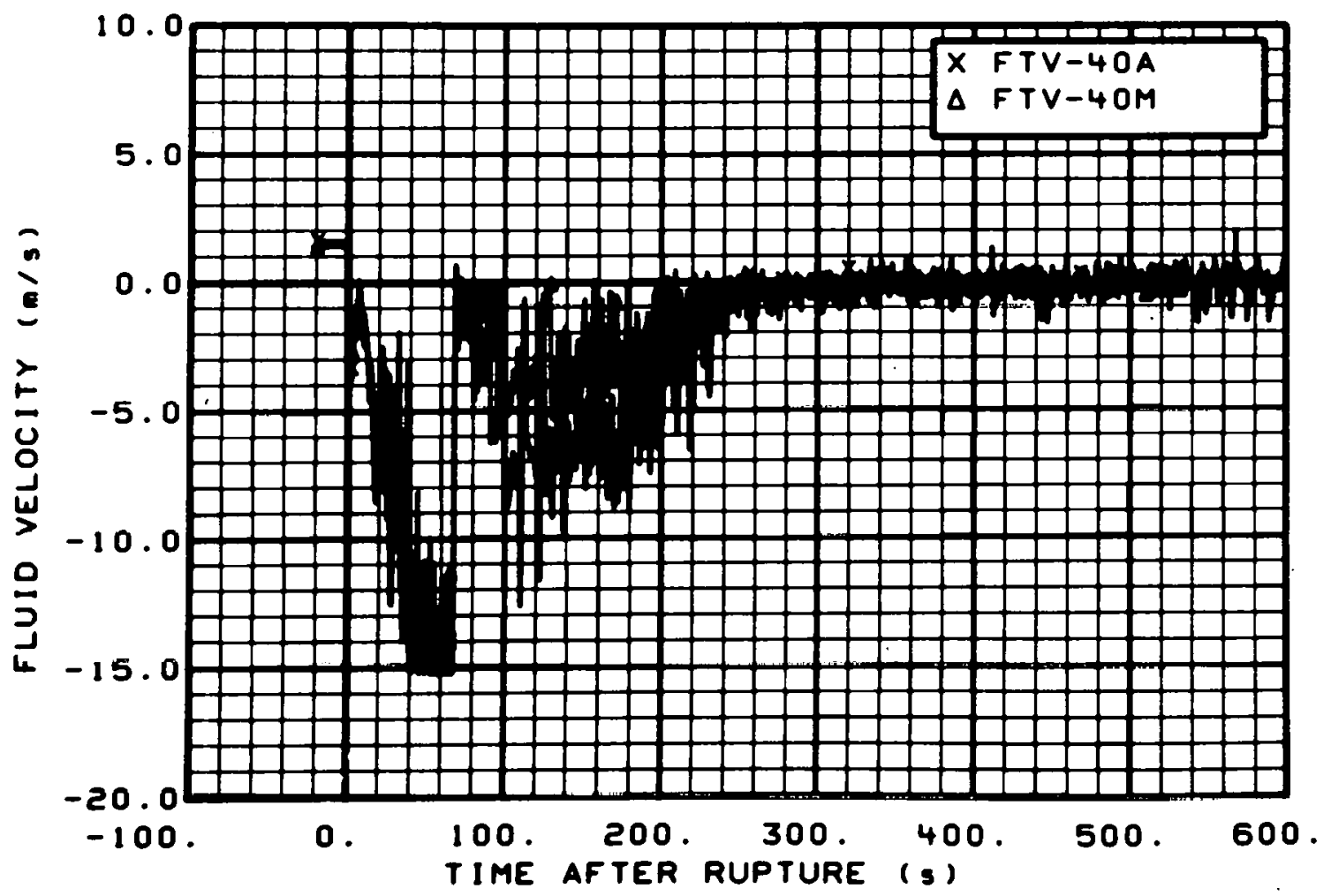

Fig. 267 Fluid velocity in vessel (FTV-40A and FTV-40M), from -20 to $600 \mathrm{~s}$.

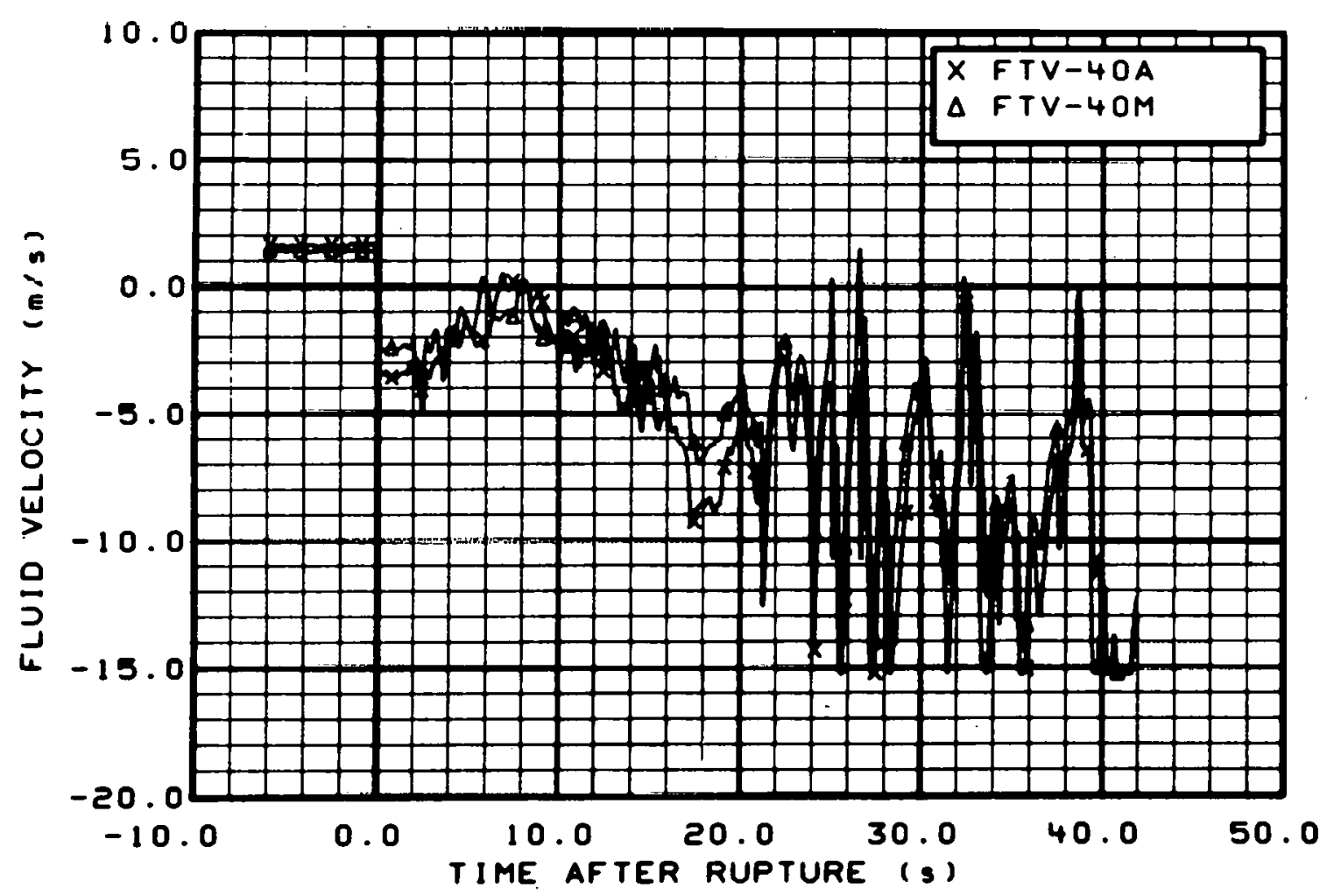

Fig. 268 Fluid velocity in vessel (FTV-40A and FTV-40M), from -6 to $42 \mathrm{~s}$. 


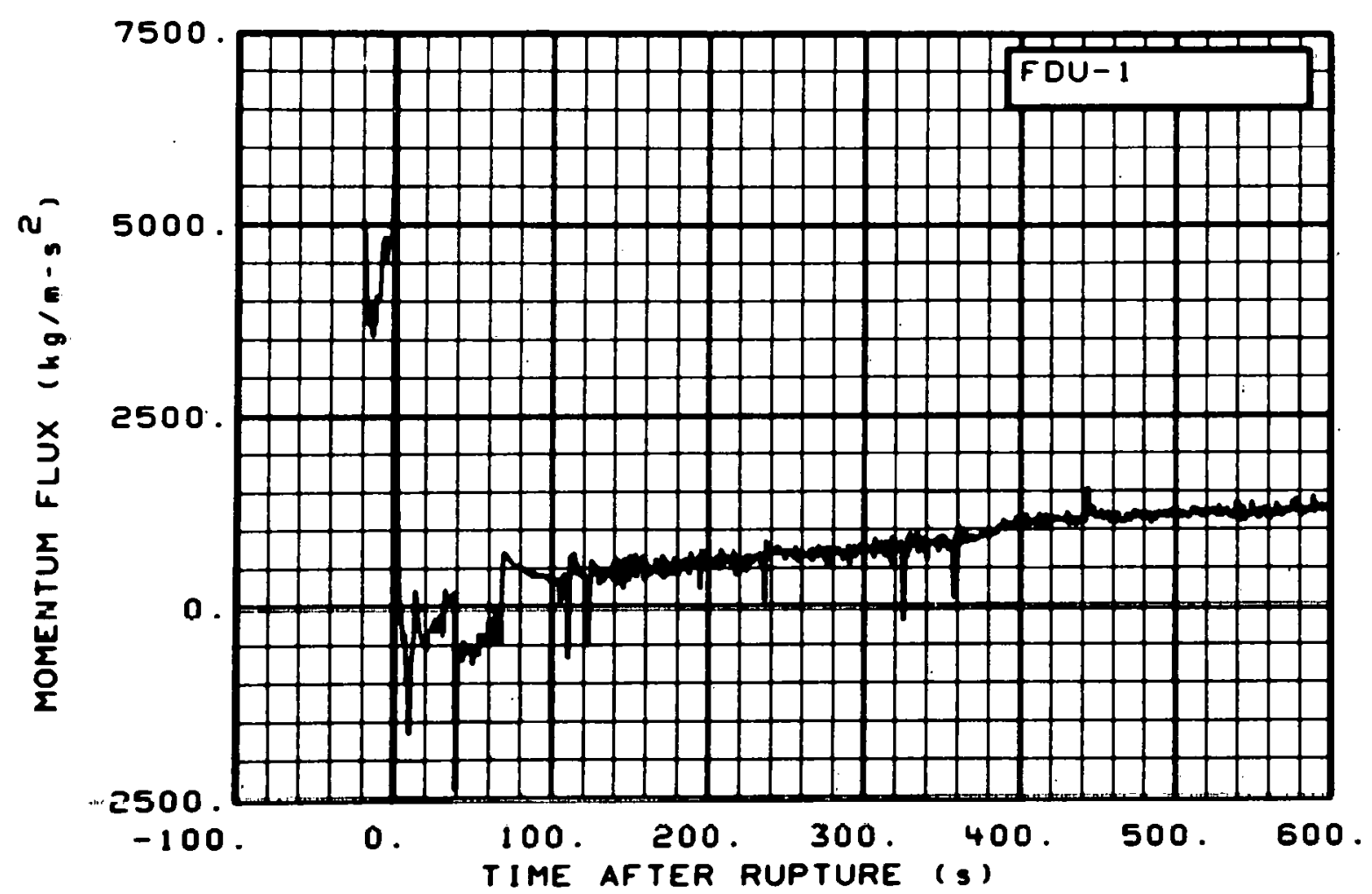

Fig. 269 Momentum flux in intact loop (FDU-1), from -20: to $600 \mathrm{~s}$.

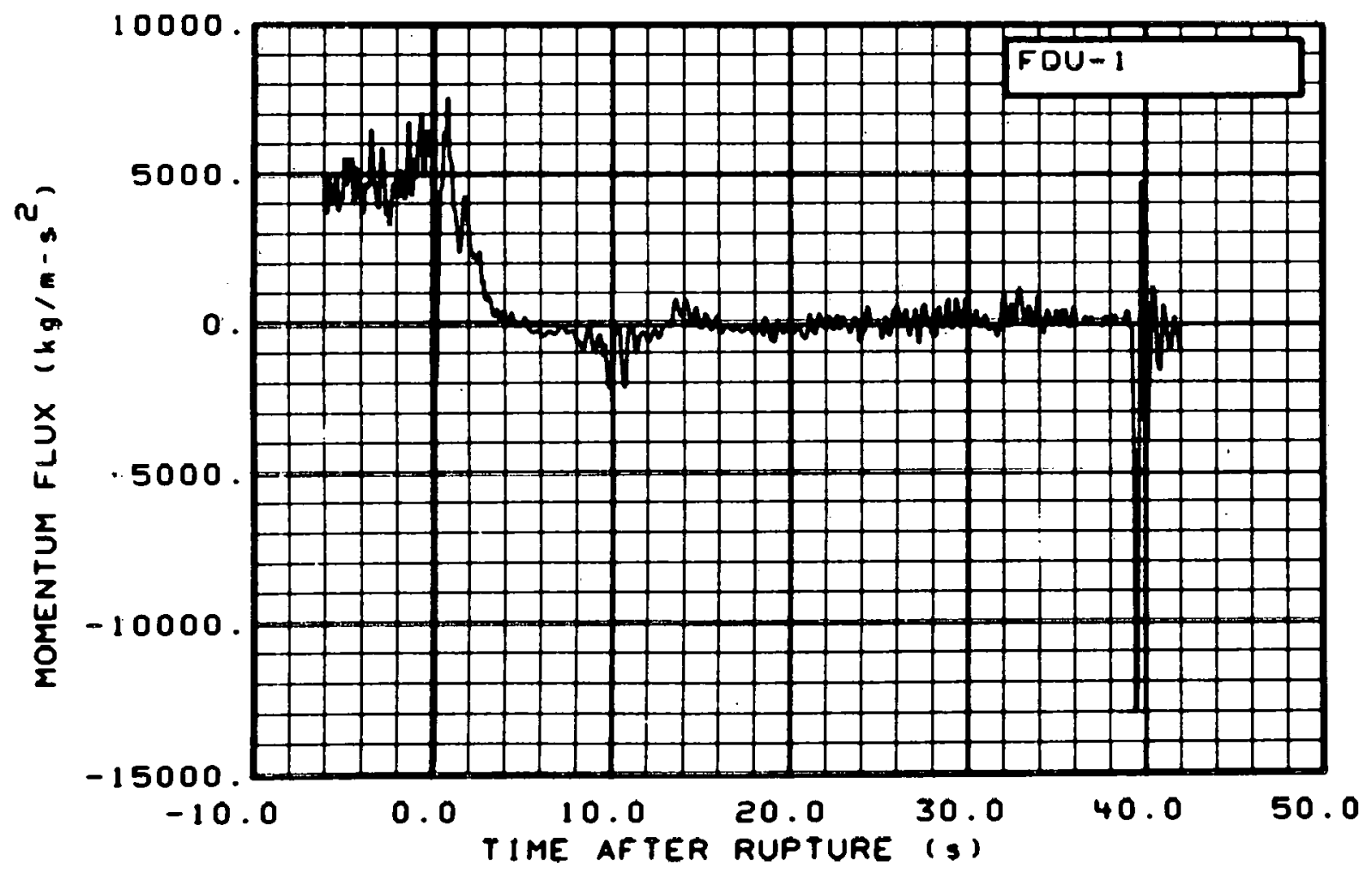

Fig. 270 Momentum flux in intact loop (FDU-1), from -6 to $42 \mathrm{~s}$. 


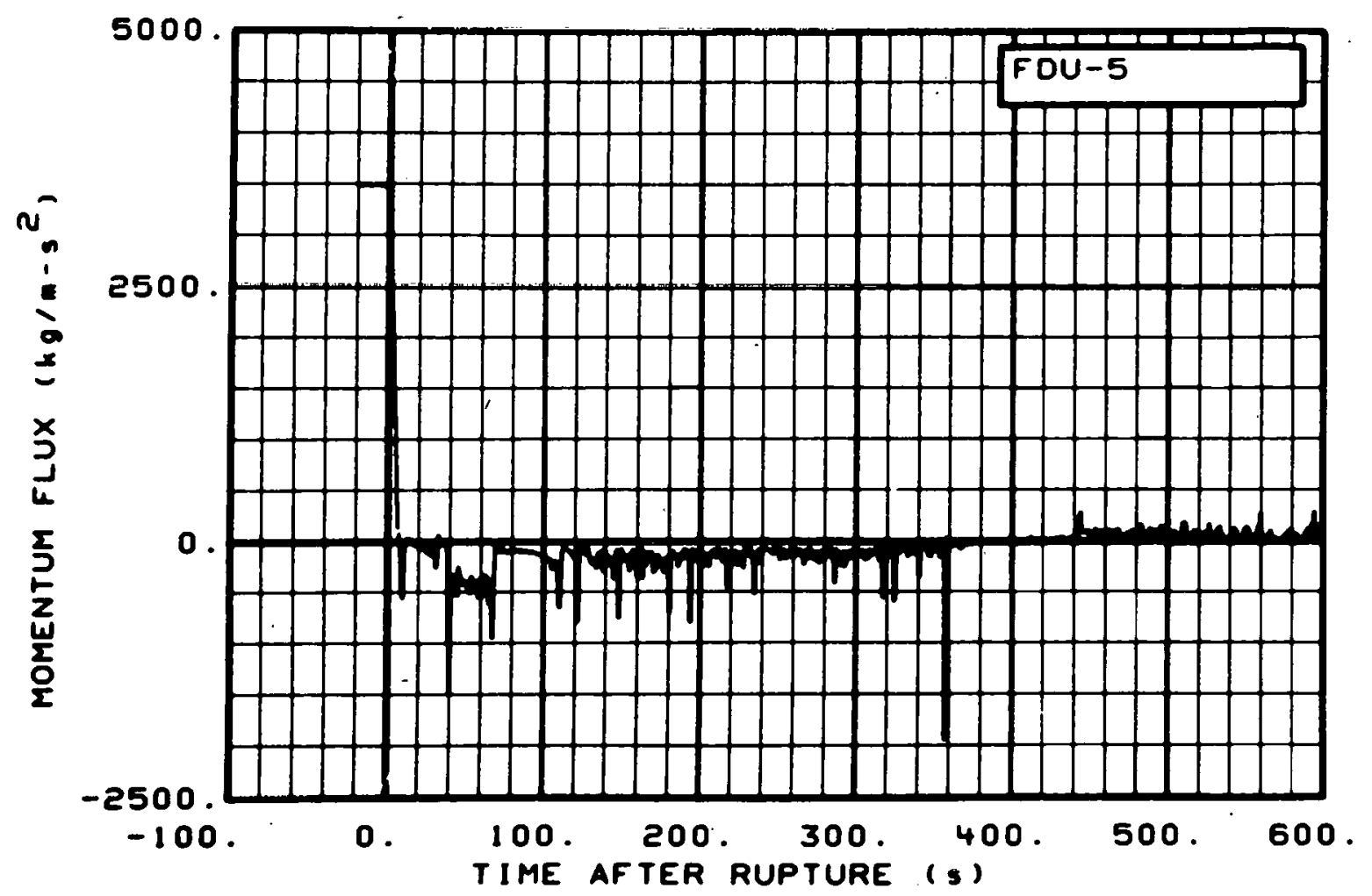

Fig. 271 Momentum flux in intact loop (FDU-5), from -20 to $600 \mathrm{~s}$.

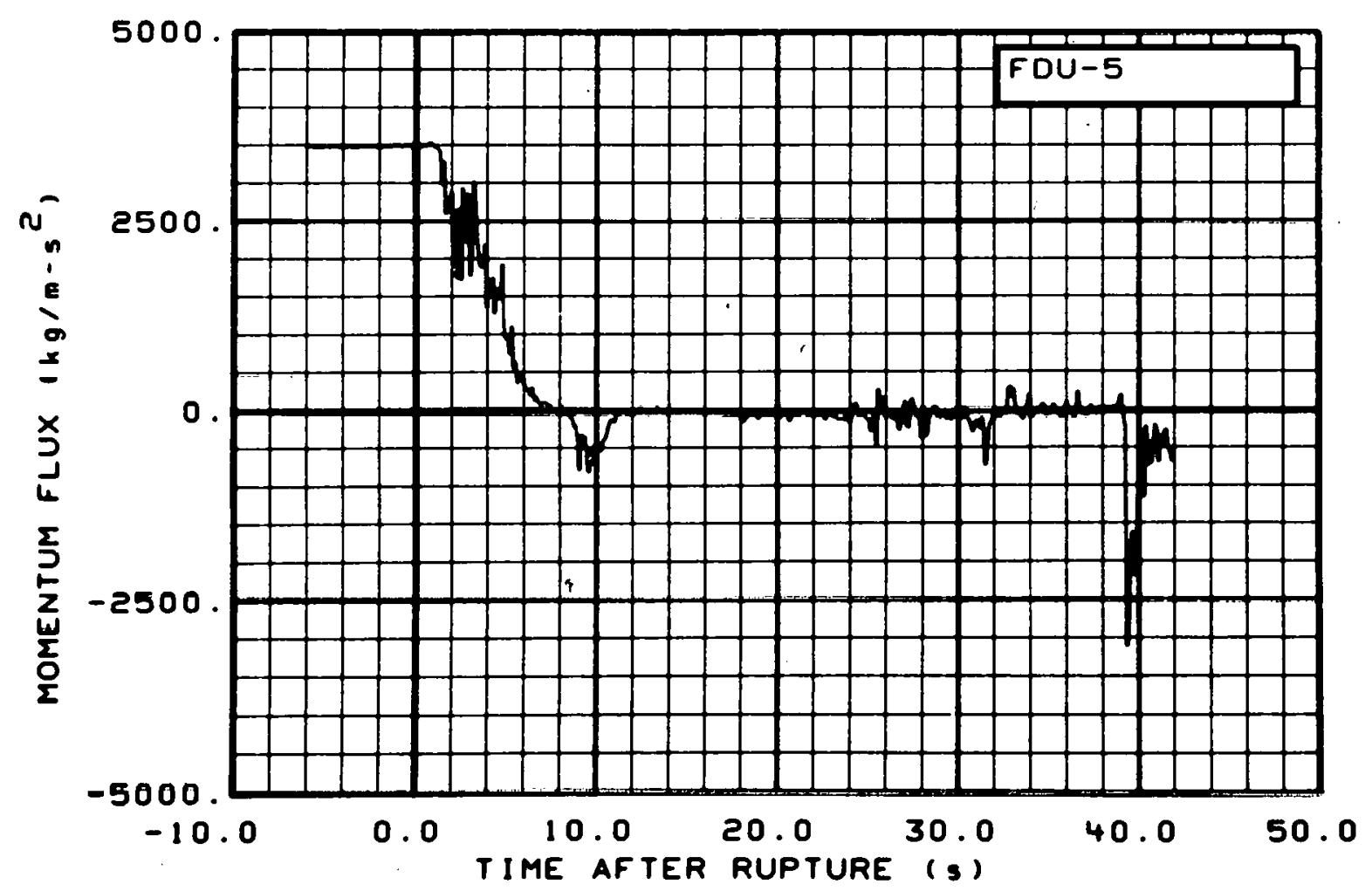

Fig. 272 Momentum flux in intact loop (FDll-5), from -6 t. 42 s. 


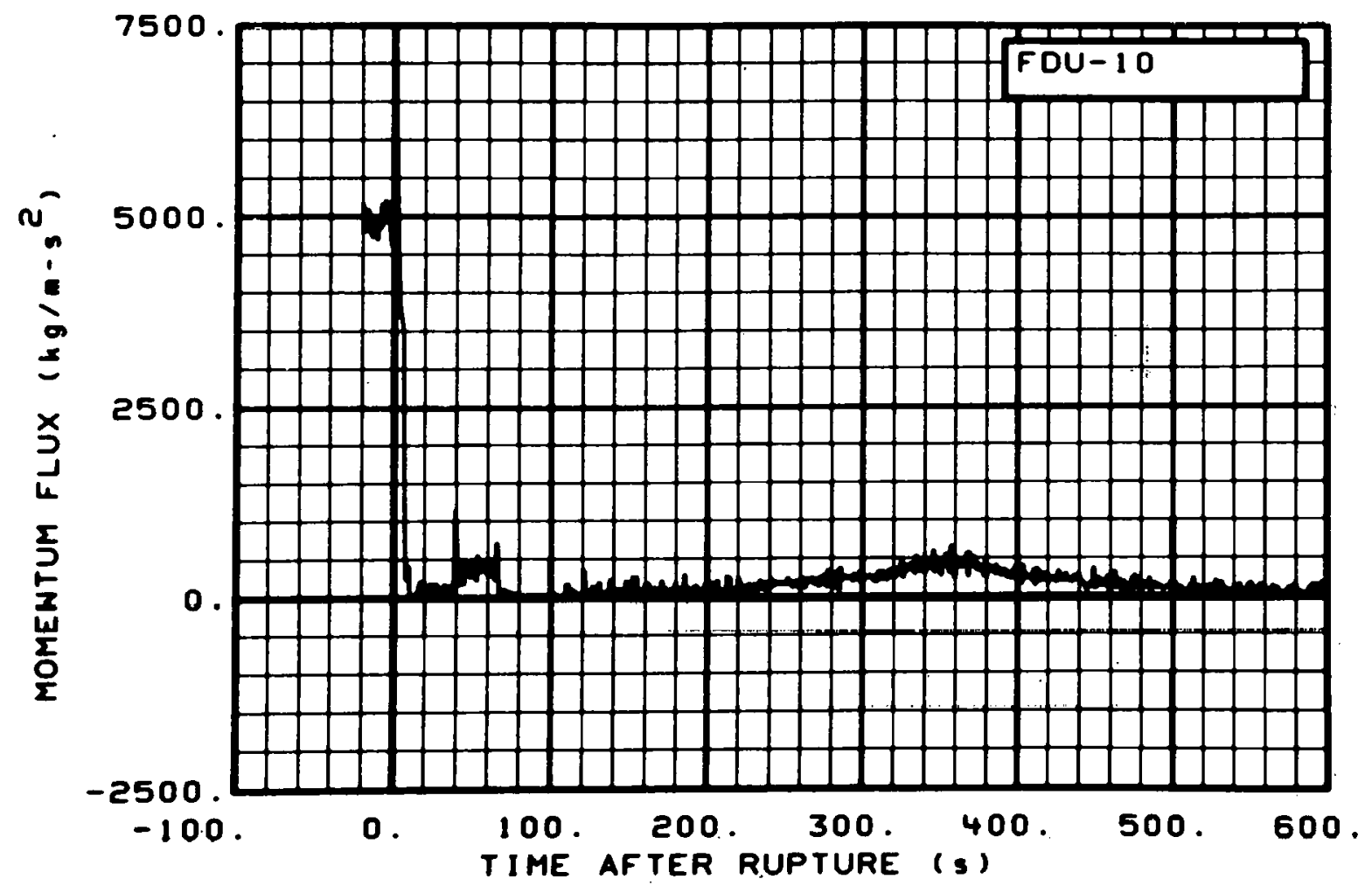

Fig. 273 Momentum flux in intact loop (FDU-10), from -20 to $600 \mathrm{~s}$.

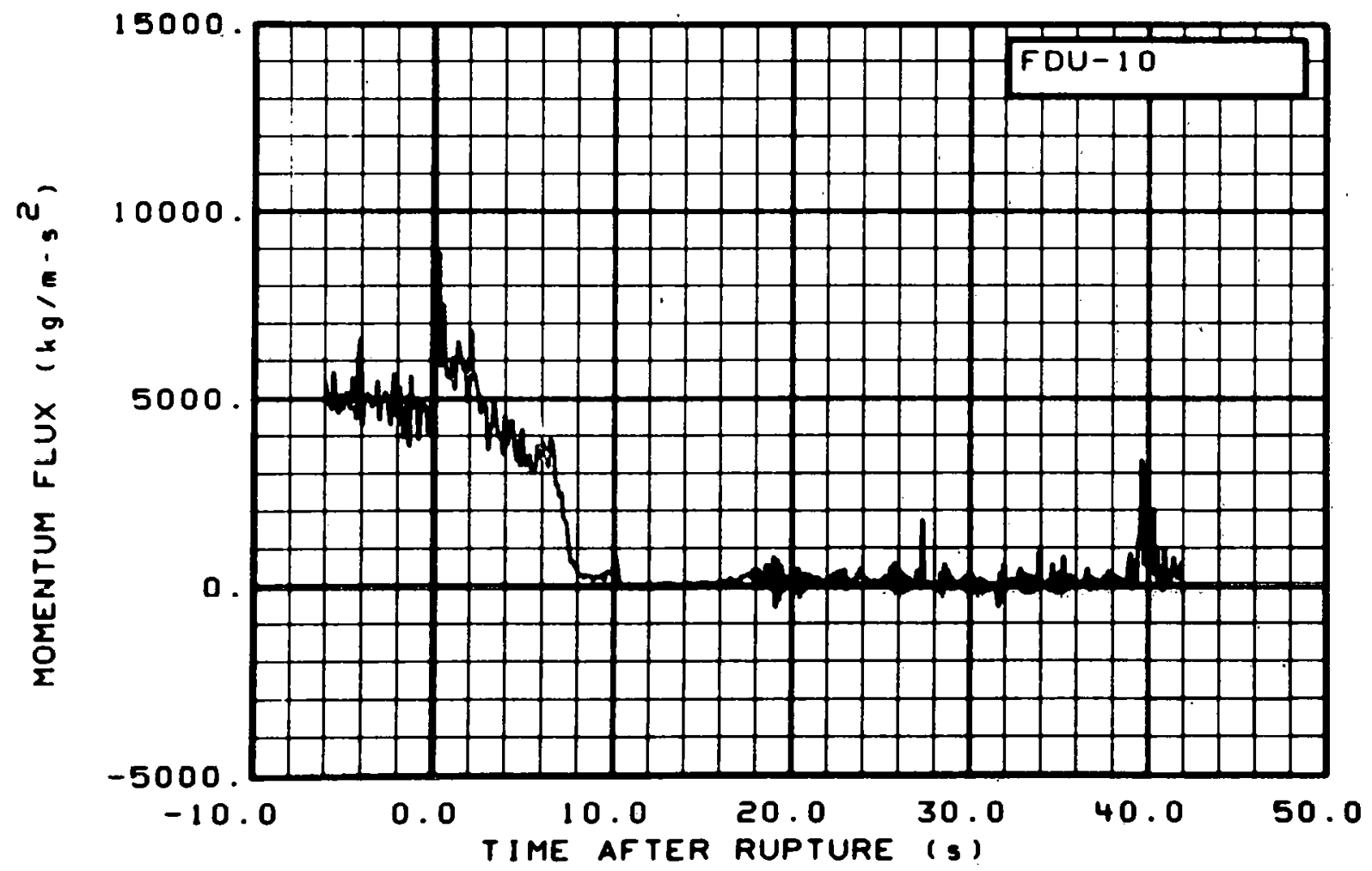

Fig. 274 Momentum flux in intact loop (FDU-10), from -6 to $42 \mathrm{~s}$. 


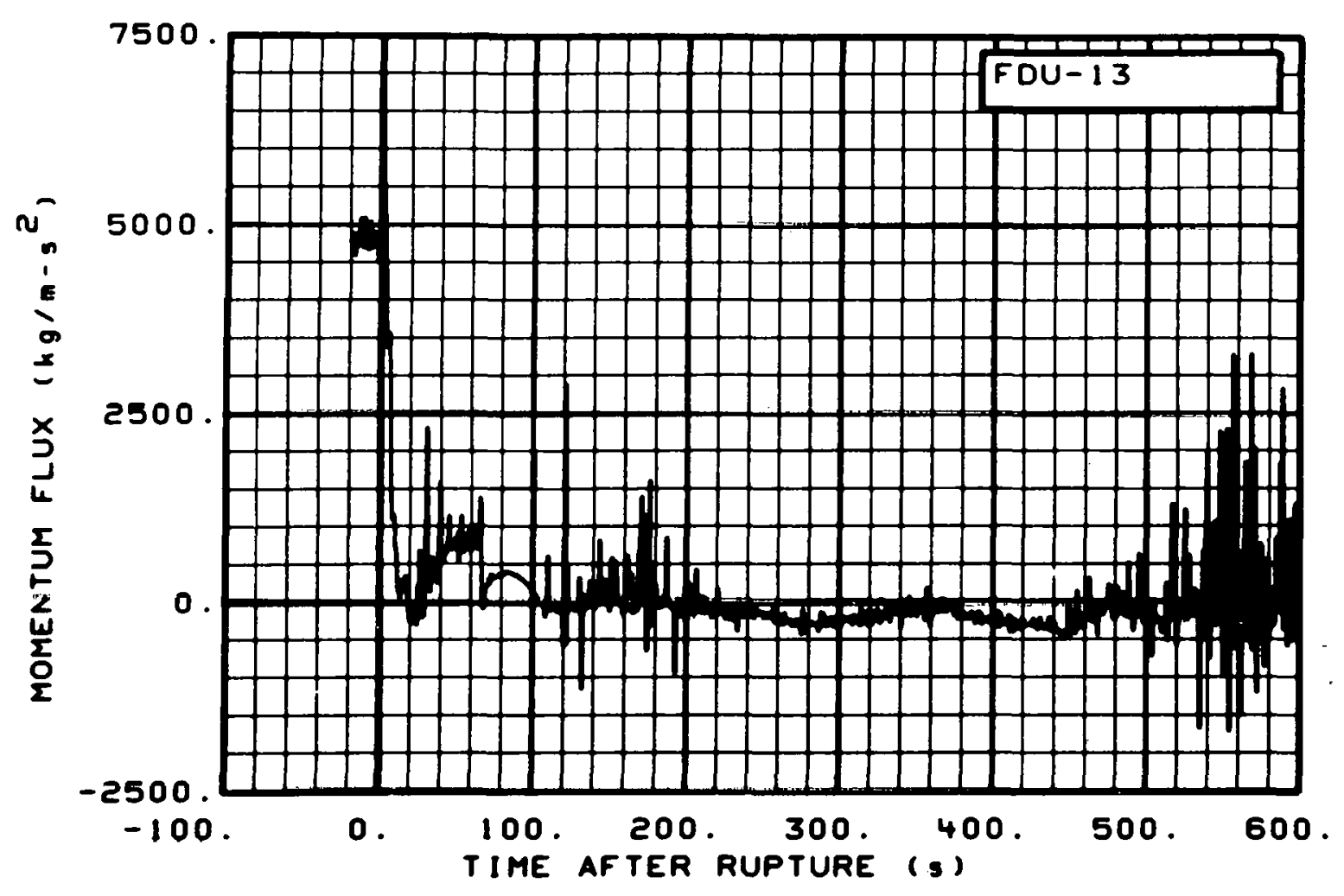

Fig. 275 Momentum flux in intact loop (FDU-13), from -20 to $600 \mathrm{~s}$.

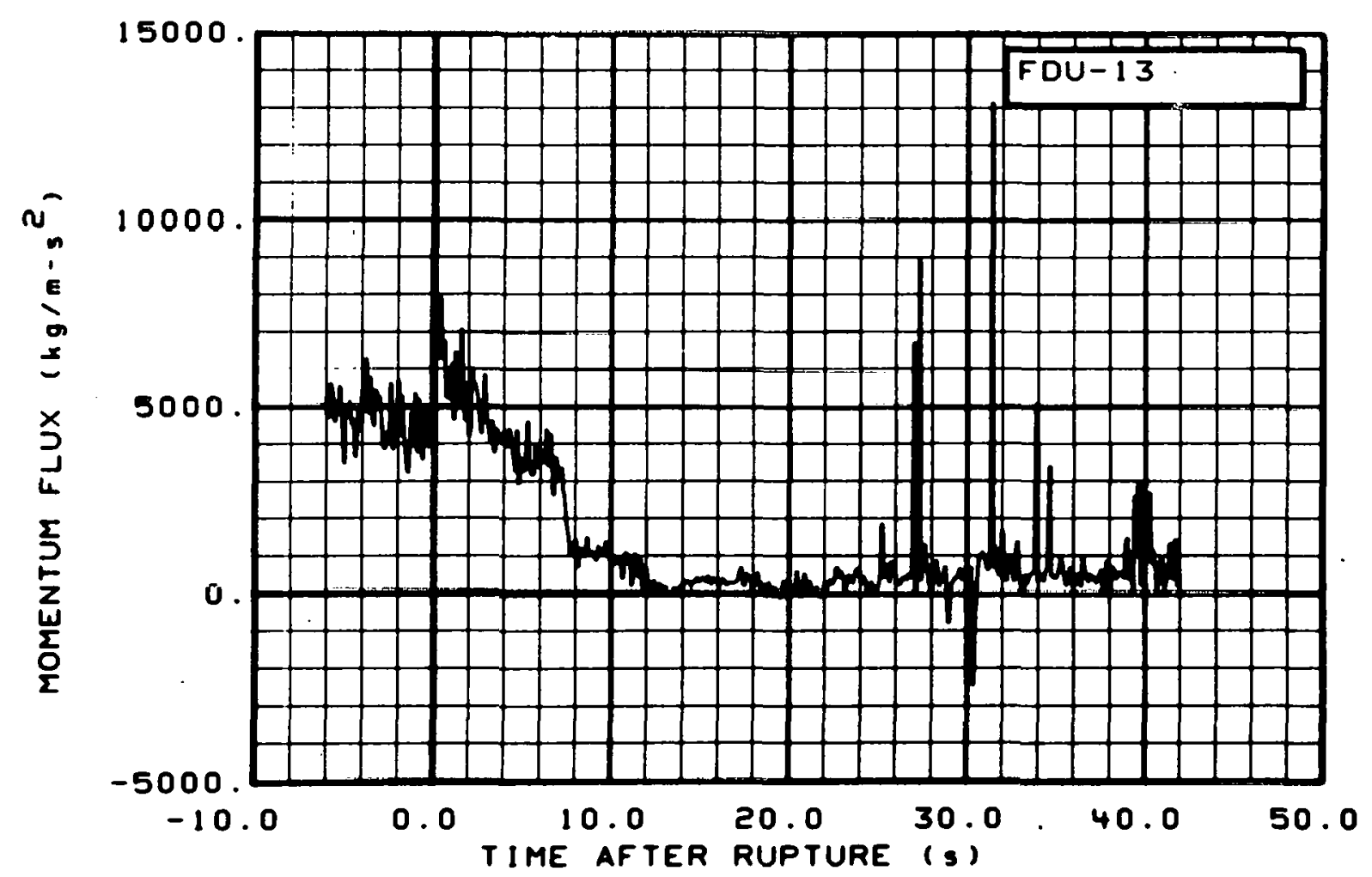

Fig. 276 Momentum flux in intact loop (FnlJ-13), from -6 to $42 \mathrm{~s}$, 


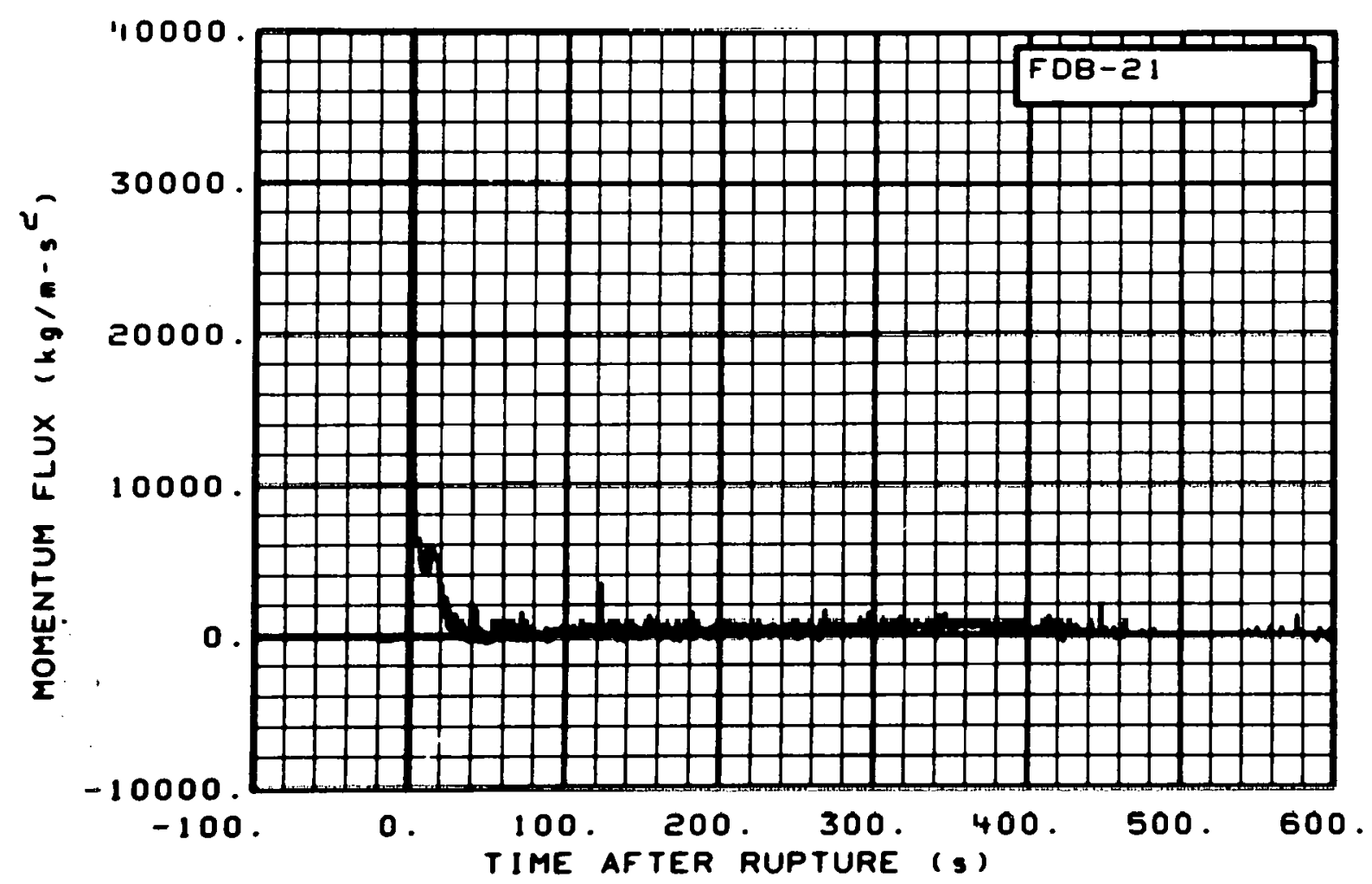

Fig. 277 Momentum flux in broken loop (FDB-21), from -20 to $600 \mathrm{~s}$.

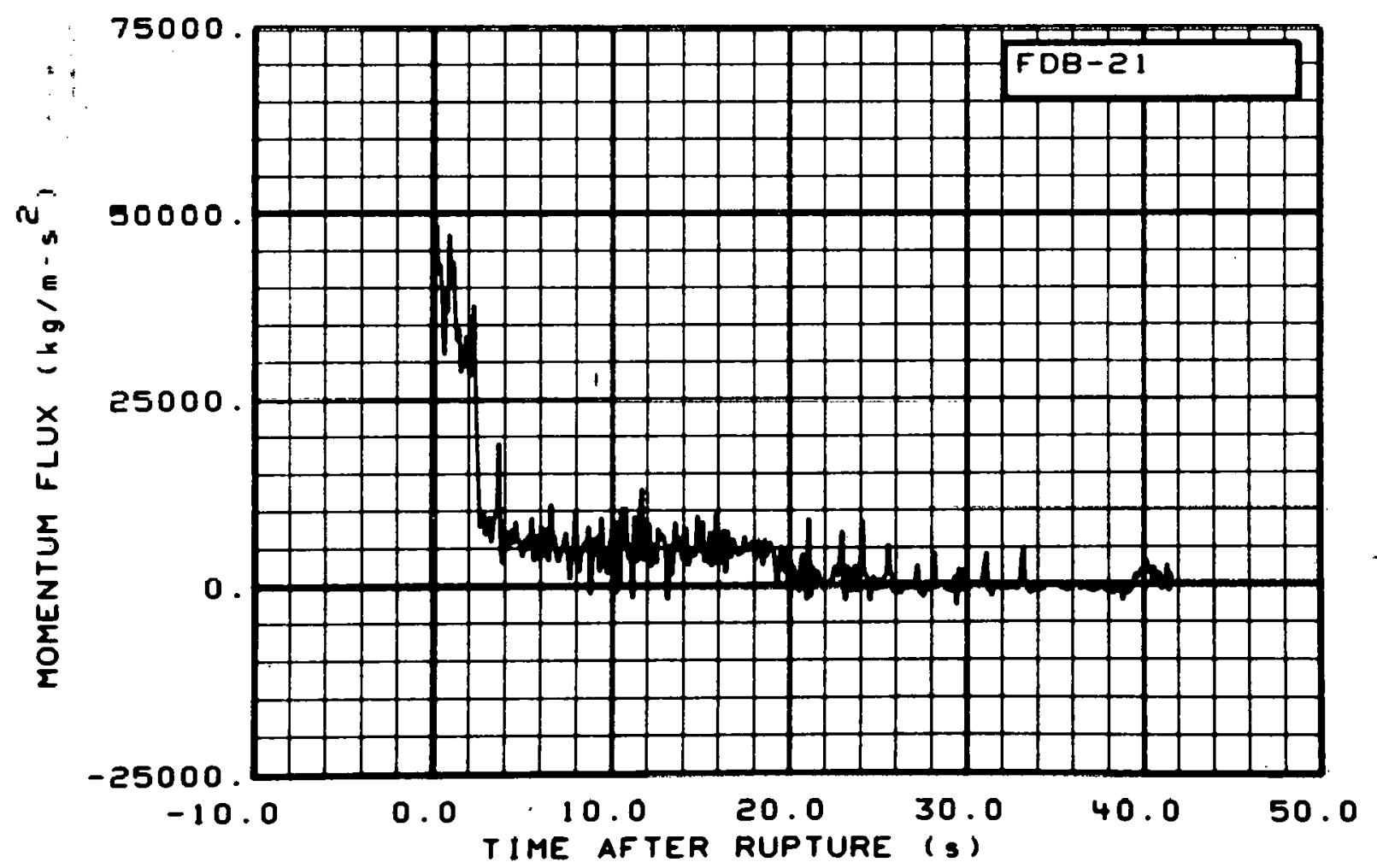

Fig. 278 Momentum flux in broken loop (FDB-21), from -6 to $42 \mathrm{~s}$. 


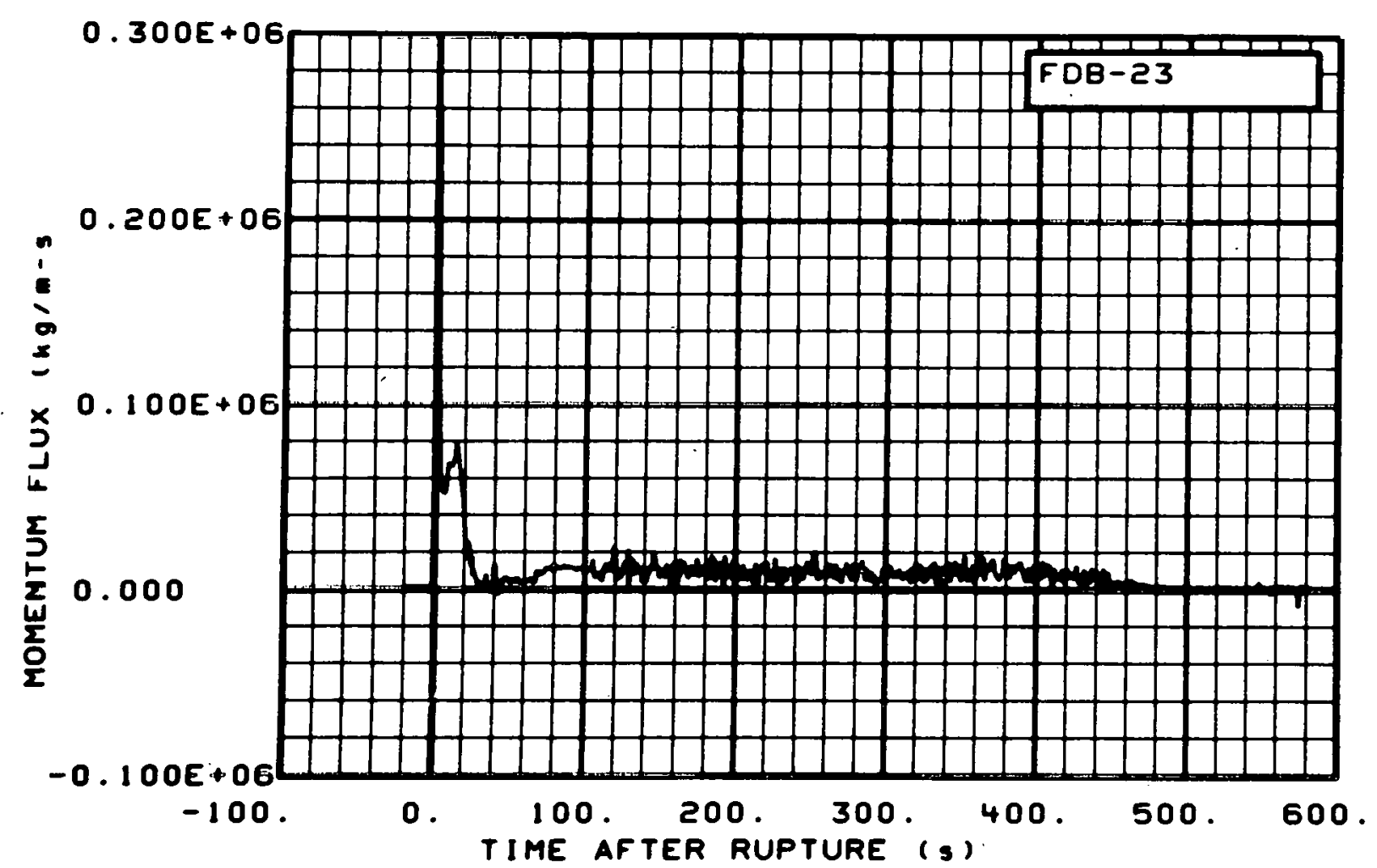

Fig. 279 Momentum flux in broken loop (FDB-23), from -20 to $600 \mathrm{~s}$.

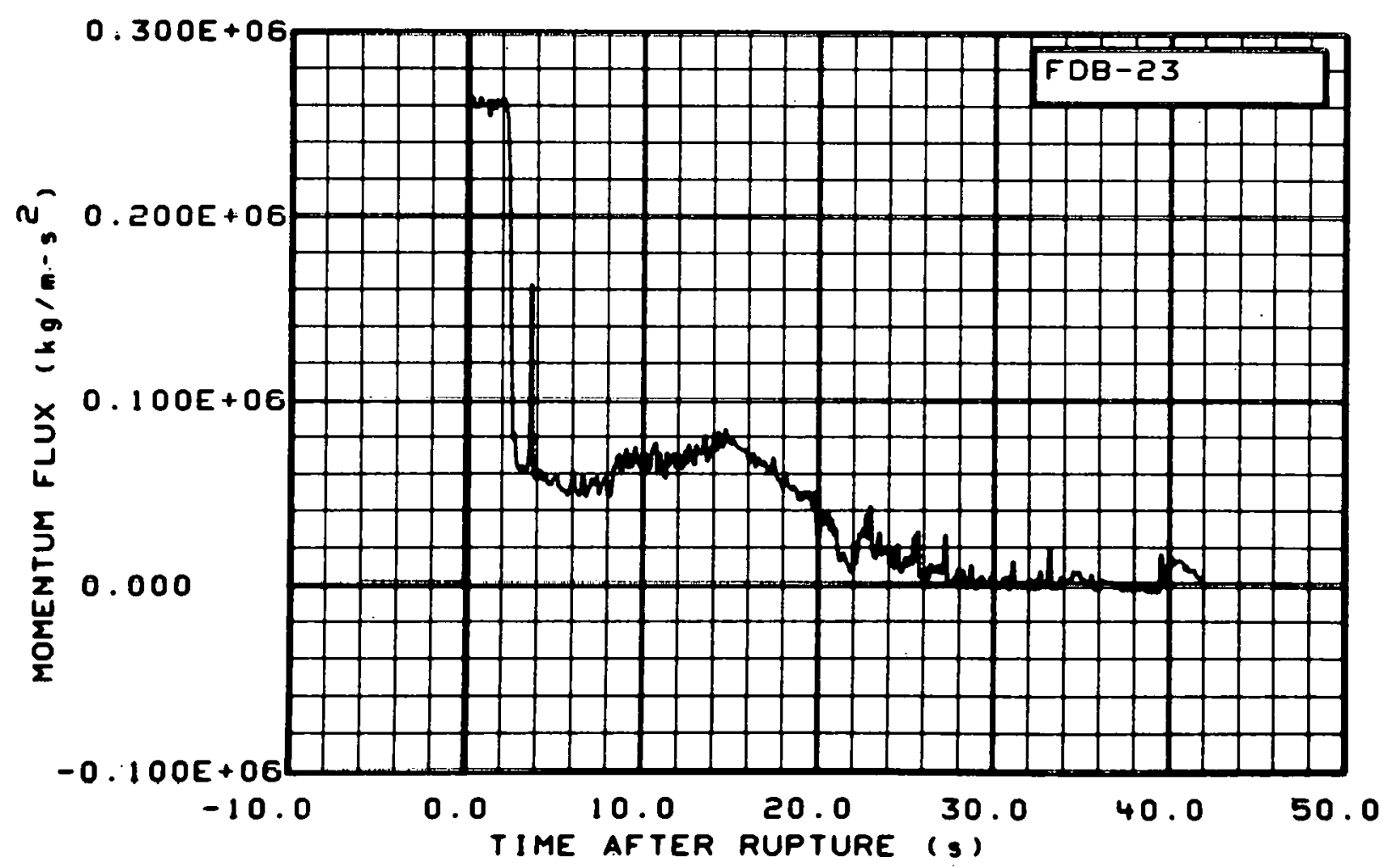

Fig. 280 Momentum flux in broken loop (FDB-23), from -6 t.o $42 \mathrm{~s}$. 


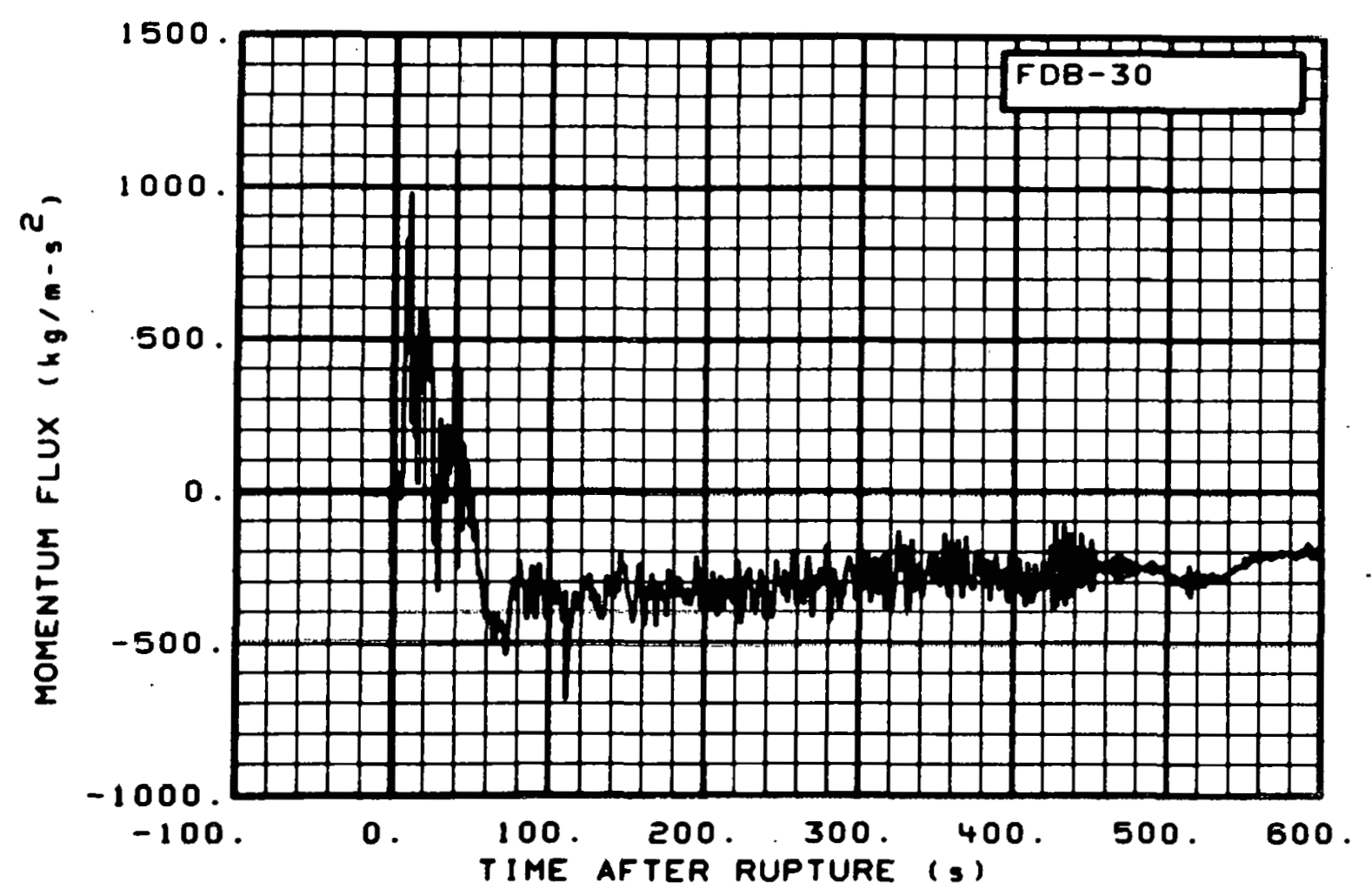

Fig. 281 Momentum flux in broken loop (FDB-30), from -20 to $600 \mathrm{~s}$.

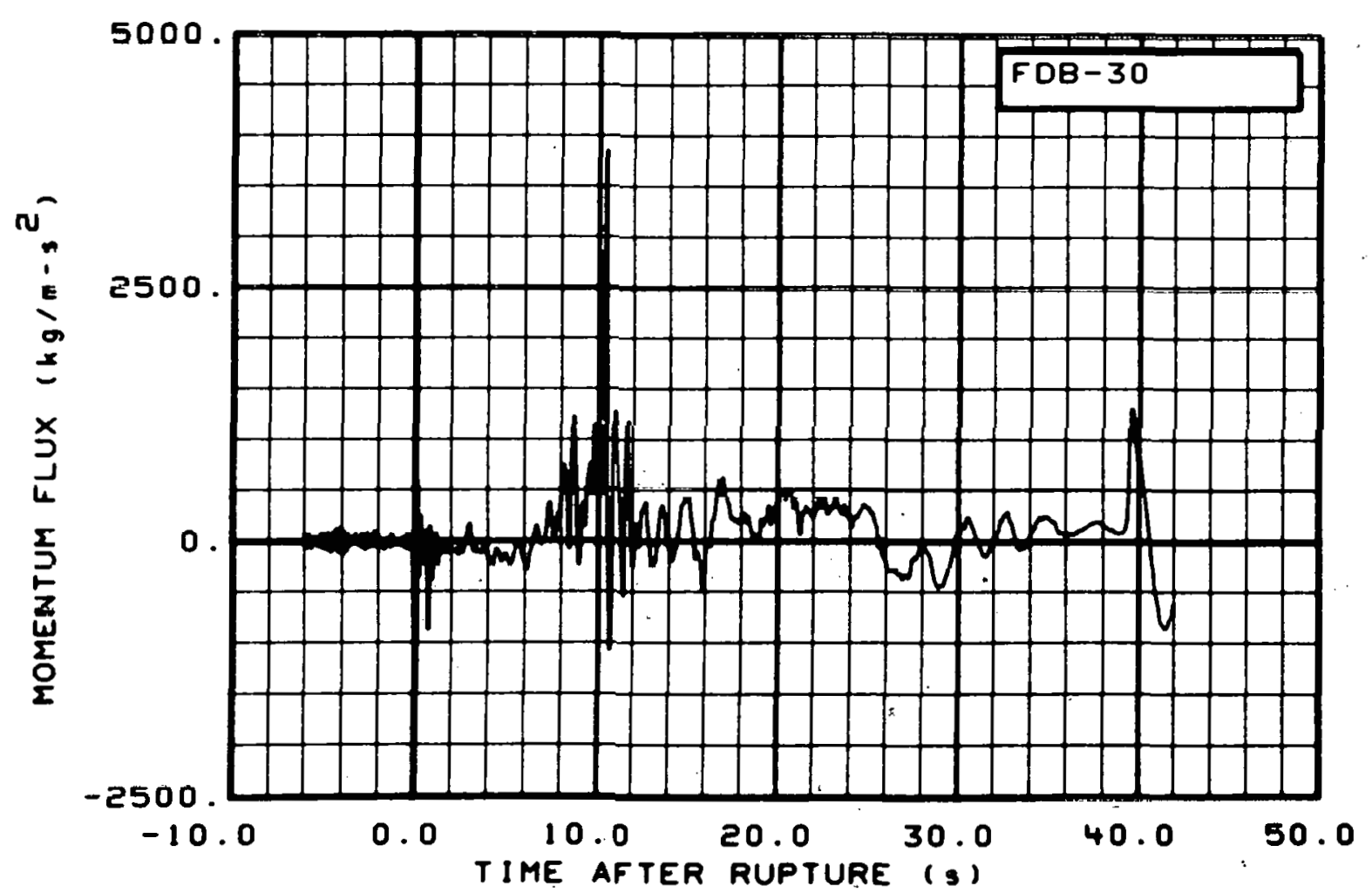

Fig. 282 Momentum flux in broken loop (FDB-30), from -6 to $42 \mathrm{~s}$. 


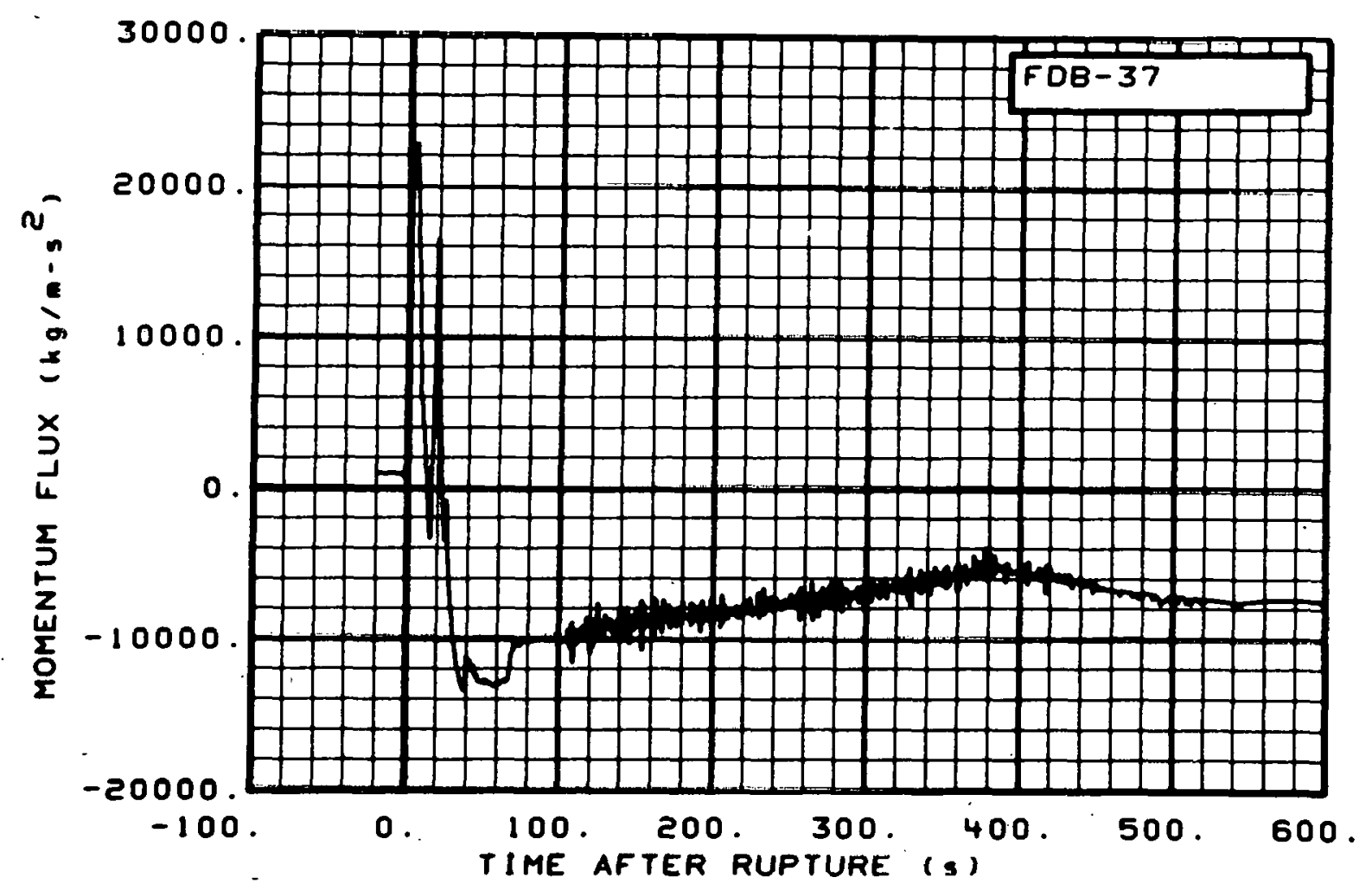

Fig. 283 Momentum flux in broken loop (FDB-37), from -20 to $600 \mathrm{~s}$.

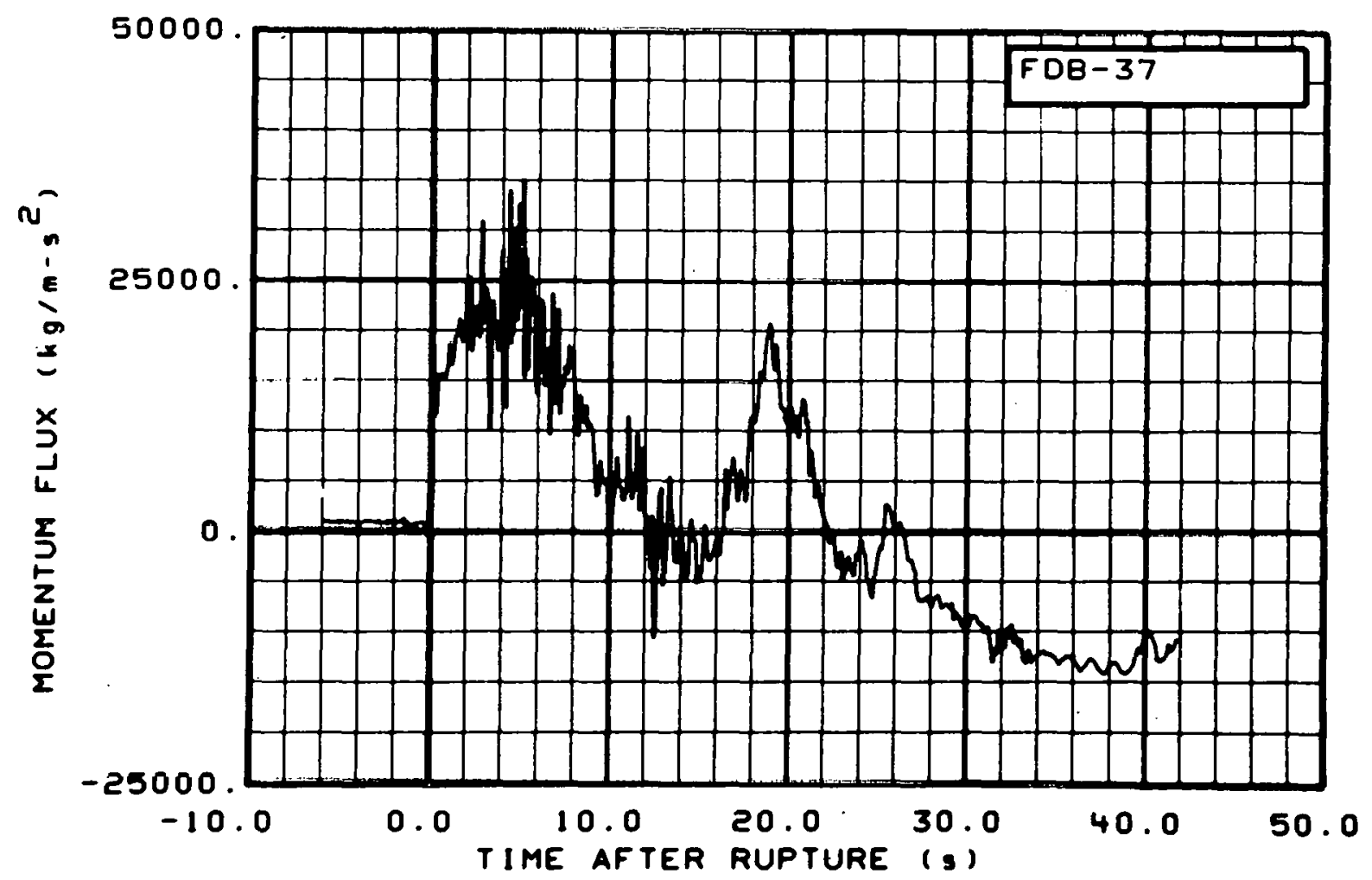

Fig. 284 Momentum flux in broken loop (FDB-37), from -6 to $42 \mathrm{~s}$. 


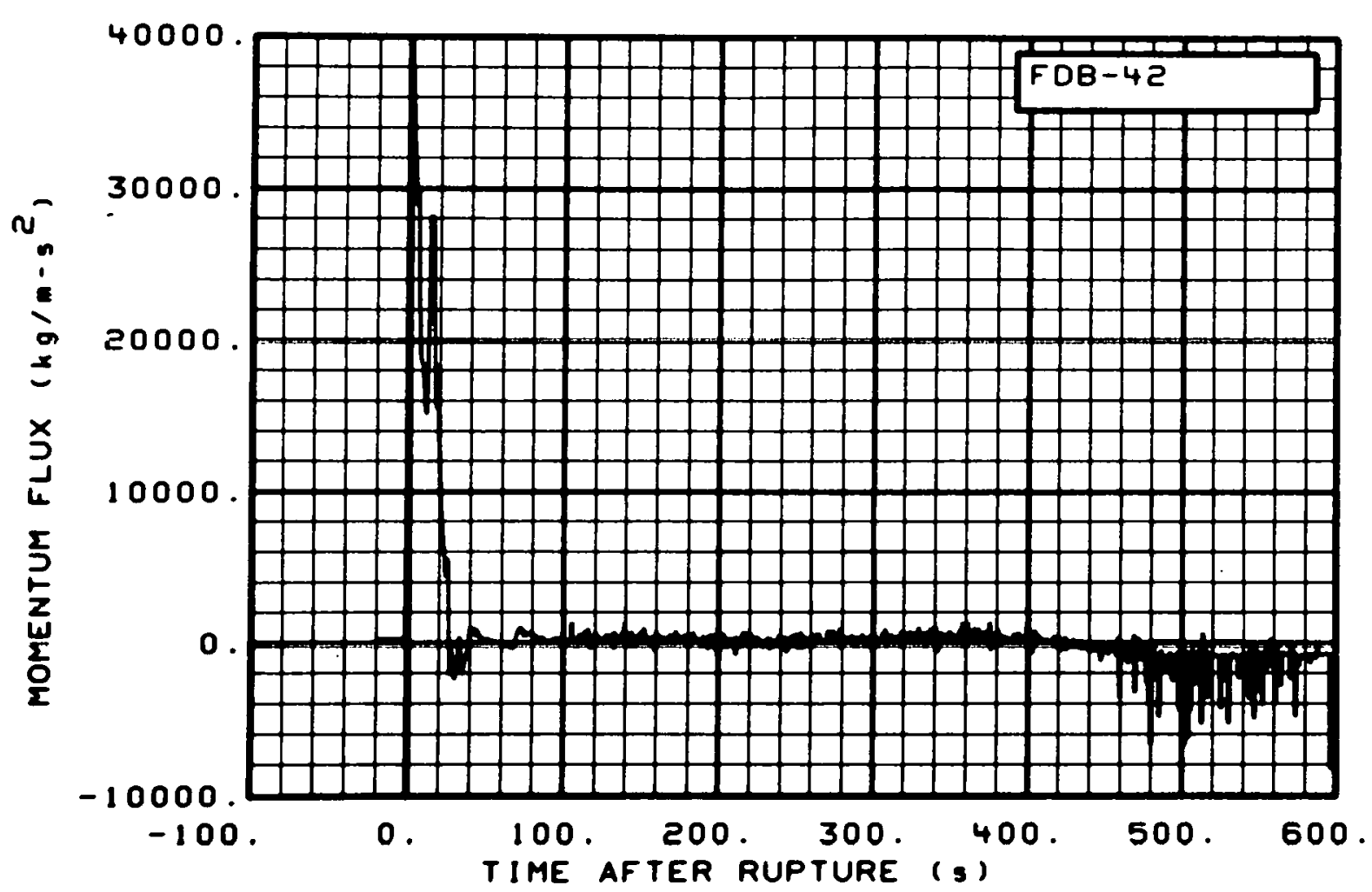

Fig. 285 Momentum flux in broken loop (FDB-42), from -20 to $600 \mathrm{~s}$.

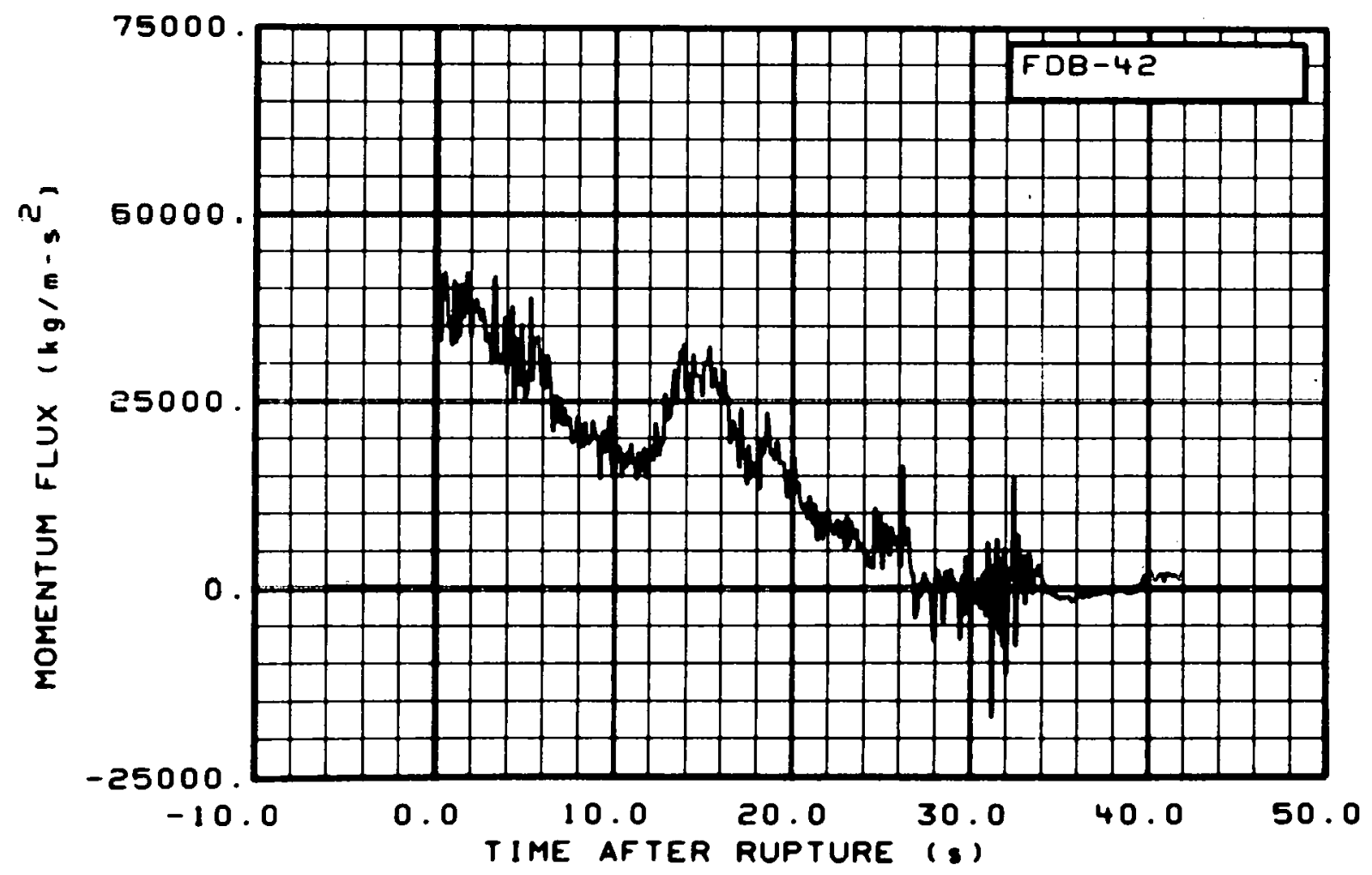

Fig. 286 Momentum flux in broken loop (FDB-42), from -6 to $42 \mathrm{~s}$. 


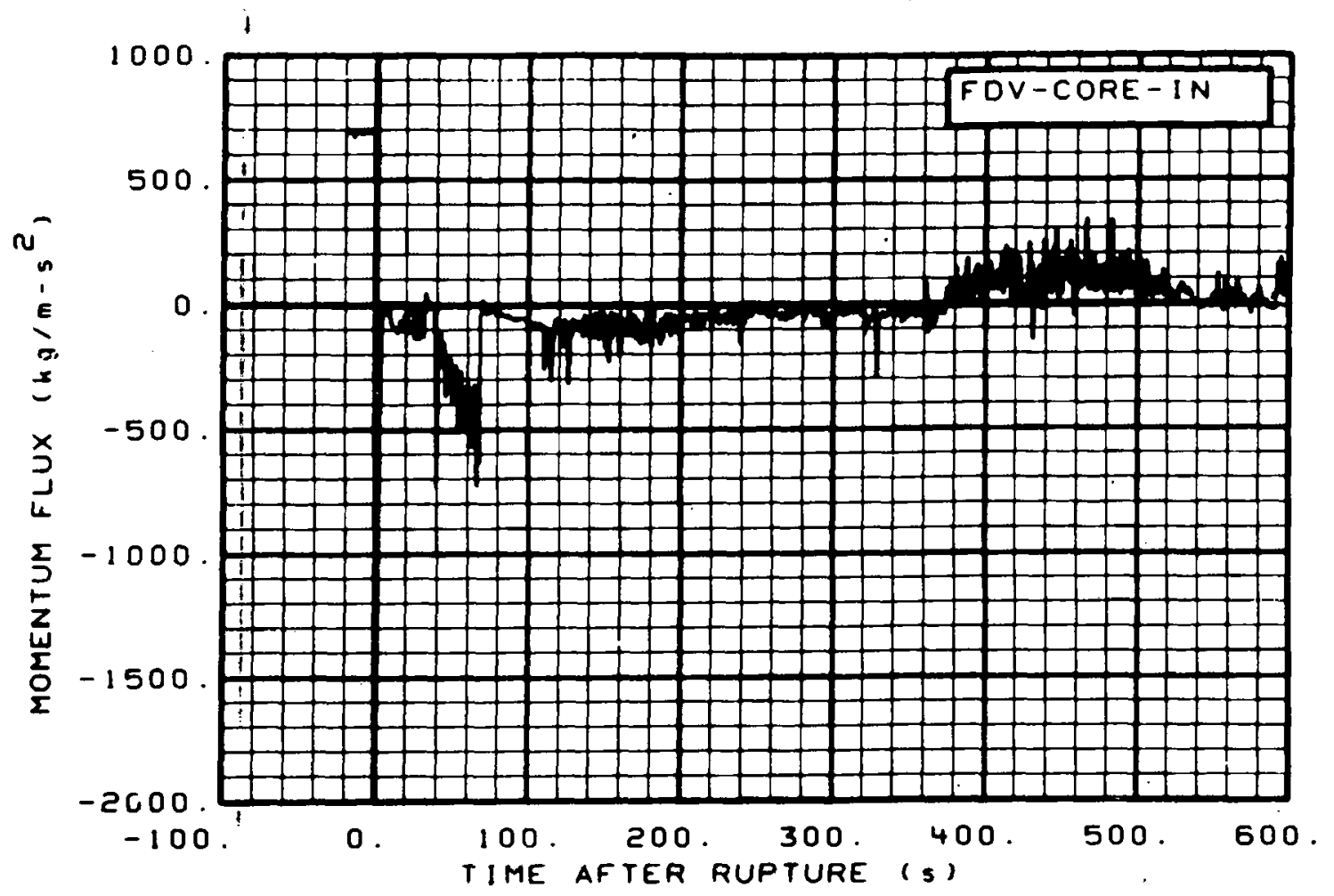

Fig. 287 Momentum flux in core entrance (FDV-CORE-IN), from -20 to $600 \mathrm{~s}$.

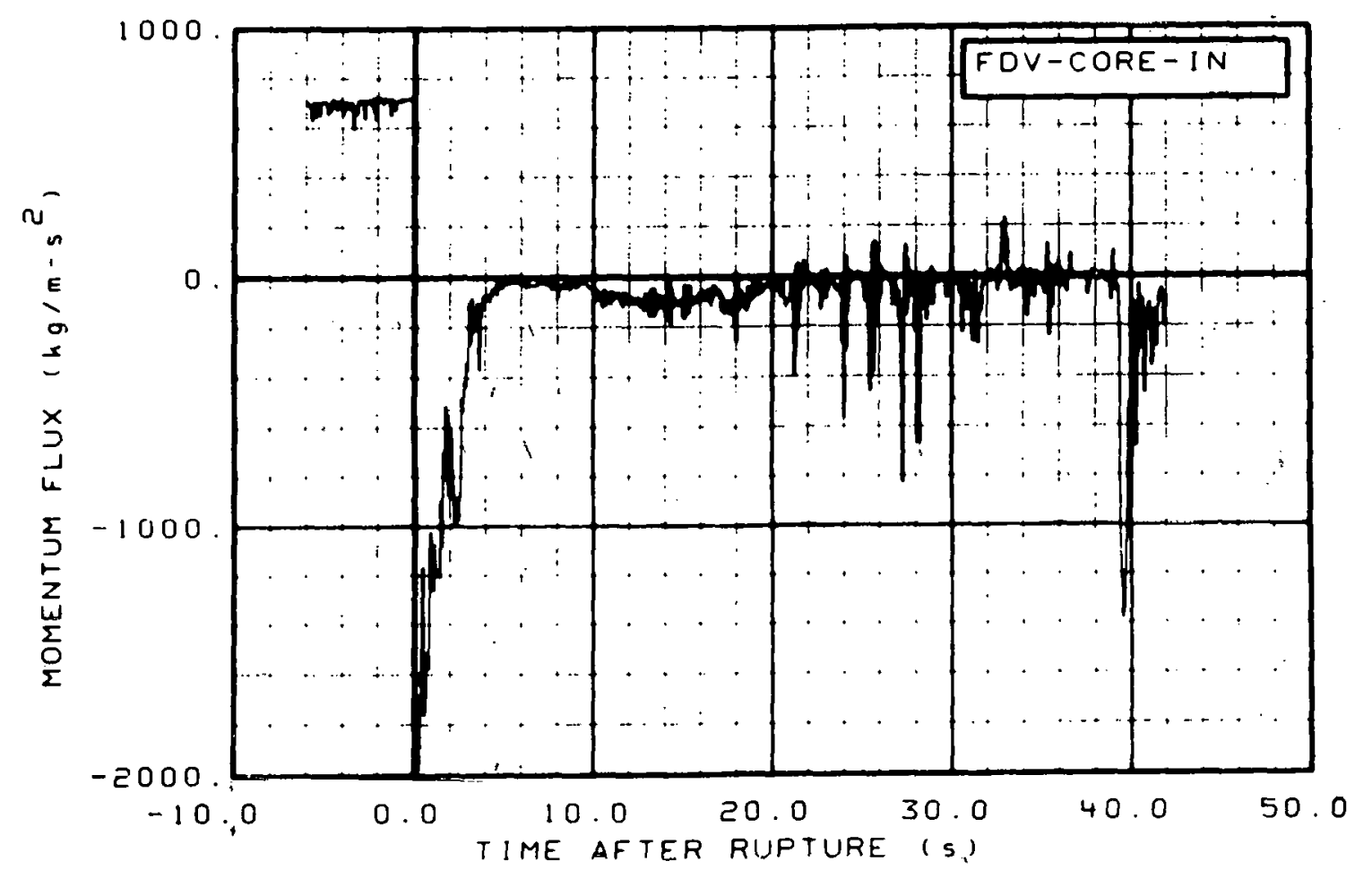

Fig. 288 Momentum flux in core entrance (FDV-CORE-IN), from -6 to $42 \mathrm{~s}$. 


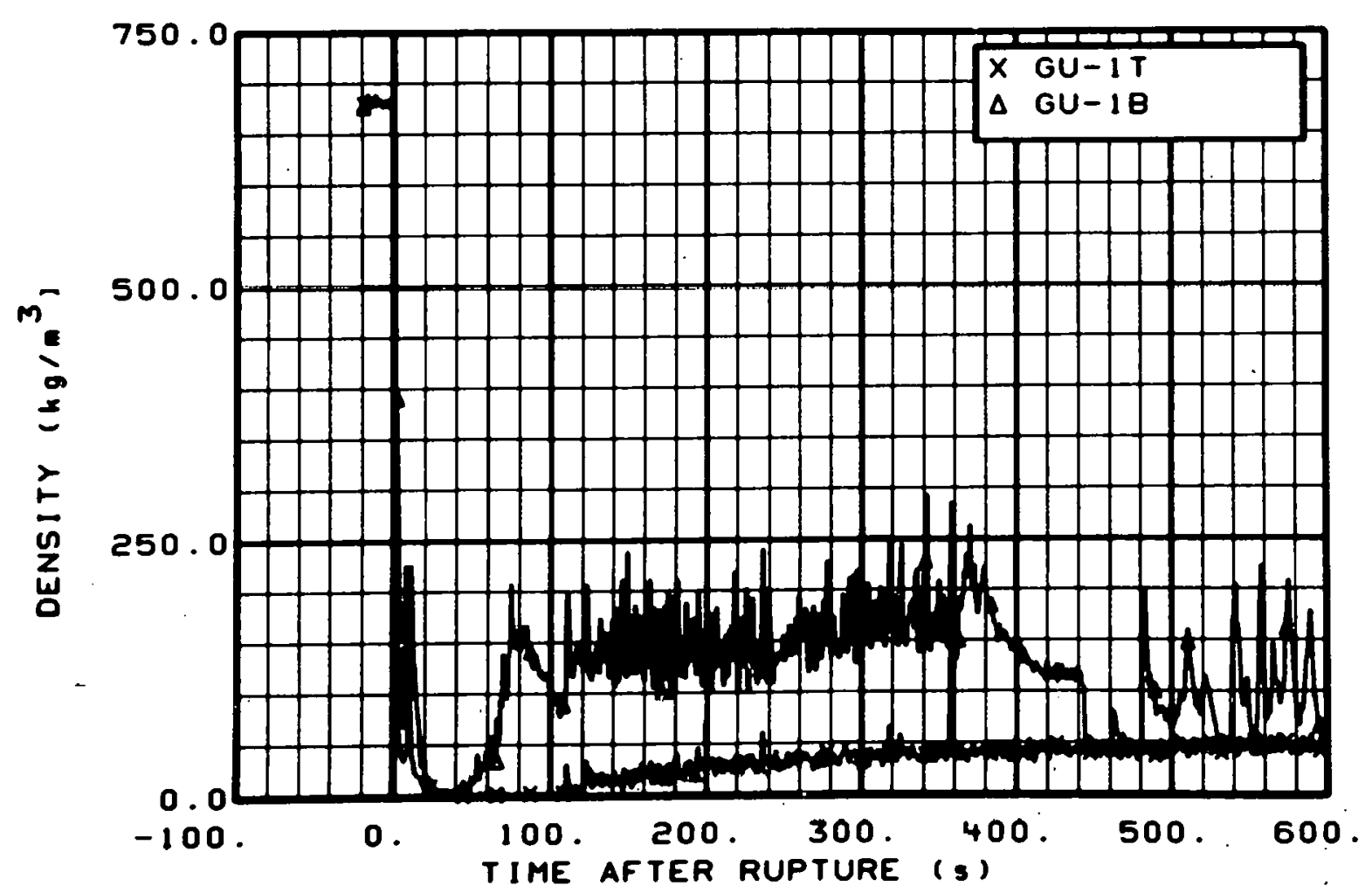

Fig. 289 Density in intact loop (GU-1T and GU-1B), from -20 to $600 \mathrm{~s}$.

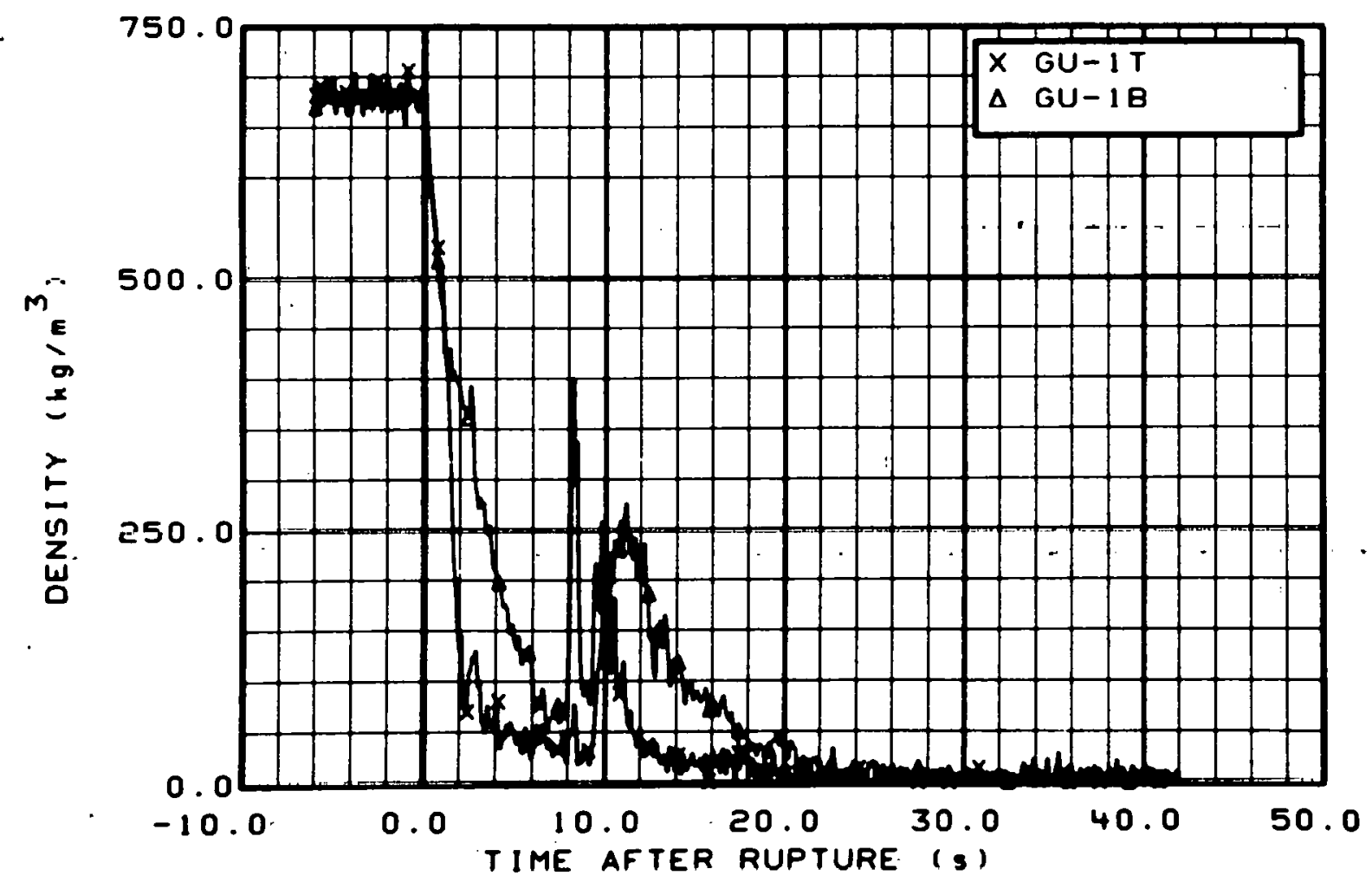

Fig. 290 Density in intact loop (GU-1T and GU-1B), from -6 to $42 \mathrm{~s}$. 


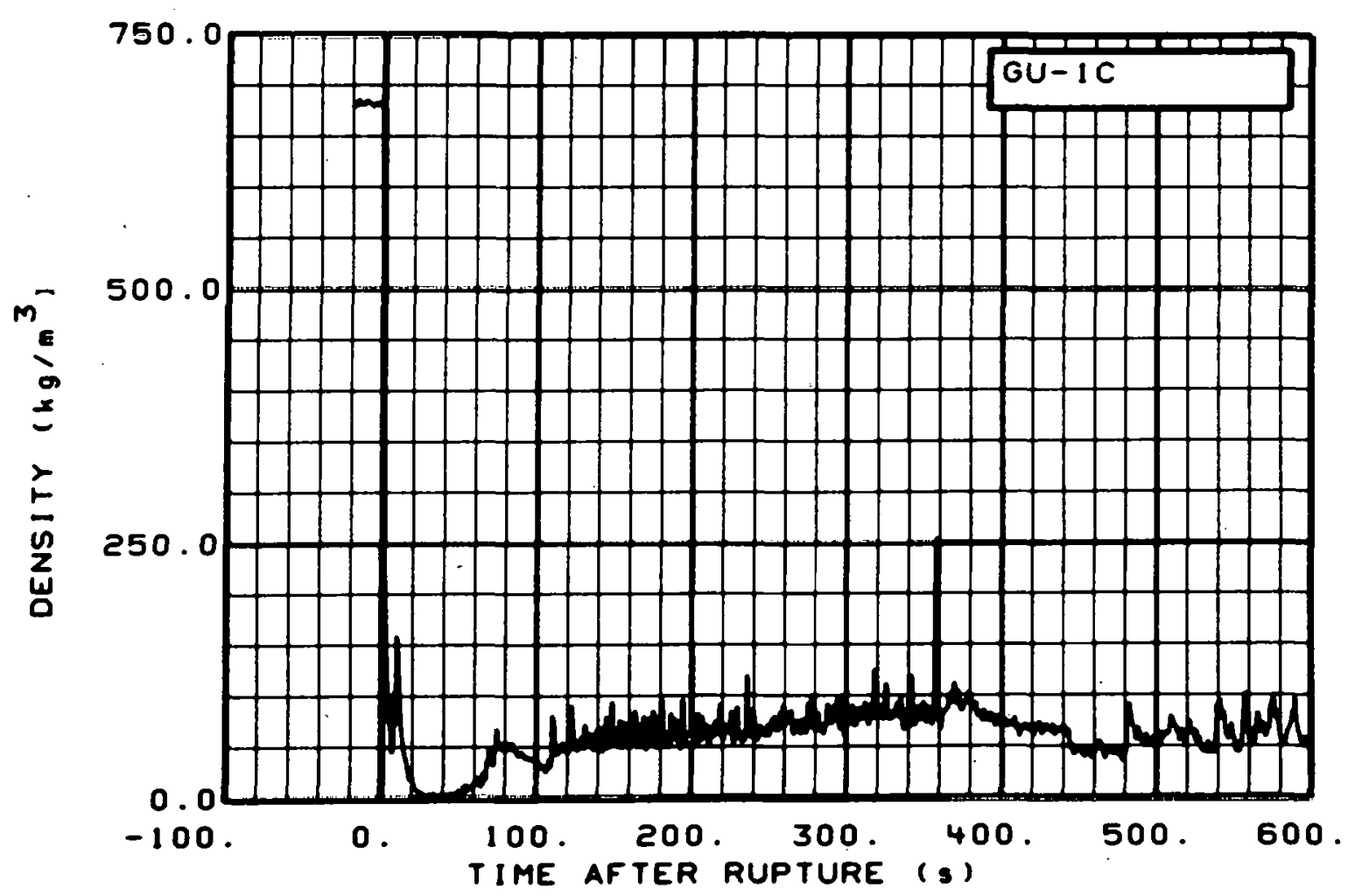

Fig. 291 Density in intact 10op (GU-1C), from -20 to $600 \mathrm{~s}$.

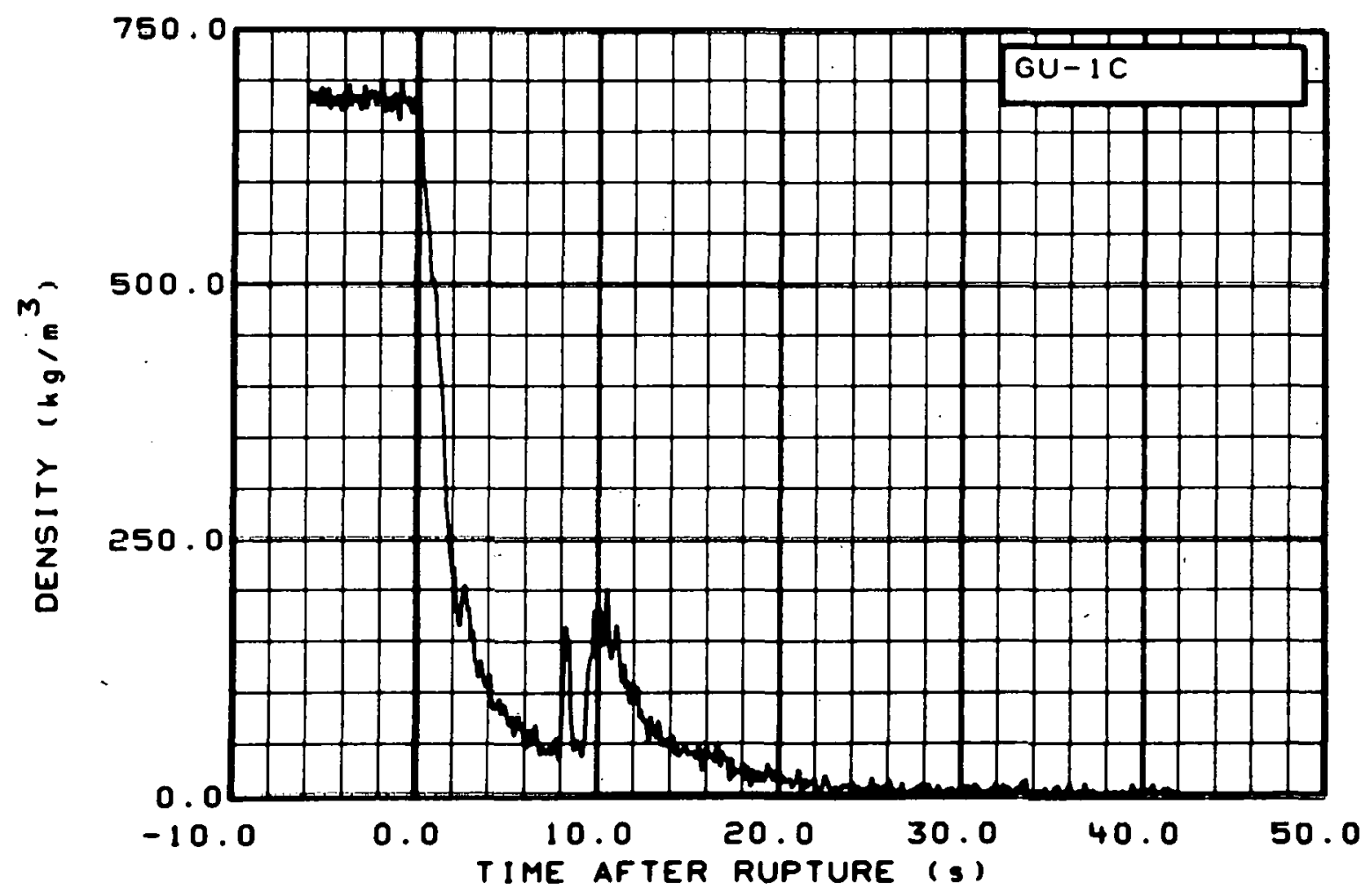

Fig. 292 Density in intact loop (GU-IC), from -6 to $42 \mathrm{~s}$. 


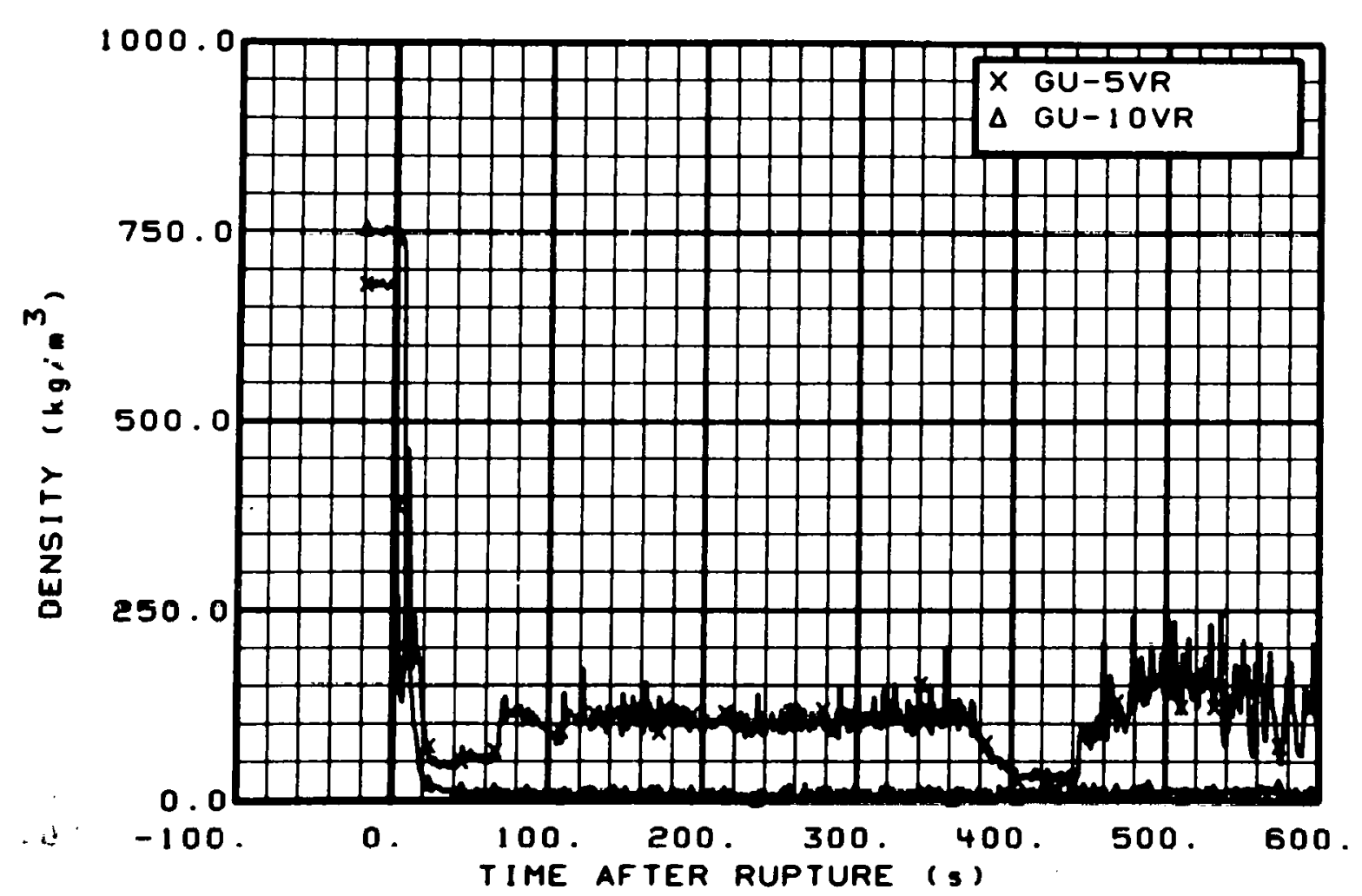

Fig. 293 Density in intact 100p (GU-5VR and GU-10VR), from -20 to $600 \mathrm{~s}$.

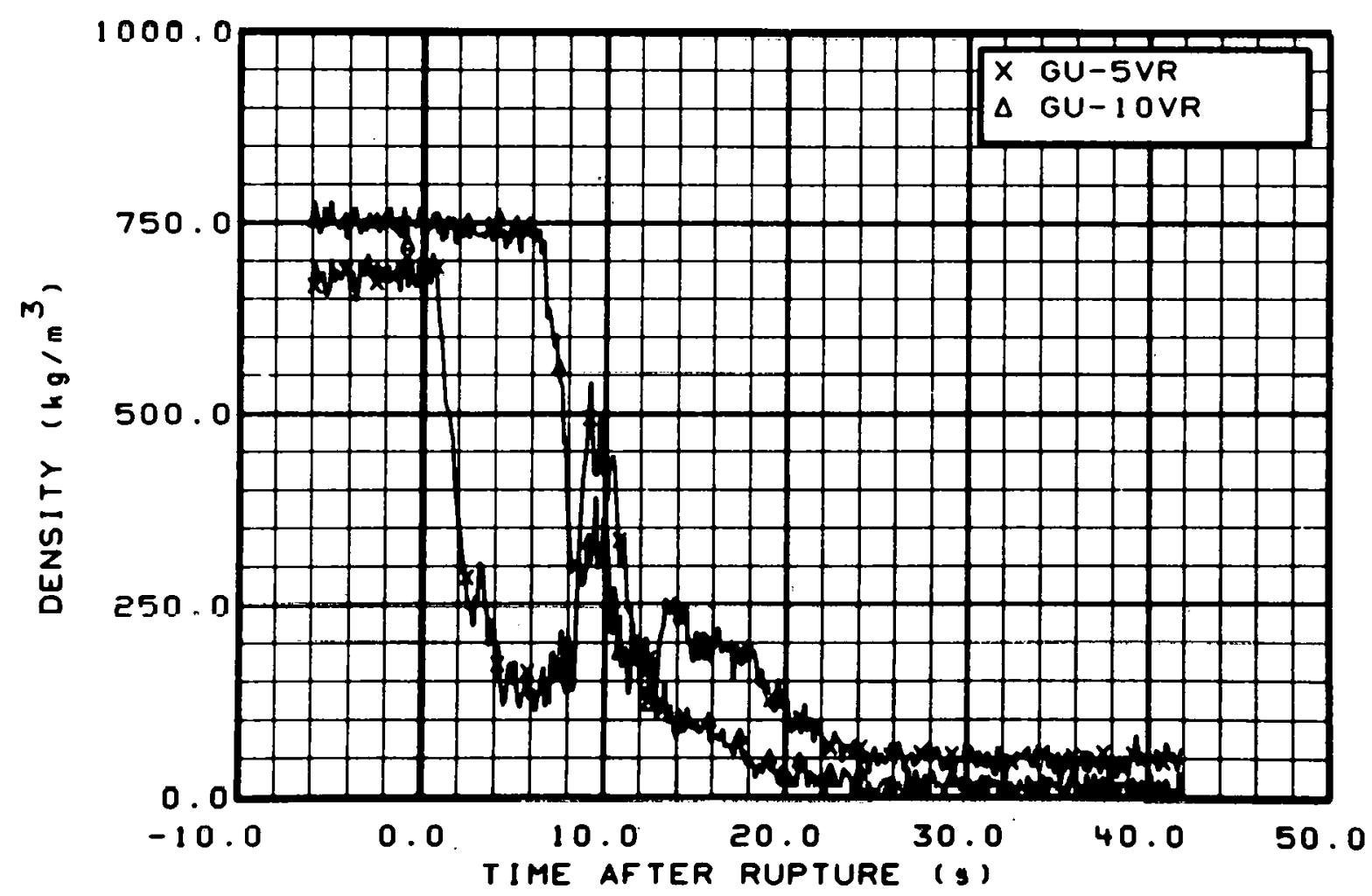

Fig. 294 Density in intact 100p (GU-5VR and GU-10VR), from -6 to $42 \mathrm{~s}$. 


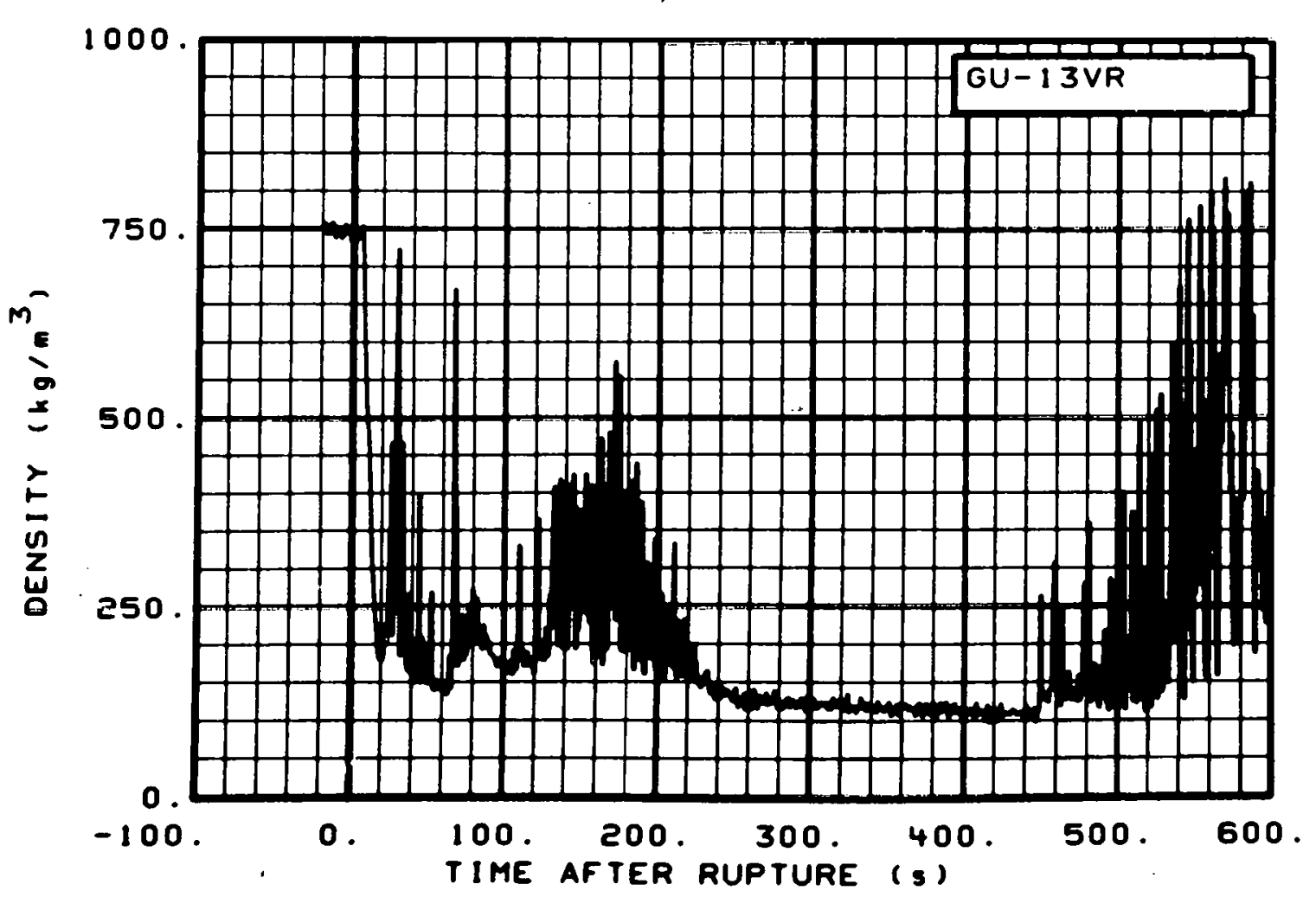

Fig. 295 Density in intact loop (GU-13VR), from -20 to $600 \mathrm{~s}$.

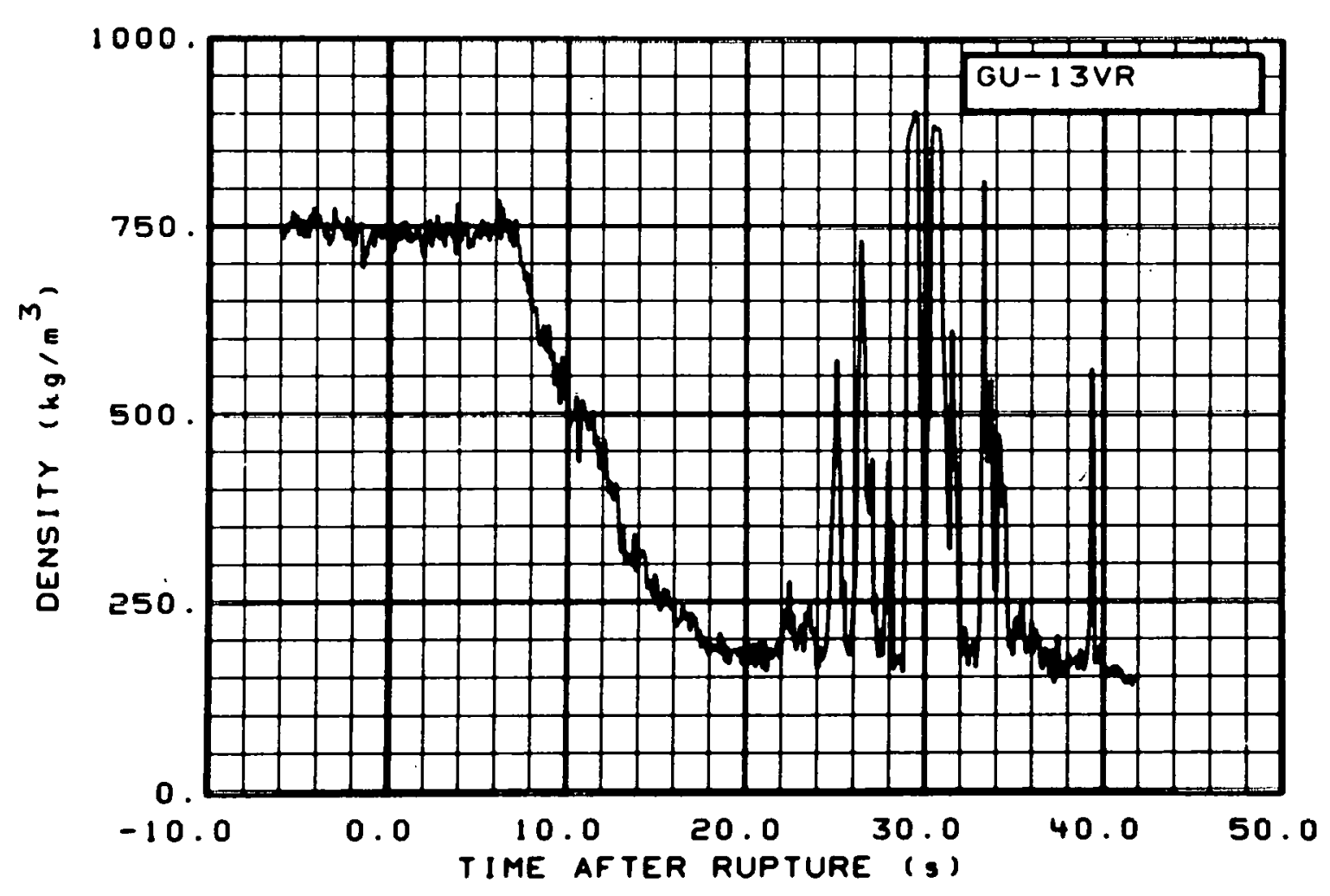

Fig. 296 Density in intact loop (GU-13VR), from -6 to $42 \mathrm{~s}$. 


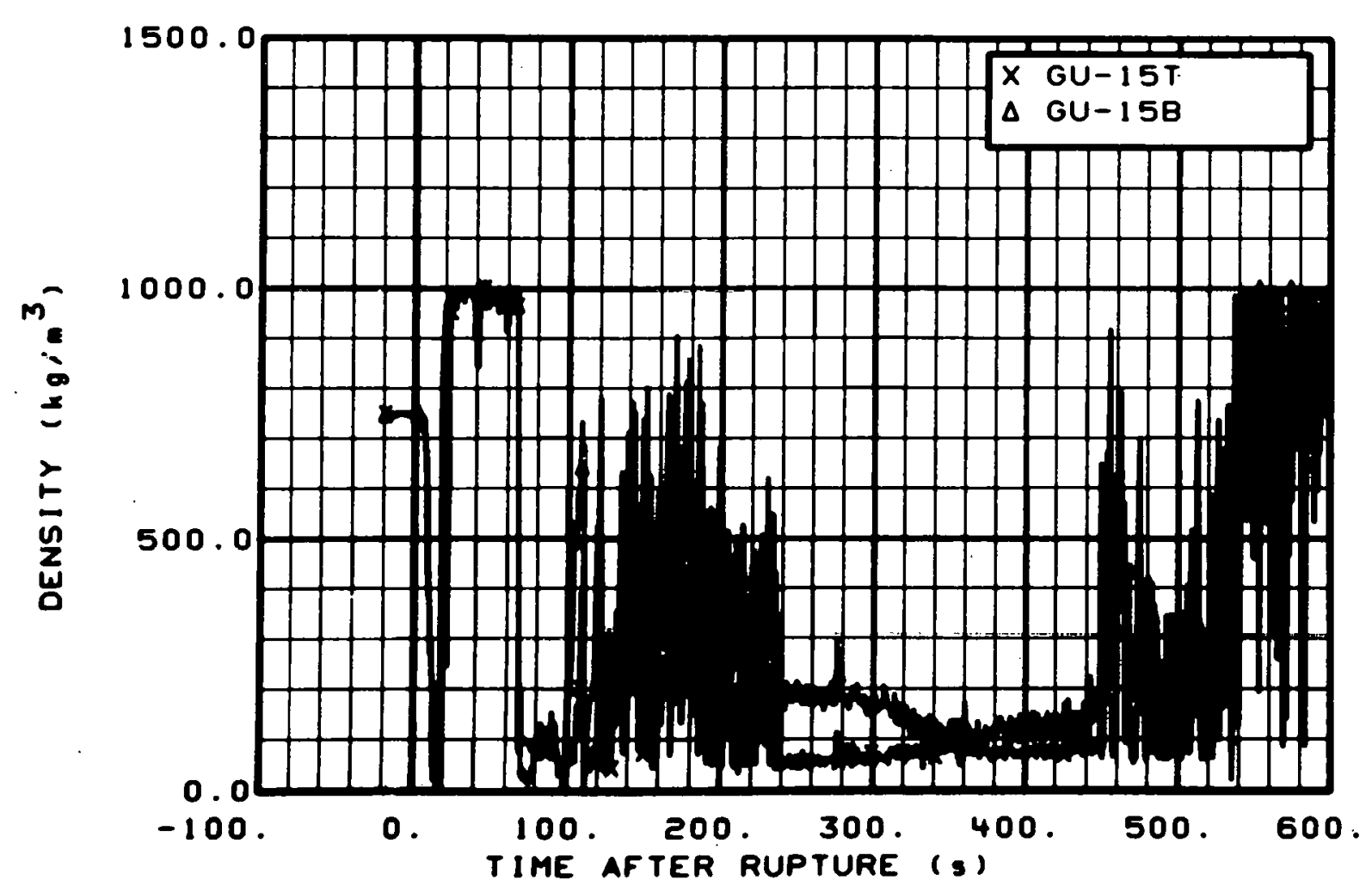

Fig. 297 Density in intact 10op (GU-15T and GU-15B), from -20 to $600 \mathrm{~s}$.

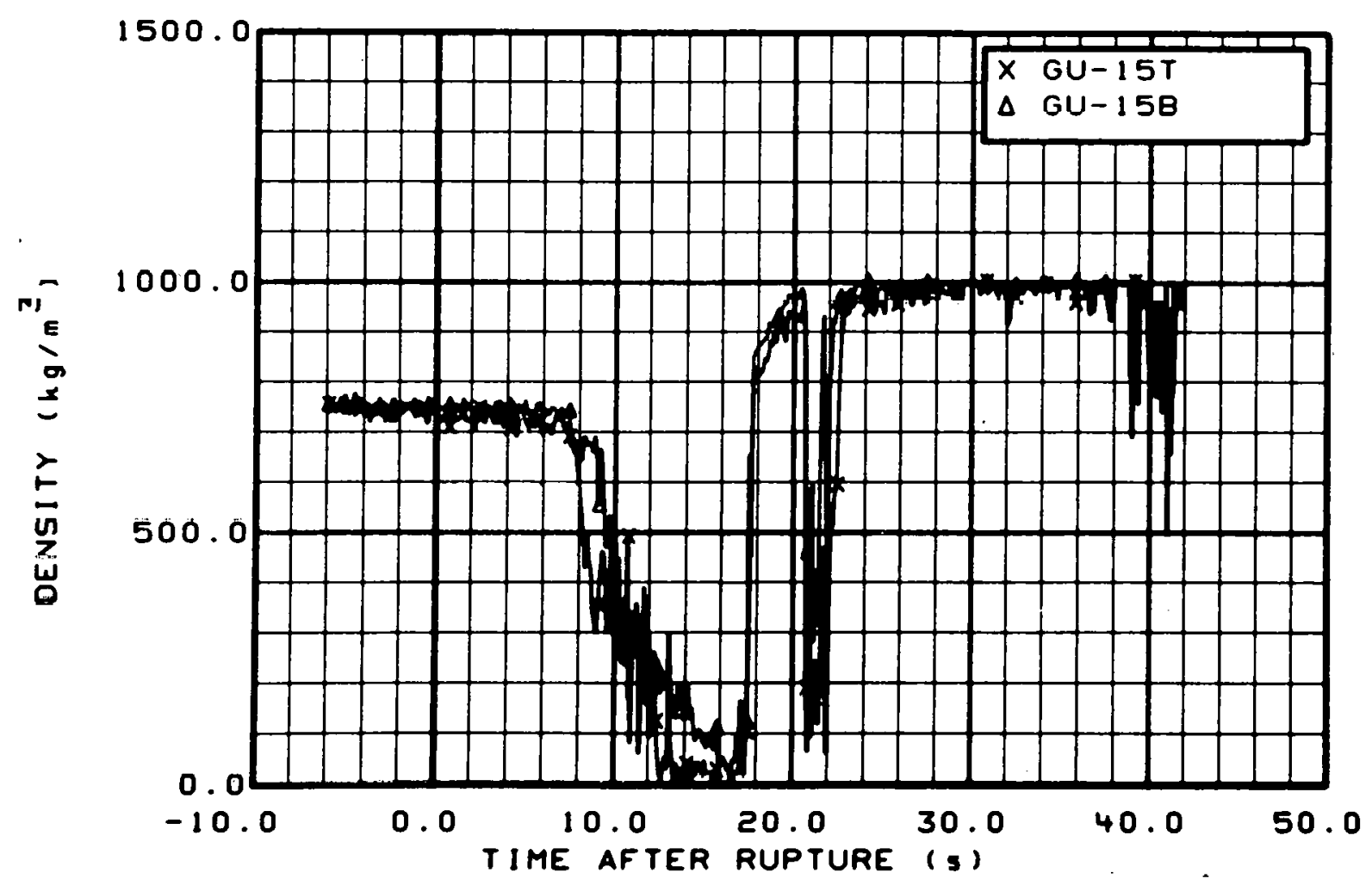

Fig. 298 Density in intact 10op (GU-15T and GU-15B), from -6 to $42 \mathrm{~s}$. 


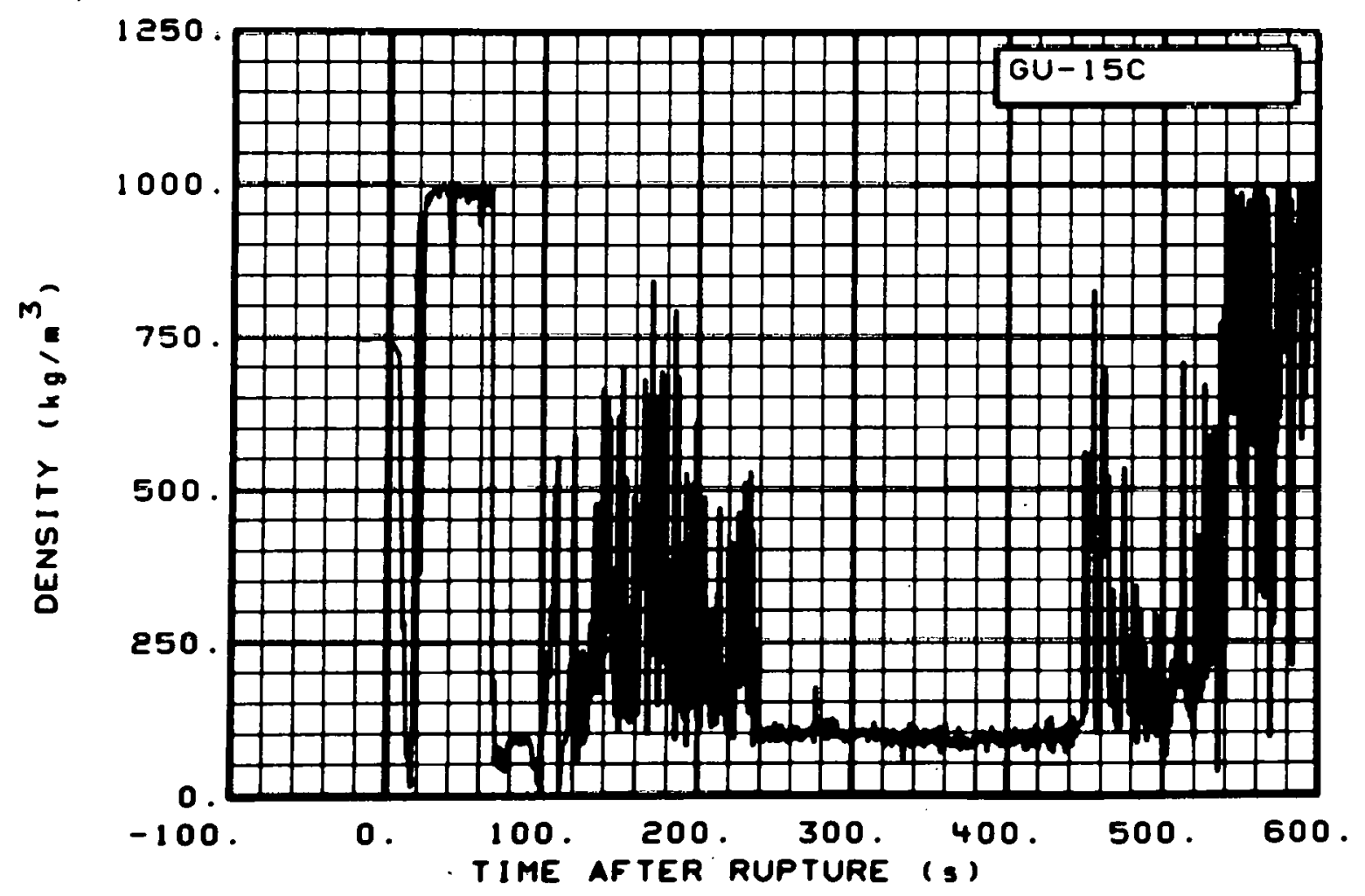

Fig. 299 Density in intact loop (GU-15C), from -20 to $600 \mathrm{~s}$.

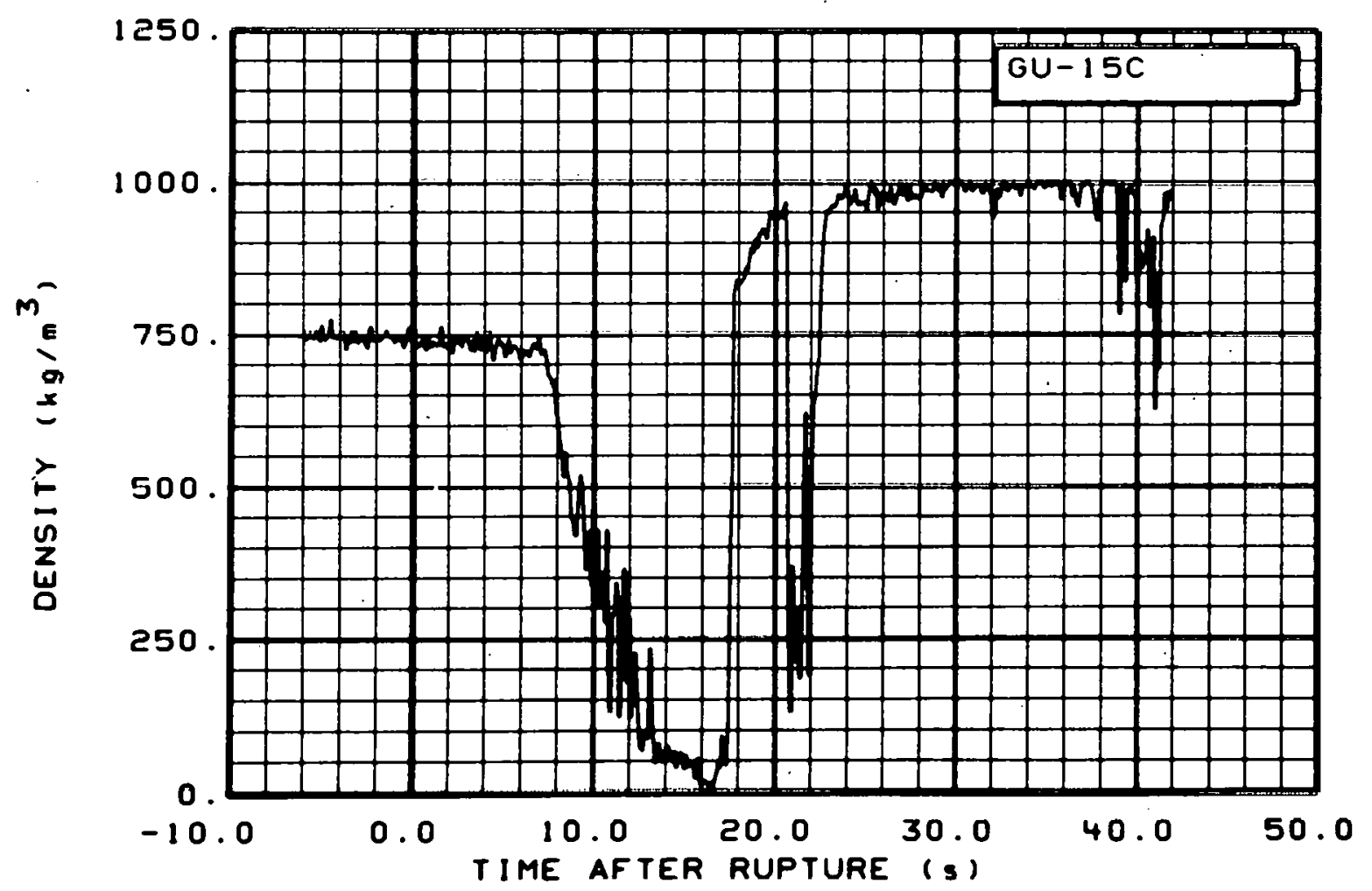

Fig. 300 Density in intact loop (GU-15C), from -6 to $42 \mathrm{~s}$. 


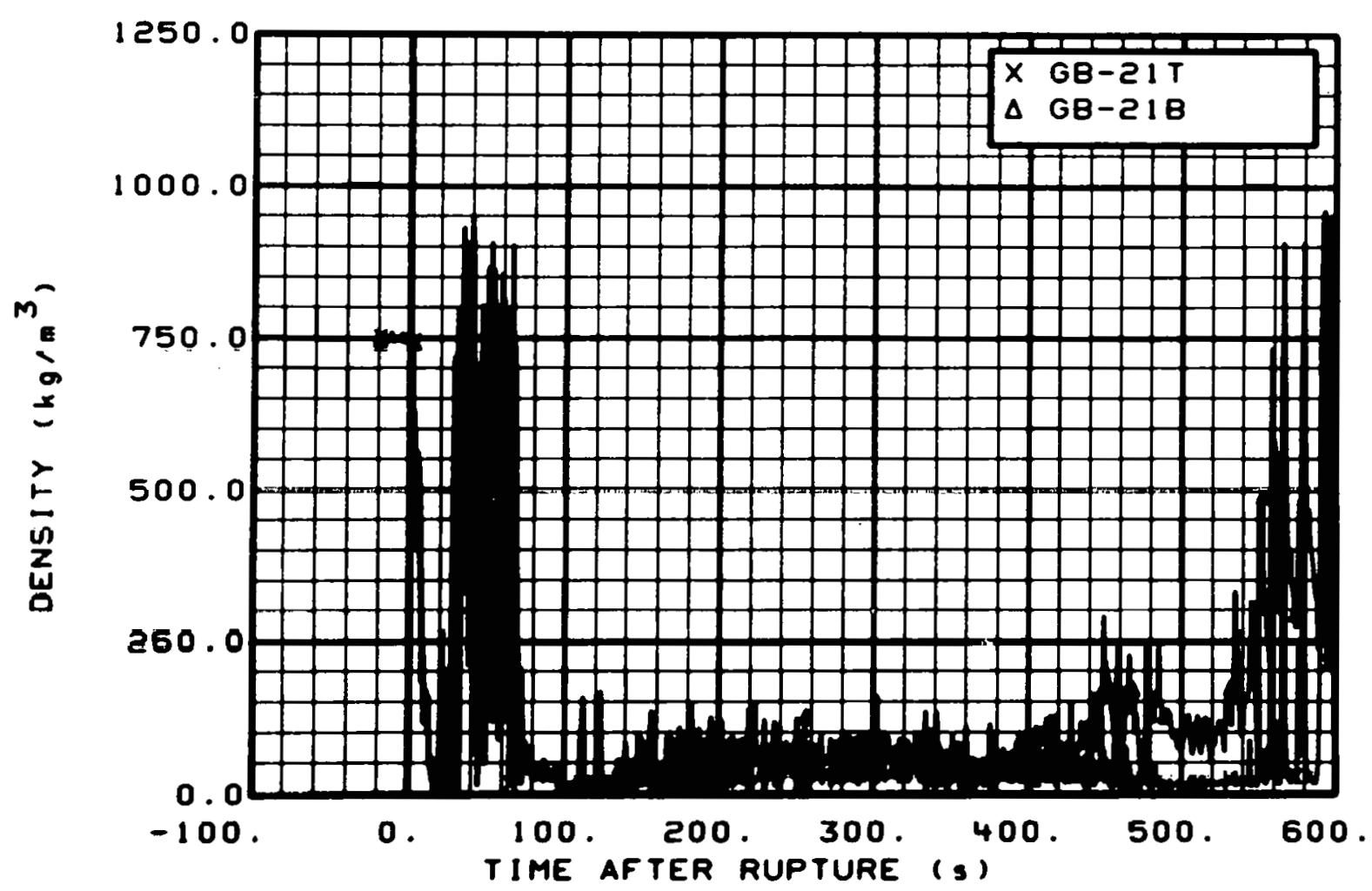

Fig. 301 Density in broken loop (GB-21T and GB-21B), from -20 to $600 \mathrm{~s}$.

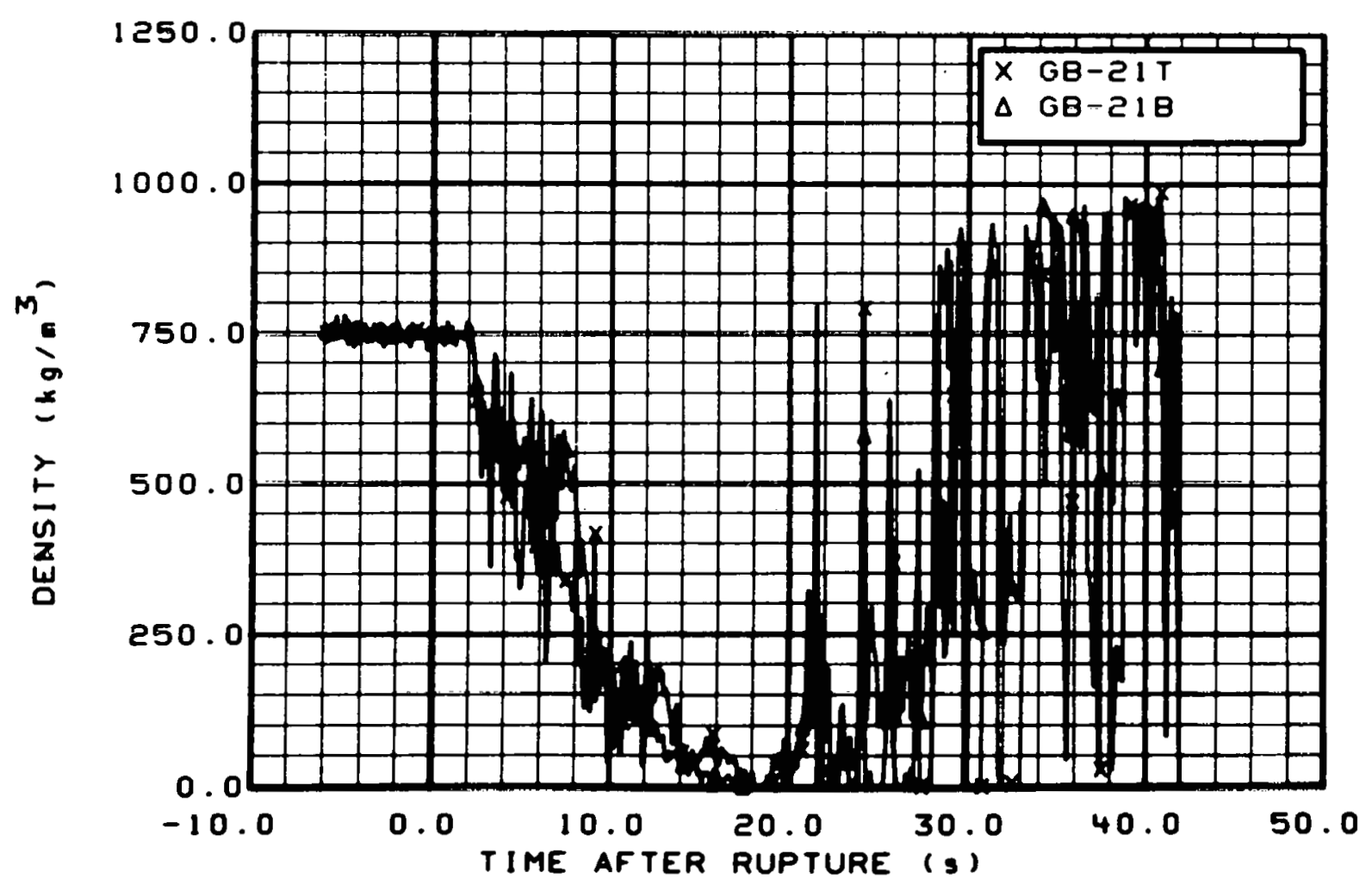

Fig. 302 Density in broken loop (GB-21T and GB-21B), from -6 to $42 \mathrm{~s}$. 


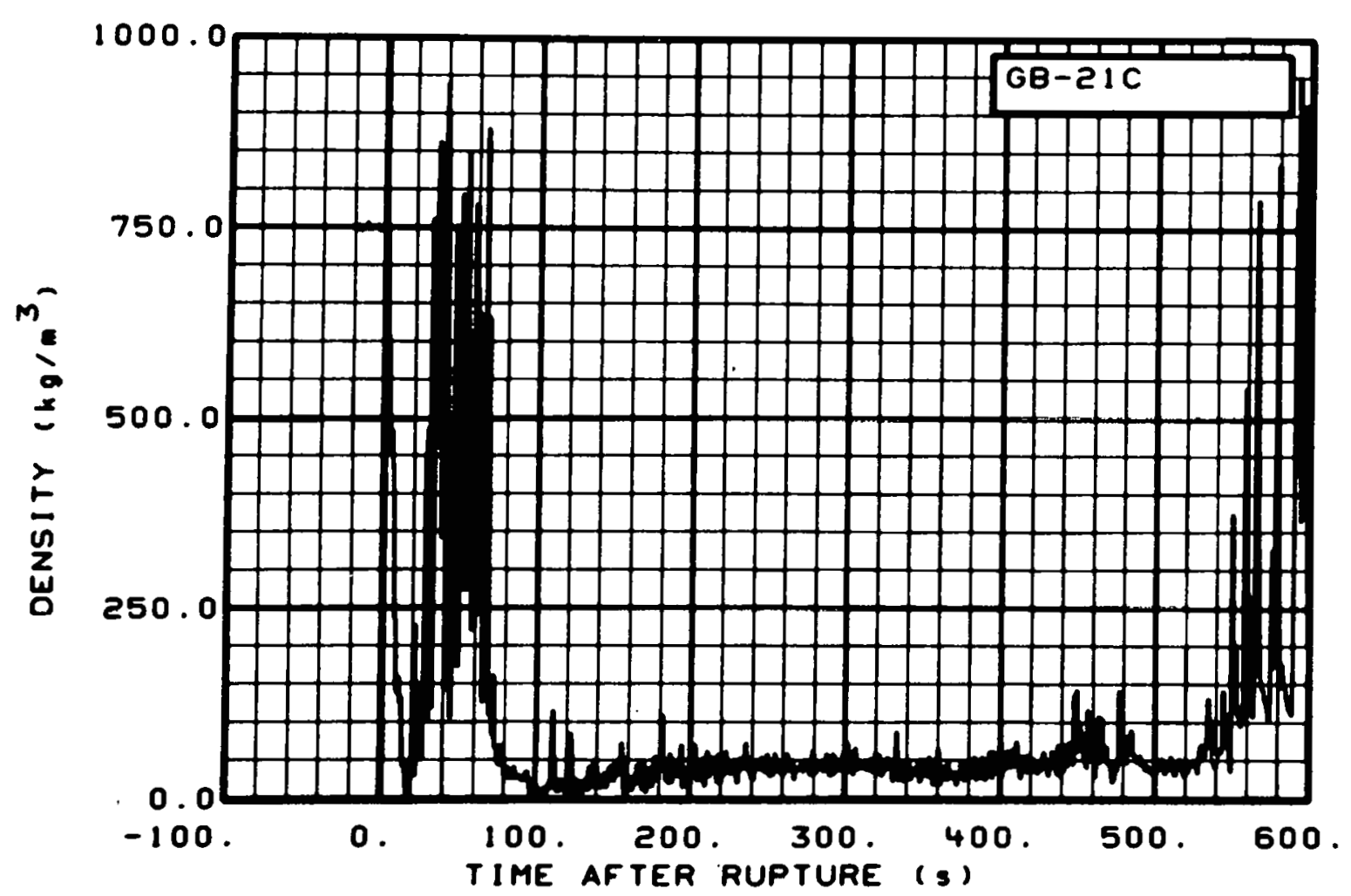

Fig. 303 Density in broken loop (GB-21C), from -20 to $600 \mathrm{~s}$.

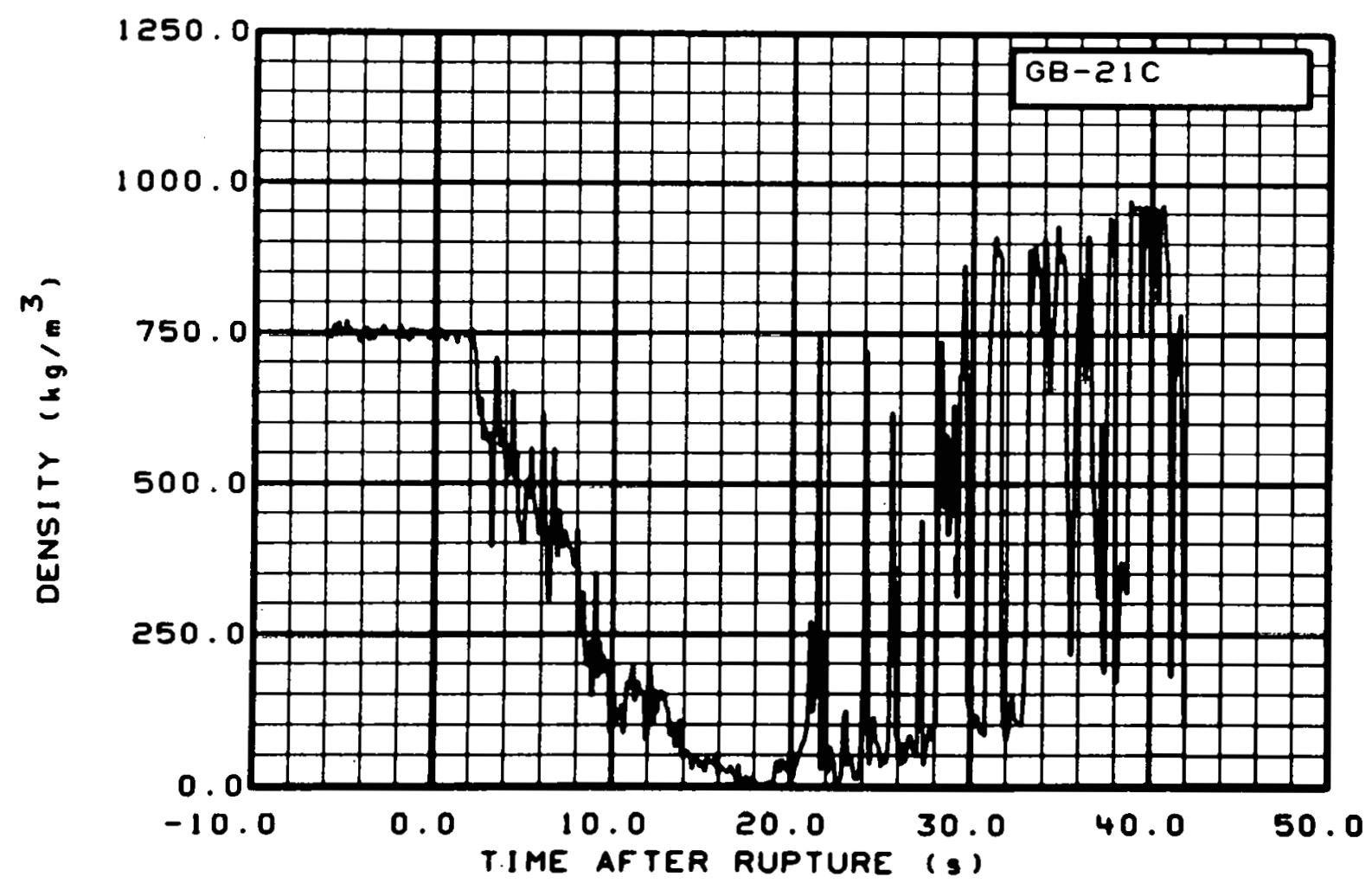

Fig. 304 Density in broken 1onp (GR-21C), from -6 t. 4 ? $s$. 


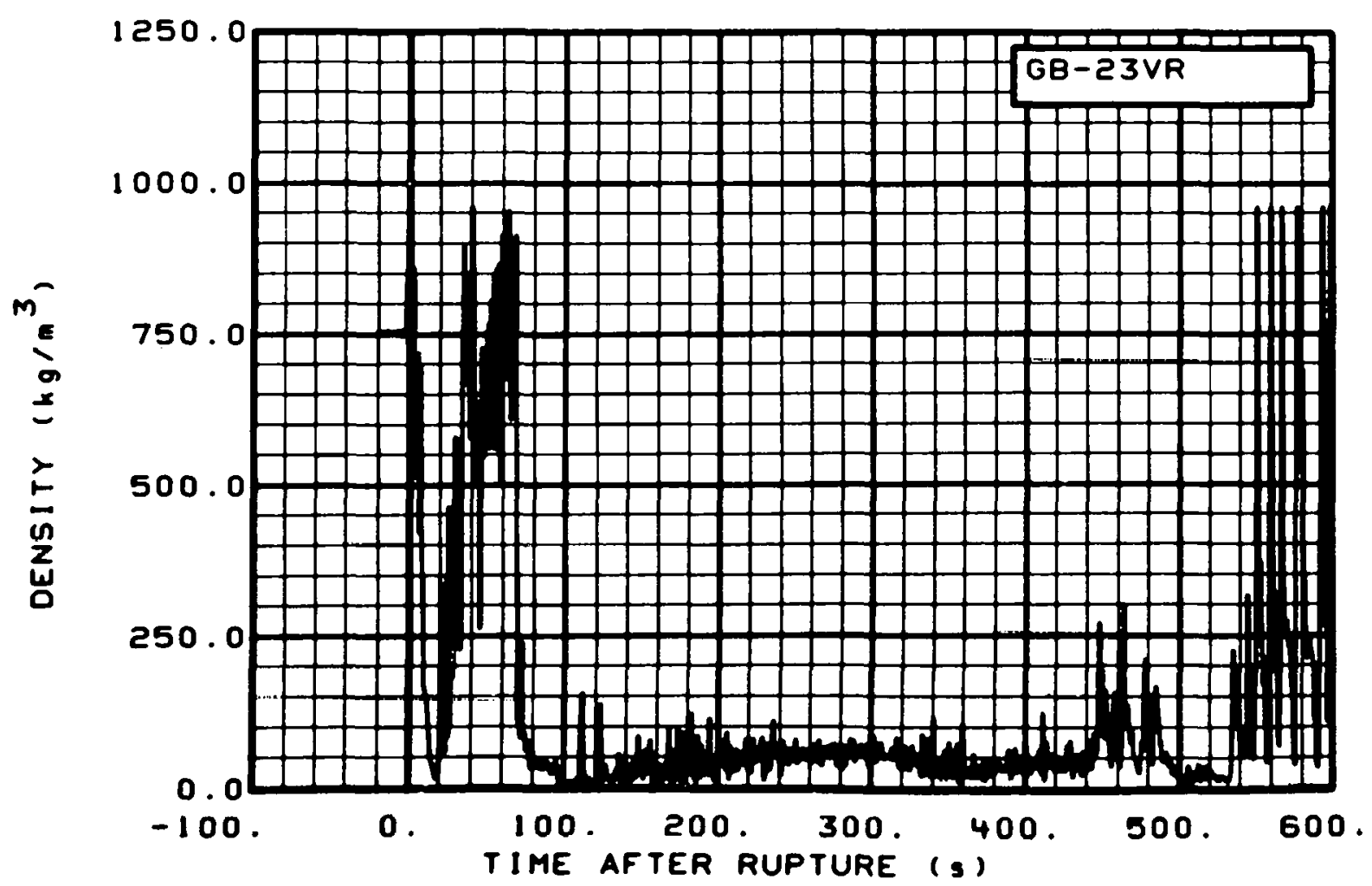

Fig. 305 Density in broken loop (GB-23VR), from -20 to $600 \mathrm{~s}$.

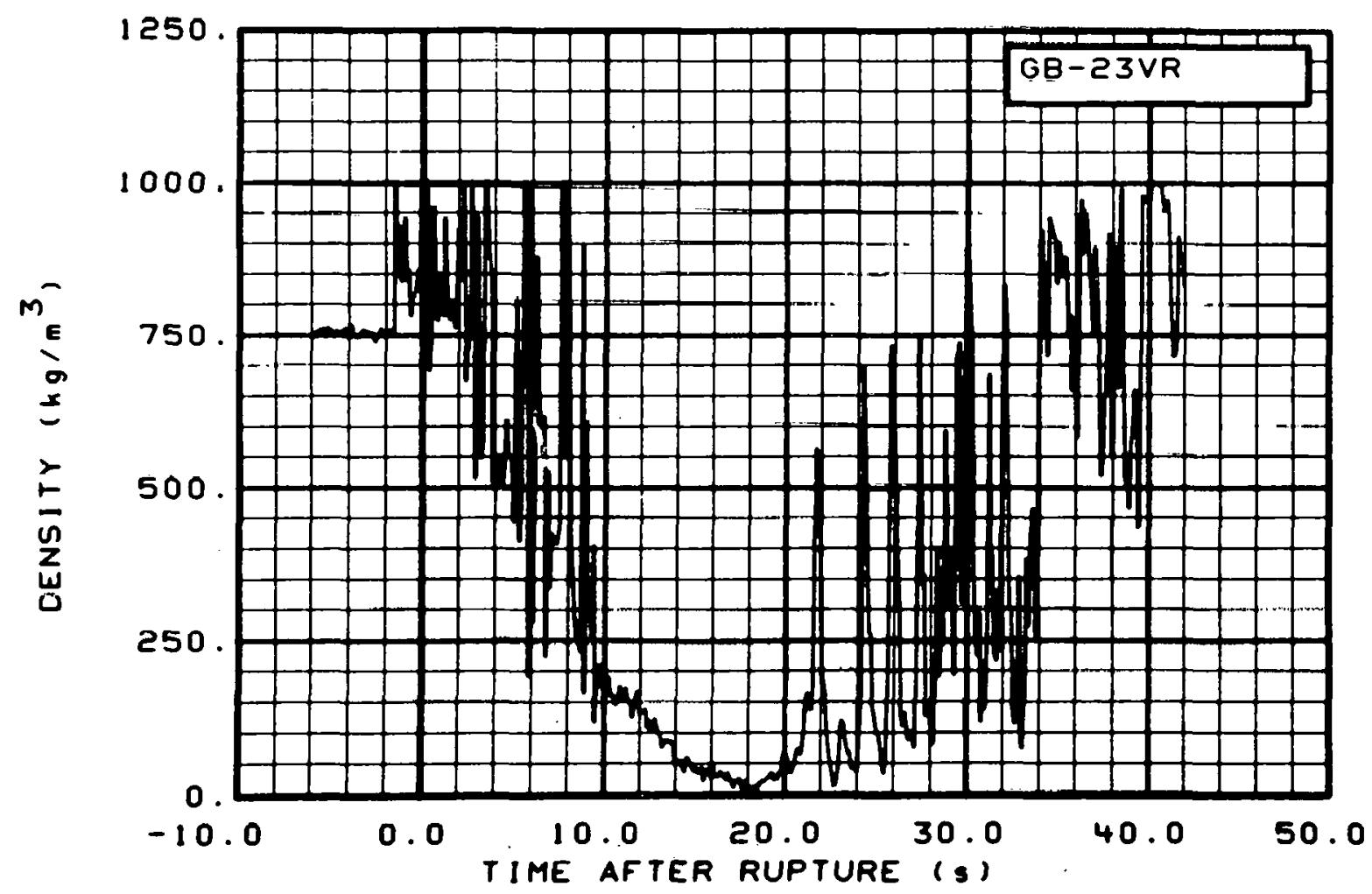

Fig. 306 Density in broken loop (GB-23VR), from -6 to $42 \mathrm{~s}$. 


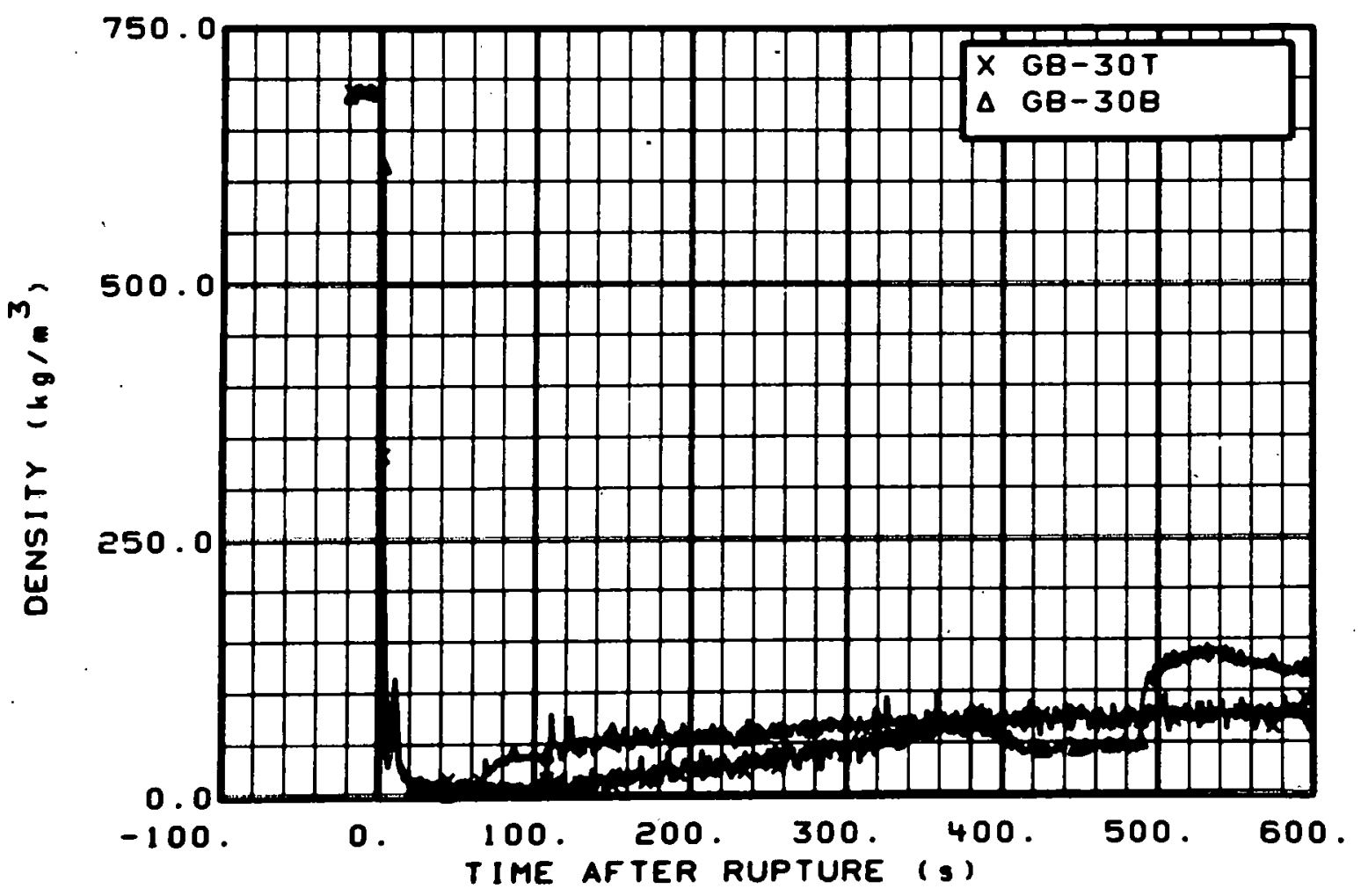

Fig. 307 Density in broken loop (GB-30T and GB-30B), from -20 to $600 \mathrm{~s}$.

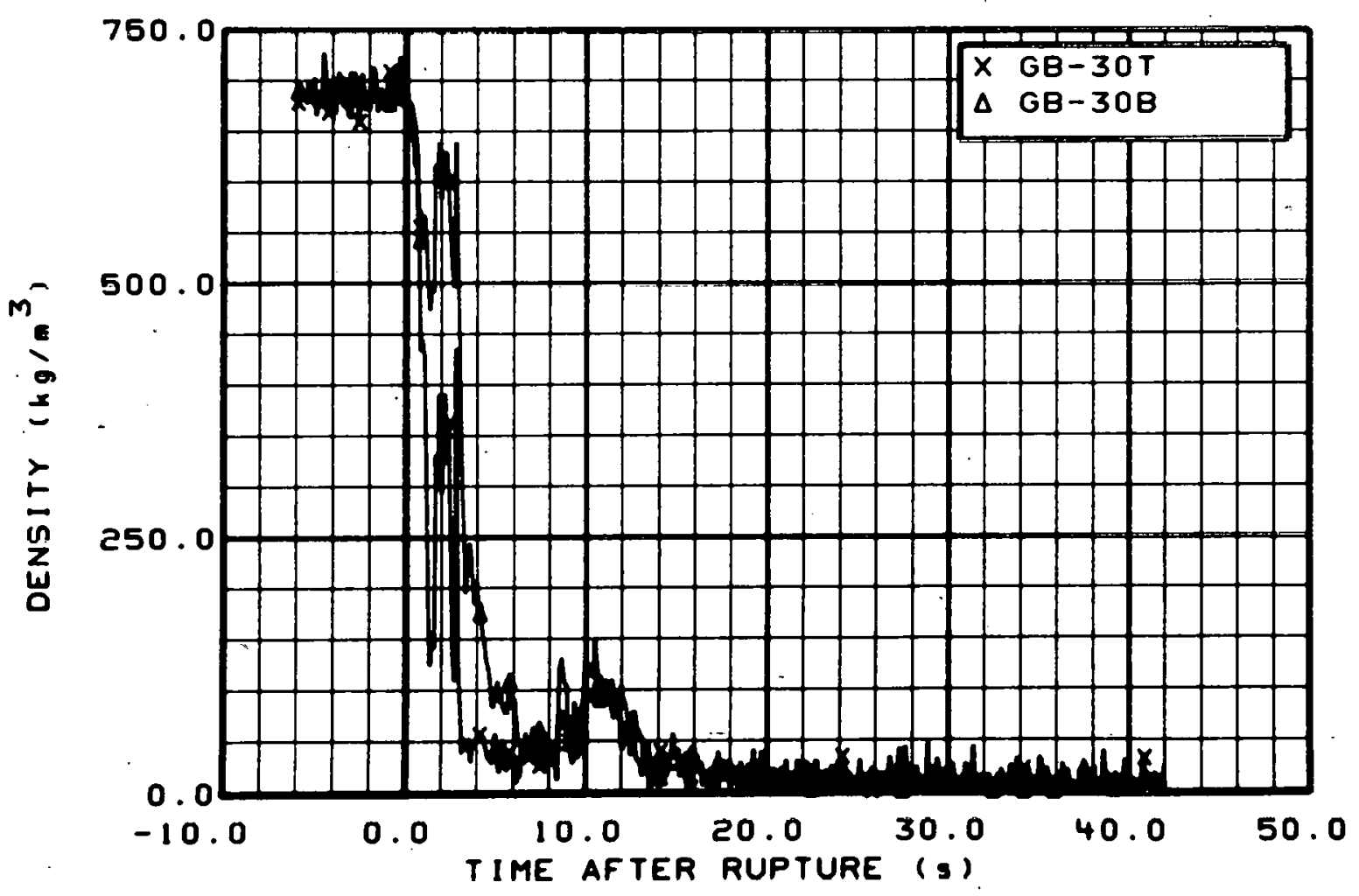

Fig. 308 Density in broken 10op (GB-30T and GB-30B), from -6 to $42 \mathrm{~s}$. 


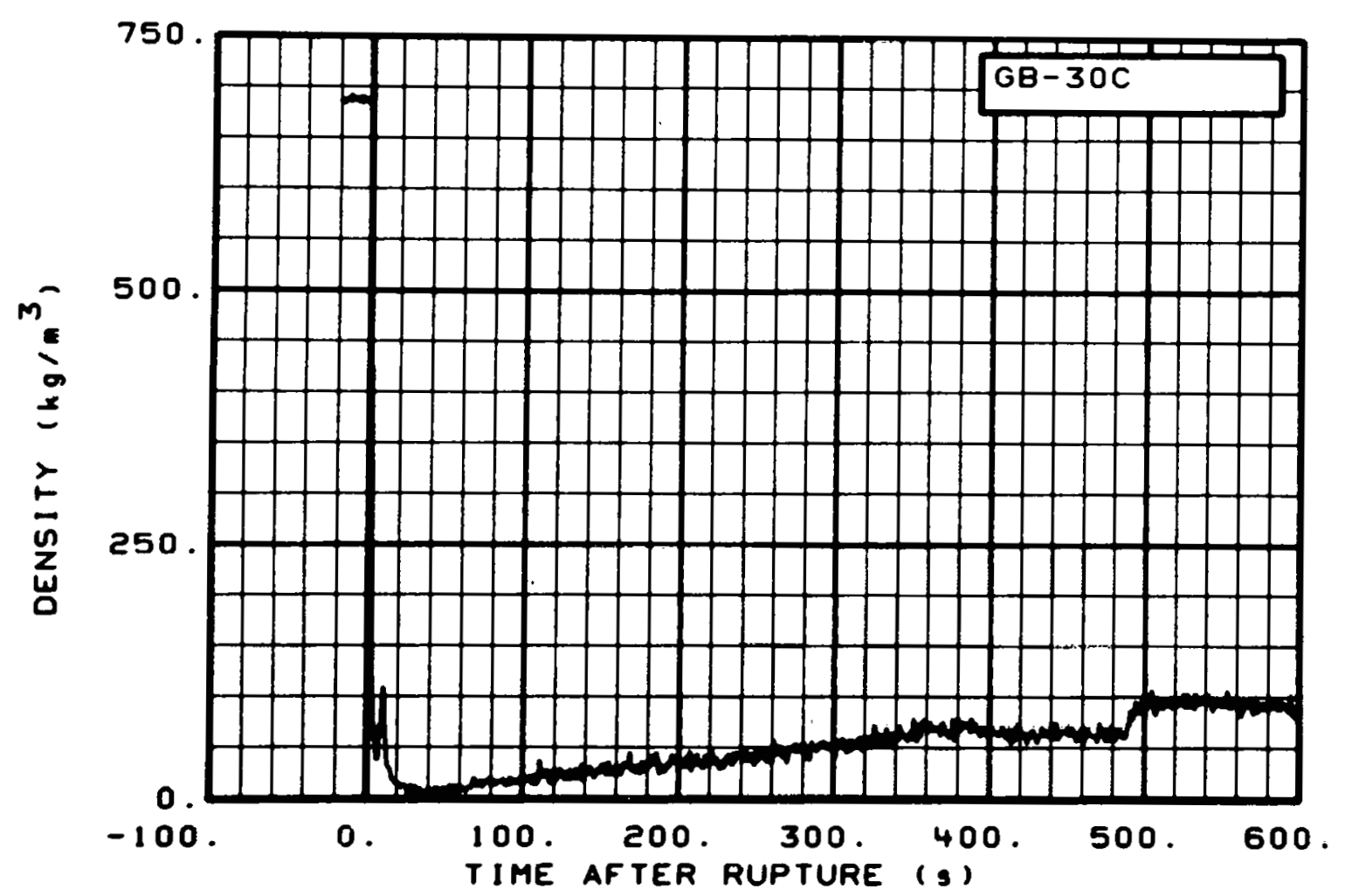

Fig. 309 Density in broken loop (GB-30C), from -20 to $600 \mathrm{~s}$.

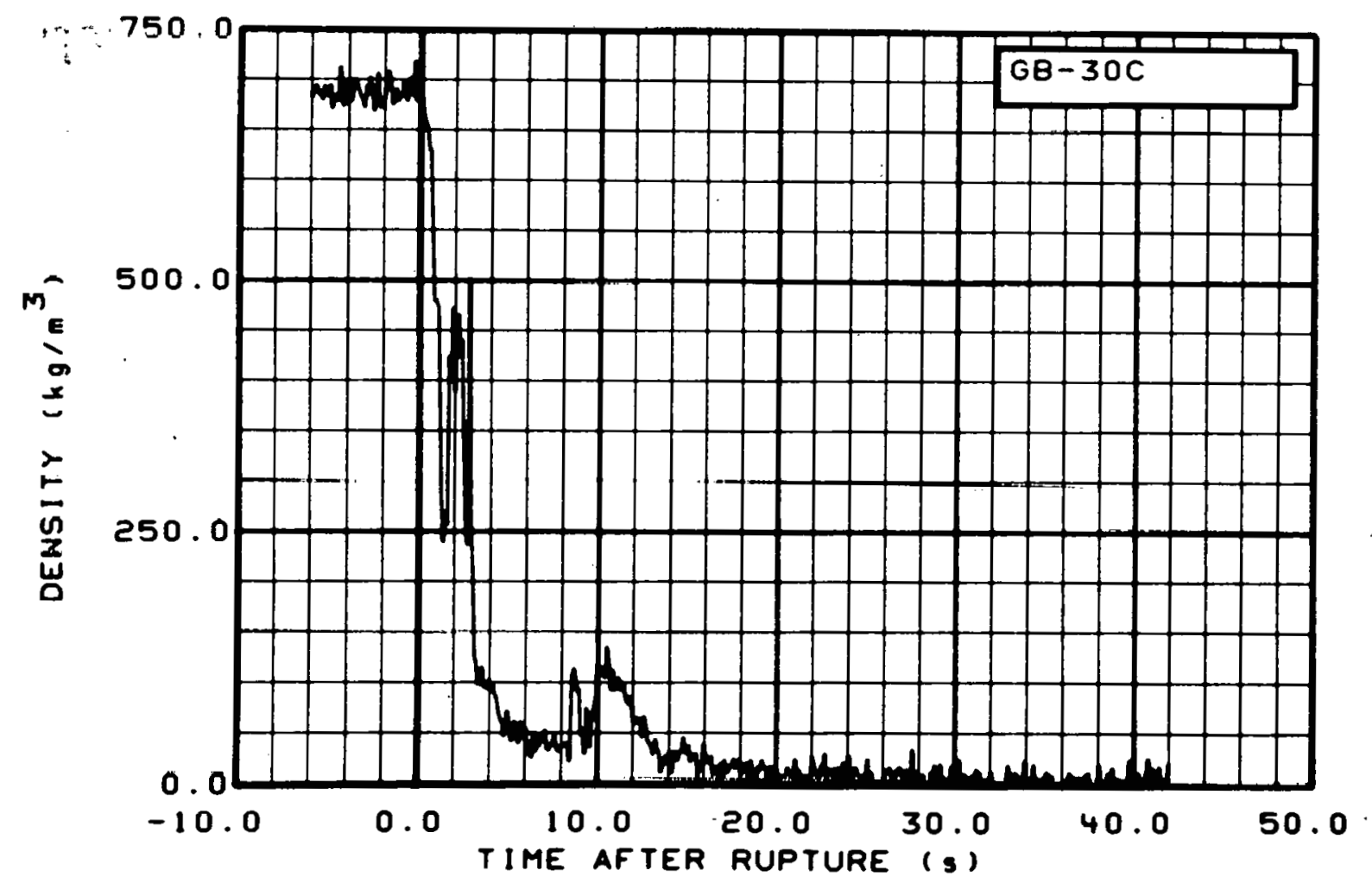

Fig. 310 Density in broken loop (GB-30C), from -6 to $42 \mathrm{~s}$. 


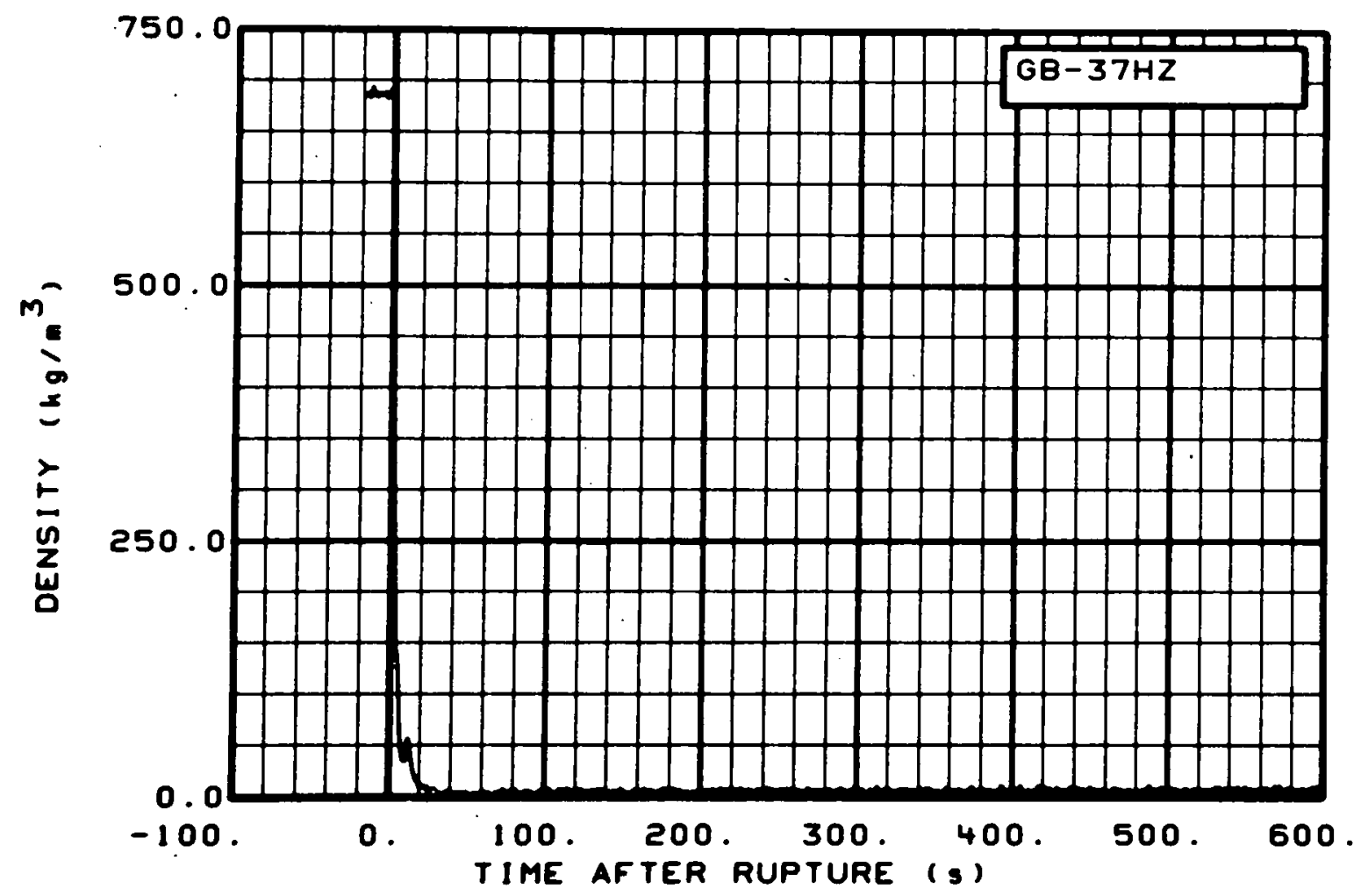

Fig. 311 Density in broken loop (GB-37HZ), from -20 to $600 \mathrm{~s}$.

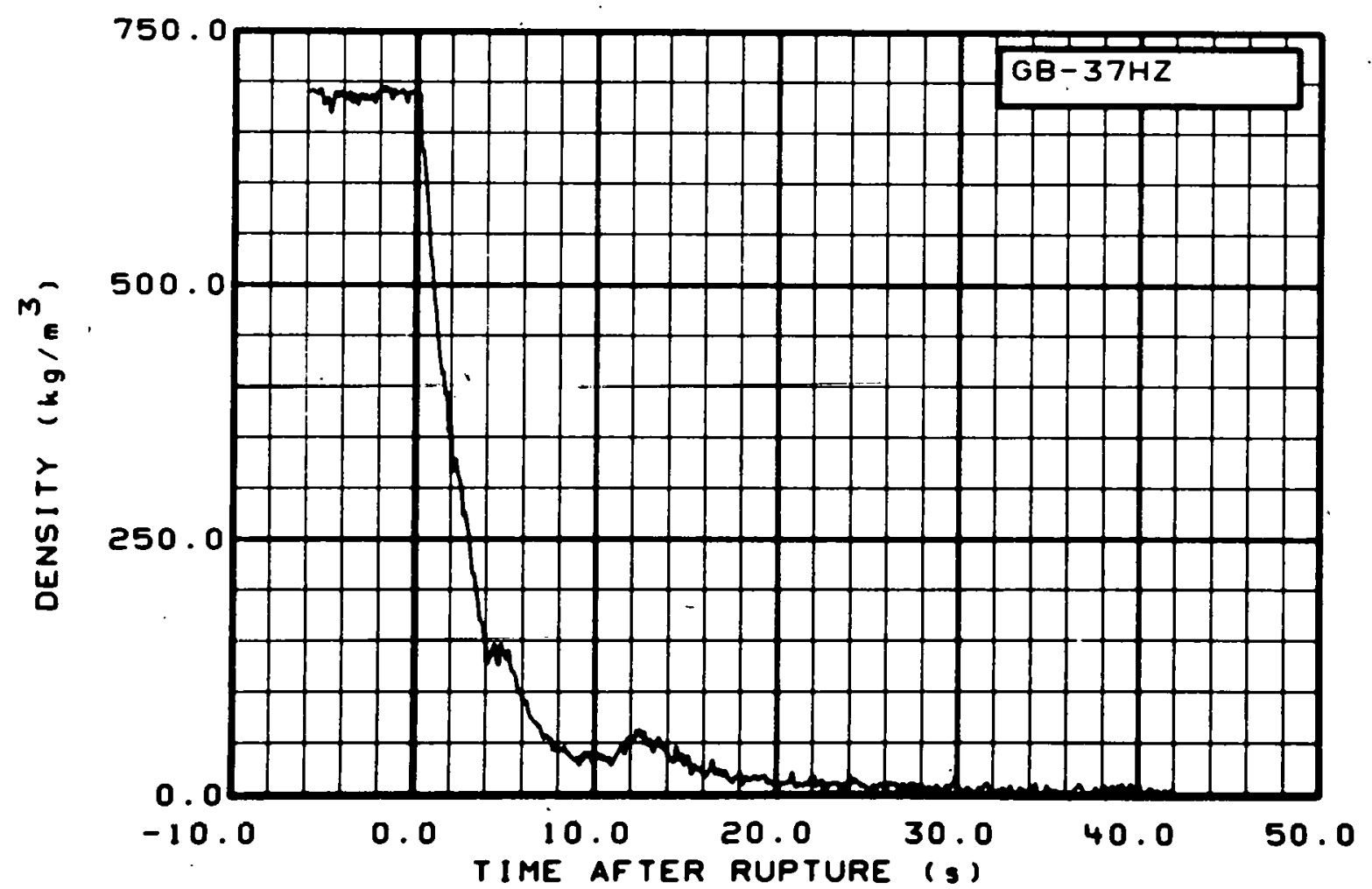

Fig. 312 Density in broken loop (GB-37HZ), from -6 to $42 \mathrm{~s}$. 


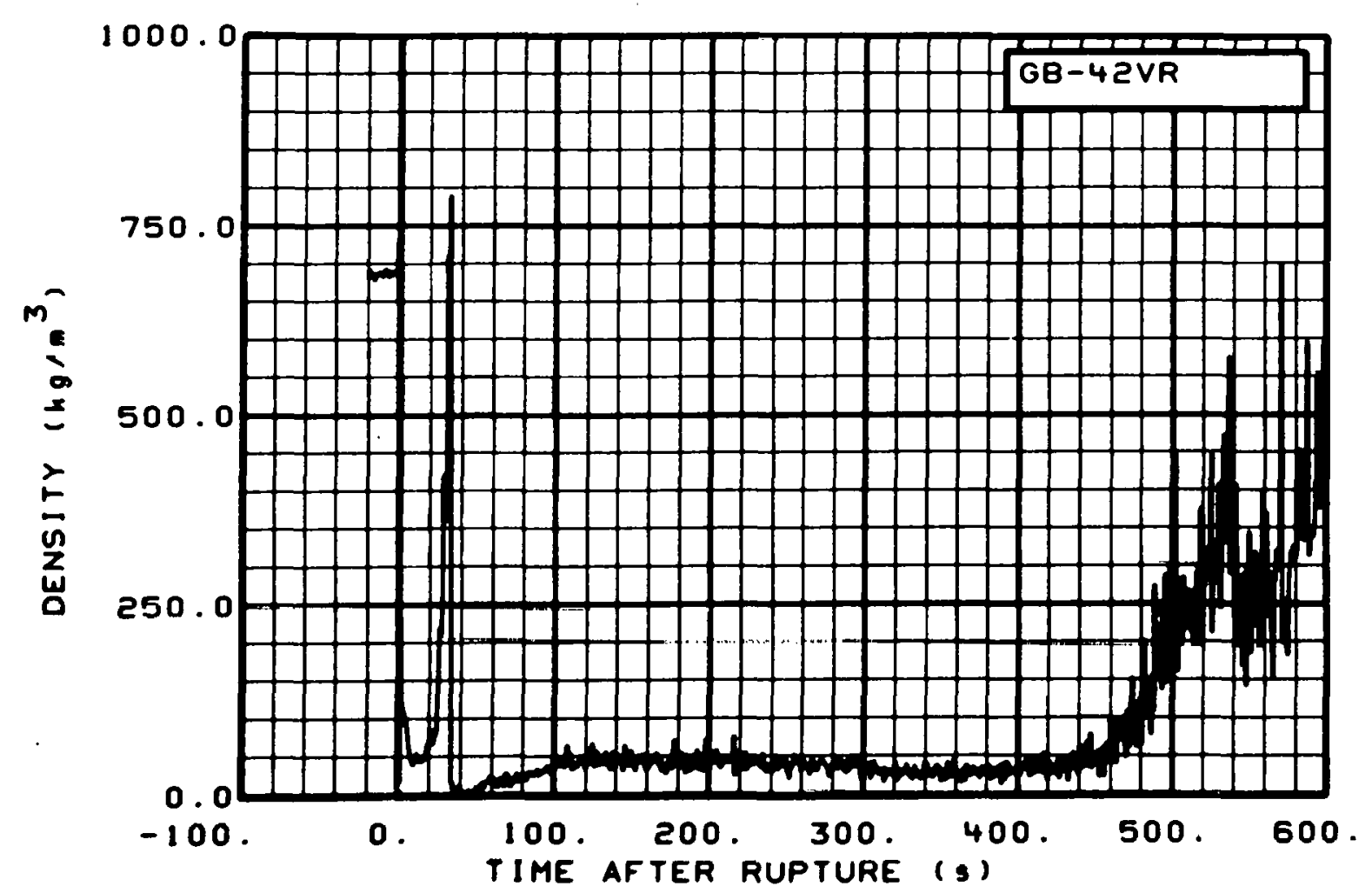

Fig. 313 Density in broken loop (GB-42VR), from -20 to $600 \mathrm{~s}$.

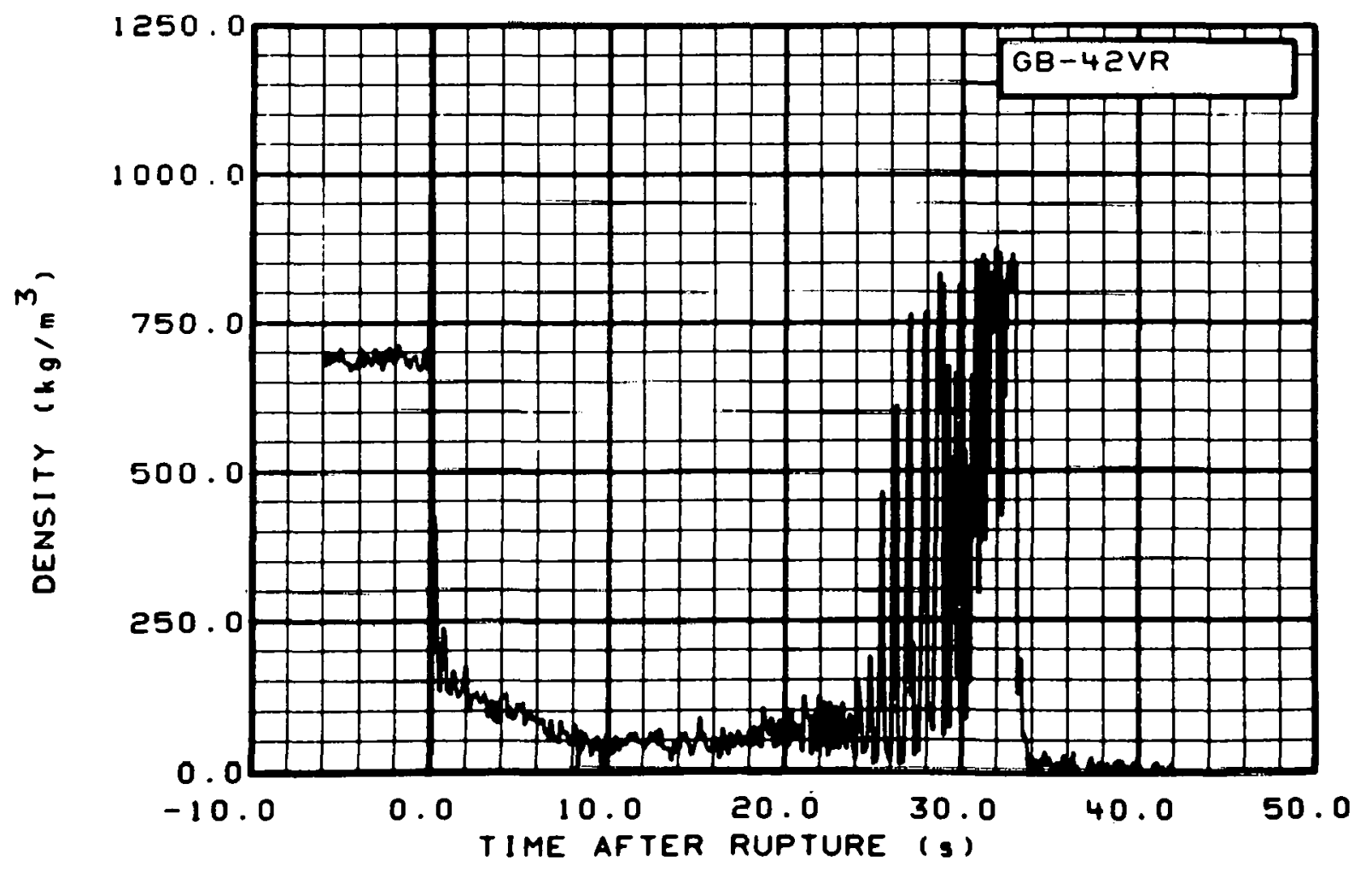

Fig. 314 Density in broken loop (GB-42VR), from -6 to. $42 \mathrm{~s}$. 


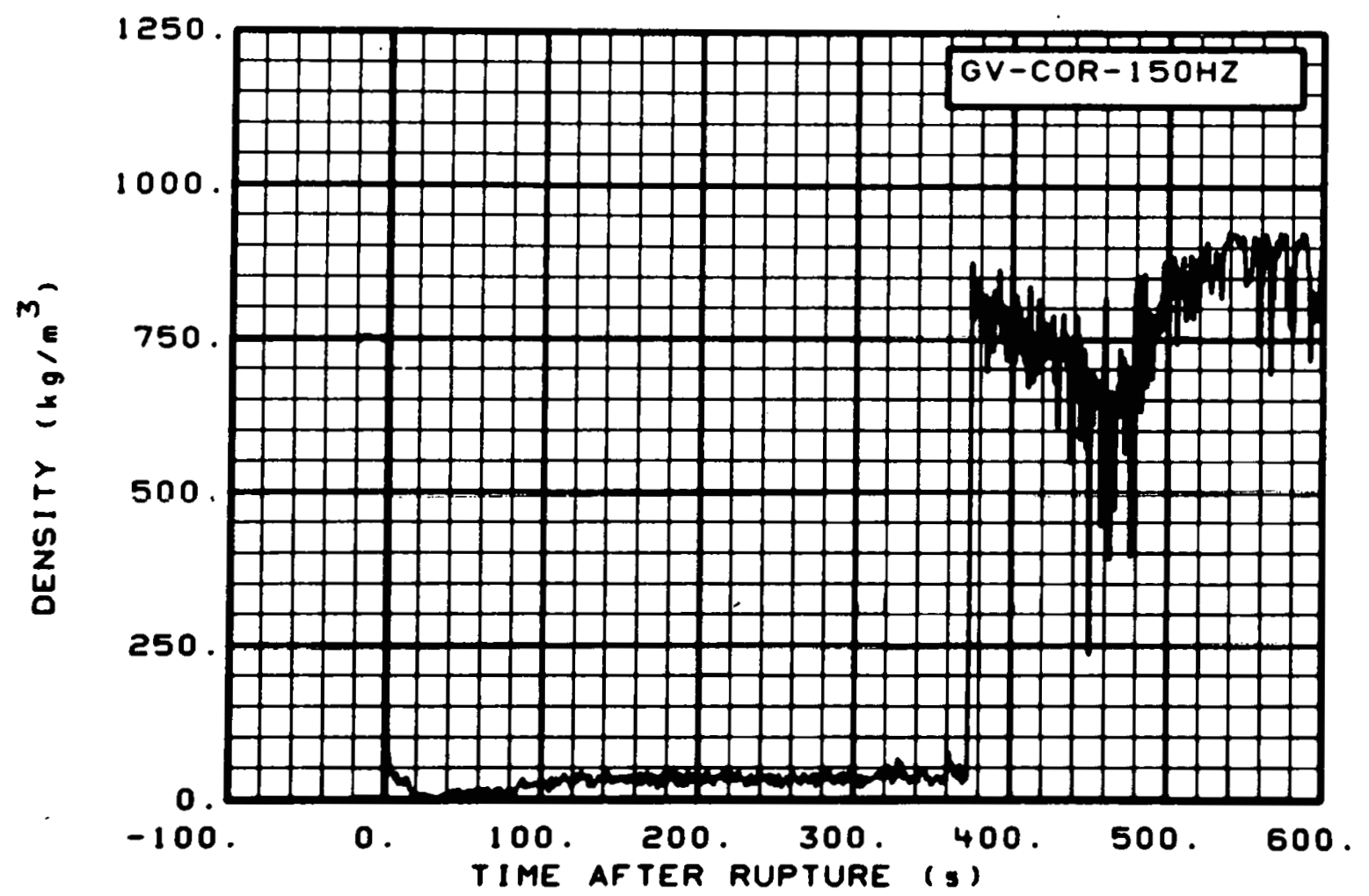

Fig. 315 Density in vessel (GV-COR-150HZ), from -20 to $600 \mathrm{~s}$.

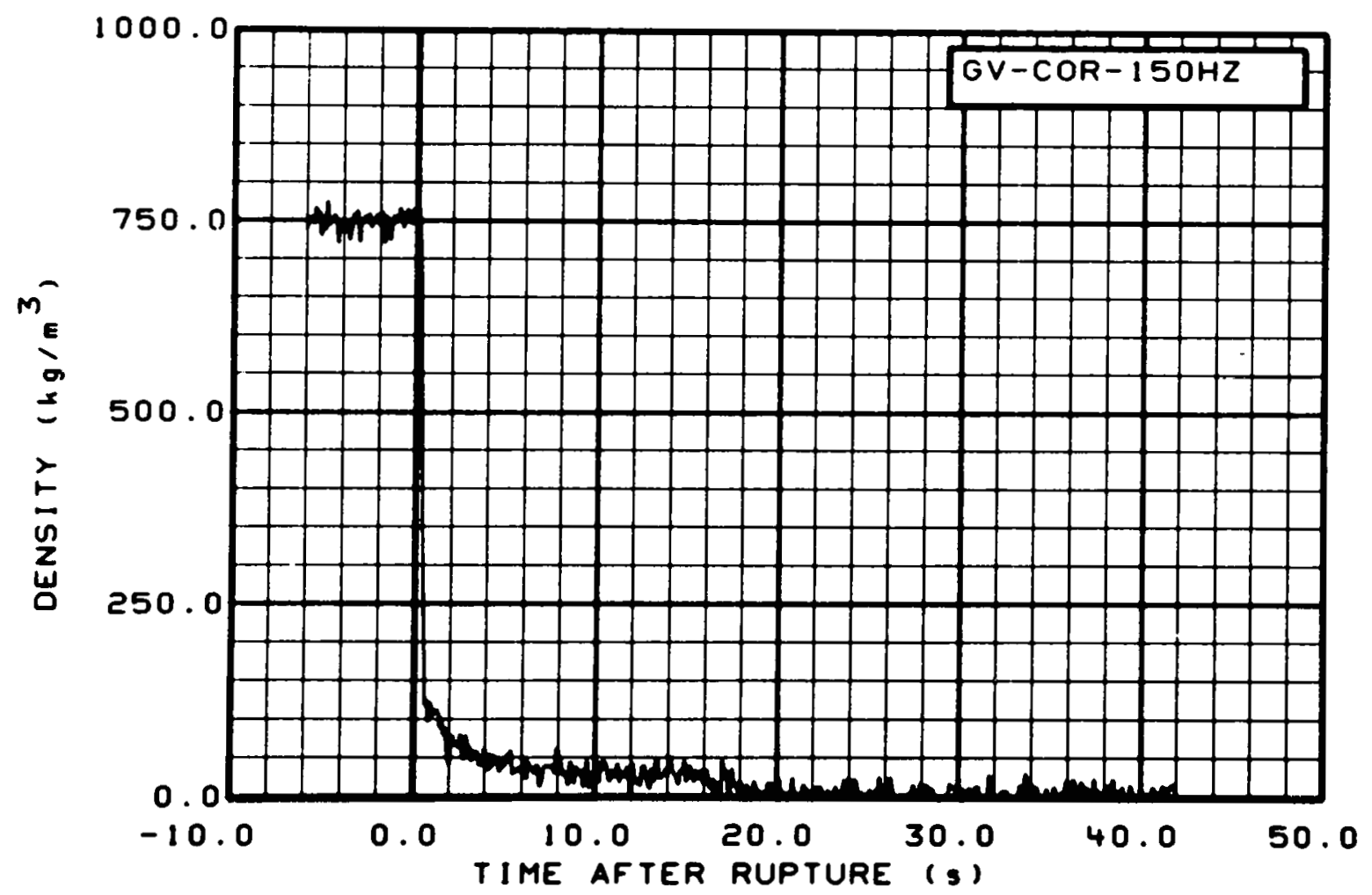

Fig. 316 Density in vessel (GV-COR-150HZ), from -6 to $42 \mathrm{~s}$. 


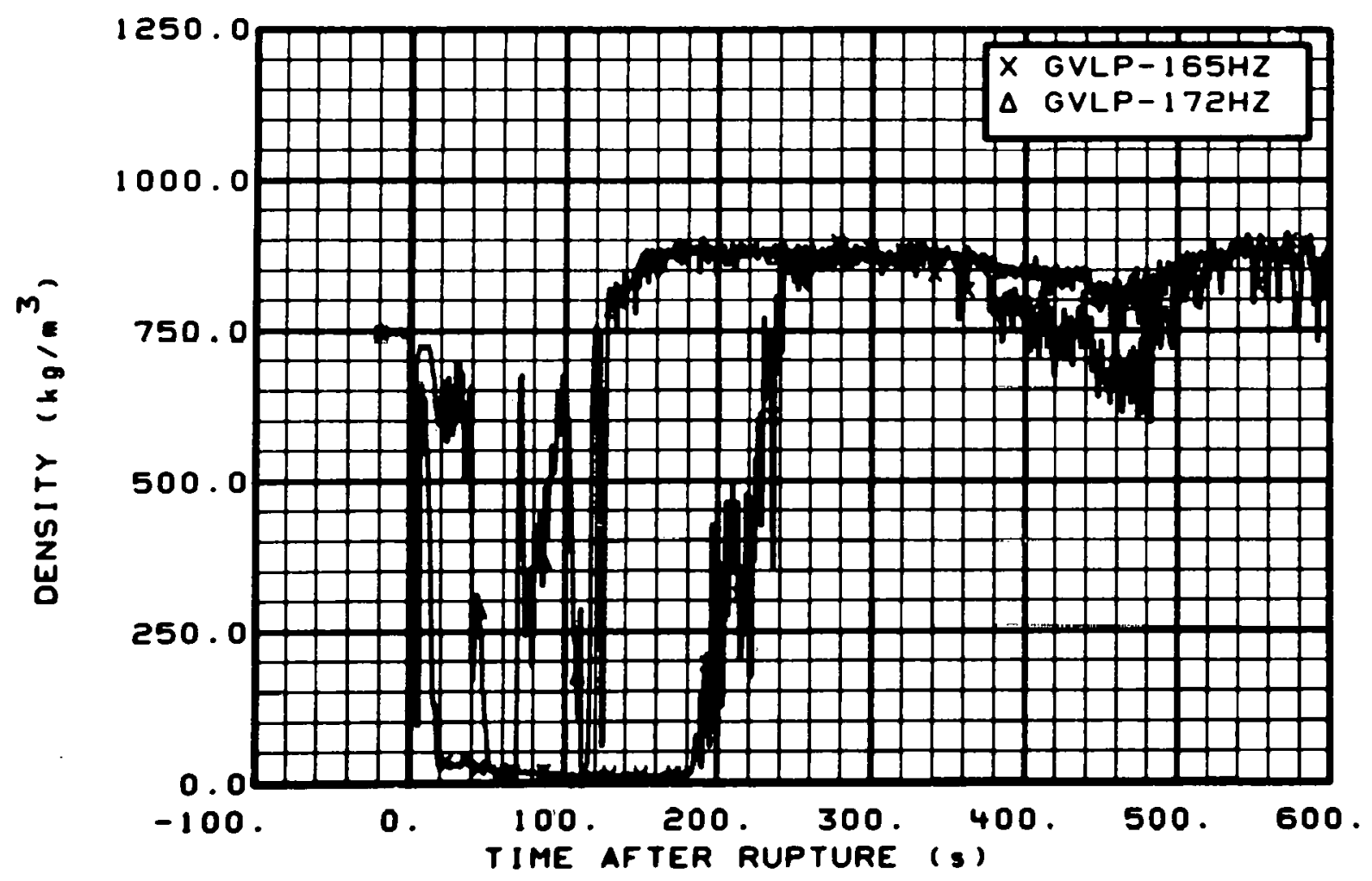

Fig. 317 Density in vessel (GVLP-165HZ and GVLP-172HZ), from -20 to $600 \mathrm{~s}$.

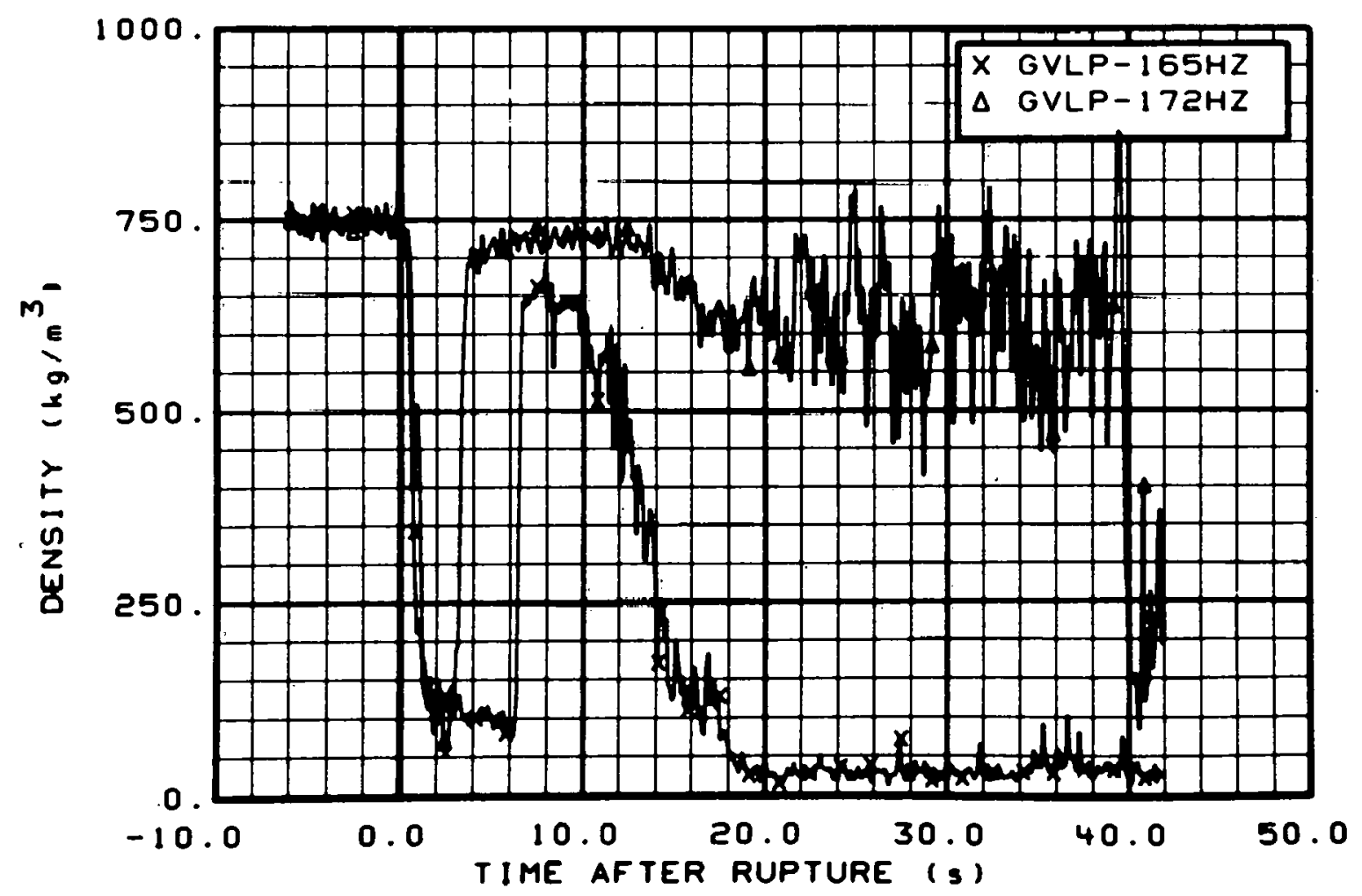

Fig. 318 Density in vessel (GVLP-165HZ and GVLP-172HZ), from -6 to $42 \mathrm{~s}$. 


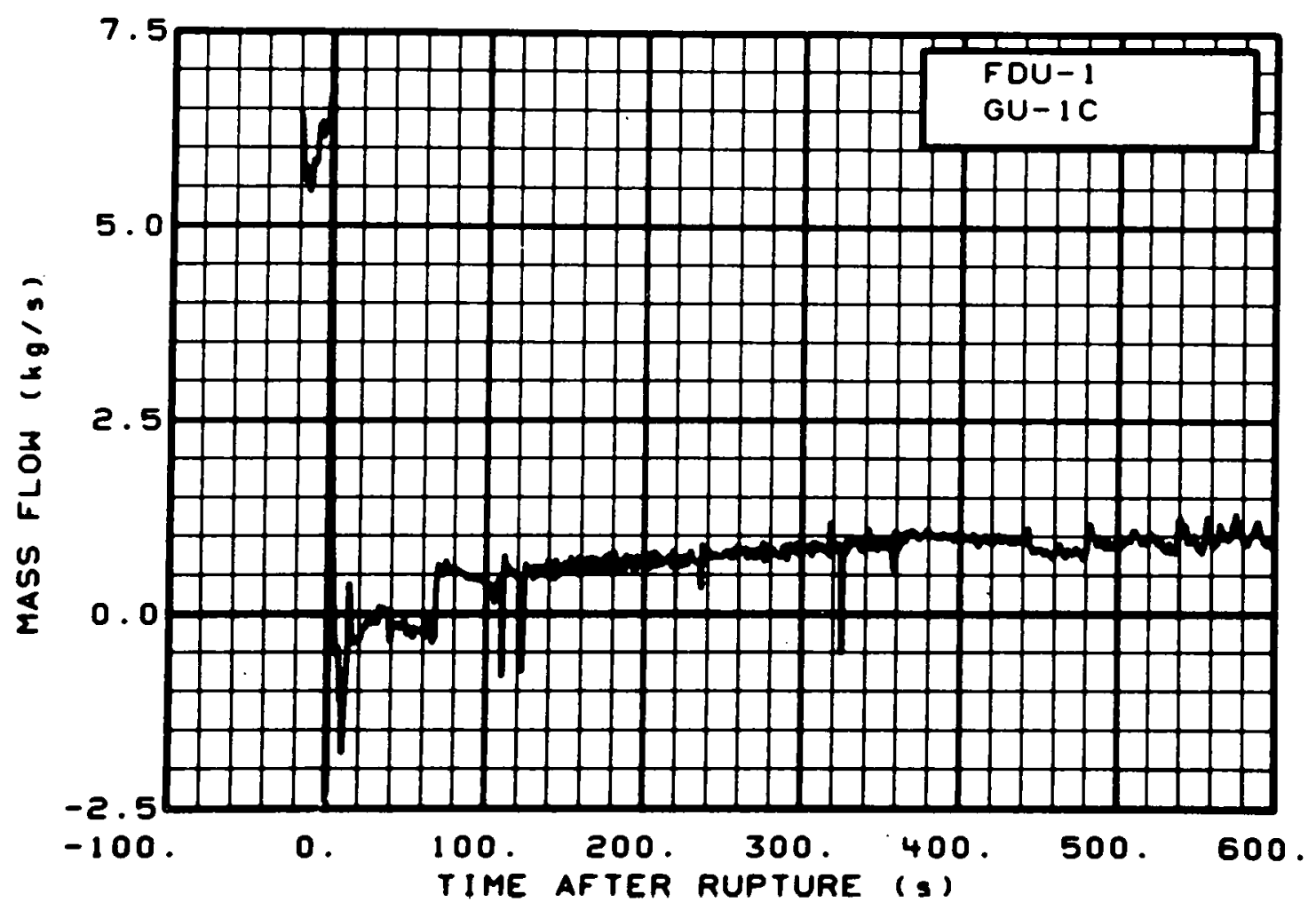

Fig. 319 Mass flow in intact loop (FDU-1, GU-1C), from -20 to $600 \mathrm{~s}$.

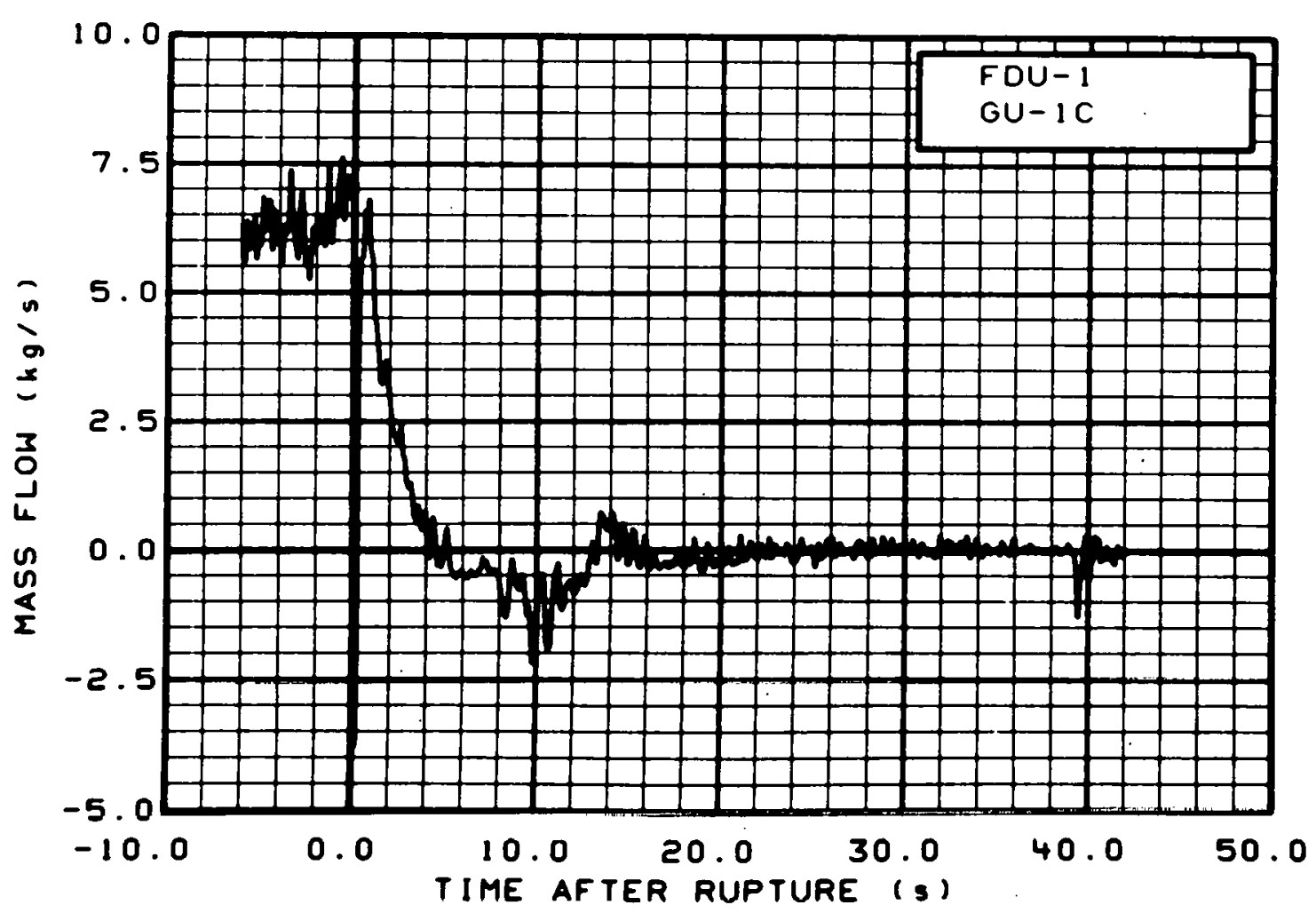

Fig. 320 Mass flow in intact loop (FDU-1, GU-1C), from -6 to $42 \mathrm{~s}$. 


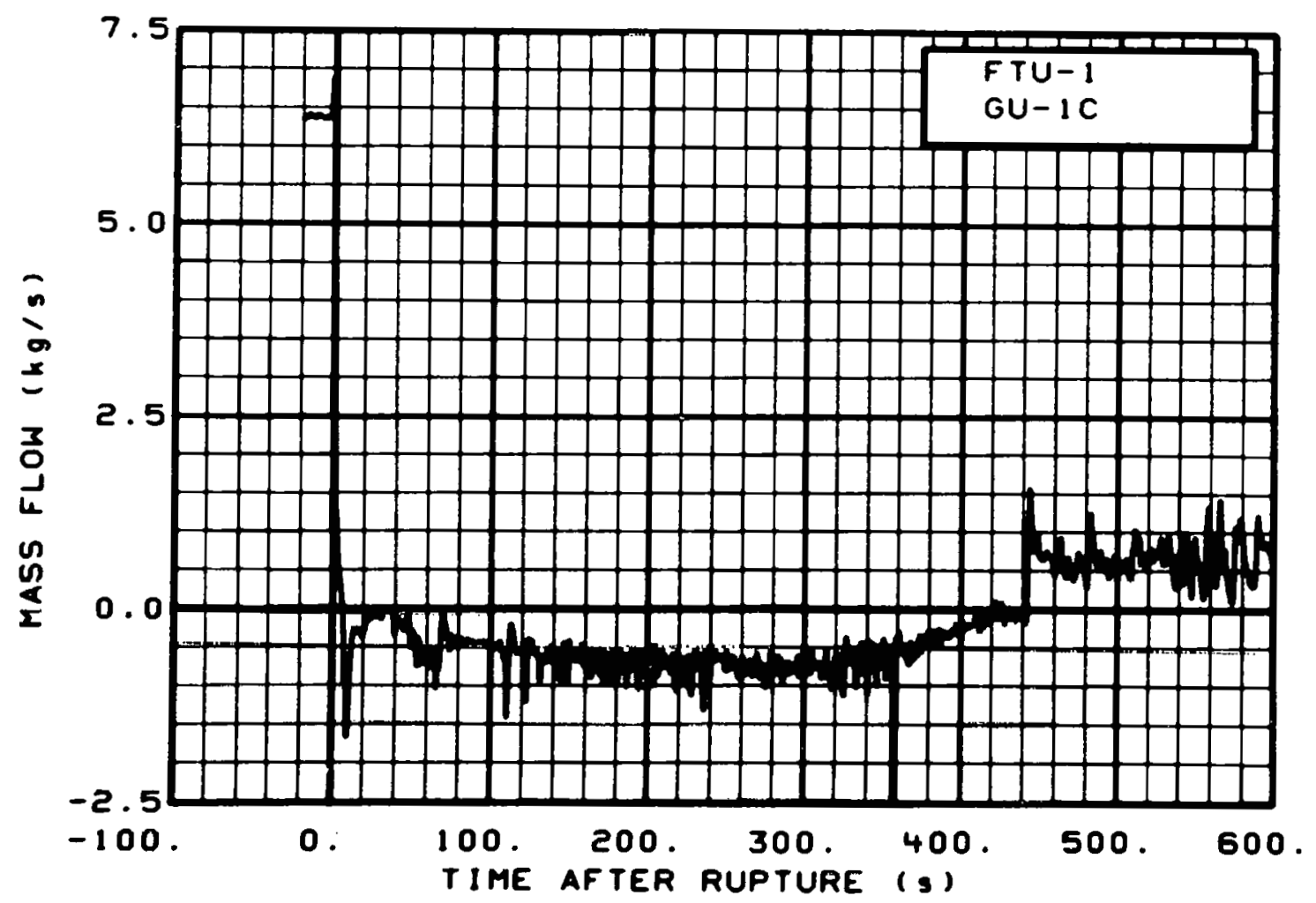

Fig. 321 Mass flow in intact loop (FTU-1, GU-1C), from -20 to $600 \mathrm{~s}$.

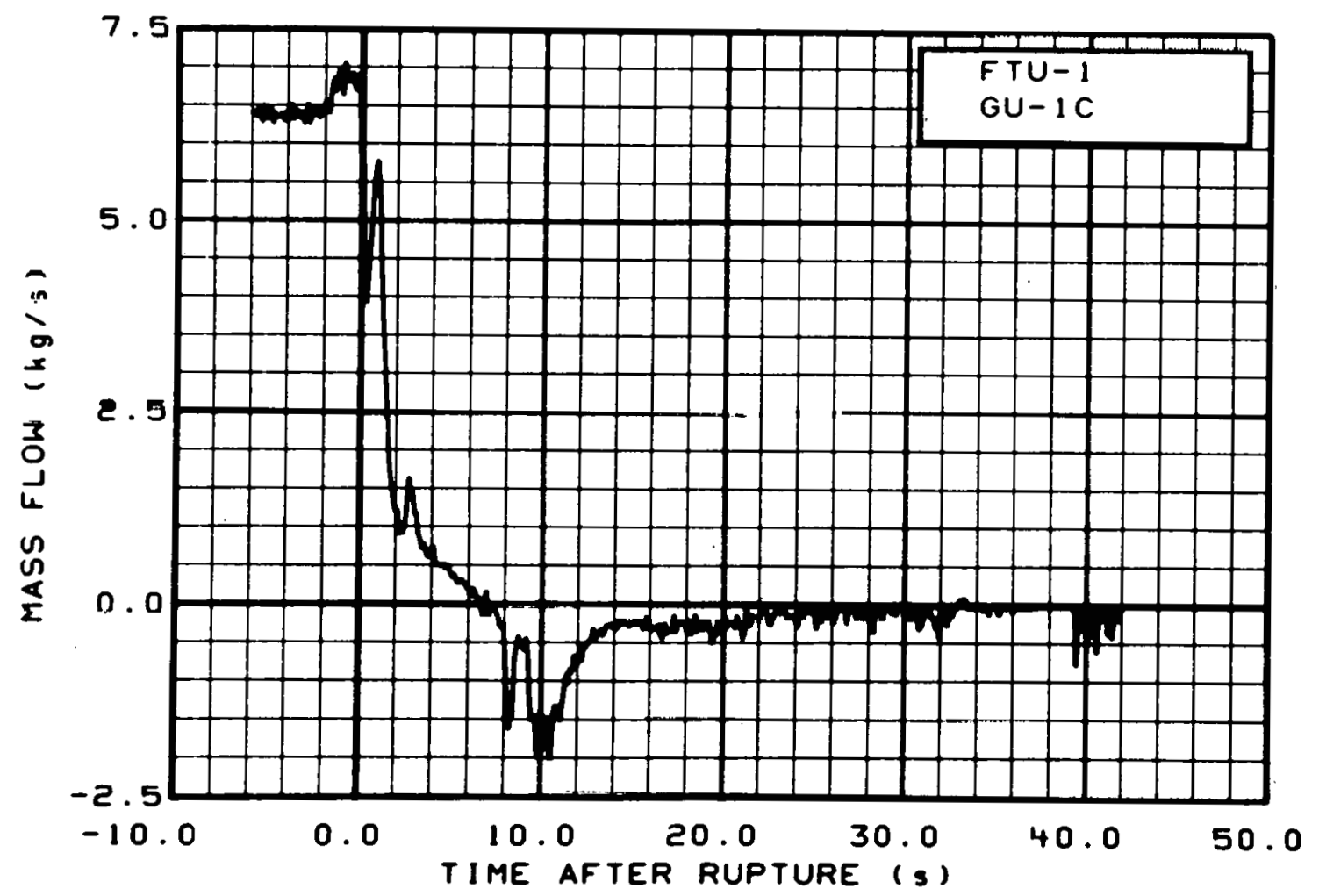

Fig. 322 Mass flow in intact loop (FTU-1, GU-1C), from -6 to $42 \mathrm{~s}$. 


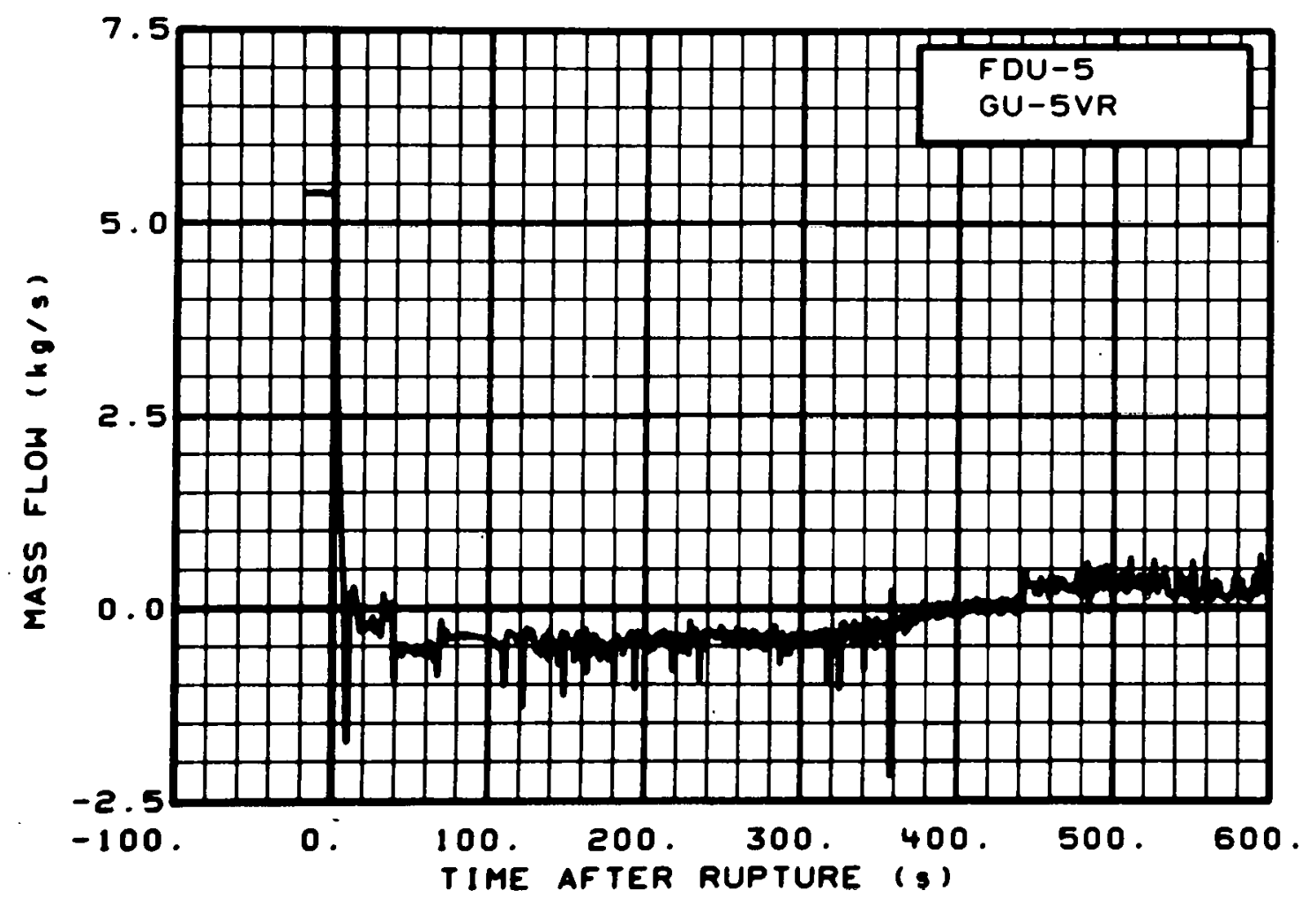

Fig. 323 Mass flow in intact loop (FDU-5, GU-5VR), from -20 to $600 \mathrm{~s}$.

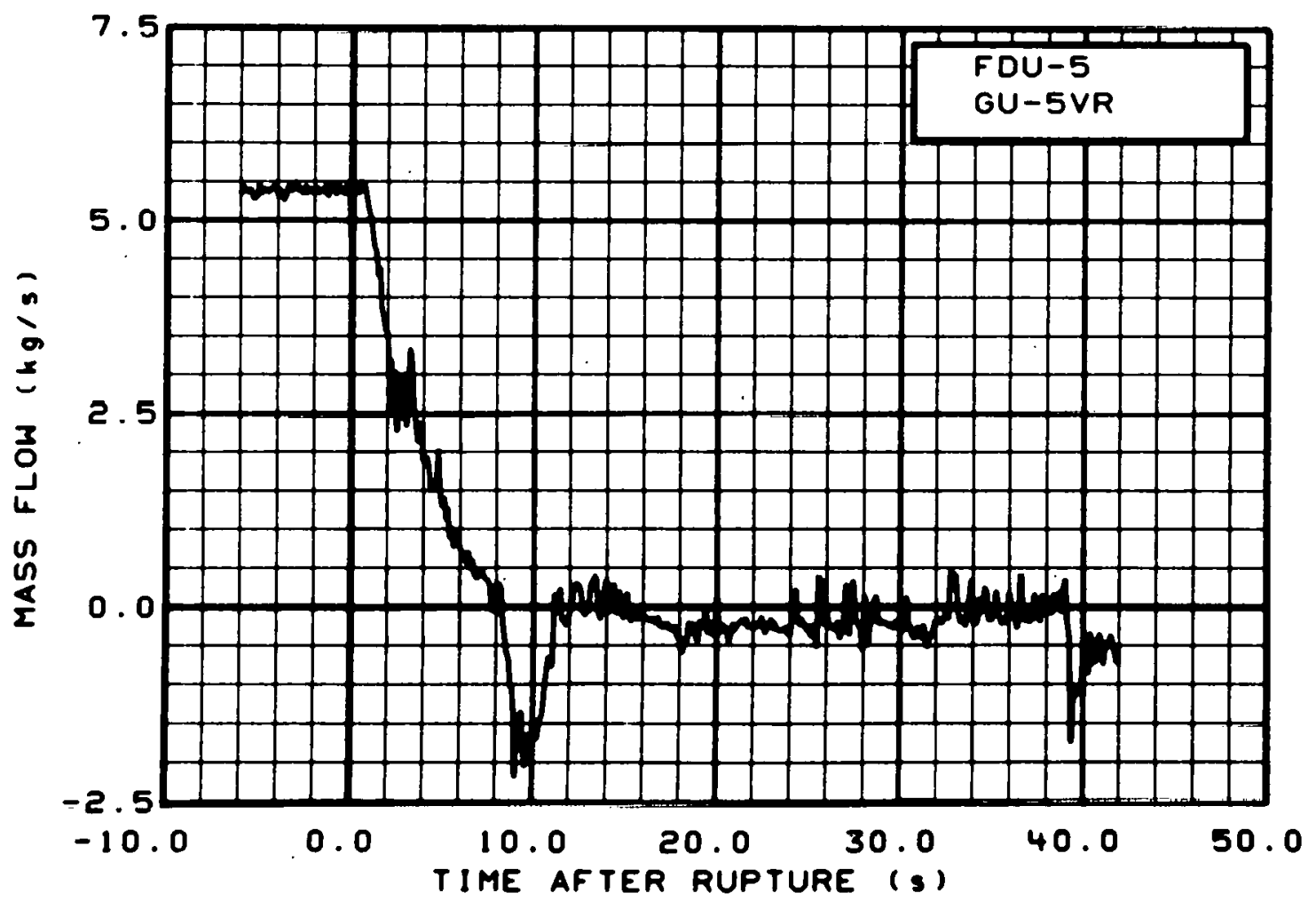

Fig. 324 Mass flow in intact loop (FDU-5, GU-5VR), from -6 to $42 \mathrm{~s}$. 


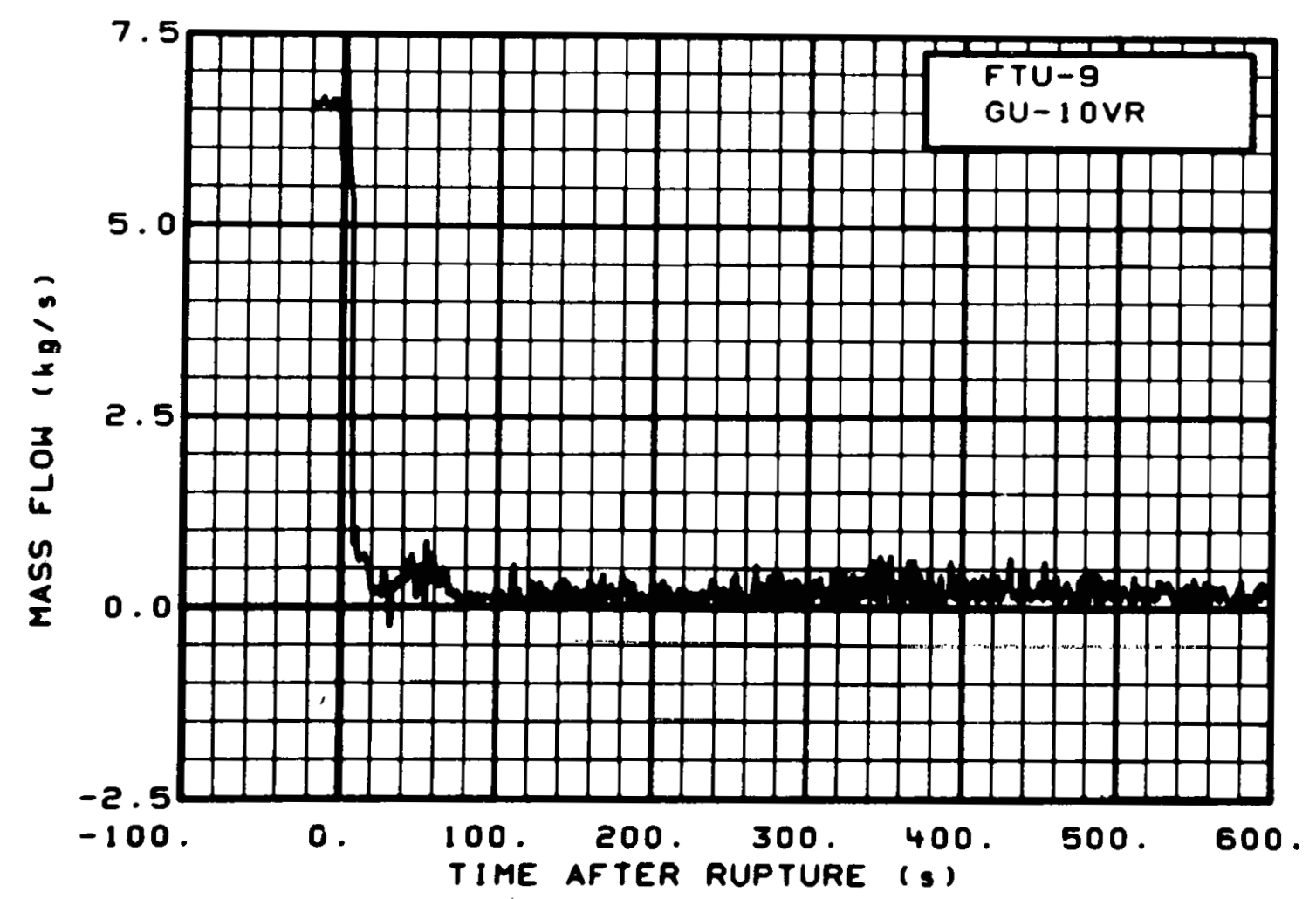

Fig. 325 Mass flow in intact loop (FTU-9, GU-10VR), from -20 to $600 \mathrm{~s}$.

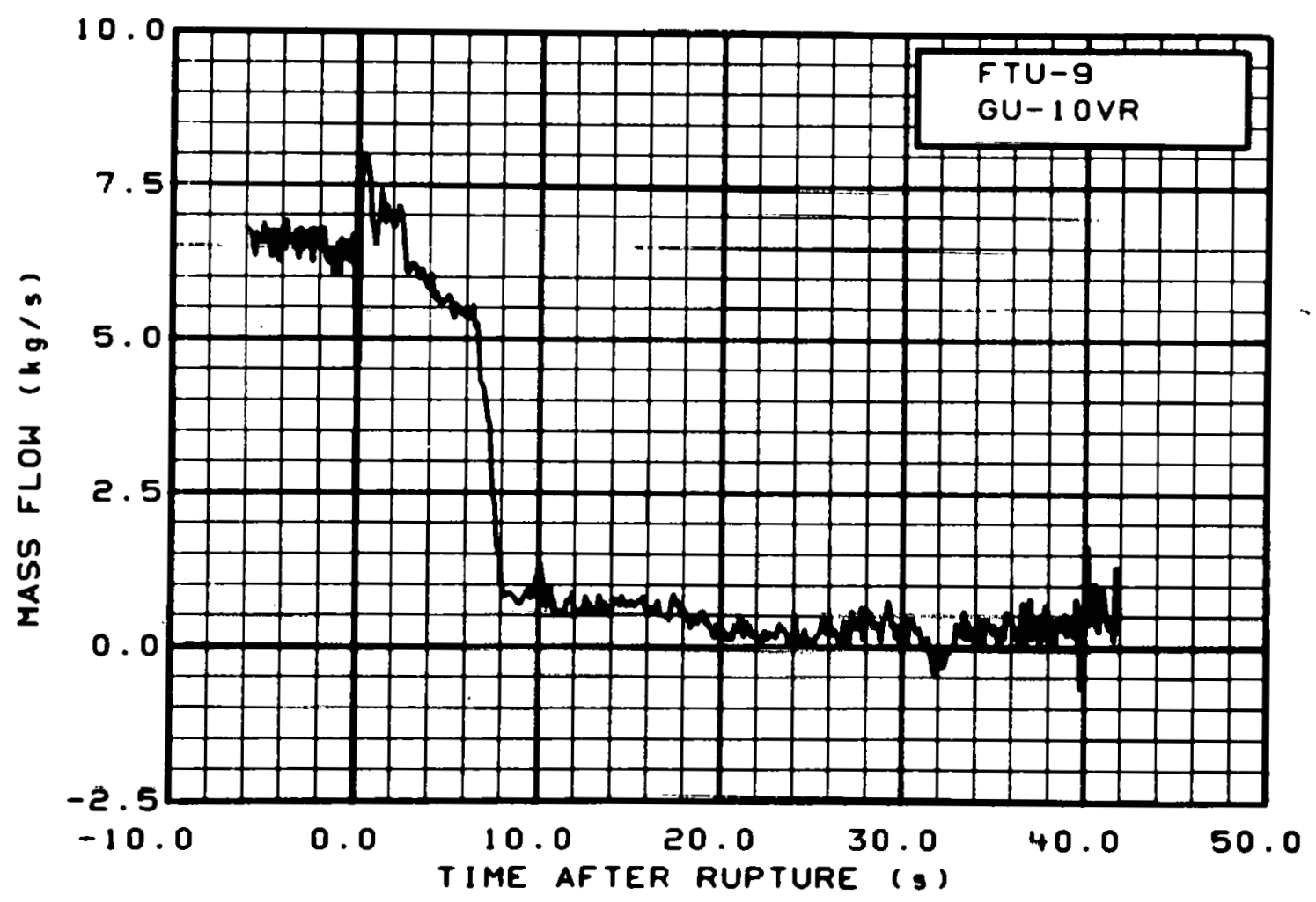

Fig. 326 Mass flow in intact loop (FTU-9, GU-10VR), from -6 to $42 \mathrm{~s}$. 


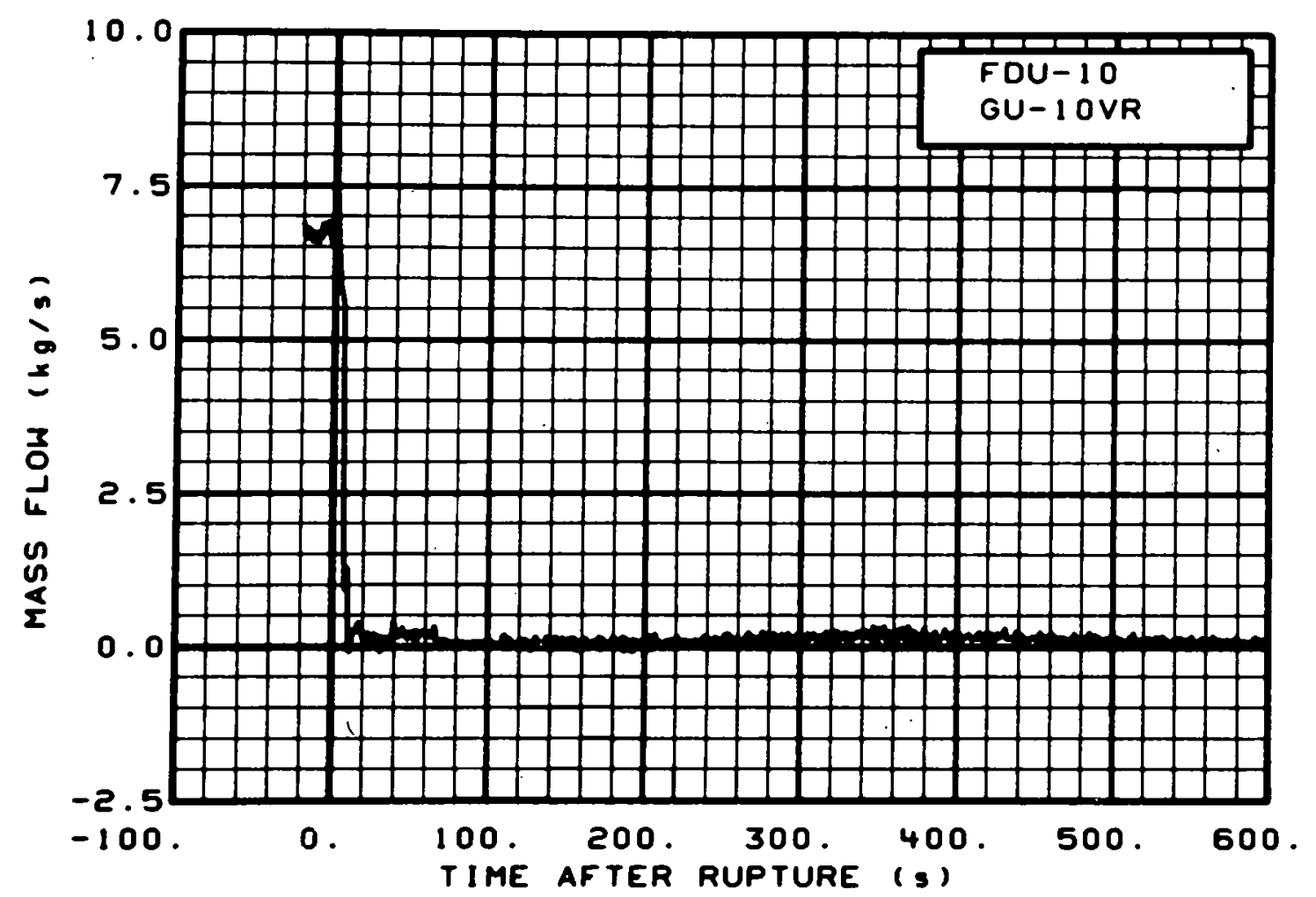

Fig. 327 Mass flow in intact loop (FDU-10, GU-10VR), from -20 to $600 \mathrm{~s}$.

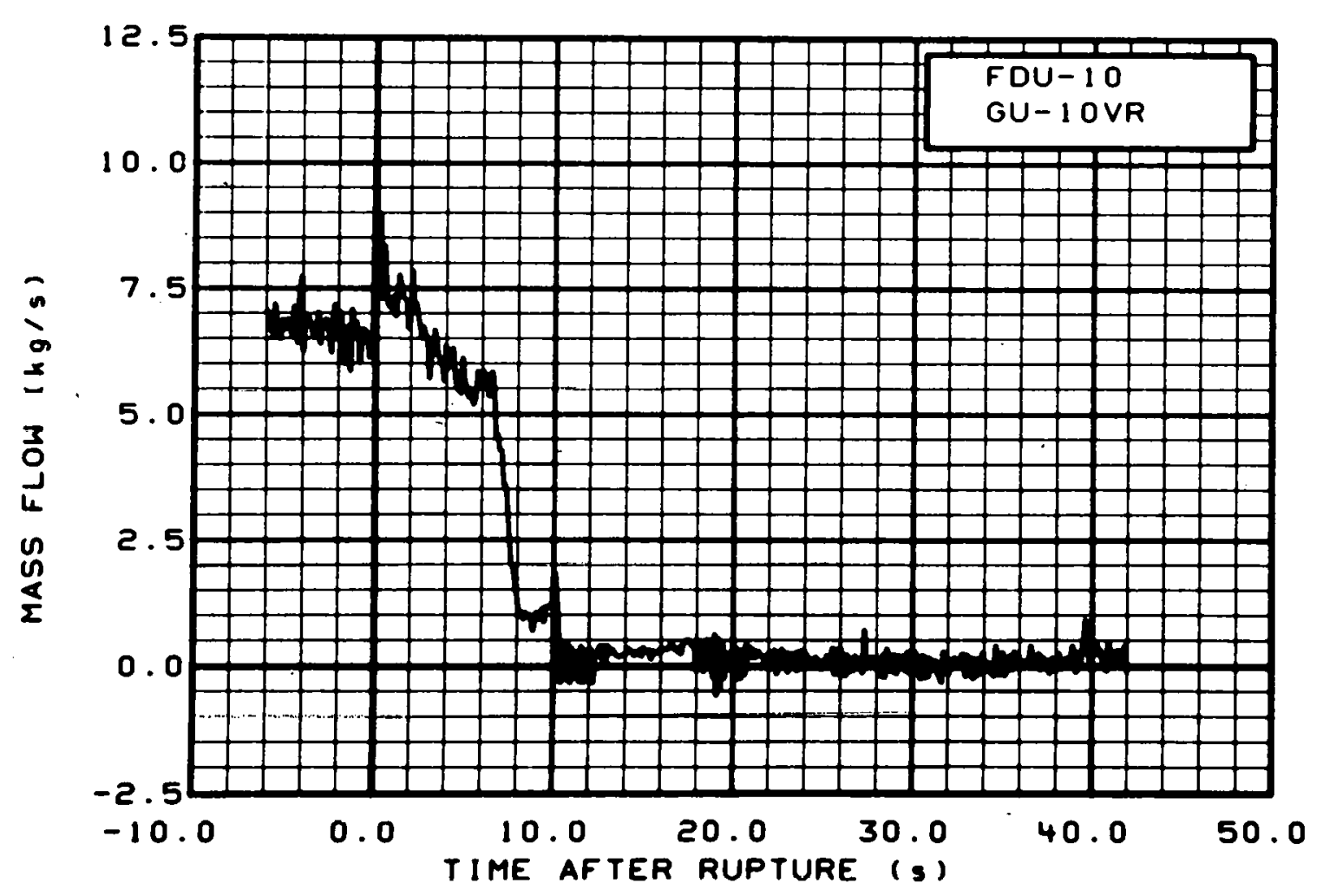

Fig. 328 Mass flow in intact loop (FDU-10, fill-10VR), from -6 to $42 \mathrm{~s}$. 


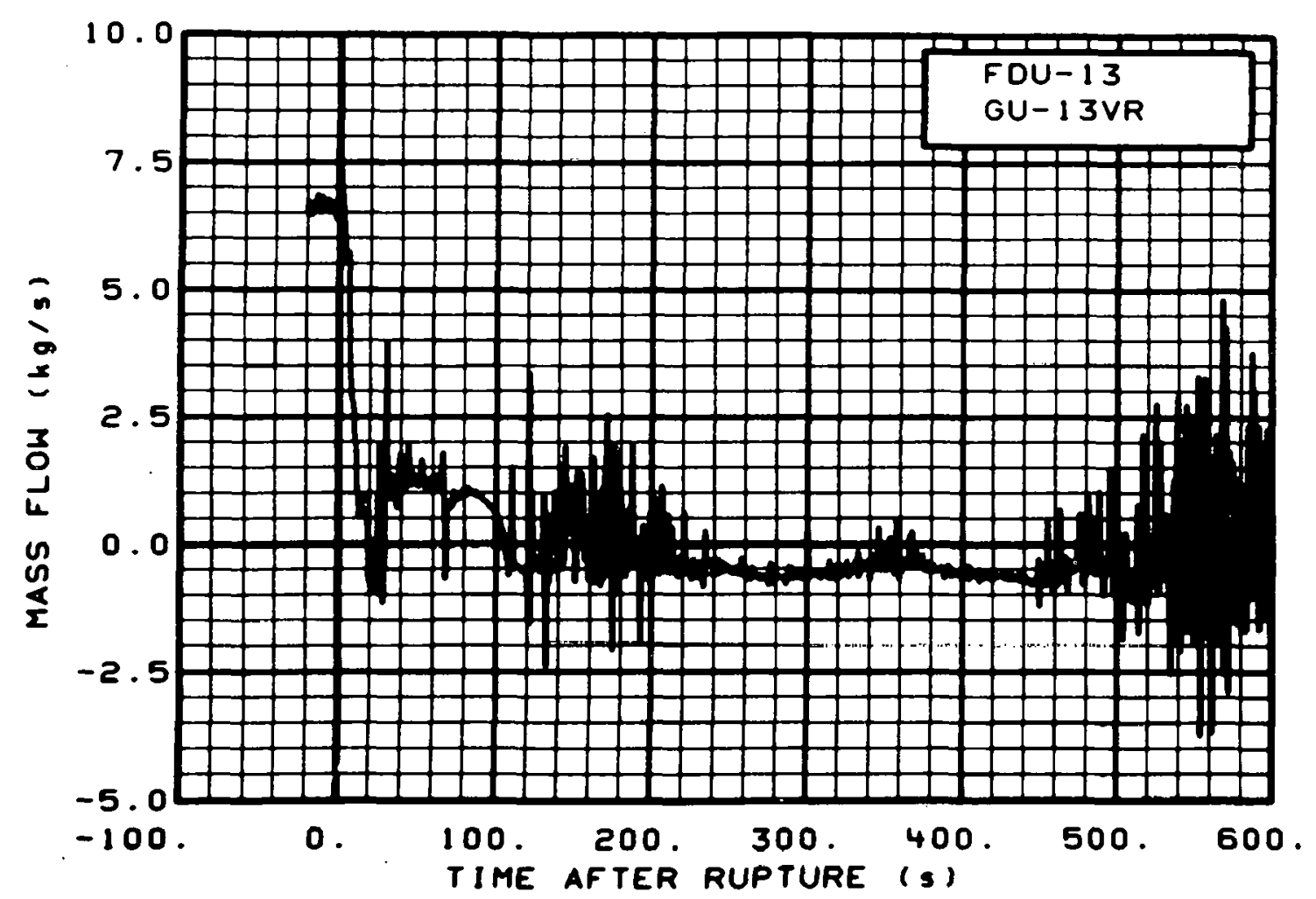

Fig. 329 Mass flow in intact loop (FDU-13, GU-13VR), from -20 to $600 \mathrm{~s}$.

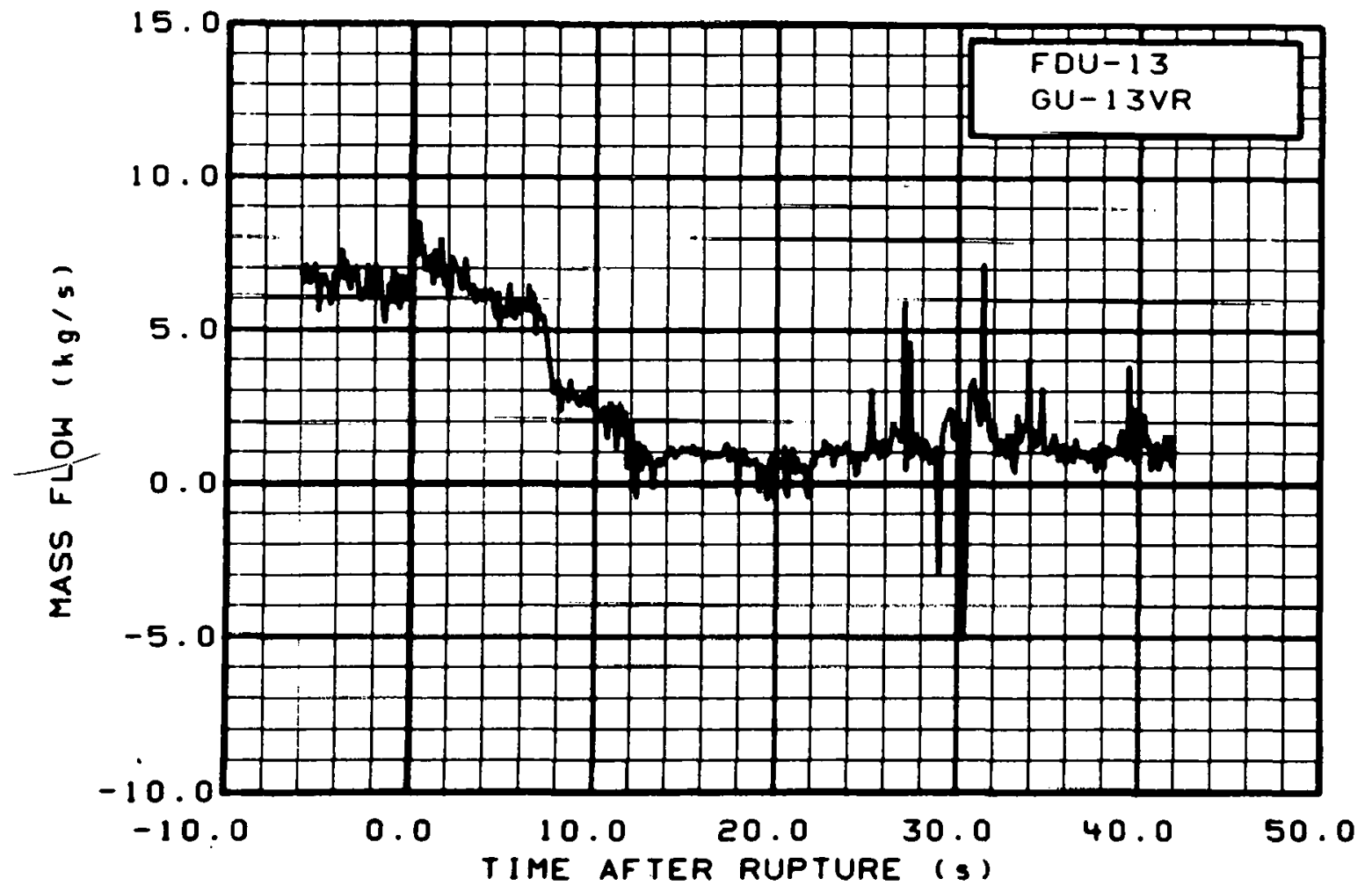

Fig. 330 Mass flow in intact 1oop (FDU-13, GU-13VR), from -6 to $42 \mathrm{~s}$. 


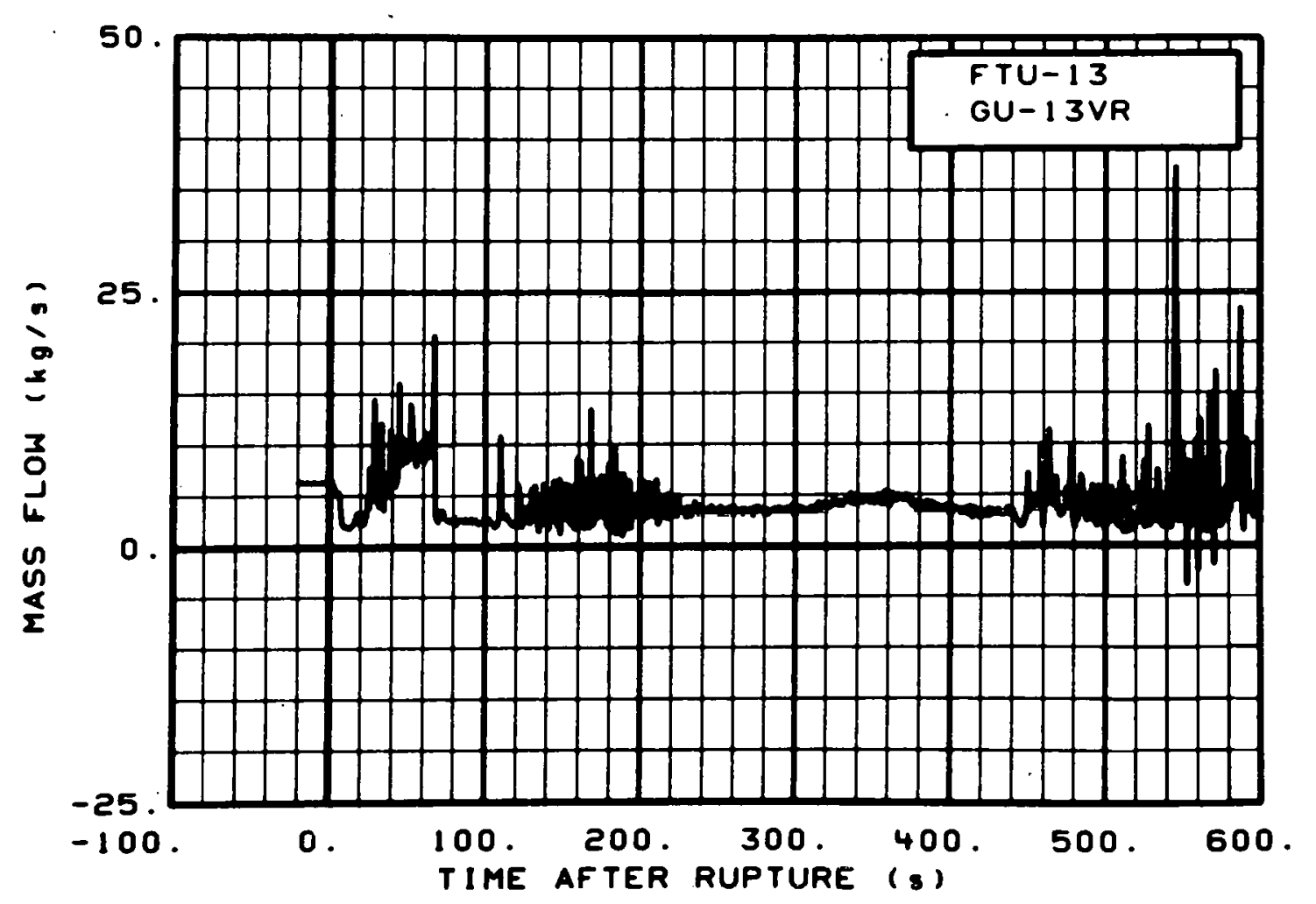

Fig. 331 Mass flow in intact 10op (FTU-13, GU-13VR), from -20 to $600 \mathrm{~s}$.

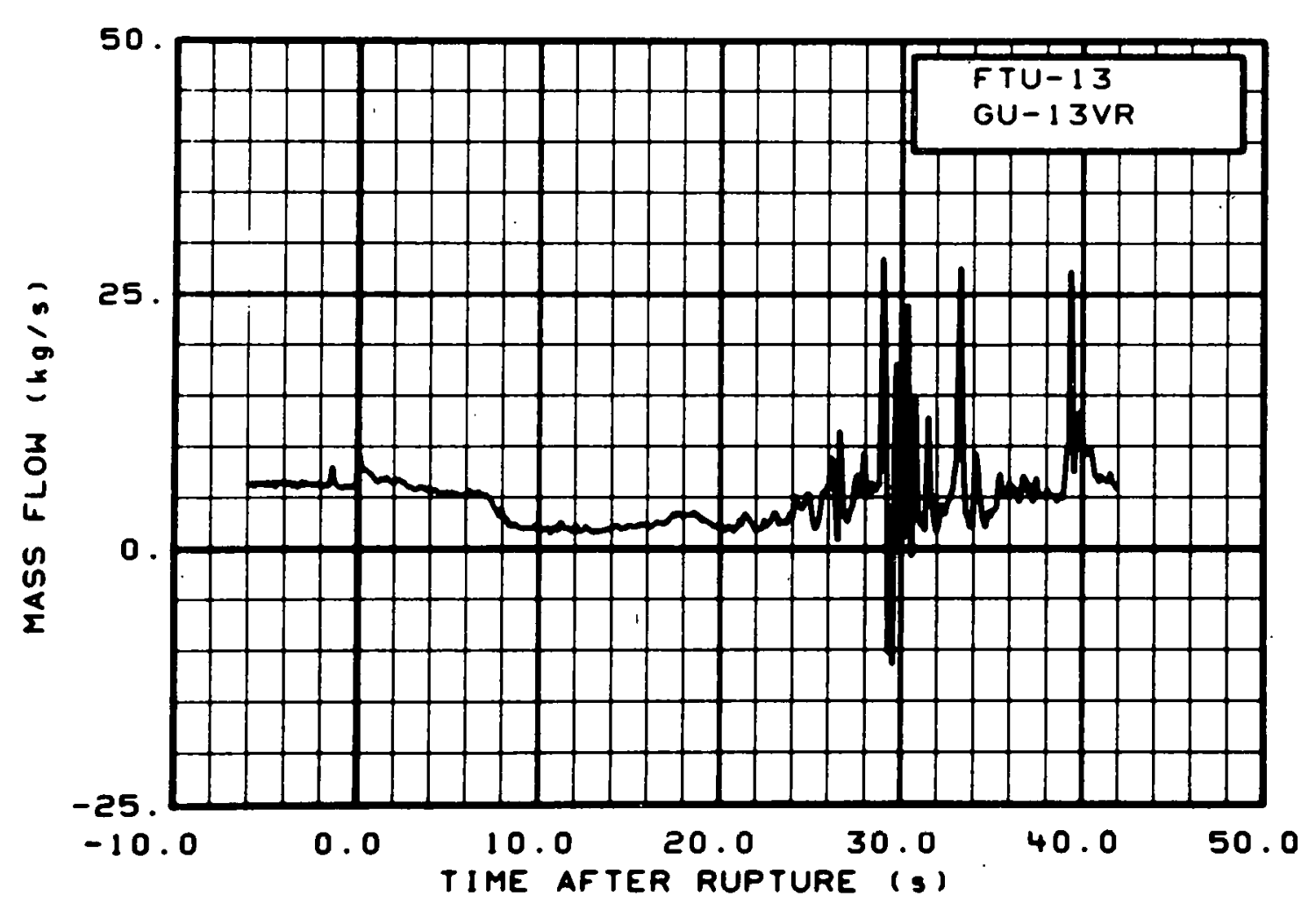

Fig. 332 Mass flow in intact loop (FTU-13, GU-13VR), from -6 to $42 \mathrm{~s}$. 


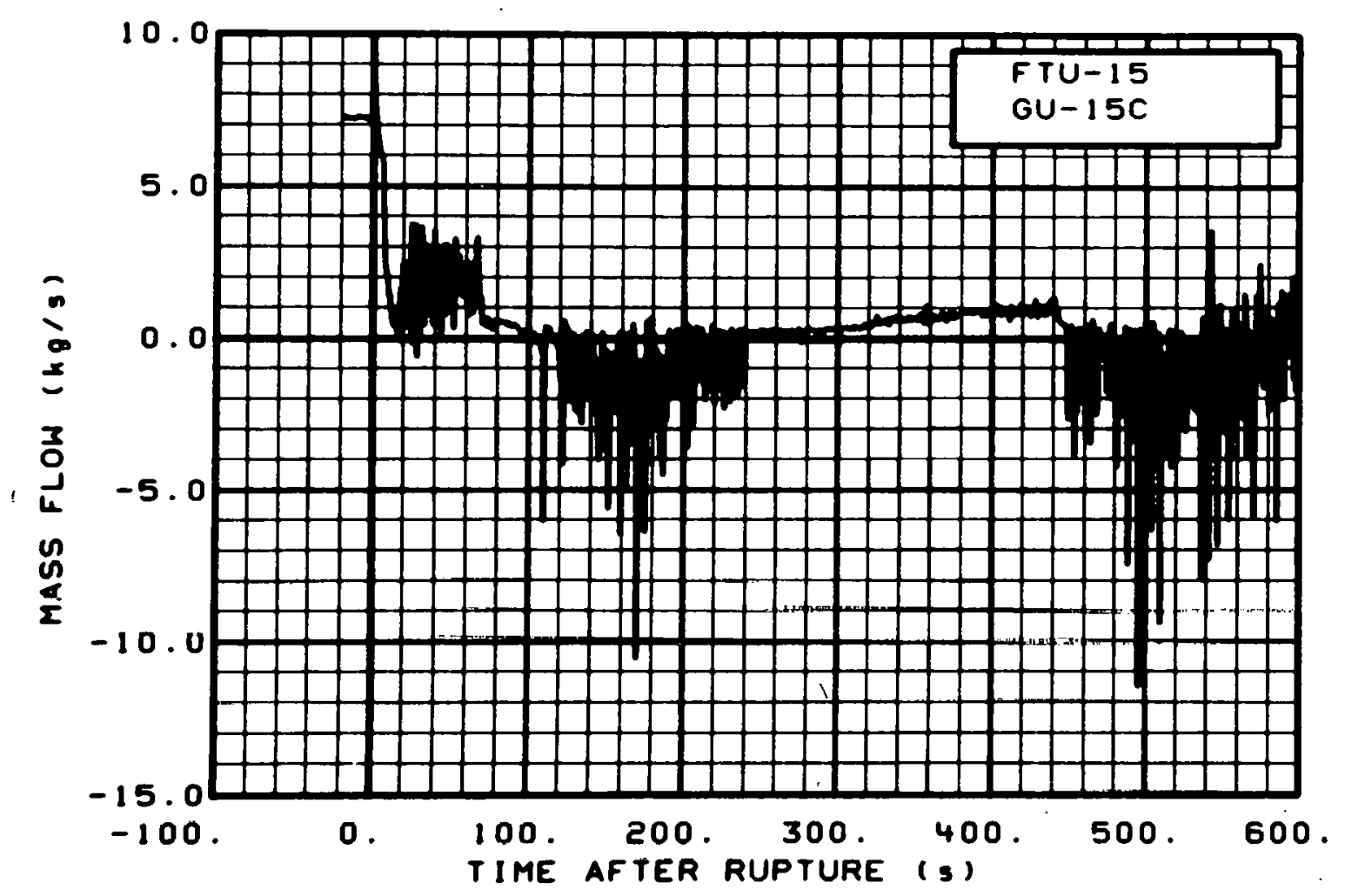

Fig. 333 Mass flow in intact loop (FTU-15, GU-15C), from -20 to $600 \mathrm{~s}$.

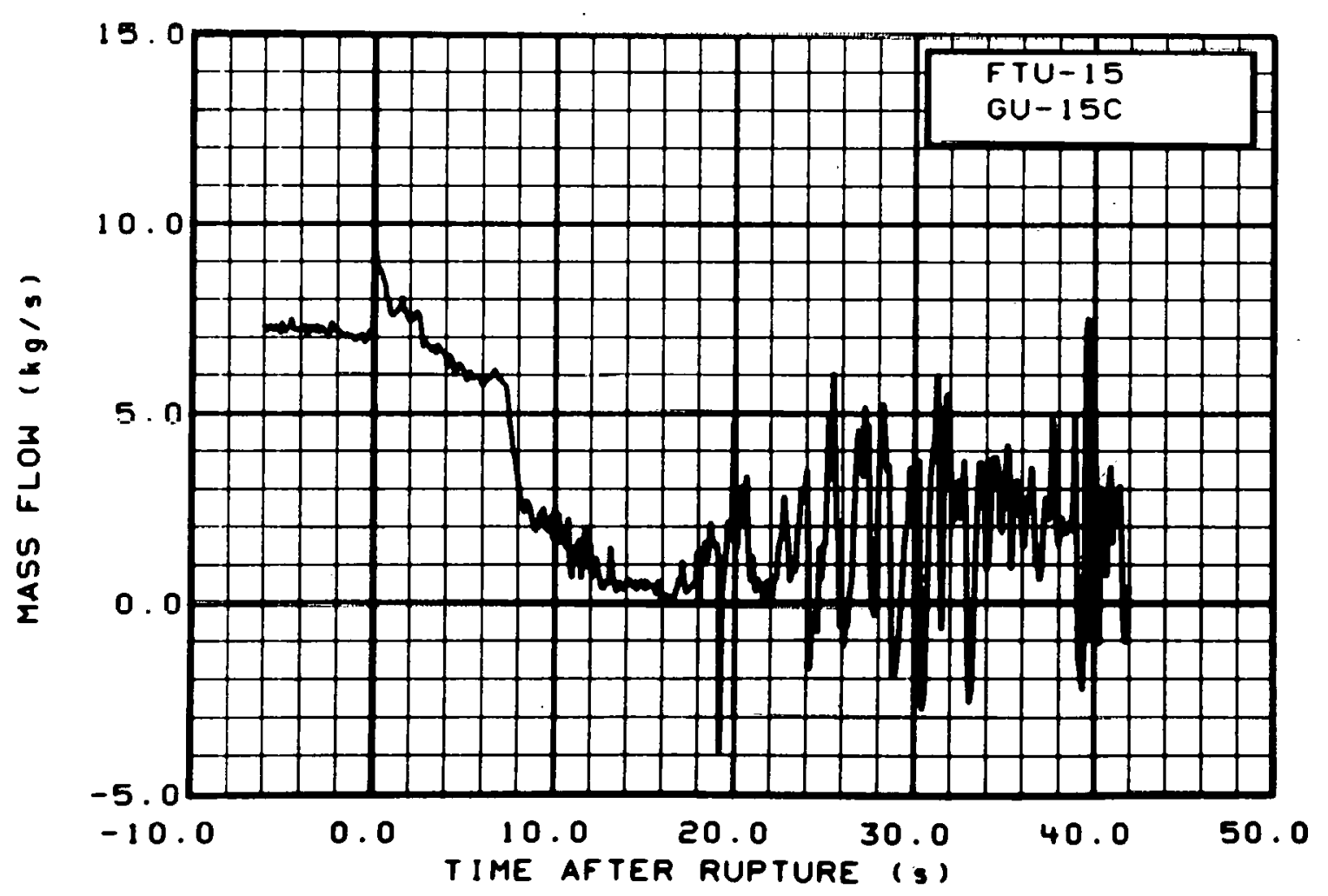

Fig. 334 Mass flow in intact loop (FTU-15, GU-15C), from -6 to $42 \mathrm{~s}$. 


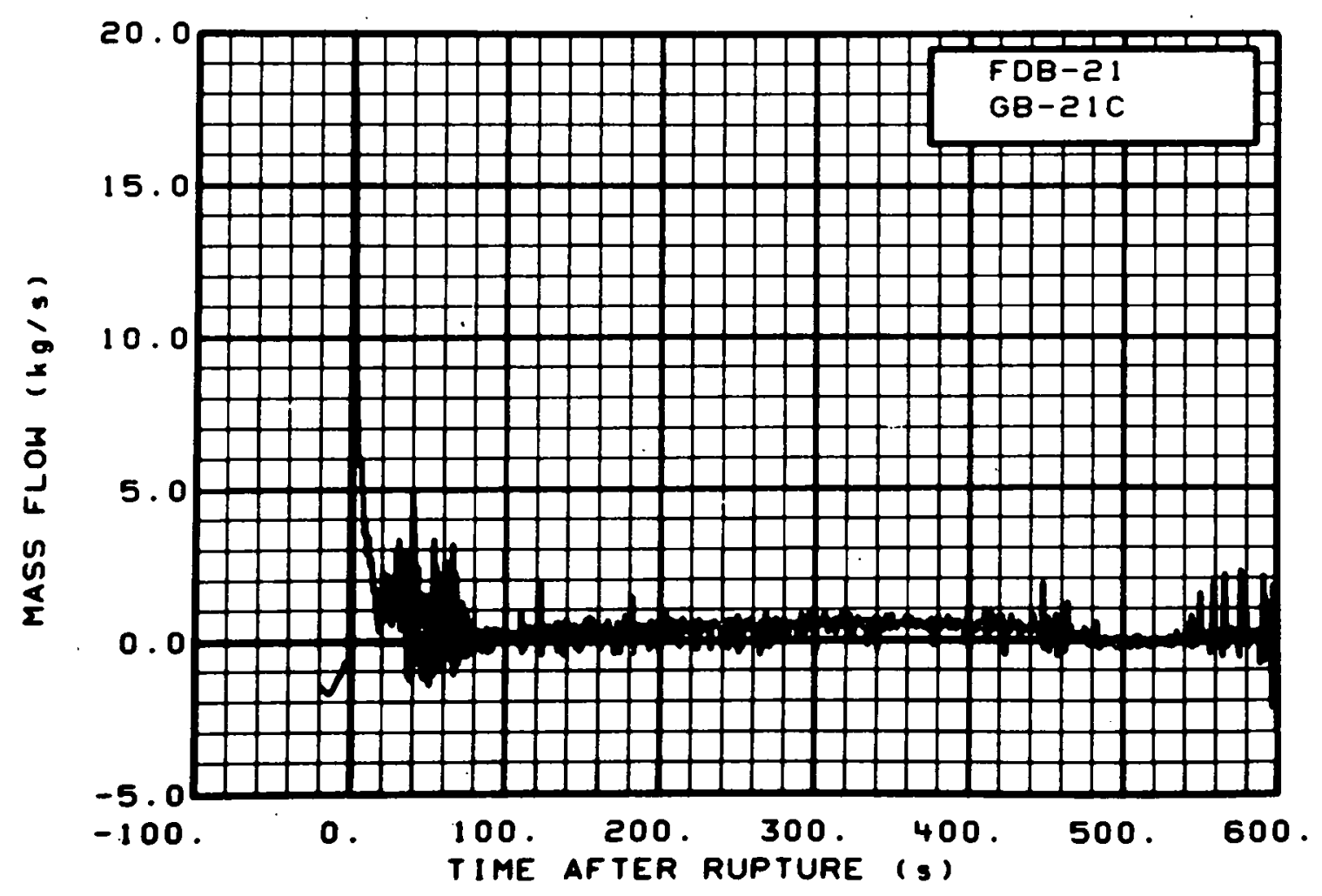

Fig. 335 Mass flow in broken loop (FDB-21, GB-21C), from -20 to $600 \mathrm{~s}$.

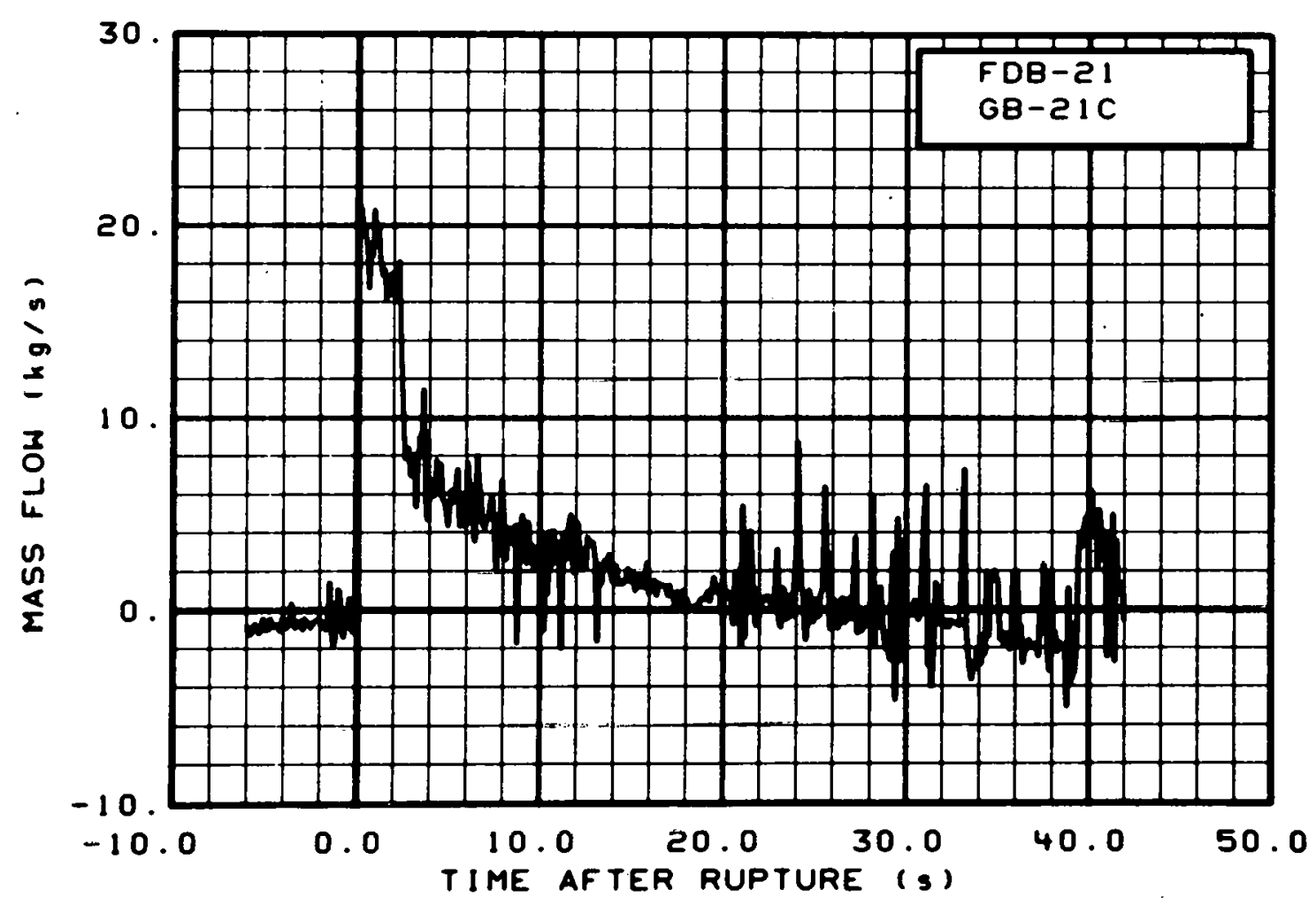

Fig. 336 Mass flow in broken loop (FDB-21, GB-21C), from -6 to $42 \mathrm{~s}$. 


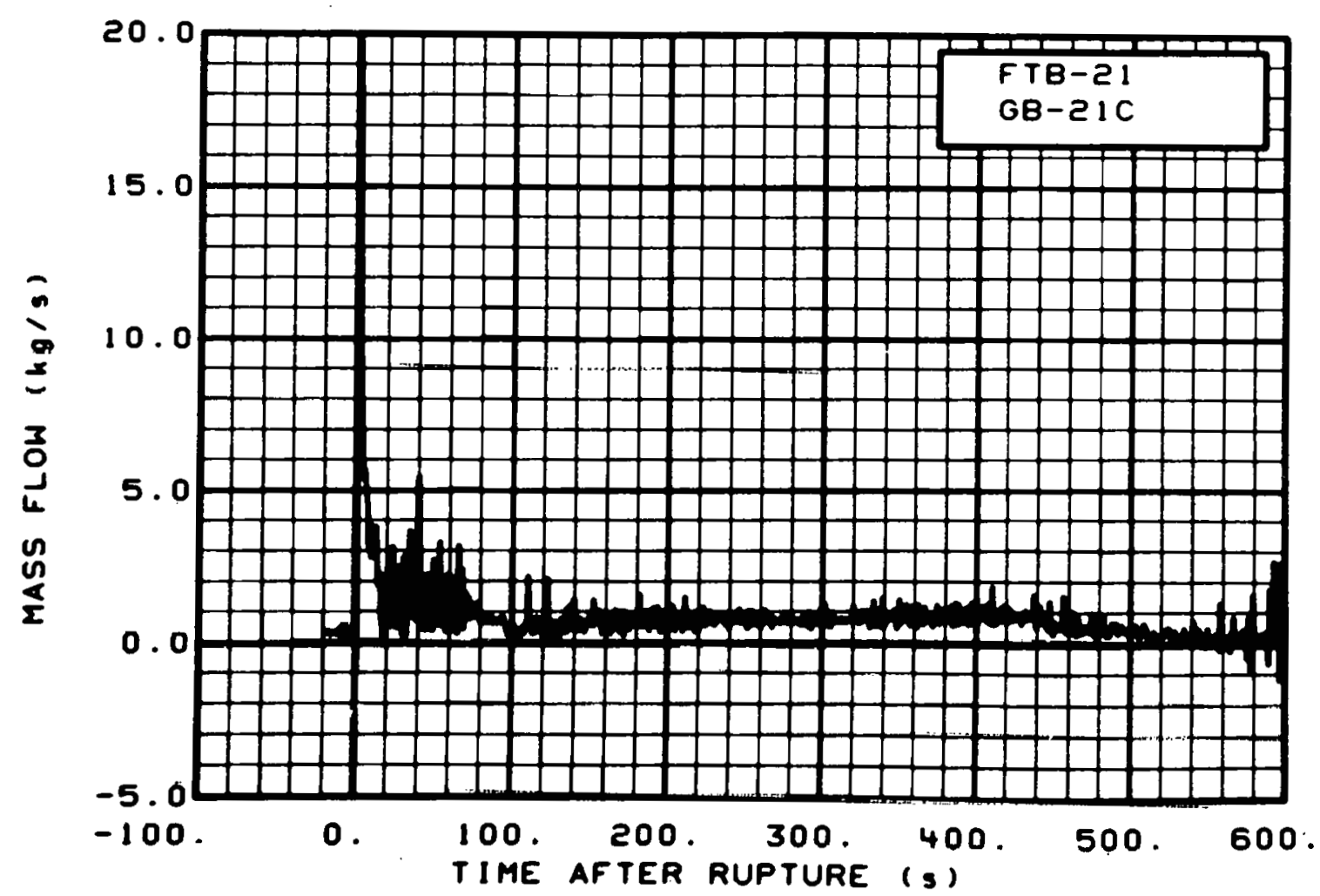

Fig. 337 Mass flow in broken loop (FTB-21, GB-21C), from -20 to $600 \mathrm{~s}$.

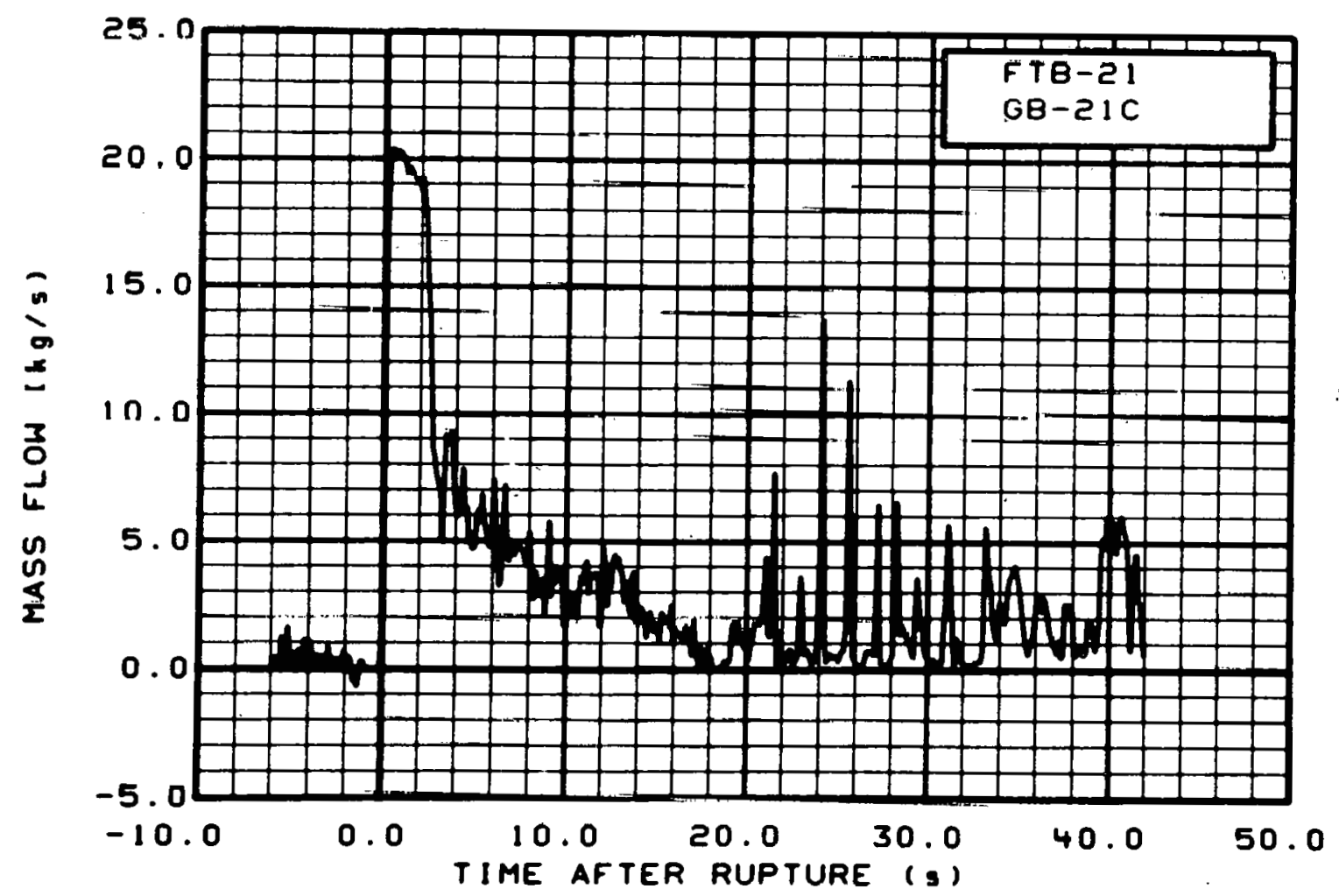

Fig. 338 Mass flow in broken loop (FTB-21, GB-21C), from -6 to $42 \mathrm{~s}$. 


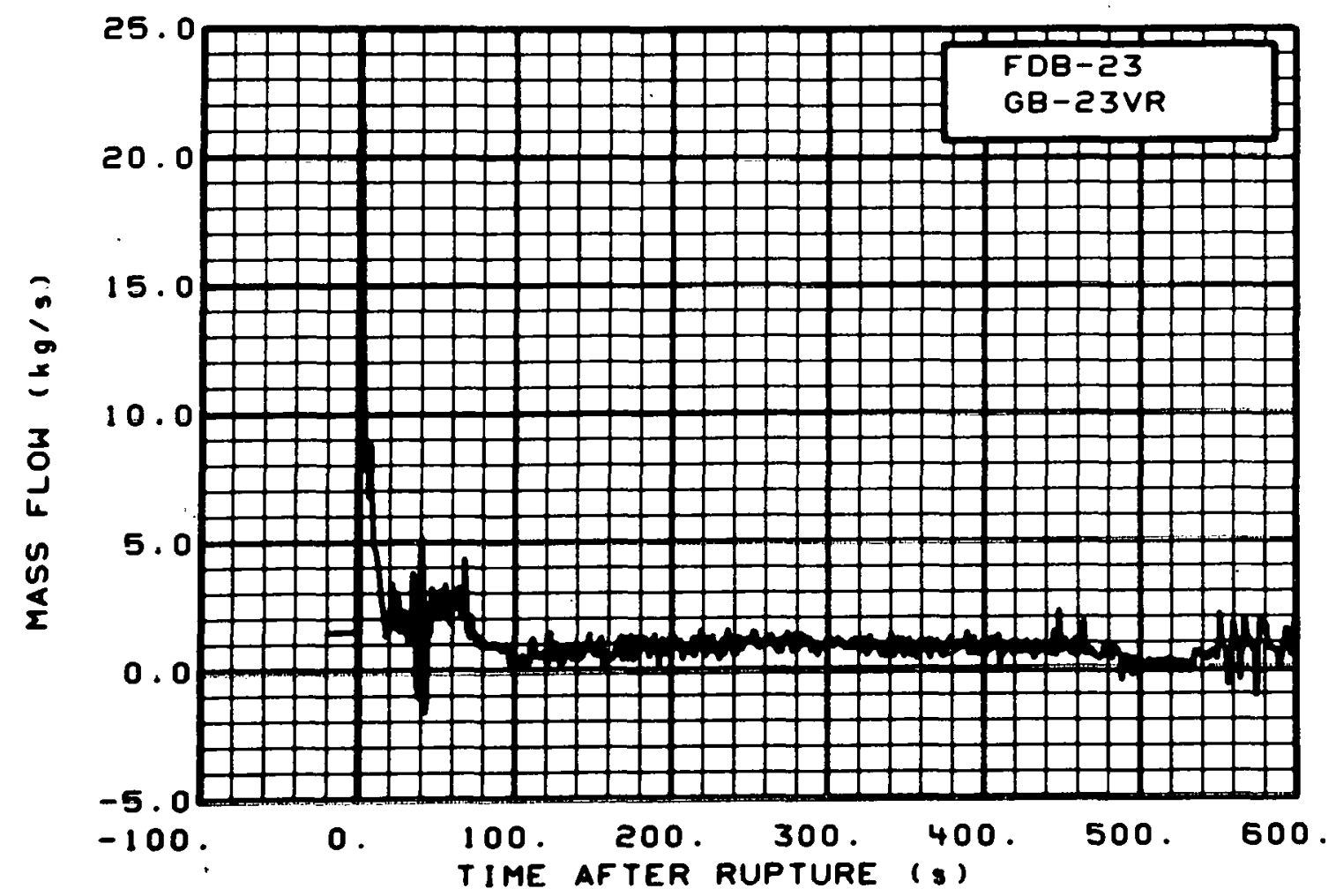

Fig. 339 Mass flow in broken loop (FDB-23, GB-23VR), from -20 to $600 \mathrm{~s}$.

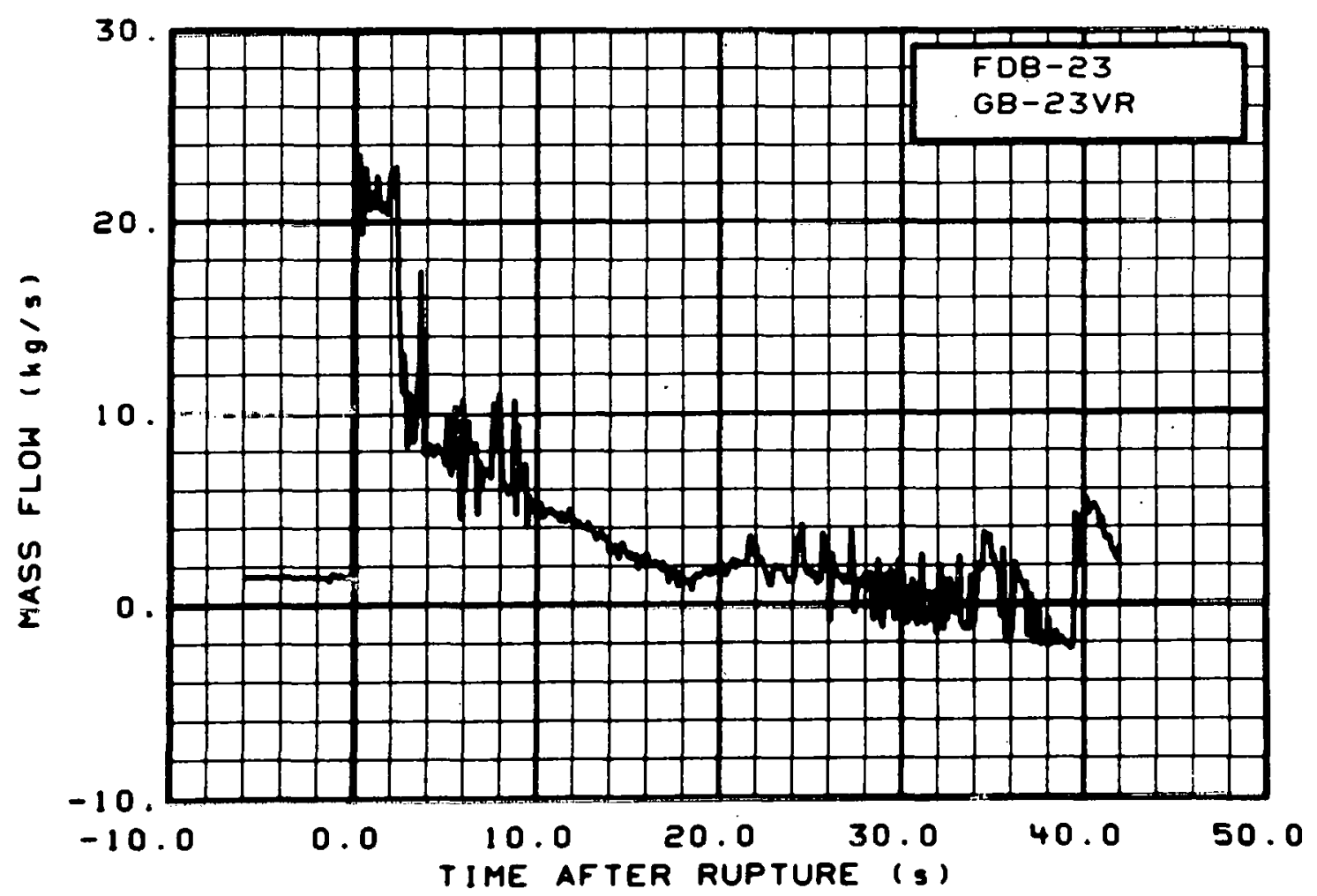

Fig. 340 Mass flow in broken loop (FDB-23, GB-23VR), from -6 to $42 \mathrm{~s}$. 


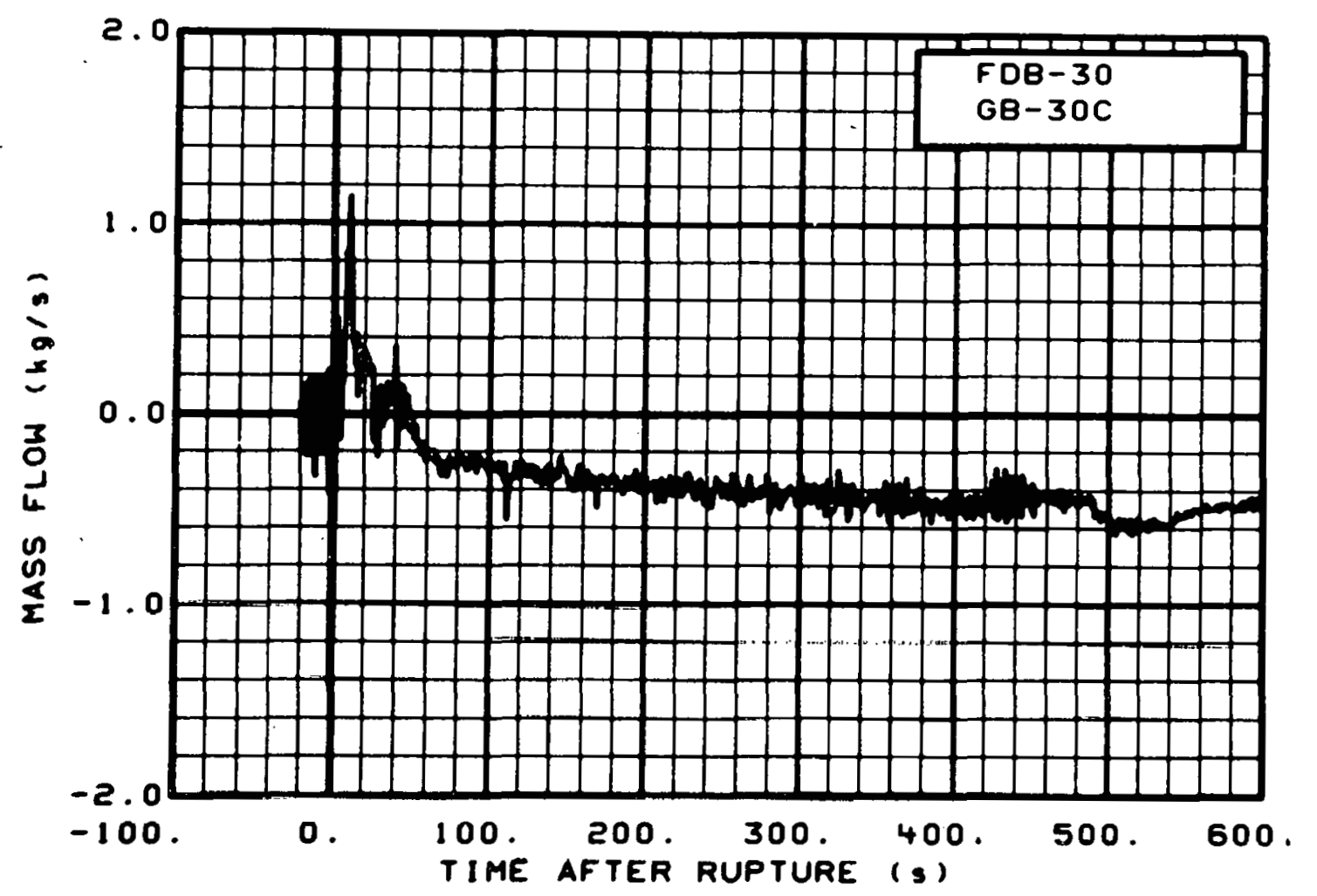

Fig. 341 Mass flow in broken loop (FDB-30, GB-30C), from -20 to $600 \mathrm{~s}$.

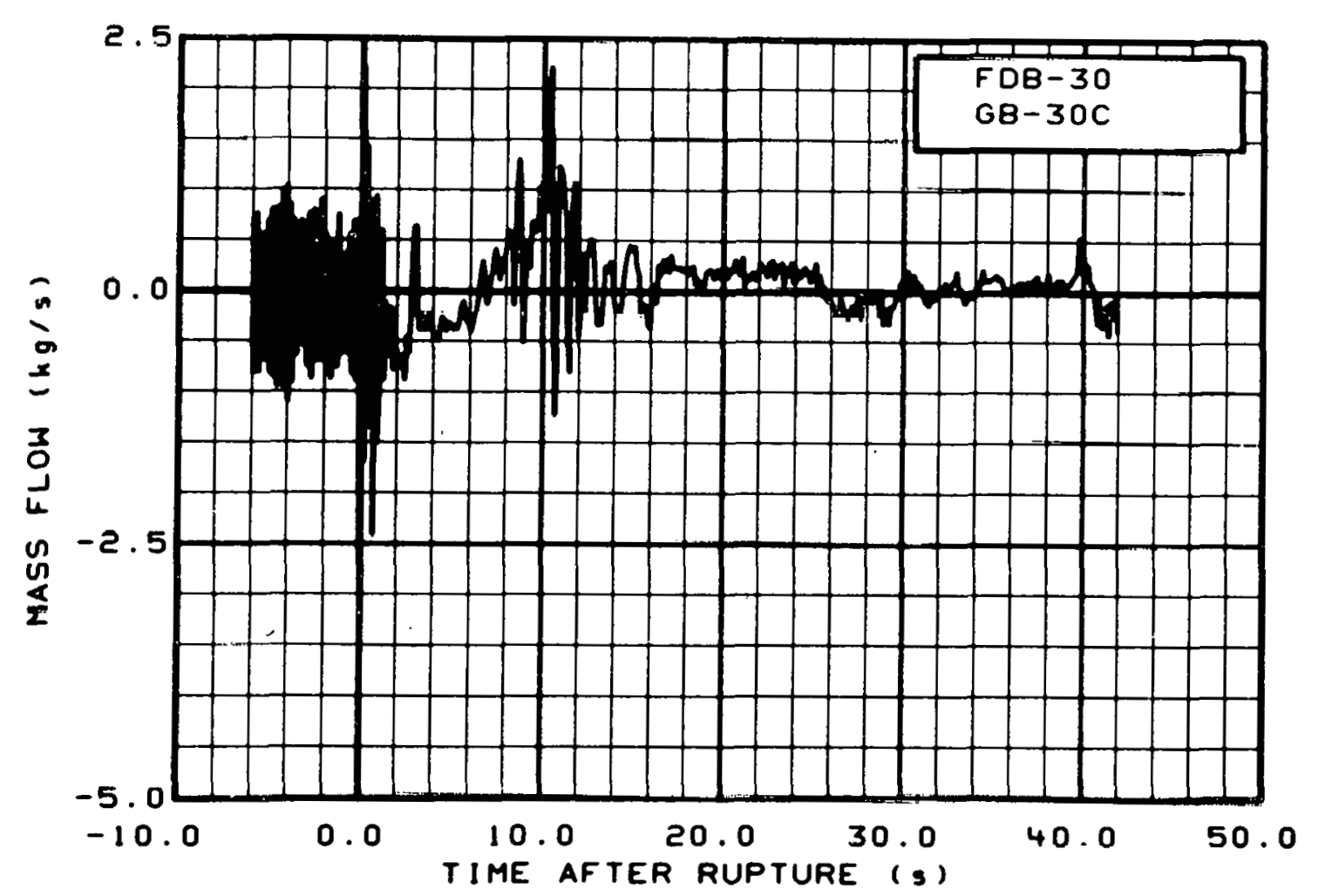

Fig. 342 Mass flow in broken loop (FDB-30, GB-30C), from -6 to $42 \mathrm{~s}$. 


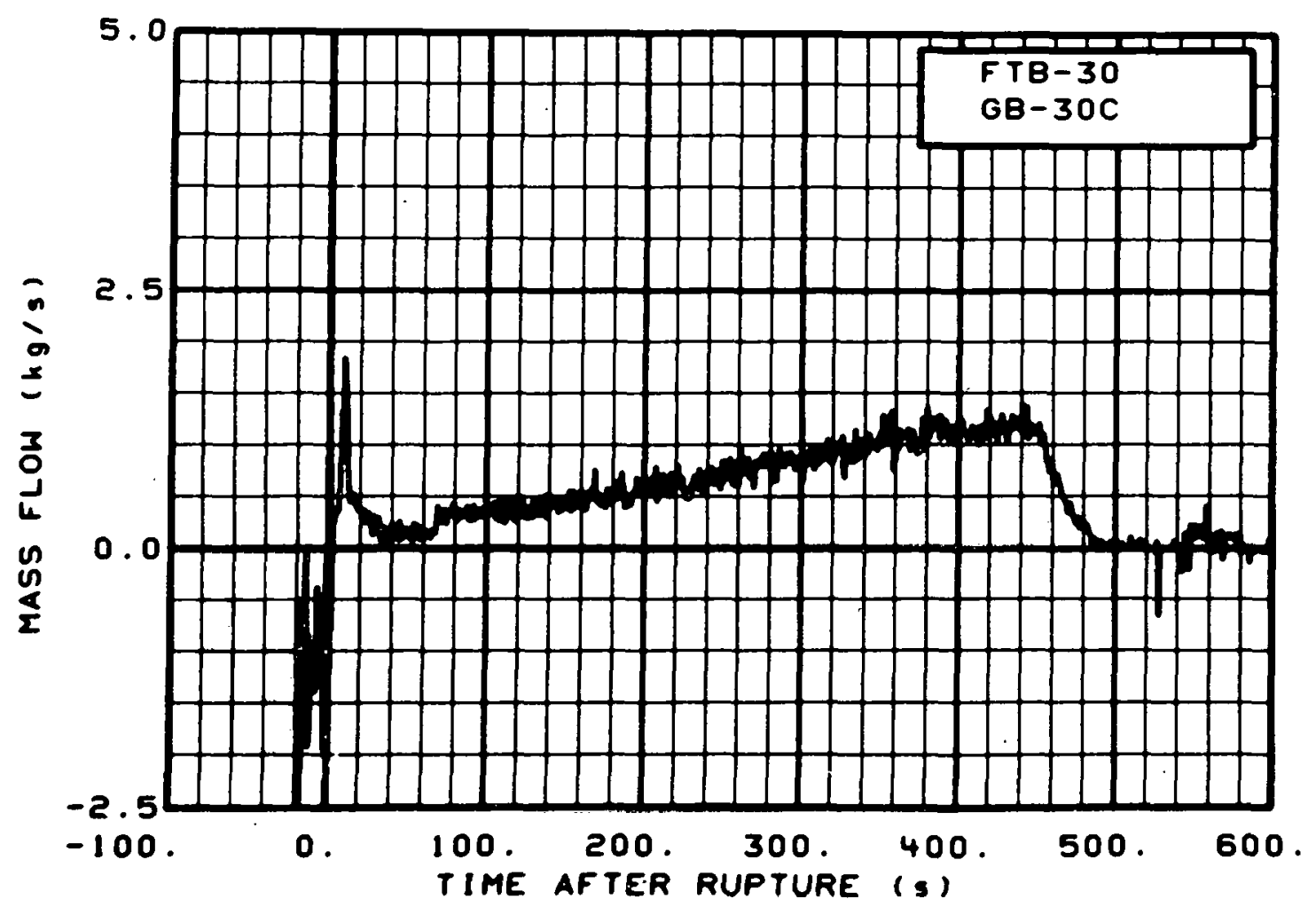

Fig. 343 Mass flow in broken loop (FTB-30, GB-30C), from -20 to $600 \mathrm{~s}$.

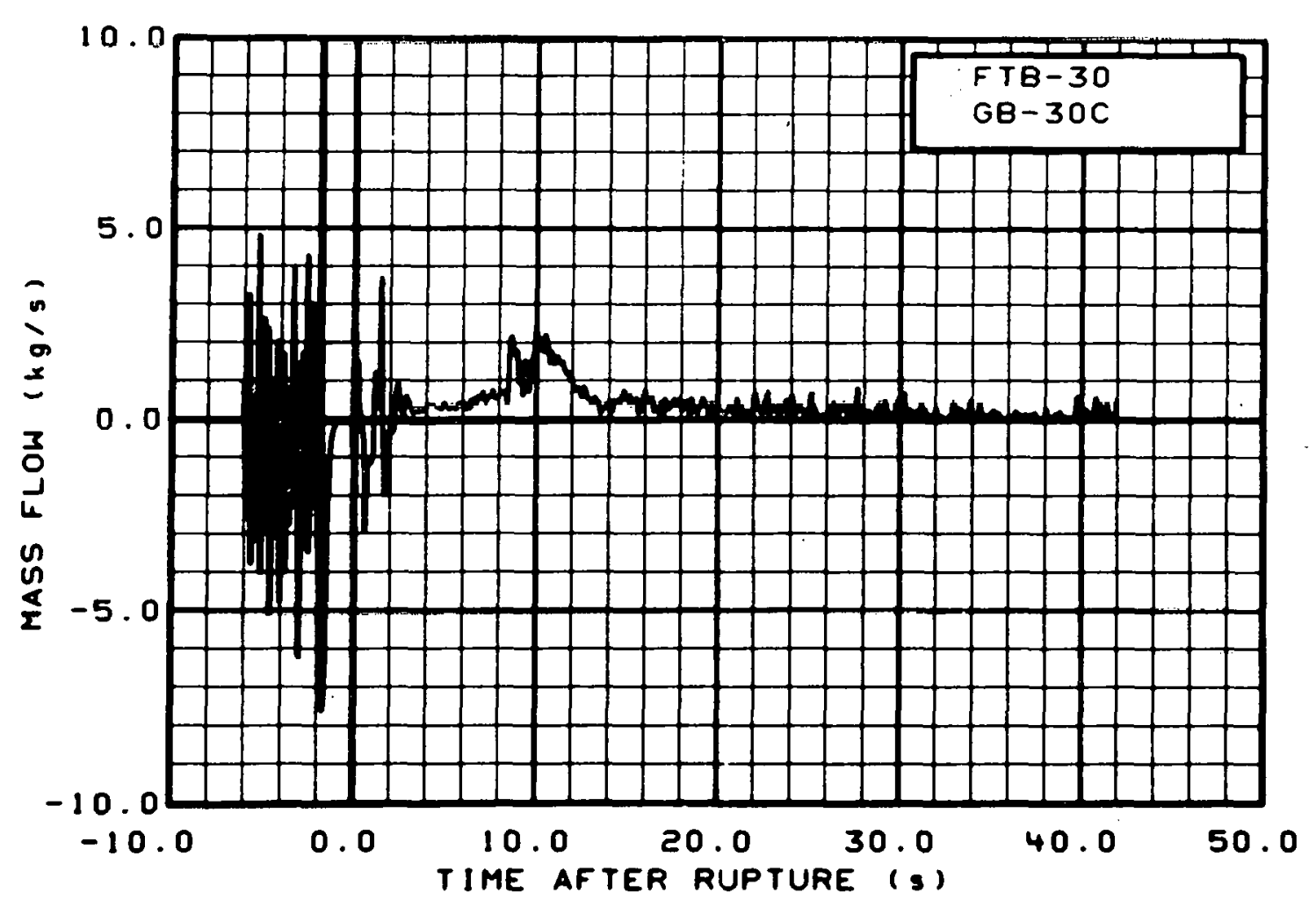

Fig. 344 Mass flow in broken loop (FTB-30, GB-30C), from -6 to $42 \mathrm{~s}$. 


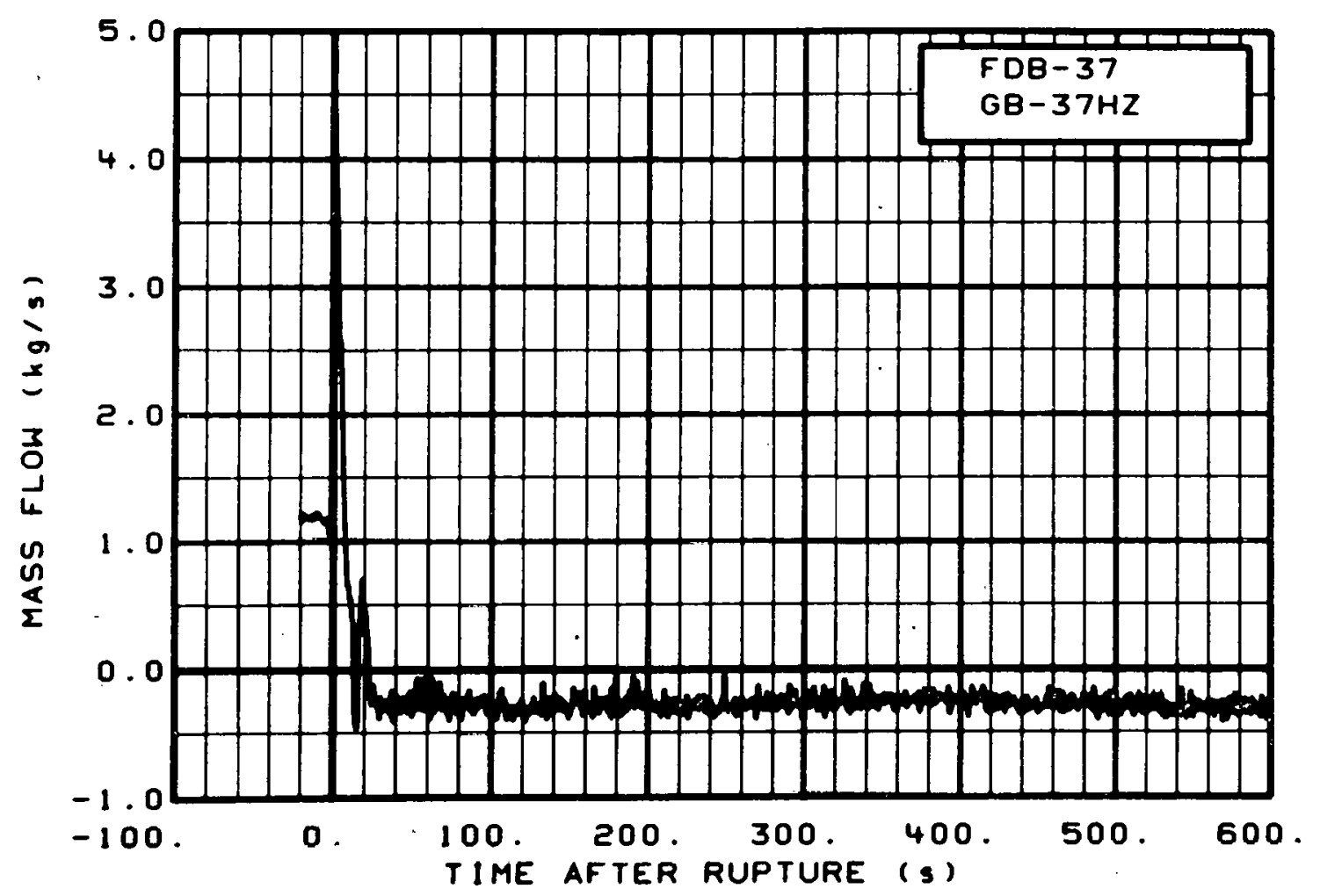

Fig. 345 Mass flow in broken loop (FDB-37, GB-37HZ), from -20 to $600 \mathrm{~s}$.

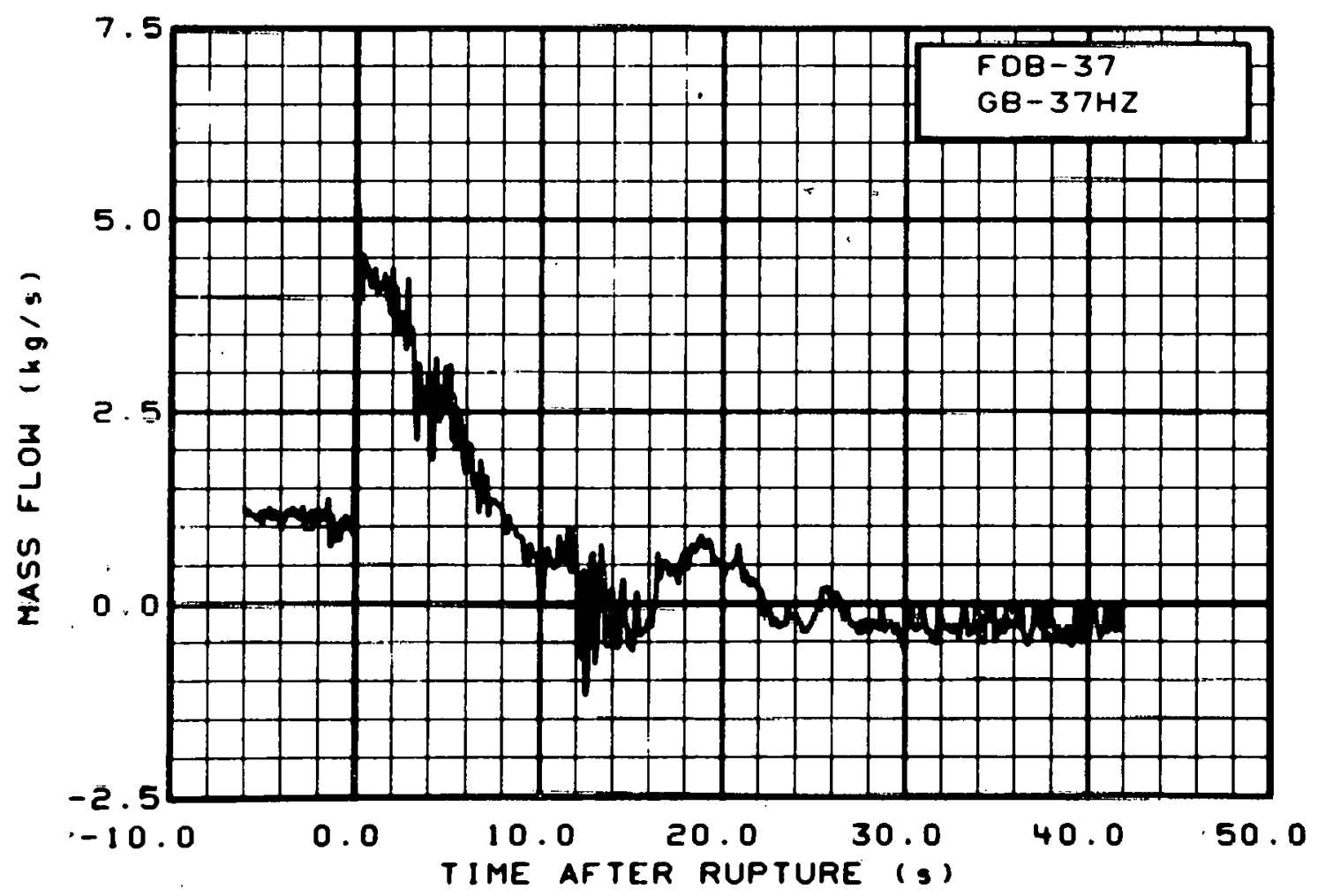

Fig. 346 Mass flow in broken loop (FDB-37, GB-37HZ), from -6 to $42 \mathrm{~s}$. 


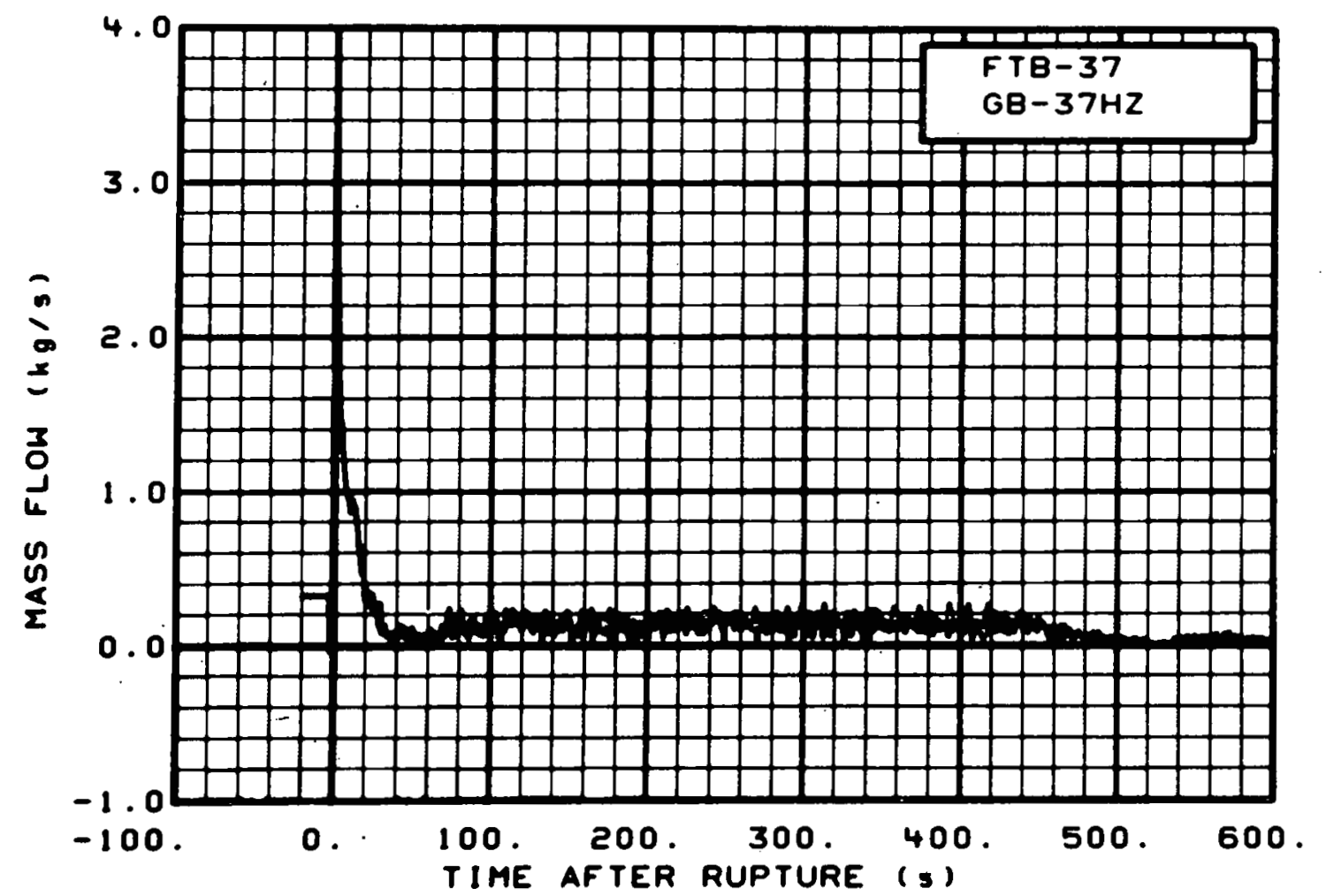

Fig. 347 Mass flow in broken loop (FTB-37, GB-37HZ), from -20 to $600 \mathrm{~s}$.

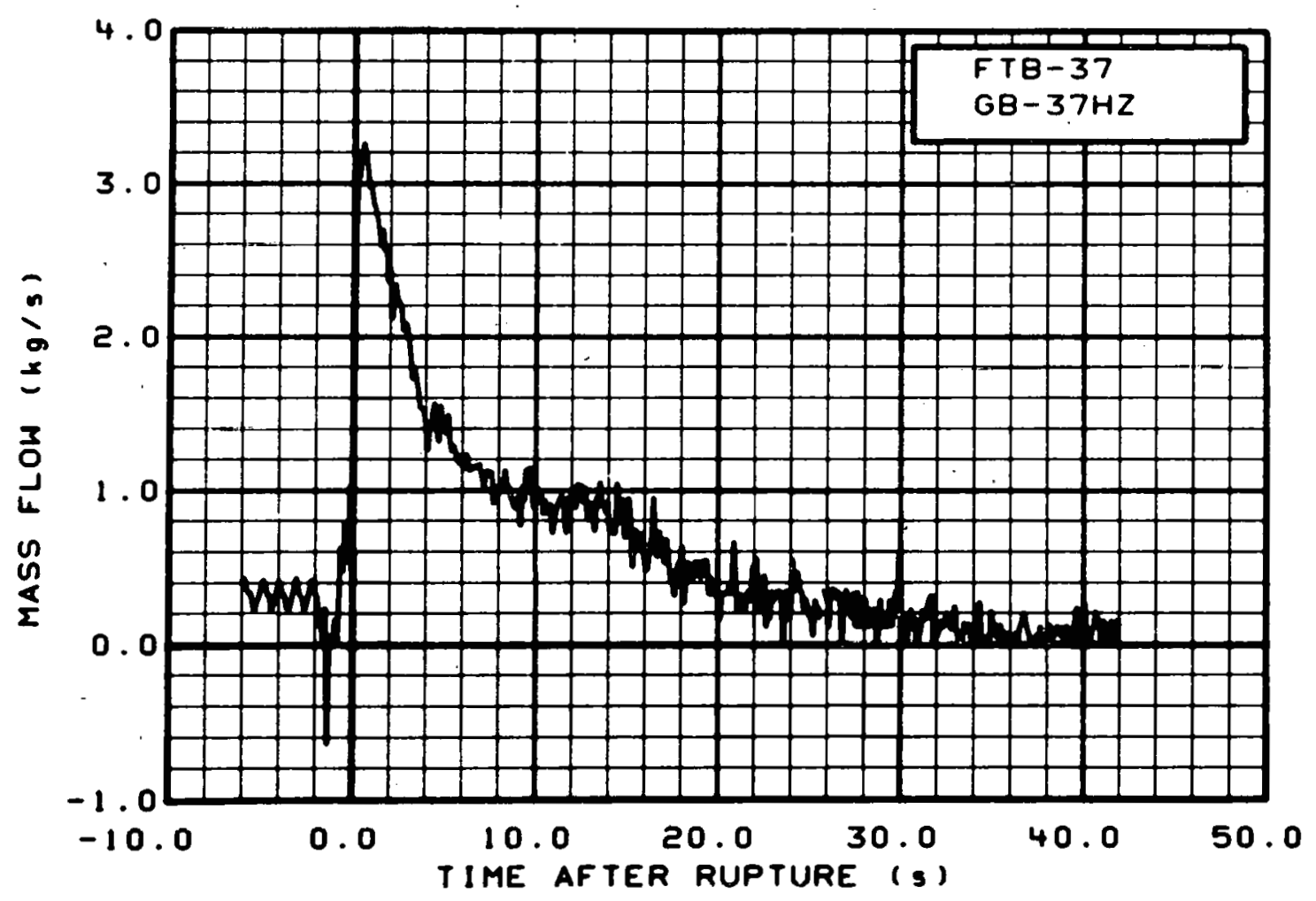

Fig. 348 Mass flow in broken loop (FTB-37, GB-37HZ), from -6 to $42 \mathrm{~s}$. 


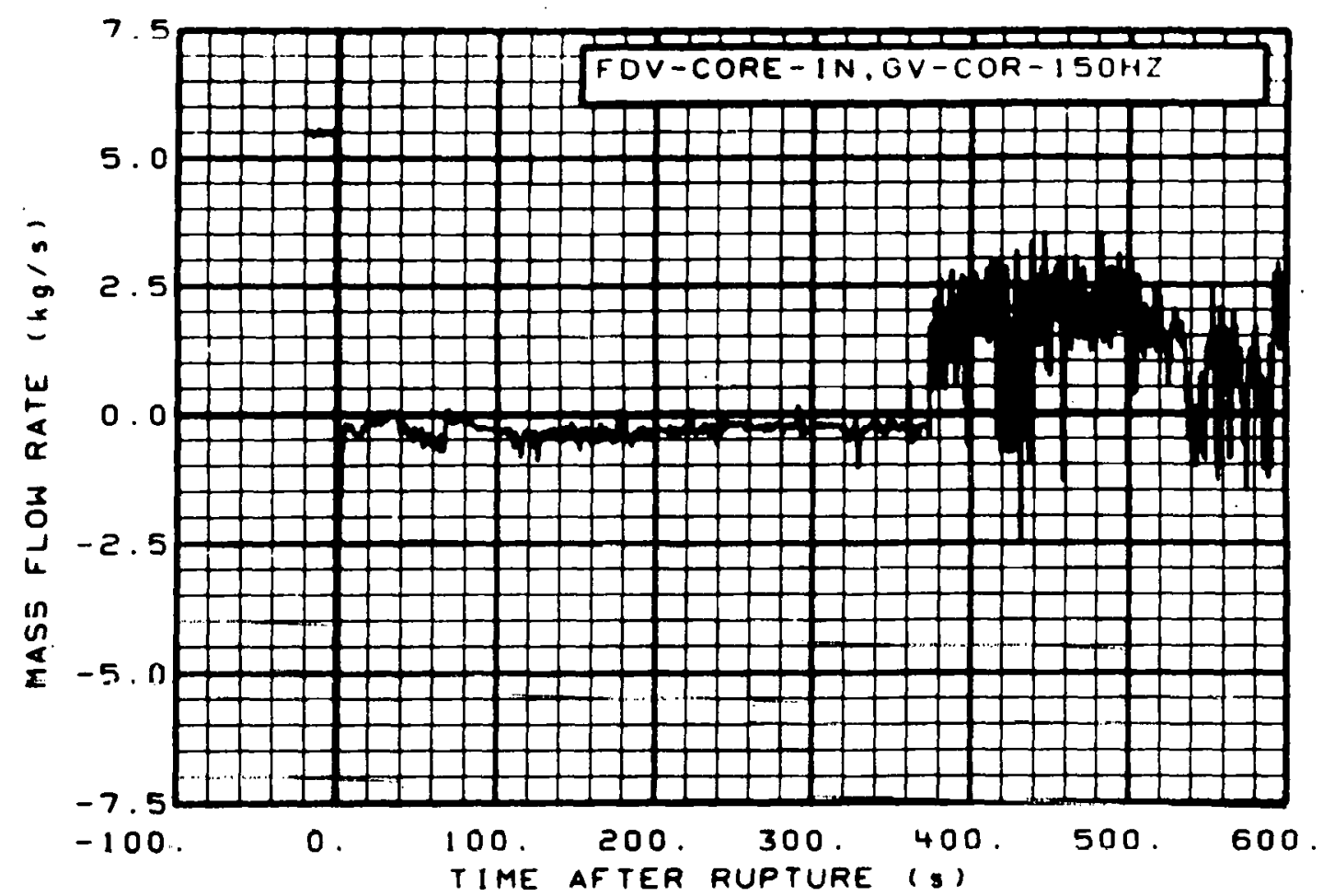

Fig. 349 Mass flow in vessel (FDV-CORE-IN, GV-COR-150HZ), from -20 to $600 \mathrm{~s}$.

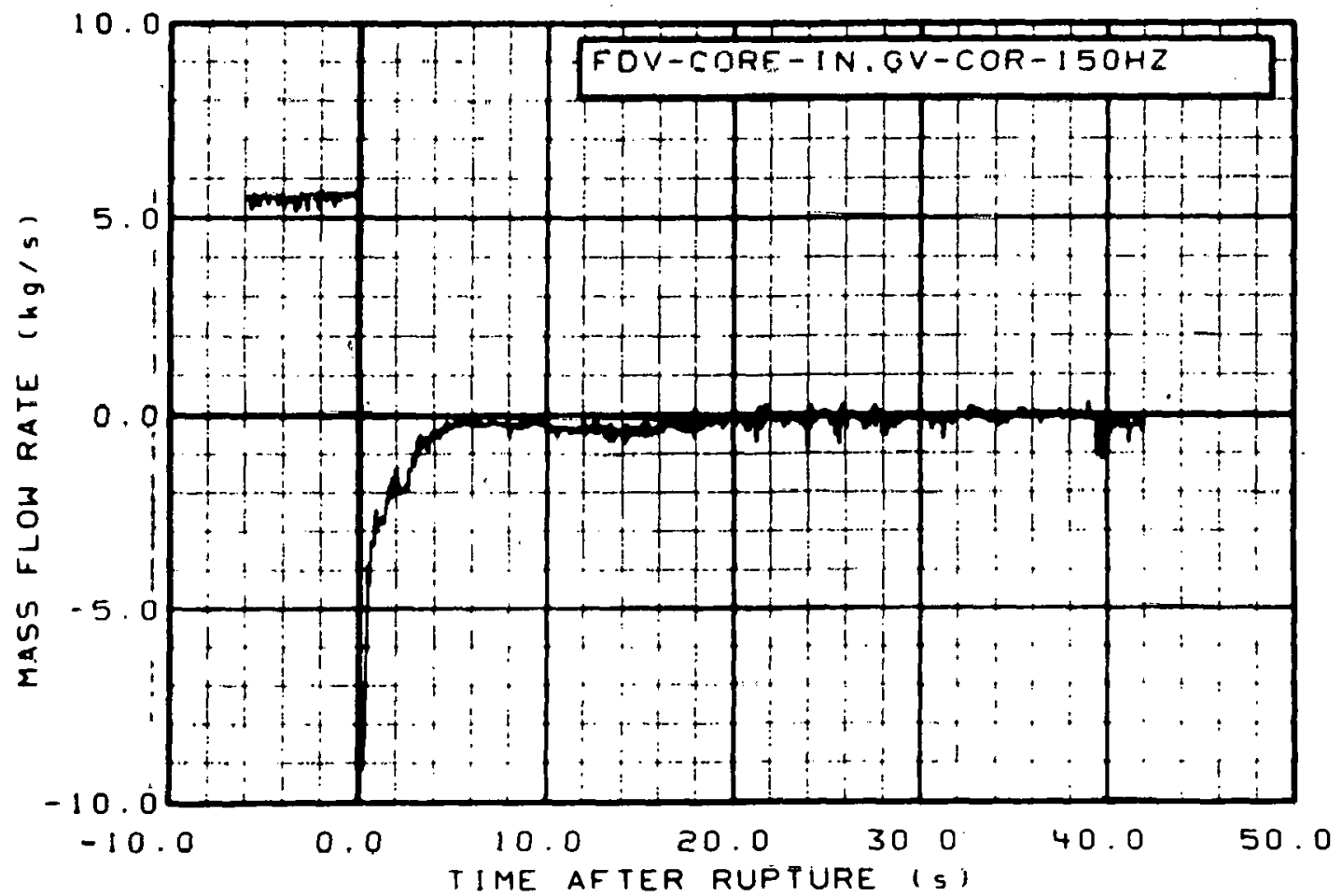

Fig. 350 Mass flow in vessel (FDV-CORE-IN, GV-COR-150Hz), from -6 to $42 \mathrm{~s}$. 


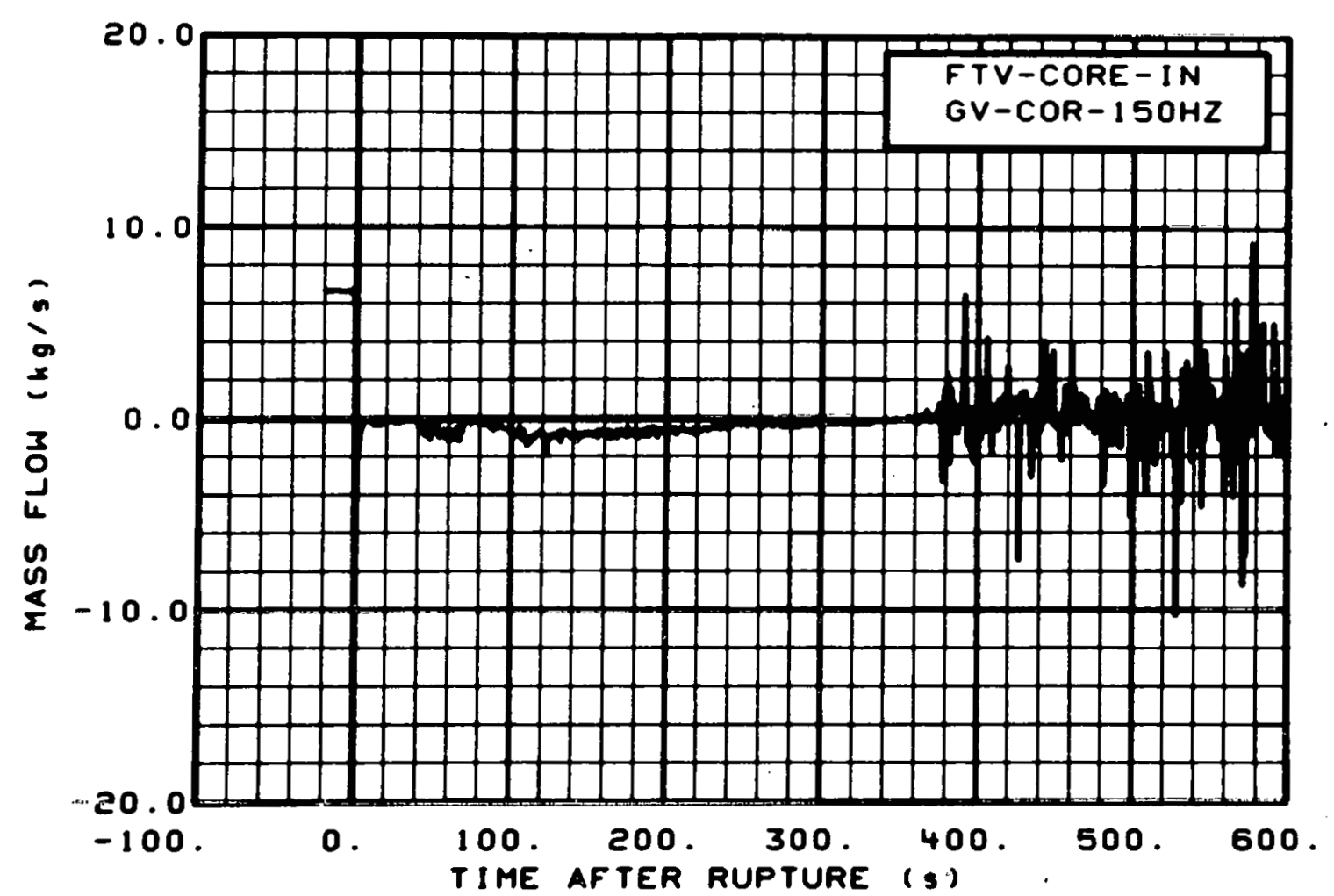

Fig. 351 Mass flow in vessel (FTV-CORE-IN, GV-COR-150HZ), from -20 to $600 \mathrm{~s}$.

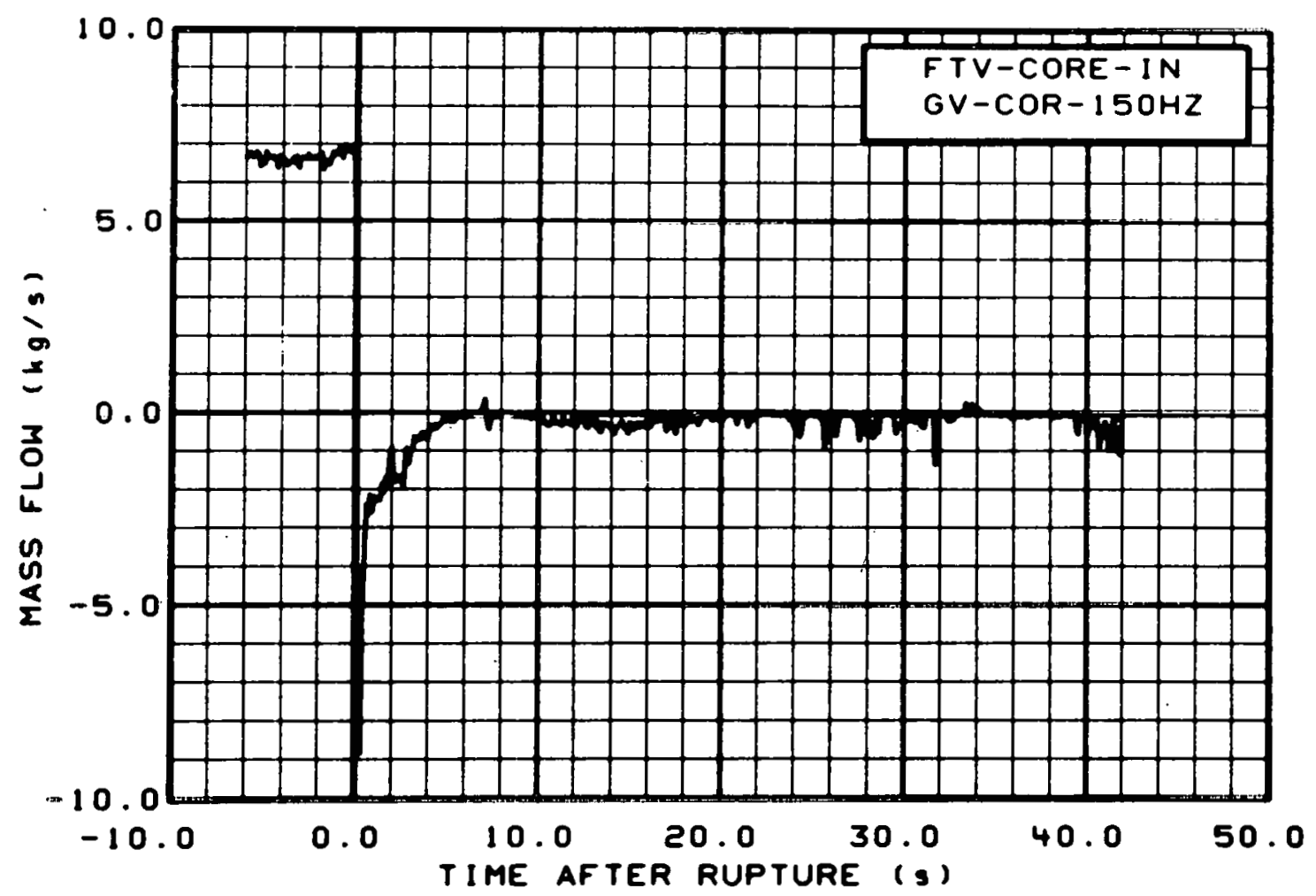

Fig. 35? Mass flow in vessel (FTV-CORE-IN, GV-COR-150HZ), from -6 to 42 s. 


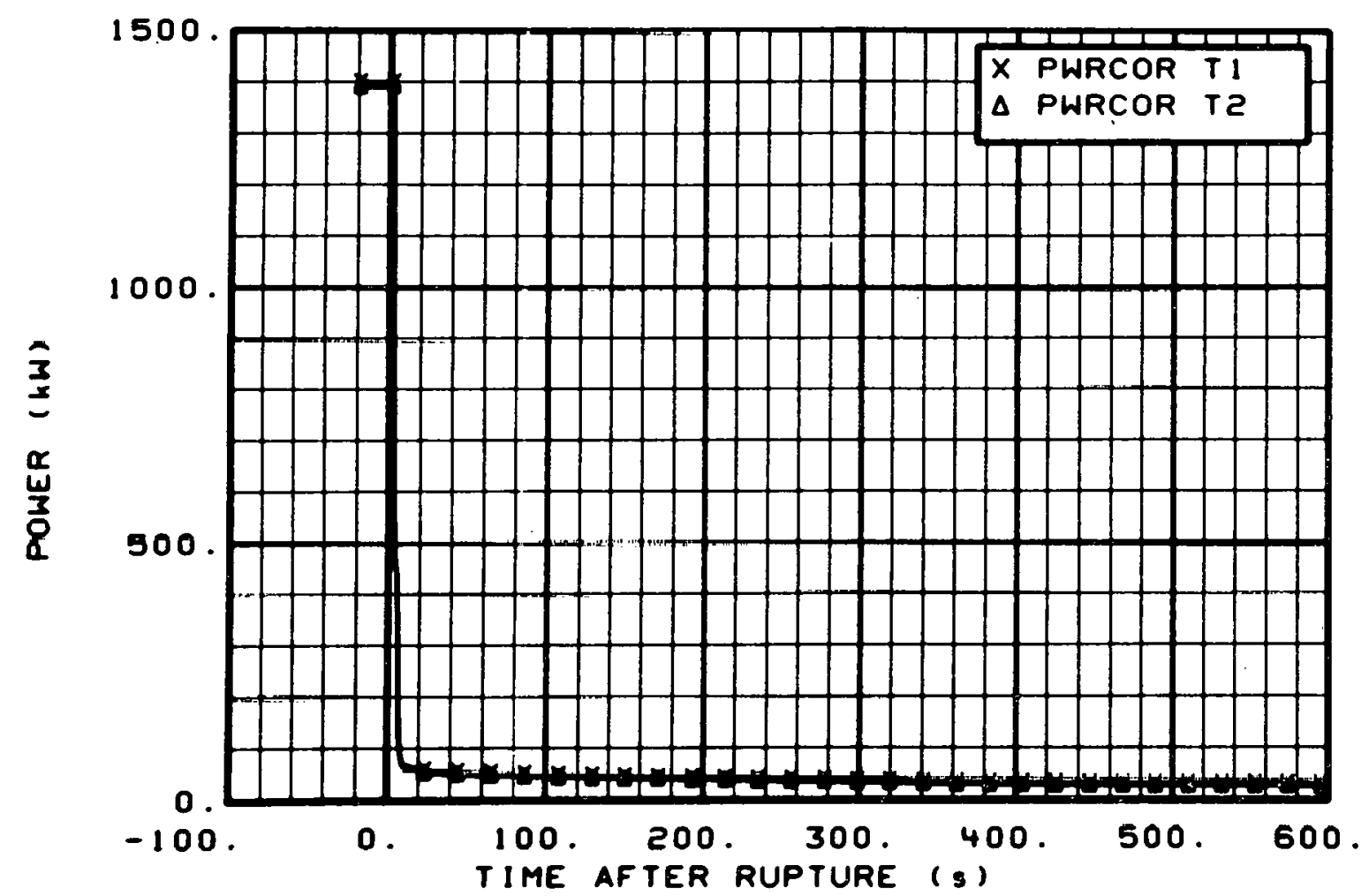

Fig. 353 Core heater rod total power (PWRCOR T-1 and PWRCOR T-2), from -20 to $600 \mathrm{~s}$.

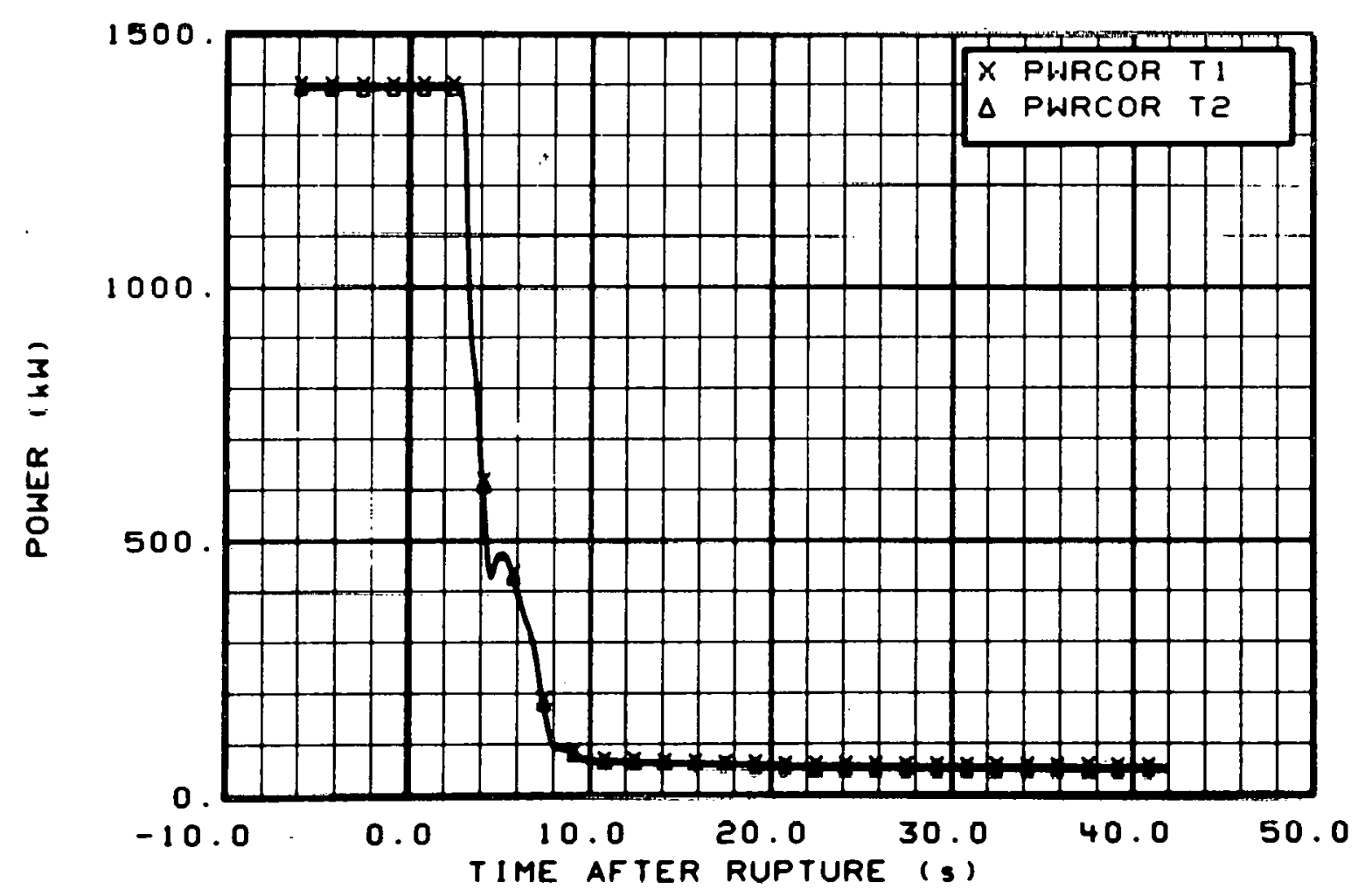

Fig. 354 Core heater rod total power (PWRCOR T-1 and PWRCOR T-2), from -6 to $42 \mathrm{~s}$. 


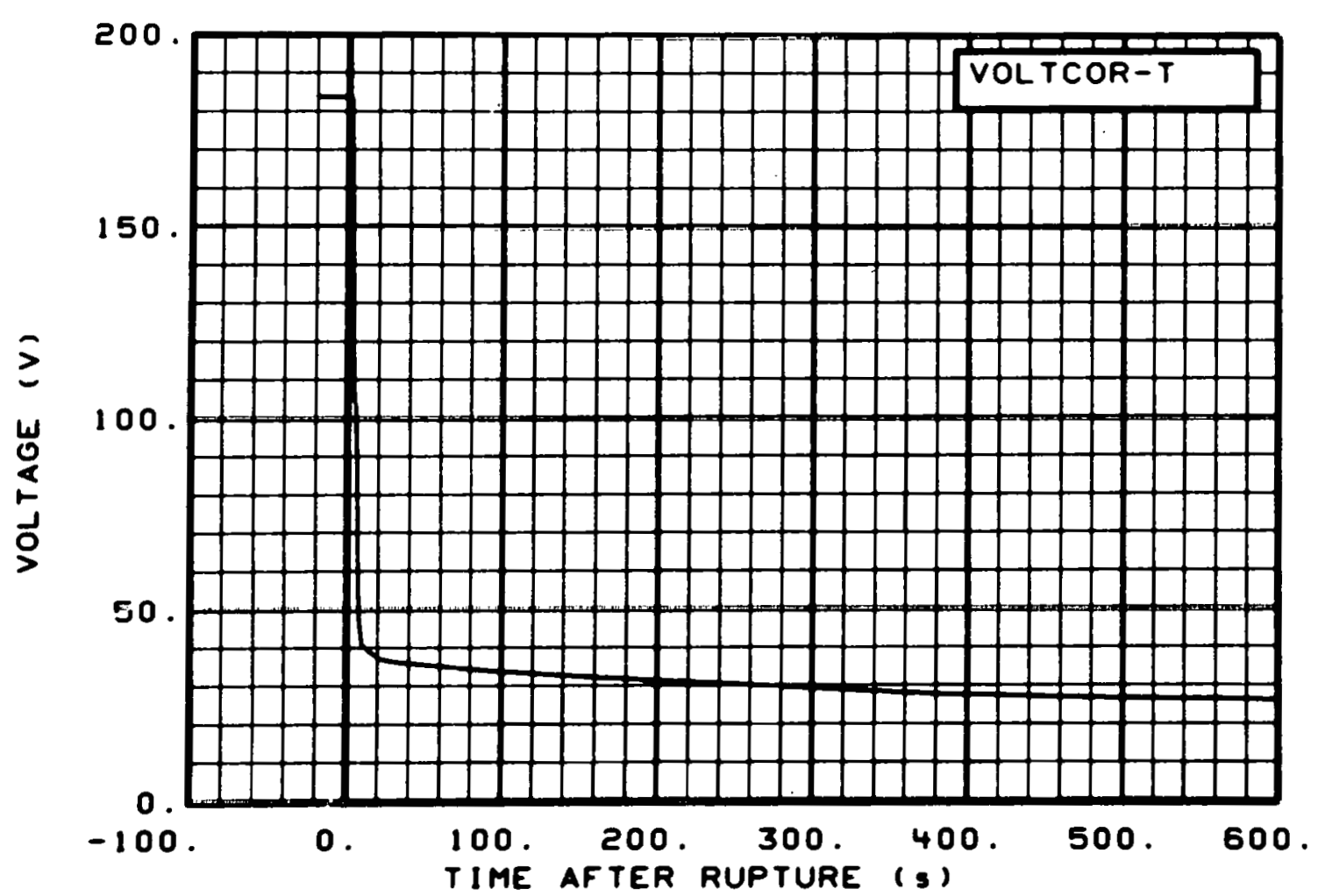

Fig. 355 Core heater voltage (VOLTCOR-T), from -20 to $600 \mathrm{~s}$.

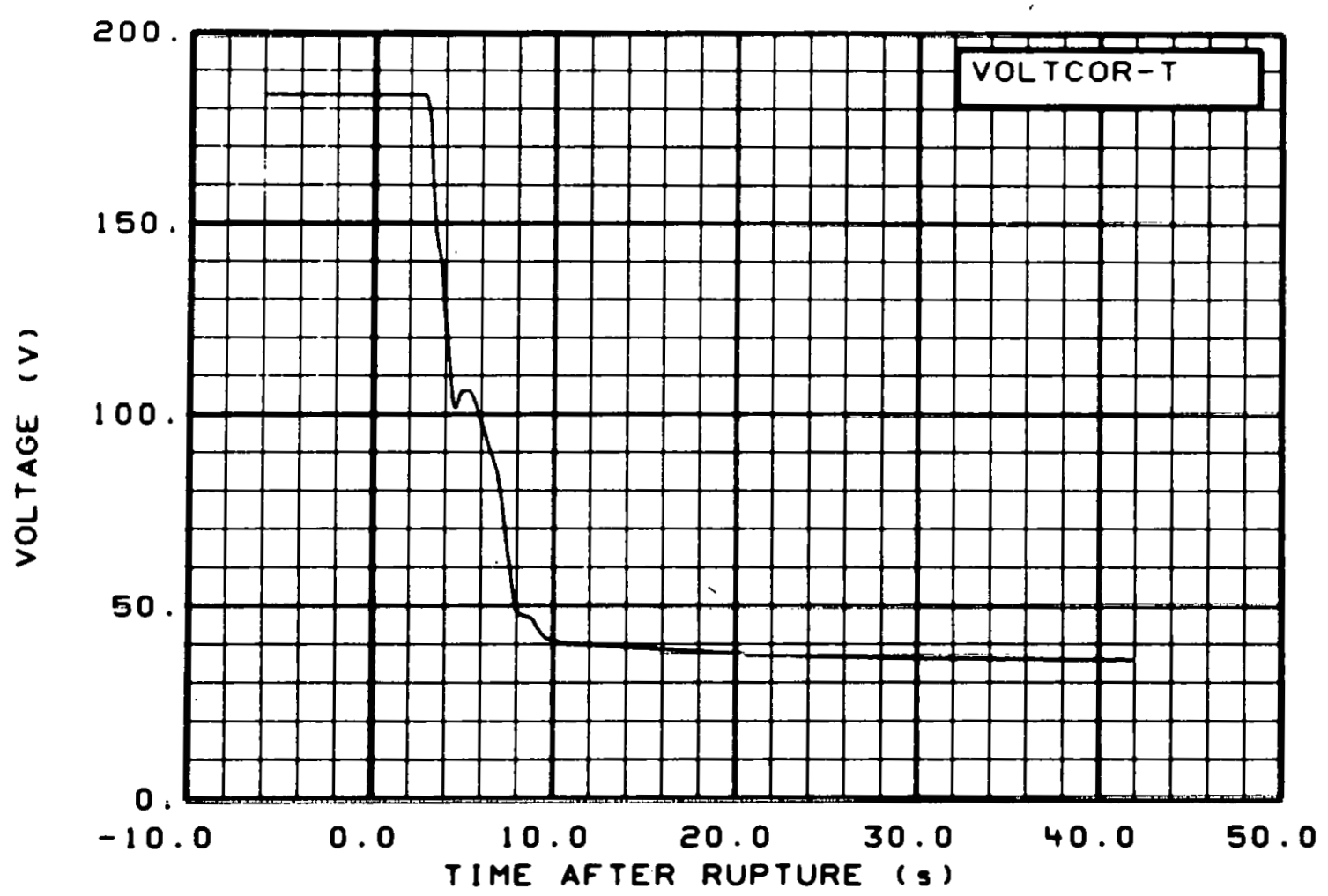

Fig. 356 Core heater voltage (VOLTCOR-T), from -6 to $42 \mathrm{~s}$. 


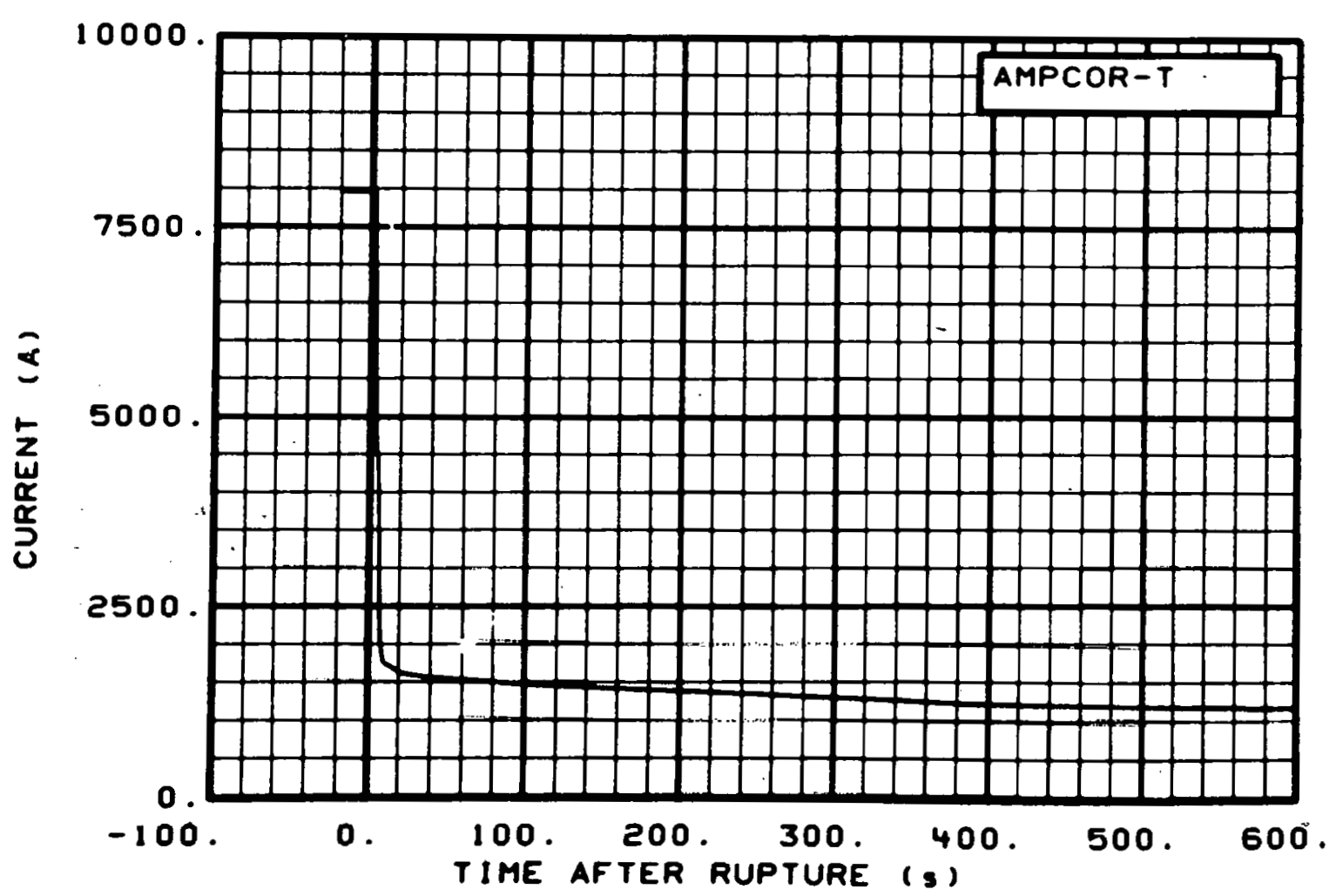

Fig. 357 Core heater total current (AMPCOR-T), from -20 to $600 \mathrm{~s}$.

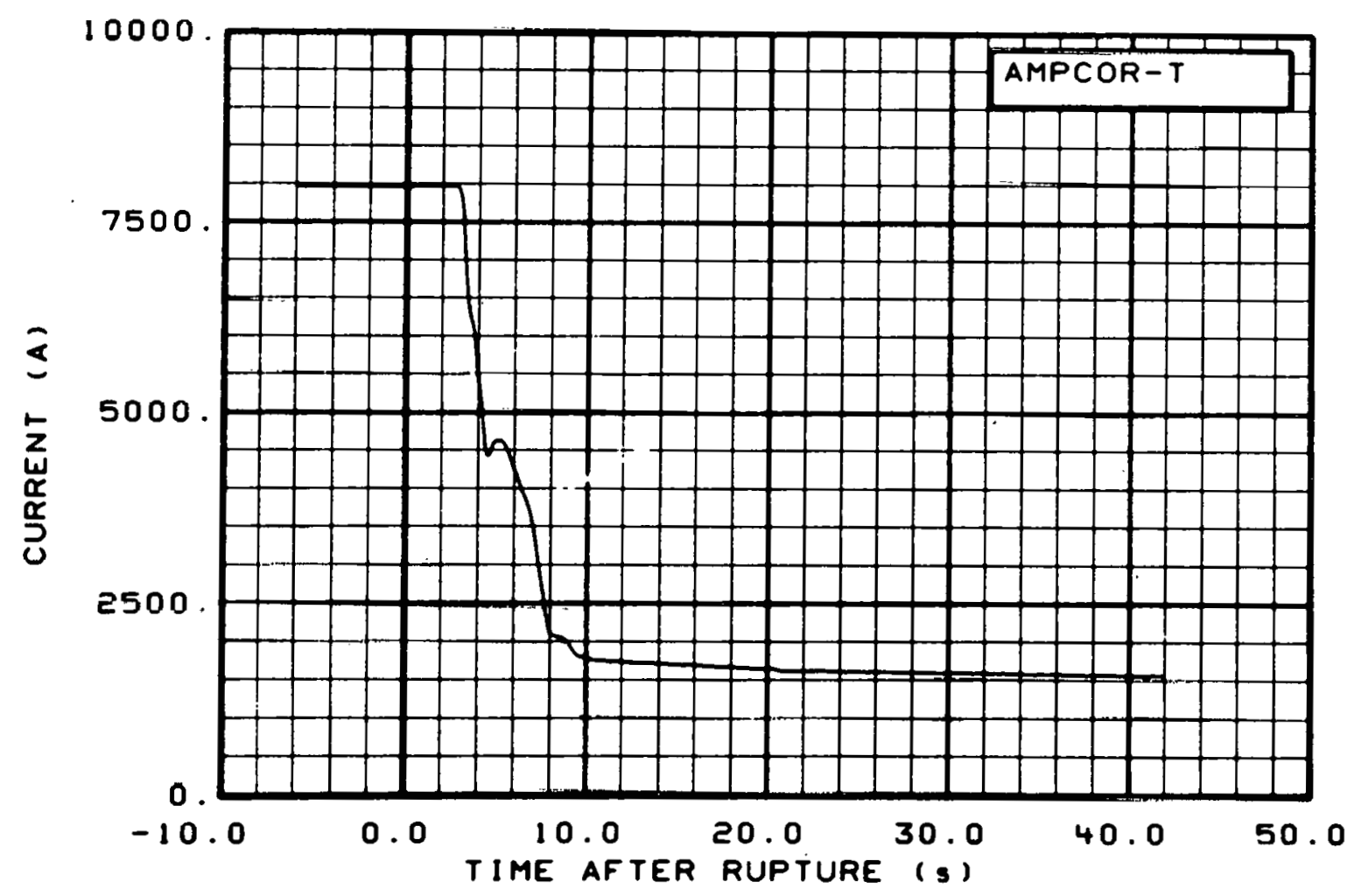

Fig. 358 Core heater total current (AMPCOR-T), from -6 to $42 \mathrm{~s}$. 


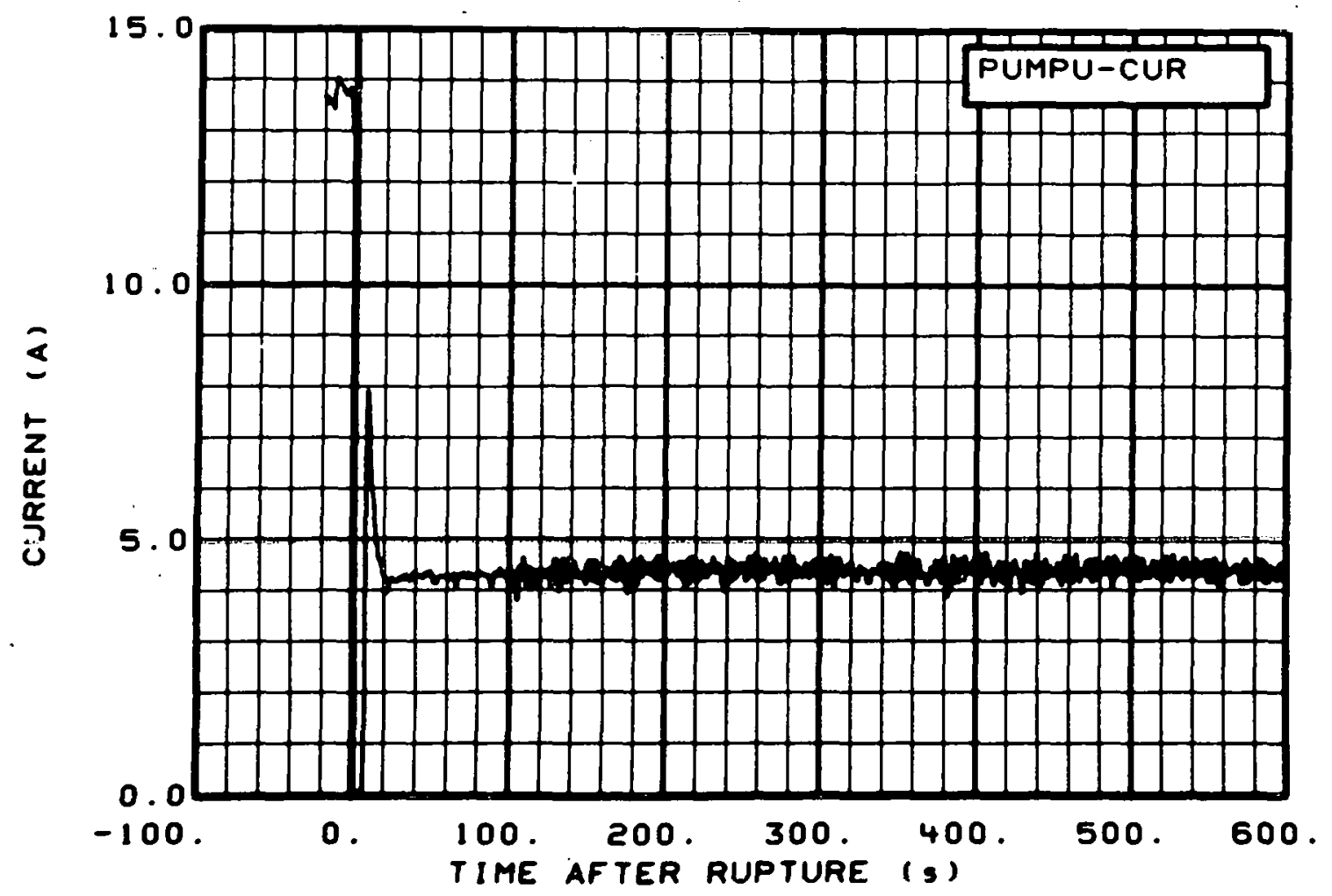

Fig. 359 Primary pump current (PUMPU-CUR), from -20 to $600 \mathrm{~s}$.

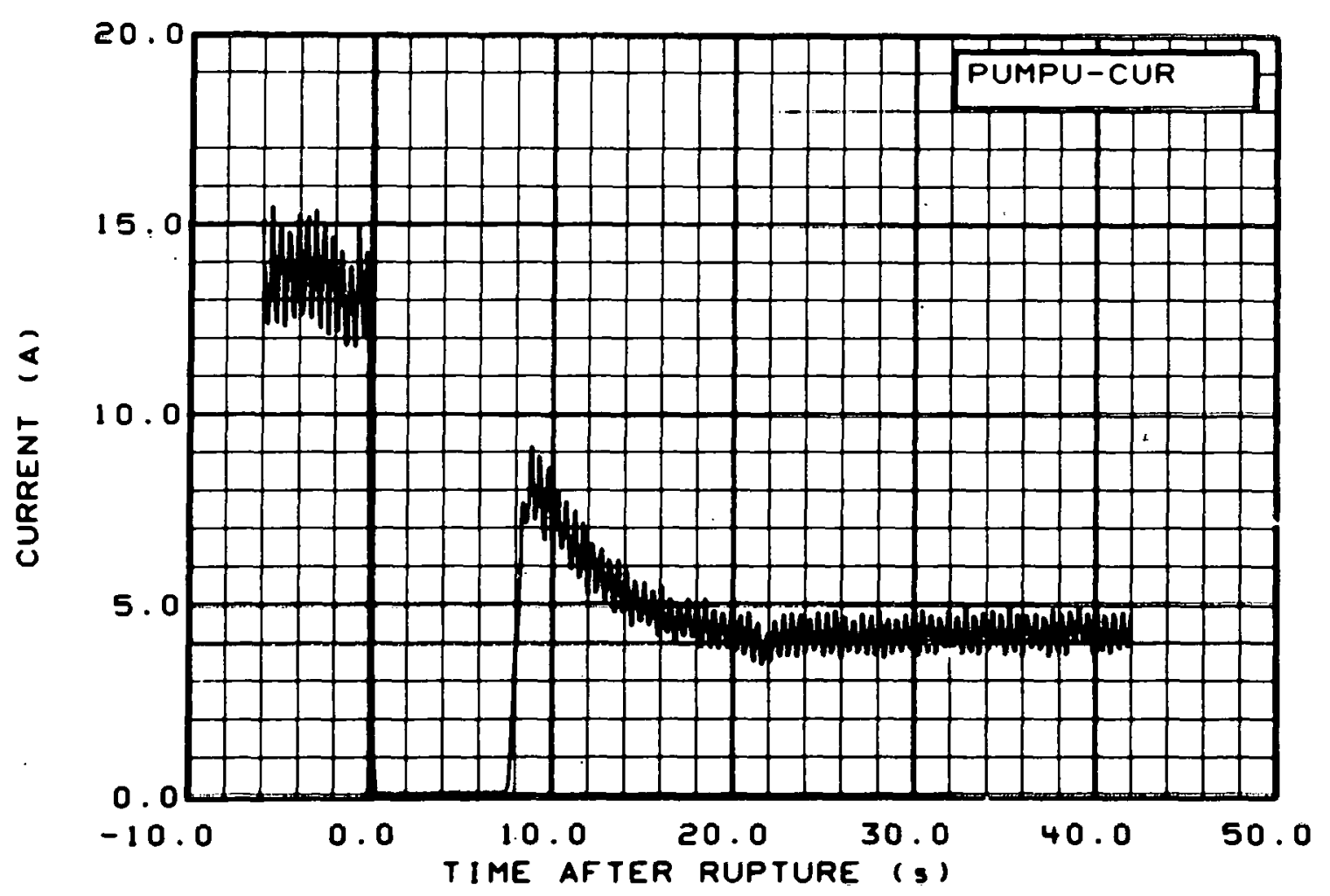

Fig. 360 Primary pump current (PUMPU-CUR), from -6 to $42 \mathrm{~s}$. 


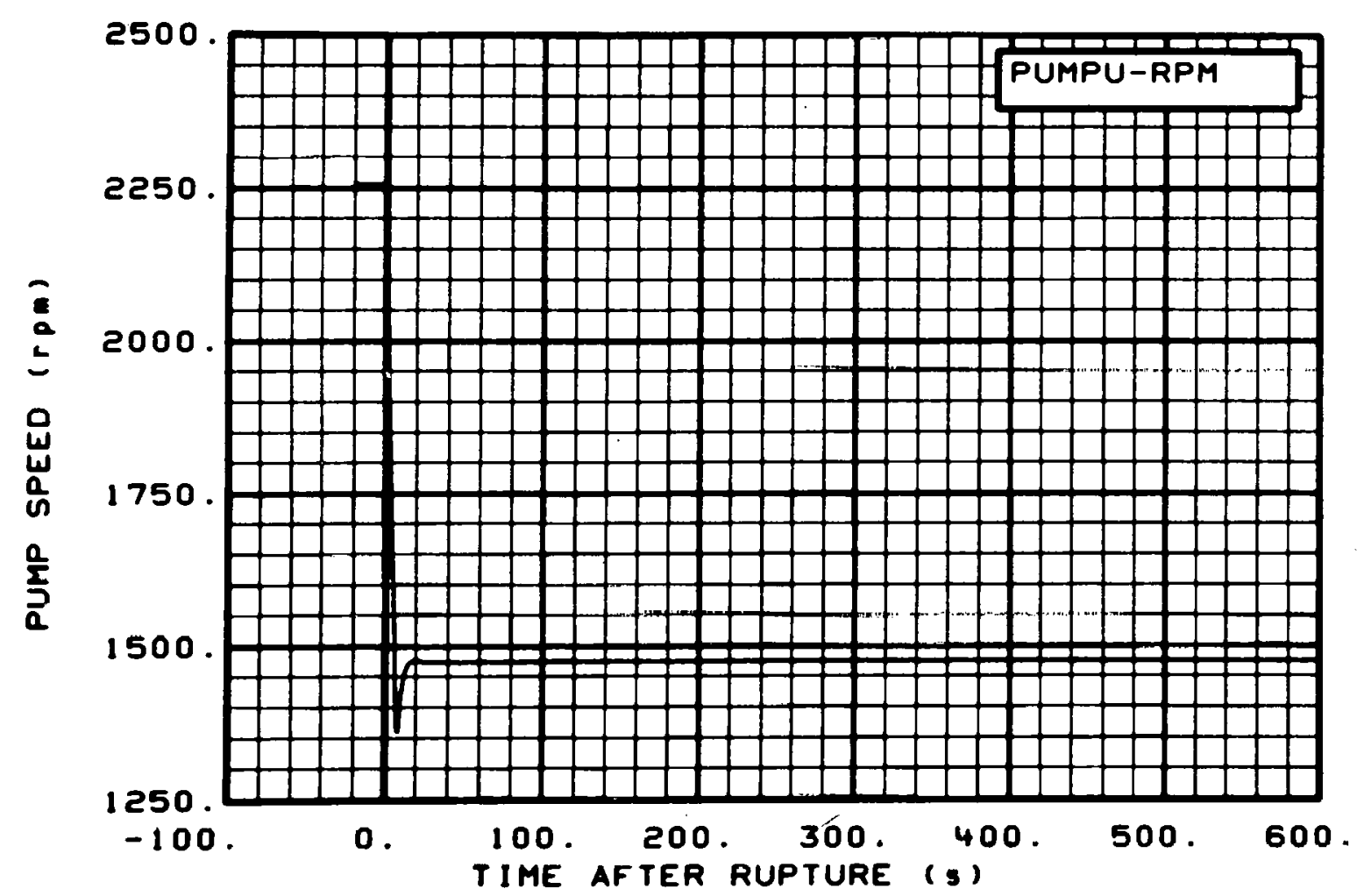

Fig. 361 Primary pump speed (PUMPU-RPM), from -20 to $600 \mathrm{~s}$.

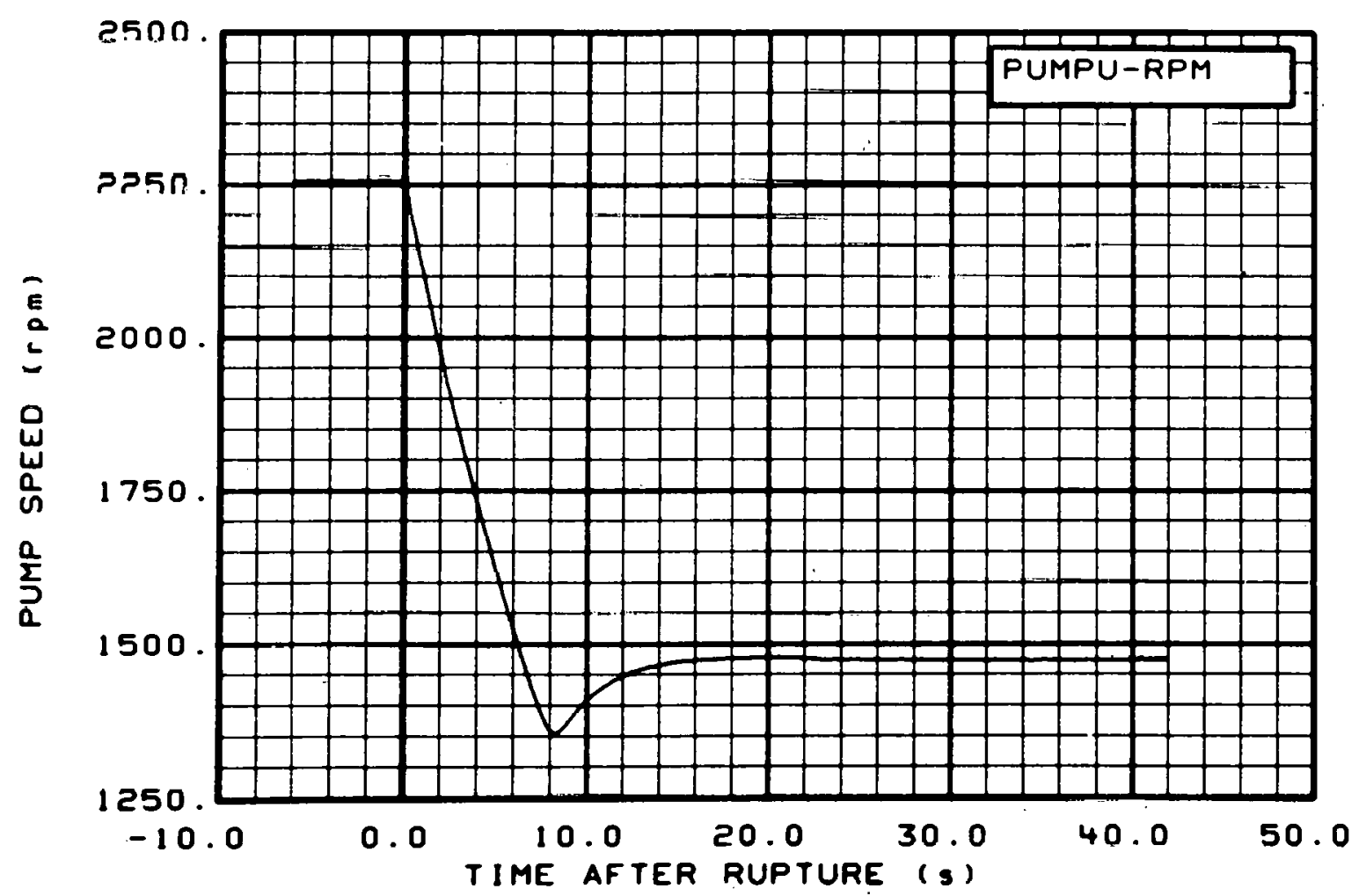

Fig. 362 Primary pump speed (PUMPU-RPM), from -6 to $42 \mathrm{~s}$. 


\section{REFERENCE}

1. E. M. Feldman and D. J. Olson, Semiscale Mod-1 Program and System Description for the Blowdown Heat Transfer Tests (Test Series 2), ANCR-1230 (August 1975). 


\section{THIS PAGE}

\section{WAS INTENTIONALLY \\ LEFT BLANK}


APPENDIX A

\section{DATA ACQUISITION SYSTEM CAPABILITIES}




\section{THIS PAGE \\ WAS INTENTIONALLY \\ LEFT BLANK}




\section{APPENDIX A}

\section{DATA ACQUISITION SYSTEM CAPABILITIES}

The Semiscale Mod-1 system provides for the acquisition, processing, and presentation of test data. Detectors, signal conditioners, signal processors; and recording and display equipment comprise the test data system. The data obtained are principally recorded on an on-line digital system. Selected data channels are also recorded on an analog system.

The on tine digital system is called the digital data acquisition and processing system (DDAPS). The DDAPS has dual and single speed capabilities with identical storage and data output limitations. The dual speed mode is used to extend the recording time when obtaining high frequency data.

From each of up to 240 data channels, the test data system stores 20 blocks of data. Each block of data contains 920 words (each word is the abscissa and ordinate of a data point) of digital information. These 920 words represent a fixed storage display.

The maximum measured throughput rate for the system is 24000 words per second. This throughput rate can be reduced in increments of 100 words per second. The throughput rate, the number of data channels recorded, and the fixed display of 920 words per block determine the time base for displaying the data.

After the data have been stored, data reduction can be made for presentation and analysis purposes. Because of hardware limitations and aesthetic considerations of data presentation, only certain time bases are used when the data are reduced. For data displayed from -20 to $300 \mathrm{~s}$, the recorded data are made to occupy a $320 \mathrm{~s}$ span yielding a time base of $16 \mathrm{~s}$, which is the $320 \mathrm{~s}$ span divided by the 20 blocks of recorded data.

Generally, 920 words from a given data channel are displayed in the nominal time base of $16 \mathrm{~s}$. Integral ( 1 to 20 ) multiples of $16 \mathrm{~s}$ may be used as variations on the nominal time base. Because the output is fixed at 920 words, data compression is done by averaging adjacent data points to give the desired compression. 


\section{THIS PAGE}

\section{WAS INTENTIONALLY}

LEFT BLANK 
APPENDIX B

\section{POSTTEST ADJUSTMENTS TO DATA FROM SEMISCALE MOD-1}

TEST S-28-4 


\section{THIS PAGE}

\section{WAS INTENTIONALLY LEFT BLANK}




\title{
APPENDIX B
}

\section{POSTTEST ADJUSTMENTS TO DATA FROM SEMISCALE MOD-1}

\author{
TEST S-28-4
}

\begin{abstract}
Many of the transducers used in the Semiscale Mod-1 system exhibit significant sensitivity to one or more spurious inputs. Strain gage bridge circuits used in pressure transducers, differential pressure transducers, and drag discs are sensitive to changes in ambient temperature. Differential pressure cells are also sensitive to changes in system pressure. Photomultiplier tubes used as gamma ray detectors in the density transducers are sensitive to temperature changes, as well as to random variations in the locations of the radiation sources. Core power measurements depend on a calibrated resistor, whose resistance changes in value as a function of time and power level as it heats up.
\end{abstract}

Although the errors introduced into the data by spurious secondary inputs generally do not exceed the specified error ranges of the transducers, significant improvement in measurement accuracy can be achieved if the secondary sensitivity can be identified and removed. In the case of the drag discs, corrections are absolutely necessary because the signal due to temperature fluctuations can exceed that due to flow by several hundred percent. Since the exact values of the spurious inputs to which different transducers might be sensitive cannot often be easily predicted and are sometimes inconvenient to measure, secondary effects have been accounted for by correcting the data after the test rather than by using elaborate real time programs in the data acquisition system computer. The methods and results of the posttest data correction analysis for Test S-28-4 are presented in the following paragraphs and tables.

\section{PRESSURE MEASUREMENTS}

Corrections to pressure transducer measurements in the main system loop are based on data taken from the standard reference (Heise) gauge at Spool 4, taken $15 \mathrm{~s}$ before initiation of blowdown and at $300 \mathrm{~s}$ after initiation of blowdown. The pressure readings are adjusted to account for pressure variations around the main loop, using the readings of nearby differential pressure cells. A linear correction is then applied to the pressure data to match the data to the calculated reference data at the two specified time points.

Correction of the pressurizer pressure (PU-PRIZE) is done in the same manner as for the main loop pressures using a Heise gauge installed expressly for this purpose.

The data from the pressure transducer for the pressure suppression system (P-PSS) are corrected to match the process instrumentation at preblowdown conditions. 
Pressure measurement corrections are performed using the data acquisition system (DAS) computer using the following equation:

where

$$
F^{\prime}(t)=c_{0}+C_{1}[F(t)]
$$

$$
\begin{aligned}
& F^{\prime}(t)=\text { corrected data } \\
& F(t)=\text { raw data } \\
& C_{0}=\text { offset, } \mathrm{kPa} \\
& C_{1}=\text { scaling factor. }
\end{aligned}
$$

The values of the offset and scaling factor are given in Table B-I.

TABLE B-I

CONSTANTS FOR PRESSURE MEASUREMENT

CORRECTIONS (TEST S-28-4)

\begin{tabular}{lll}
\hline $\begin{array}{c}\text { Detector } \\
\text { Identification }\end{array}$ & $\frac{C_{0}}{C_{1}}$ & $\frac{c_{1}}{2}$ \\
PU-PRIZE & -108.9 & 0.9990 \\
PB-4\% & -5.3 .8 & 1.0205 \\
\hline
\end{tabular}

\section{DIFFERENTIAL PRESSURE MEASUREMENTS}

Pressure sensitivity in the differential pressure cells in the main system loop is determined from the pretest system pressure check. Digital data are recorded for all measurements at ambient temperature, with no system flow, at pressures of ambient, 1930, $5070,7140,8850,12190$, and $15560 \mathrm{kPa}$. The output of the differential pressure cells is plotted against system pressure, with the resulting plots used to describe the pressure response of the transducers.

Pressure cell ambient offsets are evaluated using a posttest, system-drained digital data scan. The measured transducer outputs are compared with values calculated from the differences in standing leg heights for the sense lines to each pressure cell. The difference between the measured value and the calculated value is the ambient offset. 
For some differential pressure measurements, other references are used. The liquid level measurements in the intact loop accumulator (DPU-ACC1-TB), the broken loop accumulator (DPB-ACC2-TB), and the steam generator secondary injection accumulator (DPU-SGS3-TB) are referenced to calculated values based on geometrical considerations at the time when the water is depleted from the accumulators and gas flow begins.

In correcting differential pressure data for pressure sensitivity, the data are initially corrected for errors in amplification and ambient offsets. The data are then corrected for pressure sensitivity to arrive at the final values. Corrections were made using the following equations:

where

$$
\begin{aligned}
& F^{\prime}(t)=\text { data corrected for amplification and ambient offsets, } k P a \\
& k=\text { amplification factor } \\
& F(t)=\text { raw data, } k P a \\
& C_{0}=\text { ambient offset, } k P a \\
& F^{\prime \prime}(t)=F^{\prime}(t)+C_{1} \text { for } t<t_{1} \\
& F^{\prime \prime}(t)=\quad F^{\prime}(t)+C_{i}+\frac{t-t_{i}}{t_{i+1}-t_{i}}\left(C_{i+1}-C_{i}\right) \text { for } t_{i} \leqslant t \leqslant t_{i+1} \\
& F^{\prime \prime}(t)=\quad F^{\prime}(t)+C_{n} \text { for } t>t_{n}
\end{aligned}
$$

where

$$
\begin{aligned}
& \mathrm{t}=\text { time } \\
& \mathrm{F}^{\prime \prime}(\mathrm{t})=\text { final corrected data } \\
& \mathrm{C}_{\mathrm{i}}=\text { data correction points } \\
& \mathrm{t}_{\mathrm{i}}=\text { times corresponding to data correction points. }
\end{aligned}
$$

The values of the constants are given in Table B-II. 


\begin{tabular}{|c|c|c|c|c|c|c|c|c|}
\hline $\begin{array}{c}\text { Detector } \\
\text { Identification } \\
\end{array}$ & $K$ & $\mathrm{C}_{0}$ & $c_{1}$ & $\underline{t_{1}}$ & $c_{2}$ & $t_{2}$ & $c_{3}$ & $t_{3}$ \\
\hline DPV-0-9GQ & 1 & & -2.55 & 0 & -2.28 & 0.01 & -0.34 & 36 \\
\hline DPV-9-166QQ & 1 & & 0.34 & 0 & 0.28 & 0.01 & 0 & 36 \\
\hline DPV-9-260Q & 1 & & 0.41 & 0 & 0.37 & 0.01 & 0.07 & 36 \\
\hline DPV-26-55QM & 1 & -0.60 & -1.59 & 0 & -1.45 & 0.01 & -0.21 & 36 \\
\hline$D P V-166 Q+10$ & 1 & 2.81 & & & & & & \\
\hline DPU-PRESLL & 1 & 1.20 & & & & & & \\
\hline DPU-PR-4 & 1 & -1.59 & & & & & & \\
\hline DPU-SGS- 6 & -7 & & & & & & & \\
\hline DPU-SG-SEC & 1 & -4.18 & & & & & & \\
\hline DPU-SGSJ-TD & 1 & -5.10 & & & & & & \\
\hline DPU-7-10 & 1 & 2.15 & & & & & & \\
\hline DPU-12-15 & 0.5 & & & & & & & \\
\hline DPU-ACCl - TB & 1 & -10.34 & & & & & & \\
\hline DPB-38-40 & 0.5 &. & & & & & & \\
\hline DPB-ACC2-TB & 1 & -1.2 .07 & & & & & & \\
\hline DPB-42-HN] & -1 & & & & & & & \\
\hline DPU-15-3 & 1 & -4.27 & & & & & & \\
\hline UHU-15-3L & 1 & -4.21 & & & & & & \\
\hline
\end{tabular}

\section{MOMENTUM FLUX MEASUREMENT}

The temperature sensitivity of drag discs is determined from pretest warmup data taken at 366 and $533 \mathrm{~K}$ with no system flow. The temperature and pressure sensitivity is removed before the data are converted to momentum flux. The temperature of each transducer is taken from the signal of a nearby fluid or metal temperature thermocouple. 
Slight corrections for errors in setting the transducer output to zero at ambient condition are also made at this time. Corrections are made using the following equation:

$$
F^{\prime}(t)=F(t)+C_{0}-T_{1} T(t)-P_{1} P(t)
$$

where

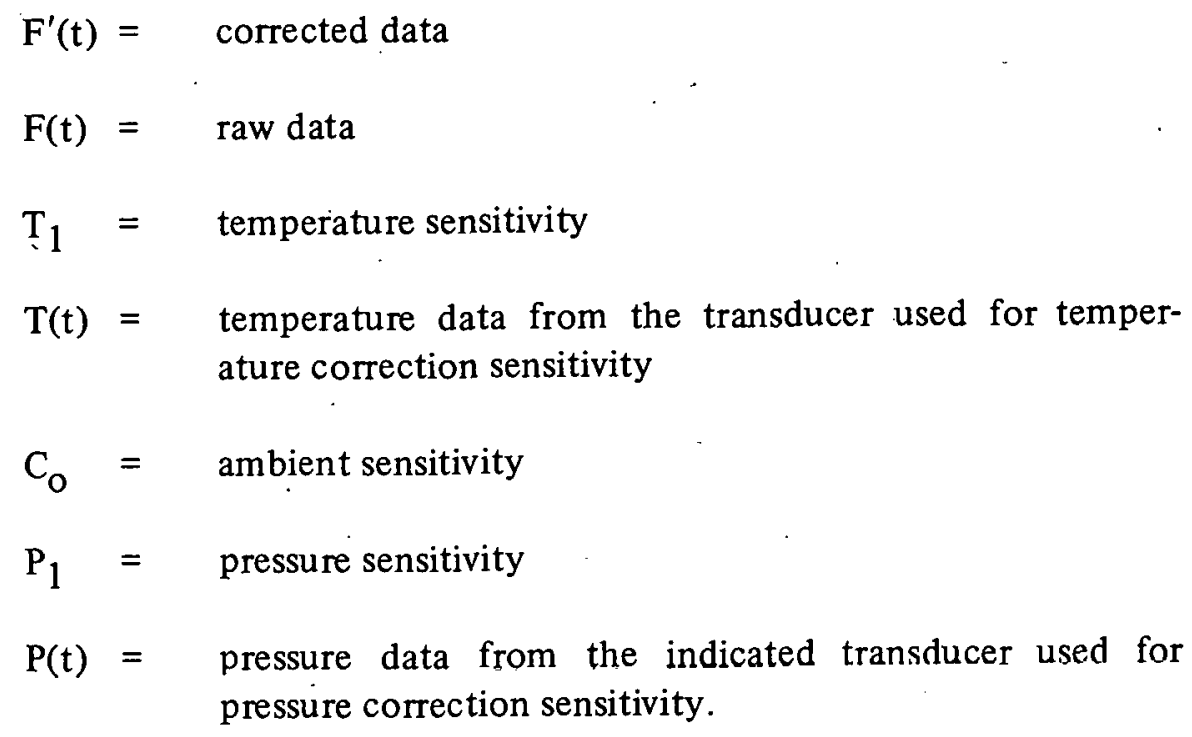

Values of the constants are given in Table B-III. 
TABLE B-III

CONSTANTS FOR MOMENTUM FLUX

MEASUREMENT CORRECTIONS (TEST S-28-4)

\begin{tabular}{|c|c|c|c|c|c|c|}
\hline \multicolumn{2}{|c|}{ ID } & $\mathrm{C}_{0}$ & $\mathrm{~T}_{1}$ & $T(t)^{[a]}$ & $P_{1}$ & $P(t)^{[b]}$ \\
\hline \multicolumn{2}{|c|}{ FDU -5} & 0 & -0.000427 & TFU-6. & +0.000 001 b & $\mu V-U P+10$ \\
\hline \multicolumn{2}{|c|}{ FDV-CORE-IN } & 0 & -0.000063 & TFV-CORE-IN & & \\
\hline \multicolumn{2}{|c|}{ FDU- 10} & 0 & 0.000243 & TFU-10 & +0.0000018 & $P U-13$ \\
\hline \multicolumn{2}{|c|}{ FDU-13 } & 0 & 0.001652 & RBU-14A & +0.0000018 & PU-13 \\
\hline \multicolumn{2}{|c|}{ FDB $-30^{\lfloor\mathrm{c}\rfloor}$} & 0 & -0.001539 & TFB-30 & +0.0000017 & $P V-U P+10$ \\
\hline \multicolumn{2}{|c|}{ FDB-21. } & 0 & -0.001240 & TFB-20 & -0.0000039 & $P B-21$ \\
\hline \multicolumn{2}{|c|}{$F D B-23$} & 0 & -0.001485 & TFB-23 & -0.000 .0018 & $P B-23$ \\
\hline \multicolumn{2}{|c|}{ FDB -42} & -0.040 & 0.001656 & TFB -42 & -0.0000023 & $P B-42$ \\
\hline \multicolumn{2}{|c|}{$\mathrm{FDB}-37^{[\mathrm{c}]}$} & +0.340 & 0.000905 & TFB-37 & & \\
\hline \multicolumn{2}{|c|}{ FDU-1 } & +0.115 & 0.001012 & $\mathrm{RBU}-2$ & -0.0000007 & $P V-U P+10$ \\
\hline$[\mathrm{a}]$ & \multicolumn{6}{|c|}{$\begin{array}{l}T(t) \text { is the temperature data used for temperature sensitivity } \\
\text { correction. The symbols listed identify the thermocouples from } \\
\text { which lie lala are obtained. }\end{array}$} \\
\hline$\lceil\mathrm{b}\rceil$ & \multicolumn{6}{|c|}{$\begin{array}{l}P(t) \text { is the pressure data from the indicated transducer used for } \\
\text { pressure sensitivity correction. Ine symbols } 11 \text { sted ldenlify life } \\
\text { pressure transducers from which the data are obtained. }\end{array}$} \\
\hline$[c]$ & \multicolumn{6}{|c|}{$\begin{array}{l}\text { Temperature sensitivity corrections were applied as usual; however, } \\
\text { because FDB- } 30 \text { and FDB-37 are mounted horizontally, during blowdown } \\
\text { they were partially filled with subcooled water which affected the } \\
\text { temperature sensitivity. Therefore, the temperature sensitivity } \\
\text { correction is more uncertain than that apjlied to other detectors. }\end{array}$} \\
\hline
\end{tabular}




\section{DENSITY MEASUREMENTS}

Density calculations are based on the voltage output of the photomultiplier tubes in the gamma-attenuation densitometer assemblies. The equation used for converting voltage to density is as follows:

$$
\rho=(1 / C) \ln \{D /[A F(t)+B]\}
$$

where

$$
\begin{aligned}
& \rho=\text { the density in } \mathrm{kg} / \mathrm{m}^{3} \\
& \mathrm{C}=\text { a constant based on the length of the gamma beam path } \\
& D=\text { a theoretical voltage for zero attenuation inside the vessel } \\
& \mathrm{A}=\text { an amplification factor } \\
& \mathrm{B}=\text { a biasing factor. } \\
& \mathrm{F}(\mathrm{t})=\text { the transducer voltage output. }
\end{aligned}
$$

Constants A and B are adjusted to match the final data to density values calculated from measured pressure and temperature values at the preblowdown and postdrain conditions, effectively giving the data an in-place calibration. The values of the constants for various transducers are given in Table B-IV.

The density measurements GVLP-172HZ and GV-COR-150HZ use amplifiers which precalculate the logarithm function, and hence have a simpler conversion formula:

$$
\begin{array}{ll}
\text { GVLP-172HZ } & \rho=-28.512 F(t)-1967.0 \\
\text { GV-COR-150HZ } & \rho=-50.185 F(t)-1122.9 .
\end{array}
$$

Some density measurements are obtained using a two-beam gamma densitometer which operates on the same basic principle of gamma attenuation as does the single-beam gamma densitometer. Each beam originates from the same gamma source and is allowed to pass through separate portions of the piping cross-sectional flow area to obtain an average density measurement in that particular region. The geometrical relationship of the gamma beam path through the piping and geometrically related variables used for processing of data from a two-beam gamma densitometer are shown in Figure B-1.

The average density measured by each individual gamma beam is obtained using the same equation as is used for the single-beam gamma densitometers. Values for the constants for the single-beam density measurements obtained with the two-beam gamma densitometers are presented in Table B-IV along with the constants for single-beam gamma densitometers. 


\section{TABLE B-IV}

CONSTANTS FOR DENSITY MEASUREMENT

CONVERSIONS TO ENGINEERING UNITS (TEST S-28-4)

\begin{tabular}{|c|c|c|c|c|}
\hline $\begin{array}{l}\text { Detector } \\
\text { Identification }\end{array}$ & $A$ & B & C & $\begin{array}{l}: \\
\mathrm{D}\end{array}$ \\
\hline GU- 15C & 0.333 & 4.280 & 0.000 .50 & 6.42 \\
\hline GU-5VR & 1.176 & -0.741 & 0.00059 & 5.43 \\
\hline GU- TOVR & 1.098 & -0.435 & 0.00059 & 6.81 \\
\hline G.II- 1.3VR & 1.353 & -1.036 & 0.00059 & 3.38 \\
\hline GB-12VR & 0.986 & 0.402 & 0.00037 & 8.08 \\
\hline $\mathrm{F} R-.37 \mathrm{HZ}$ & 1.880 & -3.559 & 0.00059 & 4.40 \\
\hline GB-23VR & 1.235 & -1.309 & 0.00037 & 6.90 \\
\hline GVLP- $165 \mathrm{HZ}$ & 1.041 & -0.116 & 0.00150 & 4.24 \\
\hline$G B-21 B$ & 1.062 & -0.190 & 0.00050 & 6.83 \\
\hline$G B-21 T$ & 1.103 & -0.379 & 0.00036 & 5.96 \\
\hline$G B-30 B$ & 1.064 & -0.187 & 0.00050 & 6.62 \\
\hline $\mathrm{GB}-30 T$ & 1.104 & -0.765 & 0.00036 & h. 48 \\
\hline$G B-1 B$ & 1.025 & 0.060 & 0.00050 & 6.70 \\
\hline$G B-1 T$ & 1.095 & -0.332 & 0.00036 & 6.22 \\
\hline$G B-15 B$ & 1.094 & -0.340 & 0.00050 & 5.85 \\
\hline$G U-15 T$ & 1.183 & -0.781 & 0.00036 & 5.59 \\
\hline
\end{tabular}




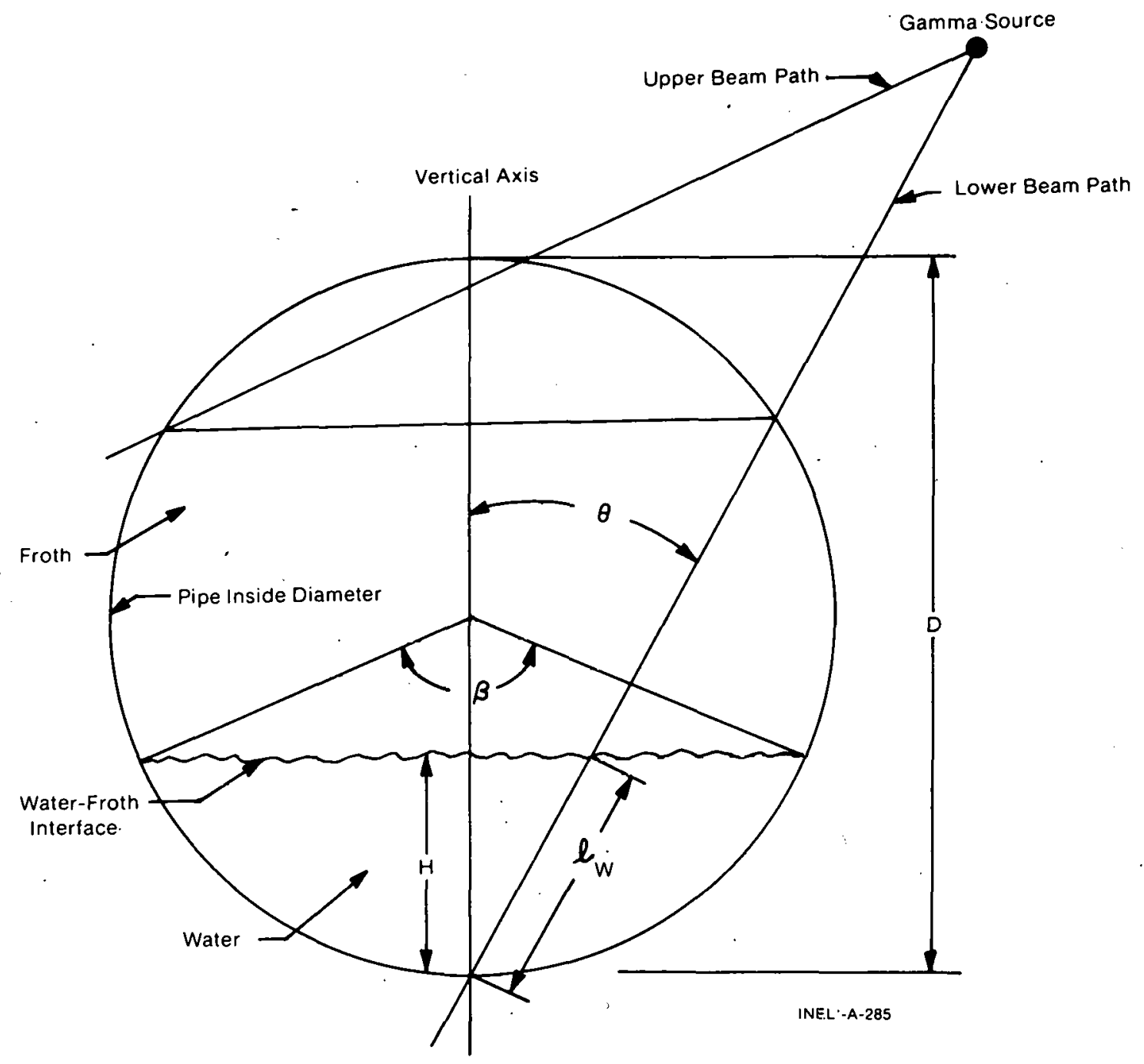

- Fig. B-1 Geometry used for processing of density data obtained from two-beam gamma densitometers.

In the Semiscale Mod-1 system, two-beam gamma densitometers provide added information which allows the calculation of a better average density than that obtained from a single beam. A mathematical model is used for processing the two-beam data to obtain the improved average density information. The processing method used is based on a froth-water model coupled with information from the two individual gamma beams and related beam path and piping cross-sectional geometry. The resulting information is recorded and reported under the density measurement identification ending with a " $\mathrm{C}$ ", for example, GB-21C.

The use of the froth-water model for obtaining average density from a two-beam gamma densitometer is based on observations indicating that flow regimes in the Semiscale Mod-1 system can be modeled by a layer of water on the bottom of the pipe with a degree of froth on the surface. For homogeneous flow conditions such as all froth or all liquid the 
model remains valid. At any point in time slug flow is also modeled. The froth-water model does not model annular or inverted annular flows very well. However, thesc flows are not expected to exist for significant portions of a Semiscale Mod-1 system blowdown in horizontal piping. Density gradients from the top to the bottom of the pipe may cxist showing no distinct location change from water to froth. This flow is neither totally homogeneous nor stratified, but the froth-water model does provide an adequate approximation of the average density characteristic of this flow pattern.

The average density obtained by using the gamma beam geometry shown in Figure B-1 and by applying the froth-water model is given by

$$
\bar{\rho}=\alpha_{f} \rho_{1}+\left(1-\alpha_{f}\right) \rho_{w} \mathrm{~kg} / \mathrm{m}^{3}
$$

where.

$$
\begin{aligned}
& \bar{p}=\text { iverage cruss-sectional donsity } \\
& \rho_{1}=\begin{array}{l}
\text { average density measured by the upper gamma beam } \\
\text { (medsures the froth density) }
\end{array} \\
& \rho_{\mathrm{w}}=\text { density of liquid water (at local system conditions) } \\
& \alpha_{\mathrm{f}}=1+(1 / 2 \pi)(\sin \beta-\beta)=\text { froth fraction. }
\end{aligned}
$$

The angle which $\beta$ represents is shown in Figure B-1. Values for $\beta$ are oblained as follows:

$$
\beta=2 \cos ^{-1}(1-2 h)
$$

where

$$
\mathrm{h}=\frac{\mathrm{H}}{\mathrm{D}}=\cos ^{2} \theta \frac{\rho_{2}-\rho_{1}}{\rho_{\mathrm{W}}-\rho_{1}}
$$

where

$$
\begin{aligned}
& \mathrm{H}=\ell_{\mathrm{w}} \cos \theta\left(\ell_{\mathrm{w}} \text { and } \theta \text { are defined in Figure } \mathrm{B}-1\right) \\
& \mathrm{D}=\text { piping inside diameter } \\
& p_{2}=\text { the average density measured by the lower gamma beam. }
\end{aligned}
$$

Average density is not calculated using the two-bcam froth-water model when the angle $\theta$ is not favorable due to system hardware restrictions in positioning the source. The froth-water model requires separate density sampling in both the upper and lower portions of the piping cross section. 
APPENDIX C

SELECTED DATA WITH ESTIMATED TOTAL ERROR

BANDS FROM SEMISCALE MOD-1 TEST S-28-4 
THIS PAGE

\section{WAS INTENTIONALLY LEFT BLANK}




\title{
APPENDIX C \\ SELECTED DATA WITH ESTIMATED TOTAL ERROR
}

\author{
BANDS FROM SEMISCALE MOD-1 TEST S-28-4
}

Analysis has been performed on selected data from Test S-28-4 to provide a guide to the uncertainty associated with data measurements in the Semiscale Mod-1 system. The end result of the analysis is presented as error bands about the measured data which represent a $95 \%$ confidence level.

The error bands are obtained by combining uncertainties obtained from analysis of the data itself (random error) and engineering analysis of the measurement system (engineering error). The procedure by which error bands were established for the data presented in this appendix is described in the following paragraphs.

The data trace under analysis was empirically fitted with a linear difference equation, which was subject to a white noise input at each sampling time point. The objective of the empirical fitting procedure was to characterize the white noise, which was taken to represent the random error. The procedures for fitting the difference equation are discussed in depth in Reference C-1. A data trace was often segmented and different equations were fitted to each segment with statistical correlations between successive observations accounted for by the fitting procedure. The white noise input was assumed to arise from a normally distributed population. The standard deviation of the white noise, as found during the fitting procedures, was taken as an estimate of the random error standard deviation and is shown in Table C-I. The data traces of the error band analysis are shown in Figures $\mathrm{C}-1$ through C-40.

Other errors in the data exist because of such factors as variability in installation procedures and techniques, calibration errors, variability in materials, and temperature and pressure sensitivities. These errors and the procedures for estimating them are discussed in Reference C-2. They are referred to as engineering errors and the estimates are largely subjective. Because of the continuing effort to improve the accuracy of the measured data, such as through the use of better transducers, better signal conditioning and processing equipment, and better calibration and installation techniques, the engineering errors for data from most of the transducer systems have changed from those published in Reference C- 2 . Table C-II provides a summary of engineering error values obtained from current analysis techniques as applied to the data presented herein.

In addition to the normal hardware and installation related sources of engineering error, a significant measurement uncertainty results when the current transducer systems are subjected to separated two-phase flow regimes during the course of the blowdown transient. Accordingly, for those data affected (fluid density, momentum flux, volumetric flow, and 
TABLE C-I

RANDOM ERROR VARIANCE (TEST S-28-4)

\begin{tabular}{|c|c|c|c|c|}
\hline Measurement & $\begin{array}{c}\text { Random Error } \\
\text { Variance } \\
\sigma R \\
\end{array}$ & $\begin{array}{l}\text { Period of } \\
\text { Application } \\
\text { (s) }\end{array}$ & Figure & Comments \\
\hline TFB-23 & $\begin{array}{r}12.293 \\
1.996\end{array}$ & $\begin{array}{rl}0 & \text { to } \\
71 & 71 \\
71 & \text { to } 200\end{array}$ & $C-1$ & \\
\hline TFV-ANN-35A & $\begin{array}{r}14.998 \\
0652\end{array}$ & 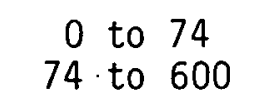 & $C-2$ & \\
\hline TFV LP 7 & $\begin{array}{r}36.012 \\
0.315\end{array}$ & $\begin{array}{r}0 \text { to } 131 \\
134 \text { to } 600\end{array}$ & C 3 & \\
\hline TFU-PR:IZE & $\begin{array}{l}7.010 \\
0.291\end{array}$ & 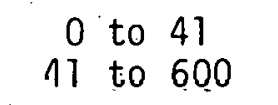 & $C-4$ & \\
\hline TMU-1T16 & $\begin{array}{l}0.952 \\
0.118\end{array}$ & $\begin{array}{r}0 \text { to } 357 \\
357 \text { to } 600\end{array}$ & $C-5$ & \\
\hline$T M V-C I-70 A$ & 1.784 & 0 to 600 & $C-6$ & \\
\hline TH-E4-09 & $\begin{array}{r}2.813 \\
47.563 \\
1.001\end{array}$ & $\begin{array}{r}0 \text { to } 191 \\
191 \text { to } 201 \\
201 \text { to } 600\end{array}$ & $C-7$ & \\
\hline TH-E4-27 & $\begin{array}{r}6.536 \\
60.262 \\
2.677\end{array}$ & $\begin{array}{r}0 \text { to } 140 \\
140 \text { to } 151 \\
\cdot 151 \text { to } 600\end{array}$ & C-8 & \\
\hline TH-E.4-55 & $\begin{array}{r}2.035 \\
23.553 \\
1.549\end{array}$ & $\begin{array}{l}0 \text { to } 80 \\
80 \text { to } 92 \\
92 \text { to } 600\end{array}$ & $C-9$ & \\
\hline PU-13 & $\begin{array}{r}10.477 \\
2.039\end{array}$ & $\begin{array}{c}0 \text { to } 37 \\
37 \text { to } 600\end{array}$ & $C-10$ & \\
\hline P.B-23 & $\begin{array}{l}8.856 \\
1: 371\end{array}$ & $\begin{array}{lll}0 & \text { to } & 60 \\
60 & \text { lu } & 600\end{array}$ & $C-.7 .7$ & \\
\hline DPU-7-10 & $\begin{array}{l}0.234 \\
0.060\end{array}$ & 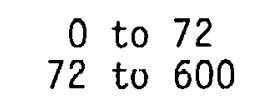 & $C-12$ & \\
\hline DPU-12-10 & $\begin{array}{l}0.551 \\
0.202\end{array}$ & $\begin{aligned} 0 & \text { to } 29 \\
29 & \text { to } 600\end{aligned}$ & $c-13$ & \\
\hline DPU-12-15 & $\begin{array}{l}0.194 \\
0.051 \\
0.166\end{array}$ & $\begin{array}{r}0 \text { to } 238 \\
238 \text { to } 481 \\
48.1 \text { to } 600\end{array}$ & $C-14$ & \\
\hline
\end{tabular}


TABLE C-I (continued)

\begin{tabular}{|c|c|c|c|c|}
\hline Measurement & $\begin{array}{c}\text { Random Error } \\
\text { Variance } \\
\text { oR }\end{array}$ & $\begin{array}{l}\text { Period of } \\
\text { Application } \\
(\mathrm{s}) \\
\end{array}$ & Figure & Comments \\
\hline FTU-1 & $\begin{array}{r}134.297 \\
23.579 \\
26.602 \\
40.452\end{array}$ & 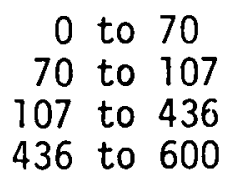 & $C-15$ & , \\
\hline FTU-15 & $\begin{array}{r}22.581 \\
67.403 \\
18.565 \\
109.007\end{array}$ & $\begin{array}{r}0 \text { to } 92 \\
92 \text { to } 240 \\
240 \text { to } 442 \\
442 \text { to } 600\end{array}$ & $C-16$ & \\
\hline FTU-HPIS & $\begin{array}{l}0.257 \\
0.058 \\
0.142\end{array}$ & $\begin{array}{r}0 \text { to } 404 \\
404 \text { to } 524 \\
524 \text { to } 600\end{array}$ & $C-17$ & . \\
\hline FTU-LPIS & $\begin{array}{l}0.313 \\
0.013\end{array}$ & 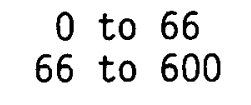 & $C-18$ & \\
\hline FTU-ACCI & 4.035 & 0 to 41 & $C-19$ & $\begin{array}{l}\text { Error bands are not } \\
\text { presented from } t=41 \\
\text { to } 600 \mathrm{~s}[\mathrm{a}] \text {. }\end{array}$ \\
\hline FTV-40A & $\begin{array}{l}6.661 \\
1.761\end{array}$ & $\begin{array}{r}0 \text { to } 238 \\
238 \text { to } 600\end{array}$ & $C-20$ & . \\
\hline FTV-40M & $\begin{array}{l}5.741 \\
1.059\end{array}$ & $\begin{array}{r}0 \text { to } 238 \\
238 \text { to } 600\end{array}$ & $C-21$ & \\
\hline GU-1T & $\begin{array}{l}2.140 \\
0.371 \\
2.715 \\
0.335\end{array}$ & $\begin{aligned} & 0 \text { to } \\
& 12 \text { to } 350 \\
& 350 \text { to } 359 \\
& 359 \text { to } 600\end{aligned}$ & $C-22$ & \\
\hline GU-1B & $\begin{array}{l}2.651 \\
0.785 \\
1.791 \\
0.404 \\
1.028\end{array}$ & $\begin{array}{r}0 \text { to } 19 \\
19 \text { to } 103 \\
103 \text { to } 376 \\
376 \text { to } 437 \\
137 \text { to } 600\end{array}$ & $C-23$ & \\
\hline GU-1C & $\begin{array}{l}1.791 \\
0.656 \\
2.762 \\
0.428\end{array}$ & $\begin{array}{r}0 \text { to } 29 \\
29 \text { to } 350 \\
350 \text { to } 359 \\
359 \text { to } 600\end{array}$ & C. -2.4 & \\
\hline GU-10VR & $\begin{array}{l}2.219 \\
0.278\end{array}$ & 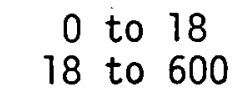 & $C-25$ & \\
\hline
\end{tabular}


TABLE C-I (continued)

\begin{tabular}{|c|c|c|c|c|}
\hline Measurement & $\begin{array}{c}\text { Random Error } \\
\text { Variance } \\
\text { oR }\end{array}$ & $\begin{array}{c}\text { Period of } \\
\text { Application } \\
\text { (s) }\end{array}$ & Figure & Comments \\
\hline GU-15T & $\begin{array}{r}10.822 \\
1.932 \\
5.526 \\
0.908 \\
10.299 \\
1.740 \\
1.4 .097\end{array}$ & $\begin{array}{r}0 \text { to } 23 \\
23 \text { to } 60 \\
60 \text { to } 68 \\
68 \text { to } 99 \\
99 \text { to } 239 \\
239 \text { tc } 444 \\
444 \text { to } 600\end{array}$ & $C-26$ & \\
\hline GU-15B & $\begin{array}{r}10.194 \\
1.415 \\
11.666\end{array}$ & $\begin{array}{r}0 \text { to } 239 \\
239 \text { to } 442 \\
442 \text { to } 600\end{array}$ & $C-27$ & \\
\hline GU- $15 \mathrm{C}$ & $\begin{array}{r}6.702 \\
6.576 \\
1.668 \\
10.270 \\
0.738 \\
12.649\end{array}$ & 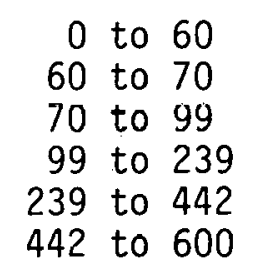 & $C-28$ & \\
\hline GB-23VR & $\begin{array}{r}10.053 \\
10.710 \\
1.584 \\
14.271\end{array}$ & $\begin{array}{r}0 \text { to } 61 \\
61 \text { to } 73 \\
73 \text { to } 528 \\
528 \text { to } 600\end{array}$ & $C-29$ & \\
\hline GV-COR-150HZ & $\begin{array}{l}0.416 \\
9.126 \\
3.706\end{array}$ & $\begin{array}{l}0.8 \text { to } 366 \\
366 \text { to } 374 \\
374 \text { to } 600\end{array}$ & $C-30$ & \\
\hline GVLP-165HZ & $\begin{array}{r}5.173 \\
0.290 \\
2.992\end{array}$ & 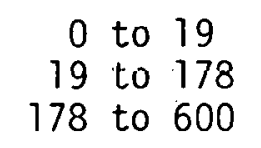 & $C-31$ & \\
\hline GVLP-172HZ & $\begin{array}{l}6.813 \\
0.851\end{array}$ & $\begin{array}{r}0 \text { to } 128 \\
128 \text { to } 600\end{array}$ & $c-32$ & \\
\hline FDU-1, GU-1C & $\begin{array}{l}0.906 \\
0.488 \\
0.205\end{array}$ & $\begin{array}{r}0 \text { to } 7 \\
7 \text { to } 125 \\
125 \text { to } 600\end{array}$ & $c-33$ & . \\
\hline FTU-1, GU-1C & $\begin{array}{l}1.558 \\
0.397 \\
0.389\end{array}$ & $\begin{array}{r}0 \text { to } 7 \\
7 \text { to } 436 \\
436 \text { to } 600\end{array}$ & $c-34$ & \\
\hline FDU-5, GU-5VR & $\begin{array}{l}0.699 \\
0.341\end{array}$ & $\begin{aligned} 0 & \text { to } 29 \\
29 & \text { to } 600\end{aligned}$ & $C-35$ & \\
\hline
\end{tabular}


TABLE C-I (continued)

\begin{tabular}{|c|c|c|c|c|}
\hline Measurement & $\begin{array}{c}\text { Random Error } \\
\text { Variance } \\
\text { oR } \\
\end{array}$ & $\begin{array}{l}\text { Period of } \\
\text { Application } \\
(\mathrm{s}) \\
\end{array}$ & Figure & Comments \\
\hline FTU-13, GU-13VR & $\begin{array}{l}1.631 \\
0.337 \\
3.197\end{array}$ & $\begin{array}{r}0 \text { to } 235 \\
235 \text { to } 448 \\
448 \text { to } 600\end{array}$ & $C-36$ & \\
\hline FTU-15, GU-15C & $\begin{array}{l}2.381 \\
0.269 \\
3.243 \\
0.265 \\
4.515\end{array}$ & 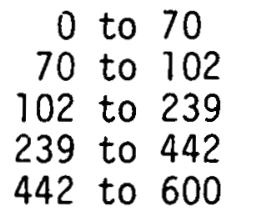 & $C-37$ & \\
\hline $\mathrm{FDB}-21, \mathrm{~GB}-21 \mathrm{C}$ & $\begin{array}{l}2.290 \\
0.849\end{array}$ & $\begin{array}{r}0 \text { to } 124 \\
124 \text { to } 600\end{array}$ & $C-38$ & \\
\hline FTB-21, GB-21C & $\begin{array}{l}3.423 \\
0.775\end{array}$ & $\begin{array}{rll}0 & \text { to } & 69 \\
69 & \text { to } & 600\end{array}$ & $C-39$ & \\
\hline $\begin{array}{l}\text { FTV-CORE-IN, } \\
\text { GV-COR-150HZ }\end{array}$ & $\begin{array}{l}0.572 \\
0.362 \\
4.197\end{array}$ & $\begin{array}{rll}0 & \text { to } & 7 \\
7 & \text { to } & 370 \\
370 & \text { to } & 600\end{array}$ & $C=40$ & \\
\hline
\end{tabular}

[a] Error bands are not represented in this region. The sensor gave a constant reading due to one of the following: (a) sensor saturation, (b) sensor dropout, or (c) sensor deadband. Random error in measurement cannot be modeled under these conditions. 


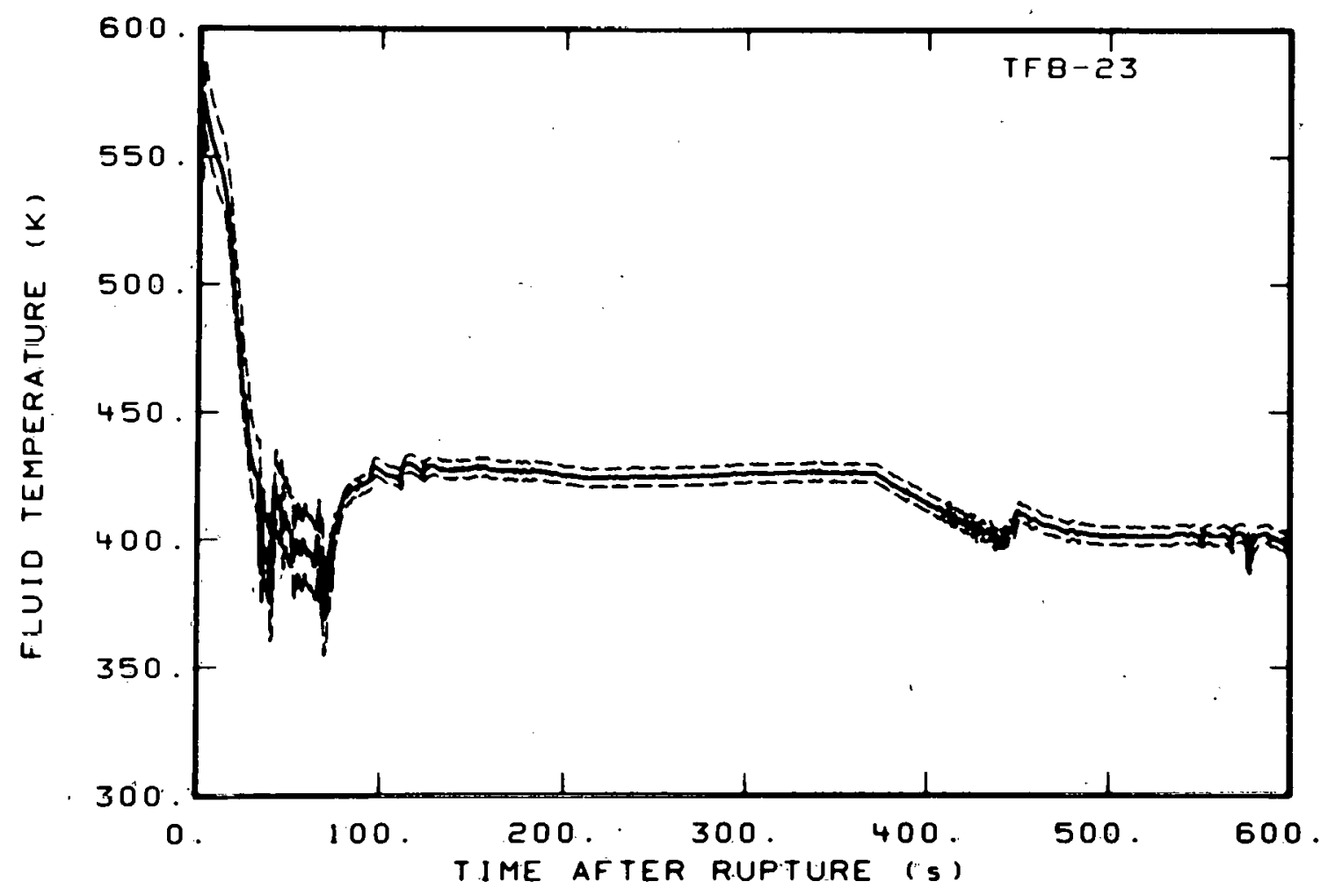

Fig. C-1 Fluid temperature in broken loop (TFB-23).

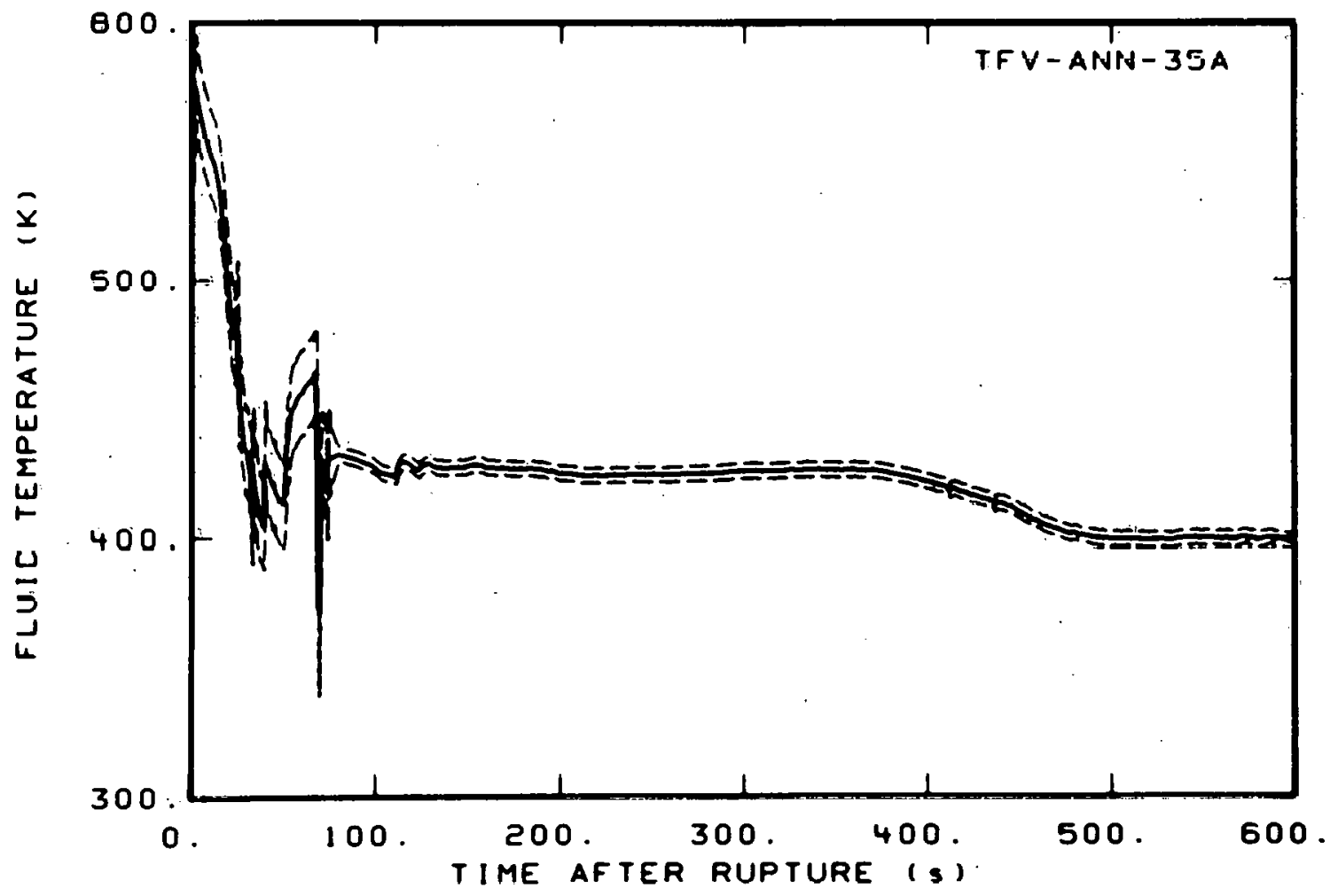

Fig. C-2 Fluid temperature in.downcomer annulus (TFV-ANN-35A). 


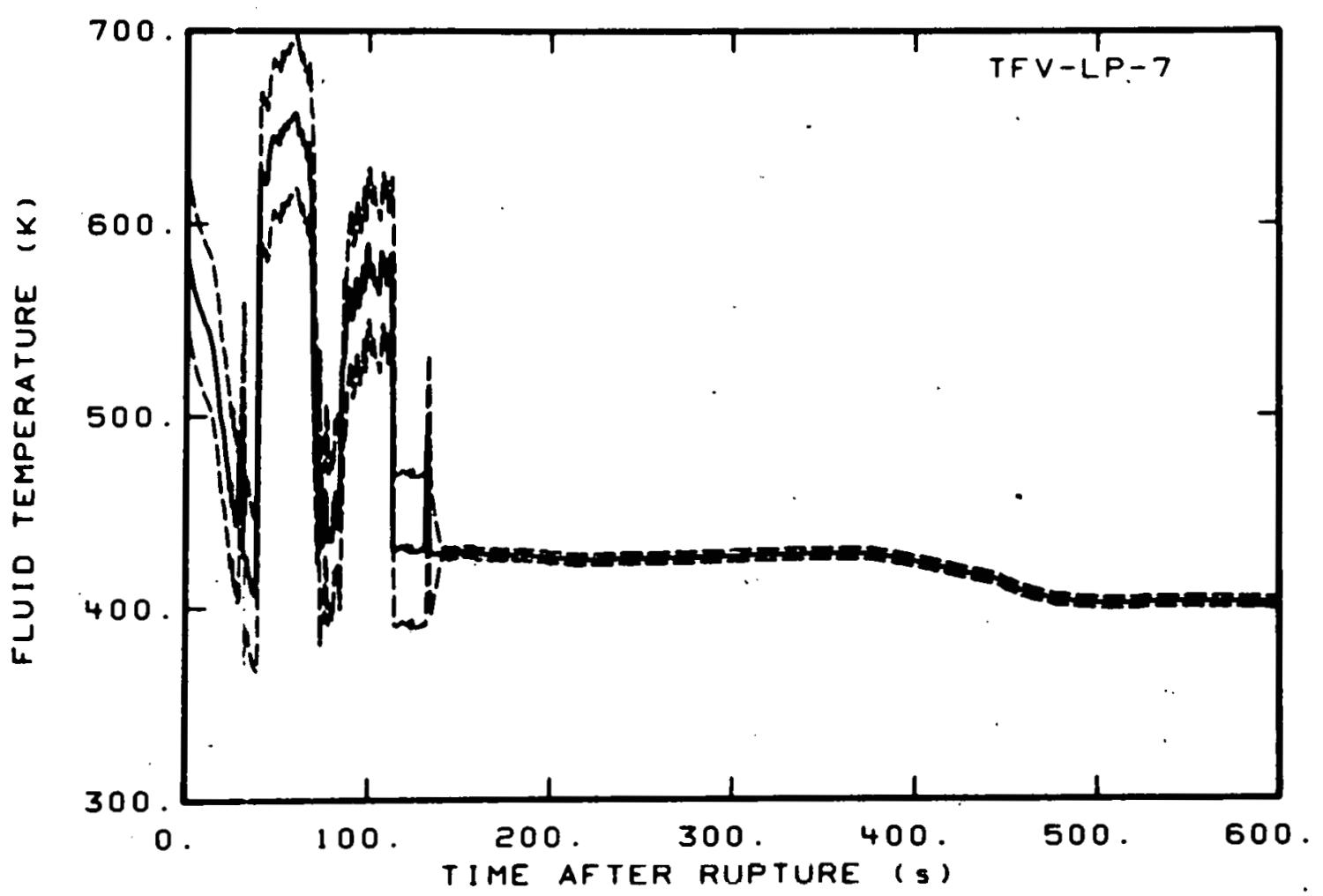

Fig. C-3 Fluid temperature in lower plenum (TFV-LP-7).

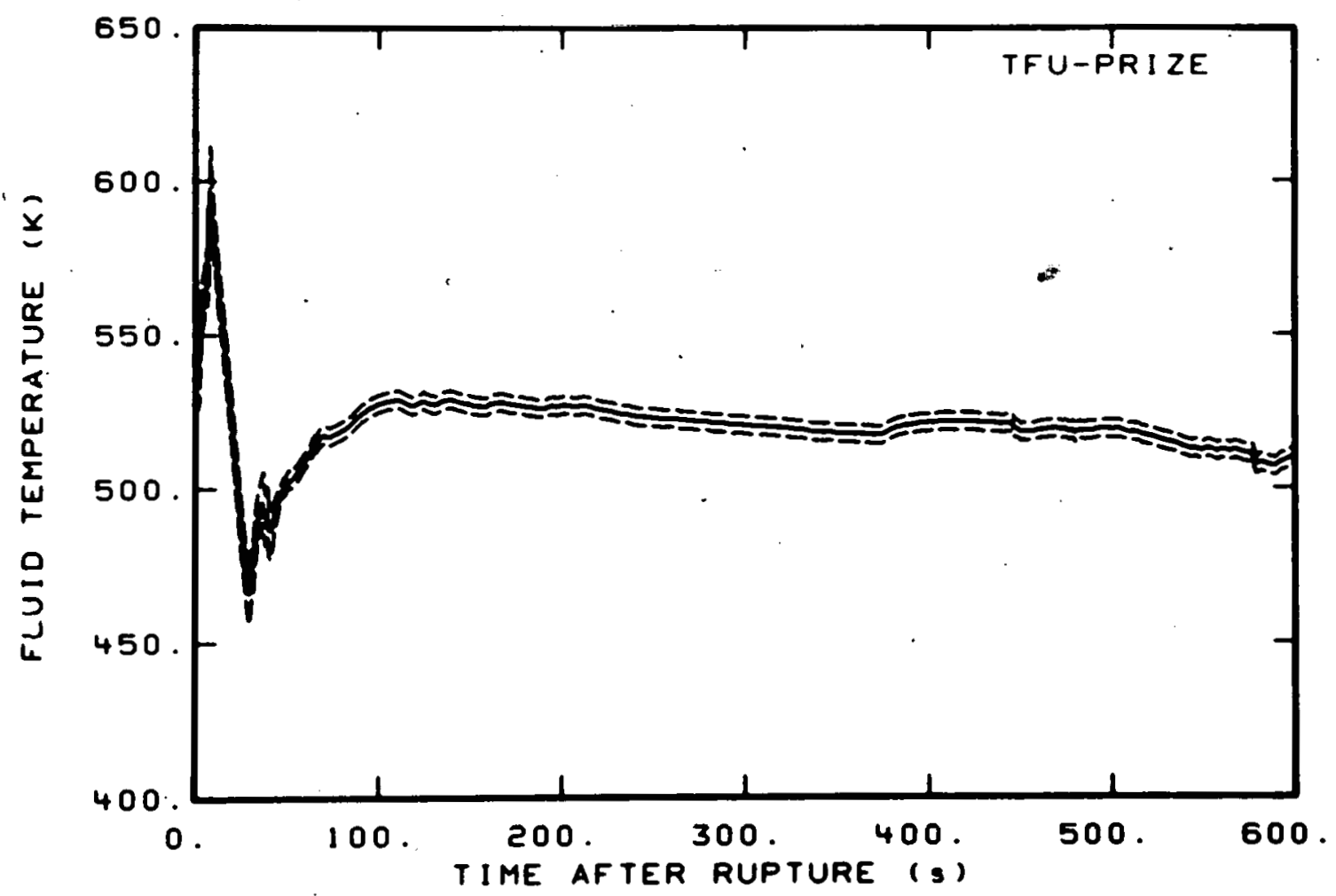

Fig. C-4 Fluid temperature in pressurizer surge line (TFU-PRIZE). 


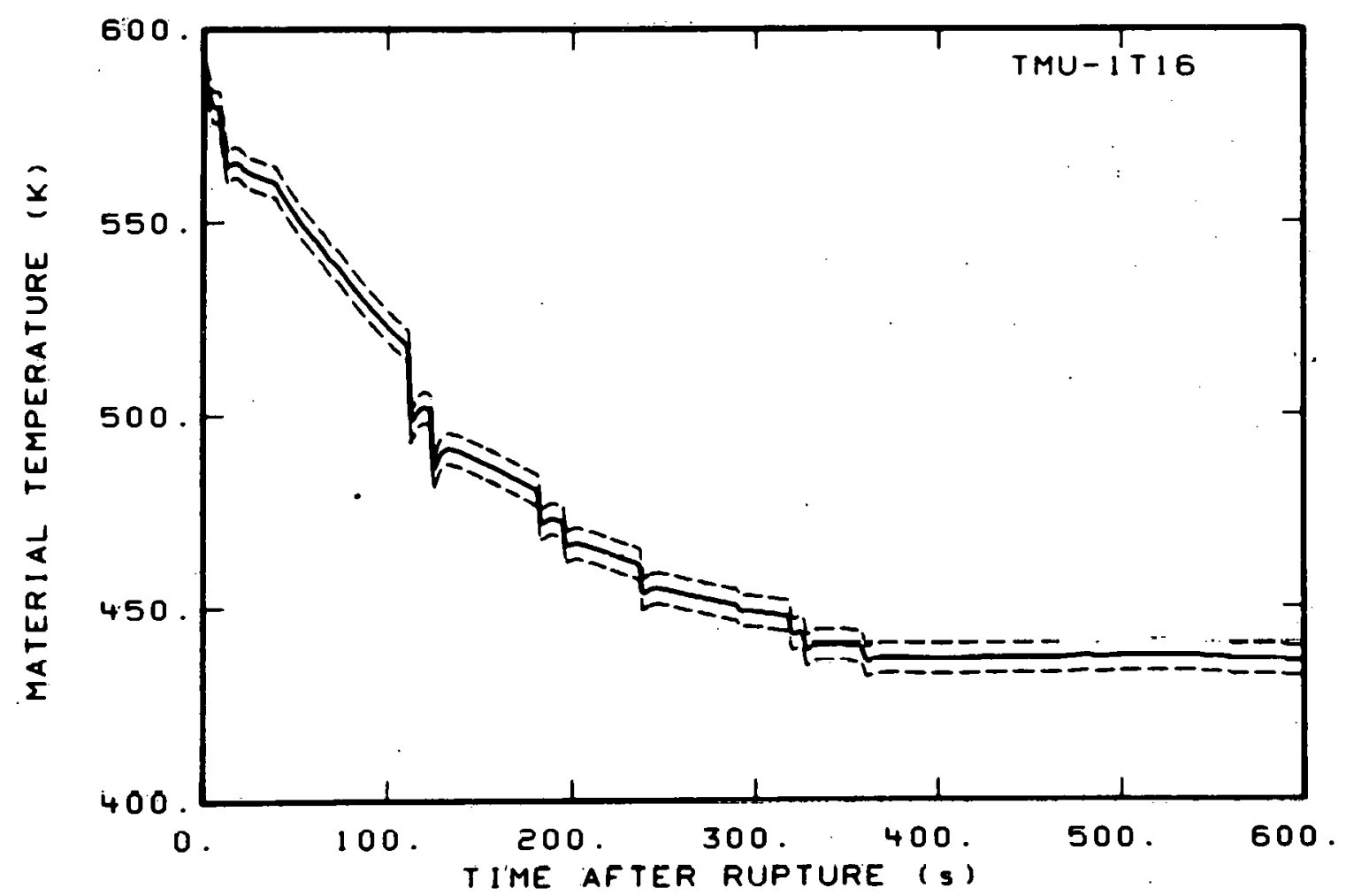

Fig. C-5 Material temperature in intact loop (TMU-1T16).

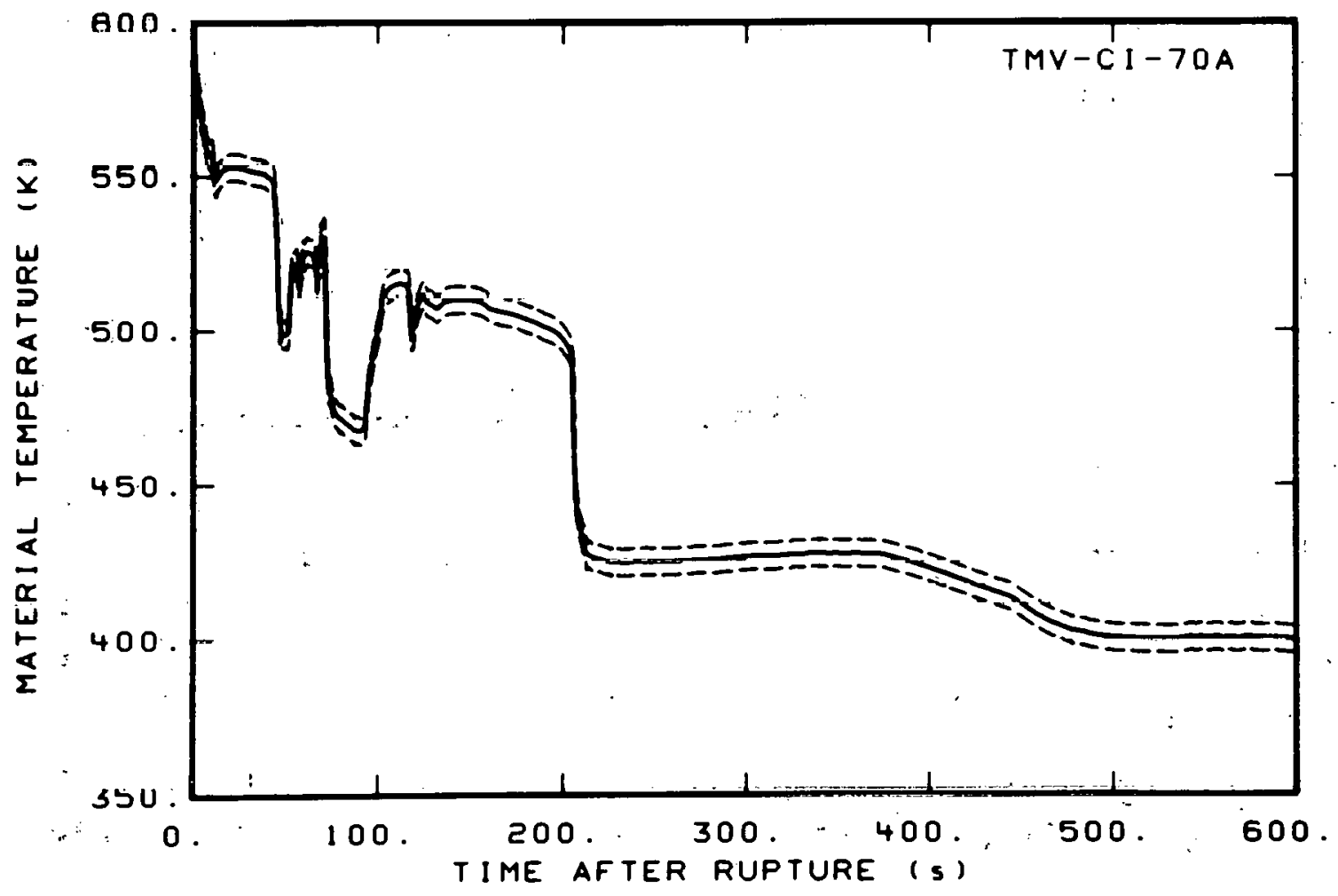

Fig: C-6 Material temperature in vessel filler (TMV-CI-70A). 


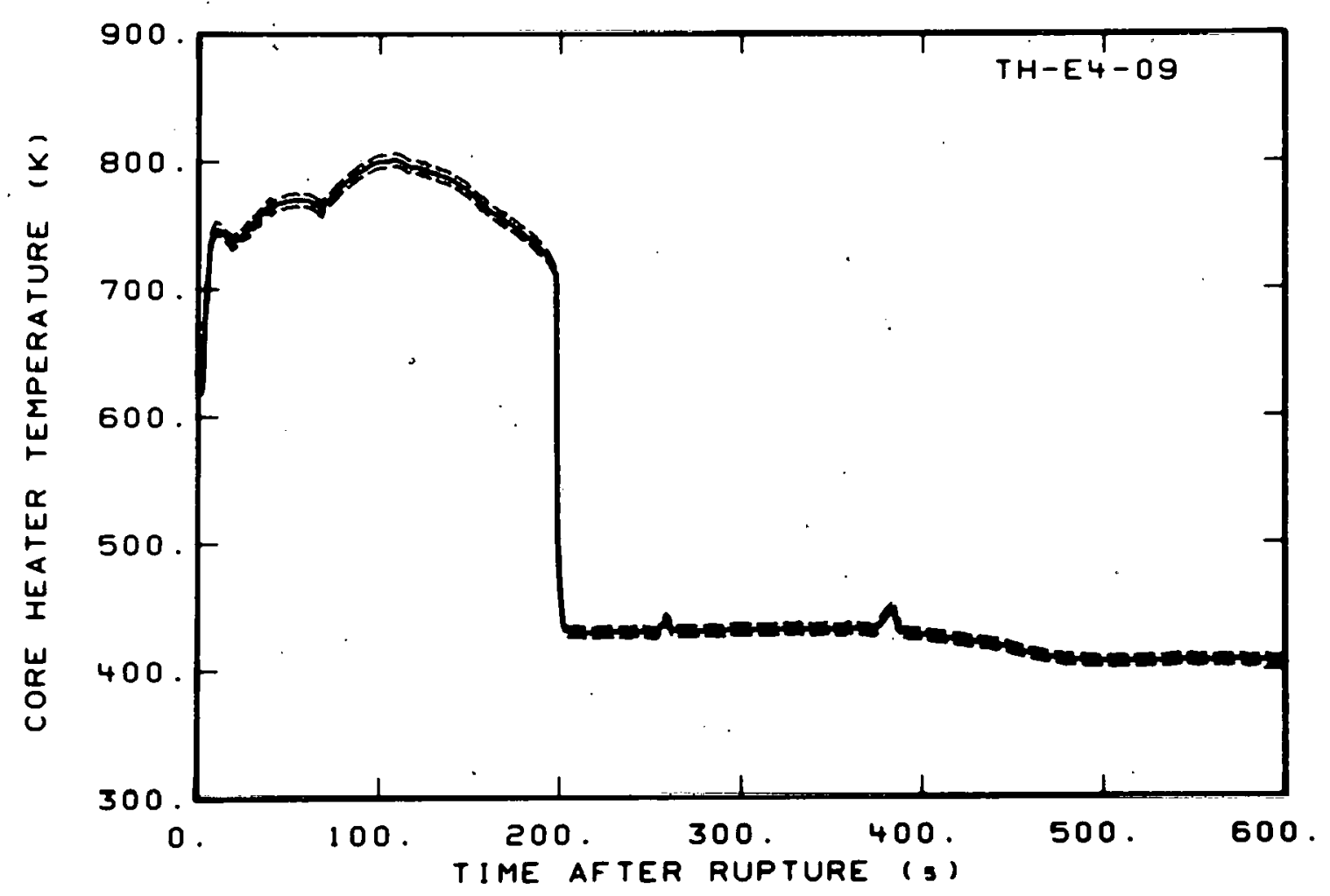

Fig. C-7 Core heater temperature, Rod E-4 (TH-E4-09).

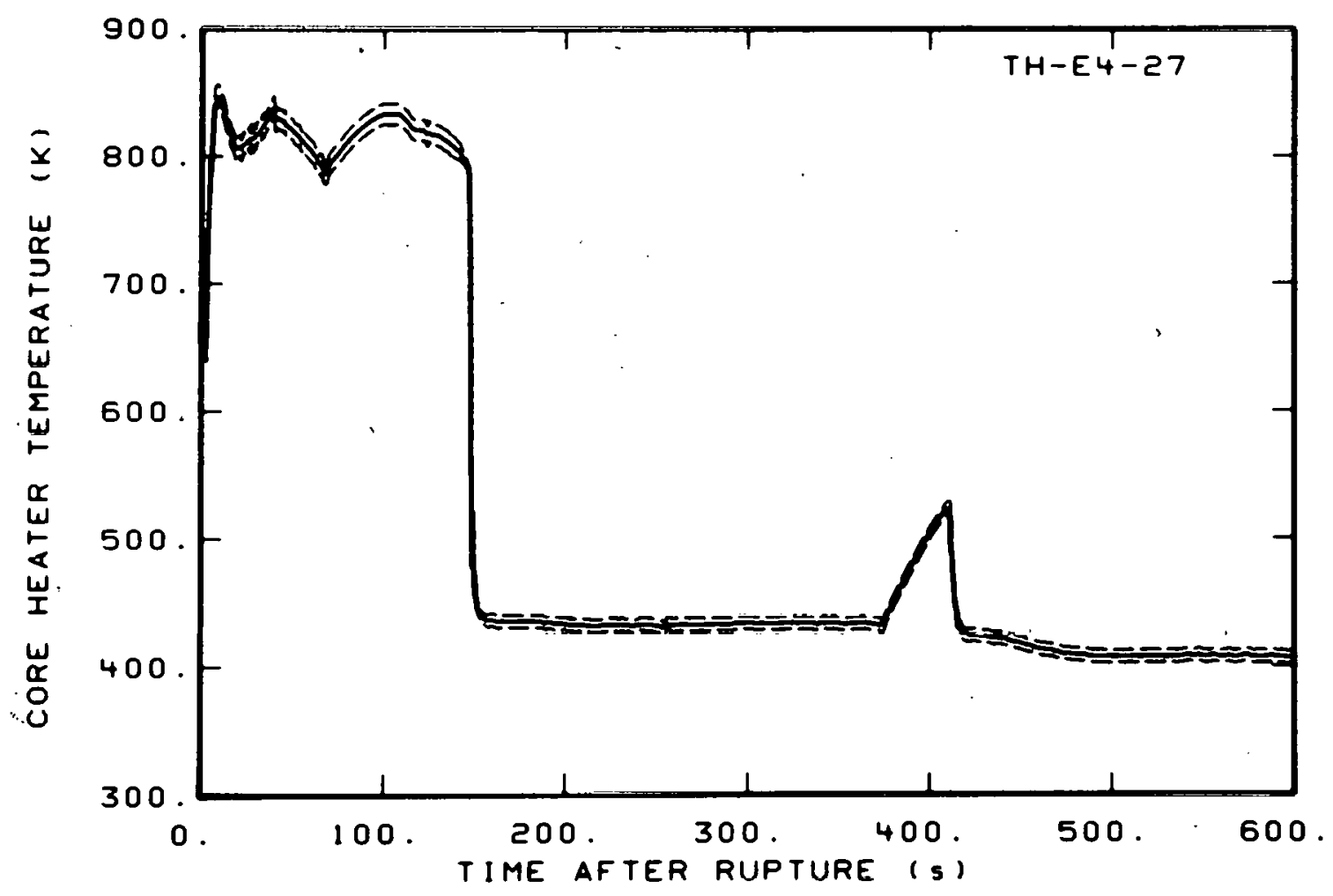

Fig. C-8 Core heater temperature, Rod E-4 (TH-E4-27). 


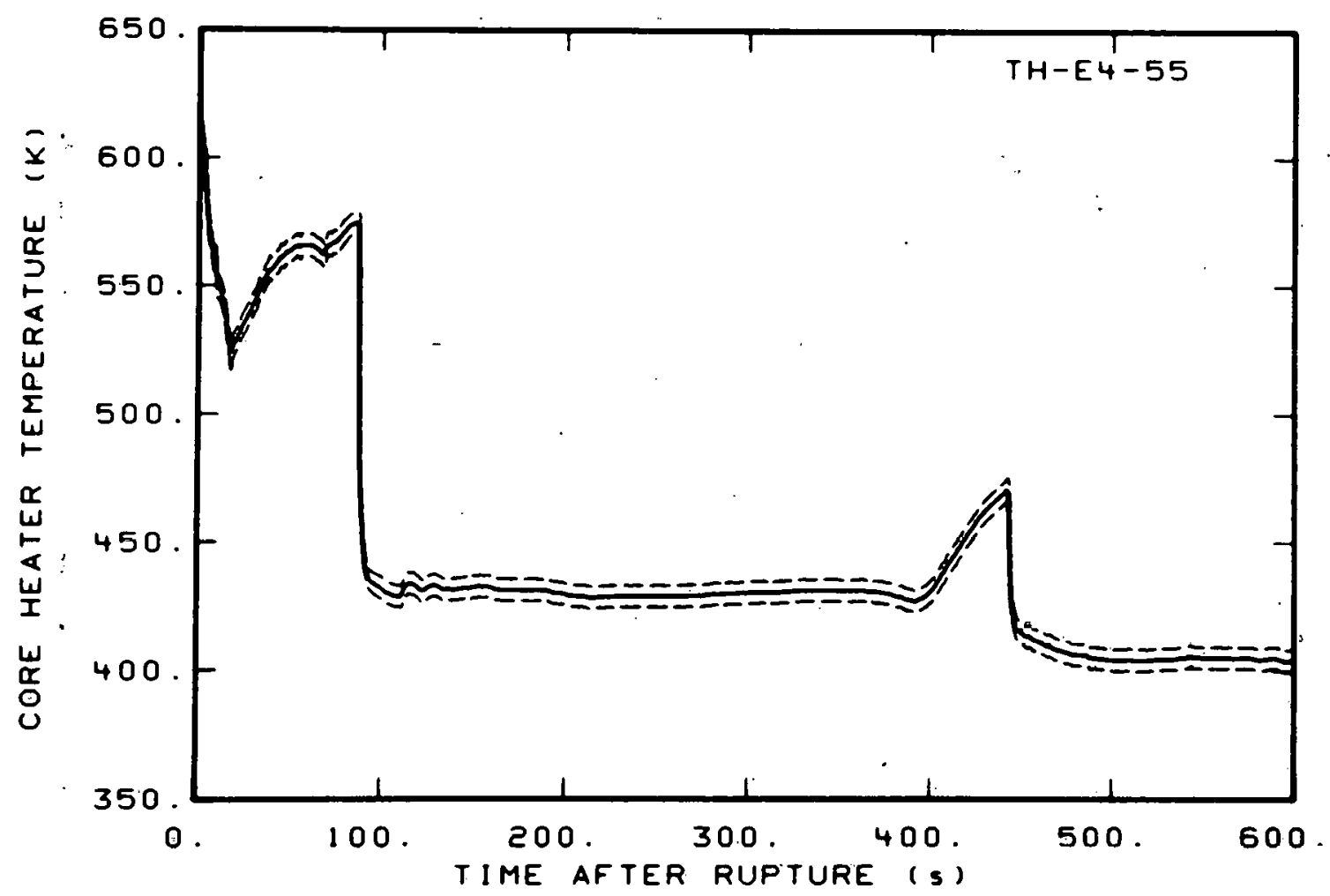

Fig. C-9 Core heater temperature, Rod E-4 (TH-E4-55).

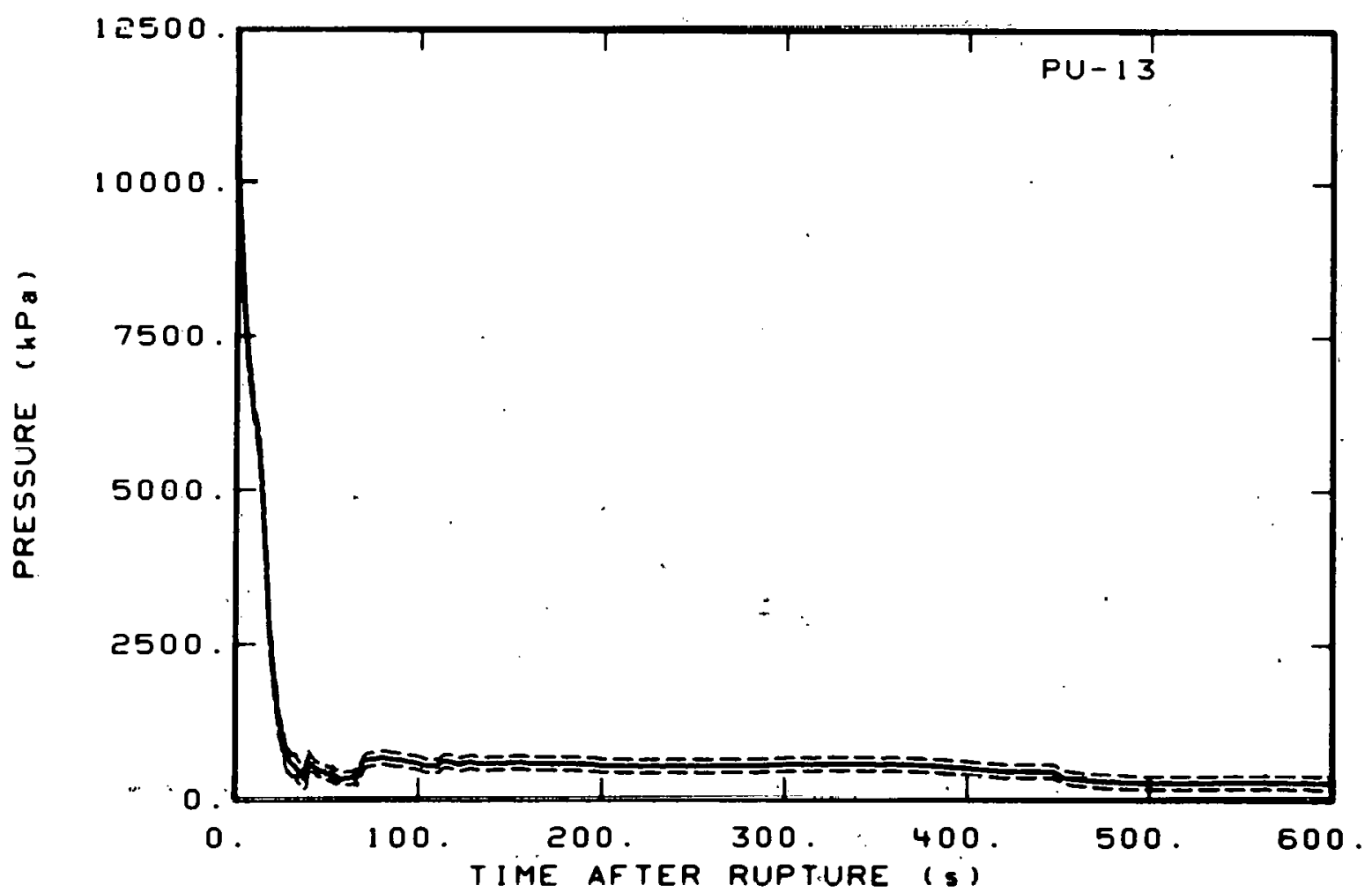

Fig. C-10 Pressure in intact loop, Spool 13 (PU-13). 


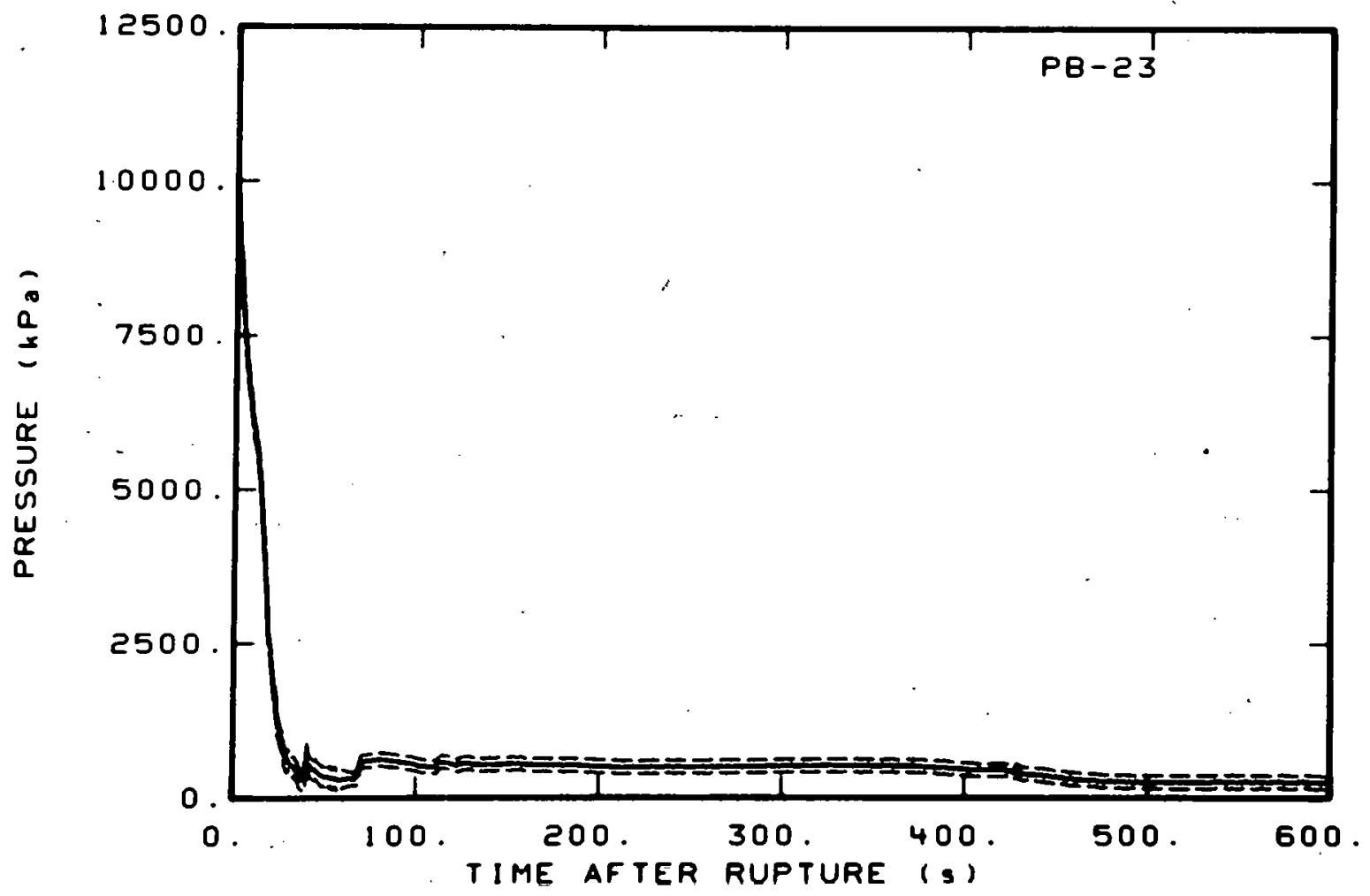

Fig. C-11 Pressure in broken loop, Spool 23 (PB-23).

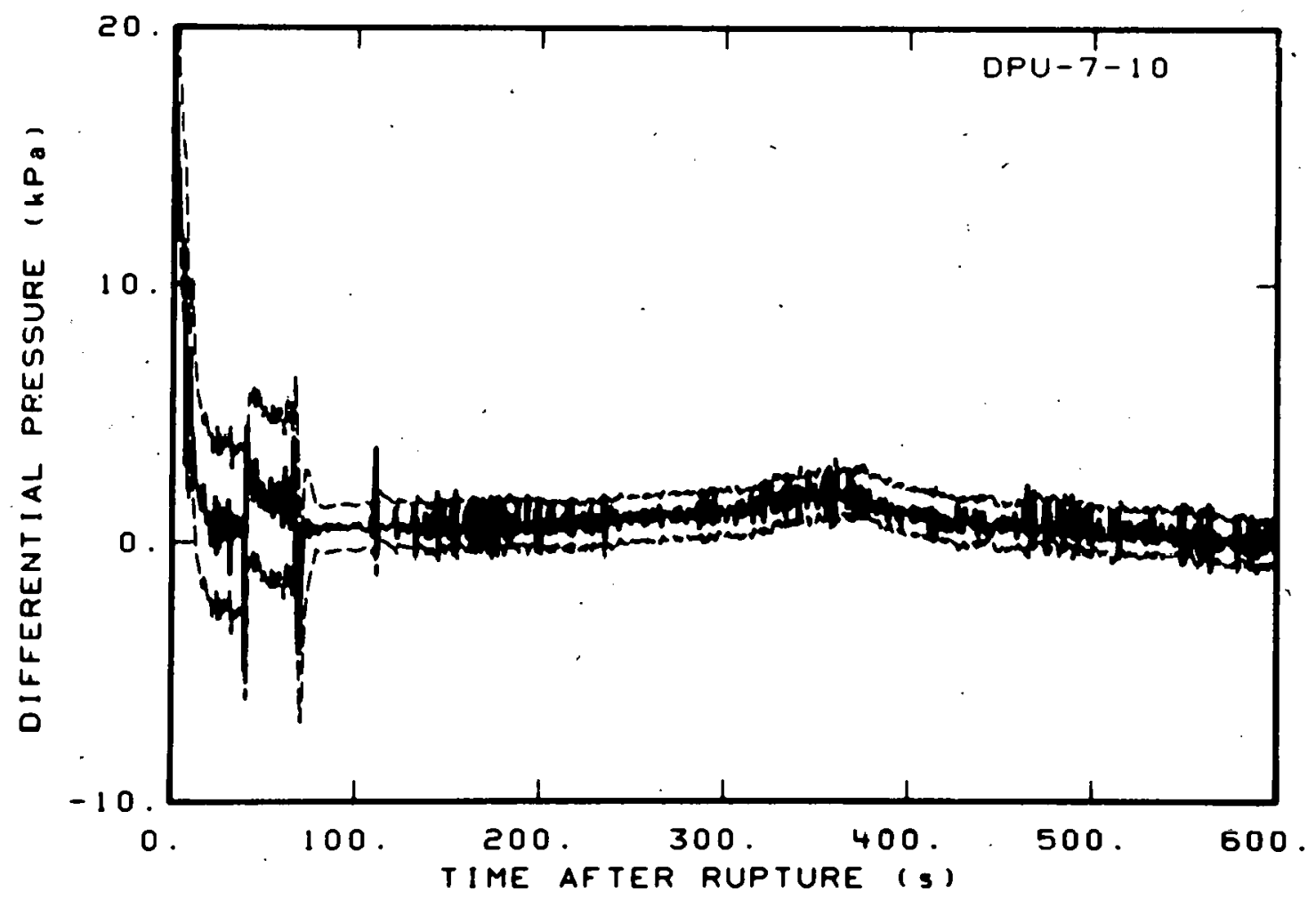

Fig. C-12 Differential pressure in intact loop (DPU-7-10). 


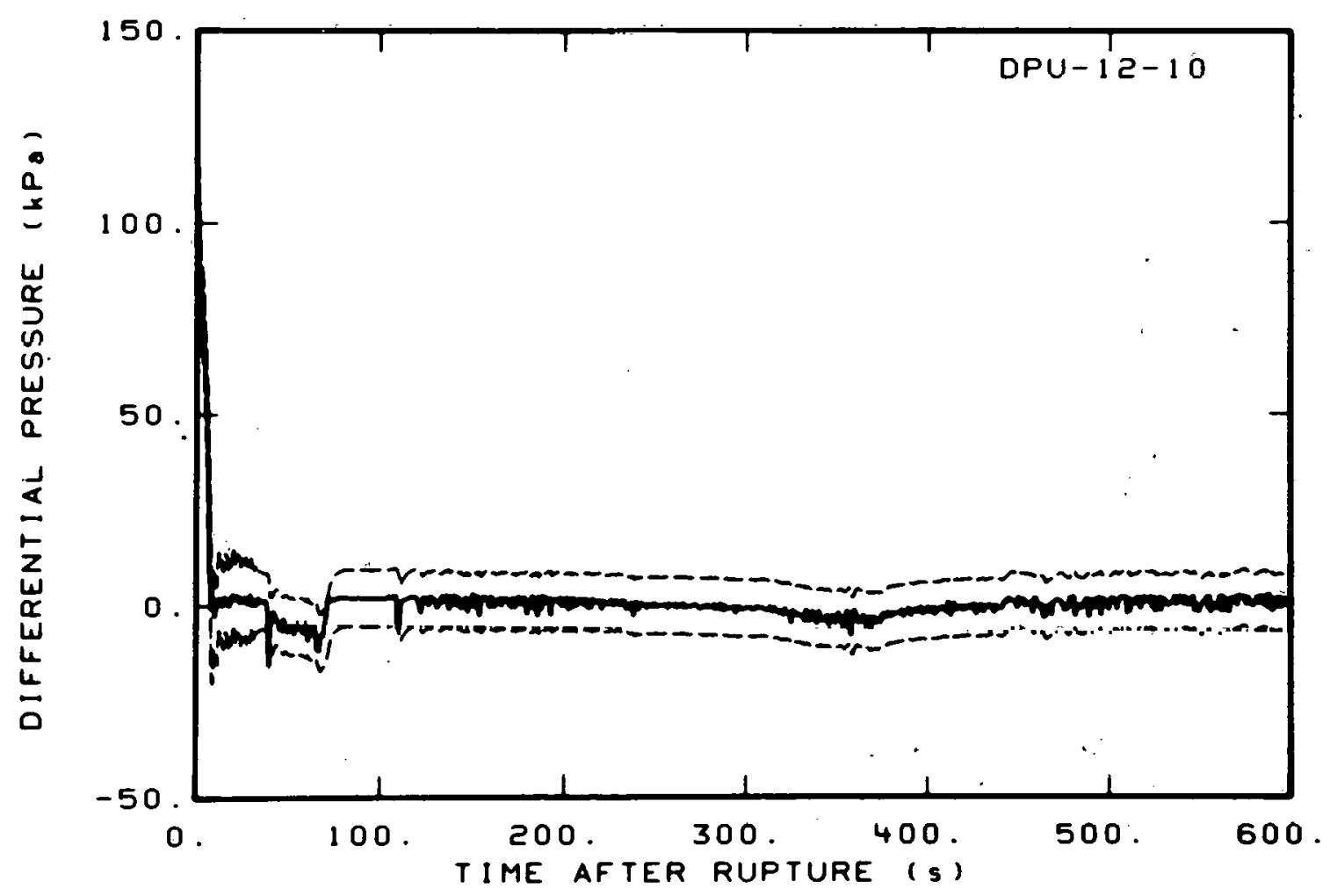

Fig. C-13 Differential pressure in intact loop (DPU-12-10).

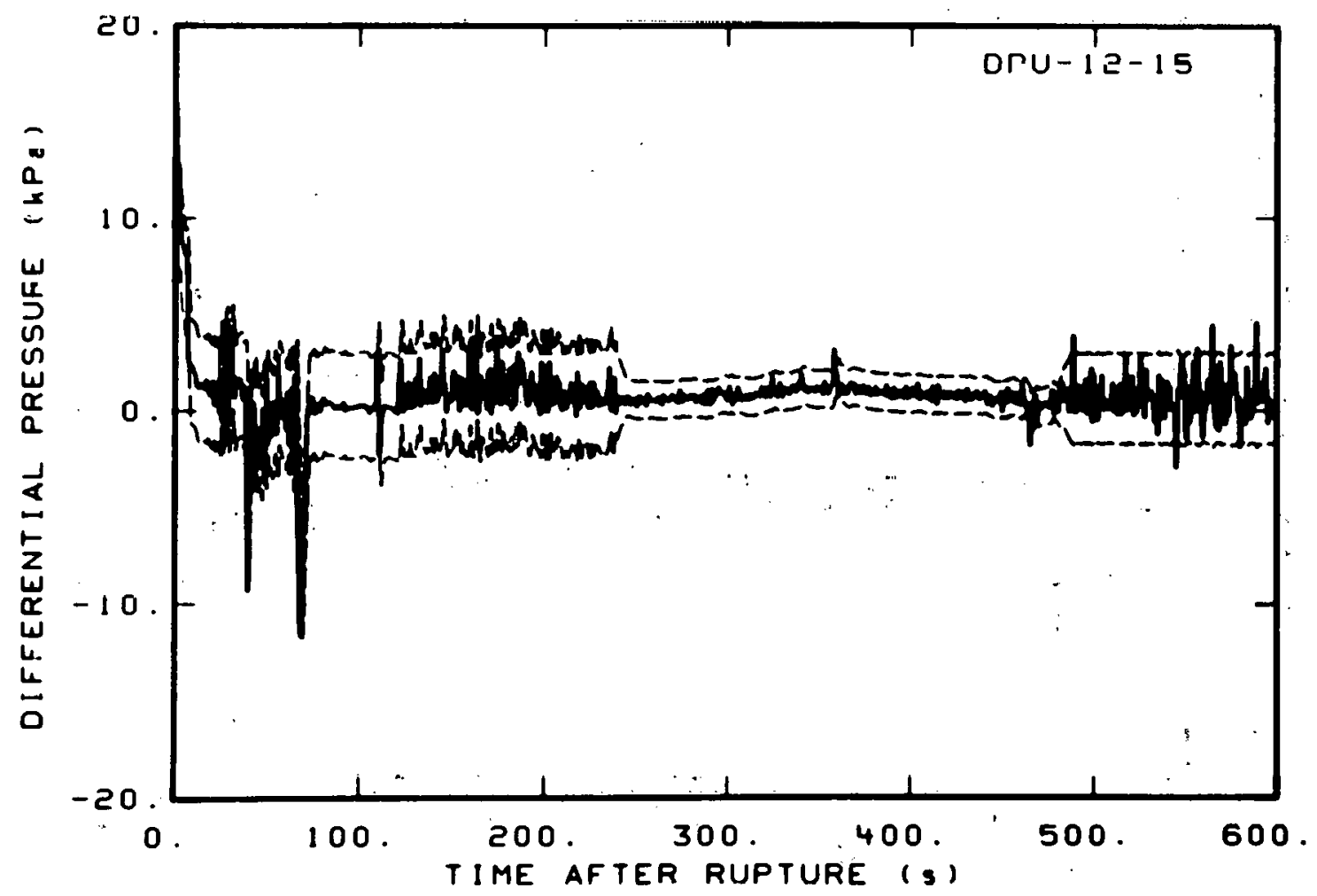

Fig. C-14 Differential pressure in intact loop (DPU-12-15). 


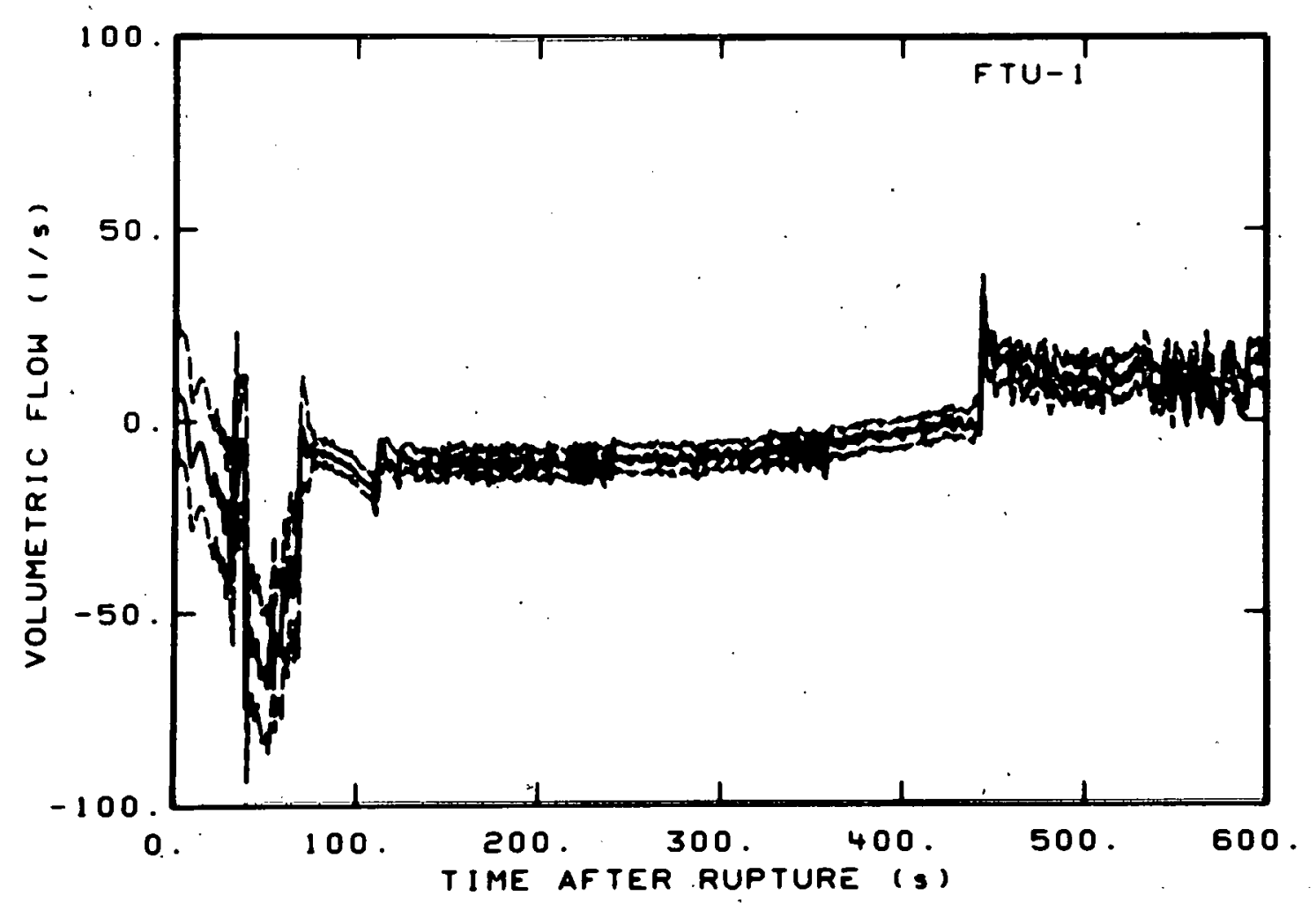

Fig. C-15 Volumetric flow in intact loop (FTU-1).

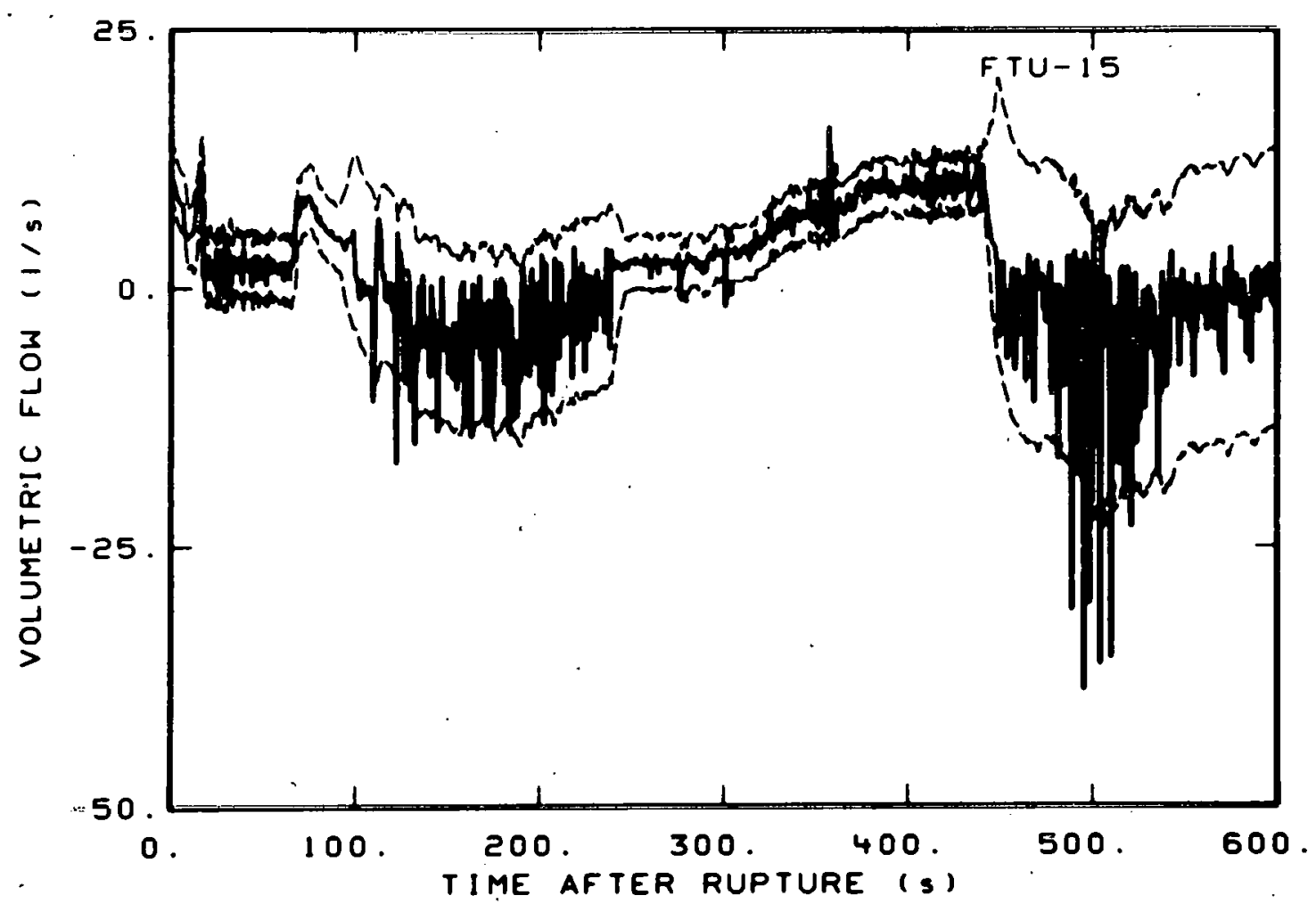

Fig. C-16 Volumetric flow in intact loop (FTU-15). 


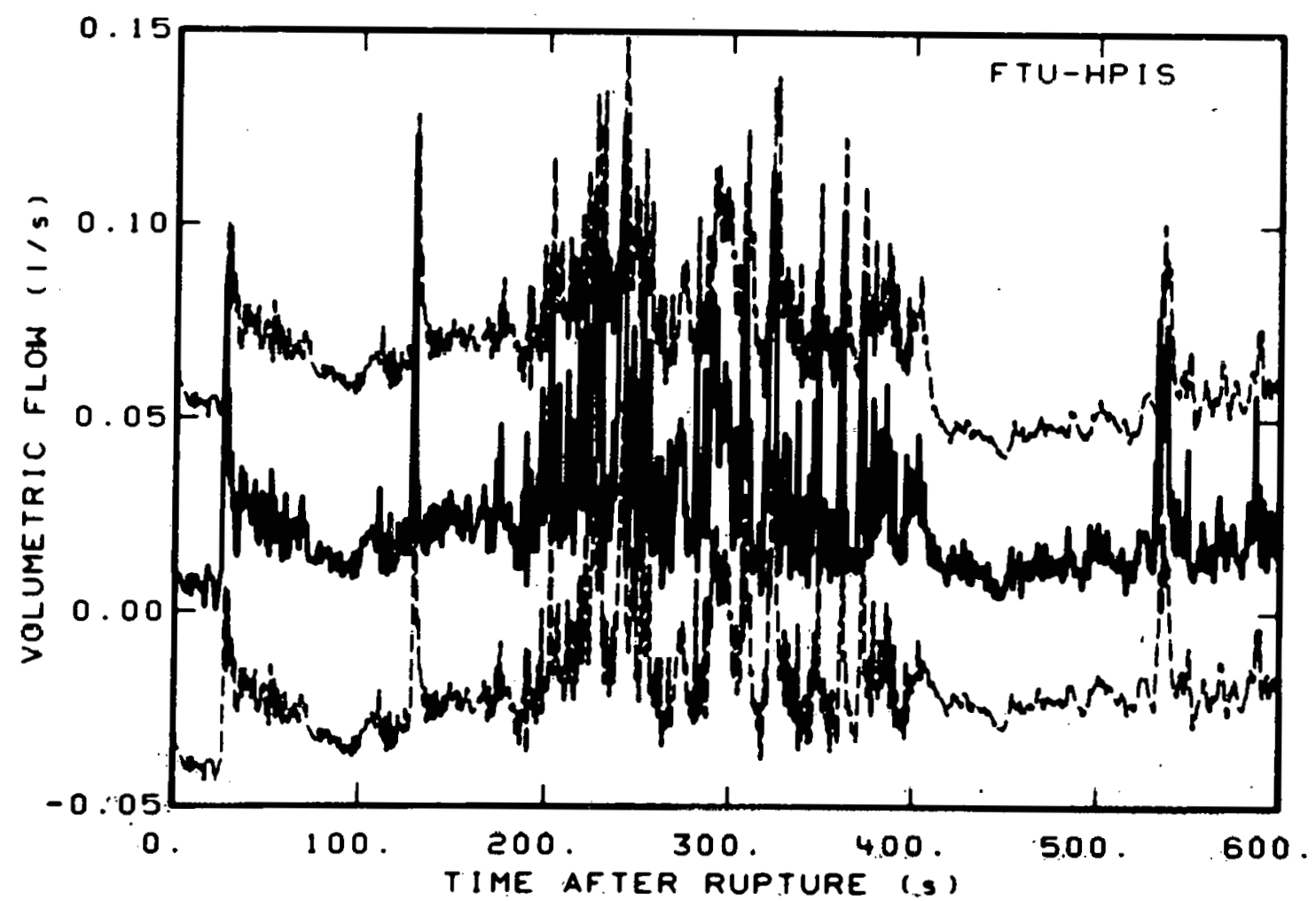

Fig. C-17 Volumetric flow in intact loop hi.gh pressure injection line (FTU:HPIS).

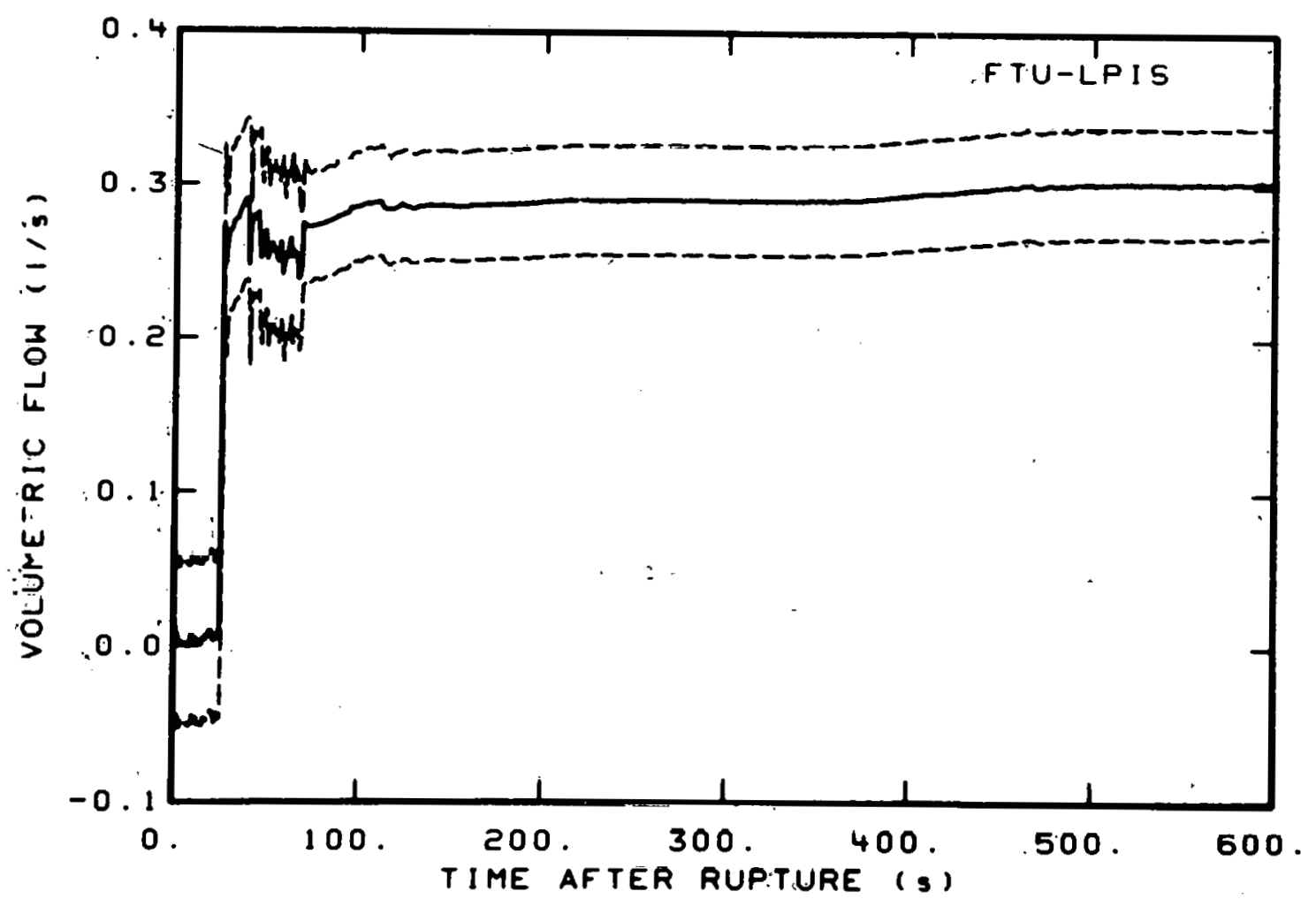

Fig. C-18 Volumetric flow in intact loop low pressure injection line (FTU-LPIS). 


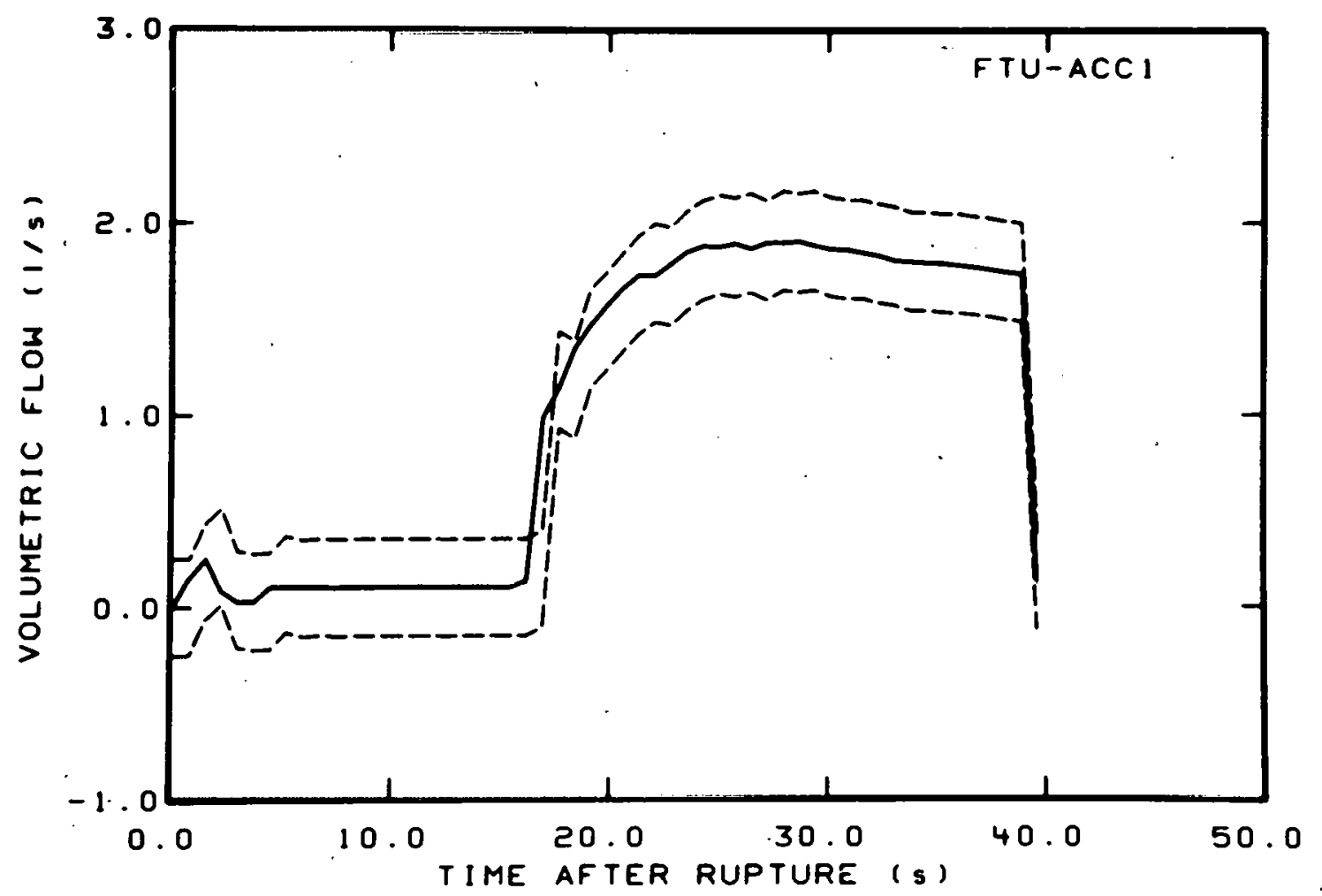

Fig. C-19 Volumetric flow in intact loop accumulator discharge line (FTU-ACC1).

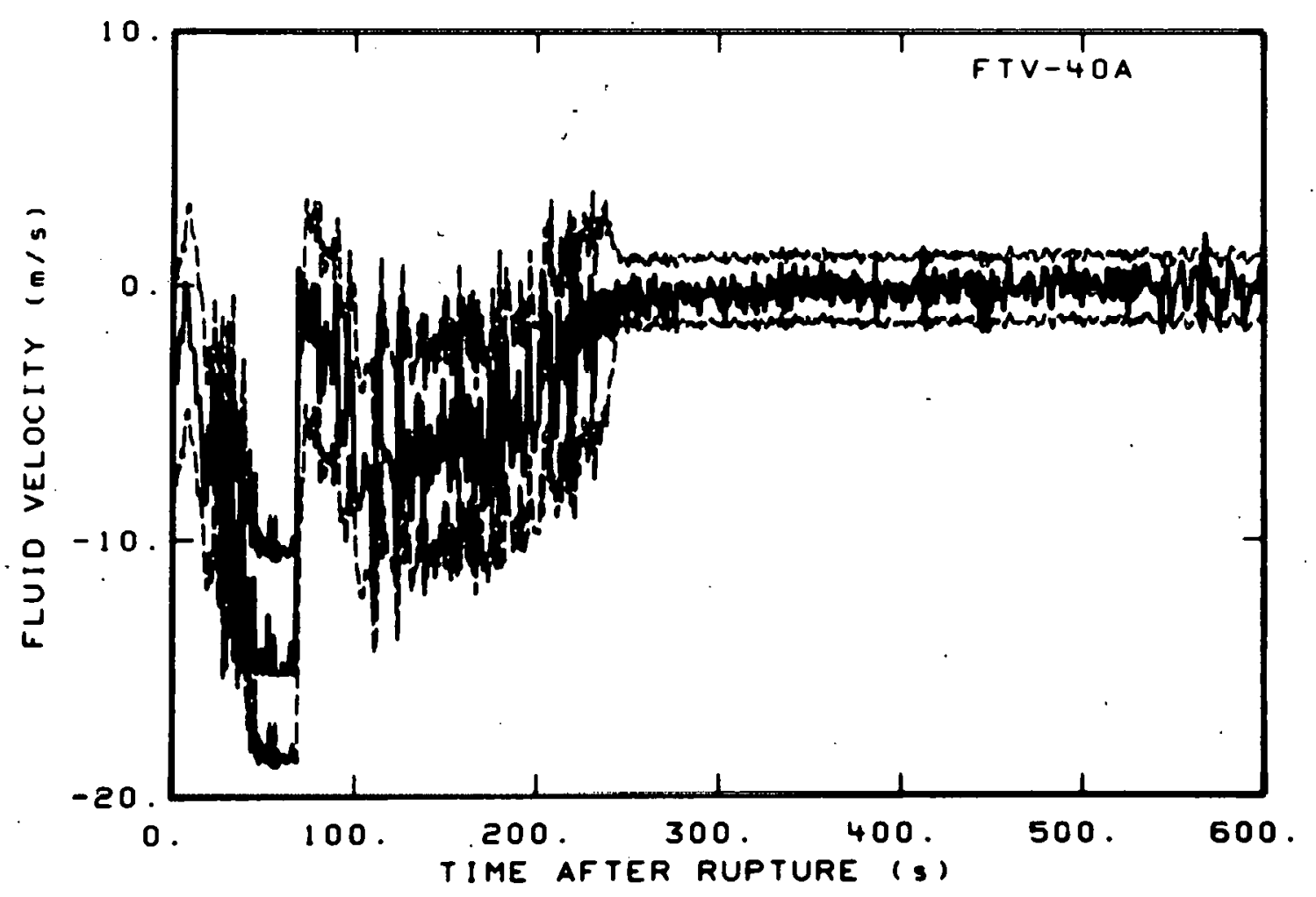

Fig. C-20 Fluid velocity in vessel (FTV-40A). 


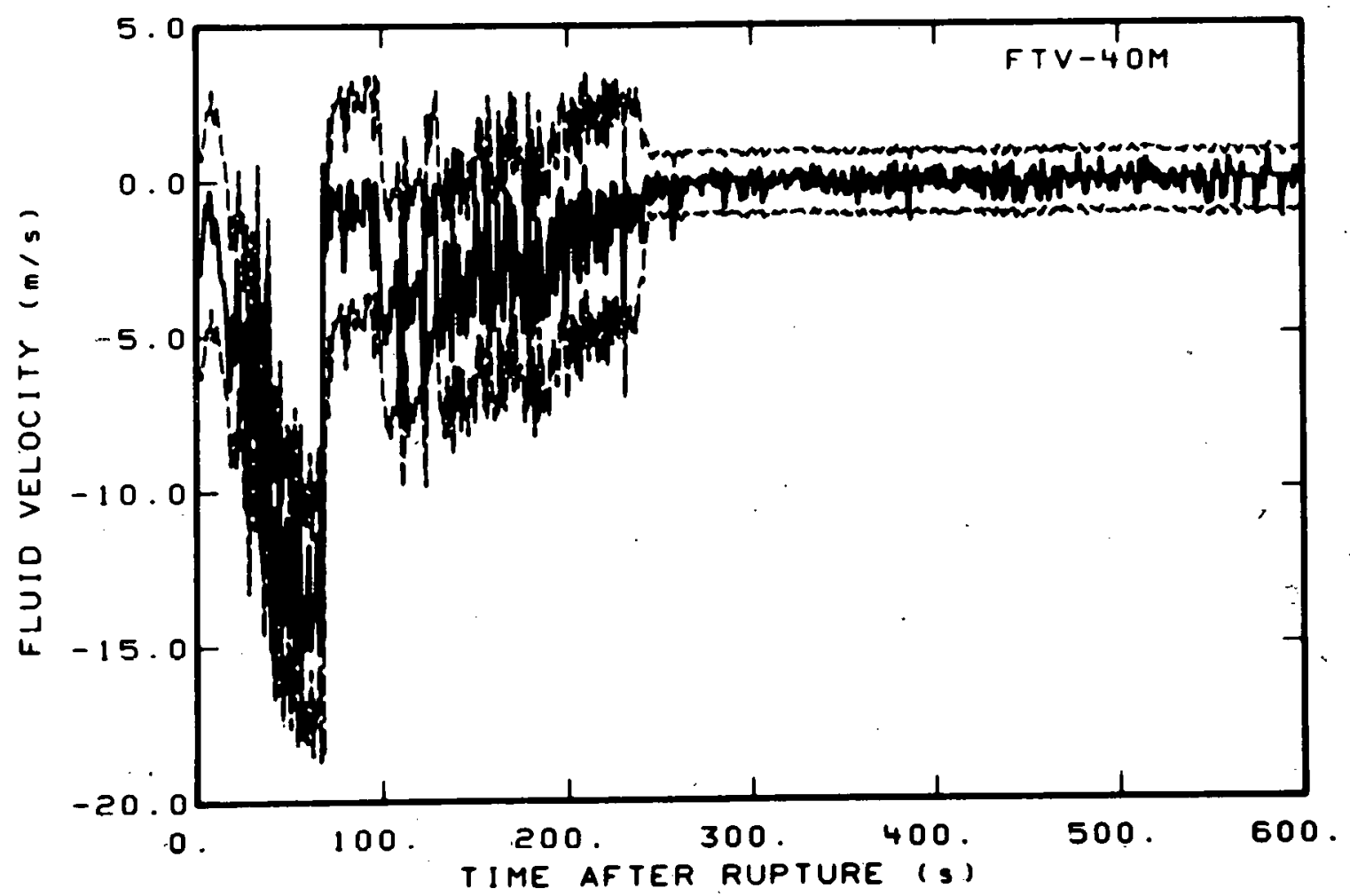

Fig. C-21 Fluid velocity in vessel (FTV-40M).

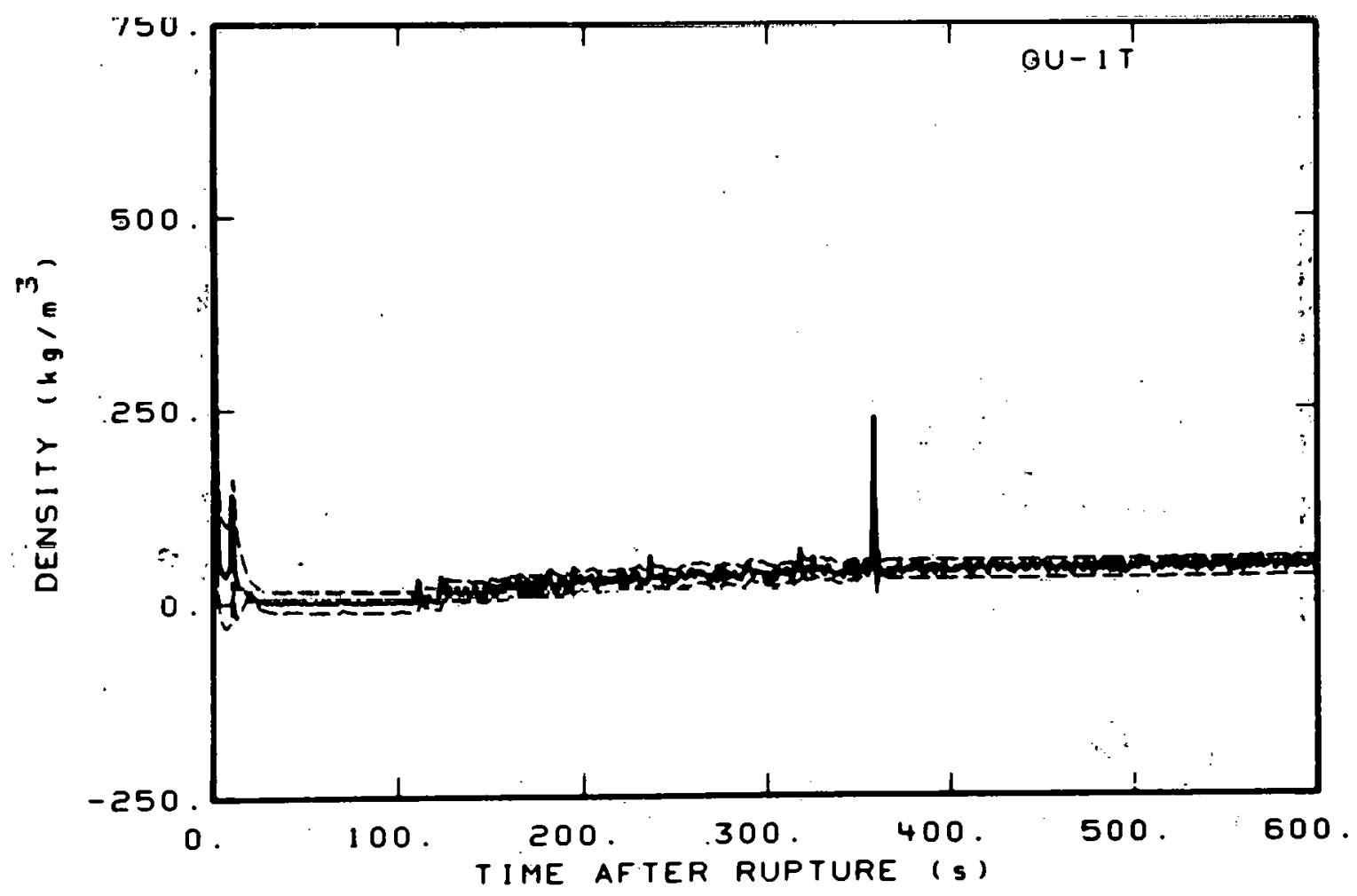

Fig. C-22 Density in intact loop (GU-1T). 


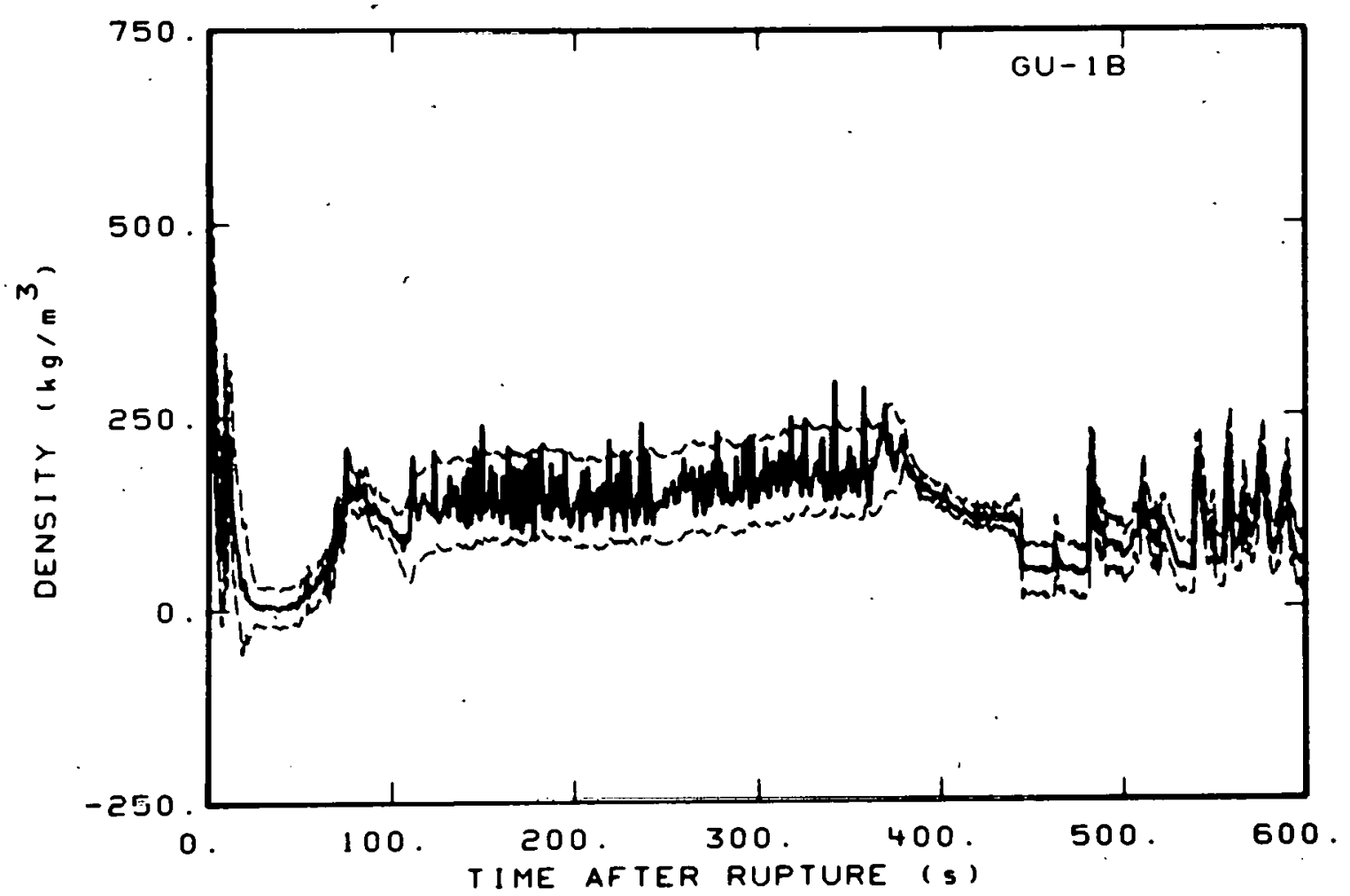

Fig. C-23 Density in intact 100p (GU-1B).

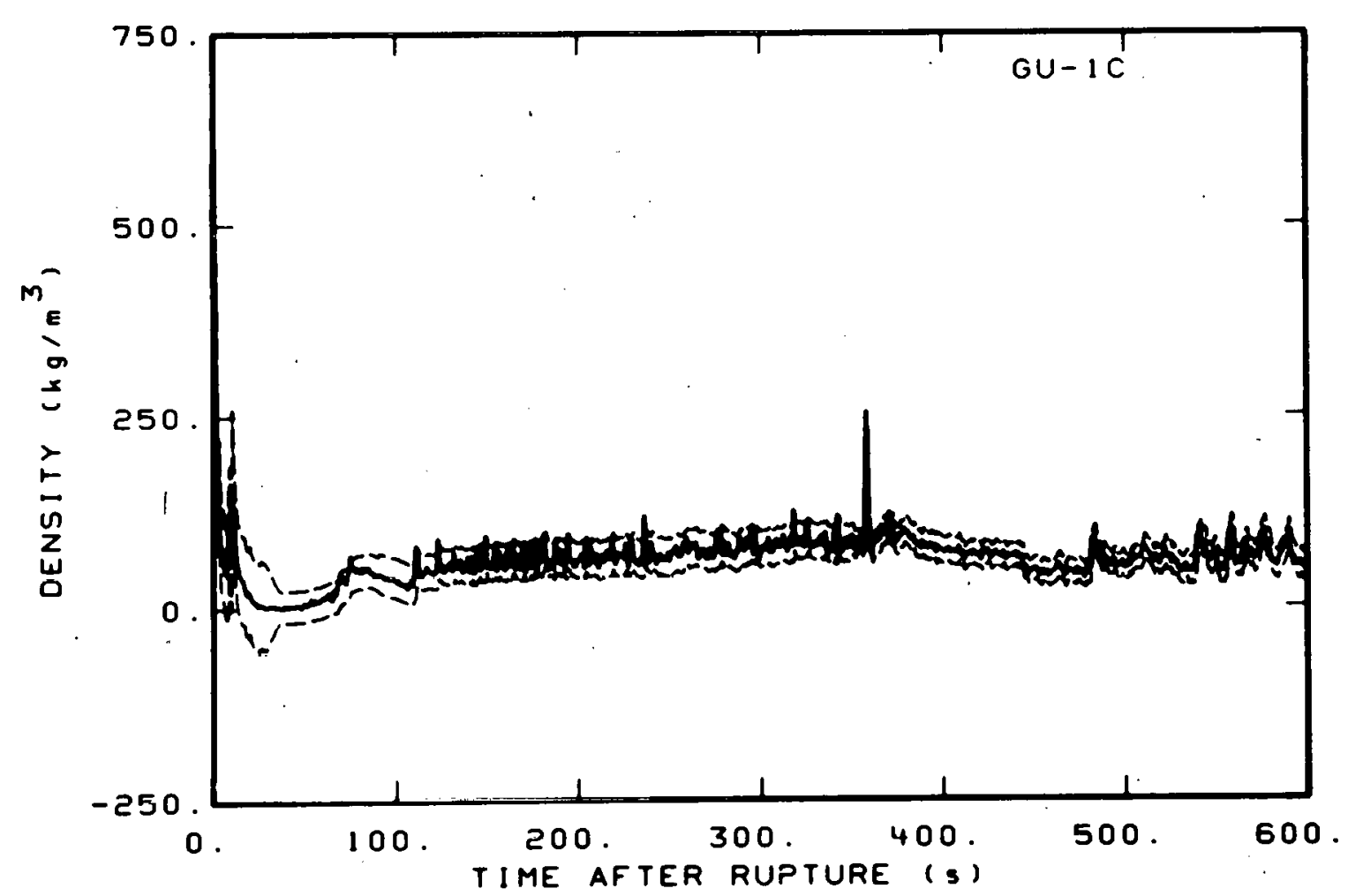

Fig. C-24 Density in intact 100p (GU-1C). 


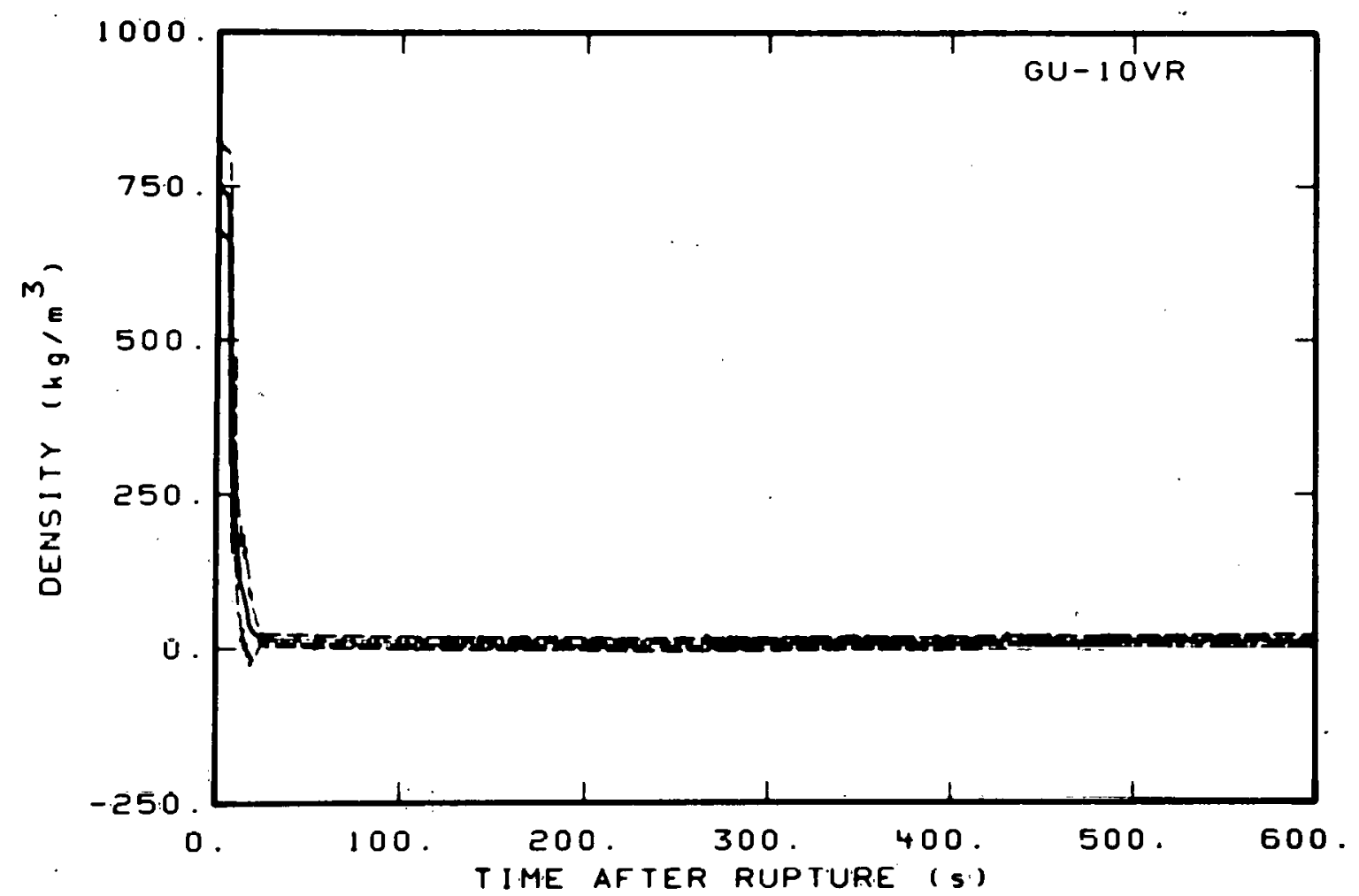

Fig. C-25 Density in intact loop (GU-10VR).

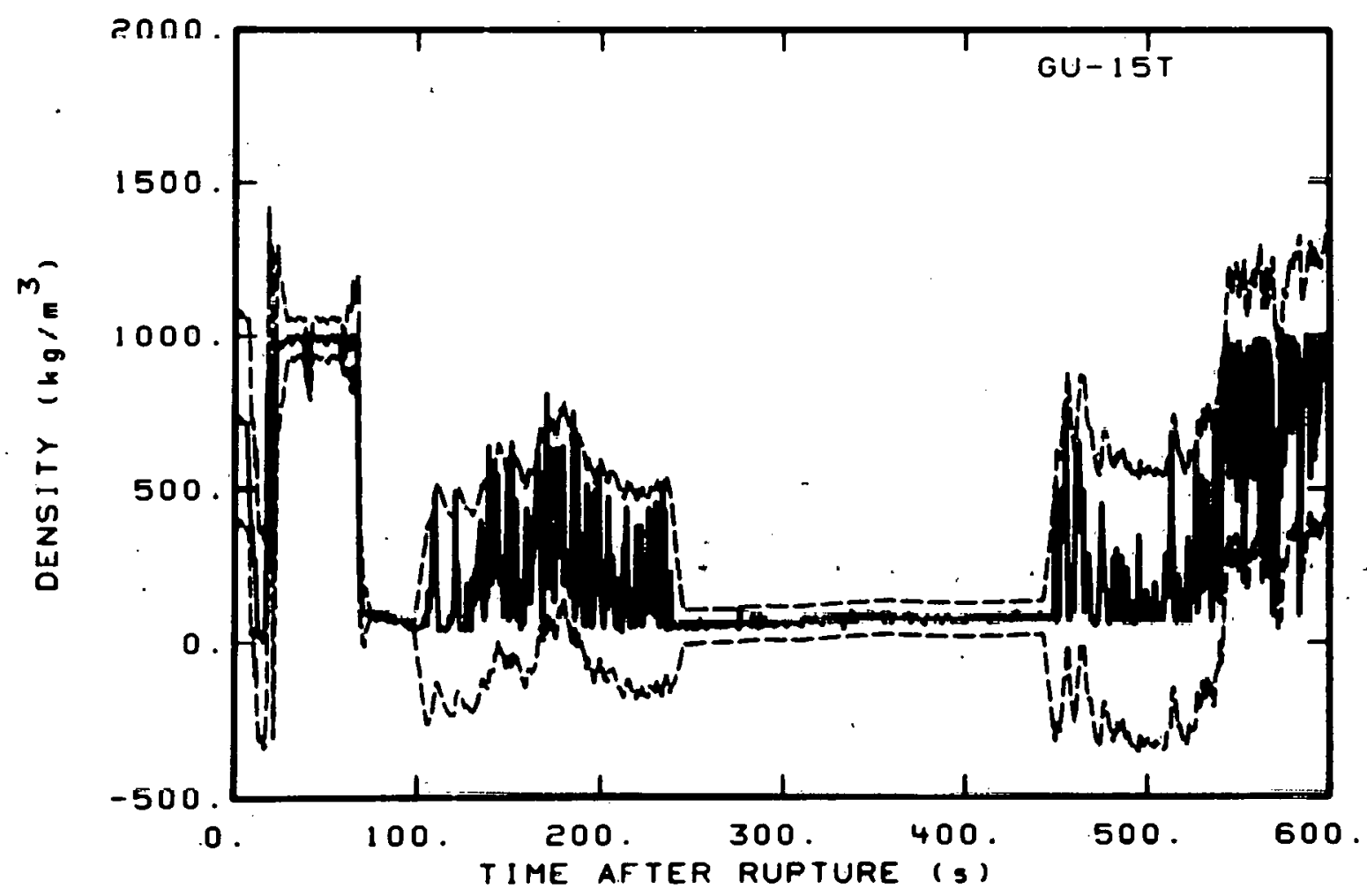

Fig. C-26 Density in intact loop (GU-15T). 


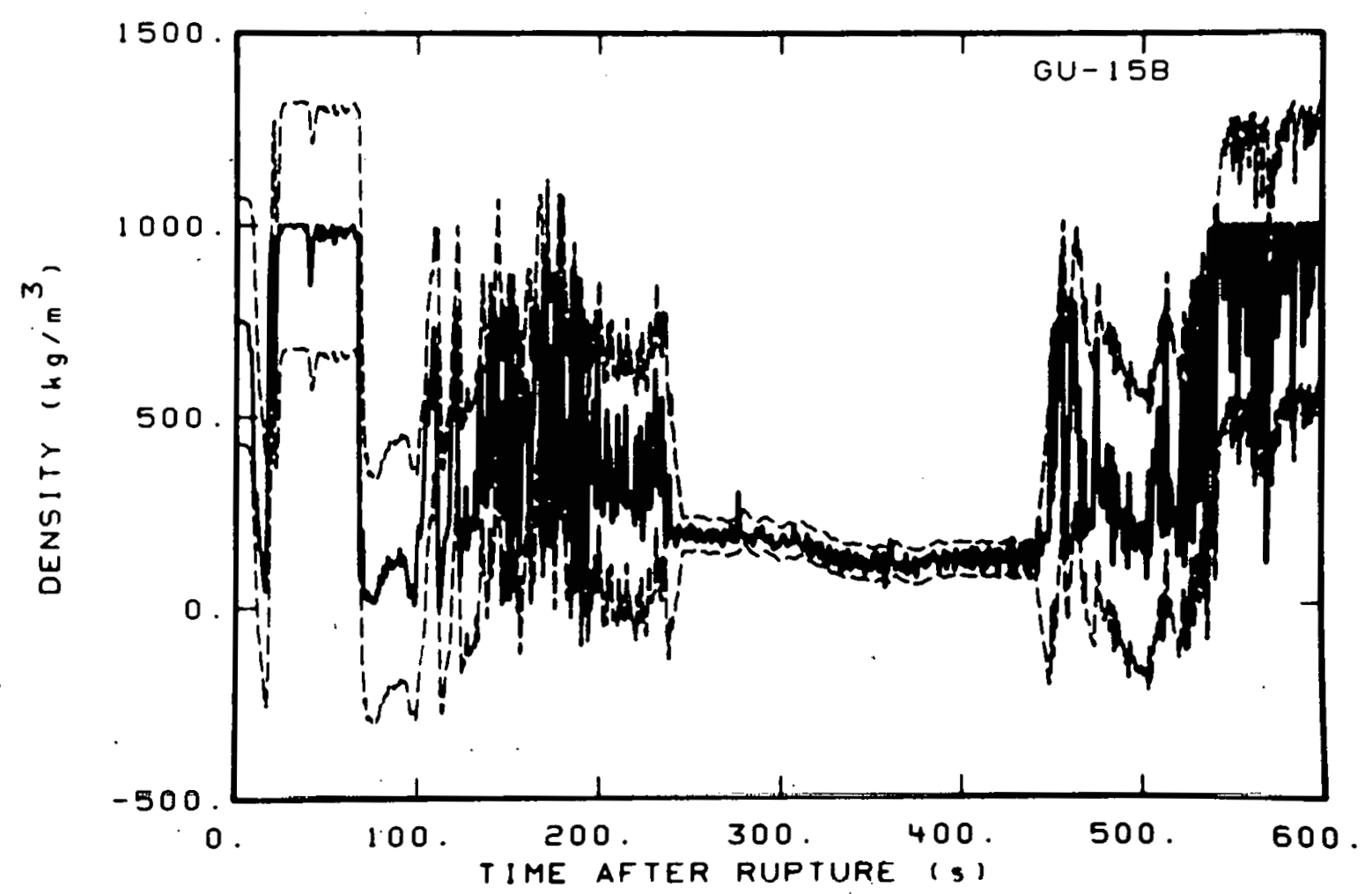

Fig. C-27 Density in intact loop (GU-15B).

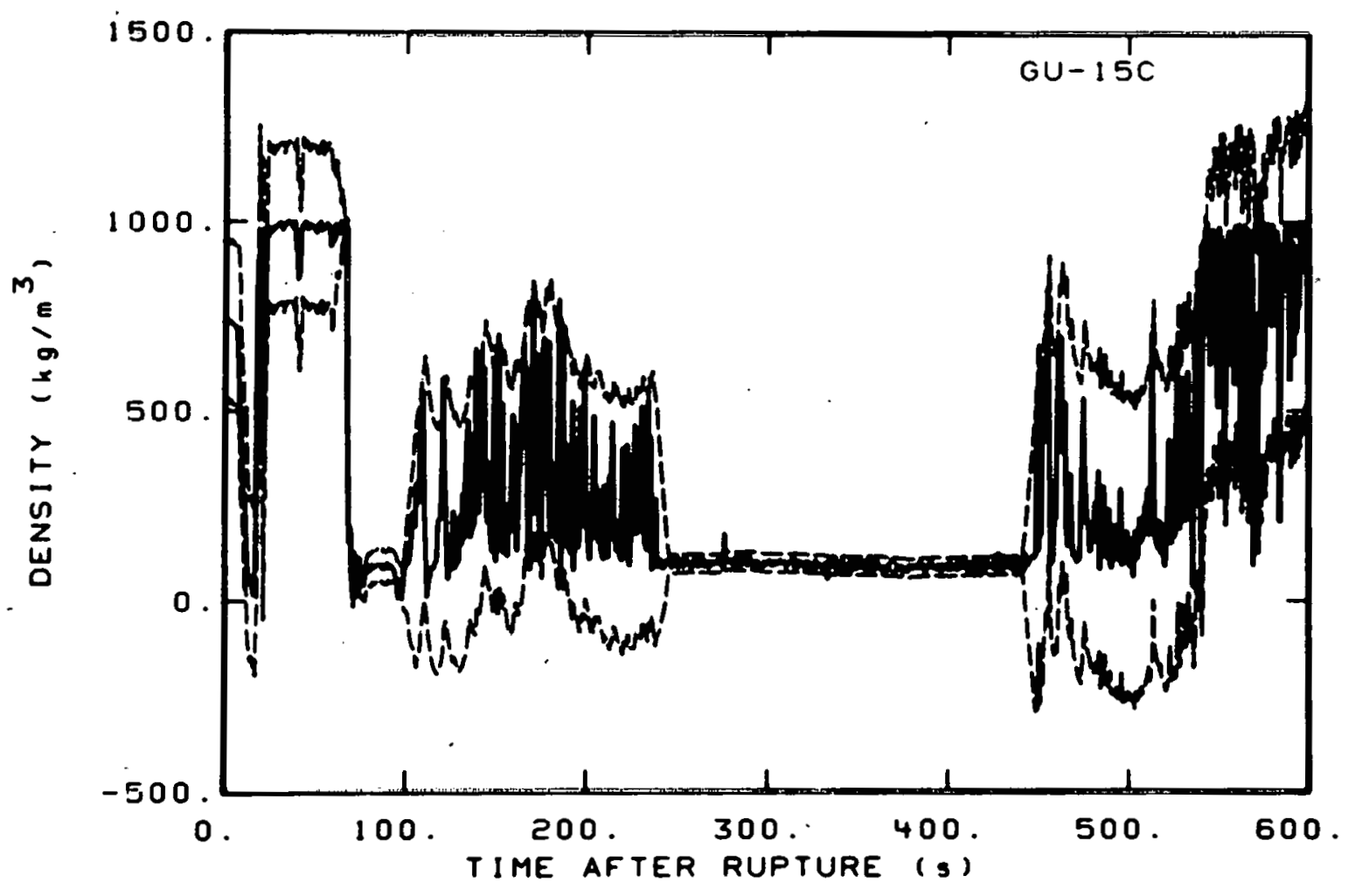

Fig. C-28 Density in intact loop (GU-15C). 


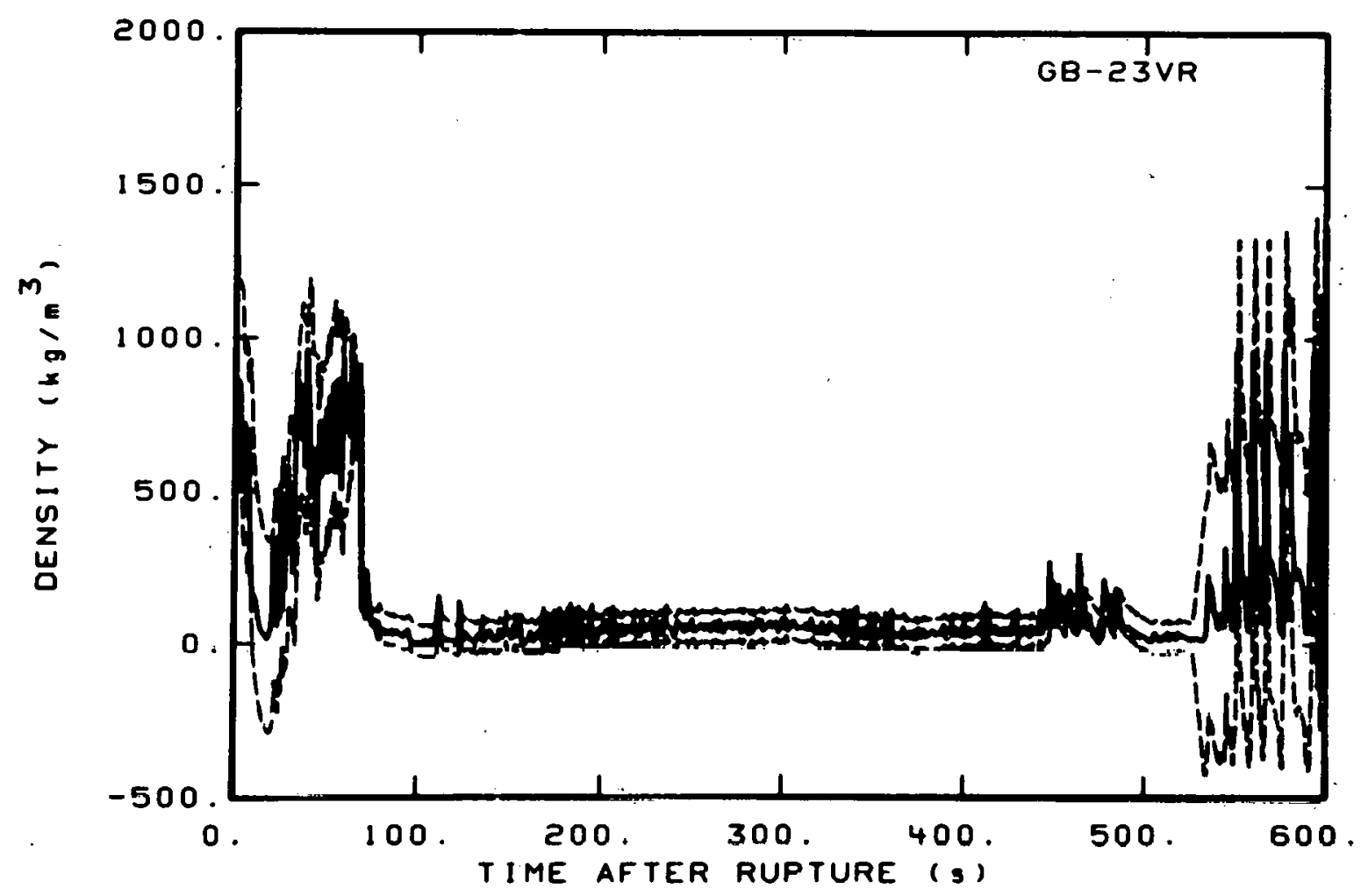

Fig. C-29 Densịty in broken loop (GB-23VR).

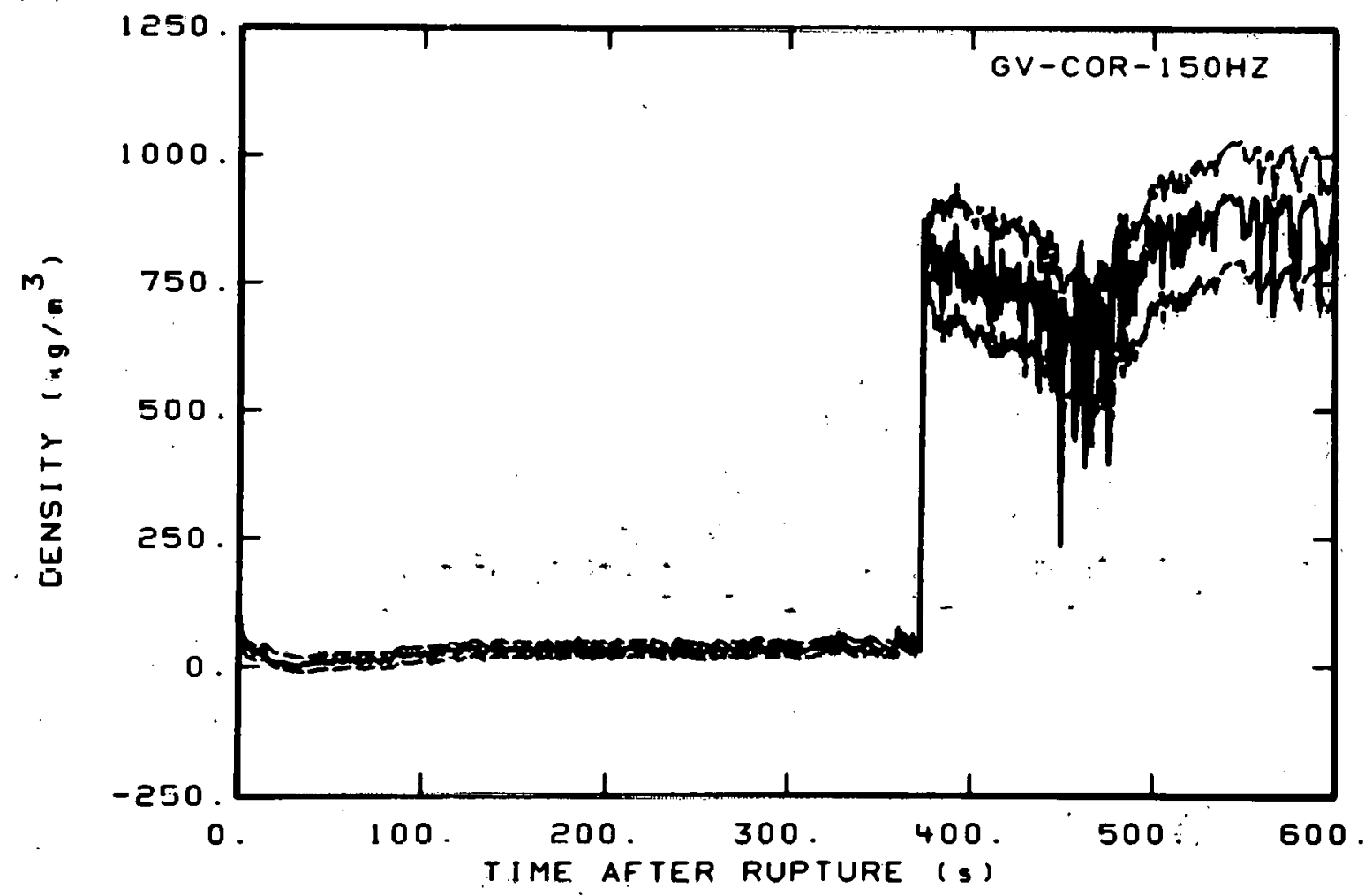

Fig. C-30 Density in vessel (GV-COR-150HZ). 


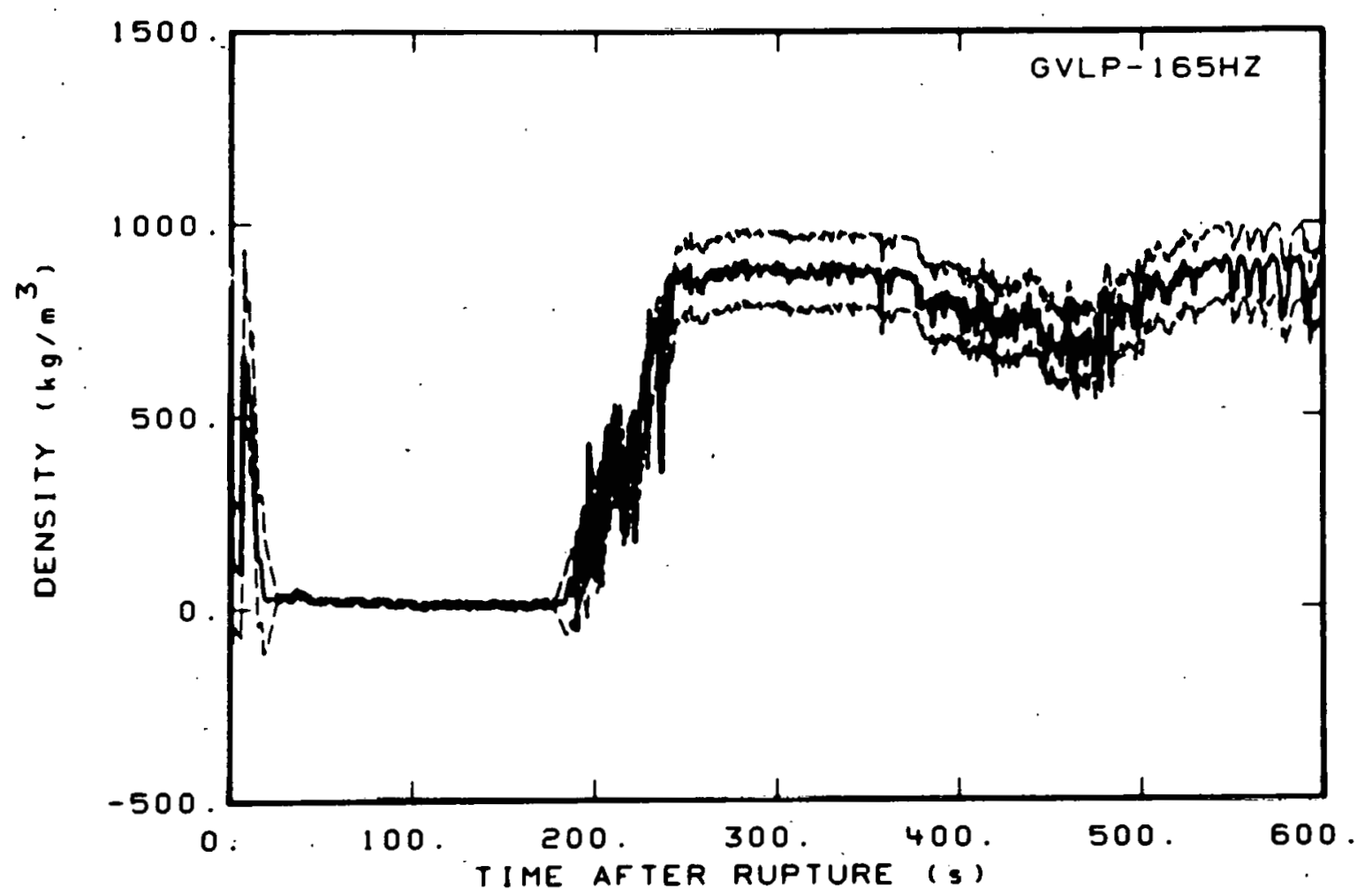

Fig. C-31 Density in vessel (GVLP-165HZ).

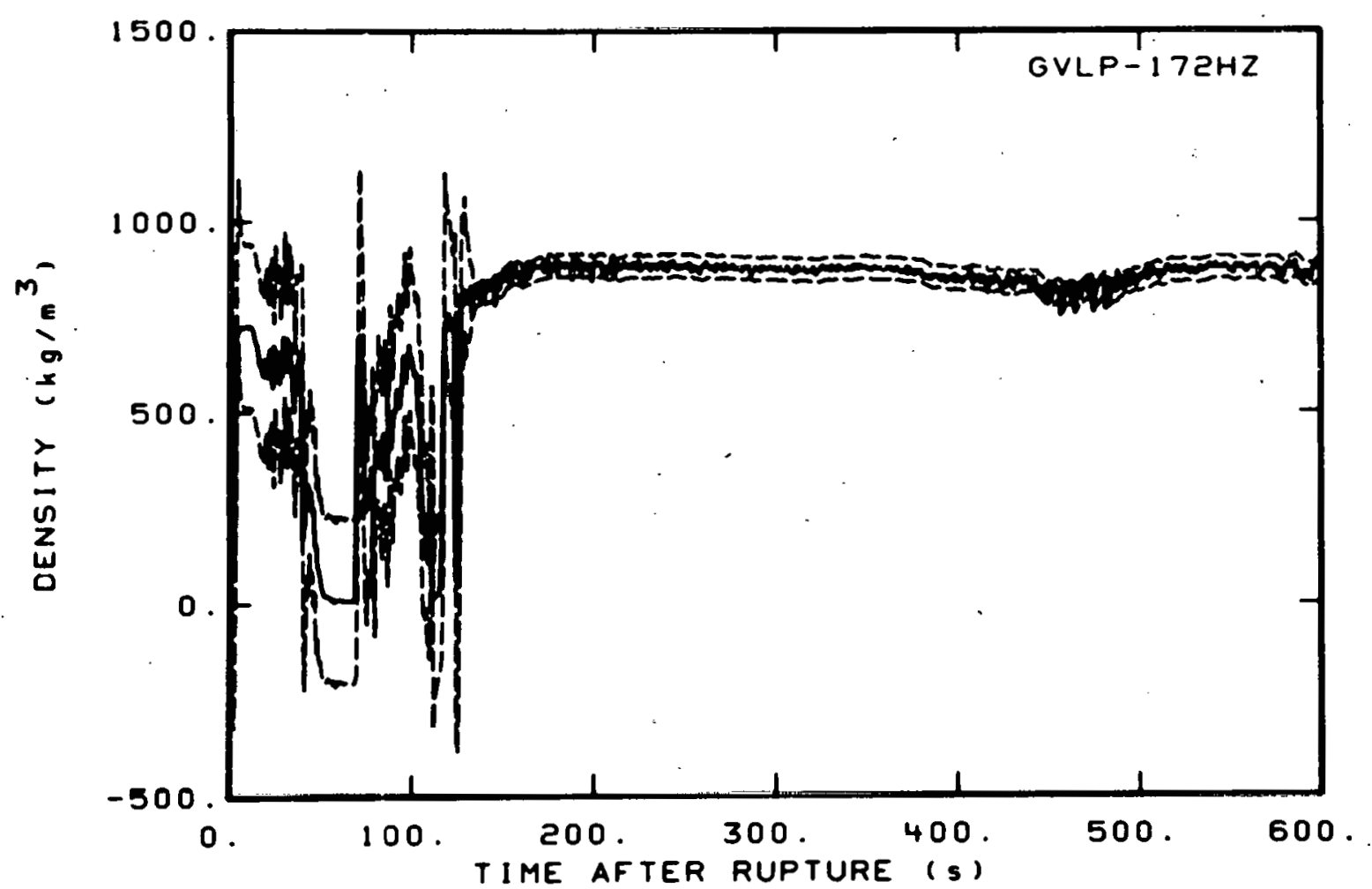

Fig. C-32 Density in vessel (GVLP-172HZ).

$24 \overline{5}$ 


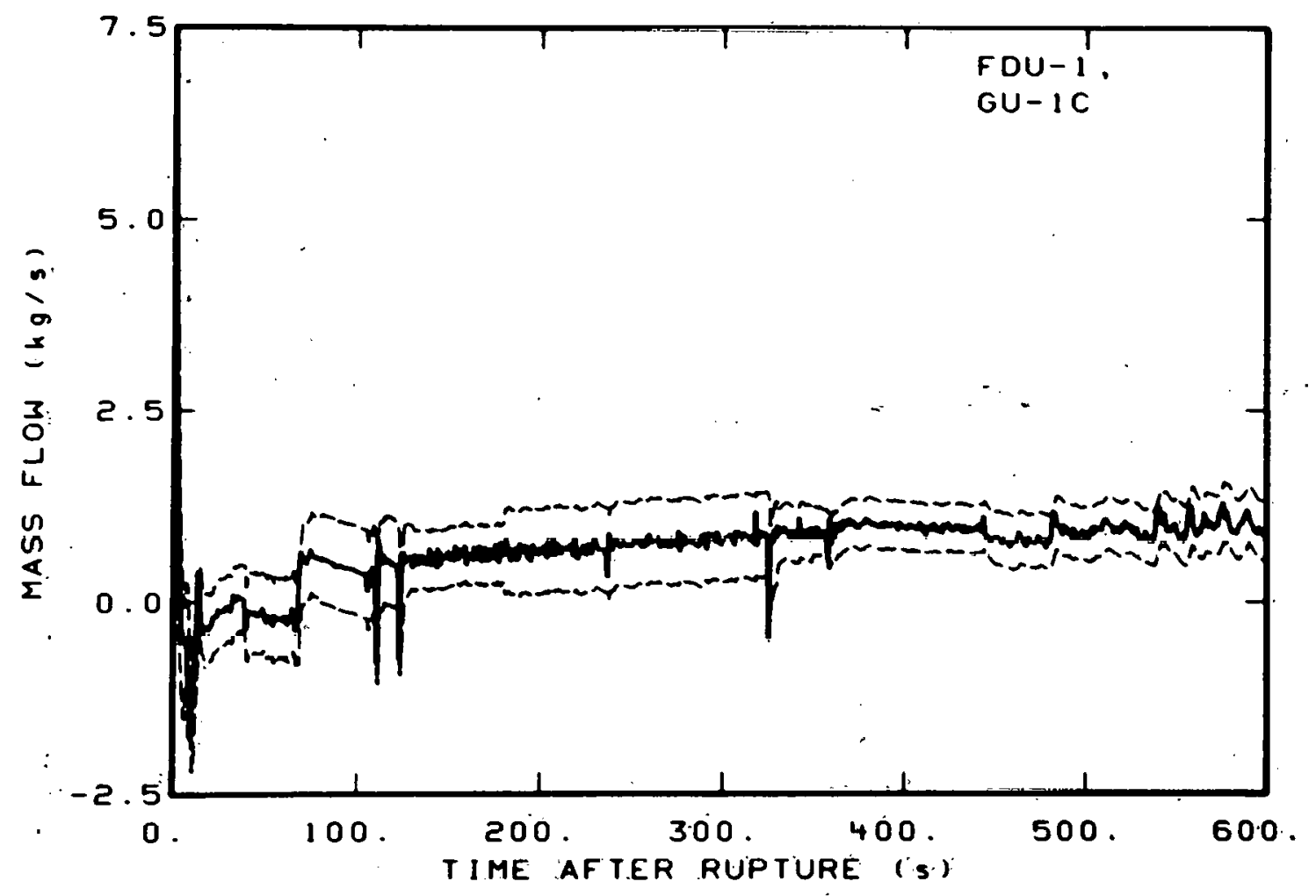

Fig. C-33 Mass flow in intact loop (FDU-T, GU-IC).

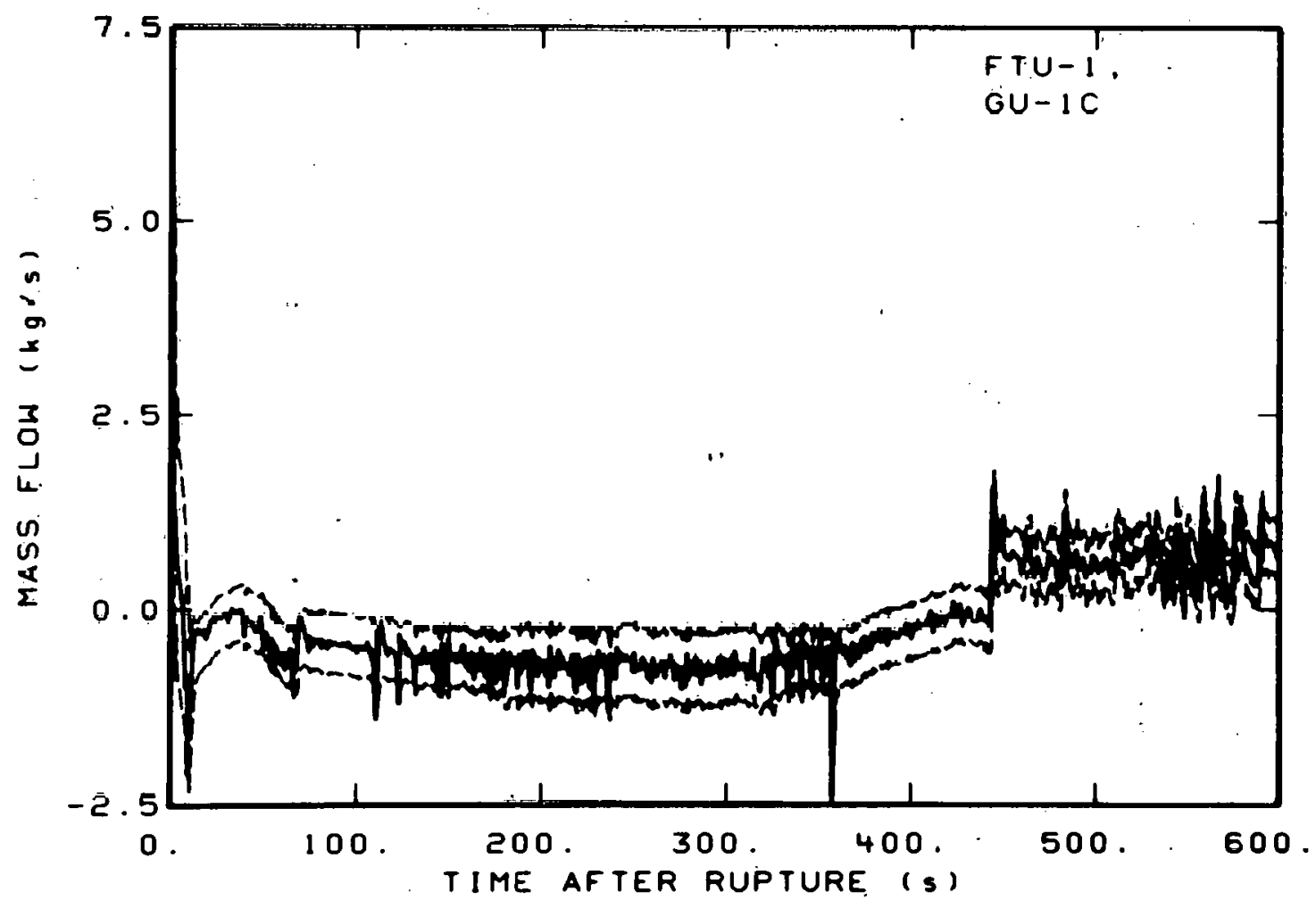

Fig. C-34 Mass flow in intact loop (FTU-1., GU-1C). 


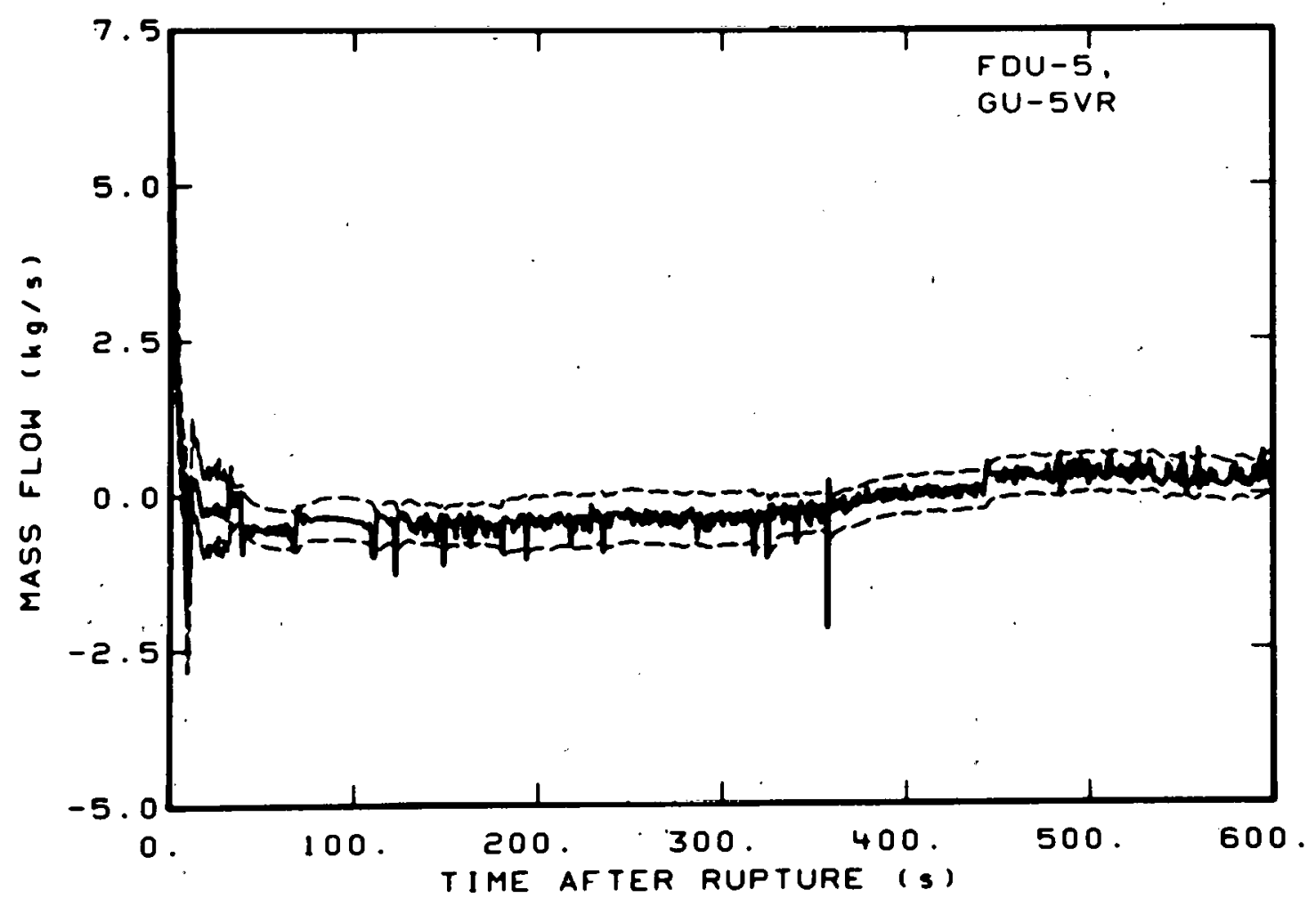

Fig. C-35 Mass flow in intact loop (FDU-5, GU-5VR).

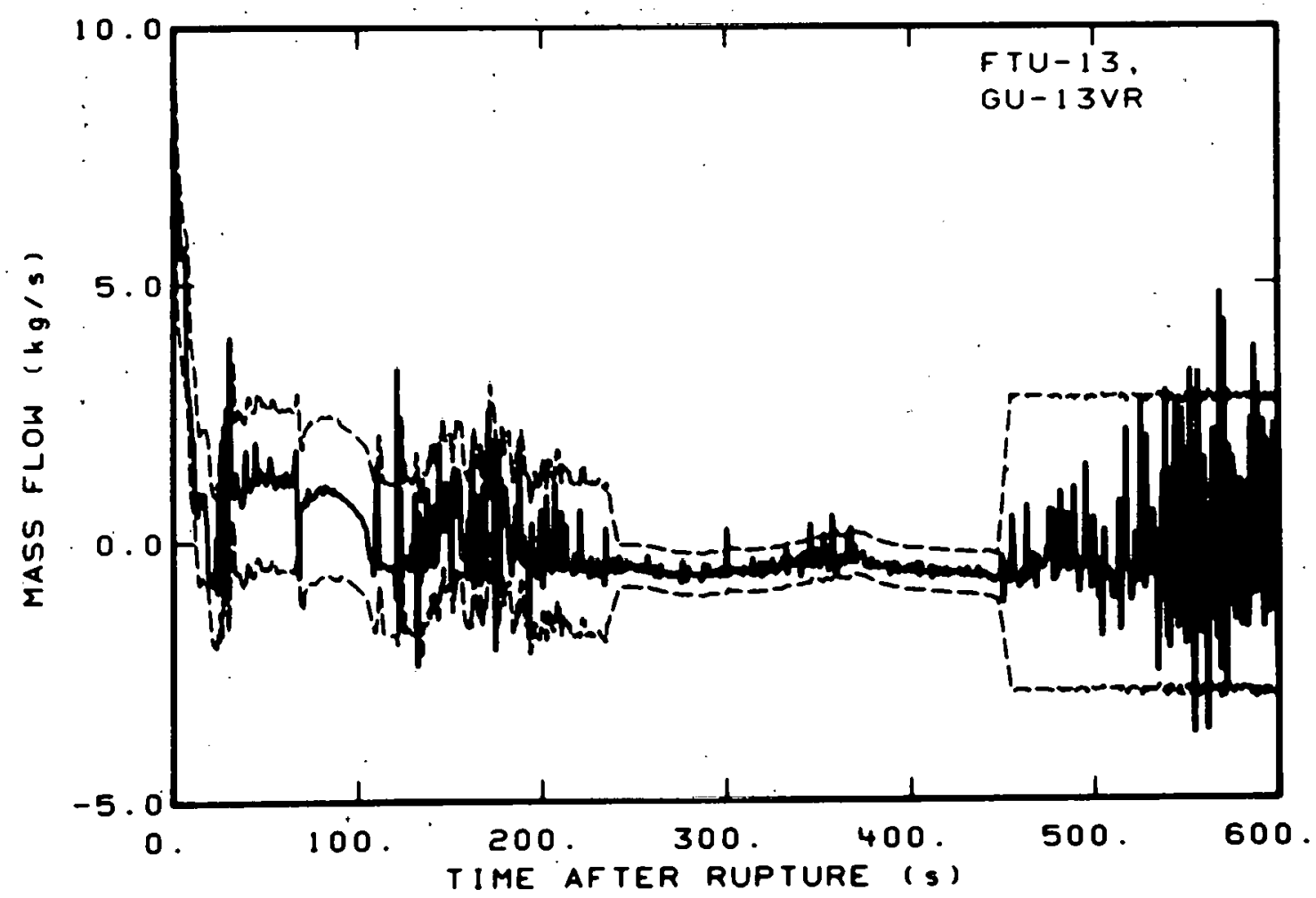

Fig. C-36 Mass flow in intact loop (FTU-13, GU-13VR). 


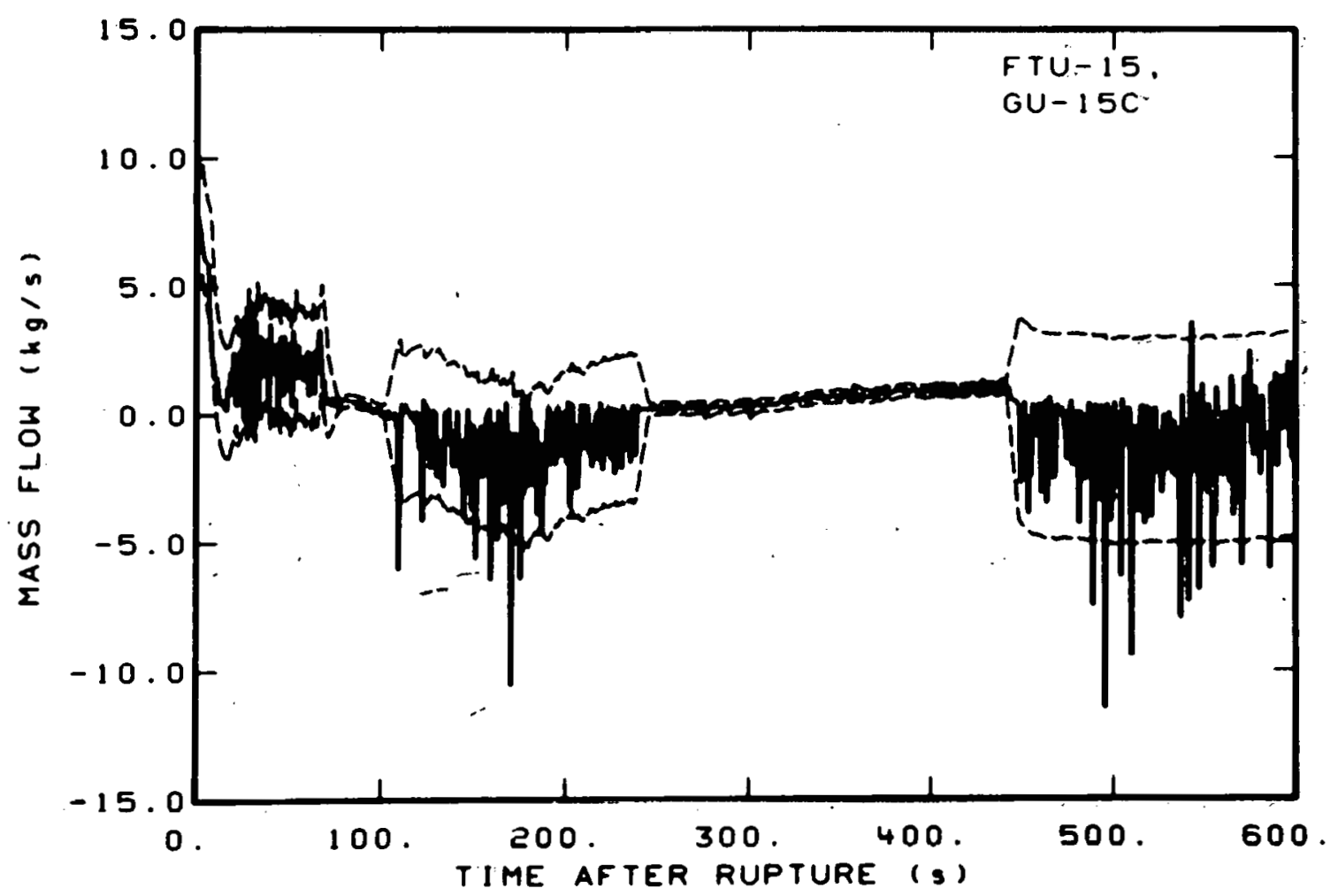

Fig. C-37 Mass flow in intact loop (FTU-15, GU-15C).

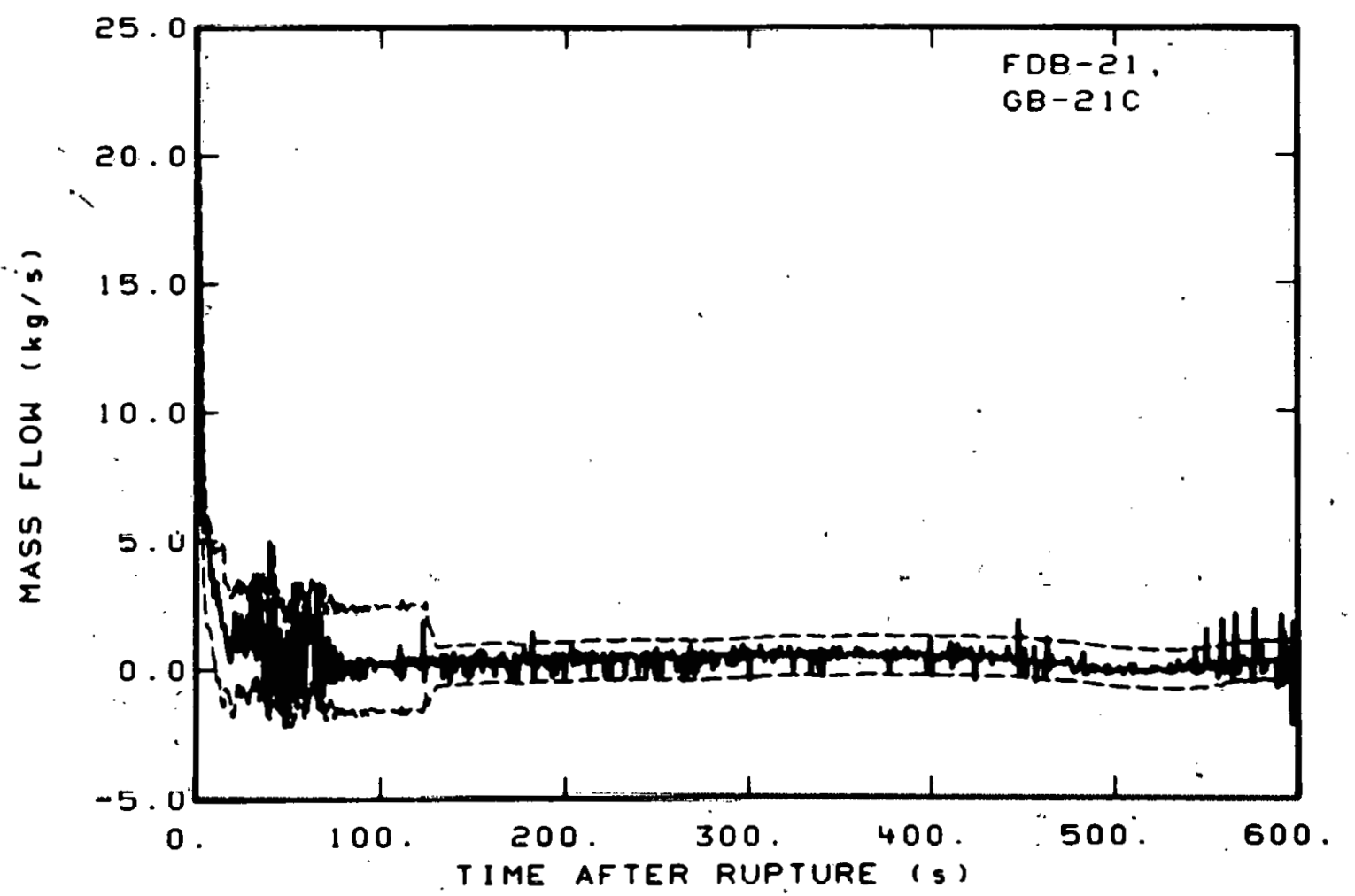

Fig. C-38 Mass flow in broken loop (FDB-21, GB-21C). 


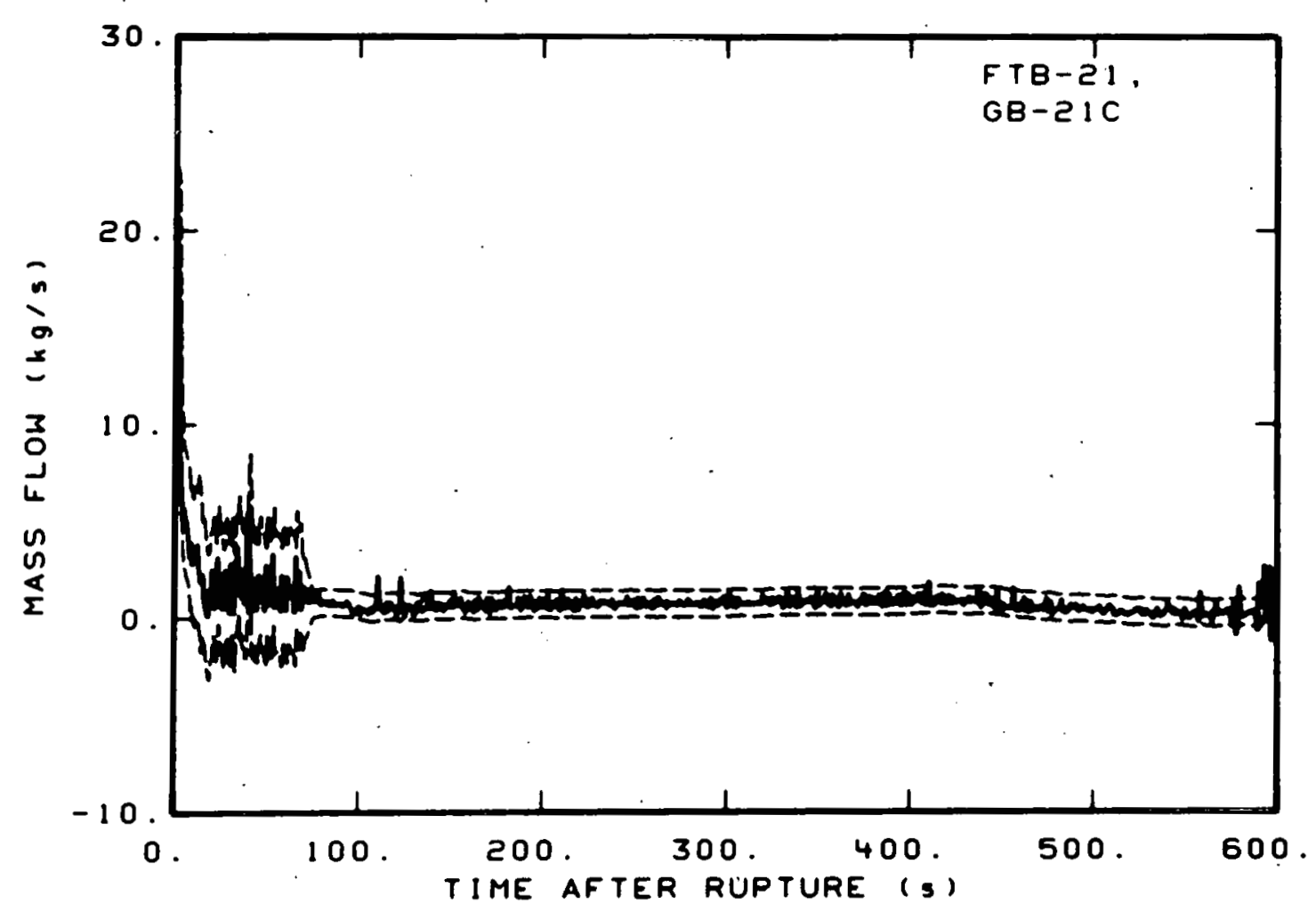

Fig. C-39 Mass flow in broken loop (FTB-27, GB-21C).

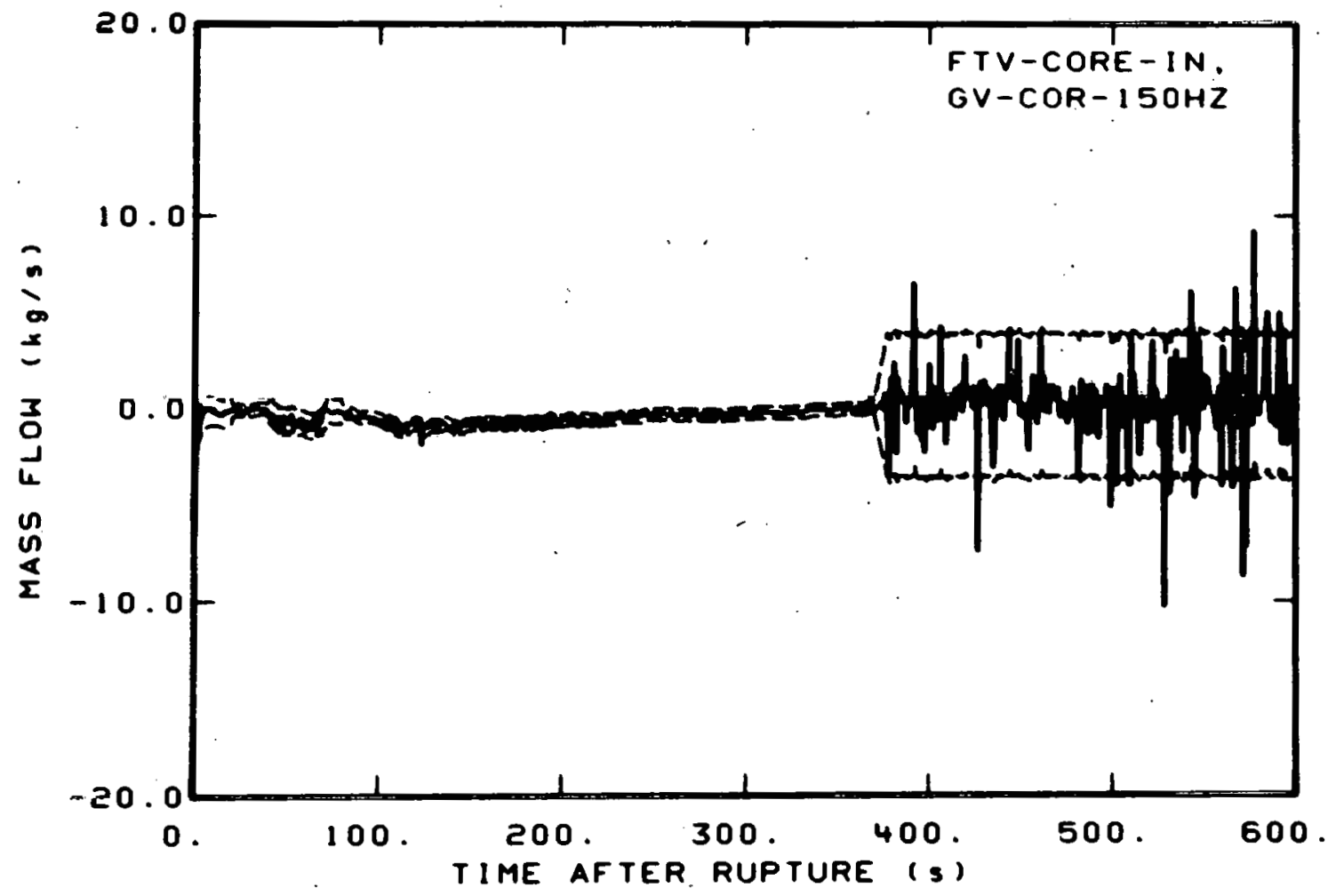

Fig. C-40 Mass flow in vessel (FTV-CORE-IN, GV-COR-150HZ). 
TABLE C-II

GENERAL MEASUREMENT ENGINEERING ERRO? SOURCES AND ERROR VALU三ذ (TEST S-28-4)

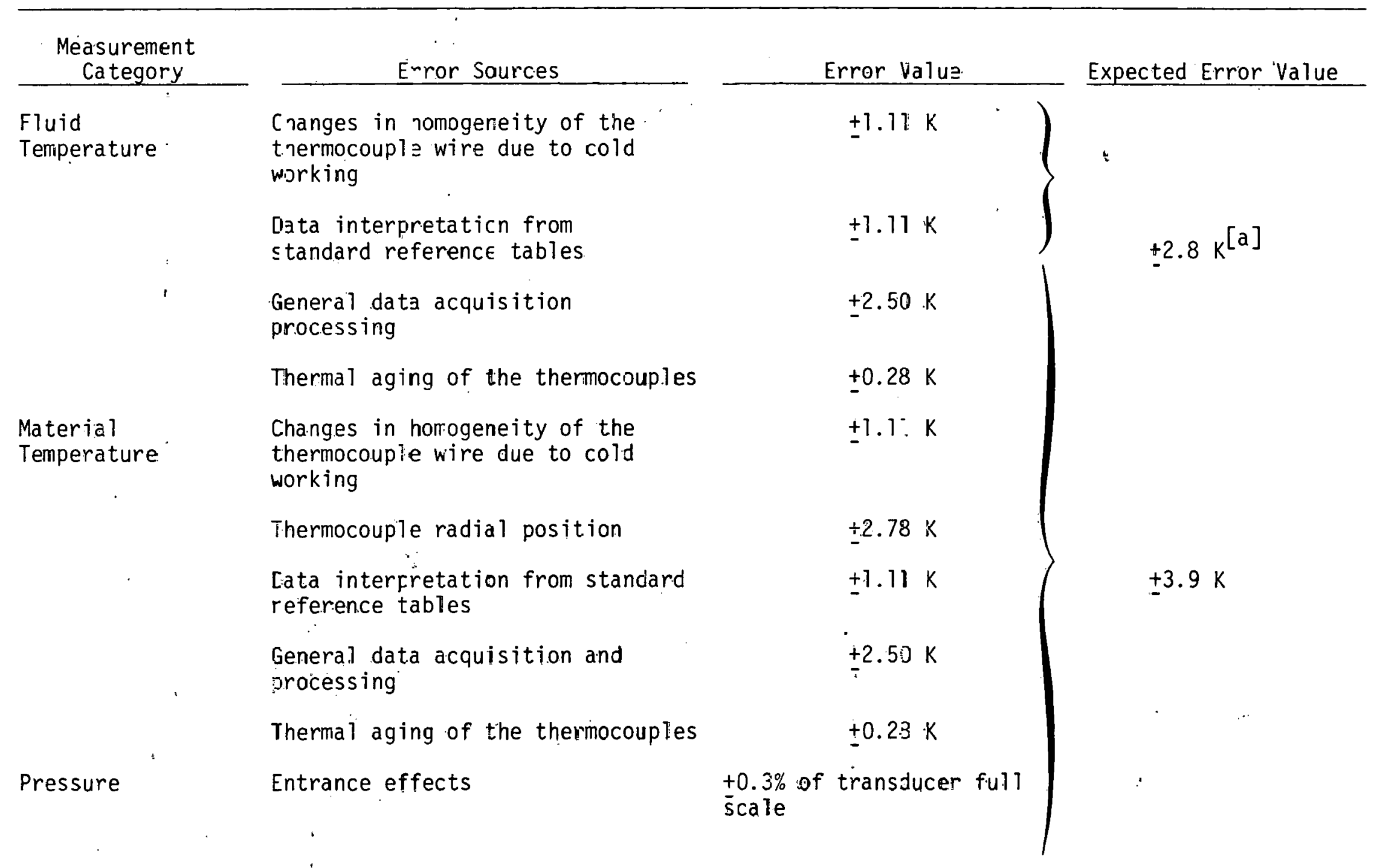


TABLE C-II (continued)

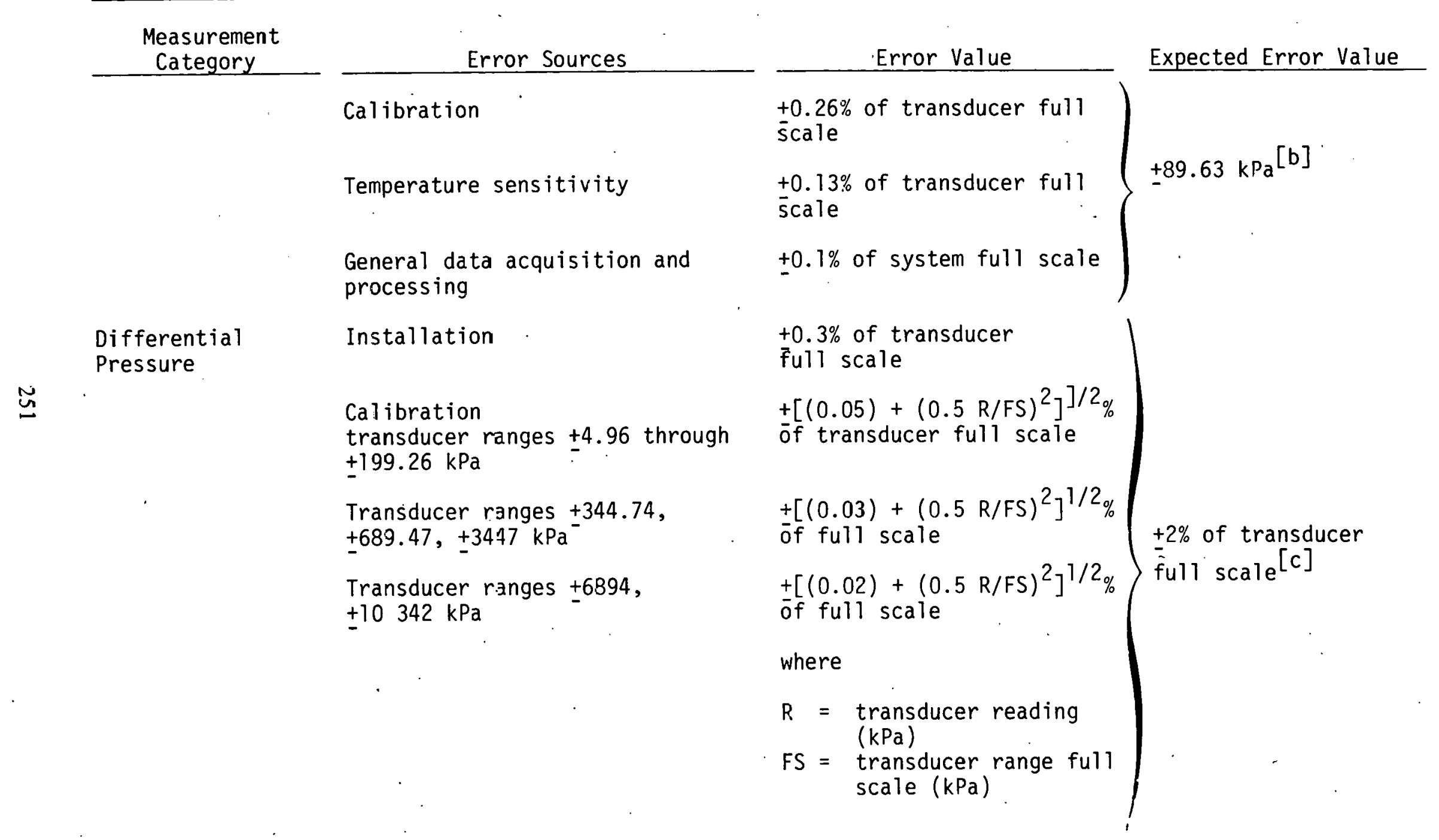




\section{TABLE C-II (continued)}

\begin{tabular}{|c|c|c|c|}
\hline $\begin{array}{l}\text { Measurement } \\
\text { Category }\end{array}$ & Error So:drces & Error Value & Expected Error Value \\
\hline \multirow{3}{*}{$\begin{array}{l}\text { Differential } \\
\text { Pressure } \\
\text { (continued) }\end{array}$} & Temperature sensitivity & $\begin{array}{l}+0.5 \% \text { of transducer } \\
\text { fult scale }\end{array}$ & \\
\hline & $\begin{array}{l}\text { General data acquisition and } \\
\text { Frocessing }\end{array}$ & $\begin{array}{l}+0.1 \% \text { of system full } \\
\text { scale }\end{array}$ & $\begin{array}{l}+2 \% \text { o }=\text { transducer } \\
\text { full scale } \\
{[\mathrm{c}]}\end{array}$ \\
\hline & Air entrapment & $\pm 0.069 \mathrm{kPa}$ & \\
\hline \multirow{4}{*}{$\begin{array}{l}\text { Fluid velocity } \\
\text { (point velocities } \\
\text { measured with } \\
\text { turboprobesi }\end{array}$} & lnstallation & $\begin{array}{l}+0.8 \% \text { of transducer } \\
\text { full scale }\end{array}$ & \\
\hline & Calibration & $\begin{array}{l}+5 \% \text { of transducer } \\
\text { full scale }\end{array}$ & $\left.(0.008 \mathrm{R})^{2}\right]^{1 / 2} \mathrm{~m} / \mathrm{s}$ \\
\hline & $\begin{array}{l}\text { Lata acquisition and processing } \\
\text { frequency conversion }\end{array}$ & $\begin{array}{l}+0.25 \% \text { of transducer } \\
\text { full scale }\end{array}$ & $\begin{array}{l}\text { where } \\
\mathrm{R}=\text { transducer read- } \\
\text { ing }(\mathrm{m} / \mathrm{s})\end{array}$ \\
\hline & jeneral & $\begin{array}{l}+0.1 \% \text { of system full } \\
\text { scale }\end{array}$ & \\
\hline \multirow[t]{3}{*}{ Density } & Calibration & $\pm 1.0 \%$ of reading $\left(\mathrm{kJ} / \mathrm{m}^{3}\right)$ & \\
\hline & Detector systam error & $\pm 2.1 \mathrm{~kg} / \mathrm{m}^{3}$ & [d] \\
\hline & $\begin{array}{l}\text { General data acquisition and } \\
\text { jrocessing }\end{array}$ & $\pm 1.6 \mathrm{~kg} / \mathrm{m}^{3}$ & \\
\hline
\end{tabular}


TABLE C-II (continued)

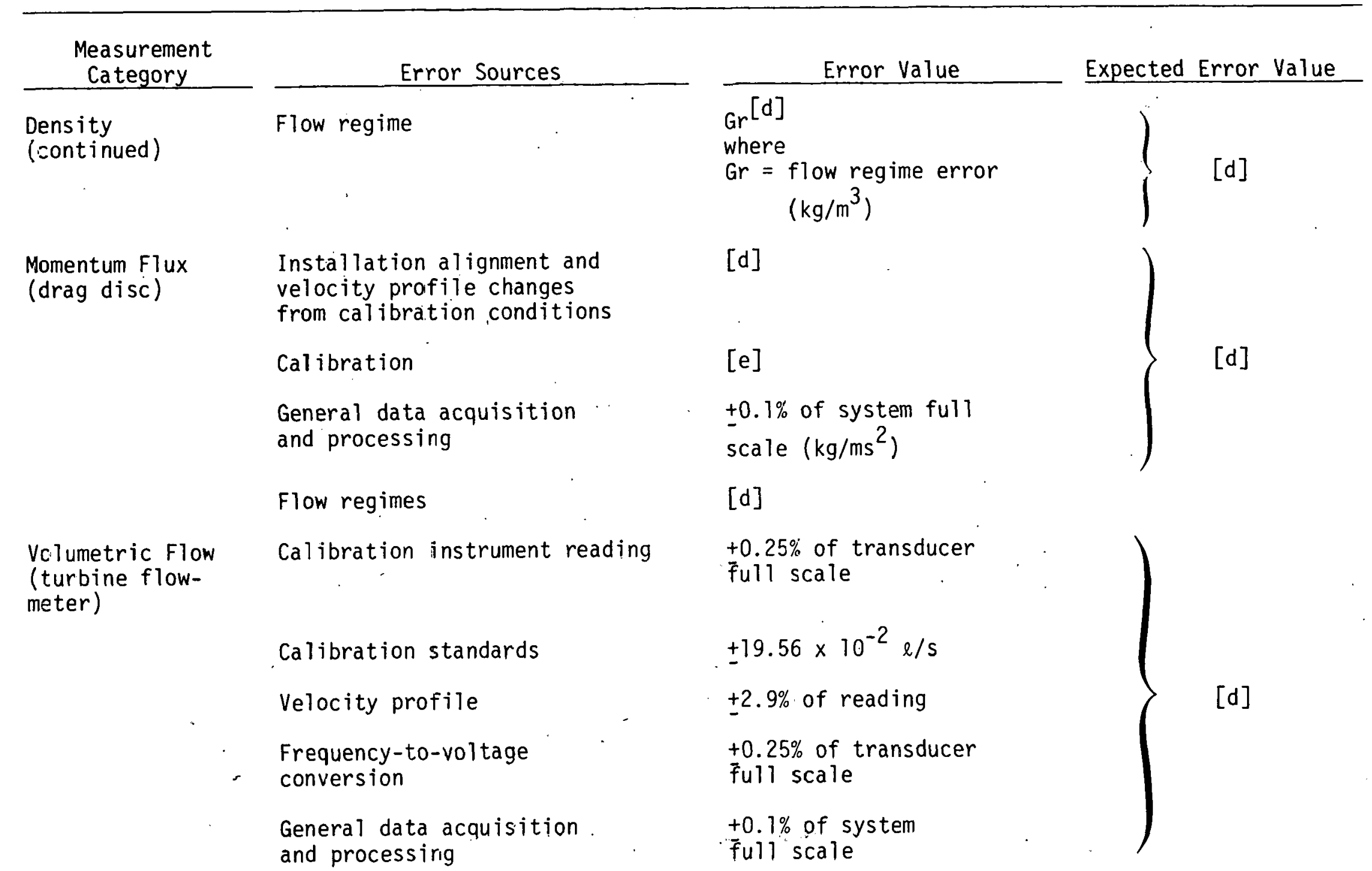




\begin{tabular}{|c|c|c|c|}
\hline $\begin{array}{c}\text { Measurement } \\
\text { Category }\end{array}$ & Error Sources & Error Vallue & Expected Error Value \\
\hline \multirow{2}{*}{$\begin{array}{l}\text { Volumetric Flow } \\
\text { (turbine flcin- } \\
\text { meter) (continued) }\end{array}$} & Dead bands & $\begin{array}{l}+5 \% \text { of transducer } \\
\text { full scale }\end{array}$ & \multirow[t]{2}{*}[d]{} \\
\hline & Flow regimes & {$[\mathrm{d}]$} & \\
\hline $\begin{array}{l}\text { Mass Flow Rate } \\
\text { (from volumetric } \\
\text { flow and density } \\
\text { data) }\end{array}$ & $\begin{array}{l}\text { Combined results from } \\
\text { individual error sources } \\
\text { for volumetric flow and density } \\
\text { date }[\mathrm{f}]\end{array}$ & {$[\mathrm{d}]$} & {$[d]$} \\
\hline $\begin{array}{l}\text { Mass Flow Rate, } \\
\text { (from momentum } \\
\text { flux and derisity } \\
\text { data) }\end{array}$ & $\begin{array}{l}\text { Combinec results from } \\
\text { individual error sources for } \\
\text { momentum flux and density da:af] }\end{array}$ & {$[d]$} & [d] \\
\hline
\end{tabular}

[a]. This value is no longer valid after thermocouple dryout occurs.

[b] Value =or transducers with 2C: $68 \mathrm{LPa}$ full-scale ranges.

[c] Value is based an observed systen perfarmance. It is more conservative than that obtained from the statisicical summation of the identified engireer errors.

[d] Error value is time and flow regime dependent.

[e] Dependent on transducer full-scale range reading.

[f] The general method for combining volumetric flow or momentum fiux with density data to obtain mass flow rate and the resulting errors in the data are explained in Reference B-2. 
mass flow), which are presented in this appendix, a more extensive assessment was conducted for additional engineering error due to flow regime effects. Table C-III identifies the data analyzed and the period in the blowdown process for which flow regime errors were included as a part of the total engineering error. The time of occurrence of separated two-phase flow and the resulting effect on the uncertainty of the data were evaluated by considering, on an individual basis, each detector output with reference to indications by other auxiliary measurements.

The gamma densitometer density measurement data are affected by two-phase separated flow regimes. The resulting transducer output is a measurement of the average attenuation of the gamma beam through the measured medium. The beam attenuation, in turn, is interpreted through physical relationship to be a measure of the average density along the beam path. When stratified type flow was considered present, the gamma beam attenuation was considered to be a result of a liquid layer and steam at system conditions. With this assumption and the system geometry, a void fraction was calculated and a new "effective" average density was calculated. The difference between the average density based on the assumption of homogeneous conditions and the average density for stratified conditions was considered to be the error.

Momentum flux measurement uncertainties for two-phase flow regimes present the most difficult engineering evaluation problems. The drag target and arm location, degree of flow stratification, transducer temperature sensitivity, and slip ratios all combine to produce possible flow regime errors ranging from a small fraction of the transducer output value to multiples of it. Therefore, the error values were obtained, where possible, through use of the observed discrepancies between the momentum flux and turbine flowmeter data in combination with system pressure measurements and the analysis of system fluid density measurements.

The flow regime errors of the turbine flowmeter were estimated by calculating a void fraction and the cross-sectional liquid and steam flow areas for stratified flow. This calculation was accomplished using methods similar to those used to calculate the average density for stratified flows. A simple model was used to equate the forces on the turbine with the assumption of a known void fiaclion, stratlfied flow, known component densities, and slip ratio greater than unity. This process provided phase velocities. With the phase densities, velocities, and void fraction, a volumetric flow rate could be calculated. The difference between this value and the measured value was considered to be the error.

The overall standard deviation of a data point is taken as the root mean of the sum of the random error variation and the lotal engineering error variance; that is,

$$
\sigma 0^{2}=\sigma R^{2} \sigma E^{2}
$$

where

$$
\sigma_{\mathrm{O}}=\text { overall standard deviation of a data point }
$$


TABLE C-I II

TIME PERIODS WHEN FLOW' REGIME ERRORS WERE APPLIED (TEST S-28-4)

Transducer

Identification

FTU-1

FTU- 15

GU-1C

GU-10VR

GU-15C

FDU-1, GU-1C

FDU-5, GU-5VR

FTU-1, GU-1C
Time during which

Flow Regime Errors were Applied (s)

Figure

0 to 8

C- -15

7 to 17

C-16

0 to 10 and

70 to 6 non

8 t.u 18

c. -25

8 to 15

$c-28$

0 to 10

$C-33$

and

70 to 600

0 to 10

and

70 to 600

0 to 10

and

70 to 600

7 to 17

0 to 22
$C-39$

FTB-21, GB-21C

${ }^{\sigma} \mathrm{R}=$ random error standard deviation

$\sigma_{E}=$ engineering error standard deviation.

The error bands for the data are computed about the value given by the fitted difference equation $y_{i}$ at time point, $i$; that is,

$$
\text { error band }=Y_{i}+1.96 \sigma_{0}
$$

The due regard to the fact that $\sigma_{E}$ has been estimated subjectively, the error band may be interpreted as an approximate $95 \%$ confidence interval within which any true value of the measured variable is consistent with the data. 
On certain occasions, the symmetrical error band given by Equation ( $C=2)$ is not appropriate. On those occasions, asymmetrical error bands were computed. (That is, with the width being greater on one side of $y_{i}$ than on the other.)

Finally, the original data trace, along with its error band from Equation (C-2), was input to a computer plot package. The resulting plot contained the actual data trace surrounded by an error band derived both from random error and engineering error considerations. The indicated error bands after thermocouple dryout occurred for the fluid temperature measurements should be ignored. Error bands for these segments of the data were not obtained and bands only appear because of limitations in the plotting package. 


\section{REFERENCES}

C-1. G. E. P. Box and B. M. Jenkins, Time Series Analysis - Foreciasting and Control; San Francisco: Holden-Day, 1970.

C-2. E. M. Feldman and S. A. Naff, Error Analysis for 1-1/2-Loop. Semiscale System Isothermal Test Data, ANCR-11'88 (May 1Y'/5). 


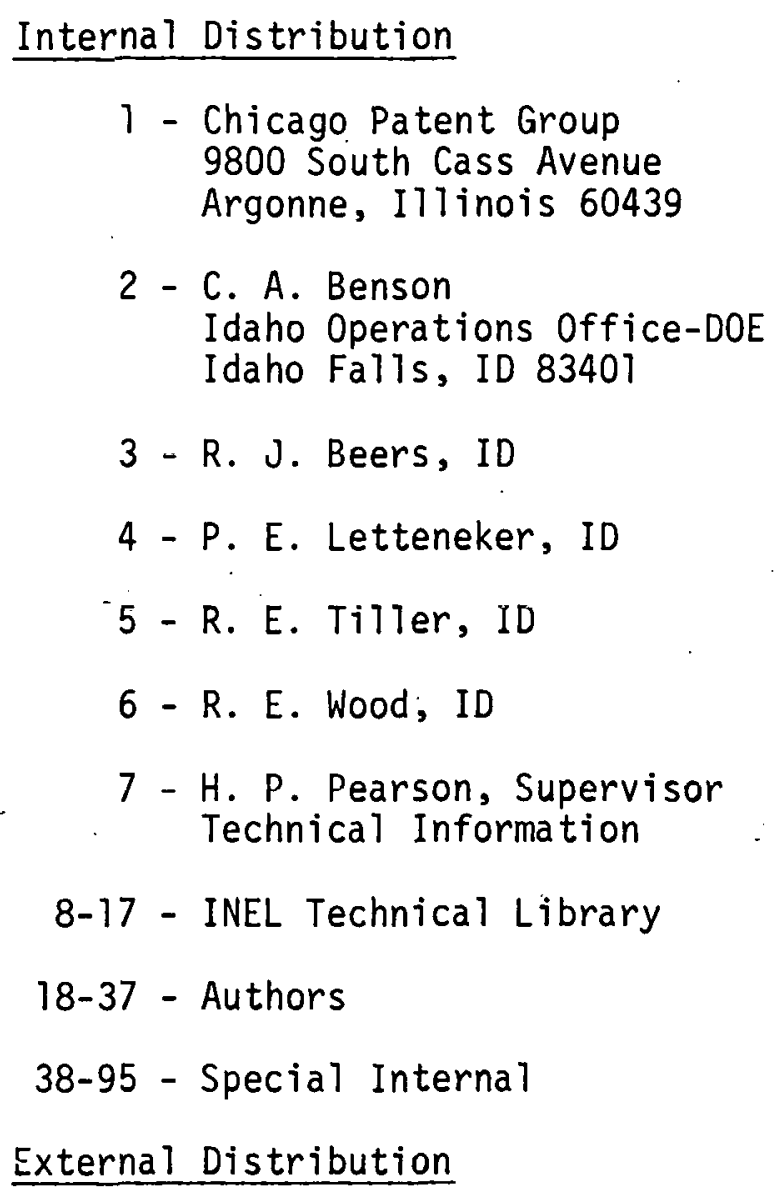

